\title{
Volume II: \\ Near-Field and Altered-Zone Environment Report
}

Chapters 2-11 and Appendix

Dale G. Wilder

August 23, 1996 


\section{DISCLAIMER}

This document was prepared as an account of work sponsored by an agency of the United States Government. Neither the United States Government nor the University of California nor any of their employees, makes any warranty, express or inplied, or assumes any legal liability or responsibility for the accuracy, completeness, or usefuiness of any information, apparatus, product, or process disclosed, or represents that its use would not infringe privately owned rights. Reference herein to any specific commercial products, process, or service by trade name, trademark, manufacturer, or otherwise, does not necessarily constitute or imply its endorsement, recommendation, or favoring by the United States Government or the University of California. The views and opinions of authors expressed herein do not necessarily state or reflect those of the United States Government or the University of California and shall not be used for advertising or product endorsement purposes.

This report has been reproduced

directly from the best available copy.

Available to DOE and DOE contractors from the

Office of Scientific and Technical Information

P.O. Box 62, Oak Ridge, TN 37831

Prices available from (615) 576-8401, FTS 626-8401

Available to the public from the

National Technical Information Service

U.S. Department of Commerce

5285 Port Royal Rd.,

Springfield, VA 22161

Prepared by Yucca Mountain Site Characterization Project (YMP) participants as part of the Civilian Radioactive Waste Management Program. The YMP is managed by the Yucca Mountain Site Characterization Project Office of the U.S. Department of Energy, Las Vegas, Nevada.

Work performed under the auspices of the U.S. Department of Energy by Lawrence Livermore National Laboratory under Contract W-7405-Eng-48. 


\section{Volume II: \\ Near-Field and Altered-Zone Environment Report}

Dale G. Wilder

Scientific Editor

August 1996 


$$
\text { , }
$$




\section{Contents}

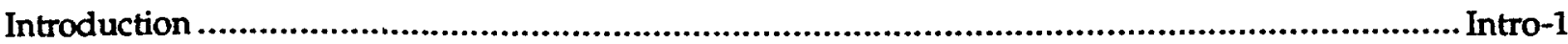

Chapter 1.0 Hydrothermal Modeling........................................................................................1.1-2

1.1 Introduction .........................................................................................................................1.1.2

1.1.1 Organization of This Chapter ..................................................................................1.1-2

1.1.2 Key Thermal-Hydrological Issues for Site Viability and Waste Isolation.......................1.1.-5

1.1.3 Modeling and Analysis Methodologies .........................................................................1.1.11

1.2 Background and Available Data on Yucca Mountain............................................................1.2-2

1.2.1 Matrix and Fracture Saturation ……..........................................................................1.2-2

1.2.2 Infiltration and Percolation.........................................................................................1.2-10

1.3 Episodic Non-Equilibrium Fracture-Matrix Flow..................................................................1.1.3-2

1.3.1 Matrix-Dominated and Fracture-Dominated Flow Regimes...........................................1.3-3

1.3.2 Implications of Flow Regimes on Engineered Barrier System/Near Field Performance .... 1.3-3

1.3.3 Summary of Fracture-Matrix Interaction at Yucca Mountain...............................................1.3-4

1.4 Preferential Flow Pathways ................................................................................................ 1.4-2

1.5 Spatial and Temporal Variability of Percolation Flux.........................................................1.5-2

1.5.1 Observations of Percolation Flux.................................................................................... 1.5-3

1.5.2 Controlling Inflow in Openings below the Water Table and its Implications for Fracture

Characteristics.............................................................................................................. 1.5-5

1.5.3 Conceptual Models ...........................................................................................................1.5-6

1.5.4 Comparison of Log-Normal Seepage Distribution to the Weeps Model.............................1-5-8

1.6 (REV 1) Impact of Repository Construction/Operational Activities.......................................1.6-2

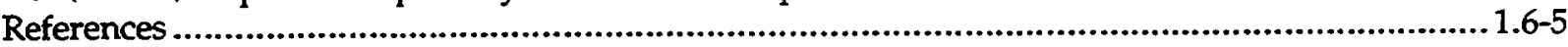

1.7 Thermal-Hydrological Processes........................................................................................1.7-2

1.7.1 Fundamental Thermal-Hydrological-Geomechanical-Geochemical Processes ...................1.7-2

1.7.2 Fracture-Matrix Vapor Transport and Condensate Flow....................................................1.7-4

1.7.3 Coupling with Geochemical Phenomena .........................................................................1.7-8

1.7.4 Coupling with Geomechanical Phenomena.................................................................. 1.7.8

1.8 Understanding and Managing the Thermal-Hydrological Effects of Decay Heat....................1.8-2

1.8.1 The Importance of Decay Heat on Moisture Movement and the Moisture Balance at Yucca

Mountain ............................................................................................................ 1.8-2

1.8.2 Thermal Loading Strategies ......................................................................................1.8-5

1.8.3 Importance of Thermal-Hydrology on Radionuclide Containment in Waste Packages.......1.8-6

1.8.4 Importance of Thermal-Hydrology for Radionucide Release and Transport......................1.8-8

1.8.5 Major Thermal-Hydrological Flow Regimes .................................................................... 1.8-8

1.9 Thermal-Hydrological Testing ............................................................................................. 1.9-2

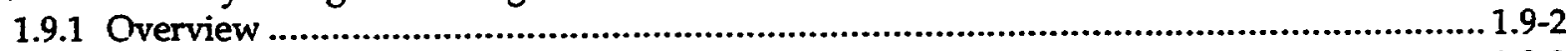

1.9 .2 Use of Hypothesis Testing ...........................................................................................1.9-3

1.9.3 Purpose of Thermal-Hydrological Testing......................................................................1.9-5

1.9.4 Factors Affecting Thermal Test Size and Duration.............................................................1.9-6

1.9.5 Physical Criteria Affecting Thermal Test Size and Duration............................................1.9-6

1.9.6 Numerical Models and Assumptions...............................................................................1.9-8

1.9.7 Post-Test Analysis of G-Tunnel Single-Element Heater Test............................................1.9-11

1.9.8 Pre-Test Analysis of ESF Thermal Tests...........................................................................1.9-13

1.10 Analysis of Drift-Scale Thermal-Hydrological Behavior in the Repository......................1.10-2

1.10.1 Overview...........................................................................................................1.10-2

1.10.2 Analysis of Localized and Extended Dryout Regimes ..................................................1.10-14

1.10.3 Performance Attributes of Engineered Backfill .........................................................1.10-19

1.10.4 Analysis of Engineered Backfill Scenarios for the FY95 Total Systems Performance

Assessment (TSPA95) ...........................................................................................1.10-23

1.10.5 Influence of Repository Design on Thermal-Hydrological Behavior............................1.10-32

1.10.6 Influence of Ambient Percolation Flux and Edge-Cooling/Rewetting/Shedding

Effects on Thermal-Hydrological Behavior ................................................................1.10-167

1.10.7 Comparison of Discrete-Fracture Model with Equivalent Continuum Model...............1.10-225 
References

Chapter 2.0 Laboratory-Determined Hydrologic Properties and Processes ........................................2-2

2.1 Laboratory-Determined Hydrologic Properties..............................................................2-2

2.1.1 Moisture Retention at Elevated Temperatures...................................................................2-3

2.1.2 Water Permeability at Elevated Pressures and Temperatures ............................................2-4

2.1.3 Electrical Resistivity as a Function of Water Saturation at Elevated Temperatures...........2-5

2.1.4 Relative Humidity as a Function of Water Saturation at Elevated Temperatures................2-7

2.2 Laboratory Study of Thermal-Hydrological-Chemical Processes............................................2-8

2.2.1 Condensation Along a Fracture......................................................................................2-8

2.2.2 Fracture Flow vs. Matrix Imbibition at Elevated Temperatures..................................... 2-10

2.2.3 Fracture Healing............................................................................................ 2-13

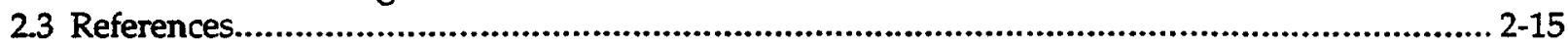

Chapter 3.0 Geochemistry .....................................................................................................3-2

3.1 Summary of Recent Studies Concerning Geochemical and Mineralogical Evolution of

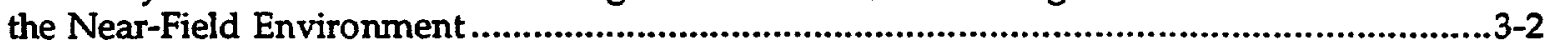

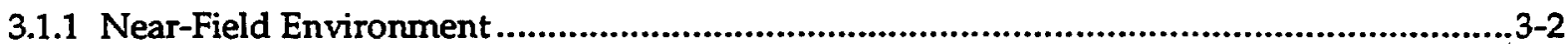

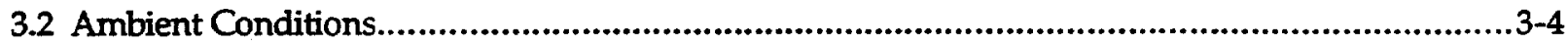

3.3 Processes That Will Modify Ambient Conditions Within the Near-Field Environment............3-5

3.3.1 References for Sections 3.1, 3.2 and 3.3 .......................................................................... 3-8

3.4 Results of Recent Geochemical Research Relating To Near-Field Geochemistry And Mineralogy

3.4.1 Equilibrium Bounds on Water Chemistry and Mineralogical Changes

Produced by Near-Field Relative Humidity Changes, by William E. Glassley,

Lawrence Livermore National Laboratory.

3.4.2 Testing EQ3/6 and GEMBOCHS Using Fluid-Mineral Equilibria in the

WairakeiGeothermal System, by Carol Bruton, Lawrence Livermore

National Laboratory.......................................................................................... 3-18

3.4.3 Mineralogy-Petrology Observations Regarding the Near-Field Environment, by David L. Bish, J. William Carey, Schon S. Levy and Steve J. Chipera, Los Alamos

National Laboratory................................................................................................... 3-30

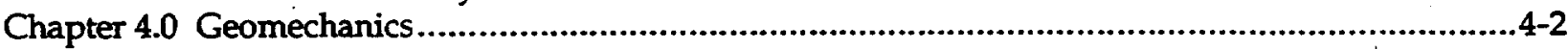

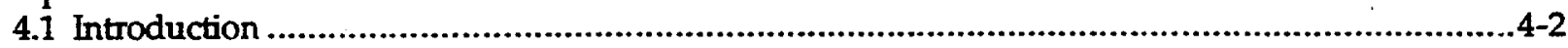

4.2 Ambient Conditions.............................................................................................................4-2

4.2.1 Physical, Thermai, and Mechanical Properties of Rock Mass and Intact Rock....................4-2

4.2.2 Temperature and Stress ..................................................................................................4-7

4.3 Processes That Perturb the Waste Package Environment ......................................................4-10

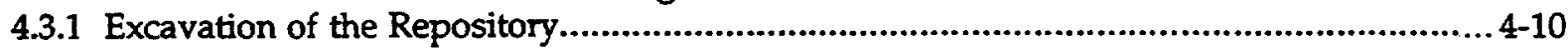

4.3.2 Thermal Effects of Waste Emplacement......................................................................4-11

4.3.3 Time-Dependent Effects ..............................................................................................4-12

4.3.4 Radiation Effects of Waste Emplacement.................................................................... 4-14

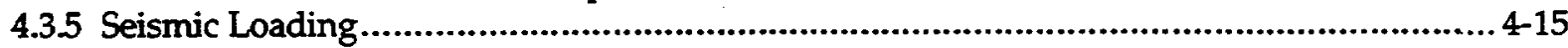

4.4 Geomechanics Modeling ..................................................................................................16

4.4.1 Discussion of Model Approaches.................................................................................4-16

4.4.2 Applications to the Near Field Environment at Yucca Mountain ....................................4-19

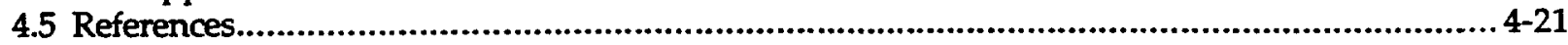

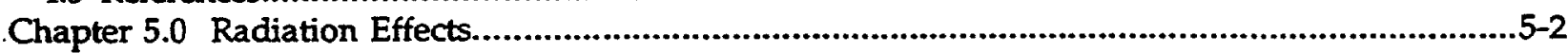

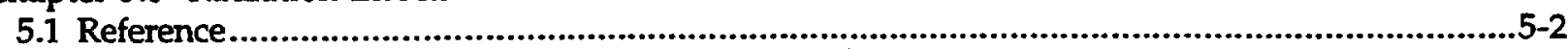

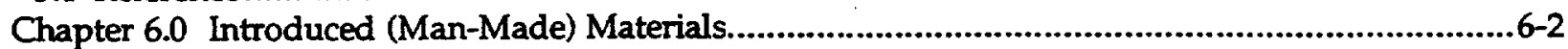

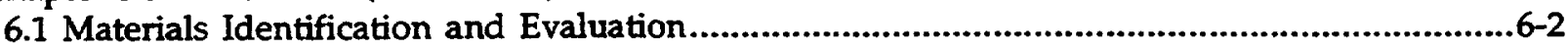

6.1.1 Original Post-Construction Conditions .......................................................................6-2

6.1.2 Evaluation of Materials by Function .....................................................................6.15

6.1.3 Tracers, Fluids and Materials Database: Retrieval of Information................................6-18

6.1.4 Assessment of Materials Considered for Repository Construction.................................... 6-20

6.2 Post-Closure Chemical Processes That May Modify Predicted Geochemistry........................... 6-21

6.2.1 Abiotic Chemistry ..................................................................................................6-22 
6.2.2 Biotic Chemistry (microbially mediated chemistry) .........................................6.46

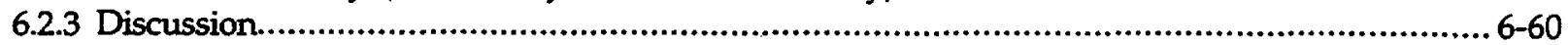

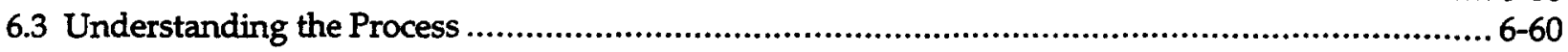

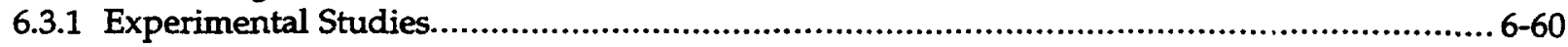

6.3.2 Historical Analogs as Long Term Experiments....................................................6.67

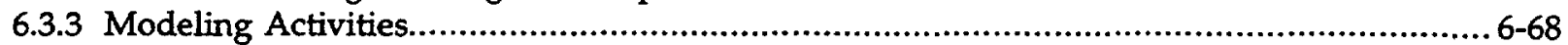

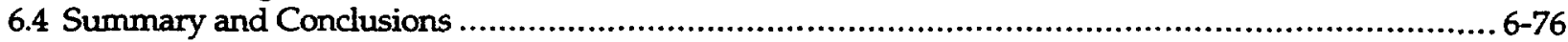

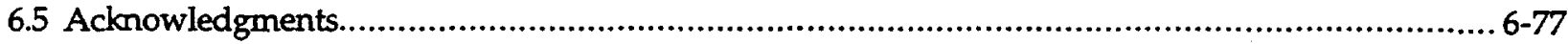

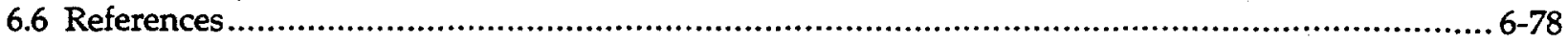

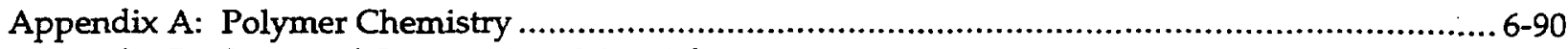

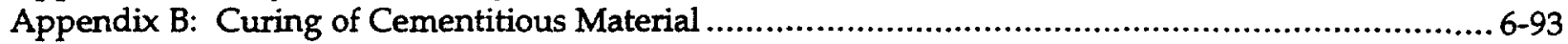

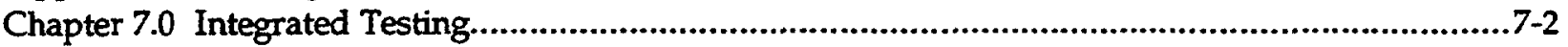

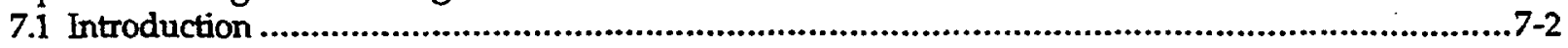

7.1.1 Scope of Integrated Testing Activities........................................................................7-2

7.1.2 Relationship of Integrated Testing Activities to Other YMP Activities............................7-2

7.2 Data Inputs Required for Bounding Transport and Source Terms.............................................7-3

7.3 Chemical, Mineralogical, and Physical Characteristics of EBS/NFE Components Expected to Significantly Affect Radionuclide Transport Through the EBS/NFE .................................7-3

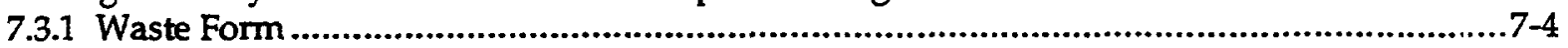

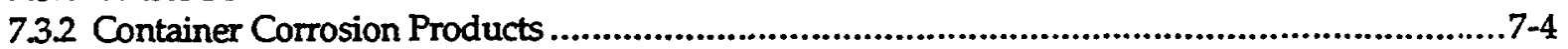

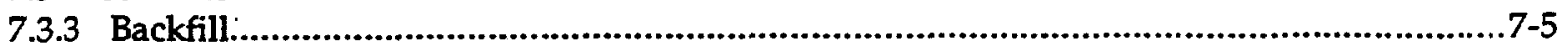

7.3.4 Characterization of Natural Colloids at Yucca Mountain ............................................... 7-5

7.3.5 Cementitious Materials....................................................................................................7-7

7.3.6 Altered Host Rock Adjacent to the Engineered Barrier......................................................7 7-8

7.4 Transport Studies in Host Rock and Minerals......................................................................7-9

7.4.1 Characterization of Repository Rock Pore Size Distribution and Diffusion of Actinides......7-9

7.4.2 Diffusion of Radionuclides in Clinoptilolite .............................................................. 7-10

7.4.3 Flow and Transport Through Topopah Spring Tuff........................................................ 7-12

7.5 Field Testing Sorption Models Under Conditions of Fracture Dominated Flow ........................7-15

7.5.1 Cation Exchange ................................................................................................... 7-16

7.5 .2 Surface Complexation ........................................................................................ 7-20

7.6 Summary ................................................................................................................ 7-24

7.7 Summary of Gaps in Information Required to Bound Radionuclide Transport

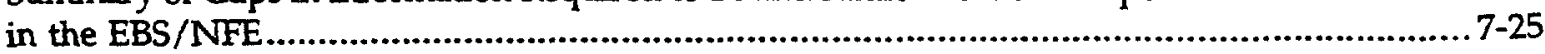

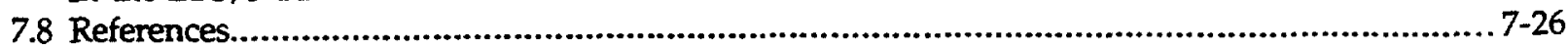

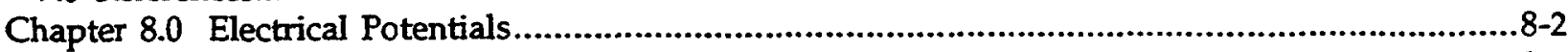

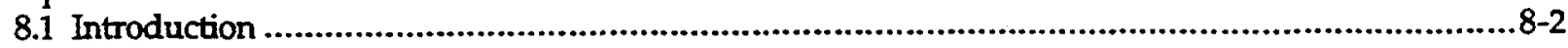

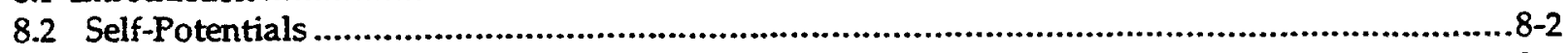

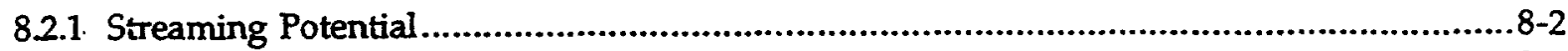

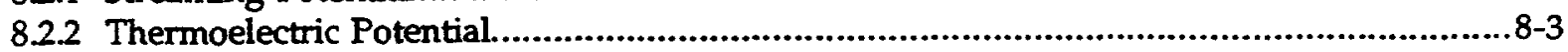

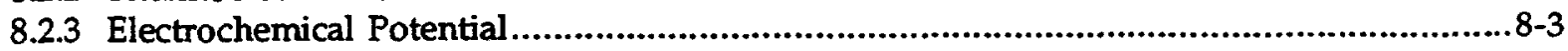

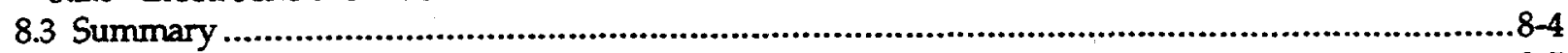

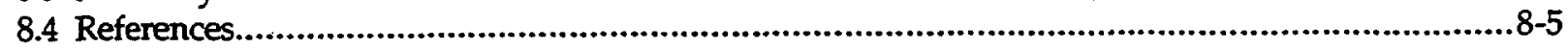

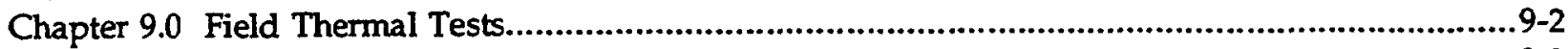

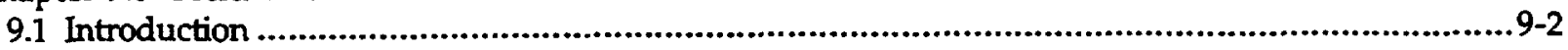

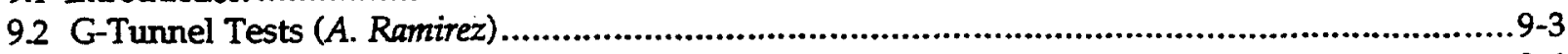

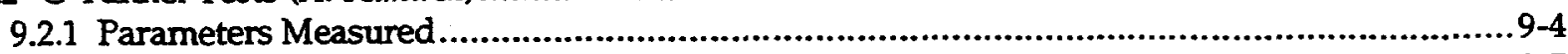

9.2.2 Test Description......................................................................................................9-5

9.2.3 Changes in Rock Mass Moisture Content ........................................................................6-6

9.2 .4 Temperature Measurements ....................................................................................9-8

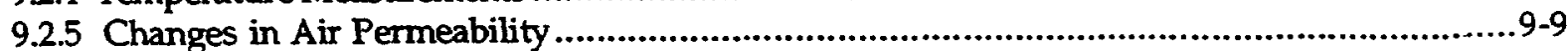

9.2.6 Steam Invading the Heater Emplacement Borehole ................................................... 9-10

9.2 .7 Summary ............................................................................................................ 9-11

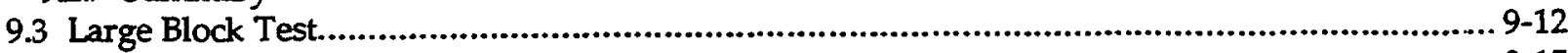

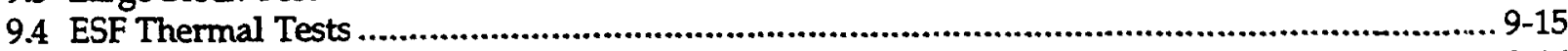

9.4.1 Single Heater Test ................................................................................................ 9-16 
9.4.2 Drift Scale Test

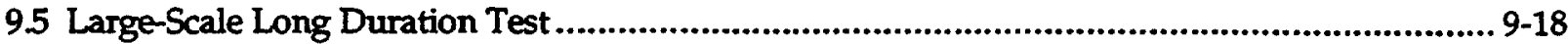

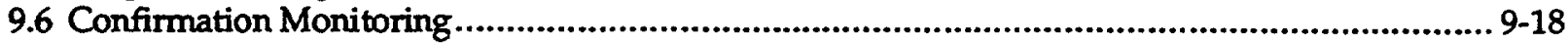

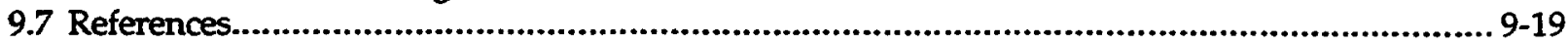

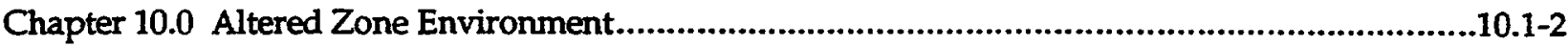

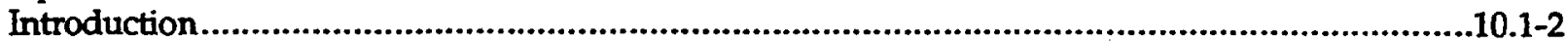

10.1 Mountain-Scale Unsaturated Zone (UZ) Thermal-Hydrology...........................................10.1-3

10.1.1 Models and Assumptions..........................................................................................10.1-7

10.1.2 Influence of Fracture Permeability Distribution.................................................10.1-15

10.1.3 Influence of Matrix Hydrological Property Distribution ..........................................10.1-43

10.1.4 Influence of Overburden Thickness ................................................................10.1-67

10.2 Mountain-Scale Saturated Zone (SZ) Thermal-Hydrology ...............................................10.2-2

10.2.1 Influence of SZ Heatflow on UZ Heatflow ..............................................................10.2-2

10.2.2 Buoyancy-Driven SZ Flow and Transport.......................................................10.2-3

10.3 Geochemistry and Mineralogy of the Altered Zone (William E. Glassley) .........................10.3-2

10.4 Summary of Recent Studies Concerning Geochemical and Mineralogical Evolution of the

Alterned Zone (William E. Glassley) ...........................................................................10.4-1

10.4.1 Hydrothermal Alteration of Vitric Tuff from Yucca Mountain, by Kevin G. Knauss and

Sally A. Copenhaver, Lawrence Livermore National Laboratory...............................10.4-3

10.4.2 Kinetics of Rock-Water Interaction: Amorphous Silica Precipitation (60 to $120^{\circ} \mathrm{C}$ );

Comparison of Laboratory and Field Rates, by Susan Carroll, Edward Mroczek,

Maureen Alai, and Margeret Ebert; Earth Sciences Division, Lawrence Livermore

National Laboratory, Livermore CA, USA, Institute of Geological \& Nuclear

Sciences, Wairakei Research Center, Wairakei, New Zealand ...................................10.4-7

10.4.3 Thermal Effects in the Altered Zone: Preliminary Bounds on the Water Composition and Secondary Mineral Development in the Altered Zone That May Influence the Near-Field Environment, by Michael Whitbeck and William Glassley, Lawrence Livermore National Laboratory .......................................................................10.4-17

10.4.4 Formation of Flow and Transport Barriers Within the Altered Zone, by James W. Johnson and William Glassley, Lawrence Livermore Nationai Laboratory .............................10.4-23

Chapter 11.0 Introduction to the Thermodynamic Data Determination.........................................11-2

11.1 The Database $11-2$

11.2 U.S. Contribution to the NEA Organization for Economic Co-operation and Development

(OECD) Critical Reviews of the Chemical Thermodynamics of the Actinides and

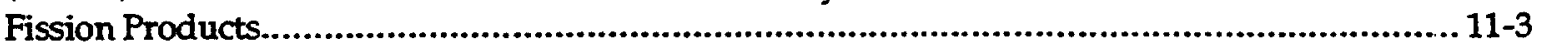

11.2.1 Lawrence Livermore National Laboratory's Role...................................................... 11-3

11.2 .2 Procedure .............................................................................................................. 11-3

11.2.3 Auxiliary Data......................................................................................................... 11-4

11.3 Qualification of Data for Using in Quality Affecting Calculations................................... 11-4

11.4 Review of Thermodynamic Data....................................................................................... 11-4

11.4.1 Chemical Thermodynamics of Uranium....................................................................... 11-4

11.4.2 Chemical Thermodynamics of Americium ................................................................ 11-5

11.4.3 Chemical Thermodynamics of Technetium ................................................................ 11-6

11.4.4 Chemical Thermodynamics of Plutonium and Neptunium........................................ 11-7

11.5 References.................................................................................................................. 11-8

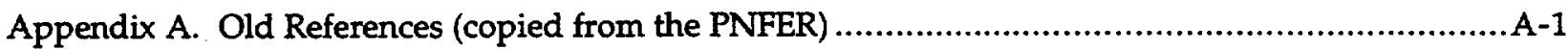

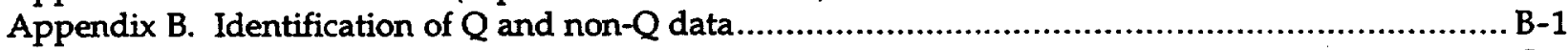

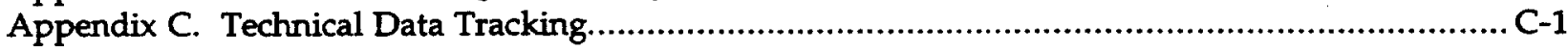




\section{Acronyms and Abbreviations}

$A C D$

APD

ASTM

bfs

BHW

CEC

CHnv

CHnz

DFM

DHLW

DOE

DST

EBS

EBSFT

ECM

ERT

ESF

ESFTT

FMM

GTUF

GWTT

HLW

LA

LAD

LBT

LLNL

LSLDT

MPBX

NF

NFE

NFER

NTS

NWTRB

PEBSFT

PPw

PTn

QA

REKA

RIB

RMR

RTD

SCP

SCPCDR

SCSSS

SEAMIST

SEM

SF

SHT

SIMS

SP

TCW

TMHC advanced conceptual design

areal power density

American Society for Testing and Materials

blast furnace slag

borehole wall

cation exchange capacity

Calico Hills, nonwelded, vitric

Calico Hills, nonwelded, zeolitized

discrete fracture model

defense high-level waste

U.S. Department of Energy

drift scale test

engineered barrier system

engineered barrier system field tests

equivalent continuum model

electrical resistivity tomography

Exploratory Studies Facility

ESF thermal tests

fracture-matrix model

G-Tunnel Underground Facility

groundwater travel time

high-level waste

license application

license application design

large block tests

Lawrence Livermore National Laboratory

large-scale long-duration tests

multiple borehole extensometer

near field

near-field environment

Near-Field Environment Report

Nevada Test Site

Nuclear Waste Technical Review Board

prototype engineered barrier system field test

Prow Pass, welded

Paintbrush, nonwelded

quality assurance

rapid estimation of $K$ (thermal conductivity) and alpha (diffusivity)

Reference Information Base (DOE, 1990)

rock-mass rating

resistance temperature device

Site Characterization Plan (DOE, 1988)

Site Characterization Plan Conceptual Design Report

Standard Canadian Shield Saline Solution

Science Engineering Associate Mambrane Insitu Sampling Technology

scanning electron microscopy

spent fuel

single-heater tests

secondary ion mass spectrometry

spontaneous electrical potentials

Tiva Canyon, welded

thermal-mechanical-hydrological-chemical 


\section{Acronyms and Abbreviations (continued)}

Tpt

TSw1

TSw2

TSw3

UNE

WP

WPP

XRD

YM

YMP

YMPO
Topopah Spring Member of the Paintbrush tuff

Topopah Sprint', welded, lithophysae-rich

Topopah Spring, welded, lithophysae-poor

Topopah Spring, welded, vitric

underground nuclear explosion

waste package

Waste Package Plan (Harrison-Giesler et al., 1991)

$x$-ray diffraction

Yucca Mountain

Yucca Mountain Site Characterization Project

Yucca Mountain Site Characterization Project Office 
s. 


$$
-
$$




\section{Contents}

Chapter 2.0 Laboratory-Determined Hydrologic Properties and Processes ..................................2-2

2.1 Laboratory-Determined Hydrologic Properties ..............................................................2-2

2.1.1 Moisture Retention at Elevated Temperatures...............................................................2-3

2.1.2 Water Permeability at Elevated Pressures and Temperatures........................................2-4

2.1.3 Electrical Resistivity as a Function of Water Saturation at Elevated Temperatures...........2-5

2.1.4 Relative Humidity as a Function of Water Saturation at Elevated Temperatures...............2-7

2.2 Laboratory Study of Thermal-Hydrological-Chemical Processes.........................................2-8

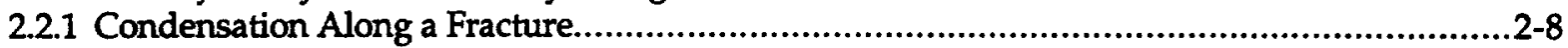

2.2.2 Fracture Flow vs. Matrix Imbibition at Elevated Temperatures......................................2-10

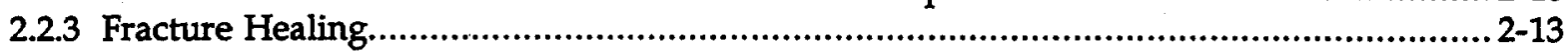

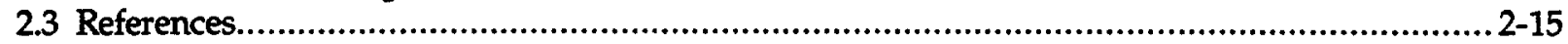




\title{
Chapter 2.0 Laboratory-Determined Hydrologic Properties and Processes
}

\author{
W. Lin and J. Roberts
}

Understanding the movement of moisture-including liquid water, steam, and vapor-in the near-field environment (NFE) of the potential nuclear-waste repository at Yucca Mountain, Nevada, is one of the goals of the waste-package environment hydrologic investigations. This chapter discusses how thermal loading resulting from waste package emplacement will affect the preconstruction hydrologic properties and processes of the NFE.

One of the main concerns about the NFE of a nuclear-waste repository is the quantity and quality of water that may be present and that may contact the waste and waste packages (near field) and be in the rock mass surrounding the repository. Water can cause property changes in the altered zone. Processes that may affect the quantity and quality of water are coupled thermal-mechanical-hydrologicalchemical (TMHC) processes. The TMHC processes may involve the in-situ pore water in the Topopah Spring tuff, water present in fractures, and/or condensate that results from water mobilized by heat, as well as any water introduced (either naturally or artificially) after the emplacement of the wastes. Field and laboratory tests are conducted to enhance our understanding of the coupled TMHC processes and to measure physical properties. The field tests are reported in Chapter 9.0. The laboratory tests of hydrologic properties and processes will be used as input data to model calculations of the coupled TMHC processes, to improve the understanding of the model calculations, to gain insight into physical processes and thus learn under what conditions specific coupled processes become dominant or important, and to help in analyzing the results of the field tests. The laboratory-determined hydrologic properties reported in this document include moisture-retention curves at elevated temperatures, water permeability at elevated temperatures and pressures, electrical resistivity as a function of water saturation at elevated temperatures, and relative humidity as a function of water saturation at elevated temperatures. The laboratory studies of the thermal-hydrological-chemical processes include fracture flow vs. matrix imbibition at elevated temperatures, fracture healing, and condensation along a fracture. All of the laboratory test results are not qualified, as defined in the quality assurance procedures.

\subsection{Laboratory-Determined Hydrologic Properties}

The work described here can generally be classified into two different areas with regard to the NFE: (1) preconstruction conditions and processes and (2) the perturbed environment. Preconstruction conditions and processes are those processes that occur prior to any disturbance; that is, they occur naturally.

The perturbed environment is the region that has changed because of some human activity. During the post-emplacement period, the near field may experience 
at least one dehydration-rehydration cycle. After waste emplacement, the rock in the near field is expected to dehydrate as a result of heating. The rate of dehydration and the movement of moisture in the rock will depend on, among other factors, the initial moisture content in the rock, the geometry and configuration of fractures, and the force of gravity. Later, as the rock temperature decreases below the boiling point of water, rehydration of the near field is expected to occur. The dehydration and rehydration processes and the effect of temperature on the hydrologic properties of tuff are discussed below.

The laboratory work described in the NFER Rev. 0 was divided into these two sections. Because of the increased number of experiments, many of them performed over a range of conditions including ambient condition, it was decided in this report to describe each experiment and the results separately. In addition, in reporting laboratory test results, it is easier to appreciate the effect of temperature on the properties if the results at room temperature and elevated temperatures are presented together. Generally, work performed at near-ambient temperatures (20$25^{\circ} \mathrm{C}$ ) applies to preconstruction conditions, while work at higher temperatures is relevant to the perturbed environment. Obvious exceptions to this are the measured physical properties at ambient conditions after a cycle of heating, pressure, or fluid flow.

\subsubsection{Moisture Retention at Elevated Temperatures}

The suction potential of rock determines the imbibition of water in the matrix. That, in turn, affects the relative importance of matrix flow and fracture flow because greater suction potential enhances matrix flow. Moisture content as a function of matric potential (moisture retention curves) of Topopah Spring tuff samples at elevated temperatures was determined using a constant-relativehumidity chamber. The method of measurement was described in Daily and Lin (1991), Roberts and Lin (1995a), and Roberts and Lin (1996a). Some of the test results have been published in Daily and Lin (1991), Roberts and Lin (1995a), and Roberts and Lin (1996a). Daily and Lin (1991) reported results of measurements at 20 and $70^{\circ} \mathrm{C}$ on Topopah Spring tuff samples from the USW H-1 borehole at a depth range from 333 to $350 \mathrm{~m}$ and from outcrops at Fran Ridge, Nevada Test Site. The Topopah Spring tuff samples used in the tests by Roberts and Lin included cores from borehole USW G-4 at a depth of about $360 \mathrm{~m}$ (1147 ft) and cores from the Large Block Test. Figures 2-1 to 2-4 show the results of Daily and Lin (1991). As noted on the figures, suction potential is a strong function of saturation below $20-30 \%$ saturation but is less dependent on saturation above $30 \%$ (varying between $200-400 \mathrm{~atm}$ ). At near-ambient temperatures the suction potential decreases much more rapidly with increasing saturation during wetting than it does during drying (samples from USW $\mathrm{H}-1$ ). This difference in behavior between wetting and drying is also seen at elevated temperatures, although the difference is not as pronounced as for ambient temperatures. Figure 2-5 summarizes the results of Roberts and Lin (1995a and 1996a) and shows the moisture retention curves of USW G-4 samples at temperatures of $24.8,78.4$, and $93.6^{\circ} \mathrm{C}$ for both drying and wetting phases. In this study there was not a consistent difference between wetting and drying curve shape, although there is a difference in the curves for $93.6^{\circ} \mathrm{C}$. 
Peters et al. (1984) and Klavetter and Peters (1987) used psychrometers to measure the suction potential of both welded and non-welded tuff from Yucca Mountain at $20^{\circ} \mathrm{C}$ during the dehydration phase. Our data at $20^{\circ} \mathrm{C}$ are within the spread of corresponding results of Klavetter and Peters, as noted on Fig. 2-3 of NFER Rev. 0.

Results from another experiment using five samples of Grouse Canyon tuff from the G-Tunnel showed that in a $100 \%$ relative humidity environment, the suction of water into rock samples is quite different from that in an environment of liquid water, although both have zero water potential (NFER Rev. 0). The samples were placed in a constant-humidity chamber at $100 \%$ humidity for more than 917 hours, after which they were removed and submersed in liquid water. Under $100 \%$ humidity the suction of moisture was limited to no more than $20 \%$ of the sample porosity. Yet, when the samples were removed from the $100 \%$ humidity environment and submersed in liquid water, the degree of saturation increased overnight to $\sim 70 \%$ of their porosity, and then continued to increase. This implies that in the NFE the moisture-content change in the matrix during the flow of steam or vapor through fractures will be quite different from that of the change during the flow of liquid water, also indicating that after the liquid water has been driven off as a result of thermal loading from waste emplacement, the rock's saturation level will not be elevated to above $\sim 20 \%$ until liquid water is able to return to the NFE. During the G-Tunnel field experiments, rehydration took place much more slowly than did dehydration, supporting the observation that saturation levels do not increase without liquid water (Ramirez et al., 1991).

Generally speaking, water saturation at a constant matric potential decreases with increasing temperature. Hysteresis between the drying and wetting phases exists at most of the temperatures. The hysteresis at $78.4^{\circ} \mathrm{C}$ is much smaller than at other temperatures. For most of the samples the hysteresis is that more moisture is retained in the samples during drying than during wetting. However at $93.6^{\circ} \mathrm{C}$ the hysteresis was reversed. The explanation for this discrepancy requires further investigation. No process has been identified that can explain smaller hysteresis at $78.4^{\circ} \mathrm{C}$ than at other temperatures, or explain the hysteresis reversal at $93.6^{\circ} \mathrm{C}$. However, in this test the samples were heated from $24.8^{\circ} \mathrm{C}$ to $93.6^{\circ} \mathrm{C}$ then cooled to $78.4^{\circ} \mathrm{C}$. This heating history may have some effect on the moisture-retention curves.

\subsubsection{Water Permeability at Elevated Pressures and Temperatures}

Water permeability in Topopah Spring tuff samples as functions of pressure and temperature has been measured to provide input data for model calculations. The techniques used to measure the permeability were described by Lin and Daily (1984). As expected, water permeability in intact Topopah Spring tuff samples was different than in fractured samples; however, it was determined that permeabilities of fractured samples responded to elevated temperature in a fundamentally different way than for unfractured samples (see Section 2.2.3) (Lin and Daily, 1984; Daily et al., 1987; Lin and Daily, 1988; Lin, 1991; Roberts and Lin, 1995b; Lin et al., 1995). The water permeability of intact Topopah Spring tuff samples is reported in this section. The water permeability of fractured tuff samples is reported in Section 2.2.3, "Fracture Healing." 
An intact Topopah Spring tuff sample machined from an outcrop at Fran Ridge, Nevada Test Site, was used by Lin and Daily (1984) to measure water permeability at various times during a series of three dehydration and rehydration cycles. The sample was under a constant confining pressure of about $5 \mathrm{MPa}$, and temperatures up to $140^{\circ} \mathrm{C}$. The water permeability of the intact tuff sample was independent of temperature, time, and dehydration and rehydration cycles. At $21^{\circ} \mathrm{C}$, before starting the dehydration-rehydration processes, the permeability was $0.34 \times 10^{-18} \mathrm{~m}^{2}(0.34$ $\mu D)$; after the first drying phase, at $98^{\circ} \mathrm{C}$, the permeability was $0.32 \times 10^{-18} \mathrm{~m}^{2}(0.32$ $\mu \mathrm{D})$; then at $140^{\circ} \mathrm{C}$, also after the first drying phase, the permeability was $0.31 \times 10^{-18}$ $\mathrm{m}^{2}(0.31 \mu \mathrm{D})$; after three drying phases at $98^{\circ} \mathrm{C}$ the permeability was $0.35 \times 10^{-18} \mathrm{~m}^{2}$ $(0.35 \mu \mathrm{D})$. The steam permeability after two drying phases, at $140^{\circ} \mathrm{C}$, was $1.99 \times 10^{-18}$ $\mathrm{m}^{2}(1.99 \mu \mathrm{D})$. The greater steam permeability may be a result of the effect of gas flow on permeability, as normally seen in gas permeability measurements due to the Klinkenberg effect. Recently, water permeability of an intact core from the Large Block Test was measured by Lin and Roberts. The results are shown in Table 2-1. The water permeability of the intact tuff sample is again independent of temperature and ranges from 0.09 to $0.67 \times 10^{-18} \mathrm{~m}^{2}(0.09$ to $0.67 \mu \mathrm{D})$. For comparison, Ramirez et al. (1991) reported water permeability, at $20^{\circ} \mathrm{C}$, of intact Grouse Canyon tuff from G-Tunnel, Nevada Test Site, to be about $10^{-18} \mathrm{~m}^{2}(1 \mu \mathrm{D})$. Moore et al. (1986) reported that the water permeability of Topopah Spring tuff samples at $20^{\circ} \mathrm{C}$ ranged from 0.85 to $64 \times 10^{-18} \mathrm{~m}^{2}(0.85$ to $64 \mu \mathrm{D})$. It is not clear if the samples used by Moore et al. were intact or fractured.

\subsubsection{Electrical Resistivity as a Function of Water Saturation at Elevated Temperatures}

Spatial distribution and temporal variation of moisture content in the rock mass in the repository horizon are among the most important parameters needed to understand the coupled TMHC processes. There are no direct methods for measuring moisture content other than drying and weighing, therefore geophysical methods are required to determine the moisture content in a rock mass. Electrical resistivity tomography (ERT) is one of the few geophysical methods that can effectively determine the distribution of moisture content in a two-dimensional plane and/or a three-dimensional region. ERT determines the distribution of electrical resistivity in an imaging region. Laboratory-determined relationships between electrical resistivity and moisture content over a range of temperatures are required to interpret the ERT results in terms of moisture content. Measuring the electrical resistivity as a function of moisture content at various frequencies can also provide information about the microscopic wetting and drying processes in rocks (Roberts and Lin, 1996b).

Laboratory-determined electrical resistivities of Topopah Spring tuff as a function of water saturation at elevated temperatures have been reported by Roberts and Lin (1994a, 1994b, and 1996b). Topopah Spring tuff samples used in this study were from holes U3hg-1 at 399-m depth, USW GU-3 at 330-m depth, and USW G-4 at 374-m depth. The connected porosity of the samples were $25-28 \%$ for U3hg-1, 9$14 \%$ for USW G-4, and 9-10\% for USW GU-3. The electrical properties measurement techniques were described in Roberts and Lin (1994a and 1994b). 
Briefly, the two-electrode method was used on thin disc-shaped samples that had sputtered gold electrodes backed by gold foil. Samples were placed in holders to inhibit the uptake or loss of moisture to the surrounding atmosphere. Water was added to the samples in small increments, and saturations were determined gravimetrically. Electrical resistivity measurements were conducted after each addition of water until a constant value was reached, at which point it was assumed the water was evenly distributed throughout the sample. This redistribution of fluid generally took between 4 and 6 hours but was dependent on saturation and the amount of sample area to which fluid was added. The time-dependent monitoring of samples was discontinued after the length of time for re-equilibration to occur was established, and measurements were made approximately daily (or 4 to 6 times as long as needed for re-equilibration to occur). We used four samples of each rock, each having a different thickness. This was done for several reasons: to check the effect of electrode contact impedance on the measurement (minimal at $1 \mathrm{kHz}$ ), to measure heterogeneity (most of the scatter in Figs. 2-6 through 2-9 results from the multiplicity of samples for each rock), and to provide more data points.

Figures 2-6 to 2-8 show the electrical resistivity of these rock samples at room temperature as a function of water saturation. The resistivity measured during the drying process is slightly greater than that measured during the wetting process. For all of these rocks the resistivity is most sensitive to the water saturation when the water saturation is below $20 \%$. The slope of the resistivity vs. saturation trend is related to the connected porosity: the U3hg-1 samples had the steepest slope; the USW G-4 samples had the most gentle slope. Roberts and Lin (1994b) also reported that the electrical resistivity in USW G-4 has only slight anisotropy: that is the rock is slightly less resistive for electrical current that flows along the bedding planes, but the difference in the resistivity is small and most likely will not affect the use of electrical resistivity measurements for determining water saturation in laboratory and field tests.

Figure 2-9 shows the electrical resistivity of samples from USW G-4 as a function of water saturation at various temperatures from 23 to $95^{\circ} \mathrm{C}$ during wetting. As expected, the resistivity decreases with increasing temperature. The temperature effect is very small when the water saturation is less than $10 \%$. The maximum decrease in resistivity as a result of temperature occurs in the $20-40 \%$ saturation range, when the decrease in resistivity due to increased saturation is also very high. Above $40 \%$ saturation the difference due to temperature is greater than the difference due to saturation.

Figure 2-10 shows the resistivity of USW G-4 samples as a function of temperature for 40 and $75 \%$ saturation. The individual data points were selected from the total data set for points that ended up having similar saturations. This means that the curve for $40 \%$ saturation, for instance, might have data points for different G-4 samples; thus there is some inherent scatter in the data. Despite this, there is a clear trend in the data. Note that the resistivity axis is linear in this case. Resistivity decreases by about a factor of 3 to 4 from 20 to $100^{\circ} \mathrm{C}$. The data are described by simple power-law fits of the form $\rho=a\left(T^{-b}\right)$ where $\rho$ is the resistivity in ohm- $\mathrm{m}, \mathrm{T}$ is temperature in ${ }^{\circ} \mathrm{C}$, and $\mathrm{a}$ and $\mathrm{b}$ are fitting parameters. The fits shown have values of 23920 and 19896 for $a$ and values of 0.9184 and 0.9811 for $b$ for 40 and 
$75 \%$ saturation respectively. These values are relevant only to the specific data set for which they were derived, and we caution that more data points are needed to confirm any systematic relationship.

Based on these results, we conclude that using electrical resistivity to determine the distribution and variation of moisture content in Topopah Spring tuff is most effective when the saturation is less than $40 \%$. For greater levels of saturation, the method is still useful but potentially with less accuracy, depending on how well temperature changes can be determined. It will be necessary to have a separate determination of temperature to get the most accurate saturation estimates. For water saturation greater than $50 \%$, relative permittivity (dielectric constant) may be more sensitive to water saturation than resistivity (Roberts and Lin, 1994b).

\subsubsection{Relative Humidity as a Function of Water Saturation at Elevated Temperatures}

Relative humidity in the waste package environment is a key factor affecting the integrity of the waste canister. The purposes of determining the relative humidity as a function of water saturation in Topopah Spring tuff are to provide experimental data for comparison with the calculated relative humidity in the near-field environment, to assess the ambient (pre-heat) relative humidity in the repository, and to understand the diffusion process of vapor through the matrix of the tuff.

The technique of measuring the relative humidity as a function of water saturation was described in Lin et al. (1996). One cylindrical Topopah Spring tuff sample was machined from a small block of the tuff collected at the Large Block Test site. A Humicap humidity sensor was sealed in a hole about $1.0 \mathrm{~cm}$ in diameter, in the central portion of the sample. Distilled water was added to the outer surface of the sample, and the relative humidity was monitored continuously until a steady state was reached. The experiment is still under way, and at this reporting time the experiment has only been completed at room temperature. Although it is planned to conduct the experiment at elevated temperatures, we do not believe that increasing temperature in the sample will change the conclusions reported here.

Figure 2-11 shows the current status of the test results. Prior to adding water to the sample, as is indicated by the first spike in the figure, the relative humidity in the entire system was monitored for about one week. Because the experiment started with a dry sample, the relative humidity inside the sample was approximately zero during the pre-test monitoring period, while the room humidity was about 30 to $40 \%$. Water was added to the sample in increments. Each spike in the figure was due to exposing the Humicap to the room air during the water-adding processes. The three spikes in the last segment of the relativehumidity curve were due to some electronic noise of unknown source occasionally received by the data acquisition system. The noise does not seem to affect the quality of the data. The water saturation at each increment of relative humidity shown in the figure was determined based on the amount of water in the sample (by weighing the sample) when the relative humidity had reached a steady state. Currently the relative humidity in the sample is approaching $95 \%$ with a saturation level of about $15.9 \%$. 
These experimental results indicate that in a closed system very high relative humidity can be reached with very small moisture content. The ambient moisture content in the Exploratory Studies Facility (ESF) is estimated to be about $85 \%$. With this ambient moisture content we expect that the relative humidity in the waste package environment, without drying out the rock and without considering thermal gradients, to be near $100 \%$. Corrosion rates in AISI carbon steel were observed to increase notably at relative humidities above 75-80\% (Estill and Gdowski, 1996). The moisture content in the rock will have to be below about $10 \%$ saturation to maintain an environment that dry. At greater temperatures we expect the relative humidity at a given saturation level to be less than shown here, but we don't expect the temperature effect to be great enough to alter the conclusion for the rock itself. However, thermal gradients can modify the relative humidity in drifts or near waste packages by a significant amount. Another observation in this test is the slowness of the vapor diffusion in an intact rock. If this process also occurs in the Topopah Spring tuff rock mass, the increase of moisture content in the matrix due to vapor flow in the fractures will be very slow. Earlier tests indicate that moisture content increases via vapor diffusion are limited to about $20 \%$ saturation. This is consistent with data presented in Section 2.1.1 that show a large decrease in suction potential at saturations near $20 \%$. For greater saturations, the suction potential decreases very little with increasing saturation, an indication that matrix saturation above $20 \%$ by way of vapor transport alone is unlikely.

\subsection{Laboratory Study of Thermal-Hydrological-Chemical Processes}

\subsubsection{Condensation Along a Fracture}

Thermal-hydrological model calculations predict that radioactive decay heat from the waste packages will dry out the surrounding rock mass by evaporating the pore water and will move the vapor away from the waste packages. Based on hydrological tests, both in the laboratory and in the field, and on model calculations, it is believed that fractures are fast paths for the movement of vapor and steam. How the vapor flows within fractures and how the water, which is condensed from the vapor/steam, moves within the fractures affects the moisture distribution in the near field environment. To help understand the thermal-hydrological model predictions and future field thermal tests, we are conducting a laboratory test on a core to study the condensation of vapor in a single fracture.

The core is about $5 \mathrm{~cm}$ in diameter and $35.56 \mathrm{~cm}$ in length. It was machined from a Topopah Spring tuff block that was collected from the Large Block Test site. The core was split in two by a longitudinal saw cut. Eleven pairs of gold shims, $25 \mu \mathrm{m}$ in thickness, were placed evenly along both edges of the saw cut to serve as electrodes and to control the aperture. The 11 electrode pairs were used to measure electrical . resistance in the saw cut, and the measured electrical resistance was used to detect moisture movement within the saw cut. A high-input impedance bridge was used to measure the resistance ( $1 \mathrm{kHz}$ measurement frequency) of each electrode pair at regular time intervals. The largest resistance measurable was $100 \mathrm{M} \Omega$. Ten 
thermocouples were mounted in holes in the sample $90^{\circ}$ from the plane of the saw cut. One thermocouple was placed in each of the top and bottom brass end-caps; one thermocouple was placed in the rock about $2 \mathrm{~mm}$ from the top and bottom ends; six thermocouples were placed within the core, evenly spaced along its axis. The measuring tips of the thermocouples were located very close to the saw cut (within $\sim 3 \mathrm{~mm}$ ). Water was added to the core to obtain a water saturation level of about 95\%. The cylindrical surface of the core was coated with high-temperature RTV silicon cement to prevent moisture loss. The sample assembly was placed vertically on a hot plate. A vapor release tube was installed in the top end-cap and connected to a water collecting bottle. Fiberglass insulation was used to cover the entire cylindrical surface of the core. The core was heated to a constant temperature of about $160^{\circ} \mathrm{C}$ at the bottom; the temperature at the top of the core reached and stayed at about $33^{\circ} \mathrm{C}$. Copper coils for a heat exchanger to control the top temperature were installed on the top of the core, but it was not necessary to use the heat exchanger in this test. Ambient temperature and electrical resistance data were collected for a few hours before the heating started. The sample was heated for about 245 hours, then the heater was turned off. The experiment is now at about 700-hour elapsed time. Data acquisition continued throughout the heating and cool-down phases. Some observations of the test are summarized in the following paragraph. The test is still in progress, therefore the observations and conclusions presented below are preliminary and are subject to reinterpretation upon conclusion of the test.

Figure 2-12 shows the temperature distribution in the sample assembly for the first 300 hours of the test. For the rest of the test beyond 300-hour elapsed time, the temperatures in the sample are all at room temperature. Thermocouple \#1 (Tc1) and thermocouple \#10 (Tc10) were in the bottom brass end-cap and top brass end-cap respectively. Tc2 and Tc9 were located about $2 \mathrm{~mm}$ from the bottom and top of the core respectively. Tc3 to Tc8 were evenly distributed along the core axis from bottom to top respectively. During most of the test the temperatures in the sample were constant. The step-down in temperature at the 200-hour mark was probably caused by an unplanned decrease in the power output from the hot plate. Just before the heater was turned off, at about 245 hours, we opened the insulation material to inspect the integrity of the RTV moisture coating. No obvious breakage in the RTV was observed. Based on the temperature distribution in the core, cooling of the core seems to be slightly faster than the heating. This may be related to the different thermal capacities of the saturated versus partially saturated rock. The reason for the step-up in temperature at the 100-hour mark (Tc2 to Tc10) is unknown. It was probably a real temperature increase, because there was a simultaneous resistance decrease at electrode pairs 6 to 8. Figure 2-13 shows the electrical resistance measured from electrode pairs 1 to 8 for the entire 700-hour duration of the test. The resistance of electrode pairs 9 to 11 were off-scale during the entire period of this test, and therefore are not shown in Fig. 2-2 through 2-13. The high resistance in the upper portion of the core was probably due to water loss in the upper portion of the core. The water loss was likely due to gravity drainage to the lower portion of the core or through a leak near the vapor collection system at the top of the sample. The resistance of all electrode pairs went off-scale at about the 220-hour mark, indicating substantial dry-out before the heater was turned off. This figure shows sequential 
drying of the saw cut from the bottom upward. Figures 2-14 and 2-15 show more detailed variance of the resistance at electrode pairs 1-4 and 5-8 respectively. The resistance decreased at the beginning of the experiment because of the heating of the pore water. As heating continued, resistance increased when the saw cut was drying out because of evaporation. The changing slope of the resistance-time trend in electrode pairs 3 to 8 may be caused by the slowing down of the dry-out process in these portions of the saw cut. The slowing down of the dry-out process may be caused by many factors, such as slower dry-front propagation rate into the matrix, and moisture supply from above, in the form of condensate refluxing. In addition, the resistivity as a function of saturation and temperature for tuff is not a simple relationship, as demonstrated in Section 2.1.3. More detailed observation will be conducted in the future to determine the real cause of this phenomenon.

No vapor was observed to exit the top of the core, and no water was collected in the bottle. The temperature in the core has been decreased to room temperature for at least 350 hours, but no change in the electrical resistance, which would indicate re-wetting, has been observed. Future tests to verify the current observations will be conducted. Those include model calculation of the experimental setup, measurement of electrical resistance perpendicular to the saw cut, thickening the RTV layer to minimize vapor loss, and an improved vapor collection system at the top.

\subsubsection{Fracture Flow vs. Matrix Imbibition at Elevated Temperatures}

As mentioned in Section 2.1.4, the diffusion of vapor into the matrix because of the vapor flow in fractures may not be very effective in transporting moisture. The understanding of how water imbibes into the matrix during fracture flow will become more important for enhancing our knowledge about the coupled TMHC processes. The purpose of this test is to visualize the fracture flow and matrix imbibition process when the sample is at elevated temperatures. By this visualization we hope to determine the parameters, such as fracture aperture, infiltration rate (i.e., the fracture flow rate), initial moisture content of the matrix, and thermal gradient, that may affect the coupling between water flow in fractures and the imbibition into the matrix. The experimental techniques and procedures, and some of experimental results were reported by Roberts and Lin (1996c). Basically, a linear $\mathrm{x}$-ray source of $160 \mathrm{kVp}$ was used to conduct vertical scans of blocks of Topopah Spring tuff containing vertical fractures. Water, doped with KI to enhance the $x$-ray attenuation contrast, was introduced into the top of the fracture. X-ray radiographs were taken periodically to image the movement of water in the fracture and the matrix. Images were normalized using aluminum standards. After the normalization, difference images were created by subtracting a beginning image from the subsequent images. In this manner only the relative changes in the $x$-ray images are studied. All the $x$-ray images presented in this report use the following convention: darker shades indicate higher $\mathbf{x}$-ray attenuation (or changes in attenuation) and imply higher water content, and lighter shades indicate relatively low x-ray attenuation (or changes in attenuation) and imply lower water content. Quantitative saturation fields can be calculated but are not presented here (see Tidwell and Glass, 1994, or Roberts and Lin, 1996c). 
So far four experiments have been conducted: (1) fracture flow and matrix imbibition in an artificially induced tensile fracture without shims; (2) fracture flow and matrix imbibition in the same fracture as in experiment (1) with four shims of $25-\mu \mathrm{m}$ thickness; (3) after completion of test (2), dehydration of the sample under a thermal gradient of about $95^{\circ} \mathrm{C}$ at the bottom and $33^{\circ} \mathrm{C}$ at the top; and (4) fracture flow and matrix imbibition against a thermal gradient, tested in another Topopah Spring tuff block that contained nine $25-\mu \mathrm{m}$ gold shims. The results of the first three experiments were reported in Roberts and Lin (1996c) and are summarized later in this report. The sample dimensions for experiments (1), (2), and (3) were $14 \times 10 \times 2.5$ $\mathrm{cm}$ (length, height, width). Experiment (4) is described in the following paragraph, and its results are summarized later, along with the results of the first three experiments.

In the fourth experiment, a dry block of Topopah Spring tuff machined from a small block of the rock collected at the Large Block Test site was used. The dimensions of the block were $29.21 \mathrm{~cm}$ tall by $15.1 \mathrm{~cm}$ wide by $2.65 \mathrm{~cm}$ thick. The sample preparation and test procedures were similar to the preceding experiments, with the exceptions noted here. Nine $25-\mu \mathrm{m}$ gold shims were placed inside the tensile fracture at regular intervals. Five thermocouples were placed inside the rock at $0.2,7.5,14.8,22.1$, and $29.1 \mathrm{~cm}$, from the bottom of the sample to the top, respectively. The temperatures in the dry rock prior to flow were 115, 48.4, 33.8, 29.4, and $28.1^{\circ} \mathrm{C}$, from bottom to top. The temperature between the heater and the bottom of the sample was $126^{\circ} \mathrm{C}$. Even though insulation was used wherever possible, a relatively large temperature gradient existed at the bottom of the sample. Initial images were taken, and then water was permitted to pond on the sample. Only the fractured region on top $(\sim 1 \mathrm{~cm}$ wide) was exposed directly to the ponded water, the other areas having been coated with RTV.

The results of the four fracture flow and matrix imbibition experiments are summarized here. Figure 2-16 shows the $x$-ray difference image of fracture flow and matrix imbibition in a tensile fracture without shims, at room temperature. The fracture is located near the left edge of the image. Water was ponded at the top of the image. The darker region represents the region where water has wetted the sample, 47.3 hours after the ponding started. The roughly V-shaped wetted region, with the tip of the "V" at the front of the fracture flow, is very similar to that of fracture flow in a block of plaster of Paris with 25- $\mu \mathrm{m}$ shims that had been used as a test of analytical approaches of fracture/matrix interactions (Fig. 2-17). The matrix permeability of the tuff is about 3 orders of magnitude less than that of the plaster of Paris. The result of this experiment indicates that fracture flow and matrix imbibition in an unshimmed tensile fracture in tuff is qualitatively similar to that in a material with a higher permeability matrix that contains a fracture with greater aperture. Figure 2-18 shows a sequence of $x$-ray difference images of fracture flow and matrix imbibition in the same fracture shown in Fig. 2-16, except that four gold shims of $25-\mu \mathrm{m}$ thickness were placed in the fracture. The test was also conducted at room temperature. There is no V-shaped wetted region, as seen in Figs. 2-16 and 2-17. Water flowed through the fracture within a couple of minutes (Fig. 2-18a), then matrix imbibition began. The imbibition into the matrix was faster on the right side of the sample as compared to the left side. This is more evident at longer times 
(Fig. 2-18c). Examination of the fractured sample after the experiment revealed pumice fragments near the areas where lateral imbibition was the fastest. Small microfractures around the edges of these fragments are believed responsible for the enhanced lateral imbibition.

The larger fracture aperture changed significantly both the volume of flow through the fracture and the rate and amount of imbibition into the matrix. These effects are being studied further because they have bearing on models of repository performance.

Figure 2-19 shows the movement of the wetting front versus the square root of time for three locations: within the fracture $(\sim 1 / 3$ the distance from the top of the sample on both sides of the fracture) and the top of the sample $(\sim 3.5 \mathrm{~cm}$ from the left edge of the sample). The wetting front was arbitrarily defined as $75-80 \%$ saturated. The large variability in matrix imbibition is evident in this figure. The imbibition from ponded water on top of the sample was slowed considerably by a relatively impermeable crystal-lined cavity (low attenuation region-may be porous area) $\sim 1 \mathrm{~cm}$ beneath the surface. After an initial time lag, all three locations are linear with respect to time ${ }^{1 / 2}$. The slope of this line is related to permeability.

Figure 2-20 shows the $x$-ray image of the drying process of the sample as in experiment (2) after the infiltration had totally wetted the sample. Again, as in the previous experiment, the fracture had four shims of $25-\mu \mathrm{m}$ thickness within it. The drying was created by using a heater at the bottom of the sample to maintain the temperature there at about $95^{\circ} \mathrm{C}$, while the temperature at the top of the block was about $30^{\circ} \mathrm{C}$. The image shows that the fracture was dried out within hours after the heater was turned on. A darker horizontal region near the lower part of the image seems to indicate greater $x$-ray attenuation. The greater attenuation may be because of increase in water saturation or deposition of KI. Because the higher attenuation band changed shape and moved up and down slightly during the sequence, it is believed that it represents increased saturation in this instance.

As mentioned previously, the fourth experiment was designed to visualize the fracture flow and matrix imbibition in a heated block of fractured Topopah Spring tuff. Based on examination of difference images, several important features were noted. Figure 2-21 $(a, b, c)$ shows images taken at $1.7,73.5$, and 360 hours respectively and illustrates most of the following points. Initially, water flowed relatively quickly into the rock with minimal lateral imbibition into the matrix from the fracture, similar to that in Experiment (2). By 1.6 hours, water had flowed $\sim 16 \mathrm{~cm}$ down the fracture with the width of the highly saturated zone $\sim 0.8$ to $1.5 \mathrm{~cm}$ (Fig. 2-21a). At this point, downward flow slowed considerably and lateral imbibition continued. The most likely reason for the stop in downward flow is the existence of a low density (i.e., more porous) pumice fragment at $\sim 16 \mathrm{~cm}$ from the top. After $\sim 23$ hours the water began to move past this region as a V-shaped wetting front. The highly saturated zone was $\sim 2.2$ to $3.5 \mathrm{~cm}$ wide. Water continued to travel down the fracture until $\sim 27$ hours, when a narrow region of high $x$-ray attenuation began to develop in the fracture between $\sim 22.6$ and $26.3 \mathrm{~cm}$ (from top). At longer periods of time, a circular region of high $x$-ray attenuation developed near the bottom of the sample, centered on the fracture (Fig. 2-21b). Because this is the hottest region of the rock, where temperature was above the boiling point of water, a likely reason is the 
concentration of $\mathrm{KI}$ (used as a dopant to increase $\mathrm{x}$-ray attenuation) in these regions. Water never penetrated the entire sample; that is, water never was observed to exit the bottom of the sample past the "boiling zone." Although dependent upon many factors (i.e., hydraulic head, porosity, permeability, pore size distribution), this could be a very important observation because it indicates that condensate will not penetrate the boiling zone for fractures less than some critical aperture. Additional studies are needed to verify and determine the aperture dependence. Continued lateral imbibition was observed up until the experiment was stopped at $\sim 360$ hours elapsed time; however, it appeared that the rate of advancement of the wetting front slowed as time progressed (Fig. 2-21c).

The results of this experiment suggest that rock heterogeneity plays a significant role in the speed at which water flows down gradient in a fracture. Although not conclusive, the existence of a boiling region stopped downward flow, while lateral imbibition continued. Post-experimental examination of the fracture surface near the boiling zone revealed small crystals. It is thought that these are $\mathrm{KI}$ crystals indicative of boiling and would explain the higher $x$-ray attenuation discussed above. Thus the resultant increased $x$-ray attenuation in the boiling region was probably a result of crystal formation rather than of increased saturation.

\subsubsection{Fracture Healing}

As mentioned in Section 2.1.2, the laboratory-determined water permeability of fractured Topopah Spring tuff samples at elevated temperatures behaves differently than that of intact samples. The water permeability in the fractured tuff samples decreases with increasing temperature. A series of laboratory experiments were conducted to understand the mechanism(s) that may cause the fracture healing. Those experiments have been reported by Lin and Daily (1984), Daily et al. (1987), Lin and Daily (1988), Lin (1991), Roberts and Lin (1995b), and Lin et al. (1995). The experimental techniques were described in Lin and Daily (1984). All of these experiments were designed to measure water permeability in fractured Topopah Spring tuff samples as functions of temperature, under various sample and experimental conditions that included reopened natural fractures, introduced tensile fracture, saw cut without shims, naturally fractured sample in a thermal gradient, and naturally fractured sample with variable pressure differences (confining pressure minus pore pressure). To understand the fracture healing process, we also conducted tests to investigate the effects of temperature and pressure on dry gas permeability, the effect of heating a saturated sample with water not flowing on the water permeability at room temperature, and the effect of flowing steam on gas permeability. In some of these experiments, the water that flowed through the samples was analyzed for concentration of certain elements, such as $\mathrm{Si}, \mathrm{Ca}, \mathrm{K}$, etc. Also for some experiments the scanning electron microscope (SEM) was used to image the fracture surfaces before and after the experiments. The results of earlier experiments and a discussion of the mechanisms of fracture healing were reported in NFER Rev. 0 . The results of these experiments are summarized in the following paragraphs.

The results of all of these experiments showed that flowing high-temperature (greater than $90^{\circ} \mathrm{C}$ ) water through fractured tuff samples under compression caused 
water permeability to decrease significantly. This was true for both uniformly heated samples and samples under a thermal gradient. Flowing steam through a naturally fractured sample for about one week also decreased the dry $\mathrm{N}_{2}$ permeability measured at room temperature before and after the steam-flowing by about one order of magnitude. Flowing dry $\mathrm{N}_{2}$ gas in fractured tuff samples under the same temperature and pressure conditions did not affect the gas permeability. Heating a saturated fractured tuff sample when water was not allowed to flow during heating did not affect the water permeability at room temperature. Based on these observations and the results of chemical analyses of the water, and SEM studies of the fracture surfaces, we concluded that dissolution and deposition of minerals, such as silica by the water in the fracture surfaces, may smooth out asperities and cause the fracture aperture to decrease under confining pressure. These processes are relatively insensitive to the type of fracture surface, such as natural fracture, rough tensile fracture, and smooth saw cut (NFER Rev. 0).

Recent study of fracture healing at various differential pressures reveals more detailed information about the healing mechanism. Figure 2-22 shows the water permeability of a naturally fractured tuff sample with respect to time. The figure also shows water permeability and confining pressure with respect to time during the experiment. The pore pressure in the sample was kept constant at $0.5 \mathrm{MPa}$, therefore the variation of confining pressure equals the variation of differential pressure. The experiment consisted of several parts. First the confining pressure was cycled from 1 to 5 to $1 \mathrm{MPa}$ at ambient temperature. Next were several cycles in temperature, from approximately 25 to 150 to $25^{\circ} \mathrm{C}$ at constant confining pressures $(1,2,3$, and $5 \mathrm{MPa})$.

The first decrease in permeability, as shown in Fig. 2-22 at about 400 hours elapsed time, was caused by increasing confining pressure at room temperature. When the confining pressure was released, the permeability recovered to its original value. This shows that a confining pressure of $5 \mathrm{MPa}$ at room temperature is not enough to cause any nonelastic deformation on the fracture surfaces. Upon heating, the permeability began to decrease as soon as temperature started to increase, even at the lowest differential pressure, $0.5 \mathrm{MPa}$. For the entire experiment the permeability decreased from about $18 \times 10^{-15} \mathrm{~m}^{2}(18 \mathrm{mD})$ to about $2 \times 10^{-15} \mathrm{~m}^{2}(2 \mathrm{mD})$. Most of that decrease in permeability was accomplished during the first heating cycle.

Figure 2-23 shows the $\mathrm{Si}$ concentration in the water that flowed through the sample during the test, and temperature as a function of the elapsed time. The two $x$ 's at the zero elapsed time are the Si concentration in the virgin J-13 water, before it flowed through the sample. With regard to $\mathrm{Si}$ concentration and permeability decreases, the experiment can be divided into two parts as indicated by the line at $\sim 2000 \mathrm{hr}$ on both Figure 2-22 and 2-23. The largest decrease in permeability occurred during the first thermal cycle prior to $2000 \mathrm{hr}$ (from $18 \times 10^{-15} \mathrm{~m}^{2}$ to about $6 \times 10^{-15}$ $\mathrm{m}^{2}$ [18 to $\left.6 \mathrm{mD}\right]$ ). Also note that during the first thermal cycle the Si concentration in the water was below that in the virgin J-13 water until the temperature reached $150^{\circ} \mathrm{C}$, and the fluid exiting the sample was undersaturated with respect to Si during this period. This indicates that during the first heating phase $\mathrm{Si}$ may have been deposited on the fracture surfaces. After $2000 \mathrm{hr}$, during subsequent heating cycles, the permeability change is much less than the first thermal cycle (about $6 \times 10^{-15} \mathrm{~m}^{2}$ to $2 \times 10^{-15} \mathrm{~m}^{2}$ [6 to $\left.2 \mathrm{mD}\right)$ and the water is saturated with respect to $\mathrm{Si}(\alpha-$ 
cristobalite; W. Glassley, personal communication, 1995). As observed in Figure 2-23, the $\mathrm{Si}$ concentration is strongly correlated with temperature during this period. During this period permeability does show a relationship with confining pressure, because permeability decreases with increasing confining pressure. As shown in Fig. 2-22, slight increases in permeability were observed at the end of thermal cycles because of cooling (e.g., $2900 \mathrm{hr}$ ). Under the condition of Si saturation, both dissolution and deposition of Si can occur. However, the dissolution and deposition were probably not very active because the corresponding decreases in permeability were not significant. In addition, during the later part of the test the fracture surfaces may be smoother than before; therefore the effect of dissolution and deposition on permeability may be reduced.

The coupled processes that are evident in this experiment demonstrate a complex relationship, and the subsequent effect they have on the permeability is often difficult to fully understand. This experiment provides us with some indication of which specific process is active during the different portions of the test. During the first temperature cycle, thermal-chemical processes seem to dominate hydrologic changes. Later, when the Si concentration reached saturation, thermalmechanical processes appear to most affect the permeability. This test confirms the previous conclusion that rock-water interaction is probably the cause of the fracture healing. In addition, it shows that permeability in fractured tuff samples can decrease even at very low pressure. It also indicates that the rock-water interaction was most active during the initial heating of the sample. In terms of modeling and understanding repository design and performance, this is an extremely important result and is worthy of more study. If the laboratory-observed phenomena also occur in situ, these coupled processes can have a potentially large effect on the movement of condensate, the importance of preferential pathways, and the effective local permeability, as well as on other issues related to repository design. 


\subsection{References}

Daily, W., W. Lin, and T. Buscheck, 1987, "Hydrology of Topopah Spring TuffLaboratory Measurements," J. Geophys. Res. 92, No. B8, pp. 7854-7864. NNA.19900123.0064

Daily, W., and W. Lin, 1991, "Laboratory Determined Suction Potential of Topopah Spring Tuff at High Temperatures," Proceedings of the Second Annual International Conference on High Level Radioactive Waste Management, Las Vegas, NV, April 28May 3, 1991, American Nuclear Society, Inc., La Grange Park, IL, pp. 583-588. NNA.19910304.0097

Estill, J.C., and G.E. Gdowski, 1996, "Water vapor effects of the corrosion of carbon steel," Proceedings of the Seventh Annual International Conference on High Level Radioactive Waste Management, Las Vegas, NV, April 29-May 3, 1996, American Nuclear Society, Inc., La Grange Park, IL, pp. 457-458.

Klavetter, E.A., and R.R. Peters, 1987, An Evaluation of the Use of Mercury Porosimetry in Calculating Hydrologic Properties of Tuff from Yucca Mountain, Nevada, SAND860286, Sandia National Laboratory, Albuquerque, NM. NNA19890327.0056

Lin, W., 1991, "Variation of Permeability with Temperature in Fractured Topopah Spring Tuff Samples," Proceedings of the Second Annual International Conference on High Level Radioactive Waste Management, Las Vegas, NV, April 28-May 3, 1991, American Nuclear Society, Inc., La Grange Park, IL, pp. 988-993. NNA.19910523.0105

Lin, W., and W. Daily, 1984, Transport Properties of Topopah Spring Tuff, Lawrence Livermore National Laboratory UCRL-53602, Livermore, CA. NNA.19891026.0025

Lin, W., and W. Daily, 1988, "Hydrological Properties of Topopah Spring Tuff under a Thermal Gradient, Laboratory Results," International Journal of Rock Mechanics, 27, \#5, pp. 373-385. NNA.19880503.0014

Lin, W., J.J. Roberts, W. Glassley, and D. Ruddle, 1995, The Effect of Rock-water Interaction on Permeability, Lawrence Livermore National Laboratory UCRL-JC119574, Livermore, CA. MOL.19960416.0275

Lin, W., J.J. Roberts, and D. Ruddle, 1996, "Relative humidity in the near-field environment," Proceedings of the Seventh Annual International Conference on High Leoel Radioactive Waste Management, Las Vegas, NV, April 29-May 3, 1996, American Nuclear Society, Inc., La Grange Park, IL, pp. 128-129. MOL.19960422.0127

Moore, D.E., C.A. Morrow, and J.D. Byerlee, 1986, "High-temperature permeability and groundwater chemistry of some Nevada Test Site Tuffs," J. Geophys. Res., 91, No. B2, pp. 2163-2171.

Peters, R.R., E.A. Klavetter, I.J. Hall, S.C. Blair, P.R. Heller, and W.G. Gee, 1984, Fracture and Matrix Hydrologic Characteristics of Tuffaceous Materials from Yucca Mountain, Nye County, Nevada, SAND84-1471, Sandia National Laboratory, Albuquerque, NM. NNA.19900810.0674 
Ramirez, A., T. Buscheck, R. Carlson, W. Daily, K. Lee, W. Lin, N. Mao, T. Ueng, H. Wang, and D. Watwood, 1991, Prototype Engineered Barrier System Field Test (PEBSFT) Final Report, A. Ramirez, Scientific Editor, Lawrence Livermore National Laboratory UCRL-ID-106159, Livermore, CA. NNA.19910711.0047 Roberts, J.J., and W. Lin, 1994a, Hydrological Property Measurements of Topopah Spring Tuff, Lawrence Livermore National Laboratory UCRL-ID-119033, Livermore, CA. MOL.19950501.0032

Roberts, J.J., and W. Lin, 1994b, "Electrical properties of Topopah Spring tuff as a function of saturation," Proceedings of the Fifth Annual International Conference on High Level Radioactive Waste Management, Las Vegas, NV, May 22-26, 1994, American Nuclear Society, Inc., La Grange Park, IL, pp. 2112-2120.

NNA.19940524.0018

Roberts, J.J., and W. Lin, 1995a, Hydrological Property Measurements of Topopah Spring Tuff, Lawrence Livermore National Laboratory UCRL-ID-119033, Livermore, CA. MOL.19950501.0032

Roberts, J.J., and W. Lin, 1995b, "Permeability of Fractured Tuff as Functions of Temperature and Confining Pressure," Proceedings of the Sixth Annual International Conference on High Level Radioactive Waste Management, Las Vegas, NV, April 30-May 5, 1995, American Nuclear Society, Inc., La Grange Park, IL, pp.44-45. MOL.19960109.0097

Roberts, J.J., and W. Lin, 1996a, Report on Laboratory Tests of Drying and Re-Wetting of Intact Rocks, Lawrence Livermore National Laboratory UCRL-ID-121513, Livermore, CA. MOL.19960409.0179

Roberts, J.J., and W. Lin, 1996b, Electrical Properties of Partially Saturated Topopah Spring Tuff. Water Distribution as a Function of Saturation, Lawrence Livermore National Laboratory UCRL-JC-123763, Livermore, CA. (submitted to Water Resources Research)

Roberts, J.J., and W. Lin, 1996c, "X-ray radiography of fracture flow and matrix imbibition," Proceedings of the Seventh Annual International Conference on High Level Radioactive Waste Management, Las Vegas, NV, April 29-May 3, 1996, American Nuclear Society, Inc., La Grange Park, IL, pp. 128-129. MOL.19960409.0159 Tidwell, V.C., and R.J. Glass, 1994, "X-ray and visible light transmission for laboratory measurement of two-dimensional saturation fields in thin-slab systems," Water Resources Research, 30, 2873-2882.

Data Tracking Information in this Chapter:

2.1.1 Moisture Retention at Elevated Temperatures

(Data Tracking Numbers: LL950404604242.012 and LL950812704242.017)

2.1.3 Electrical Resistivity as a Function of Water Saturation at Elevated Temperatures (Data Tracking Numbers: LL950404604242.012 and LL960201404244.011)

2.1.4 Relative Humidity as a Function of Water Saturation at Elevated Temperatures (Data Tracking Numbers: LL960100604244.007 and LL960201304244.010)

2.2.2 Fracture Flow vs. Matrix Imbibition at Elevated Temperatures (Data Tracking Number: LL960100704244.008)

2.2.3 Fracture Healing

(Data Tracking Numbers: LL950404604242.012, LL950916504242.018, LL950406104242.016, and

LL940800704242.002) 


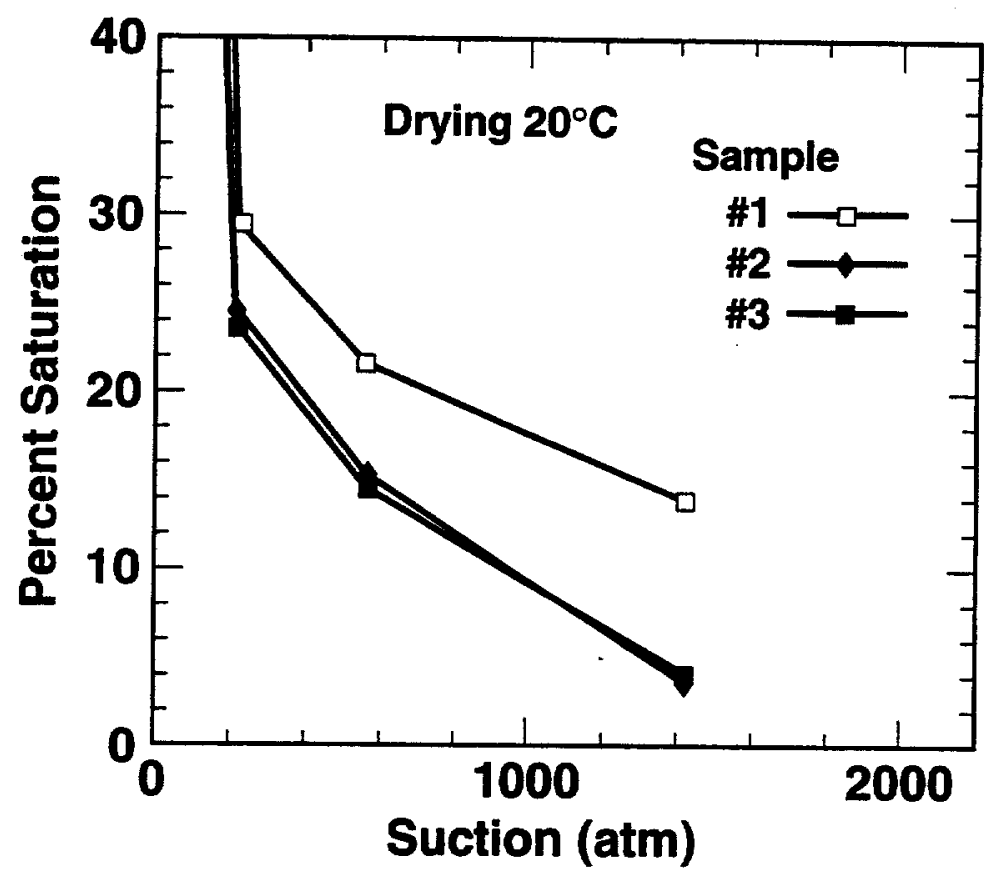

Figure 2-1. Percent saturation as a function of suction potential measured at $20^{\circ} \mathrm{C}$ for three samples of Topopah Spring tuff. Samples were initially saturated so that these data are the capillary suction for drying. All samples were taken from USW H-1 core.

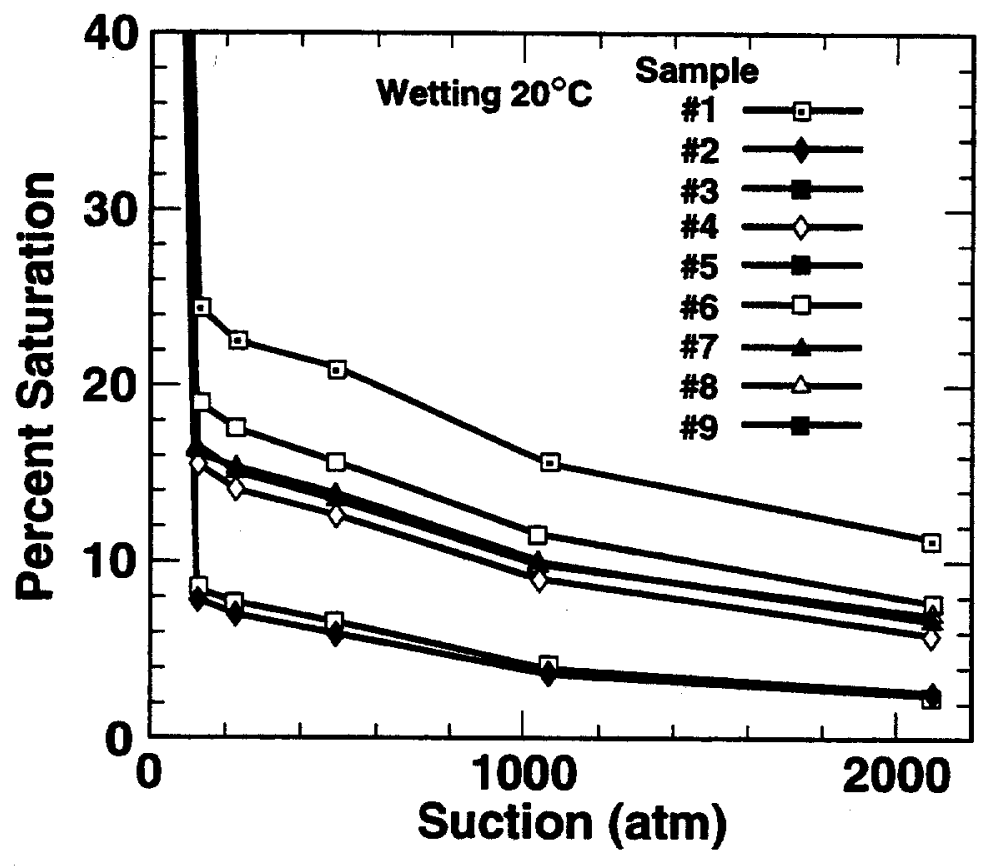

Figure 2-2. Percent saturation as a function of suction potential measured at $20^{\circ} \mathrm{C}$ for nine samples of Topopah Spring tuff. Samples were initially dry so that these data are the capillary suction for wetting. Samples 1-3 were taken from USW H-1 core; samples 4-9 were taken from Fran Ridge outcrop. 


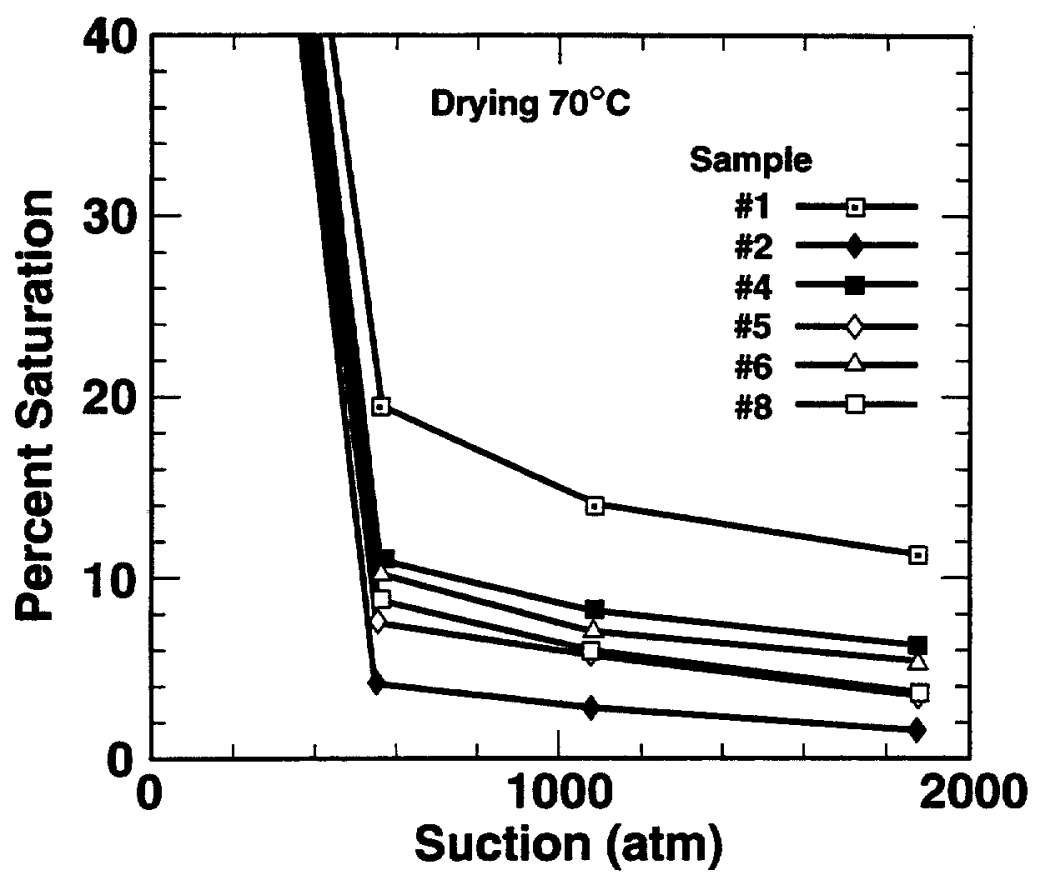

Figure 2-3. Percent saturation as a function of suction potential measured at $70^{\circ} \mathrm{C}$ for six samples of Topopah Spring tuff. Samples were initially saturated so that these data are the capillary suction for drying. Samples 1 and 2 were taken from USW H-1 core, and the others were taken from Fran Ridge outcrop.

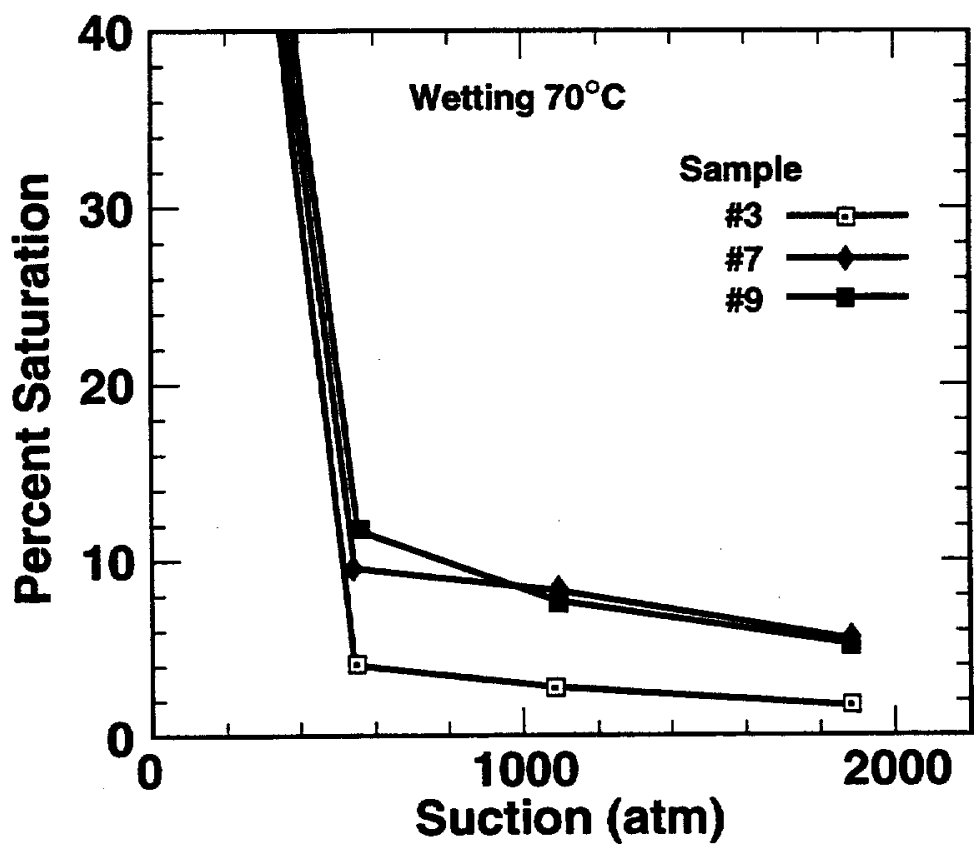

Figure 2-4. Percentage saturation as a function of suction potential measured at $70^{\circ} \mathrm{C}$ for three samples of Topopah Spring tuff. Samples were initially dry so that these data are the capillary suction for wetting. Sample 3 was taken from USW H-1 core; samples 7 and 9 were taken from Fran Ridge outcrop. 
- 


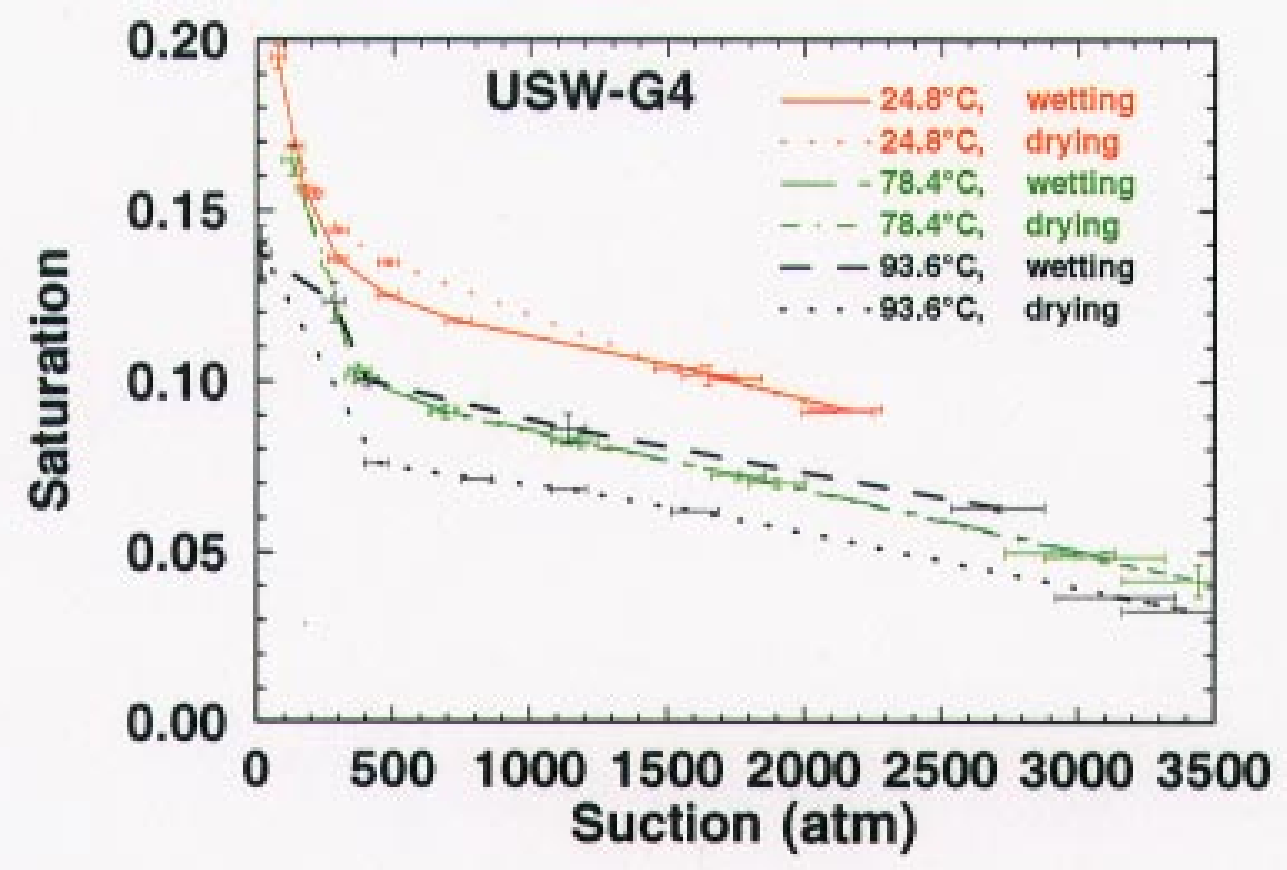

Figure 2-5. Saturation as a function of suction (atmospheres) for USW G-4. Wetting and drying curves are shown for three temperatures. The lines are not fitted curves but indicate the connection between points that are averaged for several samples. Error bars for suction assume $2 \%$ error in the relative humidity measurement. Note the reversal in hysteresis from low to high temperature.

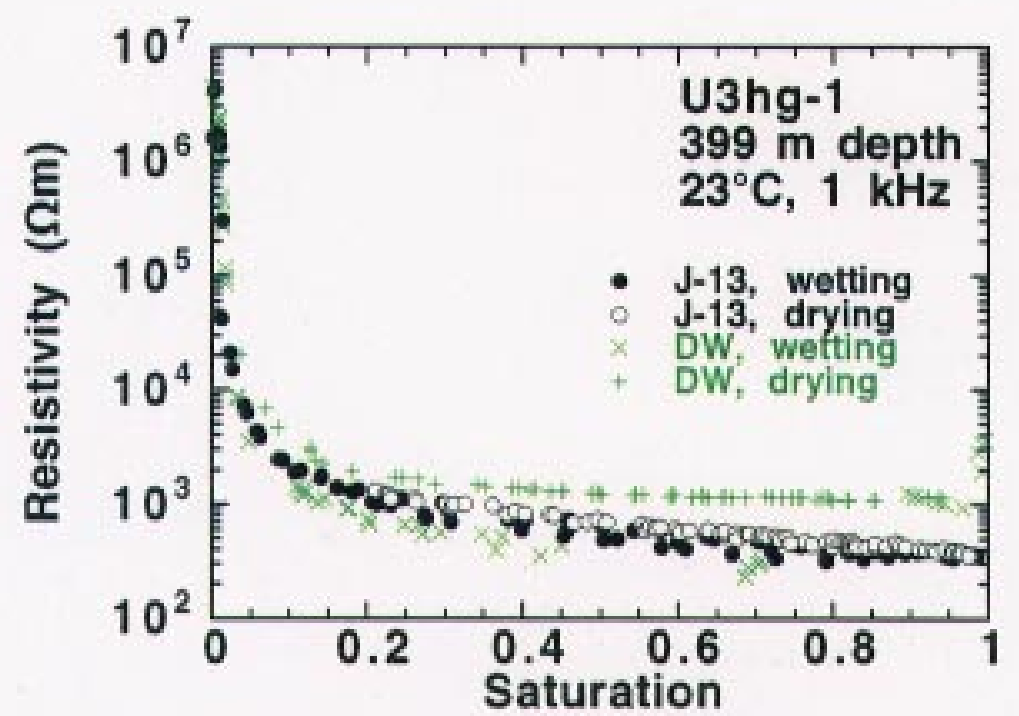

Figure 2-6. Electrical resistivity of U3hg-1 samples as a function of water saturation at room temperature, using J-13 water and distilled water (DW) as saturating fluid. 



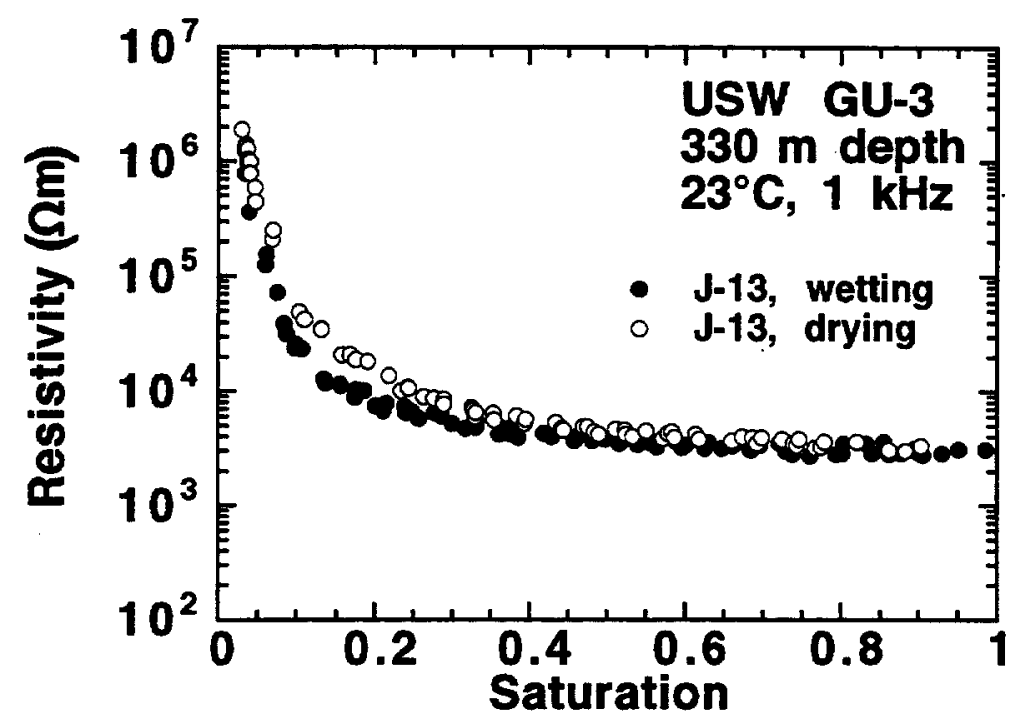

Figure 2-7. Electrical resistivity of USW GU-3 samples as a function of water saturation at room temperature, using $\mathrm{J}-13$ water as saturating fluid.

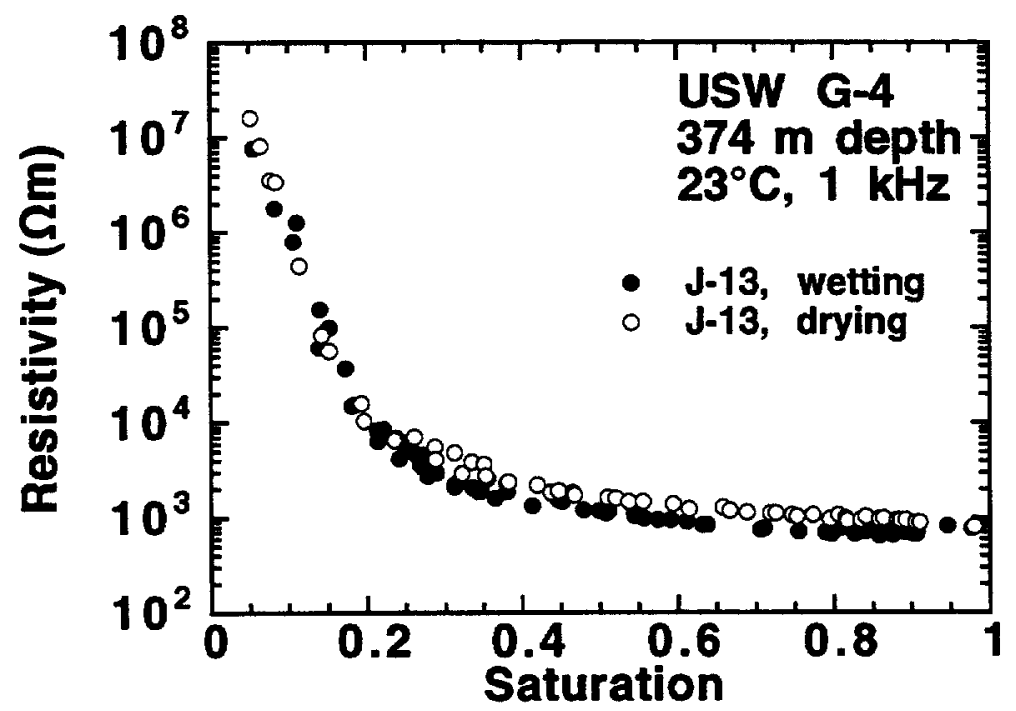

Figure 2-8. Electrical resistivity of USW G-4 samples as a function of water saturation at room temperature, using $\mathrm{J}-13$ water as saturating fluid. 


$$
-
$$




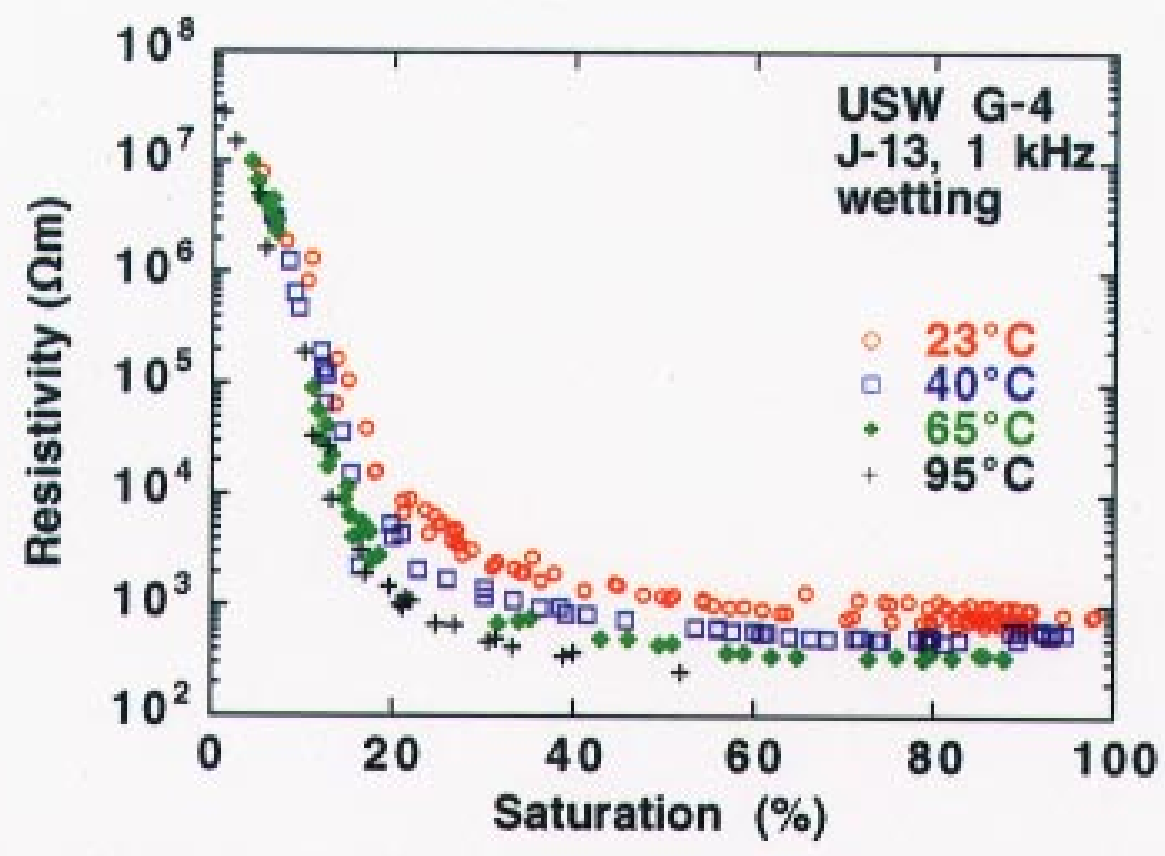

Figure 2-9. Electrical resistivity of USW G-4 samples as a function of water saturation at elevated temperatures, using J-13 water as saturating fluid.

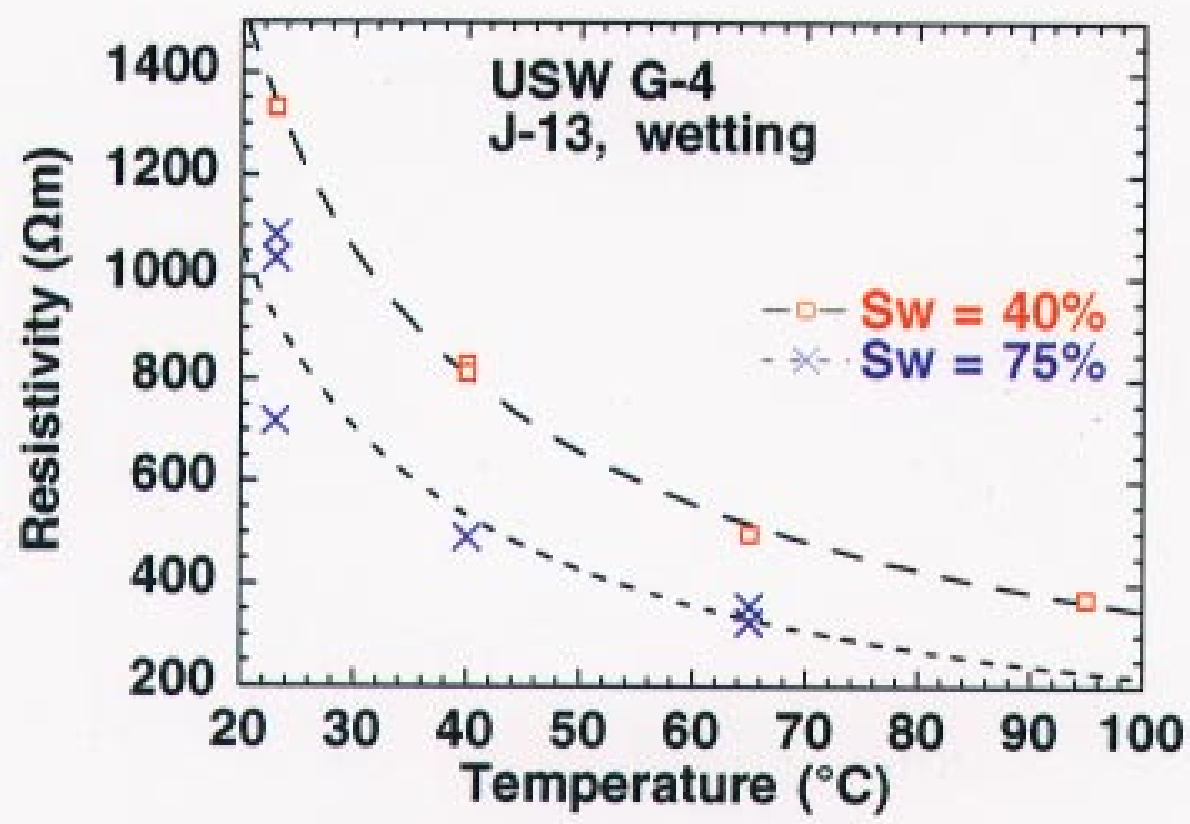

Figure 2-10. Resistivity $(\Omega \mathrm{m})$ of Topopah Spring tuff as a function of temperature for two saturations, 40 and $75 \%$. Data are for the saturation cycle of samples from USW G-4 using J-13 water. Curves are power law fits. Between 20 and $100^{\circ} \mathrm{C}$ there is approximately a factor of 3 to 4 reduction in resistivity. Over the same temperature span the resistivity of J-13 water decreases by about a factor of 2 . 


$$
-
$$




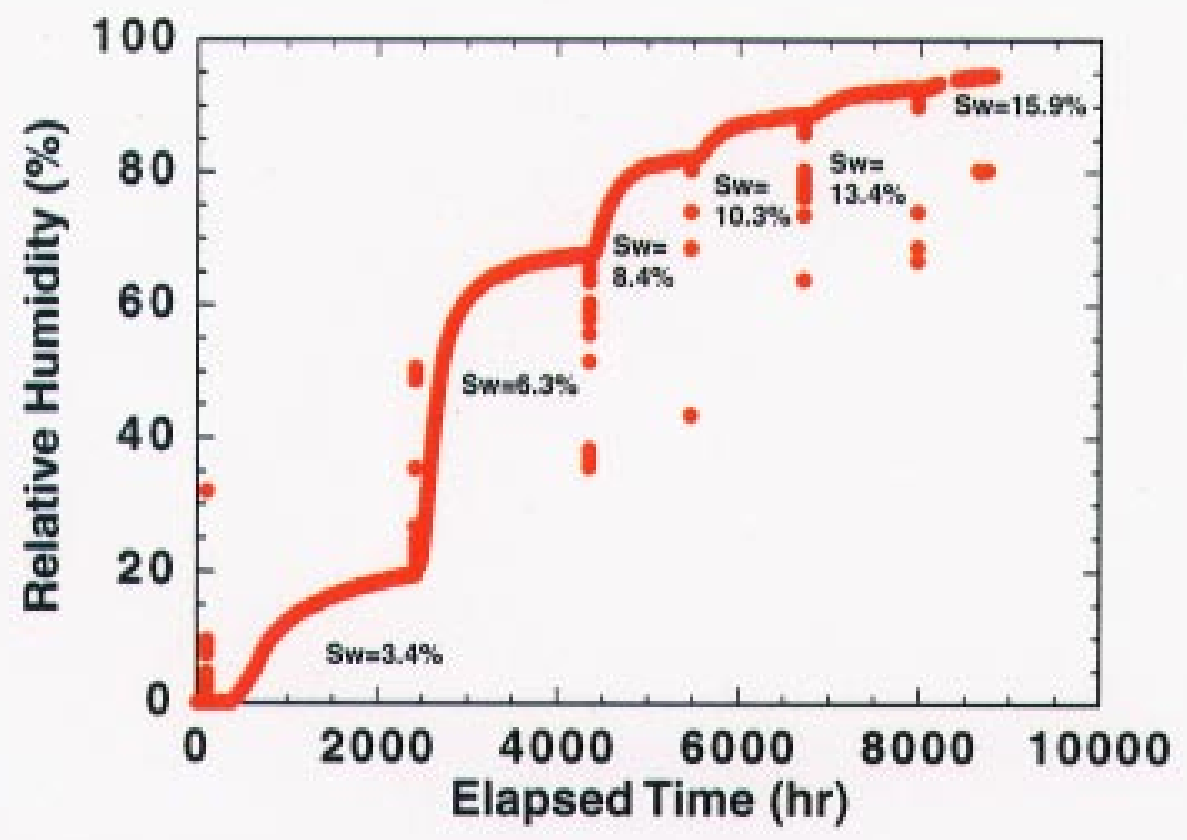

Figure 2-11. Relative humidity in an intact Topopah Spring tuff sample and water saturation as a function of elapsed time.

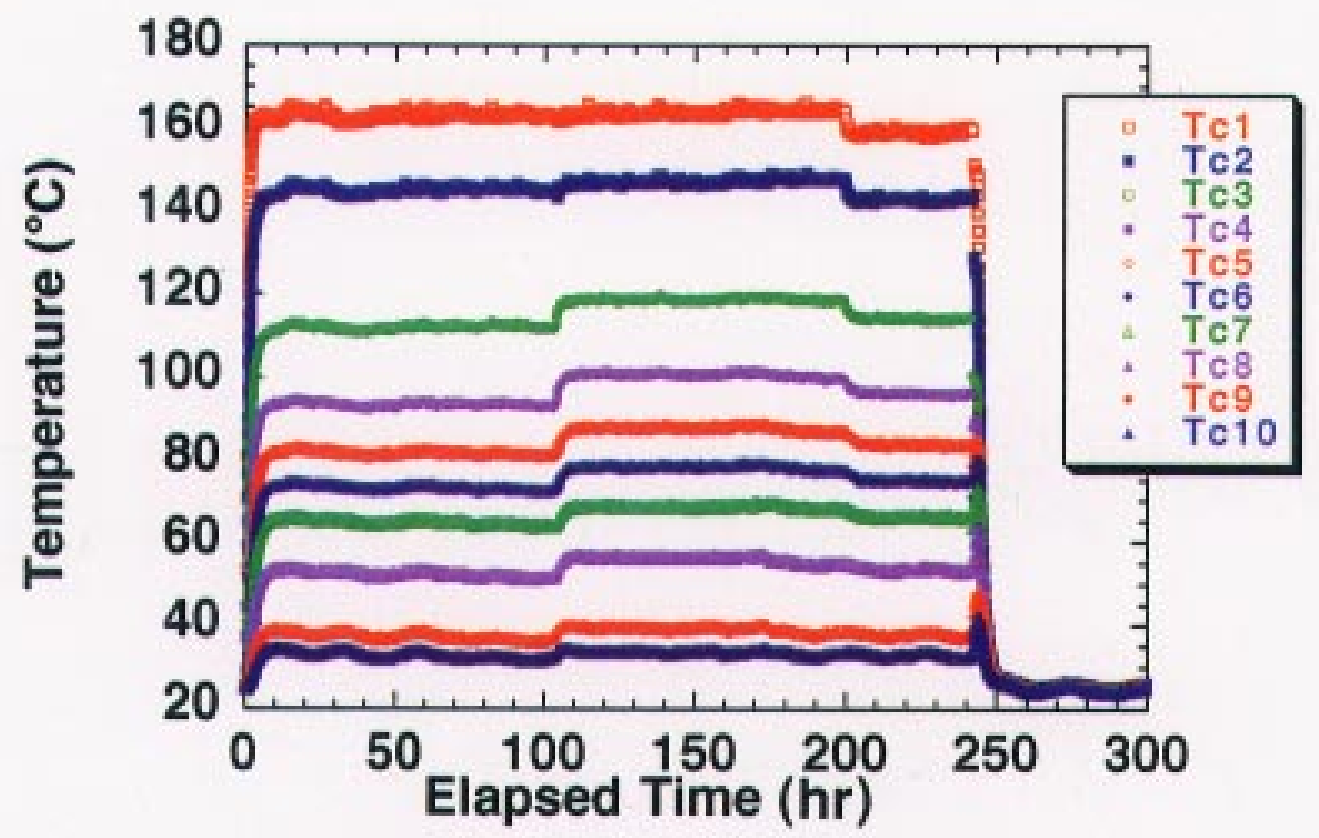

Figure 2-12. Temperatures in the 35.56- $\mathrm{cm}$ core during the vapor condensation along a fracture experiment as a function of time. Thermocouples Tc1 to Tc10 are from the bottom to the top of the sample, respectively. 



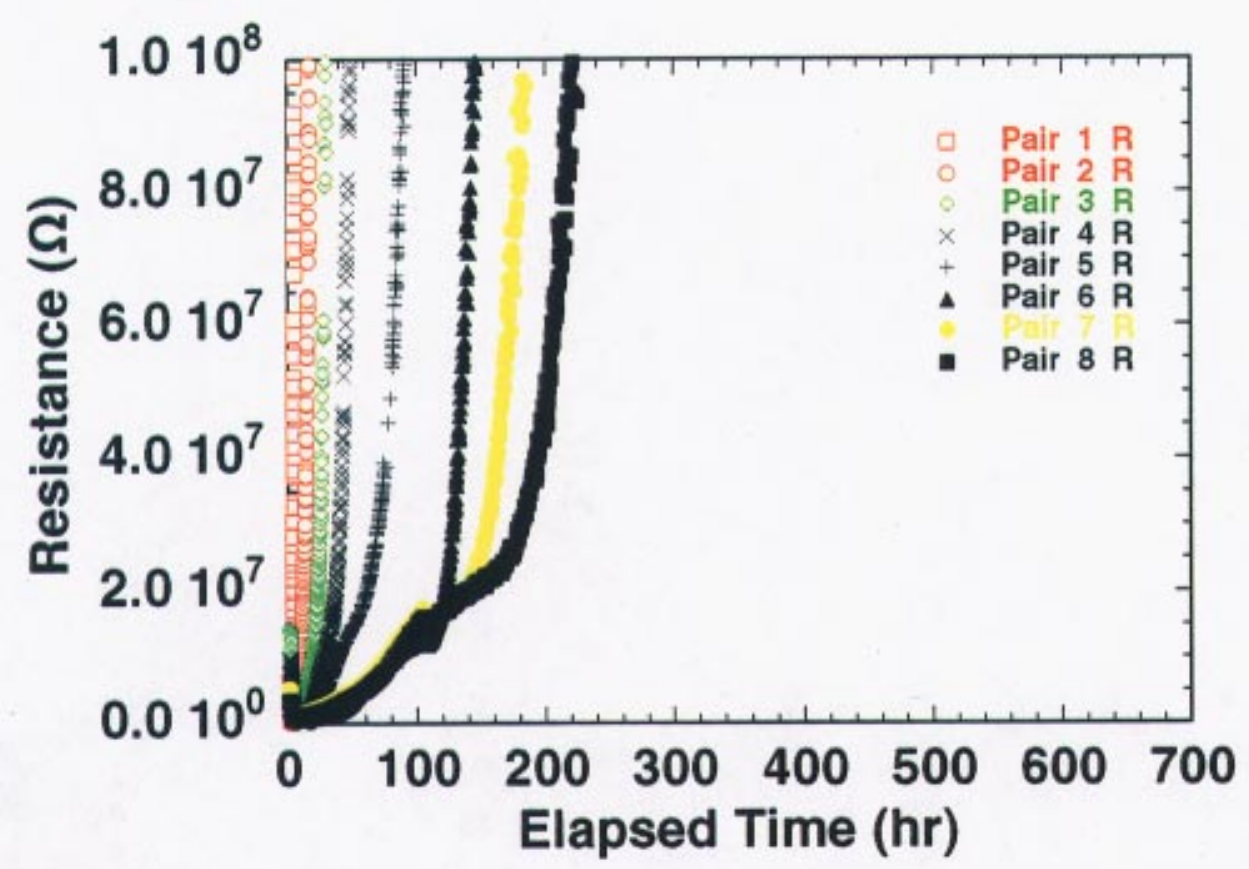

Figure 2-13. Electrical resistance in the $35.56-\mathrm{cm}$ core during the vapor condensation along a fracture experiment as a function of time. Electrode pairs 1 to 8 are from the bottom to the top of the sample, respectively.

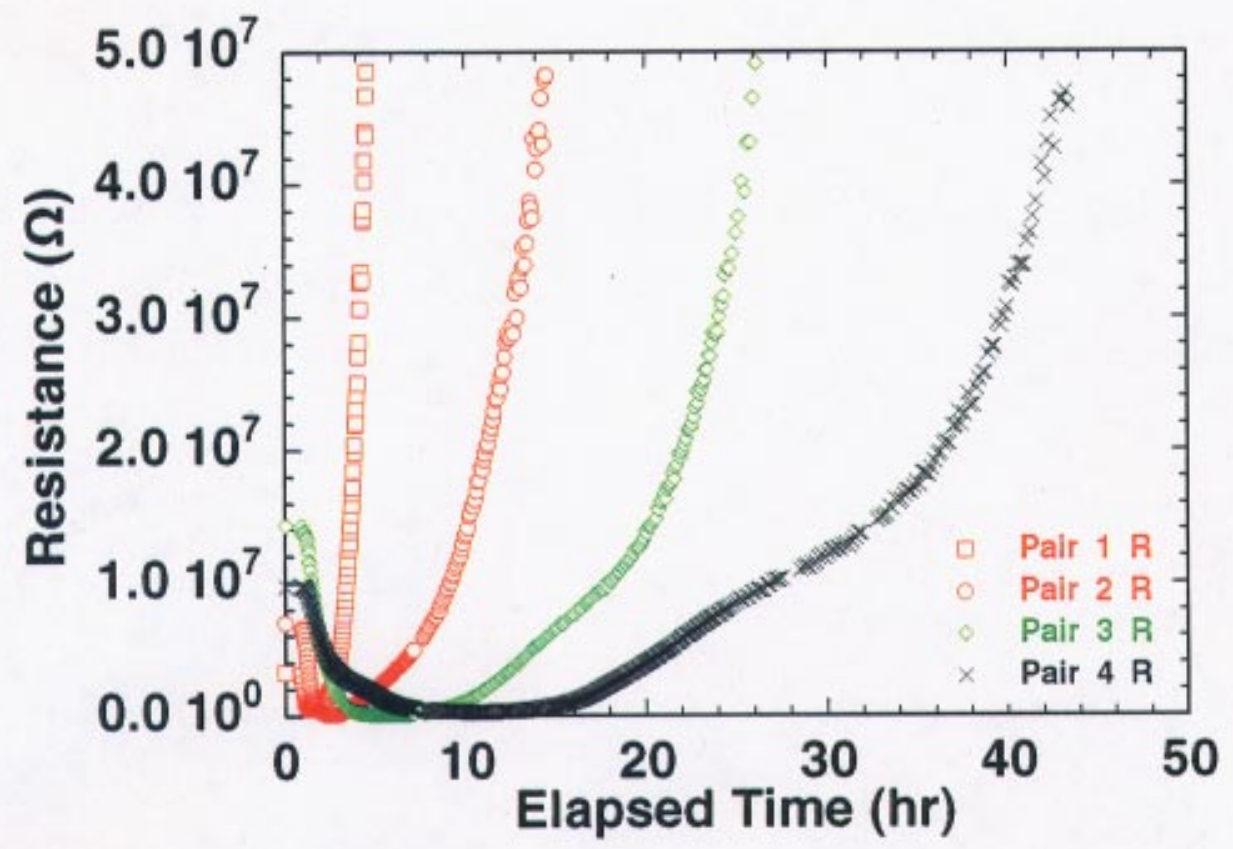

Figure 2-14. Electrical resistance at electrode pairs 1 to 4 in the $35.56-\mathrm{cm}$ core during the vapor condensation along a fracture experiment as a function of time. 
7
7
7
7
7
7
$?$
7
7
7
7
7
7
7
7
9
7
7 


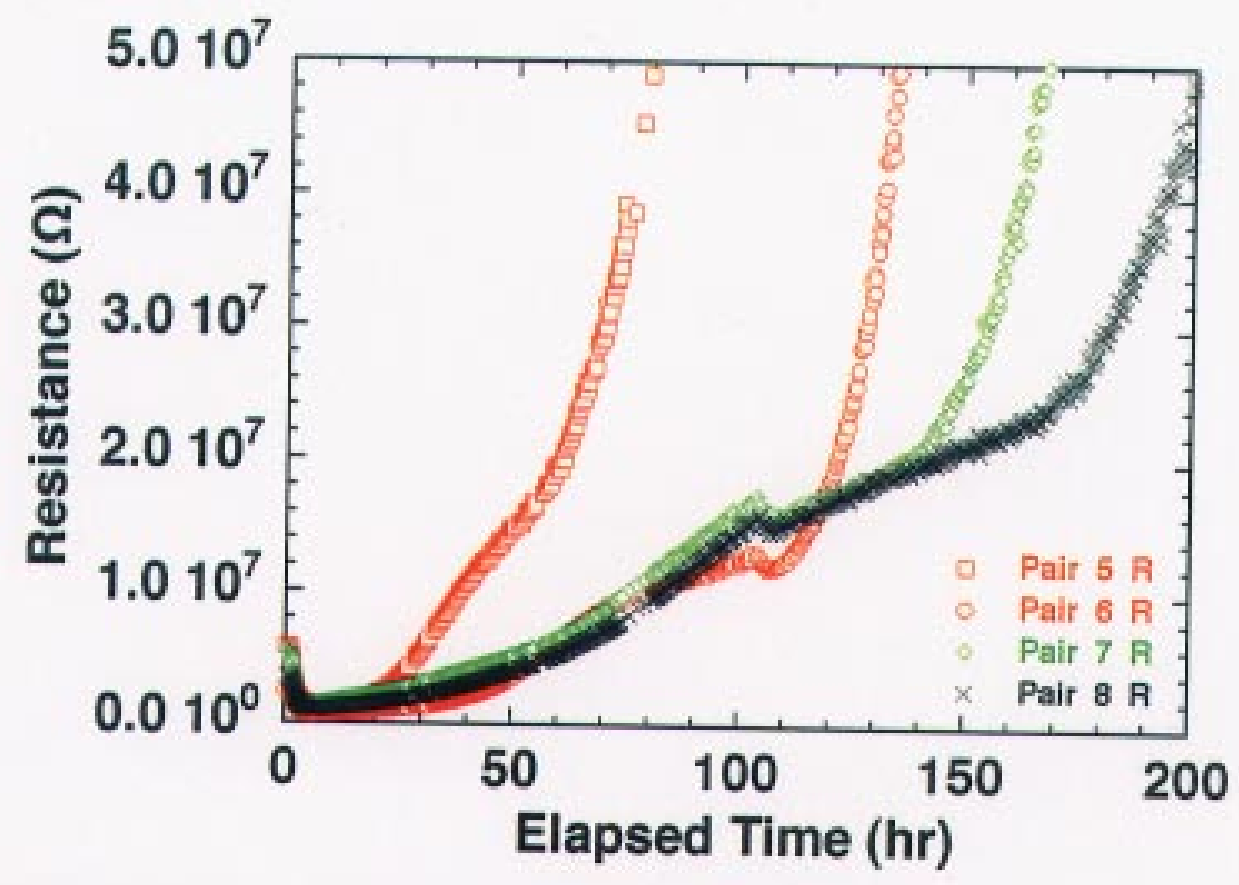

Figure 2-15. Electrical resistance at electrode pairs 5 to 8 in the $35.56-\mathrm{cm}$ core during the vapor condensation along a fracture experiment as a function of time.

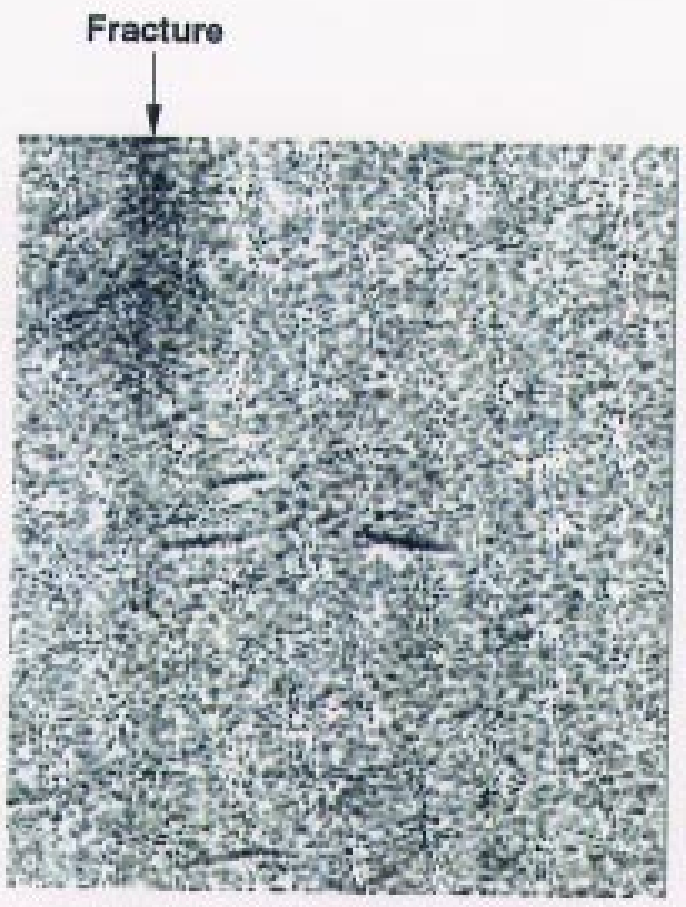

Figure 2-16. $X$-ray difference image sequence of radiographs of tuff containing a tensile fracture. No shim was put in the fracture. The experiment was performed at room temperature. Water containing KI to enhance attenuation of $\mathrm{x}$ rays was ponded on top of the sample. A roughly V-shape wetting front was observed at 47.5 hours. 
7

7

4

7

$?$

7

7

7

?]

$?$

9

i!

$?$

$T$

$?$

7

$T$ 


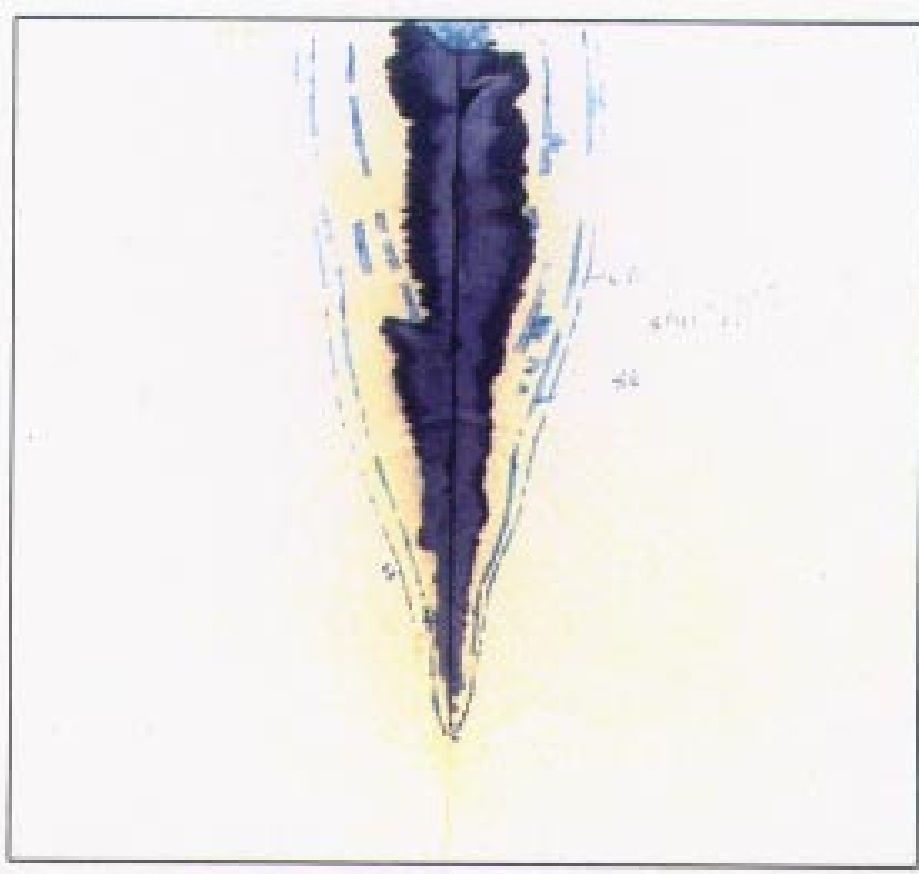

Figure 2-17. Fracture flow and matrix imbibition in plaster of Paris. Liquid containing dye was ponded on top of the sample and flowed into the fracture. The fracture was held open by $25-\mu \mathrm{m}$ gold shims. The lines indicate the progress of the wetting front as a function of time (hours). 


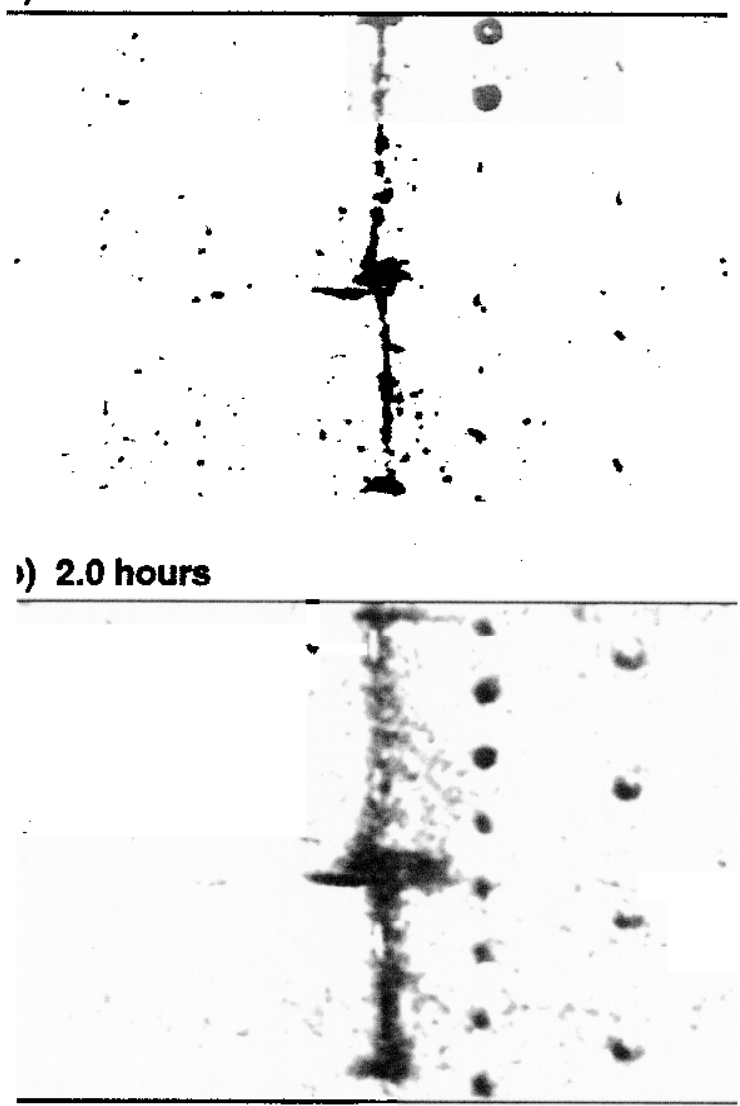

\section{(c) 70.0 hours}

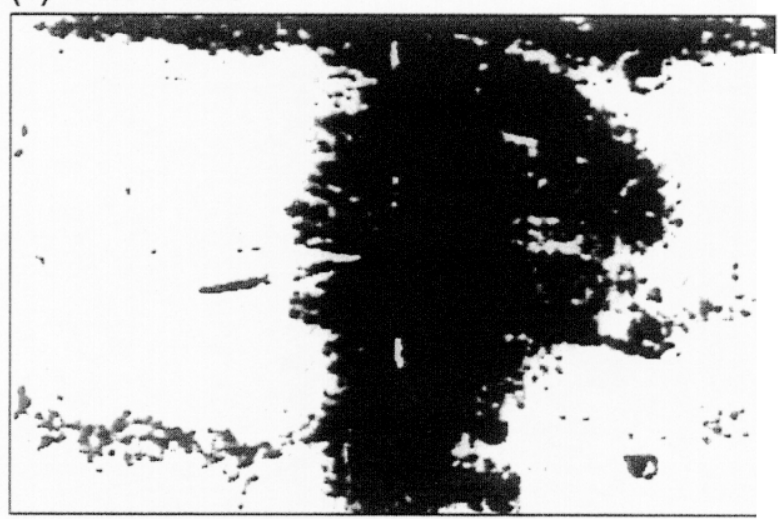

Figure 2-18. $X$-ray difference image sequence of radiographs of tuff containing a tensile fracture. Four $2-\mu \mathrm{m}$ gold shims held the fracture open. The experiment was performed at room temperature. Water containing $\mathrm{KI}$ to enhance attenuation of $x$ rays was ponded on top of the sample. The elapsed time of each image is (a) 0.03 , (b) 2.0 , and (c) 70.0 hours. Darker shades represent a large change in attenuation (the addition of water from the first radiograph). The spots on the right side of the images are holes that were plugged with RTV after the start of the experiment. (a) After 0.03 hours, water had already flowed the length of the fracture. (b) At later times, 2.0 hours, water began to imbibe laterally into the matrix. (c) After 70 hours the non-uniformity of matrix imbibition is evident (see text). 
(a) 1.73 hours

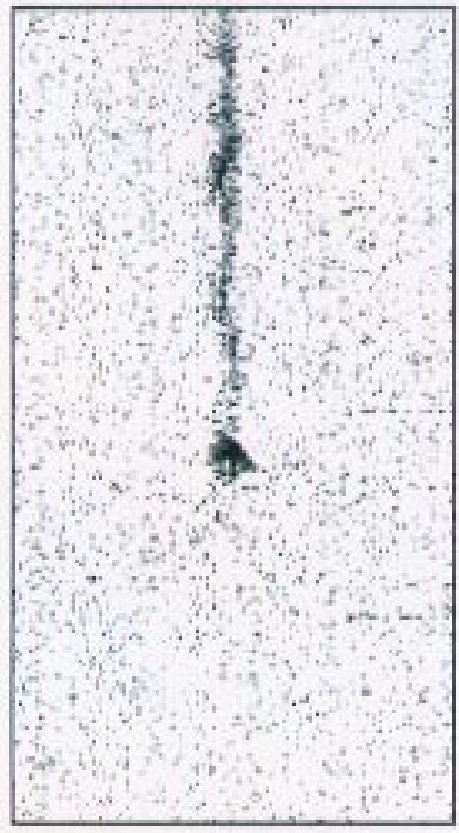

(b) after 73.5 hours

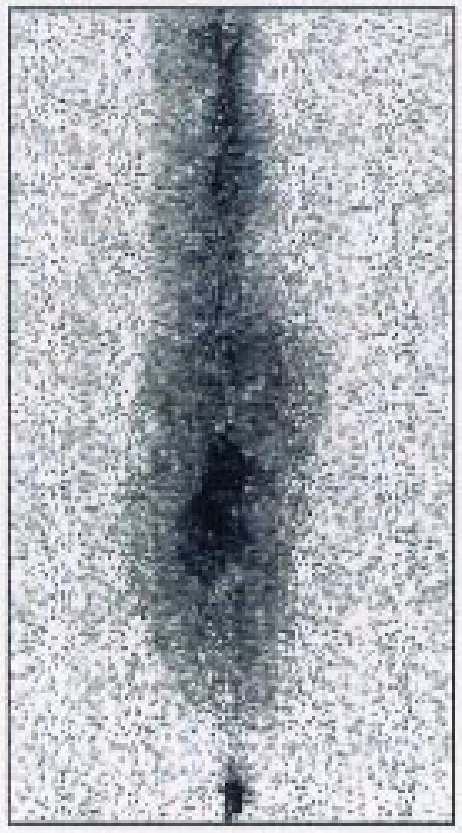

(c) 360 hours

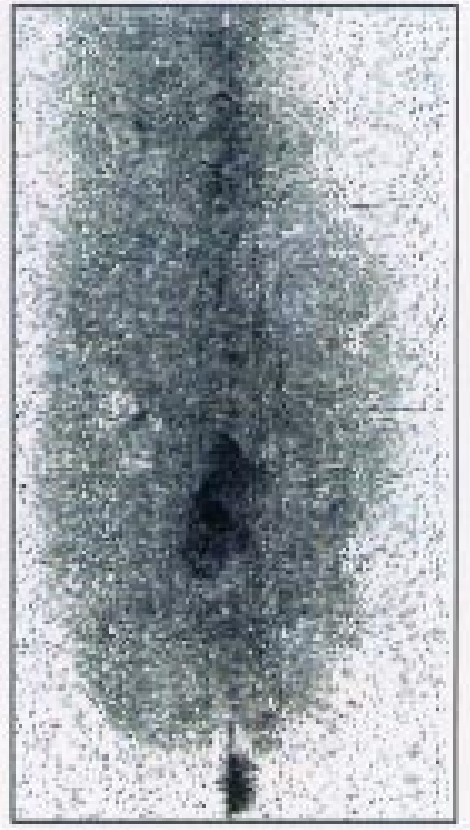

Figure 2-21. X-ray difference image sequence of radiographs of tuff containing a natural fracture. Nine 25$\mu \mathrm{m}$ gold shims held the fracture open. The sample was initially heated (faint traces of the thermocouples can be seen) to above boiling at the bottom of the sample. The top of the sample was approximately $28^{\circ} \mathrm{C}$. Water was ponded on top of the sample near the fracture only (as opposed to the entire sample top). Water quickly flowed into the fracture (similar to the unheated experiment in Fig. 2-18) after which the progress of the fracture flow slowed, shown in (a) 1.73 hours. The point at which flow slowed was found to be a relatively porous low $\mathrm{x}$-ray attenuation region intersected by the fracture. At greater times, flow eventually proceeded past this region (after $\sim 23$ hours). There was also considerable lateral imbibition by this time. (b) Shows progress of fluid after 73.5 hours. The darkest region indicates the porous region now highly saturated. At the bottom of the sample centered on the fracture is a second dark region. This is interpreted as a region of high attenuation because of KI precipitation during boiling. (c) At 360 hours, water continued to imbibe laterally but never penetrated past the bottom of the sample.

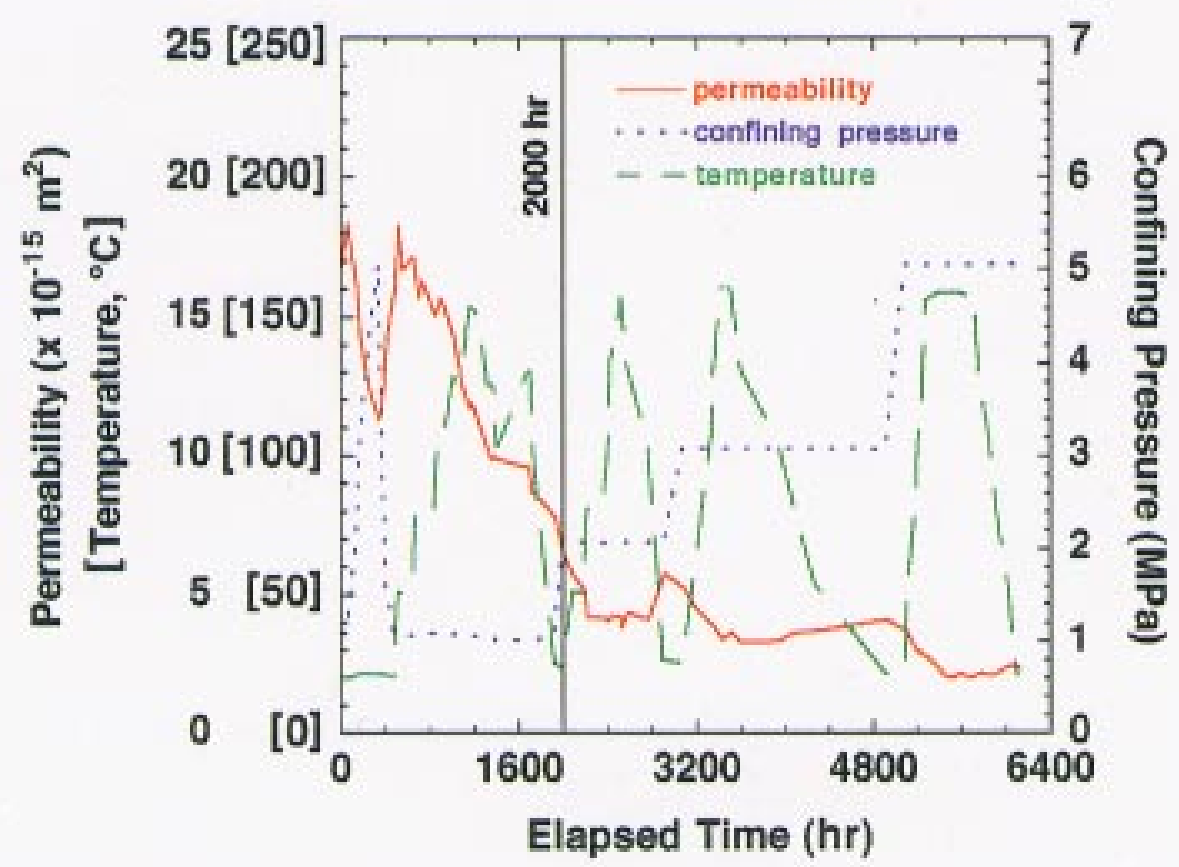

Figure 2-22. Permeability, confining pressure, and temperature of tuff containing a single fracture as a function of elapsed time. The vertical line at $2000 \mathrm{hr}$ is explained in the text. 

Table 2-1. Permeability Measurements on Intact Core Sample SPC00504573.4

\begin{tabular}{cccc}
\hline $\begin{array}{c}\text { Temperature, } \\
{ }^{\circ} \mathbf{C}\end{array}$ & $\begin{array}{c}\text { Confining Pressure, } \\
\mathbf{M P a}\end{array}$ & $\begin{array}{c}\text { Differential Pressure, } \\
\mathbf{M P a}\end{array}$ & $\begin{array}{c}\text { Permeability, } \\
\mu \mathrm{D}\end{array}$ \\
\hline 23 & 5.06 & 1.92 & 0.12 \\
25 & 5.07 & 2.47 & 0.14 \\
26 & 5.06 & 2.59 & 0.67 \\
26 & 5.06 & 2.61 & 0.20 \\
53 & 5.06 & 2.42 & 0.11 \\
53 & 5.06 & 1.91 & 0.15 \\
83 & 5.06 & 2.02 & 0.17 \\
91 & 5.06 & 2.17 & 0.14 \\
92 & 5.06 & 1.60 & 0.14 \\
130 & 5.05 & 1.46 & 0.13 \\
130 & 5.05 & 2.04 & 0.11 \\
154 & 5.06 & 1.61 & 0.09 \\
\hline
\end{tabular}






\section{Contents}

Chapter 3.0 Geochemistry................................................................................................ 3-2

3.1 Summary of Recent Studies Concerning Geochemical and Mineralogical Evolution of the Near-

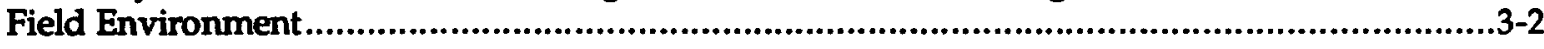

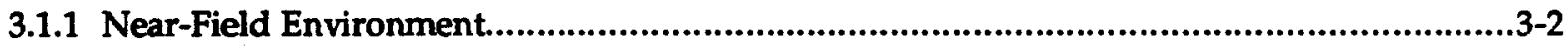

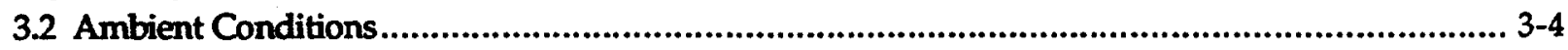

3.3 Processes That Will Modify Ambient Conditions Within the Near-Field Environment........... 3-5

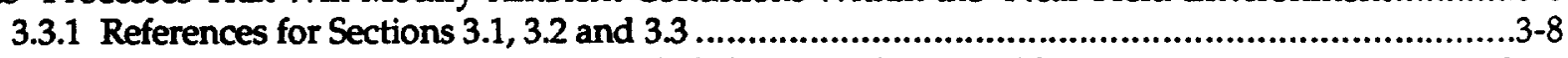

3.4 Results of Recent Geochemical Research Relating To Near-Field

Geochemistry And Mineralogy.

3.4.1 Equilibrium Bounds on Water Chemistry and Mineralogical Changes

Produced by Near-Field Relative Humidity Changes, by William E. Glassley,

Lawrence Livermore National Laboratory

3.4.2 Testing EQ3/6 and GEMBOCHS Using Fluid-Mineral Equilibria in the Wairakei Geothermal System, by Carol Bruton, Lawrence Livermore National Laboratory.

3.4.3 Mineralogy-Petrology Observations Regarding the Near-Field Environment, by David L. Bish, J. William Carey, Schon S. Levy and Steve J. Chipera, Los Alamos National Laboratory. 


\section{Chapter 3.0 Geochemistry}

\subsection{Summary of Recent Studies Concerning Geochemical and Mineralogical Evolution of the Near-Field Environment}

This section provides a brief summary of the more detailed results presented in Sections 3.4 and Chapters 10.3 and $\mathbf{1 0 . 4}$ of this report. As appropriate, reference is made to the relevant subsections where the detailed information can be located. The results described here use, as a basis, the research summarized in the Preliminary Near-field Environment Report, Volumes I and II. The primary change between the PNFER and this report reflects a change in modeling approach, rather than a change in models or data. The results described in Sections 3.4.2, 3.4.3, and Chapters 10.3 and 10.4, document that limitations in thermodynamic and kinetic data, which are used to describe future mineralogical and chemical changes, constrain our ability to simulate future mineralogical and chemical conditions. Therefore an approach is proposed in which general mineral assemblages ('facies') will be used to describe future mineralogical and chemical conditions, rather than detailed descriptions of mineral assemblages that include specific mineral types and compositions. See Section 3.4.2 for a thorough discussion of this issue.

\subsubsection{Near-Field Environment}

The results of three studies are reported here that consider the geochemical and mineralogical evolution of the NFE. Since the temperature in this region will be significantly above ambient for many years, evaporation of pore water will occur. One study (Section 3.4.1, Equilibrium Bounds on Water Chemistry and Mineralogical Changes Produced by Near-Field Relative Humidity Changes) examines these effects through numerical simulation of water chemistry changes resulting from evaporation. This study found that the main controls on water composition, and the secondary minerals precipitated as water evaporates, are the composition of the gas phase in equilibrium with the water, and the degree of evaporation. The numerical simulations show that the coexisting gas phase composition primarily influences $\mathrm{pH}$ and redox state of the pore water. If the water remains in equilibrium with air, for example, $\mathrm{pH}$ increases significantly, reaching values in excess of 9.5 , while the Eh decreases to values on the order of $+500 \mathrm{mv}$. On the other hand, if the water is isolated from the atmosphere and the coexisting gas phase evolves in equilibrium with the water, $\mathrm{pH}$ decreases to values less than 6.75 and the Eh becomes more oxidizing, reaching values in excess of $+650 \mathrm{mv}$.

The numerical simulations show that carbonates, phosphate, Al-silicates, and $\mathrm{Si}$ polymorphs are saturated in the water at very low degrees of evaporation $(<10 \%)$. However, the only phases that may develop in significant abundance $\left(>10^{-3}\right.$ moles per kilogram of water) are carbonate and Si-polymorphs, even at relatively high degrees of evaporation (70\% to $90 \%$ ). At higher degrees of evaporation, chloride salts 
may precipitate, in volumes that are ca. $10^{-6}$ of the original fluid volume. However, it is also to be expected that, as evaporation approaches $100 \%$, very small volume films of high salinity brines will form in restrictions (pore throats, restricted channels, etc.), and persist to high temperatures due to the effect of salinity on water vapor pressure. These results suggest that the initial volumes of water entering the dry-out region, after the initial thermal pulse, should be expected to have ionic strengths and salinities that are elevated above ambient, due to dissolution of the previously precipitated mineral phases.

A second study (Section 3.4.2, Testing EQ3/6 and GEMBOCHS Using FluidMineral Equilibria in the Wairakei Geothermal System) was undertaken to determine the extent to which numerical simulations could provide detailed descriptions of which minerals may develop as the repository heats up and cools down. This study used detailed chemical and mineralogical data obtained from the Wairakei Geothermal system in New Zealand, where rocks that are virtually identical to those that make up Yucca Mountain are undergoing alteration as they interact with water at elevated temperatures.

These observational data were compared to the results of numerical simulations, which used thermodynamic data from different sources. Employing a technique which considers the computed temperature-dependent affinity of several different mineral species, it is possible to identify suites of minerals that are predicted to stably coexist.

Comparison of these predicted mineral suites to the observed mineral assemblages in the Wairakei rocks, allows one to determine the adequacy of different thermodynamic data sets. In all cases, it was possible to select a thermodynamic data set that best reproduced the observed mineral assemblages. Nevertheless, regardless of the data set employed, some minerals are predicted to occur which are not observed in the natural assemblages. This result leads to the conclusion that a facies concept should be used when describing the mineralogical evolution of the repository block. In such a concept, it is recognized that a specific suite of mineral types are expected to occur, but precise prediction of the mineral structures and compositions is not attempted, since small, local variations in intensive and extensive parameters, and uncertainties in thermodynamic and kinetic data, will lead to variations among the mineral assemblages that may actually form.

A third study (Section 3.4.3 Mineralogy-Petrology Observations Regarding the Near-Field Environment; also see "Summary and Synthesis Report on Mineralogy and Petrology Studies for the Yucca Mountain Site Characterization Project," 3-volume report, in preparation) summarizes host rock mineralogy, and some data on mineral stability relevant for near-field processes. The bulk-rock mineralogy within the near-field environment varies with depth and laterally across Yucca Mountain. Comparatively soluble silica phases, including cristobalite, tridymite, opal-CT, and volcanic glass are ubiquitous within the NFE. Limited data illustrate that major amounts of clinoptilolite and mordenite are common directly underlying the host rock in the eastern portion of Yucca Mountain, in and below the lower vitrophyre of the Topopah Spring Tuff. Natural alteration in the lower vitrophyre exemplifies hydrothermal modification of rock porosity by the 
dissolution of volcanic glass and precipitation of smectite, zeolite, and silica. This is consistent with several previous detailed studies which documented that significant changes in bulk rock solid volume will occur during rock-water interaction and temperature change, and that these changes may significantly modify rock and fracture porosity and permeability (Meike and Glassley, 1990; Glassley, 1993; Glassley et al., 1994; Lin et al., 1995). Simplified mass balance calculations are presented in Section 3.4.3 that substantiate those previous conclusions. The rates at which mineral reactions will occur in the presence of water are dependent upon dissolution and precipitation kinetics of mineral phases. This was pointed out in the PNFER, where studies completed to 1990 were summarized in Section 3.3.2, "Kinetics". Since then, several additional studies have been completed (kaolinite, Carroll and Walther, 1990, Nagy, et al., 1991, Nagy and Lasaga, 1993; gibbsite, Nagy and Lasaga, 1992; heulandite, Ragnarsdottir, 1993; cristobalite, Carroll et al., 1995, Renders et al., 1995) that established the kinetics of dissolution for a variety of phases important for modeling repository-relevant rock-water interaction as a function of time. As an addition to this database, recent results of dissolution kinetics experiments on clinoptilolite and analcime are discussed in Section 3.4.3, as well as recent data on the thermodynamic properties of analcime and clinoptilolite. Based on existing data, the dissolution of clinoptilolite appears to be slower than analcime, by a factor near 100 . The energetics of solid-solutions and cation exchange models were discussed in the PNFER, Section 3.3.3. In this report, additional models for exchange are discussed in Section 3.4.3.

\subsection{Ambient Conditions}

The rock unit that is being characterized for waste emplacement is within the Topopah Spring member of the Paintbrush Tuff and has been designated as unit TSw 2 on the thermal and mechanical stratigraphic map of the region (Ortiz et al., 1985). TSw2 is a devitrified, welded, rhyolitic tuff and consists of intact blocks separated by fractures. Price et al. (1987) report that the majority of the rock contains fine-grained matrix regions and gray-colored, vapor-phase-altered regions. In addition to these main components, the rock contains small lithophysae (open and closed) and fractures, some of which are filled with quartz, calcite, or other minerals. The porosities of the matrix and vapor-phase-altered regions are between 8 and 49\% (Price et al., 1985; 1987). The matrix in the potential repository horizon has an estimated mean water saturation of $65 \%$ (Montazer and Wilson, 1984). Existing data also indicate that the fracture density may be approximately 40 per $\mathrm{m}^{3}$, and predominantly oriented in the vertical direction (Scott and Castellanos, 1984).

Field, petrographic, electron microprobe, scanning electron microscopy, and $X-$ ray diffraction analyses (Carlos, 1985, 1987, 1989; Schuraytz et al., 1986; Broxton et al., 1987, 1989; Bish and Chipera, 1989; Chipera and Bish, 1989; Carlos et al., 1990, 1993; 1995; Levy et al., 1996) have shown that the tuff consists of both primary and secondary minerals. The primary minerals (sanidine, plagioclase, quartz, biotite, $\mathrm{Fe}-$ Ti oxides, allanite, and zircon) were formed at temperatures in excess of $600^{\circ} \mathrm{C}$ in a magma chamber prior to eruption of the tuff. Secondary minerals such as 
cristobalite, opal, tridymite, quartz, alkali feldspar, carboantes, and smectite collectively make up a substantial portion of the rock and were formed at temperatures less than $500^{\circ} \mathrm{C}$, either during cooling, or later as alteration products. See Section 3.4.3 for a more detailed discussion.

\subsection{Processes That Will Modify Ambient Conditions within the Near-Field Environment}

Emplacement of waste packages in this environment will modify the thermal and radiation fields experienced by the host rock, and may lead to complex chemical reactions between the near-field fluids and minerals. The nature of these reactions will depend on a variety of parameters, including the temperature of the environment, the composition of the fluid phase, the rate at which the thermal field changes, the kinetics of reactions, fluid movement rates and pathways, and the amount and nature of radiolysis products. The values of these parameters will change through time as the thermal and radiation fields decay.

Numerous simulations of the hydrological evolution of the WP environment (Nitao and Buscheck, 1989; Buscheck et al., 1991, 1993, 1994; Buscheck and Nitao, 1992, 1993; Nitao et al., 1992) have suggested that four different hydrothermal regimes will form in the vicinity of WPs:
A. A regime in which temperatures are elevated, but are below the boiling point;
B. A regime in which boiling occurs;
C. A regime in which temperatures are above boiling and relative humidities may be low $(<95 \%)$
D. A regime in which rock properties are permanently modified, such that rock characteristics during cool down do not recover to pre-emplacement state or values.

These regimes form because pore water will be heated as energy is transferred from the WPs to the surrounding rock. This heating will lead to (1) evaporation of pore water as temperature rises, (2) condensation of water vapor in cooler regions, and (3) boiling and desiccation in those regions that reach or exceed the nominal boiling temperature. The local heat budget will thus reflect the local balance between convective and conductive processes. The kinds of processes and effects that may develop are described below.

Regime A: Temperature $<T_{\text {boiling. This regime encompasses those areas in which }}$ the temperature is between ambient and boiling. It is therefore significant for all regions that undergo heating. As heating occurs, in situ pore water is heated and evaporates. Water vapor moving in fractures to lower temperature regions will condense on fracture surfaces. The condensed water either will be imbibed into the matrix by capillary suction or will flow along fracture surfaces, depending on the degree of matrix saturation and the permeability of the fracture surfaces.

Within a few tens of meters of the walls of drifts within which waste has been emplaced, Regime A will persist for a very brief period of time (less than 10 years) 
because of the rapid rate of heat deposition. In contrast, rock that is hundreds of meters from emplacement drifts will heat up slowly, resulting in the persistence of Regime A for hundreds to thousands of years.

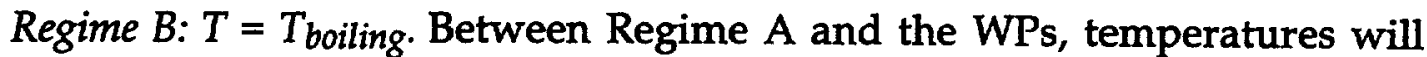
eventually reach the boiling point for virtually all scenarios with APDs greater than $20 \mathrm{~kW} /$ acre. When this condition is met, pore water will vaporize and the resulting steam will migrate to cooler regions where it will condense. Imbibition of the condensed steam into the matrix of fracture-bound blocks will eventually result in fully saturated rock adjacent to fractures transporting steam. Thus, this rock volume is one in which temperature is essentially constant at the nominal boiling point $\left(\sim 96^{\circ} \mathrm{C}\right)$, and much of the rock may be at $100 \%$ saturation. Above the repository, this may lead to a region of water refluxing in which water will cycle from the boiling zone to the condensation front (as vapor), and back again (as liquid). Below the repository, refluxing will not occur, but the saturation zone will be widened as condensed hot water flows downward along fractures.

The water that condenses is distilled, and thus must be treated as a liquid that is far from equilibrium with either the host rock or fracture lining minerals. Extensive dissolution of rock matrix and fracture lining minerals must be anticipated for this region.

This regime grows in volume as long as the thermal envelope around the repository is expanding. The regime thickness varies, being virtually zero at the edge of emplacement drift walls when the boiling point is first reached shortly after waste emplacement, to thicknesses that may be in excess of 100 meters several hundred to thousands of years after the repository is closed. This regime will be one of the most chemically active since a high temperature is achieved at full saturation for long time periods (10's to 100 's of years).

Regime $C: T>T_{\text {boiling. }}$ Regime $C$ is bounded by the boiling point isotherm outward, and the repository inward, and represents the region within which temperatures are above the boiling point and relative humidity is variable (<90\%). Local persistence of liquid water to very high temperatures, perhaps as high as 150 to $210^{\circ} \mathrm{C}$, may result from (1) vapor pressure lowering due to increased salinity of trapped water in restricted pores, (2) boiling point elevation associated with high vapor pressures in block interiors, where vapor migration to fractures may be restricted, or (3) water adsorbed onto mineral surfaces. In general, however, it is expected that this regime will be one dominated by relative drying of the rock, with a persistent but very small volume of water remaining.

Regime $D: T<T_{\text {local max }}$. This regime develops after the local thermal maximum has been achieved. It encompasses rock that has been physically modified during the heat-up period, either as a result of mineral dissolution or precipitation or both, or because of mechanical effects. These effects will be evident as changes in bulk and fracture porosity and permeability, and mineralogy. In those regions where saturation had increased above pre-emplacement ambient values, slow removal of water will lead to decreasing saturation. Those regions that had experienced 
decreased saturation relative to pre-emplacement ambient saturations will begin to rehydrate slowly as the local thermal maximum passes. Current modeling suggests that the rates of resaturation are so slow that it will be 100's of 1000's of years before pre-emplacement ambient saturations are approached. This regime could be realized in all of the other regimes, as cooldown proceeds.

Preliminary modeling has suggested that regimes A and B may quickly pass through the NFE, if thermal loadings are $>100 \mathrm{~kW} /$ acre (Nitao, 1988). Nevertheless, complex coupling of fluid velocities and mineralogical reactions in fractures and matrix blocks suggests that mineralogical equilibrium may be approached for some portions of the NFE, even under these conditions (Glassley, 1993). This work has shown that, as evaluated using classic Damkohler numbers or characteristic times of silicate reactions, reaction rates are fast enough to establish chemical steady state relative to transport rates in all regions except the immediate vicinity of emplacement drifts, or in regions of rapid refluxing and rapid fracture flow. At lower thermal loadings, or for certain scenarios in which there is wide spacing between emplacement drifts, regimes $A$ and $B$ may persist within portions of the NFE for hundreds of years. For this reason, the effects of all regimes must be considered as potentially significant for the NFE.

The composition of water that may contact waste containers will depend on the mineralogy of the near-field which, in turn, will be influenced by recrystallization processes that will occur during the period of time prior to incursion of liquid water (see Bish et al., this volume), and on the presence of materials placed within emplacement drifts during construction (see the Introduced and Man-Made Materials Chapter in this report). Within this section (Section 3) only those effects that result from interaction with the in situ rock will be discussed.

The primary chemical and mineralogical effects will be the result of interaction of the distilled, condensed water with rock matrix and fracture lining minerals. The main mechanisms responsible for the chemical evolution of the water will be dissolution and precipitation of along flow pathways. Water composition will also be influenced by evaporation, boiling, mixing of waters from different sources or regions, and infiltration. The effects of some of these processes on near-field water composition are discussed in Sections 3.4 and Chapter 10.3.

Such effects of rock-water interaction will change the local hydrological properties of the rock by dissolving pre-existing materials, and thus increasing local porosity and permeability, or precipitating minerals, thus decreasing porosity and permeability. Efforts to characterize these effects along flow pathways are in progress. 


\subsubsection{References for Sections 3.1, 3.2 and 3.3}

Bish, D.L. and S.J. Chipera (1989), Revised Mineralogical Summary of Yucca Mountain, Nevada, Los Alamos National Laboratory, NM, LA-11497-MS, 57p.

Broxton, D.E., Bish, D.L., and Warren, R.G., 1987, Distribution and chemistry of diagenetic minerals at Yucca Mountain, Nye County, Nevada. Clays and Clay Minerals 35, 89-110.

Broxton, D.E., Warren, R.G., and F.M. Byers, 1989, Chemical and mineralogic trends within the Timber Mountain-Oasis Valley caldera complex, Nevada: evidence for multiple cycles of chemical evolution in a long-lived silicic magma system. J. Geophys. Res. 94, 5961-5985.

Bruton, C.J., Glassley, W.E., and Meike, A., 1995, Geothermal Areas As Analogues To Chemical Processes In The Near-Field And Altered Zone of Potential Yucca Mountain, Nevada Repository, Lawrence Livermore National Laboratory, Livermore, Calif., UCRL-ID-119842.

Buscheck, T. A., and J. J. Nitao (1992), The Impact of Thermal Loading on Repository Performance at Yucca Mountain, Lawrence Livermore National Laboratory, Livermore, Calif., UCRL-JC-109232.

Buscheck, T. A., and J. J. Nitao (1993), The Impact of Repository Heat on Thermohydrological Performance at Yucca Mountain, Lawrence Livermore National Laboratory, Livermore, Calif., UCRL-JC-114791.

Buscheck, T. A., D.G. Wilder, and J. J. Nitao, 1993, Large-scale in situ heater tests for hydrothermal characterization at Yucca mountain, Lawrence Livermore National Laboratory, Livermore, Calif., UCRL-JC-112445.

Buscheck, T. A., J. J. Nitao and S.F. Saterlie (1994), Evaluation of ThermoHydrological Performance in Support of the Thermal Loading Systems Study, In Proceedings of the 5th International High Level Nuclear Waste Management Conference, Las Vegas, NV, American Nuclear Society, La Grange, IL, p. 592-610.

Buscheck, T. A., J. J. Nitao, and D.A Chesnut, 1991, The impact of episodic nonequilibrium fracture-matrix flow on repository performance at the potential Yucca mountain site, Lawrence Livermore National Laboratory, Livermore, Calif., UCRL-JC-107920.

Carlos, B.A., 1985, Minerals in fractures of the unsaturated zone from drill core USW G-4, Yucca Mountain, Nye County, Nevada. Los Alamos National Laboratory, LA-10415MS.

Carlos, B.A., 1987, Minerals in fractures of the saturated zone from drill core USW G-4, Yucca Mountain, Nye County, Nevada. Los Alamos National Laboratory, LA-10927MS.

Carlos, B.A., 1989, Fracture-coating minerals in the Topopah Spring Member and Upper Tuff of Calico Hills from drill hole J-13. Los Alamos National Laboratory, LA-11504MS.

Carlos, B.A., Bish, D.L., and Chipera, S.J., 1990, Manganese oxide minerals in fractures of the Crater Flat Tuff in drill core USW G-4, Yucca Mountain, Nevada, Los Alamos National Laboratory, LA-11787-MS. 
Carlos, B.A., Chipera, S.J., Bish, D.L., and Craven, S.J., 1993, Fracture-lining manganese oxide minerals in silicic tuff, Yucca Mountain, Nevada, U.S.A. Chemical Geology 107, 47-69.

Carlos, B.A., Chipera, S.J., Bish, D.L., and Raymond, R., 1995, Distribution and chemistry of fracture-lining zeolites at Yucca Mountain, Nevada, in Natural Zeolites '93 (D.W. Ming and F.A. Mumpton, eds.), Comm. Natural Zeolites, Brockport, N.Y., p. 547-563.

Carroll S. A., Mroczek, E., Bourcier, B., Alai, M. and Ebert, M. (1995) Comparison of field and laboratory precipitation of amorphous from geothermal waters at $100^{\circ} \mathrm{C}$. Lawrènce Livermore National Laboratory Yucca Mountain Site Characterization Project Milestone MOL207.

Carroll, S.A. and Walther, J. V., 1990 . Kaolinite dissolution at $25^{\circ} \mathrm{C}, 60^{\circ} \mathrm{C}$, and $80^{\circ} \mathrm{C}$. Amer. j. Sci. 290, 797-810.

Chipera, S. J., and D. L. Bish (1989), Quantitative X-ray Diffraction Analyses of Samples Used for Sorption Studies by the Isotope and Nuclear Chemistry Division, Los Alamos National Laboratory, Los Alamos National Laboratory, Los Alamos, NM, LA11669-MS, $19 \mathrm{pp}$.

Glassley, W.E. (1993), Coupled Hydro-Geochemical Processes and Their Significance for Yucca Mountain Site Characterization, in Proceedings of FOCUS '93, Las Vegas, NV, American Nuclear Society, La Grange, IL, p. 221-224

Glassley, W.E., Bruton, C.J., Bourcier, W.L., 1994, Testing long-term predictions from hydrogeochemical models. Materials Res. Soc. Symposium Proc. 333, 805-810.

Levy, S.S., Norman, D.I., and Chipera, S., 1996, Alteration history studies in the exploratory studies facility, Yucca Mountain, Nevada, USA Mat. Res. Soc. Symp., 412, 783-790.

Lin, W., Roberts, J.J., Glassley, W.E., and Ruddle, D., 1995. The effect of rock-water interaction on permeability. Proceedings of the Eighth International Congress on Rock Mechanics, Tokyo, Japan, and Lawrence Livermore National Laboratory UCRL-JC119574.

Meike, A. and Glassley, W.E., 1990, In situ observation of the alpha/beta cristobalite transition using high voltage electron microscopy. Materials Res. Soc. Symposium Proc. 178, 631-639.

Montazer, P., and W. E. Wilson, 1984, Conceptual Hydrologic Model of Flow in the Unsaturated Zone, Yucca Mountain, Nevada, U.S. Geol. Survey, Denver, CO, Water Resources Inv. Rep. 84-4345. Scott and Castellanos, 1984

Nagy, K.L., and Lasaga, A.C., 1992, Dissolution and precipitation kinetics of gibbsite at $800 \mathrm{C}$ and $\mathrm{pH} 3$ : The dependence on solution saturation state. Geochim.

Cosmochim. Acta 56, 3093-3111.

Nagy, K.L., and Lasaga, A.C., 1993, Simultaneous precipitation kinetics of kaolinite and gibbsite at $80^{\circ} \mathrm{C}$ and $\mathrm{pH} 3$. Geochim. Cosmochim. Acta 57, 4329-4336.

Nagy, K.L., Blum, A.E., and Lasaga, A.C., 1991, Dissolution and precipitation kinetics of kaolinite at $80^{\circ} \mathrm{C}$ and $\mathrm{pH}$ 3: The dependence on solution saturation state: Amer. J. Sci. 291, 649-686.

Nitao, J.J. (1988), Numerical Modeling of the Thermal and Hydrological Environment Around a Nuclear Waste Package Using the Equivalent Continuum Approximation: 
Horizontal Emplacement, Lawrence Livermore National Laboratory, Livermore, CA, UCID-21444.

Nitao, J.J. and T.A. Buscheck, 1989, On the movement of a liquid front in an unsaturated, fractured porous medium, Part I. , Lawrence Livermore National Laboratory, Livermore, Calif., UCID-21714.

Nitao, J.J., T.A. Buscheck, and D.A. Chesnut, 1992, The implications of episodic nonequilibrium fracture-matrix flow on site stability and total system performance, Lawrence Livermore National Laboratory, Livermore, Calif., UCRL-JC-109216.

Ortiz, T. S., R. L. Williams, F. B. Nimick, B. C. Whittet, and D. L. South (1985), A Three-Dimensional Model of Reference Thermal/Mechanical and Hydrologic Stratigraphy at Yucca Mountain, Southern Nevada, Sandia National Laboratories, Albuquerque, NM, SAND84-1076.

Price, R. H., F. B. Nimick, J. R. Connolly, K. Keil, B. M. Schwartz, and S. J. Spence (1985), Preliminary Characterization of the Petrologic Bulk and Mechanical Properties of a Lithophysal Zone within the Topopah Spring Member of the Paintbrush Tuff, Sandia National Laboratories, Albuquerque, NM, SAND84-0860.

Price, R. H., J. R. Connolly, and K. Keil (1987), Petrologic and Mechanical Properties of Outcrop Samples of the Welded, Devitrified Topopah Spring Member of the Paintbrush Tuff, Sandia National Laboratories, Albuquerque, NM, SAND86-1131.

Ragnarsdottir, K.V., 1993, Dissolution kinetics of heulandite at $\mathrm{pH}$ 2-12 and 25 degrees C. Geochim. Cosmochim. Acta 57, 2439-2449.

Renders, P. J. N., Gammons, C. H., and Barnes, H. L. (1995) Precipitation and dissolution rate constants for cristobalite from 150 to $300^{\circ} \mathrm{C}$. Geochimica Cosmochimica Acta, 59, 77-85.

Schuraytz, B. C., T. A. Vogel, and L. W. Younker (1986), Geochemical Gradients on the Topopah Spring Member of the Paintbrush Tuff. Evidence for Eruption Across a Magmatic Interface, Lawrence Livermore National Laboratory, Livermore, CA, UCRL-53698. 


\subsection{Results of Recent Geochemical Research Relating To Near-Field Geochemistry And Mineralogy}

\subsubsection{Equilibrium Bounds on Water Chemistry and Mineralogical Changes Produced by Near-Field Relative Humidity Changes, by William E. Glassley, Lawrence Livermore National Laboratory}

3.4.1.1 Introduction. Radioactive decay heat will lead to interaction of rock and water at high temperatures in the vicinity of emplacement drifts (Buscheck and Nitao, 1992; Nitao et al., 1992; Buscheck, et al., 1993). In order to determine how possible thermal histories will affect water chemistry and near-field mineralogy, the evolution of water compositions over a range of scenarios must be determined. This section describes how water chemistry may change due to evaporation. It does not consider the role of rock-water interaction, or the role of boiling, in the development of water compositions. Those aspects will be treated in a later report.

Evaporation of water is an important consideration for establishing the nature of secondary precipitates that may be deposited along fracture surfaces, in rock pores during various phases of the thermal evolution of the repository, or on waste containers from dripping water. The specific precipitates that may develop will reflect the initial water composition. In using J-13 well water (see below) this study considers those scenarios in which water evaporation begins with a dilute water that is close to equilibrium with high silica rhyolite similar to that which makes up the repository horizon at Yucca Mountain.

The chemical consequences of evaporation are distinct from those of boiling, due to the contrast in behavior of dissolved gases during evaporation and boiling. During open-system boiling, dissolved, volatile weak electrolytes (e.g., $\mathrm{CO}_{2}, \mathrm{H}_{2} \mathrm{~S}$ ) will exsolve from the liquid phase to varying degrees, depending upon the water composition. Their behavior can be described by means of Henry's law relationships which can take into account the relative "volatilities" of the dissolved species (Drummond and Ohmoto, 1985). Rayleigh distillation models can then be used to describe the overall evolution of the water chemistry during boiling (e.g., Arthur and Murphy, 1989; Criscenti and Arthur, 1991). Evaporation, on the other hand, can be approximated as a simple removal of water from a system, with the dissolved gas behavior expressed by temperature-dependent changes in the equilibrium partial pressure of the gas coexisting with the water.

3.4.1.2 Previous Work. Numerous studies have summarized the chemical characteristics of natural ground waters and pore waters in the vicinity of the repository block (Ogard and Kerrisk, 1984; Benson and McKinley, 1985; Yang et al., 1988; Bruton, et al., 1993). Those waters provide an indication of the degree of local compositional variability that may be expected. As a step in determining how these water compositions may be influenced by evaporation, a water composition typical of well J-13 was used in the simulations described here. This water was selected because it is a typical example of the type of water that occurs in the region, that is, it 
is a relatively dilute chloride- and sulfide- and sulfate-poor, bicarbonate groundwater (Glassley, 1986; Harrar, et al., 1990; Bruton, Glassley and Viani, 1993). Other water compositions will be considered as funding permits.

3.4.1.3 Approach. Evaporation of J-13 water was simulated using the EQ3/6 code package (Wolery, 1992 a,b; Wolery and Daveler, 1992) by removing water at a specified rate during reaction progress in an EQ6 simulation (Wolery and Daveler, 1992). Water was evaporated at constant temperatures of $31^{\circ} \mathrm{C}$ and $90^{\circ} \mathrm{C}$. It was also evaporated at increasing temperatures using arbitrary relationships between amount of water evaporated, and temperature change, from $31^{\circ} \mathrm{C}$ to $95^{\circ} \mathrm{C}$ (see Fig. 3.4-1 for the different temperature-evaporation trends used). Differences in the relationship between temperature and the moles of water evaporated had no discernible effect on the results. The variable temperature calculations allowed consideration of the effects of disequilibrium between heating and evaporation rate.

These simulations were conducted with and without controls on the composition of the coexisting gas phase. The simulations done without gas-phase controls simulate scenarios in which there is no influence of atmospheric gases on the composition of the evolving gases or water. Simulations conducted in which $\mathrm{O}_{2}$ and $\mathrm{CO}_{2}$ gas fugacities were assumed to remain constant at their atmospheric values ( 0.2 and 0.0004 bars, respectively) address scenarios in which equilibration of atmospheric gases with pore waters is rapid, relative to the rate at which evaporation occurs. Although disequilibrium may occur between water and gas, these simulations bound the extreme case where equilibrium is achieved, and water $\mathrm{pH}$ may be most severely affected by carbonate.

Simulations were conducted with and without precipitation of quartz, tridymite and talc. Suppression of these phases simulates scenarios in which metastable precipitation of other phases is allowed to occur. This is consistent with experimental studies in which the aqueous $\mathrm{SiO}_{2}$ concentration is controlled by the least stable silica polymorph present in the coexisting rock, and the fact that, at low temperatures similar to those considered here, the minerals that form most readily are those which most significantly lower the system's free energy and not necessarily the phases that are thermodynamically stable (see summary in Bruton et al., 1993). Although a number of other phases could also be justifiabley suppressed, these particular ones were selected because they are among those phases which commonly occur as precipitates in simulations, but which are not observed in experimental studies. Simulations in which these minerals were not suppressed consider scenarios in which the most thermodynamically stable phases precipitate. These contrasting approaches allow consideration of the relative importance of metastable precipitation of phases on the aqueous chemistry.

As a note of caution, it must be pointed out that the phases which occur as the "most thermodynamically stable" are identified as such on the basis of the thermodynamic properties compiled in the EQ3/6 database. Uncertainties in the values of thermodynamic properties, which are inherent in a compilation of this sort (see Johnson, et al., 1992 for discussion of this issue), make problematic the identification of the actual phases that would precipitate during evaporation. The phases that appear in the simulations, therefore, must be viewed as an 
approximation to the mineral assemblages that would develop in the course of evaporation. In addition, metastable crystallization of phases, due to nucleation or other kinetic effects in real systems, may also influence the actual sequence of minerals that would form during evaporation. Hence, the general sequence of precipitation that is obtained during the simulations may not be the same as that observed in the laboratory or in nature. However, efforts to evaluate the accuracy of simulations have been undertaken, using data from the New Zealand geothermal system (see Section 3.4 .2 ).

Interaction with rock was not considered. These simulations, therefore, apply to the extreme case where evaporation occurs at very high rates, relative to the rates of dissolution or precipitation of rock components. Although later studies were planned that would consider the consequences of reacting rock with evaporating waters, such studies have been indefinitely postponed due to budgetary and schedule constraints. Laboratory studies and simulations of rock interacting with J-13 well water have been carried out over a range of conditions, and are reported elsewhere (Knauss and Peiffer, 1986; Knauss et al., 1986; Knauss, 1987; Delaney 1985; Bruton et al, 1993).

The simulations reported here were conducted using the extended Debye-Hückle activity coefficient model (Helgeson, 1969; Helgeson et al., 1970). This model is applicable only to systems in which the ionic strength is less than ca. 0.5 molal, which is approximately equivalent to evaporation of 55 moles of water from $1 \mathrm{~kg}$ of $\mathrm{J}-13$ well water ( $1 \mathrm{~kg}$ of water equals ca. 55.51 moles of water). Although the simulations were carried to higher degrees of evaporation, only the results that were obtained well within the region over which the extended Debye-Hückle approach is valid (i.e., for $<53$ moles of evaporated water, which is approximately $95 \%$ evaporation) are reported here. Simulations at higher ionic strengths, using more appropriate models of ion interactions, will be conducted when applicable data are available.

3.4.1.4 Results and Discussion. The results of the simulations are shown in Figs. 3.4-2 through 3.4-14.

The effect of controlling gas composition can be dramatic, for some aqueous species and solids. In those cases where the effect is evident, circles are used in the figures to indicate values computed with no gas phase controls. Squares are used to indicate cases where gas phase controls were implemented. Solid symbols indicate simulations in which quartz, tridymite and talc precipitation was not suppressed, and open symbols are used for cases where they were suppressed.

Although calculations were conducted for both constant temperature and varying temperature conditions, the results were similar. Hence, the following discussion and data presentations only deal with the case in which temperature changed during evaporation.

Evaporation that occurs in the absence of any controls on the composition of the coexisting gases results in water compositions in which the $\mathrm{pH}$ remains near neutral, and the Eh slightly oxidizing (Figs. 3.4-2 and 3.4-3). In addition, $\mathrm{Na}$ (Fig. 3.4-4), $\mathrm{S}$ (Fig. 3.4-5), $\mathrm{Cl}$ (Fig. 3.4-6), and $\mathrm{F}$ (Fig. 3.4-7) concentrations increase linearly as the activity of $\mathrm{H}_{2} \mathrm{O}$ decreases. For $\mathrm{Na}, \mathrm{S}$, and $\mathrm{Cl}$, no solids precipitate that 
incorporate these elements, hence their concentrations increase by the same factor (i.e., 23 times). F, on the other hand, is incorporated into fluor-apatite and fluorite during evaporation. However, fluor-apatite precipitates during the very early stages of evaporation and remains constant in abundance, and fluorite only occurs in small concentrations toward the end of the evaporation, hence the relative behavior of $\mathrm{F}$ in solution mimics that of $\mathrm{Na}, \mathrm{S}$, and $\mathrm{Cl}$, but at a lower degree of enrichment (ca. 15 times).

The concentrations of Ca (Fig. 3.4-8), P (Fig. 3.4-9), and Si (Fig. 3.4-10), on the other hand, are effected by precipitation of carbonates, phosphates, and silicates as evaporation proceeds. Changes in $\mathrm{Ca}$ concentration mainly correlate with precipitation of calcite, which is the most abundant precipitate formed, after the silica polymorphs (Fig. 3.4-11). Dolomite precipitation also influences $\mathrm{Ca}$ concentration, but to a small degree (Fig. 3.4-12). $P$ variation reflects the effects of precipitation of fluor-apatite. Si variation is controlled by the solubility limits of quart $z$ and chalcedony, with which the waters are saturated; the particular polymorph that occurs in the simulations reflects whether quartz precipitation was inhibited.

For conditions in which the coexisting gas phase is fixed at atmospheric $\mathrm{O}_{2}$ and $\mathrm{CO}_{2}$ fugacities, the fluid composition evolution is significantly different in $\mathrm{pH}$, Eh, $\mathrm{Ca}$, and $\mathrm{Si}$. Because of the effect $\mathrm{CO}_{2}$ fugacity has on the stability of carbonate and bicarbonate ions, the $\mathrm{pH}$ is more alkaline, reaching values $>9.0$. In addition, the Eh is more oxidizing at low temperature, but becomes more reducing at high temperatures, than for the simulations in which the gas composition is uncontrolled. This behavior reflects both the effect of $\mathrm{CO}_{2}$ abundance on the carbonate-bicarbonate system, and the retrograde solubility of calcite at elevated temperatures. Together, these processes influence the relative solubilities of components that make up the main redox couples in the system (ferric-ferrous and sulfide-sulfate). These effects lead to much greater $\mathrm{Ca}$ and $\mathrm{Si}$ concentrations in solution. $\mathrm{Cl}, \mathrm{F}, \mathrm{S}$, and $\mathrm{P}$ concentrations are virtually the same as in the case where gas composition is not controlled.

It is clear in these simulations that the specific silica polymorph that is allowed to precipitate has only a second order effect on the solution composition. This is mainly expressed in the $\mathrm{Si}$ and $\mathrm{Ca}$ concentrations. The latter is sensitive to the impact of Si concentration on the occurrence of Ca-bearing aluminosilicates (e.g, saponite clays and the zeolite stilbite; Figs. 3.4-13 and 3.4-14).

In all of these simulations, regardless of the specific conditions imposed on the system, fluor-apatite, nontronite, and pyrolusite occur as small abundance precipitates at constant concentration regardless of the degree of evaporation. Their occurrence reflects the low solubilities of these solids.

3.4.1.5 Conclusions. Simulated evaporation of J-13 well water suggests that the most significant variable that controls the evolution of the water chemistry and the solids that precipitate, is the composition of the coexisting gas phase, and whether that gas phase is in equilibrium with the water. The most significant effects can be seen in the divergence of $\mathrm{pH}$ and $\mathrm{Eh}$ (Figs. 3.4-2 and 3.4-3) as evaporation proceeds with and without equilibrium with a gas phase. These effects influence total 
concentration of elements that occur in silicates and carbonates that have solubilities sensitive to moderate changes in solution $\mathrm{pH}$. Conservative elements $(\mathrm{Cl}, \mathrm{F}, \mathrm{S})$ change concentration linearly as evaporation proceeds, since they do not play a role in any of the precipitates that form.

Further work should focus on how these changes will be modified by rock-water interaction during evaporation, and on bounding the range of water variability using the spectrum of water chemistries exhibited by the analyzed groundwaters. 


\subsubsection{References}

Arthur, R.C., and W.M. Murphy, 1989, An Analysis of Gas-Water-Rock Interactions

During Boiling in Partially Saturated Tuff: Sci. Geol. Bulletin, 42(4), 313-327.

Benson, L.V., and P.W. McKinley, 1985, Chemical Composition of Groundwater in the

Yucca Mountain Area, Nevada, 1971-1984: U.S. Geological Survey, Denver, CO,

OFR-85-484. (NNA.900207.0281).

Bruton, Carol, William E. Glassley, and Brian E. Viani, 1993, Preliminary Near-Field

Environment Report Volume II: Scientific Overview of Near-Field Environment and

Phenomena, Chapter 3, Geochemistry: Lawrence Livermore National Laboratory

UCRL-LR-107476 Vol. 2, p. 37-60.

Buscheck, T.A., and John. J. Nitao, 1992, The Impact of Thermal Loading on

Repository Performance at Yucca Mountain: in Proceedings of the Third

International Conference on High Level Radioactive Waste Management, Las Vegas,

Nevada, p. 1003-1017.

Buscheck, T.A., John. J. Nitao, and Dwayne A. Chesnut, 1993, Preliminary Near-Field

Environment Report Volume II: Scientific Overview of Near-Field Environment and

Phenomena, Chapter 1 Hydrothermal Modeling: Lawrence Livermore National

Laboratory UCRL-LR-107476 Vol. 2, p. 5-27.

Criscenti, L.J., and R.C. Arthur, 1991, The Calculated Effects of Isothermal Boiling on

Tuff-Water Interactions: Radiochimica Acta 52/53, 513-517.

Glassley, W.E., 1986, Reference Waste Package Environment Report: Lawrence

Livermore National Laboratory, Livermore, CA UCRL-53726 (NNA.920506.0035).

Harrar, J.E., J.F. Carley, W.F. Isherwood, E.Raber, 1990, Report of the Committee to

Review the Use of J-13 Well Water in Nevada Nuclear Waste Storage Investigations:

Lawrence Livermore National Laboratory, Livermore, CA, UCID-21867

(NNA.910131.0274).

Helgeson, H.C., 1969, Thermodynamics of Hydrothermal Systems at Elevated

Temperatures and Pressures: American Journal of Science 267, 729-804.

Helgeson, H.C., T.H. Brown, A. Nigrini, and T.A. Jones, 1970, Calculation of Mass

Transfer in Geochemical Processes Involving Aqueous Solutions: Geochimica

Cosmochimica Acta 34, 569-592.

Johnson, J. W., Eric H. Oelkers, and Harold C. Helgeson, 1992, SUPCRT92: A

Software Package For Calculating The Standard Molal Thermodynamic

Properties of Minerals, Gases, Aqueous Species, and Reactions From 1 to 5000

Bars and 0 to $1000^{\circ} \mathrm{C}$ : Computers and Geosciences 18. 899-947.

Knauss, K.G., 1987. Zeolitization of Glassy Topopah Spring Tuff Under

Hydrothermal Conditions: Mat. Res. Soc. Symp. Proc. 84, 737-745

(NNA.920302.0050).

Knauss, K.G., J.M. Delany, W.J. Beiriger, and D.W. Peiffer, 1986, Hydrothermal

Interaction of Tonopah Spring Tuff with J-13 Water As a Function of

Temperature: Mat. Res. Soc. Symp. Proc. 44, 539-546 (NNA.870407.0364).

Knauss, K.G., and D.W. Peiffer, 1986, Reaction of Vitric Topopah Spring Tuff and J-13

Groundwater Under Hydrothermal Conditions Using Dickson-Type, Gold-Bag Rocking

Autoclaves: Lawrence Livermore National Laboratory, Livermore, CA UCRL-

53795 (NNA.891102.0117). 
Nitao, J.J., T.A. Buscheck, and D.A. Chesnut, 1992, The Implications of Episodic Nonequilibrium Fracture-Matrix Flow on Site Suitability and Total System Peformance: in Proceedings of the Third International Conference on High Level Radioactive Waste Management, Las Vegas, Nevada, p. 279-296.

Ogard, A.E., and J.F. Kerrisk, 1984, Groundwater Chemistry Along Flow Paths Between a Proposed Repository Site and the Accessible Environment: Los Alamos National Laboratory, Los Alamos, NM, LA-10188. (NNA.890907.0118)

Wolery, T.J., 1992a, EQ3/6, A Software Package for Geochemical Modeling of Aqueous Systems: Package Overview and Installation Guide: Lawrence Livermore National Laboratory, Livermore, CA UCRL-MA-110662 PT. I.

Wolery, T.J., 1992b, EQ3NR, A Geochemical Program For Aqueous Speciation-Solubility Calculations: Theoretical Manual, User's Guide, and Related Documentation: Lawrence Livermore National Laboratory, Livermore, CA UCRL-MA-110662 PT. III. Wolery, T.J., and S. A. Daveler, 1992, EQ6, A Computer Program for Reaction Path Modeling of Aqueous Geochemical Systems: Theoretical Manual, User's Guide, and Related Documentation (Version 7.0): Lawrence Livermore National Laboratory, Livermore, CA UCRL-MA-110662 PT. IV.

Yang, I.C., A.K. Turner, T.M. Sayre, and P. Montazar, 1988, Triaxial-Compression Extraction of Pore Water from Unsaturated Tuff, Yucca Mountain, Nevada: U.S. Geological Survey, Water Resources Investigations Report 88-4189 (NNA.890309.0161). 


\subsubsection{Testing EQ3/6 and GEMBOCHS Using Fluid-Mineral Equilibria in the Wairakei Geothermal System, by Carol Bruton, Lawrence Livermore National Laboratory}

3.4.2.1 Introduction. It is necessary to establish well defined bounds on the range of chemical conditions that may develop within a nuclear waste repository in order to evaluate the extent to which corrosion of waste containers, dissolution of waste forms, and transport of radionuclides may occur. This information forms part of the basis for total system and sub-system performance assessment evaluations, and site suitability determination.

To achieve this goal, simulations of geochemical processes over long time periods (i.e., thousands of years) are required, since experimental studies can be conducted only for a few years, at most. However, the accuracy and precision of numerical simulations is often limited by the supporting thermodynamic and kinetic data that are used in the simulations. One method for ascertaining the accuracy and precision of simulation capabilities is to compare the results of simulations with observed geochemical and mineralogical characteristics of natural systems in which the same processes occur that are anticipated in the potential repository.

The ability of the EQ3 and EQ6 geochemical modeling codes and the GEMBOCHS thermodynamic data bases (Wolery, 1992; Wolery and Daveler, 1992) to simulate geochemical changes in the post-emplacement environment at the potential repository at Yucca Mountain was tested using observed mineral-fluid relations in the Taupo Volcanic Zone of New Zealand. This site was selected for use in the comparisons because of its close geological similarity to the potential repository site, and because processes of interest and an extensive data base are accessible for study (Bruton et al., 1995). Comparisons between observed equilibria and simulations of field relations in the Wairakei geothermal system were used to test the codes and data bases in high temperature $\left(>200^{\circ} \mathrm{C}\right)$ systems. Tests at lower temperatures have been planned, but have yet to receive funding.

The conditions selected for initial evaluation are those that most closely approximate processes in the near-vicinity of emplacement drifts. Numerical models of the post-emplacement temperature field (Buscheck and Nitao, 1993) show the potential for peak temperatures about $200^{\circ} \mathrm{C}$ near the waste, and attendant changes in relative humidity, "drying-out," boiling, condensation, one- and twophase fluid flow, mineral precipitation and dissolution, ion exchange, and surface complexation. The work described here documents tests conducted to evaluate the ability of the EQ3/6 geochemical modeling codes and their associated GEMBOCHS thermodynamic data bases to model mineral-fluid relations in order to:

1. Test the conditions and manner in which EQ3/6 can be used to forecast changes in rock and fluid chemistry during the flow of heated fluids through silicic rocks;

2. Test the thermodynamic data in GEMBOCHS and to select appropriate thermodynamic data when multiple sources exist.

To accomplish this work, it is necessary to select representative water and gas compositions from Wairakei wells (called boreholes), reconstruct downhole fluid 
compositions, calculate the minerals predicted to be in equilibrium with each fluid, and compare simulation results with observed vein and vug mineralogy.

All calculations described were carried out using version 7.2a R134 of EQ3 and version 7.2a R130 of EQ6. The SUPCRT and COM subsets of the R24 version of GEMBOCHS were used as indicated.

3.4.2.2 Fluid chemistry: choice of representative waters and gases. Reyes, Giggenbach and Christenson (1993) reviewed available well discharge data for the Wairakei area. Details of the process of reconstructing downhole fluid chemistry from surface gas and water analyses are described in Bruton (1995). Tables 3.4-1 and 3.4-2 summarize the as-analyzed and reconstructed fluid analyses used in this study.

Redox state was set by the $\mathrm{SO}_{4}=\mathrm{H}_{2} \mathrm{~S}$ buffer, assuming an initial concentration of aqueous $\mathrm{H}_{2} \mathrm{~S}$ of $0.3 \mathrm{mg} / \mathrm{kg}$ in WK-28 based on concentration data from nearby wells. This assumption represents an initial test of modeling strategies regarding control of redox in the subsurface. This initial study did not focus on phases containing $\mathrm{Mg}, \mathrm{Fe}$, and/or S as primary components. The latter two elements are strongly dependent on redox state, which can vary significantly in hydrothermal systems owing to boiling. Chlorite is the major mineral phase containing $\mathrm{Mg}$ in these systems, but no chlorite solid solutions are provided for in the SUPCRT data base. The COM data file provides for an ideal solid solution model for chlorite as well as saponites, which are $\mathrm{Mg}$-rich smectites.

3.4.2.3 Alteration mineralogy. Alteration mineralogy seems to be strongly controlled by temperature. A representative set of minerals, called a mineral facies, is composed of secondary minerals which commonly occur in a given temperature range. The minerals in the facies occur in various combinations, called mineral assemblages. Different mineral assemblages in a given facies can coexist on spatial scales as small as a single hand specimen or petrographic thin section (Bruton, et al., 1994).

Mineral assemblages identified at downhole temperatures of $240-260^{\circ} \mathrm{C}$ in the main feed zones at Wairakei (wells WK-28, 72 and 81) (Reyes, Giggenbach and Christenson, 1993; Steiner, 1977) include: wairakite; adularia (a variety of Kfeldspar); epidote solid solution; wairakite \pm quartz; quartz + adularia; wairakite + epidote \pm calcite; albite + quartz + epidote + chlorite + calcite; prehnite; wairakite + prehnite.

The above mineral assemblages represent the secondary minerals that coexist with the fluids described in the previous section.

3.4.2.4 Calculational approach. Three reconstructed downhole fluids were used to compute predicted secondary mineralogy at depth, which was then compared to observed mineral assemblages.

The approach taken was as follows.

- Select representative sets of coexisting water and gas analyses from Wairakei wells and reconstruct downhole fluid chemistry by adding steam and gases lost during production back into the liquid phase. 
- Identify mineral assemblages along fractures and flow zones closely associated with source of produced fluids.

- Calculate affinity (A) of potential secondary minerals, where $A=R T \ln (Q / K)^{1}$ using version R24 of the SUPCRT and COM subsets of the GEMBOCHS thermodynamic data base.

- Compare calculated and observed mineral assemblages.

Phase relations were examined with the use of affinity-temperature diagrams. Affinity is a measure of a mineral's saturation state. If:

$A=0$, the mineral is at equilibrium with the solution

$A<0$, the mineral is undersaturated with respect to the solution

A $>0$, the mineral is supersaturated with respect to the solution.

Potential mineral assemblages are inferred when multiple affinity-temperature curves have a common intersection at $A=0$. Identification of potential mineral assemblages in this manner is especially useful when thermodynamic data may be suspect or kinetics controls the formation of precipitates. Downhole temperature can be estimated by noting the temperature at which the affinity curves converge on zero (equilibrium).

Calculations assume that pressures correspond to the liquid/vapor saturation curve for $\mathrm{H}_{2} \mathrm{O}$. Solid solutions for epidote and muscovite were considered. Clinozoisite as used in this paper refers to the clinozoisite end member of an ideal epidote solid solution (Bird and Helgeson, 1980) with an activity of 0.4 , as calculated from microprobe analyses of epidote at Wairakei. Muscovite refers to the muscovite end member of an ideal illite solid solution with an activity of 0.5 , estimated by analogy to illite from the Kawerau geothermal field in New Zealand.

3.4.2.5 Results: Water-rock equilibrium calculations. Comparisons between predicted and observed mineral stabilities that will be described in the following sections allowed us to determine:

1. Quartz solubility data that best describes controls of aqueous silica concentrations at temperatures greater than about $200^{\circ} \mathrm{C}$.

2. Importance of gas phase chemistry to mineral equilibria, and mineral indicators of variations in $\mathrm{pH}$.

3. Thermodynamic data for aqueous $\mathrm{Al}$ species that best describe mineral stabilities at temperatures greater than about $200^{\circ} \mathrm{C}$.

4. Corrections to thermodynamic data for wairakite, a high temperature zeolite.

5. Need for better usage and interpretation of calorimetric thermodynamic data for zeolites.

6. Appropriateness of utilizing the mineral facies concept to infer mineral stability rather than exact prediction of the precise secondary minerals to precipitate at temperature.

In all affinity-temperature diagrams shown below, some discretion was used to select the minerals to be plotted. Phases were chosen based on their occurrence in observed mineral assemblages, and their extent of supersaturation or closeness to

1. $Q=$ ion activity product; $K=$ equilibrium constant; $R=$ gas constant; $T=$ temperature in $K$. 
equilibrium. Minerals that were generally depicted on the diagrams include: quartz, K-feldspar, albite, muscovite, calcite, prehnite, wairakite and clinozoisite. These minerals most often appear in stable mineral assemblages identified by Reyes in the temperature range $240-260^{\circ} \mathrm{C}$ (Reyes, et al., 1993).

\subsection{Choice of quartz solubility data: Well WK-81. Figure 3.4-15 shows} differences in the concentrations of $\mathrm{SiO}_{2}$ (aq) predicted according to quartz solubility data from Walther and Helgeson (1977) and Fournier (1983). Fournier's data predict significantly higher $\mathrm{SiO}_{2}$ (aq) concentrations in solution than the quartz solubility data of Walther and Helgeson (1977) at temperatures exceeding about $150^{\circ} \mathrm{C}$.

Figures 3.4-16 and 3.4-17 contrast computations of mineral equilibria in Wairakei well WK-81 using Fournier (1983) and Walther and Helgeson (1977) data, respectively. The adiabatic quartz geothermometer based on data from Walther and Helgeson predicted a downhole temperature of $263^{\circ} \mathrm{C}$, whereas that of Fournier predicted $240^{\circ} \mathrm{C}$. As can be seen from Figs. 3.4-16 and 3.4-17, the affinity curves seem to converge more closely on the downhole temperature predicted using the Fournier (1983) quartz solubility data. It is apparent that calculated mineral equilibria more closely correspond to observed mineralogy when Fournier's (1983) quartz geothermometer is used.

Ragnarsdottir and Walther (1983) measured the pressure dependence of quartz solubility at $250^{\circ} \mathrm{C}$, and concluded that the pressure dependence accounts for the discrepancy between results of Fournier and Walther and Helgeson. Calculations with GEMBOCHS are currently restricted to the liquid/vapor saturation curve for $\mathrm{H}_{2} \mathrm{O}$. However, according to the results of Ragnarsdottir and Walther (1983), the hydrostatic fluid pressures maintained at Wairakei are not large enough to impact quartz solubility significantly.

For calculations of quartz solubility above about $200^{\circ} \mathrm{C}$ at the present time, the quartz solubility data of Fournier (1983) should be used in place of that of Walther and Helgeson (1977), which is contained in all current versions of GEMBOCHS.

3.4.2.5.2 Impact of changes in gas chemistry: WK-72. Vapor compositions vary with time owing to production and the partitioning of components between vapor and liquid phases. Figure 3.4-18 shows the variation of $\mathrm{CO}_{2}$ with time in wells WK28,72 and 81 . Changes of this magnitude will greatly impact calculated fluid-mineral equilibria owing to its impact on $\mathrm{pH}$. The variation of component ratios, discharge enthalpy and other well parameters with time can be used to try to derive reasonable estimates of the quantity of volatile species in the original, undisturbed fluids. However, uncertainties persist.

Use of different gas compositions for a given fluid analysis can produce significant changes in predicted mineralogy owing to the impact of $\mathrm{CO}_{2}$ on $\mathrm{pH}$. The greater the $\mathrm{CO}_{2}$ content of the produced vapors, the lower the predicted $\mathrm{pH}$ of the reconstructed downhole fluid. For example, the calculated downhole $\mathrm{pH}$ is reduced from 6.2 to 5.9 when the $3 / 78$ gas analysis for WK-72 with $258 \mathrm{mmol} \mathrm{CO} 2 / \mathrm{mol} \mathrm{TD}$ is used rather than the $5 / 61$ analysis with $102 \mathrm{mmol} \mathrm{CO} / \mathrm{mol} \mathrm{TD}$, where TD is defined as the total discharge, that is, the combined chemistry of the steam and liquid phases. 
Figures 3.4-19 and 3.4-20 illustrate the mineralogical consequences of using the high $(3 / 78)$ and low $(5 / 61) \mathrm{CO}_{2}$ gas estimates, respectively. The stabilities of $\mathrm{K}-$ feldspar and albite are largely unaffected by changes in $\mathrm{pH}$, whereas the stabilities of prehnite, muscovite and calcite are sensitive to $\mathrm{pH}$, as reflected by the shift of their affinity-temperature curves. The dissolution/precipitation of muscovite, prehnite and calcite may thus serve as sensitive indicators of changes in downhole fluid chemistry. In contrast, the stabilities of $\mathrm{K}$-feldspar and albite are largely unaffected by uncertainties in gas chemistry and $\mathrm{pH}$, and are therefore good tests of equilibrium and the adequacy of thermodynamic data for aqueous $\mathrm{Al}$ species.

Figures 3.4-19 and 3.4-20 also suggest that the earlier, lower $\mathrm{CO}_{2}$ gas analysis better represents downhole conditions, as shown by the fact that the curves tend to converge more closely on the downhole temperature than in the high $\mathrm{CO}_{2}$ gas case.

This finding may have implications for Yucca Mountain with regard to the timing and mass of ${ }^{14} \mathrm{C}$ release. If released as $\mathrm{CO}_{2}$ and in sufficient quantities while water is present, the waters can be made more chemically aggressive if initially neutral, or neutralized if initially alkaline from contact with cementitious materials in the engineered barrier system. The consequences of interactions with cementitious materials before contact with tuff must also be taken into account.

Of perhaps more importance is the variation in gas phase chemistry, particularly $\mathrm{CO}_{2}$ content, in the vapor phase in the two-phase (gas and water) zones predicted to occur by Buscheck and Nitao (1993). The $\mathrm{CO}_{2}$ content will control the $\mathrm{pH}$ of the fluid with which it is in contact, and thus the extent and type of fluid-rock interaction. The fluid-rock interaction, in turn, may have a large impact on tuff permeability and fluid flow pathways. Bruton and Viani (1992) suggested that water may behave as if it were $100 \%$ saturated at liquid saturations greater than about $20 \%$ at temperatures up to $100^{\circ} \mathrm{C}$. However, the coexisting gas phase will have a large impact on the water's chemical reactivity. Any forecasts of fluid-rock interaction in two-phase zones will require the gas phase chemistry to be considered, as addressed in the boiling scenarios evaluated by Criscenti and Arthur (1991) and Arthur and Murphy (1989).

\subsection{Thermodynamic data for aqueous Al species: WK-28. Downhole} mineral equilibria in well WK-28 were calculated using two different data bases that are in current use. One is based on SUPCRT92, and the other is an updated version of the same data base but with thermodynamic data for aqueous $\mathrm{Al}$ species from Pokrovskii and Helgeson (1995) (SUPCRT R24). The latter data will be used in GEMBOCHS.

Figure 3.4-21 shows the simulation results using data from Pokrovskii and Helgeson, whereas Fig. 3.4-22 was constructed using the SUPCRT92 data base. The convergence of affinity curves at zero affinity (equilibrium) at the downhole temperature in Fig. 3.4-21 for phases that are observed as secondary phases suggests that Pokrovskii and Helgeson's data for aqueous Al species work quite well. In 
contrast, the data in SUPCRT92 ${ }^{2}$ do not reproduce downhole mineralogy well. In these calculations, measured $\mathrm{Al}$ concentrations were used; that is, they were not automatically set using mineral equilibria as is often done, especially at lower temperature (e.g Bowers and Burns, 1990; Chipera, Bish and Carlos, 1995).

Given the above results, thermodynamic data for aqueous $\mathrm{Al}$ species should be sourced from Pokrovskii and Helgeson (1995). Further simulations should be undertaken in the range $100-200^{\circ} \mathrm{C}$ to evaluate the $\mathrm{Al}$ data bases at lower temperature. However, less discrepancy may be observed at lower temperatures because the main cause of discrepancy is the $\log \mathrm{K}$ for reaction between $\mathrm{Al}^{3+}$ and $\mathrm{AlO}_{2}{ }^{-}$. The two log $\mathrm{Ks}$ agree well at low temperature, but deviate increasingly with increasing temperature until a difference of about $0.4 \log$ units exists at $250^{\circ} \mathrm{C}$, producing the observed differences in the affinity vs. temperature figures.

The log $\mathrm{K}$ for reaction between $\mathrm{Al}^{3+}$ and $\mathrm{AlO}_{2}-$ from Bourcier and Knauss (1993) used in GEMBOCHS COM versions prior to $\mathrm{R} 24$ also reproduces observed mineralogy well. Users of GEMBOCHS data bases should identify the $\mathrm{Al}(\mathrm{OH})_{4}^{-} / \mathrm{Al}^{3+}$ $\log \mathrm{K}$ specified in the data base they are using, and ascertain that it is appropriate for their needs. Of course, reactions which are written balanced on $\mathrm{Al}$, such as those incorporated in many activity diagrams (e.g Bowers and Burns, 1990; Chipera, Bish and Carlos, 1995), will not be affected.

\subsection{Thermodynamic data for wairakite. Figures 3.4-17 through 3.4-22} illustrate that wairakite is predicted to be about 1 to $1.5 \mathrm{kcal} / \mathrm{mol}$ undersaturated in all wells at about $250^{\circ} \mathrm{C}$. In contrast, wairakite commonly occurs at Wairakei as a secondary phase at this temperature. Therefore, the calculations suggest that the free energy of formation from the elements of wairakite in SUPCRT92 (Helgeson et al., 1978), and in all current verions of GEMBOCHS, should be decreased by approximately $1-1.5 \mathrm{kcal} / \mathrm{mol}$ at about $250^{\circ} \mathrm{C}$ to increase its stability.

Thermodynamic data for wairakite may not seem to be relevant to the Yucca Mountain Project. However, if temperatures exceed $200^{\circ} \mathrm{C}$ with water present, wairakite would tend to be the stable zeolite relative to clinoptilolite, heulandite, and mordenite. Given the uncertainty in thermodynamic data for lower temperature zeolites such as clinoptilolite, heulandite, and mordenite (discussed below), it is useful to have some measure of data reliability for at least one zeolite with which to reference the other zeolites.

3.4.2.5.5 Thermodynamic data for zeolites. The simulations represented in Figs. 3.4-17 through 3.4-22 were run with the SUPCRT data base instead of the COM data file in part because the COM file contains thermodynamic data for zeolites such as analcime, clinoptilolite, mordenite, heulandite, stilbite, mesolite, scolecite and natrolite from Johnson and co-workers $(1982,1983,1985,1991,1992)$ and Howell et al. (1990). These data were obtained through careful calorimetric studies. When kinetic constraints are not considered and purely thermodynamic equilibrium

2. Versions of SUPCRT have been published and distributed without data for $\mathrm{AlO}_{2}^{-}$, the most important $\mathrm{Al}$ aqueous species under many conditions. The calculations in this paper provided for this species. 
calculations are made, one of the above zeolites is present in the computed equilibrium assemblage at temperatures as high as $250^{\circ} \mathrm{C}$, even though they are generally not expected to be stable at such high temperature in natural systems. Figure 3.4-23 shows a calculation of zeolite stability in well WK-28 under conditions identical to that in Fig. 3.4-21, but using GEMBOCHS version COM R24 which contains Johnson's calorimetric data for zeolites. Figure 3.4-21 can be combined with Fig. 3.4-23 to show the affinities of zeolites relative to other minerals. Note the supersaturation with respect to scolecite, mesolite, stilbite and the $\mathrm{Ca}$ end-member of a clinoptilolite solid solution (discussed by Viani and Bruton, 1992) at the downhole temperature of $246^{\circ} \mathrm{C}$.

Owing to this discovery, the first tests of the codes were made using data bases that do not contain Johnson's data for zeolites. At this time, simulations using the COM data base containing Johnson's zeolites must be made by suppressing the zeolites to artificially reflect their disappearance from natural assemblages at temperatures greater than about $200^{\circ} \mathrm{C}$.

The thermodynamic data at elevated temperature for the above zeolites from Johnson and co-workers are uncertain for a number of reasons.

First, the third law entropies $\left(S^{\circ}\right)$ for clinoptilolite, mordenite, stilbite, mesolite, scolecite, and natrolite in the COM data file are actually values for $S^{\circ}(T)-S^{\circ}(0)$, because the configurational entropies at $0 \mathrm{~K}\left(\mathrm{~S}^{\circ}(0)\right)$ were not available. Johnson and co-workers attempted to estimate configurational entropies when possible, and warned that the configurational entropy must be taken into account when computing mineral equilibria. We have not devoted effort to estimating configurational entropies because their contribution would increase zeolite stability, whereas the problem is that they seem to be too stable already.

Secondly, it is possible that $\mathrm{H}_{2} \mathrm{O}$ vapor adsorption occurred during the cooling of Johnson's drop calorimetry experiments. The exothermic reaction would produce excess heat capacity at elevated temperature (see Carey, 1993 for full discussion). Carey (1993) suggested that the heat capacity of $\mathrm{H}_{2} \mathrm{O}$ in clinoptilolite is temperatureinsensitive, rather than increasing monotonically with temperature, as shown by Johnson et al. (1991).

Thirdly, the hydration state of zeolites may decrease with increasing temperature, which would affect their stability. Water in zeolites is generally considered to have a lower free energy than bulk water, such that water desorption is endothermic. Johnson measured the thermodynamic properties of his zeolites at $50 \%$ relative humidity in recognition of their potential for changing hydration state. This potential for changing hydration state is not currently provided for in the EQ3/6 codes and data bases, however.

If the configurational entropy were appropriately accounted for, and the heat capacities corrected for readsorption phenomena, the stability of zeolites would increase because their free energies of formation would be more negative. However, zeolite stability would have to decrease if errors in thermodynamic data were the cause for the predicted stability of zeolites at temperatures greater than about $200^{\circ} \mathrm{C}$.

Until a more satisfying approach is found, EQ3/6 calculations of fluid-mineral equilibria in the post-emplacement environment at temperatures greater than about $200^{\circ} \mathrm{C}$ can be carrried out by manually suppressing the precipitation of low 
temperature zeolites. Additionally, updated thermodynamic data for zeolites, such as that described in Section 3.4.3, will be included in future simulations.

3.4.2.5.6 Ability to predict stable phase assemblages with EQ3/6. Affinitytemperature diagrams illustrate that a number of minerals are close to equilibrium with downhole fluids at Wairakei (e.g. affinity close to 0 ). This might explain the wide variety of mineral assemblages observed at Wairakei. However, all assemblages are composed of different combinations of the same set of minerals. This common phenomenon is expressed by the metamorphic facies concept.

It is not feasible to use EQ6 to predict the exact assemblage of silicate minerals in equilibrium with a given fluid. The codes cannot be used to predict blindly the stable phase assemblage because the entire calculation is "led astray" if one mineral's thermodynamic data causes its stability to be overestimated, or if the code chooses a precipitate that is inappropriate because of kinetic constraints. For example, EQ6 predicted that the stable downhole mineral assemblage in well WK-28 was calcite, quartz, and petalite (or mesolite if petalite is suppressed) using the COM R24 data base. The same calculation made using the SUPCRT R24 data base yielded an assemblage of calcite, quartz, analcime, and tremolite. Neither of these assemblages are representative of observed secondary (or primary) mineralogy.

In contrast, it is quite reasonable to use EQ3 and EQ6, when tempered with field and laboratory data and experience, to establish facies of minerals that would be expected to precipitate under given conditions. Each facies would consist of classes of minerals that would possess similar characteristics, e.g., a class of silica-rich zeolites that contains clinoptilolite, mordenite and heulandite. This is eminently more reasonable than expecting to predict whether clinoptilolite, mordenite or heulandite will precipitate. We will not know in the near future the fluid composition, thermodyamic properties of minerals, or kinetic constraints to the degree of accuracy required to do so.

Clearly, alternate approachs similar to that illustrated by the affinity-temperature diagrams should be adopted to determine the potential for mineral stability. The calculations described in Figs. 3.4-3 through 8 suggest that fluid-mineral equilibria determined in this manner agree well with observed mineralogy.

\subsection{Vein/vug os. matrix mineralogy and mineral assemblages. Alteration} mineralogy at Wairakei is controlled strongly by temperature in veins and vugs, and by both temperature and mineralogy in the matrix. Replacement minerals in the matrix are controlled in identity, morphology and location by the primary mineralogy. That is, replacement mineralogy is controlled by the dissolving phase; the components of the dissolving mineral tend to re-precipitate as secondary minerals next to the dissolving grain. This link is much weaker or non-existent, in vein- and vug-fills.

The stabilities of fracture-, vein- and vug-filling minerals are controlled by solution composition and temperature with apparently limited control by the matrix. Alteration minerals in veins and vugs are the same as those found as replacement minerals in the matrix, but they occur in assemblages composed of fewer phases. It is striking that vein and vug fills, which obviously have precipitated 
from solution, are characterized by one to three secondary minerals, fewer than the number of different replacement minerals in the matrix as a whole. The above findings suggest that the fractures, veins and vugs represent fluid-dominated systems, whereas the matrix represents a rock-dominated system.

Petrographic observations suggest that the minerals replacing plagioclase in the matrix are those that commonly comprise fracture/vein/vug mineralogy; both seem to be Ca-dominated systems. At this time, our working hypothesis is that vein mineralogy is controlled mainly by fluid chemistry in the flowing system with negligible interaction with the host rock. The number of fracture-filling minerals may be controlled by the phase rule for mobile components.

In the post-emplacement environment at Yucca Mountain, replacement mineralogy in the matrix would be expected to be controlled by temperature and primary mineralogy, provided sufficient water is present to effect such changes, whereas the stability of minerals along flow paths such as fractures would be controlled by the evolution of water composition as well as temperature. Factors that could effect impact water composition include boiling/condensation, interactions with cementitious and other manufactured materials including metal waste package components, and so on.

The degree of mass transfer between matrix and fractures in the New Zealand systems should be evaluated. If there is little chemical exchange between the matrix and fractures, mineral dissolution/precipitation during fluid flow in coupled hydrogeochemical models can be simulated much more simply because diffusion to and from the matrix does not have to be considered.

3.4.2.6 Conclusions. Vein and matrix minerals are predicted to be in equilibrium with subsurface fluids at downhole temperatures greater than $240^{\circ} \mathrm{C}$. The proximity of a variety of minerals to equilibrium suggests that small differences in fluid chemistry, temperature or pressure can significantly impact mineral assemblages. This might account for the wide variety of mineral assemblages observed at Wairakei.

The SUPCRT92 data base, combined with the data of Pokrovskii and Helgeson (1995) for aqueous Al species describes, equilibrium relations between measured Al concentrations and observed mineral equilibria better than data in the current SUPCRT92 data base. Observed changes in the stability of calcite, prehnite and illite (muscovite) can be indicative of changes in the gas content of the downhole fluid. Feldspar stabilities are largely independent of $\mathrm{pH}$ provided that $\mathrm{pH}$ values do not deviate greatly from neutrality.

Quartz solubility data from Fournier (1983) describe observed mineral assemblages better than data from Walther and Helgeson (1977). The free energy of wairakite from Helgeson et al. (1978) should be decreased by approximately $1-1.5 \mathrm{kcal} / \mathrm{mole}$ at about $250^{\circ} \mathrm{C}$. Additional work is required to determine why calorimetric data for clinoptilolite, stilbite and other zeolites from Johnson and coworkers appear to overestimate the stability of these minerals at elevated temperature.

Fluid-mineral interactions at temperatures $>200^{\circ} \mathrm{C}$ are generally believed to be controlled by equilibrium, and so were chosen as the starting point for the EQ3/6 
code and data base tests. This assumption is supported by the excellent convergence observed for computed and observed assemblages. Further studies should focus on fluid-mineral reactions in the temperature range of about $100-200^{\circ} \mathrm{C}$ at the Wairakei and Kawerau geothermal fields. Zeolites such as mordenite, dachiardite and clinoptilolite have been identified in this temperature interval. Extension of the tests to lower temperature allows us to address the controls of kinetics vs.

equilibrium on mineral stability, and to determine the stability of zeolites similar to those found at Yucca Mountain. 


\subsubsection{References}

Arthur, R.C. and Murphy, W.M., 1989, An analysis of gas-water-rock interactions during boiling in partially saturated tuff: Soc. Geol. Bull., 42, 313-327.

Bird, D.K. and Helgeson, H.C., 1980, Chemical interaction of aqueous solutions with epidote-feldspar mineral assemblages in geologic systems. 1. Thermodynamic analysis of phase relations in the system $\mathrm{CaO}-\mathrm{FeO}-\mathrm{Fe}_{2} \mathrm{O}_{3}-\mathrm{Al}_{2} \mathrm{O}_{3}-\mathrm{SiO}_{2}-\mathrm{H}_{2} \mathrm{O}-\mathrm{CO}_{2}$ : Am. Jour. Sci. 280, 907-941.

Bourcier, W.L. and Knauss, K.G., 1993, Aluminum hydrolysis constants to $250^{\circ} \mathrm{C}$ from boehmite solubility measurements: Geochim. et Cosmochim. Acta 57, 747-762.

Bowers, T.S., and Burns, R.G., 1990, Activity diagrams for clinoptilolite:

Susceptibility of this zeolite to further diagenetic reactions: Am. Min. 75, 601-619.

Bruton, C.J., 1995, Testing EQ3/6 and GEMBOCHS using fluid-mineral equilibria in the Wairakei geothermal system: Yucca Mountain Project letter report, Milestone MOL206, Chemical and Mineralogical Properties of the Waste Package Environment: Natural System Simulations, WBS Element 1.2.3.12.1, August 28, 1995.

Bruton, C.J., Glassley, W.E., and Bourcier, W.L., 1994, Field-based tests of geochemical modeling codes using New Zealand hydrothermal systems: Lawrence Livermore National Laboratory, UCRL-ID-118009.

Bruton, C.J., Glassley, W.E., and Meike, A., 1995, Geothermal areas as analogues to chemical processes in the near-field and altered zone of the potential Yucca Mountain, Nevada, repository: Lawrence Livermore National Laboratory, UCRL-ID-119842.

Bruton, C.J., and Viani, B.E., 1992, Geochemical modeling of water-rock interactions in the unsaturated zone: in Water-Rock Interaction 7, Y.K. Kharaka and A.S. Maest, eds., A.A. Balkema, Netherlands, p. 705-708.

Buscheck, T.A., and Nitao, J.J., 1993, Repository-heat-driven hydrothermal flow at Yucca Mountain, Part 1: Modeling and analysis: Nuclear Tech. 104, 418-448.

Carey, J.W., 1993, The heat capacity of hydrous cordierite above 295 K: Phys. Chem. Min. 19, 578-583.

Chipera, S.J., Bish, D.L., and Carlos, B.A., 1995, Equilibrium modeling of the formation of zeolites in fractures at Yucca Mountain, Nevada: in D.W. Ming and F.A. Mumpton, eds., Natural Zeolites '93: Occurrence, Properties, Use: Intl. Comm. on Natl. Zeolites, Brockport, N.Y., p. 565-577.

Criscenti, L.J., and Arthur, R.C., 1991, The calculated effects of isothermal boiling on tuff-water interactions: Radiochim. Acta 52/53, 513-517.

Fournier, R.O., 1983, A method of calculating quartz solubilities in aqueous sodium chloride solutions: Geochim. et Cosmochim. Acta 47, 579-586.

Howell, D.A., Johnson, G.K., Tasker, I.R., and O'Hare, P.A.G., 1990, Thermodynamic studies of the zeolite stilbite: Zeolites 10, July/August, 525-531.

Johnson, G.K., Flotow, H.E., and O'Hare, P.A.G., 1982, Thermodynamic studies of zeolites: analcime and dehydrated analcime: Am. Min. 67, 736-748.

Johnson, G.K., Flotow, H.E., and O'Hare, P.A.G., 1983, Thermodynamic studies of zeolites: natrolite, mesolite and scolecite: Am. Min. 87, 1134-1145.

Johnson, G.K., Flotow, H.E. and O'Hare, P.A.G., 1985, Thermodynamic studies of zeolites: heulandite: Am. Min. 70, 1065-1071. 
Johnson, G.K., Tasker, I.R., Flotow, H.E., O'Hare, P.A.G. and Wise, W.S., 1992, Thermodynamic studies of mordenite, dehydrated mordenite, and gibbsite: $A m$. Min. 77, 85-93.

Johnson, G.K., Tasker, I.R., Jurgens, R. and O'Hare, P.A.G., 1991, Thermodynamic studies of zeolites: clinoptilolite: J. Chem. Thermo. 23, 475-484.

Pokrovskii, V.A., and Helgeson, H.C., 1995, Thermodynamic properties of aqueous species and the solubilities of minerals at high pressures and temperatures - The system $\mathrm{Al}_{2} \mathrm{O}_{3}-\mathrm{H}_{2} \mathrm{O}-\mathrm{NaCl}$ : Am. Jour. Sci. 295, 1255-1342.

Ragnarsdottir, K.V., and Walther, J.V., 1983, Pressure sensitive "silica geothermometer" determined from quartz solubility experiments at $250^{\circ} \mathrm{C}$ : Geochim. et Cosmochim. Acta 47, 941-946.

Reyes, A.G., Giggenbach, W.F., and Christenson, B.W., 1993, First Report for the LLNLInst. Geol. Nuclear Sciences EQ3-EQ6 Code Validation Contract: Inst. Geol. Nuclear Sciences Client Report 722305.15A.

Steiner, A., 1977, The Wairakei geothermal area, North Island, New Zealand: New Zealand Geological Survey Bull. 90.

Viani, B.E., and Bruton, C.J., 1992, Modeling fluid-rock interaction at Yucca Mountain, Nevada: A progress report: Lawrence Livermore National Laboratory UCRL-ID109921.

Walther, J.V., and Helgeson, H.C., 1977, Calculation of the thermodynamic properties of aqueous silica and the solubility of quartz and its polymorphs at high pressures and temperatures: Am. Jour. Sci. 277, 1315-1351.

Wolery, T.J., 1992, EQ3NR, A computer program for geochemical aqueous speciationsolubility calculations: Theoretical manual, user's guide, and related documentation (Version 7.0): Lawrence Livermore National Laboratory Report UCRL-MA-110662 PT III.

Wolery, T.J., and Daveler, S.A., 1992, EQ6, A computer program for reaction path modeling of aqueous geochemical systems: theoretical manual, user's guide, and related documentation (Version 7.0): Lawrence Livermore National Laboratory Report UCRL-MA-110662 PT IV. 


\subsubsection{Mineralogy-Petrology Observations Regarding the Near-Field Environment,}

by David L. Bish, J. William Carey, Schon S. Levy and Steve J. Chipera, Los Alamos National Laboratory

3.4.3.1 Introduction. In order to model accurately the short- and long-term effects of repository-induced heating on the properties of rocks in the near-field environment (NFE) at Yucca Mountain, an understanding of the host rock mineralogy, past mass transfer in the host rocks, and the anticipated changes in mineral and glass stability due to emplacement of high-level radioactive waste are required. Bish and Chipera (1989) compiled a summary of mineral distributions with depth in drill holes at Yucca Mountain using available non-Q core. A more recent report (Chipera et al., 1995b) has provided similar mineralogical information using Q core. Levy (1991) and Levy and O'Neil (1989) described the application of petrologic and isotopic methods to the understanding of past mass transfer in the host rocks. A large amount of research has been conducted on the effects of repository-induced heating on the long-term stability of minerals and glasses in the near-field environment. This includes studies of the dehydration behavior of clays and zeolites in tuffs (Bish, 1984, 1988a, 1988b, Kranz et al., 1989; Carey and Bish, 1994, 1996; Chipera et al., 1994) and on the hydrothermal stability of tuffs (Blacic et al., 1986; Duffy, 1983a, 1983b, 1993). The data reported here from drill holes USW NRG-6 and UE-25 UZ\#16 are the only $Q$ data available; all other mineralogical data are non$Q$ as they were obtained from non- $Q$ core and cuttings.

3.4.3.2 Host Rock Mineralogy. The discussion of host-rock mineralogy will be confined primarily to portions of Yucca Mountain most likely to experience repository-induced conditions departing significantly from ambient conditions. This region consists primarily of the Topopah Spring Tuff and the underlying Calico Hills Formation within the repository exploration block (Fig. 3.4-24).

3.4.3.2.1 Mineralogical Data. The thin but hydrologically important upper vitrophyre of the Topopah Spring Tuff lies beneath the nonwelded Paintbrush bedded tuffs. This vitrophyre has a significant hydrologic effect despite its meager thickness $(3-7 \mathrm{~m})$ because it is the greatest single barrier to downward recharge into the unsaturated zone (Flint et al., 1993).

One of the important features examined in this vitrophyre across Yucca Mountain has been the extent of alteration, indicating whether this glassy barrier has been compromised by $12 \mathrm{Myr}$ of potential recharge into the unsaturated zone. The upper vitrophyre is composed primarily of unaltered volcanic glass. There is some noteworthy alteration of up to $11 \%$ smectite in the glassy portions. More detailed sampling in drill hole UE-25 UZ\#16 showed that the upper vitrophyre has been altered significantly by past fluid flow, with up to $18 \%$ smectite and $18 \%$ clinoptilolite-group zeolite.

The clinoptilolite-group zeolites in this zone have 020:200 intensity ratios indicative of heulandite. To confirm the identification of heulandite, aliquots of samples from drill hole UE-25 UZ\#16 were heated overnight at $400^{\circ} \mathrm{C}$ and $550^{\circ} \mathrm{C}$. The samples were analyzed by $X$-ray diffraction after each heating to determine if the 
structure had collapsed as expected for heulandite (Mumpton, 1960; Alietti, 1972). Although heating produced significant collapse, the structure was not completely

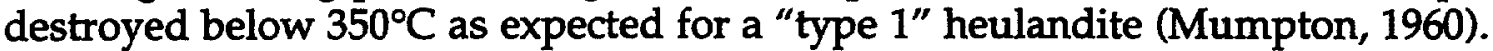
Likewise, the zeolite cannot be a pure clinoptilolite which should remain stable to temperatures in excess of $700^{\circ} \mathrm{C}$.

The amount of collapse observed suggests that the zeolite in these samples is either a mixture of heulandite with minor clinoptilolite, or it is structurally and compositionally an intermediate "type 2 " heulandite (Alietti, 1972). The presence of zeolites and smectite in this zone suggests "ponded" alteration above the relatively impermeable upper vitrophyre, it is, however, impossible, given existing data, to determine whether the extent of alteration in the upper Topopah vitrophyre is variable across Yucca Mountain. If such variability could be documented, it might then be possible to map those portions of the mountain where recharge has been, and is likely to be, concentrated.

The restriction of zeolites to the thin interval above the upper vitrophyre of the Topopah Spring Tuff, and the identification of a heulandite component in these zeolites associated with abundant cristobalite, may indicate a very early episode of zeolitization during initial heat loss from the underlying vitrophyre. This interpretation is in accord with studies of the lower vitrophyre of the Topopah Spring Tuff, where the formation of heulandite at the margin of the vitrophyre is related to the moderate-temperature events that occurred with late-stage cooling of the tuff (Levy and O'Neil, 1989).

One of the inferences that can be drawn from this interpretation is that the zeolitization observed sporadically above the upper vitrophyre of the Topopah Spring Tuff does not represent any significant accumulation of water over the last 12 million years. This inference should be considered critically in further studies of mineralogy from this interval, for although the occurrences of heulandite-aboveglass are similar in both the lower and upper Topopah Spring vitrophyres, the alteration setting is quite different. Heulandite formation in the lower vitrophyre is associated with passage from the overlying devitrification front into the vitrophyre, whereas the heulandite that formed above the upper vitrophyre marks a boundary between two vitric zones (welded and nonwelded) with markedly different porosity and transmissivity. It is also possible that the formation of this upper zeolitic zone was favored by the presence of minor amounts of perched water captured due to the low permeability of the underlying upper vitrophyre. Whatever the timing and mode of heulandite formation above the upper vitrophyre, the upper vitrophyre itself is remarkably unaltered, indicating little water/rock interaction in this relatively impermeable interval since tuff emplacement.

Mineralogic evidence of ongoing infiltration may best be found in the potentially ongoing alteration of glass to smectite and in the minor but significant accumulation of calcite in the lower part of the Paintbrush Tuff nonwelded interval in drill hole UE-25 UZ\#16. It is important to note that the quantities of smectite and calcite that occur in this interval vary markedly across Yucca Mountain. Up to $40 \%$ calcite and $40 \%$ smectite occur to the north in USW G-2, and $40 \%$ smectite but only a trace of calcite occur in UE-25a\#1. A possible implication of this variability is that those portions of the mountain where recharge has been greatest might be 
delineated by examining the extent of underlying alteration in the nonwelded tuffs between the Tiva Canyon and Topopah Spring Tuffs. This implication deserves serious consideration.

The main central portion of the Topopah Spring Tuff, which consists of densely welded, devitrified rhyolitic tuff (e.g., Broxton et al., 1989), is critical to site characterization because it is the host rock for the potential high-level nuclear waste repository.

The potential repository horizon includes the interval below the zone of abundant ( $>15 \%$ ) lithophysal cavities in the upper Topopah Spring Tuff and above the unit's basal vitrophyre. The Topopah Spring Tuff is chemically homogeneous, but the mineralogy is variable, primarily in the relative abundances of silica polymorphs (quartz, cristobalite, and tridymite).

Hematite and smectite are common minor phases, and Mn-oxides are common fracture coatings in the upper portion of the unit. However, within the exploration block, there is little variation in the mineralogy of the repository horizon, and over $98 \%$ of the mineral content of the rocks can be ascribed to tridymite, cristobalite, quartz, and alkali feldspar. The abundance of feldspar varies between about 55 and $65 \%$, with the remainder of the rock consisting of variable proportions of crystalline silica polymorphs. Thus, the total of the crystalline silica polymorphs is quite consistent throughout much of the Topopah Spring Tuff.

In most cores, tridymite occurs throughout this interval of the Topopah Spring Tuff but is most abundant in the upper portion. Quartz is often absent in the upper portion of this interval but occurs in the lower portions in tuffs with reduced tridymite abundance. Based on higher sampling densities in UE-25 UZ\#16 and USW NRG-6, there appears to be a pronounced break in the distribution of silica polymorphs at between 15 and $20 \%$ of the way downward through the Topopah Spring Tuff. This is where the transition from quartz-latite to rhyolitic composition occurs. At this point, a maximum in tridymite abundance is reached and quartz becomes more important.

Cristobalite varies markedly in relation to quartz below this transition depth. $\mathrm{X}$-ray diffraction data suggest that there may be a general reduction in cristobalite and rise in quartz with depth, beginning near the middle nonlithophysal zone.

These silica polymorphs are important, because the least stable of them (cristobalite and tridymite) can elevate the aqueous silica activity in local unsaturated-zone waters. These less stable silica minerals provide a ready source of silica for dissolution, transport, and deposition under the thermal perturbations of a repository. Cristobalite is particularly abundant in the potential repository horizon (Bish et al., 1984), and as such may be an important health hazard consideration. In addition to effects on aqueous silica activity, cristobalite is important in the nearfield environment because it undergoes a displacive phase transformation, with an associated $5 \%$ volume increase, at about $220^{\circ} \mathrm{C}$ (Peacor, 1973).

Recent studies of drill hole UE-25 UZ\#16 (Chipera et al., 1995b) emphasized our limited understanding of the rocks within the exploration block. In this drill hole, stellerite, a Ca-rich ( $\mathrm{Ca}_{4} \mathrm{Al}_{8} \mathrm{Si}_{28} \mathrm{O}_{72} \cdot 28 \mathrm{H}_{2} \mathrm{O}$ ) orthorhombic mineral similar to stilbite, was discovered in significant amounts in the central 50\% of the Topopah Spring Tuff. This zeolite occurs in bulk-rock samples between 191.5 and 332.4 meters in 
depth, in concentrations up to $14 \mathrm{wt} \%$ (avg. $\sim 3 \mathrm{wt} \%$ ) and is obviously not restricted to fractures. The occurrence of this hydrous mineral within the potential repository horizon was completely unexpected as it had previously been found only in fractures from drill holes USW G-1, G-2, and UE-25a\#1. Its significance in the remainder of the exploration block is unknown. Future analyses of cores from drill holes SD-7, SD-9, and SD-12 may clarify the stellerite distribution with the exploration block. Naturally this hydrous mineral will be particularly sensitive to changes in temperature and water-vapor pressure, and it loses most of its water below $200^{\circ} \mathrm{C}$ (Gottardi and Galli, 1985).

The effects of thermal alteration by hot emplaced waste may be most pronounced in the basal vitrophyre of the Topopah Spring Tuff, closely underlying the potential repository horizon. This vitrophyre is variably altered across Yucca Mountain, with devitrification-associated heulandite formation penetrating its highly irregular upper surface (Levy and O'Neil, 1989).

As noted by Bish et al. (1984), the so-called Zeolite Interval I occurs at the top of the basal vitrophyre. This is a 2-5-m thick interval, commonly containing up to $30 \%$ of a clinoptilolite-heulandite mineral and $45 \%$ smectite. Alteration to zeolites and smectite is often gradational in the upper and lower margins of the basal vitrophyre, and smaller amounts of other zeolites (e.g., erionite) also invade the lower and upper margins, usually in fractures. The minerals in Zeolite Interval I are potentially quite important in the near-field environment because (1) they represent the first occurrence of significant amounts of sorptive minerals beneath the repository horizon; and (2) they represent the first occurrence of minerals that are particularly sensitive to changes in temperature and/or water-vapor pressure.

The basal vitrophyre itself is a 10 - to $30-\mathrm{m}$ thick zone consisting predominantly of densely welded glass (40-90\%), with smaller amounts of feldspar, quartz, and opalCT. Perlitic fractures in the vitrophyre are commonly lined with smectite or zeolites. The perlitic glass in this interval contains from 2.8 to $4.6 \%$ water, approximately three-fourths of which is lost at temperatures below $300^{\circ} \mathrm{C}$ in dry heating experiments (Vaniman et al., 1993).

In the eastern portion of Yucca Mountain, the nonwelded base of the Topopah Spring Tuff and all of the underlying Calico Hills Formation are extensively zeolitized to clinoptilolite and mordenite. These zeolitic rocks contain up to $83 \%$ clinoptilolite and up to $43 \%$ mordenite. The primary silica phase associated with this zeolitization is authigenic opal-CT, with minor amounts of quartz and alkali feldspar in the highly zeolitized horizons. Percentages of smectite up to $50 \%$ occur in the Topopah Spring Tuff bedded tuffs immediately underlying the lower vitrophyre, but the thoroughly zeolitized rocks at greater depth typically contain very little smectite. In the western portion of Yucca Mountain, the few core samples available suggest that this entire interval is vitric and largely unaltered. This vitric interval consists of moderately welded to non-welded glassy tuffs, with 30 to $80 \%$ glassy shards and minor amounts of alkali feldspar, cristobalite, and quartz. Alteration to smectite is minor in this interval.

The available data suggest that an alteration front may have been associated with past rises in the static water level (SWL), giving rise to zeolitized Calico Hills Formation rocks to the east. However, the nature of this zeolitic/vitric transition 
and the implications for past fluctuations in the SWL will remain speculative until further core samples from the potential repository block (e.g., SD-7, -9, and -12) are analyzed. The nature of the lateral and vertical transitions between zeolitic and vitric portions of the Calico Hills Formation is of fundamental importance to understanding (1) the maximum amount of zeolitic tuff between the host rock and the static water level; (2) the transport pathways from the potential repository toward the saturated zone and (3) the potential for thermal alteration or dehydration of existing zeolites and possible formation of new zeolites from heated glass (Vaniman and Bish, 1995).

The Calico Hills Formation at the potential repository site is underlain by the mostly devitrified, poorly welded Prow Pass Tuff of the Crater Flat Group. The devitrified portions of the Prow Pass Tuff are composed of feldspar and a silica mineral. Available data show that cores taken from locations in which the Prow Pass is high above the SWL and underlies vitric portions of the Calico Hills Formation contain the same variable silica-polymorph associations (tridymite, cristobalite, and quartz) found in the devitrified Topopah Spring Tuff (e.g., USW H-3 and H-5). In cores where the Prow Pass is closer to or within the saturated zone and is overlain by zeolitized portions of the Calico Hills Formation, only quartz is preserved. If borne out in further drill cores, this alteration-associated variability in the Prow Pass may prove to be an important component in predicting the future silica activity, and hence the extent of silica mobilization, to be expected in thermally-perturbed portions of the Prow Pass Tuff.

\subsection{Distribution of Silica Phases. As noted above, the nature of the silica} phases is particularly important in the NFE. Alteration reactions in the tuffs involving zeolites and smectite are quite sensitive to the aqueous silica activity (e.g., Chipera et al., 1995a). In addition, cristobalite and the hydrous silica phases are susceptible to thermally induced modifications.

The variability of silica polymorph distributions throughout the unsaturated zone reveals a stratigraphy of minerals capable of generating widely varying silica activity in water/rock interactions. Earlier studies (Bish et al., 1984) of core samples showed a crude stratigraphy of silica polymorphs in the Topopah Spring Tuff, with tridymite concentrated in the upper portions of the devitrified tuff. It was principally concentrated in the quartz-latite portion that was erupted from a significantly hotter part of the magma chamber than the rhyolite; see Lipman, 1971. Quartz was restricted to the lower, rhyolitic portions where tridymite is only a minor phase. Cristobalite is ubiquitous throughout the Topopah Spring Tuff.

More recent studies show that although this stratigraphic model continues to be upheld, the lower portion of the Topopah Spring devitrified zone generally contains all three of these crystalline silica polymorphs. Small amounts of tridymite $(\sim 0-6 \%)$ and larger amounts of cristobalite (typically 10-20\%) occur throughout the rhyolitic portion of the Topopah Spring Tuff. Thus, in most drill holes examined within the repository block, even at the potential repository horizon, cristobalite and usually tridymite are present to provide relatively soluble silica for dissolution, transport, and deposition under repository thermal conditions. 
Recently completed analysis of samples from the Exploratory Studies Facility (ESF) suggest that the ratio of total crystalline silica polymorphs to alkali feldspar is reasonably constant at $0.75 \pm 0.03$ within the host rock. Within the host rock in the ESF, cristobalite is the dominant silica polymorph at $23 \pm 5 \%$, with quartz at $12 \pm 5 \%$ and tridymite at $4 \pm 1 \%$.

The distribution of the least-stable silica form in Yucca Mountain cores (apart from volcanic glass), opal-CT, was outlined by Bish and Chipera (1989). The occurrence of this phase is strongly correlated with stratified occurrences of zeolites (clinoptilolite/mordenite), where it averages $18 \%$ of zeolitic rocks, and with the lower vitrophyre of the Topopah Spring Tuff, where it averages $10 \%$ of these glassy rocks. Opal-CT in earlier-analyzed drill cores was lumped together with cristobalite, hence one can obtain the mistaken impression from the earlier data that this correlation does not hold. The occurrence of opal-CT in the lower vitrophyre is not universal (e.g., absent in core UE-25a\#1; Bish and Chipera, 1989). Moreover, opal-CT has not been found in the upper vitrophyre, although small amounts of cristobalite occur there (1-2\% in UE-25 UZ\#16 and in trace amounts in other cores near the exploration block). The presence or absence of opal-CT in glassy tuffs is important to note, suggesting different environments of alteration. As with the potentially different origins of heulandite in upper and lower vitrophyres, the silicification of the lower vitrophyre and not of the upper vitrophyre point to different alteration regimes. It is possible that alteration was predominantly associated with the advancement of a devitrification front into the lower vitrophyre, whereas alteration may be largely associated with "ponding" above the upper margin of the upper vitrophyre.

\subsubsection{Past Mass Transfer in Host Rock Tuffs}

\subsection{Syngenetic Alteration of the Topopah Spring Tuff. The Topopah} Spring Tuff was emplaced at temperatures up to 700 to $800^{\circ} \mathrm{C}$ and probably required about $10^{2}$ to $10^{3}$ years to cool (Riehle, 1973). Early in the cooling period, the interior welded by viscous flow and compaction of the glass particles. The process of welding continued to temperatures as low as $475^{\circ} \mathrm{C}$ in the basal vitrophyre (Rosenbaum, 1986). After substantial welding had occurred, the tuff in the hottest parts of the interior devitrified, that is, it crystallized to an assemblage of feldspars and silica minerals. Escaping gases created gas cavities (lithophysae or lithophysal cavities) with vapor-phase mineral deposits. The faster cooling upper and lower margins of the deposits did not weld and experienced little or no devitrification. Some of the moderately to densely welded portions toward the outer margins did not devitrify and have survived in a glassy state (upper and lower vitrophyres). Localized alteration, caused by a combination of trapped water and infiltrating meteoric water that interacted with the rock, occurred during the very late stages of cooling, at nearambient temperatures. The tuffs were also subject to fracturing, faulting, and brecciation during cooling.

The alteration history of the Topopah Spring Tuff have been reconstructed from field studies and examination of outcrop samples, drill core and cutting samples, and rock samples from the ESF. Thin sections of samples were examined by optical 
microscopy. Scanning-electron microscopy, using an ISI model DS-130 scanning electron microscope (SEM) operated at $19 \mathrm{kV}$ with a Kevex model 7000 energydispersive X-ray analytical system, provided details of textural relations. Minerals were identified from energy-dispersive $X$-ray spectra and crystal morphology. X-ray powder diffraction data and quantitative mineral analyses were obtained as described above. All of the data in this section are non- $Q$ because they are derived from non-Q drill core. The data-tracking numbers are LA000000000024.001 and LA000000000101.001. The record packages containing traceability information are EES-1-9-92-5 and LA-EES-1-TIP-94-008.

\subsection{Alteration in the lower Topopah Spring Devitrified-Vitric Transition} Zone. The lower Topopah Spring Tuff devitrified-vitric transition zone marks the downward change from the pervasively devitrified, densely welded tuff (Tptpln) to underlying vitrophyre (Tptpv3: densely welded, glassy tuff). The transition zone is an interval of slightly to almost completely devitrified vitrophyre in which devitrification is sporadic and localized around fractures (Levy, 1984a). In the uppermost parts of the transition zone, where devitrification is almost complete, the tuff is distinguishable from ordinary devitrified tuff by the presence of incompletely devitrified pumice clasts that have been replaced primarily by clinoptilolite-heulandite. Further down, the most common alteration features are fractures with devitrified borders up to $0.3 \mathrm{~m}$ thick. Some of the devitrified borders are downward extensions from the overlying completely or predominantly devitrified tuff.

The transition zone is an interval of variable vertical dimension, extending from about $3 \mathrm{~m}$ to $30 \mathrm{~m}$ downward into the vitrophyre, with discontinuous distributions of secondary minerals both vertically and horizontally. This altered zone does not possess the attribute of thickness in the sense that intervals of zeolitized nonwelded tuffs elsewhere in the pyroclastic section have reliably measurable thicknesses and km-scale lateral continuity.

The devitrified fracture borders have a common textural and mineralogic zonation developed more or less symmetrically about the fracture traces. The inner margins of devitrified borders are mineralogically and texturally similar to the overlying devitrified rock, but with increasing amounts of yellow cryptocrystalline devitrification toward the outer margins. The outermost margins of devitrified borders contain clinoptilolite-heulandite, smectite, and minor silica. Dissolution cavities may be present in the adjacent vitrophyre. Quartz, chalcedony (microscopically fibrous quartz), opal, and clinoptilolite-heulandite are locally abundant as fracture and void fillings, along with small quantities of iron and manganese minerals. Minute to major quantities of erionite may also be present.

Field and microscopic textural relations show a ubiquitous association between the hydrous minerals and devitrification features within the transition zone. The relations indicate that hydrous mineral crystallization was connected to devitrification during cooling of the pyroclastic unit. The observed textural relations, together with evidence for abundant fluid flow along fractures downward into the vitrophyre, indicate that devitrification, glass dissolution, and hydrous mineral deposition were caused by downward movement of heated water from the 
central hottest part of the cooling tuff. Temperatures calculated from oxygen isotope geothermometry of quartz associated with zeolite in fracture fillings and secondary pore fillings are in the range of $40^{\circ}$ to $100^{\circ} \mathrm{C}$ (Levy and O'Neil, 1989).

There is textural evidence that alteration in the transition zone resulted in the genesis, transport, and deposition of colloidal material (Levy, 1992). Pores and fractures contain layered or nonlayered accumulations of colloidal particles. These accumulations, or gels, later crystallized to clinoptilolite-heulandite, silica, and zeolite-silica mixtures. Silica products include opal, chalcedony, and cristobalite, locally in combination with each other. Additional minor gel products include hematite and manganese minerals. Relict colloidal accumulations also fill primary and secondary pores in moderately welded tuffs below the vitrophyre.

3.4.3.3.3 Mass Transfer During Natural Alteration. Glasses representative of the starting materials, smectite, and zeolites in the altered rocks were analyzed by electron probe microanalysis using a Cameca model Camebax electron microprobe operated at $15 \mathrm{kV}$ accelerating potential and 5 to $15 \mathrm{nA}$ beam currents. Normalized analyses of starting materials and secondary mineral products, plus the calculated elemental mass per unit volume for selected elements, are presented in Table 3.4-3. Glass analyses used as input for mass balance calculations were recalculated to a uniform $3 \mathrm{wt} \%$ water content. The $3 \%$ value falls within the range of $2.8 \%$ to $4.6 \%$ water measured in Topopah Spring Tuff lower vitrophyre samples (Vaniman et al., 1993). The materials used in those studies were not collected as natural-state samples to preserve in situ moisture contents. In addition, the samples are perlitic and may not represent the water content of glasses at the onset of alteration.

Normalization of the water content in glasses, as well as in clay and zeolites, eliminates compositional variability due solely to differences in water content at the time of analysis. The use of this convention means that chemical changes during glass hydration (i.e., the earliest stage of alteration) are not represented in the calculations and are not accounted for in mass-transport determinations. Clinoptilolite-heulandite analyses were recalculated to a water content of $17 \mathrm{wt} \%$ corresponding to measured values at $\sim 100 \%$ relative humidity and $23^{\circ} \mathrm{C}$; smectite analyses were recalculated to a water content of $30 \mathrm{wt} \%$ (Chipera, personal communication, 1994).

Mass-balance and transport calculations used published density data for minerals. The composition of cristobalite was assumed to be $100 \% \mathrm{SiO}_{2}$ with a density of 2.30 (Deer et al., 1963), yielding a calculated value of $0.03828 \mathrm{~mole} \mathrm{Si} / \mathrm{cm}^{3}$. A grain density value for Topopah Spring Tuff lower vitrophyre from a depth of $369.9 \mathrm{~m}$ in drill hole GU-3 (Anderson, 1984) was used for the calculations.

3.4.3.3.4 Alteration of Topopah Spring Basal Vitrophyre Glass. The effects of vitrophyre glass alteration on rock porosity depend in part on the amounts of secondary minerals formed during the alteration process, whether natural or repository-related. There is substantial lateral variation in the abundances and proportions of alkali feldspar, smectite, clinoptilolite-heulandite, and silica that comprise the characteristic secondary-mineral assemblage (Table 3.4-4). Instead of attempting to determine abundance values of general validity, the alternative 
approach taken here is to calculate bounding values for the amounts of secondary minerals that could form from the constituents of dissolved glass.

Alkali feldspar is typically the most abundant component of the natural alteration in the upper part of the devitrified-vitric transition zone, closest to the completely devitrified rock (candidate host rock). However, alteration assemblages from lower in the transition zone, with little or no feldspar, are simpler to model and may be more representative of alteration products to be expected in a waste repository-induced hydrothermal regime (Knauss and Peifer, 1986).

Dissolution of vitrophyre glass and precipitation of secondary minerals is represented qualitatively by the reaction

$$
\text { glass } \rightarrow \text { smectite }+ \text { heulandite }+ \text { cristobalite }
$$

Smectite and zeolite, alone or in combination, were typically the first-formed alteration products of glass dissolution. SEM photographs suggest that these minerals were commonly deposited at or near the dissolution sites. Silica was more likely to be transported and deposited elsewhere as fracture or pore fillings of cristobalite, chalcedony, quartz, or opal. Aluminum was the limiting constituent that determined the maximum amount of smectite or zeolite that was produced, so long as no additional $\mathrm{Al}$ was introduced in solution or colloidal suspension. Figure 3.4-25 is a graphic representation of reaction (1), balanced for all possible combinations of smectite and clinoptilolite-heulandite. Input values for the figure are from Table 3.4-3. The graph balances the reaction with respect to $\mathrm{Al}$ and $\mathrm{Si}$, but not $\mathrm{Na}, \mathrm{Ca}, \mathrm{K}$, or other elements. Also, the very small primary porosity was not factored into the calculations.

The most important result illustrated in Fig. 3.4-25 is that any combination of secondary minerals produces an increase in volume of 13 to $24 \%$ over the volume of the reacted glass. The higher volume increase is for a smectite-rich assemblage in which the smectite accounts for less than the original glass volume and cristobalite is almost half of the original volume. In a zeolite-dominated assemblage, the volume of zeolite produced is approximately equal to the volume of glass consumed, with cristobalite comprising the additional $13 \%$.

For vitrophyre with a bulk porosity around 1.4\% (Anderson, 1984), alteration products in principle could seal all of the porosity in a volume of rock at least ten times larger than the volume of altered vitrophyre. This has not been observed in the naturally altered rock. Bulk porosity in the vitrophyre probably corresponds to the pervasive perlitic fracture system (Blacic et al., 1982), but larger-aperture through-going fractures also exist. The wider fractures, along with devitrification cavities, provided pathways for fluid flow and space for secondary-mineral deposition during the period of alteration. The alteration must have caused an overall reduction in porosity, but this does not appear to have resulted in pervasive sealing or plugging of flow paths below the repository horizon. 


\subsubsection{Effects of Repository-Induced Thermal Load on Minerals And Glasses in the Near-Field Environment}

3.4.3.4.1 Rationale and approach. The purpose of this section is to summarize thermodynamic and kinetic data on minerals and glass relevant to the near-field environment. These data are necessary to model mineral development in the nearfield environment as a function of their thermodynamic properties and of the mineral reaction kinetics. The implications of the thermodynamic and kinetic data on the factors controlling stability of minerals and glasses at Yucca Mountain and anticipated changes in these factors are discussed in some detail. The observed range of mineral assemblages at Yucca Mountain as a function of depth and paleotemperatures suggests that the following materials are the likely reactants and products of any mineralogical reactions in response to heat derived from the highlevel nuclear waste: (1) Reactions of unstable silica polymorphs tridymite, cristobalite, and opal-CT to quartz; (2) Reaction of alkali feldspar under hydrothermal conditions to gibbsite, kaolinite, illite, smectite, analcime, and/or clinoptilolite; (3) Hydrothermal alteration of vitric units to assemblages of smectite, clinoptilolite/heulandite, and mordenite; (4) Dehydration/hydration reactions of clinoptilolite, mordenite, and smectite in response to changing temperature and fluid saturation; (5) Decomposition of clinoptilolite and smectite in response to elevated temperatures or changed fluid compositions.

The minerals discussed in detail here are clinoptilolite (hydration/dehydration reactions, solubility, kinetics of dissolution/precipitation), analcime (solubility and kinetics of dissolution/precipitation), smectite (hydration/dehydration reactions), and cristobalite (solubility and kinetics of dissolution/precipitation). Additional data gathered from the recent literature are presented on the thermodynamic and kinetic properties of these and other minerals.

\subsection{Silica polymorph control of mineral stability. Mineral assemblages} observed in a wide variety of low-temperature volcanic environments indicate that the silica polymorph plays a determinative role in mineral stability. For example, it has been observed that the presence of clinoptilolite is correlated with the occurrence of cristobalite or opal-CT, and analcime with that of quartz (Duffy, 1993). These relations indicate that metastable silica polymorphs allow other metastable mineral assemblages to persist and suggest that the evolution of mineral assemblages may be at least partly controlled by the kinetics of silica reactions.

The primary silica phases at Yucca Mountain are quartz, cristobalite, tridymite, and opal-CT. The ground water sampled at Yucca Mountain and vicinity is generally supersaturated with respect to quartz and cristobalite, with an aqueous silica activity between amorphous silica and opal-CT solubility. The equilibrium silica polymorph is quartz. Because the solutions are saturated or even supersaturated with respect to cristobalite, there is no thermodynamic driving force for the dissolution of cristobalite, even though it is metastable with respect to quartz. In such aqueous systems, the primary thermodynamic driving force is for the precipitation of quartz. Therefore, the rate-limiting step for the conversion of cristobalite to quartz appears to be the precipitation of quartz. As quartz precipitates, the aqueous silica content 
decreases, and then some cristobalite can dissolve. This is consistent with the model presented by Duffy (1993). Similarly, analcime may be stable with respect to clinoptilolite at quartz saturation but metastable at cristobalite saturation. As a consequence, there is no thermodynamic driving force for the dissolution of clinoptilolite and precipitation of analcime until the silica solubility drops below that of cristobalite.

Duffy (1993) considered the reactions of clinoptilolite to analcime, clinoptilolite to smectite, analcime to albite, and feldspar to illite, to all be effected by the silica polymorph in equilibrium with the fluid.

\subsection{Stability of Selected Minerals and Glass}

\subsection{Clinoptilolite (and heulandite). Compositions of clinoptilolite and} heulandite at Yucca Mountain are highly variable, with $\mathrm{Si} / \mathrm{Al}$ ratios between 3 and 5 and the dominant exchangeable cation varying between $\mathrm{Na}^{+}, \mathrm{K}^{+}$, and $\mathrm{Ca}^{2+}$ (Broxton et al., 1987). Consequently, it is evident that thermodynamic and kinetic models capable of addressing the effect of compositional variations in clinoptilolite minerals are essential for accurate prediction of the dissolution or precipitation of clinoptilolite and heulandite. Because clinoptilolite is the most abundant zeolite at Yucca Mountain, considerable attention has been focused on the thermodynamic properties of this mineral. The work that will be reviewed here includes the following:

1. The effect of exchangeable cation in clinoptilolite on molar volumes (Bish, 1984);

2. Thermal analysis investigations of the dehydration behavior of clinoptilolite and heulandite (Bish, 1988a);

3. The effect of dehydration on molar volume (Bish, 1995);

4. Estimation of the thermodynamic properties of clinoptilolite and heulandite as a function of chemical composition (Chipera et al., 1995a);

5. Determination of the equilibrium water content of clinoptilolite as a function of exchangeable cation (Carey and Bish, 1996a);

6. Determination of the energetics of hydration and dehydration processes in clinoptilolite as a function of exchangeable cation (Carey and Bish, 1996b); and

7. The solubility and kinetics of dissolution and precipitation of Naclinoptilolite (MacInnis et al., 1995; Barnes and Wilkin, 1995).

\subsection{Thermodynamic Stability. The thermodynamic properties of} clinoptilolite and heulandite have been investigated by modeling, calorimetry, and solution chemistry. The various results are difficult to compare because of differences in $\mathrm{Si} / \mathrm{Al}$ ratio and exchangeable cation (Table 3.4-5). Note that Barnes and Wilkin (1995) conducted solubility measurements on an almost completely exchanged $\mathrm{Na}$-clinoptilolite that should be a very useful end-member in thermodynamic calculations. The complete results of Barnes and Wilkin's solubility data from 25 to $265^{\circ} \mathrm{C}$ are summarized in Table 3.4-6. The Gibbs free energy of formation of Na-clinoptilolite calculated from the measured solubility products is 
almost linear in temperature (Fig. 3.4-26). A linear regression of these values provided the enthalpy of formation and the third-law entropy for Na-clinoptilolite (Table 3.4-5).

3.4.3.4.2.3 Effect of cation-exchange. The thermodynamic data for Na-clinoptilolite (Barnes and Wilkin, 1995) provide a basis for the calculation of the end-member thermodynamic properties of $\mathrm{K}$ - and $\mathrm{Ca}$ - and $\mathrm{Sr}$-clinoptilolite by incorporating the results of Pabalan (1994) and Pabalan and Bertetti (1994). The latter studies are binary cation-exchange experiments for $\mathrm{Na}-\mathrm{K}, \mathrm{Na}-\mathrm{Ca}$, and $\mathrm{Na}-\mathrm{Sr}$ compositional pairs. Calculation of the integral Gibbs free energy of exchange combined with the Gibbs free energy of formation of the aqueous cations and Na-clinoptilolite gives endmember thermodynamic properties that differ by 180 to $97 \mathrm{~kJ} / \mathrm{mol}$ from Naclinoptilolite (72 oxygen basis; Table 3.4-7). These differences are small compared with the differences reported in Table 3.4-3. Consequently, the variability of results in Table 3.4-3 reflects either the large energetic affect of $\mathrm{Si} / \mathrm{Al}$ substitutions or some other source of difference or error (e.g., $\mathrm{Al} / \mathrm{Si}$ order/disorder).

As is common with many other natural zeolites, the energetic preference for cations is in the order $\mathrm{K}>\mathrm{Sr}>\mathrm{Ca}>\mathrm{Na}$ (cf., Sherry 1969). Pabalan (1995) demonstrated that clinoptilolite is enriched in $\mathrm{K}$ relative to $\mathrm{Na}$ in aqueous solutions. The situation for the exchange of $\mathrm{Ca}$ and $\mathrm{Sr}$ for $\mathrm{Na}$ is more complex: dilute, Na-rich solutions favor preferential sorption of $\mathrm{Ca}$ and $\mathrm{Sr}$; whereas concentrated, Na-poor solutions show enrichment of $\mathrm{Na}$ in clinoptilolite. These relations indicate that the presence of K-rich, Ca-poor, dilute solutions will result in clinoptilolite with compositions significantly removed from the $\mathrm{Na}$ end-member. In such solutions, clinoptilolite will be stabilized relative to Na-rich minerals that do not readily cation exchange, such as analcime and albite.

3.4.3.4.2.4 Effects of hydration/dehydration of clinoptilolite. Hydration and dehydration of clinoptilolite may have significant consequences in the near-field environment. Dehydration will destabilize clinoptilolite relative to less hydrous assemblages (albite and analcime); release significant amounts of $\mathrm{H}_{2} \mathrm{O}$; have a significant effect on the thermal budget; and result in porosity changes due to changes in molar volume. The experimental data necessary to assess all of these factors have been obtained by Bish (1995) and Carey and Bish (1996a and b).

3.4.3.4.2.5 Equilibrium. The equilibrium $\mathrm{H}_{2} \mathrm{O}$ contents of clinoptilolite as a function of temperature $\left(25-250^{\circ} \mathrm{C}\right)$, water-vapor pressure (0-35 mbar), and exchangeable cation ( $\mathrm{Na}^{+}, \mathrm{K}^{+}$, and $\mathrm{Ca}^{2+}$ ) were determined by Carey and Bish (1996a). These experiments were conducted by determining the equilibrium mass of clinoptilolite at a measured temperature and water-vapor pressure using a thermogravimetric balance.

These experiments show that clinoptilolite hydrates and dehydrates reversibly up to temperatures $\leq 215^{\circ} \mathrm{C}$ (Fig. $3.4-27$ ). Above $215^{\circ} \mathrm{C}$, Na-clinoptilolite suffers a slight loss in water adsorption capacity. $\mathrm{K}$ - and $\mathrm{Ca}$-exchanged clinoptilolite maintain reversibility to temperatures $>250^{\circ} \mathrm{C}$. Equilibration time for hydration and dehydration of powders is on the order of an hour, so that the kinetics of 
hydration/dehydration do not appear to be relevant to processes at Yucca Mountain. The $\mathrm{H}_{2} \mathrm{O}$ content of clinoptilolite is a smooth function of temperature and pressure (Fig. 3.4-28), and there are no discontinuities in the dehydration behavior at the boiling point of water. Clinoptilolite retains substantial $\mathrm{H}_{2} \mathrm{O}$ to temperatures > $150^{\circ} \mathrm{C}$, even in a nominally dry atmosphere.

The measured thermogravimetric equilibrium data were fit to a thermodynamic function describing the reaction:

anhydrous clinoptilolite $(\mathrm{aCpt})+\mathrm{H}_{2} \mathrm{O} \leftrightarrow$ hydrous clinoptilolite (hCpt)

The equilibrium constant, $K_{i d e a l}$, containing ideal mixing terms for this reaction is:

$$
\ln K_{\text {ideal }}=\left(\frac{\theta}{(1-\theta) f_{H_{2} O}}\right)
$$

where $\theta$ is the ratio of the amount of $\mathrm{H}_{2} \mathrm{O}$ in clinoptilolite relative to the maximum amount clinoptilolite contains.

The thermodynamic function was determined by analysis of the equilibrium constant as a function of temperature and composition (Fig. 3.4-29). The variations in $\mathrm{K}$ were described with an equation giving the Gibbs free energy of hydration, the enthalpy of hydration, and two mixing parameters $\left(W_{1}\right.$ and $\left.W_{2}\right)$ :

$$
-R \ln K=\Delta \mu_{H y}^{o} / T_{o}+\Delta \bar{H}_{H y}^{o}\left(1 / T-1 / T_{0}\right)-3 R\left(\ln \left(T / T_{0}\right)+\left(T_{o} / T-1\right)\right)+W_{1} / T \theta+W_{2} / T \theta^{2}
$$

Fits of the data yielded thermodynamic parameters describing hydration in Na-, $\mathrm{K}-$, and Ca-exchanged clinoptilolite (Table 3.4-8; Figs. 3.4-28 and 3.4-29). The results indicate that the energetics of hydration increase from $\mathrm{K}<\mathrm{Na}<\mathrm{Ca}$ clinoptilolite (Table 3.4-9).

The results for clinoptilolite are energetically similar to those of mordenite and intermediate between strongly (analcime) and weakly (cordierite) interacting systems. The similarity of the integral values of hydration for mordenite and clinoptilolite suggest that in the absence of additional thermodynamic data the hydration energetics of mordenite may be approximated by those of clinoptilolite. Note that the energetics of hydration are significantly greater than condensation of water vapor.

As discussed by Pabalan (1994), cation-exchange in clinoptilolite is accompanied by hydration and dehydration reactions. Consequently, the Gibbs free energy of exchange measured by Pabalan contains a contribution due to hydration reactions in 
addition to cation-exchange. The results described here may be used to "correct" the Gibbs free energy of exchange data to give energetics solely due to cations.

The equation of state for clinoptilolite (Equation 4) allows calculation of the equilibrium water content of clinoptilolite under conditions of interest in the NFE. Under conditions of rising temperature, clinoptilolite dehydrates even in the presence of an aqueous phase (Fig. 3.4-30). However, if dryout of the rock units occurs, as may happen if temperatures rise above $100^{\circ} \mathrm{C}$, the degree of dehydration of clinoptilolite increases markedly. The equilibrium water content as a function of maximum sustainable water-vapor pressure, is shown in Fig. 3.4-30 for maximum pressures ranging between 1 and 20 bars.

3.4.3.4.2.6 Energetics. The energetics of hydration and dehydration of clinoptilolite have been measured calorimetrically by Carey and Bish (1996b). In these experiments, $\mathrm{Na}-, \mathrm{K}-$, and $\mathrm{Ca}$-exchanged clinoptilolite samples were partially dehydrated, sealed in an evacuated ampoule, and placed in water where the heat of immersion was measured. The enthalpy of hydration (which is equivalent to the heat of immersion in the experiments) increases with decreasing water content in clinoptilolite (Fig. 3.4-31). This demonstrates that the energetic cost of dehydration increases as dehydration proceeds. The partial molar enthalpy of hydration was fit to an equation of the form (Table 3.4-10; Fig. 3.4-32):

$$
\Delta \bar{H}_{H y}=\Delta \bar{H}_{H y}^{o}+W_{1} \theta+W_{2} \theta^{2}
$$

A combination of the equilibrium and calorimetry studies can be used to assess the potential effects of hydration and dehydration processes on heat flow and pore saturation at Yucca Mountain. A simple numerical model was used that considers the thermal and hydrologic evolution of a thermally insulated block of clinoptilolite that receives a constant source of thermal energy. In the model, a $1-\mathrm{m}^{3}$ box has $10 \%$ porosity, is initially at $25^{\circ} \mathrm{C}, 100 \%$ relative humidity, and receives a thermal flux of 14 watts while maintaining a uniform temperature (the value of the thermal flux is representative of those considered for Yucca Mountain). The thermal flux is consumed by the heat capacity of clinoptilolite and by dehydration processes. It is assumed that the box is porous to water vapor and a maximum pressure of 1 bar is attained. The temperature achieved by the box is dramatically lower when clinoptilolite is allowed to dehydrate (Fig. 3.4-33). The model without dehydration reached $395^{\circ} \mathrm{C}$ after 844 days, whereas that allowing dehydration reached only $250^{\circ} \mathrm{C}$ over the same period. The kink in the temperature evolution at $100^{\circ} \mathrm{C}$ is the point at which the pores attained the maximum water-vapor pressure of 1 bar. During the dehydration process, the clinoptilolite released 1.63 pore volumes of liquid water. In other words, the model constraints require that an amount of water equal to $16 \%$ of the rock volume must drain away ( $10 \%$ porosity).

These calculations demonstrate that dehydration and hydration of clinoptilolite can affect the temperature and saturation field in the NFE. Whether clinoptilolite has a significant effect depends on the interplay of factors such as: the rate of heating 
versus the rate of thermal dissipation; and the ratio of water released by clinoptilolite to the amount infiltrating the rock unit in a given period of time. These can only be quantitatively addressed using coupled numerical models of clinoptilolite hydration/dehydration and thermo-hydrologic processes.

\subsection{Changes in Molar Volume of Clinoptilolite. The molar volume of} clinoptilolite is a sensitive function of temperature, exchangeable cation, and hydration state (Bish, 1984; Bish, 1995). Changes in molar volume of clinoptilolite may be important in the Calico Hills Formation, where clinoptilolite constitutes from 50 to $70 \%$ of the rock. Bish (1984) observed that decreases in molar volume on heating to $300^{\circ} \mathrm{C}$ ranged from 1.6 to 3.6 to $8.6 \%$ for $\mathrm{K}-, \mathrm{Ca}-$, and Na-exchanged samples, respectively. Apparently the bulk of the volume decrease was a direct result of dehydration. For a rock with $50 \%$ clinoptilolite, an $8 \%$ decrease in volume could result in the development of $4 \%$ additional rock porosity.

\subsection{Analcime}

3.4.3.4.2.8.1 Thermodynamic Stability. Natural analcime is Na-rich with a Si/Al ratio that varies from nearly stoichiometric $(\mathrm{Si} / \mathrm{Al}=2)$ in hydrothermal environments to siliceous compositions ( $\mathrm{Si} / \mathrm{Al}=2.55$ ) typical of sedimentary or diagenetic environments (e.g., Gottardi and Galli, 1985). The analcime at Yucca Mountain is a siliceous, sodic variety with $\mathrm{Si} / \mathrm{Al} \sim 2.75$ (Broxton et al., 1987). Most studies of the thermodynamic properties of analcime have been conducted on nearly stoichiometric material derived from hydrothermal environments. Thus the important effect of variations in $\mathrm{Si} / \mathrm{Al}$ ratio on the stability of analcime were largely unknown until recently.

As a part of the mineralogical investigations at Los Alamos National Laboratory, a study of the solubility of two analcime samples with $\mathrm{Si} / \mathrm{Al}$ ratios of 2.0 and 2.55 were conducted in collaboration with Pennsylvania State University and Yale University (Barnes and Wilkin, 1995). These data complement the calorimetric studies reported by Robie et al. (1979) and Johnson et al. (1982) and the solubility study of Murphy et al. (1996) on stoichiometric analcime. The study by Barnes and Wilkin allows the direct calculation of the energetic effect of the substitution $\mathrm{Na}+$ $\mathrm{Al}=\mathrm{Si}$ and, as discussed below, provides a basis for determining the effect of similar substitutions in other zeolites, such as clinoptilolite.

The reported uncertainty in the measured Gibbs free energy of formation of analcime varies between 3 and $5 \mathrm{~kJ} / \mathrm{mol}$ (Table 3.4-11; Fig. 3.4-34). Note, however, that Johnson et al. (1992) revised their measured value for analcime by almost $9 \mathrm{~kJ} / \mathrm{mol}$ due to a change in the reference value of silica and gibbsite used in the solution calorimetry. This revised value may be more accurate than the earlier result, but earlier work and many internally consistent thermodynamic data bases are implicitly built on the previous reference states. As a consequence, it is probably advisable to retain the old value until a consensus on the most useful reference value for silica can be achieved. The results of Barnes and Wilkin (1995) for both samples ( $\mathrm{Si} / \mathrm{Al}=2$ and 2.55 ) were obtained by extrapolation from experiments at 50 to $300^{\circ} \mathrm{C}$. The measured solubility at $25^{\circ} \mathrm{C}$ for the Mt. St. Hilaire $(\mathrm{Si} / \mathrm{Al}=2)$ sample is 
also provided in Table 3.4-11, but Barnes and Wilkin showed that their results at $25^{\circ} \mathrm{C}$ are not consistent with results extrapolated from higher temperatures.

Thermodynamic values for analcime have also been derived from phase equilibria constraints by Helgeson et al. (1978) and estimated by using polyhedral summation methods by Chermak and Rimstidt (1989) and Chipera et al. (1995a; Table 3.4-12 and Fig. 3.4-34). The summation methods allow calculation of the Gibbs free energy of formation for arbitrary compositions, but such summations must be checked against actual measurements.

The data presented by Barnes and Wilkin allow calculation of an empirical relationship giving the relationship of the Gibbs free energy of formation of analcime as a function of $\mathrm{Si} / \mathrm{Al}$ ratio:

$$
\Delta G_{f}^{\text {analcime }}=-3090+98.8\left(S i / \mathrm{Al}^{-2}\right)
$$

Their results agree well with the intermediate value measured by Johnson et al. (1982; Fig. 3.4-34), and they noted that their results are consistent with the ideal solution model of Wise (1984) for $\mathrm{Si} / \mathrm{Al}$ mixing in analcime.

The value derived by Helgeson et al. (1978) is also in good agreement with the measurements. The estimation methods of Chermak and Rimstidt (1989) are slightly high and those of Chipera et al. (1995a) are somewhat better. Interestingly, these estimation methods also provide reasonable estimates of the trends in the value of the Gibbs free energy of hydration as a function of $\mathrm{Si} / \mathrm{Al}$ ratio. The equation derived from Chermak and Rimstidt is (in $\mathrm{kJ} / \mathrm{mol}$ ):

$$
\Delta G_{f}^{\text {analcime }}=-3099+298(S i-2)
$$

and that of Chipera et al. is

$$
\Delta G_{f}^{\text {analcime }}=-3094+281(S i-2)
$$

These conclusions regarding the compositional effects of analcime thermodynamics are consistent with the calorimetric study of Petrovic and Navrotsky (1995) on the energetics of the $\mathrm{Na}+\mathrm{Al}=\mathrm{Si}$ substitution in faujasite. They found that the increase in the enthalpy of formation per mole of Si was $267 \hat{\mathrm{E}} \mathrm{kJ} / \mathrm{mol}$, very similar to the values of 281 and 298 for the Gibbs free energy of formation obtained by estimation (Equations 7 and 8 ).

For a variety of common reactions involving analcime, the relations in Equations 6, 7, and 8 indicate that siliceous analcime is destabilized relative to stoichiometric analcime with respect to sodium end-member phases such as albite or clinoptilolite (Fig. 3.4-35). The degree of destabilization for a reaction balanced on 
aluminum of analcime relative to another sodic framework-aluminosilicate (such as albite or clinoptilolite) can be calculated with the aid of one of these equations. For example, for the reaction

$$
(18-3 \mathrm{x} /(1-\mathrm{x})) \mathrm{SiO}_{2} \mathrm{aq}+6 /(1-\mathrm{x}) \mathrm{Na}_{1-\mathrm{x}} \mathrm{Al}_{1-\mathrm{x}} \mathrm{Si}_{2+\mathrm{x}} \mathrm{O}_{6} \cdot \mathrm{H}_{2} \mathrm{O}+19 \mathrm{H}_{2} \mathrm{O}=
$$

$\mathrm{Na}_{6} \mathrm{Al}_{6} \mathrm{Si}_{30} \mathrm{O}_{72} \cdot 2 \mathrm{H}_{2} \mathrm{O}$

the degree of destabilization corresponds to

$$
\frac{1}{R T 2.303}\left(\Delta G_{f}^{o, ~ a n a l ~}\left(\frac{-x}{1-x}\right)-98.8\left(\frac{3 x}{(1-x)^{2}}\right)+\Delta G_{f, \text { SiO }}^{o, ~ a q u e o u s}\left(\frac{3 x}{1-x}\right)\right)=\left(\frac{3 x}{1-x}\right) \log \left(a_{\text {SiO }_{2}}^{\text {aqueous }}\right)
$$

where Equation 7 has been used to calculate the effect.

The effects of a $5 \mathrm{~kJ} / \mathrm{mol}$ uncertainty in the Gibbs free energy of formation on phase relations involving analcime are considerable (Fig. 3.4-36). The uncertainty introduced by analcime for a given reaction in terms of the equilibrium constant can be calculated as

$$
\log K= \pm n \frac{5000 \mathrm{~J} / \mathrm{mol}}{2.303 R T}= \pm n(0.876) @ 25{ }^{\circ} \mathrm{C}
$$

where $n$ is the stoichiometric coefficient of analcime in the reaction. For example, the breakdown of clinoptilolite to analcime calculated by Chipera et al. (1995a):

$$
\begin{gathered}
\left(\mathrm{K}_{0.3} \mathrm{Na}_{0.1} \mathrm{Ca}_{1.5}\right) \mathrm{Al}_{3.4} \mathrm{Si}_{14.6} \mathrm{O}_{36} \cdot 10.8 \mathrm{H}_{2} \mathrm{O} \text { (clinoptilolite) }+3.3 \mathrm{Na}^{+}+3.95 \mathrm{H}_{2} \mathrm{O} \Leftrightarrow \\
4.25 \mathrm{Na}_{0.8} \mathrm{Al}_{0.8} \mathrm{Si}_{2.2} \mathrm{O}_{6} \cdot \mathrm{H}_{2} \mathrm{O} \text { (analcime) }+0.3 \mathrm{~K}^{+}+1.5 \mathrm{Ca}^{2+}+5.25 \mathrm{Si}(\mathrm{OH})_{4}
\end{gathered}
$$

is shifted by \pm 2.5 log units on activity-activity diagrams commonly used to analyze phase relations at Yucca Mountain (Fig. 3.4-36).

Thermodynamic data for analcime at elevated temperature was obtained by Barnes and Wilkin (1995) using solubility data at temperatures between 25 and $300^{\circ} \mathrm{C}$. The Gibbs free energy of formation of analcime was calculated from these data (Table 3.4-13). Linear regression of the Gibbs free energy of formation as a function of temperature provided the enthalpy of formation and standard state entropy (the heat capacity of the dissolution reaction was assumed to be zero; Table 3.4-14). Additional high-temperature data include heat capacity measurements of analcime between 25 and $350^{\circ} \mathrm{C}$ (Johnson et al., 1992). However, Carey (1993) 
argued that the heat capacity of hydrous analcime above $25^{\circ} \mathrm{C}$ is more accurately given by the sum of the heat capacities of anhydrous analcime (Johnson et al., 1992), $\mathrm{H}_{2} \mathrm{O}$ vapor (Robie et al., 1979), and a constant factor accounting for $\mathrm{H}_{2} \mathrm{O}$ sorption which is equal to the gas constant.

\subsection{2 Estimated Thermodynamic Properties of Zeolites and Clays.} Thermodynamic data are limited for several important zeolites and clays and still less available for treating compositional variation of these phases (see also Section 3.4.2). One method of addressing this deficiency is to make semi-quantitative calculations using estimated thermodynamic properties. Chipera et al. (1995a) provide the most comprehensive example of this method, obtaining estimated Gibbs free energies and enthalpies of formation, third-law entropies, and heat capacity values for zeolites and clays with compositions representative of those at Yucca Mountain (Table 3.4-15). These data provide a very useful framework for understanding potential reactions among zeolites and clays as a function of temperature, pressure, and solution chemistry (Chipera et al., 1995a).

3.4.3.4.2.9 Smectite. Hydration and dehydration reactions in smectite have a $\mathrm{H}_{2} \mathrm{O}$ significant effect on smectite stability and molar volume (due to swelling/collapse of the aluminosilicate layers). These reactions may also affect pore-water saturation, fracture filling, and the osmotic swelling capacity (Bish, 1988b). The hydration and dehydration behavior of smectite is difficult to model thermodynamically because of the pronounced hysteresis in molar volume and water content (Fig. 3.4-37). Although the hydration/dehydration behavior of smectite is an important component in modeling the effects of repository-induced heating on the repository water budget, the highly reversible nature of these reactions suggests that the longterm effects on rock properties may be minor. One of the most important phenomena observed during heating of smectites is the dramatic decrease in osmotic swelling ability after only short-term heating under steam conditions (e.g., Couture, 1985). Such behavior can have very important implications for the longterm behavior of smectites in the NFE and for their importance in affecting transport. For example, it is likely that NFE conditions will be conducive to the total loss of osmotic swelling capacity of smectites that occur both in fractures in the host rock and in the altered zone immediately underlying the host rock. Such a reaction would thus dramatically increase the hydraulic conductivity of smectite-lined fractures.

Data obtained from drill cores taken from the north and east of the exploration block show that the well-known reaction of smectite to interstratified illite/smectite occurs with increasing depth (Bish, 1989). Both experimental data and field observations demonstrate that this transformation develops progressively from 100 to $250^{\circ} \mathrm{C}$. The swelling capacity of smectite is steadily reduced during this diagenetic reaction from 25 to $100^{\circ} \mathrm{C}$ (cf. Bish, 1989, for a more complete discussion).

3.4.3.4.2.10 Vitrophyre (volcanic glass). The effects of elevated temperatures on Yucca Mountain volcanic glasses have been studied experimentally (see Chapter 10 for a discussion of glass alteration in the presence of water, and Knauss and Peiffer, 
1986, Knauss, 1987). Dehydration and hydration of a sample of the basal vitrophyre of the Topopah Spring Tuff were studied by thermogravimetry and by long-term dry heating experiments (Vaniman et al., 1993). The glass initially contained 2.8 to $4.6 \mathrm{E} w t \% \mathrm{H}_{2} \mathrm{O}$. Approximately three-fourths of the water was lost during long-term heating at $200^{\circ} \mathrm{C}$, but $\sim 1 \mathrm{wt} \% \mathrm{H}_{2} \mathrm{O}$ was not lost at temperatures less than $400^{\circ} \mathrm{C}$, even after long-term heating. Rehydration of the samples at room temperature and $79 \%$ relative humidity was continuous but did not reach completion after 10,000 hours. No devitrification reactions were observed during the dry heating experiments, even at $400^{\circ} \mathrm{C}$ for 10,000 hours, but up to $60 \%$ of the fluorine in the glass was evolved.

3.4.3.4.2.11 Kinetics of Dissolution and Precipitation. The long-term fate of minerals in the NFE cannot be determined without measurements of the kinetics of reactions as a function of degree of saturation and temperature. These measurements are usually made by dissolution or precipitation of a given mass of material of known surface area (typically a BET surface area) in a known volume of fluid. The studies are conducted either in a batch mode with continuously changing solution compositions (e.g., Murphy et al., 1996) or preferably in flow-through devices at constant solution composition (e.g., Nagy et al., 1991). The results reported below have been interpreted using transition state theory (e.g., Nagy et al., 1991) in which the rate of dissolution or precipitation is expressed as

$$
R\left(\text { moles } / \mathrm{m}^{2}-\mathrm{s}\right)=-\mathrm{k}_{\mathrm{diss}}\left(1-I A P / K_{e q}\right)
$$

where the ratio of the ion-activity-product (IAP) to the equilibrium constant $\left(\mathrm{K}_{\mathrm{aq}}\right)$ expresses the degree of saturation and $k_{\text {diss }}$ is the rate constant for the dissolution reaction. The parameter $k_{\text {diss }}$ is not an intrinsic rate parameter but may depend on $\mathrm{pH}$ and other surface-adsorbed species (Nagy et al., 1991). Equation 13 indicates that the rate of dissolution reaches a constant value $\left(-k_{\text {diss }}\right)$ for significant degrees of undersaturation but that the rate of precipitation increases without bound for increasing supersaturation. Table 3.4-16 summarizes relevant data pertinent to phases important at Yucca Mountain, in addition to more recent data obtained for clinoptilolite and analcime by Murphy et al. (1996) and MacInnis et al. (1995).

3.4.3.4.2.12 Kinetic data for clinoptilolite and analcime. The dissolution rate obtained for clinoptilolite by MacInnis et al. (1995) using a flow-through apparatus appears to be anomalous with respect to other minerals and is not in agreement with the batch study of Murphy et al. (1996). Unfortunately, the study of MacInnis et al. is the only source of data for dissolution rates of clinoptilolite at elevated temperatures $(50,80$, and $125^{\circ} \mathrm{C}$ ). Their results were expressed as 


$$
R=-\mathrm{k}_{\mathrm{o}} \exp \left(-E_{a} / R T\right) a_{H^{+}}^{-0.54}\left(I A P / K_{e q}\right)
$$

where $\mathrm{k}_{\mathrm{o}}=2 \pm 27 \times 10^{5} \mathrm{~mol} / \mathrm{m}^{2}-\mathrm{s} ; \mathrm{E}_{\mathrm{a}}=35.1 \pm 9.2 \mathrm{kcal} / \mathrm{mol}$; and the experiments were conducted at $\mathrm{pH} 7.5$ to 9.0. The difference between Equations 13 and 14 is a consequence of the fact that MacInnis et al. did not observe a constant dissolution rate at significant undersaturation, but they showed data indicating a linear relationship between rate and undersaturation. Consequently, the dissolution process they observed may be distinct from that modeled by transition state theory (Equation 13). MacInnis et al. also observed some evidence of inhibition by aqueous $\mathrm{Al}$, but were unable to quantify this effect.

There is no single study providing rate data for analcime at more than one temperature. Lasaga et al. (1994a) determined the dissolution of analcime at $80^{\circ} \mathrm{C}$ with flow-through methods. Their rate equation is similar to that determined by MacInnis et al. (1995) in which the rate depends linearly on the degree of saturation:

$$
R=-10^{-12.4} a_{A l(O H)_{4}^{-}}^{-0.27}\left(\left|\Delta G \mathrm{kcal} \mathrm{mol}^{-1}\right|\right)^{1.05}
$$

where the measurements were made at $\mathrm{pH} 8.6-8.9$ and the degree of saturation is represented by the Gibbs free energy of the dissolution reaction. Typical values at $80^{\circ} \mathrm{C}$ for the net dissolution rate constant, $\log \left(\mathrm{k}_{\text {diss }}\right)$, are approximately -11 . Again, these rate constants do not agree well with the batch study values of Murphy et al. (1996) where rates were -11 at $25^{\circ} \mathrm{C}$.

In summary, the available kinetic data for both analcime and clinoptilolite are not well constrained and reflect the incomplete status of kinetic data measurement for these minerals. Based on existing data, the dissolution of clinoptilolite does appear to be slower than analcime, by a factor near 100 .

\subsubsection{Acknowledgments}

We are grateful to D. Vaniman for a thorough review of this manuscript. 


\subsubsection{References}

Alietti, A. (1972), Polymorphism and crystal-chemistry of heulandites and clinoptilolites: American Mineralogist 57, 1448-1462.

Anderson, L. (1984) Rock property measurements on large-volume core samples from Yucca Mountain USW GU-3/G-3 and USW G-4 boreholes, Nevada Test Site, Nevada: U. S. Geological Survey Open-File Report, USGS-OFR-84-552, 39 p.

Barnes, H. L., and Wilkin, R. T. (1995), Kinetic measurements on the silicates of the Yucca Mountain potential repository (Yucca Mountain final report for FY95): Los Alamos National Laboratory, Los Alamos, NM.

Barrer, R. M., and Cram, P. J. (1971), Heats of immersion of outgassed and ionexchanged zeolites. In Molecular Sieve Zeolites-II: E. M. Flanigen, and L. B. Sand, eds., 105-131. American Chemical Society, Washington, DC

Berman, R. G., and Brown, T. H. (1985), Heat capacity of minerals in the system $\mathrm{Na}_{2} \mathrm{O}-\mathrm{K}_{2} \mathrm{O}-\mathrm{CaO}-\mathrm{MgO}-\mathrm{FeO}-\mathrm{Fe}_{2} \mathrm{O}_{3}-\mathrm{Al}_{2} \mathrm{O}_{3}-\mathrm{SiO}_{2}-\mathrm{TiO}_{2}-\mathrm{H}_{2} \mathrm{O}-\mathrm{CO}_{2}$ : Representation, estimation, and high temperature extrapolatio: Contributions to Mineralogy and Petrology 89, 168-183.

Bish, D. L. (1984), Effects of exchangeable cation composition on the thermal expansion/contraction of clinoptilolite: Clays \& Clay Minerals 32, 444-452.

Bish, D. L. (1988a), Effects of composition on the dehydration behavior of clinoptilolite and heulandite: In Occurrence, Properties and Utilization of Natural Zeolites, D. Kallo and H. S. Sherry, eds. Akademiai Kiado, Budapest.

Bish, D. L. (1988b), Smectite dehydration and stability. Applications to radioactive waste isolation at Yucca Mountain: Los Alamos National Laboratory, Los Alamos, NM, LA-11023-MS, $31 \mathrm{pp}$.

Bish, D. L. (1989), Evaluation of past and future alterations in tuff at Yucca Mountain, Nevada, based on the clay mineralogy of drill cores USW G-1, G-2, and G: Los Alamos National Laboratory, Los Alamos, NM, LA-10667-MS, 40 pp.

Bish, D. L. (1995), Thermal behavior of natural zeolites. In Natural Zeolites '93: Occurrence, Properties, Use, D. W. Ming and F. A. Mumpton, eds., 259-269.

Bish, D. L., and Chipera, S. J. (1986), Mineralogy of drill holes J-13, UE-25A\#1, and USW G-1 at Yucca Mountain, Nevada: Los Alamos National Laboratory, Los Alamos, NM, LA-10764-MS, HQS.880517.1957.

Bish, D. L., and Chipera, S. J. (1988) Problems and solutions in quantitative analysis of complex mixtures by X-ray powder diffraction. Advances in X-Ray Analysis 31, 295-308, NNA.890405.0178.

Bish, D. L., and Chipera, S. J. (1989), Revised mineralogic summary of Yucca Mountain, Nevada: Los Alamos National Laboratory, Los Alamos, NM, LA-11497-MS, 68 pp., NNA.891019.0029.

Bish, D. L., and Chipera, S. J. (1991), Detection of trace amounts of erionite using Xray powder diffraction: Erionite in tuffs of Yucca Mountain, Nevada, and central Turkey: Clays \& Clay Minerals 39, 437-445.

Bish, D. L., and Chipera, S. J. (1995), Accuracy in quantitative X-ray powder diffraction analyses: Advances in X-ray Analysis 38 47-57.

Bish, D. L., and Reynolds, R. C., Jr. (1989), Sample preparation for X-ray diffraction. In Modern Powder Diffraction: D. L. Bish and J. E. Post, eds., Mineralogical Society of America, Washington, D.C., Vol. 20, 73-99. 
Bish, D. L., Ogard, A. E., Vaniman, D. T., and Benson, L. (1984), Mineralogy-petrology and groundwater geochemistry of Yucca Mountain tuffs: Materials Research Society Symposium Proceedings 26, 283-291.

Blacic, J., Carter, J., Halleck, P., Johnson, P., Shankland, T., Anderson, R., Spicochi, K., and Heller, A. (1982), Effects of long-term exposure of tuffs to high-level nuclear waste-repository conditions: Preliminary repor: Los Alamos National Laboratory, Los Alamos, NM, LA-9174-PR.

Blacic, J. D., Vaniman, D. T., Bish, D. L., Duffy, C. J., and Gooley, R. C. (1986), Effects of long-term exposure of tuffs to high-level nuclear waste repository conditions: Final Report: Los Alamos National Laboratory, Los Alamos, NM, LA-9330-MS, $33 \mathrm{pp}$.

Broxton, D. E., Warren, R. G., Hagan, R. C., and Luedemann, G. (1986), Chemistry of diagenetically altered tuffs at a potential nuclear waste repository, Yucca Mountain, Nye County, Nevada: Los Alamos National Laboratory, Los Alamos, NM, LA-10802MS, 160 pp.

Broxton, D. E., Bish, D. L., and Warren, R. G. (1987), Distribution and chemistry of diagenetic minerals at Yucca Mountain, Nye County, Nevada: Clays and Clay Minerals 35, 89-110.

Broxton, D. E., Warren, R. G., Byers, F. M., Jr., and Scott, R. B. (1989), Chemical and mineralogic trends within the Timber Mountain-Oasis Valley caldera complex: Evidence for multiple cycles of chemical evolution in a long-lived silicic magma system: Journal of Geophysical Research 94, 5961-5985.

Buscheck, T. A., and Nitao, J. J. (1992), The impact of thermal loading on repository performance at Yucca Mountain: High-Level Radioactive Waste Management, Proceedings of the 3rd Annual International Conference, April 27-May 1, 1992, Las Vegas, Nevada.

Byers, F. M., Jr. (1985), Petrochemical variation of Topopah Spring tuff matrix with depth (stratigraphic level), drill hole USW G-4, Yucca Mountain, Nevada: Los Alamos National Laboratory, Los Alamos, NM, LA-10561-MS.

Byers, F. M., Jr., and Moore, L. (1987), Petrographic variation of the topopah spring tuff matrix within and between cored drill holes, Yucca Mountain: Los Alamos National Laboratory, Los Alamos, NM, LA-10901-MS.

Carey, J. W. (1993), The heat capacity of hydrous cordierite above 295 K: Physics and Chemistry of Minerals 19, 578-583.

Carey, J. W. (1995), A thermodynamic formulation of hydrous cordierite: Contributions to Mineralogy and Petrology 119, 155-165.

Carey, J. W., and Bish, D. L. (1994), Hydration energetics of zeolites. Proceedings of the 31st Annual Meeting of the Clay Minerals Society, Saskatoon, Saskatchewan, p. 52.

Carey, J. W., and Bish, D. L. (1996a), Equilibrium in the clinoptilolite- $\mathrm{H}_{2} \mathrm{O}$ system: American Mineralogist (in press).

Carey, J. W., and Bish, D. L. (1996b), Calorimetric measurement of the enthalpy of hydration of clinoptilolite (submitted to Clays and Clay Minerals).

Carlos, B. A. (1987) Minerals in fractures of the saturated zone from drill core USW G-4, Yucca Mountain, Nye County, Nevada: Los Alamos National Laboratory, Los Alamos, NM, LA-10927-MS, 32 pp. 
Carlos, B. A., Chipera, S. J., Bish, D. L., and Raymond, R. (1995a), Distribution and chemistry of fracture-lining zeolites at Yucca Mountain, Nevada: in Natural Zeolites '93: Occurrence, Properties, Use: D. W. Ming and F. A. Mumpton, eds., 547-563.

Carlos, B. A., Chipera, S. J., and Bish, D. L. (1995b), Distribution and chemistry of fracture-lining zeolites at Yucca Mountain, Nevada: Los Alamos National Laboratory, Los Alamos, NM, LA-12977-MS, 92 pp.

Carlos, B. A., Chipera, S. J., and Snow, M. G. (1995c), Multiple episodes of zeolite deposition in fractured silicic tuff. In Proceedings of the 8th International Symposium on Water-Rock Interaction-WRI-8: Y. K. Kharaka and O. V. Chudaev, eds; Balkema, Rotterdam, 67-71.

Chermak, J. A., and Rimstidt, J. D. (1989), Estimating the thermodynamic properties ( $\mathrm{Gf}$ and $\mathrm{Hf}$ ) of silicate minerals at $298 \mathrm{~K}$ from the sum of polyhedral contributions: American Mineralogist 74, 1023-1031.

Chipera, S. J., and Bish, D. L. (1988), Mineralogy of drill hole UE-25P\#1 at Yucca Mountain, Nevada: Los Alamos National Laboratory, Los Alamos, NM, LA-11292MS.

Chipera, S. J., and Bish, D. L. (1995), Multi-reflection RIR and intensity normalizations for quantitative analyses: Applications to feldspars and zeolites: Powder Diffraction 10, 47-55.

Chipera, S. J., Carey, J. W. and Bish, D. L. (1994), The nature of interlayer water in smectite: Proceedings of the 31st Annual Meeting of the Clay Minerals Society, Saskatoon, Saskatchewan, p. 53.

Chipera, S. J., Bish, D. L., and Carlos, B. A. (1995a), Equilibrium modeling of the formation of zeolites in fractures at Yucca Mountain, Nevada: in Natural Zeolites '93: Occurrence, Properties, Use, D. W. Ming and F. A. Mumpton, eds., 565-577.

Chipera, S. J., Vaniman, D. T., Carlos, B. A., and Bish, D. L. (1995b), Mineralogic variation in drill core UE-25 UZ\#16, Yucca Mountain: Los Alamos National Laboratory, Los Alamos, NM, LA-12810-MS, 39 pp.

Chung, F. H. (1974) Quantitative interpretation of X-ray diffraction patterns of mixtures. I. Matrix-flushing method for quantitative multicomponent analysis: Journal of Applied Crystallography, 7, 519-525, NNA.890405.0179.

Couture, R. A. (1985), Steam rapidly reduces the swelling capacity of bentonite. Nature 318, 50-52.

Czarnecki, J. B. (1985), Simulated effects of increased recharge on the ground-water flow system of Yucca Mountain and vicinity, Nevada-California: U. S. Geol. Survey Water Resources Invest. Report, 84-4344.

Deer, W., Howie, R., and Zussman, J. (1963), Rock-Forming Minerals: Vols. 3 and 4. Longmans, London.

Domenico, P. A., and Schwartz, F. W. (1990), Physical and Chemical Hydrogeology. John Wiley \& Sons, New York.

Duffy, C. J. (1983a), Hydrothermal stability studies: in Research and Development Related to the Nevada Nuclear Waste Storage Investigations July 1-September 30, 1982, W. R. Daniels, B. R. Erdal, and D. T. Vaniman, compilers: Los Alamos National Laboratory, Los Alamos, NM, LA-9577-PR. 
Duffy, C. J. (1983b), Permeability, porosity, and hydrothermal reactions: in Research and Development Related to the Nevada Nuclear Waste Storage Investigations January 1-March 30, 1983, K. Wolfsberg, D. T. Vaniman, and A. E. Ogard, compilers: Los Alamos National Laboratory, Los Alamos, NM, LA-9793-PR.

Duffy, C. J. (1993), Preliminary conceptual model for mineral evolution in Yucca: Los Alamos National Laboratory, Los Alamos, NM, LA-12708-MS.

Ervin, E. M., Luckey, R. R., and Burkhardt, D. J. (1993), Summary of revised potentiometric-surface map for Yucca Mountain and vicinity, Nevada: in High Level Radioactive Waste Management, American Nuclear Society and American Society of Civil Engineers, Proceedings of the 4th Annual International Conference, Las Vegas, Nevada, 1554-1558.

Fabryka-Martin, J., Dixon, P., Levy, S., Liu, B., Turin, J., and Wolfsberg, A. (1996), Systematic sampling for chlorine-36 in the Exploratory Studies Facility: Los Alamos National Laboratory, Los Alamos, NM, YMSCP letter report.

Flint, A. L., Flint, L. E., and Hevesi, J. A. (1993), The influence of long term climate change on net infiltration at Yucca Mountain, Nevada: in High Level Radioactive Waste Management, American Nuclear Society and American Society of Civil Engineers, Proceedings of the 4th Annual International Conference, Las Vegas, Nevada, 152-159.

Glassley, W. E. (1995), Characterization of chemical and mineralogical changes in the post-emplacement environment: YMSCP Study Plan for SCP Section 8.3.4.2.4.1, R1, p. 69.

Gottardi, G., and Galli, E. (1985), Natural Zeolites: Springer-Verlag, Berlin, 409 pp.

Helgeson, H. C., Delany, J. M., Nesbitt, H. W., and Bird, D. K. (1978), Summary and critique of the thermodynamic properties of rock-forming minerals: American Journal of Science 278-A, 229 p.

Hemingway, B. S., and Robie, R. A. (1984), Thermodynamic properties of zeolites: low-temperature heat capacities and thermodynamic functions for phillipsite and clinoptilolite. Estimates of the thermochemical properties of zeolitic water at low temperature: American Mineralogist 69, 692-700.

Holland, T. J. B. (1989), Dependence of entropy on volume for silicate and oxide minerals: A review and a predictive model: American Mineralogist 74, 5-13.

JCPDS (1986), Mineral Powder Diffraction File Data Book: International Centre for Diffraction Data, Swarthmore, Pennsylvania.

Johnson, G. K., Flotow, H. E., O'Hare, P. A. G., and Wise, W. S. (1982), Thermodynamic studies of zeolites: Analcime and dehydrated analcime: American Mineralogist 67, 736-748.

Johnson, G. K., Flotow, H. E., O'Hare, P. A. G., and Wise, W. S. (1985), Thermodynamic studies of zeolites: Heulandite: American Mineralogist 70, 1065-1071.

Johnson, G. K., Tasker, I. R., Jurgens, R., and O'Hare, P. A. G. (1991), Thermodynamic studies of zeolites: Clinoptilolite: Journal of Chemical Thermodynamics 23, 475-484.

Johnson, G. K., Tasker, I. R., Flotow, H. E., O'Hare, P. A. G., and Wise, W. S. (1992), Thermodynamic studies of mordenite, dehydrated mordenite, and gibbsite: American Mineralogist 77, 85-93.

Klug, H. P., and Alexander, L. E. (1974), X-ray Diffraction Procedures for Polycrystalline and Amorphous Materials, John Wiley \& Sons, Inc., New York. 
Knauss, K. (1987), Zeolitization of glassy Topopah Spring tuff under hydrothermal conditions. Mat. Res. Soc. Symposium, v. 84, p. 737-745.

Knauss, K., and Peifer, D. (1986,) Reaction of vitric Topopah Spring Tuff and J-13 ground water under hydrothermal conditions using Dickson-type, gold-bag rocking autoclaves. Lawrence Livermore National Laboratory Report, UCRL-53795.

Kranz, R. L., Bish, D. L., and Blacic, J. D. (1989), Hydration and dehydration of zeolitic tuff from Yucca Mountain, Nevada. Geophysical Research Letters, 16, 1113-1116.

Lasaga, A. C. (1984), Chemical kinetics of water-rock interactions. Journal of Geophysical Research, 89, 4009-4025.

Lasaga, A. C., Ganor, J., and MacInnis, I. N. (1994a), Progress report on the kinetic measurements of the reactions of the silicates at the Yucca Mountain potential repository site (August, 1994) Los Alamos National Laboratory, Los Alamos, NM.

Lasaga, A. C., Soler, J. M., Ganor, J., Burch, T. E., and Nagy, K. L. (1994b) Chemical weathering rate laws and global geochemical cycles. Geochimica et Cosmochimica Acta, 58, 2361-2386.

Levy, S. S. (1984a), Studies of altered vitrophyre for the prediction of nuclear waste repository induced thermal alteration at Yucca Mountain, Nevada: in Scientific Basis for Nuclear Waste Management VII, G. L. McVay, ed., Elsevier, New York, 959-966.

Levy, S. S. (1984b), Petrology of samples from drill holes USW H-3, H-4, and H-5, Yucca Mountain, Nevada. Los Alamos National Laboratory, Los Alamos, NM, LA-9706-MS, 77 pp.

Levy, S. S. (1991), Mineralogic alteration history and paleohydrology at Yucca Mountain, Nevada: in High Level Radioactive Waste Management, American Nuclear Society and American Society of Civil Engineers, Proceedings of the 4th Annual International Conference, Las Vegas, Nevada, 477-485.

Levy, S. S. (1992), Natural gels in the Yucca Mountain area, Nevada, USA. Applied Clay Science, 7, 79-85.

Levy, S. S., and O'Neil, J. R. (1989), Moderate-temperature zeolitic alteration in a cooling pyroclastic deposit. Chemical Geology, 76, 321-326.

Lipman, P. W. (1971), Iron-titanium oxide phenocrysts in compositionally zoned ash-flow sheets from southern Nevada. Journal of Geology, 79, 438-456.

MacInnis, I. N., Wilkin, R. T., Mercy, M. A., Barnes, H. L., and Lasaga, A. C. (1995), A rate law for clinoptilolite dissolution/precipitation at $50-125^{\circ} \mathrm{C}$ in basic solutions. YMSCP Milestone No. LA3445. Los Alamos National Laboratory, Los Alamos, NM, LA-EES-1-TIP-95-017.

Marshall, B. D., Peterman, Z. E., and Stuckless, J. S. (1993), Strontium isotopic evidence for a higher water table at Yucca Mountain: in High Level Radioactive Waste Management, American Nuclear Society and American Society of Civil Engineers, Proceedings of the 4th Annual International Conference, Las Vegas, Nevada, 1948-1952.

Mumpton, F. A. (1960), Clinoptilolite redefined. American Mineralogist, 45, 351-369.

Murphy, W. M., Pabalan, R. T., Prikryl, J. D., and Goulet, C. J. (1996), Reaction kinetics and thermodynamics of aqueous dissolution and growth of analcime and Na-clinoptilolite at $25^{\circ} \mathrm{C}$ : American Journal of Science 296, 128-186. 
Nagy, K. L., Blum, A. E., and Lasaga, A. C. (1991), Dissolution and precipitation kinetics of kaolinite at $80^{\circ} \mathrm{C}$ and $\mathrm{pH} 3$ : The dependence on solution saturation state. American Journal of Science 291, 649-686.

Pabalan, R. T. (1994), Thermodynamics of ion exchange between clinoptilolite and aqueous solutions of $\mathrm{Na}^{+} / \mathrm{K}^{+}$and $\mathrm{Na}^{+} / \mathrm{Ca}^{2+}$ : Geochimica et Cosmochimica Acta 58, 4573-4590.

Pabalan, R. T., and Bertetti, F. P. (1994), Thermodynamics of ion exchange between $\mathrm{Na}^{+} / \mathrm{Sr}^{2+}$ solutions and the zeolite mineral clinoptilolite: in Scientific Basis for Nuclear Waste Management XVII, Barkatt, A., and Van Konynenburg, R. A., eds., Materials Research Society Symposium Proceedings 333, 731-738.

Paces, J. (1996), "Submission of Milestone: 3GQH455, Due February 29, 1996," Memorandum to R. W. Craig, Chief, Yucca Mountain Project Branch, WRD, Las Vegas, NV, February 23, 1996.

Peacor, D. R. (1973), High-temperature single-crystal study of the cristobalite inversion: Zeitschrift für Kristallographie 138, 274-298.

Petrovic, I., and Navrotsky, A. (1995), Thermochemistry of Na-faujasites with varying $\mathrm{Si} / \mathrm{Al}$ ratios (submitted to Microporous Materials).

Renders, P. J. N., Gammons, C. H., and Barnes, H. L. (1995), Precipitation and dissolution rate constants for cristobalite from 150 to $300^{\circ} \mathrm{C}$ : Geochimica et Cosmochimica Acta 59, 77-85.

Riehle, J. R. (1973), Calculated compaction profiles of rhyolitic ash-flow tuffs. Geological Society of America Bulletin, 84, 2193-2216.

Rimstidt, J. D., and Barnes, H. L. (1980), The kinetics of silica-water reactions. Geochimica et Cosmochimica Acta 44, 1683-1699.

Robie, R. A., Hemingway, B. S., and Fisher, J. R. (1979), Thermodynamic Properties of Minerals and Related Substances at $298.15 \mathrm{~K}$ and $1 \mathrm{Bar}\left(10^{5}\right.$ Pascals) Pressure and at Higher Temperature: U.S. Geological Survey Bulletin, 1452.

Rosenbaum, J. G. (1986), Paleomagnetic directional dispersion produced by plastic deformation in a thick miocene welded tuff, southern Nevada: Implications for welding temperatures: Journal of Geophysical Research 91, 12,817-12,834.

Sheppard, R. A., Gude, A. J., 3rd., and Fitzpatrick, J. J. (1988), Distribution, characterization, and genesis of mordenite in Miocene silicic tuffs at Yucca Mountain, Nye County, Nevada: U.S. Geological Survey Bulletin, 1777, 22 pp.

Sherry, H. S. (1969), The ion-exchange properties of zeolites: in Ion Exchange, J. A. Marinsky , ed., Marcel Dekker, Inc., New York, 89-133.

Smith, D. K., Nichols, M. C., and Zolensky, M. E. (1983), POWD10, A FORTRAN IV Program for Calculating X-Ray Powder Diffraction Patterns, Version 10:Pennsylvania State University, College of Earth and Mineral Sciences report, NNA.890602.0030. Smyth, J. R., and Bish, D. L. (1988), Crystal Structures and Cation Sites of the RockForming Minerals: Allen \& Unwin, London, 332 pp.

Vaniman, D. T., and Bish, D. L. (1995), The importance of zeolites in the potential high-level radioactive waste repository at Yucca Mountain, Nevada: in Natural Zeolites '93: Occurrence, Properties, Use, D. W. Ming and F. A. Mumpton, eds., 533-546.

Vaniman, D., Bish, D., and Chipera, S. (1993), Dehydration and rehydration of a tuff vitrophyre: Journal of Geophysical Research 98, 22309-22320. 
Wise, W. S. (1984), Thermodynamic studies of zeolites. Analcime solid solutions. In Proceedings of the Sixth International Zeolite Conference, D. Olson, and A. Bisio, eds., Butterworths, Surrey, UK, 616-622. 


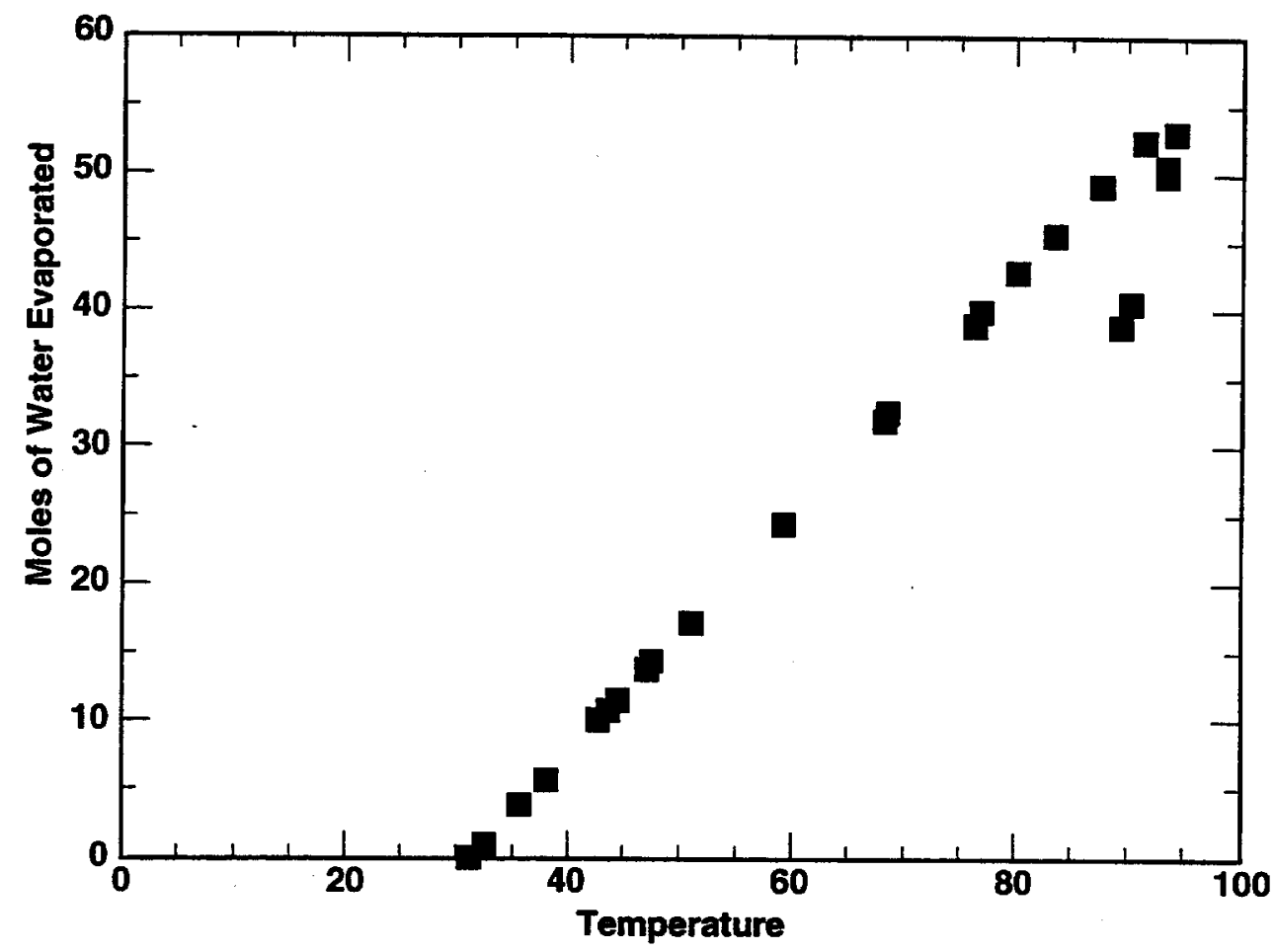

Figure 3.4-1. The trend of number of moles of water evaporated, as a function of temperature. Two different trends at the high temperature end of the sequence were used in the calculations to determine to what extent such differences would influence the chemical and mineralogical evolution of the system. In all cases, the results derived from the two trends differed by less than $1 \%$ (relative).

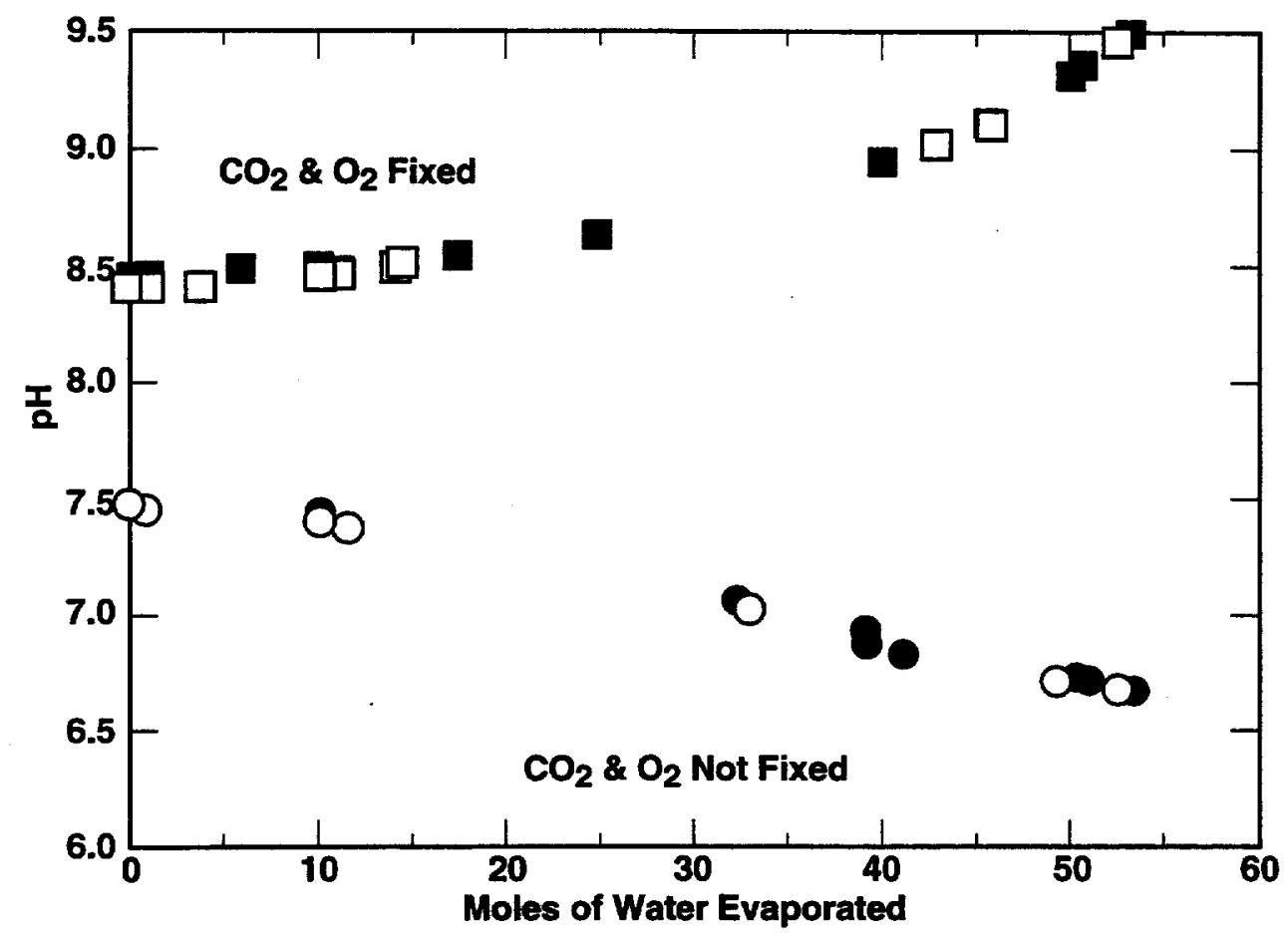

Figure 3.4-2. $\mathrm{pH}$ as a function of moles of water evaporated. In this, and in all subsequent figures, square symbols represent results obtained from simulations in which $\mathrm{CO}_{2}$ and $\mathrm{O}_{2}$ fugacities were fixed at atmospheric values throughout the runs, circles represent results obtained from simulations in which $\mathrm{CO}_{2}$ and $\mathrm{O}_{2}$ fugacities were not fixed, filled symbols indicate runs in which precipitation of solids was not restricted, and open symbols indicate runs in which quartz, tridymite, and talc were suppressed. 


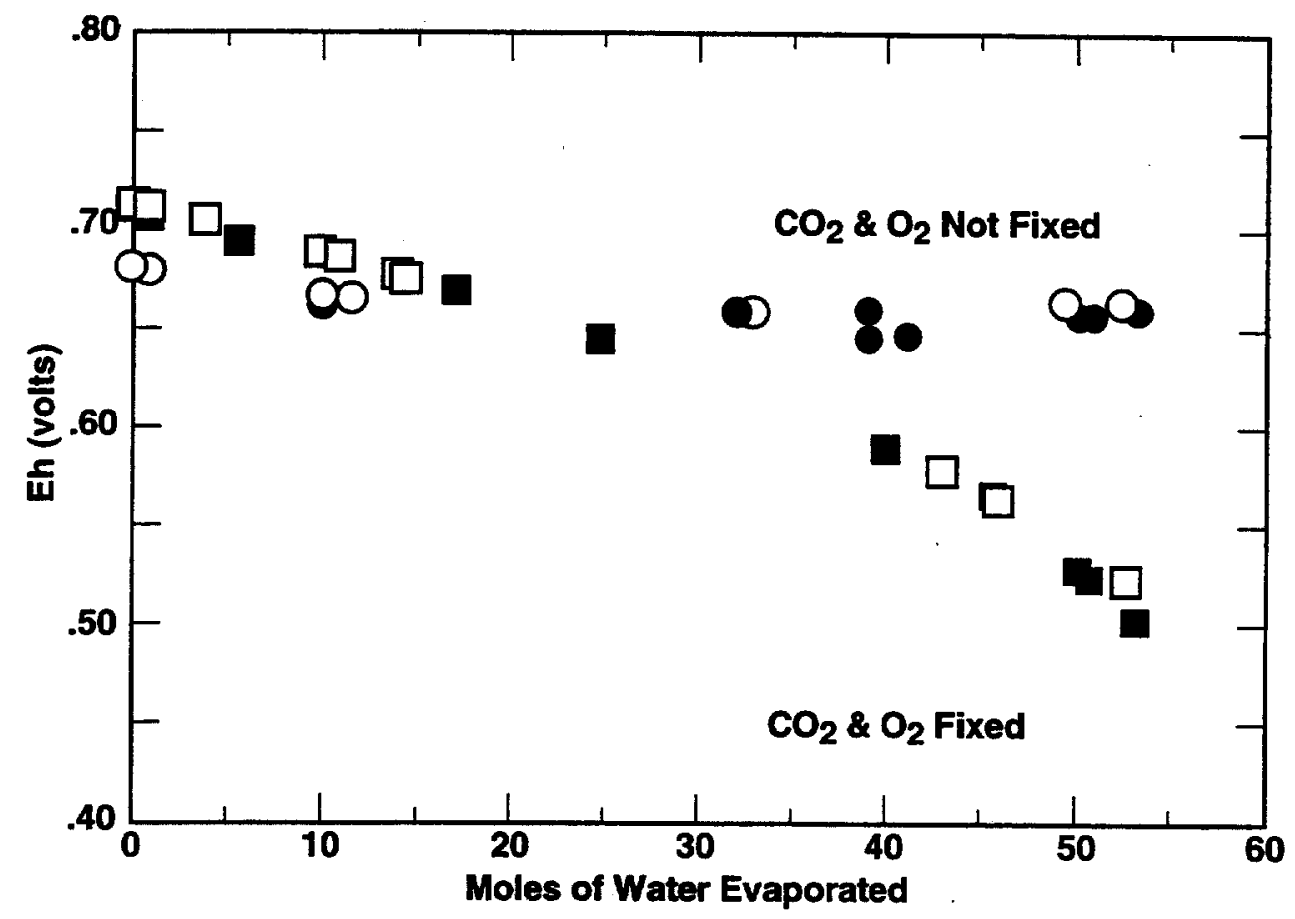

Figure 3.4-3. Eh, in volts, as a function of moles of water evaporated. Symbols as described in caption to Figure 3.4-2.

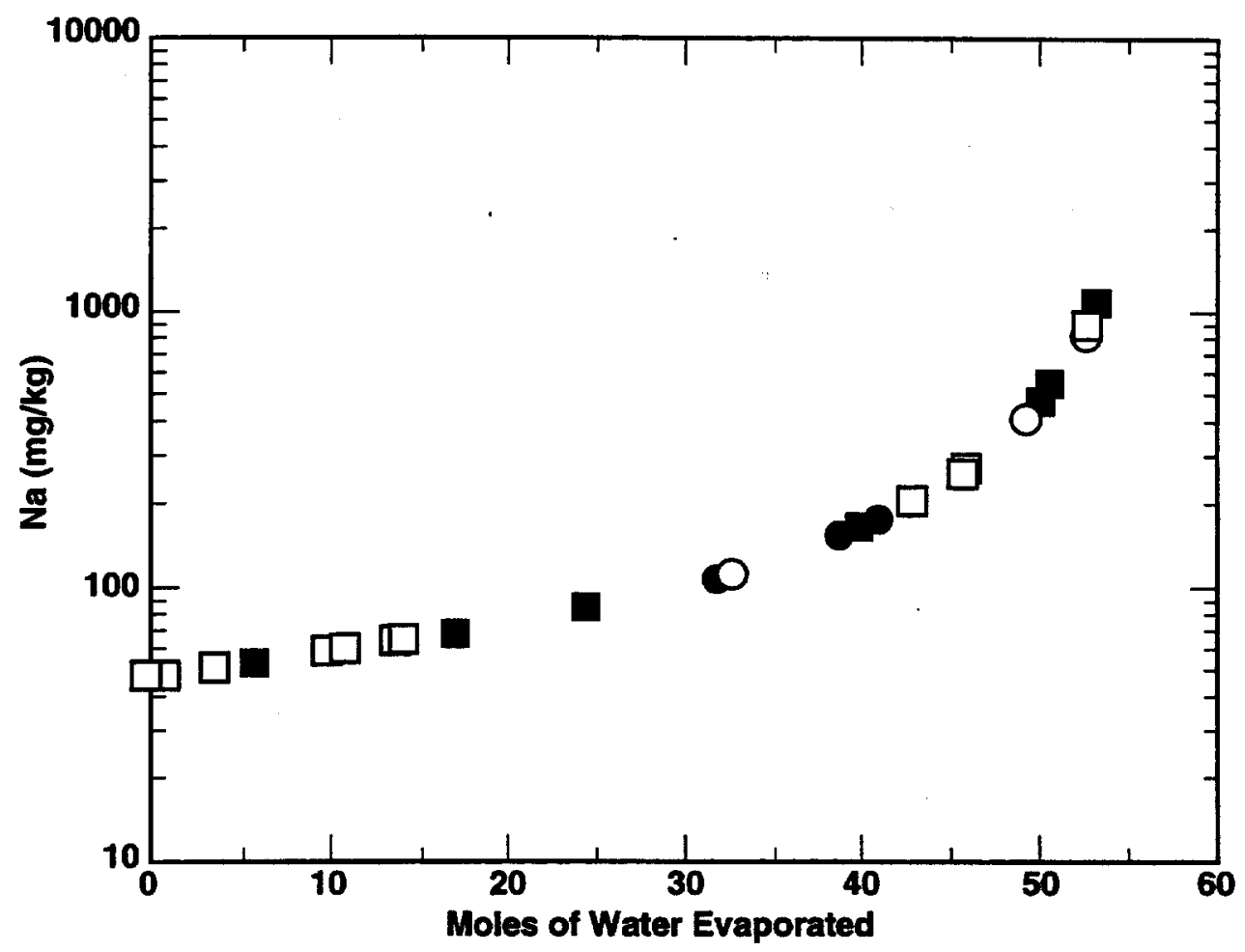

Figure 3.4-4. Total $\mathrm{Na}$ in solution, in $\mathrm{mg} / \mathrm{kg}$, as a function of moles of water evaporated. Symbols as described in caption to Fig. 3.4-2. 


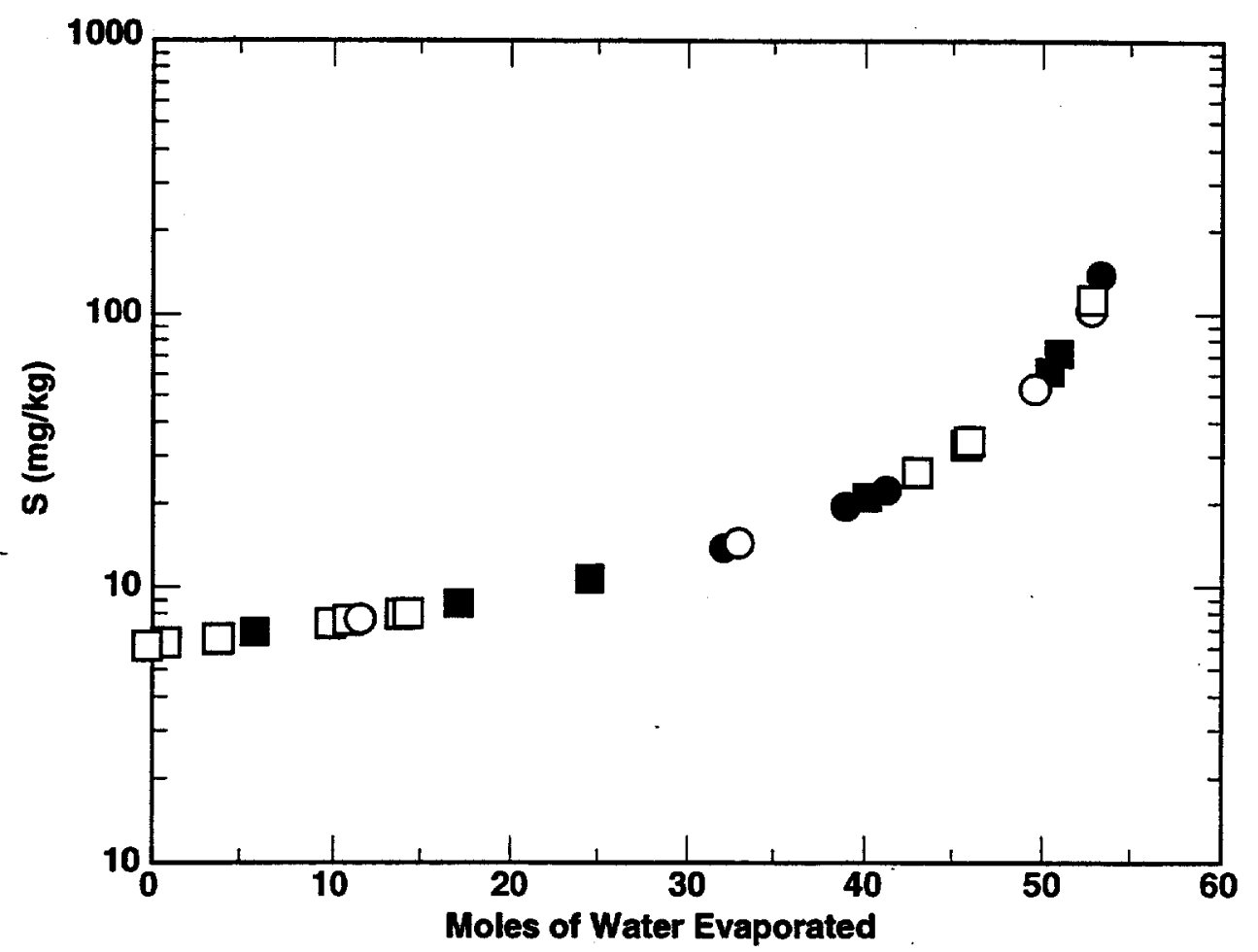

Figure 3.4-5. Total $\mathrm{S}$ in solution, in $\mathrm{mg} / \mathrm{kg}$, as a function of moles of water evaporated. Symbols as described in caption to Fig. 3.4-2.

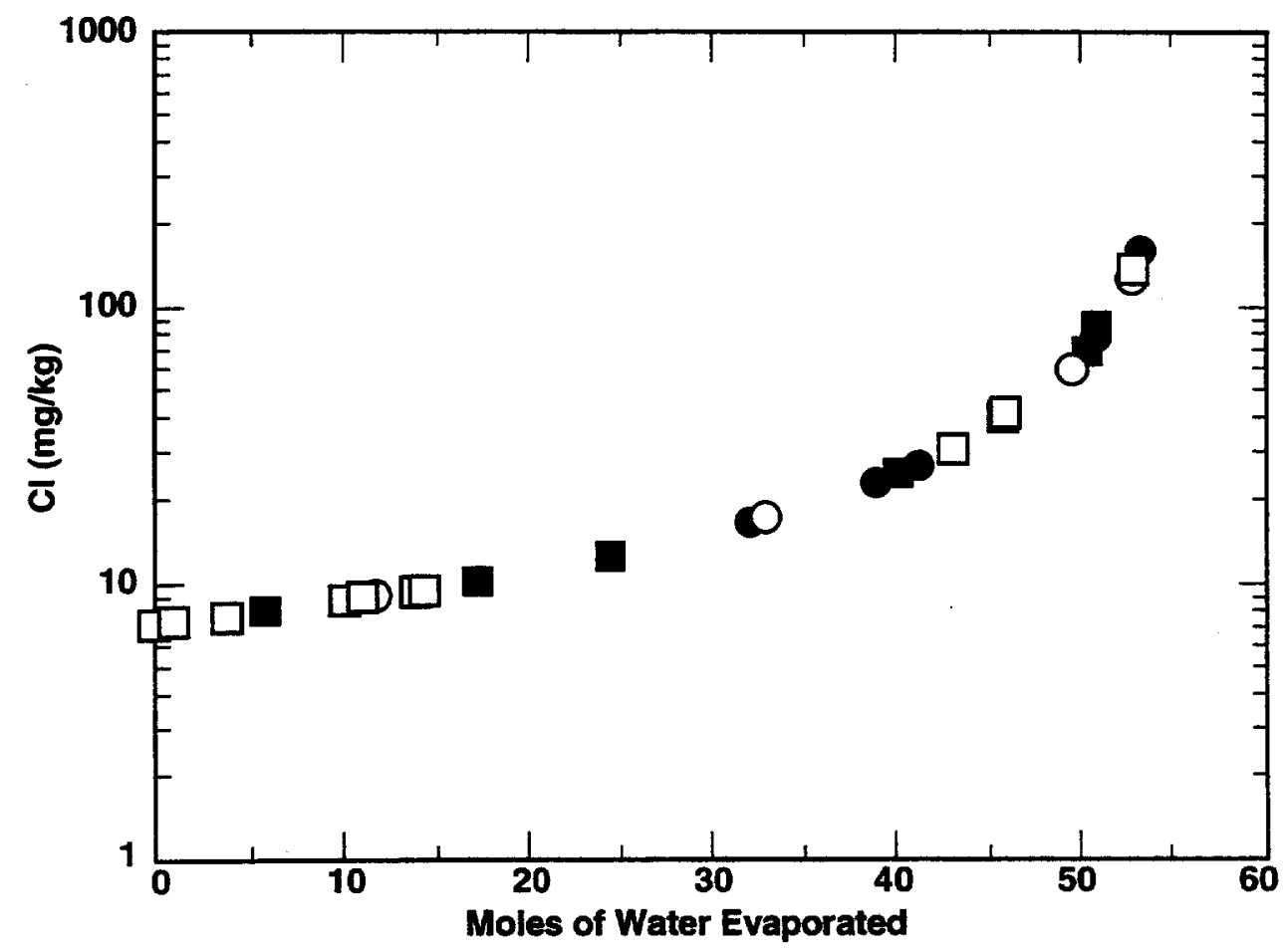

Figure 3.4-6. Total $\mathrm{Cl}$ in solution, in $\mathrm{mg} / \mathrm{kg}$, as a function of moles of water evaporated. Symbols as described in caption to Fig. 3.4-2. 


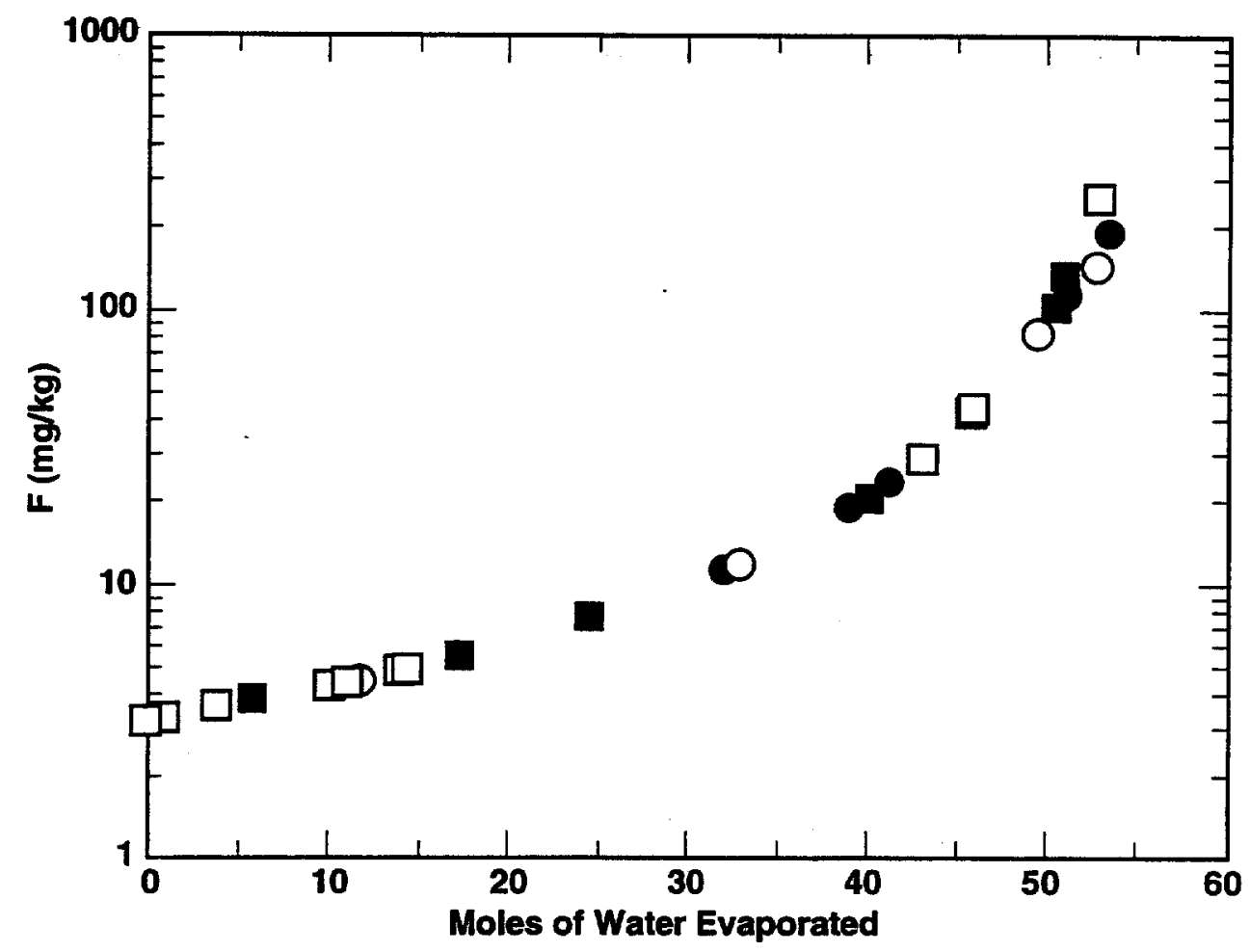

Figure 3.4-7. Total $\mathrm{F}$ in solution, in $\mathrm{mg} / \mathrm{kg}$, as a function of moles of water evaporated. Symbols as described in caption to Fig. 3.4-2.

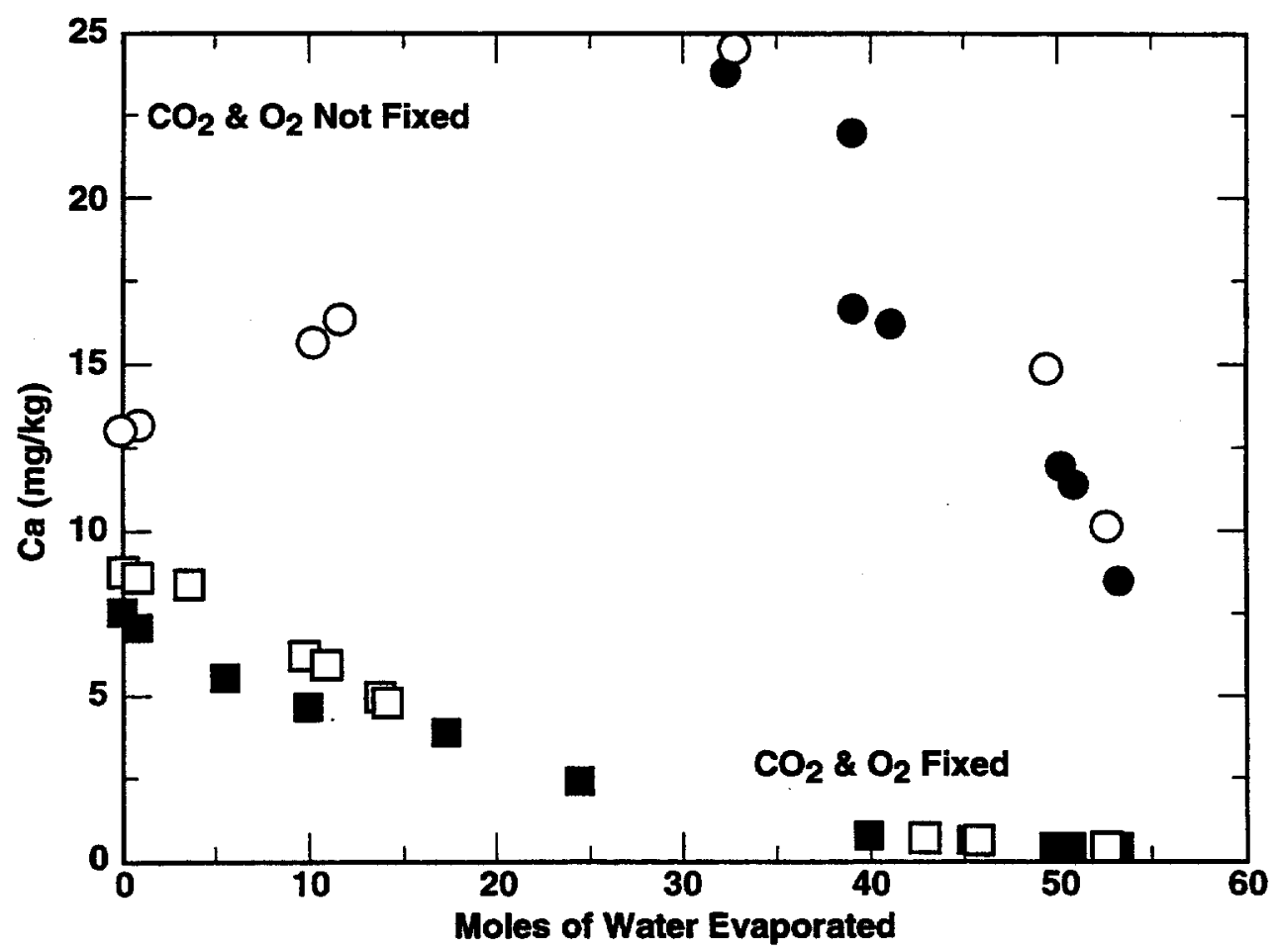

Figure 3.4-8. Total $\mathrm{Ca}$ in solution, in $\mathrm{mg} / \mathrm{kg}$, as a function of moles of water evaporated. Symbols as described in caption to Fig. 3.4-2. Note that the peak concentration for the uncontrolled $\mathrm{CO}_{2}$ and $\mathrm{O}_{2}$ case corresponds to calcite saturation (compare with Fig. 3.4-11). 


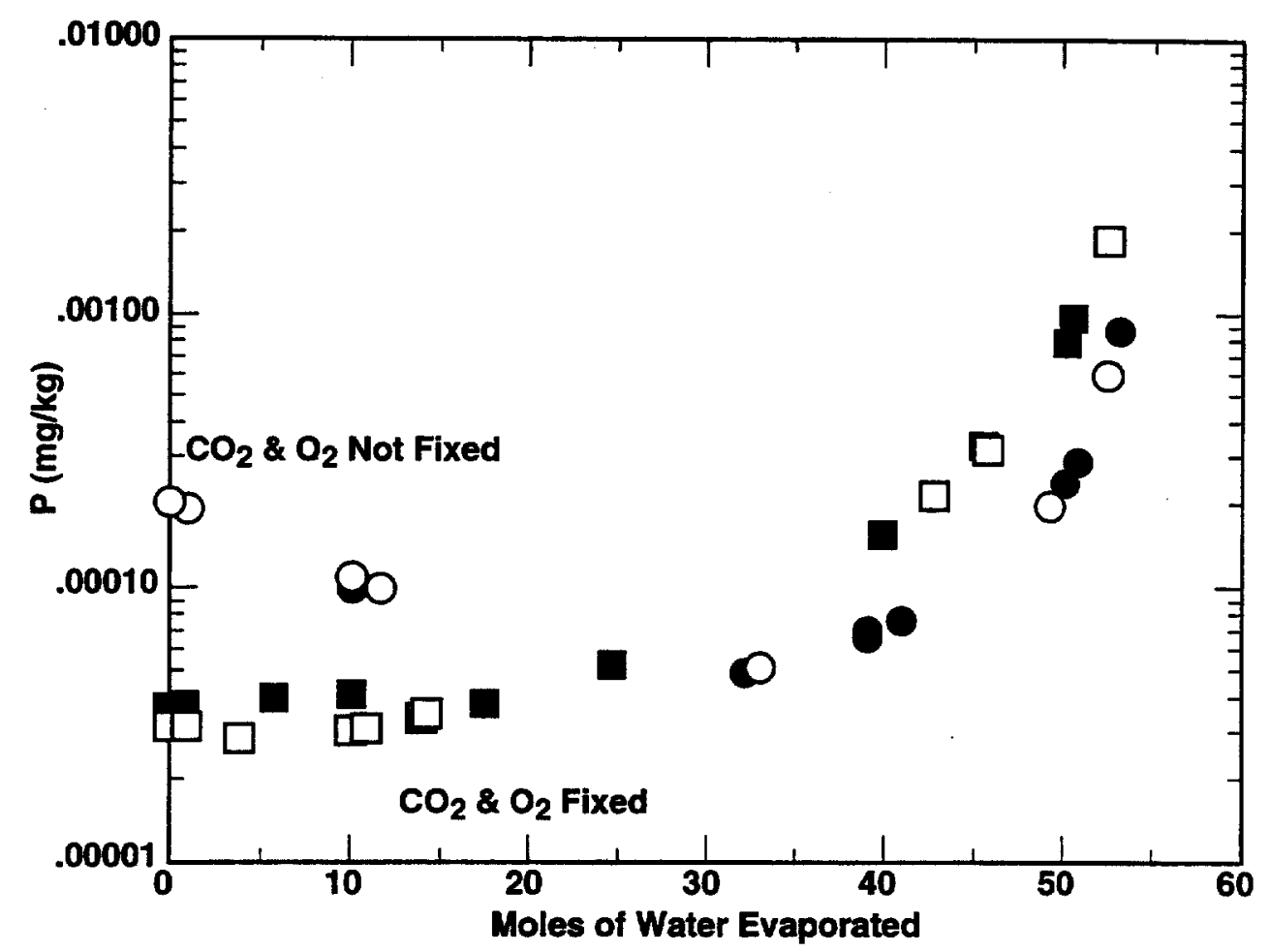

Figure 3.4-9. Total $\mathrm{P}$ in solution, in $\mathrm{mg} / \mathrm{kg}$, as a function of moles of water evaporated. Symbols as described in caption to Fig. 3.4-2.

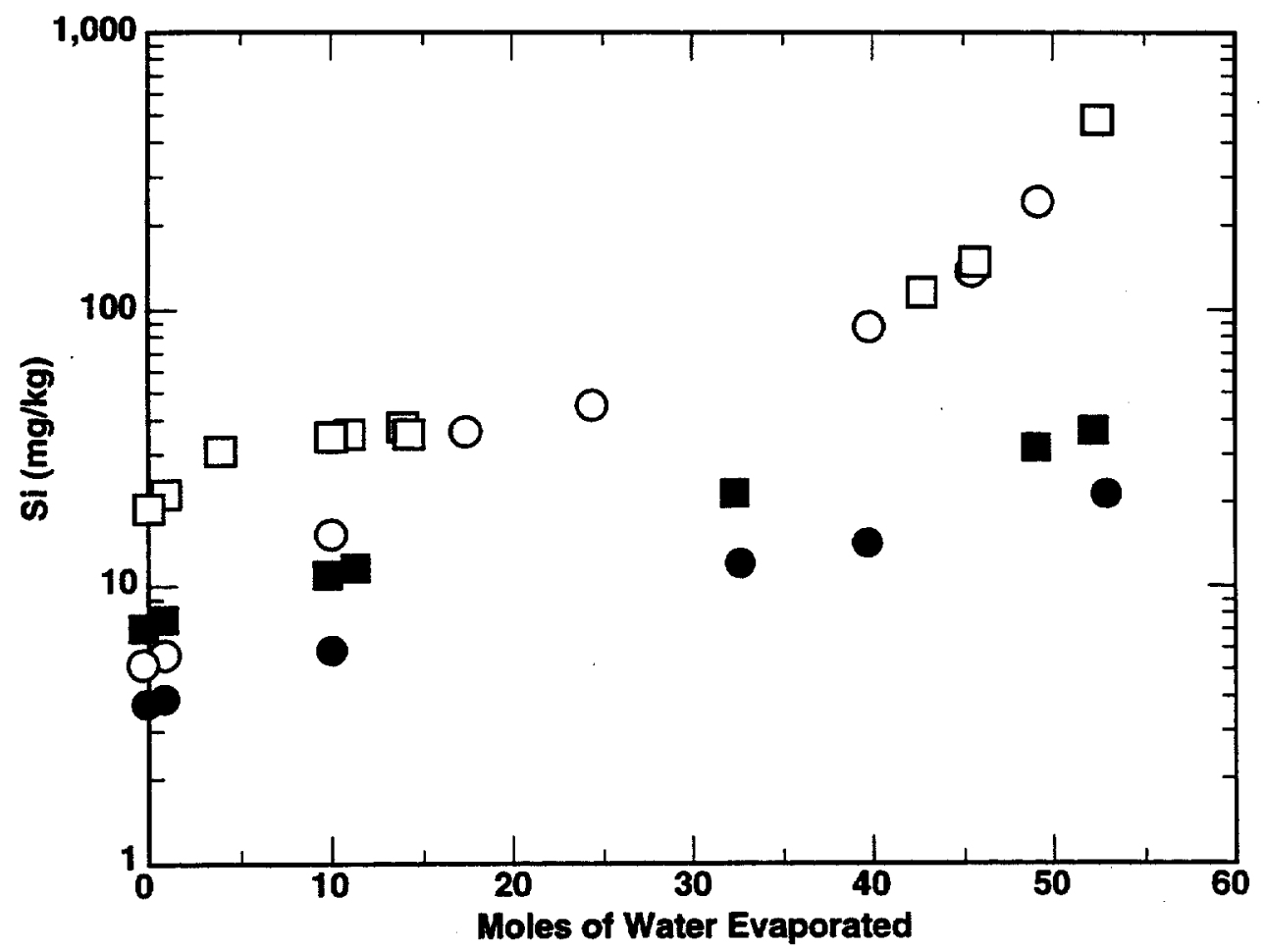

Figure 3.4-10. Total $\mathrm{Si}$ in solution, in $\mathrm{mg} / \mathrm{kg}$, as a function of moles of water evaporated. Symbols as described in caption to Fig.3.4-2. 


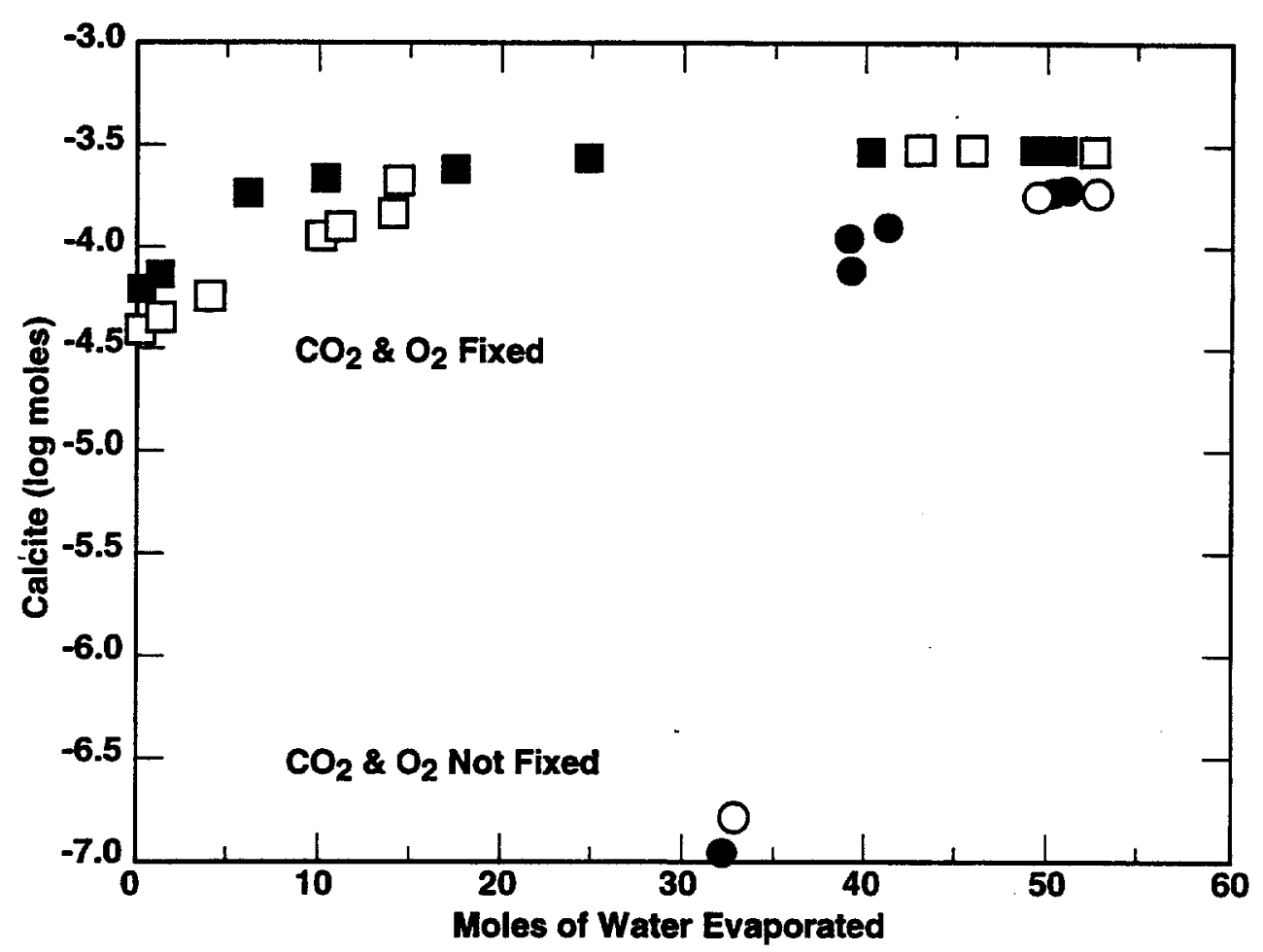

Figure 3.4-11. Log of the number of moles of calcite precipitated, as a function of moles of water evaported. Symbols as described in caption to Fig. 3.4-2.

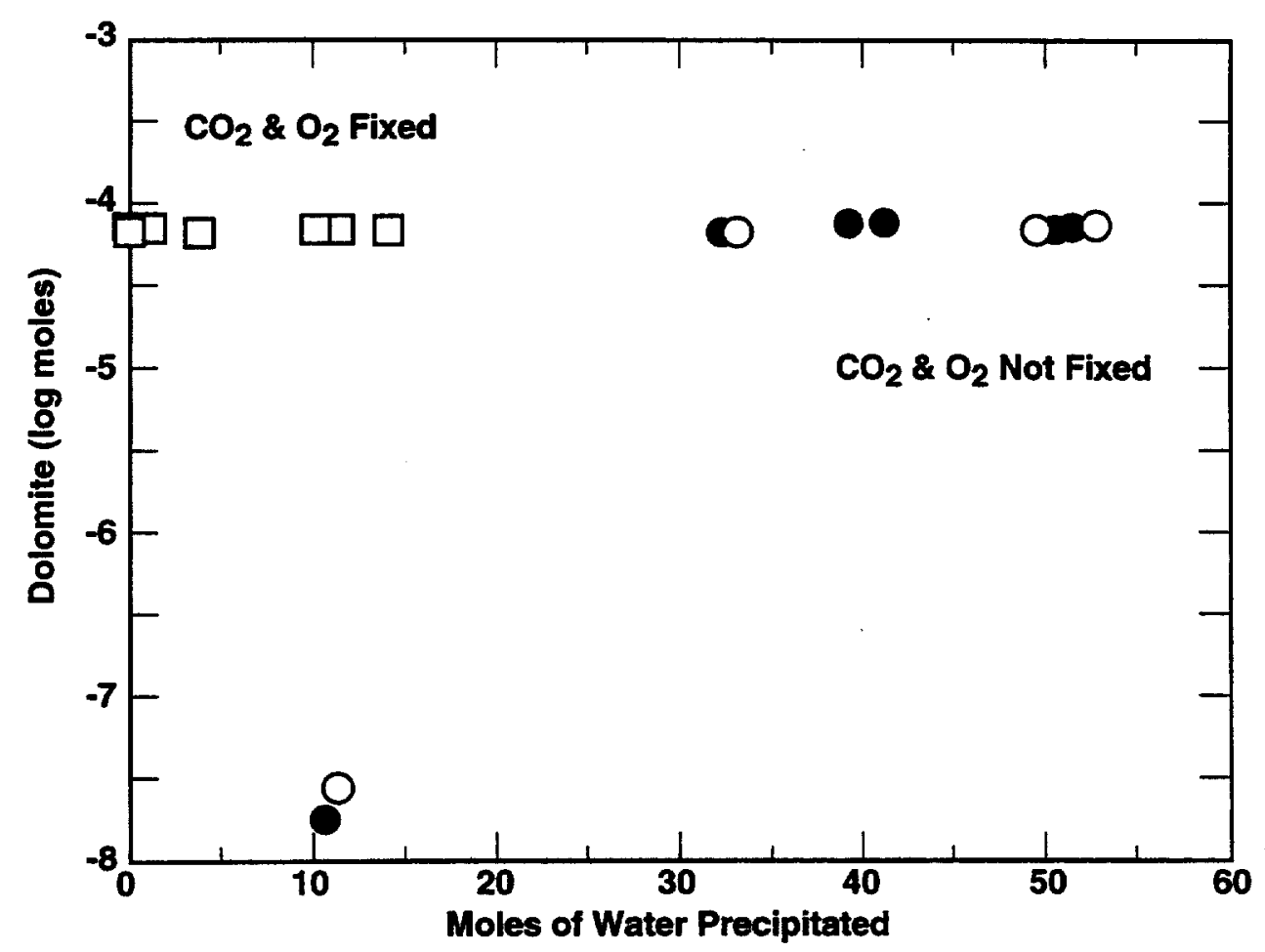

Figure 3.4-12. Log of the number of moles of dolomite precipitated, as a function of moles of water evaported. Symbols as described in caption to Fig.3.4-2. 


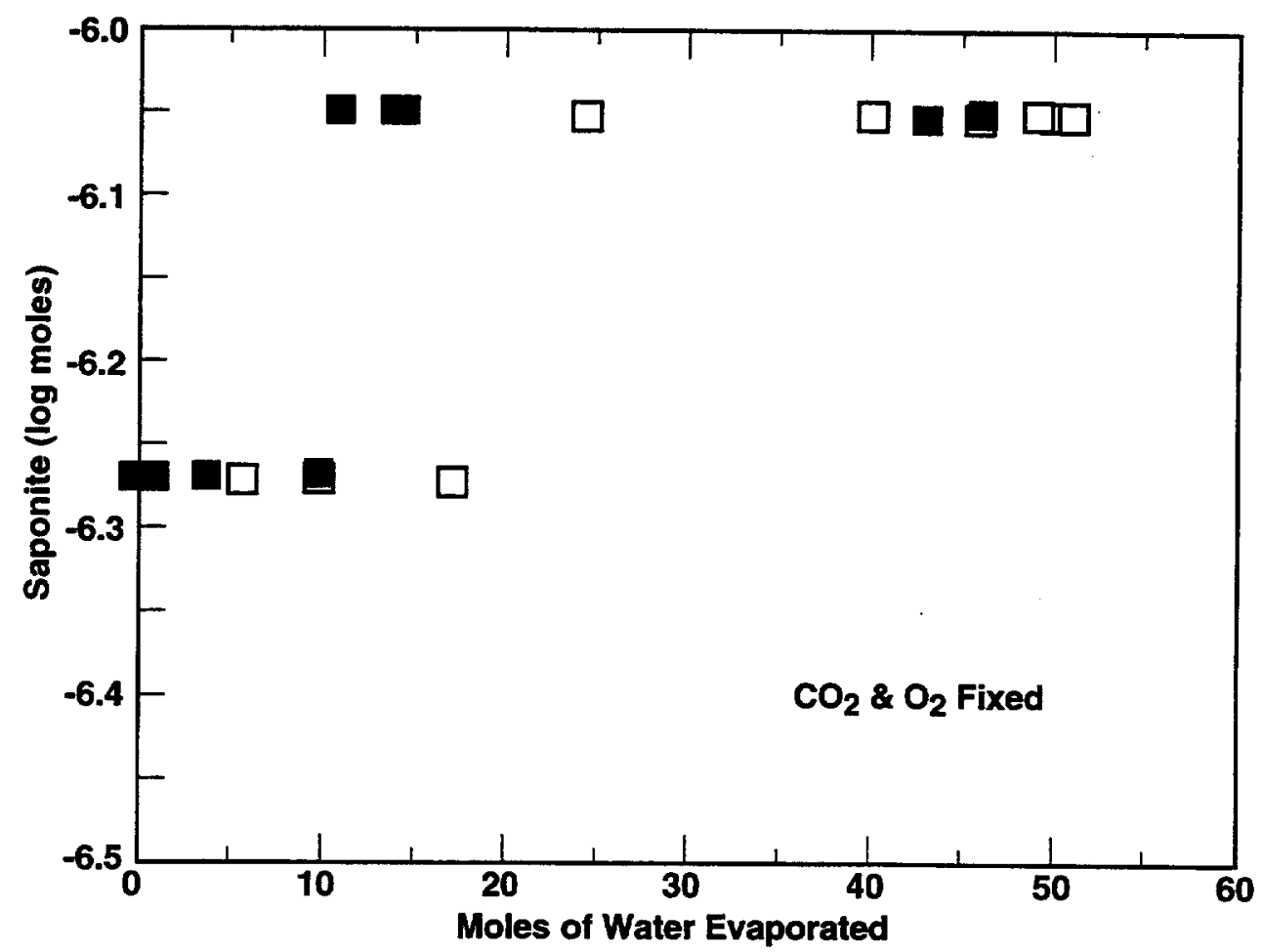

Figure 3.4-13. Log of the number of moles of saponite precipitated, as a function of moles of water evaported. Symbols as described in caption to Fig. 3.4-2.

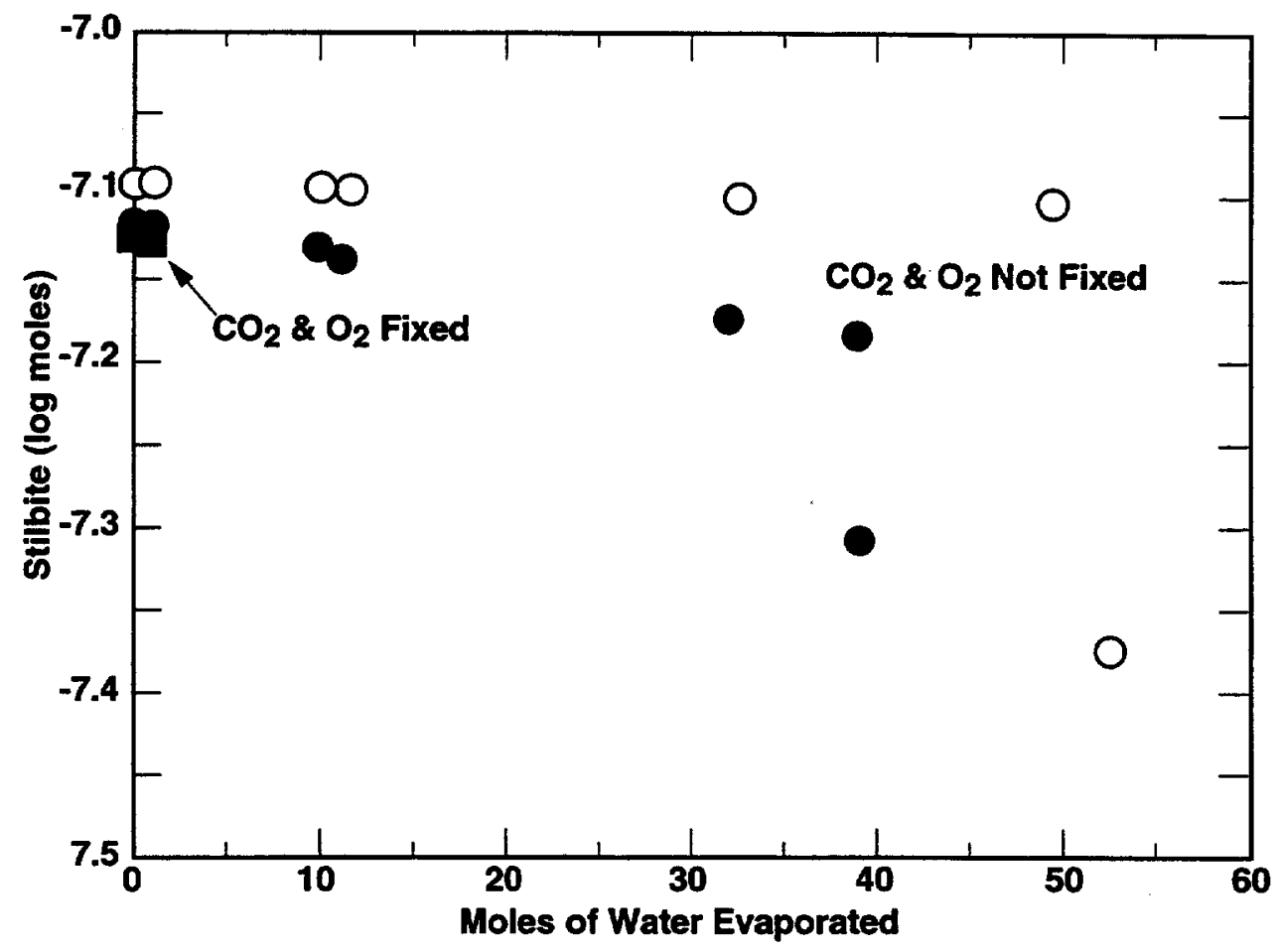

Figure 3.4-14. Log of the number of moles of stilbite precipitated, as a function of moles of water evaported. Symbols as described in caption to Fig. 3.4-2. 


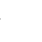




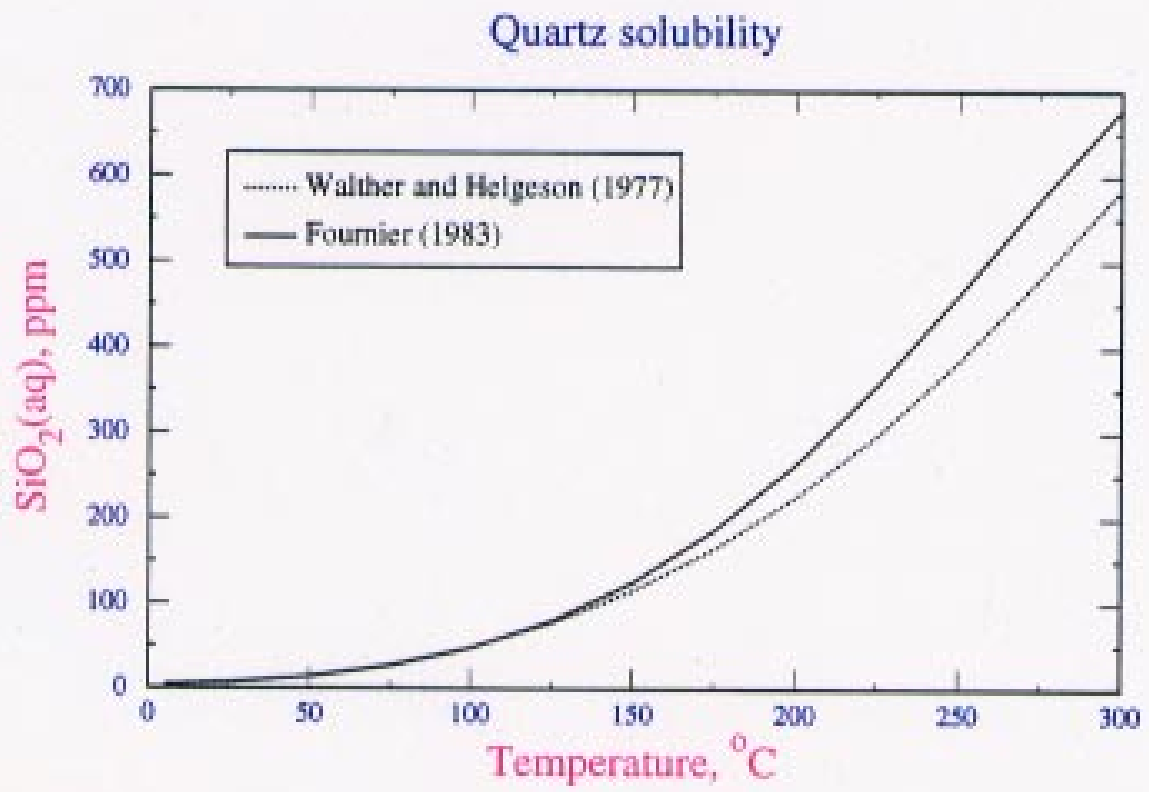

Figure 3.4-15. $\mathrm{SiO}_{2}$ (aq) concentrations in equilibrium with quartz using thermodynamic data from Walther and Helgeson (1977) and Foumier (1983).

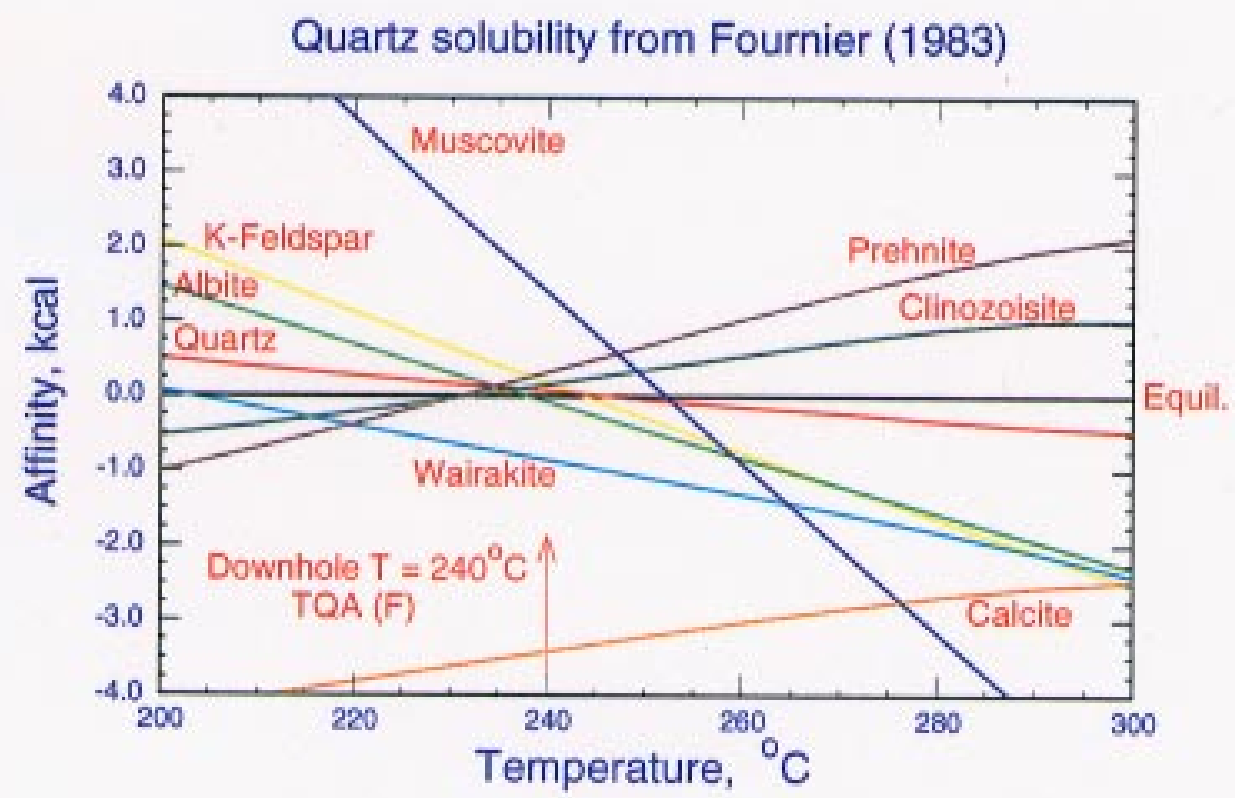

Figure 3.4-16. Affinity vs. temperature diagram for well WK-81 using quartz solubility from Fournier (1983). 
Quartz solubility from Walther and Helgeson (1977)

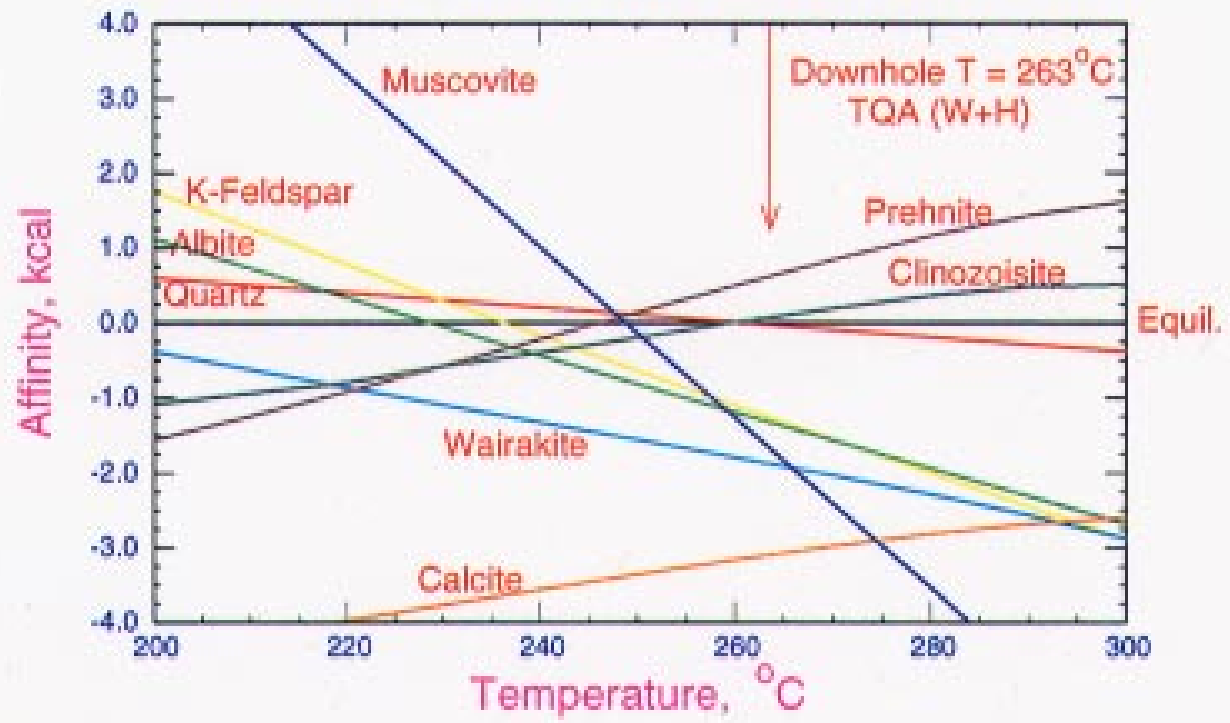

Figure 3.4-17. Affinity vs. temperature diagram for well WK-81 using quartz solubility from Walther and Helgeson (1977).

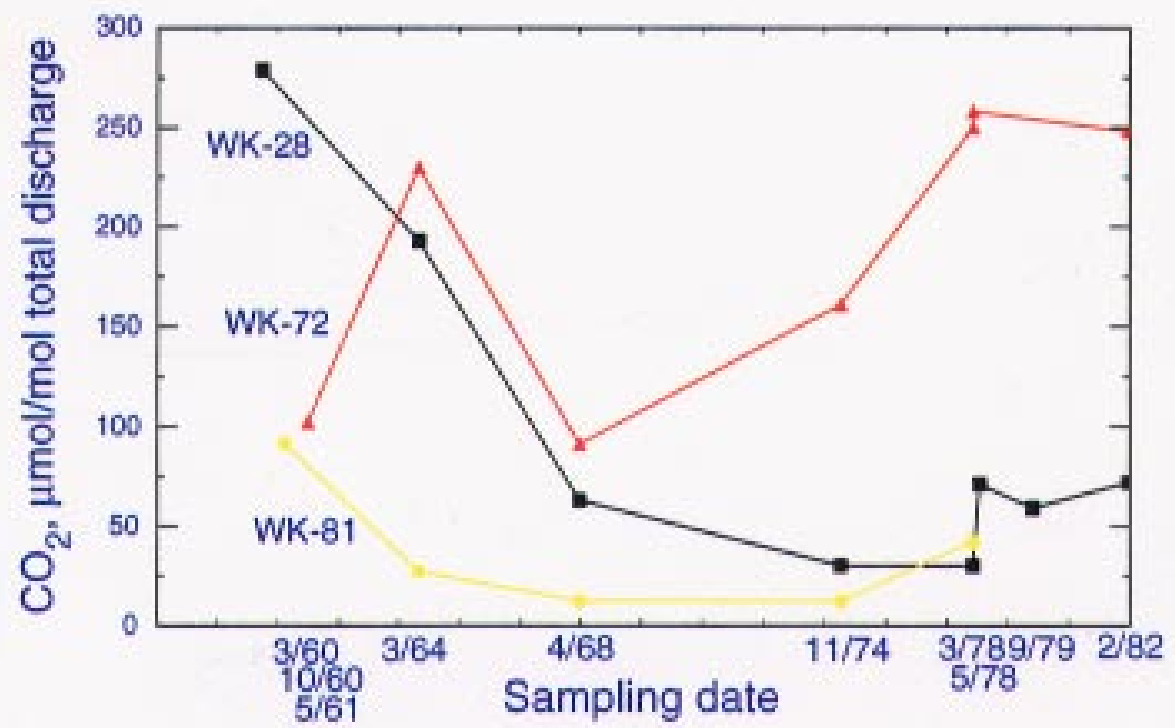

Figure 3.4-18. $\mathrm{CO}_{2}$ concentrations (in $\mu \mathrm{mol} / \mathrm{mol}$ water) measured in Wairakei wells WK-28, 72 and 81 as a function of time. 

High $\mathrm{CO}_{2}$ gas ( $3 / 78$ analysis)

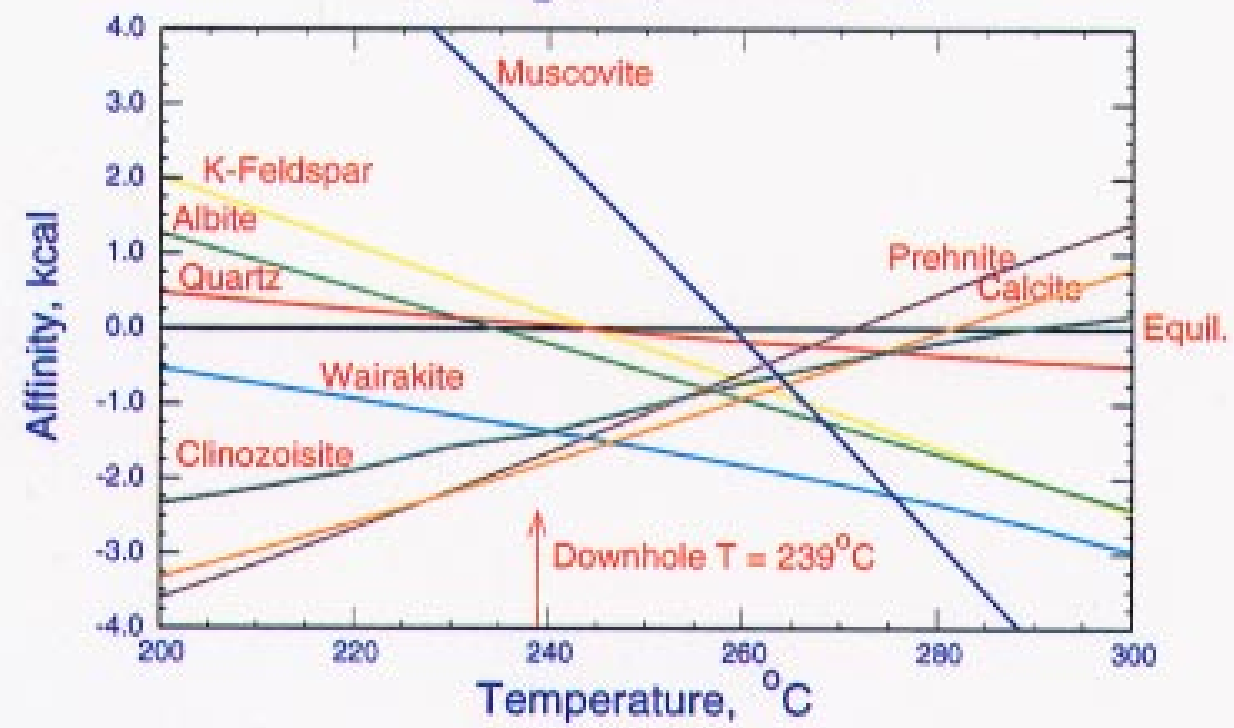

Figure 3.4-19. Affinity vs. temperature diagram for well WK-72 using $3 / 78$ gas analysis with $258 \mathrm{mmol} \mathrm{CO} 2 / \mathrm{mol} \mathrm{TD}$ (see text). Quartz data from Fournier (1983).

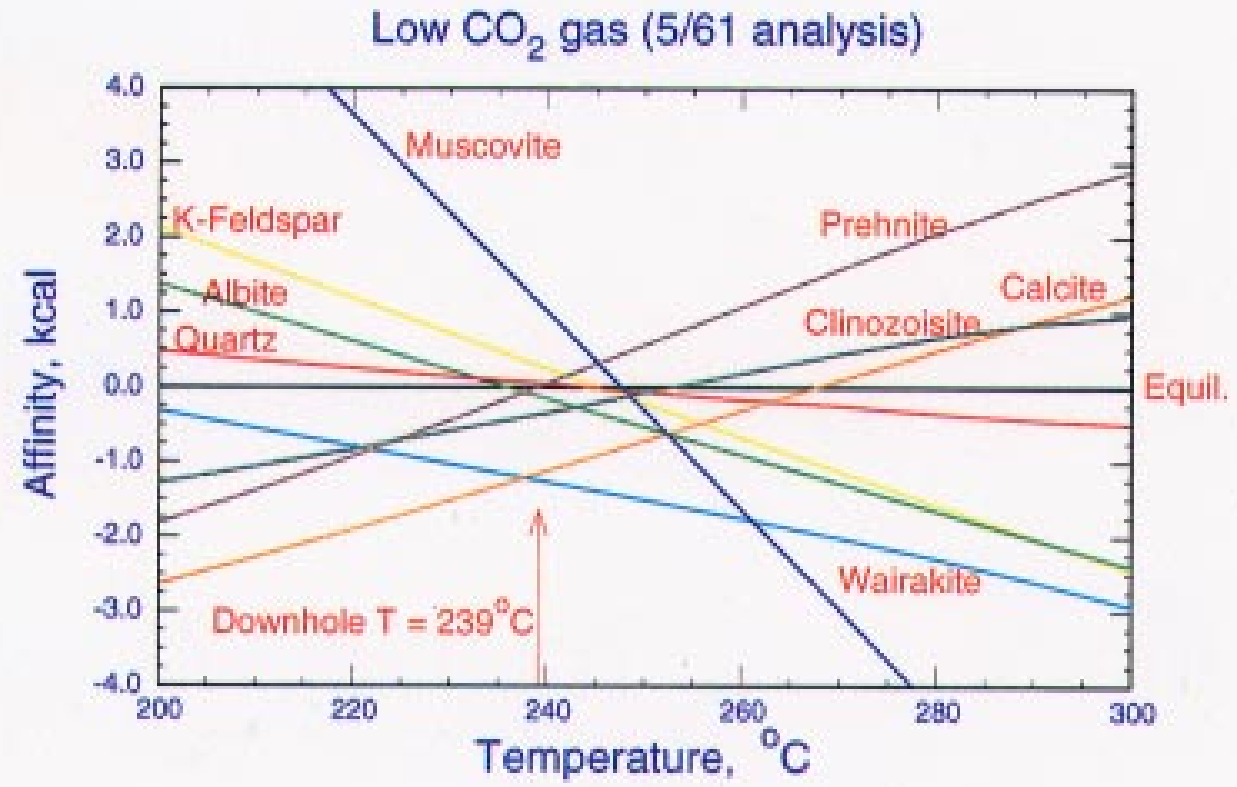

Figure 3.4-20. Affinity vs, temperature diagram for well WK-72 using $5 / 61$ gas analysis with $102 \mathrm{mmol} \mathrm{CO} / \mathrm{mol}$ TD (see text). Quartz data from Fournier (1983). 

SUPCRT92 data base with Pokrovskii and Helgeson Al data

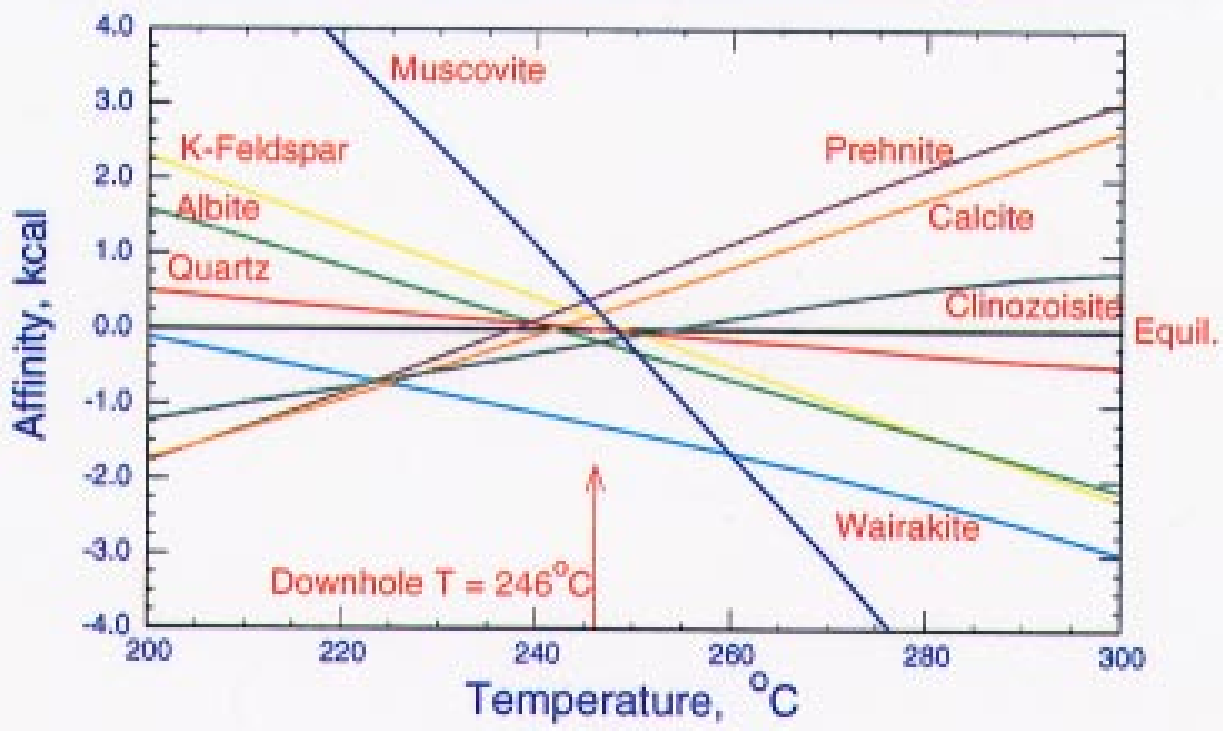

Figure 3.4-21. Affinity vs, temperature diagram for well WK- 28 using thermodynamic data for Al aqueous species from Pokrovskii and Helgeson (1995). Quartz data from Fournier (1983).

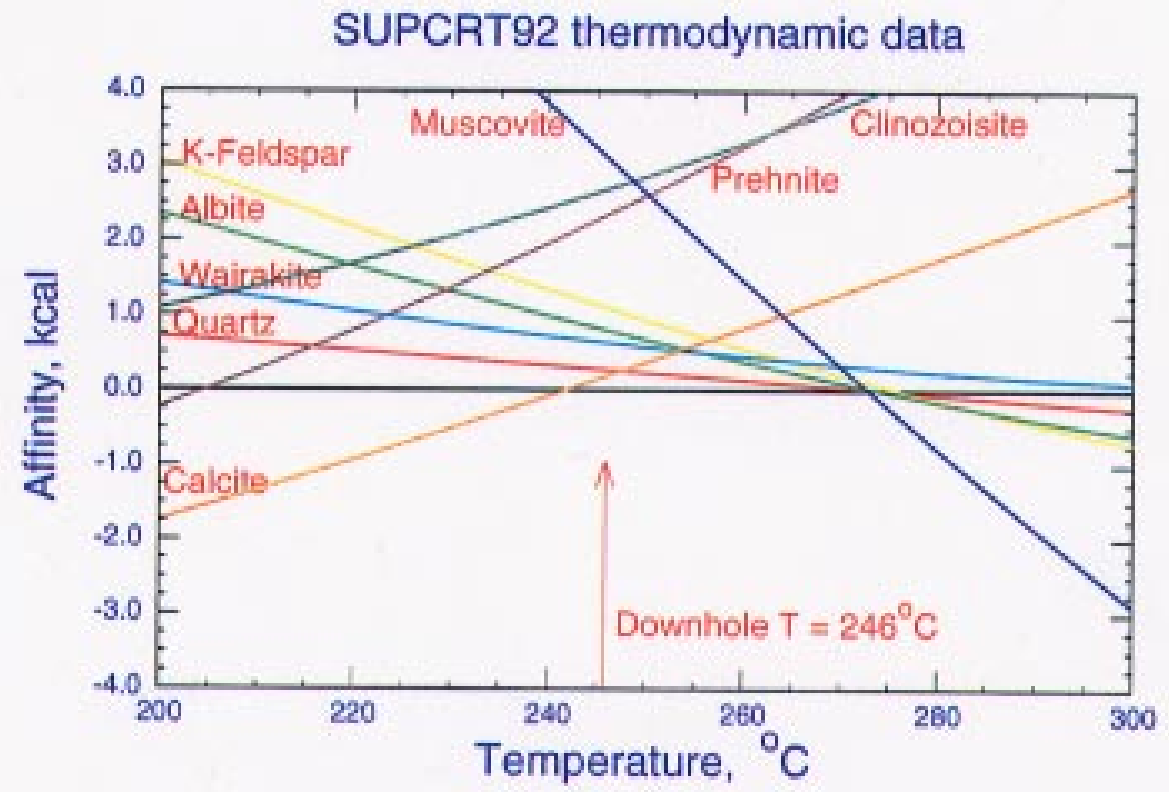

Figure 3.4-22. Affinity vs. temperature diagram for well WK- 28 using thermodynamic data for $\mathrm{Al}$ aqueous species from the SUPCRT92 version of the GEMBOCHS data base. Quartz data from Fournier (1983). 



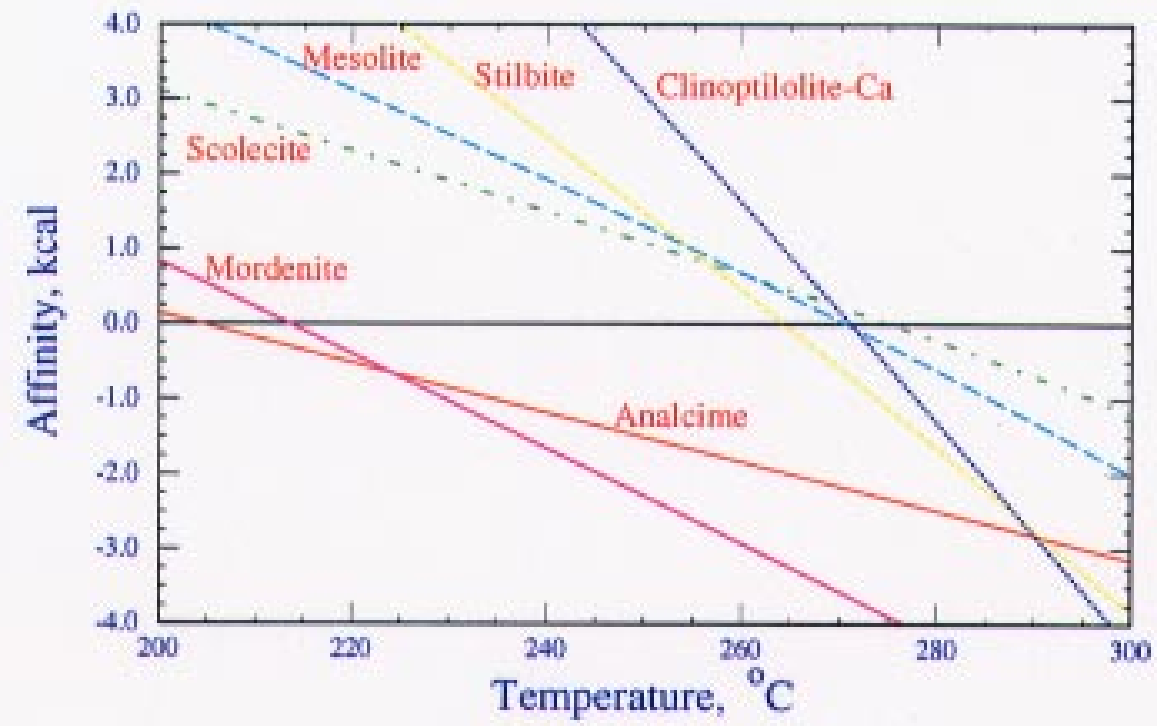

Figure 3.4-23. Zeolite affinities vs. temperature diagram for well WK-28 using thermodynamic data for Al aqueous species from Pokrovskii and Helgeson (1995). See Figure 7 for stabilities of additional minerals. Clinoptilolite-Ca refers to the Ca endmember of a clinoptilolite solid solution. Quartz data from Fournier (1983). 


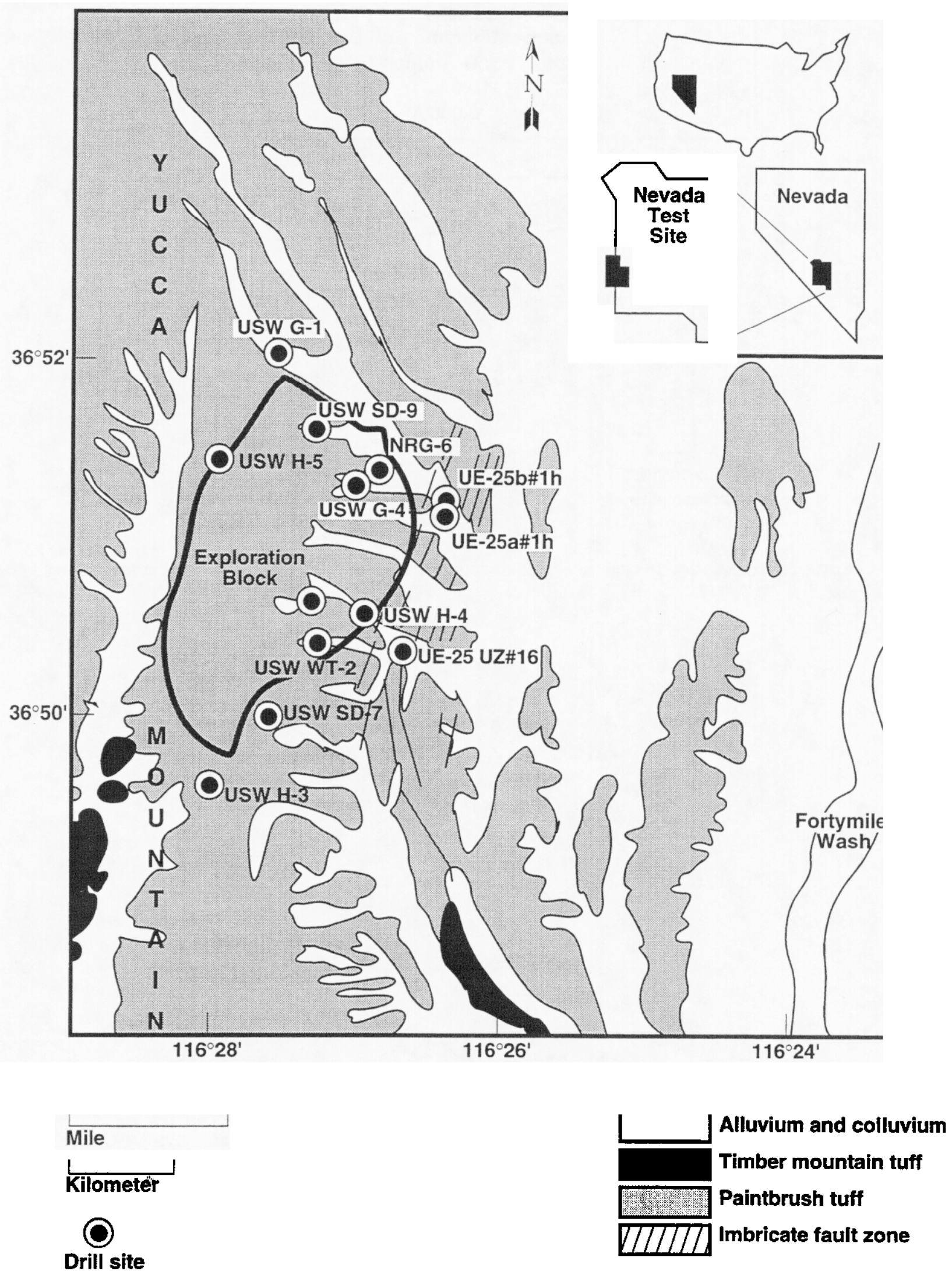

Figure 3.4-24. Map of Yucca Mountain, Nevada, showing locations of drill holes within or near the exploration block where mineralogical data have been collected mentioned in the appendices. 
Alteration of Vitrophyre Glass

\begin{tabular}{|ccccc}
\hline \multicolumn{5}{c}{ Moles cation/ $\mathrm{cm}^{3}$} \\
& Glass & Smectite & Heul-clinopt. & Cristobalite \\
SI & $\mathbf{0 . 0 2 9}$ & $\mathbf{0 . 0 1 4}$ & 0.024 & 0.038 \\
Al & $\mathbf{0 . 0 0 6}$ & $\mathbf{0 . 0 0 8}$ & $\mathbf{0 . 0 0 6}$ & $\mathbf{0}$
\end{tabular}

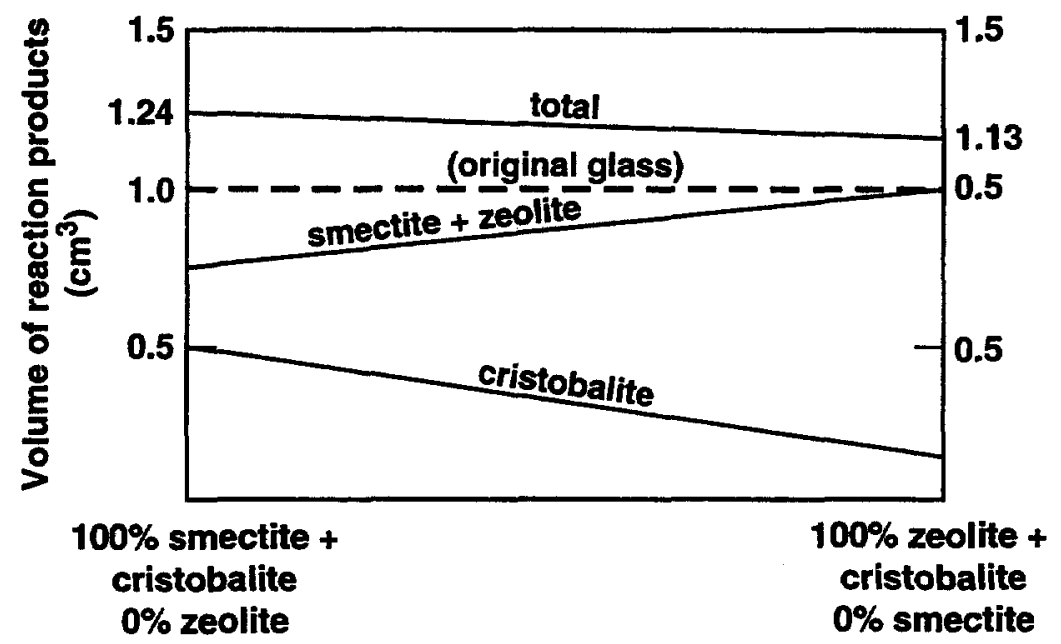

Figure 3.4-25. Graphic representation of reaction (1), balanced for all possible combinations of smectite and clinoptilolite-heulandite. 
Na-exchange Clinoptilolite (Barnes and Wilkin 1995)

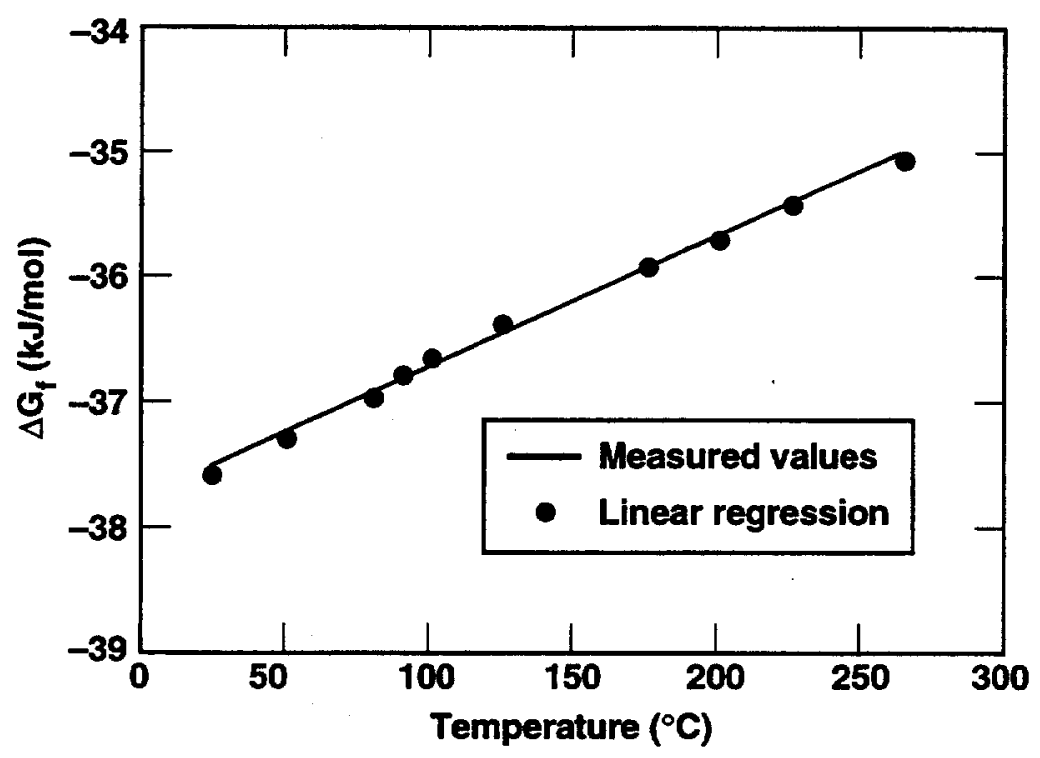

Figure 3.4-26. The Gibbs free energy of formation of Na-exchanged clinoptilolite derived from solubility measurements (Barnes and Wilkin, 1995). The solid line is a linear regression of the data from 50 to $265^{\circ} \mathrm{C}$.

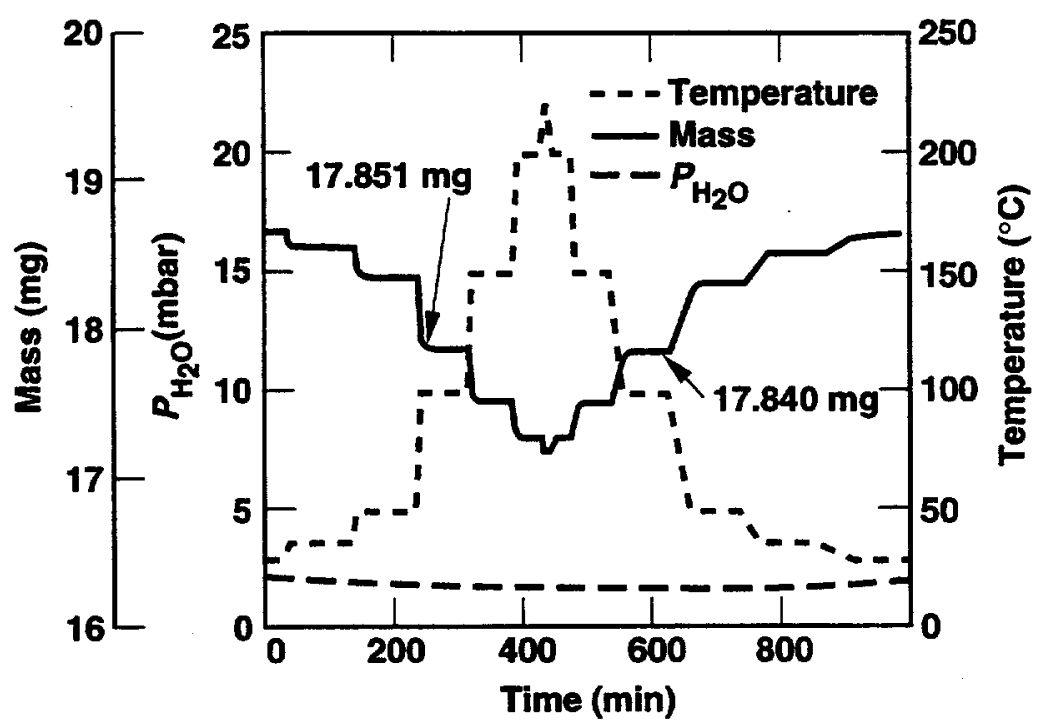

Figure 3.4-27. Results of a single thermogravimetric experiment on Ca-clinoptilolite conducted over a series of isothermal stages from 25 to $220^{\circ} \mathrm{C}$ at an approximately constant water-vapor pressure of $2 \mathrm{mbar}$ (Carey and Bish 1996a). Two mass measurements at $100^{\circ} \mathrm{C}$ are indicated to illustrate reversible hydration and dehydration. 


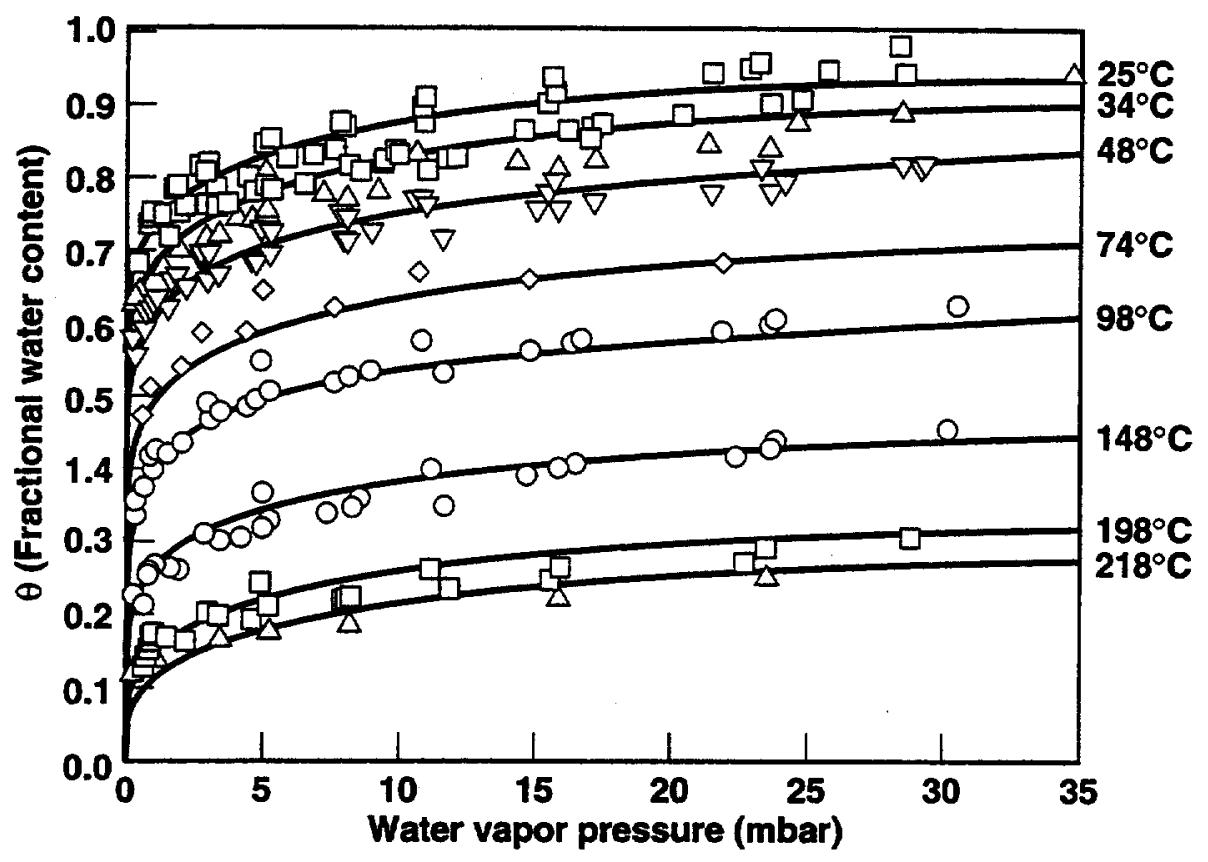

Figure 3.4-28. Equilibrium $\mathrm{H}_{2} \mathrm{O}$ content of Na-clinoptilolite determined by thermogravimetry between 25 and $218{ }^{\circ} \mathrm{C}$ (Carey and Bish 1996a). The fractional water content, $\theta$, is the observed $\mathrm{H}_{2} \mathrm{O}$ content divided by the maximum $\mathrm{H}_{2} \mathrm{O}$ content. The calculated lines were derived by a single linear regression of all the data.

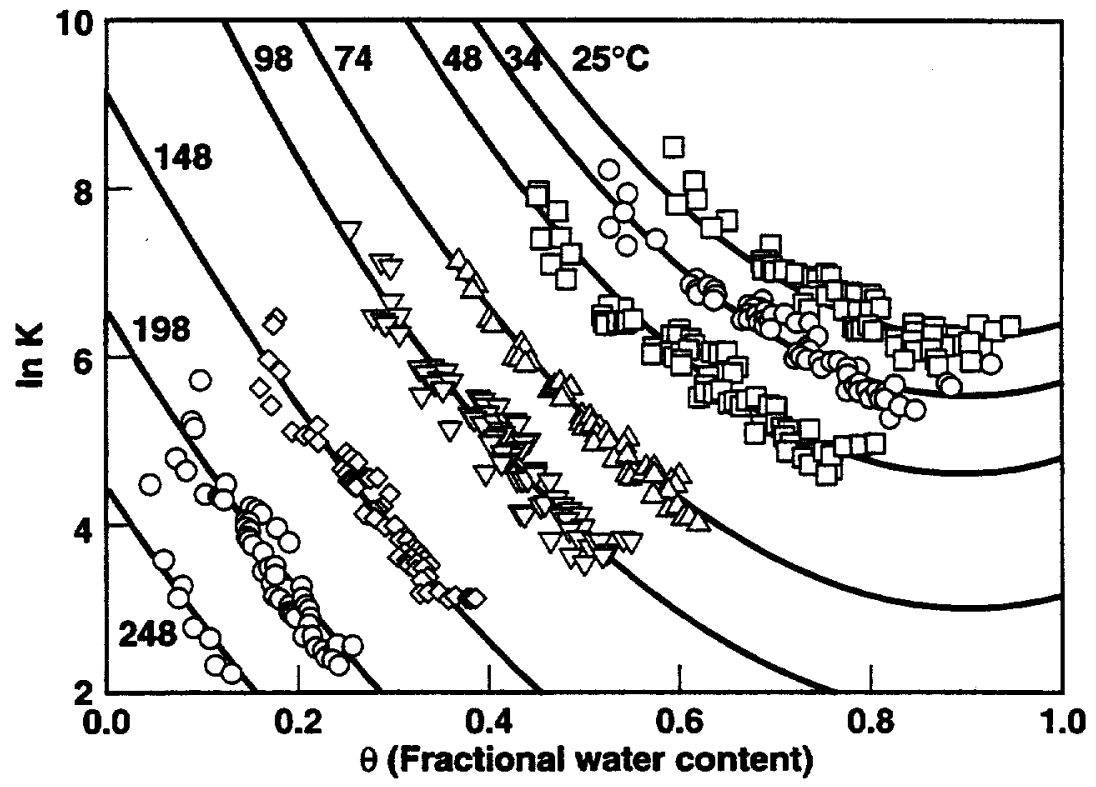

Figure 3.4-29. Comparison of the experimental data for K-clinoptilolite (symbols) with the calculated fit (solid lines) for water content versus equilibrium constant at several temperatures (Carey and Bish 1996a). The numbers labeling the curves are the temperature $\left({ }^{\circ} \mathrm{C}\right)$ of the experiment. $\ln \mathrm{K}$ is defined as $\ln (\theta /(1-\theta) / \mathrm{P})$, and $\theta$ is the ratio of the observed water content to the maximum water content at $25^{\circ} \mathrm{C}$. 


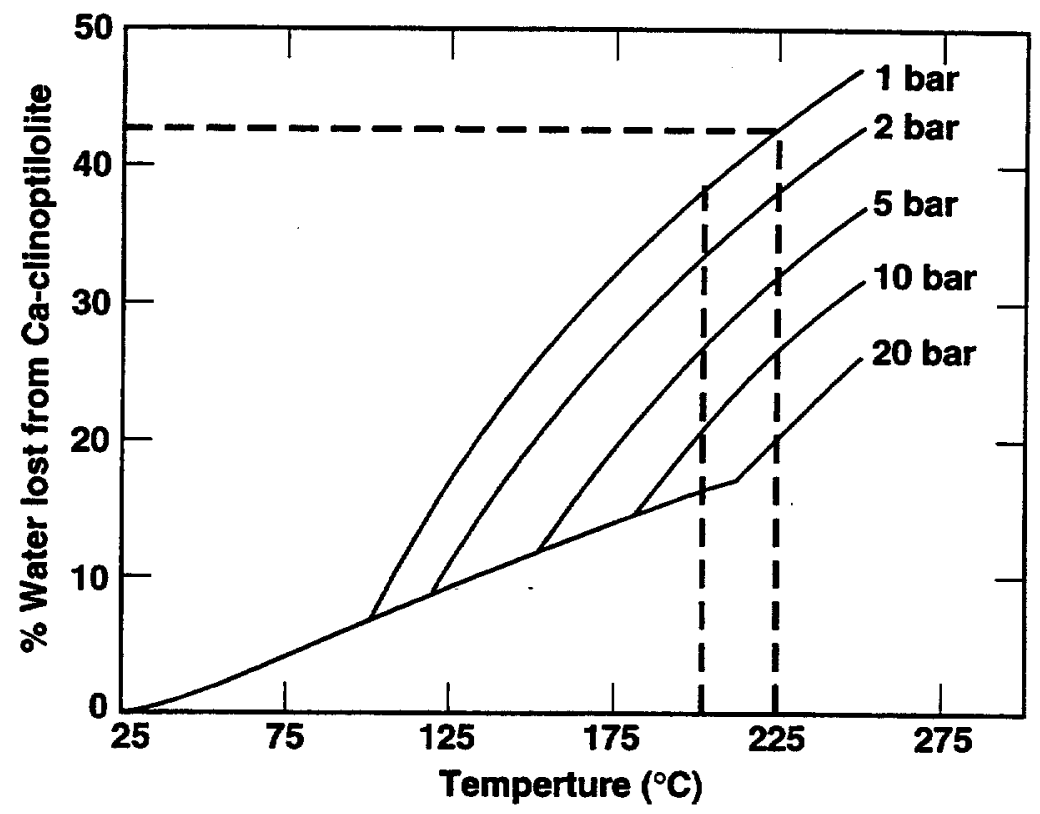

Figure 3.4-30. Calculated dehydration evolution of Ca-clinoptilolite under conditions of rising temperature and differing maximum pressures. Dehydration occurs along the boiling curve until the maximum pressure is reached (Carey and Bish 1996a).

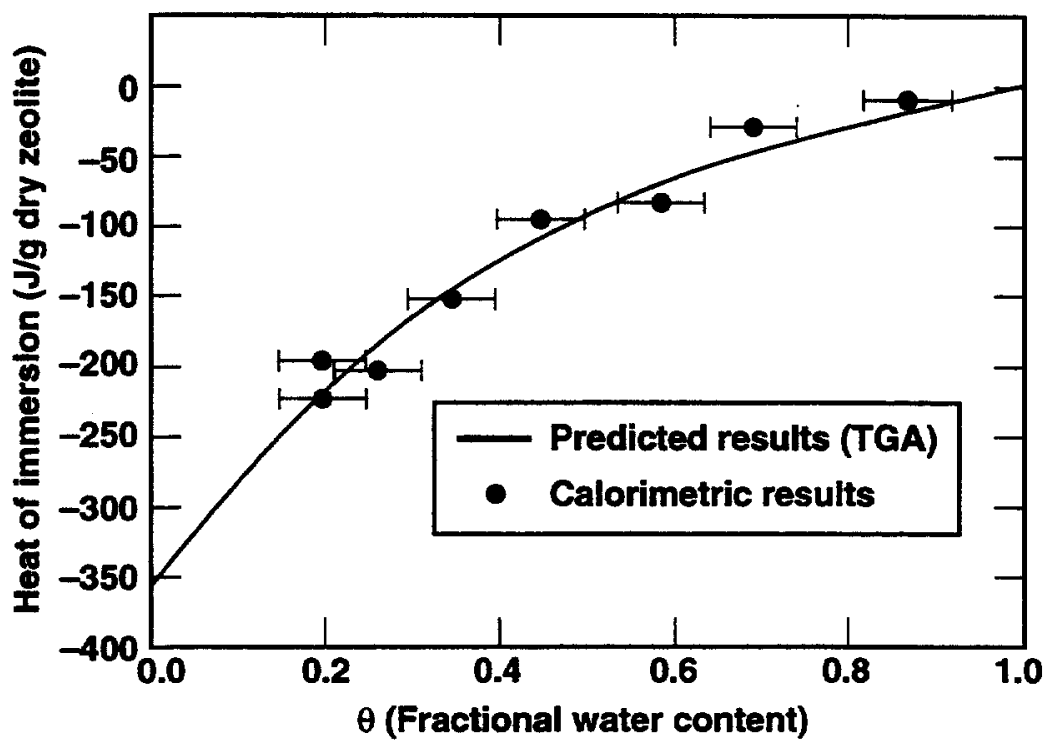

Figure 3.4-31. Calorimetric measurements of the integral heat of immersion of Ca-clinoptilolite (Carey and Bish 1996b) and calculated heats of immersion (TGA) from the study of Carey and Bish (1996a). 


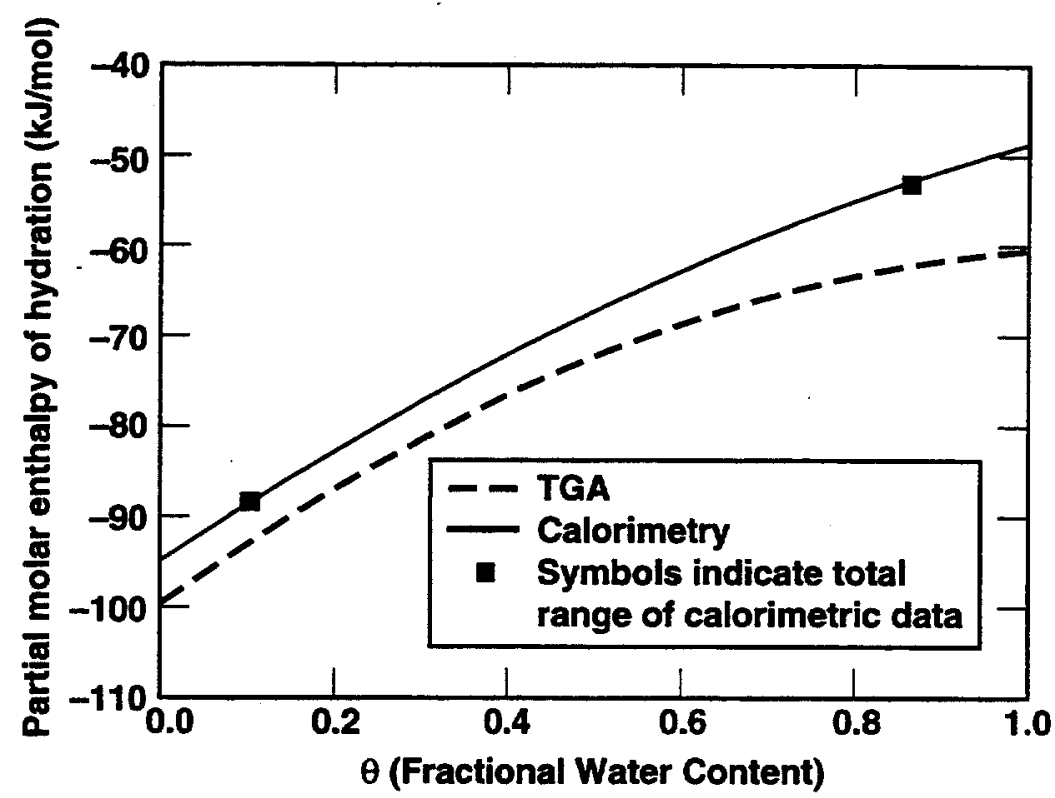

Figure 3.4-32. Partial molar enthalpy of hydration of Na-clinoptilolite derived from linear regression of the immersion calorimetry data (Carey and Bish 1996b) compared to the thermogravimetric results (TGA) of Carey and Bish (1996a).

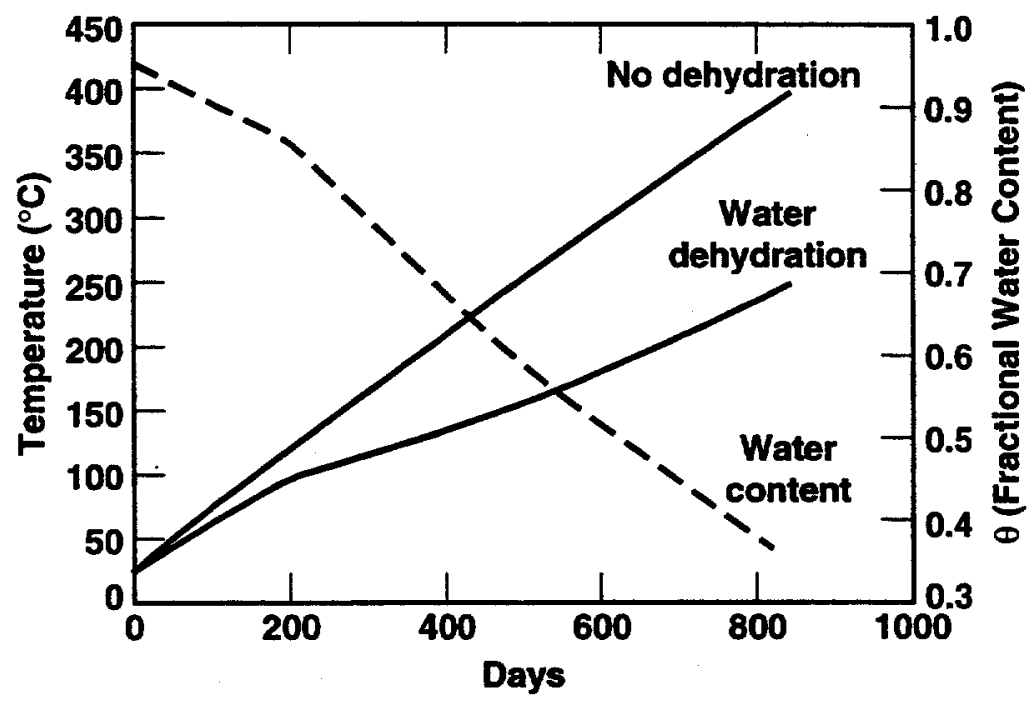

Figure 3.4-33. Calculated thermal and hydrologic evolution of a $1 \mathrm{~m}^{3}$ block of K-clinoptilolite with $10 \%$ porosity, insulated boundaries, maximum water-vapor pressure of $1 \mathrm{bar}$, and receiving 14 watts of thermal energy. The two solid lines show the temperature of a block with K-clinoptilolite that dehydrates and one which does not dehydrate. The dotted line shows the water content of the clinoptilolite in the dehydrating block (Carey and Bish 1996a). 


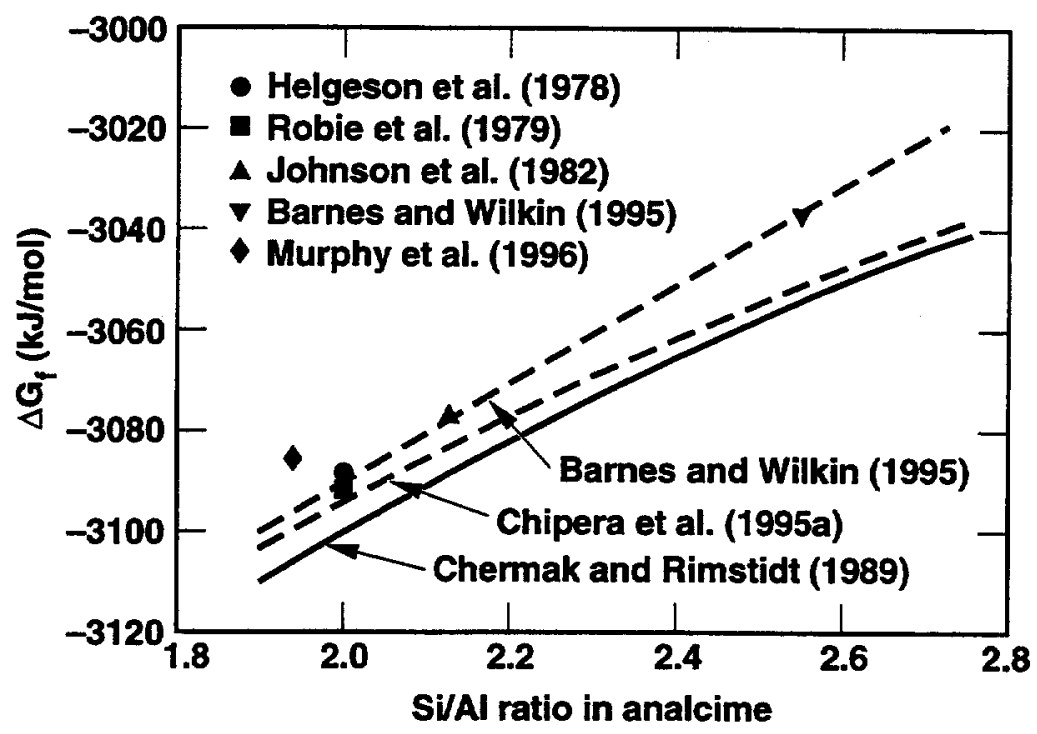

Figure 3.4-34. The Gibbs free energy of formation of analcime of differing $\mathrm{Si} / \mathrm{Al}$ ratio determined by calorimetry, solubility measurements, phase equilibria analysis, and by estimation methods.

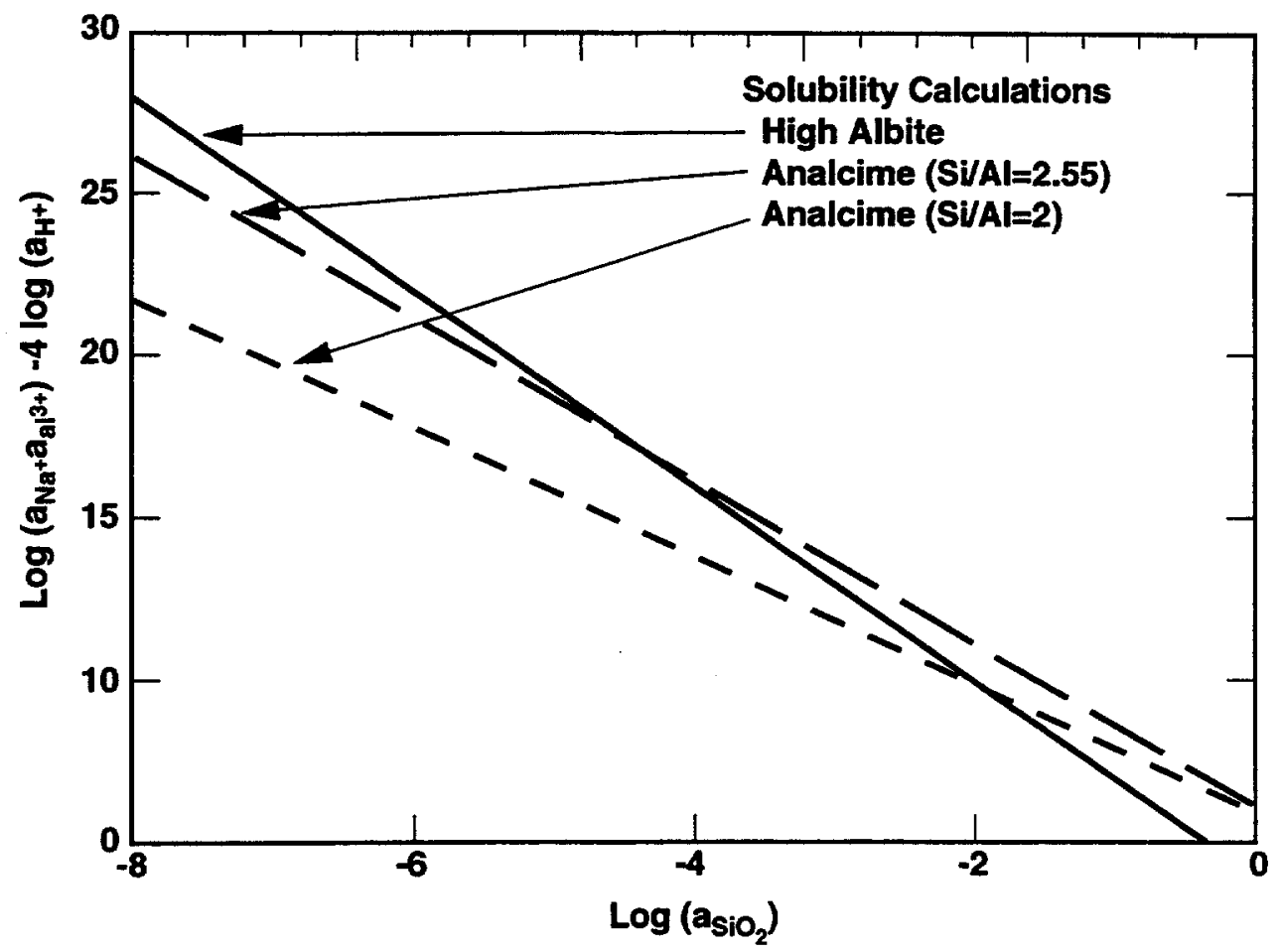

Figure 3.4-35. Solubility of stoichiometric and siliceous analcime (Barnes and Wilkin 1995) compared to the solubility of high albite (EQ3 Com data base). 


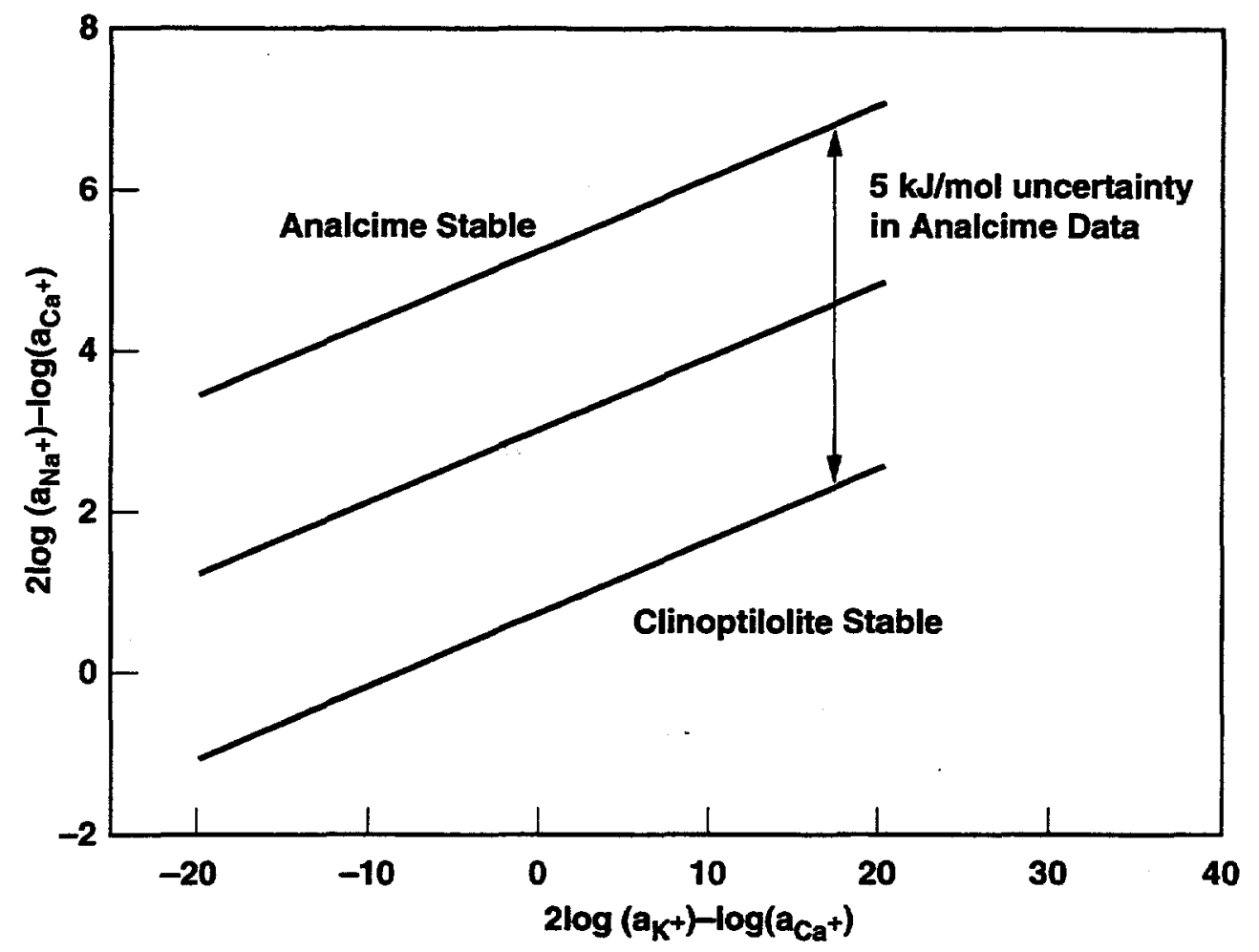

Figure 3.4-36. Reaction of clinoptilolite and analcime, balanced on aluminum, and plotted at cristobalite saturation. The reaction corresponds to Equation 12 of the text and uses the thermodynamic properties of analcime and clinoptilolite shown in Table 3.4-15. 

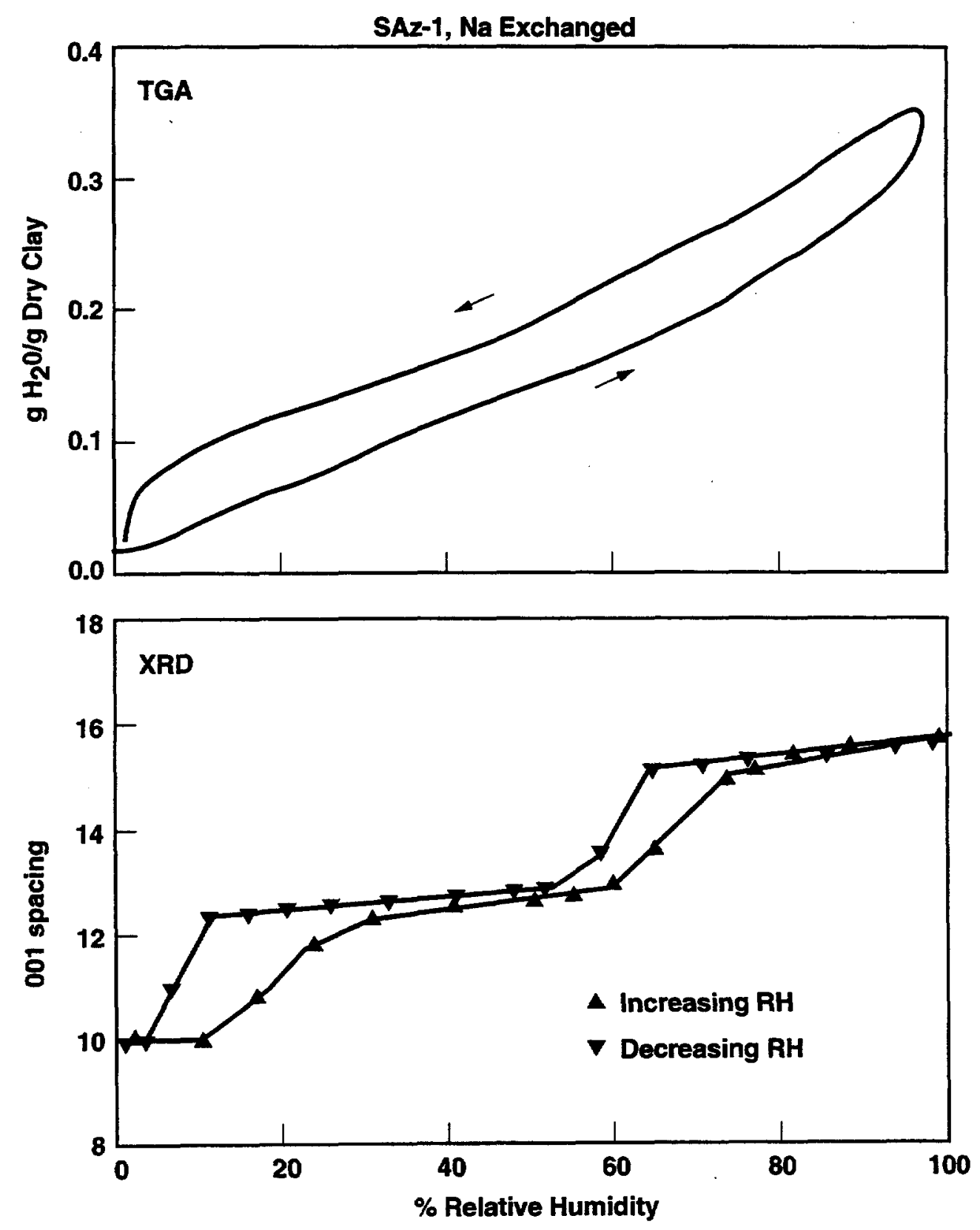

Figure 3.4-37. Hysteresis in Na-exchanged smectite as a function of relative humidity at $25^{\circ} \mathrm{C}$. The $\mathrm{H}_{2} \mathrm{O}$ contents were determined by thermogravimetry and the $001 \mathrm{~d}$-spacings were determined by $\mathrm{X}$-ray diffraction. 
Table 3.4-1. Major constituents of discharge from Wairakei wells WK-28 (sampled on 3/60), WK-72 (sampled on 4/61) and WK81 (sampled on 10/74) (in $\mathbf{m g} / \mathbf{k g}$ ) (from Reyes, Giggenbach and Christenson, 1993).

\begin{tabular}{|c|c|c|c|c|c|c|}
\hline Component & $\begin{array}{c}\text { WK-28 } \\
\text { analyzed }\end{array}$ & $\begin{array}{c}\text { WK-28 } \\
\text { corrected }\end{array}$ & $\begin{array}{c}\text { WK-72 } \\
\text { analyzed }\end{array}$ & $\begin{array}{c}\text { WK-72 } \\
\text { corrected }\end{array}$ & $\begin{array}{c}\text { WK-81 } \\
\text { analyzed }\end{array}$ & $\begin{array}{c}\text { WK-81 } \\
\text { corrected* }\end{array}$ \\
\hline $\mathrm{Na}$ & 1260 & 898 & 1295 & 942 & 1256 & 917 \\
\hline $\mathrm{K}$ & 200 & 142 & 215 & 157 & 182 & 133 \\
\hline $\mathrm{Ca}$ & 16 & 11.4 & 18 & 13 & 22 & 16 \\
\hline $\mathrm{Mg}$ & 0.035 & 0.025 & 0.014 & 0.01 & 0.0035 & 0.0026 \\
\hline $\mathrm{Fe}^{*}$ & NA & $0.6 e-6$ & NA & $0.38 \mathrm{e}-3$ & NA & $0.19 e-2$ \\
\hline $\mathrm{Al}^{* *}$ & NA & 0.27 & NA & 0.26 & 0.37 & 0.27 \\
\hline $\mathbf{R b}$ & NA & NA & NA & NA & 2.52 & 1.8 \\
\hline $\mathrm{Li}$ & 14 & 10 & 12.9 & 9.4 & 11.8 & 8.6 \\
\hline Cs & NA & NA & NA & NA & 2.4 & 1.8 \\
\hline B & 28.2 & 20 & NA & NA & 25.3 & 19 \\
\hline $\mathrm{Cl}$ & 2213 & 1530 & 2241 & 1636 & 2083 & 1587 \\
\hline $\mathrm{HCO}_{3}$ & 48 & 979 & NA & 345 & NA & 41 \\
\hline $\mathrm{SO}_{4}$ & 34 & 24 & $34^{* * 4}$ & 20 & 34 & 25 \\
\hline $\mathrm{H}_{2} \mathrm{~S}^{* * * *}$ & NA & 15 & $\mathrm{NA}$ & 9 & NA & 4 \\
\hline $\mathrm{SiO}_{2}$ & 660 & 470 & 600 & 438 & 612 & 447 \\
\hline $\mathrm{pH}$ & $8.2\left(20^{\circ} \mathrm{C}\right)$ & $6.3\left(246^{\circ} \mathrm{C}\right)$ & $8.3\left(20^{\circ} \mathrm{C}\right)$ & $6.2\left(239^{\circ} \mathrm{C}\right)$ & $7.4\left(20^{\circ} \mathrm{C}\right)$ & $6.1\left(240^{\circ} \mathrm{C}\right)$ \\
\hline $\mathrm{TQA}^{* * * * *}$ & & $246^{\circ} \mathrm{C}$ & & $239^{\circ} \mathrm{C}$ & & $240^{\circ} \mathrm{C}$ \\
\hline
\end{tabular}

* Corrected for steam and gas loss; calculated assuming equilibrium with pyrite at TQA; $\mathrm{Cl}$ adjusted to obtain electrical neutrality

** From analysis of other samples from same wells3

*** From average of other samples from WK-72

**** Analyzed value for all samples assumed to equal $0.3 \mathrm{mg} / \mathrm{kg}$, typical of WK-28 waters.

***** Downhole temperature calculated from the adiabatic quartz geothermometer (TQA) using quartz solubility data from Fournier (1983)4

3 The previous study by Bruton, Glassley and Bourcier (1994) assumed that Al concentration was controlled by equilibrium with K-feldspar.

4 Implications of using data from Fournier (1983) vs. Walther and Helgeson (1977) for quartz solubility are discussed in the text. 
Table 3.4-2. Major chemical components of vapors discharged from Wairakei wells WK-28, 72 and 81 sampled on $3 / 60,5 / 61$ and 11/74, respectively (in $\mu \mathrm{mol} / \mathrm{mol}$ water)

\begin{tabular}{|l|c|c|c|}
\hline Component & WK-28 & WK-72 & WK-81 \\
\hline $\mathrm{CO}_{2}$ & 279 & 102 & 12 \\
\hline $\mathrm{H}_{2} \mathrm{~S}$ & 8 & 4.5 & 1.9 \\
\hline
\end{tabular}

Table 3.4-3. Chemical Compositions of Glass and Secondary Minerals

\begin{tabular}{|c|c|c|c|}
\hline & $\begin{array}{c}\text { GU-3 } \\
1195 C \\
\text { glass }\end{array}$ & $\begin{array}{l}\text { H-5 } 1666 \\
\text { smectite }\end{array}$ & $\begin{array}{r}\text { GU-3 } 1195 \\
\text { heulandite }\end{array}$ \\
\hline \multicolumn{4}{|c|}{ Weight Percent } \\
\hline $\mathrm{SiO}_{2}$ & 74.1 & 43.2 & 64.8 \\
\hline $\mathrm{TiO}_{2}$ & 0.09 & 0.13 & 0.00 \\
\hline $\mathrm{Al}_{2} \mathrm{O}_{3}$ & 12.4 & 21.4 & 12.0 \\
\hline $\mathrm{FeO}$ & 0.82 & 1.57 & n.d.* \\
\hline $\mathrm{MnO}$ & 0.00 & 0.05 & 0.09 \\
\hline $\mathrm{MgO}$ & 0.02 & 0.89 & 0.88 \\
\hline $\mathrm{CaO}$ & 0.19 & 2.48 & 3.84 \\
\hline $\mathrm{BaO}$ & 0.06 & 0.00 & 0.00 \\
\hline $\mathrm{Na}_{2} \mathrm{O}$ & 3.55 & 0.14 & 0.59 \\
\hline $\mathrm{K}_{2} \mathrm{O}$ & 5.77 & 0.15 & 0.78 \\
\hline $\mathrm{H}_{2} \mathrm{O}$ & 3.0 & 30.0 & 17.0 \\
\hline Total & 100.0 & 100.0 & 100.0 \\
\hline \multicolumn{4}{|c|}{ Density $\mathrm{g} / \mathrm{cm}^{3}$} \\
\hline & $2.36 t$ & $2.00 \pm$ & $2.20 \mp$ \\
\hline \multicolumn{4}{|c|}{ Mole/cm ${ }^{3}$} \\
\hline $\mathrm{Si}$ & 0.02904 & 0.01437 & 0.02372 \\
\hline Al & 0.00560 & 0.00840 & 0.00550 \\
\hline $\mathrm{Ca}$ & 0.00008 & 0.00088 & 0.00160 \\
\hline $\mathrm{Na}$ & 0.00270 & 0.00009 & 0.00045 \\
\hline $\mathrm{K}$ & 0.00288 & 0.00006 & 0.00039 \\
\hline
\end{tabular}

*n.d. = not detected

tAnderson (1984)

fDeer et al.(1963) 
Table 3.4-4. X-ray diffraction mineralogy of altered Topopah Spring vitrophyre (weight percent)

\begin{tabular}{|c|c|c|c|c|c|c|c|c|}
\hline Sample & $\begin{array}{l}\text { Depth } \\
\text { (m) }\end{array}$ & $\begin{array}{c}\text { Smec- } \\
\text { tite }\end{array}$ & $\begin{array}{l}\text { Heulan- } \\
\text { dite }\end{array}$ & Quartz & $\begin{array}{c}\text { Cristo- } \\
\text { balite }\end{array}$ & $\begin{array}{c}\text { Alkali } \\
\text { feldspar }\end{array}$ & $\begin{array}{c}\text { Opal- } \\
\text { CT }\end{array}$ & Other \\
\hline \multicolumn{9}{|l|}{ GU-3* } \\
\hline 1195.7 & 364.5 & n.d. $\S$ & $\sim 1$ & $8 \pm 2$ & $22 \pm 3$ & $70 \pm 5$ & n.d. & tracet \\
\hline \multicolumn{9}{|l|}{$G-4^{*}$} \\
\hline 1299 & 395.9 & $2 \pm 1$ & $5 \pm 2$ & $8 \pm 2$ & $23 \pm 4$ & $62 \pm 10$ & n.d. & tracet \\
\hline 1314 & 400.5 & $45 \pm 10$ & $28 \pm 5$ & $2 \pm 1$ & $14 \pm 4$ & $11 \pm 5$ & n.d. & \\
\hline \multicolumn{9}{|l|}{$\mathrm{H}-5$} \\
\hline 1666 & 507.8 & $37 \pm 16$ & $20 \pm 5$ & $3 \pm 1$ & n.d. & $24 \pm 7$ & $15 \pm 7$ & $\sim 0.6 \ddagger$ \\
\hline
\end{tabular}

*From Bish and Chipera (1989).

Sn.d. = not detected.

tmica.

ferionite. Special techniques to detect erionite were used for this sample only (Bish and Chipera , 1991). 
Table 3.4-5. Summary of standard state thermodynamic data for clinoptilolite and heulandite.

\begin{tabular}{|c|c|c|c|c|c|c|c|}
\hline Reference & $\begin{array}{c}\text { Johnson et al. } \\
\text { (1991) }\end{array}$ & $\begin{array}{c}\text { Johnson et al. } \\
(1991)^{*}\end{array}$ & $\begin{array}{c}\text { Hemingway and } \\
\text { Robie (1984) } \\
\end{array}$ & $\begin{array}{c}\text { Murphy et al. } \\
\text { (1996) }\end{array}$ & $\begin{array}{c}\text { Barnes and } \\
\text { Wilkin (1995) }\end{array}$ & $\begin{array}{c}\text { Johnson et al. } \\
\text { (1985) }\end{array}$ & $\begin{array}{c}\text { Johnson et al. } \\
(1985)^{*}\end{array}$ \\
\hline Sample & $\begin{array}{l}\text { Malheur, OR } \\
\text { clinoptilolite }\end{array}$ & $\begin{array}{l}\text { Malheur, OR } \\
\text { clinoptilolite }\end{array}$ & $\begin{array}{c}\text { Mojave county, } \\
\text { AZ } \\
\text { clinoptilolite }\end{array}$ & $\begin{array}{l}\text { Death Valley } \\
\text { Junction, CA } \\
\text { clinoptilolite }\end{array}$ & $\begin{array}{l}\text { Castle Creek, ID } \\
\text { clinoptilolite }\end{array}$ & $\begin{array}{c}\text { Gunnadah, } \\
\text { Australia, } \\
\text { heulandite }\end{array}$ & $\begin{array}{c}\text { ref. state } \\
\text { modified } \\
\text { heulandite }\end{array}$ \\
\hline Study type & Calorimetric & Calorimetric & Calorimetric & Solubility & Solubility & Calorimetric & Calorimetric \\
\hline $\mathrm{Na}(72 \mathrm{O})$ & 1.908 & & 0.56 & 5.412 & 6.36 & 1.532 & \\
\hline K & 1.086 & & 0.98 & 0.369 & 0.18 & 0.528 & \\
\hline $\mathrm{Ca}$ & 1.522 & & 1.50 & 0.009 & 0 & 2.34 & \\
\hline Mg & 0.248 & & 1.23 & 0.105 & $\mathbf{0}$ & 0 & \\
\hline Mn & 0.004 & & & $\mathbf{0}$ & $\mathbf{0}$ & $\mathbf{0}$ & \\
\hline $\mathbf{B a}$ & 0.124 & & & $\mathbf{0}$ & 0 & 0.26 & \\
\hline $\mathrm{Sr}$ & 0.072 & & & $\mathbf{0}$ & $\mathbf{0}$ & 0.7 & \\
\hline $\mathrm{Fe}$ & 0.034 & & 0.3 & 0.132 & $\mathbf{0}$ & 0 & \\
\hline Al & 6.900 & & 6.7 & 5.841 & 6.6 & 8.66 & \\
\hline Si & 29.066 & & 29 & 30 & 29.4 & 27.34 & \\
\hline 0 & 72 & & 72 & 72 & 72 & 72 & \\
\hline $\mathrm{H}_{2} \mathrm{O}$ & 21.844 & & 22 & 22.29 & 21 & 24 & \\
\hline $\mathrm{Si} / \mathrm{Al}$ & 4.21 & & 4.33 & 5.14 & 4.45 & 3.16 & \\
\hline$\Delta \mathrm{G}_{\mathrm{f}} \mathrm{kJ} / \mathrm{mol}$ & -38156.8 & -38042.4 & & -38124 & -37506 & -39228 & -39114 \\
\hline$\Delta \mathrm{H}_{\mathrm{f}} \mathrm{kJ} / \mathrm{mol}$ & -41290 & -41176 & & & -40646 & -42490 & -42376 \\
\hline $\mathrm{S}^{\circ} \mathrm{J} / \mathrm{mol}-\mathrm{K}$ & 2966.10 & 2966.10 & 2872.3 & & 2830.32 & 3068.72 & 3068.72 \\
\hline high $\mathrm{T}$ data** & yes & & no & mo & yes & & yes \\
\hline
\end{tabular}

*These values have been corrected back to a reference state based on quartz (cf. Johnson et al., 1992 and discussion in the section on analcime). **Indicates whether data at temperatures above $250 \mathrm{C}$ were collected. 
Table 3.4-6. Gibbs free energy of formation of $\mathrm{Na}$ clinoptilolite determined by solubility measurements (Barnes and Wilkin, 1995).

\begin{tabular}{cc}
\hline $\begin{array}{c}\text { Temperature } \\
\left({ }^{\circ} \mathrm{C}\right)\end{array}$ & $\begin{array}{c}\Delta \mathrm{G}_{\mathrm{f}}{ }^{\circ} \\
\mathbf{k J} / \mathbf{m o l}\end{array}$ \\
\hline 25 & -37577.4 \\
50 & -37282.8 \\
80 & -36958.2 \\
90 & -36785.4 \\
100 & -36633.0 \\
125 & -36375.6 \\
175 & -35910.0 \\
200 & -35679.0 \\
225 & -35404.8 \\
265 & -35031.0 \\
\hline
\end{tabular}

Table 3.4-7. Calculated Gibbs free energies of formation of end-member clinoptilolite.

\begin{tabular}{ccc}
\hline & $\begin{array}{c}\Delta \mathbf{G} \text { binary } \\
\text { exchange for Na } \\
\text { J/mol }\end{array}$ & $\begin{array}{c}\Delta \mathbf{G}_{\mathbf{f}} \\
\mathbf{k J} / \mathbf{m o l}\end{array}$ \\
\hline Na-clinoptilolite & 0 & -37506 \\
K-clinoptilolite & -7980 & -37688 \\
Ca-clinoptilolite & -925 & -37604 \\
Sr-clinoptilolite & -1371 & -37624 \\
\hline
\end{tabular}


Table 3.4-8. Standard-state values for the thermodynamics of hydration in cationexchanged clinoptilolite with errors derived from regression analysis. The values (except entropy) are used in Equation 4.

\begin{tabular}{lcccccc}
\hline \multicolumn{1}{c}{ Parameter* } & \multicolumn{2}{c}{ Ca-Exchanged } & \multicolumn{2}{c}{ Na-Exchanged } & \multicolumn{2}{c}{ K-Exchanged } \\
\hline & Value & std error & Value & std error & Value & std error \\
$\Delta \mu_{H y}^{o}(\sigma / \mathrm{mol})$ & -79685 & 2414 & -55080 & 3273 & -48949.2 & 1171 \\
$\Delta \boldsymbol{H}_{H y}^{o}(\mathrm{~J} / \mathrm{mol})$ & -120477 & 2232 & -99593 & 2910 & -91183 & 1031 \\
$\Delta \boldsymbol{S}_{H y}^{\circ}(\sigma / \mathrm{mol} / \mathrm{K})$ & -136.82 & 3.08 & -149.30 & 5.03 & -141.65 & 1.86 \\
$\mathrm{~W}_{1}(\mathrm{~J} / \mathrm{mol})$ & 137070 & 3332 & 72214 & 34123 & 74649 & 1277 \\
$\mathrm{~W}_{2}(\mathrm{~J} / \mathrm{mol})$ & -74935 & 2129 & -32111 & 2248 & -41726 & 920 \\
\hline
\end{tabular}

*Excess significant figures are retained for calculations.

Table 3.4-9. Molar values of the thermodynamics of hydration for cationexchanged clinoptilolite determined in this study compared with values measured in clinoptilolite, other zeolites, and $\mathrm{H}_{2} \mathrm{O}$.

\begin{tabular}{lccc}
\hline Material & $\Delta \tilde{G}_{H y}\left(\mathbf{k J} / \mathrm{mol}^{\left.-\mathrm{H}_{2} \mathrm{O}\right)}\right.$ & $\Delta \tilde{H}_{H y}\left(\mathbf{k J} / \mathrm{mol}^{\left.-\mathrm{H}_{2} \mathrm{O}\right)}\right.$ & $\Delta \tilde{S}_{H y}\left(\mathrm{~J} / \mathbf{m o l}-\mathrm{H}_{2} \mathrm{O} / \mathrm{K}\right)$ \\
\hline${\mathrm{Ca}-\mathrm{Cpt}^{1}}^{1}$ & $-36.13 \pm 3.02$ & $-76.92 \pm 2.88$ & $-136.8 \pm 3.1$ \\
$\mathrm{Na}-\mathrm{Cpt}^{1}$ & $-29.68 \pm 3.77$ & $-74.19 \pm 3.46$ & $-149.3 \pm 5.0$ \\
${\mathrm{~K}-\mathrm{Cpt}^{1}}^{1}$ & $-25.53 \pm 1.37$ & $-67.78 \pm 1.25$ & $-141.7 \pm 1.9$ \\
Sodic-Cpt $^{2}$ & n.d. & -65.5 & n.d. \\
${\mathrm{Na}-\mathrm{Cpt}^{3}}^{3}$ & n.d. & -66.1 & n.d. \\
$\mathrm{H}_{2} \mathrm{O}^{4}$ & -8.57 & -44.02 & -118.9 \\
Cordierite $^{5}$ & -9.5 & -41.8 & -108.2 \\
Analcime $^{6}$ & -44.9 & -84.9 & -133.8 \\
Mordenite $^{7}$ & -33.5 & -73.8 & -134.8
\end{tabular}

${ }^{1}$ This study. Uncertainties are derived from the standard errors of the egression coefficients.

2Johnson et al. (1991) adiabatic and solution calorimetry.

3Barrer and Cram (1971) immersion calorimetry.

${ }^{4}$ Robie et al. (1979) condensation of water vapor.

${ }^{5}$ Carey (1995) phase equilibria.

6Johnson et al. (1982) adiabatic and solution calorimetry.

7Johnson et al. (1992) adiabatic and solution calorimetry. 
Table 3.4-10. Parameters for the calculation of the partial and integral molar enthalpy of hydration from calorimetric data (cal). Also included are the less accurate values derived from the thermogravimetric experiments (TGA).

\begin{tabular}{ccccc}
\hline Clinoptilolite & $\begin{array}{c}\Delta H_{H y}^{\circ} \\
\mathrm{J} / \mathrm{mol}\end{array}$ & $\begin{array}{c}\mathrm{W}_{\mathbf{1}} \\
\mathrm{J} / \mathrm{mol}\end{array}$ & $\begin{array}{c}\mathrm{W}_{\mathbf{2}} \\
\mathrm{J} / \mathrm{mol}\end{array}$ & $\begin{array}{c}\Delta H_{H y} \\
\mathbf{k J} / \mathbf{m o l}\end{array}$ \\
\hline $\mathrm{Ca}$ (Cal) & -95274 & 34169 & 14400 & -73.4 \\
$\mathrm{Na}$ (Cal) & -94760 & 66112 & -19468 & -68.2 \\
$\mathrm{~K}$ (Cal) & -99161 & 100460 & -52575 & -66.5 \\
$\mathrm{Ca}$ (TGA) & -120477 & 1370706 & -74935 & -76.9 \\
$\mathrm{Na}$ (TGA) & -99593 & 72214 & -32111 & -74.2 \\
$\mathrm{~K}$ (TGA) & -91183 & 74649 & -41726 & -67.8 \\
\hline
\end{tabular}

Table 3.4-11. Standard-state Gibbs free energy of formation of analcime from the elements determined from calorimetric and solubility measurements.

\begin{tabular}{|c|c|c|c|c|}
\hline Sample & Si/Al Ratio & $\begin{array}{c}\Delta \mathbf{G}_{\mathbf{f}} \\
\mathbf{k J} / \mathbf{m o l}\end{array}$ & $\begin{array}{c}\text { Uncertainty } \\
\mathrm{kJ} / \mathrm{mol}\end{array}$ & Reference \\
\hline Mt. St. Hilaire & 1.94 & -3085.4 & 5 & Murphy et al. (1996) \\
\hline Table Mountain & 2 & -3091.73 & 3.682 & Robie et al. (1979) \\
\hline Mt. St. Hilaire & 2 & $-3090^{*}$ & 5 & Barnes and Wilkin (1995) \\
\hline Mt. St. Hilaire & 2 & $-3105.3^{* *}$ & 5 & Barnes and Wilkin (1995) \\
\hline Skookumchuck & 2.125 & -3077.2 & 3.3 & Johnson et al. (1982) \\
\hline Skookumchuck & 2.125 & $-3086.1^{+}$ & 3.3 & Johnson et al. (1982) \\
\hline Wikieup & 2.55 & -3036 & 5 & Barnes and Wilkin (1995) \\
\hline
\end{tabular}

*Value obtained by linear regression from 50 to $300^{\circ} \mathrm{C}$

**Actual value measured at $25^{\circ} \mathrm{C}$ (Barnes and Wilkin, 1995).

'Revised value (Johnson et al., 1992). 
Table 3.4-12. Standard-state thermodynamic properties of analcime derived from phase equilibria constraints or by polyhedral estimation techniques.

\begin{tabular}{lccl}
\hline \multicolumn{1}{c}{ Sample } & Si/Al Ratio & $\begin{array}{c}\Delta \mathbf{G}_{\mathbf{f}} \\
\mathbf{k J} / \mathbf{m o l}\end{array}$ & \multicolumn{1}{c}{ Reference } \\
\hline Phase equilibria studies & 2 & -3088.22 & Helgeson et al. (1978) \\
Arbitrary composition & 2 & -3093.77 & Chipera et al. (1995a) \\
Arbitrary composition & 2.75 & -3037.5 & Chipera et al. (1995a) \\
Arbitrary composition & 2 & -3099.72 & Chermak and Rimstidt (1989) \\
Arbitrary composition & 2.75 & -3040.1 & Chermak and Rimstidt (1989) \\
\hline
\end{tabular}

Table 3.4-13. Gibbs free energy of formation $(\mathrm{kJ} / \mathrm{mol})$ of analcime determined from solubility data by Barnes and Wilkin (1995). Predicted values from linear regression

\begin{tabular}{ccccc}
\hline Temperature $\left(^{\circ} \mathrm{C}\right)$ & $\begin{array}{c}\text { Mt. St. } \\
\text { Hilaire* }\end{array}$ & Predicted & Wikieup** & Predicted \\
\hline 25 & -3105.3 & -3089.95 & & -3035.82 \\
50 & -3080.5 & -3071.31 & & -3017.49 \\
80 & -3048.1 & -3048.95 & & -2995.5 \\
90 & -3036.2 & -3041.49 & -2989 & -2988.17 \\
125 & -3010.4 & -3015.4 & -2961.7 & -2962.5 \\
175 & -2977.5 & -2978.13 & -2925.2 & -2925.84 \\
225 & -2939.8 & -2940.86 & -2889.8 & -2889.19 \\
275 & -2905 & -2903.59 & & -2852.53 \\
300 & -2887.2 & -2884.96 & & -2834.2 \\
\hline
\end{tabular}

${ }^{*} \mathrm{Na}_{0.99} \mathrm{AlSi}_{2} \mathrm{O}_{6} \cdot \mathrm{H}_{2} \mathrm{O}$ (minor $\mathrm{K}$ ignored).

** $\mathrm{Na}_{0.86} \mathrm{Al}_{0.84} \mathrm{Si}_{2.14} \mathrm{O}_{6} \cdot \mathrm{H}_{2} \mathrm{O}$ (minor $\mathrm{K}, \mathrm{Ca}, \mathrm{Mg}$ ignored).

Table 3.4-14. Enthalpy of formation and standard-state entropy of analcime derived by linear regression of the solubility data of Barnes and Wilkin (1995). Johnson et al.'s (1982) data on Mt. St. Hilaire analcime are shown for comparison.

\begin{tabular}{lccc}
\hline & Mt. St. Hilaire & Wikieup & Johnson et al. (1982) \\
\hline$\Delta \mathrm{H}_{\mathrm{f}} \mathrm{kJ} / \mathrm{mol}$ & -3312.19 & -3254.42 & -3296.9 \\
$\mathrm{~S}^{\circ} \mathrm{J} / \mathrm{mol}-\mathrm{K}$ & 220.05 & 223.71 & 226.75 \\
\hline
\end{tabular}


Table 3.4-15. Thermodynamic data estimated using representative chemical formulae for Yucca Mountain zeolites.

\begin{tabular}{|c|c|c|c|c|c|c|c|c|}
\hline Mineral and Representative Formula & $\begin{array}{c}\Delta G_{f} \\
\left(\mathbf{k} / \mathrm{mol}^{\prime}\right)\end{array}$ & $\begin{array}{c}\Delta H_{\mathbf{f}} \\
(\mathrm{kJ} / \mathrm{mol})\end{array}$ & $\begin{array}{c}\mathrm{S}^{\circ} \\
(\mathrm{J} / \mathrm{mol} \bullet \mathrm{K})\end{array}$ & $\begin{array}{c}\text { Volume } \\
\left(\mathrm{cm}^{3} / \mathrm{mol}\right)\end{array}$ & $\begin{array}{r}\mathbf{k} 0 \\
\times 100 \\
\end{array}$ & $\begin{array}{r}\mathbf{k} 1 \\
\times 10^{-2} \\
\end{array}$ & $\begin{array}{r}\mathbf{k 2} \\
\times 10^{-5} \\
\end{array}$ & $\begin{array}{r}\mathbf{k} 3 \\
\times 10^{-7} \\
\end{array}$ \\
\hline
\end{tabular}

Analcime (Broxton et al., 1986)

$\mathrm{Na}_{0.8} \mathrm{Al}_{0.8} \mathrm{Si}_{2.2} \mathrm{O}_{6} \cdot 1.0 \mathrm{H}_{2} \mathrm{O}$
Chabazite (Gottardi and Galli, 1985)

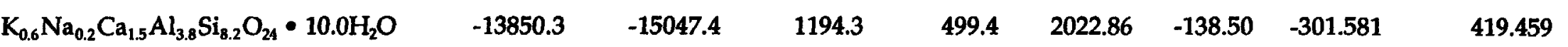

Clinoptilolit (Broxton et al., 1986)

e

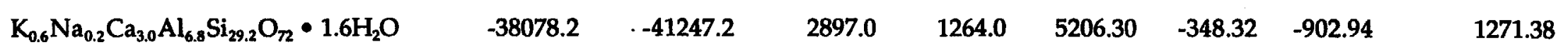

Erionite Approximated from USW UZ-14 1364 data

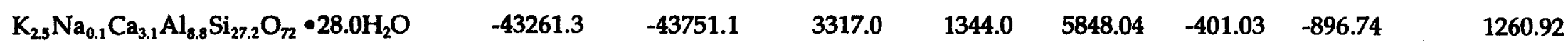

Erionite USW H-5 1666 (Levy, 1984b)

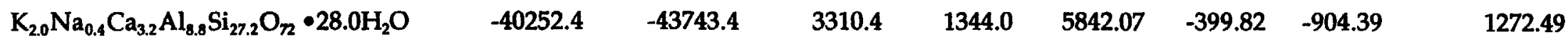

Heulandite USW UZ-14 1364

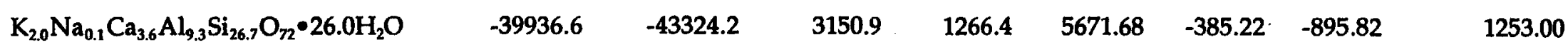

Heulandite USW H-5 1666 (Levy, 1984b)

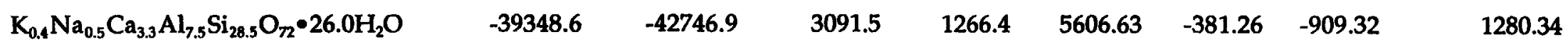

Heulandite USW G-2 1488 "prismatic" (Carlos et al., 1995b)

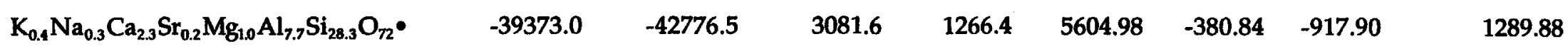
$26.0 \mathrm{H}_{2} \mathrm{O}$ 
Table 3.4-15: continued.

\begin{tabular}{|c|c|c|c|c|c|c|c|c|}
\hline \multicolumn{9}{|c|}{ Heulandite USW G-2 1505 "prismatic" (Carlos et al., 1995b) } \\
\hline $\mathrm{K}_{0.5} \mathrm{Na}_{0.3} \mathrm{Ca}_{2.5} \mathrm{Sr}_{0.2} \mathrm{Mg}_{0.8} \mathrm{Al}_{7.8} \mathrm{Si}_{28.2} \mathrm{O}_{72} \cdot 26.0$ & -39413.9 & -42815.8 & 3087.3 & 1266.4 & 5609.67 & -381.20 & -914.91 & 1285.32 \\
\hline \multicolumn{9}{|l|}{$\mathrm{H}_{2} \mathrm{O}$} \\
\hline \multicolumn{9}{|c|}{ Heulandite UE-25a\#1 1243 "tabular core" (Carlos et al., 1995c) } \\
\hline $\mathrm{K}_{0.2} \mathrm{Na}_{0.5} \mathrm{Ca}_{2.8} \mathrm{Sr}_{0.7} \mathrm{Mg}_{0.1} \mathrm{Al}_{7.9} \mathrm{Si}_{28.1} \mathrm{O}_{72} \cdot 26.0$ & -39364.4 & -42771.6 & 3069.6 & 1266.4 & 5609.98 & -381.02 & -909.99 & 1277.85 \\
\hline \multicolumn{9}{|l|}{$\mathrm{H}_{2} \mathrm{O}$} \\
\hline \multicolumn{9}{|c|}{ Heulandite UE-25a\#1 1243 "tabular rim \& prismatic" (Carlos et al., 1995c) } \\
\hline $\mathrm{K}_{0.1} \mathrm{Na}_{0.2} \mathrm{Ca}_{2.3} \mathrm{Sr}_{0.2} \mathrm{Mg}_{12} \mathrm{Al}_{7.7} \mathrm{Si}_{28.3} \mathrm{O}_{72} \cdot 26.0$ & -39469.8 & -42869.2 & 3091.0 & 1266.4 & 5596.09 & -380.29 & -918.16 & 1287.96 \\
\hline \multicolumn{9}{|l|}{$\mathrm{H}_{2} \mathrm{O}$} \\
\hline \multicolumn{9}{|l|}{ Laumontite (Gottardi and Galli, 1985) } \\
\hline $\mathrm{K}_{0.2} \mathrm{Na}_{0.2} \mathrm{Ca}_{1.8} \mathrm{Al}_{4} \mathrm{Si}_{8} \mathrm{O}_{24} \cdot 8.0 \mathrm{H}_{2} \mathrm{O}$ & -13431.2 & -14525.9 & 1011.2 & 406.4 & 1842.70 & -122.73 & -301.22 & 414.72 \\
\hline \multicolumn{9}{|c|}{ Mordenite (Carlos, 1987; Broxton et al., 1987; Sheppard et al., 1988) } \\
\hline $\mathrm{K}_{0.3} \mathrm{Na}_{0.7} \mathrm{Ca}_{0.5} \mathrm{Al}_{2} \mathrm{Si}_{10} \mathrm{O}_{24} \cdot 7.3 \mathrm{H}_{2} \mathrm{O}$ & -12621.0 & -13677.6 & 986.1 & 424.5 & 1752.07 & -116.17 & -317.63 & 456.08 \\
\hline \multicolumn{9}{|c|}{ Phillipsite USW GU-3 1200.1 (Carlos et al., 1995b) } \\
\hline $\mathrm{K}_{0.7} \mathrm{Na}_{0.7} \mathrm{Ca}_{1.1} \mathrm{Al}_{3.6} \mathrm{Si}_{12.4} \mathrm{O}_{32} \cdot 12.6 \mathrm{H}_{2} \mathrm{O}$ & -17817.7 & -19375.1 & 1491.9 & 609.2 & 2608.70 & -177.81 & -415.85 & 591.77 \\
\hline \multicolumn{9}{|c|}{ Stellerite USW G-2 1488.5 and 1505 (Carlos et al., 1995b) } \\
\hline $\mathrm{Ca}_{3.9} \mathrm{Na}_{0.1} \mathrm{Al}_{7.9} \mathrm{Si}_{28.1} \mathrm{O}_{72} \cdot 28.0 \mathrm{H}_{2} \mathrm{O}$ & -39960.1 & -43468.5 & 3224.3 & 1331.0 & 5774.01 & -396.39 & -898.38 & 1257.38 \\
\hline $\begin{array}{l}1 \text { Gibbs free energies and enthalpies of fo } \\
2 \text { Entropies of formation were estimated } \\
3 \text { Volumes from Smyth and Bish (1988). } \\
4 \text { Heat capacity terms (k) estimated using }\end{array}$ & $\begin{array}{l}\text { mation wer } \\
\text { sing Hollan } \\
\text { Berman and }\end{array}$ & $\begin{array}{l}\text { stimated } \\
\text { 1989). }\end{array}$ & & & & & & \\
\hline
\end{tabular}


Table 3.4-16. Summary of $25^{\circ} \mathrm{C}$ dissolution rate constants for minerals.

\begin{tabular}{|c|c|c|c|}
\hline Mineral & $\log k_{\text {diss }} *$ & $\begin{array}{l}\text { Log K normalized to } 2 \\
\text { structural oxygen }\end{array}$ & $\begin{array}{c}\text { Molar Volume } \\
\text { (cc/mole) }\end{array}$ \\
\hline analcime $e^{* *}$ & -11 & -11.48 & 97.1 \\
\hline gibbsite & -11.45 & -11.63 & 31.956 \\
\hline sanidine & -12 & -12.60 & 109.008 \\
\hline albite & -12.26 & -12.86 & 100.07 \\
\hline prehnite & -12.41 & -13.19 & 140.33 \\
\hline microcline & -12.50 & -13.10 & 108.741 \\
\hline epidote & -12.61 & -13.42 & 139.2 \\
\hline Na-clinoptilolite ${ }^{* *}$ & -13.15 & -14.23 & 420.87 \\
\hline amorphous silica ${ }^{+}$ & -12.2 & -12.20 & 29 \\
\hline$\beta$-cristobalite ${ }^{+}$ & -12.34 & -12.34 & 27.38 \\
\hline muscovite & -13.07 & -13.85 & 140.71 \\
\hline kaolinite & -13.28 & -13.93 & 99.52 \\
\hline$\alpha$-cristobalite ${ }^{+}$ & -12.77 & -12.77 & 25.74 \\
\hline quartz & -13.39 & -13.39 & 22.688 \\
\hline Na-clinoptilolite ${ }^{\ddagger}$ & -15.623 & -17.18 & 1262.6 \\
\hline
\end{tabular}

" $k_{\text {diss }}$ in moles $/ \mathrm{m}^{2}-\mathrm{s}$

All values from Lasaga et al. (1994b) except as noted.

**Murphy et al. (1996)

Timstidt and Barnes (1980)

MacInnis et al. (1995) 



\section{.}




\section{Contents}

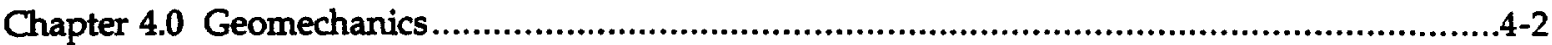

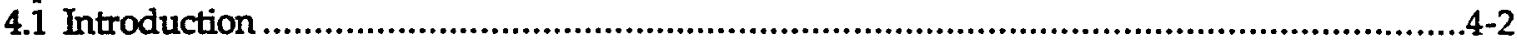

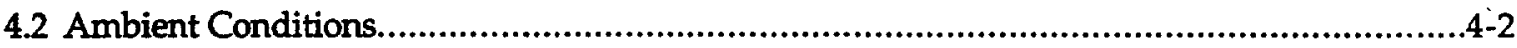

4.2.1 Physical, Thermal, and Mechanical Properties of Rock Mass and Intact Rock.............4-2

4.2.2 Temperature and Stress ...................................................................................4-7

4.3 Processes That Perturb the Waste Package Environment ............................................4-10

4.3.1 Excavation of the Repository.........................................................................4-10

4.3.2 Thermal Effects of Waste Emplacement.................................................................4-11

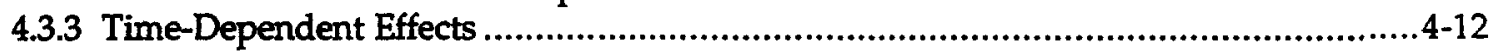

4.3.4 Radiation Effects of Waste Emplacement..........................................................4-14

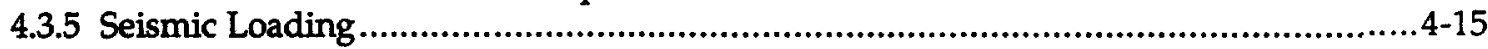

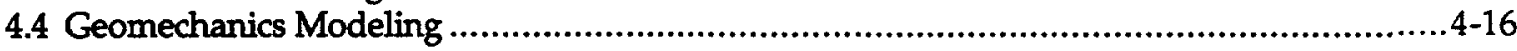

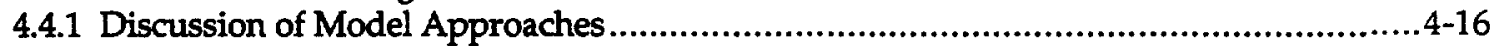

4.4.2 Applications to the Near Field Environment at Yucca Mountain .............................4-19

4.5 References....................................................................................................... $4-21$ 


\title{
Chapter 4.0 Geomechanics
}

\author{
Stephen C. Blair \\ Patricia A. Berge
}

\subsection{Introduction}

Information on the geomechanical characteristics of the near-field environment (NFE) is needed for design of the waste package (WP) and engineered barrier system (EBS) and for the assessment of their performance over the lifetime of the repository. Specifically, information is needed on (1) the amount and type of rockinduced loading that might be expected on the waste package, (2) the geomechanical properties of rock in the NFE and how they will change over time, and (3) any coupling of changing geomechanical properties to other near-field properties (e.g., geochemical or hydrologic). Two types of rock-induced loading need to be considered: impact loads and static loads. Impact loads may be caused by the sudden movement of blocks of rock along pre-existing fractures, or by sudden spalling of excavation walls. The WP must be able to withstand the maximum expected impact load without damage. Static loads may result from spalling or sloughing of rock chips from the drift walls, or from slow movement of rock blocks. Static loads provide contact between the rock and the Waste Package, transport pathways into the wall rock, and sites for surface corrosion of the WP. The WP and EBS must be designed to accommodate the expected static loads and still meet the performance objectives over the lifetime of the repository.

Changes in the mechanical properties of the near-field rock over time are also very important. Several processes including creep, microfracturing, radiation damage, and others could contribute to changes in hydrologic and geochemical processes that affect transport. Information on the geomechanical properties of nearfield rock away from excavations is also needed to assess the transport properties of the NFE over time.

\subsection{Ambient Conditions}

\subsubsection{Physical, Thermal, and Mechanical Properties of Rock Mass and Intact Rock}

The most effective way to determine the ambient physical, thermal and mechanical properties of the rock mass forming the NFE is to tunnel into the rock mass, observe composition and fracture distributions, take samples of the rock for laboratory testing, and perform in situ tests of the thermal-hydrologic-mechanicalchemical (THMC) performance. At the time of writing of this report a tunnel boring machine (TBM) is creating a tunnel through the potential repository horizon, a thermal testing alcove is under construction, and rock samples obtained from the tunnel are being tested in various laboratory facilities. In addition, a series of boreholes has been drilled into the potential repository horizon, and these holes 
have been logged and samples from them have been tested and characterized in several ways. The ESF operations and studies of associated boreholes have produced a significant amount of new data describing the properties of the ESF. However, because the studies at the ESF are ongoing at this time of writing, the ESF data presented here are subject to frequent revision, and the reader is cautioned to check for updates to the data base.

An extensive series of laboratory tests on core samples obtained from boreholes that intersect the potential repository horizon has been done over a period of several years. The results of these tests have been compiled in the Yucca Mountain Project Reference Information Base (RIB) (DOE, 1994). It is important to note that the values presented in the $R I B$ are subject to frequent revision and that references for some of the values in the $R I B$ are not readily available. Consequently, an evaluation of the significance of differences between values reported in the RIB and published values cannot be made at this time.

4.2.1.1 Physical Properties. Physical properties including porosity, grain density, bulk density at in situ saturation, and dry bulk density have been determined from core samples and values for these parameters are given in Table 4-1. These values were obtained from a statistical analysis of available data and can be found in chapter 1, sections 1.1321 and 1.1325 of the RIB; additional data can be found in Price et al. (1985), Martin et al. (1994), and Roberts and Lin (1995).

4.2.1.2 Thermal Properties. Thermal properties of the repository horizon are presented in Tables 4-1, 4-2, and 4-3. The values for matrix and in situ thermal conductivity in Table 4-1 are from Nimick (1990) and reflect the values from the $R I B$. The coefficient of thermal expansion for welded tuff is determined by the tuff's mineralogy (as reflected in matrix conductivity), matrix porosity, matrix saturation, and fracture porosity.

Measurements of linear thermal expansion have been made on samples from the Topopah Spring welded unit, lithophysae-poor layer (TSw2) and Table 4-2 presents the coefficients of linear thermal expansion. These coefficients are the tabulated results of a statistical analysis of thermal expansion data and can also be found in Chapter 1, section 1.1326 of the RIB. The values represent coefficients of linear thermal expansion during heating, and the coefficients shown for the intact rock should be used for calculations that do not involve very near-field regions. Coefficients of linear thermal expansion during heating for very near-field regions are also shown and apply only to welded, devitrified tuffs that are near or at a free surface and are in an essentially unconfined initial-stress state. Table 4-2 gives the mean coefficient of linear thermal expansion $(\bar{\propto})$; the standard deviation of the sample group ( $s$ ); and the number of samples analyzed $(n)$. Note that these coefficients should not be used for calculations of displacements or stresses during cooling; thermal expansion behavior is hysteretic and depends on the maximum temperature reached by the material. Coefficients of linear thermal expansion $(\bar{c})$ are assumed to be identical for both intact rock and the rock mass. This assumption will be evaluated during the underground heater tests that are currently planned to be conducted in the ESF. 
Unconfined thermal expansion measurements on silicate rocks generally show an increase in the expansion coefficient as temperature increases. This is thought to result from a mismatch between the expansion coefficient of constituent grains, which results in local distortions and the formation of new microcracks in an uncracked material or in the shear-related opening of pre-existing microcracks (Cooper and Simmons, 1977). The presence of a mineral, such as cristobalite, that undergoes a phase transformation at a temperature of about $230^{\circ} \mathrm{C}\left( \pm 20^{\circ} \mathrm{C}\right)$ (Meike and Glassley, 1990) with an accompanying 5\% increase in volume (Cohen and Klement, 1975), will also cause thermal expansion to vary with temperature. The $\mathrm{SiO}_{2}$ polymorphs cristobalite and tridymite make up as much as $30 \%$ by volume of Topopah Spring tuff groundmass in some parts of the formation (Connolly, 1991, 1994). However, the volume of rock expected to be heated above $200^{\circ} \mathrm{C}$ is a small percentage of the total rock mass.

Martin et al. (1996) conducted thermal expansion measurements as a function of confining pressure and at temperatures to $250^{\circ} \mathrm{C}$ on core samples of Topopah Spring tuff. These authors found that the coefficient of thermal expansion for welded tuff increased with temperature. At temperatures below $100^{\circ} \mathrm{C}$ the value of this parameter was in the range 7.7 to $10.8 \times 10^{-6}{ }^{\circ} \mathrm{C}^{-1}$, and as temperature was increased to near $250^{\circ} \mathrm{C}$, values of the coefficient of thermal expansion increased to between 14.2 and $20.6 \times 10^{-6}{ }^{\circ} \mathrm{C}^{-1}$. These authors found that confining pressure had a small effect of the coefficient of thermal expansion.

Thermal capacitance has also been estimated for the Topopah Spring welded unit, lithophysae-poor layer (TSw2) for various temperatures, and the values listed in Table 4-3 are reported in section 1.1326 of the RIB. This value incorporates an estimate of rock-heat capacity based on bulk chemical analyses of the rock, the effects of the transformation of the minerals tridymite and cristobalite, the boiling of pore water, and the decrease in saturation of pore water as temperature is increased from 95 to $115^{\circ} \mathrm{C}$. Figure 4-1 is taken from the RIB and shows thermal capacitance in more detail. This figure plots values computed from a series of equations presented in section 1.1326 of the RIB for thermal capacitance of unit TSw2.

\subsubsection{Mechanical Properties. To properly characterize the mechanical} behavior of the NFE it is necessary to know the mechanical properties of the rock mass forming the NFE. The mechanical properties of a rock mass are difficult to measure directly and depend on the properties of both the intact rock and the fractures making up the rock mass.

The mechanical properties for intact rock of the potential repository horizon have been extensively studied via tests on core samples (Martin et al., 1995a, 1994, Price et al., 1987; Price, 1983; Price and Jones, 1982; Price, 1986; and Nimick et al., 1987). Mechanical properties for TSw2 have been analyzed statistically; the results of the statistical analysis are included in section 1.322 of the RIB and are summarized here in Table 4-4. Recent measurements of mechanical properties such as ultimate strength and elastic moduli for tuff by Teufel and McNamee (1991) and Martin et al. (1993, 1994, 1995a) are in general agreement with the values given in Table 4-4. Lin et al. (1993b) used information about intact rock mass properties and fracture/joint characteristics to develop models of rock mass properties and rock mass qualities. 
The mechanical data indicate that the intact rock is quite strong with a uniaxial strength of $155 \mathrm{MPa}( \pm 59 \mathrm{MPa}$ ) and a high deformation modulus. Uncracked samples have stress-strain curves that show nearly linearly elastic behavior until failure. Samples with cracks exhibit nonlinear stress-strain behavior as expected when stress is above $50 \%$ of the failure stress. Typical stress-strain curves for 50.8mm-diam saturated samples are shown in Fig. 4-2.

Martin et al. (1993, 1994, 1995a) measured unconfined compressive strength, static Young's modulus and Poisson's ratio, and elastic wave velocities for Topopah Spring tuff samples from Busted Butte and from the USW NRG-6 and USW NRG7/7A boreholes at Yucca Mountain. These holes intersected the path of the north ramp of the Exploratory Studies Facility (ESF) and are part of a series of holes identified as the North Ramp Geotechnical (NRG) holes. All measurements were made at ambient temperature conditions. They also made confined compressive strength and indirect tensile strength measurements for the samples from the boreholes. The unconfined compressive strength and static Young's modulus and Poisson's ratio values that they found showed more scatter than the results reported in the RIB, and some of the values were much lower than corresponding $R I B$ results. The Topopah Spring tuff samples are apparently quite heterogeneous, representing a wide range of porosities, and some samples can be much weaker than those described in the RIB. For example, some of the borehole samples failed at pressures well below $100 \mathrm{MPa}$ (Martin et al., 1994, 1995a) rather than having strengths between approximately 100 and $200 \mathrm{MPa}$ as described in the RIB. Poisson's ratio values for the borehole samples of TSw2 ranged from about 0.14 to 0.40 (Martin et al., 1994, 1995a), and the TSw2 samples from Busted Butte had static Poisson's ratio values of about 0.09 (Martin et al., 1993).

Elastic wave velocity measurements on laboratory samples are useful as they provide data for comparison with velocities measured in the field, and a means of estimating the dynamic moduli, including Poisson's ratio for the rock. They also provide a convenient method for characterizing anisotropy in the rock behavior. Compressional and shear wave velocity measurements were made at frequencies of about 300 to $800 \mathrm{kHz}$ for the Busted Butte samples and about $300 \mathrm{kHz}$ to $1 \mathrm{MHz}$ for the borehole samples, for both the dry and the saturated cases by Martin et al., 1993, 1994, 1995a. This corresponds to wavelengths of a few $\mathrm{mm}$ to a few $\mathrm{cm}$ in the tuff. Measurements were made along the core axis for the Busted Butte samples, and both parallel to and perpendicular to the core axis for the borehole samples. But since the shear wave velocities were not measured for waves propagating perpendicular to the core axis and having polarization perpendicular to the core axis (i.e., the expected fast shear wave direction for the case of transverse isotropy), these data cannot be used to quantify any velocity anisotropy. Further discussion of anisotropy in Topopah Spring tuff can be found in Martin et al. (1992).

The compressional wave velocities for the Busted Butte samples were about 4.5 to $4.7 \mathrm{~km} / \mathrm{s}$ for both the dry and the saturated cases (Martin et al., 1993). The borehole samples had similar velocities except that a few samples had velocities as low as 4.0 to $4.3 \mathrm{~km} / \mathrm{s}$ (Martin et al., 1994, 1995a). These velocities found for cores measuring a few $\mathrm{cm}$ are higher than the velocities found for the G-tunnel heated block experiment at the 1-m scale (Zimmerman et al., 1986), but are in excellent 
agreement with compressional wave velocities measured at ambient temperature and pressure conditions for a block of Topopah Spring tuff at the $0.5 \mathrm{~m}$ scale (Blair and Berge, 1996).

The shear wave velocities for the Busted Butte samples were about 2.5 to 2.8 $\mathrm{km} / \mathrm{s}$ for the saturated case, and 2.7 to $2.8 \mathrm{~km} / \mathrm{s}$ for the dry case (Martin et al., 1993). The borehole samples of tuff had only two shear wave velocity measurements for the saturated case, 2.7 and $2.9 \mathrm{~km} / \mathrm{s}$ (Martin et al., 1994, 1995a). For the dry case, the borehole samples had shear wave velocities of 2.4 to $3.0 \mathrm{~km} / \mathrm{s}$ (Martin et al., 1994, 1995a).

Martin et al. (1993) used the velocity measurements to estimate dynamic Young's modulus and Poisson's ratio for the Busted Butte samples. They found values of about 41 to $44 \mathrm{GPa}$ for dynamic Young's modulus in the dry case, and about 39 to 45 $\mathrm{GPa}$ for the saturated case. The Poisson's ratio estimates were about 0.20 to 0.22 in the dry case and about 0.23 to 0.28 for the saturated case. The dynamic Young's modulus values were slightly higher than the measured static values for the Busted Butte samples (about $34 \mathrm{GPa}$ ). A separate study of the effect of frequency on Young's modulus and elastic wave attenuation (Price et al., 1994) found that Young's modulus for Topopah Spring tuff varied slightly with frequency, having values near $38 \mathrm{GPa}$ for frequencies of about $10^{-2} \mathrm{~Hz}$ and higher values near $40 \mathrm{GPa}$ for frequencies up to about $10^{6} \mathrm{~Hz}$. For these measurements, saturation had a greater effect on Young's modulus than the frequency had.

The values that Martin et al. (1993) observed for Poisson's ratio are quite low, $0.09 \pm 0.067$, when compared to values presented in the $R I B$, about 0.22 to 0.30 . Martin et al. (1993) were unable to explain these anomalously low values for Poisson's ratio. One likely explanation is that their samples may have contained significant amounts of $\alpha$-cristobalite. This mineral has a negative Poisson's ratio for single crystals and polycrystalline aggregates (Yehaneh-Hari et al., 1992; Keskar and Chelikowsky, 1993), which means that rocks containing significant amounts of $\alpha$ cristobalite may have anomalously low values for Poisson's ratio.

Price (1986) studied the effect of sample size on mechanical properties of Topopah Spring tuff (Tpt) and found that both the ultimate strength and axial strain at failure are inversely related to sample diameter, while Young's modulus and Poisson's ratio are independent of sample diameter. Price (1986) used power-law models to describe the behavior of ultimate strength and axial strain at failure as a function of sample size and proposed the following two equations:

$$
s_{u}=(1944)(D)-0.846+69.5
$$

and

$$
e_{\mathrm{u}}=11.6 D^{-0.268}
$$

where

$$
s_{\mathrm{u}}=\text { ultimate strength (uniaxial) }(\mathrm{MPa}),
$$




$$
\begin{aligned}
& e_{\mathrm{u}}=\text { axial strain at failure (millistrain), } \\
& D=\text { sample diameter (mm). }
\end{aligned}
$$

Price illustrates the effect of sample size on ultimate strength using saturated samples in Fig. 4-3.

To date, most compressive-strength experiments have used samples that were saturated with water and then tested under drained conditions. The results represent a minimum value because rocks are generally weaker when saturated with water. Olsson and Jones (1980) show that for Grouse Canyon tuff, which is similar to rock in the potential NFE, saturated samples are about $24 \%$ weaker than dry samples in unconfined compression.

The physical properties of the rock mass must also be determined for evaluation of the NFE. Rock-mass compressive strength is defined as the strength of a representative volume of intact- and jointed-rock matrix material. Estimates of rock-mass strength are based on (1) the known behavior of intact rock, (2) the known joint characteristics, and (3) the presence of applied or confining stresses. A rock-mass strength criterion of

$$
\left(\sigma_{1}\right)_{\text {ultimate }}=16.0+10.2\left(\sigma_{3}\right)^{0.602},
$$

where $0<\sigma_{3}<25 \mathrm{MPa}$, is presented in item 1.2.6 of the RIB. Equation (4-5) is based on an assumed rock-mass rating (RMR) of 61 and an unconfined compressive strength of $16.0 \mathrm{MPa}$. The equation reflects the current understanding of the nonlinear empirical relationship between rock-mass strength and confining stress and is subject to revision as more field and laboratory data for rock characteristics become available.

\subsubsection{Temperature and Stress}

In situ stress values for the potential repository horizon have been determined from measurements in drill holes USW G-1, USW G-2, and USW G-3 (Stock et al., 1984, 1985). Table 4-5 shows the average mean value and range for vertical stress, which is the maximum principal stress and is due to the overburden rock at the site, in addition to the ratios of minimum and maximum horizontal stresses to vertical stress, and the bearings of minimum and maximum horizontal stresses.

A calculated stress profile for the in situ stress near the Exploratory Studies Facility (ESF) is reported in chapter 1, section 1.27 of the RIB. The results of the analysis are shown in Fig. 4-4. The stress values are estimated using twodimensional finite-element analysis in which the gravitational stress is the only loading mechanism modeled (Bauer et al., 1985). The calculated values are similar to those reported in both Bauer et al. (1985) and Bauer and Holland (1987), and to the values of Yucca Mountain in situ stress measurements (Stock et al., 1985). The calculations assumed plane-strain conditions and a linearly elastic material response. The maximum horizontal stress was assumed to be equal to twice the minimum horizontal stress. The values of in situ bulk density and elastic properties 
for the rock mass used in the finite-element analysis were slightly different than those reported in Table 4-5 and can be found in section 1.27 of the RIB.

4.2.2.1 Cracks and Fractures. Current knowledge of cracks and fractures in the potential repository horizon is based on observations in exploratory vertical drill holes and from recent observations made in the Exploratory Studies Facility. However, at the time of this writing, fracture mapping from the ESF are not available, but preliminary analysis indicates that the main observations determined from the drill hole data are representative of the data derived from the ESF. The drill hole indicates that jointing in the Topopah Spring welded unit, lithophysaepoor layer is mostly vertical. Scott and Catellanos (1984) reported a fracture density of about $40 / \mathrm{m}^{3}$ in the potential repository horizon, and evaluation of these data (Wilder, 1990) indicate that the fracture spacing in the rock mass may be less than $\sim 30 \mathrm{~cm}(1 \mathrm{ft})$. Fracture data are also given in chapter 1, section 1.142 of the RIB. Data on the distribution and characteristics of fractures in the Topopah Spring welded unit, lithophysae-poor layer (TSw2) along the $2800 \mathrm{~m}$ route of the north ramp of the Exploratory Studies Facility have been collected from several boreholes by Brechtel et al. (1995). Brechtel et al. (1995) averaged values over $3 \mathrm{~m}$, (10 ft) lengths along the boreholes and found that the most frequent joint spacing was from $60-200 \mathrm{~mm}$, with the joint condition characterized as slightly rough, separation $<1 \mathrm{~mm}$, and slightly weathered walls. These data confirm the conclusions of earlier work by Scott and Catellanos (1984) which indicated that potential repository horizon contained a significant number of fractures.

Lin et al. (1993a) reviewed the fracture data from drill holes USW G-1, USW G-4, USW GU-3 and UE-25a\#1 and present a description of the fracture spatial location and abundance and physical characteristics and estimated Rock Quality Designation (RQD) for the Topopah Spring member and other geologic formations intersected by the drill holes. Table 4-6 summarizes their findings for the potential repository horizon. These values are similar to those presented by MacDougall (1987). However, because these data are generated from only four exploratory vertical drill holes, additional data and analyses are needed to fully assess the potential for block movement for either borehole or drift emplacement. Moreover, additional data are currently being collected from the ESF, but these data are not available at the time of this writing.

The constitutive properties of fractures and joints present in the potential repository horizon are also important for assessment of the thermal-mechanical and thermal-hydrologic behavior of the rock. Olsson and Brown (1994) measured constitutive properties of seven fractures from drill holes NRG-4 and NRG-6 using a rotary shear apparatus. They found that the peak friction ranged from 0.89 to 1.11 , and residual friction ranged form 0.76 to 1.00 . They also report that dilation angle ranged from $5.29^{\circ}$ to $11.28^{\circ}$, and that the roughness characteristics for the fracture surfaces are in qualitative agreement with the mathematical model of Brown (1994). Olsson also examined the effect of sliding velocity on the mechanical response of an artificial joint in Topopah Spring tuff to determine the velocity-dependence of shear strength. Olsson found that different initial conditions affected the character of the stress-slip curve. In particular, slide-hold-slide tests exhibited time-dependent 
strengthening, while hold-slide tests produced slip weakening. No joint creep was observed in these tests.

Blair and Berge (1996) monitored the deformation under compression of a fracture zone in a $0.5 \mathrm{~m}$ scale block of Topopah Spring welded unit, lithophysae-poor layer (TSw2). The test is shown schematically in Fig. 4-5, and a stress-strain curve is shown in Fig. 4-6. This figure shows that deformation is nonlinear with increasing stress, and modulus increases as vertical stress increases above $4 \mathrm{MPa}$. The modulus value computed for vertical stress below $4 \mathrm{MPa}$ is $\sim 4 \mathrm{GPa}$, and that value increases to $\sim 6 \mathrm{GPa}$ as applied stress is raised above $4 \mathrm{MPa}$. These values are considerably lower than modulus values measured on core samples, and reflect that the block contains vugs and fractures. The increase in deformation modulus with increasing vertical stress can be attributed to closure of fractures and vugs that occur in the subhorizontal zone. Moreover, the curve exhibits the banana shape that is associated with the hysteretic behavior of fractures. The hysteresis shown during the initial stage of unloading is attributed to the cohesion of fractures. The plot shows that the cohesion for this zone is $\sim 1 \mathrm{MPa}$, which is an order of magnitude weaker than values often used in numerical models of rock behavior that incorporate discrete joints and fractures. As the load continues to decrease, the slope of the unloading curve decreases gradually. This is relevant to hydrologic calculations of flow during the cool down period when stresses are expected to decrease, as the opening of fractures will increase the permeability of the near field region.

Knowing the properties of the intact rock and the fractures provides basic elements for understanding rock mass behavior, and empirical methods have been developed that use information on the properties of intact rock and fractures, as well as the number and orientation for fractures to estimate properties of the rock mass. The two most widely used methods are the Rock Mass Rating (RMR) method (Bieniawski, 1979), and the " $Q$ " method (Barton et al., 1994). Brechtel et al. , 1995) used data from the NRG holes in conjunction with other data from standard laboratory tests on cores from the drill holes to estimate the condition of the rock mass using these two methods. Results indicate fair to good rock conditions in the Topopah Spring welded unit, lithophysae-poor layer. Brechtel et al. (1995) also analyzed the rock quality data using the methodology of Hardy and Bauer (1991) to estimate values of the mechanical properties of the rock mass. These estimates are derived from the RMR and $Q$ values and were computed for input for numerical modeling of thermomechanical and seismic loading of the ESF. Results of their analysis for the TSw2 layer are summarized in Table 4-7. This table shows that estimated rock mass strengths are substantially lower than strength values determined from laboratory measurements on intact rock samples form the NRG drill holes. In particular, the estimated compressive strength for unit TSw2 is 18.8 $\mathrm{MPa}$, which is approximately $10 \%$ of the mean value of compressive strength measured from intact core samples. It is interesting that the estimated Young's modulus is similar to that measured on intact core. However, these are only estimated values and more tests and analyses in both the laboratory on blocks containing multiple fractures, and in the field need to be conducted to better define the anticipated rock mass compressive strength. 
Comparison of the estimated mechanical properties for the rock mass and the values measured on intact core, indicates that the properties of the rock mass are scale dependent. This is primarily due to the presence of cracks and fractures, and unfortunately, the scaling relations for the behavior and properties of fractured tuff are not well developed. Recently, Lin et al. (1995) proposed an intermediate scale test to aid in the development of scaling relations. This test is known as the Large Block Test and is described in detail in Chapter 9 of this report. Also, Blair and Berge (1996) have measured deformation on a $0.5 \mathrm{~m}$ scale block of Topopah Spring welded unit, lithophysae-poor layer (TSw2) that contained several cracks and fractures. These authors observed Young's modulus to be about $6 \mathrm{GPa}$, with most of the deformation occurring across fractures. This indicates that the estimated value of Young's modulus given in Table 4-4 may be too high.

\subsection{Processes That Perturb the Waste Package Environment}

Development of a subsurface nuclear waste repository will significantly affect the geomechanical conditions of the near-field rock. Excavation of the repository drifts will increase the level of stress in the rock within a few meters of the excavations. Emplacement of the waste containers will cause an immediate and rapid increase in temperature in the walls of the excavations. The maximum temperature reached will depend on the nature of the waste emplaced and the repository design, but temperatures as high as $230^{\circ} \mathrm{C}$ are predicted ( $\mathrm{O}^{\prime} \mathrm{Neal}$ et al., 1984). The thermal loading will affect the stress, strength, and other properties of the rock near the excavations. The overall stress in the WP environment will increase as the rock heats and tries to expand. As heating proceeds, however, some zones of the repository may actually experience tension due to excavation and heating geometries. During cooling, the overall stress will decrease and zones put in tension will return to a compressive state. The heating and cooling of the near-field rock will also cause moisture distribution in the near field to be time-dependent and will impose a drying and rewetting cycle on the rock. Since the rock strength at elevated temperature is also a function of the water content, this must be considered in analysis of near field behavior. Finally, the emplacement of waste may impose a radiation field on rock in the first few centimeters of an excavation wall.

When imposed over long time periods, these changes in the environmental conditions may cause physical and mechanical changes in the rock that need to be considered in the design and assessment of the waste package. While the effect of these parameters on the mechanical behavior of the NFE has not been studied for the period after closure, it has been studied for the period before closure; the results of some of these studies are summarized below.

\subsubsection{Excavation of the Repository}

The excavation of repository drifts can alter the mechanical properties of the rock near the openings. Blasting creates fractures while damage due to mechanical excavation depends on the particular technique used. Pusch (1989) evaluated the influence of several excavation techniques on the structure and physical properties 
of rock around large boreholes and found that "the procedure employed in the excavation of canister disposition holes affects the structure and physical properties of the "near-field rock."' Pusch considered percussion, full-face and core drilling, and smooth blasting and found that "except for smooth blasting, the generated damage appears to be less important than the increase in 'axial' hydraulic conductivity that is caused by stress-release effects, but both combine to yield significant local flow passages. This is particularly obvious where the rock structure yields steep wedges." Pusch concludes that core drilling has the least effect, while percussion drilling causes fine-fissuring and discing within one centimeter of the borehole wall. Fullface drilling causes more extensive fissuring and the generation of new fractures in addition to the growth of pre-existing ones within several decimeters from the borehole wall. Pusch's results also indicate that smooth blasting produces a particular form of regular fractures that appear to control the hydraulic conductivity of the near-field rock. Pusch did not consider excavation of the drifts by tunnelboring machines. It is expected that this method would minimize rock damage around the drifts. While not directly applicable to the drift excavation, Pusch's results are indicative of the types of effects that could be expected in drift excavation.

Excavation of emplacement drifts will also alter the stress field in the rock near because the repository horizon is under lithostatic and regional tectonic stress. When sections of the rock are removed, the stress previously supported by the excavated rock is redistributed in the remaining rock. Generally, stress levels and stress gradients near the excavated openings increase and can result in timedependent deformation of the excavations.

\subsubsection{Thermal Effects of Waste Emplacement}

The thermal cycle, during which the rock will rapidly heat and then slowly cool, will affect the geomechanical behavior of the NFE. Figure 4-7 shows temperature profiles predicted at 150,500,1,000,5,000, and 10,000 yr after waste emplacement at a density of $83.4 \mathrm{mtu}$. This figure shows that temperatures in the near-field will remain in excess of $100^{\circ} \mathrm{C}$ for over $1,000 \mathrm{yr}$. Additional estimates of temperatures in the near field are shown in Fig. 1.10.5.2.1. The thermal loading of the NFE will alter the stress in the rock near the emplacement excavation as a function of time. During the period of temperature increase, the stress in the rock will increase as the rock tries to expand. However, because of the geometry of the excavated drifts, the stress field in the NFE will be complex and, as stated previously, some zones may even be put in tension for an extended period of time. As the temperature decreases, the overall stress levels will decrease and the entire stress field will again be compressive.

In addition, the effect of temperature on the strength of near-field rock is not well defined at this time. Rock strength, however, generally decreases with increasing temperature. Price et al. (1987) report that for samples from the potential repository horizon, Young's modulus decreases an average of $16 \%$ as temperature is raised from 22 to $150^{\circ} \mathrm{C}$. The mean ultimate strength also decreases $16 \%$ as temperature is raised from 22 to $150^{\circ} \mathrm{C}$ at both 0 and $5 \mathrm{MPa}$ confining pressures.

Several numerical modeling studies have been conducted to assess the stability of underground excavations at Yucca Mountain for the preclosure period and a 
synopsis of these studies is presented by Ehgartner and Kalinski (1988). All of the studies cited by Ehgartner and Kalinski show that drifts and shafts should be stable through repository decommissioning. However, none of the studies examined the stability of openings at times beyond decommissioning.

Several studies have also evaluated the stability of boreholes if borehole emplacement is selected including Arulmoli and St. John (1987) and Christianson and Brady (1989). Moreover, Christianson and Brady (1989) in investigating the stress field around boreholes for both vertical and horizontal emplacement geometries found for specific geometries that there were locations where compressive stresses were adequate to form zones of rock failure that occurs either prior to heating or develops as heating progresses. Christianson and Brady (1989) also estimated that for horizontal emplacement, zones of joint slip will develop prior to heating. Except for joints dipping at $45^{\circ}$, heating has the effect of reducing the tendency for joint slip, implying that there should be no progressive deformation of the borehole as heating proceeds. The opposite conclusion applies to joints dipping at $45^{\circ}$ with a local principal stress ratio of unity. In that case, progressive deterioration of the borehole may accompany heating.

To predict the postclosure geomechanical environment, time-dependent rock properties may be important because stresses in the near field are predicted to remain at levels of $20-40 \mathrm{MPa}$ for well over 100 years. Estimates of the geomechanical behavior of rock around the emplacement drift that incorporate time-dependent rock properties are still to be made. In addition, it is important to note that spalling and/or slip along fractures is expected to occur within the first 50 yr. after waste emplacement at a time when (1) the monitoring of drifts will be practical, and (2) drift support could be relied on.

\subsubsection{Time-Dependent Effects}

4.3.3.1 Microcracking and Subcritical Crack Growth. Microcracking and subcritical crack growth in the near-field rock over long periods of time is of concern because the formation, growth, and coalescence of microcracks in the rock at or near excavations could lead to excavation damage and the formation of rock chips or blocks. These chips or blocks might passively load the container and form transport pathways. The formation of microcracks may also change the physical and geochemical properties of rock in the NFE. Very little work has been done in this area. Kemeny and Cook (1990), however, used a probabilistic approach, which included time-dependent crack growth, to examine borehole emplacement. They estimated that over the lifetime of the repository, slabbing is likely to occur in a significant portion of the emplacement boreholes.

One mechanism that may cause microcracking of the matrix is the phase transformation of the mineral cristobalite. Cristobalite may occur in significant amounts in the repository horizon (Connolly, 1994), and it has been shown to invert from a tetragonal to cubical structure at approximately $230^{\circ} \mathrm{C}\left( \pm 20^{\circ} \mathrm{C}\right)$ (Meike and Glassley, 1990) with an accompanying 5\% increase in volume (Cohen and Klement, 1975). This phase transformation could increase stresses on a local scale and cause cracking of the rock matrix. 
At the elevated temperature and stress conditions expected in the near field, significant crack growth may occur even at low-crack-growth rates. Moreover, rates of subcritical crack growth may be such that, when considered over the lifetime of the repository, changes in crack length and density cannot be dismissed when estimating rock behavior. Increases in stress, temperature, and moisture have been shown to cause substantial increases in subcritical crack-growth rate for such rock types as granite and gabbro (Atkinson and Meredith, 1987). Although tests of this type are still to be made on tuff, a similar effect is expected.

Martin et al. (1995b) performed laboratory experiments to investigate creep in Topopah Spring tuff samples at ambient and elevated temperatures. They found that the observed creep deformation was consistent with a mechanism of timedependent crack growth, particularly at stresses above $90 \%$ of the uniaxial compressive strength of the tuff. The stress necessary to produce failure appeared to decrease with increasing temperature, but the data were not sufficient to quantify that effect. Temperature did cause a reduction in strength, but further tests would be required to constrain the strength and creep deformation of tuff as a function of temperature, saturation, and applied load.

Blair and Berge (1996) found that imposing low levels of compressive stress for periods of a few days on $0.5 \mathrm{~m}$ blocks of Topopah Spring tuff caused time-dependent inelastic crack closure to occur for cracks oriented parallel to the applied stress.

4.3.3.2 Joint Properties. MacDougall et. al (1987) have reported the following joint mechanical properties: joint cohesion $=0.1 \mathrm{MPa}$ and joint-friction angle $=$ $28.4^{\circ}$. Olsson $(1987,1988)$ investigated joint properties in rock samples from the potential repository horizon and found that the strength of a joint may increase with the time of stationary contact and that joint properties are dependent on stress history. However, he indicated that the latter area needs to be investigated further. To date, data on the effect of environmental variables (e.g., temperature, moisture content, and stress history) on joint properties are not available.

Lin et al. (1993a) present a description of the abundance, orientation, and physical characteristics of fractures and rock quality designation for the stratigraphic units of the potential repository at the Yucca Mountain site. Wibowo et al. (1993) and Olsson (1994) conducted laboratory experiments on fractures and joints in tuff to examine slip behavior and fracture surface damage during shear.

Blair and Berge (1996) found that imposing low levels of compressive stress for periods of a few days on $0.5 \mathrm{~m}$ scale blocks of Topopah Spring tuff caused timedependent, non-repeatable behavior to occur for cracks oriented both parallel and perpendicular to the applied stress. Under the long-term loading cracks/vugs oriented perpendicular to the applied stress showed significant closure beyond that observed in the 1-day tests performed by these authors and discussed earlier. In addition, the long-term loading caused pre-existing hairline cracks oriented in the direction parallel to the applied stress to open, which significantly reduced compressional wave velocities in this direction. Increasing temperature caused closure of some of the vertical cracks, which increased horizontal velocities. Increasing the temperature also caused a softening of the mechanical response in the direction of loading. 
Blair and Berge (1996) postulate that some properties of the rock mass may become increasingly anisotropic with time. For instance, if cracks, vugs and fractures oriented parallel to the maximum principal stress undergo time-dependent closing, permeability in this direction will be reduced and deformation modulus will increase. Moreover, opening of pre-existing hairline cracks that occur near the drift wall and are oriented parallel to it, will increase the permeability in this direction and will change the geochemical environment by exposing different mineral assemblages.

\subsubsection{Radiation Effects of Waste Emplacement}

The effect of radiation on the geomechanical properties of rock from the potential repository horizon is uncertain. Radiation is expected to have a negligible effect on the overall geomechanical behavior of the rock mass. This supposition is based on the work of Durham et al. (1986) who conducted a series of unconfined compression tests on cylinders of quartz monzonite, half of which were irradiated with gamma radiation and half of which were not. A similar series of tests were conducted by Durham et al. on samples of Westerly granite. These experiments showed no statistically significant change in unconfined compressive strength for either rock type. Null results were also found for the effect of gamma irradiation on Young's modulus and Poisson's ratio. Durham et al. concluded that gamma irradiation has no effect on the strengths of either rock type.

However, more recently Blair et al. (1996) have presented results of a suite of uniaxial compressive tests conducted to provide laboratory data to determine how radiation affects the compressive strength of Topopah Spring tuff. This study was patterned after that of Durham et al. (1986), mentioned above. Results indicate that for homogeneous, uncracked samples of Topopah Spring welded unit, lithophysaepoor layer, TSw2, exposure to gamma radiation had no discernible effect on the unconfined compressive (peak) strength or the Young's modulus. However, results for samples that contained partially healed, preexisting vertical or subvertical cracks, indicate that radiation may cause some degradation of the strength and Young's modulus.

A possible explanation of the observed behavior for the cores containing partially healed cracks is that exposure to radiation weakened the cementing material in the cracks and fractures that were present in these samples, leading to the lower values of peak strength and Young's modulus. The cementing material is thought to be largely composed of carbonates and the authors discuss two possible mechanisms that could weaken the cementing material when it is exposed to radiation (Blair et al., 1996).

These results are preliminary, and additional studies are warranted to evaluate whether radiation does weaken cementing materials in welded tuff. However, if this is a real phenomenon, it has implications for the behavior of rock in the nearfield region of a nuclear waste repository. The radiation field is expected to affect only rock exposed on the surface of excavated drifts and to penetrate only a few centimeters into the rock. However, the rock in this region will also experience the highest temperatures and stresses in a repository as well as high humidity. Weakening of fracture-filling materials may cause unanticipated spalling, which 
may change the amount and nature of rock fragments that come in contact with the waste containers. However, there are several processes that would be likely to occur that would minimize the impact of the radiation. First, radiation penetration is limited to a few centimeters of rock, and if spalling were to occur, the rubble would bulk up and form a radiation shield.

\subsubsection{Seismic Loading}

Earthquakes and explosions generally affect underground excavations through either fault slip or shaking. Damage due to fault slip will occur when an emplacement drift passes through a fault zone. Under such circumstances, damage is generally restricted to the fault zone, and may range from minor cracking of a tunnel liner to collapse of a portion of the excavation, depending on the fault displacement and the engineering properties of the NFE. If an emplacement drift is found to cross an active or potentially active fault zone, the appropriate sections of the drift will be abandoned because fault slip cannot be prevented.

Excavation damage as a result of shaking or vibratory motion has been widely investigated. For unlined underground excavations in rock, such damage occurs as rock fall, spalling, local opening of rock joints, and block motion. Subramanian et al. (1990) have provided recommendations for seismic parameters for the design of the shafts associated with the ESF. Their recommendations are summarized in section 1.22 of the $R I B$. They concluded that the shafts need only be designed to adequately ensure worker safety and reasonably uninterrupted functions. The working group concluded that deterministic methods were appropriate for establishing conservative levels of ground motion for consideration in the ESF design, and probabilistic methods were appropriate for confirming that the resulting motions are unlikely to be exceeded during the operating lifetime of the ESF. The recommendations, which were based on available site-specific seismic and geologic data, include design parameters for natural earthquakes that may occur at or near the potential repository site and for underground nuclear explosions (UNE) that may occur at the Nevada Test Site (NTS) and are given in Table 4-8.

Recommended surface-control motion values that are used for the natural earthquake design are $0.30 \mathrm{~g}$ horizontal acceleration and $30.0 \mathrm{~cm} / \mathrm{s}$ peak horizontal velocity (Subramanian et al., 1990; Table 2-1). Subramanian et al. recommend the use of control motions 1.67 times these design-basis values for performance evaluations of the ESF.

Attempts to catalogue records of the performance of underground excavations subjected to seismic loading and develop simple empirical design criteria have indicated a damage threshold of approximately $20 \mathrm{~cm} / \mathrm{s}(8 \mathrm{in} . / \mathrm{s})$. No damage should be experienced if the peak particle velocity is beneath that threshold. It is important to note, however, that ground motion resulting from earthquakes can last for several seconds, subjecting the excavation to repeated stress cycles; the number of stress cycles is critical to determining how much permanent deformation will occur within a rock mass around a tunnel when subjected to earthquake loading.

Phillips and Luke (1991) conducted at Tunnel Dynamics Experiment (TDE) to document tunnel damage corresponding to measured and observed ground motions and compared the TDE ground motions with the design basis motions for 
Yucca Mountain. Their analysis indicated that the design basis motions are relatively small and can be accommodated in the design of the repository drifts.

Implications of seismic loading for the near field environment are that over extended times, the drifts may experience shaking. At the elevated temperature and stress conditions around openings, they may be less stable than during the preclosure and spalling may occur. Backfill of the drifts will prevent contact between this rock and the surface of the cansiter. Kana et al. (1989) recently reviewed the literature on seismic loading for an underground repository and found that because studies completed to date have ignored both time-dependent fracture properties and the duration of shaking, they are of limited use in predicting the rock response to seismic loading by earthquakes. They conclude that further investigation is needed to resolve this issue.

\subsection{Geomechanics Modeling}

\subsubsection{Discussion of Model Approaches}

\section{Available Approaches}

As mentioned in the above discussion, the rock mass forming the NFE is expected to be a fractured, welded tuff. Several numerical codes have been developed for simulation of rock mass behavior which provide for discrete cracks and fractures. These codes employ finite element (FEM), distinct element, and boundary element numerical techniques, and can incorporate a wide variety of constitutive models. Some have been generalized to three dimensions. To predict rock damage over long periods, and at changing temperature and moisture conditions, existing codes must accommodate the appropriate constitutive equations for elasto-plastic moduli of the rock mass, nonlinear properties of the joints, and fracture propagation. Included properties of the rock are compressive and tensile strength, coefficient of friction, fracture stiffness, and fracture toughness, among others. The codes use these parameters along with boundary stresses and thermally induced stresses to obtain a stress distribution throughout the region of interest in the NFE.

The most common modeling approach utilizes either the finite element or finite difference technique. In this approach, the rock mass is assumed to be a continuum, and the network of cracks and fractures contained in the rock behave in a manner similar to an individual crack. Equations describing the response of an ensemble of cracks is assumed to be identical in form to that describing the response of a single isolated crack. These models handle the creation of new cracks and fracture in various ways. One method is to derive a damage vector $D$ which describes the number of cracks and fractures accumulated during the entire history of deformation (Costin, 1987).

One numerical code which uses a time-dependent finite difference algorithm is called FLAC, which is an acronym for Fast Lagrangian Analysis of Continua. This code is capable of treating both mechanical and thermally induced stresses and deformations. In this code, materials are represented by arbitrarily shaped, 
quadrilateral zones, and several built-in constitutive models are available for describing material behavior. FLAC is often used in 2-D, assuming plane strain geometry, and linear mechanical and thermal properties where mechanical properties (e.g., elastic moduli) and thermal properties (e.g., thermal expansion coefficient) are independent of stress and temperature. Constitutive relations are often either isotropic elastic or else make use of the ubiquitous joint model capability of the FLAC code. The thermal response is usually isotropic heat conduction. FLAC has recently become available in 3-D, and this new version is currently being configured to allow simulation of the 3-D stress and displacement field in the NFE over time (see discussion below).

Another widely available code is ABAQUS. This is a 3-D finite element code with capability for time-dependent analysis of thermal and mechanical behavior. The numerical model is weakly coupled in the sense that the temperature field produces thermal stresses, but that these stresses do not in turn influence temperatures. The temperature field is calculated as a function of time from a thermal diffusion model. The mechanical model uses the temperature field at various times to apply thermal loading.

The distinct element approach represents a fundamentally different approach to analysis of the mechanical behavior of a fractured rock mass. In the distinct element method, the rock mass is composed of an assembly of deformable blocks that are interfaced by discontinuities. In some of the distinct element models the blocks are discretized by means of triangular zones where the strains are assumed to be constant. In a distinct element code, fractures in the rock mass are entered individually. One of the most commonly used distinct element codes is called UDEC, and Millard et al. (1995) discuss the use of UDEC in a thermal-hydromechanical simulation.

Another very different type of modeling available for study of the NFE is statistical modeling. This type of modeling can be used to study fracture processes as well a deformation and stress in rock especially at elevated temperatures and at long times (Blair, 1994). It can be used to construct ideal systems in which all physical properties are known; this allows the effect of rock heterogeneity on the overall rock behavior to be examined in a quantitative way. In a statistical model, the body of interest is simulated using a lattice or a network of sites, bonds, or both. The behavior of each site or bond is governed by simple, one-dimensional (1-D) rules. For instance, a material may be represented by a network of springs, and each spring is assigned a modulus and a breaking strength. Stress, displacement, and/or temperature contidions are then applied, and the network is solved to determine the stress in each spring. If for a particular spring the stress exceeds the strength assigned to the spring, it is "broken" and removed from the network. Lattices of sites can be used in the same manner, or a network of sites and bonds can be constructed where both sites and bonds have properties. This approach provides a way to study complex systems using simple elements. Using simple brittle-bond elements this type of model can produce globally ductile behavior for a network where material shows strain-softening.

One of the major advantages of a statistical model for studying fracture in rock is that local heterogeneity can be incorporated very easily. Statistical models include a 
variety of lattice, network, molecular-dynamics, cellular-automata, field-theory, and other pseudo-continuum models. Herrmann and Roux (1990) have compiled a comprehensive volume describing statistical models and how they can be used to study fracture in rock.

\section{Validity Studies}

An international co-operative research project was established for theoretical and experimental studies of coupled thermal, hydrological, and mechanical processes in hard rocks. This project is called DECOVALEX and is described by Jing, Tsang, and Stephansson (1995). In this work, different mathematical models and computer codes have been used to study problems of interest to geologic disposal of nuclear waste. In particular, 11 codes were evaluated including both 2-D and 3-D finite element codes in which the rock was modeled as a porous/fracture media and a 2-D discrete element code in which the rock was modeled as discrete deformable block assemblages. Much of the work done for DECOVALEX is documented in a special issue of the International Journal of Rock Mechanics (Stephansson, 1995).

As part of the DECOVALEX program, two inter-code bench mark comparisons were carried out. The bench mark test BMT1 considered a large-scale (km) mass of rock and is described by Millard et al. (1995). The bench mark problem BMT2 involved a system of nine blocks of intact hard rock separated by two pairs of soft fractures and is described by Chan et al. (1995). For each of these exercises, both finite element and distinct element methods were used. Chan et al. (1995) found that for BMT2, heat convection significantly affects the distribution of temperature, thermal stresses, and displacements, and that the predominant coupled effect is fracture closure caused by thermal expansion of the rock blocks. Thus, coupled models of the near field need to incorporate this effect. Results for DECOVALEX also indicate that for studies BMT1 and BMT2, the different modeling techniques produced very similar results. This indicates that use of the continuum codes is merited for study of the near field. This is important because continuum codes are generally easier to use than the distinct element codes.

Other work conducted in conjunction with the DECOVALEX program includes development of an analytical solutions for coupled thermo-hydro-mechanical behavior by Rehbinder (1995), and study of thermal-mechanical-hydrological behavior of sparsely fractured rock by Nguyen and Selvadurai (1995). In addition, Jiao and Hudson (1995) have presented a fully coupled model for rock engineering systems.

\section{Model Development}

One of the necessary tasks for simulation of the geomechanical behavior in the near field is coupling of the thermal-mechanical models to the sophisticated hydrothermal models used by the hydrologic community (discussed in Chapter 1). Recently, we have initiated coupled 3-D modeling of thermal-mechanicalhydrologic behavior of the near field. The methodology being used to model the coupled behavior is as follows. Thermal-hydrologic models are used to compute the temperature distribution, this information is then passed to the thermal-mechanical model for computation of stress and deformation fields. The thermal-mechanical 
model is set-up with the same grid as the thermal-hydrologic model (see Chapter 1, Fig. 1.10.5.2.1). The particular models being used are NUFT for the thermalhydrologic behavior, and FLAC-3D for the thermal-hydrologic behavior. Progress to date includes completion of the translating program which passes the NUFT grid into FLAC-3D, and initial testing of the mechanical behavior using this grid.

As mentioned above, statistical methods also offer promise for the study of rock behavior over long periods in the NFE and Blair (1994) has developed a statistical model for fracture of rock in compression that allows rock heterogeneity to be introduced at a variety of scales. This model utilizes a field theory approach to the analysis of fracture, and incorporates the concept of superposition and the techniques of boundary element analysis and percolation theory to form a simple yet powerful method for the study of progressive fracture of rock. A conduction temperature model has been implemented into this field-theory code and using this or other statistical models, temperature-dependent behavior could be linked to the chemical state of any given site. This could be used to evaluate the behavior of Topopah Spring Tuff at conditions equivalent to those expected in the NFE. This formation is known to contain significant amounts of the mineral cristobalite and at temperatures between $175^{\circ}$ and $225^{\circ} \mathrm{C}$ this mineral undergoes a phase transformation and expands in volume by $5 \%$ or more. In addition, bound water may be given off and flash to steam when this phase transformation occurs. This provides a considerable amount of energy at the site of the mineral. The model could be used to simulate the mechanical effects of this phase transformation by assigning a portion of the sites to be cristobalite sites and imparting some special properties to these sites. When temperature reaches the transformation temperature, these sites break and impart strain energy to the system. Chemistrydependent properties could also be included by assigning to each site an appropriate chemical parameter(s) that represent the chemical state and a timer. For timedependent strength, or strength that is dependent on time and chemical environment, the time and chemical environment can be tracked and at time $t$ the strength of the site is decreased.

\subsubsection{Applications to the Near Field Environment at Yucca Mountain}

Blair, Berge, and Wang (1995) analyzed the thermal mechanical behavior of a $3 \mathrm{~m} \times 3 \mathrm{~m} \times 5 \mathrm{~m}$ block of fractured rock as part of the analysis done in anticipation of the Large Block Test (LBT) planned for Fran Ridge near Yucca Mountain (Lin et al. 1995). The purpose of this work was to provide analysis and interpretation of coupled thermal-mechanical-hydrological behavior of the block as it is heated. Particular objectives of the modeling were to aid in the experimental design of the test, to evaluate different thermal and constitutive models, and to evaluate different numerical methods. In this study, thermal-mechanical simulations of the heat-up phase of the LBT were conducted using two different numerical codes that are commercially available, a 2-D finite difference model (FLAC, Itasca, 1993) and a 3-D finite element model (ABAQUS).

The purpose of this initial numerical modeling was to calculate temperatures, stresses, and displacements in two and three dimensions for a simplified representation of the large block. In reality, numerous joints and fractures 
complicate the behavior of the large block significantly. Nonetheless, these simulations provide a general understanding of the thermal-mechanical behavior to be expected in the LBT.

In these simulations, the gridding used in the FLAC models was similar to that used by Lee (1995) for hydrothermal modeling. The second method considered is the 3-D finite element method, and the code ABAQUS was used to evaluate this method. In the 3-D simulations only one-quarter of the block was modeled; therefore, the two symmetry planes were given boundary conditions of zero displacement normal to the plane. ABAQUS requires many of the same material properties as FLAC, and for the simulations conducted in this study, the mechanical and thermal properties input to ABAQUS were identical to those used in the FLAC elastic model. In the ABAQUS modeling, an elastic model was used to simulate the large block, and no viscoelastic properties or fracture zones were used.

Blair, Berge, and Wang (1996) show that the predicted temperature fields agree well with those predicted by Lee (1995) using a code that incorporates a more sophisticated thermal-hydrological model. Two simulations were conducted in which discrete fractures present in the large block were simulated, and lower levels of stress were predicted in these simulations, indicating that the presence of compliant fractures may reduce the stress levels.

The 2-D, plane strain, FLAC model was constructed in a plane orthogonal to the heater holes proposed for the LBT. The thermal predictions made with this code show a 2-D temperature field near the heaters at early times. At later times, the code predicts a temperature field that is nearly 1-D because all the walls are insulated. Temperature fields in the 3-D simulation were very similar to those predicted by the 2-D FLAC model. For example, the temperature at the top of the block is approximately $65^{\circ} \mathrm{C}$ after 60 days in the $3-\mathrm{D}$ model and approximately $70^{\circ} \mathrm{C}$ after 55 days in the $2-\mathrm{D}$ model.

The differences are greater between the 2-D and 3-D mechanical models. The plane strain approximation used in the 2-D model assumes that the length of the heater direction is long compared with the height and width of the block. Further, the plane strain model does not incorporate the stress-free boundary faces parallel to the model plane. The plane strain model generates a large, compressive normal stress in the heater direction to suppress the thermal expansion in that direction.

Blair, Berge, and Wang (1995) conclude that the thermal-mechanical FLAC and ABAQUS modeling produced temperature fields similar to that of Lee (1995) who used a code which contains a more sophisticated thermal-hydrologic model. This suggests that the FLAC and ABAQUS codes could be used with a thermalhydrological model to better investigate coupled processes. The 2-D modeling was faster and was useful for exploring effects of different constitutive models, but was unable to simulate the outside face of the large block where stresses are highest. This is because the plane strain assumption is equivalent to assuming that the 2-D model lies at the center of the block. Note that most of the instrumentation in the LBT will be located on the outside surface of the block. The 3-D modeling required an order of magnitude more in computer time, but was able to estimate maximum stresses and displacements everywhere in the block's volume. 


\subsection{References}

Arulmoli, K., and C. M. St. John (1987), Analysis of Horizontal Waste Emplacement Boreholes of a Nuclear Waste Repository in Tuff, Sandia National Laboratories, Albuquerque, NM, SAND86-7133.

Atkinson, B. K., and P. G. Meredith (1987), "The Theory of Subcritical Crack Growth with Applications to Minerals and Rocks," Fracture Mechanics of Rocks, B. K. Atkinson, Ed. (Academic Press, London).

Barton, N. R., R. Lien and J. Lunde, 1994, "Engineering Classification of Rock Masses for the Desing of Tunnel Support," Rock Mechanics, 6, 189-236, (NNA.870406.0237)

Bauer, S. J., and J. F. Holland (1987), "Analysis of In Situ Stress at Yucca Mountain," Proc. of the 28th U.S. Symp. on Rock Mechanics, I. Farmer, Ed. (A. A. Balkema, Rotterdam, The Netherlands), pp. 707-713.

Bauer, S. J., J. F. Holland, and D. K. Parrish (1985), "Implications About In Situ Stress at Yucca Mountain," Proc. of the 26th U.S. Symp. on Rock Mechanics, E. Ashworth, Ed. (A. A. Balkema, Rotterdam, The Netherlands), pp. 1113-1120.

Bieniawski, Z.T., 1979. Engineering Rock Mass Classification, Wiley-Interscience Publication, John Wiley \& Sons, New York. (NNA.901005.0044)

Blair, S. C. (1994), "Analysis of compressive fracture in rock using statistical techniques," Ph.D. Thesis, Dept. of Materials Science and Mineral Engineering, U. C. Berkeley, Berkeley, CA.

Blair, S. C. and P. A. Berge, "Uniaxial compression behavior of small blocks of welded tuff," in Proceedings of the 1996 Int'l High Level Radioactive Waste Management Conference, April 29 - May 3, 1996, Las Vegas, NV, published by American Nuclear Soc and American Society of Civil Engineers, pp. 409-411.

Blair, S. C, P. A. Berge, and H. F. Wang (1995), "Geomechanical Analysis of the Large Block Test," UCRL-ID-122898, Lawrence Livermore National Laboratory, Livermore, CA.

Blair, S. C., J. M. Kelly, O. Pine, R. Pletcher, and P. A. Berge, "Effect of radiation on the mechanical properties of Topopah Spring tuff," UCRL-ID-122899, Lawrence Livermore National Laboratory, Feb. 1996.

Brechtel, C.E., M. Lin, E. Martin, and D.S. Kessel, 1995. Geotechnical Characterization of the North Ramp of the Exploratory Studies Facility, SAND95-0488/1 and 0488/2, Yucca Mountain Site Characterization Project, Sandia National Laboratories, Albuquerque, NM. (MOL.19950502.0004)

Brechtel, C.E., S. C. Carlisle, and J. Pott, 1993. "Rock Mass Quality Estimation, North Ramp Starter Tunnel, Upper Bench," SLTR93-7001, DTN:SNF28021693001.001, Sandia National Laboratories, Albuquerque, NM.

Brown, S.R. 1994. Simple Mathematical Model of a Rough Fracture, SAND92-2216J, Sandia National Laboratories, Albuquerque, NM. MOL 19941006.0040. 
Chan, T, K., Khair, L. Jing, M. Ahola, J. Noorishad, and E. Vuillod (1995), "International comparison of coupled thermo-hydro-mechanical models of a multiple-fracture bench mark problem: DECOVALEX Phase I, bench mark test 2," in Thermo-Hydro-Mechanical Coupling in Rock Mechanics, Int. J. Rock Mech. Min. Sci. \& Geomech. Abstr., 32(5).

Christianson, M. C., and B. Brady (1989), Analysis of Alternative Waste Isolation Concepts, U.S. Nuclear Regulatory Commission, Washington, DC, NRC-FIN D1016, NUREG/CR-5389.

Cohen, L. H., and W. Klement, Jr. (1975), "Differential Thermal Analysis Investigation of the High-Low Cristobalite Inversion under Hydrostatic Pressure to $7 \mathrm{kbar}$," Jour. Am. Cerm. Soc. 58(5-6), 206-208.

Connolly, J. R. (1991), Mineralogy, Petrology and Whole-Rock Chemistry of Selected Mechanical Test Samples of Yucca Mountain Tuffs, Sandia National Laboratories, Albuquerque, NM, SAND90-7058. (101 pp., accession number NNA.911202.0029)

Connolly, J. R. (1994), Mineralogical, Petrologic, and Whole-Rock Chemical Analysis of Fran Ridge Tuff Used in the SNL Backfill Thermal Properties Experiment, FR88-62-SNL Petrology Report, written communication from Univ. of New Mexico to Sandia National Laboratories.

Cooper, H. W., and G. Simmons (1977), "The Effects of Cracks on Thermal Expansion of Rocks," Earth and Planetary Science Letters 36, 404.

Costin, L. S. (1987), "Time-dependent deformation and failure in Fracture Mechanics of Rock," B. K. Atkinson editor, pp. 167-215, Academic Press, London. ISBN: 0-12-066265-5.

DOE (U.S. Department of Energy) (1994), Yucca Mountain Project Reference Information Base, Version 4, Yucca Mountain Site Characterization Project Office, Las Vegas, NV, YMP/CC-0002. (NNA 890330.0077)

Durham, W. B., J. M. Beiriger, M. Axelrod, and S. Trettenaro (1986), "The Effect of Gamma Radiation on the Strength and Elasticity of Climax Stock and Westerly Granites," Nuclear and Chemical Waste Management 6, 159-168.

Ehgartner, B. L., and R. C. Kalinski (1988), A Synopsis of Analyses (1981-1987) Performed to Assess the Stability of Underground Excavations at Yucca Mountain, Sandia National Laboratories, Albuquerque, NM, SAND88-2294.

Gertsch, R. and L. Ozdemir (1992), Performance Prediction of Mechanical Excavators from Linear Cutter Tests on Yucca Mountain Welded Tuffs, Sandia National Laboratories, Albuquerque, NM, SAND91-7038. (accession number NNA.920819.0247)

Hardy, M.P., and S.J. Bauer, 1991. Drift Design Methodology and Preliminary Application for the Yucca Mountain Site Characterization Project, SAND89-0837, Sandia National Laboratories, Albuquerque, New Mexico. (NNA.910808.0105) Herrmann, H. J., and S. Roux (1990), Statistical Models for the Fracture of Disordered Media (North-Holland Elsevier Science Publishers B. V.).

Itasca Consulting Group, Inc. (1993), FLAC User's Manual, vol. I-III, Minneapolis, MN.

Jiao, Y., and J. A. Hudson (1995), "The full-coupled model for rock engineering systems", Int. J. Rock Mech. Min. Sci. \& Geomech. Abstr. 32(5). 
Jing, L., C.-F. Tsang, and O. Stephansson (1995), “DECOVALEX-an international cooperative research project on mathematical models of coupled THM processes for safety analysis of radioactive waste repositories," Int. J. Rock Mech. Min. Sci. \& Geomech. Abstr. 32,5.

Kana, D. D., B. H. G. Brady, B. W. Vanzant, and P. K. Nair (1989), Critical Assessment of Seismic and Geomechanics Literature Related to a High-Level Nuclear Waste Underground Repository, Nuclear Regulatory Commission, Center for Nuclear Waste Regulatory Analyses, San Antonio, Texas.

Kemeny, J., and N. Cook (1990), "Rock Mechanics and Crustal Stress," Demonstration of a Risk-Based Approach to High-Level Waste Repository Evaluation, R. K. McGuire, Ed., Electric Power Research Institute, Palo Alto, CA, EPRI-NP-7057.

Keskar, N. R., and J. R. Chelikowsky (1993), Anomalous Elastic Behavior in Crystalline Silica, Phys. Rev. D, 48, 16,227-16,233.

Lee, K. H. (1995), "Progress report on pre-test calculations for the Large Block Test," UCRL-ID-118669, Lawrence Livermore National Laboratory, Livermore, CA.

Lin, M., M. P. Hardy, and S. J. Bauer (1993a), Fracture Analysis and Rock Quality Designation Estimation for the Yucca Mountain Site Characterization Project, Sandia National Laboratories, Albuquerque, NM, SAND92-0449. (accession number NNA.921204.0012)

Lin, M., M. P. Hardy, J. F. T. Agapito \& Associates, and S. J. Bauer (1993b), Rock Mass Mechanical Property Estimations for the Yucca Mountain Site Characterization Project, Sandia National Laboratories, Albuquerque, NM, SAND92-0450. (accession number NNA.921204.0013)

Lin, W. L., D. G. Wilder, J. A. Blink, S. C. Blair, et al. (1994), "The testing of thermalmechanical-hydrological-chemical processes using a large block," in Proceedings of the 5th Intl. High-Level Rad. Waste Mgmt. Conf., Las Vegas, ASCE (May, 1994).

Lin, W. D.G. Wilder, J. A. Blink, S. C. Blair, T. A. Buscheck, W. E. Glassley, K. Lee, M. W. Owens, \& J. J. Roberts, (1995) "A heated large block test for high level nuclear waste management," in Proceedings of the Second International Conference on the Mechanics of Jointed and Faulted Rock, Vienna, Austria, April, 1995.

MacDougall, H. R., L. W. Scully, and J. R. Tillerson, (Compilers) (1987), Site Characterization Plan Conceptual Design Report, Sandia National Laboratories, Albuquerque, NM, SAND84-2641.

Martin, R. J., III, R. H. Price, P. J. Boyd, and J. S. Noel (1993), Unconfined Compression Experiments on Topopah Spring Member Tuff at $22^{\circ} \mathrm{C}$ and a Strain Rate of $10^{-9} \mathrm{~s}^{-1}$ : Data Report, Sandia National Laboratories, Albuquerque, NM, SAND91-0894. (accession number NNA.930728.0088)

Martin, R. J., III, R. H. Price, P. J. Boyd; and R. W. Haupt (1992), Anisotropy of the Topopah Spring Member Tuff, Sandia National Laboratories, Albuquerque, NM, SAND91-0894. (28 pp., accession number NNA.920522.0041)

Martin, R. J., J.S. Noel, P.J. Boyd, and R.H. Price, 1996, "Thermal expansion as a function of confining pressure for welded tuff from Yucca Mountain," in Proceedings of the 2nd North American Rock Mechanics Symposium, Montreal, Canada, June 19-21, 1996, Aubertin, Hasssani, and Mitri eds. Balkema. Rotterdam. 
Martin, R. J., R. H. Price, P. J. Boyd, and J. S. Noel (1994), Bulk and Mechanical Properties of the Paintbrush Tuff Recovered from Borehole USW NRG-6: Data Report, Sandia National Laboratories, Albuquerque, NM, SAND93-4020. (92 pp., accession number MOL.19940811.0001)

Martin, R. J., R. H. Price, P. J. Boyd, and J. S. Noel (1995a), Bulk and Mechanical Properties of the Paintbrush Tuff Recovered from Borehole USW NRG-7/7A: Data Report, Sandia National Laboratories, Albuquerque, NM, SAND94-1996. (93 pp., accession number MOL.19950316.0087)

Martin, R. J., II, R. H. Price, P. J. Boyd, and J. S. Noel (1995b), Creep in Topopah Spring Member Welded Tuff, Sandia National Laboratories, Albuquerque, NM, SAND94-2585. (53 pp., accession number MOL.19950502.0006)

Meike, A., and Glassley, W. E. (1990), In-Situ Observation of the Alpha/Beta Cristobalite Transition Using High Voltage Electron Microscopy, MRS Symp. Proc., 176, 631-639.

Millard, A., N. Durin, A. Stietel, A. Thoraval, E. Vuillod, H. Baroudi, F. Plas, A. Bougnoux, G. Vouille, A. Kobayashi, K. Hara, T. Fujita and Y. Ohnishi (1995), "Discrete and continuum approaches to simulate the thermo-hydro-mechanical couplings in a large, fractured rock mass," Int. J. Rock Mech. Min. Sci. \& Geomech. Abstr. 32(5).

Nguyen, T. S., and A. P. S. Selvadurai (1995), "Coupled thermal-mechanicalhydrological behaviour of sparsely fractured rock: implications for nuclear fuel wasted disposal," Int. J. Rock Mech. Min. Sci. E Geomech. Abstr. 32(5).

Nimick, F. B. (1990), The Thermal Conductivity of Seven Thermal Mechanical Units at Yucca Mountain, Nevada, Sandia National Laboratories, Albuquerque, NM, SAND88-1387.

Nimick, F. B., R. G. Van Buskirk, and A. F. McFarland (1987), Uniaxial and Triaxial Compression Test Series on Topopah Spring Member from USW G-2, Yucca Mountain, Neoada, Sandia National Laboratories, Albuquerque, NM, SAND85-0703.

Olsson, W. A. (1987), Rock Joint Compliance Studies, Sandia National Laboratories, Albuquerque, NM, SAND86-0177.

Olsson, W. A. (1988), Compliance and Strength of Artificial Joints in Topopah Spring Tuff, Sandia National Laboratories, Albuquerque, NM, SAND88-0660.

Olsson, W. A. (1994), The Effect of Sliding Velocity on the Mechanical Response of an Artificial Joint in Topopah Spring Member Tuff, Sandia National Laboratories, Albuquerque, NM, SAND92-2333. (18 pp., accession number NNA.940209.0001)

Olsson, W. A., and S. R. Brown (1994), Mechanical Properties of Seven Fractures from Drillholes NRG-4 and NRG-6 at Yucca Mountain, Nevada, Sandia National Laboratories, Albuquerque, NM, SAND94-1995. (29 pp., accession number MOL.19941007.0081)

Olsson, W. A., and A. K. Jones (1980), Rock Mechanics Properties of Volcanic Tuffs from the Nevada Test Site, Sandia National Laboratories, Albuquerque, NM, SAND801453.

O’Neal, W. C., D. W. Gregg, J. N. Hockman, E. W. Russell, and W. Stein (1984), Preclosure Analysis of Conceptual Waste Package Designs for a Nuclear Waste 
Repository in Tuff, Lawrence Livermore National Laboratory, Livermore, CA, UCRL-53595.

Phillips, J. S., and B. A. Luke (1991), Tunnel Damage Resulting from Seismic Loading, Sandia National Laboratories, Albuquerque, NM, SAND90-1721C. (27 pp., accession number NNA.910424.0001)

Price, R. H. (1983), Analysis of Rock Mechanics Properties of Volcanic Tuff Units from Yucca Mountain, Nevada Test Site, Sandia National Laboratories, Albuquerque, NM, SAND82-1315.

Price, R. H. (1986), Effects of Sample Size on the Mechanical Behavior of Topopah Spring Tuff, Sandia National Laboratories, Albuquerque, NM, SAND85-0709.

Price, R. H., and A. K. Jones (1982), Uniaxial and Triaxial Compression Tests Series on Calico Hills Tuff, Sandia National Laboratories, Albuquerque, NM, SAND82-1314.

Price, R. H., F. B. Nimick, J. R. Connolly, K. Keil, B. M. Schwartz, and S. J. Spense (1985), Preliminary Characterization of the Petrologic, Bulk, and Mechanical Properties of a Lithophysal Zone Within the Topopah Spring Member of the Paintbrush Tuff, Sandia National Laboratories, Albuquerque, NM, SAND84-0860.

Price, R. H., J. R. Connolly, and K. Keil (1987), Petrologic and Mechanical Properties of Outcrop Samples of the Welded, Devitrified Topopah Spring Member of the Paintbrush Tuff, Sandia National Laboratories, Albuquerque, NM, SAND86-1131.

Price, R. H., R. J. Martin, III, and R. W. Haupt (1994), The Effect of Frequency on Young's Modulus and Seismic Wave Attenuation, Sandia National Laboratories, Albuquerque, NM, SAND92-0847. (50 pp.)

Pusch, R. (1989), Influence of Various Excavation Techniques on the Structure and Physical Properties of Near-Field Rock around Large Boreholes, Swedish Nuclear Fuel and Waste Management Co. (SKB), Stockholm, Sweden, Technical Report 89-32. Rehbinder (1995), "Analytical solutions of stationary coupled thermo-hydrogeomechanical problems," Int. J. Rock Mech. Min. Sci. \& Geomech. Abstr. 32(5). Roberts, J. R. and W. Lin, 1995, "Permeability of Fractured Tuff as Functions of Temperature oand Confining Pressure, in Proceedings of the 19965Int'l High Level Radioactive Waste Management Conference, Las Vegas, NV, published by American Nuclear Soc and American Society of Civil Engineers

Scott, R. B., and M. Catellanos (1984), Stratigraphic and Structural Relations of Volcanic Rocks in Drill Holes USW GU-3 and USW G-3, Yucca Mountain, Nye County, Nevada, U.S. Geological Survey, Denver, CO, OFR-84-491.

Stephansson, O. (1995), "Introduction to Special Issue on Thermo-Hydro-Mechanical Coupling in Rock Mechanics," Int. J. Rock Mech. Min. Sci. \& Geomech. Abstr. 32(5).

Stock, J. M., J. H. Healy, and S. H. Hickman (1984), Report on Televiewer Log and Stress Measurements in Core Hole USW G-2, Nevada Test Site, U.S. Geological Survey,

Denver, CO, OFR-84-172.

Stock, J. M., J. H. Healy, S. H. Hickman, and M. D. Zoback (1985), "Hydraulic

Fracturing Stress Measurements at Yucca Mountain, Nevada, and Relationship to Regional Stress Field," J. Geophys. Res. 90(B10), 8691-8706.

Subramanian, C. V., J. L. King, D. M. Perkias, R. W. Modd, A. M. Richardson, J. C. Calovini, E. VanEeckhout, and D. D. Emerson (1990), Exploratory Shaft Seismic Design Basis Working Group Report, Sandia National Laboratories, Albuquerque, NM, SAND88-1203. 
Teufel, L. A., and M. J. McNamee (1991), Tensile Strength Testing of Topopah Spring Tuff, Sandia National Laboratories, Albuquerque, NM, SAND91-0044. (13 pp., accession number NNA.910322.0056)

Wibowo, J., B. Amadei, S. Sture, R. H. Price, and A. B. Robertson (1993), Effect of Boundary Conditions on the Strength and Deformability of Replicas of Natural Fractures in Welded Tuff: Data Report, Sandia National Laboratories, Albuquerque, NM, SAND92-1853. (accession number NNA.930907.0001)

Wilder, D. G. (1990), “Engineered Barrier Systems and Canister Orientation Studies for the Yucca Mountain Project, Nevada," Proc. of International Symp. on Unique Underground Structures (Colorado School of Mines Press, Colorado).

Yehaneh-Hari, A., D. J. Weidner, and J. B. Parise (1992), Elasticity of $\alpha$-Cristobalite: A Silicon Dioxide with a Negative Poisson's Ratio, Science, 257, 650-652.

Zimmerman, R. M., R. L. Schuch, D. S. Mason, M. L. Wilson, M. E. Hall, M. P. Board, R. P. Bellman, and M. L. Blanford (1986), Final Report: G-Tunnel Heated Block Experiment, Sandia National Laboratories, Albuquerque, NM, SAND842620. 


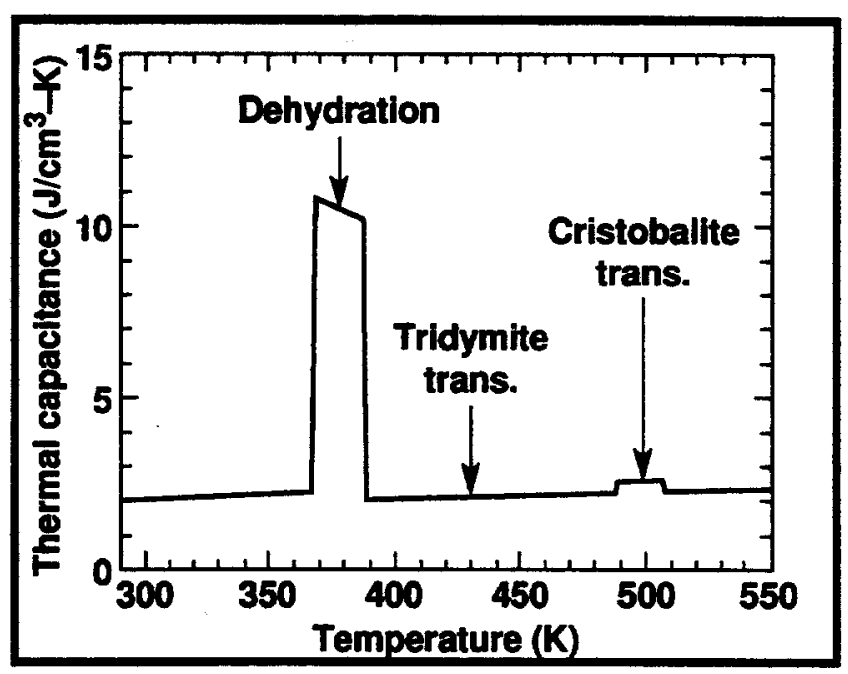

Figure 4-1. Rock-mass thermal capacitance of unit TSw2 showing the effects of dehydration and cristobalite transformation. The temperature of tridymite transformation is shown for reference. Adapted from the Yucca Mountain Project Reference Information Base (DOE, 1994).

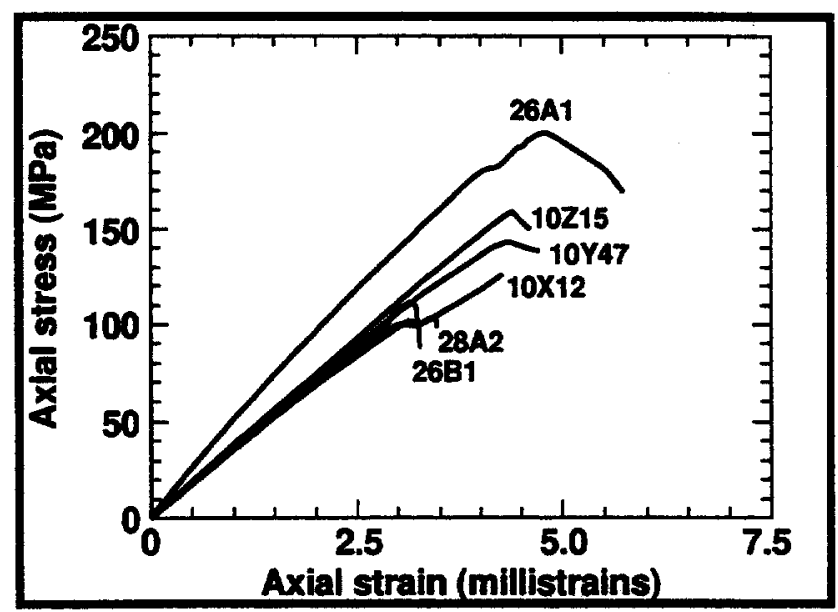

Figure 4-2. Plots of axial stress vs axial strain for uniaxial measurements on 50.8$\mathrm{mm}$ saturated Tpt samples at $22^{\circ} \mathrm{C}$. Measurements were taken at a strain rate of $10^{-}$ $5_{\mathrm{s}^{-1}}$. Adapted from Price (1986). 


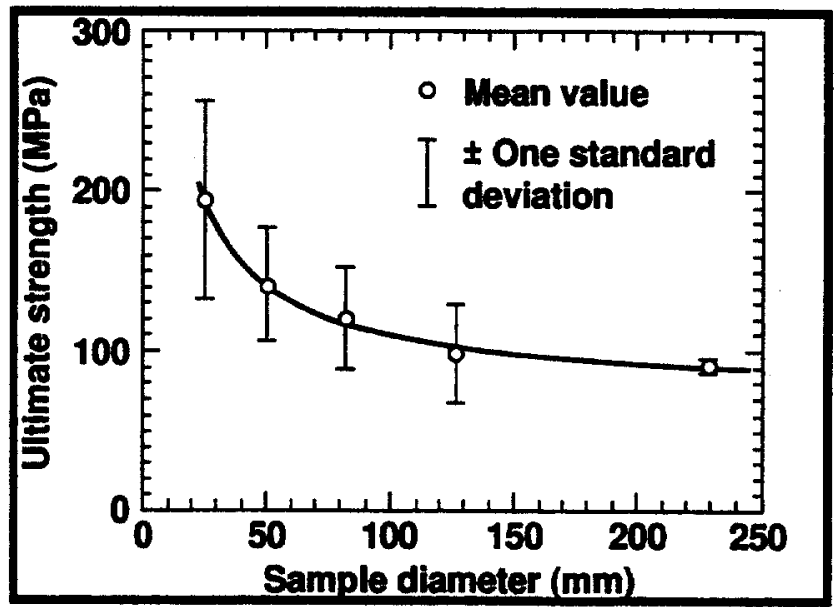

Figure 4-3. Plot of ultimate strength vs sample diameter for uniaxial measurements on saturated Tpt samples at $22^{\circ} \mathrm{C}$. Measurements were taken at a strain rate of $10^{-5} \mathrm{~s}^{-1}$. Adapted from Price (1986).

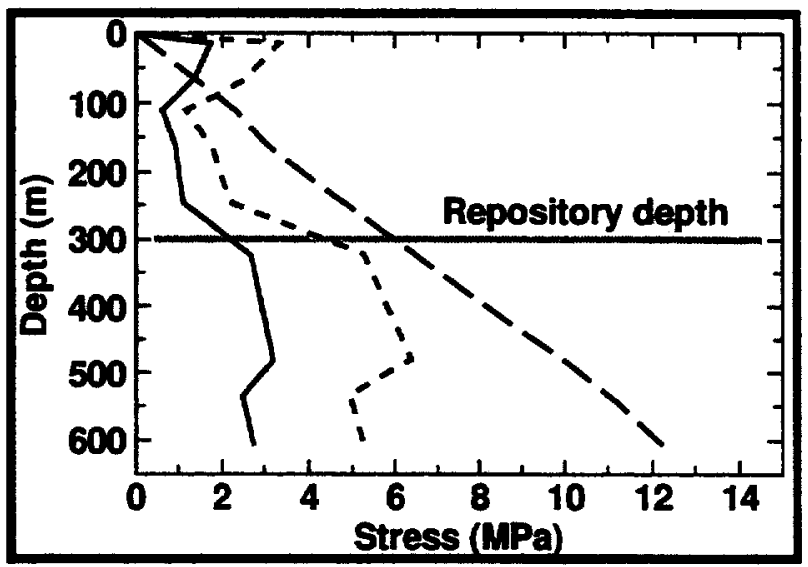

Figure 4-4. Stress profile along an exploratory shaft near the Exploratory Studies Facility. The solid line is the minimum horizontal stress, the long dashed line is the maximum horizontal stress, and the short dashed line is the vertical stress. Adapted from the Yucca Mountain Project Reference Information Base (DOE, 1994). 


\section{Applied Stress}

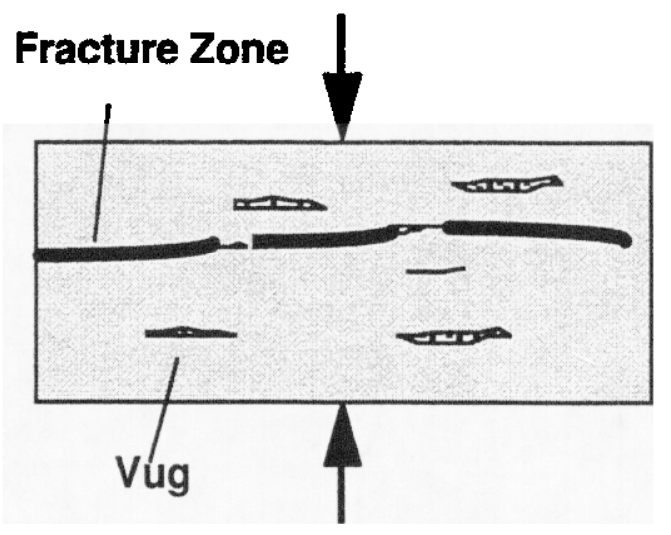

Figure 4-5. Schematic of compression test on $0.5 \mathrm{~m}$ scale block of Topopah Spring tuff.

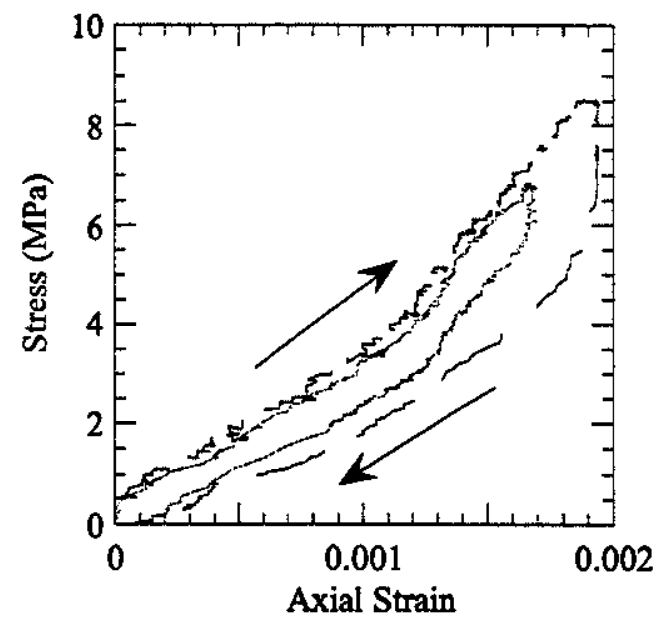

Figure 4-6. Stress-strain behavior for repeated loading of a single fracture in a $0.5 \mathrm{~m}$ block of Topopah Spring tuff. Adapted from Blair and Berge, 1996. 


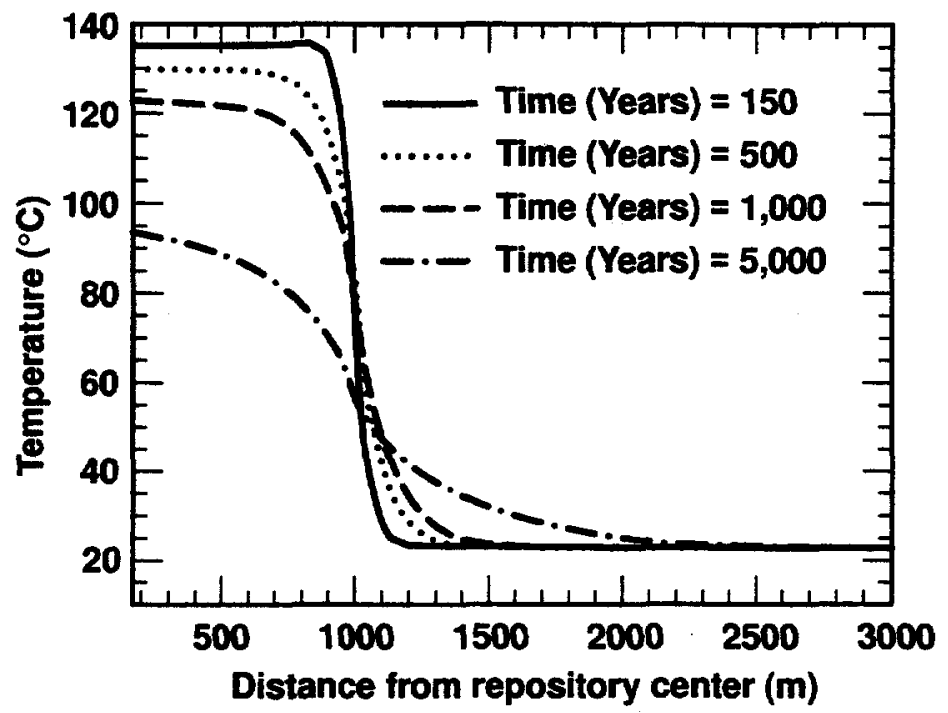

Figure 4-7. Temperature profile predicted in the rock forming the repository at $150,500,1000$, and 5000 yrs after emplacement of waste at a thermal density of 83.4 MTU per acre. 
Table 4-1. Physical and thermal properties of rock in the Topopah Spring welded unit, lithophysae-poor layer (TSw2).

\begin{tabular}{lc}
\multicolumn{1}{c}{ Parameter } & Value \\
\hline Physical Properties & $12 \pm 4^{\mathrm{a}}$ \\
Porosity $(\%)$ & $2.55 \pm 0.03^{\mathrm{a}}$ \\
Grain density $\left(\mathrm{g} / \mathrm{cm}^{3}\right)$ & $2.30 \pm 0.09^{\mathrm{a}}$ \\
Bulk density at in situ saturation $\left(\mathrm{g} / \mathrm{cm}^{3}\right)$ & $2.22 \pm 0.10^{\mathrm{a}}$ \\
Dry bulk density $\left(\mathrm{g} / \mathrm{cm}^{3}\right)$ & \\
Thermal Properties & $2.51 \pm 0.17^{\mathrm{b}}$ \\
Dry matrix thermal conductivity $(\mathrm{W} / \mathrm{mK})$ & - \\
Saturated matrix thermal conductivity $(\mathrm{W} / \mathrm{mK})$ & $2.1 \pm 0.2^{\mathrm{b}}$ \\
Dry in situ thermal conductivity $(\mathrm{W} / \mathrm{mK})$ & $2.1 \pm 0.2^{\mathrm{bc}}$ \\
Saturated in situ thermal conductivity $(\mathrm{W} / \mathrm{mK})$ &
\end{tabular}

${ }^{2} \mathrm{DOE}(1994)$

Wimick (1990)

${ }^{c} 0.65 \pm 0.19$ in situ saturation with lithophysal cavities and fractures assumed dry.

Table 4-2. Coefficients of linear thermal expansion $\left(10^{-6} /{ }^{\circ} \mathrm{C}\right)$ for Topopah Spring welded unit, lithophysae-poor layer (TSw2) during heating.

\begin{tabular}{|c|c|c|c|c|c|c|}
\hline \multirow[b]{3}{*}{ Type } & \multicolumn{5}{|c|}{ Temperature Range $\left({ }^{\circ} \mathrm{C}\right)$} & \\
\hline & $25-50^{\circ}$ & $50-100^{\circ}$ & $100-150^{\circ}$ & $150-200^{\circ}$ & $200-250^{\circ}$ & $250-300^{\circ}$ \\
\hline & $n$ & $n$ & $\bar{\propto} \quad s \quad n$ & $\bar{\propto}$ & $\bar{\propto} \quad s$ & $n s$ \\
\hline Intact rock & 9.11 .39 & 8.20 .89 & 6.80 .54 & $9.7-$ & -- & - \\
\hline $\begin{array}{l}\text { Very near } \\
\text { field }\end{array}$ & 5.42 .212 & 8.01 .512 & 9.81 .712 & 17.011 .612 & 25.015 .711 & 35.610 .87 \\
\hline
\end{tabular}


Table 4-3. Values of rock-mass thermal capacitance for Topopah Spring welded unit, lithophysae-poor layer (TSw2) at selected temperatures (DOE, 1994).

\begin{tabular}{cc}
$\begin{array}{c}\text { Temperature } \\
\left({ }^{\circ} \mathrm{C}\right)\end{array}$ & $\begin{array}{c}\text { Thermal capacitance } \\
\left(\mathrm{J} / \mathrm{cm}^{3} \mathrm{~K}\right)\end{array}$ \\
\hline 25 & 2.0324 \\
50 & 2.1280 \\
94 & 2.2638 \\
95 & 10.7683 \\
105 & 10.4690 \\
114 & 10.1984 \\
115 & 2.0065 \\
155 & 2.1114 \\
195 & 2.1912 \\
235 & 2.2692 \\
275 & 2.3410 \\
\hline
\end{tabular}

Table 4-4. Mechanical properties of intact rock for unit TSw2 (DOE, 1994).

\begin{tabular}{lc}
\hline \multicolumn{1}{c}{ Mechanical property } & Value \\
\hline Unconfined compressive strength (MPa) & $155 \pm 59$ \\
Young's modulus (GPa) & $32.7 \pm 4.6$ \\
Poisson's ratio & \\
USW G-1, USW GU-3 & $0.22 \pm 0.03$ \\
USW G-4 & $0.30 \pm 0.05$ \\
Cohesion (MPa) & \\
USW G-2 & $18.3 \pm 5.2$ \\
UE-25a\#1, USW G-4, USW GU-3 & $37.8 \pm 12.4$ \\
Angle of internal friction & \\
USW G-2 & $19.7^{\circ} \pm 5.2^{\circ}$ \\
UE-25a\#1, USW G-4, USW GU-3 & $36.5^{\circ} \pm 9.0^{\circ}$ \\
\hline
\end{tabular}


Table 4-5. Values and ranges of principal stresses in the potential repository horizon at Yucca Mountain (Stock et al., 1984, 1985).

\begin{tabular}{lcc}
\hline \multicolumn{1}{c}{ Parameter } & Average value & Range \\
\hline $\begin{array}{l}\text { Maximum principal stress (vertical) } \\
\begin{array}{l}\text { Ratio of minimum horizontal stress to } \\
\text { vertical stress }\end{array}\end{array}$ & $7.0 \mathrm{MPa}\left(10^{15} \mathrm{psi}\right)$ & 5.0 to 10.0 \\
$\begin{array}{l}\text { Ratio of maximum horizontal stress to } \\
\text { vertical stress }\end{array}$ & 0.5 & 0.3 to 0.8 \\
$\begin{array}{l}\text { Bearing of minimum horizontal stress } \\
\text { Bearing of maximum horizontal stress }\end{array}$ & 0.6 & 0.3 to 1.0 \\
\hline
\end{tabular}

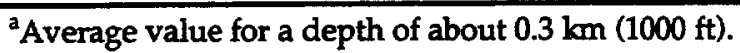

Table 4-6. Corrected linear fracture frequency $\left(\mathrm{m}^{-1}\right)$ the Topopah Spring welded unit, lithophysaepoor layer (TSw2) at Yucca Mountain (Lin, 1993a).

\begin{tabular}{lccccccccc}
\hline & $0-10^{\circ}$ & $10-20^{\circ}$ & $20-30^{\circ}$ & $30-40^{\circ}$ & $\mathbf{4 0 - 5 0 ^ { \circ }}$ & $50-60^{\circ}$ & $60-70^{\circ}$ & $70-80^{\circ}$ & $80-90^{\circ}$ \\
\hline $\begin{array}{l}\text { Upper } \\
\text { range }\end{array}$ & 0.50 & 0.60 & 0.46 & 0.35 & 0.35 & 0.44 & 0.89 & 5.92 & 24.07 \\
Mean & 0.25 & 0.29 & 0.25 & 0.22 & 0.23 & 0.24 & 0.56 & 2.51 & 11.28 \\
Lower & 0.05 & 0.05 & 0.07 & 0.05 & 0.05 & 0.06 & 0.19 & 0.81 & 2.99 \\
bound & & & & & & & & & \\
\hline
\end{tabular}

Table 4-7. Comparison of Rock Mass Strength Estimates to Intact Strength Data for Topopah Spring welded unit, lithophysae-poor layer (TSw2), adapted from Brechtel (1995).

\begin{tabular}{cccccc}
\hline $\begin{array}{c}\text { Estimated Rock } \\
\text { Mass Strength } \\
(\mathbf{M P a})\end{array}$ & $\begin{array}{c}\text { Intact } \\
\text { Strength } \\
(\mathbf{M P a})\end{array}$ & $\begin{array}{c}\text { Intact Standard } \\
\text { Deviation } \\
(\mathbf{M P a})\end{array}$ & $\begin{array}{c}\text { Ratio of Rock } \\
\text { Mass to Intact } \\
\text { Strength } \\
(\%)\end{array}$ & $\begin{array}{c}\text { Rock Mass } \\
\text { Elastic Modulus } \\
\text { (GPa) }\end{array}$ & $\begin{array}{c}\text { Rock } \\
\text { Mass } \\
\text { Poisson's } \\
\text { Ratio }\end{array}$ \\
\hline 18.8 & 178.5 & 78.3 & 10.6 & 23.51 & 0.21 \\
\hline
\end{tabular}

All values were computed using Hardy and Bauer (1991) classification 5 which is designed to include $90 \%$ of the rock in a particular unit. 
Table 4-8. Recommended motions for the design-basis UNE (Subramanian et al., 1990).

\begin{tabular}{lcc}
\hline Component & $\begin{array}{c}\text { Median } \\
\text { predicted } \\
\text { value }\end{array}$ & $\begin{array}{c}\text { Design-basis UNE values } \\
{[95 \% \text { nonexceedance }} \\
\text { level (1.65 б)] }\end{array}$ \\
\hline Vertical acceleration $(\mathrm{g})$ & 0.05 & 0.2 \\
Radial acceleration $(\mathrm{g})$ & 0.03 & 0.1 \\
Transverse acceleration $(\mathrm{g})$ & 0.03 & 0.1 \\
Vertical velocity $(\mathrm{cm} / \mathrm{s})$ & 4 & 9 \\
Radial velocity $(\mathrm{cm} / \mathrm{s})$ & 4 & 12 \\
Transverse velocity $(\mathrm{cm} / \mathrm{s})$ & 3 & 12 \\
Vertical displacement $(\mathrm{cm})$ & 1 & 2 \\
Radial displacement $(\mathrm{cm})$ & 1 & 3 \\
Transverse displacement $(\mathrm{cm})$ & 1 & 4 \\
\hline
\end{tabular}




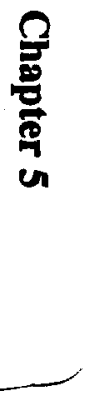

$-$ 


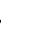

$\longrightarrow$ 


\section{Contents}

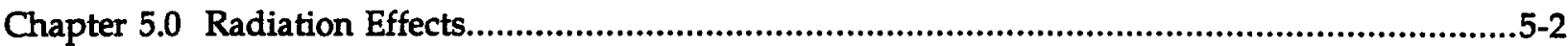

5.1 Reference.

. -2 


\section{Chapter 5.0 Radiation Effects}

\section{Richard A. Van Konynenburg}

When the previous report version was being written, we considered waste packages with relatively thin-walled containers. The gamma-ray dose rates outside such packages would be high enough that observable radiation-chemical effects would be produced in the near field, so a detailed discussion of such effects was presented. Since that time, a new waste package design philosophy has emerged. For this design, our objective is to make the waste package walls sufficiently thick, providing enough radiation shielding to reduce the dose rates to levels that will eliminate concerns about radiation-chemical effects on package corrosion $(100 \mathrm{R} / \mathrm{hr}$ or less and uneventful). No experiments have been funded to determine the dose rate at which effects on corrosion are no longer observed, but based on the literature, it is probably an order of magnitude higher than $100 \mathrm{R} / \mathrm{hr}$, although experiments would be required to confirm this. At such levels, it is likely that effects on important near-field geochemical parameters such as $\mathrm{pH}$ and Eh will also be minimal. Certainly, radiation effects will not extend beyond a few centimeters of rock or backfill. Therefore, no further discussion of radiolytic effects will be presented here. Refer to the PNFER (Wilder, 1993) for a discussion of the environmental effects that could occur if the radiation dose were many times higher than the current design allows.

\subsection{Reference}

Wilder, D. G. (1993), Preliminary Near-FIeld Environment Report Volume II: Scientific Overview of Near-Field Environment and Phenomena, Lawrence Livermore National Laboratory, Livermore, CA, UCRL-LR-107476. 


$$
\text { - }
$$




\section{Contents}

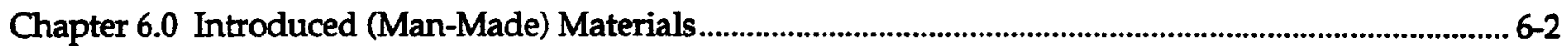

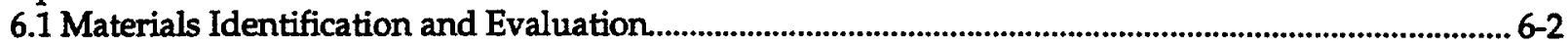

6.1.1 Original Post-Construction Conditions .......................................................................................6-2

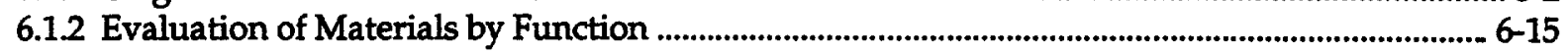

6.1.3 Tracers, Fluids and Materials Database: Retrieval of Information .............................................. 6-18

6.1.4 Assessment of Materials Considered for Repository Construction.............................................. 6-20

6.2 Post-Closure Chemical Processes That May Modify Predicted Geochemistry................................... 6-21

6.2.1 Abiotic Chemistry ........................................................................................................................................ 6-22

6.2.2 Biotic Chemistry (microbially mediated chemistry) ....................................................................... 6-46

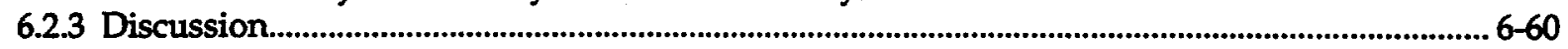

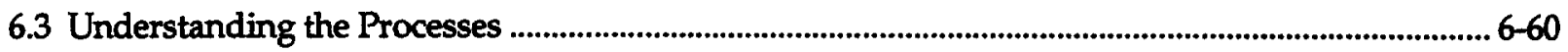

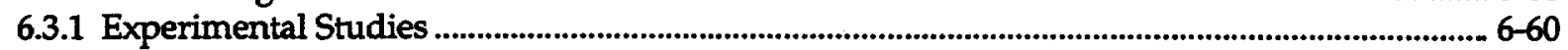

6.3.2 Historical Analogs as Long Term Experiments ..............................................................................6-67

6.3.3 Modeling Activities......................................................................................................................................6-68

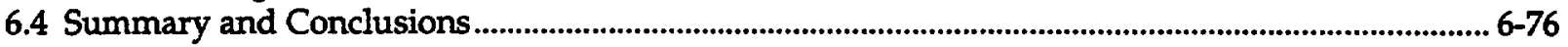

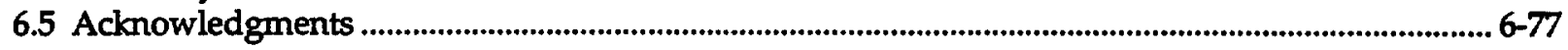

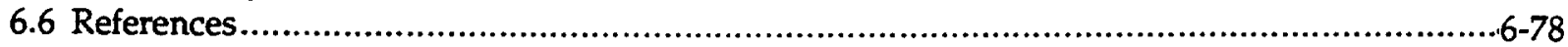

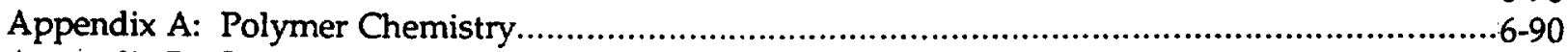

Appendix B: Curing of Cementitious Material..............................................................6-93 


\title{
Chapter 6.0 Introduced (Man-Made) Materials
}

\author{
Annemarie Meike
}

\subsection{Materials Identification and Evaluation}

The present appraisal of the potential effects of introduced materials on the chemistry and mineralogy of the post-emplacement environment is presented in three sections. The first section of this chapter seeks to identify potential inherent chemical reactions and uncertainties that are inherent in the pre-closure repository design.

The chemical significance of the materials and the chemical processes that involve them are influenced by temperature, degree of water saturation, fluid composition, and the ratio of material surface area to fluid volume. We expect heat to be generated by the waste packages and some water to enter the near-field environment, which will affect the character of the chemical and hydrological processes and the timing of their occurrence. These processes, which are part of the post-closure perturbation of the repository, are addressed in the second section.

The third section is a discussion of the status of modeling intended to predict the processes, their outcomes, and the timing of events discussed in section 6.5. Ulimately these models will be used in conjunction with geological and hydrological models to describe likely chemical and hydrological interactions among water, the host rock, the waste packages, introduced materials, and organisms. However, even in the absence of such sophisticated modeling capability, an iterative exchange between the identification and evaluation of materials, computer modeling, and performance assessment can positively influence design decisions.

\subsubsection{Original Post-Construction Conditions}

The original as-built design has inherent chemical reactions which become important parameters for predicting the chemical environment of a waste package (WP). A broad spectrum of materials and organisms may be introduced into a radioactive-waste repository as a result of its construction and operation. More than 260 items used in a mine construction setting (the Exploratory Shaft Facility) were inventoried by West (1988), together with the known chemical effects of those materials at $25^{\circ} \mathrm{C}$. A further discussion of materials that could be located in the near-field environment and some potential chemical consequences has been presented in Rev. 0 of the Near Field Environment Report. However, it is not sufficient to simply identify materials and their chemical effects in isolation. The chemical impact of a material depends upon its context: its concentration, distribution, reaction rates and products, and other materials with which it is in contact or in close proximity. In addition, the heterogeneous distribution of materials will create $\mathrm{pH}$ and chemical concentration gradients that may in themselves drive chemical reactions. The examination and comparison of these materials assemblages as chemical systems that influence water chemistry and hydrology will most effectively support design decisions. In order to develop a useful system of comparison and decision making, we identify materials 
assemblages, or collections of materials that represent the various options that are available to perform a specific function (e.g., transportation, mucking, excavation, and stabilization). The materials assemblages are based on observations drawn from the construction of the Exploratory Studies Facility (ESF).

In this chapter we will need to depart from the terminology of the Waste Isolation Evaluations (WIE) in which it is recognized that the terms "permanent," "nonpermanent," and "temporary" are used for materials disbursement in a specific manner. For materials disbursement purposes "temporary" and "non-permanent" refer to items that are removed prior to operation of a potential repository. "Permanent" refers to materials that are used at the site during the operations period, but which may be removed at closure of the potential repository. The WIE therefore uses the words "committed" and "non-committed," in which "non-committed" refers to substances are only those which are not being purposely introduced into the environment and for which reasonable assurance exists that the bulk of the substance would be removed at closure and "committed" refers to substances that are expected to be retained in the environment after closure. Because all of these terms have been applied in such a way as to imply intent, none of them are applicable to the present study. The purpose of the present study is to identify materials that may be introduced into a repository setting, and to determine the longevity of the potential chemical impact, part of which depends on the residence time of the substance. Other factors include concentration, degradation rate and environmental factors. We will use different terminology to underscore our purpose, which is to discover the residence time from actual usage data rather than to record the original intent. For our purpose we will use the terms "short-residence" and "extended-residence."

At present, although the Advanced Conceptual Design (ACD) for the potential Yucca Mountain Repository has been released, many aspects of drift engineering that are required to carry out that design are not complete. Some materials such as metals, bonding agents, and concrete may serve as active parts of the designed engineered barrier. Other materials that are introduced to serve other purposes, including surveillance (thermocouples, gauges), construction and operation (drilling rigs, roadbeds, exhaust fumes, chemical toilets, concrete, grout, rebar), and lubrication (petroleum-based products, rope dressing) may not be removed because they have either become inaccessible or have not been identified as items to be removed. In normal mining operations extended residence materials also include waste material and spills. The introduced materials will exist in gas, liquid, and solid phases, as inorganic and organic compounds, and in various reactive states. Some materials, such as concrete, may be present in large quantities. As of this writing, precast concrete is being considered as a major part of the non-removable mechanical support system as well as invert material.

Although this lack of information directly affects our present ability to predict the chemistry of the near-field environment, we have the potential to provide input to those engineering decisions that may increase the confidence of future predictions by examining and assessing materials that have a high probability of being used in a repository setting. 
6.1.1.1 Evaluation of Materials from ESF Construction. We have monitored excavation practices at the Exploratory Studies Facility (ESF) assuming that the construction methods used at the ESF represent a baseline for standard construction activities in a repository setting. Based on an examination of ESF construction techniques, we have concluded that detailed relational information is key to obtaining good estimates of construction material usage and, thus, our ability to model drift-scale chemical, hydrological and mechanical processes. Our purpose has been to obtain relational information and methods for estimating materials usage during the construction of a proposed repository at Yucca Mountain. Work in this area was initiated in December 1994 and halted in September 1995. We have attempted to determine the extent to which actual materials usage during construction and operation of an actual repository may be known or predicted, in order to more tightly constrain bounding conditions for the chemical impact of introduced materials in the near-field environment.

Materials used. Our expectation and that of many contacts from whom we requested information was that much of the materials usage information should be archived and readily available from the Tracers, Fluids and Materials (TFM) database. However, these data were not readily available (Meike and Spragge, 1995) as of September 1995. Inadequacies exist in the areas of obtaining, archiving and retrieving data. We understand that, partly because of our needs in this area, some of these inadequacies are presently being addressed.

More specific compositional information will be needed to support the needs of drift-scale modeling. However, in the absence of that information, we have begun to identify and quantify materials usage, and to recognize patterns of usage and deviations from those patterns, in order to build estimation methods and bounding parameters for the usage of various materials. In this report we identify and demonstrate important factors that affect the patterns of usage and, if monitored, will ultimately lead to more accurate predictive capabilities include geology, construction function, regulations, and procedural developments. For example, the pattern of variation between estimated and as-built materials is a function of structural and stratigraphic geological factors. The following observations have been made about materials usage and the relationship of these materials to materials called out in a design plan. In our description of materials usage we will make these important distinctions explicit.

Clearly, extended residence materials will have chemical effects, some of which may significantly impact the post-closure chemistry. What may not be so obvious is that extended residence materials include not only those materials that are explicitly named in a repository design, but also the unspecified and necessary associated materials. For example, a repository design concept that calls for precast invert sections does not necessarily explicitly include the polymer gasket that appears between many of the invert sections in the ESF. Similarly, excelsior, pine 4x4's (cribbing) and other cellulose materials have been placed in open fractures and behind steel sets for stabilization purposes and will probably remain in place permanently. Our documentation of the use of these materials and their functional relationships is well underway, although actual quantities are still to be retrieved from the TFM database when that becomes a 
possibility. Another category of extended residence, non-explicit materials is spills. Although major efforts have been taken to minimize the accidental introduction of material by reducing the occurrence of spills, cleaning them up when they occur, and reporting them, it is important to quantify that minimum. This includes a thorough documentation of reporting limits (e.g., how much diesel fuel can be spilled before a report must be filed?) and relational information (e.g., hydraulic oil is usually spilled near the TBM), as well as reported amounts.

Even "non-permanent" materials can affect the post-closure chemical environment. Short residence materials may leave a residue of significant chemical or hydrological importance, even after they have been removed. For example, a conveyor belt is used for mucking operations in the ESF. It appears to be depositing a fine layer of black organic matter on the left drift wall. More obvious are the talus piles of conveyer belt shreds and rock powder that pile up at the junction between conveyor segments. With respect to such short-residence materials, we document residual effects as a function of quantity, usage, and duration of emplacement.

We have aimed to recognize useful classification schemes and significant categories of materials for the purpose of supporting design decisions. A useful and elucidative category for discussion is the materials assemblage that represent functional units. Some of these functional units (e.g., for mechanical stabilization: steel sets or fibercrete) are substitutional.

There is also a certain amount of flexibility that is an inherent and necessary part of any construction design. For example, it is not possible to predict precisely how many rockbolts will be required to stabilize a particular section of drift. This depends on information that is acquired as the drift is excavated and must be determined to some extent by the contractor.

6.1.1.2 Uncertainty and Variability in Materials Used. The ability to translate from repository design concepts to the realities of the as-built drift, which may be the greatest source of uncertainty in estimating materials usage, has developed substantially from observations of ESF construction. We have aimed to recognize useful methods of quantification, whether they are threshold values, mean values and deviations, or degrees of uncertainty.

For data that can be quantified, we wish to obtain materials usage data at a resolution significant to the Yucca Mountain Project, which can be determined through sensitivity tests using chemical modeling codes. This degree of resolution is expected to vary depending on the material.

For data that cannot be estimated, such as unpredictable events or the results of irregular activities, we wish to determine first the significance of the information using sensitivity analyses and secondly whether bounding or statistical analyses can be used to bracket or otherwise characterize the data. This type of determination is critical to performance assessment evaluations.

Clearly, adequate data is not yet available to be used as described above. However, these goals are reflected in the manner in which the data is presented below. 


\subsubsection{Materials Explicitly Named in Construction Drawings}

\section{Metals}

Steel Sets. Steel set and lagging installation documentation is in hand for the ESF North ramp from the start of TBM operation at tunnel segment $00+58$ through section $06+00$, with tunnel sections divided into and reported by the following $200 \mathrm{~m}$ tunnel increments:

$00+58$ to $02+00$

$02+00$ to $04+00$

$04+00$ to $06+00$

Within these 200-m sections of tunnel the as-built quantities of the following construction items are documented:

Steel Set, five-piece ring (reference drawing BABEAB000-01717-2100-41101-03):

1. Top component, MK\#1A

2. Bottom components, MK\#1B (two parts per set)

3. Side components, MK\#1C (two parts per set)

4. Steel set, shims and Dutchmen (two parts per set)

5. Steel set shims (reference drawing BABEAB000-01717-210041102-03)

6. Steel lagging, $C 8 \times 11.5 \#$ channel for steel sets $\sim 4 \mathrm{ft}$ in length

7. Tie rods for steel sets (reference drawing BABEAB000-01717-2100-41102-03)

All components are of steel (see Table 6-1). Specific tunnel locations (other than the $200 \mathrm{~m}$ range cited) are not supplied. The lengths of tie rods used are not specified despite the notation of two different lengths on the drawing (see Table 6-2). According to a cover letter sent by the Kiewit/PB project manager, W. Wightman, these were the first of many actual-use TFM reports planned for input to the TFM database by early September. It was the only report available as of November 1995.

Rockbolts. An investigation of rockbolt usage in the ESF has shown that far more rockbolts are used in some sections of drift than are specified in the drawings. This is understandable and necessary because ground support depends on the type of rock encountered and must be left to the discretion of the construction company. However, a few useful observations that can be made. First, the number of rockbolts used is dependent on rock type, and secondly the rockbolt distributions referenced on engineering drawings can be considered minimum (non-conservative) values.

Rails. It is evident that rails are used presently for hauling personnel and materials in the ESF. Ultimately, rails may be used for the emplacement of waste packages. It is possible that these rails will not be removed.

\section{Concrete}

Fibercrete $^{\mathrm{TM}}$. Fibercrete ${ }^{\mathrm{TM}}$ is composed of ordinary Portland cement (OPC) grout, sand, and short, flat Flex-Ten steel fibers combined in a slurry that has a viscosity low enough to be extruded at high velocity through hoses. It is used primarily for drift consolidation, often in combination with wire mesh and after rockbolts have been 
emplaced. Table 6-3(a-c) shows the composition of the cementitious material in the Fibercrete $^{\mathrm{TM}}$. The source of the sand is specified in the MSDS. Although this provides tracking information, the mineralogy can vary considerably. The MSDS composition lists quartz, calcite, clinozoisite, and feldspars (albite and anorthite), as identified by $x$ ray diffraction (XRD). Gypsum, phlogopite, and bassanite may also be present.

Rockbolt Grout. The grout composition for the Williams ${ }^{\mathrm{TM}}$ rockbolts is stipulated by a Transmittal of Shop Drawings, Equipment Data, Materials Samples, or Manufacturer's Certificates of Compliance (SDT) (Form \#AP-5.26) dated 16 January 1995. It stipulates that the grout is type $\mathrm{E}-1(\mathrm{~K})$ and specifies the brand Wil-X-Cement ${ }^{\mathrm{TM}}$ thixotropic grout. A water/cement ratio ( $w / c)$ of 0.4 by weight is stipulated, not to exceed 0.5. It should be noted, however, for the purpose of establishing water introduced into the repository environment, that the mixing of concrete is not exact. According to the SDT, the actual amount of water is left to the operator's discretion, as it needs to be. The operator must assure that $\mathrm{w} / \mathrm{c}$ does not exceed 0.5, even though $5 / 6$ of the total amount of water to be used is added to the tank before the grout is added.

Invert. The composition of grout and aggregate for the precast invert have not yet been obtained. However, it is clear that each invert segment is reinforced with a rebar cage. Figure 6-1 illustrates the shape of an individual segment.

\subsubsection{Materials Implicit in Construction and Operation}

Fluid Reports and Consumables. Reports of water usage and equipment fluid consumption have been requested. The inventory of all water documented as used in the ESF will be complete upon the receipt of this information. As of November 1995 informal records of materials which are logged into the Exploratory Studies Facility and assumed consumed within a certain segment of tunnel had not been provided. These "records" have been described as having been made without standard documentation. Examples of these materials are paints and sealers (D. Wayman, personal comm.). However, to this date no records separate from the provided as-builts have been obtained.

A separate, but similar issue has to do with materials that may be used in much larger quantities. These materials included cribbing (metal and wood) and excelsior, which, according to LANL's weekly ESF reports, were used when poor ground conditions rendered the tunnel boring machine (TBM) gripping mechanisms inadequate. LANL's weekly reports cite use of wood cribbing, fibercrete, shotcrete, sand, and a cement-water slurry. For the same time period that these LANL's weekly - reports cover, use of these materials is not documented in the Kiewit/PB TFM reports. $A$ list of materials that were used in construction of the tunnel, but were missing from any of the materials records were requested (from D. Wayman). The response indicated a belief that no materials were missing from the records (Meike and Spragge, 1995). We suspect that some of the missing materials may be listed as "consumed." This category of materials is misleading if it includes both items that are consumed and removed (e.g., compressed air, packaging materials), as well as items that remain as a permanent part of the ESF structure (e.g., cribbing, excelsior, sand, and fibercrete). 
The TFM data record sheets of the as-built starter tunnel were obtained from REECO. Quantities are given of each material used, and annotations as to whether the materials were considered permanently or temporarily emplaced are included. We noted that materials were listed (and archived into the TFM database) by brand name, which will render retrieval of this information very time-consuming, if not impossible. We suggest that a classification system such as the one already used for construction specifications (and thus easily accessible to the construction engineer who must fill out the TFM data record) would also be useful for retrieval of the information from the TFM database and should be part of the Determination of Importance Evaluation (DIE) record rèquirement. LANL continues to provide, on a weekly basis, information detailing the position of the tunnel face, the advancement of the tunnel boring machine, and the total quantity of water introduced to the tunnel from holding tanks.

Water. Water brought into the ESF from the holding tanks is measured. It is used for dust control, cleanup, and excavation. The weekly ESF TCO report provides information on the amount of actual water use per week and the cumulative amount of water used. However, the term "water use" is actually employed to specify the quantity of water transported into the tunnel. These reports do not specify how much water was removed from the ESF, e.g., by evaporation or sorbed to rock and removed during the mucking operation. Thus, the water value represents a maximum value of water introduced from the holding tanks. Although this is not an issue at ambient temperature, water introduced and stored in solid form (e.g., cement) will be available to the drift environment upon heating and dehydration. Thus, although it is an important component, an estimate of water usage based on the holding tank usage does not necessarily represent a complete or "conservative" estimate of the introduced water budget in a post-construction repository setting.

We present the available water usage data in order to illustrate a number of the data evaluation methods that will be used. In the future it should be possible to further constrain estimates of the amount of water that remains on the site in both fluid forms by obtaining better information on water retrieval.

The water usage limit specified in the DIE of no more than 7.4 cubic meters of water per linear meter of tunnel excavated has not been exceeded (Fig. 6-2). An average of the total amount of water used to date is $2.47 \mathrm{~kL} / \mathrm{m}$. Figure 6-3 illustrates a more detailed week-by-week analysis of water usage. Figure 6-3(a) shows that to a first approximation, water usage mirrors excavation progress. From Fig. 6-3(b) it is clear that normal weekly amounts of water usage of between 2 and $4 \mathrm{~kL} / \mathrm{m}$, which is by and large a function of excavation progress, are punctuated by events of large or excess water usage. Therefore, rather than averaging total water usage, we aim to establish an average water usage per meter (of roughly between 2 and $5 \mathrm{~kL} / \mathrm{m}$ ) that can be modified by a statistical distribution of excess water events. The character of the statistical distribution will be determined by further monitoring of water usage in the ESF. The next step is to relate these events to known functions in order to predict water usage more accurately. 
Spills. Kiewit/PB has maintained records of spills/releases in the method of the Kiewit/PB Spill Response Plan in accordance with the requirements of YAP-2.8Q. They include:

- Date and time of the spill/release

- Type of material

- Source of spill/release

- Tunnel location

- Quantity

- Estimate of unrecovered quantity

- Time at completion of clean-up

- Whether follow-up cleaning was required

Records of spills for the period 10-December-94 through 09-August-95 were submitted to the TDB for input to the TFM database. Copies of the records signed by the walker/shift superintendent, environmental supervisor, and M\&O A/E site representative have been obtained for the period from 10-December-94 through April-14-95. During this period, eleven underground spills/releases were reported (Table 6-4). All were fluid spills, described as hydraulic oil or hydraulic fluid with the exception of one described as TBM lube oil (See Meike and Spragge, 1995). No specifics as to type or manufacturer were provided by these reports. However, efforts to retrieve these specifics from Kiewit/PB (through D. Wayman) have yielded some material safety data sheets (MSDS) and chemical compositions of the fluids.

Another thirteen spills/releases were recorded from 6-May-95 through 9-August 95 (Table 6-5). However, the only information available to date regarding these spills is the spill number (SRP \#) of each and the dates the spills occurred. All other information has been reported to the TFM administrator for entry in the TFM database. Because the spill number (SRP \#) of 6-May-95 is consecutive with the SRP of the last April spill reported, it is assumed that no spills were recorded between these two reports.

Cellulose. The use of excelsior for ground stabilization behind steel sets has been observed in the ESF and noted in LANL's TCO report. The use of wood 4x4's (pine or fir) has been similarly noted. These materials, although extended residence by the nature of the way that they are used, have either not been recorded or are recorded with consumables and thus are indistinguishable from items that may be removed (see the discussion above). This category of materials also includes trash that may be incorporated into invert fill material.

Polymers. Polymers are composed of long, chain-like molecules which are formed by the bonding together of relatively small molecular subunits (monomers). Although proteins (i.e., wool and silk), carbohydrates (i.e., starch and cellulose), and condensation polymers (i.e., shellac and "glue"), polynucleotides (DNA), and cellulose are also polymers, the focus here is on the synthetic polymers which have been created over the past 60 years whose many useful properties have lead to incorporation into everyday construction operation. The matter of identification is an issue because there are many "hidden" sources of polymers. For example, almost all paper products contain polymers such as phenol formaldehyde and polyvinyl alcohol. Furthermore, most adhesives are polymers, and polymers are often added to drilling water to increase 
laminar flow. Given the combination of reporting issues discussed above, and the inexplicit nature in which polymers can be used, our initial aim with respect to polymers has been to review the types of polymers that may be used in a construction setting independent of the ESF context. Below we first present some of the characteristics that are used to evaluate polymers, and then we review the relevant polymer classes. Some comments are made on the relevance of the polymers to the ESF and to a potential radioactive-waste repository. The review is useful in discovering polymers and their usages in the ESF as well as pointing out important distinctions that can be made. Some thermal and degradation mechanisms are mentioned. In section 6.2.1.4 the discussion of relevant degradation mechanisms is continued, as well as the potential significance of these characteristics to the design of a radioactive-waste repository. Concepts fundamental to polymer characterization that are significant to predicting their long-term degradation are outlined in Appendix A.

Relevant Polymers. Epoxy resin systems are made up of resin and hardener. There are literally hundreds of epoxies with different chemical structures dependent upon the resin and hardener used. Epoxy is classified as a thermosetting resin and cures from internally generated heat. When the resin and hardener are mixed together, a chemical reaction occurs which causes hardening. Because epoxy easily reacts, chain extension and crosslinking can occur without the elimination of a small molecule such as water. Thus epoxy does not shrink as much as many other thermosets. Curing, which can be carried out either through the epoxy or hydroxyl groups, gives epoxy its crosslinked character. Either catalytic systems or polyfunctional crosslinking agents may be used to link the epoxy resin molecules together. Amines, acids, anhydrides, and mercaptans all may be used as curing agents.

The range of epoxy resin applications becomes apparent when one examines its properties. The high reactivity of the three membered epoxy ring leads to many unique and desirable properties. First, epoxy resins have high chemical and corrosion resistance. This leads to many protective coating applications. Epoxies are heat resistant, with a $T_{m}$ of approximately $260^{\circ} \mathrm{C}$ (Brandup and Immergut, 1975). Low shrinkage, high flexibility, high strength and high impact resistance lend epoxy to many mechanical uses. Epoxy also has good electrical properties, is waterproof, and is lightweight. The most well known property of epoxy, however, is its great adhesion. Epoxies are used to bond metals to glass and plastics and even concrete to concrete. In fact, epoxy is often significantly stronger than the material it is bonding. Steel rebar is coated with epoxy to prevent corrosion. However, the long-term effectiveness is questionable, especially if the coating is not uniform. Corrosion can occur at the interface between the epoxy coat and cold-rolled and galvanized steel (Dickie et al.,1990). Another potential use of epoxy at Yucca Mountain will be as rockbolt grout.

Neoprene rubber is a chloroprene polymer and was the first commercially successful synthetic elastomer. It is a thermoset which is crosslinked using the vulcanization process. Vulcanization involves crosslinking of the highly reactive allylic chlorine. The accelerator is usually zinc oxide or magnesium oxide (however, other metal oxides may be used) to create a sulfide crosslink. There are two types of neoprene: dry neoprene and neoprene lattices, each of which may be further classified as general-purpose or specialty types. Latex rubbers are examples of lattice neoprenes. General purpose 
neoprenes include those that are used for molding and other product applications. Specialty types, used for adhesives and sealants, tend to crystallize much faster.

Neoprene rubber tubing, probably dry neoprene, has been used in the ESF. It is likely that it contains antioxidants, fillers and plasticizer additives, because these are often present in neoprene rubber. Antioxidants are necessary since neoprene is quite susceptible to oxidation. Processing aids are added which lubricate and tackify. Examples of these are stearic acid, microcrystalline waxes, and low molecular-weight polyethylenes. Carbon black and mineral fillers are used to give more hardness and to increase abrasion and tear resistance. Hydrated calcium silicate and precipitated silicon dioxide fillers of fine particle size are added to neoprene vulcanizates for tensile strength and hot-tear and abrasion resistance (Mark et al., 1985). Inexpensive petroleum derivatives are used as plasticizers, to lower the $T_{\mathrm{g}}$.

Polyamide is a condensation polymer made from dibasic acid and diamine derived from oil and natural gas. These polymers contain amide groups as part of their monomer unit. Nylon is the most prevalent polyamide used today, with nylon 6,6 being the most preferred due to its properties and manufacturing cost. Nylons are used primarily for fibers and engineering resins. Aromatic polyamides (Kevlar, nomax) exhibit especially good strength and temperature properties. Nylon was the first synthetic fiber forming polymer developed. It is strong, tough, lightweight, abrasion and puncture resistant, and resistant to chemicals. Nylon has a very low glass transition temperature of $50^{\circ} \mathrm{C}$ and degrades thermally to hydrocarbons and carboxyls at $265^{\circ} \mathrm{C}$. Nylon is also quite hydrophilic relative to other synthetic fibers and water acts as a plasticizer for nylon. A completely dry nylon fiber will be quite brittle whereas a fiber which is in a humid environment will be more flexible. Nylon ropes have been used at the ESF. Thus, at least some of the possible nylon usage in the potential repository will be in fiber form. Kevlar falls into the category of liquid crystalline polymers and is considered a thermoplastic polymer. Kevlar is close to completely crystalline and, thus, is quite strong. The production of Kevlar requires very strong solvents to achieve the maximum liquid crystalline phase. The linear aromatic structure of kevlar yields more strength and high-temperature stability. Kevlar ropes are used in the ESF. Although kevlar has very good thermal stability relative to other polymers, it will degrade in a high-temperature environment. Long-term chemical effects are unknown.

Polybutadiene rubber is the main component of Liquid Nails caulk which is used at the ESF. Polybutadiene is a synthetic rubber which is thermoset via vulcanization. It has a long-chain molecular structure, which gives it toughness and chemical resistance. The structure of polybutadiene has long been of interest due to its symmetry and simplicity. Its monomer, butadiene, is a highly reactive colorless gas which reacts with the characteristic of having conjugated double bonds. Butadiene reacts through a self condensation reaction to form the polymer. Dependent on length and conformation, the polymer has a melting temperature ranging from 2 to $156^{\circ} \mathrm{C}$ and a $T_{\mathrm{g}}$ below $0^{\circ} \mathrm{C}$.

Polycarbonate (PC) is a thermoplastic of very high molecular weight. It is strong, rigid, transparent, non-toxic, and weather and impact resistant, though it tends to suffer from stress cracking. It has a high glass transition temperature of $135^{\circ} \mathrm{C}$ and melting temperatures up to $200^{\circ} \mathrm{C}$. Since polycarbonate is used for many electrical applications, flame retardants are often added. There are two types of polycarbonate: aliphatic and aromatic. Of the two, aromatic is by far the most prevalent and also the most useful. 
Aromatic polycarbonates are prepared from a condensation reaction between bisphenols and carbonic acid derivatives. Plexiglas ${ }^{\mathrm{TM}}$ covers (e.g., for the ESF percolation test) are made of polycarbonate. It is likely that Plexiglas ${ }^{\mathrm{TM}}$ used during the construction of a repository can be removed and, in that case, polycarbonate will be of little or no concern.

Polyester is classified by carboxylate groups in the backbone of the polymer. They are produced by a condensation reaction of ethylene glycol and propylene glycol which are derived from petrochemicals. There are many different polyesters produced for many different chemicals and glycol derivatives, but terephthalate polyester (PET) products appear to be the dominant type used at the ESF. Polyester rope and rein-anchored bolt systems are used. The rope is a thermoplastic polyester which will soften at high temperatures before degrading. PET is produced from a reaction between a terphthalic acid and ethylene glycol. Impurities are then removed in water at elevated temperatures and pressure. Purity is especially important in PET manufacture since the final quality is affected by very small amounts of impurity. Because the intermolecular interactions in polyesters are relatively weak, small changes in structure lead to large differences in properties. PETs have melting temperatures as high as $270^{\circ} \mathrm{C}$. The degree of branching of PET determines the crystallinity (less branching, more crystallinity) and thus the toughness and stability. Polyesters are also hydrophobic and oleophillic. Polyesters are useful as both thermosets and thermoplastics. If the resins are saturated, there are no free radicals in the molecular chain for crosslinking to take place, and therefore the material remains thermoplastic. Likewise, if the resins are unsaturated, there are free radicals and crosslinking can take place.

Polyethylene (PE) is a thermoplastic which is polymerized from the monomer ethylene, obtained from the cracking of petroleum or from natural gas. It was polymerized at high temperatures until the birth of the Ziegler-Natta catalyst, which eliminated the need for high pressures. There are two primary types of polyethylene. High-density polyethylene (HDPE) is processed by low-pressure polymerization. It is tougher than low-density polyethylene (LDPE) and has better chemical and impact resistance. Low-density polyethylene is odorless and non-toxic. Polyethylene is tough, flexible and a good insulator. However, it is easily scratched, stress cracking is common and it has a low $T_{g}\left(80\right.$ to $\left.130^{\circ} \mathrm{C}\right)$. Its properties are affected by side branching. During thermal degradation, polyethylene breaks down to hydrocarbons. One use of polyethylene at Yucca Mountain is in the form of sand bags and tubing. Polyethylene is one of the most prevalent polymers and it is likely that it will also be present in other forms.

Polyisocyanate (PI) is manufactured by a condensation reaction of isocyanate monomers. Isocyanates are primarily used to manufacture polyurethanes. Isocyanates are made in the form of diisocyanates from amines. It is a highly reactive monomer and degrades from about $175^{\circ} \mathrm{C}$. In addition, it is highly reactive with water. The polymerization of pure diisocyanate leads to polymers (called nylon-1 polymers) that have $T_{\mathrm{g}}$ ranging from 40 to $180^{\circ} \mathrm{C}$. These temperatures are dependent upon the length of side chains; the longer the side chains, the less thermally stable. Polyisocyanate has been used above ground at the ESF in the form of foam sealant and synthetic enamel. In addition, it is possible that these products are actually polyurethanes which have been labeled polyisocyanates due to the prevalence of polyurethanes as foams and coatings. 
Like polyethylene, polypropylene $(P P)$ is an olefin made from carbon and hydrogen and is derived from petroleum. It is formed using the Ziegler-Natta catalyst (consisting of titanium and aluminum). It is a thermoplastic which degrades readily requiring the use of stabilizers. Polypropylene has high impact resistance and flex strength, is scratch resistant and hydrophobic. There is a strong correlation between average molecular weight and the properties of polypropylene. It is possible to have atactic, syndiotactic and isotactic forms, three different conformations, of polypropylene. The isotactic and syndiotactic forms are more readily packed and thus more crystalline than the atactic form. Higher crystallinity leads to a higher melting temperature and greater toughness. Polypropylene has been used in the form of rope and tubing at the ESF. In addition, since it is one of the most prevalent polymers, it may be present in the form of packaging.

Polystyrene (PS) is a thermoplastic. The styrene monomer is made from benzene and ethylene, both of which are petroleum feedstocks. Polystyrene is used for its highfrequency electrical insulation and its optical clarity. It is very brittle; this can be improved with orientation and the addition of plasticizers. It also has a low glass transition temperature of 80 to $90^{\circ} \mathrm{C}$. However, polystyrene has a relatively high melting point of $274^{\circ} \mathrm{C}$ (syndiotactic PS) (Ravinetti and Zini, 1992). Polystyrene "Styrofoam" insulation has been used at the ESF. In addition, polystyrene auto body filler and fiberglass resin will be used above ground. Because foam has more surface area, it is likely that the Styrofoam will degrade more quickly than a solid chunk of polystyrene.

Polytetrafluoroethylene (Teflon, or PTFE) was first discovered in 1938 by accident while scientists were attempting to produce a new type of Freon. Since then, it has been used for a wide variety of applications, most of which take advantage of its high-temperature stability (the highest of any non-aramid thermoplastic) and its low friction. The frictionless property is due to the strong bond between the fluorine and the carbon backbone, so strong that it repels other substances. Teflon's electrical properties are unchanged by temperature and frequency, lending teflon to radio and power cable applications.

Teflon is polymerized with a peroxide catalyst in the presence of water from a monomer which is a poisonous gas. The result is a polymer which is very inert, chemically resistant (there are no solvents for teflon) and self lubricating. Teflon coating called by the trademarked name Gortex serves as a waterproof coating on the roof of the Denver airport. Teflon will be used for tubes for the heater tests in the ESF. It has also been used as wire pulling lubricant and as lubricating spray. Although not used in large quantities at present, Teflon's applications continue to grow. Its high melting point $\left(330^{\circ} \mathrm{C}\right)$ may lend it to more applications in a high-level radioactive-waste repository. If so, a major effort should be conducted to understand its biodegradation.

Polyurethane (PUR) is synthesized in a condensation reaction between isocyanate and a hydroxyl compound. Isocyanate is an ester of isocyanic acid, HNCO. A wide range of physical properties can be obtained due to flexibility in selection of the reacting hydroxyl compound. Although originally produced in the form of fibers competitive with nylon, the main products of polyurethane are a variety of crosslinked polymers foams, coatings, and elastomers. Other applications of polyurethanes are adhesives, 
sealants, binders, and mine reinforcements. The flammability of polyurethane is reduced with the addition of flame retardants.

No other foam-producing system compares with that of polyurethane. It is easy to produce at a reasonable cost. Flexible and rigid foams can both be produced using polyurethane because catalysts precisely control the balance between polymerization and expansion. Flexible foams are produced by simultaneous polymerization and expanding with carbon dioxide gas. Flexible foams are used mostly as protective and cushioning materials. The production of rigid foams is similar to that of flexible foams except that expansion is achieved using a low boiling solvent. Rigid foams are used as thermal insulating materials. Although polyurethane has a tendency to burn, this is lessened by the addition of flame retardants and the bulky foam structure lends itself to good insulation properties.

Polyurethane coatings are quite hard yet are flexible. They are also resistant to abrasion, chemicals and solvents. Finally, polyurethane coatings have high light stability and weatherability.

Polyurethane elastomers may be considered block copolymers consisting of alternating polyurethane and polyol segments. Primary or secondary amines, polyester and polyether are all polyol segments which may be used. Some of the main components of polyurethane elastomers are polyester and polyether diols, diisocyantes and chain extenders. Although different polyurethane elastomers possess different properties, they usually have wonderful tear, abrasion, impact and wear resistance as well as resistance to hydrocarbon and aromatic oils.

Cast elastomers are produced from liquid starting materials which differentiates them from other natural and synthetic rubbers. Examples of cast elastomer products are skateboard wheels and O-rings. Thermoplastic elastomers are processed as thermoplastics and hence can be used for various purposes. Examples of thermoplastic elastomer products are adhesives, hose lines and films for laminating. Millable polyurethane gums are used in synthetic rubber application such as machine parts.

Reaction injection molding is a process in which a mixture of two or more reactive low-viscosity materials is injected into a mold where it polymerizes. This process yields crosslinked, network structures. The product is a solid skin over a low-density microcellular core (foam structure) in a single operation. These structural foams use the smooth hard skins as a source of impact strength, heat-distortion, temperature and combustion resistance. An example of a use for reaction injection molding is in the production of automotive body panels. In this case, the car body would be durable yet lightweight. At Yucca Mountain, polyurethane is used for insulation purposes, probably as a foam.

Polyvinyl Chloride (PVC) is one of the oldest and most widely used synthetic polymers. In the past, the vinyl monomer was formed by a reaction between hydrochloric acid $(\mathrm{HCl})$ and acetylene, which is derived from calcium carbide. More recently, however, PVC has been formed from ethylene, which is cheaper than acetylene (Nass and Heiberger, 1986). PVC is a thermoplastic which is used in rigid, non-plasticized form, and flexible, plasticized form. Although the chemical structure of PVC appears to be quite stable, there are many deviations from the ideal structure. Structural irregularities result from polymerization defects such as branching and double bonds and from oxygenated groups such as carbonyls and peroxide groups. 
Thus, the commercial success of PVC is dependent on stabilizers. PVC has a glass transition temperature of about $80^{\circ} \mathrm{C}$ and easily degrades to $\mathrm{HCl}$ without stabilizers. In addition, it has very poor chemical resistance. Thus, almost all PVC products contain a significant amount of additives, which can vary their properties greatly. Polyvinyl chloride is widely used in the ESF as cable sheath, cement for pipes, cement primer, conduit, containers, hose piping, portable toilets, sheeting and tubing. Because of its potential acidic degradation products, PVC should be either not used or should be removed from areas of drift excavation in which local acidity is a significant issue.

Silicone is derived from silica or quartz and can have diverse properties dependent upon the length of chain and organic groups, but all silicones are based on a backbone of alternating oxygen $(\mathrm{O})$ and silicon (Si) atoms. Silicones have outstanding resistance to aging and weathering, good thermal stability (up to about $315^{\circ} \mathrm{C}$ ), water repellency, and toughness. In addition, they are inert and frictionless. The first step of production of silicones involves the conversion of silica to silicone in an electric arc furnace. The silicon is then converted to methylchlorosilanes by a direct process reaction with methyl chloride in the presence of copper as a catalyst (Lynch, 1978).

This product then reacts with water to form siloxane monomers, dimers and trimers, which continue to react until termination is reached. The result is a siloxane polymer. Silicone rubber is the crosslinked form of this polymer. At Yucca Mountain, silicone rubber is used as caulk, desiccant and lubricating spray. The thermal degradation products of silicone are low-molecular-weight cyclic oligomers, which are quite inert (Brandup and Immergut, 1975). Thus, the primary concern will be failure of the products used in the repository.

\subsubsection{Evaluation of Materials by Function.}

It is evident that the blueprints show a minimum of materials that are actually used in construction. The following evaluation is intended to categorize standard suites of materials by construction function and, if more than one construction option exists for a particular function, to discriminate suites of materials by construction option. The presentation below represents the state of the work, which was in progress until November 1995. We do not present information on the following functions: utility piping and ventilation, power distribution, or communication and instrumentation.

\subsubsection{Transportation.}

Invert. The exact number of invert segments placed in the tunnel has been provided. The tunnel has been divided into the same sections as for the steel sets. All inverts are precast prior to emplacement and are of concrete composition. Rail placement and invert segment plan and sections and detail are shown in reference drawing BABFCCOOO-01717-2100-40178-02, and BABFCCOOO-01717-2100-40179-02. The use of hardware, including lifting anchors, rebar, and strap anchors, is evident from the drawings. A polyethylene foam fill material is explicitly mentioned for placement between invert sections and between invert and the drift wall. Fill material cannot be tracked in this way unless it is on structural drawing 41099. It is not included in the 
inventory of inverts and is unaccounted for. Further chemical and physical analysis should be conducted on this fill/invert area, given that in an emplacement drift, with the appropriate design, the invert may constitute an engineered barrier.

Crushed rock, an option that has been discussed for emplacement drifts, has not been tried in the ESF.

Rail system. Documentation of the materials used in the rail system had not been initiated when this work was halted. However, it is clear that the system involves the rail, anchors, ceramic inserts and rubber insulation. These aspects should be clarified in the future because they impact the ability to predict microbiology and chemistry in regions close to the waste package.

Diesel Exhaust and Fuel. One of the early concerns of the Yucca Mountain Project, in the area of materials usage, was diesel fuel and its hydrous pyrolysis products. Diesel-powered vehicles are standard and economical for hauling activities, and if they were used, spilled diesel fuel and exhaust products might become part of the postclosure repository environment.

Electric Rail. Use of electrically powered vehicles is an option that has been considered for the ESF and may be considered again for use in a potential repository at Yucca Mountain. The residual material that may be left behind by such a system could be examined by investigating the Bay Area Rapid Transit (BART) or other electric rail systems. Even a cursory examination of BART and other tunnels indicates that a carbon deposit is a likely result from the use of such a system. This and other aspects of environmental modification will need to be examined if electric rail is to be an option in a repository setting.

6.1.2.2 Stabilization. To a great extent the amount of stabilization that is required within a section of tunnel is unknown until that section is reached. However, accurate mapping of the construction materials and correlation with the ESF geologic assessment should allow us to predict materials usage in the repository more accurately than simply from blueprints.

Cribbing. In the ESF, in sections of drift where large fractures have been exposed, both wood and metal cribbing has been used for stabilization.

Steel sets. Steel sets have been used in areas of extreme rock instability, where rockbolts are insufficient. At times stabilization is required behind the steel sets. In the ESF this stabilization material has consisted of sand or excelsior (wood fiber).

Rockbolts. As mentioned above, rockbolts of a number of different lengths and designs are used in the ESF. The emplacement of some rockbolts require grout, while others require a rather large quantity of water (nine gallons per bolt). The number of rockbolts used in a given section of drift varies and is dependent on the stability of the rock and the other components of the stabilization system (Table 6-2). Rockbolts can be 
associated with wire mesh and with wire mesh and Fibercrete (refer to portal area of the ESF).

Pre-cast Concrete. Although it has not been used in the ESF, pre-cast concrete is presently being considered as a mechanical stabilization method in the context of a potential repository design. Presumably these pre-cast concrete sections will require a polymer material between the sections similar to the invert sections.

Fibercrete. Fibercrete has been used for stabilization in the portal area of the ESF (see the rockbolt discussion above).

\subsubsection{Mucking, Dust Control and Ventilation.}

Conveyor system. Although it is believed that a conveyor system used for mucking during repository construction would be removed, it is clear from observation of the ESF conveyor system that the operation of the conveyor modifies the environment chemically and physically. The moving conveyor belt generates a lot of rock powder which settles on the walls and floor of the tunnel. This could affect drift-scale hydrological properties. In addition, due to the length of the mucking operation the conveyor is composed of segments. Each segment consists of a belt, which dumps its load on the next belt and so on until the excavated rock is removed from the drift. At the junction between segments, talus piles of rubble and shredded conveyor belt (see polymer section) are evident. A very fine black deposit is also visible on the left drift wall (rib) throughout the tunnel.

Dust control. Given that the basis for the nuclear waste strategy is the minimization of water in contact with the waste packages, our goal is to minimize, to the extent possible, the amount of introduced water. Data is not available for water usage by function, so water usage is discussed below in terms of total amounts. In addition to the chemical issues, the physical modification of the environment should be acknowledged. Dust control (even pure water) will cause the heterogeneous dispersion of a coagulated rock powder, the long-term impact (hydrological and chemical) of which we have yet to understand. However, in view of the fact that for health reasons a dust suppressant must be used, and that pure water may not be the best option (due to the larger amounts needed in the absence of a surfactant), the present discussion is limited to the dust control products that were under consideration in 1995 and 1996 (see Table 6-6). The salient issues are outlined in memo LLYMP9603087.

The additives were evaluated based on the MSDS information provided for the products. Although the chemical information provided in most cases was not adequate, eight were found to contain hydrocarbons/polymers. From the perspective of test interference in the ESF, we were concerned about the introduction of compounds that might alter the baseline of chemical analyses, which had the potential of severely interfering with and rendering useless the planned Swipe Tests, which were intended to obtain sensitive isotope data of hydrocarbon compounds and air samples in the ESF. The dust control chemicals are especially invasive to those experiments due to the dispersed nature of their usage. If dust suppression is to be conducted in the ESF using 
these additives, an additional program will be required in order to discriminate between airborne diesel exhaust and vapors, and these dust suppression agents. These distinctions are critical to our ability to supply baseline information toward the understanding of potential ESF test interferences. No chemical information was provided for the last additive considered, Bio Cat 300-1, and therefore no determination can be made at this point. Based on these considerations we advised against the use of the additives that contained hydrocarbons and against Bio Cat 300-1 due to the lack of information. Given that Dustcon ${ }^{\mathrm{TM}}$ degrades rapidly, we would want to understand the chemical nature of the biodegradation products in order to make a complete assessment of test interference in the ESF.

Over the long term we are concerned about the formation of colloids and the alteration of the chemical composition of water. However, we can make some preliminary assessments. It is our understanding that tracers are introduced into the water that is used for dust control. If this is accurate, then although the dust control compound may affect chemical analysis, at least the investigator will be alerted to that fact. In a gross sense the big distinction over the long term between Dustcon ${ }^{\mathrm{TM}}$ and the other products appears be $\mathrm{pH}$, because the documentation provided cites the prevention of limestone and salt that otherwise build up at a number points in the dust control system. With the exception of $\mathrm{pH}$, the chemical effects can be considered grossly of the same type at the concentrations under consideration.

Dustcon ${ }^{\mathrm{TM}}$ appears to need much less water (especially less than non-modified water) to reduce dust to the required level than the other products under consideration, even though the amount of additive used per volume of water appears to be less than the other products. This has two advantages: first, the dust control agent is minimized, thus limiting the impact on data collected from experiments conducted in the ESF, and secondly, the amount of water introduced into the ESF for the purpose of dust control is minimized. Similar arguments could be applied to the construction of a radioactivewaste repository.

6.1.2.4 Excavation. The tunnel boring machine (TBM) is electrically powered. However, its hydraulic system requires the use of petroleum products. These have been introduced into the tunnel through spillage during maintenance and equipment failure. As mentioned above, a policy is in place regarding the reporting and clean-up of spills. According to the policy, not every spill needs to be reported, but only that above a certain value. Because not every spill is recorded, the spills on record must be regarded as a minimum number. Therefore, in estimates of material usage, the uncertainty factor may be included to account for the spills that are thought to be below the reporting limit and therefore not recorded. Water usage accompanies the excavation operation through the actual excavation, dust control and clean-up of the "dance floor."

\subsubsection{Tracers, Fluids and Materials Database: Retrieval of Information}

Much of the initial information depends upon the retrieval of large amounts of data supposedly archived in the Tracers Fluids and Materials (TFM) database. Yucca Mountain Project YMP procedural documents identify explicit methods and channels 
through which this data should be retrievable. Our attempt to retrieve data that has been archived in the TFM database suggests that the large effort expended on developing procedures to collect and archive data is not reflected in the data that can be obtained. At the time of the assessment, which ended in November 1995, searches have retrieved far more procedural documents than data. Since the assessment was conducted, the operation of the database and collection has been turned over to another group. In order to enhance the utility and retrievability of information we suggest that ANSI or other standard construction material reference numbers be used in addition to brand name. Our experiences suggest that since November 1995 some of these suggestions are being incorporated into the database. We look forward to an improved state of access to archived data and better communication between the construction team, DIE, TFM database and those that require the data, given that, as time progresses, both the quantity of data and the demand for it will increase. This data, once available, will be incorporated and interpreted in subsequent revisions of the NFER.

Routes of information retrieval (other than archival work) that have been explored include the first-hand study of the ESF and interviews with on-site construction staff. These options appear at first glance to be more time intensive than the retrieval of archived data. However, they promise to provide a more comprehensive understanding of materials usage that will ultimately be useful in extrapolating information from the ESF setting to the prediction of materials usage in a potential radioactive-waste repository.

6.1.3.1 GENISES. As should become apparent from the above review, tracers, fluids, and materials data in the form of TFM usage requests and estimates and reports of actual use of TFMs (also known as "as-builts") are a critical aspect of developing the capability to relate a repository design to a materials usage prediction. However, at present, such data remains virtually inaccessible from the YMP TFM database. The current state of the database is such that it is much less easily accessed than both status reports provided by and personal communication with the database administrator would lead one to believe. Currently, there are three databases of TFMs, as cited in the Tracers, Fluids, and Materials (TFM) Database Status Report for the Period April 1995June 1995. The first consists of the original TFM data compiled by LANL and entered into a system provided by Computer Applications Group, Inc. The transfer of this data into the GENISES database is on hold according to the status report dated June 30, 1995. The second database was compiled and input by EG\&G/EM. Because the data was submitted without standards on a variety of forms, the database will need to be retrofitted to the revised TFM system to facilitate retrieval of data. The third database conforms to the specifications of YAP-2.8Q. This database, according to the aforementioned TFM status report, contains only data reported after May 8, 1995, the effective date of YAP-2.8Q. However, to quote the status report, "no new data have been provided under this procedure." To summarize, it seems that the only readily accessible TFM database contains no data.

The only other self-evident option for obtaining specifics of TFM usage and requests was to request it from the originator. That method resulted in limited amounts of information pertaining to the following construction categories being supplied by $D$. Wayman of Kiewit/PB: 
1. North ramp spill reports

2. North ramp steel sets

3. North ramp rail/segments

This information is reflected in the discussion of materials and materials usage in the previous sections.

\subsubsection{Assessment of Materials Considered for Repository Construction}

Progress in this area consists primarily of the initiation of modeling capabilities to assess the drift-scale heterogeneity of materials and their distribution, the quantities and location of materials and the chemical composition of some of the more critical materials. To this point, materials have been considered critical if they have the potential of being located in the emplacement drift and in fairly large quantities. This work is of fundamental importance to ability to respond to the needs of Performance Assessment, Repository Design and Waste Package Design Areas of the Yucca Mountain Project.

6.1.4.1 Heterogeneity. It is clear that the emplacement drifts will be both hydrologically and chemically heterogeneous. Given that the driving force behind many important chemical processes are chemical, thermal or other gradients, and that microbial activity is frequently most active in crevices, and that permeability variations in space will affect hydrological properties, attention to heterogeneity is very important. The drift modeling work described later in this report includes an assessment of the chosen software to identify interfaces and to manipulate the level of detail required by this inherent heterogeneity of the as-built system.

6.1.4.2 Materials. The potential significance of a material to the repository environment will be determined by its modification potential (chemical or hydrological), its quantity and its location. Given that some materials may be exposed to temperatures above the standard conditions to which we are accustomed and to a time frame outside of our experience (or even, for that matter, longer than the period of time that the material has been known, e.g., plastics), it is clear that once materials are identified, it may be necessary to conduct experiments or analyze historical analogs in order to understand their potential significance in this environment. The beginning of the materials identification and quantification work has been outlined above. This information is evaluated through the experimental and modeling activities discussed below. The drift-scale model has been chosen to be able to interface with existing hydrological, chemical and coupled codes to create three dimensional renderings of drift-scale processes through time.

6.1.4.3 Materials Juxtapositions. Attention to the juxtaposition of materials is critical, not only to identify potential locations of microbial activity and possible microenvironments, but because it is highly likely that the effects of materials in contact at elevated temperatures may also be outside our standard experience. Identifying these juxtapositions is also a goal of the drift-scale modeling activities. 


\subsection{Post-Closure Chemical Processes That May Modify Predicted Geochemistry}

Modifications of the natural environment due to construction of an underground repository would, in themselves, alter the natural chemistry, some aspects of which may be critical to the robustness of the waste package or to the chemistry of the fluid leaving the repository. However, once the materials are emplaced, in the absence of changing extrinsic properties, the chemical evolution of the repository would be fixed to a specific path and hypothetically predictable. The first section of this chapter on introduced materials described the chemical evolution that is brought about by the intrinsic nature of a repository design, and the initial steps that we have taken toward quantifying aspects of repository construction. The present section discusses the aging of repository materials in response to extrinsic conditions such as temperature, relative humidity and aqueous chemistry that will vary during the lifetime of the repository. The ultimate goal of this work is use a combination of post-closure chemical processes and processes that are determined by repository design and construction to identify the resultant chemistries that are outside the envelope of possible natural chemistries.

The product phases of materials disintegration, biodegradation and corrosion may include oxides of metals, sulfides, chlorides, carbonates, and silicates, as well as organic compounds, alkali metals, and halogen elements. These materials have the potential to alter the $\mathrm{pH}$, ionic strength, and composition of water that may be present at some time in the lifetime of the repository. In addition to aging, gamma radiation effects must be considered in the WP environment as discussed in Van Konynenburg (1986b). The chemical effects of gamma radiation on man-made materials remain largely uninvestigated even though it is known that aggressive substances such as nitric acid can be a product of such processes.

The quality of water, whether present in an aqueous or vapor phase, will directly affect the dissolution of spent fuel, waste glass, and ultimately, the concentration of dissolved or suspended radionuclides in water that exits breached containers. Therefore, the introduction of some man-made materials into the WP environment may influence WP performance. The chemical data for these materials will be gathered from a wide variety of sources that represent their usage in both modern and ancient societies. This data is essential because many chemical consequences specific to the repository setting are to a large extent unknown. The information that is known, summarized below, comes from literature searches that have been initiated for some of the major categories of materials. Therefore the preponderance of data on cement-based materials represents the preliminary nature of this task rather than the relative significance of any of the materials.

In the sections that follow we distinguish between those chemical processes that are biotic, or mediated by living organisms from those that are abiotic, or not dependent on living organisms. As will be discussed in the next section, most of our predictive chemical modeling capabilities are abiotic. Thus to use that modeling capability without explicit recognition of biotic chemical processes implicitly assumes that they are insignificant compared to abiotic processes. Clearly this is untrue for some materials such as some organic compounds over long periods of time in natural environments. Given the potential confusion in terminology, we define at the outset "organic chemistry" as those processes that involve organic compounds as distinct from "biotic 
chemistry" which involves a living intermediary such as a colony of microbes. As will be discussed in Section 6.2.2, microbially mediated (biotic) processes do not necessarily depend on the presence of organic compounds and can significantly affect inorganic chemistry.

\subsubsection{Abiotic Chemistry}

In this section the chemistry of inorganic materials and organic materials that are relevant to a high level radioactive waste repository is examined. The choice of subjects examined and the length of the studies was strongly determined by the needs of the project on a yearly and some times shorter term basis.

6.2.1.1 Organic Materials. This examination of potential chemical effects of organic materials concerns two very different goals. The first goal is to assess the potential contamination of studies conducted in the ESF by introduced materials. This work supports the determination of importance evaluation of materials used in the ESF. The second goal is to examine organic materials in the context of a radioactive waste repository and whether they may react with the surrounding rocks causing changes in repository porosity, or react with the waste package or waste form and enhance the mobility of radionuclide species. It does not, however, address microbially mediated degradation.

Diesel Exhaust. A study of long term diesel exhaust effects was conducted using NTunnel (Nevada Test Site) as a historical analog (Meike et al., 1995). The study represents a broad approach to material degradation that aimed first to assess the rate determining processes before embarking on the detailed experiments. Biotic and abiotic processes were considered and organic and inorganic materials were analyzed. This study is described in Meike (1995).

Diesel Fuel. Two studies have been conducted on different aspects of diesel fuel contamination. The first was conducted primarily to assess the potential impact of diesel operation on geochemical studies conducted in the ESF. The other study was oriented toward understanding the significant long term degradation processes.

${ }^{14} \mathrm{C}$ in Diesel Fuel from the ESF. Chemical isotope studies of selected introduced materials were conducted in the ESF in support of geochemical tests to determine what the potential effect of contamination would be to those geochemical studies. One effect is the potential contamination of ${ }^{14} \mathrm{C}$ from a number of sources. The objectives of the first stage of the study were threefold. Our first objective was to verify that the sample collection protocol did not contribute "modern" ${ }^{14} \mathrm{C}$ to the fuel sample. The second was to demonstrate reproducibility between samples collected at the same location. The third objective was to verify that the fuel collected from the locomotive motor was isotopically equivalent to fuel collected directly from the fuel tank. This first stage was intended to demonstrate unequivocally that (1) our sample collection protocol was appropriate for these measurements and (2) future samples could be collected exclusively from the storage tank, thus simplifying future collection. These were 
necessary precursors to give credence to the second stage of the study which was the actual analysis of the diesel fuel.

Eight samples of $\sim 50 \mathrm{~mL}$ each were collected at the ESF at YMP. Five of the eight samples were taken from the storage tank and 3 were collected from the locomotive motor. The ${ }^{14} \mathrm{C}$ in each sample was measured using accelerator based mass spectrometry (AMS). Prior to measurement an aliquot from each sample was combusted to graphite at the LLNL environmental-level graphitization laboratory. The technique used to graphitize samples at LLNL is in widespread use at other AMS laboratories around the world and cross-calibrations with other laboratories are performed routinely. In addition to the samples procedural blanks are also graphitized to verify background activity.

From the AMS measurement an isotopic ratio $\left({ }^{14} \mathrm{C} /{ }^{13} \mathrm{C}\right)$ is derived. The AMS measurement of ${ }^{14} \mathrm{C}$ and ${ }^{13} \mathrm{C}$ is converted to an isotopic ratio by referencing to standards measured during the measurement cycle of the unknowns. The accuracy of the standards is $<1 \%$. Within counting statistics all of the samples measured were identical and their ${ }^{14} \mathrm{C}$ activity was not distinguishable from background, i.e., they were ${ }^{14} \mathrm{C}$ dead. The limits on their ages are shown in Table 6-7. All of the samples measured have ${ }^{14} \mathrm{C}$ ages of $>48 \mathrm{Kyr}$. This is essentially the background of the graphitizerspectrometer system. These samples are unequivocally ${ }^{14} \mathrm{C}$ dead. Furthermore, they are all identical, thus verifying the efficacy or the sample collection protocol. Since the samples collected from the locomotive motor were indistinguishable from those collected directly from the storage tank any future measurements could be performed exclusively on samples collected from the storage tank.

A preliminary interpretation of these results is that any possible contamination of geologic samples taken from ESF by diesel fuels would result in apparent ${ }^{14} \mathrm{C}$ ages older than their real ages. The extent to which mixing of $C$ indigenous to geologic samples taken from ESF with fuel-derived $C$ can be assessed however this task is beyond the scope of this preliminary report. It is significant that apparent young ${ }^{14} \mathrm{C}$ ages from materials taken from could not have been produced by contamination with fuel or exhaust from diesel fuel.

Hydrous Pyrolysis of Diesel Fuel. This study examined the hydrothermal production of carboxylic acid and other aqueous organic species due to thermal degradation of diesel fuel at elevated temperatures. Carboxylic acids are particularly significant because they are known to form complexes with common rock forming cations, and thus can enhance mineral dissolution rates and mineral solubility (e.g., Bell et al., 1992; Gestsdottir and Manning, 1992; Hajash et al., 1992; Fein, 1991; Bennett et al., 1988). Carboxylic acids are also known to accelerate the corrosion of steel and other alloys (Jones, 1992; Fontana and Green, 1978; Larrabee and Mathay, 1963). Furthermore, carboxylic acids are kinetically metastable for geologically long periods of time at 100$200^{\circ} \mathrm{C}$ (Palmer and Drummond, 1986). Other hydrocarbons that may be derived from diesel fuel and its degradation products are potential sources of colloidal material for radionuclide transport. These experiments were carried out at 200 and $315^{\circ} \mathrm{C}$, temperatures somewhat higher than those expected within a repository emplacement drift of the present reference design, in order to directly determine the rate and products of diesel fuel degradation within a 2 to 3 month laboratory experiment. They 
thus provide an upper limit for the rate of abiotic degradation within the chemical system studied.

Experimental. Given the complex nature of the potential interactions between diesel fuel, other relevant man-made materials, groundwater, and Yucca Mountain geology, a series of scoping experiments with increasing degree of chemical complexity were undertaken. The experiments (see Table 6-8) also represent an evolution in the development of experimental and analytical protocols. The studies of diesel fuel hydrous pyrolysis were conducted (1) at $200^{\circ} \mathrm{C}$ (Jackson and Carroll, 1994), (2) at $315^{\circ} \mathrm{C}$ to accelerate the reactions, (3) in the presence of cementitious material and analog J-13 well water to examine reactions at elevated $\mathrm{pH},(4)$ in the presence of Topopah Spring tuff and analog J-13 well water to examine possible catalytic effects, and (5) in the presence of cementitious material, Topopah Spring tuff, and analog J-13 well water. In addition, a scoping study of hydrothermal cement reactions $200^{\circ} \mathrm{C}$ was conducted for comparison with the more complicated chemical systems ( 3 and 5 above).

A wide range of analytical techniques were used because no single instrument is capable of adequately analyzing all of the wide range of substances of interest. Gas Chromatography (GC) with flame ionization (FID) and thermal conductivity (TCD) detectors or Gas Chromatography Mass Spectrometry (GCMS) were used to analyze organic phases (aromatics and alkanes in aqueous and organic solution. Gas Mass Spectrometry (GMS) was used to analyze gas phase extracted from the liquid samples. Liquid Chromatography (HPLC) was used to analyze for dissolved carboxylic acids. Inorganic aqueous species were analyzed with one of two instruments. Cations were detected using Inductively-Coupled Plasma, Atomic Emission Spectrometer (ICP-AES). Anions were detected using Ion Chromotography (IC). Inorganic carbon was detected using a $\mathrm{CO}_{2}$ Gas Analyzer. The solids were characterized mineralogically using $X-R a y$ Diffractometry (XRD) and morphologically and chemically using Scanning Electron Microscopy (SEM) with energy dispersive spectrometer (EDS) and a beryllium window.

The diesel fuel used in these experiments was obtained from the LLNL motor pool. It is composed primarily of alkanes ranging from $C_{6}$ to $C_{26}$ (Table 6-9). The total sulfur concentration is $0.55 \mathrm{wt} \%$, as measured by combustion using a LECO SC132 analyzer. Fibercrete ${ }^{\mathrm{TM}}$ wafers, weighing approximately $3 \mathrm{~g}$ each were prepared from a sample obtained from the ESF, and is described in Section 6.1.1.3. Topopah Spring Tuff (Tpt) cores taken 1232.2-1232.3 feet below the surface from drill hole USWG-1 were sliced into wafers weighing approximately 3 grams (Knauss et al., 1985a). It consists of a devitrified matrix containing plagioclase phenocrysts, alkali feldspar, cristobalite, quartz, biotite, magnetite, ilmenite, and accessory zircon and apatite, and has an average pore diameter of $0.025 \mu \mathrm{m}$ and a porosity of $6.54 \%$ (see also Warren et al., 1984; Bish et al., 1981). All waters used in the experiments were either distilled MilliQ (17.5 $\mathrm{M} \Omega$ ) filtered water or $3 \mathrm{mM} \mathrm{NaHCO}_{3}$ solution in MilliQ water. The latter composition reflects the most salient chemical feature of J-13 well water $\left(\sim 3 \mathrm{mM} \mathrm{NaHCO}_{3}\right)$ for the purpose of the experiment and will be referred to as J-13 analog water (JAW). J-13 water is considered representative of the natural ground water from Yucca Mountain (Knauss and Peifer, 1986).

The high temperature pyrolysis experiments were run in Dickson-type, gold bag autoclaves (Seyfried et al., 1987). The apparatus has been used extensively for hydrothermal experimentation, and its use in the experimental study of the hydrous 
pyrolysis of hydrocarbons is well established (Jackson et al., 1992). Within the Yucca Mountain Project the apparatus is standard equipment and is described elsewhere in geochemical studies (Knauss and Beiriger, 1984; Knauss et al., 1985a; Knauss et al., 1985b, Knauss and Peifer, 1986 and Knauss et al., 1987).

During fluid sample extraction autoclave rocking was stopped, but the experimental pressure was maintained by externally pumping deionized water into the pressure vessel. The sampling port was positioned so as to sample the desired immiscible liquid phase: the down position sampled the more dense aqueous phase, and the up position sampled the less dense organic phase. All samples were extracted from the sample port with gas-tight syringes. Approximately $1 \mathrm{~mL}$ of liquid was extracted to clear the sampling line, which was not maintained at temperature and pressure, and thus could be contaminated with precipitated phases. Another $1 \mathrm{~mL}$ of liquid was taken to measure $\mathrm{pH}$ at room temperature, which is not necessarily equal to the $\mathrm{pH}$ at temperature. However, given the experimental difficulties of measuring the $\mathrm{pH}$ at experimental temperature and the straightforward nature of the calculation, it is standard practice to calculate the value at temperature based on thermodynamic principles. In any case, the trend of $\mathrm{pH}$ changes is the same.

An additional two samples were filtered ( $0.4 \mu \mathrm{m}$ filter) for ICP-AES analysis of cations: a $3 \mathrm{~mL}$ undiluted sample acidified with concentrated nitric acid for trace element analysis, and a $1 \mathrm{~mL}$ sample diluted by a factor of 10 with $3 \mathrm{mM} \mathrm{NaHCO} 3$ and acidified with concentrated nitric acid for major element analysis. Approximately 0.5 to $1.0 \mathrm{~mL}$ of the aqueous phase was sampled for organic analyses. A $1 \mathrm{~mL}$ aqueous sample was taken to measure organic anions using HPLC. Prior to filtering samples for HPLC analyses, the gas phase, which exsolves from the sample at room temperature, was removed by passing $20 \mathrm{~mL}$ of He gas at atmospheric pressure in a gas-tight syringe through the liquid sample syringe, then the liquid sample was gently shaken for about 1 minute to allow the gas exchange to occur, and the gas was re-injected into the $25 \mathrm{~mL}$ He syringe. The total gas volume was measured after adjusting to atmospheric pressure and injected into an evacuated sampling steel cylinder for GMS analysis. This extraction procedure was repeated with the same liquid sample. The gas extractions were analyzed for inorganic and organic gases. Approximately $1 \mathrm{~mL}$ of the aqueous phase was sampled for inorganic carbon analysis with the $\mathrm{CO}_{2}$ gas analyzer.

Simulations using the Geochemist's Workbench (GW) equilibrium geochemical code (Bethke, 1994), and COM.R16 thermodynamic data base Johnson and Lundeen, 1995) were used to interpret the experimental solution concentrations and solid end products. These calculations were evaluated at $200^{\circ} \mathrm{C}$. Sulfur was assumed to be in the form $\left(\mathrm{SO}_{4}\right)^{-2}$ and the solutions were charge balanced with $\mathrm{Na}^{+}$. The lack of detectable $\mathrm{H}_{2}(\mathrm{~g})$ in the diesel fuel hydrous pyrolysis experiments suggested that oxidizing conditions existed in the experiments, which were simulated by setting $\mathrm{Eh}=0.4 \mathrm{~V}$.

Results. Diesel fuel hydrous pyrolysis is limited at 200 and $315^{\circ} \mathrm{C}$ over a two to three month reaction period. Low carbon number alkanes and aromatics were dissolved in the aqueous phase (Table 6-10). Carboxylic acids, such as acetic acid and perhaps formic acid, may have been present in the aqueous samples, but their concentrations were below the HPLC working detection limit ( $4 \mathrm{ppm})$. The room temperature $\mathrm{pH}$ of the sample taken at the end of experiment DF1, equaled 4.5. In experiment DF2, the room temperature $\mathrm{pH}$ decreased from 6 to 4.9 during the first 30 days of reaction followed by 
a slower decrease to $\mathrm{pH} 4.7$ at the end of the experiment. The exception to this trend was taken at approximately 65 days (Fig. 6-4). $\mathrm{No} \mathrm{H}_{2}$ (g) or $\mathrm{O}_{2}(\mathrm{~g}$ ) were detected by GMS and $\mathrm{CO}_{2}(\mathrm{~g})$ concentrations were on the order of $10^{-5} \mathrm{M}$. There was no measurable change in the proportions of the alkanes, as illustrated by the normalized concentrations of $n-C_{10}, n-C_{12}$ and $n-C_{14}$ with respect to hexadecane, $n-C_{16}$ for experiment DF1 (Fig. 6-5) or in the final diesel fuel analysis for experiment DF2.

The results of Fibercrete ${ }^{\mathrm{TM}}$-water interactions (DF3 and DF4) appear to be independent of the presence of diesel fuel (Fig. 6-6 through 6-8). Solution $\mathrm{pH}\left(200^{\circ} \mathrm{C}\right)$ decreases from approximately 8.8 to 8.4 in both experiments. Similarly, total sulfur concentrations increase to approximately $15 \mathrm{mM}$ and initial inorganic carbon concentrations decrease from $3 \mathrm{mM}$ to concentrations near the detection limit ( $1 \mathrm{mM})$ after the first few days of reaction. The aqueous $\mathrm{Si}$ concentrations increase rapidly during the first few days of reaction, followed by a slower increase to approximately $5 \mathrm{mM}$, whereas the aqueous $\mathrm{Al}$ concentrations decrease steadily from 2 to $1 \mathrm{mM}$. The aqueous $\mathrm{Ca}$ concentrations increase as a function of time, however the concentrations measured in the presence of diesel fuel are a factor of two lower than the concentrations measured in the absence of diesel fuel. Aqueous $\mathrm{Fe}$ and $\mathrm{Mg}$ concentrations hover around $1 \mathrm{mM}$, near the detection limit of the ICP-AES analytical technique.

In both experiments DF3 and DF4, the reacted Fibercrete ${ }^{T M}$ consists of quartz, calcite, clinozoisite, feldspars (albite and anorthite), and 11 $\AA$-tobermorite as identified by XRD (Fig. 6-9). Of these, only $11 \AA$-tobermorite is not found in the unreacted Fibercrete ${ }^{\mathrm{TM}}$. Other crystalline $\mathrm{Ca}$-Si-hydrate phases (but not all) that are associated with reactions above $100^{\circ} \mathrm{C}$ (see Meike et al., 1994); afwillite, xonotlite and foshagite, were not identified in the unreacted Fibercrete ${ }^{\mathrm{TM}}$. The absence of xonotlite, afwillite, foshagite, bassanite, phlogopite, and mesolite were not unambiguously determined by XRD, because their major peaks overlap with quartz, calcite, clinozoisite, and $11 \AA$-tobermorite. Two XRD peaks remain unidentified. SEM photomicrographs of unreacted and reacted Fibercrete ${ }^{\mathrm{TM}}$ (Fig. 6-10) show dissolution etch pits as well as prismatic growth features in the larger aggregate minerals, quartz and feldspar of the reacted crystal. The Ca-rich precipitate covering the majority of the wafer surface does not form on the aggregate or penetrate the wafer at depth. No Si was detected in association with the $\mathrm{Ca}$, thus it is possible that the $\mathrm{Ca}$-rich precipitate is calcite or an amorphous calcium hydroxide (portlandite) because $\mathrm{CO}_{3}$ and $\mathrm{OH}$ are not detected by these analytical methods. No portlandite was identified by the bulk XRD analysis. Steel fibers were not detected in the reacted Fibercrete ${ }^{\mathrm{TM}}$ with backscattering electron imaging (BEI) using SEM. However, because iron was not detected in the solution or the Ca-rich precipitate, it is likely that the corrosion of the steel fibers was minimal and that they were masked by the Ca-rich precipitate.

Modeling simulations regarding Ca-bearing phases must be considered with caution because the COM.R16 database does not contain thermodynamic data for many of the amorphous and crystalline $\mathrm{Ca}-\mathrm{Si}-\mathrm{H}_{2} \mathrm{O}$ phases that are pertinent to this chemical system at this temperature (see e.g., Meike et al., 1994) and that data that is available is not internally consistent. These simulations suggest that the aqueous phase was supersaturated with respect to mesolite ( $\mathrm{Na}-\mathrm{Ca}-\mathrm{Al}$ zeolite), close to saturation with respect to wollastonite, albite, K-feldspar, quartz and calcite, and undersaturated with respect to bassenite (least soluble of the calcium sulfates), anorthite, and gyrolite and 


\section{$11 \AA$-tobermorite (crystalline $\mathrm{Ca}-\mathrm{Si}-\mathrm{H}_{2} \mathrm{O}$ phases that are found in the COM.R16 database).}

GCMS analyses of the organic phases indicated no significant difference between the starting and post-experimental sample (Table 6-11). These results suggest that neither alkaline $\mathrm{pH}$ nor the phases present in Fibercrete ${ }^{\mathrm{TM}}$ catalyzed the hydrous pyrolysis of diesel fuel at $200^{\circ} \mathrm{C}$. However, organic compounds such as the BTEX (benzene, toluene, ethylbenzene, and xylene) compounds are water soluble at this temperature and did partition into the aqueous phase. The aqueous solubility of organic phases has significant implications for their transport which is significant to both colloidal interaction and microbial activity. However, the aqueous organic species did not appear to evolve over the course of the experiment. Within the scatter of the data: average benzene, toluene, ethylbenzene, and p-xylene are $0.04( \pm 0.01), 0.06( \pm 0.02), 0.02( \pm 0.01)$, and $0.07( \pm 0.02) \mathrm{mM}$ respectively. The concentrations of aqueous alkanes were approximately an order of magnitude less than the aqueous aromatic hydrocarbons. Little significant change was detected with respect to gases although $\mathrm{O}_{2}$ gas decreased from 21 to 20 mole percent. $\mathrm{No}_{2}$ gas was detected in the GMS analyses.

The results of DF 5, the diesel fuel-Tpt-JAW experiment at $200^{\circ} \mathrm{C}$ (Figs. 6-11 through 6-13), was similar to previous hydrothermal Topopah Spring Tuff experiments carried out in the absence of diesel fuel (Knauss and Beiriger, 1984; Knauss et al., 1985b; Knauss and Peifer, 1986; Knauss et al., 1987). At $200^{\circ} \mathrm{C}$, the system quickly reached a metastable equilibrium. The $\mathrm{pH}\left(200^{\circ} \mathrm{C}\right)$ decreased slowly from 7.7 to 7.5 over the duration of the experiment. The aqueous sulfur concentration remained constant for the duration of the experiment (near $1 \mathrm{mM}$ ). The unusually high value of $5 \mathrm{mM}$ at the end of the experiment requires verification. The inorganic carbon concentration remained constant for the duration of the experiment near its initial concentration of $3 \mathrm{mM}$. The aqueous $\mathrm{Si}$ concentration increased rapidly during the first few days of reaction to approximately $8 \mathrm{mM}$. The aqueous $\mathrm{Al}$ and $\mathrm{K}$ concentrations decreased rapidly and reach a constant concentration after 30 days of reaction. The aqueous $\mathrm{Ca}$ concentration was constant and close to the detection limit of the analytical technique for the duration of the experiment. $\mathrm{No} \mathrm{Fe}$ or $\mathrm{Mg}$ were detected in the aqueous phase.

$X R D$ analyses revealed no mineralogical differences between the reacted and unreacted tuff. Quartz, cristobalite plagioclase, alkali feldspar, ilmenite, and biotite were unambiguously identified. SEM photomicrographs of unreacted and reacted Topopah Spring tuff (Fig. 6-14) reveal a Si-rich precipitate on tuff surface. Cristobalite would be consistent with geochemical modeling. The aqueous solutions are calculated to be supersaturated with respect to mesolite ( $\mathrm{Na}-\mathrm{Ca}$-Al-zeolite) and albite, close to saturation with respect quartz, cristobalite, muscovite, and calcite, and undersaturated with respect to anorthite, wollastonite, and bassenite.

Similar to the Fibercrete ${ }^{T M}$ results (DF3 and DF4), the Topopah Spring tuff did not catalyze the pyrolysis of diesel fuel. No chemical difference was found between the constituents of the final the organic phase and the beginning diesel fuel. The dissolved organics were dominated by aromatic hydrocarbons (Table 6-12). Within the scatter of the data, the BTEX concentrations were seen to increase to a constant value after 30 days of reaction. Average values of benzene, toluene, ethylbenzene, $\mathrm{m} / \mathrm{p}$-xylene and o-xylene concentration were $0.030( \pm 0.003), 0.072( \pm 0.006), 0.013( \pm 0.005), 0.04( \pm 0.01)$ and $0.013( \pm 0.004) \mathrm{mM}$ respectively. The concentrations of aqueous alkanes are 
approximately an order of magnitude less than the aqueous aromatic hydrocarbons. The $\mathrm{O}_{2}$ gas concentration decreased from 21 to 20 mole percent. No $\mathrm{H}_{2}$ gas was detected by GMS analyses.

The results of DF6, the diesel fuel-Fibercrete ${ }^{\mathrm{TM}}$-Tpt-JAW experiment (Figs. 6-15 through 6-17), indicated little to chemically distinguish it from the Fibercrete experiments (DF3 and DF4). The solution $\mathrm{pH}\left(200^{\circ} \mathrm{C}\right)$ decreased from 8.5 to 8.2 indicating that the cementitous material dominated the system and that the tuff has little buffering capacity. The total sulfur concentration increased linearly from 1 to $14 \mathrm{mM}$ over the course of the experiment. The inorganic carbon concentration decreased from $3 \mathrm{mM}$ to a final value of $1.5 \mathrm{mM}$. During the first few days of reaction, the aqueous Si concentration increased rapidly to approximately $10.5 \mathrm{mM}$, followed by a slower decrease to $9.5 \mathrm{mM}$ at the end of the experiment. The aqueous $\mathrm{K}$ concentration decreases from $0.9 \mathrm{mM}$ to a steady-state concentration of $0.25 \mathrm{mM}$ during the first 40 days of reaction. The aqueous $\mathrm{Al}$ concentration decreases from a maximum of $0.075 \mathrm{mM}$ to a minimum of $0.025 \mathrm{mM}$ after 15 days of reaction, followed by a slow increase to $0.04 \mathrm{mM}$ by the end of the experiment. The aqueous Ca concentration increases linearly throughout the experiment, with the exception of the questionably high final data point. The aqueous $\mathrm{Mg}$ concentrations are at the detection limit of the ICP-AES spectrometer. No aqueous $\mathrm{Fe}$ was detected in the aqueous phase.

SEM analysis indicate that the majority of the reacted Fibercrete ${ }^{\mathrm{TM}}$ surface is covered with a well crystallized layered Ca-silicate (Fig. 6-18) distinct from the precipitate formed in experiments DF3 and DF4 (Fig. 6-10). This phase does not penetrate the wafer. An amorphous/poorly crystalline phase can be seen in the spaces between overlapping sheets of the precipitate. It is approximately 5 to $10 \mu \mathrm{m}$ thick, leaving open pores by not precipitating on the aggregate, as is observed in experiment DF3 and DF4, or around pores of the starting cement material. Although not rigorously determined, the ratio of $\mathrm{Ca}$ to $\mathrm{Si}$ is similar to that found in tobermorite, which was identified independently by $\mathrm{XRD}$. This phase also contains minor amounts of $\mathrm{Al}$, which is frequently a substitutional element (for $\mathrm{Si}$ ) in tobermorite. No steel fibers in the reacted Fibercrete ${ }^{\mathrm{TM}}$ are observed with backscattered electron imaging (BEI) and no measurable amounts of iron were found in the solution and surface precipitate, indicating little reaction of the steel fibers, indicating that the fibers were covered by the Ca-silicate sheet precipitate. Three different precipitates were observed on the Topopah Spring tuff: (1) small 10-20 micron wide books of the layered Ca-silicate identical to the precipitate found on the Fibercrete ${ }^{\mathrm{TM}}$, (2) calcite rhombs, and (3) Si-rich matrix covering the surface, which may have been amorphous silica or cristobalite.

The aqueous organics were dominated by aromatic hydrocarbons (Table 6-11). Average benzene, toluene, ethylbenzene, $\mathrm{m} / \mathrm{p}$-xylene and o-xylene are $0.033( \pm 0.004)$, $0.081( \pm 0.011), 0.013( \pm 0.006), 0.05( \pm 0.02)$ and $0.015( \pm 0.007) \mathrm{mM}$ respectively similar to the previous experiments. The concentrations of aqueous alkanes are approximately an order of magnitude less than the aqueous aromatic hydrocarbons. $\mathrm{No}_{2}$ gas is detected with GMS analyses. Analysis of the organic phase at the end of the experiment yields no discernible change from the starting diesel fuel.

At $200^{\circ} \mathrm{C}$, this system quickly reaches a steady state, which, according to geochemical calculations is a metastable equilibrium. The aqueous solutions were calculated to be supersaturated with respect to mesolite ( $\mathrm{Na}-\mathrm{Ca}-\mathrm{Al}-\mathrm{zeolite})$ and albite, 
close to saturation with respect quartz, cristobalite, wollastonite, K-feldspar, muscovite and calcite, and undersaturated with respect to anorthite, $11 \AA$-tobermorite, gyrolite, and bassenite.

Discussion. The experiments indicate that the abiotic degradation of diesel fuel is slow with respect to repository lifetime and, unaided by biotic degradation, would remain almost indefinitely. Our experimental results show that hydrothermal degradation of diesel fuel is minimal at mildly acid and alkaline $\mathrm{pH}$ over two to three month reaction periods at $200^{\circ} \mathrm{C}$ and 70 bars. At 200 and $315^{\circ} \mathrm{C}$, low carbon number aromatics and alkanes dissolve into the aqueous phase, but the production of carboxylic acids is limited. It is possible that the soluble aromatics and alkanes are intermediate degradation products between diesel fuel and carboxylic acids. The dominant watersoluble organics are aromatic compounds, not aliphatic carboxylic acids. At $315^{\circ} \mathrm{C}$, the diesel fuel is significantly more reactive, although the net production of carboxylic acids is minimal. However, soluble alkanes, aromatics, and carboxylic acids may be intermediates between the unstable diesel fuel and the equilibrium thermal degradation products. A probable reaction path for diesel fuel hydrous pyrolysis may be:

Diesel Fuel $\Rightarrow$ soluble aromatics and alkanes $\Rightarrow$ carboxylic acids $\Rightarrow$ carbonic acid

Although production rates of carboxylic acids at 200 and $315^{\circ} \mathrm{C}$ are too low to be quantified directly, the final $\mathrm{pH}$ values for experiments DF1 and DF2 support the presence of acetic acid, which has a $\mathrm{pK}_{\mathrm{a}}$ of 4.8 at $25^{\circ} \mathrm{C}$. In contrast to the reaction path proposed above, (Kharaka et al., 1993) and (Lundegard et al., 1992) interpret measured concentrations of carboxylic acids from oil hydrous pyrolysis experiments as simple partitioning between the aqueous and organic phases. However, if that were the case, then the organic acid concentrations and the $\mathrm{pH}$ should have been constant over time. In experiments DF1 and DF2, the solution $\mathrm{pH}$ continues to decrease slowly as a function of time.

A conservative rate of diesel fuel hydrous pyrolysis can be made from the $\mathrm{pH}$ data (measured at $25^{\circ} \mathrm{C}$ ) as a function of time from experiment DF2 $\left(315^{\circ} \mathrm{C}\right)$. To make these calculations, it is assumed that the decrease in $\mathrm{pH}$ reflects a net increase in total dissolved inorganic carbon (carbonic acid) or total dissolved acetate. In the inorganic carbon system, a total inorganic carbon concentration can be calculated from $\mathrm{pH}$ and the carbonic acid dissociation mass balance, charge balance, and total carbon equations. The dissociation reaction $\left(\mathrm{K}_{\mathbf{a}}\right)$ and mass balance expression for carbonic acid are:

$$
\mathrm{CO}_{2}(\mathrm{aq})+\mathrm{H}_{2} \mathrm{O} \Leftrightarrow \mathrm{H}^{+}+\mathrm{HCO}_{3}^{-} \quad \mathrm{K}_{\mathrm{a}}=\left(\left[\mathrm{H}^{+}\right\}\left(\mathrm{HCO}_{3}^{-}\right\} /\left\{\mathrm{CO}_{2}(\mathrm{aq})\right\}\right)
$$

where the $\mathrm{pK}_{\mathrm{a}}\left(25^{\circ} \mathrm{C}\right)=6.35$ (and $\mathrm{pK}_{\mathrm{a}}=\log \mathrm{K}_{\mathrm{a}}$ ). Total inorganic carbon mass balance (CT) and charge balance equations at the experimental $\mathrm{pH}$ are:

$$
\mathrm{C}_{\mathrm{T}}=\left[\mathrm{CO}_{2}(\mathrm{aq})\right]+\left[\mathrm{HCO}_{3}{ }^{-}\right]
$$


and

$$
\left[\mathrm{H}^{+}\right]=\left[\mathrm{HCO}_{3}^{-}\right],
$$

respectively.

Similar calculations can be made assuming the decreasing $\mathrm{pH}$ reflects an increase in the total acetate concentrations as a function of time. The acetate system is chosen to represent carboxylic acids, because the final pH of both experiments DF1 and DF2 is near the acetic acid $\mathrm{pK}$. The dissociation reaction for acetic acid and corresponding mass balance expression are:

$$
\mathrm{HAc} \Leftrightarrow \mathrm{Ac}^{-}+\mathrm{H}^{+} \mathrm{K}_{\mathrm{a}}=\left(\left(\mathrm{H}^{+}\right\}\left\{\mathrm{Ac}^{-}\right\} /\{\mathrm{HAc}\}\right)
$$

where $\mathrm{pK}_{\mathrm{a}}\left(25^{\circ} \mathrm{C}\right)=4.87$. In this model system, the total carbon mass balance and charge balance equations for the experimental $\mathrm{pH}$ may be written as:

$$
\mathrm{C}_{\mathrm{T}}=[\mathrm{HAc}]+\left[\mathrm{Ac}^{-}\right]
$$

and

$$
\left[\mathrm{H}^{+}\right]=\left[\mathrm{Ac}^{-}\right],
$$

respectively. The results of both of these simple systems are shown in Fig. 6-19. The calculated inorganic carbon concentrations increase linearly as a function of time, approaching the measured values near the detection limit after 100 days. The calculated total acetate concentrations increase linearly as a function of time, and remain well below the detection limit of the LC analytical technique, $0.4 \mathrm{mM}$. The calculated increases of inorganic carbon or total acetate can be used as conservative rates of diesel fuel hydrous pyrolysis: $8.3 \times 10^{-6} \mathrm{M} \mathrm{C} /$ day from the inorganic carbon model or $7.8 \times 10^{-7} \mathrm{M} \mathrm{C} /$ day from the acetate model. In all likelihood, the decrease in $\mathrm{pH}$ as a function of time represents contributions from both increasing concentrations of carbonic and carboxylic acids. These low concentrations cannot be accurately measured and thus long term effects remain unknown, however they can be bounded by using the detection limit as a guide.

Thermal degradation of diesel fuel is not enhanced in the presence of cementitious material or at alkaline $\mathrm{pH}$. Similarly, diesel fuel hydrous pyrolysis is not catalyzed by Fibercrete $^{\mathrm{TM}}$ or by Topopah Spring Tuff and does not accelerate dissolution of silicate 
minerals found in these solids at $200^{\circ} \mathrm{C}$. These results agree with previous studies that show that water inhibits the catalytic effects of clay minerals in contact with alkanes, alkenes, alcohols, and ethers (Weres et al., 1988; Tannenbaum and Kaplan, 1985). In a preliminary study, Bell et al. (1992) show that acetate decarboxylation reactions are enhanced in the presence of magnetite, hematite, $\mathrm{Ca}$ - and $\mathrm{Fe}$ - montmorillonite, and nonstoichiometric pyrite, indicating the $\mathrm{Fe}^{3+}-\mathrm{Fe}^{2+}$ redox couple as an important catalyst. However, in this study, the presence of metal iron in the steel fibers did not catalyze the hydrous pyrolysis of the complex organic mixture.

Secondary results support the understanding that the presence of cementitious materials will react, affecting the chemistry of the water with which it is in contact, the repository rock its own porosity, as well as its own permeability and mineral assemblage.

6.2.1.2 Cementitious Materials. The number, identity, and significance of potential coupled interactions between man-made materials are as yet not determinable. However, interactions between concrete and some other materials are known to be significant for the chemical environment. The oxidation of rebar creates a chemical environment that increases the degradation rate of concrete. Examples of this effect can be seen in many major bridges and thoroughfares, but knowledge of these processes remains qualitative. Tests in which concretes were leached at 100 to $200^{\circ} \mathrm{C}$ with either distilled water or Standard Canadian Shield Saline Solution (SCSSS) in contact with a sodium-bentonite, a waste glass, or a silica fume additive have indicated that the identity and concentration of species in solution is time-dependent (Komarneni and Roy, 1983; Burnett et al., 1985; Heimann and Hooton, 1986; Onofrei, 1987; Heimann, 1988a,b).The fate of C-S-H and the cement minerals, and their interaction with the aggregate, are a function of time, temperature, solid and aqueous solution compositions, and the availability of water. Of particular chemical concern is whether the concrete is exposed to air, $\mathrm{CO}_{2}$ or water, the aluminate and ferrite content of the cement, and the activities of carbonate and sulfate in the water. The preferred rheology of the cement at the time of emplacement dictates the quantity of water added to the dry cement mix and usually exceeds that required for complete hydration. Therefore, extra water is expected in any situation in which wet grout is emplaced. Physical properties, such as interconnected porosity, can regulate the rate of, and the long term susceptibility to chemical attack. Porosity is affected by initial water:cement $(\mathrm{w} / \mathrm{c})$ ratios and thus potentially by the method of emplacement. Leaching will preferentially dissolve some minerals such as portlandite from the set material and thus can increase permeability, which will influence the rate of degradation. Sufficiently high activities of sulfate or $\mathrm{CO}_{2}$ can react with concrete. At elevated temperatures, residual portlandite reacts with carbonates to form calcite (Milestone et al., 1987).

Disintegration and dissolution of cementitious materials may change the $\mathrm{pH}$ of water to values as high as 11.5 at $100^{\circ} \mathrm{C}$. Tobermorite $(14 \AA)$ forms in water at temperatures below $80^{\circ} \mathrm{C}$ (Fujii and Kondo, 1983). This phase begins to lose interlayer water at $70^{\circ} \mathrm{C}$ in dry $\mathrm{CO}_{2}$-free air to give $11 \AA$ tobermorite (Taylor, 1987). Sulfateresistant cements (Soo and Milian, 1989) are formulated to have a relatively low aluminum content so as to minimize the possibility of forming ettringite after the cement has set. Minimization of the volume of portlandite in the set cement controls the 
reaction of $\mathrm{Ca}(\mathrm{OH})_{2}$ with sulfate to form gypsum. The large volume increases associated with both ettringite and gypsum formation cause cracking and increase the surface area exposed to degradation.

Insight into the long-term performance of cements has been gained from examinations of (1) groundwaters that issue from rocks containing cement-type minerals, and (2) ancient concretes. Water with a pH as high as 12.5 has been collected from rocks containing portlandite, ettringite, tobermorite, and higher temperature minerals (Khoury et al., 1985; Neal and Stanger, 1984). A preliminary calculation of phases in equilibrium with the water (Barnes et al., 1982) is consistent with these natural data. Ancient Roman concretes often incorporated pyroclastics, including acidic tuffaceous material that may be applicable to modern portland cements in the sense that similar aggregate is being considered for use in the repository. Examination of these ancient materials demonstrates that low-permeability cements, and particularly pozzolanic cements, have the greatest durability (Roy and Langton, 1983, 1989). Optical and compositional comparisons between modern portland cement and a relatively young portland cement that had been submerged in water for 63 years (Rhoderick, 1981) have revealed no significant differences. Whether the resolution of data acquisition in this study is appropriate to predict change over 10,000 years has not yet been established.

The presence of cementitious material may greatly alter the geochemistry of the repository by providing a large reservoir of unstable Ca-silicate phases which will dissolve and reprecipitate at the rock-water interface. Chemical interactions between water and non-thermally treated grout at $20-60^{\circ} \mathrm{C}$ may well be dominated by the dissolution kinetics of the unstable amorphous and crystalline phases and precipitation kinetics of the metastable or stable phases (e.g., Atkins et al., 1991). This type of low temperature interaction has received much attention internationally and can be found in the radioactive waste disposal literature.

A unique aspect of the Yucca Mountain strategy relative to other high level radioactive waste strategies around the world is that water will probably contact the cementitious material only after it has been exposed to elevated temperatures $\left(>100^{\circ} \mathrm{C}\right)$ for an extended period of time ( $>150$ years). It is likely that the cementitous materials will have dehydrated and transformed to a more crystalline mineral assemblage. Many phases in the crystalline $\mathrm{Ca}-\mathrm{Si}-\mathrm{H}_{2} \mathrm{O}$ system can develop in cement exposed over long periods of time to temperatures above $25^{\circ} \mathrm{C}$. The phases themselves are found both naturally and in synthetic systems. As a consequence of their appearance in cements exposed to elevated temperatures, chemical reactions involving these phases can affect not only water chemistry, but also the relative humidity of a radioactive waste repository that contains significant amounts of cement. In order to predict and simulate these chemical reactions, we are developing an internally consistent database of crystalline Ca-Si-hydrate structures. The experimental aspects of the synthesis and characterization of pure phases for the purpose of measuring thermodynamic parameters is discussed elsewhere (e.g., Barnes et al., 1996; Martin, 1995; Bruton et al., 1994; Meike et al., 1994). A complete synopsis of the work in the cement area is not ready at present due to the premature halt of a five year study in this area.

Other reactions known to occur in cementitious materials over time would contribute to alterations in the mineral assemblage and contribute to their degradation 
and reduction of mechanical strength. These are chloride attack, the alkalai silica reaction (ASR) and delayed ettringite formation. Chloride attack works by the ingress of chloride bearing water through permeable grout or cracks to contact and corrode the metal reinforcement (rebar). Expansion of the rebar due to corrosion causes the cementitious materials to crack and spall. One of the notable sources of chloride attack for the present application is the use of aggregate from desert climates that may contain evaporated salts (Taylor, 1990). Alkali silica reaction occurs when silica bearing aggregate reacts with alkali impurities in the cement paste. As with chloride attack, expansion occurs due to formation of the product phases, causing cracking (Taylor, 1990). Delayed ettrigite formation is also a cracking process due to the late formation of sulfate bearing phases (Taylor, 1990). There is still much debate about the causes of DEF. However, some significant DEF has been related to the heat-curing of sulfatebearing cements. A phenomenon similar to DEF occurs through the formation of thaumasite, a sulfate-carbonate mineral (Crammond, 1995).

Roy and Langton $(1983,1989)$ have studied ancient concretes, to ascertain mineral stabilities and instabilities that may be applicable to modern Portland cements. The ancient concretes, which were made from lime formulations, are not completely analogous to the modern concretes which are composed of "alite" and "belite" and require higher temperatures for manufacture. Although made with unknown processes as well as varying starting materials, and mixed using unknown water/cement ratios, ancient Roman concretes often incorporated pyroclastics, including tuffaceous material. A main conclusion that Roy and Langton draw from examination of ancient materials is that low permeability cements, and particularly pozzolanic cements, have the greatest durability. A study of mortars from the Byzantine basilica of Hagia Sophia, Istanbul suggests that a calcium silicate hydrate phase is present. The degree of crystallinity is not well constrained, however, and the mortar appears to be dominated by a calcium carbonate phase. A cursory examination of a Portland cement that had been submerged in water for 63 years (Rhoderick, 1981a, b, c) suggested no "significant effect" on either composition or microstructure. Notably lacking for the purpose of the Yucca Mountain Project are studies of cementitious materials that have been exposed to elevated temperatures for extended periods of time. It is clear that at elevated temperatures will cause changes in both composition and microstructure, which would ultimately affect the chemistry of the water in contact with the material, as well as its structural integrity.

A different approach to evaluating the long-term performance of cements is to examine the occurrence of hyper alkaline groundwaters issuing from rocks that contain cement-type minerals. One such occurrence had been noted (Khoury, 1985; Neal, 1984): in Jordan, a pH 12.5 water issuing from rocks containing portlandite, ettringite, tobermorite, and higher temperature minerals. Combustion of bituminous marl generated a pre-cursor assemblage of minerals similar to modern cement. Upon contact with water, recognizable calcium silicate hydrate minerals were formed. A somewhat incomplete calculation of phases in equilibrium with the water was reported by Barnes et al. (1982). Since important constituents of the water analysis were not reported, an exact replication of the calculation using EQ3 could not be made. By using additional data from the later literature cited above, the phases showing supersaturation and the degree of saturation via an EQ3 calculation were parallel those reported in Barnes et al. (1982). 
Tobomorite synthesis and stability with respect to $\mathrm{CO}_{2}$. Observations of the extreme sensitivity of tobermorite, a cement phase expected under repository conditions, during its synthesis (Martin et al., 1994) indicate that the formation of tobermorite is sensitive to the partial pressures of $\mathrm{CO}_{2}$, and at partial pressures of $\mathrm{CO}_{2}$ greater than ambient compositional and microstructural changes are also to be expected. Ultra-pure samples tobermorite and other crystalline Ca-Si-hydrates have been synthesized and characterized in order to obtain thermodynamic data. The purpose of this thermodynamic is to fill a need for fundamental parameters that are not available in the literature. These parameters are required in order to model the interaction between water and cementitious materials (see the Fibercrete-water experiment discussed above, and Meike et al., 1994).

The starting materials for synthesis were $\mathrm{CaO}$ and an aqueous suspension of fumed $\mathrm{SiO}_{2}$ ("Cab-o-sperse") in a molar ratio of 5:6. The $\mathrm{CaO}$ was prepared from $\mathrm{CaCO}_{3}$ heated to $1050^{\circ} \mathrm{C}$ for $>4$ hours. The highly reactive $\mathrm{SiO}_{2}$ had a surface area of $100 \mathrm{~m}^{2} / \mathrm{g}$. In one case hydrochloric acid $(\mathrm{HCl})$ was added before mixing with $\mathrm{CaO}$ to neutralize the $\mathrm{SiO}_{2}$ suspension which had a $\mathrm{pH}$ of 9.8. The constituents were mixed in an argon filled glove box to inhibit $\mathrm{CO}_{2}$ uptake. $\mathrm{CO}_{2}$ free water was added in excess to obtain a homogeneous sol/gel. The gels were autoclaved at 90 and $120^{\circ} \mathrm{C}$ in pressure vessels. Individual vessels were sampled multiple times over the total length of the run in the argon glove box. Post run treatment of the aliquots included washing the product with milli- $Q$ water and ethanol before drying in desiccators. To hinder calcite formation and remove excess $\mathrm{CaO}$ in the product some of the reacted samples were titrated with $\mathrm{HCl}$ to a $\mathrm{pH}$ of 7-8.

Powder $x$-ray diffraction $(\mathrm{XRD})$ was used to identify the mineralogical phases. Two types of run products were obtained, a mixture of 1.1 and $1.4 \mathrm{~nm}$ tobermorite at $90^{\circ} \mathrm{C}$, and a $1.1 \mathrm{~nm}$ tobermorite at $120^{\circ} \mathrm{C}$. For the mixed phase runs the intensity of the $1.4 \mathrm{~nm}$ peak decreased and the $1.1 \mathrm{~nm}$ peak increased over time as the tobermorite became less hydrated (Fig. 6-20). Mixed phase samples heated and dried at $100^{\circ} \mathrm{C}$ produced a $1.1 \mathrm{~nm}$ tobermorite. $X$-ray diffraction of the higher temperature run indicated a single phase, $1.1 \mathrm{~nm}$ tobermorite (Fig. 6-20). In general, tobermorite became more crystalline over time and at higher temperature. Scanning electron microscopy (SEM) was used to determine particle morphology. Photomicrographs of the reacted material showed an aggregation of platy particles similar to those shown by Suzuki and Sinn ${ }^{3}$. No distinct morphological differences were noted between the $1.1 \mathrm{~nm}$ tobermorite and the mixed 1.1 and $1.4 \mathrm{~nm}$ tobermorite.

Measures were taken to preclude calcite formation but calcite was detected in the product and was probably due to unreacted $\mathrm{CaO}$ reacting with atmospheric $\mathrm{CO}_{2} \mathrm{(pH}$ measurements of the run products were high, 11.3). The formation of calcite was not instantaneous. X-ray diffraction patterns indicated an increase in calcite concentration in the longer runs and was most pronounced in the longest run of 161 days. Although aliquots were taken in the argon glove box, they were cooled outside of the box in the laboratory. Carbon dioxide may have diffused through the Teflon lined vessels into the run product.

Carbon dioxide concentrations were measured with a $\mathrm{CO}_{2}$ analyzer and indicated equivalent $\mathrm{CaCO}_{3}$ concentrations of up to $6 \%$. Calcite concentrations were the highest in samples exposed to atmospheric $\mathrm{CO}_{2}$ for longer periods of time. Samples titrated with 
$\mathrm{HCl}$ immediately after synthesis did not contain calcite, and XRD analysis of shelved samples containing calcite indicated that the calcite was removed from the sample with acid titration without affecting the tobermorite. The volume of $\mathrm{HCl}$ added to reduce the $\mathrm{pH}$ to approximately 8 was equivalent to an excess $\mathrm{CaO}$ concentration of approximately $8 \%$, which correlates to $\mathrm{CaCO}_{3}$ concentration of approximately $14 \%$ if completely reacted.

The extreme sensitivity of tobermorite and other crystalline Ca-Si-hydrates that may exist in ordinary portland cement to the partial pressure of $\mathrm{CO}_{2}$ suggests that, in a repository environment, much of the cementitious material could evolve into $\mathrm{CaCO}_{3}$ phases such as calcite and vaterite. The consequences to the $\mathrm{pH}$ are significant. Whereas a young cement- water system could register $\mathrm{pH}$ values of 11 or 12 , a calcite water dominated system would have a significantly lower $\mathrm{pH}$.

Significance to $Y M P$. It is clear from the extant literature and studies that have been conducted to date, that at temperatures near $25^{\circ} \mathrm{C}$ water in contact with modern ordinary portland cement can obtain extremely high pHs. However, the effects of other factors, such as microbes, heating and $\mathrm{pCO}_{2}$ above ambient have not been well established and therefore cannot be well constrained. Therefore for the purpose of chemical performance assessment the addition of cementitious materials widens boundary conditions and increases uncertainty. With regard to the potential survival of concrete, we recognize an important distinction between "performance lifetime," which is linked to the mechanical stability of the structure, and chemical lifetime which represents the duration of the chemical effects of the material long after the material has ceased to perform its function. It will be important to explicitly specify the mechanical performance lifetime required of the cements by the design, because it may be possible to obtain modern high performance formulations that will perform a mechanical function throughout the retrieval period, and perhaps stretching into some of the period after closure. However, it may not be necessary (or even possible) to engineer (or prove the stability of) a cement with a performance lifetime of thousands of years.

It is highly likely that long after the mechanical "performance lifetime" of the cementitous materials has ended, these materials could perform chemical functions such as sorbing radionuclides, especially if the formulation were to contain zeolites as aggregate or pozzolana. In fact, at the point in the evolution of the repository where sorption is required, an invert a material that is considered to have low very long term mechanical performance properties may be an asset. This is because large surface areas predominantly determine the effectiveness of a sorbant, and thus a cementitious material that becomes greatly fractured or disaggregated increases the effectiveness of the constituent sorbant materials.

6.2.1.3 Metals. Metals that are introduced into a repository environment as a result of construction are used for many different functions (see previous section) and are composed of almost as many different alloys. Thus the concern of the introduced materials studies are far different from those that are intended to select a material for the waste package. Many of the high tech alloys considered for waste packaging materials are not used widely in construction. Conversely, the alloys that are used in construction are the more common and cheaper metals that may not make the best waste package. Fortunately, most of the metals used in construction have been used for 
many years and provide a foundation of knowledge in this area. For that reason, although a significant construction material metals have not been emphasized in these studies to date.

Metals that may be introduced into the WP environment for construction purposes will be primarily iron and iron alloys, which can degrade through several mechanisms. Oxidation is one common degradation process. Such processes are strongly dependent upon the Eh and $\mathrm{pH}$ of the environment within which oxidation occurs. Cast iron, if present in large volumes, has the potential to consume large quantities of oxygen and influence the atmospheric chemistry around waste containers. Experimental studies of copper corrosion in sea water and in the presence of sulfide ions (Mor and Beccaria, 1975) indicate that a variety of copper sulfides can form that are also dependent upon $\mathrm{pH}$. The specific conductivity and resistance to corrosion of the metal are dependent upon the corrosion product, which is $\mathrm{pH}$-dependent. In general, the rate at which metal ions are added to the water is dependent on the corrosion products.

Much of our understanding of the long term chemical processes involving metals that may be used in a radioactive waste repository will be based on a firm understanding of historical analogs. Many of the processes that will affect metal construction materials are identical to those that have affected metal archaeological artifacts. Outside the Yucca Mountain Project, interest in the degradation of metals is found in disparate sources from the U.S. Naval Oceanographic and Atmospheric Research Laboratory to many oil companies. Because of this interest, and also because of the length of time that man has been working with metal materials, much more information is available on the long term degradation of metals than most other manufactured materials. A literature review on the corrosion of metal artifacts has been conducted in support of waste package design.

Studies of metal artifacts from a variety of ages demonstrate that some phases that form cannot be predicted from our present knowledge of material degradation. Some products of these man-made materials rarely occur naturally and are therefore not necessarily predictable from a geochemical data base. Botallackite, a rare hydroxide of copper chloride, for example, has been observed associated with the corrosion of a copper object exposed to chloride ion (Pollard et al., 1989). Stability fields and reactive sequences of the basic copper (II) chlorides have only recently been proposed (Pollard et al., 1989) on the basis of this and other historical data as a complement to experimental data, where experimental data alone has previously failed. That diffusion-controlled phenomena should be expected over time periods of at least 2,000 years is apparent from investigations of corrosion phenomena in ancient bronzes (Scott, 1985). Development of some phases appears to be mediated by the activity of microorganisms (McNeil et al., 1990).

In addition, information on the long-term corrosion of materials is being assembled from the New Zealand analog site (Bruton et al., 1995). In the respect that this data represents materials that are more similar to present construction materials and methods, some data from the New Zealand (e.g., Foster and Tombs, 1962; Soylemezoglu and Harper, 1982; Braithwaite and Lichti, 1981) and other geothermal fields (e.g., Dodd et al., 1960; Hermannsson, 1970; Hanck, and Nekoksa, 1980; Culivicchi et al., 1985) may be more useful to chemical model assessment than much older archaeological artifacts. 
6.2.1.4 Polymers. Assessments of the long term chemical affects of those polymers and their reaction products in the repository are based on current understanding in polymer science which can be translated into models, but given the relatively new nature of these materials, experimental data must be gathered to test these models. Several sources have cautioned that polymer behavior can not be compared with that of simpler but similar molecules. Therefore, no conclusions should be made about polymers based on the behavior of smaller molecules. However, some correlations may be made between synthetic and natural polymers and between modern polymers and their predecessors (assuming one is aware of the cautions mentioned previously). Natural polymers such as keratin, cellulose and starch as a rule degrade much more easily than synthetic polymers. One reason is that they are more hydrophilic and another is that nature is more equipped to get rid of them (i.e., enzymes). Correlations may also be drawn between silicone and silica which have the same ancestry. It must be stressed, though, that only general correlations may be drawn and that the specific polymer must be investigated for specific information.

The primary modes of degradation for synthetic polymers are thermal degradation, oxidation, and photodegradation. Biodegradation will also be discussed in the section below. The degradation of a polymer can not be followed by observing the behavior of a similar but simpler molecule. First, there are many small chemical differences between polymers and less complex molecules. The differences in termination of polymers are dependent on preparation. Often, side branches are incorporated during saturation. Polymers often undergo changes with the environment which are different from similar simpler molecules. Second, the length of polymers makes many reactions possible which are impossible in smaller molecules and reactions can be rapid in long chain molecules. Polymer degradation occurs by one of two primary structural changes: cross-linking or chain scission. Models have been developed to predict specific degradation processes over times significant to a radioactive waste repository (Burnay, 1990) however most models are for normal life times and under normal service conditions (Kenny, 1993). An activation energy must be reached before degradation begins (Ravanetti and Zini, 1992) which can be derived from thermal analysis. The Arrhenius equation is often used to predict the half lives of materials (BarrKumarakulasinghe, 1994). It has been found that thermal degradation rate is increased by higher temperatures, the presence of a radiation flux, oxidative agents, some chemical contaminants and light. In addition, many polymers can exhibit dose rate effects or synergism between radiation and temperature or chemical contamination (Burnay, 1990).

Hydrolysis involves the substitution of an $\mathrm{OH}$ for an $\mathrm{OR}$ of the polymer. For example, in polyurethane, a break would most readily occur at the carbon oxygen single bond and hydrolysis would form toluene diamine and polyether, which are almost identical to the starting material. Another method of polyurethane degradation is glycolysis, which involves the "dissolution of polyurethane (usually foam) in hot glycols, polyethers or polyamines. In this way additional monomer can be added to the solution which can then be used for a new product. However, given the difficulty with which glycolysis and hydrolysis are carried out for the purpose of recycling, the processes may not be relevant. 
There are two types of thermal degradation. The first, depolymerization, involves the breaking of the main polymer chain backbone so that at any intermediate stage, the monomer units can be recognized (Grassie, 1985). This is common for polymers which give high values of chain scission at ambient temperature (Garrett et al., 1990). The second, substitution reaction, involves the substituents attached to the backbone of the polymer molecules such that the chemical nature of the repeat unit is changed even though the chain structure may remain intact. In this case, volatile products will be unlike the monomer (Grassie, 1985)."

Leedy and Watters (1994) found that rock bolt epoxy degrades at temperatures as low as $50^{\circ} \mathrm{C}$ and should thus not be used long term mechanical support in areas that will be exposed to elevated temperature. However a variation in degradation behavior exists, probably dependent on the epoxy. It has been found that at $125^{\circ} \mathrm{C}$ the primary degradation mechanism for epoxy resins is initiated by oxygen attacks rather than a free radical mechanism. Many epoxy resin systems manifest significant oxidative degradation in air at temperatures as low as $100^{\circ} \mathrm{C}$ (Burton, 1993). A change in mass begins just below $250^{\circ} \mathrm{C}$. To $310^{\circ} \mathrm{C}$ the degradation reaction is primarily dehydration and is identical in air and an inert atmosphere. Chain scission occurs above $310^{\circ} \mathrm{C}$ with evolution of $\mathrm{SO}_{2}$. The rates of weight loss are maximal at 350 and $520^{\circ} \mathrm{C}$ (Rose et al., 1993). Although $\mathrm{Tg}$ varies dependent upon the exact epoxy, epoxies tend to have Tgs from $110^{\circ} \mathrm{C}$ to $135^{\circ} \mathrm{C}$ (Kaplan, 1991). Improved crystallinity decreases degradation at high temperatures while aromatic linear groups improve stability. Epoxy resins should not be included in the permanent structure, without detailed long term tests.

Keolar is extremely heat resistant relative to other polymers with a degradation temperature of $601^{\circ} \mathrm{C}$; at this temperature, kevlar will degrade at a rate of about 10 percent per minute (Kutty et al., 1992). However, exposure to thermal environments can alter kevlar's properties and performance. It has been found that "after 250 and $6 \mathrm{~h}$ exposure to 250 and $350^{\circ} \mathrm{C}$, respectively, the fibers turned brittle and crumbled with handling (Parimala and Vijayan, 1993)." Fibers treated at $150^{\circ} \mathrm{C}$ remained unaffected over known lifetimes. However, given the relative youth of this material, and thus the lack of historical analogs, it is not possible to predict the response to thousands of years of degradation and an extended (100-200 year) thermal pulse at the $100-200^{\circ} \mathrm{C}$ range.

Neoprene degrades by a scission reaction accompanied by cross-linking. The metal oxides are consumed during the degradation process of primarily auto-oxidation. Chemical products are dependent on additives and temperature, and should be the subject of analysis should neoprene be considered as part of the permanent repository structure.

Depolymerization and extensive chain fragmentation of polybutadiene generally take place at temperatures greater than $300^{\circ} \mathrm{C}$, when the activation energy needed for degradation is reached, and becomes appreciable at temperatures greater than $380^{\circ} \mathrm{C}$. Below this temperature, some volatile products are released as well as some structural changes such as crosslinking but these are minute. The products of thermal degradation of polybutadiene are primarily larger "fragments" but also include monomer, hydrocarbons and "volatile" products (Brandrup and Immergut, 1975). The degradation process is exothermic up to $380^{\circ} \mathrm{C}$ and above that, it is endothermic. At about $200^{\circ} \mathrm{C}$, polybutadiene becomes insoluble, "presumably in consequence of some degree of crosslinking. From NMR and IR spectroscopy, it has been found that "the polymer first 
undergoes a saturation-cyclization process, in which the vinyl groups are the first to disappear. But, at $300^{\circ} \mathrm{C}$, it becomes soluble again; in fact, after only half an hour at this temperature, "the product becomes soluble, the content of olefinic hydrogens drops to a mere 2.6\%, and aromatic structures begin to appear (Schneider et al., 1993). When studying the thermal degradation of polybutadiene (PB) it must be taken in account that different proportions of the possible structural units (cis-1,4, trans-1,4, and 1,2) can be present, and consequently differences in the overall thermal behavior may be expected (Chiantore, 1989). The composition of the solid and condensed liquid products of thermal degradation of PB depends on temperature and time. By prolonged heating at a lower temperature, products comparable to those obtained at higher temperature cannot be generated (Schneider et al., 1993).

Two main thermal degradation products of polycarbonate at temperatures up to $400^{\circ} \mathrm{C}$ are monomer (and dimer and trimer) and $p$-cresol (Imasaka et al., 1992).

At temperatures above the melting temperature at long time periods, polyesters undergo chain scission. With PET, this reaction leads to carboxyl and vinyl ester groups. These react to an acetyl ester intermediate to form carboxylic anhydride linkages and acetaldehyde. Polyester salt complexes have been synthesized for potential battery applications. It was found that the thermal stability of these complexes was significantly less than for polyester (Kay et al., 1993). However, it is unknown whether these complexes would occur outside a laboratory.

The thermal degradation of polyethylene is dependent on the degree of side branching; the more linear the polymer, the higher the stability. It is assumed that the molecular weight of polyethylene increases due to long-chain branching which increases the polymer viscosity at about $200^{\circ} \mathrm{C}$. However, after one hour of heating at $300^{\circ} \mathrm{C}$, the spectrum of branched polyethylene exhibits no chemical or conformational changes (Svoboda et al., 1990).

After heating an isotactic (probably high percent crystallinity) polypropylene sample at $300^{\circ} \mathrm{C}$, polypropylene does not exhibit chemical change. It is assumed that the molecular weight of polyethylene increases due to long-chain branching which increases the polymer viscosity at about $200^{\circ} \mathrm{C}$ (Svoboda et al., 1990) while the primary degradation mechanism is chain scission Polypropylene has been converted to gasoline range chemicals in the presence of zeolite-catalysts (Mordi et al., 1992). The process took about 2 hours at $350^{\circ} \mathrm{C}$ and no solid polymer remained at the end of the process. The addition of carbon black decreases the thermal stability while the addition of red pigment increases the stability (Wallius, 1993).

Poly(styrene) is known to undergo thermal degradation above $250^{\circ} \mathrm{C}$ to yield mainly monomer (Garrett et al., 1990). Between 200 and $300^{\circ} \mathrm{C}$, the molecular weight of PS falls, but volatilization is not significant below $300^{\circ} \mathrm{C}$ (McNeill et al., 1990). Degradation occurs via scission of the carbon backbone, either randomly or at weak links with a peak in degradation at $392^{\circ} \mathrm{C}$. Above $300^{\circ} \mathrm{C}$, the polystyrene degrades into monomer, small amounts of toluene and a-methylstyrene, and oligomers (very short chains made up of monomer). Among other products, toluene and ethylbenzene have also been found in the decomposed products of polystyrene (Sato et al., 1990; Imasaka et al., 1992).

When exposed to high temperatures (in excess of $300^{\circ} \mathrm{C}$ ), Teflon degrades to pure monomer. At high pressures (1013 mbar or higher) Teflon primarily degrades to three and four carbon fluoro-carbons and a poisonous gas monomer 
Polyurethane can be subjected to high temperatures in the absence of oxygen to obtain the original petrochemical reactants; isocyanates and alcohols (Kutty et al., 1992). It is common knowledge that the addition of reinforcing high temperature fibers to a polymer system improves many properties such as thermal resistance. In the case of polyurethane reinforced with kevlar fibers, the degradation begins at 245 to $255^{\circ} \mathrm{C}$ and reaches peaks at $383^{\circ} \mathrm{C}$ and $448^{\circ} \mathrm{C}$ (Kutty et al., 1992). However, the transition temperature of polyurethane alone is significantly lower. Serious decrease of foam thermal stability begins above $160^{\circ} \mathrm{C}$. The first evidence of weight loss in un-aged PUR foam is at temperatures between $200-300^{\circ} \mathrm{C}$ and it is caused by rupture of the primary bonds in the polymer. At temperatures between $240-540^{\circ} \mathrm{C}$ weight loss involves thermal and oxidative degradation. Aged foams showed similar but more pronounced weight loss. The $\mathrm{Tg}$ of polyurethane is $82.5^{\circ} \mathrm{C}$, the melting temperature $182.5^{\circ} \mathrm{C}$ and the decomposition temperature $250^{\circ} \mathrm{C}$ at which the polyurethane foam degraded to urethane units (Rek et al., 1990).

When $P V C$ is exposed to elevated temperatures, even below its melting point, PVC loses chlorine which forms $\mathrm{HCl}$ and becomes discolored, leading to deterioration of properties (Okieimen and Ebhoaye, 1992; Bisi et al., 1994). The $T_{\mathrm{g}}$ of PVC is about $81^{\circ} \mathrm{C}$ (Naqvi, 1991). The steps of PVC degradation (initiation, fast zip-elimination of $\mathrm{HCl}$ and simultaneous formation of [polyethylenes], and termination of the zip) are the same irrespective of the type of degradation (thermal, thermo-oxidative, photo or mechanical) (Ivan et al., 1991). Between room temperature and $185^{\circ} \mathrm{C}$ minimal weight change is observed for untreated $\mathrm{PVC}$. $\mathrm{HCl}$ is produced between $185^{\circ} \mathrm{C}$ and $375^{\circ} \mathrm{C}$. Structural reorganization occurs between $375^{\circ} \mathrm{C}$ and $550^{\circ} \mathrm{C}$. Structural degradation in which hydrocarbons are evolved occurs above $550^{\circ} \mathrm{C}$ (Chatterjee et al., 1994). The Yucca Mountain Project will be primarily concerned with the first two stages. In air, the $\mathrm{HCl}$ generation is doubled (Nass and Heiberger, 1986). Since $\mathrm{HCl}$ is corrosive and highly reactive, its presence in a potential repository will be of significance. In addition, the formation of chlorinated toxic compounds and/or other noxious substances depend on the different additives commonly used in commercial grade PVC (heat and light effect stabilizers, lubricants, extenders, pigments, dyes, etc.) (Bisi et al., 1994). PVC is intrinsically thermally unstable. PVC undergoes chain scission in the presence of metal soaps.

The great commercial importance of PVC is due to the development of effective means of stabilization. Thermal degradation is generally considered to be initiated at unstable sites within the polymer structure. Thermal stabilizers are known to function by replacing labile atoms in PVC; they inhibit or suppress the elimination of $\mathrm{HCl}$ and interrupt the formation of conjugated polyene sequence in the polymer (Okieimen and Ebhoaye, 1992). It has been shown that soaps from rubber seed oil are effective in preventing dehydrochlorination. Metal sterates ( $\mathrm{PbSt}_{2}, \mathrm{CdSt}_{2}, \mathrm{BaSt}_{2}, \mathrm{CaSt}_{2}$, and $\mathrm{ZnSt}_{2}$ ) have been used as stabilizers, reducing the rates of free $\mathrm{HCl}$ evolution destroying peroxides and peroxide radicals (Ivan et al., 1991). The main cause of instability in PVC is abnormal internal structures. The rate of dehydrochlorination may depend on internal double bonds, and allylic chlorines located at chain-end (Xu et al., 1989a). The terminal double bonds of PVC affect the intrinsic thermal stability. Fewer or greater terminal double bonds than the optimum has lower thermal stability (Xu et al., 1989b). 
Silicone rubber has a useful life of up to 20 years at $120^{\circ} \mathrm{C}$ or up to five years at $150^{\circ} \mathrm{C}$ (Lynch, 1978) which is considered outstanding relative to other polymers.

The presence of oxygen in the environment of a polymer almost always speed up degradation. If the polymer contains hetero-atoms, then polarity governs the rate of oxidation. In addition, it is important to note that stability to thermal degradation is not always the same as stability to oxidative degradation for a given polymer. Oxygen susceptibility is dependent on the state of the polymer. For example, polystyrene oxidizes readily in solution but not in solid form. In addition to chemical structure, physical structure affects the rate of oxidation.

Polyethylene is unstable in the presence of oxygen in air, eventually degrading to carbon dioxide and water. This process takes a about 18,000 hours at $20^{\circ} \mathrm{C}$, but is expedited at higher temperatures, 31 hours at $80^{\circ} \mathrm{C}$ (Barr-Kumarakulasinghe, 1994).

The oxidation of polypropylene causes the melting point to decrease (Wallius, 1993).

Plasticization and swelling result when solid polymers are exposed to various solvents (Kaplan, 1991), some of which may be present, or may be produced in a repository setting. In a poor solvent, where the interactions within the polymer chain are strong and the interactions with the solvent are weak, the polymer molecule will have a tight conformation. A stronger solvent causes the molecule to spread out so that there is more interaction between solvent and polymer. In addition, chemicals can degrade polymers. When placed in a swelling agent such as water, hydrophilic glassy polymer networks swell and form gels (Khare et al., 1992). Environmental factors affect the solvent interaction. Often, an increase in $\mathrm{pH}$ will lead to an increase in swelling force. Temperature also has an influence on solvent interaction and appears to be consistent with Arrhenius activation theory. The kinetics of equilibrium concentration can be explained by the first-order kinetic rate equation. In addition, most polymer/solvent systems follow Fickian diffusion (Khinnavar and Aminabhavi, 1992).

Epoxy resins vary in sorption characteristics with different cures and different resins. The huge variety of resins, curing agents, additives exacerbate the difficulties in understanding how solvent damage occurs. In addition swelling and plasticization occur to different extents depending on the solvent. Studies conducted at 22, 40 and $50^{\circ} \mathrm{C}$ indicate that water produces absorption to about 3 percent (Kaplan, 1991). In contrast, methanol, ethyl acetate, 1,2-dichloroethane and toluene are taken up rapidly by the epoxy from 10 to 20 percent. An increase in temperature increases the sorption of various solvents. This is because as temperature increases, there is more motion in the molecular chains and thus more interaction with solvents (Kaplan, 1991).

Polypropylene interacts with a wide variety of solvents in which it either swells or degrades.

$P E T$, in crystalline form and at room temperature, is resistant to dilute aqueous mineral acids, nonbasic salts and many organic compounds while being vulnerable to oxidizing reagents and aqueous alkalis.

The conversion of $P S$ to low molecular weight products is dependent upon both the kind of solvent used and the solvent concentration. The conversion was low in solvents that are hydrogen donors. The decrease in solvent concentration brought a rise in the conversion and the tendency was significant in good hydrogen donor solvents. These results were explained through hydrogen abstraction processes from the solvents by the polymer radicals (Murakata et al., 1993)." Specifically, "the conversion of PS to low 
molecular weight products [is] dependent on the hydrogen donating ability of the solvents used: Solvents with greater donating ability [result] is less conversion of PS (Sato et al., 1990)."

Polymer deformation often occurs when a polymer comes into contact with heat or a highly reactive solvent. Likewise, polyurethane elastomers have been found to react with solvents depending on the solvent and the temperature. In tetrahydrofuran, dioxane, cyclohexanol, acetophenone and benzyl alcohol, the polymer swells, even at room temperature. In pyridine and aniline, there is a loss of physical integrity which leads to chemical degradation reactions (Aminabhavi and Aithal, 1990). Furthermore, the addition of a basic solution would also break down the polyurethane structure.

Silicones have very good chemical resistance and remain chemically resistant at higher temperatures. In contrast, most other polymers loose their chemical resistance at higher temperatures (Lynch, 1978).

6.2.1.5 Radiation Effects. The effect of radiation on polymeric materials has been studied since the construction of the first nuclear power plants in the 1950s. When exposed to high-energy radiation, polymeric materials undergo chemical changes. The energy from the radiation excites the polymer molecules leading to chemical change. Most energy is deposited in the substrate by Compton scattering, whereby the ejection of a valence electron is accompanied by deflection of the incident photon by the electron cloud around the atom. At lower energies, the incident photon is completely absorbed by the substrate atom to produce ionization. Radiation degradation can be measured from changes in the molecular weight from which, the degree of cross-linking and scission can be determined. After irradiation, polymers continue to undergo changes. For example, irradiation in air leads to the formation of peroxides and these compounds have characteristic rate versus temperature relationships for decomposition, usually with significant rates in the range $50^{\circ}-150^{\circ} \mathrm{C}$ (O'Donnell, 1990).

Radiation enhances degradation, especially thermal effects, which often occur in parallel with radiation exposure. As energy is added to a system, the temperature is raised. The reaction rates are often quite different in a glass and rubber of a given polymer and undergo changes at the transition temperatures. The deterioration in the properties of polymers may be markedly increased by relatively small rises in temperature (Garrett et al., 1990). This tends to be the case with most chemical reactions due to the energy provided by an increase in temperature. An increase in temperature when combined with radiation leads to an increase in chain scission. Radical reaction kinetics are dependent upon the polymer morphology, crystallinity, molecular weight distribution and the main chain stability as well as its higher structure (morphology) (Kaplan, 1991). Time-temperature-dose rate models have been developed to predict the long-term aging of polymers exposed to radiation (Gillen and Clough, 1989).

The surface effects of radiation tend to be much greater than the effects to the core of a sample due to greater exposure of the surface. The polymer can be affected directly by the radiation or by the products of radiation from the polymer's environment, specifically the thermal and chemical characteristics of the environment. As a result of energy transfer, molecular components present in only small amounts may be the main sites of chemical change (O'Donnell, 1990). In addition, hydrogen atoms are often yielded due to radiation which can lead to cross-linking. The penetration of low- 
molecular-weight liquids into the volume of many polymers leads to a decrease in the radiation yield of cross linking (Smirnov and Dubova, 1992). Because light is a type of radiation, some correlations can be made between degradation caused by light (photodegradation) and gamma radiation. The energy from light is sufficient to break chemical bonds, especially short ones. In addition, chromophoric groups (double bonds) are necessary to absorb the radiation. Strong absorbers are expected to decompose roughly three orders of magnitude faster than weak absorbers (17). Because absorption of radiation is an essential first step to photo degradation, strongly absorbed radiation will be attenuated as it passes through the polymer and reaction will be concentrated in the surface layers. Thus, photolysis is often identified by the evolution of hydrogen, the development of insolubility and discoloration. In addition, UV radiation often initiates oxidation. Photo degradation can not readily be predicted from the chemical structure due to small impurities and abnormalities often present in polymer chains. It must be tested experimentally.

Thermosets have much more stability to irradiation that thermoplastics. Counterintuitively perhaps, thermosets exposed to radiation in air degrade more, the lower the dose rate. This is because of the oxygen concentration in the interior of samples. The dissolved oxygen reacts with the radiation induced radicals and builds peroxides. Thus, the thermoset becomes unstable and slowly decays by chain scission. The longer the irradiation time, the more complete is the break down of the peroxides and the damage to the material (Wilski, 1990).

Epoxy resins tend to be quite radiation resistant with fillers providing even more stabilization. Most studies have irradiated the epoxy with high doses at short time intervals. In all cases, epoxy plastics proved to be extraordinarily resistant to radiation (7). Samples exposed to a low dose rate for ten years showed the same effects as the short term, high dose samples. Strength remained the same, however surfacedependent properties were markedly influenced by the does rate (Gilfrich and Wilski, 1992).

Not surprisingly, the irradiation of nylon (polyamide) is reflected in the mechanical properties. As radiation dose is increase, the structural integrity is decreased. In one particular study on nylon 6 fibers, it was found that melting temperature decreased, as did degree of crystallinity, with radiation dose (Ellison et al., 1989). The presence of oxygen enhanced the effects of the radiation.

Polybutadiene crosslinks when exposed to radiation. The degree of cross-linking can be established using NMR to determine the amount of carbon-carbon double bonds. Radiation causes free radicals to form which then crosslink. "Upon reaching the glasstransition temperature of the elastomers, more than half of the initial radical concentration had decayed (Dole, 1973)." As energy is increased, temperature increases. Once the $\mathrm{T} g$ has been surpassed, segmental motion begins.

The degradation products of PET (polyester) exposed to radiation are carbon dioxide, carbon monoxide, methane and hydrogen gas. The products are affected by the exact structure of the PET, chemical composition and the presence of other reactants such as moisture and oxygen (Dole, 1973).

The degree of degradation due to the irradiation of polythylene is a function of its crystallinity; the higher crystallinity samples were found to be mechanically stronger after irradiation (Torikai et al., 1990). In addition, irradiation of low density PE yields a 
lot of cross-linking while chain scission is primarily achieved in medium and high density PE. It is thought that segmental motion of the polymer chains affects the polymer stability (Torikai et al., 1994). Radiation increases the degradation of polyethylene, especially when in contact with a solvent such as toluene, xylene or benzene (Smirnov and Dubova, 1992). The degradation products have little effect on plutonium solubility (Greenfield et al., 1993), however the potential formation of colloids is not known. Radiation causes both cross-linking and oxidative degradation. Irradiation of polyethylene caused both oxidative degradation and crosslinking, and the kinetics of the first process were controlled by diffusion of atmospheric oxygen into the bulk of the material (Spadaro, 1993). In addition, the temperature affects the mobility of free radicals.

In the case of polypropylene, the lower the crystallinity, the lower the irradiated degradation. In addition, the narrower the molecular weight distribution, the more stable the polymer is to radiation degradation. Four main radical species formed during the irradiation of polypropylene are alkyls, allyls, polyenyls and peroxys (Williams, 1990). Radiation effects on polypropylene are greatest when oxygen is present due to oxidation which is accelerated by radiation. This leads to discoloration and embrittlement. Oxidation occurs at a greater rate on the surface of samples and the degradation continues after radiation exposure. Published results show that postirradiation degradation of [polypropylene] occurs by oxidative mechanism due to the free macro-radicals trapped in the crystalline regions (Khoylou and Katbab, 1993). One study followed post-radiation affects for 12 months and found that degradation continued via chain scission mechanism. The recommendation was that semi-crystalline polypropylene should be stabilized against post-irradiation degradation, if it is going to be irradiated by high energy radiation sources (Khoylou and Katbab, 1993). Quenched polypropylene with a lower crystallinity has a higher radiation durability in than unquenched polypropylene. Also, higher molecular weight polypropylene degrades less than does lower molecular weight polypropylene (Ishigaki and Yoshii, 1992).

Polystyrene is quite radiation resistant and has been used in many early applications (Dole, 1973). However, radiation exposure expedites the degradation process. In the case of polystyrene, IR spectrometry has shown that the aromatic and aliphatic groups are broken down exponentially while carbonyl groups are increased (El-Agramy and Shabaka, 1990). Radiation was found to enhance the rate of thermal degradation, corresponding to an increase in temperature of about $100^{\circ} \mathrm{C}$ (Garrett, 1990).

Although Teflon has superior thermal and chemical stability, its well known sensitivity to radiation limits its use in many cases (Wheeler and Pepper, 1990). Radiation damage is usually concentrated on the surface of the material. X-ray photoelectron spectroscopy (XPS) has been used to model Teflon and it is thought that the surface is made up of a network of branched or cross-linked fluorocarbon chains. With radiation, there is a loss of fluorine and an appearance of unsaturation as saturated fluorocarbon gas is evolved (Svoboda et al., 1990). This continues until a certain level of damage is reached, after which the material degrades into saturated and unsaturated fluorocarbons.

As with other polymers, exposure to radiation accelerates degradation reactions. According to Nass and Heiberger (1986), "If unstabilized PVC is exposed to heat (temperatures above $100^{\circ} \mathrm{C}$ ), ultraviolet light, or gamma radiation, then depending on 
the intensity of the exposure and the type of PVC, a cleavage of $\mathrm{HCl}$ accompanied by polyene sequence formation and cross-linking along the chain or intermolecularly can occur," which is intensified by the presence of oxygen. However, PVC has been shown to have little effect on plutonium solubility even after extensive $\alpha$-irradiation (Imasaka et al., 1992).

When silicone is exposed to radiation, it initially forms crosslinks but as the radiation generates more heat in the silicone, it degrades. The crosslinks cause the silicone to become more rigid. Thus, the physical lifetime of silicone exposed to radiation is often dependent on the flexibility needed from the sample (Lynch, 1978).

6.2.1.6 Colloid Sorption and Chelation. Colloids exist naturally as fracture-lining materials, clays, bacteria, algae, and humic acid, but they can also be the product of degradation of man-made materials and debris, such as glass, fuels and greases, metals, biomass evolved on introduced materials and organic waste (see e.g., Meike and Wittwer, 1994). A number of processes have already been identified as potential originators of radionuclide sorbing colloids in the WP environment (Olofsson et al., 1981, 1982a,b). These are:

1. Leaching of the waste form by groundwater.

2. Corrosion of canister material (iron oxides and hydroxides).

3. Degradation of backfill material (if present).

4. Naturally occurring colloids such as clays, organics, and precipitates.

5. Organic materials that result from man-made modification of the NFE.

7. Extracellular and cellular microbial biomass.

Hydrocarbons that result from the thermal decomposition of greases, paints, and other organic items can form ligands that may enhance radionuclide transport. The little data that exists on this subject suggests that organics more effectively complex radionuclides than inorganic complexes or single ions (Raloff, 1990). The presence of colloidal and organic products may thus produce an environment that greatly enhances radionuclide migration. As a result, the movement of radionuclides may not be predictable through inorganic chemistry alone. The number and significance of other materials to be used in the repository that fall into this same category are still unknown.

Polymers do not readily sorb metals, however, there have been many polymers which have been chelated in order to promote sorption of metals. The stereochemistry and the nature of the complexes are markedly dependent upon the molar ratios of the reactants, the $\mathrm{pH}$ of the system and the nature of the anions involved (El-Sonbati et al., 1994). There are also data for metal complexes involving aliphatic alcohol compounds binding through deprotonated hydroxyl groups. The data for these complexes indicated that deprotonated hydroxyl binding is strong compared to carboxylate binding, especially at higher $\mathrm{pH}$ values (Greenfield et al., 1993). An extensive project undertaken by Raber and Garrison (1983) to determine which materials would limit the effects of radionuclide sorption. It was found that polypropylene and polyethylene sorbed the least.

There have been many studies of metal chelates of polymers for high performance and filtering applications, especially of epoxy. In one study (Kurnoskin, 1992), it was found that synthesized metalliferous epoxy chelate polymers have high thermal stability and chemical resistance when compared to the polymer alone. 
Metal adsorption sites on polypropylene are likely to be carboxyl and carbonyl groups formed as the surface degrades under the influence of oxygen, heat or light, other sites are contributed by catalysts, plasticizers and fillers (Kim and Hill, 1993). Polypropylene is known to absorb significant amounts of lead from solutions. A study which compared the sorption of lead to polypropylene and borosilicate glass found that at $\mathrm{pH}$ 7.0, polypropylene "adsorbed significantly more lead than borosilicate glass and that at pH 5.5 polypropylene adsorbed less than the glass," indicating a fundamental change in the nature of the polypropylene surface (Kim and Hill, 1993).

Many chelating resins have been developed with the intent to separate and recover metal ions (i.e., from dilute solutions). It has been found that the hydrophobic character of the polystyrene backbone negatively affects the access of metal ions to the chelating groups in the resin. The presence of hydrophilic ligands in the polymer network improves chelation (Chessa et al., 1991). Column experiments have shown that $\mathrm{pH}$ is also a factor owing to the different rate of formation of the immobilized chelated species. At $\mathrm{pH}=6, \mathrm{Pt}(\mathrm{IV})$ flows unaffected from a mixture of $\mathrm{Pd}(\mathrm{II}), \mathrm{Pt}(\mathrm{IV})$ and $\mathrm{Au}(\mathrm{II})$, whereas $\mathrm{Au}$ (III) and $\mathrm{Pd}$ (II) are both retained and successively separated by selective elution. From the same mixture at $\mathrm{pH} \leq 0$ only $\mathrm{Au}(\mathrm{III})$ is sorbed by anionic exchange (Chessa et al., 1991).

Russian studies have suggested that the sorption of various radionuclides from sea water on Teflon is time dependent. Others have shown that in the presence of tetraphenylboron, there is selective sorption of trace amounts of cesium from aqueous solution onto the hydrophobic surfaces of polyethylene and Teflon (Raber and Garrison, 1983). This same study found that Teflon was the least sorptive of all the polymers tested.

General Significance to YMP. It has been found that at elevated temperatures, and for many polymers, temperatures within the range of potential repository conditions, polymers are quite susceptible to degradation, so much so that the most of the polymers will degrade within hours rather than the thousands of years which the repository must contain the waste. Given this, it may be possible to plan to observe the impacts of polymer degradation during the retrieval period. However, some care will need to be taken with respect to polymers because the high temperature effects will not be observed. Further studies and modeling should then be conducted with such rates in mind. For example, much of the chemical modeling of long-term chemical effects on the NFE may be conducted with the final products of the polymer degradation as reactants. The final products of most polymers are known, the majority are monomer, hydrocarbons and some volatile products such as toluene, xylene and cresol. Polymer resins should not be used in any structural applications and chemical significance should be assessed for each material. Because of a number of potential thermal degradation effects, epoxy resins should not be included in the permanent structure, without detailed long term tests.

\subsubsection{Biotic Chemistry (microbially mediated chemistry)}

There is growing awareness that biotic factors could affect the integrity of the repository by a number of processes. These include microbially induced corrosion (MIC) of the waste package and construction materials, alteration of the chemical environment, and contributions to the transport of radionuclides. A variety of different 
types of bacteria normally inhabit the deep subsurface. In the course of construction both new materials and non-endogenous bacteria will be introduced to the repository environment. Conditions after waste emplacement are expected to alter dramatically. Extremely elevated temperatures with accompanying desiccation, and possible radiation exposure, are among the environmental conditions expected to result from radionuclide decay. Microbes can survive and adapt to extreme environmental conditions, take advantage of microenvironments, and remain active in generated spatial gradients. Microorganisms employ extremely diverse modes of metabolism. For the purpose of repository performance, this translates to mean that microbes can be involved in a wide variety of processes in a geological setting (see Horn and Meike, 1995 for a detailed discussion of the issues). Information on the degradation of various materials of significance to a repository are being gathered from diverse sources (see the section on polymer biodegradation below) of particular use are the data that have been collected with respect to the bioremediation of landfills and other forms of chemical waste.

Microbially mediated chemical processes can significantly alter the geochemical environment and have direct impacts on repository materials. Microbes are capable of utilizing a wide range of organic compounds to serve as sources of carbon. Autotrophic organisms are capable of carbon dioxide fixation to satisfy carbon requirements for synthesis of cellular materials. Energy can be derived from either reduced organic or inorganic compounds. Hydrogen gas, nitrogen, ammonia, nitrite, ferrous iron, and reduced sulfur compounds, for example, can all be used as energy sources by various microbial groups. Similarly, oxygen or a wide array of inorganic compounds may be utilized as a terminal electron sink. Nutrient supply, rate of nutrient transport, and the composition of the repository community will govern the specific types of metabolic activities that occur. Bacteria can also bind metals, secrete metal-complexing compounds, and transform metal ions to altered speciation states. These capabilities may enable the transport of radionuclides from the near-field environment. These considerations demonstrate that microbial biota are integral to environmental mass transfer. Thus, microbial contributions to overall environmental chemistry cannot and should not be ignored if prediction of the long-term integrity of a nuclear repository is aimed at accurately reflecting environmental processes. In this paper we examine the potential effects of microbial activity on repository performance and present a perspective for future directions to better understand and predict these effects. Specifically, we provide an assessment of standard and non-standard microbiological techniques with respect to their potential for providing information of use to the Yucca Mountain Project.

6.2.2.1 Biodegradation of Polymers. While natural polymers are readily broken down by microbes, synthetic polymers are more resistant. One reason for this is that a main source of energy for micro-organisms is the breaking of the carbon-hydrogen bonds which release energy. Another reason is that the enzymes required to break down these synthetic polymers are not found in nature. The biodegradation of polymers is also dependent upon the intrinsic viscosity and the product structure. For example, a flexible foam will degrade faster than a rigid foam which will degrade faster than a solid product. A last reason is that the most important type of enzymatic 
polymer cleavage reaction is hydrolysis which occurs exclusively inside microbial cells. Thus high molecular mass polymers would need to enter the cytoplasm before depolymerization (Schink et al., 1992). It would seem that by copolymerizing a synthetic polymer with a natural polymer, degradation could be achieved. This, however, is not the case. Studies in which starch is incorporated into the polymer structure have shown that while the starch components do degrade, the synthetic polymer structure only collapses into smaller pieces which still resist degradation. However, many degradation products of polymers are biodegradable.

Because polyamides are hydrophilic it seems that they might be susceptible to microbial attacks. This, however, has been refuted in many tests and "it is well known that these compounds are generally resistant to microbial degradation as their chemical structures are not found in natural polymers (Andreoni et al., 1993). Although, polyamides have been created which can be degraded, this is a far cry from the degradation of a commercial nylon product. Even nylon 6 , which tends to have less desirable properties than the widely used nylon 6,6 are not biodegradable when the number average molecular weight is greater than 1000 (Andreoni et al., 1993) (a polymer of this small size would not be useful for any commercial products).

Polyesters used in the manufacture of a polyurethane have been shown to be degraded by fungi. The polyester segment of a the polymer is the main site for attack which could be degraded within two weeks (Kay et al., 1993). However, these experiments were supplemented with yeast and the assumption was made that the polymer was consumed as a result of cometabolism. In another study of bacterial degradation of polyester polyurethane (Kay et al., 1991), it was found that bacteria could not degrade the polymer within a 12 week test period. Clearly as in most cases of biodegradation the type of microorganism and the environmental conditions are important variables.

There has been some study of the possible degradation of polyethylene as it would be something desirable from the standpoint of diminishing the growth of land fill. It has been found that polyethylene does not readily biodegrade. One study tested several types of bacteria on their ability to degrade polyethylene. It was found that only one type could degrade the polyethylene and then only when the sample was put in a medium which was desirable for the bacteria; no degradation of the control samples occurred. The study further hypothesized that polyethylene is degraded into its simple components (Awasthi, 1993). In addition, it was found that degradation increased when oxygen levels were increased. Polyester polyurethanes have been found to degrade via microbial attack. Polyether polyurethanes have been found to be more resistant polyester polyurethanes (Kay, 1993). Thus, it is assumed that the weak "link" is the polyester rather than the polyurethane. In another study, it was found that polyester polyurethane could not be degraded by bacteria (Kay, 1991).

6.2.2.2 Microbes at Yucca Mountain. Given the wide variety of microbially mediated effects and the complexity of microbial processes, studies to assess potential impacts of microbial activity on the Yucca Mountain repository should include a variety of techniques. These investigations should include laboratory studies of Yucca Mountain-derived microbial isolates (representative of both native and introduced populations) chosen to determine bounding conditions for various microbially- 
mediated reactions. Carefully chosen analog studies can also supplement characterization of in situ reaction rates to best predict long-term microbial effects. Assessment of microbially-mediated transport of radionuclides can best be examined using perfusion analyses and determination of the binding and transformative capabilities of Yucca Mountain microbial community members. Traditionally, microorganisms are grouped and identified using physiological and metabolic typing criteria. Identification of organisms therefore provides a means of estimating their potential involvement in significant chemical impacts. These studies will generate a roster of the organisms present to the level of genus (and species, where possible and necessary), under selected temperature, humidity, and radiation conditions. The identification of entire microbial communities will allow the establishment of boundary conditions for microbial survival and activity. Traditional culturing techniques that rely on the growth of collected organisms as a means of identification are not entirely representational. Therefore, these techniques should be supplemented with molecular means of characterizing and quantifying extant Yucca Mountain microorganisms under varying conditions.

The next step is to determine whether these activities are ongoing in both perturbed and unperturbed microbial communities, and assess the magnitude and rates of those reactions that are expected to alter the repository environment. Traditional biochemical assay techniques are available to determine biogenic acid production, hydrogen sulfide generation, metal transformations, and the soluble gas evolution. However, these techniques are not wholly amenable for the determination of in situ reaction rates. Therefore, they too can be supplemented with more advanced molecular techniques to better predict the impact of microbial affects on geochemistry and repository components.

Growth of Whole YM Communities. Samples of Topopah Spring tuff were initially aseptically collected from a mined Fran Ridge outcrop (the Large Block Test Site, LB), and rock excavated during construction of the Exploratory Studies Facility (ESF, Yucca Mountain, NV). The aim was to collect rock samples which had been exposed to construction activities and were representative of the post-construction repository environment. Bacteria which had been introduced by construction machinery, introduced materials, and human intervention could thus be included in subsequent isolations and testing.

Growth rates of YM-derived microbial communities were determined by adding $10 \mathrm{~g}$ of crushed rock samples (1.7-2.4 mm grain size) to $50 \mathrm{~mL}$ of $\mathrm{R} 2$ broth, a low nutrient formulation (Reasoner and Geldreich, 1985). Samples were incubated aerobically by shaking in covered flasks at ambient temperature, $30^{\circ} \mathrm{C}$, and $50^{\circ} \mathrm{C}$. Sterile controls were prepared by repeated cycles of autoclaving $\left(120^{\circ} \mathrm{C}\right)$ and incubation. Growth was monitored by periodic live plating of appropriate dilutions on R2 agar (Difco).

Growth rates of whole communities of YM-derived microorganisms in low nutrient $\mathrm{R} 2$ broth varied somewhat, depending on the temperature of incubation. While communities grown at room temperature or $30^{\circ} \mathrm{C}$ showed altered doubling times with respect to those grown at $50^{\circ} \mathrm{C}$, all cultures, demonstrated significant increases in cell numbers, ranging to over 20,000 cells $/ \mathrm{mL}$ of media, at the conclusion of the $30 \mathrm{~h}$ growth 
period (Fig. 6-21). Additionally, it was found that some bacterial isolates, most likely spore-forming species, survived repeated exposure to $120^{\circ} \mathrm{C}$.

These results reveal that even a modest nutrient source supports significant logarithmic growth of native and introduced YM bacteria, and total microbial cell densities reach similar levels regardless of the temperature of incubation (Fig. 6-21). Probable spore-forming microbial species were able to survive repeated autoclaving $\left(120^{\circ} \mathrm{C}\right)$, demonstrating that even at the highly elevated temperatures expected to occur after waste emplacement in the repository, some of the endogenous microbiota may be able to survive through these extended periods of intense heat.

Isolation of Individual YM Bacterial Strains. Microorganisms were isolated both aerobically and anaerobically from whole and aseptically-crushed (1.7-2.4mm) rock samples at room temperature by plating directly, or washing rock samples with Artificial Pore Water (APW, equivalent in composition to J13 well water in the YM area; Amy et al., 1992), and plating onto low nutrient R2 agar. Organisms that survive in nutrient-depleted environments and at elevated temperature were isolated from crushed samples $(1.0 \mathrm{~g})$ after extended growth (aerobic incubation, $72 \mathrm{~h}$.; anaerobic incubation, 17 days) in $\mathrm{R} 2$ broth at room temperatures and $50^{\circ} \mathrm{C}$. After extended cultivation, samples were incubated on $\mathrm{R} 2$ agar at the temperature of previous growth.

Plating of whole and crushed rock/washes at room temperature on R2 agar showed higher species diversity contained in LB samples than those obtained from ESF samples. Also, crushed rock/washes displayed generally lower species diversity and cell numbers than those arising from whole rock (e.g., Fig. 6-22). Finally, greater diversity and cells numbers were obtained after growth under aerobic conditions than under anaerobic culture conditions.

Extended growth at room temperature and $50^{\circ} \mathrm{C}$ showed generally a low diversity of microbial forms (one to three cell types). However, high cell numbers were reached after extended growth under aerobic conditions $\left(2 \times 10^{8}-10^{9}\right.$ cells $\left./ \mathrm{mL}\right)$, while anaerobic conditions produced low cell densities (e.g., 140 cells $/ \mathrm{mL}$ ), and no growth was evident after extended anaerobic incubation at $50^{\circ} \mathrm{C}$.

Since manipulation of rock samples has been reported to alter the kinds and numbers of organisms recovered (Haldeman et al., 1994), our results regarding the number and types of organisms from whole versus crushed rock are thus consistent with past findings.

YM tuff was collected and crushed exposed to the ambient air, also initial transfers of organisms cultivated on oxygen-depleted agar plates and broth were briefly exposed to air. Therefore, it must be assumed that those organisms cultivated under reduced conditions are either somewhat aero-tolerant (i.e., oxygen is not completely toxic to them, for at least brief periods), or they are capable of both oxic and anoxic growth (socalled "facultative anaerobes"). This became more evident in the results of subsequent experiments (below).

It may also be expected that both higher temperatures and anoxic conditions could result in lower cell numbers and diversity of those microbes obtained under these culture conditions. Topopah Spring tuff and its associated pore water has been characterized as generally containing a significant amount of oxygen (Buscheck and Nitao, 1994), such that strictly anaerobic, or even facultatively anaerobic organisms, 
might be expected in lower abundance relative to strict aerobes. Since elevated temperatures are not the norm in the subsurface, those organisms adapted to growth at $50^{\circ} \mathrm{C}$ may not likewise be immediately expected to be present in high abundance. However again, the demonstration that at least some organisms at the $\mathrm{YM}$ site are capable of growth at higher temperatures and under lower oxygen tensions shows that a subset of the extant YM microbial community harbor the potential to grow and survive at elevated temperatures and under reducing conditions.

LB samples, originating from a Fran Ridge outcrop that more closely resembles the geological characteristics of the repository unit, display greater microbial diversity (on R2 agar) than those from the ESF-excavated rock, which had not yet reached the repository horizon. Thus, greater microbial diversity may be extant in the repository horizon than in overlying geological units.

The paucity of microbial forms after extended growth is expected. It is accepted that under stressed conditions, such as those created by the depletion of nutrients, that only a few members of the community are equally well-adapted to exploit the minimal resources available; these will outgrow those species less able to compete.

While any given growth media (e.g., R2) permits only the growth of a small fraction of a microbial community (Atlas, 1982; Roznak and Colwell, 1987), a multiplicity of microbial types were still detected from whole and crushed YM rock on R2 media; henceforth these were treated as a sample of the total microbial community present at this site. A representative group of distinct individual isolates were purified by repeated streaking of single colonies, many of these were identified by fatty acid analysis (Welch, 1991; Analytical Services, Inc., VT), but some remain unidentified. All purified isolates (ca. 60) were preserved for use in further experiments.

Identified and preserved YM bacterial isolates included representatives of the following genera: Bacillus, Arthrobacter, Cellulomonas, Corynebacterium, Pseudomonas, Staphylococcus, Xanthomonas, and Flavobacterium. These bacterial classes collectively contain members that are capable of forming spores, producing acids, degrading a wide variety of organic compounds, and remaining active under both oxic and anoxic conditions.

Enrichment of Corrosion-Specific Bacteria from YM Tuff. The oxidation of Fe(II) to Fe(III) and the reduction of sulfate to sulfide are elements of different microbial metabolic pathways that have been linked to metal corrosion processes (Lee et al., 1994; Borenstein, 1994). Therefore, efforts were made to culture organisms that carry out these transformations from YM geologic samples.

Iron oxidizers, such as species of bacteria of the genus Thiobacillus, utilize $\mathrm{Fe}(\mathrm{II})$ as an energy (electron) source with the concomitant production of $\mathrm{Fe}(\mathrm{III})$, and they obtain carbon for cellular growth by fixing carbon dioxide from the surrounding atmosphere. The ferric iron produced by these bacteria can react with iron sulfide (pyrite) spontaneously to form more ferrous ions and sulfuric acid. As a result, iron oxidizing bacteria have evolved to function under very acidic conditions.

Iron oxidizing microorganisms were cultured from $\mathrm{YM}$ tuff by inoculating $5 \mathrm{~g}$ samples of crushed tuff into media previously reported to support the growth of these organisms (i.e., ATCC Media \#64, containing Fe(III), no exogenous carbon source, and at $\mathrm{pH} 2.8$; Gherna et al., 1989). As a control for suitable growth conditions, three known 
and characterized iron-oxidizing microbial strains were grown in parallel with those enriched from YM tuff (Thiobacillus ferrooxidans ATCC\#21834, \#14119, \#33020; Gherna et al., 1989).

Sulfate reducing bacteria use sulfate as a terminal electron sink, thereby transforming it to sulfide. These organisms typically are grown with lactate as a carbon and electron source. Thus, to encourage the growth of these organisms from YM geologic media, $5 \mathrm{~g}$ samples of aseptically ground tuff were similarly inoculated into two types of media containing sulfate and lactate (Baar's media and sulfate-reducing media; Gherna et al., 1989; Atlas of Microbiological Media-ref). The suitability of growth conditions was judged by the growth of a known sulfate-reducer, Desulfovibrio vulgaris ATCC\#29579 (Gherna et al., 1989), grown in parallel with test samples.

All cultures were incubated at room temperature and periodically, $5-10 \%$ of the culture was transferred to fresh media; a total of four transfers were made over several months of incubation. In this fashion, if iron-oxidizing or sulfate-reducing organisms were extant within the samples, their growth would be encouraged due to hospitable culture conditions, over other members of the microbial community.

All control strains grew well under the conditions provided, showing that the media and conditions used did allow growth of these types of organisms. The iron-oxidizing enrichments from both LB and ESF geologic samples, likewise produced iron-oxidizing cultures (as judged by later plating on solid ISP media; Manning, 1975; e.g., Fig. 6-23). However, sulfate reducing bacteria were not recovered from all ESF geologic samples, despite repeated attempts using two types of sulfate reducing media and the growth of the control strain under the same conditions. Sulfate reducing bacteria were recovered using the same enrichment techniques from some select sites within the ESF however, demonstrating that the presence of sulfate reducing bacteria, key players in the corrosion process, are not ubiquitous.

Enrichment cultures may or may not be a single bacterial species or strain. Thus, it must be assumed in the absence of further characterization, to be a consortium of bacteria having either predominantly sulfate-reducing or iron-oxidizing metabolic modes. Iron-oxidizing enrichment cultures were frozen for preservation and use in further experiments, as were the sulfate reducers that were obtained outside the immediate YM site.

Iron reducing strains, which use $\mathrm{Fe}(\mathrm{III})$ as a terminal electron acceptor producing Fe(II), may effect corrosion directly by anodic depolarization (Westlake et al., 1986), and affect the availability and source of $\mathrm{Fe}$ (II) for subsequent microbial iron oxidation. As an initial attempt to enrich these organisms from YM rock, $5 \mathrm{~g}$ of crushed ESF and LB material was inoculated into a media formulation that provided lactate as a carbon and energy source and nitrate as an electron acceptor (Meyers and Nealson, 1990). This type of media has been shown to support the growth of iron reducing strains under aerobic growth conditions, however it should be noted that it will also support the growth of other types of organisms as well. A characterized iron reducer, Shewanella putrifaciens ATCC\#8071 (Gherna et al., 1989), was grown in parallel as a control. Growth was observed of both the control strain and arising from crushed $Y M$ rock samples, and periodic transfer of the cultures were carried out (as above). Finally, after four transfers, the enrichment culture was frozen for future analysis. 
Calorimetric assays for determining the concentrations of $\mathrm{Fe}(\mathrm{II})$ and $\mathrm{Fe}(\mathrm{III})$ using ferrozine reagent (Lovley and Phillips, 1987; Greenberg et al., 1985) were tested using water as a solvent. Linear standard curves were obtained [with a dynamic range extending 5-100 ppm Fe(III)] under these conditions. Iron oxidizing and possible ironreducing consortia will be analyzed to quantify their rates of iron reduction/oxidation using these assay techniques.

Screening for Acid-Producing Bacteria. The production of organic acids as products of microbial central metabolism is well-documented (Horn and Meike, 1995). The generation of acids has been both directly and indirectly linked to metal corrosion. Microbially-generated acids have been shown to directly dissolve the protective calcareous film on stainless steel (Little, 1987). Coupling of protons with electrons results in electron removal from the cathode (Borenstein, 1994), and forms hydrogen which is a substrate for microbial sulfate reduction (Fig. 6-24; Pope et al., 1994). Therefore, the library of YM isolates that were recovered from LB and ESF geologic samples (above) were screened for those that demonstrated a decrease in $\mathrm{pH}$ during active growth.

As an initial screen to identify acid-producing strains among the preserved YM microbial isolates, all isolated strains were grown separately in R2B media (with or without amendment of $0.5 \%$ glucose), using the $\mathrm{pH}$ indicators bromocresol purple $\left(\mathrm{pK}_{\text {indicator }}=5.3\right)$ or methyl red $\left(\mathrm{pK}_{\text {indicator }}=4.1\right)$. Under these conditions, a change in the color of the culture indicates the production of acid, thereby providing a rapid means of assessing acid production by the 46 strains tested. Anaerobically-grown strains were incubated under anaerobic conditions, while aerobically-isolated strains were cultivated with aeration, and all strains were incubated at either room temperature or $50^{\circ} \mathrm{C}$, depending on their temperature of isolation. Sterile, uninoculated controls were included in all experiments. The $\mathrm{pH}$ endpoint was determined using a standard $\mathrm{pH}$ meter for at least one trial.

Results revealed that both growth and acid production were generally more rapid when the media was amended with glucose. This is not surprising given that acid production is largely a result of carbon utilization; addition of glucose provides at once more carbon and energy for growth, together with a greater potential rate of acid generation. When 46 bacterial isolates were tested with glucose amendment, 10 (21.7\%) of these displayed a decrease in $\mathrm{pH}$ (from about $\mathrm{pH} 7.0$ ) to $\mathrm{pH} 5.3$ or less after a period of growth lasting from 3 to 16 days. When glucose was not added to the media, only 5 strains tested showed similar extents of acid production. Sterile control cultures maintained the initial $\mathrm{pH}$ of the media. While there was some interference of the $\mathrm{pH}$ indicator with measurement of the $\mathrm{pH}$ endpoint (probably due to titration of protons by the indicator) and even growth in some instances, the lowest $\mathrm{pH}$ attained was 4.46 after a 76 hour incubation by a Pseudomonas stutzeri LB isolate in media with added glucose and the methyl red indicator.

These results indicated that microbially-induced metal corrosion will be accelerated with inclusion of a readily metabolizable carbon source which promotes both growth and acid production. Thus, materials testing should include added glucose in the media, as glucose will contribute towards accelerated testing conditions. Compilation of the screening results revealed eleven strains that produce acid under the described 
conditions of growth, which included members of the genera Cellulomonas, Pseudomonas, Flavobacterium, Bacillus, and Arachnia. (Table 6-12). Five of these strains were further analyzed to determine their rates and extents of acid generation, and to further determine conditions under which acid is produced; these strains would be considered for specific inclusion in accelerated materials testing (below).

Screening for Sulfide Producing Bacteria. Microbially-produced sulfide may be corrosive to metals, as are the ferrous sulfides that form when produced sulfide reacts with solubilized ferrous ions. Most often these activities are associated with sulfate reducing bacteria, which directly promote corrosion by depolarizing the cathode through consumption of available hydrogen from the metal surface (Borenstein, 1994). Attempts to isolate sulfate reducers from the immediate $\mathrm{YM}$ environs demonstrated that these organisms are not uniformly distributed. However, microbes can also produce sulfide by the decomposition of proteins, a process known as "putrefaction" or "desulfurylation," in which the sulfur-containing amino acids methionine and cysteine are broken down, releasing sulfide in the process.

While the evidence that sulfide and ferrous sulfide directly contribute to metal corrosion is not entirely conclusive (Licina, 1988), a screening technique was devised to detect desulfurylating microbes among the preserved isolates contained in the $\mathrm{YM}$ library. These efforts were aimed at determining whether YM microorganisms harbor desulfurylation capabilities, assessing the potential contribution of desulfurylation to metal corrosion (i.e., the direct effects of sulfide and ferrous sulfide), and to ascertaining those alloys that may be more resistant to these microbial products.

All preserved isolates were screened in test tubes containing $\mathrm{R} 2$ agar supplemented with $0.75 \%$ proteose peptone \#3 (Difco), to provide an excess supply of amino acids for desulfurylation reactions ( $R 2$ normally contains only $0.05 \%$ of peptone; Reasoner and Geldreich, 1985). Additionally, the media contained $0.05 \%$ lead acetate, which precipitates as lead sulfide when sulfide is produced as result of microbially-driven peptone decomposition; the resulting lead sulfide is detected by its blackening of the agar medium.

The library of YM bacteria were each individually inoculated into $\mathrm{R} 2+$ peptone+lead acetate agar media contained in screw-top test tubes, by streaking on top of the agar surface (exposed to the air in the headspace of the tube) and stabbing into the agar within the tube (under which conditions growth is anoxic or micro-aerobic). Sterile, uninoculated control tubes were monitored in parallel with inoculated ones. All samples were incubated at room temperature or $50^{\circ} \mathrm{C}$, depending on the temperature of strain isolation. Growth and (lead) sulfide generation was monitored over a 34 day period.

Twenty-one of the forty-five aerobic strains tested (46.7\%) demonstrated sulfide production in the oxic area of the culture (none of these were strains that were isolated and incubated at $50^{\circ} \mathrm{C}$ ), whereas only three of the aerobically-isolated strains (all $50^{\circ} \mathrm{C}$ isolates) showed sulfide production in the anoxic area of the culture. Three of the 17 (17.6\%) anaerobically-isolated bacteria tested showed sulfide production in the anoxic butt of the tube, one of these had significant sulfide production under aerobic conditions as well. A total of 7 of the $17(41.2 \%)$ anaerobic isolates displayed some 
detectable sulfide production under aerobic conditions. No sulfide production was detected in any of the sterile controls.

These results demonstrate that a significant proportion of $Y M$ bacterial isolates are capable of producing sulfide via putrefaction under both oxic and anoxic conditions, at least when provided with excess protein substrate. Isolates of Pseudomonas, Flavobacterium, Bacillus, Arachnia, and Cellulomonas were all found to produce sulfide; four of these isolates were found to produce both acid and sulfide using these screening techniques. The use of these putrefying bacteria in accelerated corrosion tests should allow a more precise determination of whether hydrogen sulfide and associated metal sulfides are directly capable of causing corrosion to waste package alloys. Since these microbes generate sulfides in the absence of sulfate reduction (and hydrogen utilization), the effects of only sulfides on corrosion can be assessed absent cathodic depolarization effects.

All strains were incubated under aerobic conditions, by streaking on top of the agar, as well as under [somewhat] reducing conditions by stabbing into the semi-solid agar surface. Many of the aerobic strains were capable of growth within the agar (all of the $50{ }^{\circ} \mathrm{C}$-incubated cultures grew well under these anoxic conditions), and some of the anaerobes were also capable of growth under aerobic conditions. This may have been expected since the selection and transfer protocols used (above) precluded the isolation of "strict" anaerobes (i.e., those to which oxygen is toxic). Employed methods resulted in isolation of organisms that were at least tolerant to limited exposure to oxygen or socalled "facultative anaerobes," which are capable of both oxic and anoxic metabolism. Likewise, some of the "aerobes" can be facultatively capable of anoxic growth. Several of the identified sulfide producers were further quantitatively analyzed for their rates and extents of sulfide production (below).

Screening for Slime under Varying Culture Conditions. The production and export of polysaccharides (long chain sugar polymers) to the exterior of cells is characteristic of many bacterial species. Exopolysaccharide production results in the build-up of a slime layer which protects, embeds, and allows anchorage of cells to solid surfaces. The microenvironments contained within slime layers (or "biofilms") can be drastically altered from the general conditions in the exterior meileu, and from other areas within the biofilm. Generally, it can be expected that differential nutrient concentrations, relative humidity, and oxygen tensions exist throughout the film (Costerton and Geesey, 1985). Consortia composed of different microbial species can become embedded by polysaccharide produced by one or more consortial members. These slime capsules provide a three dimensional spatial matrix that permits concentration gradients and facilitates intermicrobial interactions. Slime producing organisms probably indirectly contribute to corrosion by permitting adherence and facilitating interactions among the different types of organisms that cause corrosion. Direct effects of slime on corrosion include the creation of differential aeration cells and localized elevations of ions, which in turn form crevices under which corrosion is accelerated (Borenstein, 1994; Costerton and Boivin, 1991).

Since slime production is an integral element of microbially-induced corrosion, the library of $Y M$ bacterial isolates was screened for slime production first on R2 agar and then $\mathrm{R} 2+0.5 \%$ glucose agar, $\mathrm{R} 2+0.75 \%$ peptone agar, and $\mathrm{R} 2+0.5 \%$ glucose $+0.75 \%$ 
peptone agar. All isolates were incubated anaerobically or aerobically at room temperature or $50^{\circ} \mathrm{C}$, depending on their mode of isolation. Slime production was assessed by observation of gross colony morphology: the appearance and quantity of a viscous slime layer was noted and scored (e.g., Fig. 6-25).

Prodigious amounts of polysaccharide were produced by two Bacillus isolates and two as yet unidentified isolates with very similar colony morphologies. All of these strains were identified as sulfide producers in former screening analyses, however none of these were identified acid-producers. Moderate quantities of slime were generated by five other YM strains that included representatives of the genera Arthrobacter and Pseudomonas. Retesting of six of these slime generators on R2 agar supplemented with peptone and glucose revealed that slime production varied with media type. The greatest degree slime production occurred on media containing glucose for two of the strains tested. This observation is in agreement with the fact that the synthesis of polysaccharides requires sugar precursors; amended glucose provides a source of building blocks to support slime synthesis. The other isolates showed little difference in the quantity of polysaccharide produced between media types, and one strain showed no growth at all on $\mathbf{R} 2+$ peptone. A single anaerobic isolate demonstrated copious slime generation on $\mathrm{R} 2$ agar.

These results demonstrate that $\mathrm{YM}$ isolates are capable of slime production under low nutrient conditions, and could therefore play a role in corrosion of waste package materials. Generally it appears that the availability of carbohydrates could increase slime production, and possibly accelerate corrosive microbial activities.

Rates of Acid Production Under Varying Growth Conditions. Five strains identified in preliminary screening for the production of acids (above) were further analyzed for their rates and extents of acid generation in $\mathrm{R} 2$ media containing additional peptone and glucose. Each strain was separately inoculated into R2, R2+0.5\% glucose, R2+0.75\% peptone, and R2+peptone+glucose. Cultures were incubated either anaerobically in serum bottles with pre-reduced media, or aerobically in shake flasks at either $30^{\circ} \mathrm{C}$ or $50^{\circ} \mathrm{C}$, depending upon the mode of isolation. The $\mathrm{pH}$ was monitored in withdrawn samples periodically over a three to five day period (Fig. 6-26).

The two anaerobic strains (one a possible Arachnia propionica, the other unidentified) showed a negligible effect of added glucose and peptone, and the $\mathrm{pH}$ did not fall below pH5.2 in either of these cultures. The aerobically-incubated strains, however, showed greater dependence of the composition of the growth media on the production of acids. The Pseudomonas stutzeri isolate, LB-71h-RT-13, only generated acid when glucose was added to the $\mathrm{R} 2$ media, displaying a decrease to $\mathrm{pH}$ 4.2. The $\mathrm{pH}$ probably did not decrease coordinately after growth of the $P$. stutzeri in $\mathrm{R} 2+$ glucose+peptone media due to deamination of amino acids contained in the added peptone, which releases alkaline amines, counteracting the effects of acid production. This counter-effect of added peptone was not as evident in the Flavobacterium esteroaromaticum isolate, ESF-71h-RT-4, which showed decreases in $\mathrm{pH}$ after growth in both $\mathrm{R} 2+$ glucose and $\mathrm{R} 2+$ glucose+peptone, as did a $50^{\circ} \mathrm{C}$-isolated strain, LB-71h-50-3 (most probably a Bacillus) (Fig. 6-26).

In summary, the effect of available nutrients on the production acids by $\mathrm{YM}$ isolates varies by strain. Some isolates are only capable of acid production when supplied with 
an added carbon source, others are less affected by this requirement and are capable of acid generation even when available carbohydrate concentrations are minimal. Also, the presence of other metabolizable nutrient sources can affect overall $\mathrm{pH}$; if end products include alkaline compounds (such as amines produced by deamination of amino acids), then acid production can be mitigated. The rates of acid production, in view of the long time spans that must be considered to evaluate the integrity of the YM repository, are significant. Rates of acid production over a three to seven day period are measurable and result in orders of magnitude differences in proton concentrations.

Rates of Sulfide Production by YM Isolates. Seven YM isolates identified as sulfide producers (via desulfurylation) were analyzed for their rates of sulfide production under aerobic and anaerobic conditions, because it had already been shown that many isolates are capable of growth at high or low oxygen tensions (above). All strains were inoculated into R2 media amended with $0.75 \%$ peptone. Both anaerobic (contained in serum bottles with pre-reduced media, cysteine as a reducing agent and rezasurin as a redox indicator) and aerobic (contained in flasks) were incubated at $30^{\circ} \mathrm{C}$ or $50^{\circ} \mathrm{C}$ unshaken to minimize air stripping of the produced hydrogen sulfide. Uninoculated media was also incubated to detect spontaneous abiotic sulfide production.

Periodically, samples were withdrawn, cells removed by filtration, and the supernatants analyzed using a modification of the methylene blue assay, which relies on the reaction of sulfide, ferric chloride and dimethyl-p-phenylenediamine to produce methylene blue (measured spectrophotometrically, $664 \mathrm{~nm}$; Greenberg et al., 1985). Standard curves were prepared using sodium sulfide diluted in the appropriate media, and sample sulfide concentrations were calculated by interpolation of the standard curve.

Preliminary results (depicted in Fig. 6-27) showed that sulfide production via desulfurylation increased for all tested strains within a two day incubation period, even in anaerobic cultures which metabolize and grow more slowly than do aerobic cultures. Sulfide concentrations increased to about $500 \mathrm{ppb}$ for all strains grown under anaerobic conditions and to approximately $150 \mathrm{ppb}$ for the same isolates incubated aerobically. Sulfide concentrations continued to increase in aerobically grown cultures, reaching a maximum of approximately $330 \mathrm{ppb}$ over a 7 day period, although extents of maximal sulfide concentrations varied between the strains tested. Thereafter, aerobic sulfide production, in general, decreased until 22 days after initiation of growth, when there was again a trend towards increasing sulfide found in the media.

These aerobic incubation results could be explained by volatilization of hydrogen sulfide from the culture (or precipitation from the soluble phase), combined with an initial growth phase, followed by cell death. In "batch" cultures such as those tested (which are not continually fed), growth of aerated cultures continues for a relatively short time, probably at the most for a week, after which nutrients are exhausted. While efforts were made to minimize the loss of sulfide through volatilization, sulfide losses could have resulted from inadvertent air-stripping or precipitation by media components in the death phase of the cultures where little or no new sulfide production could replace that which had been lost. The final increase at day 22 may be due to the growth of surviving cells on those that had died, with concomitant sulfide production resulting from metabolism of the amino acid content of dead cells. 
Anaerobically-grown cultures also displayed a decrease in sulfide concentrations, starting after two days of incubation. In most cases, these decreased to zero over a 17 day period of incubation. These cultures were contained in sealed vials, and maintained under reducing conditions. Thus, loss of hydrogen sulfide from the media through volatilization is unlikely. Rather, since the employed assay only detects the presence of soluble sulfides, it is likely that sulfide may have precipitated by interacting with other media components.

While these preliminary analyses are not entirely conclusive, it is important to note that microbially induced sulfide production increased significantly above background levels, was detected among a wide variety of YM isolates under both aerobic and anaerobic conditions, at least when strains were provided with an excess amino acid source (in the form of added peptone). These preliminary results additionally aid in determining conditions under which to conduct accelerated testing of alloy candidates, and which strains to include in accelerated corrosion tests.

Significance to YMP. Native microorganisms reside within the potential repository environment. Microbial communities have been characterized from a variety of deep subsurface environments, and ongoing work has already identified some of the native microbiota in the Yucca Mountain region (e.g., Russell et al., 1994).

Microbes vary widely in their types of metabolic activities, and the consequent alterations to the surrounding environment that they can facilitate (Horn and Meike, 1995). Historically, bacteria (and the closely related Archea) have been classified according to their individual metabolic types. The potential reactions actually performed by bacteria are dictated by both innate metabolic ability, and the conditions to which they are exposed. The type of metabolic activities that are possible are governed by the availability of substrates. For example, sulfate reduction with the concomitant generation of hydrogen sulfide is only possible if sulfate reducing bacteria are present and sulfate is available to this class of organisms. Presumably, native microbes that are currently present have or have had adequate resources. The establishment of bacteria introduced through drift construction will likewise be dependent on adequate nutrient supplies and their rates of adaptation to the repository environment.

Conditions anticipated upon waste emplacement in the proposed Yucca Mountain repository will include extreme heat, desiccation, and possibly high levels of ionizing radiation. The initial presence of extreme conditions within the repository may not completely preclude microbial activity; even if general conditions extend beyond those able to support microbial activity there may be microenvironments in which environmental extremes are mitigated. In any case, eventual repopulation of the nearfield environment through reentry of water carrying both nutrients and microbes, is anticipated as overall repository conditions become less extreme. We may expect that organisms that thrive at high temperatures and those that form spores under adverse conditions will be extant within the native or introduced microbial communities at Yucca Mountain, and maintain or regain activity as conditions become favorable. Microbial populations may acidify and otherwise alter the pore water chemistry of the near field repository environment, as well as directly affect the corrosion of repository waste packages. The degradation of materials and the consequent alteration of the 
aqueous chemical environment, with accompanying effects on repository performance, will depend on the presence of adequate nutrients and water to maintain at least a minimum level of activity.

The demands of establishing boundary conditions for microbial activity in the context of a radioactive waste repository extend beyond the information that is presently available in the literature. As a first step organisms collected from the ESF have been cultured and assembled into a YMP library. These microbes were grown in low nutrient media with various amendments and screened for various activities of significance to the long term chemical and hydrological properties of the NFE. Both the production of acid and slime was assessed under these conditions. The generation of both acid and slime for at least some isolates was increased when an easily metabolized carbohydrate (glucose) was incorporated into the media. Other culled YM acid and slime producers did not demonstrate a dependence of corrosion activities on sugar availability. It might be noted however, that the availability of carbohydrates should increase growth rates of those organisms depending on reduced carbon sources for food, such that even if sugars are not required directly for these processes, increased growth rates might be expected to indirectly contribute to increasing acid and slime production rates. These microbes have been used in estimating the required conditions for corrosion-related microbial activities, and to further optimize conditions for accelerated testing of candidate barrier alloys.

The analysis of acid production in different media types revealed that other metabolites (i.e., bacterial products), might ameliorate the results of acid production. If alkaline products are secreted to the media then acid generation is mitigated.

Taken together, while media composition plays a part in the rates and extents of acid and slime production for some isolates, it appears to have little direct effect on other isolated organisms. This demonstrates that even with a minimal supply of nutrients both of these processes are possible. Further analyses should include assessment of these activities under a broader set of conditions, including those which more closely mimic anticipated repository conditions.

Sulfide and metal sulfides have been identified as probable corrosive bacteriallygenerated products, most often associated with the activity of sulfate reducing microorganisms. The distribution of sulfate reducers at the proposed $\mathrm{YM}$ repository site was not found to be ubiquitous, thus an alternative pathway for microbial sulfide production was explored. Many of the YM microbes contained within the assembled library were found to have the capacity to make sulfides through desulfurization of sulfur-containing amino acids; this process occurred under both anaerobic and aerobic conditions when a supplementary source of amino acids was added to the media. YM microorganisms were not tested for sulfide production in the absence of amended amino acids, however it was found in preliminary experiments that the rates of desulfurylation and concomitant sulfide accumulation increased quickly up to $0.5 \mathrm{ppm}$. Thereafter, most probably due to the culture conditions employed, sulfide concentrations were found to decrease.

Use of these desulfurylating $\mathrm{YM}$ organisms alone in accelerated corrosion tests should indicate the degree to which they can promote corrosion. If the contribution of sulfides and their metal derivatives is significant in increasing corrosion rates, then these processes should be analyzed further to determine their bounding conditions, 
rates, and contribution to other corrosive processes. The rates of these processes were very rapid when compared to the long term periods that must be considered for repository performance. Given adequate nutrients, slime, acid and sulfide generation rose to their highest levels within a matter of days or weeks. Thus, the period required for these organisms to reach their greatest corrosive potential, given the right conditions, is almost instantaneous in comparison to the functional lifetime of the repository.

\subsubsection{Discussion}

It is clear that the addition of man-made materials to the near-field environment (NFE) may modify the chemical environment and influence the geochemical reactions that may occur. An example of the interaction between introduced materials, rock and water is as follows. The repository horizon and the adjacent horizons contain zeolites, or they may develop zeolites during interaction of water with rock at elevated temperatures. Zeolites are common molecular sieves and sorbates. Clinoptilolite, for example, is used as a molecular sieve for the ammonium ion (Barrer, 1978b; Breck, 1974), which has the potential to degrade the repository environment. This potential beneficial effect may be counteracted by other man-made materials that could destroy the zeolite structure or provide preferentially adsorbed ions. The balance of these effects at the repository is unknown at present. Application of geochemical models to this area, where the appropriate databases exist will provide guidance and some bounding constraints for repository design and performance assessment. Modeling and databases are described in the next section.

\subsection{Understanding the Processes}

\subsubsection{Experimental Studies}

In order to predict chemical properties over a long period of time we need to know fundamental properties of the appropriate materials. These fundamental properties are often better known for geological materials because the interest in very long term chemical prediction has existed for decades. A similar interest in fabricated materials has appeared only relatively recently, and most commonly in relationship to radioactive waste disposal efforts. Previous efforts in the area of fabricated materials has focused on optimizing fabrication conditions. This is hardly the data that is needed for predicting processes in which the environment $w$ ill not be controlled. It is for this reason that an application driven program finds itself in need of generating fundamental data.

\subsubsection{Data Availability and Modeling Requirements Regarding Cementitious} Materials. Of the major reactant phases of cement powder-alite, belite, possible residual glass, gypsum, and ferrite $\left[C_{2}(A, F)\right]$ (See Appendix $B$ for standard cement formula nomenclature)-only the thermochemical data for gypsum are complete. Data are available for the pure calcium end-member equivalents of alite and belite (Haas et al., 1981), but not for their solid solutions. The significance of solid-solution characteristics of alite and belite to performance assessment may be great because not only do alkalis and other minor impurities stabilize phases, but substitution of $\mathrm{Al}_{2} \mathrm{O}_{3}$ 
and $\mathrm{Fe}_{2} \mathrm{O}_{3}$ may affect reaction kinetics. It is suspected that aluminum and iron substitution do not affect early hydration but slow hydration over a period of $24 \mathrm{hr}$ (Ghosh, 1983). The stabilization of phases by alkali substitution has been investigated (Xiuji and Shizong, 1986) but remains poorly understood. Most of the detailed kinetic studies of hydration have employed the pure calcium end-members $C_{3} S$ and $\beta-C_{2} S$. The thermochemical data for the calcium aluminates have been rigorously evaluated by Ellezer et al. (1981). However, no calorimetric measurements were found for the $C_{2}(A, F)$ solid solution, which has been characterized structurally by Jeffrey (1964).

Most of the hydrous phases of cement and the anhydrous and hydrous solid solutions lack calorimetric data. The kinetics of transformation of C-S-H into other phases at its upper temperature limit is significant to predictions of cement behavior in the repository, which will stay at 80 to $120^{\circ} \mathrm{C}$ for an extended time. Of prime importance for $25^{\circ} \mathrm{C}$ performance modeling are calorimetric data for ettringite and tobermorite and well characterized solid solutions of these phases. The prediction of chemical reactions at greater temperatures requires more data than is presently available. Geochemical codes are also useful in the absence of these data for conducting a sensitivity analysis to determine the solid solutions or end-member phases that are critical for calorimetry. The original $\Delta \mathrm{H}$ of formation $\left(20^{\circ} \mathrm{C}\right)$ from $\mathrm{CaO}$ and silica gel thermodynamic data for all $\mathrm{Ca}_{2} \mathrm{SiO}_{4}$ phases are evaluated by Haas et al. (1981). Qualitative rate information has been obtained for ettringite components (Majling et al., 1985). Other than an enthalpy of dehydration (Maycock et al., 1974) and $C_{\mathrm{p}}$ data (Ederova and Satava, 1979) obtained over the range of 273 to $333^{\circ} \mathrm{K}$, thermochemical data for ettringite are calculated (Sarker et al., 1982; Babushkin et al., 1985). The only experimental data for "monosulfate" $\left(\mathrm{C}_{4} \mathrm{ASH}_{12}\right)$ located to date is $\mathrm{C}_{\mathrm{p}}$ data from 273 to $353^{\circ} \mathrm{K}$ (Ederova and Satava, 1979). As discussed previously, the kinetics of the relevant reactions are even less well understood.

Comparisons of cement leachates with calculations performed using available data and standard thermochemical tables (Barnes and Roy, 1983) suggest the best agreement with the solutions buffered by tobermorite and possibly gyrolite. Calculated activity products have been compared with (1) experimentally obtained solution compositions $\left(\mathrm{Ca}^{++}, \mathrm{Na}^{+}, \mathrm{K}^{+}, \mathrm{pH}\right.$, and $\mathrm{SO}_{4}{ }^{\prime}$, but not $\mathrm{Al}$ or $\left.\mathrm{CO}_{3}=\right)$ from cement hydrated for up to $3 \mathrm{hr}$ (Gartner et al., 1985), and (2) pure $\mathrm{C}_{3} \mathrm{~S}$. The comparisons suggest that although no difference in supersaturation was observed with respect to portlandite, gypsum, and syngenite $\left[\mathrm{CaK}_{2}\left(\mathrm{SO}_{4}\right)_{2} \cdot \mathrm{H}_{2} \mathrm{O}\right]$, thermodynamic equilibrium is not achieved during early hydration (Moragues et al., 1987, 1988), and high ionic concentrations of the solutions cause departure from Debye-Huckel theory. The most successful chemical models to date have been achieved by working with a limited number of equations that include $C$ $\mathrm{S}-\mathrm{H}$ solid solutions, monosulfate solid solution, and ferrite solid solution. Glasser et al. (1985) analyze a simplified cement system as the ternary $\mathrm{CaO}-\mathrm{SiO}_{2}-\mathrm{H}_{2} \mathrm{O}$. Barret and Bertrandie (1986) make a similar analysis of the system $\mathrm{CaO}-\mathrm{Al}_{2} \mathrm{O}_{3}-\mathrm{CO}_{2}-\mathrm{H}_{2} \mathrm{O}$. Incorporation of aggregate into repository concrete will increase the complexity of geochemical modeling. Calculations that include portland cement, special cements, and concretes that incorporate bfs, fly ash, and silica fume (Berner, 1987) have achieved some success for equilibrium-solid-phase and pore-solution-composition data obtained from experiment, but they do not readily take reaction progress into account. 
The use of numerical simulations to integrate the effects of the variables described in Sec. 6.2 complements experimental and historical investigations. Eventually, coupled chemical effects that are difficult or inaccessible through experiment can be examined. However, even the present chemical data base (Sarker et al., 1982; Babushkin et al., 1985), although limited, can be manipulated to obtain insight into some effects that may be expected due to man-made materials. Conversely, the data base will be enhanced over time by incorporation of new thermodynamic data from the experimental and historical investigations.

6.3.1.2 Generation of short term thermodynamic data. The work that has been conducted in the area of generating more thermodynamic data has focused on phases that are expected to be part of the drift scale chemical system at elevated temperatures if OPC cement is a significant element of drift construction. As described by Meike (1995), much of the data required for long term modeling of the same caliber that presently allows us to predict the chemical interactions of the natural system is unavailable. $\mathrm{A}$ program was begun to obtain that data. Synthesis of $\mathrm{Ca}-\mathrm{Si}-\mathrm{H}_{2} \mathrm{O}$ phases had been completed and measurement of thermodynamic data had just begun when the program was halted in November 1995. Heat capacity and entropy measurements were obtained for $11 \AA$ tobermorite using heat pulse calorimetry, but the data has not yet been analyzed. The work on other phases was halted.

In order to provide a means of verifying experimental data, and ultimately developing a means to calculate necessary thermodynamic parameters and better understand the relationship between relative humidity and the stability of $\mathrm{Ca}-\mathrm{Si}-\mathrm{H}_{2} \mathrm{O}$ phases a program was initiated to conduct electronic structure calculations of $\mathrm{Ca}-\mathrm{Si}$ Hydrates (Sterne and Meike, 1995). Given the difficulties inherent in direct measurement of the thermodynamic parameters of these phases we have undertaken a set of first principles electronic structure calculations.

Electronic structure calculations, and the Linear Muffin Tin Orbital (LMTO) theory in particular are standard methods for approaching the physical properties of metals and metal alloys, semi-conductors and simple insulators (see, for example, Anderson, 1975; Skriver, 1984). In the past these methods have been confined to small systems of less than 20 atoms in a unit cell. Thus calculations for wollastonite and xonoitlite, which contain a 30 atom unit cell and 62 atom unit cell respectively would have been out of reach normally. However, recent developments in algorithms and computer power have brought larger systems within the range of these calculational techniques.

The goal of this modeling effort is to determine the energetics of hydration for crystalline $\mathrm{Ca}$-Si-hydrate phases. The work performed to date represents an initial step in this direction. The initial results for the first phases undertaken for phases representing the water poor end members, wollastonite $\left(\mathrm{CaSiO}_{3}\right)$ and xonotlite $\left(\mathrm{Ca}_{6} \mathrm{Si}_{6} \mathrm{O}_{6} 17(\mathrm{OH})_{2}\right)$. The results, reported in Sterne and Meike (1995), are summarized below.

The calculated ground state properties of wollastonite and xonotlite are in very good agreement with experiment, and provide equilibrium lattice parameters within 1-1.4\% of the experimentally reported values. The roles of the different types of oxygen atoms, which are fundamental to understanding the energetics of crystalline Ca-Si-hydrates, examined in terms of their electronic state densities, appear to be in good agreement 
with experiment for the lattice parameters and internally consistent when comparisons are drawn between the two structures. The exercise, completed with wollastonite and xonotlite, demonstrates the applicability of these electronic structure methods in calculating the fundamental properties of these phases. The electronic structure calculation methods are demonstrated to give reliable results, even for the relatively large wollastonite and xonotlite unit cells. Thus, the application of this new approach to the study of calcium silicate hydrates appears to be fruitful not only in terms of the ability to calculate heats of formation, but also by virtue of the insight that it can provide into the nature of hydration and dehydration.

6.3.1.3 Generation of short term kinetic data. The need for kinetic data is similar to that described above for thermodynamic data, but was also halted in November 1995. However, in the process of conducting the diesel fuel experiments described above, we have obtained some data regarding the degradation of cementitious material, specifically Fibercrete ${ }^{\mathrm{TM}}$. In all experiments containing Fibercrete ${ }^{\mathrm{TM}}$ (DF3, DF4, and DF6), $11 \AA$-tobermorite formed. Thus, $11 \AA$-tobermorite appears to be a stable, or at least metastable, phase at $200^{\circ} \mathrm{C}$. As is observed in experiment DF6, the precipitation of $11 \AA$ tobermorite, calcite and cristobalite may control geochemistry and effect porosity and permeability for waters contacting both cements and Topopah Spring tuff. The importance in the dissolution and precipitation kinetics can be seen in the slow changes in solution $\mathrm{pH}$ and dissolved silica concentrations and the small fraction of the initial starting material dissolved to form secondary precipitates at the Fibercrete ${ }^{\mathrm{TM}}$ and Topopah Spring tuff surfaces. In the absence of Fibercrete ${ }^{\mathrm{TM}}$, cristobalite appears to be the dominant secondary mineral formed in Topopah Spring Tuff experiments, in agreement with previous studies (Knauss et al., 1985; Knauss and Peifer, 1986; Knauss et al., 1987).

Calculations using the current data base appear to be contradictory. Aqueous chemical modeling results suggest that mesolite should precipitate from the solution. They predict that the chemical system is saturated with respect to quartz and calcite after 20 days of reaction and undersaturated with respect to $11 \AA$-tobermorite. Zeolites were not detected in any of the experiments, suggesting either that the thermodynamic data is not correct, that zeolite nucleation from solution has a very large activation energy, or that zeolite precipitate rates are very slow even in very supersaturated solutions. Given the painful lack of thermodynamic and kinetic data pertinent aqueous degradation of $\mathrm{Ca}-\mathrm{Si}-\mathrm{H}_{2} \mathrm{O}$ phases the first option is very likely. Thermodynamic data for $\mathrm{Ca}-\mathrm{Si}-\mathrm{H}_{2} \mathrm{O}$ phases are sparse and contradictory (Vieillard and Rassineux, 1992; Bruton et al., 1994; Meike et al., 1994). The constant 11 $\AA$-tobermorite saturation index after 40 days of reaction and the identification of $11 \AA$-tobermorite in the final solid material indicates that the solubility of $11 \AA$-tobermorite is over estimated in the current data base. Previous experiments which have investigated the stability of various phases are typically only a couple of days (Lea, 1971). Atkins et al. (1991) determined the solubility of cement hydrate phases after four weeks of reaction at $25^{\circ} \mathrm{C}$. Clearly longer reaction periods are required for the crystalline phases to reach equilibrium.

From the present work, it is possible to calculate a $11 \AA$-tobermorite solubility constant $(\mathrm{K})$ at $200^{\circ} \mathrm{C}$ to be $10^{39.7( \pm 0.6)}$, using the experimental ion activity product for the following solubility expression for each aqueous sample after 20 days of reaction: 


$$
\begin{aligned}
& \mathrm{Ca} 5\left(\mathrm{SiO}_{2}\right)_{6}\left(\mathrm{OH}_{10} 0^{* 0} 0.5 \mathrm{H}_{2} \mathrm{O}+10 \mathrm{H}^{+}=5 \mathrm{Ca}^{2+}+6 \mathrm{SiO}_{2}+10.5 \mathrm{H}_{2} \mathrm{O}\right. \\
& \operatorname{IAP}\left(200^{\circ} \mathrm{C}\right)=\frac{\left\{\mathrm{Ca}^{2+}\right\}_{\left\{\mathrm{SiO}_{2}\right\}^{6}}}{\{\mathrm{H}+\}^{10}}
\end{aligned}
$$

assuming $a \mathrm{H}_{2} \mathrm{O}=1$ and unit activity of the solid phase. This simplifying assumption is also taken that only crystalline tobermorite of pure composition is involved in the chemical reaction. In the absence of other data, this IAP may prove to be a useful guide. However, the derivation does not allow for the interaction of complexes or other amorphous or crystalline $\mathrm{Ca}-\mathrm{Si}-\mathrm{H}_{2} \mathrm{O}$ phases that are known to precipitate under these conditions. This calculation thus requires verification using independent checks for internal consistency.

6.3.1.4 Material behavior as a function of pH. A major unknown in the prediction of the chemistry of the potential Yucca Mountain repository is $\mathrm{pH}$. A large part of that has to do with cementitious materials, if they are present as invert or stabilizing material. The $\mathrm{pH}$ of water in contact with relatively young cement can be relatively high (10-12). However, there are a number of considerations that lend a good deal of uncertainty to a general assumption that the $\mathrm{pH}$ of water in contact with cement will be high throughout the lifetime of the repository.

The first consideration is the temperature. The reason that the $\mathrm{pH}$ of water in contact with cements equilibrates at such a high value is that the water is in equilibrium with the amorphous $\mathrm{Ca}-\mathrm{Si}-\mathrm{H}_{2} \mathrm{O}$ gel and other metastable phases. These phases will transform into less hydrous and more stable crystalline phases with time and with elevated temperature. It has not been established that the newly formed $\mathrm{Ca}-\mathrm{Si}-\mathrm{H}_{2} \mathrm{O}$ phases also are in equilibrium with water at such elevated $\mathrm{pH}$. In fact, there is evidence to the contrary. Hillebrandite and wollastonite, water poor end-members of the $\mathrm{Ca}-\mathrm{Si}-\mathrm{H}_{2} \mathrm{O}$ system do not produce such elevated $\mathrm{pH}$.

The second consideration is microbial. In general the microbial activity of pumping protons through a chemical system serves to reduce $\mathrm{pH}$. This is beneficial for the microorganism because it tends to solubilize solids and thus provide nutrients.

6.3.1.5 Material behavior as a function of RH. Water adsorption studies of okenite ( $\mathrm{Ca} 10 \mathrm{Si} 18 \mathrm{O} 46 \cdot 18 \mathrm{H}_{2} \mathrm{O}$ ) conducted at ambient temperature, (Martin et al., 1995) demonstrate the extreme sensitivity of some of the crystalline $\mathrm{Ca}-\mathrm{Si}-\mathrm{H}_{2} \mathrm{O}$ phases to relative humidity.

As part of an experimental and modeling program to characterize the effect that cement will have on the water budget at the potential Yucca Mountain repository, water sorption studies of crystalline calcium silicate hydrate phases are being performed. An adsorption study was conducted on okenite $\left(\mathrm{Ca} 10 \mathrm{Si}_{18} \mathrm{O}_{46} \cdot 18 \mathrm{I}_{2} \mathrm{O}\right)$ at ambient temperature over a range (3.5-97\%) of relative humidity $(\mathrm{RH})$ conditions. A sample of okenite from Poona, India, equilibrated at ambient $\mathrm{RH}$, was divided and dried over phosphorus pentoxide $\left(\mathrm{P}_{2} \mathrm{O}_{5}\right)$ and placed in chambers containing saturated salt solutions to control the $\mathrm{RH}$. X-ray diffraction analysis (XRD) indicated that interlamellar swelling occurred along the (001) axis. An increase in the $\mathrm{d}(001)$ spacing with hydration was on the order of $2.5 \AA$ at a $\mathrm{RH}$ of $11 \%$ and remained unchanged at higher $\mathrm{RH}$. This 
swelling is consistent with a monomolecular water layer in the interlamellar space. Comparison of the XRD peak positions from the $97 \%$ RH sample with an undried, natural sample $(33 \% \mathrm{RH})$ indicates that the interlamellar water adsorption is reversible. A broadening of the XRD peaks after drying the sample over $\mathrm{P}_{2} \mathrm{O}_{5}$ was noted and the peaks remained broad with subsequent wetting suggesting that the dehydration process caused some disordering. A comparison of the adsorption isotherm with the XRD data allows us to conclude that water adsorbed at $97 \%$ RH ( $11 \%$ by weight) included water located within the crystal structure as well as that externally adsorbed and capillary condensate. Future experiments will be performed at elevated temperatures with a sorption system fitted with an evaporator to control the RH and the results will be compared with those at ambient temperature.

\subsubsection{Material behavior as a function of growth of microbial biomass. The} impacts of the native and introduced bacteria on the performance of geologic nuclear waste disposal facilities were evaluated because these bacteria could promote corrosion of repository components and alteration of chemical and hydrological properties of the surrounding engineered and rock barriers. As a first step towards investigating these potentialities, native and introduced bacteria obtained from post-construction Yucca Mountain (YM) rock were isolated under varying conditions, including elevated temperature, low nutrient availability, and the absence of available oxygen. Individual isolates are being screened for activities associated with microbially induced corrosion of metals (MIC). Preliminary determination of growth rates of whole YM microbial communities under varying conditions was also undertaken. This work is reported in Horn et al. (1996).

Methods. Samples of Topopah Springs tuff collected from a mined Fran Ridge outcrop, and rock excavated during construction of the Exploratory Studies Facility tunnel (Yucca Mountain, NV) were collected aseptically. Microorganisms were isolated both aerobically and anaerobically from whole and aseptically crushed (1.7-2.4 $\mathrm{mm}$ ) rock samples at room temperature by plating onto low nutrient $\mathrm{R} 2$ agar (Difco). Organisms that survive in nutrient-depleted environments and at elevated temperature $\left(50^{\circ} \mathrm{C}\right)$ were isolated from crushed samples $(1.0 \mathrm{~g})$ using low nutrient $\mathrm{R} 2{ }^{1}$ broth. The resulting whole microbial communities were grown for extended periods (aerobic incubation, $72 \mathrm{~h}$; anaerobic incubation, 17 days) at room temperatures and $50^{\circ} \mathrm{C}$. After extended cultivation, samples were incubated on $\mathrm{R} 2$ agar at the temperature of previous growth. A representative group of morphologically distinct individual isolates were purified by repeated streaking of single colonies, which were identified primarily using fatty acid analysis. The growth of microbes that possess sulfate-reducing and ironoxidizing capabilities was encouraged from crushed rock samples using other specialized growth media.

Growth rates were determined by adding $10 \mathrm{~g}$ of crushed rock samples to $50 \mathrm{~mL}$ of R2 broth. Samples were incubated aerobically by shaking in covered flasks at ambient temperature, $30^{\circ} \mathrm{C}$, and $50^{\circ} \mathrm{C}$. Sterile controls were prepared by repeated cycles of autoclaving $\left(120^{\circ} \mathrm{C}\right)$ and incubation. Growth was monitored by periodic live plating of appropriate dilutions on $\mathrm{R} 2$ agar. 
Crude calorimetric screens were used to identify individual strains that produced the greatest quantity of a range of MIC-related capabilities. Acid producers were identified after growth of individual isolates in $\mathrm{R} 2$ broth containing $\mathrm{pH}$ indicators, the color change of which gave a qualitative indication of acid production. Production of hydrogen sulfide by individual isolates was detected by the ability to precipitate ferrous iron after growth in various media. Generation of exopolysaccharide capsular material was assessed after gross examination of folony morphology. Ferrous iron was assayed calorimetrically using ferrozine reagent. ${ }^{2}$

Results. While any given growth media permits only the growth of a small fraction of a microbial community, a multiplicity of microbial types were still detected from whole and crushed $Y M$ rock on $R 2$ media; henceforth these were treated as a sample of the total microbial community present at this site. In general, the greatest diversity of those microorganisms culturable on R2 arose from plated rock samples grown under aerobic conditions at room temperature, although 17 anaerobic strains were purified from rock samples incubated at ambient temperature under anoxic conditions. Extended growth at room temperature and $50^{\circ} \mathrm{C}$ showed a low diversity of microbial forms (one or two cell types). However, high cell numbers were reached after extended growth under aerobic conditions $\left(2 \times 10^{8}-10^{9}\right.$ cells $\left./ \mathrm{mL}\right)$, while anaerobic conditions produced low cell densities (e.g., 140 cells $/ \mathrm{mL}$ ), and no growth was evident after extended anaerobic incubation at $50^{\circ} \mathrm{C}$. In total, a group of over 60 isolates were preserved for further study. After one month, growth of iron oxidizers and sulfate reducers is not evident in specialized media, although efforts continue to isolate these types of organisms.

Growth rates of whole communities of YM-derived microorganisms in low nutrient $\mathrm{R} 2$ broth varied depending on the temperature of incubation. While communities grown at room temperature or $30^{\circ} \mathrm{C}$ showed an average mean doubling time of $1.8 \mathrm{~h}$, those growing at $50^{\circ} \mathrm{C}$ demonstrated doubling times of $3.2 \mathrm{~h}$ over a 9 or 10 hour growth period. All cultures, however, demonstrated significant increases in cell numbers, ranging to over 20,000 cells $/ \mathrm{mL}$ of media, at the conclusion of the $10 \mathrm{~h}$ growth period.

Preliminary screening of over $60 \mathrm{YM}$-isolates shows that $27 \%$ produced enough acid to decrease the $\mathrm{pH}$ of the growth media $(\mathrm{pH} \leq 5.3)$ under aerobic conditions; 5 of these strains produced acid when incubated at $50^{\circ} \mathrm{C}$. $44 \%$ of those examined after growth in anoxic conditions generated acid. Several isolates demonstrated marked production of capsular exopolysaccharide material. Studies aimed at screening isolates for sulfide production and iron oxidation are ongoing.

Discussion. We expect that both native microorganisms and those introduced as a result of construction activities are represented in our samples. While identification of all microbial community members requires application of alternative techniques (i.e., ribosomal DNA analyses), these studies examined that portion of the YM community capable of growth on R2 media under the conditions specified. These primary findings demonstrate that microbes present at the YM site are capable of survival and growth under conditions approaching those anticipated after waste deposition. Some examined members of the total microbial community can grow in the absence of oxygen and at temperatures of at least $50^{\circ} \mathrm{C}$. Growth rates are measurable at ambient and elevated 
temperatures, and probable spore-forming organisms are even capable of surviving repeated exposure to $120^{\circ} \mathrm{C}$. Further in vitro determinations will aid in determining in situ rates of growth, which can then be correlated with hydrologic flow rates. Depleted nutrient conditions favor the growth of only a select group of community members, but these are capable of reaching high cell densities under aerobic conditions, even at $50^{\circ} \mathrm{C}$. Of those anaerobic isolates capable of growth on R2 media, it appears the combination of elevated temperatures and depleted nutrients are deleterious to growth.

Initial studies of MIC-associated activities demonstrate that YM microbial inhabitants possess the abilities to both produce acidic conditions and biofilmgenerating materials. Production of biofilm "slimes" could facilitate the growth of organisms even at a very low relative humidity. Other microbial activities identified with MIC are currently being assessed and crude screening methods are being followed by more refined analysis to better characterize those isolates identified in primary screening protocols. Finally, microbial isolates that demonstrate the highest MICassociated activity rates will be used to assess the MIC resistance of various alloys intended for use in waste deposition.

Clearly, further correlation of environmental conditions and their effects on relevant microbial activities is required to accurately predict the effects of microorganisms on waste containment. However, these studies provide evidence that microbial impacts are pertinent to risk assessment of nuclear waste storage facilities.

\subsubsection{Material behavior as a function of gradients of chemical potential,} concentration, temperature. As was discussed previously, at the drift scale a radioactive waste repository is extremely heterogeneous. This heterogeneity is the basis for the existence of gradients in chemical composition, temperature, relative humidity and even porosity. These gradients are the basis of thermodynamic driving forces: chemical potential, fugacity, concentration, temperature. As such they can drive reactions and cause substances to dissolve and precipitate in a manner that is not predicted based on average values for those parameters.

\subsubsection{Historical Analogs as Long Term Experiments}

In order to verify predictive capability we need to compare predictions to test cases where similar processes are occurring. These analogs need not mimic the potential repository in all aspects, but rather must be able to provide information regarding a significant process in detail.

6.3.2.1 New Zealand. Microbially influenced degradation (MID) of concrete is thought to occur when microorganisms present in the environment produce mineral or organic acids that dissolve or disintegrate the concrete matrix. Three groups of bacteria are known to create conditions which are conducive to destroying concrete integrity. These microorganism are ubiquitous in the environment. They will, therefore, eventually be found in any repository facility, regardless of depth, because of the free movement of environmental contaminates into the confined space. The concrete facility of interest is an operational, passive cooling tower shell located at the Ohaaki Power Station near Wairakei, New Zealand. 
Concrete samples from the tower walls were obtained by coring, chiseling, and scraping. Biofilm was retrieved by peeling it from the wall surface. Holes left from the removal of cored samples were used for the emplacement of five concrete specimens (including two proposed for the YMP) made from different cement formulations.

Altogether a total of 29 specimens were recovered. The presence of microbes known to be involved in MID have been verified. Further work in this area was canceled due to lack of funds.

Reference concrete and concrete-waste package composite specimens were emplaced in hydrothermal springs along with the specimens described in the geochemistry section. The samples were retrieved, but have not been analyzed because the program was canceled.

\subsubsection{Modeling Activities}

The license application (LA) for a potential nuclear waste repository at Yucca Mountain in Nevada must be submitted in the near future. As part of this application process, we must better understand the long-term chemical implications of introducing natural and fabricated materials as well as microbes into a radioactive waste repository. Some of these materials are introduced as a necessity of construction and others are introduced passively and even unintentionally. Of the former explicitly chosen materials, there may be an option to substitute alternates for some materials. Other materials may not be interchangeable.

There are three reasons for using modeling to understand the chemical modifications of the natural environment in a repository setting. The first is that the chemical consequences of some of the materials under consideration are not common to our experience for the long periods of time and/or the conditions of an underground radioactive waste repository. Computer modeling using fundamental chemical principles allows us to project chemical conditions far into the future and to examine the system from selected points in time. The second reason is that modeling can significantly reduce the number of experimental trials required to demonstrate a similar understanding of chemical processes. Modeling chemical processes is economical and efficient for both simulating long periods of time and for investigating the consequences of multiple combinations of materials. The third reason is to maintain the flexibility required to support repository design and performance assessment efforts at this stage in the design decision process where the advantages and disadvantages of multiple options are being considered.

Modeling is effective, not as an end in itself, or as a tool to be used independently of other efforts, but rather as a facet of a program that is coordinated with experimental and historical analog activities. Such a coordinated program on a small scale is demonstrated in progress report on the long-term chemical impact of diesel exhaust (Meike et al., 1994). The strategy to model drift scale chemistry has been to focus on two areas. First, we are developing materials specific modules that can be either operated independently or can be inter-connected to simulate design and construction options under consideration. Secondly and concurrently to the first, we are developing the capability to simulate and visualize chemical processes in three-dimensions within the geological context of the Yucca Mountain. Conceptually, the modeling program was 
most advanced in the area of cementitious materials (ordinary Portland cement (OPC) grouts and concretes.

The most important role of the material specific chemical module is to reflect the material's chemical significance in the most streamlined manner possible. Thus, if it can be demonstrated that a material has no effect on the chemical environment, then it can be eliminated from the modeling of that scenario. Similarly, and probably more realistically, if it can be demonstrated that a material is involved to a significant extent only in certain chemical processes, then there is only need for computer simulation of those processes. Of course, the modules are only as robust as their foundations, and thus the chemical role that any materials play must be examined carefully across the range of changing parameters to assure that overly simplistic assumptions have not been made. If done correctly the modular approach can streamline the computer modeling significantly without affecting the capability to comment on questions significant to repository design.

At present our chemical modeling strengths lie in the ability to model the abiotic geological system over long periods and a range of temperature and chemical conditions using aqueous geochemical modeling packages such as EQ3/6. This code is based on fundamental chemical principles and thus should be adaptable to any materials. However, the adaptation of this code to simulate the long term chemical degradation of non-traditionally geologic materials involves two considerations: first, the adequate representation of significant chemical processes, and second the representation of data for the appropriate phases in materials specific databases that support the modeling packages. The database needs will be described in detail below with respect to cement. In the process, it is hoped that some general considerations involving the databases will become clear. There are two aspects of chemical processes to consider. First are those processes that have not yet been included in the code, abiotic processes such as redox processes that are fundamentally important to modeling the degradation of metals (and this is presently being developed within the Geochemical Modeling Task). Second are those processes which were not intended to be part of the code. These include all biotic processes, specifically the chemical consequences of microbial activity.

With respect to biotic processes, the needs of chemical modeling in the repository diverge significantly from the abilities of the traditional geological models. Abiotic chemistry has seemed to adequately describe the rates and results of chemical processes in systems of traditional geological interest. This may not be the case for a radioactive waste repository. The abiotic chemistry is only one part of the chemical needs because, in a natural system even in the deep subsurface, as is discussed by Horn and Meike (1995) microbes are bound to be present (native and introduced), and many of the materials that may be introduced into a radioactive waste repository may provide nutrient sources to initiate microbial blooms.

At present no work is being conducted in the modeling area.

6.3.3.1 Drift scale thermochemical models. Our intent is to work from drift scale to repository and ultimately mountain scale progressively establishing those spatial and temporal characteristics that need to be transferred to the next larger scale. Thus, we have not chosen a software program that has provided ease in initial rendering of the 
engineered features. Rather, we have worked closely with a software company (Dynamic Graphics, Inc.) to push the limits of a geological modeling program (EarthVision ${ }^{\mathrm{TM}}$ ) in its ability to render engineering details.

The purpose of this work was to determine whether it would be possible to represent repository design features at an appropriate level of detail within the EarthVision $^{\mathrm{TM}}$ software modeling framework. This is not a simple computer generated architectural design (CAD) program. In fact, developing the visual display was much less straight forward than might be immediately apparent. The various features that are shown in these models were produced by routines that were originally formulated to produce geological features. Therefore, all of the physical features were produced by combinations of faulting, deposition, erosion and drilling "wells".

Certainly the work that went into producing these three-dimensional representations of potential repository designs would not be worthwhile if they were only intended as graphical representations. However, once built, the potential ultimate benefits are great. Our goal is to use these representations for drift, repository and mountain scale hydrological and chemical modeling that include modifications due to construction. The advantage of this software is that physical attributes can be assigned to the various forms and thus they can be used to visualize the evolution of complex chemical, hydrological and coupled chemical-hydrological models. An additional intention is to locate materials, calculate volumes with ease, and locate the interfaces between materials of interest.

EarthVision ${ }^{\mathrm{TM}}$ software has a number of significant potential advantages: 1) the ability to use existing Nevada State Survey coordinate data to interface with existing geochemical and hydrogeologic models. 2) the ability to develop an interactive approach between drift, repository and mountain scales to address hydrological and chemical questions. We expect that the first use of this software will be in support of drift scale hydrological and chemical modeling, using the chemical formulations for grout and steel that have been used in the ESF.

This exercise has pushed the limits of the EarthVision ${ }^{\mathrm{TM}}$ software in a number of ways. The capabilities of the software are demonstrated in the figures. The representation of a repository layout presently under consideration (Fig. 6-28) is plotted using Nevada State coordinate grid references, so that it can easily be placed into any other EarthVision representation of Yucca Mountain processes. The actual relative sizes of main and emplacement drifts are shown. We have demonstrated a level of detail sufficient to initiate modeling in support of major hydrological and chemical questions concerning repository construction.

Figures 6-29 and 6-30 illustrate various aspects of the emplacement tunnel. The cutaway view of the emplacement tunnel demonstrates the capability of the EarthVision ${ }^{\mathrm{TM}}$ software to represent discontinuous shapes (Fig. 6-29). It was found that waste packages were more easily modeled with rounded ends. Although the depiction in this case is for computational simplicity, the shape may have some merits for structural integrity. Figure 6-30 is illustrated to scale: a $25 \mathrm{~m}$ section of $4.3 \mathrm{~m}$ diam. emplacement tunnel, with concrete invert, gantry tracks and concrete waste package supports.

Various aspects of the service tunnel are depicted in Figs. 6-31 through 6-33. The simplified cross-section rendering of a $20-\mathrm{m}$ section of $7.6 \mathrm{~m}$ diam. service tunnel (Fig. 6-31) shows concrete invert, shotcrete layer, and rockbolts for the metal grate 
platform anchored into the surrounding rock. The metal platform supports are placed at roughly $2 \mathrm{~m}$ intervals. A similar length of exposed service tunnel (Fig. 6-32) demonstrates the level of detail that can be obtained for chemical and hydrological modeling at the scale of tens of meters. The cementitious materials, concrete invert and shotcrete are illustrated. The metal materials illustrated are the gantry car rails, platform supports, platform and platform anchor rockbolts. Rock support rockbolts are illustrated in Figs. 6-33 through 6-37. The oblique view of the service tunnel (Fig. 6-33) illustrates rockbolt holes. Given standard spacing $(1.5 \mathrm{~m})$ as depicted on engineering drawings, 104 rockbolts would be found in this length of tunnel. A cross-sectional rendering (Fig. 6-34) and cut-away view (Fig. 6-35) of service tunnel showing rockbolt holes. The cross-sectional rendering (Fig. 6-36) and cut-away view (Fig. 6-37) show 36 rockbolts in a 20-m section of emplacement tunnel, given the standard spacing $(1.5 \mathrm{~m})$ as depicted on engineering drawings. Using these visual/calculational tools we can examine the chemical and hydrological effects of a plume of fluids equilibrated with cement (e.g. elevated $\mathrm{pH}$ ) moving into the mountain. It is also clear that the orientation and spacing of rockbolts can heavily influence hydrology. Using EarthVision ${ }^{\mathrm{TM}}$ software it will be possible to examine the influence of rockbolts on hydrology on a number of scales from single drifts to the repository and the entire mountain.

Because of its level of detail, EarthVision ${ }^{\mathrm{TM}}$ allows the display and manipulation of individual rockbolts with grout (Figures 6-38, 6-39). We have also pushed the ability to model finite objects. Calculation of material volumes is straightforward, as is illustrated in the calculation of the volume of cementitious materials (approximately $54.1 \mathrm{~m}^{3}$ ) (Fig. 6-40), and the calculation of volume of metal materials (approximately $14.4 \mathrm{~m}$ ) (including the waste packages of wall thickness $\sim 0.2 \mathrm{~m}$ ) in a $20-\mathrm{m}$ section of 4.3 diam. emplacement drift (Fig. 6-41).

6.3.3.2 Abiotic Models . The EQ3NR/EQ6 software package (Wolery, 1992; Wolery and Daveler, 1992) is composed of three executable programs (EQPT, EQ3NR and EQ6) and a number of databases that are used at the modeler's discretion (Fig. 6-42). EQPT simply formats databases to be readable by EQ3NR and EQ6, and is not shown in the figure. The input file for EQ3NR contains the analytical composition of the solution (including total concentrations of dissolved components, $\mathrm{pH}$, Eh and oxygen fugacity). The code calculates the distribution of chemical species, using thermodynamic data located in the selected database. The output consists of an output and a pickup file, which is used to initialize the EQ6 input file. EQ6 models the reaction of the aqueous solution with a set of minerals and gases, as well as fluid mixing and temperature changes. A set of five data files is now available. Three of these (COM, SUP and NEA) may be used with either the Davies equation, or the B-dot equation to calculate the activity coefficients. Their use is restricted to rather dilute solutions (ionic strength less than the sea water reference value). The two other data files (HMW, PIT) use Pitzer's equations (Pitzer, 1979), and are suitable for the modeling of high concentrations solutions. These databases are outlined below.

1. SUP database. Based entirely on the SUPCRT92 program (Johnson et al., 1992), this database has a high level of internal consistency. The database covers a wide range of chemical species. However for the purpose of drift scale chemical 
modeling it doesn't contain necessary data related to calcium-silicate-hydrate species that might be formed in cements at temperatures between 60 and $300^{\circ} \mathrm{C}$.

2. NEA database. This database was produced by the Data Bank of the Nuclear Energy Agency of the European Community (Grenthe, 1992), and is specifically tailored to conduct uranium studies.

3. HMW database. This dataset is based on Harvie, Moller and Weare (1984). It can be applied to both dilute solutions and concentrated brines, at $25^{\circ} \mathrm{C}$. It has also a very high degree of internal consistency but it only treats the components present in the "sea-salt-water" system. Important elements to the modeling of cement in a geologic repository, like $\mathrm{Al}$ and $\mathrm{Si}$ are not included in this database.

4. PIT database. This database is based primarily on data summarized by Pitzer (1979). This data file can also be applied to concentrated brines between $25^{\circ} \mathrm{C}$ and $100^{\circ} \mathrm{C}$. It covers a larger set of species than the HMW database, but it does not address the silica and inorganic carbon species that are necessary to model cement in a geologic repository. In addition, it contains some internal inconsistencies.

5. COM database. This dataset represents a melange of data found in the SUP and NEA datasets, as well as data from the HMW dataset. Other data in this database have been obtained by correlation or interpolation. This set therefore offers the least assurance of internal consistency. However, it is the only means available to model problems with a high degree of compositional complexity.

The development of a cement specific database that would allow the modeling of cement-water, and ultimately cement-water-rock interactions has been interrupted.

EXPLORER ${ }^{\mathrm{TM}}$ software is most often utilized to visualize complex data sets from existing FORTRAN and C programs, especially those for which properties are linked to a three dimensional spatial coordinate system. However, because it has the capacity to accept user-built modules it can also be used to encapsulate an existing program (in FORTRAN or in C) into a "module" (Fig. 6-43). Our intention is to utilize the complex chemical modeling capabilities and the modular format to develop materials specific modules and preserve entire complex

It is our intention is to use EXPLORER ${ }^{\mathrm{TM}}$ as a tool to encapsulate the EQ3/6 software package into three modules: EQPT, EQ3NR and EQ6. The ability to produce module maps and to imbed whole maps inside modules creates a functional hierarchy of computational maps that facilitates the series of complex and repetitive calculations that must be conducted over a number of levels as the scenarios are developed and compared. Each three module set will be encapsulated into a material specific module using the appropriate default settings, databases and integrating the appropriate biotic modules.

The material specific modules are powerful tools for repository design. They allow the flexibility to deal with variable levels of uncertainty and the ability to model and compare materials specific drift scale implications of repository design.

The material specific modules are the building blocks of design specific drift scale modeling that can be saved as "maps" in Explorer. The maps, which store complex chemical modeling paths at a level above what can be done with current modeling routines, can thus be used to retrace complex calculational steps and minimize operator error. As such it also represents a step forward in the documentation of computer 
modeling. The maps will interface with the EarthVision model described above to provide access to time stepped three-dimensional understanding of repository chemistry and hydrology.

6.3.3.3 Biotic Models (modeling microbiological activities). Although it is not possible to produce rigorous models of microbially related chemistry at this time, much progress can be made toward determining the relative significance of microbial effects with a simple box model. A box model treats microbial processes as a simplified chemical reactor. We can view microbial reactions as enzymatically-controlled chemical processes which are governed by the size, identity and metabolic state of the microbial community as well as the traditional abiotic chemical parameters such as $\mathrm{pH}$ and temperature. Each microbe must have an energy supply, a source of carbon, and a set of nutrients essential for life. The energy supply generally involves an electron acceptordonor process, the carbon supply is usually some form of organic matter or carbon dioxide, and most microbes need sufficient amounts of nitrogen, phosphorous, and sulfur to live. Other elements are needed in trace amounts but are generally not limiting in terms of microbial growth, especially in a heterogeneous repository environment. Water is also essential, and temperature is an important limiting factor. For a review of these considerations with regard to a potential repository at Yucca Mountain, see Horn and Meike (1995). Although specific microbes exist over subsets of this range, it is possible to establish, for this first step, a range of temperature over which microbes are active, as opposed to inactive (e.g. spore, dormant or dead state).

The first step in using a box model to understand microbial effects in a repository is to establish limits to the total amount of microbial activity possible in the repository based on the microbial needs listed above (e.g. energy, carbon, nutrients, water, appropriate temperature). This type of approach is described well by McKinley \& Hagenlocher (1993) for the Swiss High Level Waste (HLW) and Low/Intermediate Level Waste (ILLW) repositories. They examine the energies available from all redox reactions possible for the materials present in the repository which can be utilized by microbes. This information is combined with an estimate of how much energy is needed to synthesize the compounds which make up biomass (this number is 0.1 mole of ATP to produce one gram of dry cell mass, which is equivalent to $450 \mathrm{~kJ} / \mathrm{mol}$ if the efficiency of energy utilization is $10 \%$ ). With this approach, the total biomass that can be sustained can be related to the masses of redox species that are present. Finally, if one can assume an average biomass metabolic rate, then the chemical effects of the biomass in terms of corrosion enhancement, ligand production, gas production or any other rate of chemical change can be estimated and related to overall repository behavior.

A similar simplified approach can be used to determine the maximum possible biomass based on the amounts of essential nutrients (phosphorous, nitrogen, and sulfur) present in the repository. An average biomass is defined in McKinley \& Hagenlocher (1993), to have the composition $\mathrm{C}_{160}\left(\mathrm{H}_{250} \mathrm{O}_{80}\right) \mathrm{N}_{30} \mathrm{P}_{2} \mathrm{~S}$. The total amount of possible biomass is simply the total amount of accessible nutrient divided by its weight fraction in biomass.

This is complicated somewhat by the fact that nutrient availability may be a function of corrosion rates of repository materials, whose rates themselves depend on active biomass. Some nutrients are available only if they are released during corrosion of 
repository materials. The overall process is therefore coupled and amenable to modeling provided that some quantitative information on the type of coupling is available.

Applying this approach to the Swiss HLW repository, McKinley \& Hagenlocher (1993) found that for a bounding calculation not limited by microbe mobility, the overall biomass was limited by energy availability, and not nutrient availability. The amounts of nitrogen, phosphorous, and sulfur available in the backfill in particular are much higher than the total mass of electron donors needed to fuel microbial growth. The only exception is during the first ten years of repository existence where the availability of oxygen is expected to be high and, as a consequence, energy availability should also be high. The availability of $\mathrm{O}_{2}$ over time in a potential Yucca Mountain repository drift is still under discussion. This is because the availability of air through the mountain's fracture system, the amount of time that the repository drifts will be ventilated artificially, and the amount of chemically conditioned backfill that may affect the $\mathrm{fO}_{2}$ have not yet been bounded. The proposed Yucca Mountain repository differs from the Swiss in many ways, for example, the former is an unsaturated environment. However although the Swiss conditions are not necessarily analogous to the Yucca Mountain repository in many important aspects including, for example $\mathrm{fO}_{2}$, it is illustrative to follow through the calculation as an exercise.

The biomass production rates calculated for the Swiss HLW repository range decrease from an initial rate of about 300 grams dry biomass/year/waste package to long-term rates of about $0.3 \mathrm{~g} / \mathrm{y} / \mathrm{wp}$. These values can be used to constrain likely production rates of by-products such as organic ligands and gas generation, which in turn affect radionuclide transport rates and repository performance. For this case, even at maximum biological activity, the total production of organic complexing agents is only approximately equal to the estimated release rates of radionuclides. The net effect of microbial activity in terms of solubilization of radionuclides is therefore small for this repository.

Given that the conditions of the Swiss repository (e.g. granitic rock, repository design, saturated rock) are quite different, the findings of McKinley \& Hagenlocher (1993) cannot be directly applied to the proposed Yucca Mountain repository. Information gained from this simple box model approach should be used to prioritize and guide more detailed work on microbial effects. More sophisticated models of microbial effects should then be generated using this more detailed information. However, because of the complex nature of microbial processes, and in particular their abilities to evolve with time, express new genes when environmental conditions change, and the diverse nature of microbial communities, it is unlikely that we could produce a reliable mechanistic chemical model for microbial behavior in the short term. Our best approach is to use our information on microbial behavior to define worst-case scenarios, identify parameters that limit microbial productivity, and incorporate these results into our task of designing the engineered barrier system.

Thermal and other perturbations of a microbially mediated chemical system occur as a complex function of microbial identity, microbial activity and colony growth (biomass). In addition, individual species function over a relatively narrow temperature range. Thus, even with respect to the traditional chemical parameters, biological reactions operate according to different laws than the abiotic reactions. However, 
although not identical to the abiotic case, it should be productive to take an approach similar to existing abiotic chemical modeling to use the chemical laws of microbial chemistry to predict long-term chemistry. This approach is also consistent with the ultimate goal which is to develop models which can be operated in tandem with the abiotic models.

The net chemical effect of a community of microbes can be thought of as a set of mass inputs and outputs. For example, an autotrophic bacteria may take in bicarbonate as a carbon source, and oxidize iron to ferrous iron as an energy source. As by-products, the bacteria may make acetate and as a consequence of oxidizing iron, lower the $\mathrm{pH}$. Based on experimental observations of this type of bacteria in an environment similar to an anticipated repository environment, it should be possible to write a reaction that describes the overall chemical effects of this bacterial population. For each gram of active biomass, there can be related a positive flux of acetate and acid generation, and a negative flux of iron and bicarbonate.

At the most simple level, models of microbial activity can be used as input into EQ3 / 6 (Wolery, 1992). This approach offers the potential for modeling at a fairly high level of complexity in a short period of time. Although microbial activity is not explicitly provided for, the overall effect of microbial activity on repository corrosion processes can be. Such an approach allows the net effects, in terms of how microbes alter the local chemistry of their environments, to be accounted for. Thus the chemical effects of microbial activity can be rigorously coupled to materials interactions in the repository without specific identification of all microbial species in the repository or explicitly providing for the details of microbial activity.

This type of model obviously lacks feedback from system parameters to the microbial processes. Feedback between environmental conditions and microbial activity is the most difficult part of implementing microbial activity into the simulation. But if empirical relationships between microbial activity and environmental parameters such as temperature and $\mathrm{pH}$ are available, they can readily be incorporated into the simulation. For example, microbial productivity is almost certainly $\mathrm{pH}$ dependent. Most bacteria live only over a restricted $\mathrm{pH}$ range.

The next step in making this type of model more realistic would be to incorporate feedback between environmental parameters and microbial productivity. If the $\mathrm{pH}$ changed significantly, it is likely that a new type of microbial population would exist, with a different set of chemical effects. Likewise, if microbial activity were to change the $\mathrm{pH}$, the equilibrium condition between the aqueous fluid and the material with which it is in contact, is changed. EQ3/ 6 currently has the capability to incorporate these types of complexities into the simulation. Experimental data on the biomass production rates of any variety of microbial populations which are dependent on $\mathrm{pH}$, or on any other parameter related to the chemical response or influence of microbial activity, can be entered as reactants in the simulation. Kinetic control of these rates is also possible if appropriate rate data are known. Given the complexity and interdependency of some of these factors, it may be necessary to enter the numerical relationships as reactants into EQ3/6 and in a step-wise or iterative fashion to take into account the chemical effects of the microbial population.

The presence of other repository materials can also be included in the simulation so that coupling between all chemical processes is properly accounted for. For example, 
the simulation may include the host rock, a metal canister, and cement. As the reaction proceeds, the effect of acid generation on $\mathrm{pH}$ stability, the effect of acetate generation on metal corrosion, the affects of bicarbonate utilization are all accounted for. The system will evolve and have a pH which is controlled by the coupled interactions of all these $\mathrm{pH}$-dependent reactions. Likewise, the complete solution composition can be calculated for any step along this reaction progress. The ability to do this stage of modeling will be enhanced by the use of Explorer ${ }^{\mathrm{TM}}$ software.

Our ultimate aim is to find an approach that can be integrated into a sophisticated feedback linkage with the existing EQ3/6 code. We aim to frame descriptions of microbial activity in forms that mimic the abiotic thermodynamic and kinetic descriptions. To do this we must distinguish between the two types of processes: those that can be seen as perturbations from an equilibrium state, or as part of a new, microbially mediated equilibrium state and thus comprise a module that will interact with EQ3, and those considerations that affect rates of change and thus the kinetics and thus comprise a module that will interact with EQ6 (Fig. 6-44). In developing the descriptions we seek to define microbial activities in terms of three types of processes: processes or conditions that can represent standard states, processes that can be described in terms of rates of change, and processes in which transfer of mass, energy or other quantifiable units sum to zero. The advantage of these definitions is that they translate well into the pre-existing abiotic thermodynamic/kinetic framework. We will define standard states as points of reference that will allow us to quantify deviations from those points. Describing processes in terms of equations that sum to zero has many advantages. For example it ensures internal consistency and provides a foundation for expanding from simple to multi-component systems.

\subsection{Summary and Conclusions}

Progress has been made in the identification and quantification of materials that may be used as part of the construction of a radioactive waste repository at Yucca Mountain. The major significant processes affecting the chemical impact of those materials on the Near Field Environment and the waste packages have also been identified, as well as the data that is required to be able to predict the outcome of many of these processes over long periods of time. In the past we have emphasized those processes and materials that would take the water chemistry or certain processes outside of the bounds that are assumed based on the natural geochemistry, or the limited knowledge of long term behavior. Our work in the near future is to use this information to provide some bounds for chemical and mechanical modeling, but also to narrow those bounds where they make a significant difference to performance assessment modeling. Many of the fundamental tools are in place to better bound chemistries and behaviors, but others are still missing.

To date the most significant unknowns that have been identified in the area of introduced materials are the effects of microbial activity on water chemistry and degradation rate of important materials (and our ability to model those effects), the effects of cement-water-rock chemistry over time, and the effect of metals corrosion over time. 


\subsection{Acknowledgments}

W. Bourcier, M. Caffee, L. Clodic, S. A. Carrol, A. Miller, M. Sprague, and P. A. Sterne contributed to this chapter. 


\subsection{References}

Aminabhavi, T. M., and U. S. Aithal (1990), J. Appl. Polym. Sci. 41, 2113-2131.

Andersson, K., B. Allard, M. Bengtsson and B. Magnusson (1989) Chemical composition of cement pore solutions. Cem. Concr. Res. 19, 327-332.

Andreoni, V., G. Baggi, C. Guaita, and P. Manfrin (1993). Int. Biodeterioration Biodegradation 31, 41-53.

Atkins, M., F. P. Glasser, A. Kindness, and D. E. Macphee (1991), Solubility Data for Cement Hydrate Phases $\left(25^{\circ} \mathrm{C}\right)$, U.S. Department of Energy, Washington, DC, $\mathrm{DOE} / \mathrm{HMIP} / \mathrm{RR} / 91 / 032$.

Atlas, R. M. (1982), Enumeration and Estimation of Biomass of Microbial Components in the Biosphere, in Experimental Microbial Ecology, R. G. Burns and J. H. Slater, Eds., (Blackwell Scientific Publishers, Oxford, England), pp. 84-102.

Awasthi, S. (1993), Natl. Acad. Sci. Lett. 16, 143-144.

Babushkin, V. I., G. M. Matveyev and 0. P. Mchedlov-Petrossyan (1985) Thermodynamics of Silicates. Springer-Verlag. 459 pp.

Barnes, I., T. S. Presser, M. Saines, P. Dickson, and A. F. K. van Groow (1982), "Geochemistry of Highly Basic Calcium Hydroxide Groundwater" in Jordan, Chem. Geol. 35, 147-154.

Barnes, M. W., and D. M. Roy (1983), The Buffering Mechanisms in Leaching of Composites of Cement with Radioactive Waste, Mater. Res. Soc. Symp. Proc. 15, 159166. NNA.19920131.0250

Barns, S. M., R. E. Fundyga, M. W. Jeffries, and N. R. Pace (1994), Remarkable Archael Diversity Detected in a Yellowstone National Park Hot Spring Environment, Proc. Natl. Acad. Sci USA 91, 1609-1613.

Barr-Kumarakulasinghe, S. A. (1994), Polymer 35, 995-1003.

Barrer, R.M., (1978), Zeolites and Clay Minerals as Sorbents and Molecular Sieves, Academic Press, New York, $497 \mathrm{p}$.

Barret, P. and D. Bertrandie (1986) Fundamental hydration kinetic features of the major cement constituents: $\mathrm{Ca}_{3} \mathrm{SiO}_{5}$ and b-Ca2SiO4. J. Chemie Phys. 83, 765-775.

Bell J. L. S., D. A. Palmer, and H. L. Barnes (1992), Acetate in Hydrothermal Solutions: Decomposition Kinetics and Metal Complexation, in Water-Rock Interaction, Y. Kharaka and A. Maest, Eds., (Balkema, Rotterdam), pp. 307-310.

Bennett, P. C., M. E. Melcer, D. I. Siegel, and J. P. Hassett (1988), The Dissolution of Quartz in Dilute Aqueous Solution of Organic Acids at $25^{\circ} \mathrm{C}$, Geochim. Cosmochim. Acta 52, 1521-1530. NNA.19921106.0027

Bensted, J. (1983a) Hydration of portland cement. p. 307-347 in Ghosh, 5. N. (ed.) (1983a).

Bensted, J. (1983b) Early hydration of portland cement - effects of water/cement ratio. Cem. Concr. Res. 13, 493-498.

Bensted, J. (1989) Oil well cements - a general review. Chem. Ind., 20 Feb. 1989, p. 100105.

Berner, U. R. (1987). Modelling porewater chemistry in hydrated portland cement. Mat. Res. Soc. Symp. Proc. 84, 319-330.

Berry, W. E. (1983), Durability of Marker Materials for Nuclear Waste Isolation Sites, Office of Nuclear Waste Isolation, Battelle Memorial Institute. NNA.19920131.0430 
Bethke, C. M. The Geochemist's Workbench ${ }^{\mathrm{TM}}$ A Users Guide to RXN, ACT2, TACT, REACT, and GTPLOT. Urbana, Ilinois: C. Bethke, c1992.

Bish, D. L., F. A. Caporuscio, J. F. Copp, B. M. Crowe, J. D. Purson, J. R. Smyth, and R.

G. Warren (1981), Preliminary Stratigraphic and Petrologic Characterization of Core Samples from USW G-1, Yucca Mountain, Nevada, Los Alamos National Laboratory, Los Alamos, NM, LA-8840-MS. NNA.19870406.0099

Bisi, M., C. Nicolella, E. Palazzi, M. Rovatti, and G. Ferraiolo (1994), Chem. Eng. Technol. 17, 67-72.

Borenstein, S.W. (1994). Microbially Influenced Corrosion Handbook. New York, NY, Industrial Press Inc.

Braithwaite, W. R., and K. A. Lichti (1981), Surface Corrosion of Metals in Geothermal Fluids at Broadlands, New Zealand, American Society for Testing and Materials. Brandrup, J., and E. H. Immergut, Eds. (1975), Polymer Handbook John Wiley, New York, NY).

Breck, D.W. (1974). Zeolite Molecular Sieves, J. Wiley and Sons, New York, 771 p. Brock, T. D., and M. T. Madigan (1991), Biology of Microorganisms (Prentice-Hall, Englewood Cliffs, NJ).

Brown, P. W., E. Franz, G. Frohnsdorff, and H. F. W. Taylor (1984). Analyses of the aqueous phase during early $\mathrm{C}_{3} S$ hydration. Cem. Concr. Res. 14, 257-262.

Brown, P. W., J. Pommersheim and G. Frohnsdorff (1985). A kinetic model for the hydration of tricalcium silicate. Cem. Concr. Res. 15, 35-41.

Bruton, C. J., B. L. Phillips, A. Meike, S. Martin, and B. E. Viani (1994), Cement Minerals at Elevated Temperature: Thermodynamic and Structural Characteristics, Mater. Res. Soc. Symp. Proc. 333, 327-334, UCRL-JC-115796. NNA.19940318.0011

Bruton, C. J., W. E. Glassley, et al. (1995), Geothermal Areas as Analogues to Chemical Processes in the Near-Field and Altered Zone of the Potential Yucca Mountain, Nevada Repository, LLNL, Lawrence Livermore National Laboratory, Livermore, CA, UCRLID-119842. MOL.19960408.0210

Burnay, S. G., Ed. (1990), A Practical Model for Prediction of the Lifetime of Elastomeric Seals in Nuclear Environments (American Chemical Society, Washington, DC), pp. 524-533.

Burnett, N. C., R. D. Hooton, R. B. Heimann and M. Onofrei (1985). The development of durable cementitious materials for use in a nuclear fuel waste disposal facility. Mat. Res. Soc. Symp. Proc. 50, 461-468.

Burton, B. L. (1993). J. Appl. Polym. Sci. 47, 1821-1837.

Buscheck, T.A. and J.J. Nitao (1994). The impact of buoyant gas-phase flow and heterogeneity on thermo-hydrological behavior at Yucca Mountain. Proceedings of the International High Level Radioactive Waste Management Conference, 22-26 May, 1994, Las Vegas, NV and Dept. of Energy, Lawrence Livermore Natl. Laboratory Report \#UCRL-JC-115351.

Carlson, V. E.O. Bennett, and J.A. Rowe. (1961). Microbial flora in anumber of oilfield water injection systems. J. Soc. Pet. Eng. 1, 72.

Carroll, S. A., M. Alai, and S. A. Copenhaver (in press), Experimental Investigation of Hydrous Pyrolysis of Diesel Fuel: Potential Impact on the Proposed High-Level Radioactive Waste Repository, Yucca Mountain, Nevada, Lawrence Livermore National Laboratory, Livermore, CA, UCRL-ID (in press). 
Chapman, N. and I. McKinley (1990), Radioactive Waste: Back to the Future? New Scientist (May 5, 1990), 36-40.

Chapman, N., P. Cloke, et al. (1995), Applications of Natural Analogue Studies to Yucca Mountain as a Potential High Level Radioactive Waste Repository, The Natural Analogue Review Group. MOL.19960508.0064

Chessa, G., G. Marangoni, B. Pitteri, N. Stevanato, and A. Vavasori (1991), Reactive Polym. 14, 143-150.

Chiantore, O., M. P. L. d. Cortemigilia, and M. Guaita (1989), Makromolekulare Chemie 190, 3143-3152.

Costerton, J.W. and G.G. Geesey. (1985) The microbial ecology of surface colonization and of consequent corrosion. Proceedings of the International Conference on Biologically Induced Corrosion, June 10-12, 1985, Gaithersburg, MD.

Costerton, J.W. and J. Boivin. (1991) The role of biolfilms in microbial corrosion in Microbially Influenced Corrosion and Biodeterioration, N.J.E. Dowling, M.W. Mittleman, and J.S. Danko, eds. National Association of Corrosion Engineers, Houston, TX.

Coughlin, J. P. and C. J. O'Brien (1957). High temperature heat contents of calcium orthosilicate. Am. Chem. Soc. J.61, 767-769.

Crammond, N. (1996) The thaumasite form of sulphate attack-Discussion of possible reaction mechanisms Gordon Research Conference, Plymouth, New Hampshire, July, 1996.

Culivicchi, G., C. G. Palmerini, and V. Scholari (1985). Behaviour of Materials in Geothermal Environments, Geothermics 14(1), 73-90.

Dickie, R. A., J. W. Holubka, and J. E. Devries (1990), J. Adhesion Sci. Technol. 4, 57-67.

Dodd, F. J., A. E. Johnson, and W. C. Ham (1960), Material and Corrosion Testing at the Geysers Geothermal Power Plant, Department of Eng. Research, Pacific Gas and Electric Company.

Dole, M., Ed. (1973), The Radiation Chemistry of Macromolecules (Academic Press, New York, NY).

Ederova, J. and V. Satava (1979). Heat capacities of $\mathrm{C}_{3} \mathrm{AH}_{6}, \mathrm{C}_{4} \mathrm{ASH}_{12}$ and $\mathrm{C}_{6} \mathrm{AS}_{3} \mathrm{H}_{32}$. Thermochim. Acta 31, 126-128.

El-Agramy, A. A. Shabaka (1990), Isotopenpraxis 26, 229-231.

El-Sonbati, A. Z., A. A. El-Bindary, M. A. Diab, M. A. El-Ela, and S. A. Mazrouh (1994), Polymer 35, 647-652.

Ellezer, I., N. Ellezer, R. A. Howald and P. Viswanadham (1981). Thermodynamic properties of calcium aluminates. J. Phys. Chem. 85, 2835-2838.

Ellison, M. S., S. H. Zeronian, and Q. Xie (1989), Textile Res. J. 59, 657-660.

EPA (Environmental Protection Agency), 1985, Environmental Standards for the Management and Disposal of Spent Nuclear Fuel, High-Level and Transuranic Wastes: Final Rule, U.S. Code of Federal Regulations, 40 CFR Part 191, Washington, DC. HQO.19871113.0033

Fein, J. B. (1991), Experimental Study of Aluminum-, Calcium-, and Magnesium-Acetate Complexing at $80^{\circ} \mathrm{C}$, Geochim. Cosmochim. Acta 55, 955-964.

Fontana, M. G., and N. D. Breen (1978), Corrosion Engineering (McGraw-Hill Publishing, New York, NY), pp. 263-265. NNA.19891018.0176

Foster, P. K., and A. Tombs (1962), Corrosion by Hydrothermal Fluids, New Zealand J. Science 5 (1), 28-41. 
Freemantle, M. (1994), Chemical Techniques Help Conserve Artifacts Raised from Titanic Wreck, Chem. Eng. News, 49-52.

Fujii, X. and W. Kondo (1983). Estimation of thermochemical data for calcium silicate hydrate (C-S-H). Am. Ceram. Soc. J. 66, C220-C221.

Garrett, R. W., et al. (1990), Temperature Dependence of the Radiation Chemistry of Polymers (American Chemical Society, Washington, DC).

Gartner, E. M., F. J. Tang and S. J. Weiss (1985). Saturation factors for calcium hydroxide and calcium sulfates in fresh portland cement pastes. Am. Ceram. Soc. J. 68, 667-673.

Gestsdottir, K., and D. A. C. Manning (1992), An Experimental Study of the Dissolution of Albite in the Presence of Organic Acids, in Water-Rock Interaction, Y. Kharaka and A. Maest, Eds., (Balkema, Rotterdam), pp. 315-318.

Gettens, R. J. and C. Frondel (1956). Studies in Conservation, 2, 64.

Gherna, R., P. Pienta, and R. Cote., eds. (1989). Catalogue of Bacteria and Bacteriophages. 17 th edition. Rockville, MD, American Type Culture Collection.

Ghosh, S. N. (1983) Portland cement phases: polymorphism, solid solution, defect structure and hydraulicity. in Ghosh (ed) Advances in Cement Technology. Pergamon Press. pp. 289-305.

Gilfric, H. P., and H. Wilski (1992), Int. J. Rad. Applic. Instrumen. C 39, 401-405.

Gillen, K. T., and R. L. Clough (1989), Polymer Degradation and Stability 24, 137-168.

Glasser, F. P., A. A. Rahman, D. Macphee, M. Atkins, N. Beckley and E. E. Lachowski (1986) Immobilization of radioactive waste in cement-based matrices. United Kingdom Dept. of the Environment Report DOE RW 86.084. 110 pp.

Glasser, F. P., S. Diamond and D. M. Roy (1987b) Hydration reactions in cement pastes incorporating fly ash and other pozzolanic materials. Mat. Res. Soc. Proc. 85, 167-186. [This paper also appears in Mat. Res. Soc. Proc. 86]

Glasser, F. P., M. J. Angus, C. E. McCulloch, D. Macphee and A. A. Rahman (1985) The chemical environment in cements. Mat. Res. Soc. Proc. 44, 849-858.

Grassi, N., and G. Scott, Eds. (1985), Polymer Degradation and Stabilisation (Cambridge Univerisity Press, Cambridge).

Greenberg, A.E., R.R. Trussell, L.S. Clesceri, and M.A.H. Franson, eds. (1985). Standard Methods for the Examination of Water and Wastewater. 16th edition. Washington, D.C., American Public Health Association.

Greenfield, B. F., C. M. Linklater, A. D. Moreton, M. W. Spindler, and S. J. Williams (1993), The Effects of Organic Degradation Products on Actinide Disposal, AEA Technol.

Grutzeck, M. W. and A. R. Ramachandran (1987) An integration of tricalcium silicate hydration models in light of recent data. Cem. Concr. Res. 17, 164-170.

Haas, J. L. Jr., G. R. Robinson, Jr. and B. 5. Hemingway (1981) Thermodynamic tabulations for selected phases in the system $\mathrm{CaO}-\mathrm{Al}_{2} \mathrm{O}_{3}-\mathrm{H}_{2} \mathrm{O}$ at $101.325 \mathrm{KPa}(1 \mathrm{~atm})$ between 273.15 and 1800 K. J. Phys. Chem. Ref. Data 10, 575-669.

Hajash, A., S. P. Franklin and C. L. Reed (1992), Experimental Feldspar Dissolution in Acetic and Oxalic Acids at $100^{\circ} \mathrm{C}$, in Water-Rock Interaction, Y. Kharaka and A. Maest, Eds., (Balkema, Rotterdam), pp. 325-328.

Haldeman, D. L., and P. S. Amy (1993), Bacterial Heterogeneity in Deep Subsurface Tunnels at Rainier Mesa, Nevada Test Site, Microb. Ecol. 25, 183-194. 
Haldeman, D. L., P. S. Amy, D. Ringelberg, and D. C. White (1993), Characterization of the Microbiology within a $21-\mathrm{m}^{3}$ Section of Rock from the Deep Subsurface, Microb. Ecol. 26, 145-159.

Haldeman, D.L., P.S. Amy, D.C. White, and D. Ringelberg. (1994). Changes in bacteria recoverable from subsurface volcanic rock samples during storage at $4^{\circ} \mathrm{C}$. Appl. Environ. Microbiol. 60, 2697-2703.

Hanck, J. A., and G. Nekoksa (1980), Corrosion Rate Monitoring at The Geysers Geothermal Power Plant, Department of Eng. Research, Pacific Gas and Electric Company.

Hedges, R. E. M. (1976), On the Occurrence of Bromine in Corroded Silver, Studies in Conservatism 21, 44-46. NNA.19931005.0006

Hedrick, D. B., and D. C. White (1986), Microbial Respiratory Quinones in the Environment. I. A Sensitive Liquid Chromatographic Method, J. Microbiol. Meth. 5, 243-254.

Heimann, R. B. (1988a) Interaction of cement and radioactive waste forms in multicomponent systems tests at $200^{\circ} \mathrm{C}$. Part 1: Leaching and sorption of cesium, strontium and actinides. Cem. Concr. Res. 18, 389-400.

Heimann, R. B. (1988b) Interaction of cement and radioactive waste forms in multicomponent systems tests at $200^{\circ} \mathrm{C}$. Part 2: Mineralogical changes of cement. Cem. Concr. Res. 18, 554560.

Heimann, R. B. and R. D. Hooton (1986) Mineralogical changes of various cement formulations during reaction with groundwater in the presence of $\mathrm{Ca}$ and $\mathrm{Na}$ bentonite at $150^{\circ} \mathrm{C}$. Can. Min. 24, 289-302. Also issued as AECL-8895.

Hermannsson, S. (1970), Corrosion of Metals and the Forming of a Protective Coating on the Inside of Pipes Carrying Thermal Waters Used by the Reykjavik Municipal District Heating Service, Geothermics 2 (Special Issue: U.N. Symposium on the Development and Utilization of Geothermal Resources, Pisa), pp. 1602-1611.

Horn, J. M., and A. Meike (1995), Microbial Activity at Yucca Mountain, Lawrence Livermore National Laboratory, Livermore, CA, UCRL-ID-122256.

Horn, J. M., and A. Meike (1996), A Program to Assess Microbial Impacts on Nuclear Waste Containment, in Proceedings of the 1996 High Level Radioactive Waste Meeting, Las Vegas Nevada, Lawrence Livermore National Laboratory, Livermore, CA, UCRL-JC-122732. MOL.19960409.0194

Horn, J. M., B. Economides, A. Meike, and R. D. McCright (1996), Initial Studies to Assess Microbial Impacts on Nuclear Waste Disposal, in Proceedings of the 1996 High Level Radioactive Waste Meeting, Las Vegas Nevada, Lawrence Livermore National Laboratory, Livermore, CA, UCRL-JC-122587. MOL.19960409.0710

Imasaka, T., M. Hozumi, and N. Ishibashi (1992) Anal. Chem. 64, 2206-2209.

Ishigaki, I., and F. Yoshii (1992), Radiation Physics and Chemistry, Int. J. Rad. Applic. Instrum. C 39, 527-533.

Ivan, B., B. Turcsanyi, T. Kelen, and F. Tudos (1991), Die Angewandte Makromolekulare Chemie 189, 35-49.

Jackson, K. J., A. K. Burnham, R. L. Braun, and K. G. Knauss (1992), Measurement of Pressure Effects on N-Hexadecane Cracking Rates, 37, 1614-1620.

Jackson, K. J., and S. A. Carroll (1994), Experimental Investigation of Hydrous Pyrolysis of Diesel Fuel and the Effect of Pyrolysis Products on Performance of the Candidate 
Nuclear Waste Repository at Yucca Mountain, Mater. Res. Soc. Symp. Proc. 333, 841847, UCRL-JC-116352. MOL.19950728.0064

Jeffrey, J. W. (1964) The crystal structures of the anhydrous compounds. pp. 131-164 in

Taylor, H.F.W. (ed.) The Chemistry of Cements. Academic Press.

Johnson, A. B. J., and B. Francis (1980), Durability of Metals from Archaeological Objects,

Metal Meteorites, and Native Metals, Pacific Northwest Laboratory, U.S. Department

of Energy. NNA.19910604.0005

Johnson, J. W., and S. R. Lundeen (in press), GEMBOCHS Thermodynamic Data Files for

Use with the EQ3/6 Software Package, Lawrence Livermore National Laboratory,

Livermore, CA, UCRL-ID.

Jones, P. A. (1992), Principles and Prevention of Corrosion (MacMillan Publishing, New

York, NY), 392-393.

Kaplan, M. L. (1991), Polym. Eng. Sci. 31, 689-698.

Kay, M. J., L. H. G. Morton, and E. L. Prince (1991), Int. Biodeterioration 21, 204-222.

Kay, M. J., R. W. McCabe, and L. H. G. Morton (1993). Int. Biodeterioration Biodegradation 31, 209-225.

Kenny, J. M., L. Torre, and L. Nicolais (1993), Thermochim. Acta 227, 97-106.

Kharaka, Y., P. D. Lundegard, G. Ambats, W. C. Evans, and J. L. Bischoff (1993), Generation of Aliphatic Acid Anions and Carbon Dioxide by Hydrous Pyrolysis of Crude Oils, Appl. Geochem. 8, 317-324.

Khare, A. R., N. A. Peppas, G. Massimo, and P. Colombo (1992), J. Controlled Release 22, 239-244.

Khinnavar, R. S., and T. M. Aminabhavi (1992), J. Appl. Polym. Sci. 46, 909-920.

Khoury, H. N., E. Salameh, and Q. Abdul-Jaber (1985), Characteristics of an Unusual Highly Alkaline Water from the Maqarin Area, Northern Jordan, J. Hydrol. 81, 79-91. NNA.19920131.0287

Khoylou, F., and A. A. Katbab (1993), Radiation Phys. Chem. 42, 219-222.

Kim, N. D., and S. J. Hill (1993), Environ. Technol. 14, 1015-1026.

Knauss, K. G., and W. J. Beiriger (1984), Report on Static Hydrothermal Alteration Studies of Topopah Spring Tuff Wafers in J-13 Water at $150^{\circ} \mathrm{C}$, Lawrence Livermore National Laboratory, Livermore, CA, UCRL-53576. HQS.19880517.2007

Knauss, K. G., W. J. Beiriger, and D. W. Peifer (1985a), Hydrothermal Interaction of Solid Wafers of Topopah Spring Tuff and J-13 Water at 90, 150, and $250^{\circ} \mathrm{C}$ Using Dickson-Type, Gold-Bag Rocking Autoclaves: 1. Short-Term Experiments, Lawrence Livermore National Laboratory, Livermore, CA, UCRL-53645. NNA.19900207.0282

Knauss, K. G., W. J. Beiriger, and D. W. Peifer (1985b), Hydrothermal Interaction of Crushed Topopah Spring Tuff and J-13 Water at 90, 150, and $250^{\circ} \mathrm{C}$ Using Dickson-Type, Gold-Bag Rocking Autoclaves, Lawrence Livermore National Laboratory, Livermore, CA, UCRL-53630. NNA.19931005.0010

Knauss, K. G. and D. W. Peifer (1986), Reaction of Vitric Topopah Spring Tuff and J-13 Groundwater under Hydrothermal Conditions Using Dickson-Type, Gold-Bag Rocking Autoclaves, Lawrence Livermore National Laboratory, Livermore, CA, UCRL-53795. NNA.19891102.0017

Knauss, K. G., W. J. Beiriger, and D. W. Peifer (1987), Hydrothermal Interaction of Solid Wafers of Topopah Spring Tuff with J-13 Water and Distilled Water at 90 and $150^{\circ} \mathrm{C}$ Using 
Dickson-Type, Gold-Bag Rocking Autoclaves: Long-Term Experiments, Lawrence Livermore National Laboratory, Livermore, CA, UCRL-53722. NNA.19870713.0081 Komarneni, S. and D. M. Roy (1983) Hydrothermal interactions of cement or mortar with zeolites or montmorillonites. Mat. Res. Soc. Symp. Proc. 15, 55-62.

Kurnoskin, A. V. (1992), J. Appl. Polym. Sci. 46, 1509-1530.

Kutty, S. K. N., T. K. Chaki, and G. B. Nando (1992), Polym. Degradation Stability 38, 187192.

Larrabee, C. P., and W. L. Mathay (1963), in F. L. LaQue and H.R. Copsum, Eds., Corrosion Resistance of Metals and Alloys (Reinhold Publishing Co.), 319-323. NNA:19870406.0431

Lea, F. M. (1971), The Chemistry of Cement and Concrete (Chemical Publishing Co.), 727 pp. NNA.19890713.0195

Leed, W. T., and R. J. Watters (1994), Assessment of Rock Bolt Systems for Underground Waste Storage. High Level Radioactive Waste Management, Las Vegas, Nevada, American Nuclear Society, Inc. American Society of Civil Engineers.

Licina, G.J. (1988). Sourcebook for Microbiologically Influenced Corrosion in Nuclear Power Plants. EPRI NP-5580, Electric Power Reasearch Institute, Palo Alto, CA.

Little, B.J., P.A. Wagner, and D. Duquette. (1987) Microbially induced cathodic depolarization. Corrosion/87, National Association of Corrosion Engineers, Houston, TX.

Livingston, R. A., P. E. Stutzman, R. Mark and M. Erdik (1992) Preliminary analysis of the masonry of the Hagia Sophia Basilica, Istanbul. Mat'l.Res. Soc. Symp. Proc. Vol. 267, 721-735.

LLYMP9603087 (1996), Memo from A. Meike to J. Montgomery of M\&O/MorrisonKnudsen Corp. Subject: Assessment of Dust Suppression Additives.

Lovley, D.R. and E.J.P. Phillips. (1987). Rapid asay for microbially reducible ferric iron in aquatic sediments. Appl. Environ. Microbiol. 53, 1536-1540.

Lucey, V. F. (1972), Developments Leading to the Present Understanding of the Mechanism of Pitting Corrosion of Copper, Br. Corrosion J. 7, 36-41. NNA.19891004.0341

Lundegard, P. D., Y. K. Kharaka, and R. J. Rosenbauer (1992), Petroleum as a Potential Diagenetic Agent: Experimental Evidence, in Water-Rock Interaction Y. Kharaka and A. Maest, Eds., (Balkema, Rotterdam), pp. 329-335.

Lynch, W. (1978), Handbook of Silicone Rubber Fabrication. (Van Nostrand Reinhold Company, New York, NY).

Macphee, D. E., K. Luke, F. P. Glasser and E. E. Lachowski (1989) Solubility and aging of calcium silicate hydrates in alkaline solutions at $25^{\circ} \mathrm{C}$. Am. Ceram. Soc. J. 72, 646654.

Majling, J., V. Tomkova and E. Istenikova (1985) Calorimetric study of reactions in the system $\mathrm{C}_{4} \mathrm{~A}_{3} \mathrm{~S}-\mathrm{CH}$ - CS - H. Thermochim. Acta 85, 219-222.

Manning, H.L. (1975). New medium for isolating iron-oxidizing and heterotrophic acidophilic bacteria from acid mine drainage. Appl. Microbiol. 30, 1010-1016.

Mark, H. S., N. M. Bikales, C. G. Overberge, G. Menge, and J. I. Kroschwitz, Eds. (1985), Encyclopedia of Polymer Science and Engineering (John Wiley, New York, NY).

Marshall, E. (1990), Clovis Counterrevolution, 249(August 17, 1990), pp. 738-741. 
Martin, S. I, B. Viani, and A. Meike (1995), Synthesis of $1.1 \mathrm{~nm}$ Tobermorite: A Cement Phase Expected under Repository Conditions, in Proceedings of the 1995 High Level Radioactive Waste Management Meeting, Las Vegas, Nevada, Lawrence Livermore National Laboratory, Livermore, CA, UCRL-JC-119131， MOL.19950913.0005 Martin, S. I, B. Viani, and A. Meike (1996), Water Adsorption by Okenite $\left(\mathrm{Ca}_{10} \mathrm{Si}_{18} \mathrm{O}_{46} \cdot 18 \mathrm{H}_{2} \mathrm{O}\right)$ at Ambient Temperature, Lawrence Livermore National Laboratory, Livermore, CA, UCRL-ID (in preparation).

Maycock, J. N., J. Skalny and R. 5. Kalyoncu (1974) Thermal decomposition of cementitious hydrates. pp. 697-711 in R. 5. Porter and J. F. Johnson, eds. Analytical Calorimetry. Plenum.

McNeil, M.B., D.W. Mohr and B.J. Little (1990). Correlation of laboratory results with observations on long-term corrosion of iron and copper alloys. Proceedings of the Materials Research Society 1990 Spring Meeting, Symposium on Materials Science in Archeology (in press).

McNeill, I. C., M. Zulfiqar, and T. Kousar (1990), Polym. Degradation Stability 28, 131-151. Meike, A. (1993), Chemical and Mineralogical Concerns for the Use of Man-Made Materials in the Post-Emplacement Environment, Lawrence Livermore National Laboratory, Livermore, CA, UCRL-ID-113383. MOL.19930809.0021

Meike, A. (1994), Chemical Implications for the Presence of Introduced Materials in the Post-Emplaceent Environment, Mater. Res. Soc. Symp. Proc. 333, 835-840. NNA.19940408.0028

Meike, A., and C. Wittwer (1994), Introduced Materials and Colloid Formation: A Report on the Current State of Knowledge, in Proceedings of the Materials Research Society (Fall 1993), pp. 783-789, UCRL-JC-114122. NNA.19940316.0115

Meike, A., M. Onofrei, C. J. Bruton, and B. E. Viani (1994), Progress in Understanding the Structure and Thermodynamics of Calcium Silicate Hydrates, in High Level Radioactive Waste Management, Proceedings of the Fifth Annual International Conference (Las Vegas, NV, May 1994), pp. 2590-2596, UCRL-JC-116358. NNA.19940517.0127

Meike, A., W. L. Bourcier, M. Alai, D. L. Haldeman, P. S. Amy, T. Lagadinos, and L. Hersman (1994), Long-Term Chemical Effects of Diesel Fuel Emissions on a Mining Environment: A Preliminary Assessment Based on Data from a Deep Subsurface Tunnel at Rainier Mesa, Nevada Test Site, YMP-MOL-73. MOL.19950406.0141

Meike, A., and M. Spragge (1995) Progress Report \#1 on the Materials Identification, Characterization and Evaluation Activity: Acquisition of Materials Data from the Exploratory Studies Facility, Yucca Mountain Site Characterization Project Milestone Report \#MOL132. MOL.19960415.0416

Meike, A., Ed. (1995), Potential Long-Term Chemical Effects of Diesel Fuel Emissions on a Mining Environment: A Preliminary Assessment Based on Data from a Deep, Subsurface Tunnel at Rainier Mesa, Nevada Test Site, Lawrence Livermore National Laboratory, Livermore, CA, UCRL-ID-121046. MOL19950406.0141

Meike, A. (1996) Man-Made Materials, Chapter 6 in Preliminary Near-Field Environment Report Update Volume II: Scientific Overview of Near-Field Environment and Phenomena, D. G. Wilder, Ed., Lawrence Livermore National Laboratory, Livermore, CA, UCRLID (in prepration). 
Meike, A., Ed. (in press), The State of Chemical Modeling Modules for the Degradation of Concrete and Cements, Lawrence Livermore National Laboratory, Livermore, CA, UCRL-ID 123275.

Milestone, N. B., T. Sugama, L. E. Kukacka and N. Carciello (1987) Carbonation of geothermal grouts - part 3: $\mathrm{CO}_{2}$ attack on grouts containing bentonite. Cem. Concr. Res. 17, 295-306.

Mor, E. D., and A. M. Beccaria (1975), Behaviour of Copper in Artificial Sea Water Containing Sulphides, Br. Corrosion J. 10(1), 33-38. NNA.19920506.0040

Moragues, A., A. Macias and C. Andrade (1987) Equilibria of the chemical composition of the concrete pore solution. Part I: Comparative study of synthetic and extracted solutions. Cem. Concr. Res. 17, 173-182.

Moragues, A., A. Macias and J. Losada (1988) Equilibria of the chemical composition of the pore concrete solution, part II: Calculation of the equilibria constants of the synthetic solutions. Cem. Concr. Res. 18, 342-350.

Mordi, R. C., R. Fields, and J. Dwyer (1992), J. Chem. Soc. Chem. Commun. (Febuary 15, 1992), 374-375.

Murakata, T., Y. Saito, T. Yosikawa, T. Suzuki, and S. Sato (1993), Polymer 34, 1436-1439.

Naqvi, M. K. (1991), Polym. Degradation Stability 33, 367-375.

Nas, L. I., and C. A. Heiberger, Eds. (1986), Resin Manufacture and Properties (Marcel Dekker, New York, NY).

Neal, C. and G. Stanger (1984) Calcium and magnesium hydroxide precipitation from alkaline groundwaters in Oman, and their significance to the process of serpentinization. Min. Mag. 48, 237-241.

Neal, C., and G. Stanger (1984), Calcium and Magnesium Hydroxide Precipitation from Alkaline Groundwaters in Oman, and Their Significance to the Process of Serpentinization, Min. Mag. 48, 237-241. NNA.19920131.0315

NRC (Nuclear Regulatory Commission), 1988, Disposal of High-Level Radioactive Wastes in Geologic Repositories: Licensing Procedures, Code of Federal Regulations, Energy, Title 10, Part 60, Washington, DC. NNA.19890715.0655

O'Donnell, J. H., and S. W. Shalabys, Eds. (1990), Chemistry of Radiation Degradation of Polymers. Radiation Effects on Polymers (American Chemical Society, Washington DC).

Okieimen, F. E., and J. E. Ebhoaye (1992), Europ. Polym. J. 28, 1423-1425.

Olofsson, U., Allard, B., Andersson, K., and B. Torstenfelt (1981), Formation and Properties of Radiocolloids in Aqueous Solution-A Literature Survey. Programradet for Radioaktivt Abfall, National Council for Radioactive Waste, Report Proav 4.25.

Olofsson, U., Allard, B., Andersson, K., and B. Torstenfelt (1982a), Formation and Properties of Americium Colloids in Geologic Systems. Scientific Basis For Nuclear Waste Management, 4, S. Topp, Ed.

Olofsson, U., Allard, B., Torstenfelt, B. and K. Andersson (1982b), Properties and Mobilities of Actinide Colloids in Geologic Systems. Scientific Basis For Nuclear Waste Management, 5, W. Lutze, Ed., 755-764

Onofrei, M. (1987) Leaching studies of concrete materials for nuclear fuel waste immobilization containers. pp. 351-396 in Brookins, D. G. ed. The Geological Disposal of High Level Radioactive Wastes. Athens, Greece: Theophrastus Publications.

Pace, N. R., D. A. Stahl, D. J. Lane and G. J. Olsen (1986), The Analysis of Natural Microbial Populations by Ribosomal RNA Sequences, Adv. Microb. Ecol. 9, 1-55. 
Palmer, D. A., and S. E. Drummond (1986), Thermal Decarboxylation of Acetate. Part I. The Kinetics and Mechanism of Reaction in Aqueous Solution, Geochim. Cosmochim. Acta 50, 813-823.

Parimala, H. V., and K. Vijayan (1993), J. Mater. Sci. Lett. 12, 99-101.

Pollard, A.M., R.G. Thomas and P.A. Williams (1989), Synthesis and stabilities of the basic copper (II) chlorides atacamite, paratacamite and botallackite, Mineral. Mag., 53, 557-563.

Pope, D. H., S. Lockwood, A. Lee, R. Skultety, and K. Keas. (1994). Mitigation of microbiologically influenced corrosion in natural gas storage facilities. Corrosion/94 National Association of Corrosion Engineers, Houston, TX.

Raber, E., and J. Garrison (1983), Radioactive Waste Management and the Nuclear Fuel Cycle 4, 41-52.

Raloff, J. (1990), The colloid threat, Science News, March 17, 1990, p. 169.

Ravanetti, G. P., and M. Zini (1992), Thermochim. Acta 207, 53-64.

Reasoner, D. J., and E. E. Geldreich (1985), A New Medium for the Enumeration and Subculture of Bacteria from Potable Water, Appl. Environ. Microbiol. 49, 1-7.

Rek, V., D. Hace, M. Bravar, and A. Jagodar (1990), Die Angewandte Makromolekulare Chemie 176, 135-146.

Rhoderick, J. E. (1981) Examination of samples of grout after 63 years exposure underground. ONWI-248. $6 \mathrm{pp}$.

Rhoderick, J. E., and A. D. Buck (1981a), Petrographic Examination of Several Four-YearOld Laboratory Developed Grout Mixtures, U.S. Army Engineer Waterways Experiment Station, Structures Laboratory. SRX.19830722.0111

Rhoderick, J. E., G. S. Wong, et al. (1981b), Examination of Samples of Bell Canyon Test 1-FF Grout, U.S. Army Engineer Waterways Experiment Station, Structures Laboratory. SRX.19811020.0177

Rhoderick, J. E., and A. D. Buck (1981C), Examinations of Simulated Borehole Specimens, U.S. Army Engineer Waterways Experiment Station. SRX.19830107.0010

Rogers, R.D. (1995), Assessment of the Effects of Microbially Influenced Degradation on a Massive Concrete Structure. Final Report to Introduced Materials Task. July 8, 1995, Lawrence Livermore National Laboratory, Livermore, CA, UCRL-CR-122068.

Rose, N., M. L. Bras, R. Delobel, B. Costes, and Y. Henry (1993), Polym. Degradation Stability 42, 307-316.

Roy, D. M., and C. A. Langton (1983), Characterization of Cement Based Ancient Building Materials in Support of Repository Seal Materials Study, BMI/ONWI-523.139 pp. SRX.19870127.0146

Roy, D. M., and C. A. Langton (1989), Studies of Ancient Concrete as Analogs of Cementitious Sealing Materials for a Repository in Tuff, Los Alamos National Laboratory, Los Alamos, NM, LA-11527-MS. 101 pp. HQS.19880517.3281

Roy, D. M. and C. A. Langton (1989) Studies of ancient concrete as analogs of cementitious sealing materials for a repository in tuff. LA-11527-MS. $101 \mathrm{pp}$.

Roznak, D.B. and R.R. Colwell. (1987). Survival strategies of bacteria in the natural environment. Microbiol. Rev. 51, 365-379.

Russell, C. E., R. Jacobsen, D. L. Haldeman and P. S. Amy. (1994). Heterogeneity of deep subsurface microorganisms and correlations to hydrogeological and geochemical parameters. Geomicrobiol. J. 12, 37-51. 
Sarker, A. K., M. W. Barnes and D. M. Roy (1982) Longevity of borehole and shaft sealing materials: Thermodynamic properties of cements and related phases applied to repository sealing. ONWI-201. $47 \mathrm{pp}$.

Sato, S., T. Murakata, S. Baba, Y. Saito, and S. Watanabe (1990), J. Appl. Polym. Sci. 40, 2065-2071.

Schneider, B., D. Doskocilova, J. Stokr, and M. Svoboda (1993), Polymer 34, 432-436.

Scott, D.A. (1985), Periodic corrosion phenomena in bronze antiquities, Studies in Conservation, 30, 49-57.

Seyfried, W. E., D. R. Janecky, and M. E. Berndt (1987), Rocking Autoclaves for Hydrothermal Experiments. II. The Flexible Reaction-Cell System, in Hydrothermal Experimental Techniques, G. C. Ulmer and H. L. Barnes, Eds. Wiley and Sons, New York. pp. 216-239.

Shewmon, P. G. (1963), Diffusion in Solids (McGraw-Hill, New York, NY).

Shrivastava, 0. P. and F. P. Glasser (1986) Ion-exchange properties of ll-A tobermorite. React. Solids 2, 261-268.

Smirnov, V. V., and E. B. Dubova (1992), High Energy Chem. 26, 173-177.

Soo, P. and L. W. Milian (1989) Sulfate-attack resistance and gamma-irradiation resistance of some portland cement based mortars. NUREG/CR-5279. $35 \mathrm{pp}$.

Soylemezoglu, S., and R. Harper (1982), Oxygen Ingress into Geothermal Steam and Its Effect on Corrosion of Low Carbon Steel at Broadlands, New Zealand, Geothermics 11(1), 31-42.

Spadaro, G. (1993), Europ. Polym. J. 29, 851-854.

Sterne, P. A., and A. Meike (1995), Electronic Structure Calculations of Calcium Silicate Hydrates, in Proceedings of the Materials Research Society (Boston, MA, December 1995), Lawrence Livermore National Laboratory, Livermore, CA, UCRL-JC-121437.

Suzuki, S., and E. Sinn. (1993), $1.4 \mathrm{~nm}$ Tobermorite-Like Calcium Silicate Hydrate Prepared at Room Temperature from $\mathrm{Si}(\mathrm{OH})_{4}$ and $\mathrm{CaCl}_{2}$ Solutions, J. Mater. Sci. Lett. $12,542$.

Svoboda, M., J. Stokr, and B. Schneider (1990), Collection of Czechosovak Chemical Communications 55, 2233-2243.

Tannenbaum, E., and I. R. Kaplan (1985), Low-Mr Hydrocarbons Generated during Hydrous and Dry Pyrolysis of Kerogen, Nature 317, 708-709.

Taylor, H. F. W. (1986) Proposed structure for calcium silicate hydrate gel. Am. Ceram. Soc. J. 69, 464-467.

Taylor, H. F. W. (1990), Cement Chemistry (Academic Press, London, San Diego), 123 pp.

Taylor, H. F. W. and D. M. Roy (1980) Structure and composition of hydrates. 7th Int. Congr. Chem. Cement II-2/1-13.

Taylor, H. F. W. (1987) Bound water in cement pastes and its significance for pore solution compositions. Mat. Res. Soc. Symp. Proc. 85, 47-53.

Torikai, A., R. Geetha, and S. Nagaya (1990), J. Polym. Sci. A, Polym. Chem. 28, 3639-3646. Torikai, A. (1994), Die Angewandte Makromolekulare Chemie 216, 225-241.

Tylecote, R. F. (1979), The Effect of Soil Conditions on the Long-Term Corrosion of Buried TinBronzes and Copper, British Nuclear Fuels Limited.

Van Konynenburg, R.A. (1986), Radiation Doses in Granite Around Emplacement Holes in the Spent Fuel Test - Climax (Final Report). UCRL-53580. Lawrence Livermore National Laboratory, Livermore, CA. 
Vieillard, P., and F. Rassineux (1992), Thermodynamic and Geochemical Modelling of the Alteration of Two Cement Matrices, Appl. Geochem. Suppl. 1, 125-136.

Wallius, S. (1993), Die Angewandte Makromolekulare Chemie 212, 103-119.

Ward, D. M., R. Weller, and M. M. Bateson (1990), 16S rRNA Sequences Reveal Numerous Uncultured Microorganisms in a Natural Community, Nature 345, 63-65.

Warren, R. S., F. M. Byers, and F. A. Caporuscio (1984), Petrography and Mineral Chemistry of Units of the Topopah Spring, Calico Hills, and Crater Flat Tuffs, and Older Volcanic Units, with Emphasis on the Samples from Drill Hole USW G-1, Yucca Mountain, Nevada Test Site, Los Alamos National Laboratory, Los Alamos, NM, LA-10003-MS. HQS.19880517.2569

Welch, D.F. (1991). Applications of cellular fatty acid analysis. Clin. Microbiol. Rev. 4, 422-438.

Weres, O., A. S. Newton, and L. Tsao (1988), Hydrous Pyrolysis of Alkanes, Alkenes, Alcohols and Ethers, Org. Geochem. 12, 433-444.

West, K. A. (1988), Nevada Nuclear Waste Storage Investigations Exploratory Shaft Facility Fluids and Materials Evaluation, Los Alamos National Laboratory, Los Alamos, NM, LA-11398-MS. NN1.19981213.0021

Westlake, D.W.S., K.M. Semple, and C.O. Obuekwe (1985). Corrosion by ferric ironreducing bacteria isolated from oil production systems. Proceedings of the International Conference on Biologically Induced Corrosion, June 10-12, 1985, Gaithersburg, MD.

Wheeler, D. R., and S. V. Pepper (1990), J. Vac. Sci. Technol. 8, 4046-4056.

Williams, J. L., Ed. (1990), Stability of Polypropylene to Gamma Irradiation (American Chemical Society, Washington, DC), pp. 554-568.

Wilski, H. (1990), Influence of Ionizing Radiation on Thermoset Plastics (American Chemical Society, Washington, DC).

Winograd, I. J. (1986), Archaeology and Public Perception of a Trans-Scientific Problem: Disposal of Toxic Wastes in the Unsaturated Zone, U.S. Geological Survey. NNA.19910627.0007

Woese, C. R. (1987), Bacterial Evolution, Microbiol. Rev. 51, 221-271.

Wolery, T., K. J. Jackson, et al. (1990), Current Status of the EQ3/6 Software Package for Geochemical Modeling, in Chemical Modeling in Aqueous Systems II. Lawrence Livermore National Laboratory Report. NNA.19900716.0363

$\mathrm{Wu}, \mathrm{Z}-\mathrm{Q}$. and J. F. Young (1984) Formation of calcium hydroxide from aqueous suspensions of tricalcium silicate. Am. Ceram. Soc. J. 67, 48-51.

Xiuji, F. and L. Shizong (1986) Investigation of the effect of minor ions on the stability of b- $\mathrm{C}_{2} \mathrm{~S}$ and the mechanism of stabilization. Cem. Concr. Res. 16, 587-601.

Xu, P., D. Zhou, and D. Zhao (1989a), Europ. Polym. J. 25, 581-583.

Young, J. F., H. S. Tong and R. L. Berger (1977) Compositions of solutions in contact with hydrating tricalcium silicate pastes. Am. Ceram. Soc. J. 60, 193-198. 


\section{Appendix A: Polymer Chemistry}

Polymerization. Polymerization occurs via addition or condensation polymerization. These basic chemical reactions are achieved through one of four primary techniques by which polymers are formed from monomers (bulk, solution, suspension, and emulsion). There are three properties which differentiate addition polymerization from condensation polymerization. First, the repeat unit in the polymer and the monomer have the same composition, although the bonding is different in each for addition polymerization. Second, the mechanism of these reactions places addition polymerization in the kinetic category of chain reactions, with either free radicals or ionic groups responsible for propagating the chain reaction. Lastly, the product molecules usually have a carbon chain backbone, with pendant substituent groups. Chain growth polymers include polyethylene, polystyrene, polyvinylchloride (PVC), polyisobutylene, and Teflon.

Chemical characterization. Chemical characterization of polymers is a complex issue because even within a given polymer class, it is not possible to make correlations between polymers and simpler but chemically similar molecules, because each polymer has its own unique set of properties that depend on chemical structures, chain lengths, conformations, and degrees of branching and crystallinity. This diversity is further complicated by the addition of filler, plasticizers, stabilizers as well as other additives. Two products of the same polymeric substance but with different additives can react differently to the same conditions. Thus, in order to completely understand the affects of a given product, the range of chemical composition must be known. Beginning in the 1920 s cellulose nitrate and cellulose acetate became widely used as well as phenolformaldehyde (Bakelite) which was the first synthetic thermoset (crosslinked) polymer. Given this relatively recent arrival, limited insight can be gained on long-term behavior through historical analogs. Thus, extension back in time will require a sound understanding of fundamental chemical principles, which are outlined below. It must be emphasized that the degradation behavior is based on relatively short term experiments and should only act as a first estimate for the prediction of long-term stability in the context of a radioactive waste repository.

Molecular Weight Distribution. A polymeric material is made up of many polymer molecules which are held together by entanglements and intermolecular forces and crosslinks. It is the exception when polymerization is carried out so that all polymers have the same degree of polymerization. Thus it is difficult to define useful thermodynamic parameters for these materials. Molecular weight distribution reflects the number of bonds or degree of polymerization and is a fundamental diagnostic polymer property. Properties that are dependent on the number of molecules in a system, called colligative properties, are osmotic pressure, boiling point, and freezing point. Measurement of these properties can thus be used to determine the average molecular weight and the degree of polymerization. Colligative properties have also been used to assess the thermodynamic behavior of polymers in solution. The 
molecular weight distribution represents the variation from the average of the polymers within the material. A broad distribution in the degree of polymerization of a polymer population is represented as a large "degree of freedom".

Theta Condition. When a polymer is in the theta condition, the tendency to spread out is exactly balanced with the excluded volume effect (real polymer conformations should be more spread out than those predicted because only one polymer segment can take up a certain space at a given time). Solvents which yield this "equilibrium" are referred to as theta solvents and the temperature at which the theta condition is reached for a given polymer/solvent pair is known as the theta temperature.

Many parameters are known for a theta polymer thus, interpretation can be less complex if the polymer is in the theta condition. Given that much information about polymers is in the realm of synthesis, where a theta condition may be sought, it is to be expected that information for conditions outside of the theta condition (which will be the rule rather than the exception under repository conditions) are far less complete.

Thermoplastics vs Thermosets. All solid polymers can be categorized as either thermoplastics and thermosets. The polymer molecules of thermoplastics are held together by intermolecular forces. Thermoplastics soften when heated but do not degrade until a certain temperature. They can be molded and remolded with the use of heat. Examples of thermoplastics are nylon and polystyrene. Thermosets on the other hand contain polymer molecules which are joined by chemical crosslinks. They are achieved by a chemical reaction which creates a crosslinked polymer which can not be remolded once it is set. The crosslinks prevent bond motion (in some cases, the crosslinked polymer can be stretched but the crosslinks prevent the remolding possible with thermoplastics). Examples of thermosets are epoxy and vulcanized rubber. The polymer is still a polymer before crosslinking but it is primarily used in its crosslinked form. Polyester is an example of a polymer that is used as a thermoplastic and which can be crosslinked to become a thermoset.

Polymer Elasticity. Depending on the length of the polymer chains and on the temperature, a particular type of polymer may occur as a viscous liquid, a rubbery solid, a glass or a partially crystalline solid. The longer the average length of the polymer chains, the less viscous the polymer at a given temperature. The polymer chains are coiled and intertwined with each other. If the polymer is stretched, then the chains slowly untangle and the polymer appears to flow. The relative movement of polymer chains can be decreased by connecting the polymer chains with chemical bonds called crosslinks. When the crosslinked network is stretched, the coils become elongated, but when the stress is released or more energy is put into the system, the polymer network returns to its original coiled state.

Transition Temperature. The physical state of polymers is temperature dependent. Like most materials, polymers have a melting point $\left(T_{\mathrm{m}}\right)$. In addition, within the solid state ( $T<T_{m}$ ), polymers can be in a "glassy" state or in a "rubber" state (different from a crosslinked rubber). The glass transition temperature $\left(T_{g}\right)$ determines the turning point between "glass," where there is not rotation around bonds and "rubber," where 
segmental bond motion begins. A polymer in the glass state, is stiff and often brittle, but upon passing through its glass transition temperature becomes flexible and malleable. Thus $T_{\mathrm{g}}$ and factors that affect $T_{g}$ determine the mechanical characteristics of the polymer.

The $T_{g}$ increases with molecular weight or degree of polymerization, as well ass crystallinity. Side branching usually decreases $T_{g}$ by leading to a less ordered structure as does heterogeneity of the polymer chain (i.e. copolymers). Chemical composition and configuration (syndiotactic, atactic, isotactic) both affect $T_{\mathrm{g}}$. In addition, $T_{\mathrm{g}}$ can be lowered by the addition of plasticizers (a plasticizer is defined as any substance which when added to the polymer, lowers its glass transition temperature). For example, water acts as a plasticizer in nylon. Most thermoplastic polymers for consumer applications (e.g. plastic bags, nylon running shorts and 2-L soda bottles) have a glass transition temperature below room temperature for flexibility .

Crystalline and Amorphous States. The orientation of a polymer chain can be ordered by physical force. This is how fibers, as well as most plastic consumer products are formed. A force is applied to the material above the $T_{\mathrm{g}}$ and then the material is cooled. Because it is now a glass, the polymer will not return to its original disordered state. However, as soon as the thermoplastic polymer is heated, it will return to its original form. Crystalline regions are created by the packing of molecular chains together. The crystallinity is dependent on the material itself as well as the production method. For example, an isotactic polymer can be more easily packed than an atactic polymer. Crystals can only be formed above the $T_{\mathrm{g}}$ and below the melting temperature $\left(T_{m}\right)$. Crystallinity can also be achieved by adding particles to the polymer melt which create an area of reduced energy so that a crystal can propagate(more order means more energy). Crystallinity affects most polymer properties including $T_{g}$ (increased crystallinity increases $T_{\mathrm{g}}$ ), and wettability (crystallinity reduces wettability).

The noncrystalline or amorphous regions are important determinants of polymer properties. Amorphous regions allow for wettability and elasticity in the polymer. Many structures of polymers in terms of crystalline and amorphous regions have been suggested but the exact structure of polymers are not known.

Additives. Additives to polymer resins improve strength, flexibility, flame retardance, or appearance. The term antioxidant is broadly used to refer to inhibitors for autoxidation: heat stabilizers, melt stabilizers, light stabilizers, antifatigue agents and antiozonants. All of these agents interfere with the free radical reactions that lead to the incorporation of oxygen into macromolecules. For example, N-phenyl B-napthylamine and butylated hydroxytoluene respectively are added to elastomers and plastics to reduce deterioration related to autoxidation (Mark et al., 1985). Plasticizers lower the glass transition temperature of a material making processing easier and the polymers more flexible. Phtalic esters are common plasticizers (Mark et al., 1985; Khinnavar and Aminabhavi, 1992). 


\section{Appendix B: Curing of Cementitious Material}

Cement is predominantly composed of calcium-bearing phases that crystallize when water is added to a mixture of carbonate, silicate, and other phases. Table B-1 briefly describes the nomenclature and standards of cement chemistry. The reactions and structural changes take place over time scales of a few seconds to a year or longer and are sensitive to temperature within the range of interest to the repository. Table B-2 summarizes the chemistry of the major cement hydration reactions. Hydration reactions that predominate below $100^{\circ} \mathrm{C}$ as well as those that predominate above $100^{\circ} \mathrm{C}$ are summarized (Bensted, 1989). Table B-3 lists formulas of cement phases.

The most important reaction in curing cement at ambient conditions is probably the hydration of calcium silicates. Alite, $\mathrm{C}_{3} \mathrm{~S}$, is known to hydrate considerably faster than belite, an impurity-stabilized form of $\mathrm{C}_{2} \mathrm{~S}$ at $25^{\circ} \mathrm{C}$, and the former is thus the primary contributor to the early strength of concretes. Alite has often been chosen for detailed study because of this kinetic advantage. Other important phases in the hydration and crystallization process include a calcium silicate hydrate gel, C-S-H (no stoichiometry, crystallinity, structure, or degree of polymerization is implied), which is common to most cements. The literature distinguishes at least two forms of this "gel": an early phase that consumes most of the anhydrous starting material within about 28 days (Glasser et al., 1987), and a more polymerized phase that increases in length as the material ages. Although the details are poorly documented, some structural characteristics of the C-S-H phase are well known. The quasi-crystalline C-S-H phases that develop with aging are considerably more crystalline, with either an imperfect tobermorite-like structure or a jennite-like structure. Tobermorite-like phases appear to be favored as aging progresses in cements that contain siliceous blending agents (Shrivastava and Glasser, 1986). The microstructural changes that accompany these solid-state phase transformations may affect virtually all measurable thermal, mechanical, and physical properties. These effects have not been described, and they remain unpredictable. The polymers appear to incorporate a range of ions, and the C:S ratio can also vary. As a consequence, the kinetics and degree of polymerization may differ as a function of the composition of the starting materials.

Kinetic data are limited primarily to the formation of C-S-H from pure beta- $\mathrm{C}_{2} \mathrm{~S}$ and $\mathrm{C}_{3} \mathrm{~S}$. A review of the literature on the kinetics of belite and alite hydration (Barret and Bertrandie, 1986) suggests that the mechanisms may be debated, but that the markedly slower hydration of belite is thought to be similar to alite. In both cases, rapid dissolution within a few minutes of hydration is followed by a somewhat linear increase to a maximum ion concentration that represents supersaturation with respect to portlandite. Subsequently, the concentration decreases, first rapidly, then slowly and linearly (Wu and Young, 1984; Brown et al., 1984). Competition between chemical reactions that start at different times and differ in progress of reaction will determine the overall rate. Brown et al. (1985) proposed that an initial hydrate forms that eventually nucleates a more stable hydrate. The consequent increase in the rate of $\mathrm{Ca}^{++}$ and $\mathrm{OH}^{-}$liberation eventually supersaturates the solution with respect to $\mathrm{Ca}(\mathrm{OH})_{2}$, which precipitates. The subsequent hydration of $\mathrm{C}_{3} \mathrm{~S}$ is diffusion-controlled. Grutzeck and Ramachandran (1987) propose that a precipitate of a very-fine-grained C-S-H 
initially forms on the surface of $C_{3} S$ as a result of supersaturation and controls subsequent hydration via diffusion. New material forms at the solid/hydrate interface while the fine-grained outer layer dissolves. A sufficiently supersaturated solution at a $\mathrm{pH}$ of 11.5 will form relatively-coarse-grained C-S-H(II) at the expense of the finegrained initial C-S-H. Bensted (1983a) finds that most of the initial ettringite is formed from $\mathrm{C}_{3} \mathrm{~A}$ at the greatest rate during the first $5 \mathrm{~min}$, followed by a steady increase for up to $2 \mathrm{hr}$. After 8 to $26 \mathrm{hr}$, when the gypsum is gone, ettringite reacts with $\mathrm{C}_{4} \mathrm{AH}_{13}$ to form monosulfate (Bensted, 1983b). The iron from ferrite is thus freed to participate in hydrous phases. Alkalis, whether present in the original grout or contributed by additives or aggregate, are released in temperature-sensitive reactions from clinker phases to the pore fluids within days (Glasser and Marr, 1984; Glasser et al., 1985), and reach concentrations of 0.05 to $1.0 \mathrm{M}$. The presence of alkalis depresses calcium solubility and thus (1) determines the pH of the pore fluid (Macphee et al., 1989), and (2) affects the hydration of alite and belite (Wu and Young, 1984).

Ettringite is the most prevalent sulfate-bearing hydration product below $80^{\circ} \mathrm{C}$ and is an important trivalent-ion-bearing phase. Within broad limits, ettringite appears to form independently of the degree of hydration (Bensted, 1983a,b), but it is not stable above 75 to $80^{\circ} \mathrm{C}$ under $100 \%$ relative humidity. Prediction of the fate of much of the $\mathrm{Al}^{+++}$and $\mathrm{SO}_{4}=$ in the hydrated cement, and possibly $\mathrm{Fe}^{+++}$, is dependent on the knowledge of ettringite thermochemistry. Ettringite formed from aluminate and ferrite phases composes a continuous hydrated solid-solution. Analogous solid-solutions of other phases may be formed from ferrite and aluminate. Above about $100^{\circ} \mathrm{C}$, iron-rich monosulfate often forms as a consequence of reactions that consume ettringite, which loses much of its structural water on heating to $60^{\circ} \mathrm{C}$ and transforms to $\mathrm{C}_{6} \mathrm{AS}_{3} \mathrm{H}_{8}$ at $110^{\circ} \mathrm{C}$ (Taylor, 1987) at $\mathrm{pH} 11$. Ettringite ultimately decomposes to gypsum, aragonite, and $\mathrm{Al}(\mathrm{OH})_{3}$ (Grounds et al., 1985), and to crystalline calcium silicates that include tobermorite, xonotolite, gyrolite, hydrogarnet, stratlingite, alpha- $\mathrm{C}_{2} \mathrm{SH}$, and $\mathrm{C}_{6} \mathrm{~S}_{2} \mathrm{H}_{3}$ (Bensted, 1989). Tobermorite-11 $\AA$ is a disordered structure (Taylor, 1964) that precipitates in water at temperatures greater than $100^{\circ} \mathrm{C}$, but which has been observed from cements leached at $25^{\circ} \mathrm{C}$ and those cured at $60^{\circ} \mathrm{C}$ (Barnes and Roy, 1983). "Normal" tobermorite- $11 \AA$ decreases to $9.3-\AA$ spacing by $300^{\circ} \mathrm{C}$. These products are also expected of cement formed at ambient conditions, cured, and subsequently heated to $\geq 100^{\circ} \mathrm{C}$ (Scheetz and Roy, 1989a,b), a scenario that is anticipated for the waste repository.

The consequences of incorporating aggregate materials, blending agents, and other additives such as fly ash, blast furnace slag (bfs), silica fume, rice husk ash, and natural pozzolan into cement have been investigated to a limited extent (Glasser et al., 1986; Macphee et al., 1989; Andersson et al., 1989). Glasser et al. (1987) provide a summary of the chemical and mineralogical effects of these cement additives. Pozzolanic aggregate materials react chemically to give the cement advantageous properties. A pertinent example of natural aggregates that behave as pozzolanas are some siliceous welded tuffaceous rocks. Other materials that may be added to cements to influence the rate at which they cure include an anhydrous material, "clinker" which is produced by cement kilns, and gypsum. Gypsum, which is added to prevent flash setting, can lose water during grinding with clinker to form hemihydrate. Rehydration of gypsum when water is added to the cement can compete with cement minerals such as ettringite and 
influence their aging kinetics. An aggregate of bfs creates a reducing environment and thus may influence the mobility of ions and complexes that are sensitive to oxidation conditions. The bfs additive contains materials foreign to the usual cement chemistry: large amounts of ferrous iron, considerably more $\mathrm{Mg}^{++}$than is present in usual cement formulations, and, possibly, dispersed iron metal and iron sulfide. $\mathrm{Mg}^{++}$is known to react with $\mathrm{C}-\mathrm{S}-\mathrm{H}$ to form $\mathrm{Mg}(\mathrm{OH})_{2}$ and thus destroy the main cohesive phase of concretes. The oxidation of $S$ and Fe could cause significant volumetric changes. 


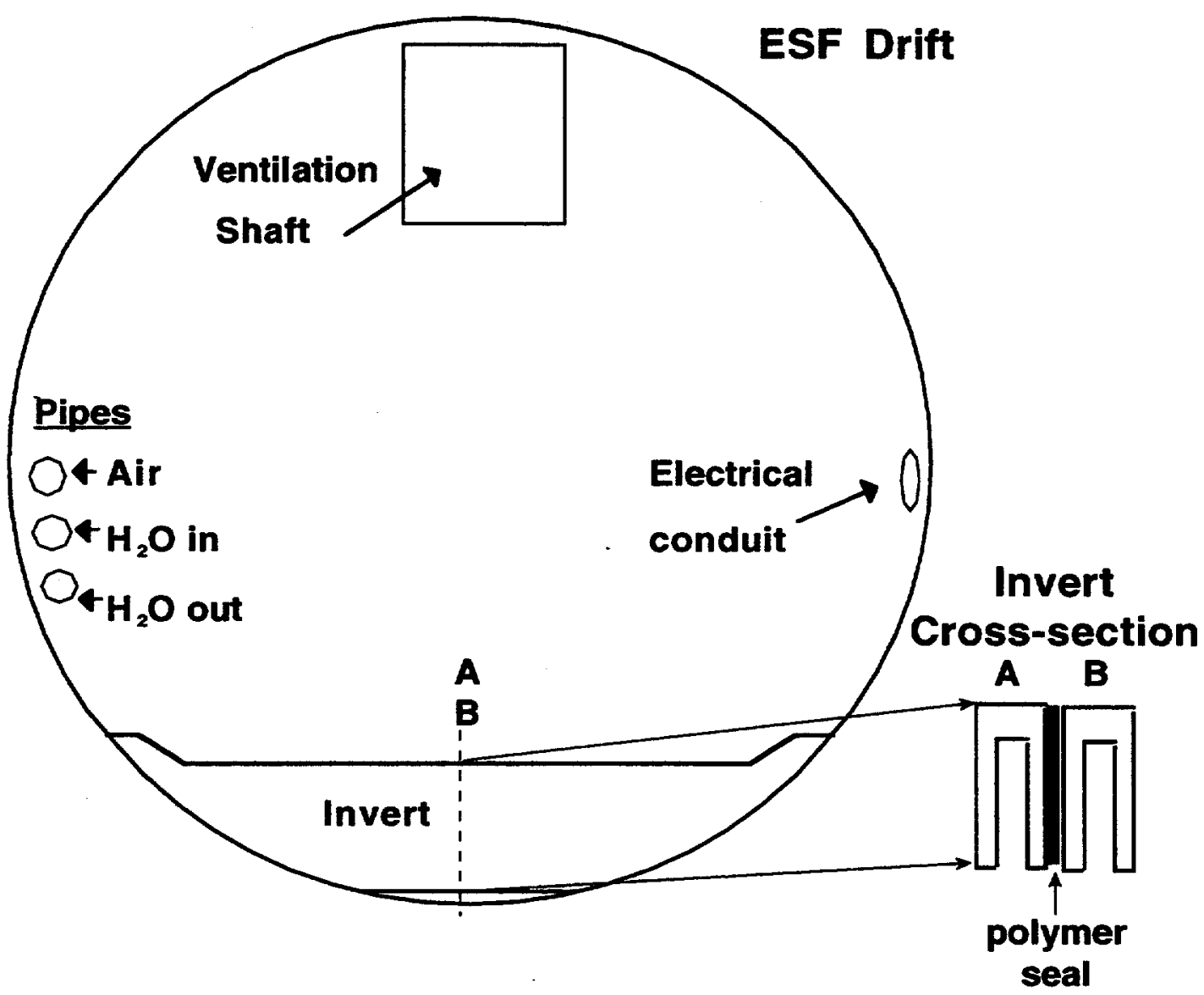

Figure 6-1. Schematic view (not to scale) of ESF drift cross-section illustrates the placement of some materials. The shape of the invert is illustrated in tunnel cross-section, and the invert cross-section parallel to the tunnel axis.

1995 Water Input v. Tunnel Progress

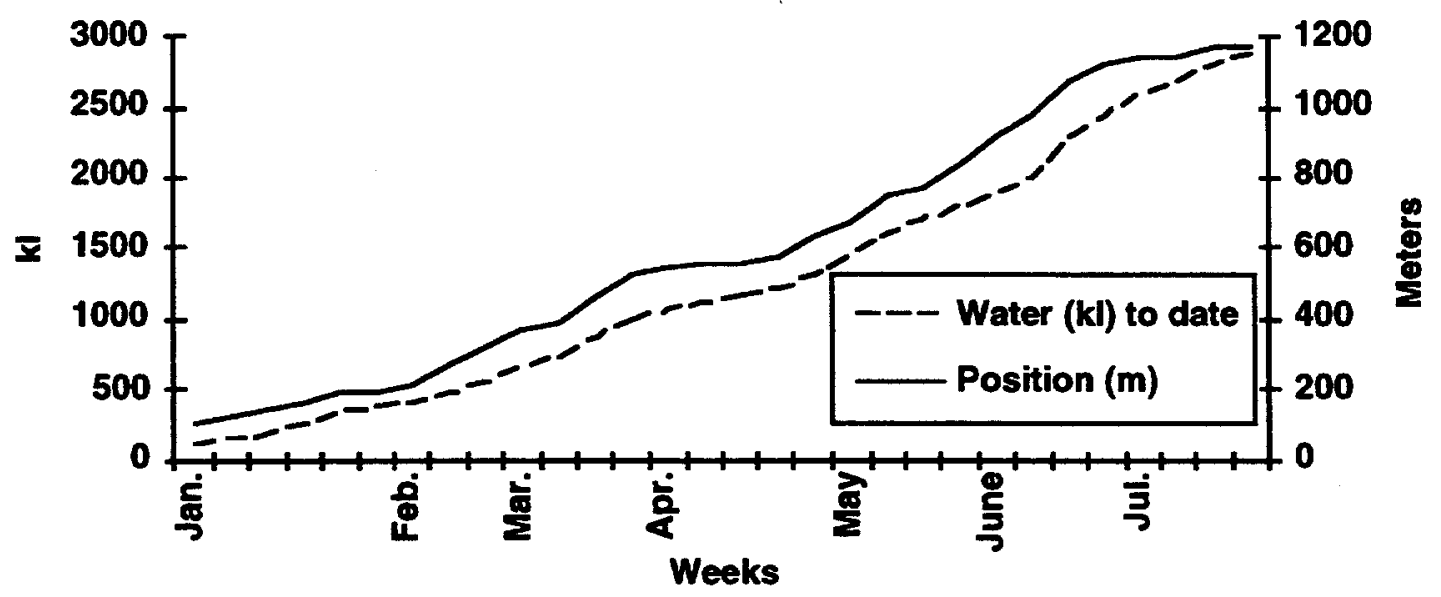

Figure 6-2. Total water usage and total meters excavated are plotted as a function of time. It is clear that the limit specified in the DIE, no more than 7.4 cubic meters of water per linear meter of tunnel excavated, has not been exceeded. Total water usage to date averages roughly $2.47 \mathrm{~kL} / \mathrm{m}$. 
(a)

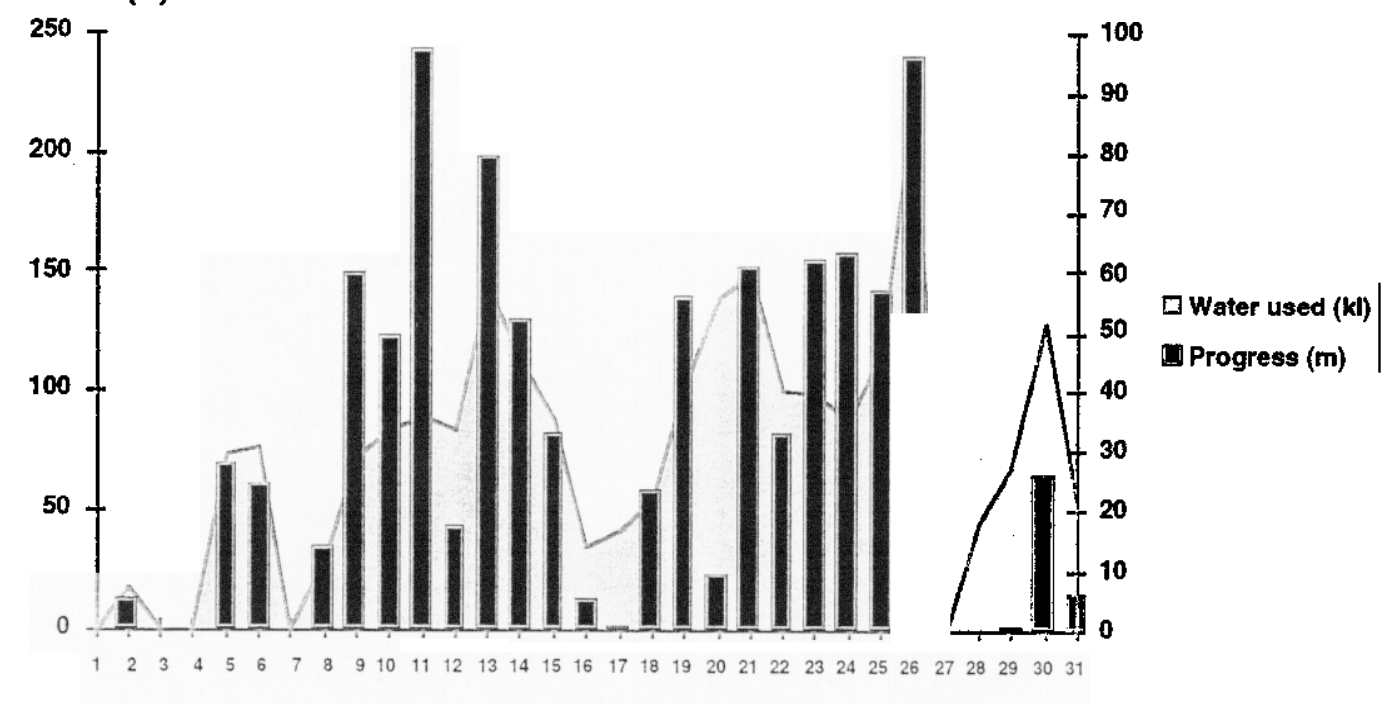

Weekly Water Usage $1995(\mathrm{kl} / \mathrm{m})$

(b)
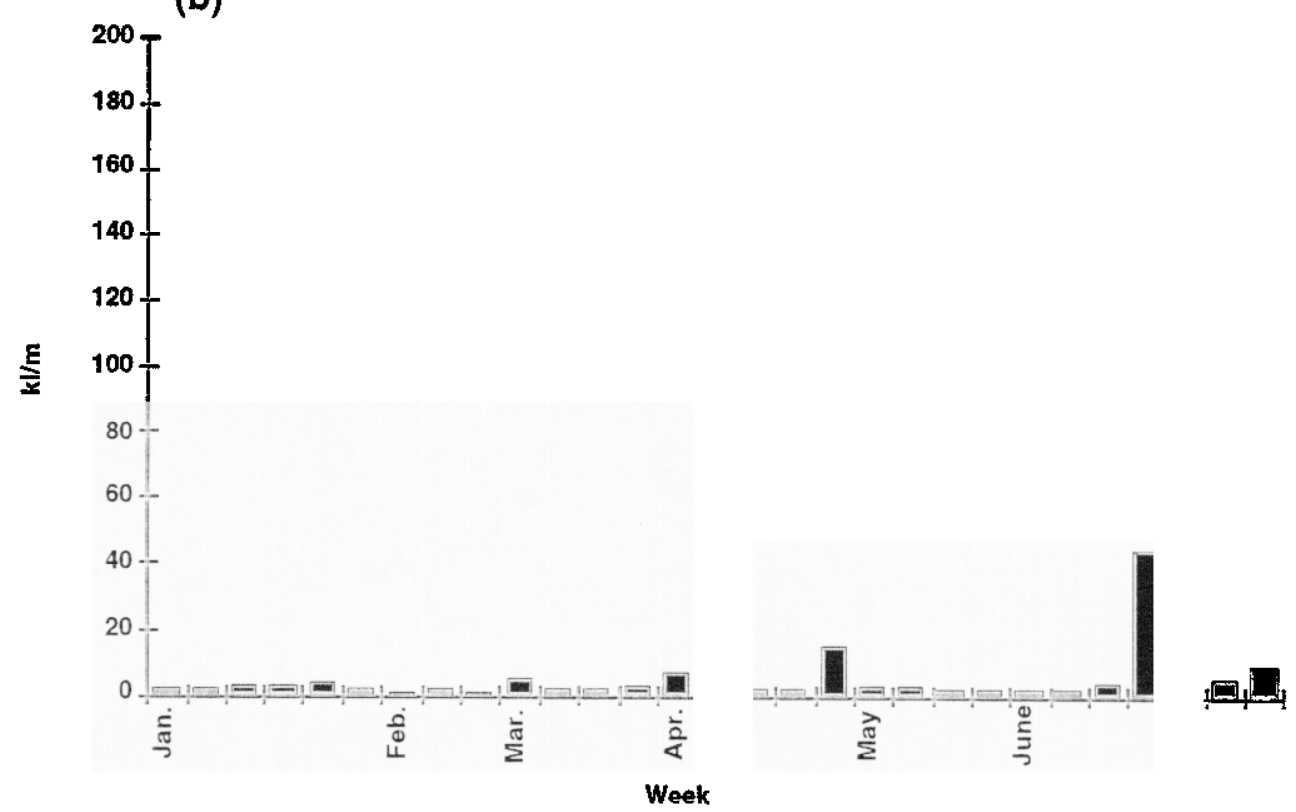

Figure 6-3. (a) A plot of weekly water usage and weekly excavation progress as a function of time suggests a strong correlation between water usage and excavation progress. (b) A plot of water usage as a function of time demonstrates that an average amount of water usage of between 2 and $4 \mathrm{~kL} / \mathrm{m}$ is punctuated by episodes of large water usage. 


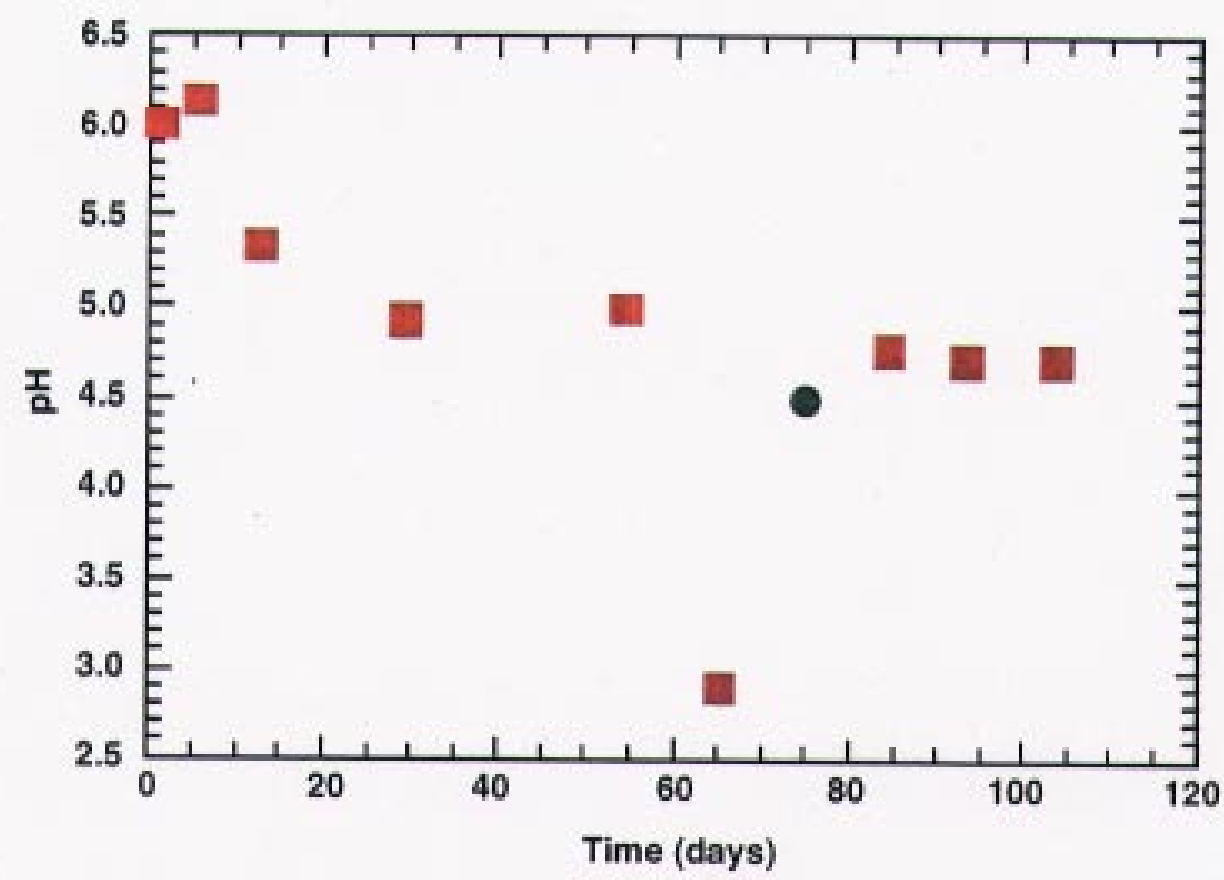

Figure 6-4. Experimental $\mathrm{pH}\left(25^{\circ} \mathrm{C}\right)$ as a function of time from diesel fuel hydrous pyrolysis experiments DF1 at $200^{\circ} \mathrm{C}$ (circle) and DF2 at $315^{\circ} \mathrm{C}$ (squares).

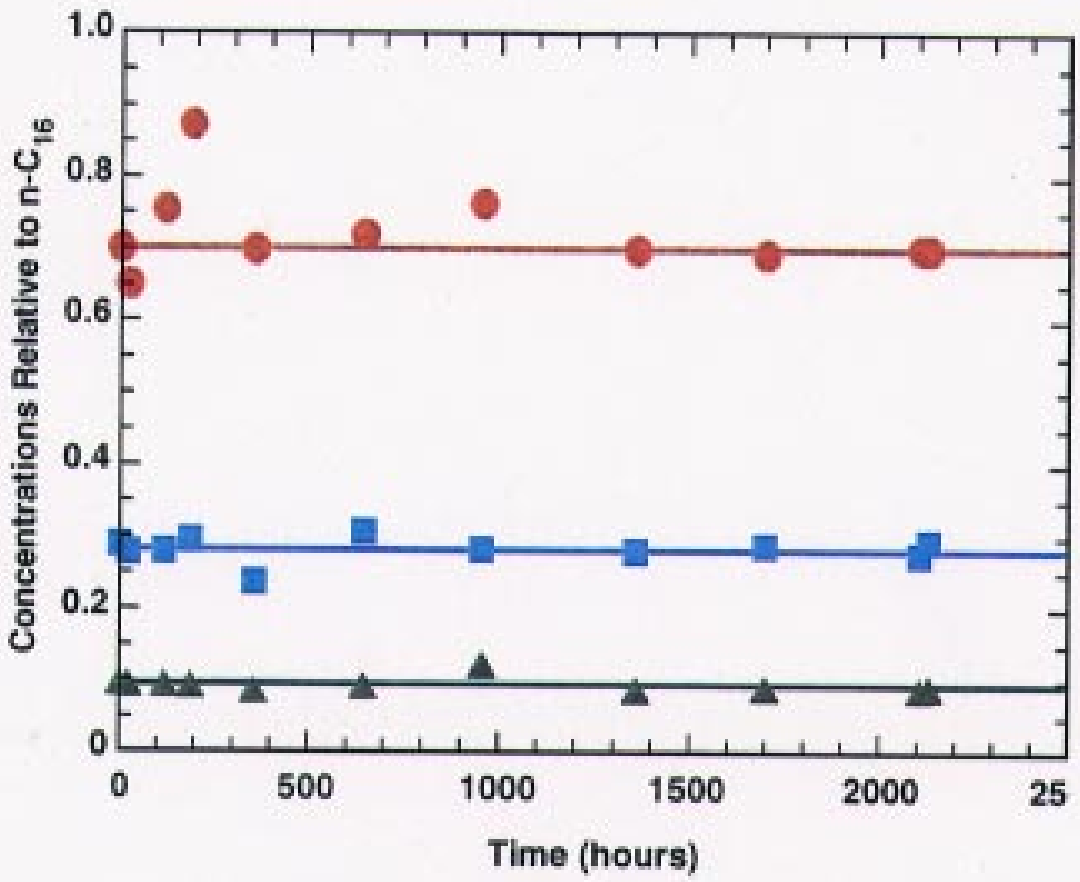

Figure 6-5. Diesel fuel relative concentrations of $C_{10-14}$ normalized with respect to $C_{16}$ as a function of time for experiment DF1. The circles, squares, and triangles are alkanes, $C_{14}, C_{12}$, and $C_{10}$ respectively. 


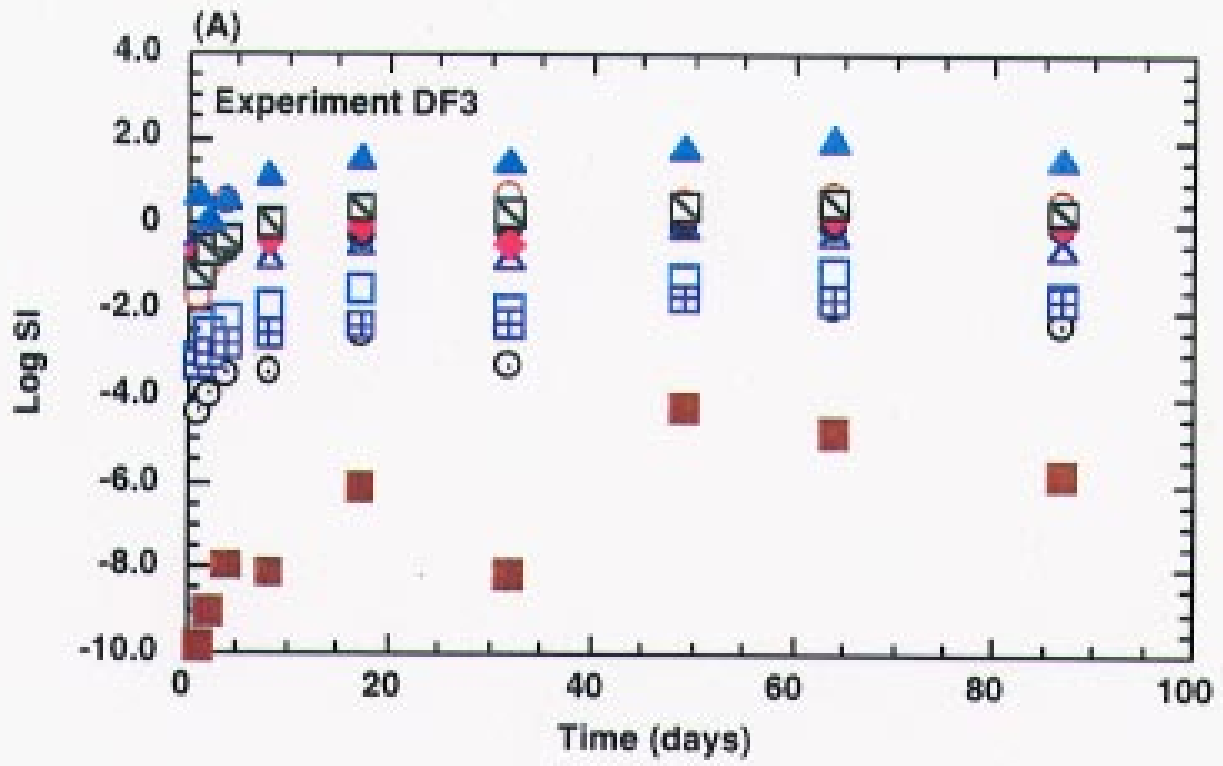

(B)

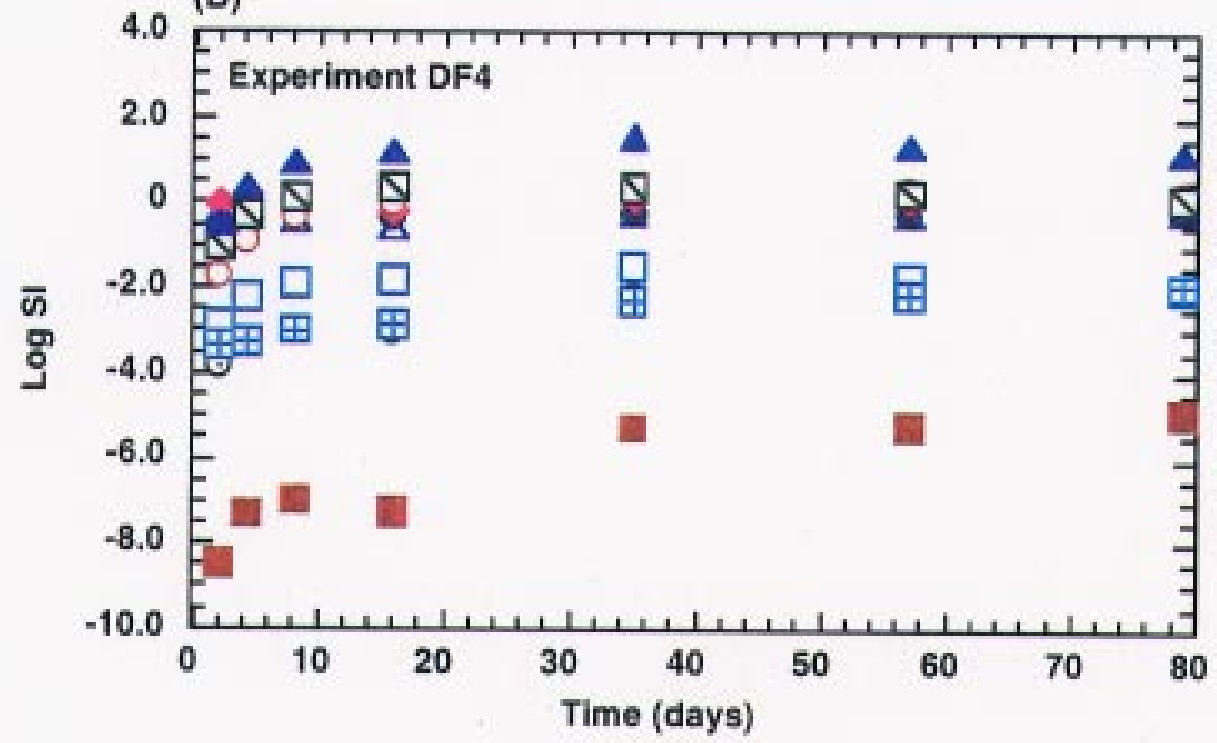

Figure 6-6. Experiment DF3 (A) and DF4 (B) Fibercrete ${ }^{7 x}$-wvater interactions plotted as the log SI with respect to quartz (solid circle), wollastonite (solid diamond), K-feldspar (square with a slash), albite (open circle), anorthite (open square), calcite (open triangle), mesolite (solid triangle), gyrolite (open circle with center dot), $11 \hat{A}$-tobermorite (solid square), and bassanite (open square with cross). The saturation index (SI) is equal to the IAP / $\mathrm{K}_{\text {eq }}$ for a given mineral. A log SI greater than, equal to, or less than zero, indicates that the solution is supersaturated, saturated, or undersaturated respectively in regard to a given mineral, where LAP is the ion activity product and $\mathrm{K}_{\mathrm{eq}}$ is the equilibrium constant. 


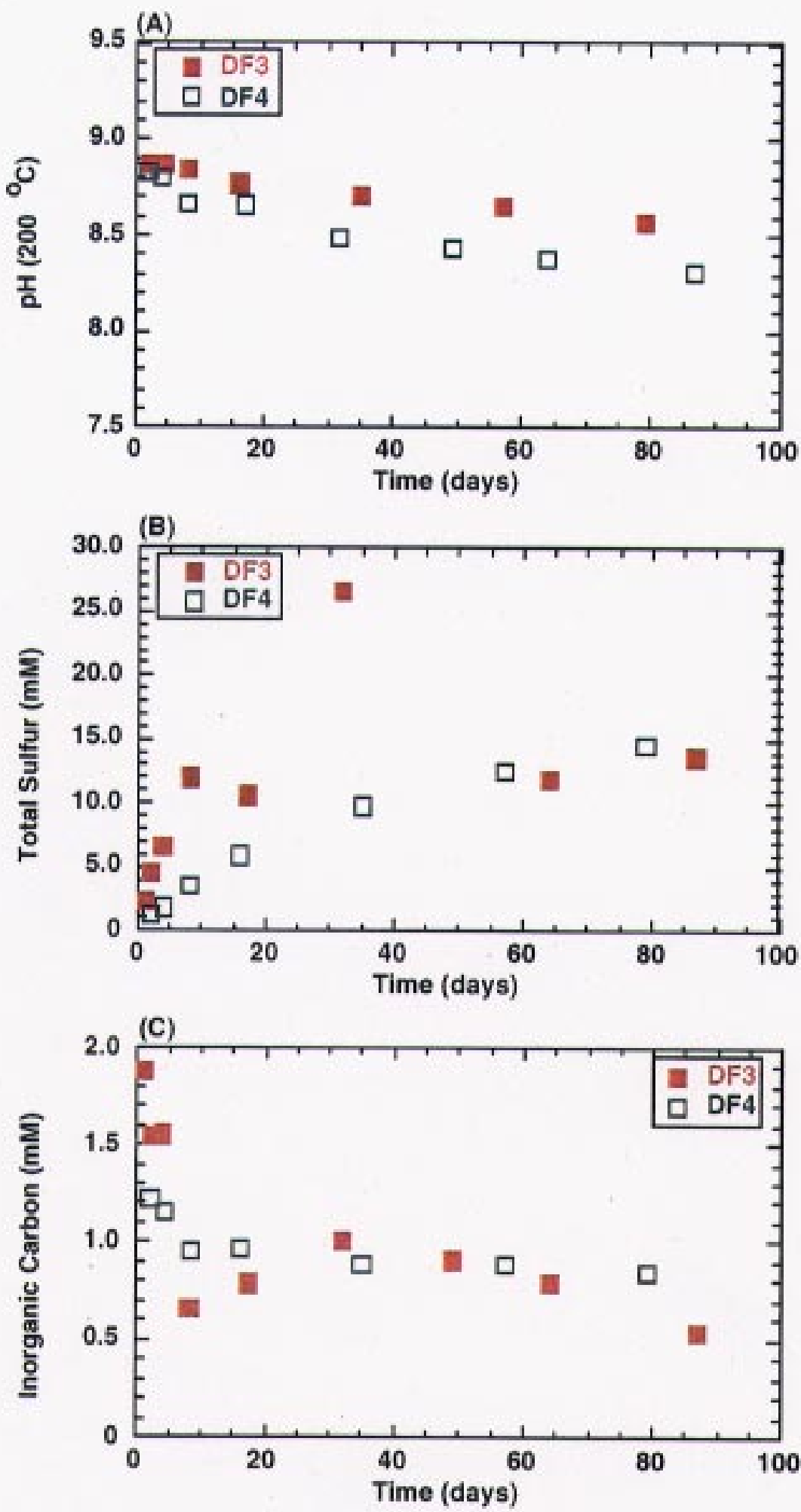

Figure 6-7. Aqueous composition of experiments DF3 and DF4. (A) pH (200 $\left.{ }^{\circ} \mathrm{C}\right),(\mathrm{B})$ total sulfur, and (C) inorganic carbon are plotted as a function of time. 


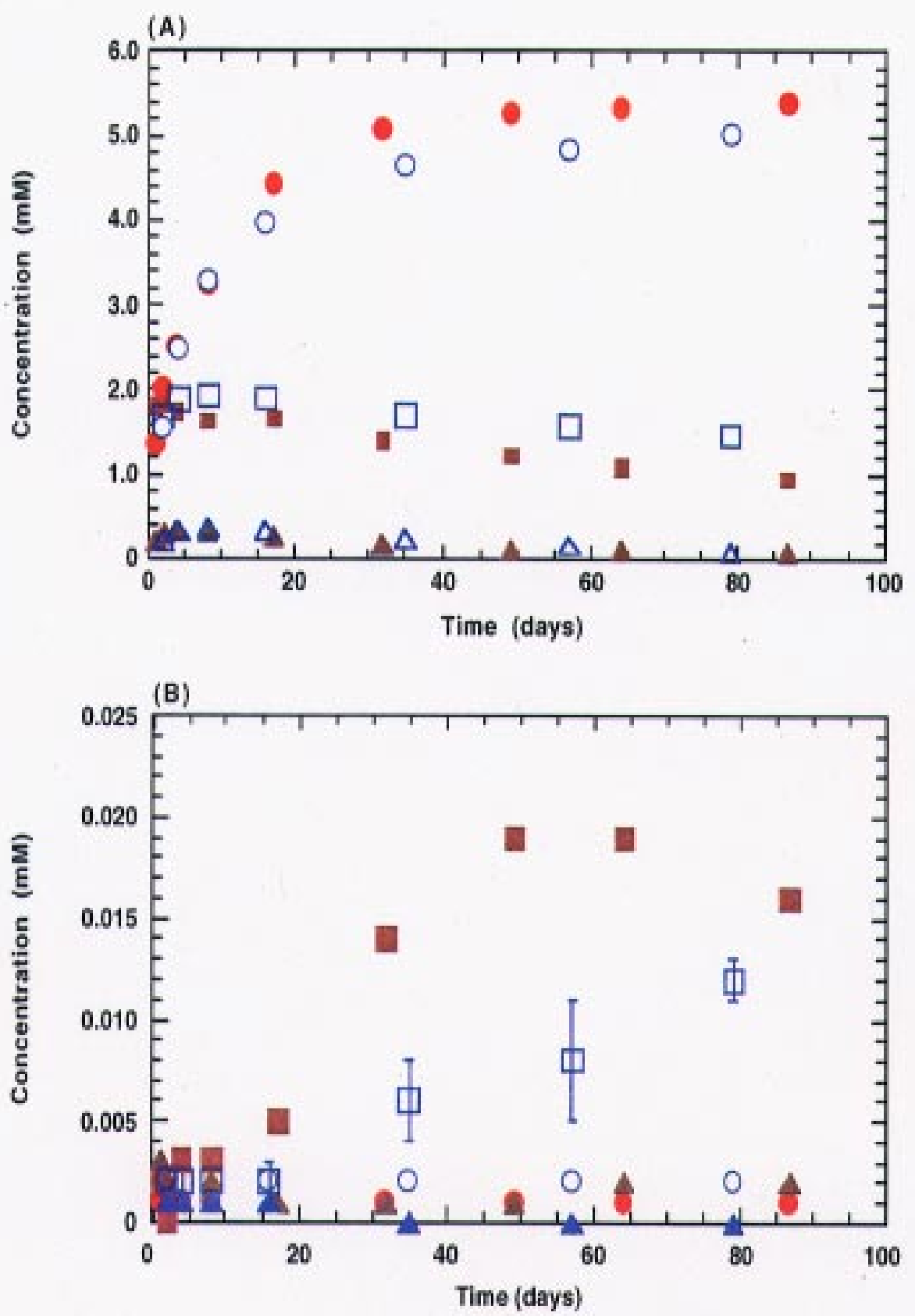

Figure 6-8. Aqueous composition of experiment DF3 (solid symbols) and DF4 (open symbols) plotted as function of time. (A) Si (circles), $\mathrm{Al}$ (triangles) and $\mathrm{K}$ (squares) and (B) $\mathrm{Ca}$ (squares), $\mathrm{Mg}$ (circles) and Fe (triangles). 


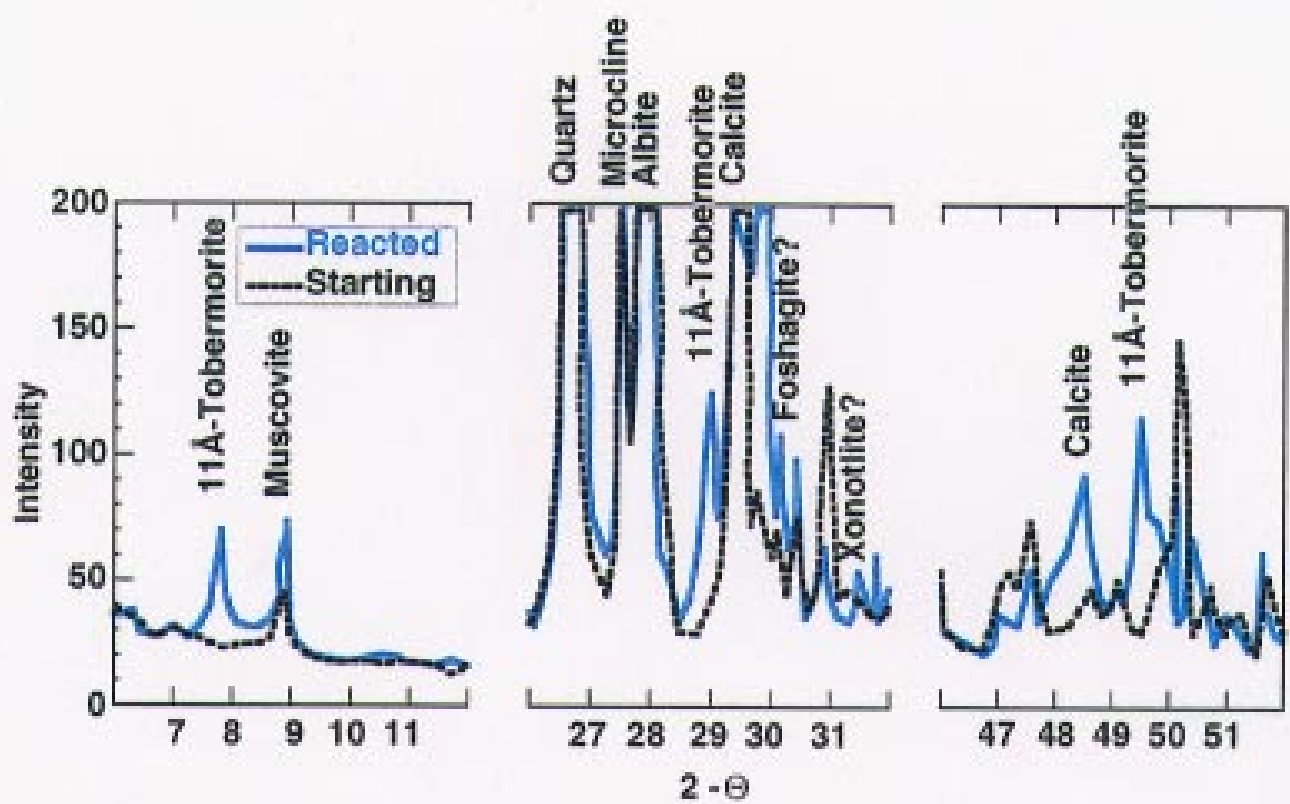

Figure 6-9. XRD pattern showing the three most intense peaks for $11 \dot{A}$-tobermorite in the reacted Fibercrete $^{\mathrm{TM}}$. 

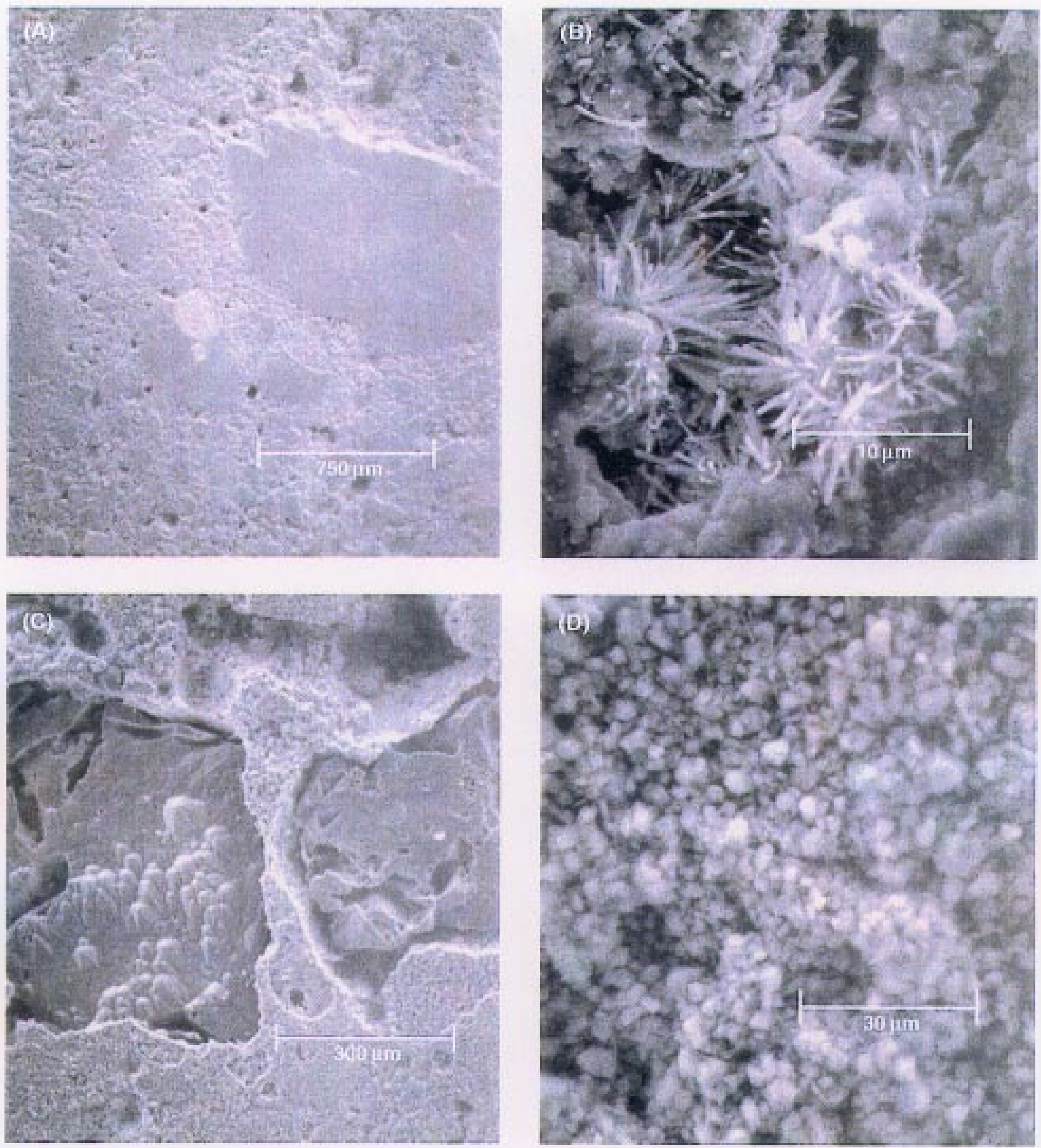

Figure 6-10. SEM photomicrographs of unreacted (A, B) and reacted Fibercrete ${ }^{\text {TM }}$ (C, D). (A) Fibercrete ${ }^{\text {TM }}$ consists of large quartz and feldspar aggregate minerals and steel fibers (light area near center) in a grout matrix. (B) Magnification of the grout matrix showing crystallites. (C) Reacted Fibercrete ${ }^{\mathrm{TM}}$ showing both dissolution precipitation features on the quart 2 aggregate minerals and the precipitation of $\mathrm{Ca}$-rich phase at the Fibercrete ${ }^{1 \mathrm{M}}$ surface. (D) Enlargement of the Ca-rich phase showing blocky morphology. 



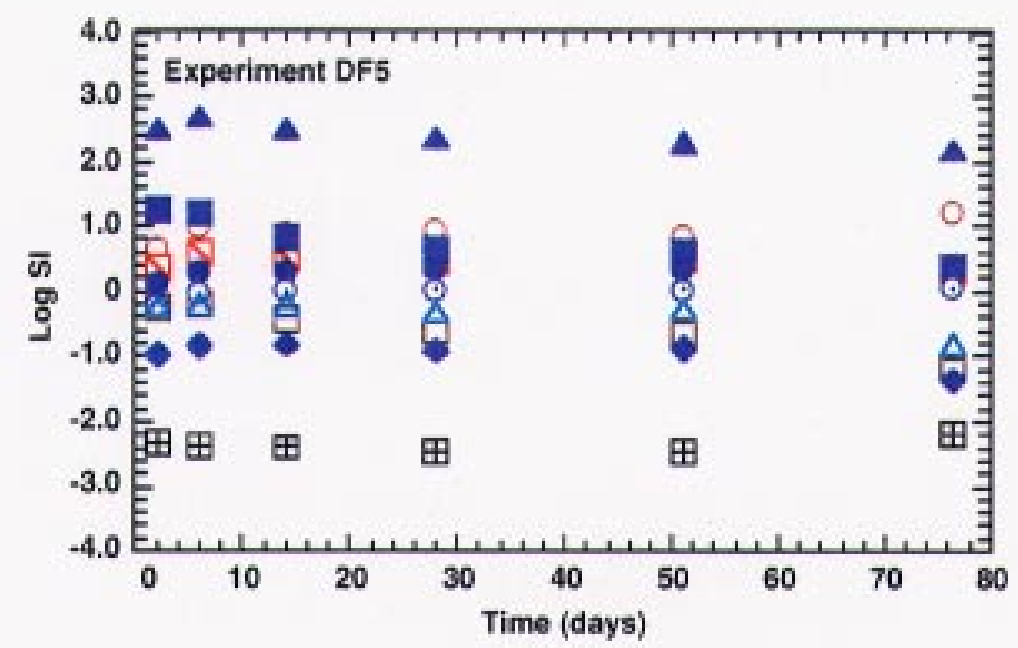

Figure 6-11. Experiment DF5. Topopah Spring tuff - water - diesel fuel interactions plotted as the log SI with respect to quartz (solid circle), cristobalite (open circle with center dot), wollastonite (solid diamond), K-feldspar (square with a slash), albite (open circle), anorthite (open square), muscovite (solid square), calcite (open triangle), mesolite (solid triangle), and bassanite (open square with cross). 


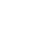



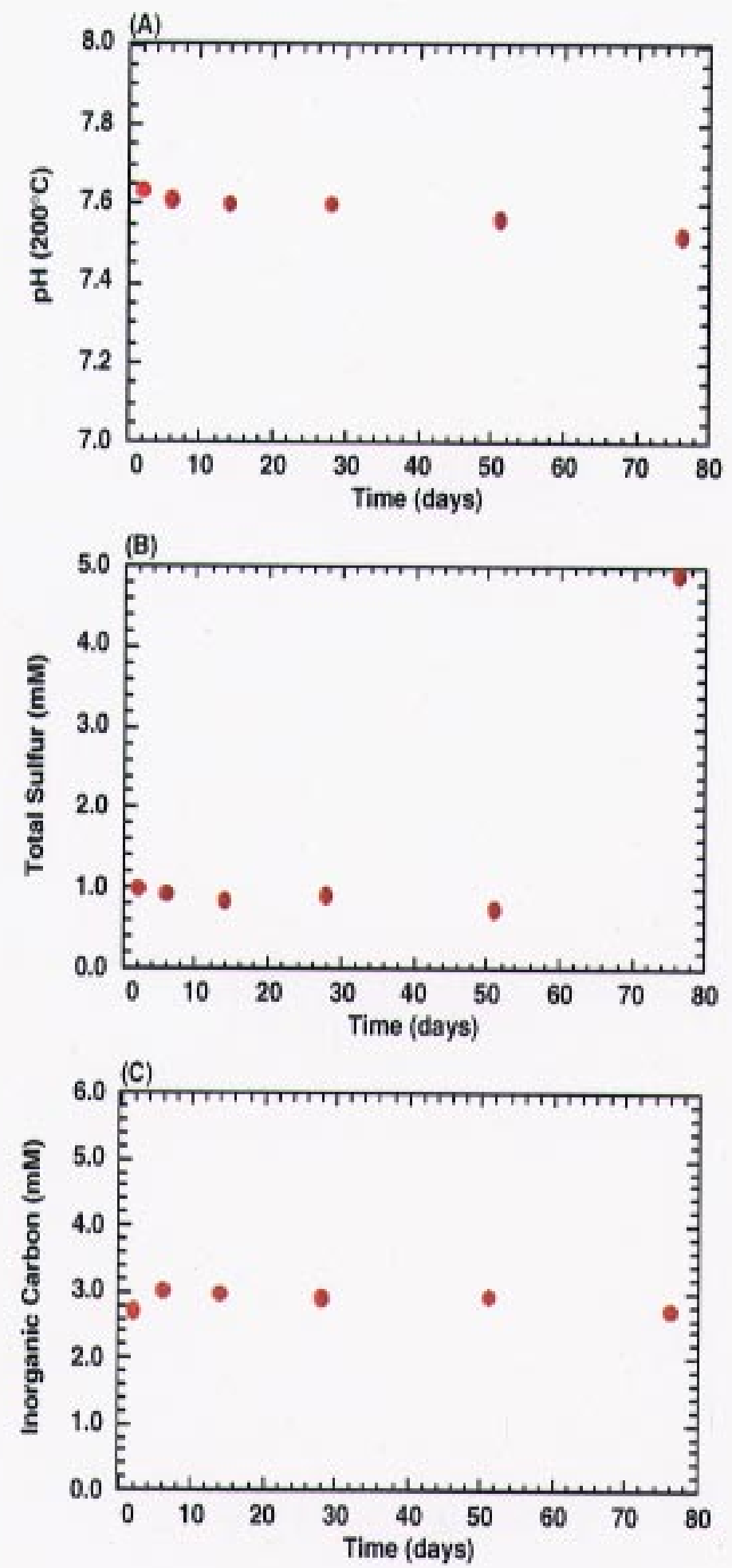

Figure 6-12. Aqueous (A) $\mathrm{pH}\left(200^{\circ} \mathrm{C}\right.$ ), (B) total sulfur, and (C) inorganic carbon of experiment DF5 plotted as a function of time. 


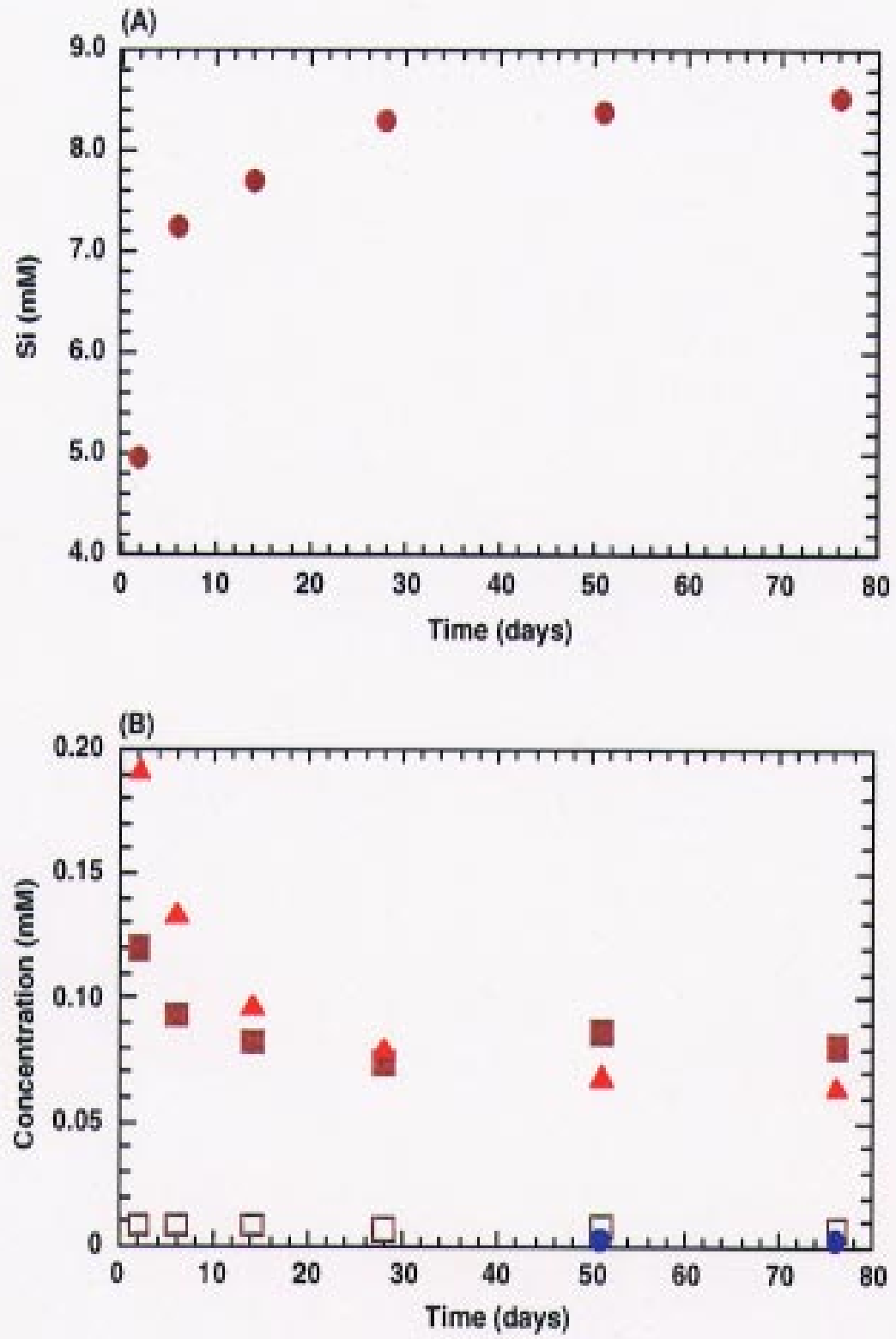

Figure 6-13. Aqueous (A) Si (circles) (B) Al (triangles), K (squares), $\mathrm{Ca}$ (open squares), and $\mathrm{Mg}$ (circles) of experiment DF5 plotted as function of time. 

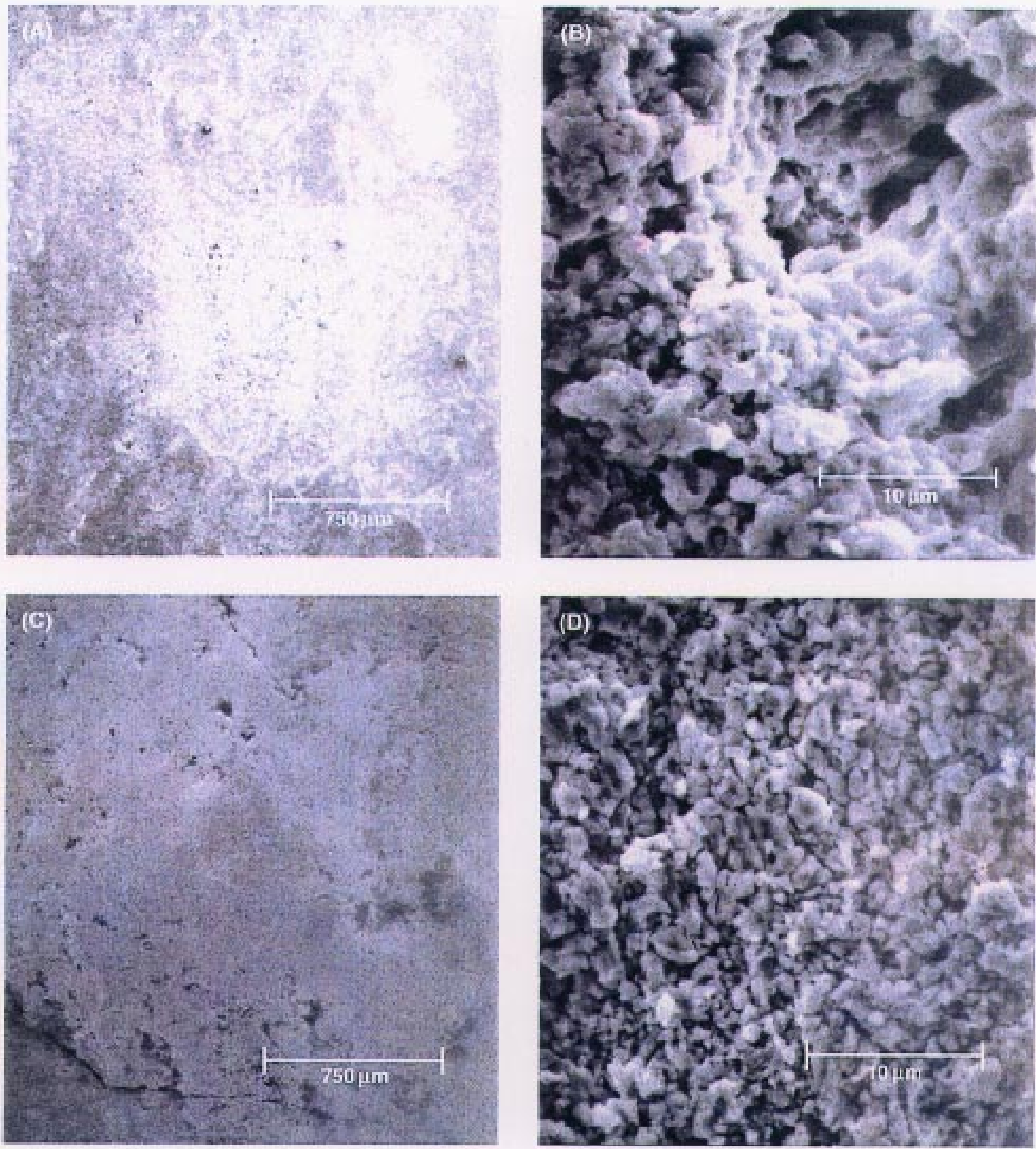

Figure 6-14. SEM photomicrographs of unreacted (A, B) and reacted Topopah Spring tuff (C, D). (B) Magnification of the glassy matrix in the tuff. (C) Reacted Topopah Spring tuff showing a precipitated Si-rich phase (D) Enlargement of the Si-rich precipitate. 
, 


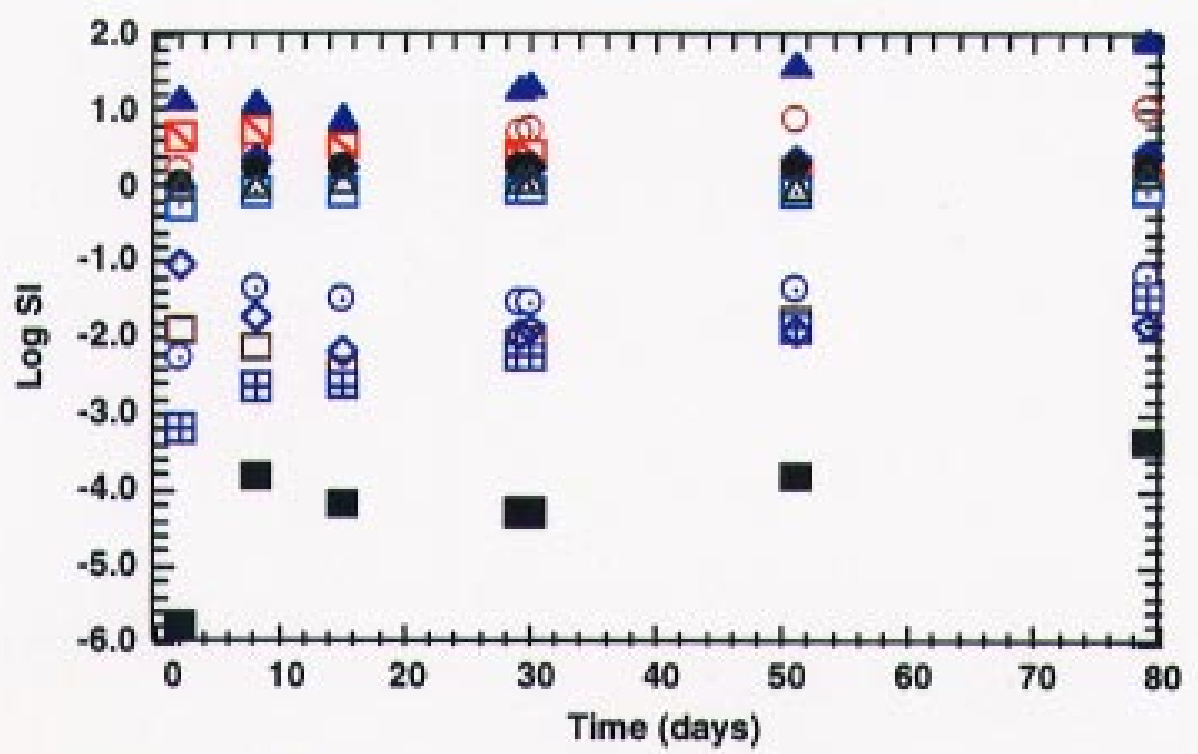

Figure 6-15. Experiment DF6. Topopah Spring tuff - Fibercrete ${ }^{\mathrm{TW}}$-water - diesel fuel interactions plotted as the log SI with respect to quartz (solid circle), cristobalite (open square with center dot), wollastonite (solid diamond), K-feldspar (square with a slash), albite (open circle), anorthite (open square), muscovite (open diamond), calcite (open triangle), mesolite (solid triangle), bassanite (open square with cross), gyrolite (open circle with center dot), and $11 \AA$-tobermorite (solid square). 

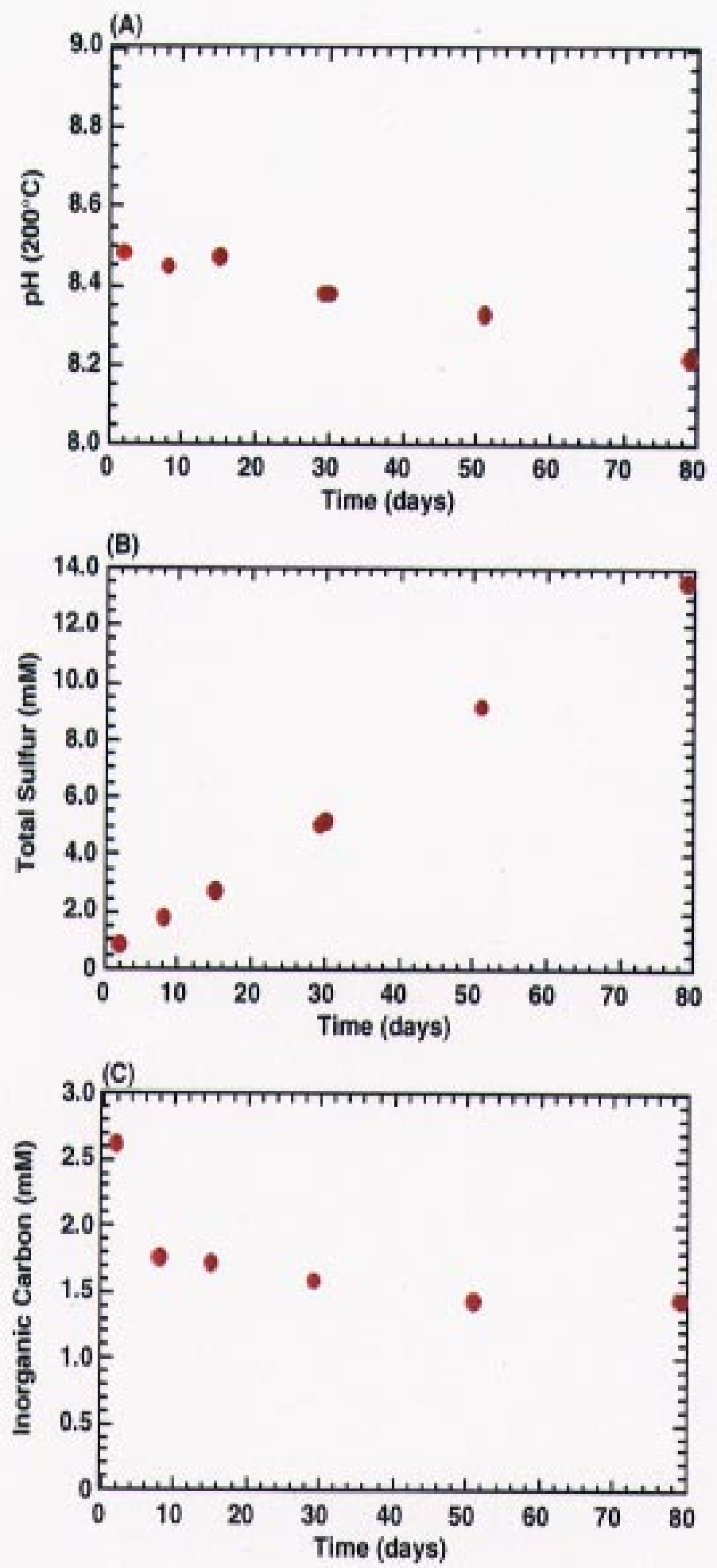

Figure 6-16. Aqueous (A) pH (200 $\left.{ }^{\circ} \mathrm{C}\right)$, (B) total sulfur, and (C) inorganic carbon of experiment DF6 plotted as a function of time. 


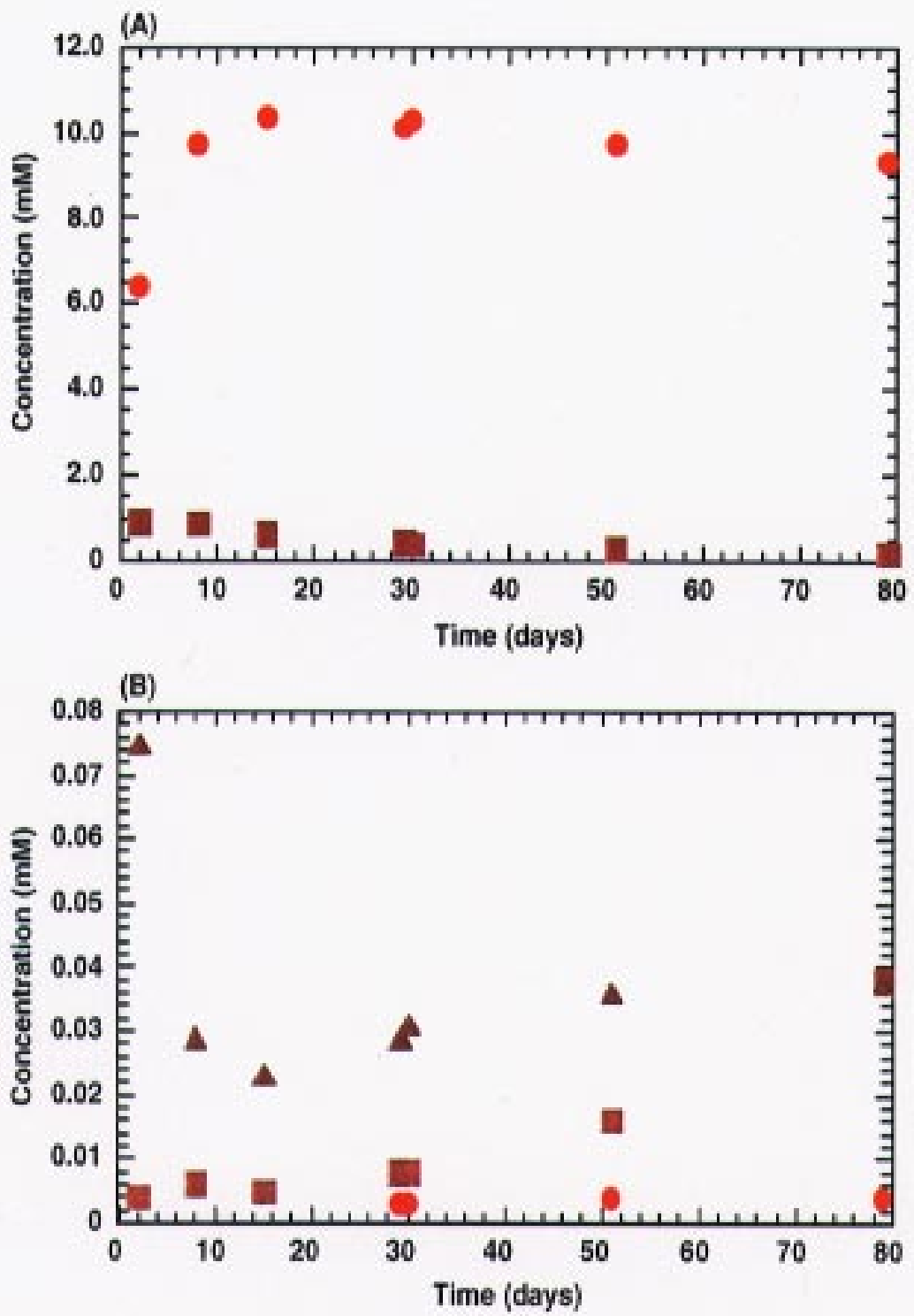

Figure 6-17. Composition of aqueous phase plotted as function of time, experiment DF6. (A) Si (circles) and $\mathrm{K}$ (squares) (B) $\mathrm{Al}$ (triangles), $\mathrm{Ca}$ (squares), and $\mathrm{Mg}$ (circles). 


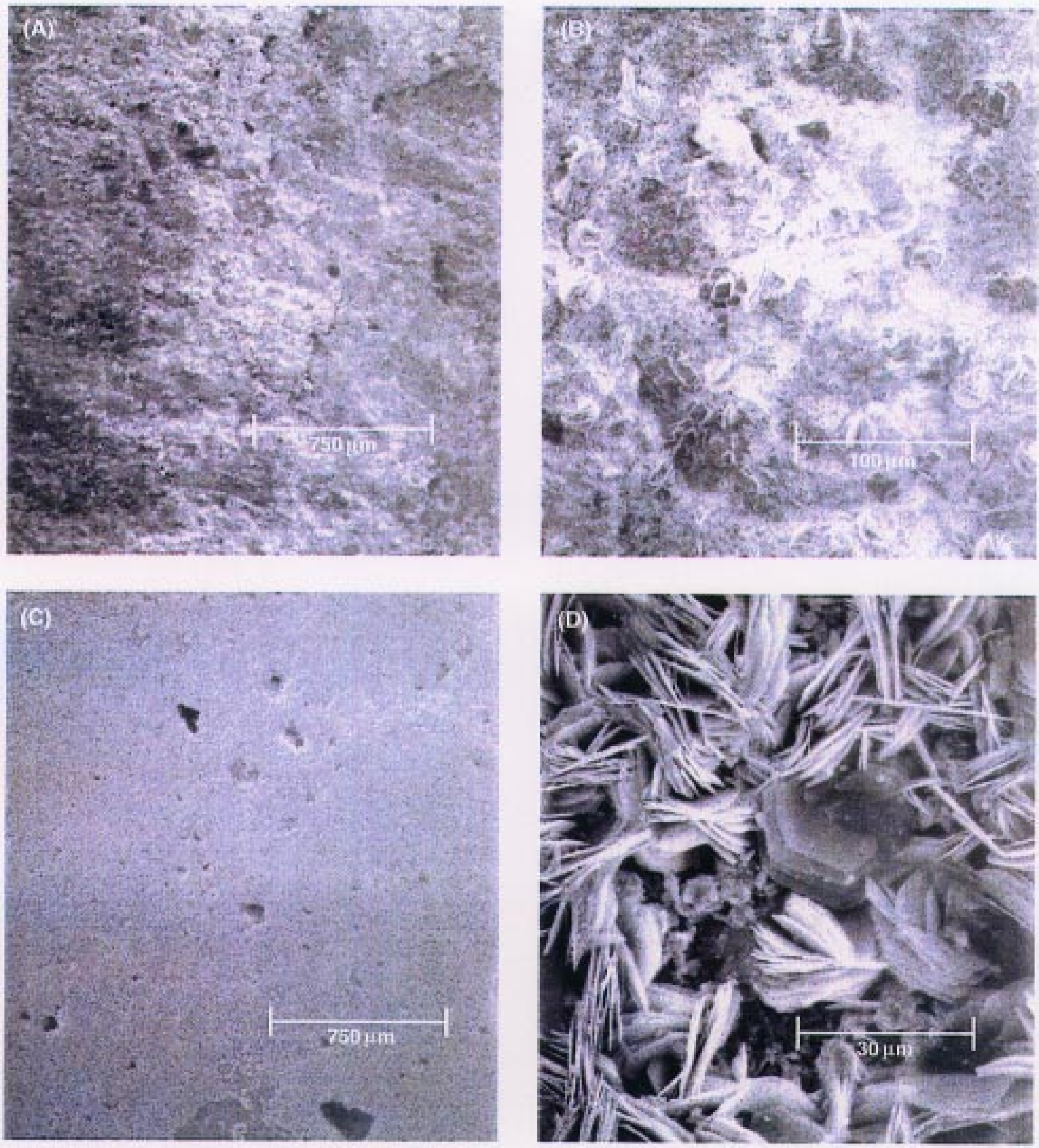

Figure 6-18. SEM photomicrographs from experiment DF6 of reacted Topopah Spring tuff (A, B) and reacted Fibercrete ${ }^{\text {TM }}$ (C, D). (B) Enlargement of the precipitates that form on the tuff surface, showing books of layered $\mathrm{Ca}$-silicate, calcite rhombs, and smaller pure silicate precipitate which may be cristobalite. (D) Enlargement of the Ca-silicate phase found on the reacted Fibercrete ${ }^{\text {TM }}$ surface. 


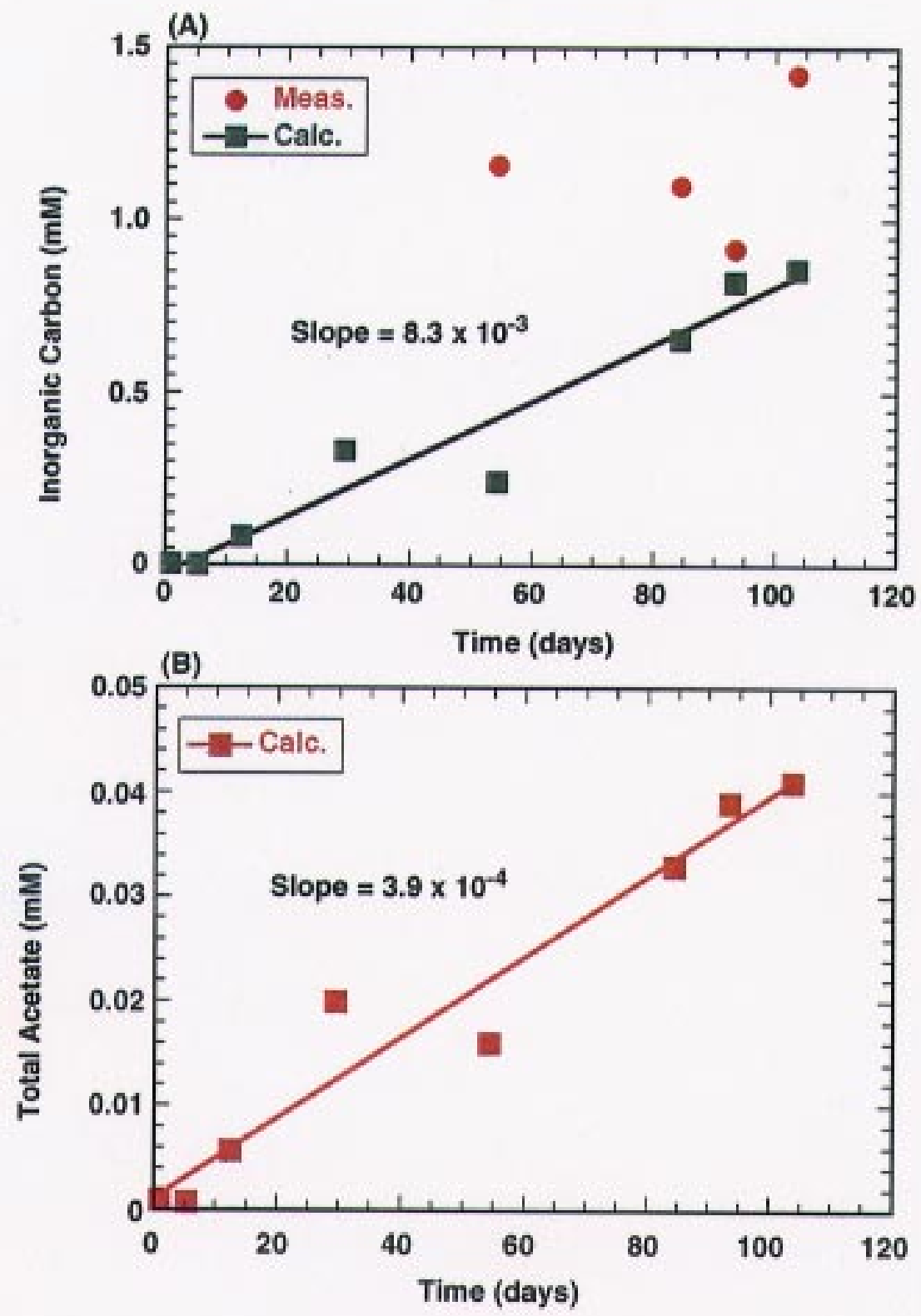

Figure 6-19. The calculated (A) inorganic carbon concentration, and (B) total acetate concentration in a solution of changing $\mathrm{pH}$ as a function of time. See text for detailed description of the assumptions and calculations. 


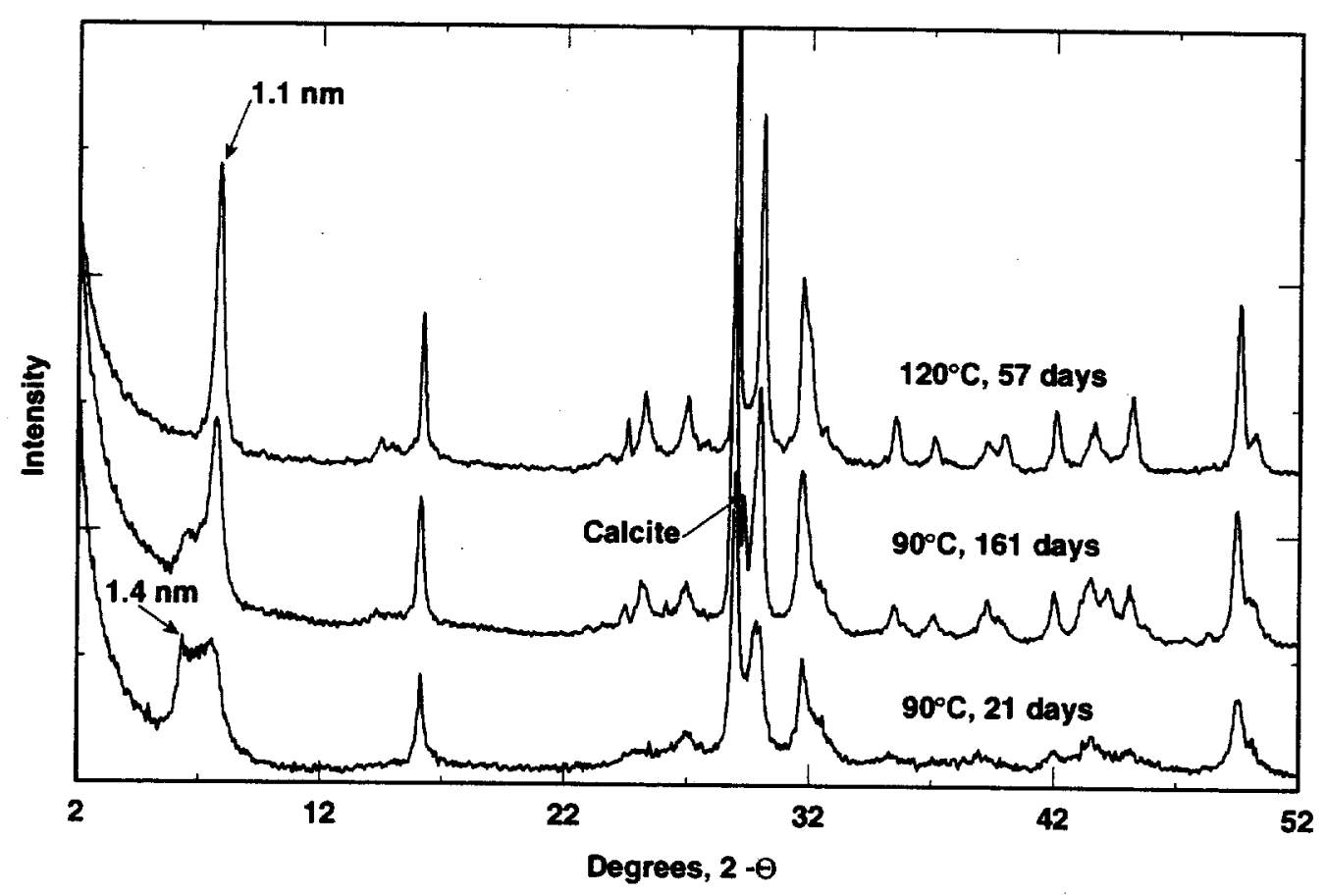

Figure 6-20. XRD patterns of tobermorite run products; the $90^{\circ} \mathrm{C}$ XRD patterns show a peak shift from 1.4 to $1.1 \mathrm{~nm}$ tobermorite with time; the $120^{\circ} \mathrm{C}$ XRD pattern shows only a single phase tobermorite; crystallinity increased with longer run times and higher temperature.

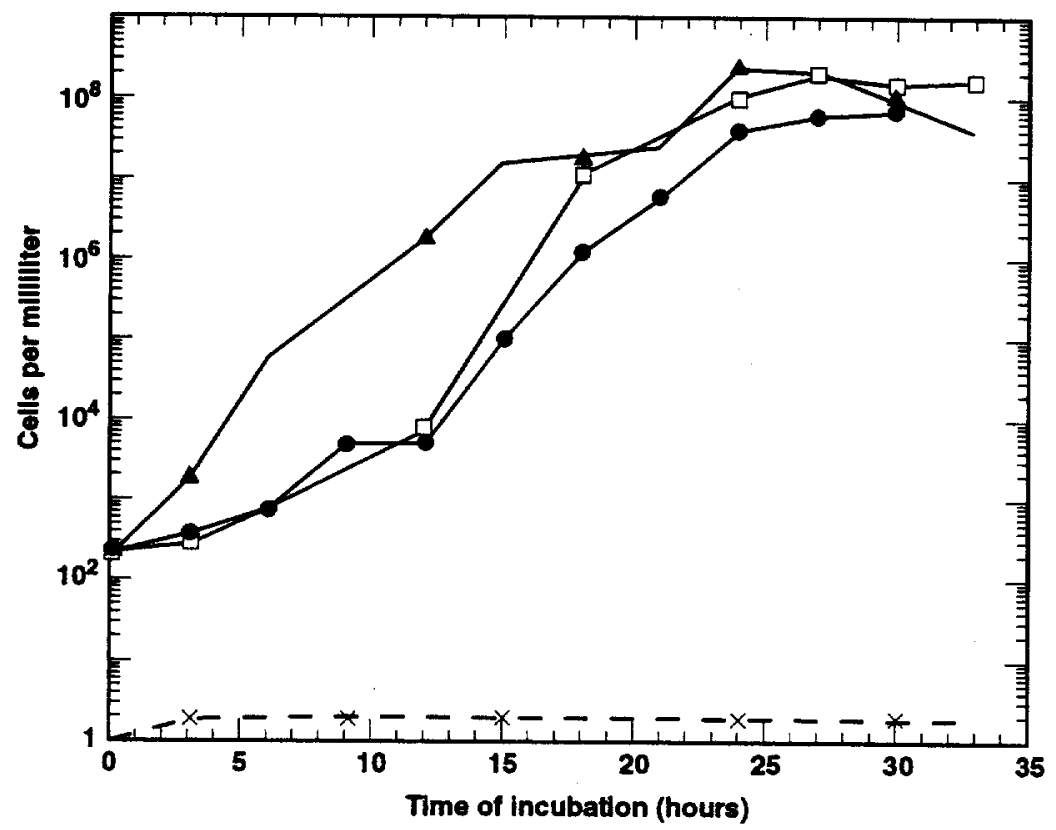

Figure 6-21. Effect of temperature on the growth rates of whole $\mathrm{YM}$ microbial communities in $\mathrm{R} 2$ media. Rates varied depending on temperature of incubation. Crushed $Y M$ tuff was inoculated in media and incubated aerobically at $20^{\circ} \mathrm{C}(\bullet), 30^{\circ} \mathrm{C}(\square)$, or $50^{\circ} \mathrm{C}(\Delta)$. Periodically samples were withdrawn and cell count was determined by live planting $(x)$, sterile uninoculated media incubated at $20^{\circ} \mathrm{C}$. 


\section{Bacteria derived from excavated ESF and Large Block Test rock}

\section{(A) ESF}

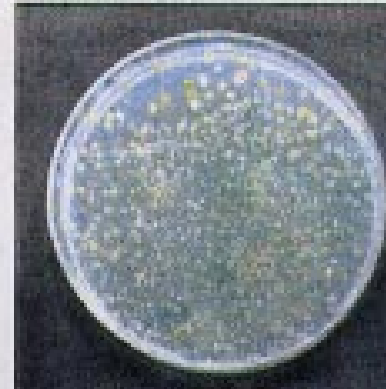

Uncrushed Hack Fines

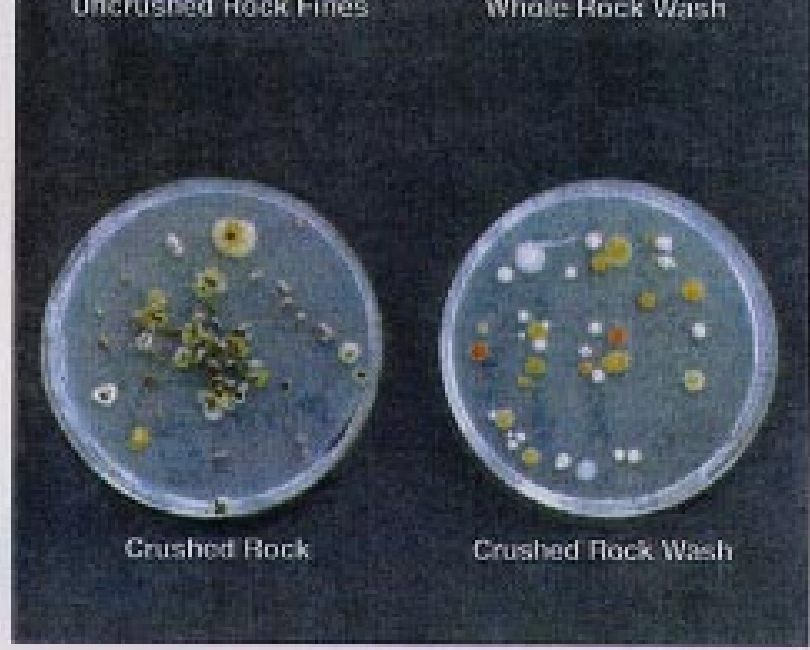

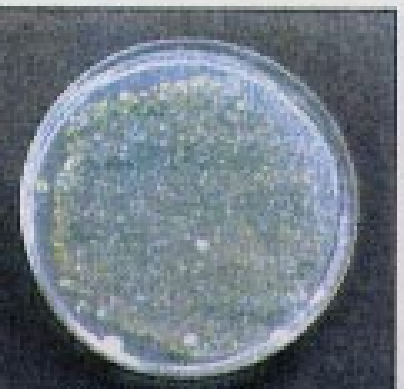

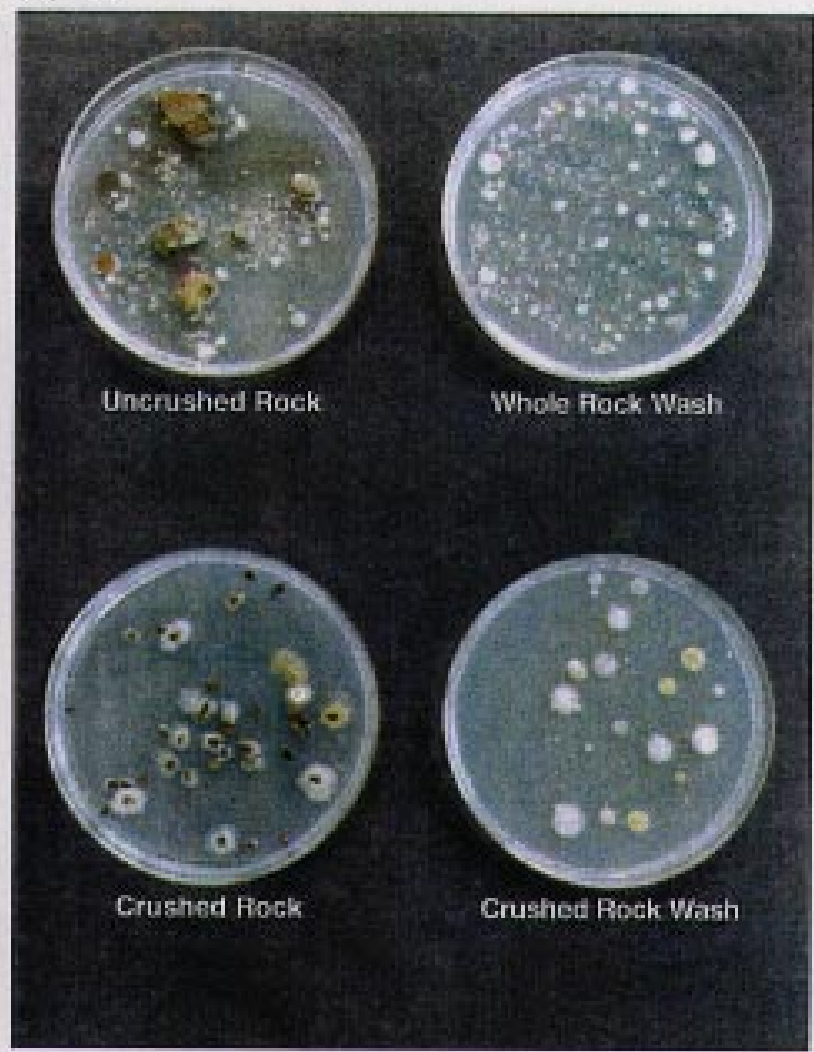

Figure 6-22. Plated samples of whole and crushed rock and rock washes (using sterialized artificial pore water) obtained from (A) the ESF muck pile and (B) the Large Block (LB) Test area suggest that the LB samples show greater culturable species diversity. Future DNA analyses will better indicate total diversity of culturable and unculturable species.
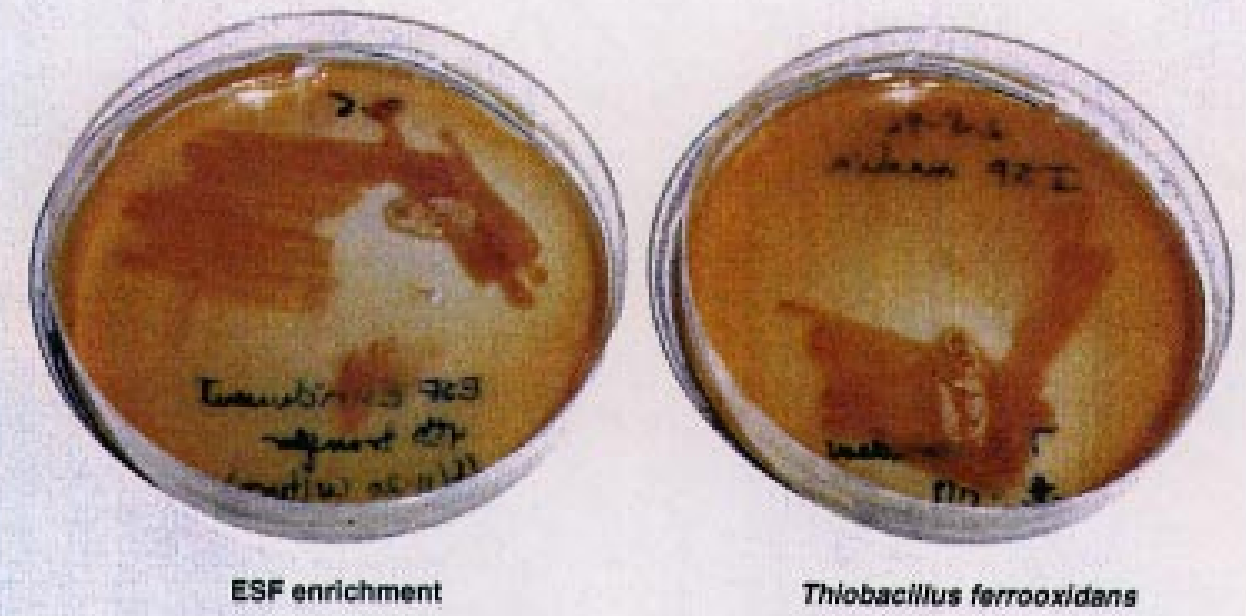

Thiobacillus forrooxidans

Figure 6-23. Screening tests for iron oxidizers indicate that ESF samples produced iron-oxidizing cultures. 



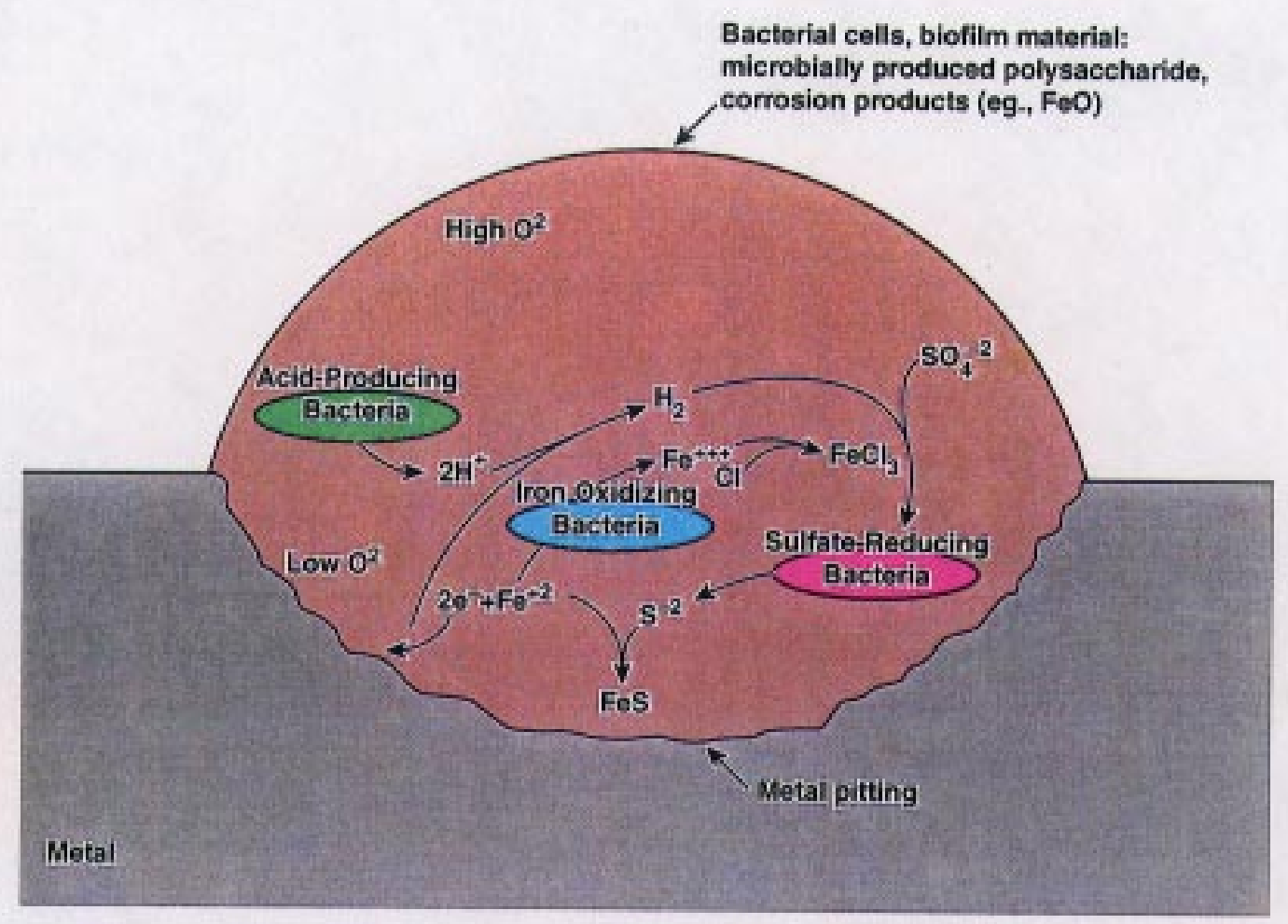

Figure 6-24. Microbially induced corrosion (MIC). Microbially-generated acids directly dissolve the protective calcareous film on stainless steel. Coupling of protons with electrons results in electron removal from the cathode, and forms hydrogen which is a substrate for microbial sulfate reduction.

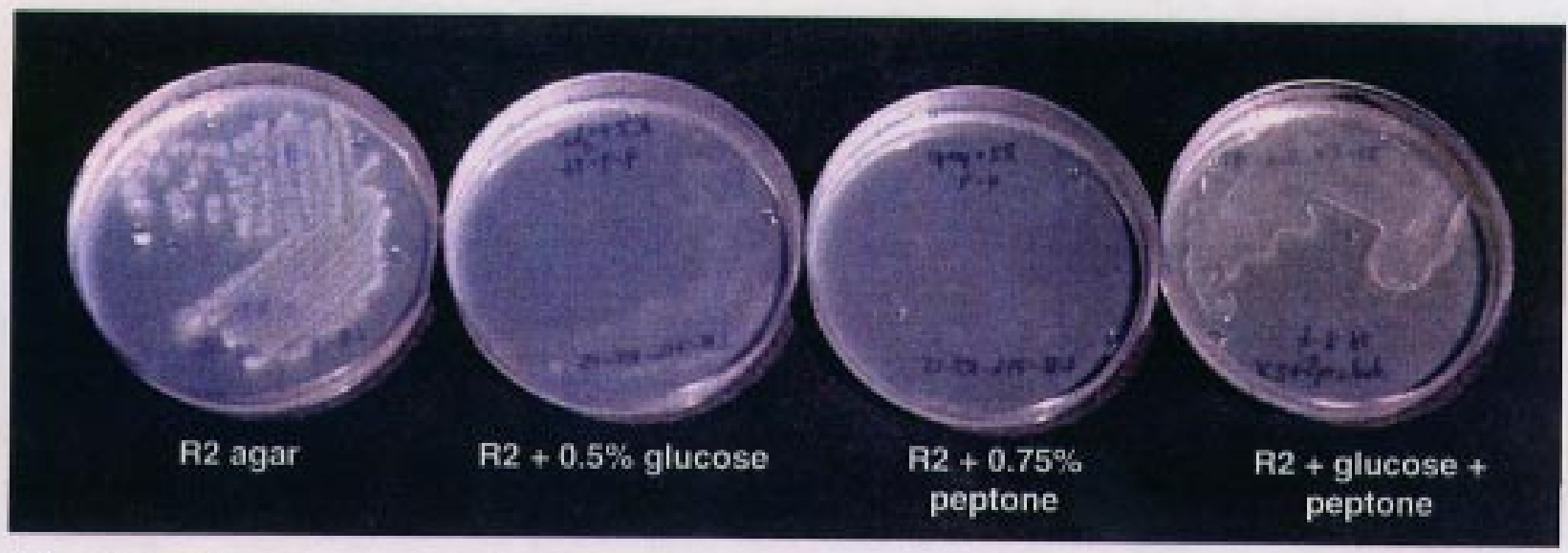

Figure 6-25. Screening tests for slime producers indicate that large quantities of slime can be produced by some bacteria that are extant in the ESF and LB. 


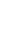



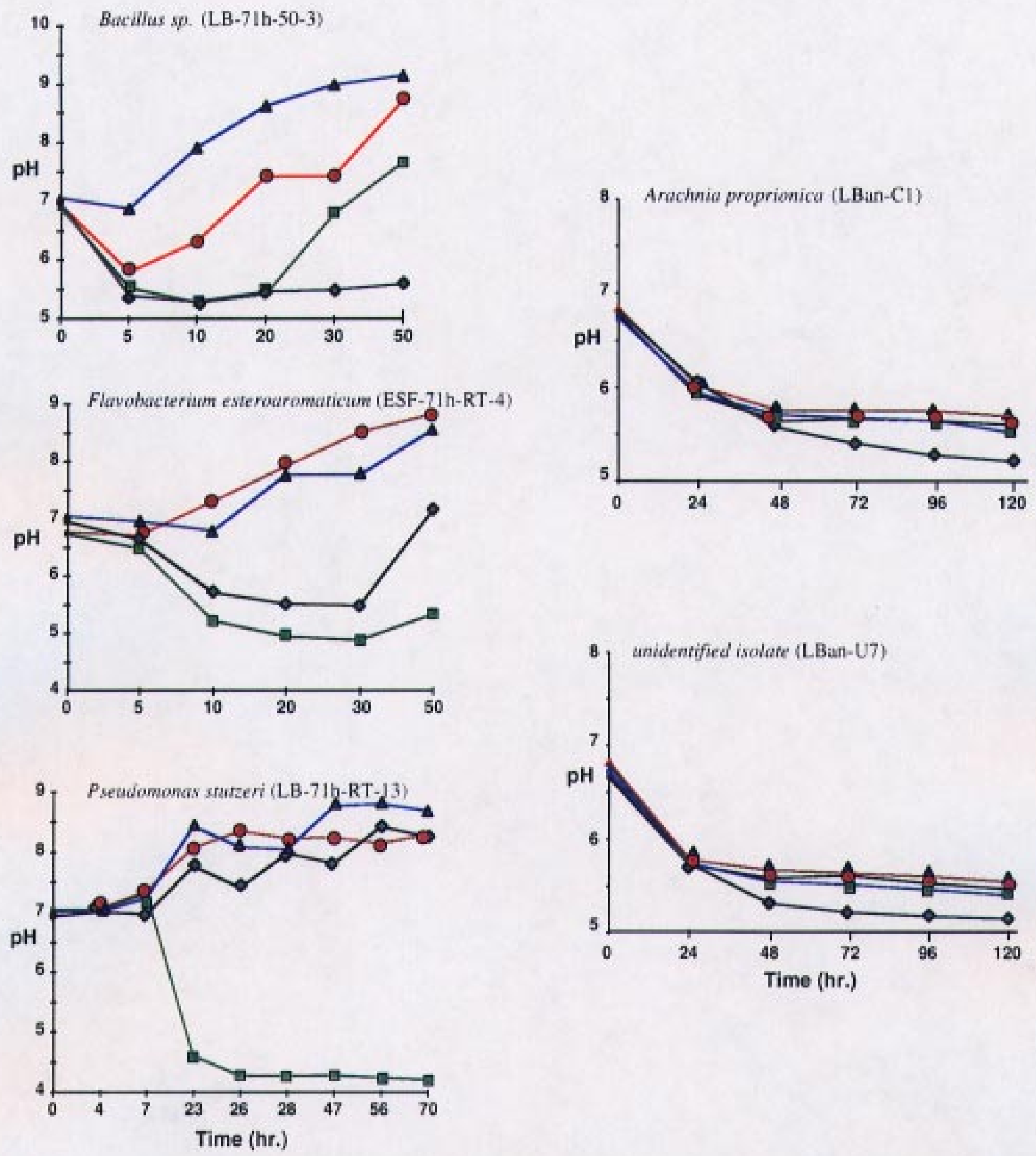

Figure 26. Effect of nutrients and growth on acid production in individual YM isolates. Each indicated isolate was inoculated into $\mathrm{R} 2$ media (e), $\mathrm{R} 2+0.5 \%$ glucose $(\boldsymbol{\Xi}), \mathrm{R} 2+0.75 \%$ proteose peptone $\# 3(\mathbf{\Delta})$, and R2 + glucose and peptone ( $\bullet$ ). Periodically, through subsequent growth the $\mathrm{pH}$ of the media was determined. 

ESF and LB Isolates: Hydrogen Sulfide Production

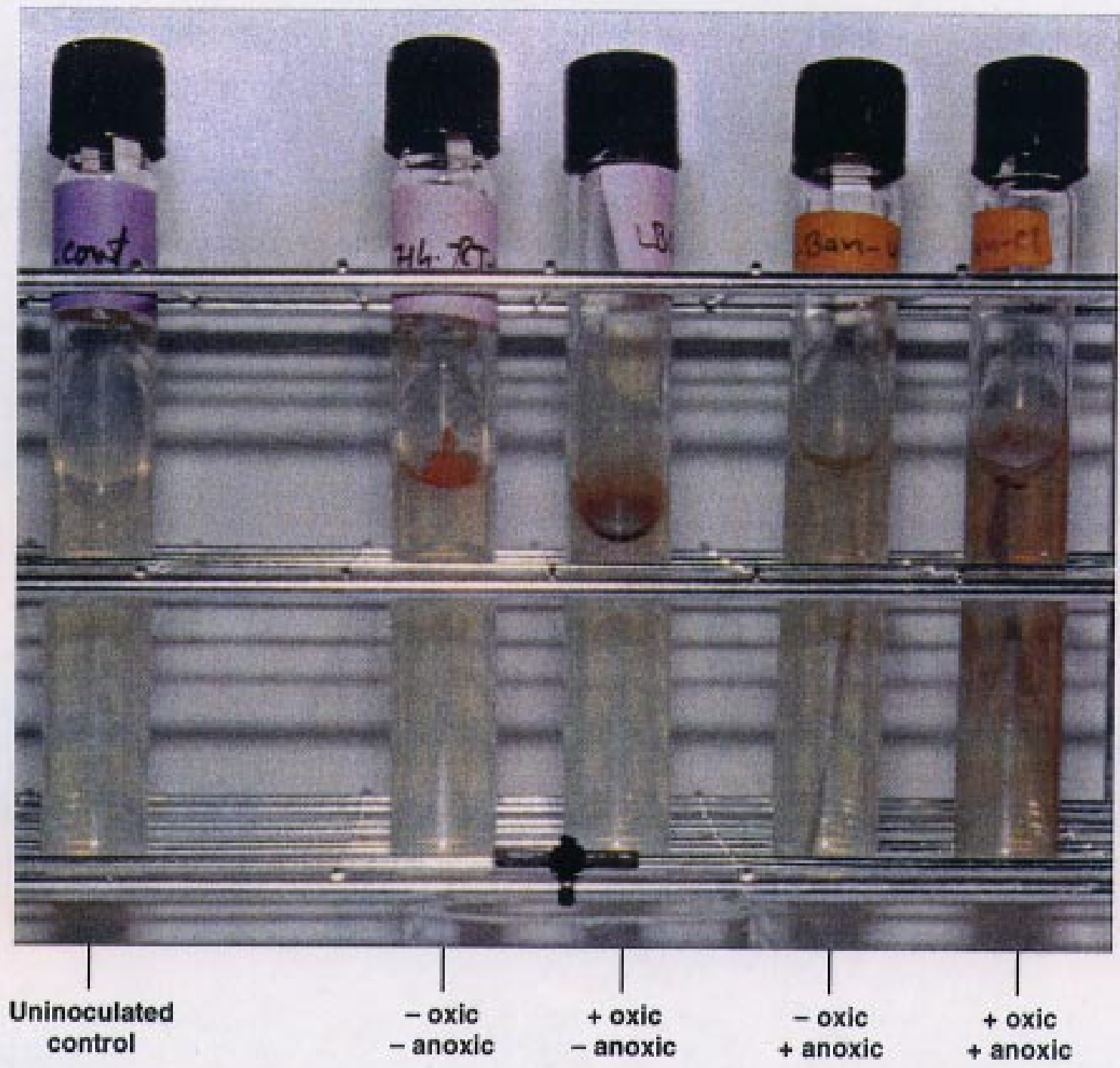

Figure 6-27. Preliminary results showed that sulfide production via desulfurylation increased for all tested strains within a two day incubation period, even in anaerobic cultures which metabolize and grow more slowly than do aerobic cultures. R2B media $+0.75 \%$ Proteose peptone $\# 3$, lead acetate 12 days incubation at room temperature and at $50^{\circ} \mathrm{C}$. 



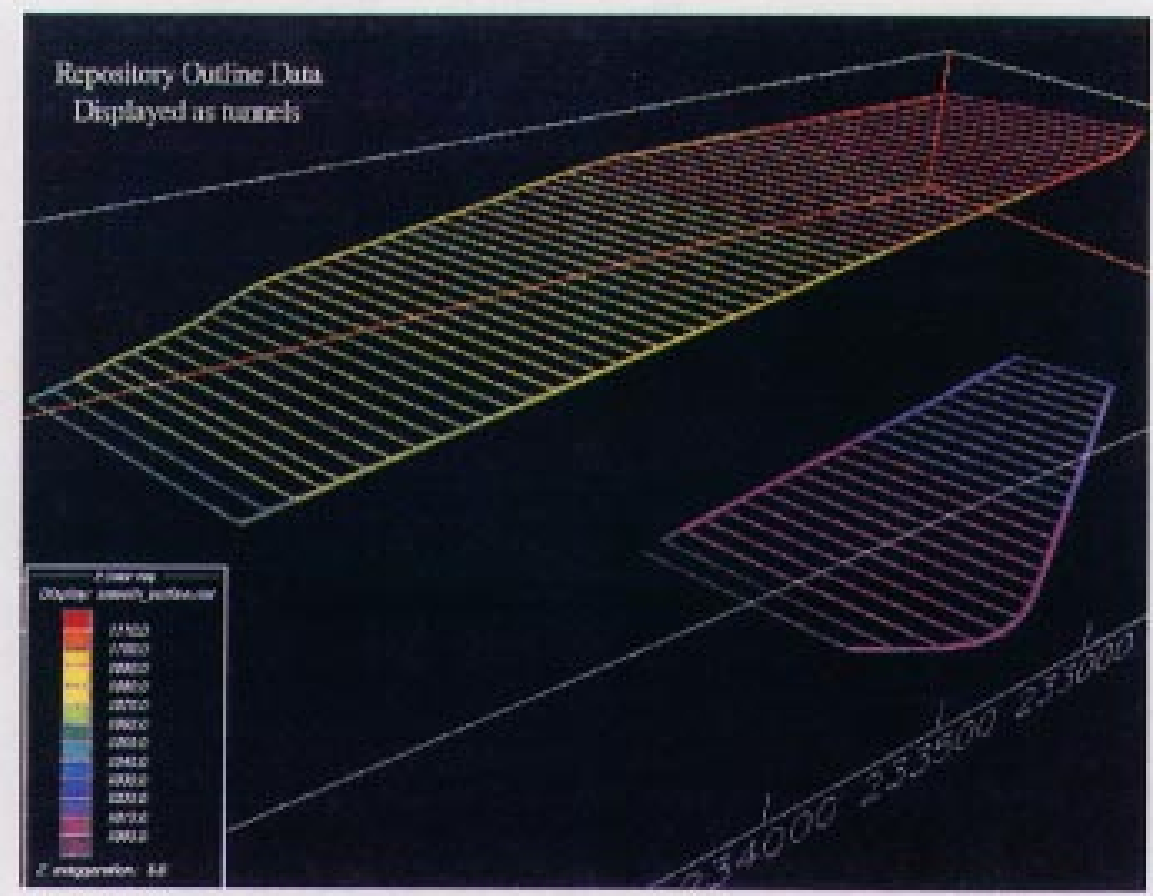

Figure 6-28. Emplacement tunnel footprint is illustrated in the Nevada State coordinate grid, which will allow for easy integration of existing Yucca Mountain geological data. Relative sizes of main and emplacement drifts are shown. Colors indicate elevation (see legend).

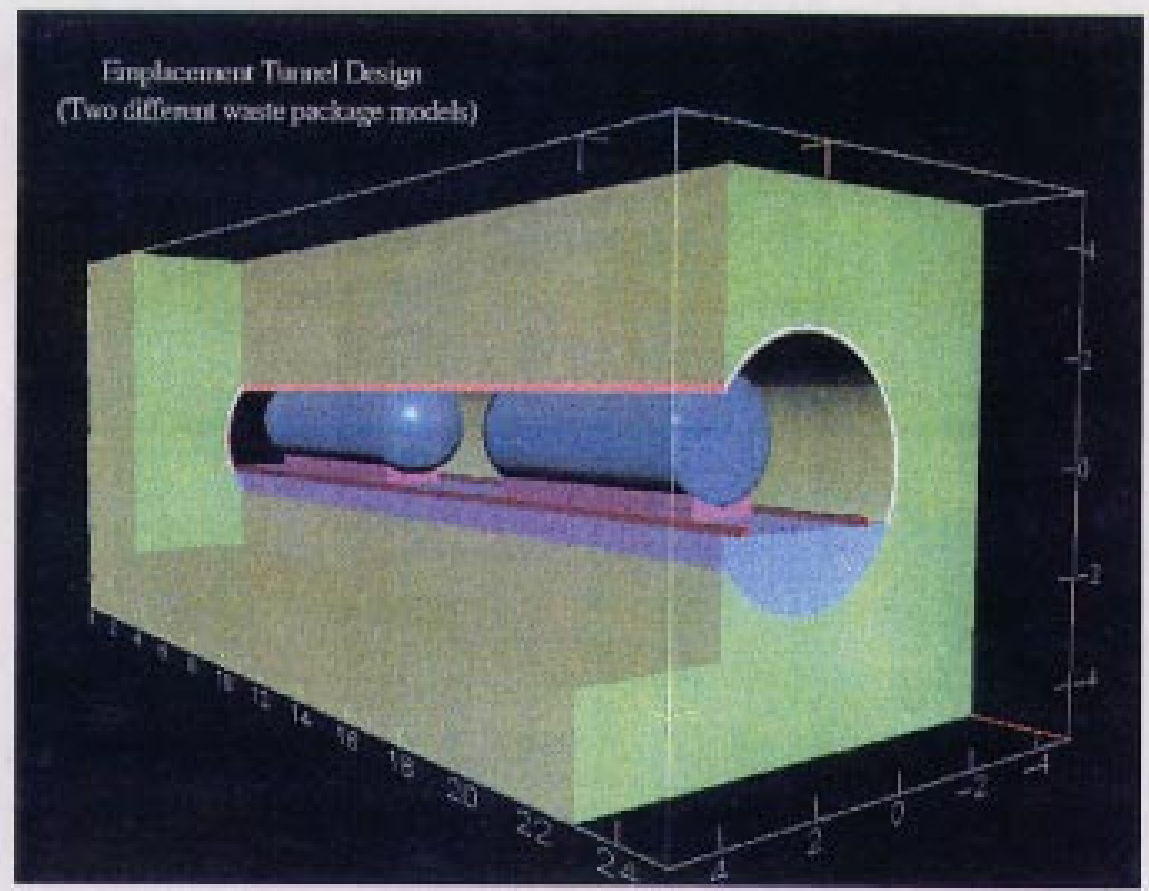

Figure 6-29. Cut away view of the emplacement tunnel demonstrates the capability of the EarthVision ${ }^{\mathrm{TM}}$ software to represent discontinuous shapes (scale bar in meters). In this simplified model waste packages (blue; $6 \mathrm{~m} \times 0.2 \mathrm{~m}$ diam), cementitious materials (pink and lavender) gantry tracks (red) are installed in the surrounding rock (green). 



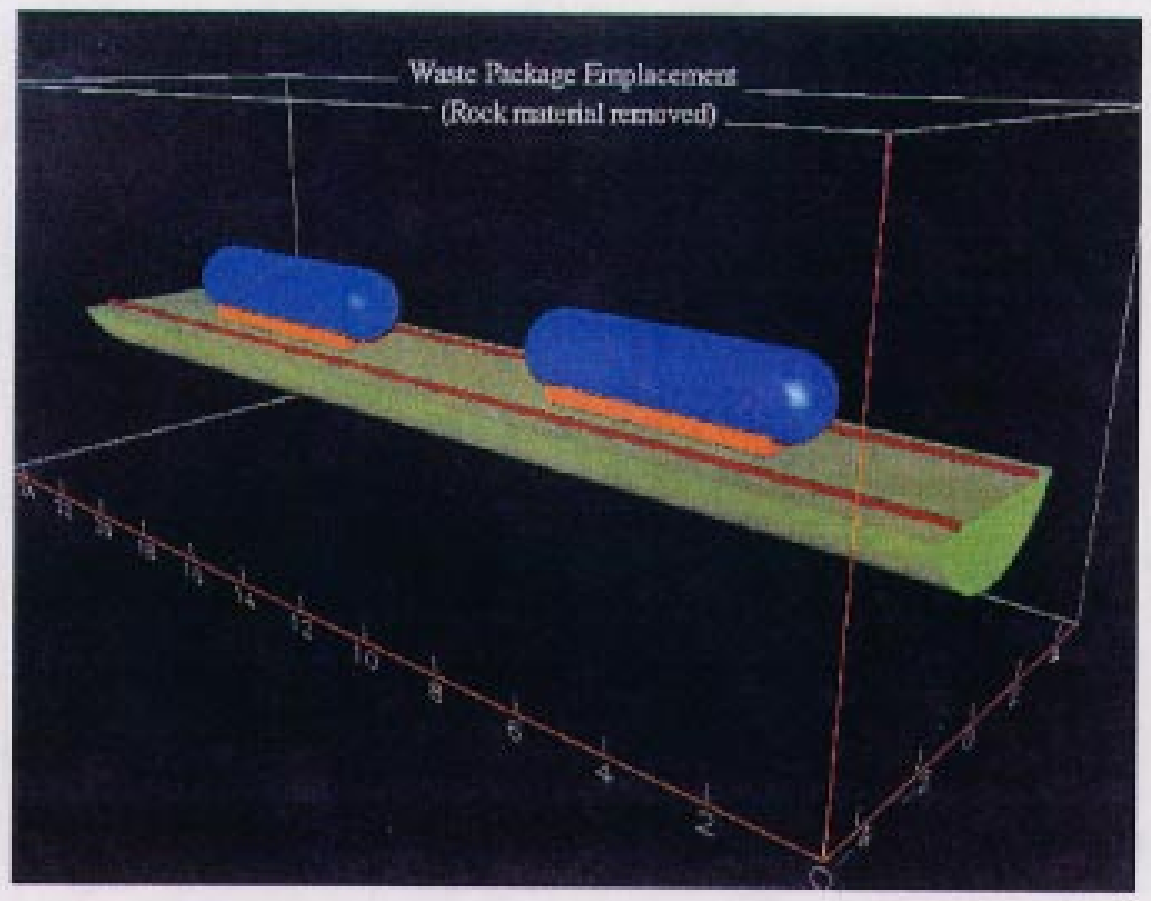

Figure 6-30. Illustration of a $25 \mathrm{~m}$ section of $4.3 \mathrm{~m}$ diam. emplacement tunnel (scale bar in meters). Waste packages (blue; $6.5 \times 1.75 \mathrm{diam}$ ), concrete invert (green; roughly $1.5 \mathrm{~m} \mathrm{x} 4 \mathrm{~m}$ ), gantry tracks (red; roughly $3.5 \mathrm{~m}$ between tracks), and concrete waste package supports (gold; $5.3 \mathrm{~m}$ length) are shown to scale.

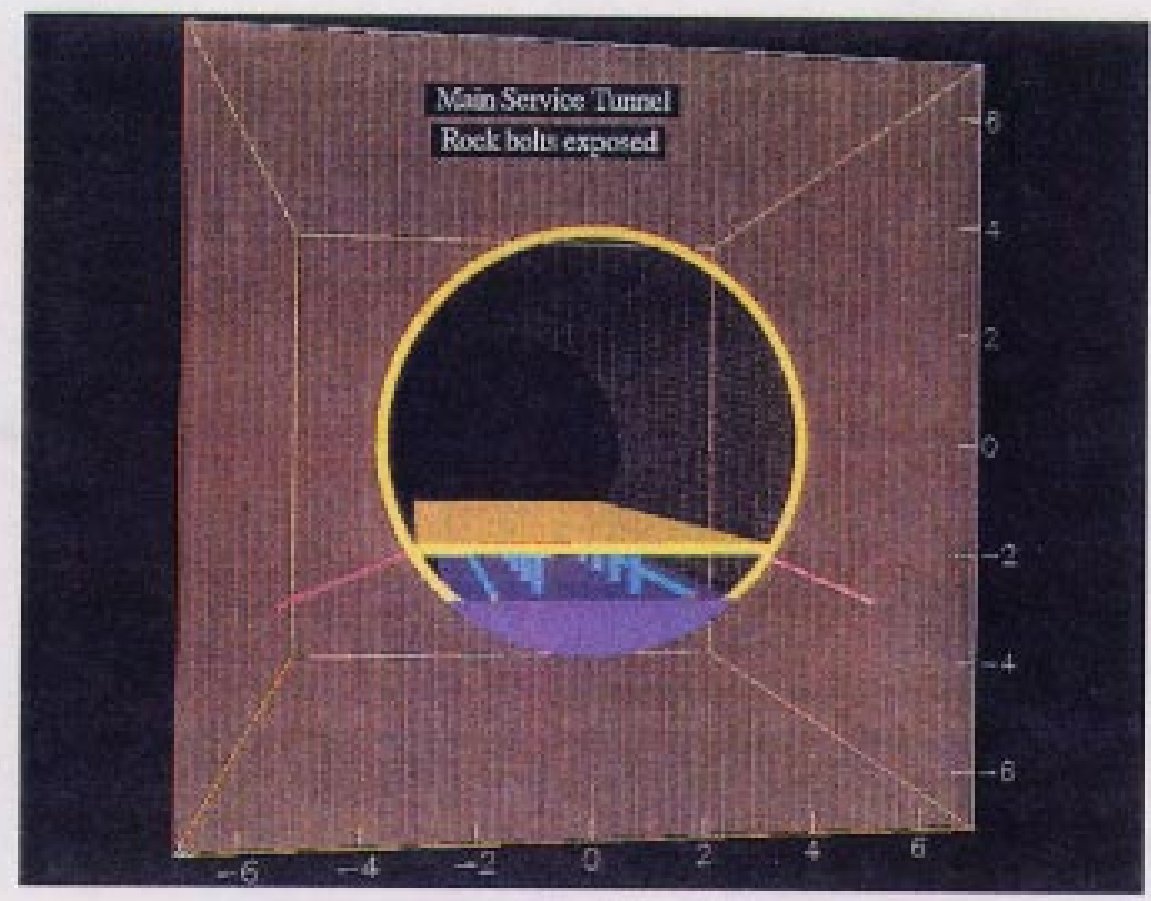

Figure 6-31. Simplified cross-section rendering of a 20-m section of 7.6-m diam. service tunnel (scale bar in meters) shows rockbolts (pink; approximately $3 \mathrm{~m}$ long and 0.10 diam.) for the metal grate platform (yellow; approximately $0.2 \mathrm{~m}$ thick) anchored into the surrounding rock (brown). The metal platform supports (light blue; approximately $0.2 \times 0.3 \times 1.0 \mathrm{~m}$ ) are placed at roughly $2 \mathrm{~m}$ intervals. A concrete invert (purple; roughly $1.5 \mathrm{~m}$ ) and shotcrete layer (gold; $0.2 \mathrm{~m}$ thick) are shown 



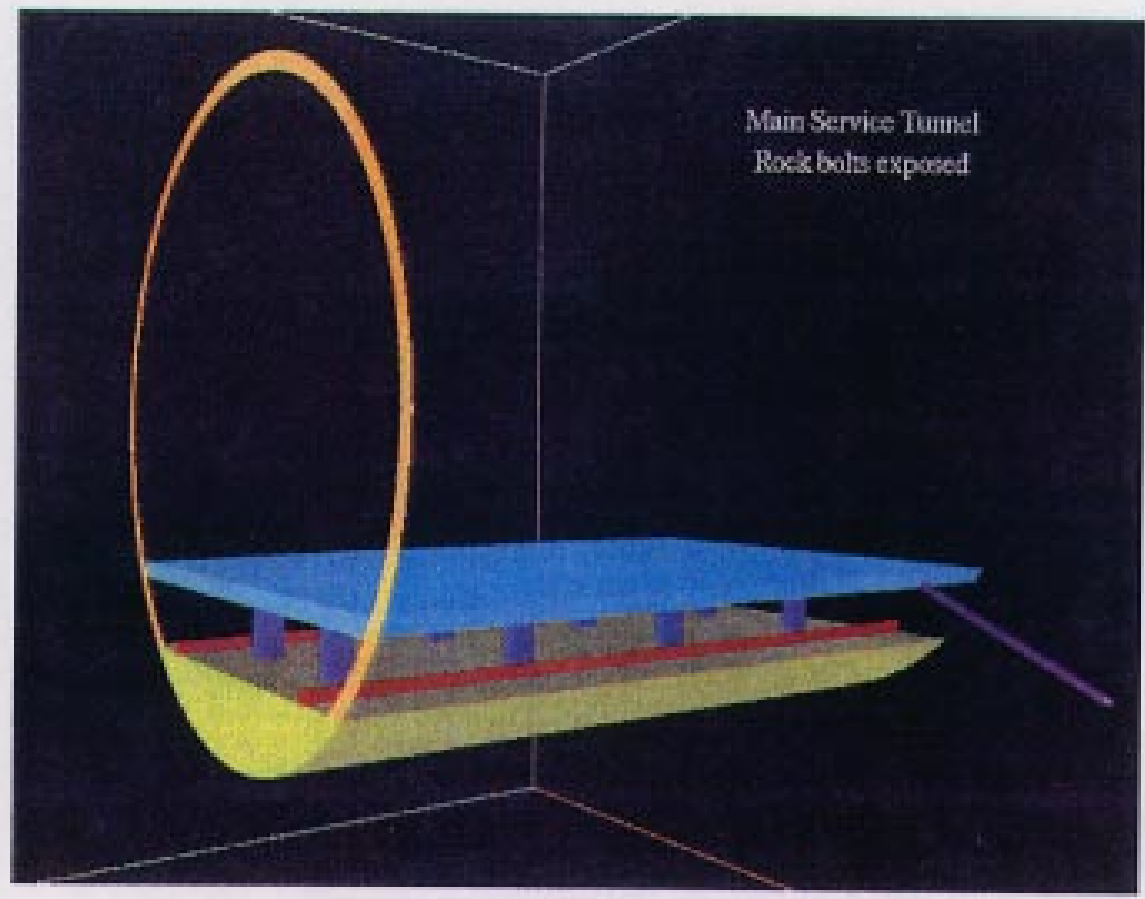

Figure 6-32. Exposed 20-m section of 7.6-m diam. service tunnel (scale bar in meters) demonstrates the level of detail that can be obtained for chemical and hydrological modeling at a scale of meters. Concrete invert (green) and shotcrete (gold) are the cementitious materials that are shown. Metal materials illustrated are the gantry car rails (turquoise) platform supports (blue) platform (yellow) and platform anchor rockbolts.

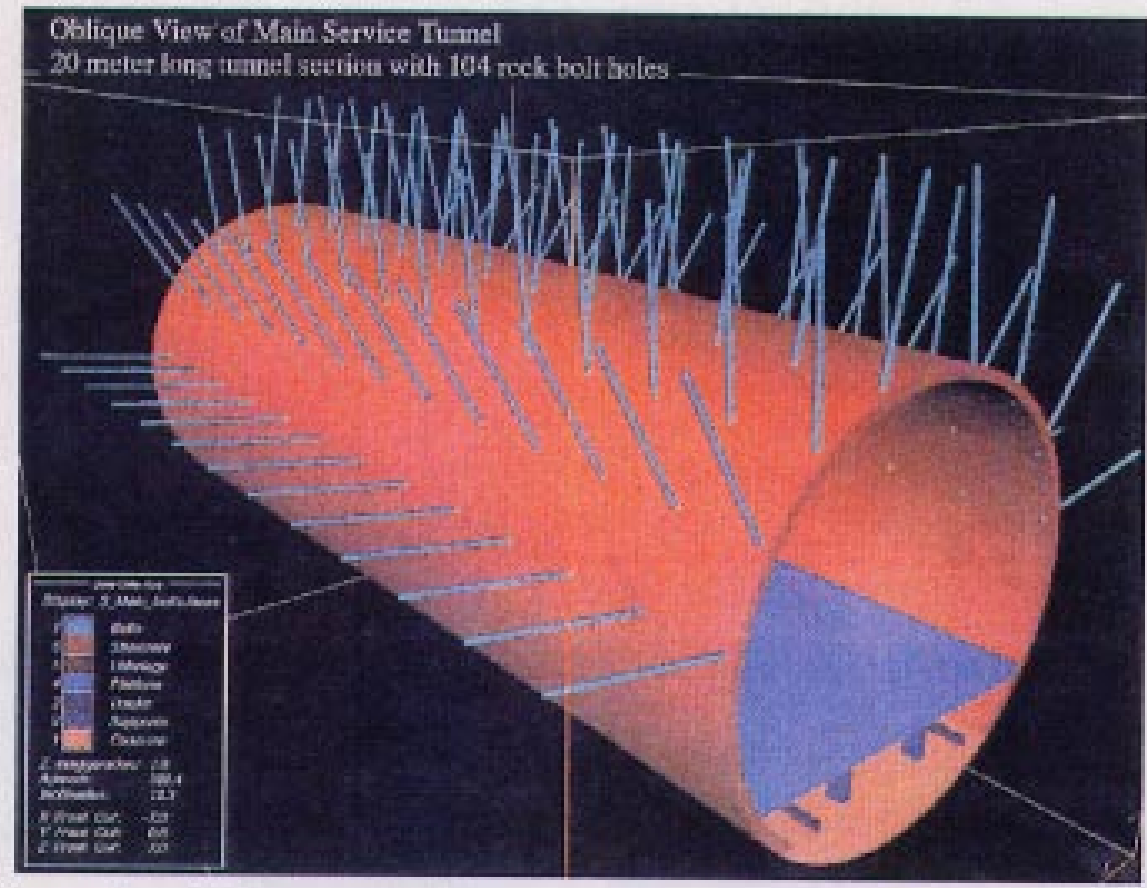

Figure 6-33. Oblique view of $20-\mathrm{m}$ section of 7.6 -m diam service tunnel showing rockbolt holes. Given standard spacing $(1.5 \mathrm{~m})$ as depicted on engineering drawings, 104 rockbolts would be found in this length of turnel. 



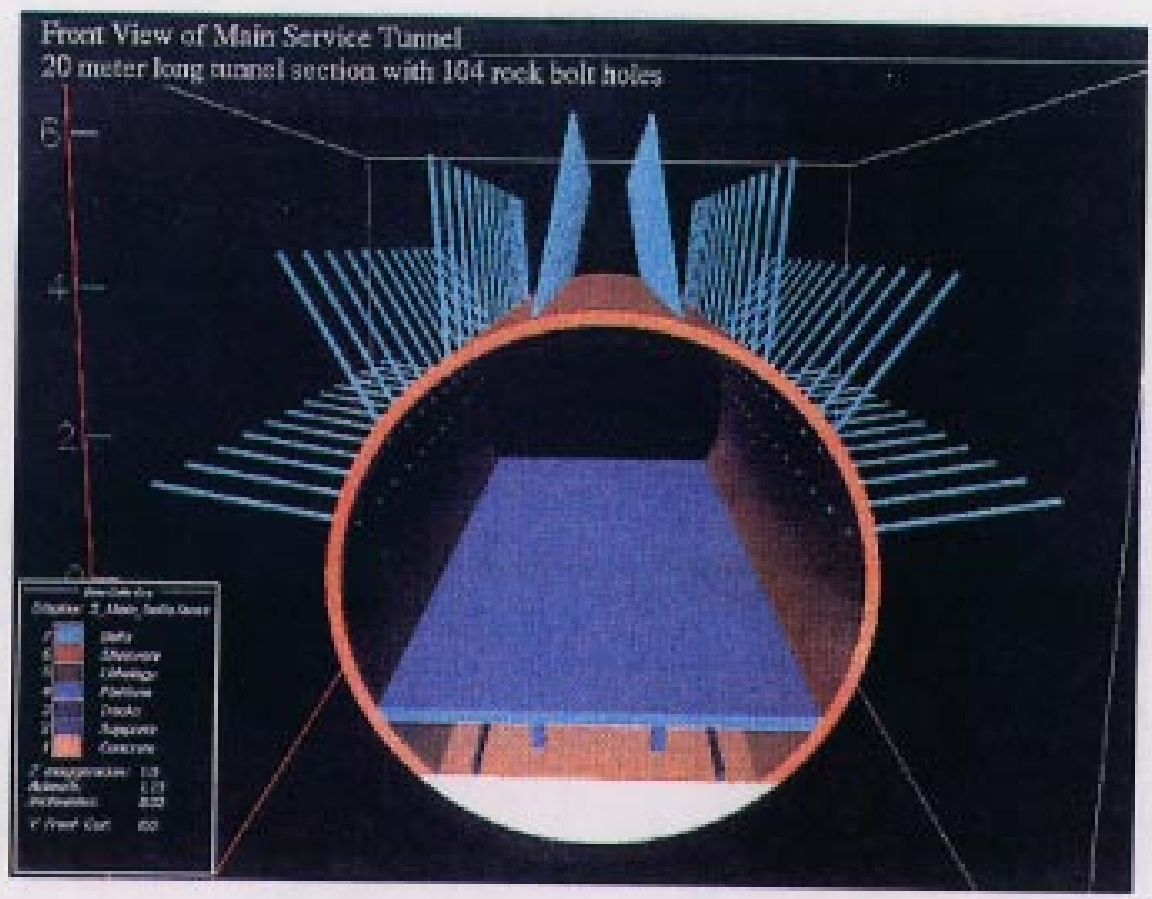

Figure 6-34. Cross-sectional rendering of 20-m section of 7.6-m diam service tunnel showing rockbolt holes.

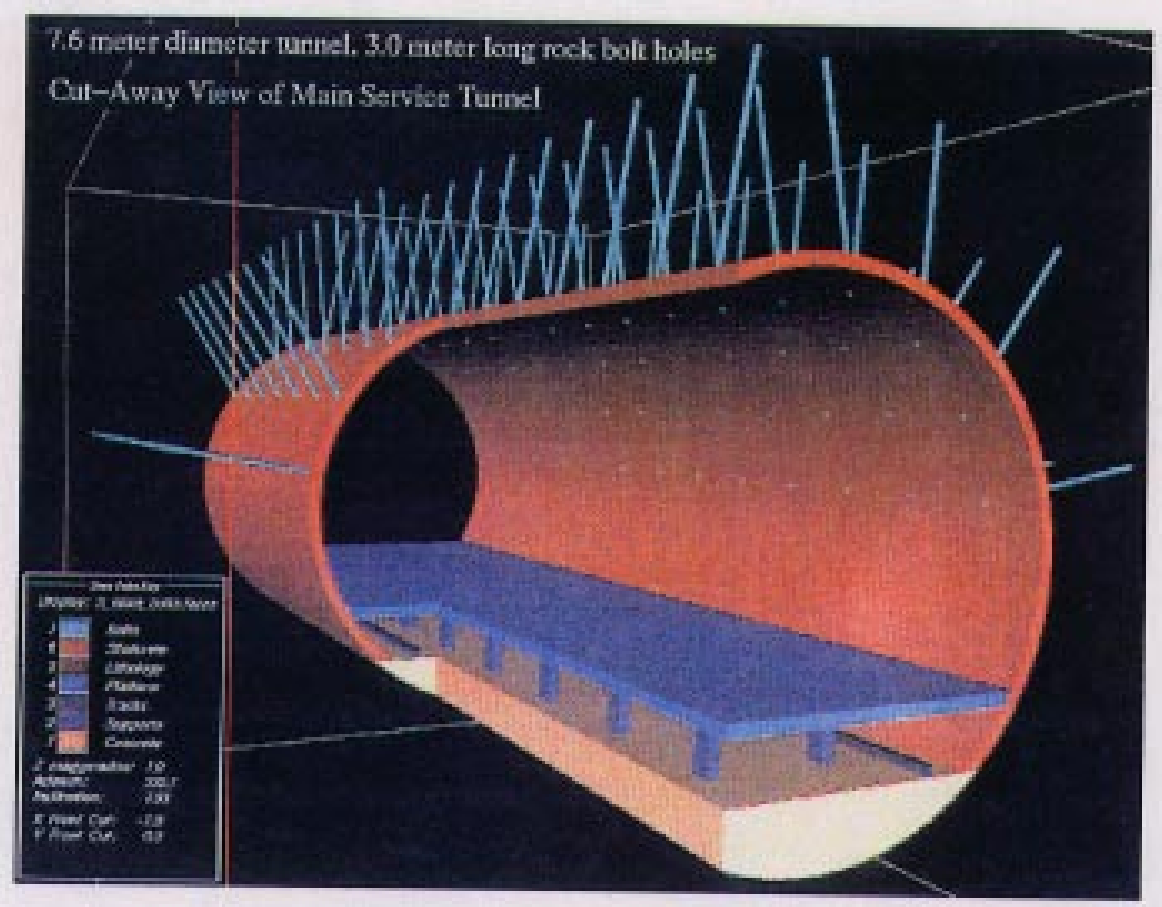

Figure 6-35. Cut-away view of $20-\mathrm{m}$ section of $7.6-\mathrm{m}$ diam, service tunnel showing rockbolt holes. 



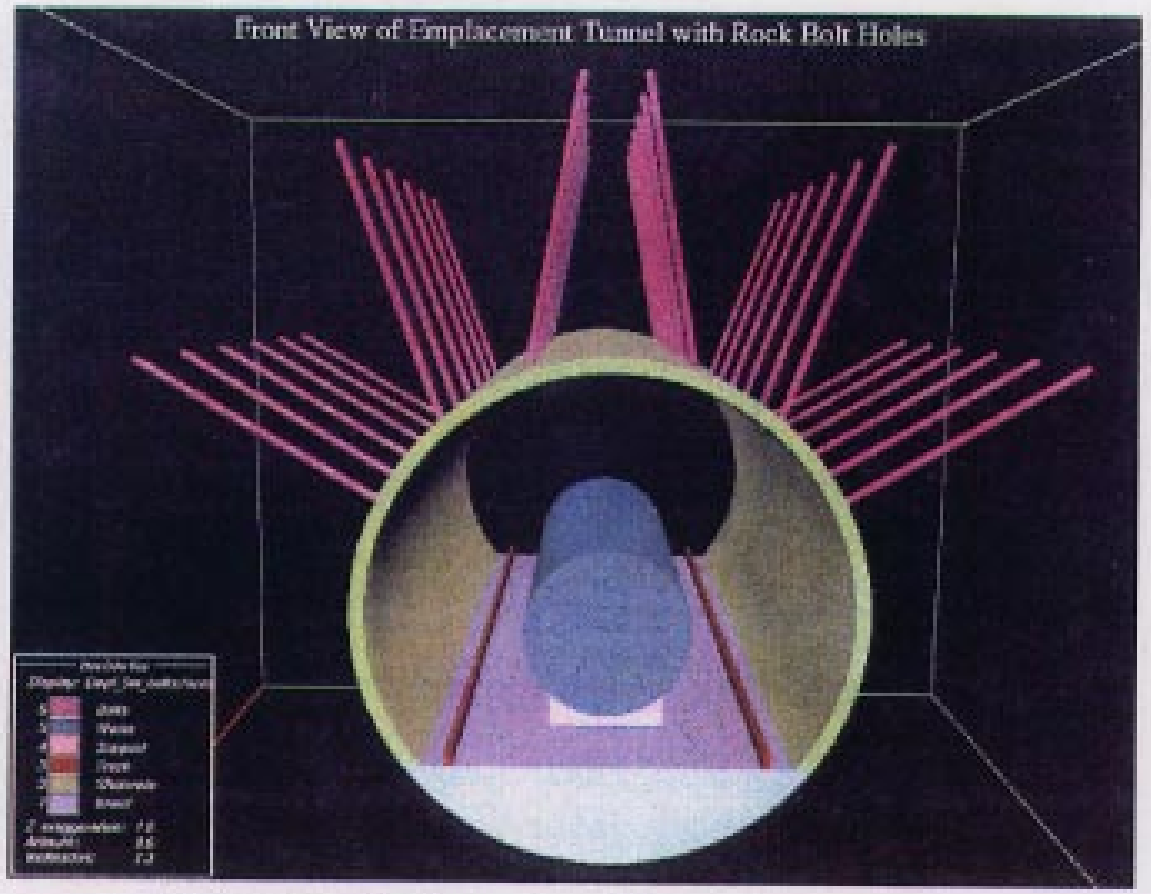

Figure 6-36. Cross-sectional rendering of $20-\mathrm{m}$ section of $5.0-\mathrm{m}$ diam. emplacement tunnel showing rockbolt holes. Given standard spacing $(1.5 \mathrm{~m})$ as depicted on engineering drawings, 36 rockbolts would be found in this length of tunnel.

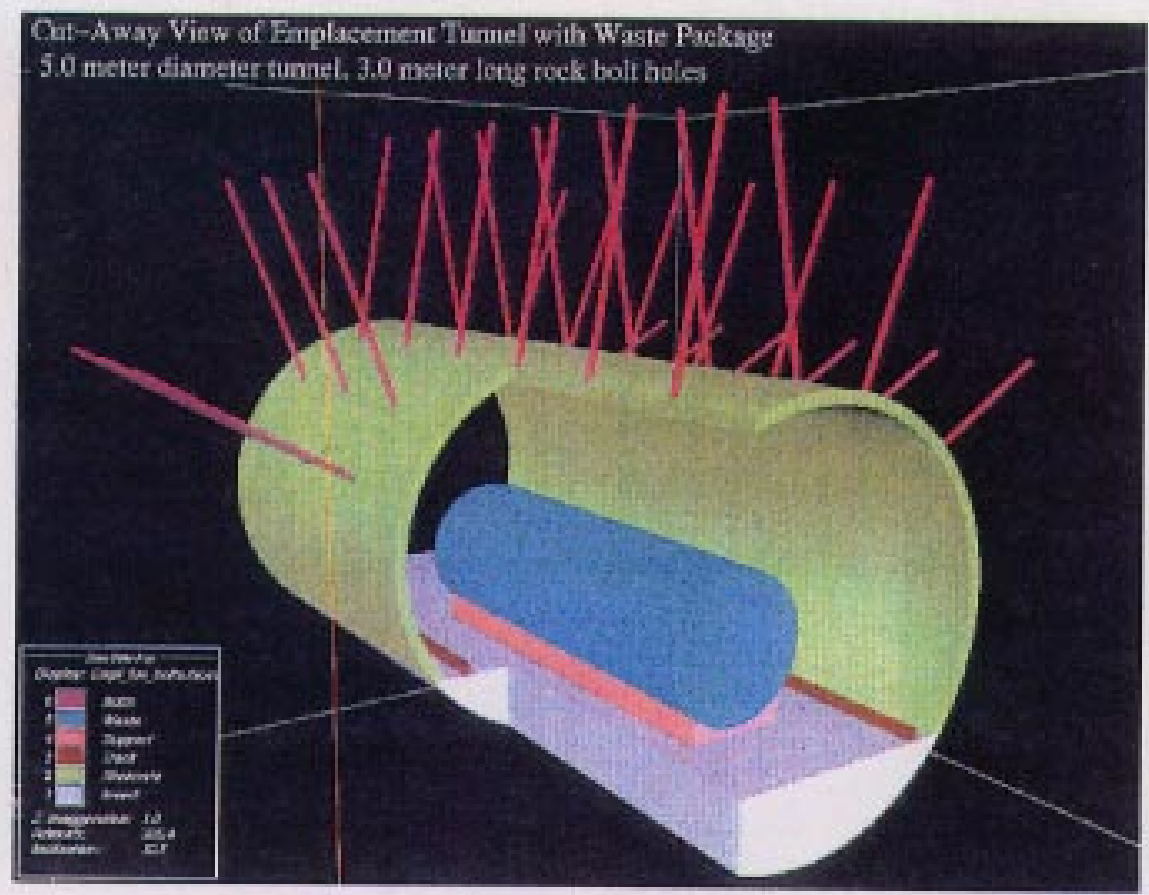

Figure 6-37. Cut-away view of 20 -m section of 5.0-m diam service tunnel showing rockbolt holes. 
. 


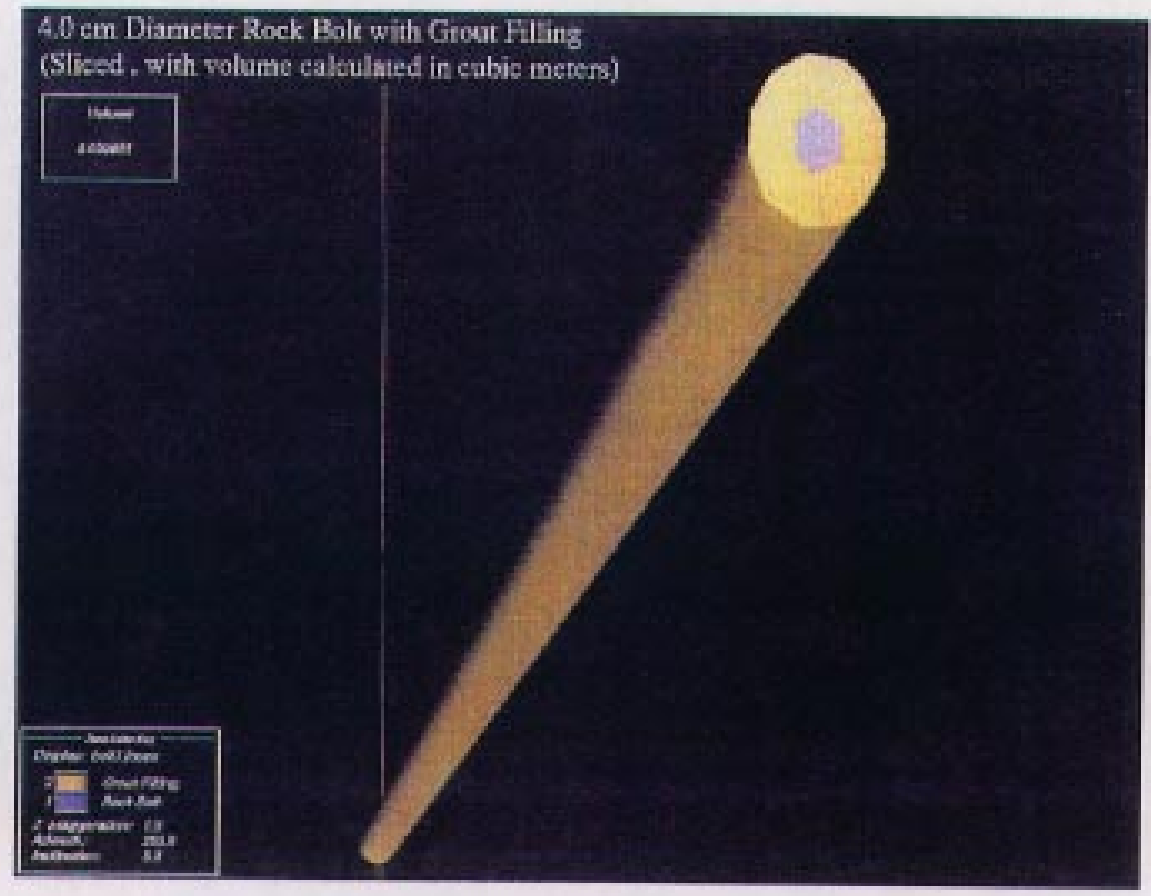

Figure 6-38. Rockbolt detail showing steel rockbolt (gray) and exterior grout filling.

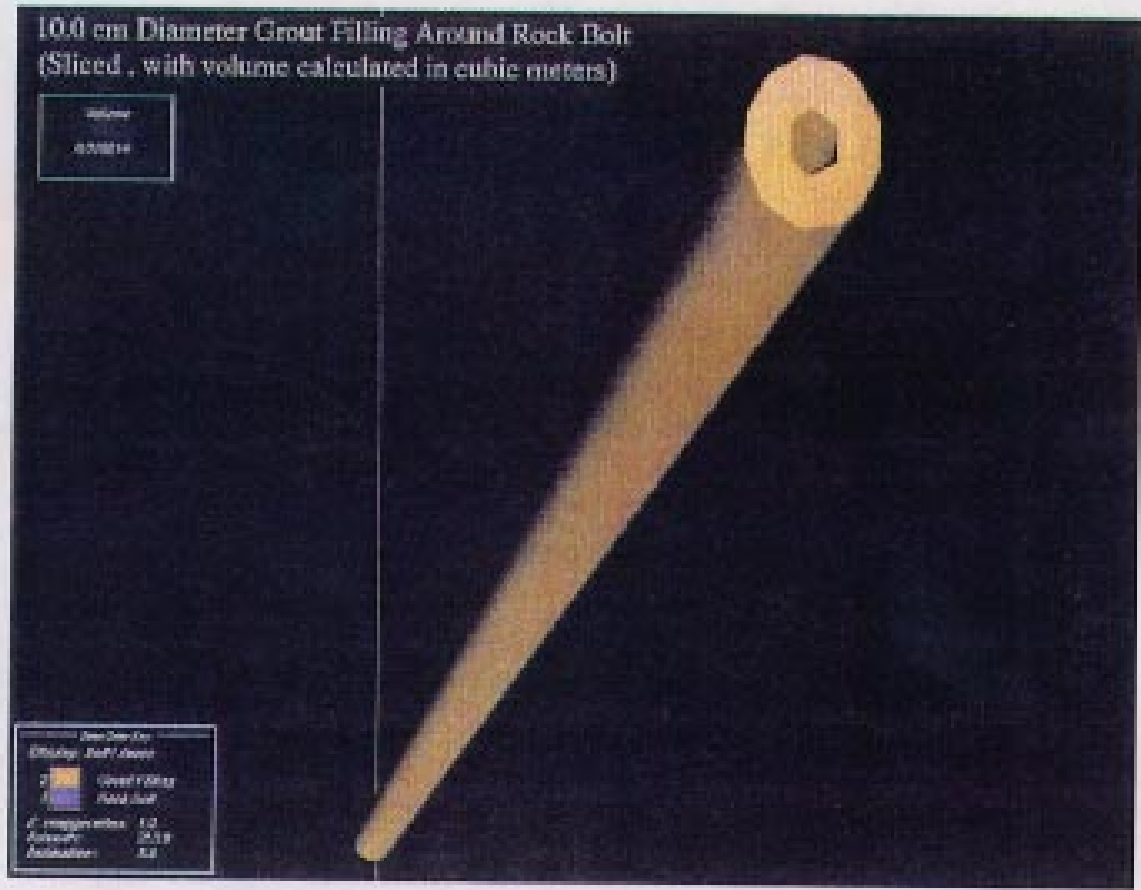

Figure 6-39. Calculational detail of volume of grout $(0.018214 \mathrm{~m})$ used for one rockbolt. 


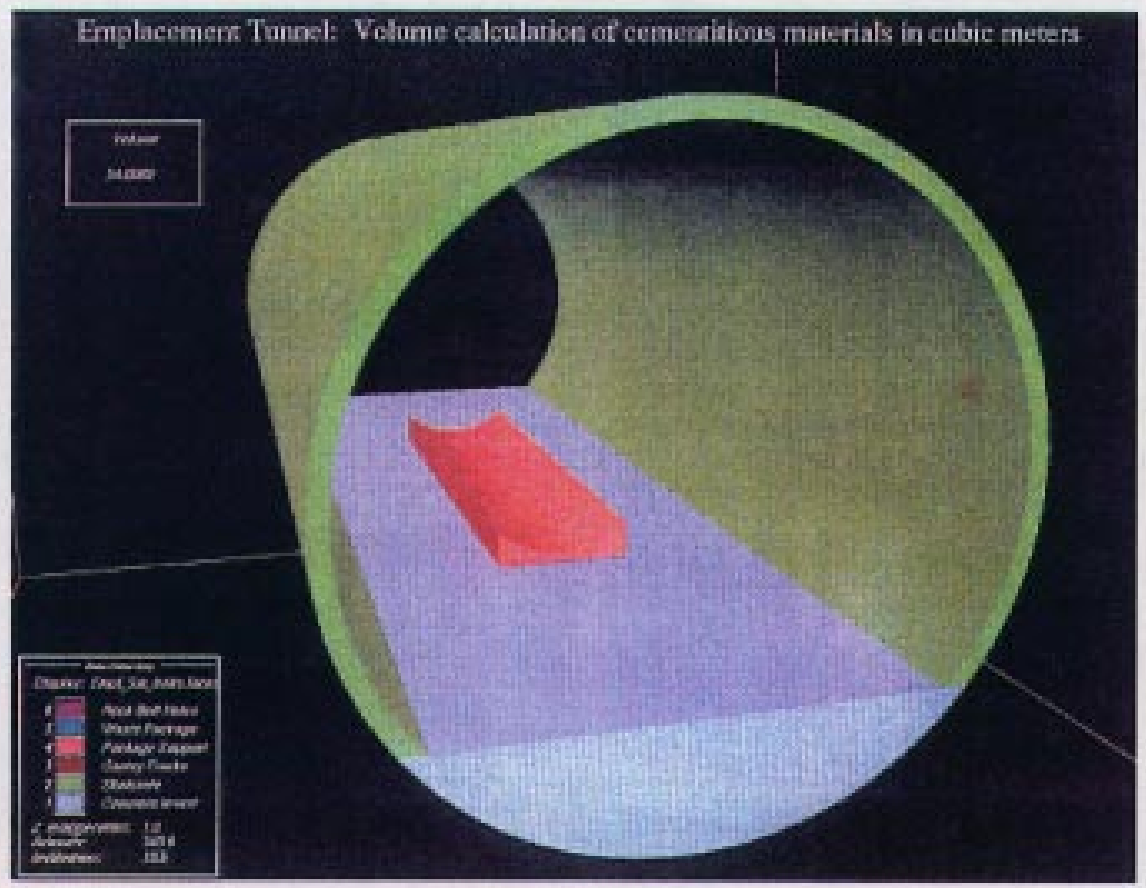

Figure 6-40. Calculation of material volumes is straightforward, as is illustrated in this calculation of the volume of cementitious materials (approximately $54.1 \mathrm{~m}^{3}$ ) in a $20-\mathrm{m}$ section of 4.3 diam. emplacement drift.

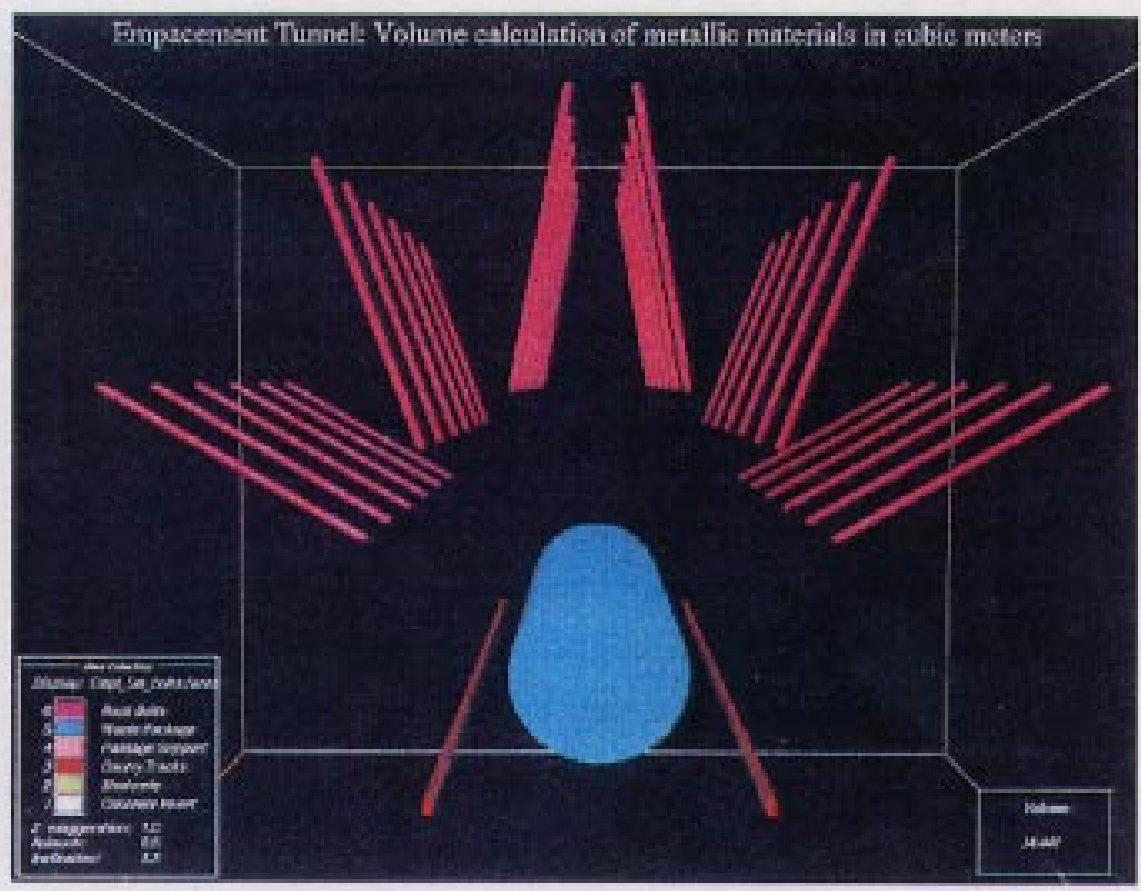

Figure 6-41. Calculation of volume of metal materials (approximately $14.4 \mathrm{~m}^{3}$ ) (including the waste packages of wall thickness of roughly $0.2 \mathrm{~m}$ ) in a 20 -m section of 4.3 diam. emplacement drift. 


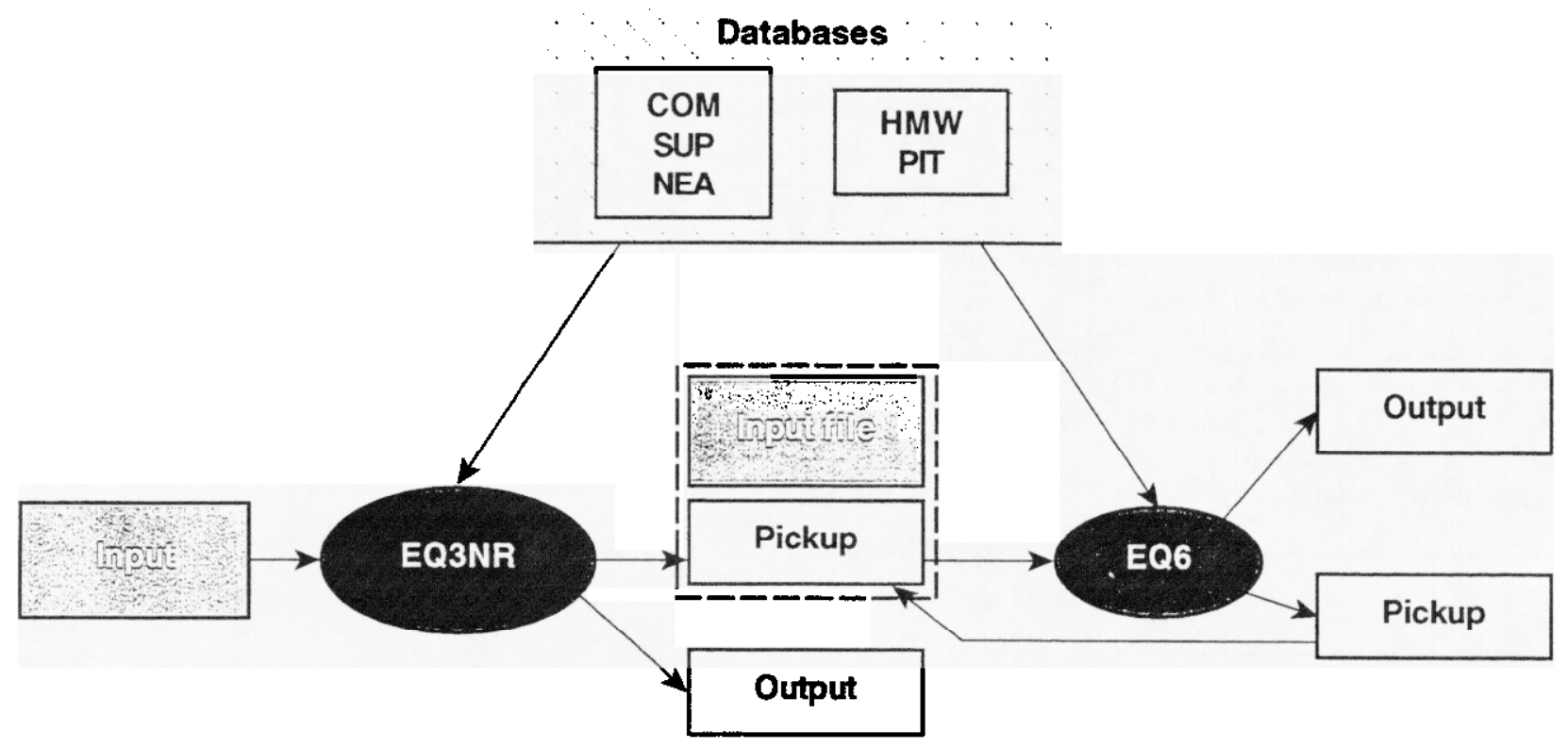

Figure 6-42. Diagram of interaction between various parts of EQ3/6. At present these interactions are conducted manually by the modeler. In order to simulate systems at a higher level of complexity, it will be necessary to automate some of these steps.

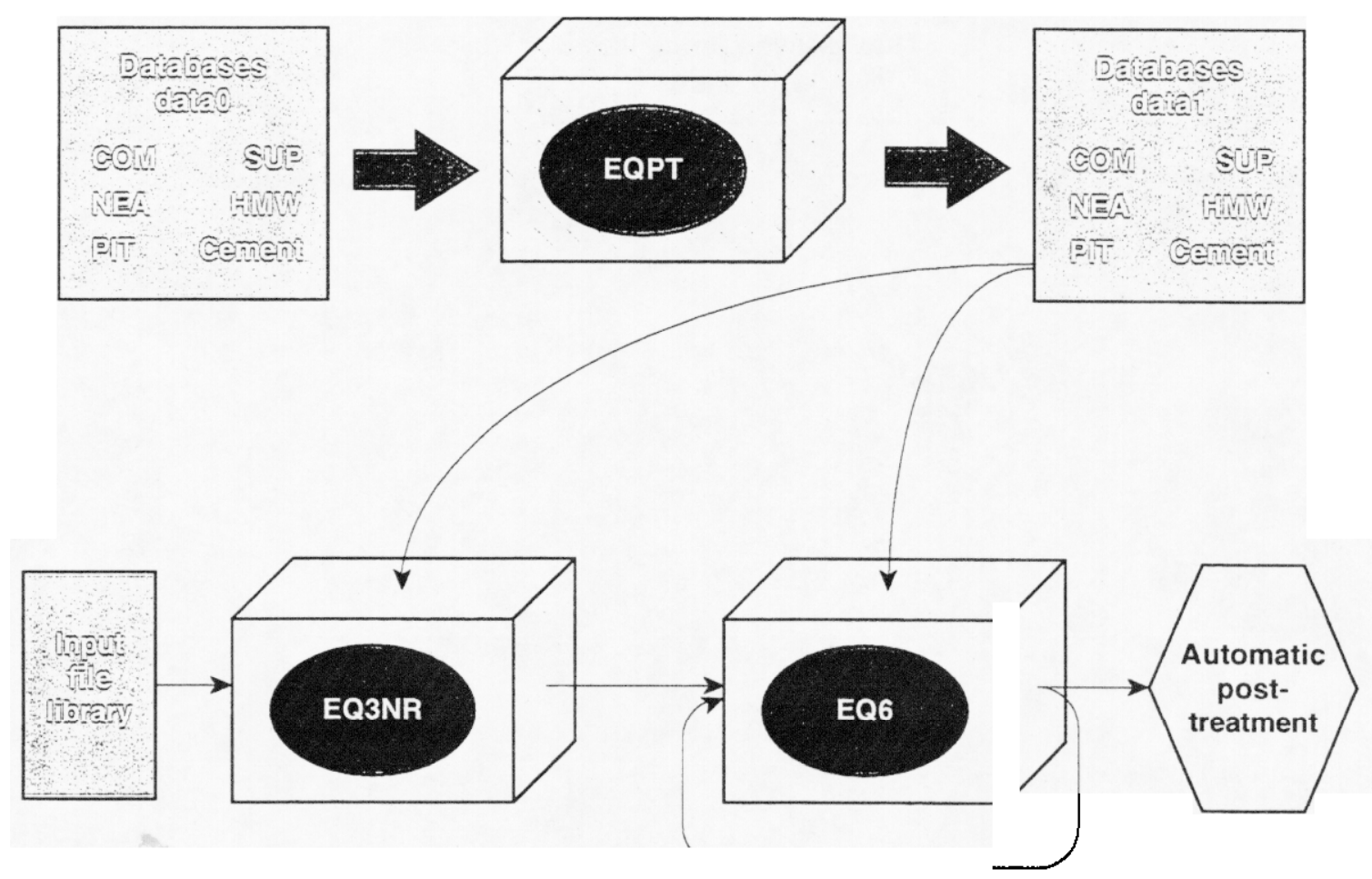

Figure 6-43. Schematic diagram of the flow of information between EQ3NR, EQ6, the databases and the input and output files. 


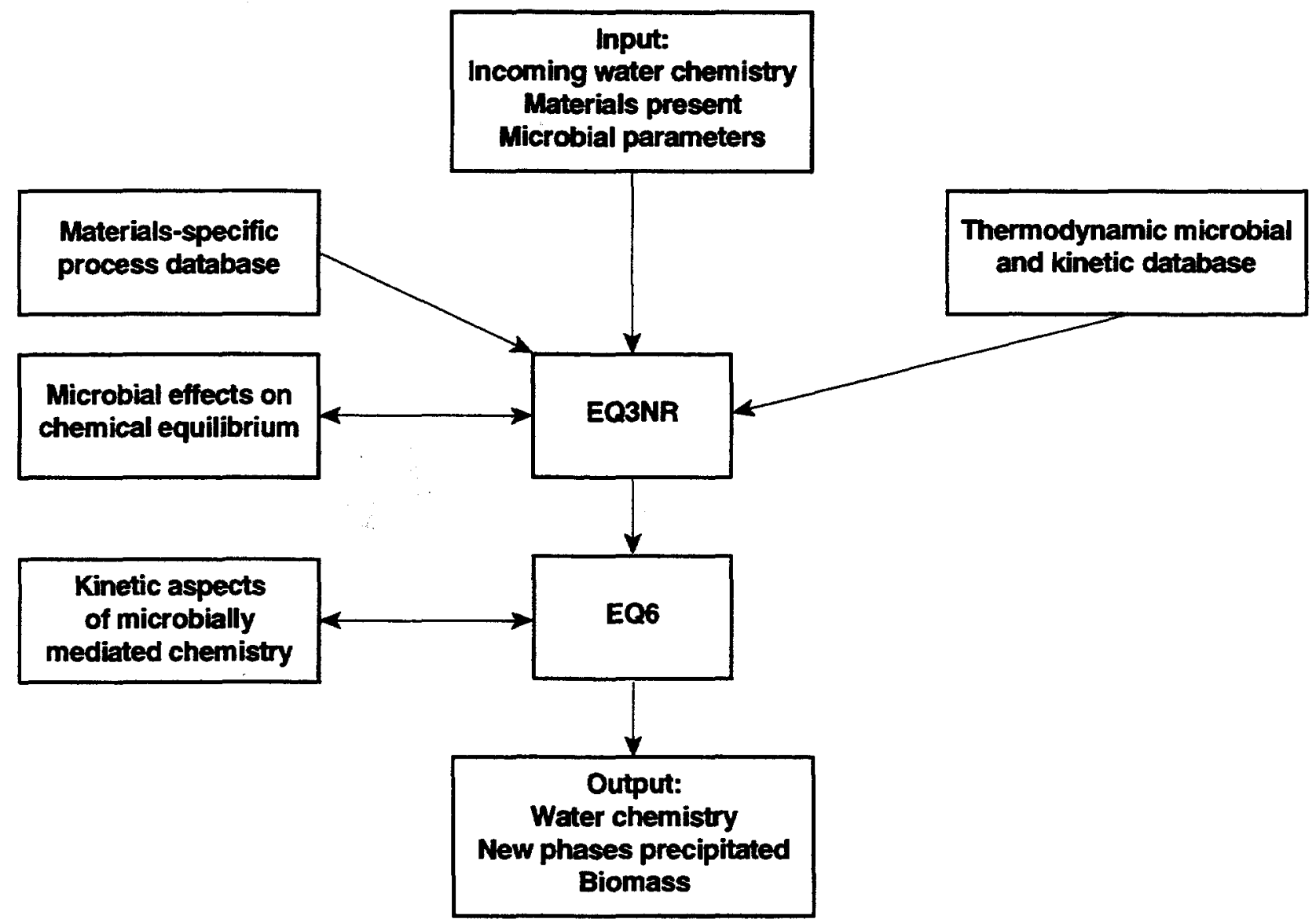

Figure 6-44. Conceptual view of interaction between EQ3/6 modules and modules that simulate biotic effects. 
Table 6-1. Steel set materials and ESF locations.

\begin{tabular}{|c|c|c|c|}
\hline Component * & $\begin{array}{c}\text { Quantity between } \\
\begin{array}{c}00+58 \text { and } \\
02+00 \mathrm{ft}\end{array}\end{array}$ & $\begin{array}{c}\text { Quantity between } \\
02+00 \text { and } \\
04+00 \mathrm{ft}\end{array}$ & $\begin{array}{c}\text { Quantity between } \\
04+00 \text { and } \\
06+00 \mathrm{ft}\end{array}$ \\
\hline Item \#1 & 116 & 83 & 132 \\
\hline Item \#2 & 232 & 166 & 264 \\
\hline Item \#3 & 232 & 166 & 264 \\
\hline Item \#4 & 232 & 166 & 264 \\
\hline Item \#5 & 468 & 835 & 1879 \\
\hline Item \#6 & 3521 & 3567 & 6017 \\
\hline Item \#7 & 1276 & 891 & 1430 \\
\hline
\end{tabular}
(1)Top component, MK\#1A
(2) Bottom components, MK\#1B ( 2 parts per set)
(3) Side components, MK\#1C (2 parts per set)
(4) Steel set, shims and Dutchmen (2 parts per set)
(5) Steel Set Shims (reference drawing BABEAB000-01717-210041102-03)
(6) Steel Lagging, $C 8 \times 11.5 \#$ Channel for Steel Sets $\sim 4 \mathrm{ft}$ in length
(7) Tie rods for steel sets (reference drawing BABEAB000-01717-2100-41102-03)

Table 6-2. Rockbolt types and associated materials

\begin{tabular}{|c|c|c|}
\hline Rockbolt type & $\begin{array}{l}\text { Explicitly referred to on } \\
\text { engineering diagrams }\end{array}$ & Associated \\
\hline $\begin{array}{l}\text { Super Swellex }{ }^{\mathrm{TM}} 1 \\
\text { (long and short) }\end{array}$ & $\begin{array}{l}\text { long only } \\
\text { ( } 3000 \mathrm{~mm} . \text { nom.) }\end{array}$ & $\begin{array}{l}\text { water is applied a } \\
\text { pressure to inflate }\end{array}$ \\
\hline $\begin{array}{l}\text { Solid \#8 Threaded1 } \\
\text { (long and short) }\end{array}$ & $\begin{array}{l}\text { long only } \\
\text { (3000 mm. nom.) }\end{array}$ & grouted into place \\
\hline $\begin{array}{l}\text { Williams }{ }^{\mathrm{TM}} \text { Hollow } \\
\text { Core }^{1}\end{array}$ & (3000 mm. nom.) & grouted \\
\hline Split Set ${ }^{2}$ & no & unknown \\
\hline \multicolumn{3}{|c|}{$\begin{array}{l}\text { ' BABEABOOO-01717-2100-40157-01. } \\
2 \text { Personal communication, Eugene Pokomy. }\end{array}$} \\
\hline $\begin{array}{l}\text { Grout } \\
\text { mineralogy }\end{array}$ & Formula & $\begin{array}{l}\text { Composition } \\
\text { (wt\%) }\end{array}$ \\
\hline Tricalcium silicate & $3(\mathrm{CaO}) \mathrm{SiO}_{2}$ & 61 \\
\hline Dicalcium silicate & $2(\mathrm{CaO}) \mathrm{SiO}_{2}$ & 15 \\
\hline Tricalcium aluminate & $3(\mathrm{CaO}) \mathrm{Al} 2 \mathrm{O} 3$ & 6 \\
\hline Tetracalcium aluminoferri & $4(\mathrm{CaO}) \mathrm{Al} 2 \mathrm{O} 3 \mathrm{Fe} 2 \mathrm{O} 3$ & 9 \\
\hline
\end{tabular}


Table 6-3b. Grout composition of Fibercrete $^{\mathrm{TM}}$.

\begin{tabular}{lc}
\hline \multicolumn{1}{c}{ Oxide } & Composition (wt\%) \\
\hline $\mathrm{SiO}_{2}$ & 21.4 \\
$\mathrm{Al}_{2} \mathrm{O}_{3}$ & 4.3 \\
$\mathrm{Fe}_{2} \mathrm{O}_{3}$ & 2.9 \\
$\mathrm{CaO}$ & 64.9 \\
$\mathrm{MgO}$ & 1.7 \\
$\mathrm{SO}_{3}$ & 2.7 \\
$\mathrm{Na}_{2} \mathrm{O}$ & 0.53 \\
Loss on ignition & 0.87 \\
Insoluble residue & 0.2 \\
\hline
\end{tabular}

Table 6-3c. Steel fiber composition of Fibercrete $^{\mathrm{TM}}$.

\begin{tabular}{cc}
\hline Element & Composition (wt\%) \\
\hline Fe & 99.8 \\
$C$ & 0.018 \\
Mn & 0.075 \\
P & 0.040 \\
S & 0.050 \\
\hline
\end{tabular}

Table 6-4. Details of spills 001 through 010.

\begin{tabular}{ccccc}
\hline $\begin{array}{c}\text { Spill } \\
\text { No. }\end{array}$ & Date & $\begin{array}{c}\text { Tunnel } \\
\text { station }\end{array}$ & $\begin{array}{c}\text { Affected } \\
\text { surface }\end{array}$ & Fluid \\
\hline SRP-001 & $12 / 10 / 94$ & $0+87$ & invert & oil \\
SRP-002 & $01 / 07 / 95$ & $1+09$ & invert & oil \\
SRP-003 & $02 / 23 / 95$ & $02+84$ & TBM & oil \\
SRP-004 & $03 / 03 / 95$ & $04+05$ & invert segment & oil \\
SRP-005 & $03 / 21 / 95$ & $04+60$ & unknown & oil \\
SRP-006 & $03 / 24 / 95$ & $05+03$ & TBM & hydraulic fluid \\
SRP-006a & $03 / 24 / 95$ & $05+01$ & TBM & oil \\
SRP-007 & $03 / 25 / 95$ & $05+1376$ & TBM & oil \\
SRP-008 & $03 / 25 / 95$ & $05+1667$ & TBM & oil \\
SRP-009 & $03 / 28 / 95$ & $05+10$ & TBM & hydraulic fluid \\
SRP-010 & $04 / 14 / 95$ & $05+45$ & TBM & hydraulic fluid \\
\hline
\end{tabular}


Table 6-5. Spills reported through 09-August-95.

\begin{tabular}{cc}
\hline Spill No. & Date \\
\hline SRP-011 & $05 / 06 / 95$ \\
SRP-012 & $05 / 31 / 95$ \\
SRP-013 & $06 / 01 / 95$ \\
SRP-014 & $06 / 06 / 95$ \\
SRP-014a & $06 / 21 / 95$ \\
SRP-015 & $06 / 24 / 95$ \\
SRP-016 & $06 / 20 / 95$ \\
SRP-017 & $06 / 30 / 95$ \\
SRP-018 & $07 / 05 / 95$ \\
SRP-019 & $07 / 22 / 95$ \\
SRP-020 & $07 / 24 / 95$ \\
SRP-021 & $08 / 03 / 95$ \\
SRP-022 & $08 / 09 / 95$ \\
\hline
\end{tabular}

Table 6-6. Dust control agents that have been considered for use in the ESF.

\begin{tabular}{lll}
\multicolumn{1}{c}{$\begin{array}{c}\text { Product } \\
\text { name }\end{array}$} & \multicolumn{1}{c}{ Constituents } & \multicolumn{1}{c}{ Company } \\
\hline Bio Cat 300-1 & unknown & Applied Natural Systems, Inc. \\
Soil Master & PVAC/acrylic latex/tripolycate & ESSI/ EBCO \\
Petrotac & asphalt, vacuum gas, oil, metal tallate & SynTech Products Corp. \\
Coherex & petroleum hydrocarbons & Witco \\
Lignosite & calcium lignin sulfonate and sugars & Georgia Pacific \\
R-8376 Surfactant & sodium dodecylbenzene sulfonate & Nevada Dust Control \\
Agriloc & $\begin{array}{l}\text { assumed hydrocarbon based on } \\
\text { decomposition products }\end{array}$ & Swift Adhesives \\
Chem Loc 411 & Vinyl acetate and acetaldehyde & Golden West Industries, Inc. \\
EMC Squared & $\begin{array}{l}\text { assumed hydrocarbon based on physical } \\
\text { properties }\end{array}$ & Soil Stabilization Products \\
& citrus oil & Polo Citrus \\
\hline
\end{tabular}


Table 6-7. ${ }^{14} \mathrm{C}$ analyses of $50 \mathrm{~mL}$ diesel fuel samples collected at the ESF. Five samples were taken from the storage tank and three were collected from the locomotive motor. Prior to measurement using accelerator based mass spectrometry (AMS) an aliquot from each sample was combusted to graphite.

\begin{tabular}{ccccccc}
\hline $\begin{array}{c}\text { CAMS } \\
\text { No. }\end{array}$ & $\begin{array}{c}\text { Sample } \\
\text { name }\end{array}$ & $\begin{array}{c}\text { Fraction } \\
\text { modern }\end{array}$ & \pm & $\mathrm{D}^{14} \mathrm{C}$ & \pm & 14C age $^{\text {(4) }}$ \\
\hline 26826 & M-DF-95-1 & 0.0003 & 0.0007 & -999.7 & 0.7 & $>51200$ \\
26827 & IM-DF-95-2 & 0.0005 & 0.0007 & -999.5 & 0.7 & $>50300$ \\
26828 & M-DF-95-3 & -0.0007 & 0.0007 & -1000.7 & 0.7 & $>\mathbf{5 2 8 0 0}$ \\
26829 & IM-DF-95-5 & 0.0001 & 0.0008 & -999.9 & 0.8 & $>52200$ \\
26830 & IM-DF-95-4 & 0.0006 & 0.0009 & -999.4 & 0.9 & $>49900$ \\
26831 & IM-DF-95-6 & 0.0009 & 0.0008 & -999.1 & 0.8 & $>48800$ \\
26832 & IM-DF-95-8 & 0.0001 & 0.0007 & -999.9 & 0.7 & $>52200$ \\
26833 & IM-DF-95-9 & 0.0000 & 0.0009 & -1000.0 & 0.9 & $>52800$ \\
26834 & IM-DF-95-7 & 0.0007 & 0.0007 & -999.3 & 0.7 & $>\mathbf{4 9 5 0 0}$ \\
\hline
\end{tabular}


Table 6-8. Experimental matrix. Diesel Fuel Hydrous Pyrolysis.

\begin{tabular}{|c|c|c|c|c|c|c|c|c|c|c|}
\hline $\begin{array}{l}\text { Exp. } \\
\text { No. }\end{array}$ & $\begin{array}{l}\text { Temp. } \\
\left({ }^{\circ} \mathrm{C}\right)\end{array}$ & $\begin{array}{c}\text { Nominal } \\
\text { pressure } \\
\text { (bars) }\end{array}$ & $\begin{array}{c}\text { Duration } \\
\text { (days) }\end{array}$ & Rocking & $\begin{array}{l}\text { Water } \\
\text { comp. }\end{array}$ & $\begin{array}{c}\text { Sample } \\
\text { composition }\end{array}$ & $\begin{array}{c}\text { Solid } \\
\text { analysis }\end{array}$ & $\begin{array}{c}\text { Organic } \\
\text { liquid } \\
\text { analysis }\end{array}$ & $\begin{array}{c}\text { Aqueous } \\
\text { phase } \\
\text { analysis }\end{array}$ & $\begin{array}{c}\text { Gas } \\
\text { analysis }\end{array}$ \\
\hline DF1 & 200 & 70 & 75 & $\begin{array}{l}\text { not } \\
\text { continuous }\end{array}$ & MilliQ & $\begin{array}{l}1 \text { water: } \\
1 \text { diesel fuel }\end{array}$ & $\mathrm{n} / \mathbf{a}$ & $\begin{array}{l}\mathrm{GC} \\
\left(\mathrm{CS}_{2}\right. \\
\text { dilution) }\end{array}$ & HPLC & GMS \\
\hline DF2 & 315 & 150 & 105 & no & MilliQ & $\begin{array}{l}10 \text { water: } \\
1 \text { diesel fuel }\end{array}$ & $n / a$ & n.a. & $\begin{array}{l}\text { HPLC } \\
\text { GC } \\
\mathrm{CO}_{2} \text { gas anal. }\end{array}$ & GMS \\
\hline DF3 & 200 & 70 & 87 & $\begin{array}{l}\text { continuous } \\
\text { after } \\
66 \text { days }\end{array}$ & $\begin{array}{l}3 \mathrm{mM} \\
\mathrm{NaHCO}_{3}\end{array}$ & $\begin{array}{l}\text { water } \\
+ \text { Fibercrete } \\
\text { wafer }\end{array}$ & $\begin{array}{l}\text { XRD } \\
\text { SEM } \\
/ \text { EDS }\end{array}$ & n.a. & $\begin{array}{l}\text { ICP-AES } \\
\text { IC } \\
\mathrm{CO}_{2} \text { gas anal. }\end{array}$ & GMS \\
\hline DF4 & 200 & 70 & 80 & yes & $\begin{array}{l}3 \mathrm{mM} \\
\mathrm{NaHCO}_{3}\end{array}$ & $\begin{array}{l}10 \text { water: } \\
1 \text { diesel fuel } \\
+ \text { Fibercrete } \\
\text { wafer }\end{array}$ & $\begin{array}{l}\text { XRD } \\
\text { SEM } \\
\text { /EDS }\end{array}$ & n.a. & $\begin{array}{l}\text { HPLC } \\
\text { GC } \\
\mathrm{CO}_{2} \text { gas anal. } \\
\text { ICP-AES } \\
\text { IC }\end{array}$ & GMS \\
\hline DF5 & 200 & 70 & 76 & yes & $\begin{array}{l}3 \mathrm{mM} \\
\mathrm{NaHCO}_{3}\end{array}$ & $\begin{array}{l}10 \text { water: } \\
1 \text { diesel fuel } \\
+ \text { Tpt wafer }\end{array}$ & $\begin{array}{l}\text { XRD } \\
\text { SEM } \\
\text { /EDS }\end{array}$ & n.a. & $\begin{array}{l}\text { HPLC } \\
\text { GC } \\
\mathrm{CO}_{2} \text { gas anal. } \\
\text { ICP-AES } \\
\text { IC }\end{array}$ & GMS \\
\hline F6 ${ }^{D}$ & 200 & 70 & 79 & yes & $\begin{array}{l}3 \mathrm{mM} \\
\mathrm{NaHCO}_{3}\end{array}$ & $\begin{array}{l}10 \text { water: } \\
1 \text { diesel fuel } \\
+ \text { Tpt and } \\
\text { Fibercrete } \\
\text { wafers }\end{array}$ & $\begin{array}{l}\text { XRD } \\
\text { SEM } \\
\text { /EDS }\end{array}$ & n.a. & $\begin{array}{l}\text { HPLC } \\
\mathrm{GC} \\
\mathrm{CO}_{2} \text { gas anal. } \\
\text { ICP-AES } \\
\mathrm{IC}\end{array}$ & GMS \\
\hline
\end{tabular}

n/a: not applicable , n.a.: not analyzed 
Table 6-9. Starting diesel fuel (LLNL motor pool) compositions measured by $\mathrm{GC}$ of $\mathrm{CS}_{2}$ extractions.

\begin{tabular}{cc}
\hline Carbon No. & $\begin{array}{c}\text { Average } \\
\text { \% peak area }\end{array}$ \\
\hline$C_{6}-C_{9}$ & $4.7 \pm 0.6$ \\
$C_{10}-C_{14}$ & $29.5 \pm 1.6$ \\
$C_{15}-C_{19}$ & $52.6 \pm 2.6$ \\
$C_{20}-C_{26}$ & $13.3 \pm 1.9$ \\
Total & 100.1 \\
\hline
\end{tabular}


Table 6-10. Organic compounds identified by GMS analyses of gas extraction from aqueous samples from experiments DF1, DF2, DF4, DF5 and DF6.

\begin{tabular}{|c|c|c|c|c|c|c|}
\hline $\begin{array}{l}\text { Organic } \\
\text { compound }\end{array}$ & Formula & DF1 & DF2 & DF4 & DF5 & DF6 \\
\hline methane & $\mathrm{CH}_{4}$ & $Y$ & $\mathrm{Y}$ & $Y$ & & \\
\hline ethane & $\mathrm{C}_{2} \mathrm{H}_{6}$ & & $\mathbf{Y}$ & $Y$ & & $\mathbf{Y}$ \\
\hline propylene & $\mathrm{C}_{3} \mathrm{H}_{6}$ & $\mathrm{Y}$ & $\mathrm{Y}$ & & & \\
\hline n-butane & $\mathrm{C}_{4} \mathrm{H}_{10}$ & $\mathbf{Y}$ & $Y$ & $Y$ & & \\
\hline i-butane & $\mathrm{C}_{4} \mathrm{H}_{10}$ & $Y$ & $\mathbf{Y}$ & $Y$ & & \\
\hline trans-2-butene & $\mathrm{C}_{4} \mathrm{H}_{8}$ & & $Y$ & & & \\
\hline propane & $\mathrm{C}_{3} \mathrm{H}_{8}$ & $\mathrm{Y}$ & $\mathrm{Y}$ & $Y$ & & \\
\hline i-pentane & $\mathrm{C}_{5} \mathrm{H}_{12}$ & & $\mathrm{Y}$ & $Y$ & $\mathbf{Y}$ & \\
\hline n-pentane & $\mathrm{C}_{5} \mathrm{H}_{12}$ & $\mathbf{Y}$ & $\mathrm{Y}$ & & & \\
\hline 2-pentene & $\mathrm{C}_{5} \mathrm{H}_{10}$ & $Y$ & $\mathrm{Y}$ & & & \\
\hline 2-methylpentane & $\mathrm{C}_{6} \mathrm{H}_{14}$ & & $\mathbf{Y}$ & & $Y$ & \\
\hline 2-methyl-1-pentene & $\mathrm{C}_{6} \mathrm{H} 12$ & & $Y$ & & & \\
\hline cyclohexene & $\mathrm{C}_{6} \mathrm{H}_{10}$ & & $\mathbf{Y}$ & & & \\
\hline 2,2-dimethylbutane & $\mathrm{C}_{6} \mathrm{H}_{14}$ & & $\mathrm{Y}$ & & & \\
\hline benzene & $\mathrm{C}_{6} \mathrm{H}_{6}$ & & $Y$ & $Y$ & $\mathbf{Y}$ & \\
\hline 2,hexene (cis,trans) & $\mathrm{C}_{6} \mathrm{H}_{12}$ & & $\mathrm{Y}$ & & & \\
\hline n-heptane & $\mathrm{C}_{7} \mathrm{H}_{16}$ & & $\mathrm{Y}$ & & & \\
\hline 1-heptene & $\mathrm{C}_{7} \mathrm{H}_{14}$ & & $\mathbf{Y}$ & & & \\
\hline ethylcyclopentane & $\mathrm{C}_{7} \mathrm{H}_{14}$ & & $\mathbf{Y}$ & & & \\
\hline toluene & $\mathrm{C}_{7} \mathrm{H}_{8}$ & & $\mathbf{Y}$ & $\mathbf{Y}$ & $\mathbf{Y}$ & $\mathbf{Y}$ \\
\hline 1-methylcyclohexene & $\mathrm{C}_{7} \mathrm{H}_{12}$ & & $\mathrm{Y}$ & & & \\
\hline 1,1-dimethylcyclopentane & $\mathrm{C}_{7} \mathrm{H}_{14}$ & & $\mathbf{Y}$ & & & \\
\hline 1,2-dimethylcyclopentane & $\mathrm{C}_{7} \mathrm{H}_{14}$ & & $\mathrm{Y}$ & & & \\
\hline 1-ethylcyclohexene & $\mathrm{C}_{8} \mathrm{H}_{14}$ & & $\mathbf{Y}$ & & & \\
\hline xylene & $\mathrm{C}_{8} \mathrm{H}_{10}$ & & $Y$ & $\mathbf{Y}$ & $\mathbf{Y}$ & \\
\hline n-octane & $\mathrm{C}_{8} \mathrm{H}_{18}$ & & $\mathbf{Y}$ & & & \\
\hline n-nonane & $\mathrm{C}_{9} \mathrm{H}_{2} \mathrm{O}$ & & $Y$ & & & \\
\hline
\end{tabular}


Table 6-11. Major hydrocarbons and their abundances relative to maximum peak area as determined by GCMS of final aqueous samples from experiments DF4, DF5, and DF6.

\begin{tabular}{|c|c|c|c|c|c|}
\hline \multirow[b]{2}{*}{$\begin{array}{l}\text { Retention } \\
\text { time (min) }\end{array}$} & \multirow[b]{2}{*}{ Compound } & \multirow[b]{2}{*}{$\begin{array}{c}\text { Boiling } \\
\text { point }\left({ }^{\circ} \mathrm{C}\right)\end{array}$} & \multicolumn{3}{|c|}{$\begin{array}{l}\text { Percent of maximum peak } \\
\text { area }\end{array}$} \\
\hline & & & DF4 & DF5 & DF6 \\
\hline 13.06 & benzene & 80.1 & 23.66 & 18.32 & 25.87 \\
\hline 18.86 & toluene & 110.6 & 100 & 100 & 100 \\
\hline 24.56 & ethyl benzene & 136.2 & 31.37 & 28.21 & 21.65 \\
\hline 25.19 & p-xylene \& m-xylene & 138.3 & 82.19 & 80.45 & 66.77 \\
\hline 26.51 & o-xylene & 144.4 & 49.38 & 40.82 & 35.79 \\
\hline 30.22 & $\begin{array}{l}\text { 1-ethyl 3-methyl } \\
\text { benzene }\end{array}$ & 161.3 & 26.90 & 24.43 & 17.27 \\
\hline 30.56 & $\begin{array}{l}1,3,5 \text { - trimethyl } \\
\text { benzene }\end{array}$ & 165 & 16.03 & 14.53 & 10.73 \\
\hline 30.96 & $\begin{array}{l}\text { 1-ethyl 2-methyl } \\
\text { benzene }\end{array}$ & 165.2 & 16.00 & 13.97 & 11.09 \\
\hline 31.63 & $\begin{array}{l}\text { 1,2,4-trimethyl } \\
\text { benzene }\end{array}$ & 169 & 52.67 & 49.77 & 37.08 \\
\hline 32.64 & $\begin{array}{l}\text { 1,2,3-trimethyl } \\
\text { benzene) }\end{array}$ & 176 & 30.60 & 26.84 & 21.05 \\
\hline 33.03 & indane & 177.8 & 14.78 & 13.39 & 10.55 \\
\hline 36.62 & $\begin{array}{l}\text { 1-methyl-2-(2- } \\
\text { propenyl) benzene }\end{array}$ & 198 & 24.05 & & \\
\hline 36.91 & $\begin{array}{l}\text { tetrahydro } \\
\text { naphthalene }\end{array}$ & 207.6 & 20.48 & 14.74 & 12.53 \\
\hline 37.44 & naphthalene & 218 & 39.45 & 33.9 & 30.35 \\
\hline
\end{tabular}


Table 6-12. Yucca Mountain bacterial isolates displaying corrosion-related activities.

\begin{tabular}{|c|c|c|c|c|}
\hline Strain\#" & Species Identification ${ }^{b}$ & Acid Production $^{c}$ & Sulfide Production ${ }^{d}$ & Slime Production \\
\hline ESF-C1 & Cellulomonas flavigena & $\mathbf{X}$ & $X$ (oxic) & \\
\hline LB - 7 1h-RT-13 & Pseudomonas stutzeri & $\mathbf{X}$ & & \\
\hline ESF-71h-RT-4 & Flavobacterium esteroaromaticum & $\mathbf{X}$ & $X$ (oxic) & \\
\hline LBan-U7 & uncharacterized & $\mathbf{X}$ & & \\
\hline LBan-UW2 & Cellulomonas turbata & $\mathbf{X}$ & & \\
\hline LB $-71 \mathrm{~h}-50-3$ & probably Bacillus sp. & $\mathbf{X}$ & & \\
\hline ESFan-U4 & Bacillus circulans & $\mathbf{X}$ & & \\
\hline LBan-C1 & Arachnia propionica (poor match) & $\mathbf{X}$ & $\mathrm{X}$ (oxic/anoxic) & \\
\hline LBan-UW2 & Cellulomonas turbata & $\mathbf{X}$ & & \\
\hline LBan-U1 & Cellulomonas galida & $\mathbf{x}$ & & \\
\hline LBan-U2 & Bacillus pabuli & $\mathbf{X}$ & $X$ (anoxic) & \\
\hline LBan-U3 & Bacillus pantothenticus & & $X$ (anoxic) & $\mathbf{X}$ \\
\hline $\mathrm{LB}-71 \mathrm{~h}-50-2$ & Bacillus pumilus subgroup B & & $X$ (anoxic) & \\
\hline$L B-71 h-50-4$ & Bacillus subtilus & & $\mathrm{X}$ (anoxic) & $\mathbf{X}$ \\
\hline $\mathrm{LB}-71 \mathrm{~h}-50-6$ & probably Bacillus sp. & & $X$ (anoxic) & $\mathbf{x}$ \\
\hline ESF-71h-RT-1 & Flavobacterium esteroaromaticum & & $X$ (oxic) & \\
\hline LB-C1 & uncharacterized & & $X$ (oxic) & $\mathbf{X}$ \\
\hline LB-C2 & uncharacterized & & $X$ (oxic) & \\
\hline LB-C7 & Pseudomonas stutzeri & & $X$ (oxic) & \\
\hline LB-71h-RT-15 & Pseudomonas pseudoflava & & & $\mathbf{X}$ \\
\hline LB-71h-RT-4 & Pseudomonas pseudoflava & & & $\mathbf{x}$ \\
\hline $\mathrm{LB}-\mathrm{CW}-6$ & Arthrobacter oxydans & & & $\mathbf{X}$ \\
\hline
\end{tabular}

'ESF=Exploratory Study Facility; LB=Large Block; an=isolated under anaerobic conditions; $C=c$ crushed rock isolate; $U=$ uncrushed rock isolate; $W=$ isolated from after washing rock; $71 \mathrm{~h}=$ isolated after 71 hours of growth; $R T=$ room temperature isolate; $50=50^{\circ} \mathrm{C}$. isolate.

betermined by fatty acid analysis using the MIDI/Hewlett Packard microbial identification system (MIS; Analytical Services, Inc., VT); identification of given isolates may be tentative due to a lesser degree of similarity with type organisms contained in the MIS database.

'Determined after growth in R2 media (Reasoner and Geldreich, 1985) with or without $0.5 \%$ glucose and pH indicators bromocresol purple and methyl red.

${ }^{d}$ Determined after growth in R2 agar media (Difco) containing $0.75 \%$ proteose peptone \#3 (Difco) and lead acetate.

'Determined after growth on R2 agar (Difco). 
Table B-1. Cement nomenclature and standards. Designations for cements are standardized by organizations such as the American Society for Testing and Materials (ASTM) and the American Petroleum

Institute. Cement chemists have developed a nomenclature for phase composition that is based on ratios of oxides; the notation carries no structural implications. The following shorthand is standard.

\section{Letter}

designation

Phase composition

$\begin{array}{ll}\mathrm{C} & \mathrm{CaO} \\ \mathrm{S} & \mathrm{SiO}_{2} \\ \mathrm{M} & \mathrm{M}_{8} \mathrm{O} \\ \mathrm{H} & \mathrm{H}_{2} \mathrm{O} \\ \overline{\mathrm{C}} & \mathrm{CO}_{2} \\ \overline{\mathrm{S}} & \mathrm{SO}_{3} \\ \mathrm{~N} & \mathrm{Na}_{2} \mathrm{O} \\ \mathrm{P} & \mathrm{P}_{2} \mathrm{O}_{5} \\ \mathrm{~A} & \mathrm{Al}_{2} \mathrm{O}_{3} \\ \mathrm{~F} & \mathrm{Fe}_{2} \mathrm{O}_{3} \\ \mathrm{~K} & \mathrm{~K}_{2} \mathrm{O} \\ \text { AFt } & \mathrm{Calcium} \text { aluminum trisulfate (e.g., ettringite) } \\ \text { AFm } & \text { Calcium aluminum monosulfate } \\ & \text { (e.g., "monosulfate") } \\ \text { OPC } & \text { Ordinary portland cement } \\ \text { SRPC } & \text { Sulphate-resisting portland cement }\end{array}$


Table B-2. Summary of major hydration reactions (Bensted, 1989).

\section{Below $100^{\circ} \mathrm{C}$}

(1)

Tricalcium silicate (alite): $2 \mathrm{C}_{3} \mathrm{~S}+6 \mathrm{H} \Rightarrow>\left(\mathrm{C}_{3} \mathrm{~S}_{2} \mathrm{H}_{3}\right)+3 \mathrm{CH}(\mathrm{C}-\mathrm{S}-\mathrm{H})$

(2)

Dicalcium silicate (belite): $2 \mathrm{C}_{2} \mathrm{~S}+4 \mathrm{H}=>\left(\mathrm{C}_{3} \mathrm{~S}_{2} \mathrm{H}_{3}\right)+\mathrm{CH}$

(3)

Tricalcium aluminate (aluminate):

(a) $\mathrm{C}_{3} \mathrm{~A}+3 \overline{\mathrm{CS}} \mathrm{H}_{2}+26 \mathrm{H}=>\mathrm{C}_{3} \mathrm{~A} \cdot 3 \mathrm{C} \overline{\mathrm{S}} . \mathrm{H}$ (ettringite)

(b) When the gypsum is used up: $\mathrm{C}_{3} \mathrm{~A}+\mathrm{CH}+12 \mathrm{H} \Rightarrow \mathrm{C}_{4} \mathrm{AH}_{13}$

(c) This then reacts with the ettringite formed: $\mathrm{C}_{3} \mathrm{~A} \cdot 3 \mathrm{C} \overline{\mathrm{S}} \cdot \mathrm{H}_{32}+2 \mathrm{C}_{4} \mathrm{AH}_{13}=>$ $3\left(\mathrm{C}_{3} \mathrm{~A} \cdot \mathrm{C} \overline{\mathrm{S}} \cdot \mathrm{H}_{12}\right)+2 \mathrm{CH}+2 \mathrm{OH}$ ("monosulphate")

(4)

Calcium aluminoferrite (ferrite):

(a) $\mathrm{C}_{2} \mathrm{~A}_{0.5} \mathrm{~F}_{0.5}+\mathrm{CH}+3 \mathrm{CSH}_{2}+25 \mathrm{H} \Rightarrow \mathrm{C}_{3} \mathrm{~A}_{0.5} \mathrm{~F}_{0.5} 3 \mathrm{C} \overline{\mathrm{S}} . \mathrm{H}_{32}$ (ettringite)

(b) When the gypsum is used up: $\mathrm{C}_{2} \mathrm{~A}_{0.5} \mathrm{~F}_{0.5}+2 \mathrm{CH}+11 \mathrm{H} \Rightarrow \mathrm{C}_{4} \mathrm{~A}_{0.5} \mathrm{~F}_{0.5} \mathrm{H}_{13}$

(c) This then reacts with the ettringite formed: $2 \mathrm{C}_{4} \mathrm{~A}_{0.5} \mathrm{~F}_{0.5} \mathrm{H}_{13}+$

$$
\mathrm{C}_{3} \mathrm{~A}_{0.5} \mathrm{~F}_{0.5} 3 \mathrm{C} \overline{\mathrm{S}} . \mathrm{H}_{32}=3\left(\mathrm{C}_{3} \mathrm{~A}_{0.5} \mathrm{~F}_{0.5} \cdot \mathrm{CS} \cdot \mathrm{H}_{12}\right)+2 \mathrm{CH}+2 \mathrm{OH}
$$

Above $100^{\circ} \mathrm{C}$

(1) Main product is $\alpha$-dicalcium silicate hydrate, $\mathrm{C}_{2} \mathrm{SH}$, which has high permeability and low compressive strength; above $200^{\circ} \mathrm{C}$ it forms tricalcium silicate hydrate, $\mathrm{C}_{6} \mathrm{~S}_{2} \mathrm{H}_{3}$.

(2) Additions of $\sim 35$ to $40 \%$ silica yield tobermorite, $\mathrm{C}_{5} \mathrm{~S}_{6} \mathrm{H}_{5}$, which has low permeability and good compressive strength; above $150^{\circ} \mathrm{C}$ it forms xonotlite, $\mathrm{C}_{6} \mathrm{~S}_{6} \mathrm{H}$ and gyrolite, $\mathrm{C}_{2} \mathrm{~S}_{3} \mathrm{H}_{2}$, which has higher permeability and lower compressive strength.

(3) Hydrogarnet, $\mathrm{Ca}_{3}(\mathrm{Al}, \mathrm{Fe})_{2}\left[\mathrm{SiO}_{4} /(\mathrm{OH})_{4}\right]_{3}$ and stratlingite $\mathrm{Ca}_{2}(\mathrm{Al}, \mathrm{Fe})_{2} \mathrm{SiO}_{7} 8 \mathrm{H}_{2} \mathrm{O}$ are also formed from the ferrite and aluminate phases. 
Table B-3. Names, formulas, and standard terms of cement phases. CA is the chemical abstracts number.

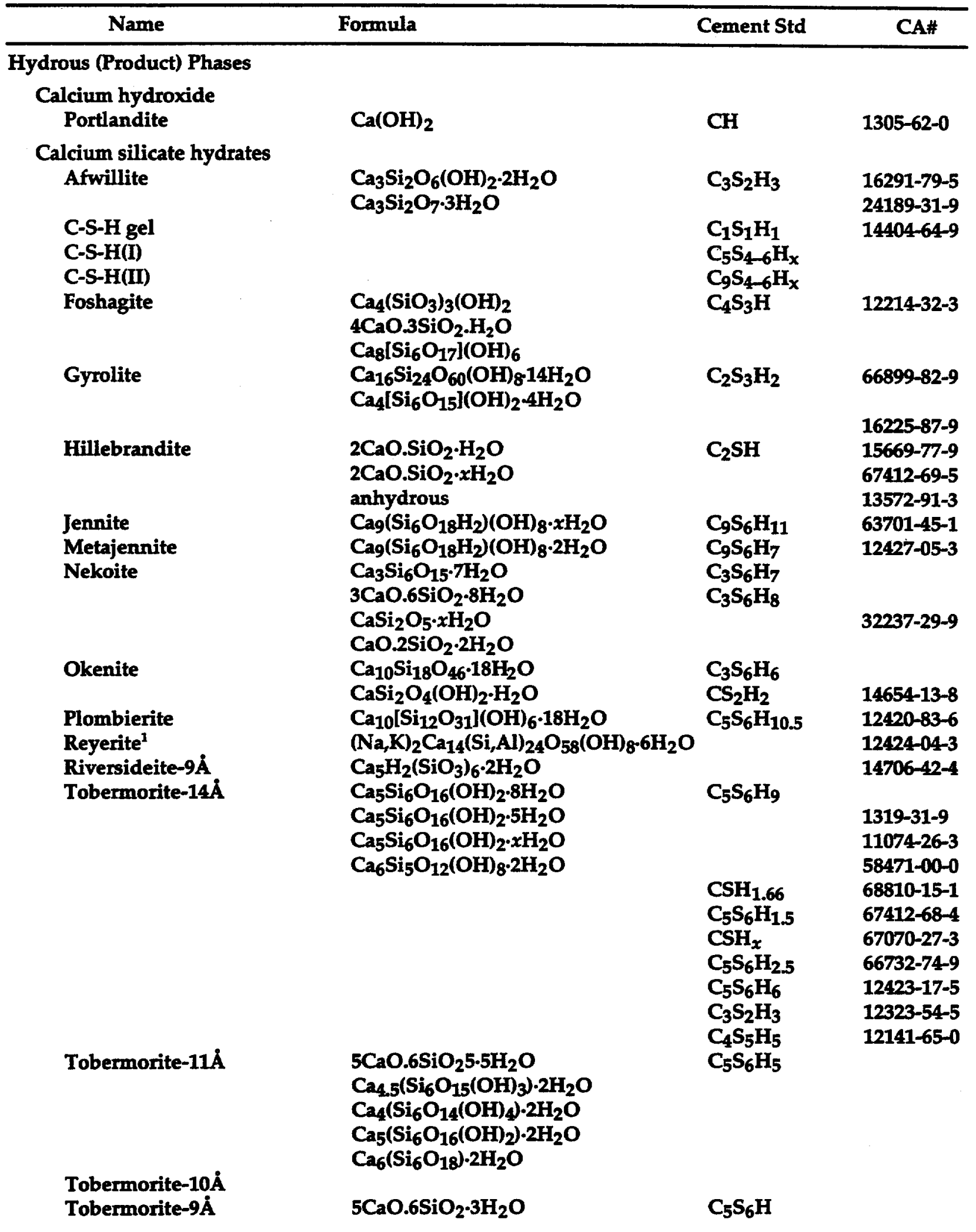


Table B-3. (Continued.)

\begin{tabular}{|c|c|c|c|}
\hline Name & Formula & Cement Std & CA\# \\
\hline \multicolumn{4}{|c|}{ Anhydrous (Reactant) Phases } \\
\hline $\begin{array}{l}\text { Calcium oxide } \\
\text { Lime }\end{array}$ & $\mathrm{CaO}$ & C & 1305-78-8 \\
\hline $\begin{array}{l}\text { Calcium silicat } \\
\text { Belite }\end{array}$ & beta- $\mathrm{Ca}_{2} \mathrm{SiO}_{4}$ & $\beta-C_{2} S$ & $\begin{array}{l}14981-10-3 \\
10034-77-2\end{array}$ \\
\hline Alite & $\mathrm{Ca}_{3} \mathrm{SiO}_{5}$ & $\mathrm{C}_{3} \mathrm{~S}$ & 12168-85-3 \\
\hline Calcium alumi & $\begin{array}{l}\mathrm{CaAl}_{4} \mathrm{O}_{7} \\
\mathrm{CaO} . \mathrm{Al}_{2} \mathrm{O}_{3} \\
\mathrm{Ca} \mathrm{Al}_{2} \mathrm{O}_{6}\end{array}$ & $\begin{array}{l}\mathrm{CA}_{2} \\
\mathbf{C A} \\
\mathrm{C}_{3} \mathrm{~A}\end{array}$ & $12042-78-3$ \\
\hline $\begin{array}{l}\text { Calcium iron al } \\
\text { "Ferrite" }\end{array}$ & $\underset{\text { solid solution }}{\mathrm{Ca}_{4} \mathrm{Fe}_{4} \mathrm{O}_{10}-\mathrm{Ca}_{4} \mathrm{FeAl}_{3} \mathrm{O}_{10}}$ & $C_{2}(A, F)$ & \\
\hline
\end{tabular}

${ }^{1}$ Formula for end-member ( $\mathrm{Ca}-\mathrm{Si}-\mathrm{H}_{2} \mathrm{O}$ system) is not yet determined. 

$-$

$+$ 



\section{Contents}

Chapter 7.0 Integrated Testing.....................................................................................................7-2

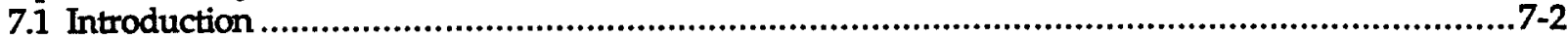

7.1.1 Scope of Integrated Testing Activities.......................................................................7-2

7.1.2 Relationship of Integrated Testing Activities to Other YMP Activities...........................7-2

7.2 Data Inputs Required for Bounding Transport and Source Terms ...........................................7-3

7.3 Chemical, Mineralogical, and Physical Characteristics of EBS/NFE Components Expected to Significantly Affect Radionuclide Transport Through the EBS/NFE ................................7-3

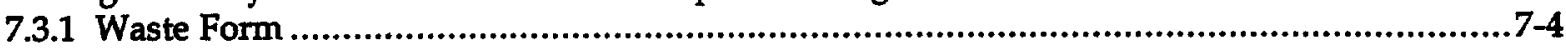

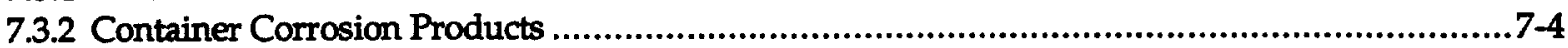

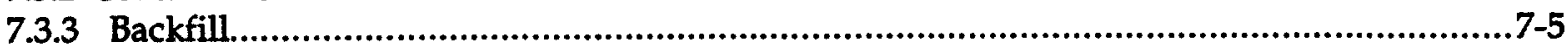

7.3.4 Characterization of Natural Colloids at Yucca Mountain ..........................................7-5

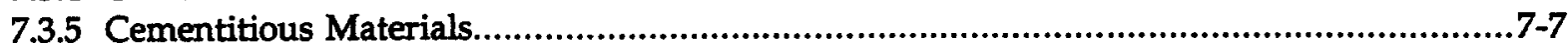

7.3.6 Altered Host Rock Adjacent to the Engineered Barrier.................................................7-8

7.4 Transport Studies in Host Rock and Minerals.........................................................................7-9

7.4.1 Characterization of Repository Rock Pore Size Distribution and Diffusion of Actinides .....7-9

7.4.2 Diffusion of Radionuclides in Clinoptilolite ................................................................. 7-10

7.4.3 Flow and Transport Through Topopah Spring Tuff..................................................... 7-12

7.5 Field Testing Sorption Models Under Conditions of Fracture Dominated Flow ....................... 7-15

7.5.1 Cation Exchange .................................................................................................... 7-16

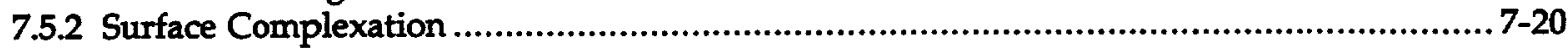

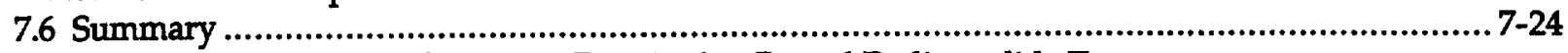

7.7 Summary of Gaps in Information Required to Bound Radionuclide Transport

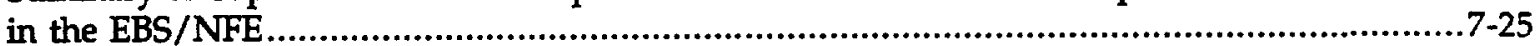

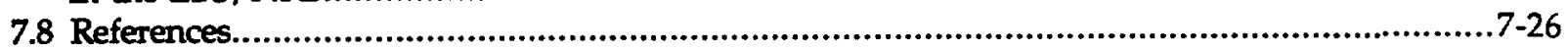




\title{
Chapter 7.0 Integrated Testing
}

\author{
Brian E. Viani
}

\subsection{Introduction}

The role of the Integrated Radionuclide Release: Tests and Model Development activity (Integrated Testing) is to bound the flux of radionuclides that pass the Engineered Barrier System/Near Field Environment (EBS/NFE) (Viani, 1995a). The purpose of this activity is to measure and model the transport of radionuclide elements from the waste form through the introduced materials, their alteration products, and altered host rock that will comprise the post-containment near field environment of the potential repository at Yucca Mountain. Experimental measurements will be combined with conceptual and mechanistic models to bound the concentrations of radionuclide elements that will be released from the EBS/NFE for any given release from the waste form. The estimated releases will be used by the EBS/NFE Subsystem Performance Assessment task (EBS/NFE PA) to calculate the source term to be used in Total System Performance Assessment (TSPA).

\subsubsection{Scope of Integrated Testing Activities}

Integrated Testing activities are directly concerned with measuring and modeling the effects that hydrothermally altered EBS/NFE materials have on the transport of radionuclides released from the waste form as it interacts with groundwater reentering the repository after the dry-out period. These interactions, which may include sorption, precipitation, and matrix imbibition, are an important element of the strategy for evaluating the Yucca Mountain site (CRWMS M\&O, 1996). The most important materials to be addressed include: waste package corrosion products, backfill/packing, cementitious materials, and altered repository rock (Viani, 1995b).

\subsubsection{Relationship of Integrated Testing Activities to Other YMP Activities}

To address the issues of radionuclide dispersion, retardation, and depletion in the EBS/NFE, Integrated Testing activities will require material, data, and models from the following activities: ambient and altered zone geochemistry and thermohydrology, waste package materials and waste form testing, and man-made materials (Viani, 1995a).

7.1.2.1 Current Status of Integrated Testing Activities. As a result of the change in reference repository design from a borehole emplaced waste package to a drift emplaced waste package, the scope of Integrated Testing activities has expanded to include the interaction of materials other than the host repository rock adjacent to the waste package. Earlier Integrated Testing activities were focused on the processes expected to play a role in controlling radionuclide transport in the altered host rock. Because of the expanded scope there are many areas that have not been addressed that are important to the overall waste isolation strategy put forward by 
the project (CRWMS M\&O, 1996). To date, the Integrated Testing activity has addressed data and models related to:

1. Diffusion of radionuclides through, and pore-size distribution of, repository rocks.

2. Characterization of colloids in Yucca Mountain groundwaters and in experimental fluids passed through repository rocks.

3. Transport of soluble conservative tracers through fractured repository rock at elevated temperatures.

4. The role of diffusion in controlling sorption by the zeolite clinoptilolite.

5. Testing cation exchange and surface complexation models against field data for a fractured aquifer system.

\subsection{Data Inputs Required for Bounding Transport and Source Terms}

To assess the role of the EBS/NFE in controlling the flux of radionuclides leaving the repository, the following information is necessary.

Near field environment properties that will be required include:

1. The temperature range over which transport will occur.

2. The flux of radionuclide-bearing groundwater exiting the waste canister.

3. The mode of groundwater flow; i.e., saturated, unsaturated, episodic, etc.

4. The saturation state of the EBS/NFE materials comprising the flow path.

5. The potential of water in the system; i.e., $p / p^{\circ} \mathrm{H}_{2} \mathrm{O}$.

EBS/NFE flow-path-component material properties that will be required include:

1. The composition of the radionuclide-bearing groundwater after it contacts the waste form ( $\mathrm{pH}$, soluble species, colloidal species).

2. The elemental, mineralogical, microbial, and physical properties of container corrosion products, hydrothermally altered backfill material, hydrothermally altered concrete and other introduced materials, and hydrothermally altered repository rock.

\subsection{Chemical, Mineralogical, and Physical Characteristics of EBS/NFE Components Expected to Significantly Affect Radionuclide Transport Through the EBS/NFE}

Except for episodic fracture flow, the low water flux expected in the postemplacement and post-containment environment will result in the fluid chemistry being controlled by the flow-path component through which the fluid is passing. The chemical and mineralogical properties of certain of the EBS/NFE materials comprising the effective flow path of radionuclide-bearing groundwaters are expected to play a major role in the transport of radionuclides. The following sections summarize and highlight some of the features that can be important to transport. The reader is to refer to reports and papers regarding the flow-path elements listed below, some of which can be found in the Geochemistry, Man-Made Materials, and Altered Zone sections of this report. 


\subsubsection{Waste Form}

The waste form will control the rate at which radionuclides are released to the contacting groundwaters. An expected scenario for water to contact the waste form would include the following events:

1. During the period of complete containment, container materials are corroded by interaction with liquid and vapor-phase water at elevated temperature.

2. After containers are breached, waste forms interact primarily with vapor phase water during the period of rehydration of the repository, at a temperature above ambient.

3. Liquid water contacts the vapor-altered waste and flows across it and eventually out of the containers into the surrounding altered EBS/NFE materials.

4. Without explicit provision for an oxygen sink, the EBS/NFE environment is assumed to be oxygenated during the time period of radionuclide transport through it.

Because of the unsaturated nature of the repository environment, and the expected low flux of water contacting the waste form following breaching of the waste container, waste forms will have an important effect on the composition of the groundwater leaving the container; i.e., the fluid exiting the waste container will be strongly conditioned by the waste itself (and by interaction with the ancillary materials in the container; e.g., filler, spacers, etc.).

Groundwater reacting with spent fuel will have reduced levels of Si and other constituents compared with ambient groundwater as a result of formation of uranium silicates and other silicates (Wilson, 1990; Bates et al., 1995a). Layer silicate, uranium-oxide, and uranium-silicate colloids will be released during the interaction of groundwater with spent fuel (Bates et al., 1995a).

Interactions of groundwater with glass waste form may yield a distinctly different chemistry than spent fuel. Laboratory experiments have shown that fluids reacted with glass at high solid to solution ratios (saturated, and under dripping conditions) have relatively high $\mathrm{pH}$, and elevated levels of $\mathrm{Si}, \mathrm{B}$, and $\mathrm{Li}$, and distinctly different colloids than spent fuel (Bates et al., 1995b). The actual pH expected in the repository will also depend on the reservoir of $\mathrm{CO}_{2}$ in gas phase in the system. A large reservoir of $\mathrm{CO}_{2}$ could buffer the system at a lower $\mathrm{pH}$ than is observed in laboratory experiments. Colloids released from glass are predominantly layer silicates with some colloidal phosphates also observed.

We may expect that fluids emanating from the waste package are likely to contain considerable quantities of radionuclide-bearing colloids, be depleted in dissolved oxygen and $\mathrm{Si}$ (for spent fuel), and potentially high in $\mathrm{pH}$ (for glass). The stability of the colloids that do leave the container is an issue that has not been resolved.

\subsubsection{Container Corrosion Products}

It would be expected that breaching the waste container would occur as a result of corrosion of the metallic components of the waste package in the humid, elevated temperature regime anticipated during the repository cool-down period. Hence, the first materials likely to be encountered by radionuclide-bearing fluids leaving the 
container are the corrosion products from the waste container. These corrosion products are likely to be oxides and/or silicates of the metals comprising the container wall and the internal structures of the container.

Mineralogically, these products would be expected to be dominated by oxides and oxy-hydroxides of iron that may be substituted with various other metal elements, and may be intermixed with other oxides formed from other metallic constituents of the waste package. Physically, these materials would be expected to be finely divided porous media that, depending on whether they were contained by surrounding materials, could be loose (i.e., a pile of sloughed off material) or relatively compact.

Chemical interaction of radionuclide-bearing fluids with canister corrosion products is expected to be dominated by surface chemical effects. Retardation of $U$, $\mathrm{Np}$, and other metals via surface complexation reactions (Meijer, 1990; Dzombak and Morel, 1990) would be considerably greater than in Yucca Mountain tuffs (Table 7-1). Adsorption of inorganic carbon and dissolved silica may also be significant (Van Geen et al., 1994; Waite et al., 1994; Dzombak and Morel, 1990).

Because the corrosion products are expected to be finely divided, there may be a potential for addition of iron oxide and other metallic oxide colloids to the groundwater. There will also be a potential for filtration of waste-form derived colloids.

\subsubsection{Backfill}

Although the emplacement of backfill has yet to be finalized, if tuff is used, its chemical effects will be moderate in comparison with its physical effects. Hydrothermal alteration of the tuff is not expected to alter its mineralogical or chemical composition outside the range displayed by the tuffs presently existing at Yucca Mountain (Viani and Bruton, 1992b). However, redistribution of relatively small quantities of silica, coupled with precipitation/dissolution of sorptive minerals could significantly change the behavior of a specific crushed tuff with respect to radionuclide transport. A crushed tuff of coarse sand to gravel would present an effective barrier to transport as long as it remains unsaturated (Conca, 1990). However, episodic flow might short circuit the backfill and potentially entrain significant quantities of colloids. The colloids derived from this material should be similar in composition, but not in quantity, to those found in present day Yucca Mountain groundwaters.

\subsubsection{Characterization of Natural Colloids at Yucca Mountain}

We have characterized the types of colloids that are found naturally in Nevada Test Site (NTS) and Yucca Mountain groundwaters and in core flow experiments using TSw2 tuff (Buchholtz-ten Brink et al., 1990, 1992; Martin et al., 1991; Viani and Martin, 1994b).

The transport of radionuclides through the EBS/NFE and the far field may be affected by the presence and/or formation of colloids suspended in the fluid phase (Triay et al., 1993a). Suspended colloids may affect the transport of radionuclides by increasing the partitioning of the radionuclide into the fluid phase, by changing the flow path of the radionuclide, and by reducing the groundwater travel time to the 
accessible environment. The primary focus of colloid studies carried out in the Integrated Testing activity has been to develop techniques to identify inorganic colloidal particles $(<1 \mu \mathrm{m})$ that may be present in natural and experimental aqueous fluids. The methods developed were used to characterize colloids in groundwater collected from the NTS, including water from well J13, and in fluid obtained from laboratory core-flow experiments (Viani and Martin, 1994a).

7.3.4.1 Colloids in Yucca Mountain groundwaters. Groundwaters from 10 wells were sampled and the suspended colloids characterized by filtration and gravimetric analysis, $x$-ray diffraction (XRD), x-ray fluorescence (XRF), light scattering, scanning electron microscopy (SEM), and transmission electron microscopy (TEM) [including energy dispersive $x$-ray spectroscopy (EDS) and selected area electron diffraction (SAED)] (Viani and Martin, 1994b).

The gravimetrically measured concentration of suspended particles $>0.15 \mu \mathrm{m}$ was on the order of $1 \mathrm{mg} / \mathrm{L}$. In light of previously published colloid concentrations for deep groundwaters (McCarthy and Degueldre, 1993) and for water from Well J13 (Ogard, 1987), it is likely that these measurements overestimate the in situ groundwater colloid load. Given the strong relationship between pumping rate and colloid load (Puls et al., 1992), it is probable that colloids may have been stripped from the well-bore area during sampling.

Characterization of the colloids using the instrumental techniques listed showed that with the exception of a few particles that were obvious contaminants (e.g., metal particles), the colloidal particles that were identified were consistent with the lithology of the aquifer from which the groundwater was drawn. Of the particles identified by SAED and EDS, a large fraction are layer silicates. Based on the mineralogy of the groundwater-bearing rocks, it appears that these particles are present in the groundwater at a greater fraction than they are in the rock. This may represent a bias toward fracture-filling minerals, which are often layer silicates, or it could represent a pervasive contaminant. There may also be a bias toward identifying layer silicates because of their stability under the electron beam (contrasted with zeolites) and because they may dominate the larger $(>0.5 \mu \mathrm{m})$ particles that were suitable for identification by SAED. Colloidal silica polymorphs (quartz, cristobalite, amorphous silica) and iron oxides were also identified in the groundwater samples.

7.3.4.2 Colloids in J13 groundwater. Groundwater from Well J13 was analyzed for colloids on samples collected about $2.5 \mathrm{yr}$ apart. The colloid concentration from the earlier sampling was determined by filtration and gravimetry. For the later sampling ${ }^{(1)}$, colloid concentration was determined by counting particles retained on $0.015-\mu \mathrm{m}$ polycarbonate filters.

The number of particles ranged between 0.6 and $1.5 \times 10^{10}$ particles/L. These values are similar to Degueldre's estimate for an earlier sampling of Well J13

(1) Water samples were collected under the direction of Ines R. Triay, LANL. Unfiltered, 0.4- $\mu \mathrm{m}$, and $0.05-\mu \mathrm{m}$ filtered samples were collected on $11 / 16 / 93$ and sent to LLNL where they were refrigerated until analyzed. 
groundwater (GIT, 1993). If the number of particles counted in the later sample of J13 ( $<0.4-\mu \mathrm{m}$ fraction) is converted to mass according to McCarthy and Degueldre's formula (1993) (assuming a density of $2 \mathrm{~g} / \mathrm{cm}^{3}$ ), the concentration would range between $0.007-0.016$ and $0.05-0.125 \mathrm{mg} / \mathrm{L}$, for 100 and $200 \mathrm{~nm}$ spherical particles respectively. These estimates are similar to Ogard's (1987) estimate, but are one to two orders of magnitude smaller than the concentration for J13 measured gravimetrically $(1.7 \mathrm{mg} / \mathrm{L})$. It is likely that the latter value overestimates the colloid load because of contamination or too rapid a pumping rate during sampling.

The role that natural colloids may play in transporting radionuclides through the EBS/NFE will depend directly on their affinity for radionuclide species that may sorb to them, the reversibility of sorption, and their concentration. For linear instantaneous sorption of a radionuclide species on suspended colloids, the ratio of the radionuclide carried in the solution in the presence of the colloid to that in the absence of the colloid is approximated by:

$$
C_{c+s} / C_{s}=+m_{c} K_{d}
$$

where, $m_{c}$ is the concentration of colloid in suspension, and $K_{d}$ is the equilibrium linear partition coefficient for the radionuclide species on the colloid. This relationship holds for soluble radionuclide species whose concentrations are controlled by either a solubility limit or by partitioning to the host rock. It is apparent that very large $\mathrm{K}_{\mathrm{d}}$ 's $\left(>10^{5} \mathrm{~mL} / \mathrm{g}\right)$ and colloid concentrations $(>2 \mathrm{mg} / \mathrm{L})$ are required to increase the radionuclide carrying capacity of the solution by a significant amount (Fig. 7-1). Of the colloids identified, only illite and clinoptilolite (for Cs), and the iron oxides $\left(\mathrm{U}, \mathrm{Np}\right.$ ) have the potential for $\mathrm{K}_{\mathrm{d}}$ 's above $10^{4} \mathrm{~mL} / \mathrm{g}$. Waste package corrosion products have the potential to add considerable quantities of colloidal oxides to the EBS/NFE. Because Np has been identified by total system performance analysis (TSPA) calculations as a major contributor to released dose, the issue of colloidal transport of $\mathrm{Np}$ will need to be addressed.

7.3.4.3 Colloids in effluent from flow experiments. Suspended particles in samples of fluids that had passed through a saw-cut fracture (25- $\mu \mathrm{m}$ aperture) in a core of Topopah Spring tuff (Viani and Martin, 1993, 1994a) were analyzed by TEM, EDS, and SAED. These particles consisted of iron oxides (hematite) and layer silicates (mica, illite), and could be reasonably ascribed to the core sample or derived from the tools used to create the fracture.

\subsubsection{Cementitious Materials}

The most likely flow-path component a radionuclide-bearing fluid will encounter after passing through waste package corrosion products is the hydrothermally altered remains of concrete-bearing invert or other structures. The chemical effect of these materials on radionuclide transport will be most important. The $\mathrm{pH}$ of fluids within this flow-path component would be expected to be quite high ( $>12$ ) when the cement is relatively fresh (young). Calcium aluminosilicate gels 
present in fresh cement will eventually alter to crystalline phases. Because the thermodynamic data for cement minerals are sparse (Bruton et al., 1993), predicting the mineralogical and chemical composition of the hydrothermally altered cements, and the effect of this alteration on radionuclide transport, is uncertain.

Experiments and modeling have suggested that the $\mathrm{pH}$ of fluids passing through concretes at ambient temperatures would be expected to remain very high for tens of thousands to hundreds of thousands of years (Atkinson et al., 1989). However, the $\mathrm{pH}$, sorptive capacity, and ability of the hydrothermally altered material to sequester radionuclides could be significantly different from unaltered concrete.

Radionuclide partition coefficients, $\mathrm{K}_{\mathrm{d}}$ 's, measured for cements (Table 7-1) appear quite favorable in comparison to $K_{d}$ 's for Yucca Mountain devitrified tuffs, especially for $\mathrm{U}$ and $\mathrm{Np}$ (the radionuclide with the greatest long-term impact on repository performance). It is possible that the $K_{d}$ 's that are measured for $U$ (potentially $\mathrm{Np}$ as well) in cement may reflect the precipitation of a relatively insoluble phase in addition to sorption (Atkins et al., 1988).

At least during the early stages of the repository, the cement components would be expected to release significant quantities of colloids (Ramsay et al., 1988). It is not known whether this release of colloidal material would continue after the cement has undergone chemical and mineralogical alteration associated with long-term heating.

The physical state of concretes and other cementitious materials may evolve from a consolidated and fractured porous medium to a highly fractured and/or crushed porous medium as a result of chemical and physical alteration.

\subsubsection{Altered Host Rock Adjacent to the Engineered Barrier}

The host rock immediately adjacent to the EBS that will likely be altered by hydrothermal interaction with groundwater and the potentially reactive fluids leaving the repository is the last flow-path component considered part of the EBS/NFE.

In the absence of influx of alkaline fluids, the alteration products and chemistry of the flow-path component would be expected to be similar to that of a crushed-tuff backfill flow-path component. However, interaction of alkaline fluids derived from cementitious materials with the repository host rock may cause significant alteration of the flow-path, especially the hydrologic connection between fracture and matrix. A potential for dissolution of rock at the contact with cement or concrete by alkaline fluids, and subsequent downstream precipitation of calcite, calcium silicates, and zeolites could potentially reduce the porosity adjacent to the fracture and also the permeability in a direction normal to the fracture wall, thus "armoring" the fracture, and reducing the extent of radionuclide retardation due to matrix imbibition and diffusion (Steefel and Lichtner, 1994). This could also potentially decrease the permeability so that fluid flow rates might be significantly reduced, resulting in longer travel times. 


\subsection{Transport Studies in Host Rock and Minerals}

\subsubsection{Characterization of Repository Rock Pore Size Distribution and Diffusion of Actinides}

Based on the earlier concept of waste package emplacement in boreholes within the repository rock, Integrated Testing studies focused on diffusive transport of radionuclides in near-field TSw2 rock. Pore size distribution measurements (Buchholtz-ten Brink et al., 1992; Klavetter and Peters, 1986) and direct measurement of elemental tracer concentration profiles in TSw2 samples exposed to actinide-bearing solutions (Phinney et al., 1987, McKeegan et al., 1989) are in agreement. A volumetrically small $(<\sim 2-5 \%)$ proportion of the interconnected rock porosity permits relatively rapid diffusion (on the order of the limit in aqueous solutions; i.e., $1 \times 10^{-5} \mathrm{~cm}^{2} / \mathrm{s} @ 25^{\circ} \mathrm{C}$ ). A slower diffusive component, having apparent diffusion coefficients on the order of $1 \times 10^{-16} \mathrm{~cm}^{2} / \mathrm{s}\left(@ 90^{\circ} \mathrm{C}\right)$, is also observed.

7.4.1.1 Pore-size-distribution. Mercury porosimetry measurements (Buchholtz ten Brink et al., 1992; Klavetter and Peters, 1986) have shown that the large majority $(>95 \%)$ of pores in the matrix of TSw2 are on the order of several hundredths of a micrometer. A small component of porosity is contained in pores on the order of one to several micrometers. This porosity appears to be associated with microfractures.

7.4.1.2 Diffusion. Secondary Ion Mass Spectrometry (SIMS) allows the direct measurement of the concentration profile of a diffusing species in a solid. The concentration profile can be used to determine the diffusion coefficient for the element. Analysis of polished wafers of Tsw2 samples that were exposed to radionuclide-bearing solutions shows diffusion to be bimodal. Long-term exposures of the tuff samples to radionuclide-tracer solutions $\left(180 \mathrm{~d} @ 90^{\circ} \mathrm{C}\right)$ yielded concentration profiles that could be modeled assuming a single diffusion coefficient on the order of $1 \times 10^{-16} \mathrm{~cm}^{2} / \mathrm{s}$ (Phinney et al., 1987). In short-term exposures ( $8 \mathrm{~h} @$ $25^{\circ} \mathrm{C}$ ), concentration profiles could not be modeled using a single diffusion coefficient. Elevated levels of tracer (3-40 $\times$ background) were observed at depths of $\sim 10-15 \mu \mathrm{m}$, indicating that fast paths allow a proportion of the diffusing species to be transported at rates approaching that in solution (McKeegan et al., 1989). These fast paths may not be identifiable visually or by scanning electron microscopy or optical microscopy. The resulting distribution of diffusing species is distinctly non-uniform and reflects the non-uniform distribution of the $\mu \mathrm{m}$-scaled fast paths. These results suggest both fast and slow diffusional paths will need to be accounted for to realistically predict retardation of radionuclides due to matrix imbibition.

In contrast to these results, Rundberg (1987) inferred from the concentration variation with time for $\mathrm{Cs}$ and $\mathrm{Sr}$ tracer solutions in contact with Yucca Mountain tuff wafers that diffusion is relatively rapid $\left(1 \times 10^{-6} \mathrm{~cm}^{2} / \mathrm{s}\right)$ but mass transport is limited by slow $\left(1 \times 10^{-14} \mathrm{~cm}^{2} / \mathrm{s}\right)$ intracrystalline diffusion in zeolite and smectite cation exchangers. The diffusion of actinide tracers were not able to be modeled 
using this approach, presumably because they were excluded from the internal regions of the cation exchangers. Because zeolites and smectite exchangers are not abundant $(<2 \%)$ in TSw2, intracrystalline diffusion cannot explain the concentration profiles determined using SIMS.

\subsubsection{Diffusion of Radionuclides in Clinoptilolite}

Hydrothermal alteration of TSw2 repository rock and other tuffs in the EBS/NFE (e.g., crushed tuff backfill and/or invert) may create additional masses of sorbing minerals such as clinoptilolite or smectite. Although not abundant in the TSw2, smectite and clinoptilolite are significant phases lining fractures that are expected to be the main hydraulic pathways for radionuclide migration from the waste package (Carlos, 1985). The retardation of radionuclides due to interaction with these minerals via cation exchange will be less than expected if the cation exchange reaction is limited by the rate of intracrystalline diffusion. Secondary ion mass spectrometry (SIMS) was used to obtain information regarding the rate of intracrystalline diffusion of $\mathrm{Cs}$ and $\mathrm{Sr}$ during cation exchange (Roberts et al., 1995; Viani et al., 1994).

Clinoptilolite crystals oriented to either the (010) or (001) crystallographic face by mounting in epoxy were rendered nominally homoionic with respect to $\mathrm{Na}, \mathrm{K}$, and Ca by exchange with $\mathrm{NaCl}, \mathrm{KCl}$, or $\mathrm{CaCl}_{2}$ salt solutions as verified by quantitative wavelength dispersive spectroscopy using an electron microprobe (EMP). The homoionic crystals were then exposed to either a $\mathrm{Cs} /$ cation or $\mathrm{Sr} /$ cation (cation = $\mathrm{Na}, \mathrm{K}, \mathrm{Ca})$ solution at two different temperatures $\left(30-32^{\circ} \mathrm{C}\right.$ and $\left.90^{\circ} \mathrm{C}\right)$. The mounted crystals were placed in the bottom of a teflon Erlenmeyer flask and $100 \mathrm{~mL}$ of the relevant diffuser/cation solution was added to the flask. The sealed flasks were placed in an orbital shaker for the ambient temperature experiment $\left(\sim 30-32^{\circ} \mathrm{C}\right)$; and a shaking water bath held at $90^{\circ} \mathrm{C}$ for the higher temperature experiment.

The geochemical modeling code EQ3/6 (Wolery et al., 1990) was used to select binary solution compositions that would not change significantly $(<5 \%)$ during the course of the diffusion experiment so as to maintain a constant concentration boundary condition. Solution compositions were selected so that the equilibrium amount of diffusing trace cation in clinoptilolite (Cs or $\mathrm{Sr}$ ) would be small ( 1 mol$\%$ of the exchange cations), and the concentration of the trace cation in solution would be analytically measurable.

Concentration vs. depth profiles were then determined by SIMS. These were obtained for $\mathrm{Cs}, \mathrm{Sr}, \mathrm{Ca}, \mathrm{Na}, \mathrm{K}, \mathrm{Rb}, \mathrm{Al}$, and $\mathrm{Si}$ by sputtering through the crystal while rastering the ion beam over a $100 \mu \mathrm{m}$ square. The conversion of sputtering time to depth was made by measuring the depth of the sputtered raster using a profilometer.

Figure 7-2 shows the SIMS depth profile for the $\mathrm{Cs} / \mathrm{Ca}$ ambient temperature experiment. The SIMS raw data has been corrected for background, ratioed to the $\mathrm{Al}$ signal, and then normalized to a nominal surface concentration value of 0.01 (consistent with EQ3/6 modeling predictions and with the post-diffusion EMP Cs analysis data). An attempt was made to fit this data to a single (constant) diffusion coefficient using the analytical solution to the diffusion equation for a constant concentration boundary condition and an infinite half-plane (Viani et al., 1994). The 
shape of the experimental data is such that no choice of a constant diffusion coefficient will reasonably match the data.

In contrast, if the binary interdiffusion coefficient $D$, is compositionally dependent, and is functionally related to composition and trace diffusion coefficients according to (Lanford et al., 1979):

$$
D=\frac{D_{\text {in }} D_{\text {out }}}{X_{\text {in }} D_{\text {in }}+\left(1-X_{\text {in }}\right) D_{\text {out }}}
$$

where $X_{\text {in }}$ is the mole or equivalent fraction (relative concentrations) of the inward diffusing component and $D_{\text {in }}$ and $D_{\text {out }}$ are the trace diffusion coefficients for the inward and outward diffusing components, then it is possible to effectively match the observed data by appropriate choice of $D_{\text {in }}$ and $D_{\text {out }}$. The inward and outward tracer diffusion coefficients that result from matching model to data are $2.0 \times 10^{-13}$ and $1.5 \times 10^{-18} \mathrm{~cm}^{2} / \mathrm{s}$, respectively. Although no direct measurements of diffusion coefficients have been reported for clinoptilolite, these data agree with radiochemical measurements of self diffusion coefficients of $\mathrm{Cs}$ and $\mathrm{Ca}$ in a similar zeolite, mordenite (Breck, 1984), and with diffusion coefficients inferred from batch adsorption experiments for clinoptilolite-bearing tuffs (Rundberg, 1987). Further analysis of the SIMS data for this experiment, for experiments conducted at other concentrations of $\mathrm{Cs}$ and $\mathrm{Sr}$, and at other diffusion times are necessary before this simple two-component model can be verified.

Analysis of Cs diffusion profiles into nominally $\mathrm{Ca}$ clinoptilolite for ambient and $90^{\circ} \mathrm{C}$, and for $\mathrm{Sr}$ diffusion into $\mathrm{Ca}$ clinoptilolite at ambient temperature reveal several important points:

1. Using a binary interdiffusion model, the ambient temperature diffusion of Cs can be reasonably modeled.

2. The tracer diffusion coefficients estimated from the Cs and $\mathrm{Sr}$ diffusion profiles in the ambient temperature experiments indicate diffusion coefficients on the order of $10^{-13}$ and $10^{-18} \mathrm{~cm}^{2} / \mathrm{s}$ for $\mathrm{Cs}$ and $\mathrm{Sr}$, respectively.

3. The diffusion of $\mathrm{Cs}$ into the $\mathrm{Ca}$ clinoptilolite at $90^{\circ} \mathrm{C}$ was rapid enough to increase the Cs content several orders of magnitude above background to a depth of at least $35 \mu \mathrm{m}$ (the maximum depth probed) over a 12-day exposure.

4. It is apparent that small amounts of $\mathrm{Na}, \mathrm{K}$, and trace levels of $\mathrm{Rb}$ are present in the nominal $\mathrm{Ca}$ clinoptilolite crystals and their concentrations are not constant with depth. It is possible that at least some of the observed diffusion of Cs may occur by preferential exchange with the residual monovalent cations in the $\mathrm{Ca}$ exchanged crystal.

The experimental data and the parameters derived from them indicate that diffusion of $\mathrm{Cs}$ and $\mathrm{Sr}$ into clinoptilolite is probably not rapid enough to allow the assumption of local cation-exchange equilibrium for situations in which groundwater flow is relatively rapid and clinoptilolite crystal size is relatively large; e.g., in fractures. Applying equilibrium distribution coefficients obtained from batch 
adsorption experiments using fine-grained clinoptilolites $(1-2 \mu \mathrm{m})$ to predict adsorption during flow through fractured media may not be justifiable.

\subsubsection{Flow and Transport Through Topopah Spring Tuff}

Fracture flow is expected to dominate the flux of $\mathrm{H}_{2} \mathrm{O}$ in the altered repository host rock. Matrix flow, if it occurs, will be very slow in comparison. Physical processes related to high suction potential and a potentially discontinuous waste phase will tend to limit flow even beyond the limits imposed by low permeability. Baseline information regarding the potential for retardation and matrix imbibition of soluble radionuclides and/or colloids is necessary to assess flow and transport. In addition, the effects on radionuclide transport of alteration of the host rock by hydrothermal interaction with groundwater, or with reactive fluids derived from EBS/NFE introduced materials, needs to be addressed.

This section summarizes results of flow and tracer tests using core samples of devitrified Topopah Spring tuff containing saw-cut fractures. Experiments were undertaken using $\sim 5.1-\mathrm{cm}$-diameter by $5.1-\mathrm{cm}$-long cylindrical cores. A saw-cut parallel to the length of the core was made and two 1/8-inch-wide 1-mil ( 25- $\mu \mathrm{m})$ thick gold shims inserted to maintain a fixed aperture between the surfaces. The core sample was mounted in an apparatus in which confining pressure, downstream pore pressure, flow rate, and core temperature could be varied (Fig. 7-3). Initial experiments were performed using a pump without the ability to maintain constant upstream pressure or constant flow. Subsequent experiments were performed using a pump that maintained constant flow. Pressures, temperatures, and cumulative flow (initial device) or flow rate (late experiments) were monitored and periodically logged to a computer. Confining pressures were maintained between 35 and 50 bar; pore pressures varied between 0.1 and $\sim 5$ bar. Details of the apparatus and the sample treatment are given in Viani and Martin (1993, 1994a).

7.4.3.1 Bacterial plugging of flow path. To prevent the growth of bacteria during the flow test, a core sample was sterilized by autoclaving in-situ by raising the temperature of the flow test device to $120^{\circ} \mathrm{C}$ for approximately 12 hours. After cooling to ambient temperature, the temperature was again raised to $120^{\circ} \mathrm{C}$ for 12 hours. Filtered $(0.05 \mu \mathrm{m})$, deionized (milli-Q) water was pumped through the core and permeability monitored for two flow tests lasting approximately 6 and 8 weeks.

Despite sterilization of the core, flow rate, differential pressure, and permeability varied, apparently as a result of bacterial fouling of the fracture aperture. In one test, permeability showed a relatively strong correlation with differential pressure (Fig. 7-4). The observed flow behavior suggested that the fracture gradually closed due to material filling the aperture, and that by increasing the differential pressure, this material was forced out. To test this, samples of the effluent fluid were taken at times when the flow rate, differential pressure, and permeability were high (Fig. 7-4) and analyzed using transmission and scanning electron microscopy to see if particles were present that could account for the decrease in permeability.

TEM and SEM analyses identified bacteria and inorganic particles in the effluent samples. The most abundant particles appeared to be rod shaped bacteria $(\sim 1-1.5 \mu \mathrm{m}$ 
long) and were observed in all three samples. Although no obvious source of carbon was introduced into the system, it is apparent that the growth of this bacterium was sufficient to essentially close the $25-\mu \mathrm{m}$-fracture aperture. Differential pressures on the order of 0.5 bar and flow rates on the order of $5 \mathrm{~mL} / \mathrm{h}$ were necessary to "cleanse" the aperture. However, as shown in Fig. 7-4, even after increasing the flow rate by increasing the differential pressure, closing of the aperture occurred subsequently. In subsequent tests, using a constant flow pump, plugging was not observed, even though the sample was not sterilized. Although plugging is not observed under constant-flow regime, bacterial growth is almost certainly occurring. Apparently, the bacteria are continuously eluted from the fracture without building up enough to close it. Bacterial growth in the subsurface could significantly impact the path that fluids will take in the fractured flow-path components of the EBS/NFE.

7.4.3.2 Summary of flow test results. To obtain consistent hydraulic data, the constant flow pump was used for subsequent tests. A series of flow tests were performed for a single core sample at three temperatures $\left(23,59\right.$, and $\left.92^{\circ} \mathrm{C}\right)$ and two flow rates $(0.2$ and $2.0 \mathrm{~mL} / \mathrm{h})$. Bromide and iodide were used as tracers. The average permeability at $23^{\circ} \mathrm{C}$ was on the order of 0.06 millidarcy $(\mathrm{md})$ and was independent of the flow rate and average pore pressure (Table 7-2). This value is approximately one third to one fifth that of the lowest permeabilities previously observed for the same core sample (Viani and Martin, 1994a), and for a different sample having the same fracture aperture (Viani and Martin, 1993). This could reflect the growth of a bacterial population in the fracture channel as noted above, or may reflect small differences in effective fracture aperture.

The observed permeability is more than 2 orders of magnitude smaller than would be predicted (de Marsily, 1986) for a $25-\mu \mathrm{m}$ aperture with smooth walls ( $33 \mathrm{md}$ ). If one assumes all the flow is via the fracture, the effective aperture width is calculated to be $3.1 \mu \mathrm{m}$. It is possible that some reduction in the gold shim thickness may have occurred upon loading. Deformation of the core sample itself under confining pressure may also contribute to the low permeabilities observed; however, based on an analysis of the effect of confining pressure on permeability (Fig. 7-5), it appears unlikely that this could explain the observation. At $59^{\circ} \mathrm{C}$, the average permeability is slightly larger $(\sim 0.1 \mathrm{md})$ and also appeared to be independent of the flow rate and average pore pressure.

At $92^{\circ} \mathrm{C}$, the average permeability varied between 0.08 and 2.34 md and was independent of the flow rate but dependent on average pore pressure. For flow tests in which the average pore pressure was less than 0.1 bar ( 5 runs) the average permeability was $\sim 0.2 \mathrm{md}$. For runs in which the average pore pressure was greater than 0.5 bar ( 7 runs) the average permeability was $\sim 1.9 \mathrm{md}$ (Table 7-2).

It is clear that pore pressure has a significant effect on the permeability at $92^{\circ} \mathrm{C}$. This effect is non-linear; i.e., increasing pore-pressure above the $\sim 0.5$ bar threshold does not result in a continued increase in permeability. However, the phenomenon does appear to be reasonably reversible, because sequential runs taken at pore pressures below and above 0.5 bar yielded similar results to the previous runs at equivalent pore pressures. If the phenomenon were related to changes in aperture 
width, a reversible change of $\sim 5 \mu \mathrm{m}$ would be required. One possibility is that exsolution of dissolved air from the feed solution (between 23 and $92^{\circ} \mathrm{C}$, a liter of $\mathrm{H}_{2} \mathrm{O}$ would exsolve about $5 \mathrm{~cm}^{3}$ of gas at $92^{\circ} \mathrm{C}$ and $1 \mathrm{bar}$ ) may partially block the aperture. This blockage would lessen at higher pore pressures. However, the exsolution would also be expected to have affected the runs at $59^{\circ} \mathrm{C}$ as well, and this was not observed.

Permeability also varied with confining pressure. The variation in instantaneous permeability with confining pressure can be explained by a change in the fracture aperture that depends on confining pressure. In the example shown (Fig. 7-5), the effective aperture width need only change by $\sim 0.06 \mu \mathrm{m}$ to cause the change in permeability observed. This response is reversible. Similar observations were made by Roberts and Lin (1995) and Mohanty et al. (1995) for fractured welded tuffs.

7.4.3.3 Tracer experiments. A dilute $\mathrm{Na}-\mathrm{Cl}-\mathrm{HCO}_{3}$ solution containing $\mathrm{Br}^{-}$or $\mathrm{I}^{-}$ tracer was eluted through the core under constant flow conditions. Following a period of flow of the standard feed solution (dilute $\mathrm{NaCl}, \mathrm{NaHCO}_{3}, \mathrm{pH} \sim 7.5$ ), a $560 \mu \mathrm{L}$ pulse of either $\mathrm{NaBr}$ or $\mathrm{NaI}$ tracer solution $(0.75 \mathrm{mM})$ was injected upstream from the core. The average recovery of tracer downstream from the core was 95 and $102 \%$ for $\mathrm{Br}^{-}$and $\mathrm{I}^{-}$, respectively. These recoveries are within experimental error of $100 \%$; under these conditions both $\mathrm{Br}^{-}$and $\mathrm{I}^{-}$are considered to be conservative tracers.

Figure 7-6 shows an example of $\mathrm{I}^{-}$tracer breakthrough curves for replicated run conditions. The generally excellent reproducibility in the tracer breakthrough curves suggest complete flushing of the tracer between runs and no measurable changes to the hydrologic or chemical state of the sample. These results also indicate that porepressure, confining pressure, and flow rate effects are essentially reversible.

\subsection{Effect of flow rate, pore pressure, and temperature on breakthrough of} tracer. Figure 7-7 shows the effect of flow rate on elution of conservative tracer. The tracer elutes slightly sooner (in terms of volume eluted) and exhibits less tailing at a lower flow rate. This effect appears to be independent of pore pressure. Early breakthrough may reflect a relatively greater impact of longitudinal dispersion at the lower flow rate. The reduced tailing region for the breakthrough curve for the lower flow rate suggests that a given volume of post-pulse solution is more effective in "sweeping out" tracer that has diffused into the matrix during passage of the tracer pulse through the fracture. At the slower flow rate, the rate of mass transfer of tracer from matrix to fracture via diffusion relative to advection of tracer through the fracture is greater than at the higher flow rate. For the flow rates and tracer pulse volumes utilized, it is probable that diffusion into the matrix occurs primarily via the fast paths described in section 7.4.1.

Figure 7-8 shows the effect of pore pressure on the breakthrough of the tracer. This figure shows that the initial breakthrough is retarded, and the tailing region of the pulse is extended relative to the case where pore pressure is low. This suggests that pore pressure controls the fracture/matrix connectivity possibly by controlling the width of micro-fractures that may emanate from the main fracture pathway. At higher pore pressure the number and/or width of micro-fractures intersecting the 
saw-cut fracture may increase. This would increase the mass transfer of tracer into the matrix during passage of the pulse, and the volume of matrix containing tracer that must be flushed following the pulse.

Figure 7-9 shows the role that temperature plays in controlling the initial breakthrough and the extent of tailing in the tracer pulse. The volumetric elution of the tracer occurs earlier, and the tailing is less pronounced the greater the temperature of the experiment. This may reflect an increase in the diffusion coefficient of the tracer. Physical retardation expected to result from the diffusion of radionuclides into the matrix may be reduced with increasing temperature.

7.4.3.3.2 Composition of effluent. Table 7-3 shows chemical analyses for selected elements in the feed solution and after the breakthrough of the tracer. The major observation is the positive correlation of dissolved $\mathrm{Si}$ and negative correlation of $\mathrm{Ca}$ and $\mathrm{Mg}$ with temperature, and the negative correlation of $\mathrm{Si}, \mathrm{Ca}$, and $\mathrm{Mg}$ with flow rate at $92^{\circ} \mathrm{C}$. The silica concentrations observed in the $0.2 \mathrm{~mL} / \mathrm{h}$ runs at both 23 and $92^{\circ} \mathrm{C}$ indicate slight supersaturation with respect to equilibrium with quartz but significant undersaturation with respect to cristobalite. If the length of the core were longer, or the flow rate slower, it would be expected that the concentration of silica in the effluent would approach saturation with cristobalite.

The effects of confining pressure, pore pressure, flow rate, and temperature on permeability and transport of a conservative tracer through a saw-cut sample of Topopah Spring tuff have been measured and are likely to affect the degree of retardation of radionuclides in fractured materials in the near-field environment. Increasing pore pressure tends to increase the retardation due to matrix diffusion; increasing temperature has the opposite effect.

These findings strengthen the argument that transport experiments for fractured samples must be undertaken using flow-test apparatuses that allow the variation of confining and pore pressures, because not only is the permeability of the sample affected, but the so is the nature of the breakthrough curve. Experiments that have previously been conducted with core samples that were epoxied in place do not provide data to test phenomena which would be expected to play a role in the transport of radionuclides through fractured media at Yucca Mountain. Hence, relationships between physical variables such as pore pressure and confining pressure, and chemical phenomena such as radionuclide transport, will not be adequately accounted for in transport and performance assessment models unless transport experiments are undertaken using the type of apparatus used in this study. The study of biological impact on flow and transport will require experimental apparatuses that will be able to mimic the flow regime expected in the EBS/NFE; otherwise, important phenomena may be missed.

\subsection{Field Testing Sorption Models Under Conditions of Fracture Dominated Flow}

Modeling the chemical processes likely to impact the transport of radionuclides through the EBS/NFE will require coupled flow and chemical reaction models capable of predicting the effects that dissolution/precipitation, 
adsorption/desorption; and aqueous speciation have on radionuclide transport. In the EBS/NFE, transport will be strongly influenced by adsorptive retardation in flow-path components (e.g., waste package corrosion products, concrete, altered TSw2). Previous application of surface chemical models to laboratory experiments and field observations (Viani and Bruton, 1992a,b) resulted in model refinement and a better understanding of the limits of model applicability. However, there are limits to the application of laboratory experiments to confidence building and testing modeling approaches. Field testing can play an important role in this confidence building process.

The ünderground hard rock laboratory in Äspö, Sweden (HRL) afforded a unique opportunity in a well-constrained field test to assess the ability and utility of cation exchange and surface complexation models to explain the evolution of fluid composition over time in a fractured aquifer (Bruton, 1996; Viani and Bruton, $1996 a, b)$. The matrix rock at the HRL is predominantly granite. Although its chemical and hydraulic properties would be expected to differ from the matrix rocks at Yucca Mountain, the processes accounting for mass transfer between fracture and matrix, sorption and diffusion, are identical to those expected to retard radionuclide movement at Yucca Mountain.

Construction of the HRL laboratory initiated relatively rapid downward flow of dilute shallow groundwater through fractures that were intersected by the underground excavation. The groundwater in one of the intersected fracture zones (Redox Zone) was sampled just prior to the intersection of the underground tunnel with it $(@ 70 \mathrm{~m})$ and regularly thereafter for a period of several years. The shallow groundwater was also sampled before and following the initiation of flow at a depth $(<15 \mathrm{~m})$ just below where the fracture zone is expressed at the ground surface. Fractures in the dominantly granitic rocks are lined with a variety of sorbing minerals, including illite/smectite, chlorite, sericite, and iron oxides (Tullborg, 1995b).

The groundwater at tunnel depth is considerably more saline than the shallow groundwater (ionic strength 0.006 vs. $0.18 \mathrm{~m}$ ). Hence, the induced flow of groundwater into the tunnel is also accompanied by mixing of the two water types. Cation exchange has been hypothesized to play a role in controlling the observed variation in fluid chemistry (Banwart et al., 1994). A comparison of simulated mixing of groundwater using geochemical modeling codes with the observed evolution of groundwater at Aspö suggests that the groundwater mixing is accompanied by mass transfer between fluid and fracture minerals via cation exchange and surface complexation reactions.

\subsubsection{Cation Exchange}

7.5.1.1 Modeling approach. The geochemical modeling package EQ3/6 (Wolery et al., 1990; version 3245R116), to which a cation-exchange model was added (Viani and Bruton, 1992a,b), was used with an associated thermodynamic data base (version DATA0R19) to simulate the mixing between the shallow (HBH02) and native (tunnel depth; KA0483A) fluids. A cation-exchange model employing the Vanselow convention (Sposito, 1981) was used for the simulations. Details of the 
implementation of this option in EQ3/6 and examples of its application may be found in Viani and Bruton (1992a,b). Fluid chemistries predicted to result from mixing were compared with those monitored from boreholes intersecting the fracture zone.

The conceptual model of fluid mixing imposed by EQ3/6 is a simplified approximation of the actual process that is occurring at Äspö. Inherent to this simplification is the assumption that the shallow groundwater undergoes no compositional change (i.e., no reaction with its surroundings) prior to mixing with the native groundwater, and that mixing occurs only in the presence of a cation exchanger that is initially in equilibrium with the native groundwater.

7.5.1.2 Data for exchange models. The data required to simulate cation exchange using EQ3/6 are: 1) the type of cation exchanger and the binary exchange energies for cation pairs of interest (kcal/equiv); 2) the initial composition of the exchanger (mol-\% or equiv-\%); and, 3) the quantity of exchanger in contact with $1 \mathrm{~kg}$ of water (equiv $/ \mathrm{kg} \mathrm{H}_{2} \mathrm{O}$ ).

Analysis of fracture-filling minerals in the Redox Zone has shown that the layer silicate component, the most likely source of the cation exchange capacity of the rock, is composed of chlorite, illite-rich interstratified smectite/illite, and sericite (Tullborg, 1995a). A survey of cation-exchange energies (Bruggenwert and Kamphorst, 1982) reveals that for $\mathrm{Ca}, \mathrm{Mg}$, $\mathrm{Sr}$, and $\mathrm{Na}$, there is not a large difference in the exchange properties for the different layer silicates. In contrast, for $K, \mathrm{Rb}, \mathrm{Cs}$, and $\mathrm{NH}_{4}$, the energies for cation exchange are strongly dependent on mineral type, especially when trace quantities of these cations are involved. Based on the observed mineralogy, illite and smectite were chosen as the most appropriate exchangers to use to simulate the exchange components of the fracture fill.

Illite differs from smectite by having a smaller cation exchange capacity (CEC) and having multiple (3) exchange sites that differ markedly in their exchange energies (Brouwer et al., 1983). The bulk of the exchange capacity of illite is associated with the outer or basal planes of the illite crystal (planar site). This site has exchange energies similar to smectite for binary exchange involving $\mathrm{Na}$ and divalent cations (Table 7-4). The other sites on illite (sites I \& II) are present in relatively small amounts and are associated with the edges of the illite crystallites ("frayed edge sites") (Brouwer et al., 1983). These two sites show a high affinity for monovalent cations, especially those with small hydration energies (e.g., $K, \mathrm{Rb}, \mathrm{Cs}$ ). Although not abundant, these sites play a major role in the partitioning of $C s, R b$, and $\mathrm{K}$.

7.5.1.3 Simulating groundwater mixing. Groundwater mixing was simulated using EQ3/ 6 by mixing fluids with compositions equal to the shallow and native (tunnel depth) groundwaters in various proportions and calculating the resulting fluid composition after accounting for cation exchange and mineral precipitation. The comparison between model predictions and observed fluid compositions was made by assuming that $\mathrm{Cl}$ is conserved during mixing; that is, the $\mathrm{Cl}$ concentration in the groundwater is the sole determinant of the relative proportions of the two 
endmember fluids. Thus, comparisons of observed and predicted fluid compositions were made for equal $\mathrm{Cl}$ concentrations.

The initial exchanger composition was calculated by assuming it to be in equilibrium with the native groundwater. Because the quantity of exchanger was not known a priori, its mass in the system was varied to obtain the best fit with the observed data.

Modeling results suggest that approximately 0.1 equivalent of a smectite or illite exchanger per liter of groundwater is necessary to account for discrepancies between predictions from a conservative mixing model and measured $\mathrm{Na}$ and $\mathrm{Ca}$ concentrations (Fig. 7-10). This quantity of exchanger equates to an effective fracture coating thickness of $20 \mu \mathrm{m}$ or less given a fracture aperture width of $1000 \mu \mathrm{m}$ or less. This is consistent with petrographic analysis of the fractures in these rocks (Tullborg, 1995b).

Although the quantity of exchanger necessary to match the observed fluid compositions appears small, this quantity of exchanger can serve as a significant reservoir of readily available cations; i.e., cations whose participation in chemical reactions is not limited by dissolution kinetics. Table 7-5 lists the ratios of the mass of cations associated with the exchanger to the mass in the fluid. For the shallow groundwater, most of the $\mathrm{Ca}$ and $\mathrm{Mg}$, and a majority of the $\mathrm{Na}$ are associated with the exchanger, while in the native and deep groundwaters, a significant fraction of the cations are associated with the exchanger phases.

Because of the similarity of the exchange properties of smectite and those of the planar site in illite, the major cation occupancies $(\mathrm{Na}, \mathrm{Ca}$, and $\mathrm{Mg}$ ) predicted for the illite exchanger are very similar to those for smectite. In contrast, because of the high selectivity of the edge sites on illite for monovalent cations with low hydration energies, these sites are predicted to be enriched in $\mathrm{Cs}, \mathrm{Rb}, \mathrm{K}$, and $\mathrm{Na}$ relative to the planar site (Fig. 7-11 and Fig. 7-12).

The variation of the observed $\mathrm{Na}, \mathrm{Ca}$, and $\mathrm{Sr}$ with respect to $\mathrm{Cl}$ is consistent with the variation expected if mixing occurs in the presence of a cation exchanger that is initially in equilibrium with the native groundwater. In contrast, the observed variation of $\mathrm{Mg}$ with $\mathrm{Cl}$ (not shown) appears consistent with conservative mixing. For $\mathrm{K}, \mathrm{Cs}$, and $\mathrm{Rb}$ neither conservative mixing nor cation exchange can be inferred from the data because of either the scatter in, or scarcity of, the data (not shown).

The predicted effect of cation exchange by illite on fluid composition during mixing is similar to that for smectite (not shown). For $\mathrm{Ca}, \mathrm{Na}$, and especially $\mathrm{Sr}$, it appears that the form of the observed relationship between these cations and $\mathrm{Cl}$ is not the same as that predicted by the cation exchange model (Fig. 7-10). A number of causes might contribute to this discrepancy:

1. The actual mixing of fluids in the fracture system is not adequately simulated by the simple mixing algorithm embodied in EQ3/6. Because of the potentially large ratio of cations on the exchanger to those in the fluid, differences between the simulated mixing process and the actual mixing process would probably have the greatest effect on the most dilute mixed fluids.

2. More than two "endmember" fluids may be involved in the mixing and cation exchange process (Laaksoharju et al, 1995). 
3. The chosen cation-exchange model, exchange energies, or assumption of exchange equilibrium may not be correct. Of these potential shortcomings, only exchange disequilibrium would likely result in significantly different predictions. As observed for exchange equilibrium in clinoptilolite (section 7.4.2), exchange disequilibrium would likely occur only if exchange were limited by inter and intracrystalline diffusion of exchange cations in the fracture-lining exchangers. The diffusion rate in undisturbed fracture fill at the HRL has not been measured.

7.5.1.4 Predicting the level of exchangeable Cs. The ability to model the partitioning of trace elements such as $\mathrm{Cs}$ and $\mathrm{Sr}$ is a major rationale for using cationexchange models. Previous work has shown that cation-exchange models can relatively accurately predict the partitioning of $\mathrm{Sr}$ and $\mathrm{Cs}$ to zeolitized tuff from Yucca Mountain (Viani and Bruton, 1992a, 1992b).

Data available from the HRL allowed a comparison of observed vs. predicted partitioning of $\mathrm{Cs}$ in a field situation. Samples of fracture filling minerals collected at the intersection of the HRL tunnel with the fracture zone were analyzed for Cs and other trace elements using sequential extraction techniques to determine the proportion associated with the exchange sites on the minerals (Landström and Tullborg, 1995). The concentration of exchangeable Cs in the fracture fill for Redox Zone fracture was $\sim 0.6 \mathrm{ppm}$. Assuming that all of the exchangeable Cs is associated with the illite and/or sericite components of the fracture filling, and assuming their abundance to be $5 \%$, the predicted concentration of exchangeable $\mathrm{Cs}$ in the fracture fill based on the measured concentration of $\mathrm{Cs}$ in the groundwaters collected at those fractures varied between 0.9 and $1.2 \mathrm{ppm}$ (Viani and Bruton, 1996). The predicted values are in reasonable agreement with the measured values which gives further confidence in the model.

Geochemical modeling simulations of the role of cation exchange in fluid mixing and in trace metal partitioning suggest that this phenomenon plays an important role in the short-term chemical dynamics that are occurring in the Redox Zone fracture system. We conclude:

1. Because of the similarity of the exchange properties of smectite and those of the planar site in illite, the major cation occupancies $(\mathrm{Na}, \mathrm{Ca}$, and $\mathrm{Mg}$ ) predicted for the illite exchanger are very similar to those predicted for a smectite exchanger.

2. Cation exchange is a plausible mechanism to explain apparent sources and/or sinks for $\mathrm{Ca}, \mathrm{Sr}$, and $\mathrm{Na}$ during mixing of dilute shallow groundwater and native groundwater in the Redox Zone.

3. Cation-exchange simulation of the partitioning of $\mathrm{Cs}$ and $\mathrm{Rb}$ onto illite predicts that almost all of the "mobile" pool of these elements is associated with the exchanger. The predicted level of exchangeable Cs and that measured by sequential extraction of fracture gouge are in reasonable agreement.

4. The quantity of exchanger ( 0.1 equiv/L of groundwater) necessary for the simulation to match the observed fluid data is physically reasonable, and is consistent with the observed fracture mineralogy. This estimate agrees with 
estimates by Banwart et al. (1995b) that are based on modeling and on fracture fill material properties.

\subsubsection{Surface Complexation}

As shown above, the observed variability of fluid chemistry at the Äspö Hard Rock Laboratory is not fully described by conservative fluid mixing models. Ion exchange may account for some of the observed discrepancies. It is also possible that variably charged solids such as oxyhydroxides of Fe can serve as sources and sinks of anions and cations through surface complexation.

The most successful models describing adsorption onto iron and other oxides are surface complexation models (Dzombak and Morel, 1990). Surface complexation reactions on hydrous ferric oxides involve sorption of both cations and anions. Because $\mathrm{U}, \mathrm{Np}$, and other metals are strongly sorbed by iron oxides (Table 7-1), it is important to gain confidence in applying these models to predict the retardation of these radionuclides through the various oxides expected in the EBS/NFE (sec. 7.3.2).

Geochemical modeling of the surface chemistry of hydrous ferric oxides (HFOs) in equilibrium with shallow (HBH02) and native (KA0483A) HRL Redox Zone waters shows that HFOs can serve as significant, $\mathrm{pH}$-sensitive sources and sinks for cations and anions (Bruton and Viani, 1996).

A variety of cations (e.g. $\left.\mathrm{H}^{+}, \mathrm{Ca}^{++}, \mathrm{Sr}^{++}, \mathrm{Ba}^{++}\right)$and anions $\left(\mathrm{HCO}_{3}^{-}, \mathrm{SO}_{4}^{--}, \mathrm{HPO}_{4}^{-}\right)$ are known to sorb onto hydrous ferric oxides at $25^{\circ} \mathrm{C}$ (Dzombak and Morel, 1990). Hematite and Fe-oxyhydroxide are commonly found as fracture fillings at Äspö (e.g., Tullborg, 1995b). Banwart et al. (1994) estimated that the abundance of hematite in altered granite is $1-2 \%$, and that the abundance of $\mathrm{Fe}$ (III)-oxyhydroxides in the fracture coatings is $4 \%$. Microfractures close to the fracture surface contain what appears to be iron oxyhydroxide.

The approach used to simulate the effect of sorption onto iron oxides via surface complexation is similar to that taken by Viani and Bruton $(1994,1996)$ to test the hypothesis that ion exchange affects the composition of groundwaters sampled from boreholes in the HRL tunnel. Geochemical modeling computer codes containing surface complexation models capable of simulating sorption onto HFOs were used to:

1. Calculate the potential for HFOs to serve as reservoirs and sinks of ions. The dependencies of ion sorption on $\mathrm{pH}$ in shallow and deep waters from the Redox Zone at Äspö were calculated to evaluate the potential for changes in major element chemistry during fluid mixing owing to the sorptive behavior of HFOs.

2. Simulate mixing between the shallow and deep waters that are believed to contribute to the observed changes in fluid chemistry with time in the Large Scale Redox Experiment.

Surface complexation refers to chemical reactions between reactive functional groups exposed on a solid surface and aqueous species in an adjacent fluid. Surface complexation reactions lead to the sorption and desorption of anions and cations. The reactive functional groups at the solid surface (often referred to as "sites") derive from unsatisfied bonds created by the discontinuity of a three-dimensional structure. 
The reactive sites on the surfaces of oxide minerals may be negative, neutral or positive depending on the extent of their protonation. Hence, the net charge on the surface may be positive or negative, depending on the $\mathrm{pH}$ of the solution. Because the charge of reactive sites in oxides is controlled by $\mathrm{pH}$, surface complexation reactions are much more sensitive to $\mathrm{pH}$ than ion exchange; the extent of ion sorption can change drastically within a few $\mathrm{pH}$ units.

The surface complexation reactions comprising the sorption model are provided for in the React geochemical modeling code. React is a part of The Geochemist's Workbench $^{\text {TM }}$ (Bethke, 1994) set of software tools for calculating fluid-mineral-gas equilibria. React combines the calculational abilities of EQ3 and EQ6. EQ3/6, used by Viani and Bruton $(1994,1996)$ to describe ion exchange, could not be used as it does not provide for surface complexation reactions.

React can simultaneously provide for aqueous speciation in the fluid phase, mineral dissolution and precipitation, and surface complexation onto a sorbent, such as HFO. However, mineral dissolution and precipitation reactions were not considered in the calculations described here.

React employs the generalized two-layer surface complexation model of Dzombak and Morel (1990). The generalized two-layer model is an extension of the diffuse double layer model, with provision for two types of sorption sites (weak and strong) and surface precipitation (see Dzombak and Morel, 1990 for an extensive discussion of the models).

React contains a data base of surface complexation constants from Dzombak and Morel (1990) assuming a generalized two-layer surface complexation model. Although the most comprehensive compilation of constants to date, Dzombak and Morel's data set lacks complexation constants for carbonate species.

At low $\mathrm{pH}$ values, anions such as sulfate and carbonate tend to be sorbed by HFOs. Preliminary calculations with Dzombak and Morel's data set suggested that sulfate surface complexes dominate the total mass of sulfate in the fluid+sorbent system. However, the Dzombak and Morel (1990) data set does not provide for competition between sulfate and carbonate for sorption sites. Therefore, a literature search was made to identify experimental studies yielding carbonate complexation constants that could be added to the Dzombak and Morel (1990) data set.

Waite et al. (1994) determined carbonate complexation constants as part of a larger study to measure U(VI) sorption onto HFOs. They used a two-site diffuse double layer model. Van Geen, Robertson, and Leckie (1994) focused on complexation of carbonate species at the goethite surface and used a single-site diffuse double layer model to extract complexation constants from their sorption experiments.

The complexation constants from both papers were incorporated into two new versions of the React complexation constant data base from Dzombak and Morel (1990). Simulations were carried out with each of the three data bases (a) Dzombak and Morel (1990), (b) Dzombak and Morel plus carbonate complexation data from Waite et al. (1994), and (c) Dzombak and Morel plus carbonate complexation data from Van Geen, Robertson, and Leckie (1994) for comparison.

Scoping calculations using all three data bases suggested that the data of Van Geen, Robertson, and Leckie (1994) predicted significantly greater amounts of 
carbonate sorption than data from Waite et al. (1994). Because Van Geen, Robertson, and Leckie's (1994) study focused more closely on carbonate sorption than Waite et al. (1994), data bases from (a) Dzombak and Morel (1990) and (b) Dzombak and Morel plus carbonate complexation data from Van Geen, Robertson, and Leckie were used to explore the impact of sorption on fluid chemistry.

For these calculations, goethite was used as a proxy for a variety of iron oxyhydroxides such as ferrihydrite and hematite that can act as sorbents. Goethite was assumed to contain 0.205 moles of sorption sites ( 0.2 weak, 0.005 strong) per mole of Fe (Dzombak and Morel, 1990). Iron oxyhydroxides can vary significantly in terms of their surface area and corresponding total number of surface sites per mole of Fe. However, by relating our calculations to the number of surface sites available for reaction, we obtain a common frame of reference for all forms of HFOs. The mass of goethite per kilogram of $\mathrm{H}_{2} \mathrm{O}$ was varied from 0.1 to $10 \mathrm{~g} / \mathrm{kg} \mathrm{H}_{2} \mathrm{O}$ to illustrate the effects of variations in sorbent:fluid ratio. The relations between mass of goethite, number of surface sites, and fluid mass are discussed below.

The result of surface complexation reactions of goethite in the shallow and native groundwaters are shown in Fig. 7-13 and Fig. 7-14 as a function of $\mathrm{pH}$. One gram of goethite, serving as a proxy for Fe-oxyhydroxides, was assumed to be in equilibrium with $1 \mathrm{~kg}$ of $\mathrm{H}_{2} \mathrm{O}$ having the composition of the shallow or native groundwater. Sorbed fraction in Fig. 7-13 and Fig. 7-14 refers to the fraction of a given element that resides on HFO surfaces relative to the total amount of that element in the fluid+sorbent system. It is calculated as the sum of the concentrations of sorbed species containing a given element, divided by the sum of the amount of the element in solution and the amount of the element sorbed. For example, a sorbed fraction of 0.5 implies that if there are $100 \mathrm{mg} / \mathrm{kg} \mathrm{SO}_{4}$ in solution, $100 \mathrm{mg} / \mathrm{kg} \mathrm{SO}_{4}$ are bound to the HFO surface as surface complexes.

The sorbed fraction is a useful measure of the effectiveness of a sorbent as a reservoir of ions. When the sorbed fraction exceeds 0.5 , the mass of the sorbed element is greater than that in the fluid. A change in solution composition, such as $\mathrm{pH}$, could release those ions and significantly increase the ion concentration in the fluid.

Carbonate surface complexes comprise a significant fraction of total carbonate in the fluid+sorbent system. For example, Table 7-6 shows that over 10 times as much carbonate (1121 mg/kg expressed as bicarbonate) is sorbed onto HFO surfaces as is contained in the fluid ( $114 \mathrm{mg} / \mathrm{kg}$ ) given a sorbent:fluid ration of $10 \mathrm{~g}$ of goethite per kilogram of $\mathrm{H}_{2} \mathrm{O}$. Thus, the calculations suggest that HFOs at shallow depths may serve as important reservoirs or sources of carbonate if conditions, such as an increase in $\mathrm{pH}$, favor desorption of carbonate.

Competition for surface sites can be appreciated by considering the results of simulations for which carbonate surface complexes are excluded (not shown). Under these conditions, the percent sulfate predicted to be adsorbed is 5 to 50 times greater for the shallow groundwater and 3 to 4 times greater for the native groundwater. It is apparent that carbonate species are sorbed to a much greater extent than sulfate.

To relate the calculations described in this report to attributes of natural systems, we must establish the relevance of the masses of goethite used per $\mathrm{kg} \mathrm{H}_{2} \mathrm{O}$. For a given fracture width, we calculated the thickness of a continuous goethite fracture 
coating yielding 1 and 10 grams of goethite per $\mathrm{kg} \mathrm{H}_{2} \mathrm{O}$ (Fig. 7-15), assuming a fully saturated system. Goethite, hematite, and iron oxide stains are common in the fracture fill at Äspö, with estimated abundances as great as several percent by weight of the fracture fill (Banwart et al., 1994, 1995; Tullborg, 1995a,b). For a fracture fill with a fractional porosity of 0.1 , a rock density of $2800 \mathrm{~kg} / \mathrm{L}$, and $0.1 \%$ by weight of iron oxide, approximately $25 \mathrm{~g}$ of iron oxide would be associated with each $\mathrm{kg}$ of pore water. Thus, considering the petrographic observations of the abundance and distribution of HFOs observed at Aspö, the quantities of goethite per $\mathrm{kg}$ of $\mathrm{H}_{2} \mathrm{O}$ used in the calculations are reasonable and conservative. Based on $0.205 \mathrm{~mol}$ of sites $/ \mathrm{mol}$ Fe (Dzombak and Morel, 1990), there are $2.31 \times 10^{-3}$ moles of surface sites per gram of goethite. Even though goethite does not form continuous surface layers in nature, the calculation nonetheless demonstrates that the masses of goethite considered in this report are conservative, yet can account for a great deal of surface complexation.

The results of geochemical simulations such as those described here are only as reliable as the surface complexation constants and the complexation model upon which the predictions are based. For example, if the carbonate complexation constants from Van Geen, Robertson and Leckie (1994) overestimate the degree of formation of surface carbonate complexes, the degree of $\mathrm{SO}_{4}$ sorption would increase.

The reliability and robustness of surface complexation models and their data bases in simulating controlled and natural systems have not yet been explored fully. The results of these simulations should therefore not be used at this time as absolute, quantitative predictions of system behavior, but rather as a guide to how systems will behave in response to a change in the physical and/or chemical state such as induced by fluid mixing or changes in $\mathrm{pH}$ and redox state.

Hydrous ferric oxides are important sources and sinks of carbonate in both the shallow and native waters at Äspö through surface complexation. The corrosion products derived from waste package materials will create a similar source and sink in the EBS/NFE that will significantly impact the chemistry of the fluids passing through it. Carbonate surface complexation is favored over sulfate surface complexation at neutral to acid $\mathrm{pH}$. $\mathrm{Ca}$ and $\mathrm{Sr}$ sorption increase as $\mathrm{pH}$ increases.

The sorbent:fluid ratios used to evaluate the effects of sorption on fluid chemistry are consistent with observations of HFO abundance at Äspö. Geochemical simulations of mixing between shallow and native waters suggest that major elements such as $\mathrm{Ca}, \mathrm{Sr}$, and $\mathrm{SO}_{4}$ are not significantly affected by surface complexation onto HFOs. Thus, surface complexation does not account for observed deviations from a conservative mixing model for $\mathrm{Ca}$ and $\mathrm{SO}_{4}$, at least for the ranges of sorbent:fluid ratios used in the calculations. 


\subsection{Summary}

The EBS/NFE flow-path components appear to have the ability to significantly retard and/or sequester the movement of radionuclides from the waste form. The extent of this retardation will depend on a number of factors including the specific components used in the waste package, the nature of backfill and additives, the groundwater flux and dominant mode of transport, and the specific alteration products that develop during the period of substantially complete containment.

With regard to transport of radionuclides through fractured host rock, preliminary results indicate that diffusion from the fracture into the matrix will be bimodal in nature, with fast paths allowing diffusion at nearly the rate observed in bulk fluids, and slow paths through which diffusion is many orders of magnitude slower. Intracrystalline diffusion of radionuclides may limit the attainment of ionexchange equilibrium for all but the smallest crystals or slowest flow rates.

The physical retardation of soluble species resulting from diffusion into the matrix of fractured flow-path components will be affected by temperature, pore pressure, and confining pressure; hence thermo-mechanical effects of repository construction and waste emplacement may significantly alter the transport properties of the existing fracture network.

In addition to chemical effects of introduced materials, the presence of significant biological activity could significantly affect flow paths by plugging fractures.

Natural groundwater colloids are ubiquitous, but may not be present in large enough quantities to significantly affect radionuclide transport. Introduced materials, such as container corrosion products, backfill, and cements will add to the colloid population that is available for transporting radionuclides.

Surface chemical models that describe sorption via cation exchange and surface complexation approaches have been used to simulate mixing of groundwater mixing in a fractured aquifer and found to be consistent with observation. This enhances our confidence that these models/approaches will have applicability to Yucca Mountain and can be applied once material and design issues are resolved. 


\subsection{Summary of Gaps in Information Required to Bound Radionuclide Transport in the EBS/NFE}

Very little experimental data exists for radionuclide transport through EBS/NFE materials at the temperatures and fluxes expected in the repository. Hence, modeling efforts to derive the flux of radionuclides through the EBS/NFE will not be constrained by data. In addition to basic thermodynamic data regarding solubility and speciation of radionuclides at elevated temperature in the chemical environments expected in the EBS/NFE, bounding the flux of radionuclides through the EBS/NFE will also require:

1. Sorptive/chemical properties of the altered internal components of the waste package.

2. Sorptive properties of waste package corrosion products. Experimental measures of transport of critical soluble and/or colloidal radionuclides through waste package corrosion products at elevated temperatures.

3. Mineralogy and physical status of altered cementitious materials. Characterization of the mode of interaction of actinides with altered cementitious materials. Experimental measures of transport of critical soluble and/or colloidal radionuclides through altered cementitious materials. Characterization of colloids derived from altered cementitious materials. 


\subsection{References}

Albinsson, Y., Andersson, K., Borjesson, S., Allard, B. 1993. Diffusion of radionuclides in concrete/bentonite systems. Swedish Nuclear Fuel and Waste Management Co. Technical Report 93-29. Stockholm, Sweden.

Atkins, M., Beckley, A.N., and Glasser, F.P. 1988. Influence of cement on the near field environment and its specific interactions with uranium and iodine. Radiochimica Acta 44/45:255-261.

Atkinson, A., Everitt, N.M., and R.M. Guppy. 1989. Time dependence of $\mathrm{pH}$ in a cementitious repository. Mat. Res. Soc. Proc. Vol. 127:813-821. Mat. Res. Soc. Proc. Vol. 127:439-446.

Banwart, S., Gustafsson, E., Laaksoharju, M., Nilsson, A-C., Tullborg, E-L. and Wallin, B., 1994. Large-scale intrusion of shallow water into a vertical fracture zone in crystalline bedrock: Initial hydrochemical perturbation during tunnel construction at the Äspö Hard Rock Laboratory, southeastern Sweden. Water Resources Res., v. 30, p. 1747-1763.

Banwart, S., Laaksoharju, M., Pitkänen, P., Snellman, M., and Wallin, B. 1995. Development of a site model for reactive element dynamics. pp. 188-218. In Banwart, S. (ed.) The Redox Experiment in Block Scale: Final Reporting of Results from the Three Year Project. SKB Äspö Hard Rock Laboratory Progress Report 25-95-06, Stockholm.

Bates, J.K., Brown, N.R., Buck, E.C., Dietz, N.L., DiSanto, T., Ebert, W.L., Ellison, A.J.G., Emery, J.W., Fortner, J.A., Hafenrichter, L.D., Hoh, J.C., Mazer, J.J., Surchik, M.T., Wolf, S.F., and Wronkiewicz, D.J. 1995b. ANL Technical Support Program for DOE Environmental Restoration and Waste Management. ANL-95/20. Argonne National Laboratory, Argonne, IL.

Bates, J.K., Fortner, J.A., Finn, P.A., Wronkiewicz, D.J., Hoh, J.C., Emery, J.W., Buck, E.C., and Wolf, S.F. 1995a. Yucca Mountain Project - Argonne National Laboratory Report, FY 1994. ANL-94/42. Argonne National Laboratory, Argonne, IL.

Bethke, C.M. 1994. A Users Guide to Rxn, Act2, Tact, React, and Gtplot. Copyright Craig M. Bethke, University of Illinois, Champaign, IL.

Breck, DW. 1984. Zeolite Molecular Sieves. R.E. Krieger Pub., Malabar, FL, pgs. 559 and 574-575. (NNA.19890522.0211)

Brouwer, E., Baeyens, B., Maes, A., and Cremers, A. 1983. Cesium and rubidium ion equilibria in illite clay. J. Phys. Chem. 87: 1213

Bruggenwert, M.G.M., and Kamphorst, A. 1982. Survey of experimental information on cation exchange in soil systems. pp. 141-203. In Bolt, G.H. (ed.) Soil Chemistry B. Physico-Chemical Models. Elsevier, Amsterdam.

Bruton, C.J., and Viani, B.E. 1996. Ion Sorption onto Hydrous Ferric Oxides: Effect on Major Element Fluid Chemistry at Aspo, Sweden. Lawrence Livermore National Laboratory report UCRL-JC-124329. Livermore, CA. 
Bruton, C.J., Meike, A., Viani, B.V., Martin, S., and Phillips, B.L. 1993.

Thermodynamic and structural characteristics of cement minerals at elevated temperature. Proc. Topical Meeting on Site Characterization and Model Validation, FOCUS '93, Las Vegas, NV, pg. 150-156, American Nuclear Soc., La Grange Park, IL. (MOL. 19940913.0047)

Buchholtz-ten Brink, M., Martin, S.I., Viani, B.E., Gerlach, D.C., and Rego, J.H. 1990. Characterization and transport of colloidal particles in groundwaters from the Nevada Test Site. AGU 1990 Fall Mtng., Abstr., EOS, Trans., Vol. 71, p. 1306.

Buchholtz-ten Brink, M., Martin, S.I., Viani, B.E., Smith, D.K., and Phinney, D. 1992. Heterogeneities in radionuclide transport: Pore-size, particle-size, and sorption. in McCarthy, J.F. (ed.), Concepts in Manipulating Groundwater Colloids for Environmental Restoration. Lewis publishers, Chelsea, MI. (NNA.19910523.0101)

Carlos, B.A. 1985. Minerals in Fractures of the Unsaturated Zone from Drill Core USW G4, Yucca Mountain, Nye County, Nevada. Los Alamos National Laboratory report LA-10415-MS. (NNA.19920506.0037)

Conca, J.L. 1990. Diffusion barrier transport properties of unsaturated Paintbrush tuff rubble backfill. Proc. First International Meeting High Level Radioactive Waste Management, Las Vegas, NV, Vol 1, pg. 394-401, American Nuclear Soc., La Grange Park, IL. (NNA.19900710.0198).

Cornell, R.M. 1993. Adsorption of cesium on minerals: A review. J. Radioanalytical Nucl. Chem., Articles. 171:483-500.

CRWMS M\&O. 1996. Strategy for Focused Evaluation of Waste Containment and Isolation at the Yucca Mountain Site. Civilian Radioactive Waste Management System Management and Operation Contractor, Las Vegas, NV.

De Marsily, G. 1986. Quantitative Hydrogeology. p. 55 Academic Press, Inc. New York. Dzombak, D.A., and Morel, F.M. 1990. Surface Complexation Modeling: Hydrous Ferric Oxide. Wiley, New York.

Fletcher, P. and Sposito, G. 1989. The chemical modeling of clay-electrolyte interactions for montmorillonite. Clay Minerals, v. 24, p. 375-391.

Gast, R.G. 1972. Alkali metal cation exchange on Chambers montmorillonite. Soil Sci. Soc. Amer. Proc. 36:14.

GIT (YMP Geochemistry Integration Team) 1993. Claude Degueldre measured the particulates in a sample of J13 collected by W. Steinkampf (USGS) and found $1.7 \times 107$ particles $/ \mathrm{mL}$. Minutes of the October 18, 1993 Geochemistry Integration Team Teleconference.

Ho, C.H., and Miller, N.H. 1986. Adsorption of uranyl species from bicarbonate solution onto hematite particles. J. Coll. Inter. Sci. 110:165-171.

Klavetter, E.A. and Peters, R.R. 1986. Estimation of Hydrologic Properties of an Unsaturated, Fractured Rock Mass. Report SAND-84-2642, Sandia National Laboratory, Albuquerque, NM. (NNA.19870317.0738)

Laaksoharju, M., Banwart, S., Skarman, C., Gustafsson, E., Pitkänen, P., and Snellman, M. 1995. Hydrochemistry overview. pp. 17-46. In Banwart, S. (ed.) The Redox Experiment in Block Scale: Final Reporting of Results from the Three Year Project. SKB Äspö Hard Rock Laboratory Progress Report 25-95-06, Stockholm. 
Landström, O., and Tullborg, E-L. 1995. Interactions of Trace Elements with Fracture Filling Minerals from the Äspö Hard Rock Laboratory. SKB Technical Report 95-13, Swedish Nuclear Fuel and Waste Management Co., Stockholm, Sweden.

Lanford, W.A., Davis, K., Lamarche, P., Laursen, T., Groleau, R., and Doremus, R.H. 1979. Hydration of soda-lime glass. J. Non-Crystalline Solids 33:249-266.

(NNA.19900306.0089)

Martin, S.I., Buchholtz-ten Brink, M., and Viani, B.E. 1991. Characterization of colloids in groundwaters using transmission electron microscopy. AGU 1991 Fall Mtng., Abstr., EOS, Trans., Vol. 72, Supplement, p. 154.

McCarthy, J.F., and Degueldre, C. 1993. Sampling and characterization of colloids and particles in ground water for studying their role in contaminant transport. in van Leeuwen, H.P. and Buffle, J. (eds.), Environmental Particles, IUPAC Environmental Analytical and Physical Chemistry Series, Vol. II, Lewis Publishers, Chelsea, MI. (NNA.19930607.0075)

McKeegan, K.D., Phinney, D., Oversby, V.M., Buchholtz ten Brink, M., and Smith, D.K. 1989. Uranium transport in Topopah Spring tuff: An ion-microscope investigation. Mat. Res. Soc. Proc. Vol. 127:813-821. (NNA.19900620.0330)

Meijer, A. 1990. A strategy for the derivation and use of sorption coefficients in performance assessment calculations for the Yucca Mountain site. Pg 9-40. Proceeding of the DOE/Yucca Mountain Site Characterization Project Radionuclide Adsorption Workshop at Los Alamos Laboratory. LA-12325-C. (NNA.19930629.0011)

Mohanty, S., Manteufel, R.D., Chowdhury, A.H., and Philip J. 1995. Fracture permeability under effect of normal and shear stress: A preliminary experimental investigation. Proc. Sixth International Meeting High Level Radioactive Waste Management, Las Vegas, NV, pg. 41-43, American Nuclear Soc., La Grange Park, IL.

Ogard, A. 1987. Importance of radionuclide transport by particulates entrained in flowing groundwaters in Groundwater Chemistry at Yucca Mountain, Nevada, and Vicinity. Los Alamos National Laboratory Report LA-10929-MS. Los Alamos, NM. (NNA.19870507.0017)

Phinney, D.L., Ryerson, F.J., Oversby, V.M., Lanford, W.A., Aines, R.D., and Bates, J.K. 1987. Integrated testing of the SRL-165 glass waste form. Mat. Res. Soc. Proc. Vol. 84:433-446. (NNA.19891120.0003)

Puls, R.W., Clark, D.A., Bledsoe, B., and Powell, R.M. 1992. Metals in ground water Sampling artifacts and reproducibility. Hazardous Waste \& Hazardous Materials. 9:149-162.

Ramsay, J.D.F., Avery, R.G., and Russell, P.J. 1988. Physical characteristics and sorption behaviour of colloids generated from cementitious systems. Radiochimica Acta 44/45:119-124. (NNA.19931005.0015)

Roberts, J.J., and Lin, W. 1995. Permeability of fractured tuff as functions of temperature and confining pressure. Proc. Sixth International Meeting High Level Radioactive Waste Management, Las Vegas, NV, pg. 44-45, American Nuclear Soc., La Grange Park, IL. (MOL19950501.0025)

Roberts, S., Viani, B.E., and Phinney, D. 1995. Radionuclide Diffusion in Clinoptilolite. Yucca Mountain Project Milestone MOL133.(M0L.19951213.0093) 
Rundberg, R.S. 1987. Assessment Report on the Kinetics of Radionuclide Adsorption on Yucca Mountain Tuff. Los Alamos National Laboratory Report LA-11026-MS, Los Alamos, NM (NNA.19930405.0075)

Sposito, G. 1981. Thermodynamics of Soil Solutions. Oxford University Press, New York, NY. (NNA.19900416.0124)

Steefel, C.I., and Lichtner, P.C. 1994. Diffusion and reaction in rock matrix bordering a hyperalkaline fluid-filled fracture. Geochim. Cosmochim. Acta 58:3595-3612.

Thomas, K.W. 1987. Summary of Sorption Measurements Performed with Yucca Mountain, Nevada Tuff Samples and Water from Well J-13. Report LA-10960-MS. Los Alamos National Laboratory, Los Alamos, NM.(NNA.19890602.0026)

Ticknor, K.V. 1994. Uranium sorption on geological materials. Radiochimica Acta 64:229-236. (MOL.19950117.0119)

Todorovic, M., Milonjic, S.K. Comor, J.J. and Gal, I.J. 1992. Adsorption of radioactive ions ${ }^{137} \mathrm{Cs}^{+}, 85 \mathrm{Sr}^{2+}$, and ${ }^{60} \mathrm{Co}^{2+}$ on natural magnetite and hematite. Sep. Sci. Tech. 27:671-679.

Triay, I., Simmons, A., Levy, S., Nelson, S., Nuttall, H., Robinson, B., Steinkampf, W., and Viani, B. 1993a. Colloid-facilitated radionuclide transport at Yucca Mountain. Los Alamos Report LA-12779-MS. Los Alamos, NM. (NNA.19930628.0067)

Triay, I.R., Robinson, B.A., Mitchell, A.J., Overly, C.M., and Lopez, R.M. 1993b. Transport of neptunium through Yucca Mountain tuffs. Mat. Res. Soc. Symp. Proc. 294:797-802. (NNA.19930924.0106)

Tullborg, E-L. 1995a. Mineralogical/geochemical investigations in the fracture zone. pp. 81-101. In Banwart S. (ed) The Redox Experiment in Block Scale: Final Reporting of Results from the Three Year Project. SKB Äspö Hard Rock Laboratory Progress Report 25-95-06, Stockholm.

Tullborg, E-L. 1995b. Mineralogical and Chemical Data on Rocks and Fracture Minerals from Äspö. Äspö Hard Rock Laboratory Technical Note $25-95-07 \mathrm{~g}$, Stockholm.

Van Geen, A., Robertson, A.P. and Leckie, J.O., 1994. Complexation of carbonate species at the goethite surface: Implications for adsorption of metal ions in natural waters. Geochim. et Cosmochim. Acta, v. 58, p. 2073-2086.

(NNA.19940210.0041)

Viani, B.E. 1995a. Scientific Investigation Plan for YMP WBS Element 1.2.3.10.3.1 Integrated Radionuclide Release: Tests and Model Development (Integrated Testing). SIPIT-01. Rev. 0. Lawrence Livermore National Laboratory, Livermore, CA. (MOL.19960329.0044)

Viani, B.E. 1995b. Strategies for Integrating Materials Properties Activities with Integrated Radionuclide Transport Activities. YMP Milestone Rept. M0L135. (M0L.19960307.0233)

Viani, B.E., and Bruton, C.J. 1996. Assessing the Role of Cation Exchange in Controlling Groundwater Chemistry During Fluid Mixing in Fractured Granite at Aspo, Sweden. Lawrence Livermore National Laboratory report UCRL-JC-121527. Livermore, CA. (M0L.19960419.0049) 
Viani, B.E., and Bruton, C.J. 1994. Effect of cation exchange on major cation chemistry in the Large Scale Redox Experiment at Äspö. In Banwart, S., ed., Proc. Äspö International Geochemistry Workshop, June 2-3, 1994, Äspö Hard Rock Laboratory, p. B-78-B-96. Also issued as Lawrence Livermore National Laboratory report UCRL-JC-118592. Livermore, CA.

Viani, B.E., and Bruton, C.J. 1992a. Modeling ion exchange in clinoptilolite using the EQ3/6 geochemical modeling code. In Kharaka; Y. and Maest, A.S., eds., WaterRock Interaction, Proceedings of the 7th International Symposium, vol. 1, A.A. Balkema, Brookfield, VT, p. 73-77. (M0L.19960607.0056)

Viani, B.E., and Bruton, C.J. 1992b. Modeling Fluid-Rock Interaction at Yucca Mountain, Nevada: A Progress Report. Lawrence Livermore National Laboratory, Livermore, CA, UCRL-ID-109921, 61 p. (NNA.19920805.0002)

Viani B.E., and Martin, S.I. 1994a. Core Flow Experiment Protocol. YMP Milestone Report MOL04. (MOL.19950727.0022)

Viani B.E., and Martin, S.I. 1994b. Groundwater Colloid Characterization. YMP Milestone Report MOL03. (M0L.19950622.0014)

Viani, B.E., and Martin, S.I. 1993. Core-Flow Through Apparatus: Letter Report Documenting Testing Phase. YMP Milestone Report M0L06. (NNA.19940120.0124)

Viani, B.E., Roberts, S., Martin, S.I., and Phinney, D. 1994. YMP Milestone report MOL05: Progress Report on Diffusion of Radionuclides in Clinoptilolite. (MOL.19950406.0145)

Waite, T.D., Davis, J.A., Payne, T.E., Waychunas, G.A., and Xu, N., 1994. Uranium(VI) adsorption to ferrihydrite: Application of a surface complexation model, Geochim. et Cosmochim. Acta, v. 58, p. 5465-5478.

Wilson, C.N. 1990. Results from NNWSI Series 3 Spent Fuel Dissolution Tests. Pacific Northwest Laboratory report PNL-7170. Pacific Northwest Laboratory, Richland, WA. (NNA.19900329.0142)

Wolery, T.J., Jackson, K.J., Bourcier, W.L., Bruton, C.J., Viani, B.E., Knauss, K.G., and Delany, J.M. 1990. Current status of the EQ3/6 software package for geochemical modeling. pp. 104-116. In Melchior, D.C. and Bassett, R.L. (eds.) Chemical Modeling of Aqueous Systems II. American Chemical Society, Washington, D.C. (NNA.19900716.0363) 


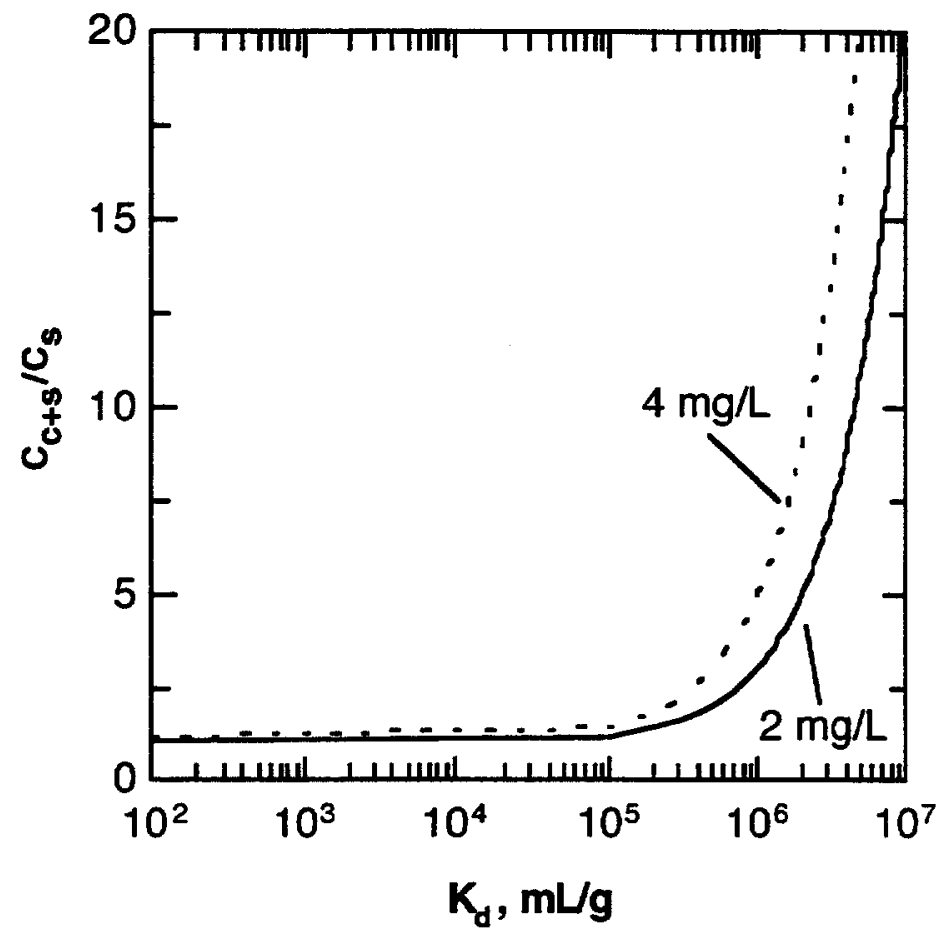

Figure 7-1. Relationship between ratio of concentration of radionuclide carried by solution in presence of colloid to that in absence of colloid, $C_{c+s} / C_{s}$, vs. $K_{d}$ for radionuclide on colloid, at two concentrations of colloid.

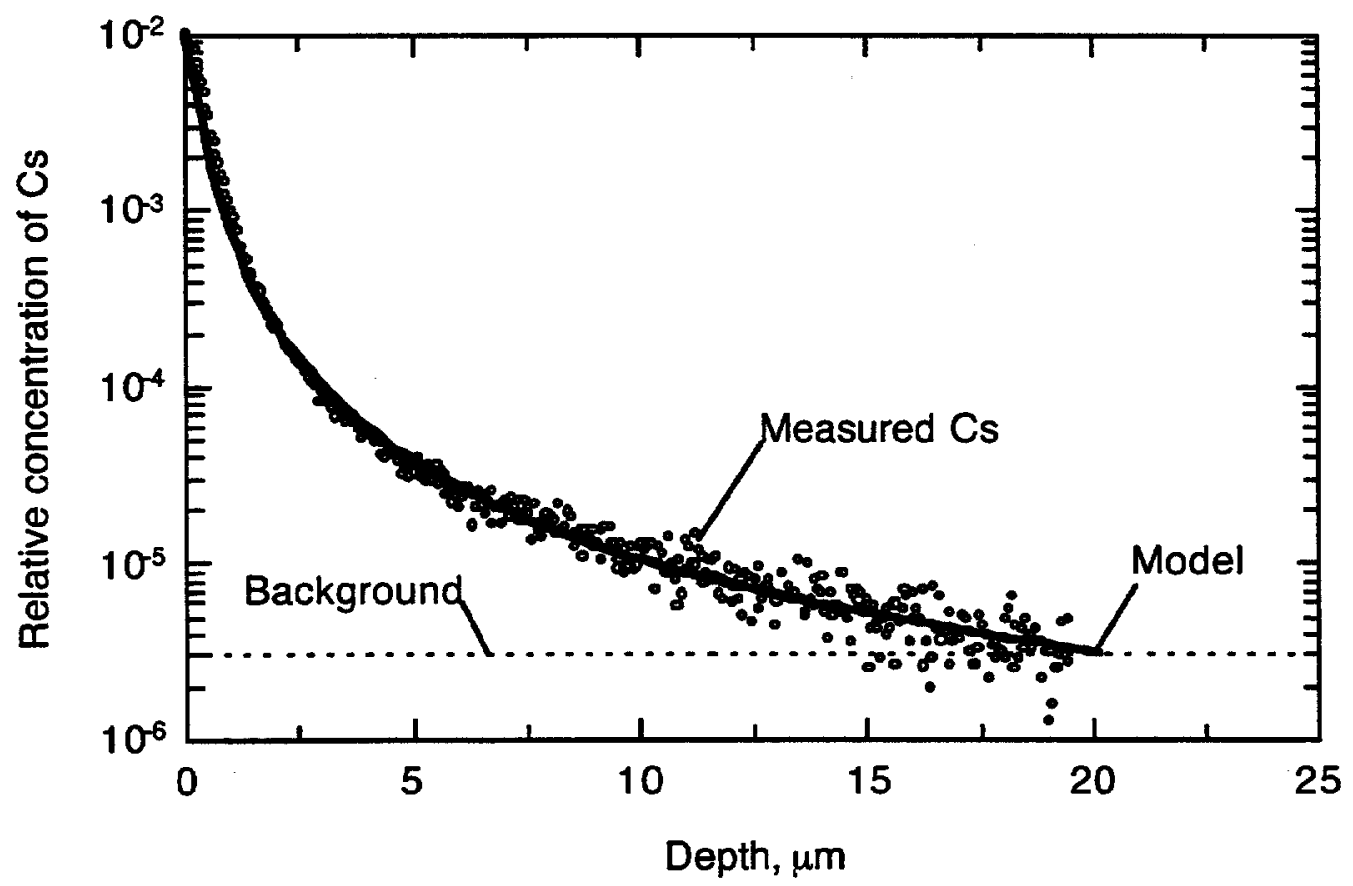

Figure 7-2. Variation of Cs with depth as measured by SIMS for nominally homoionic Ca-clinoptilolite in contact with a Cs/Ca solution at $30^{\circ} \mathrm{C}$ for $32 \mathrm{~d}$. Open circles are data points; solid line represents binary interdiffusion model with $D_{\text {in, }, s}=2.0 \times 10^{-13}$ and $D_{\text {out }, c_{a}}=1.5 \times 10^{-18} \mathrm{~cm}^{2} / \mathrm{s}$; dashed line represents background required to fit the model to the data. 


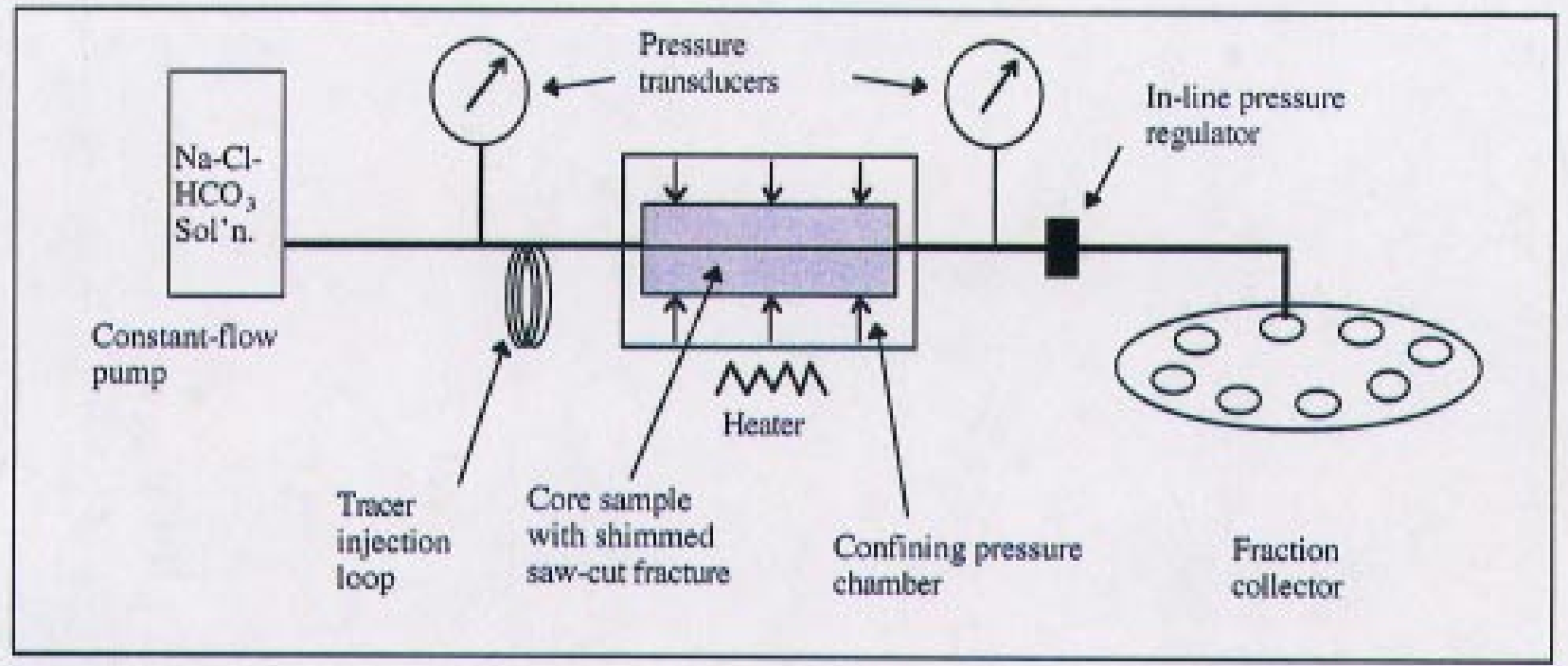

Figure 7-3. Schematic diagram of device used for flow and tracer tests.

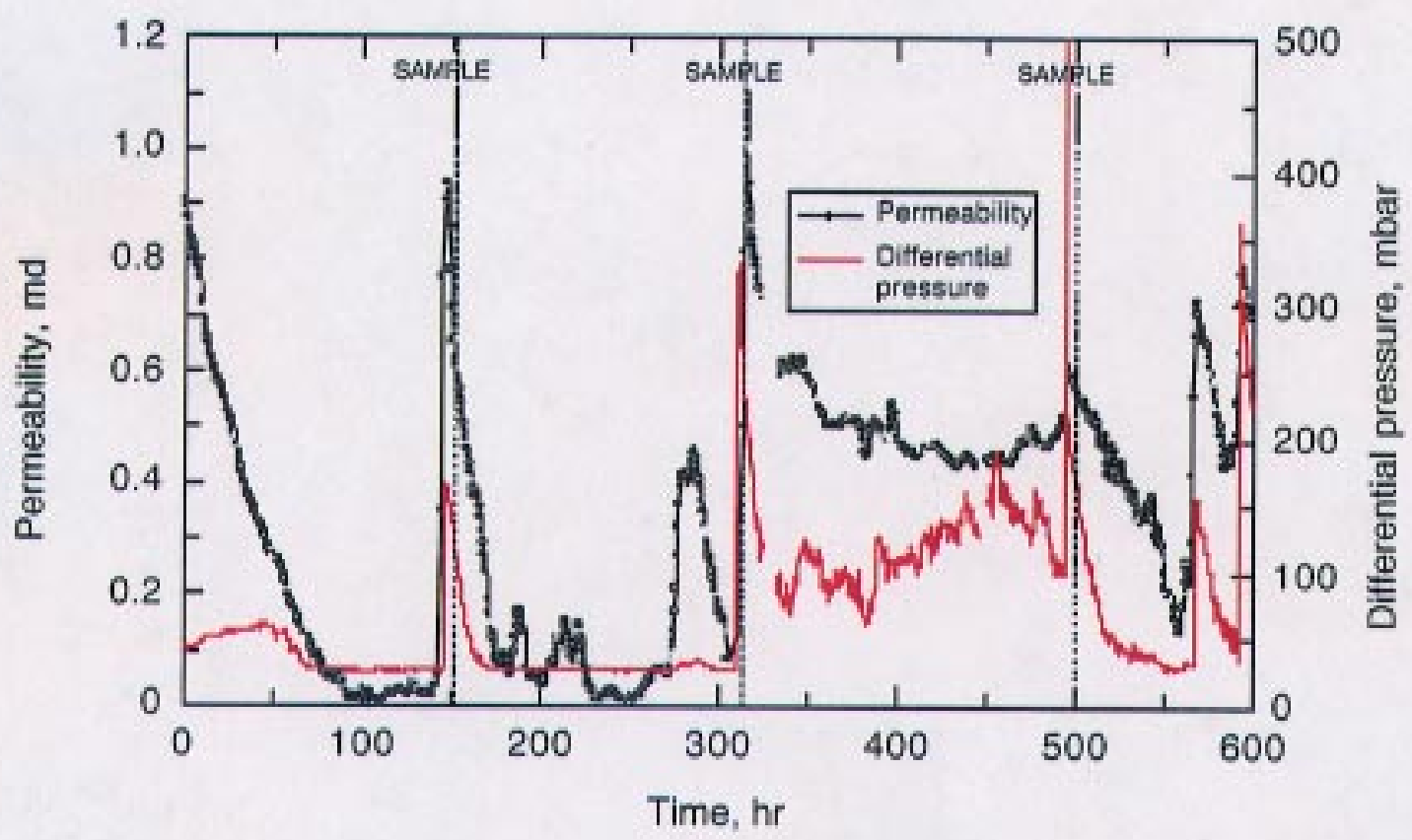

Figure 7-4. Variation of permeability and differential pressure with time for partial segment of flow test (FT040293) at $22^{\circ} \mathrm{C}$, showing repetitive loss of permeability due to bacterial plugging of a saw-cut fracture. Dotted vertical lines indicate points at which samples were taken for microscopic analysis. The apparatus used for this flow-test did not have the ability to maintain a constant flow rate. 



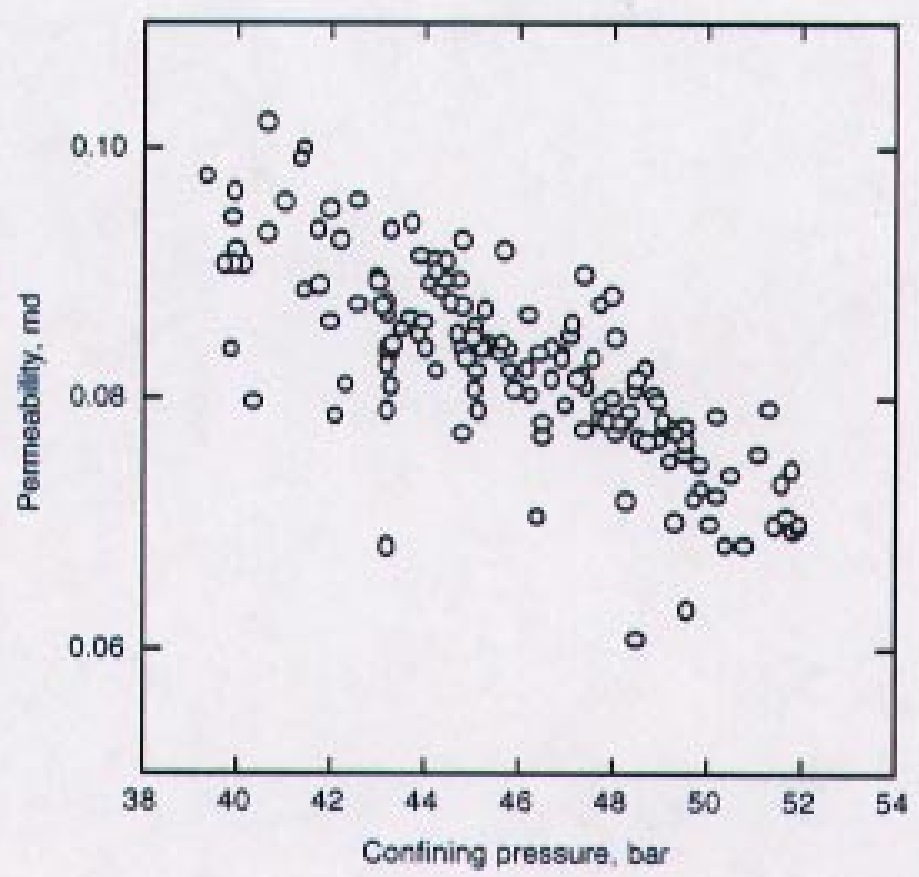

Figure 7-5. Variation in instantaneous permeability due to variation in confining pressure. $\left(\mathrm{T}=59^{\circ} \mathrm{C}\right.$; flow rate $=0.2 \mathrm{~mL} / \mathrm{h}$, FT050295).

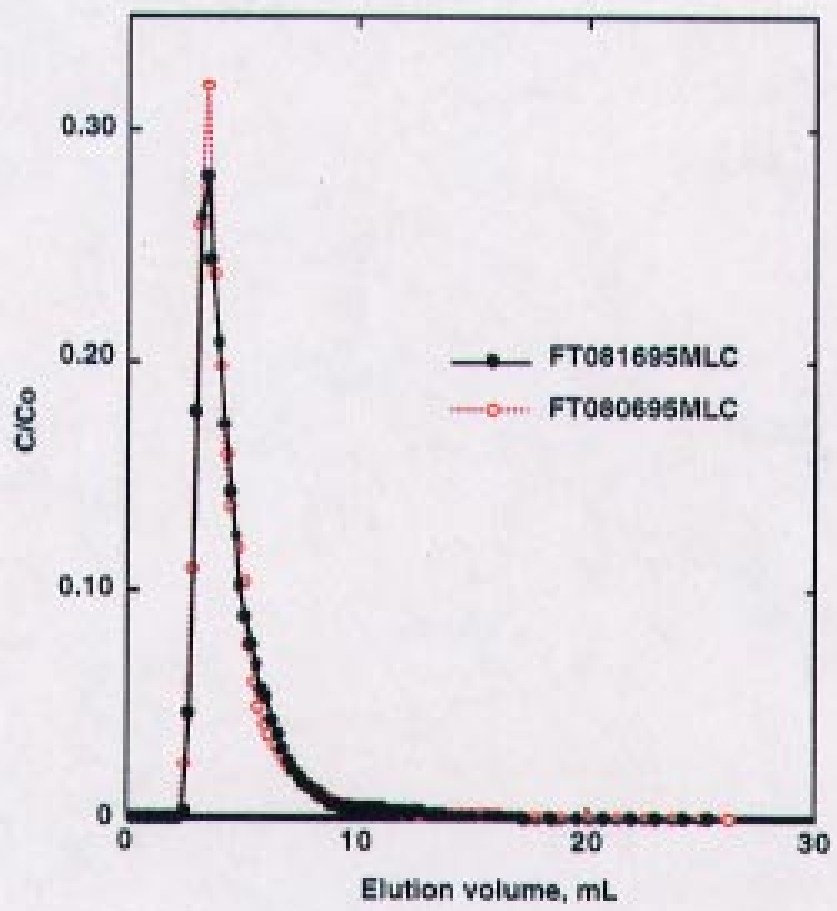

Figure 7-6. Relative concentration (C/C) breakthrough of two separate $560-\mu \mathrm{L}$ pulses of $\mathrm{1}^{-}$tracer for 0.2 $\mathrm{mL} / \mathrm{h}$ flow rate, $92{ }^{\circ} \mathrm{C}$, and low pore pressure (collected 10 days apart). 



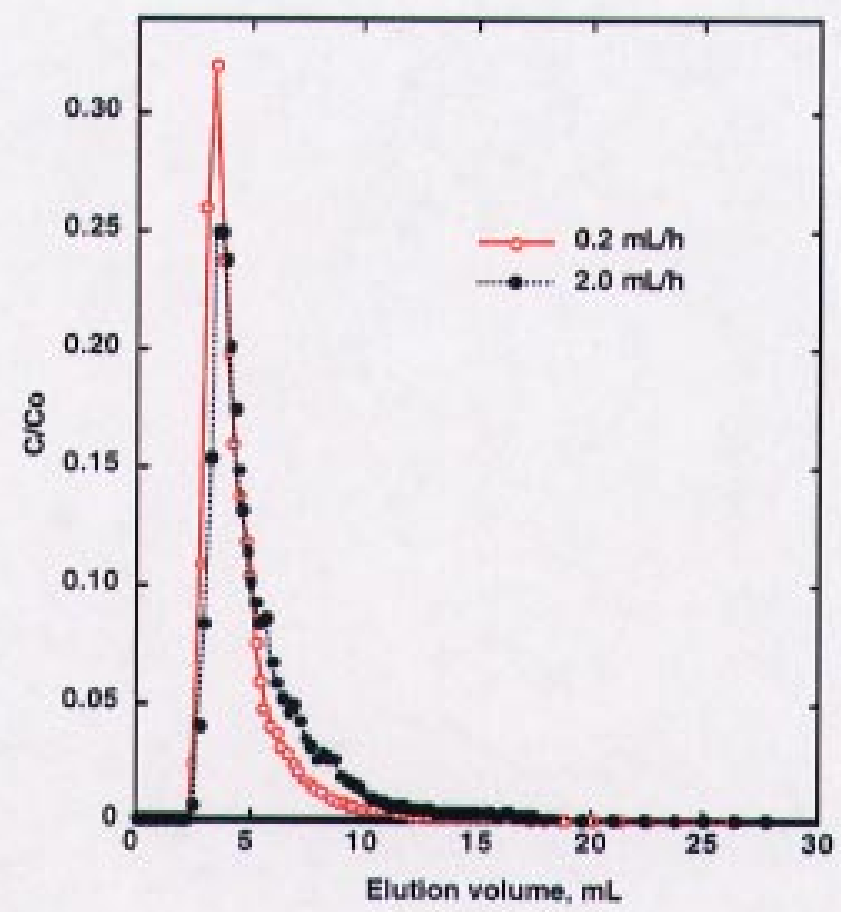

Figure 7-7. Relative concentration $\left(\mathrm{C} / \mathrm{C}_{\mathrm{c}}\right)$ breakthrough of $560-\mu \mathrm{L}$ pulse of $\mathrm{I}^{-}$tracer for 0.2 (FT080695MLC) and 2.0 (FT072695MLC) $\mathrm{mL} / \mathrm{h}$ flow rates at $92{ }^{\circ} \mathrm{C}$ and low pore pressure.

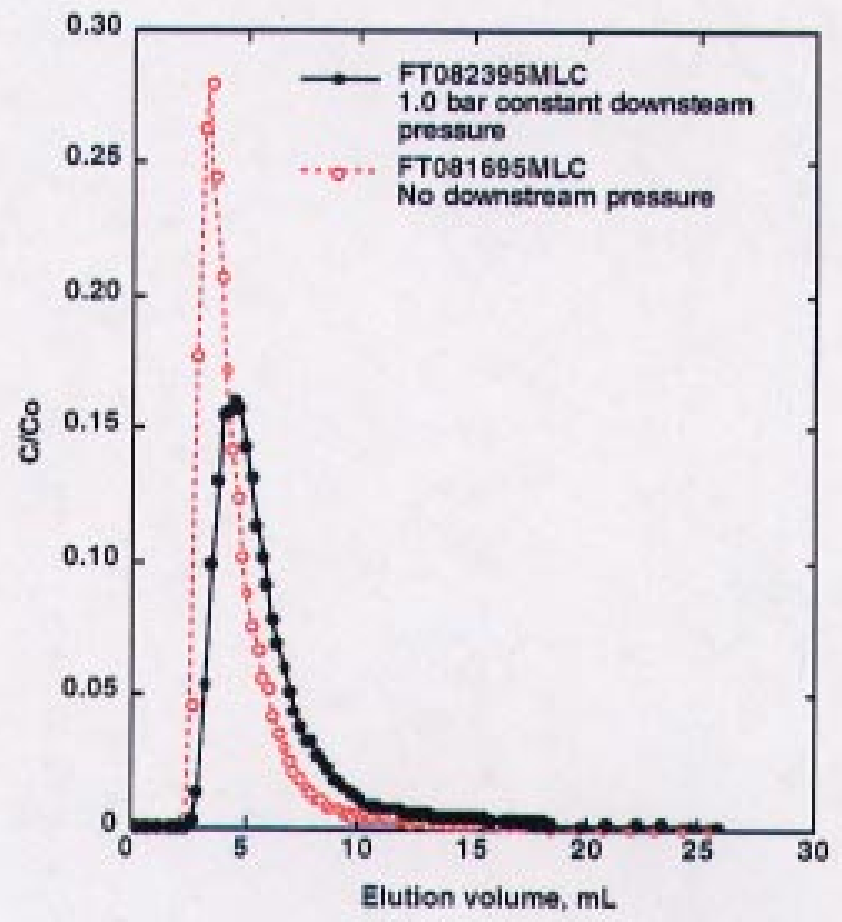

Figure 7-8. Relative concentration $\left(\mathrm{C} / \mathrm{C}_{2}\right)$ breakthrough of $560 \mu \mathrm{L}$ pulse of $\mathrm{I}^{-}$tracer for $0.2 \mathrm{~mL} / \mathrm{h}$ flow rate at $92^{\circ} \mathrm{C}$ and 1 bar (FT082395MLC) and low (FT081695MLC) pore pressure. 




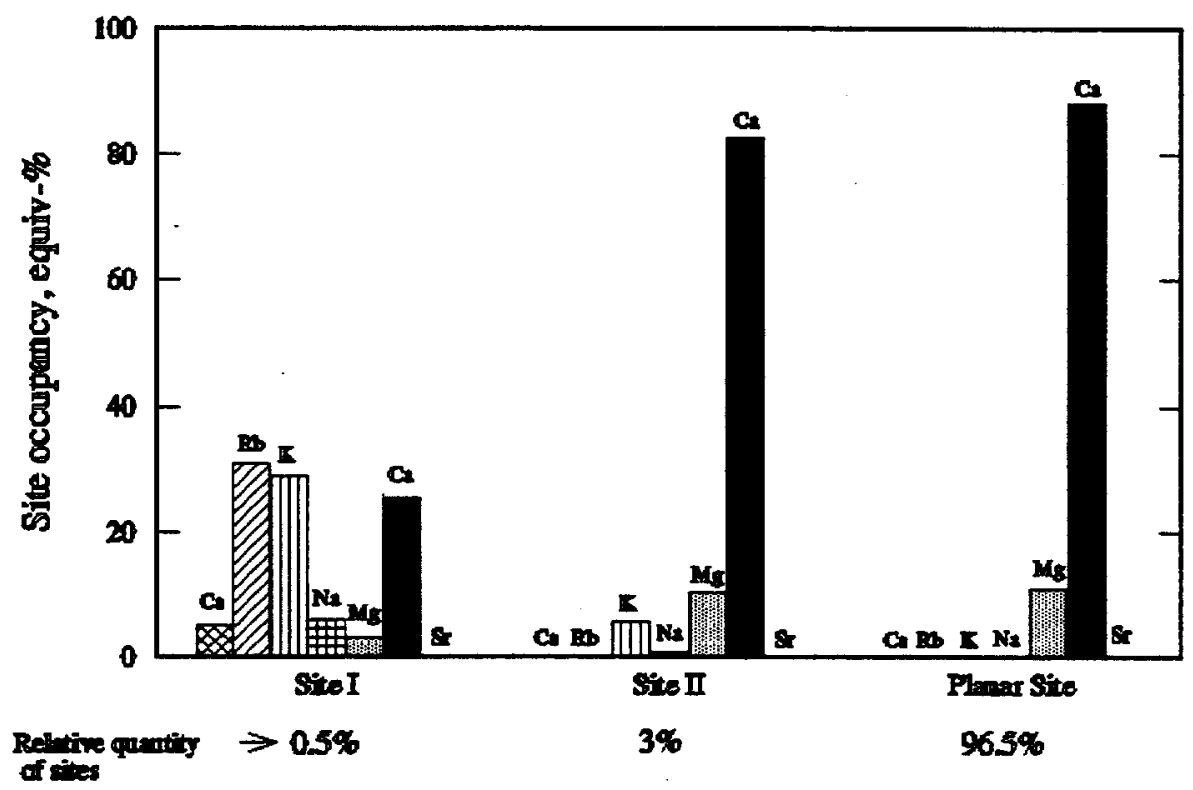

Figure 7-11. Predicted occupancies of exchange sites for illite in equilibrium with shallow (HBH02) groundwater.

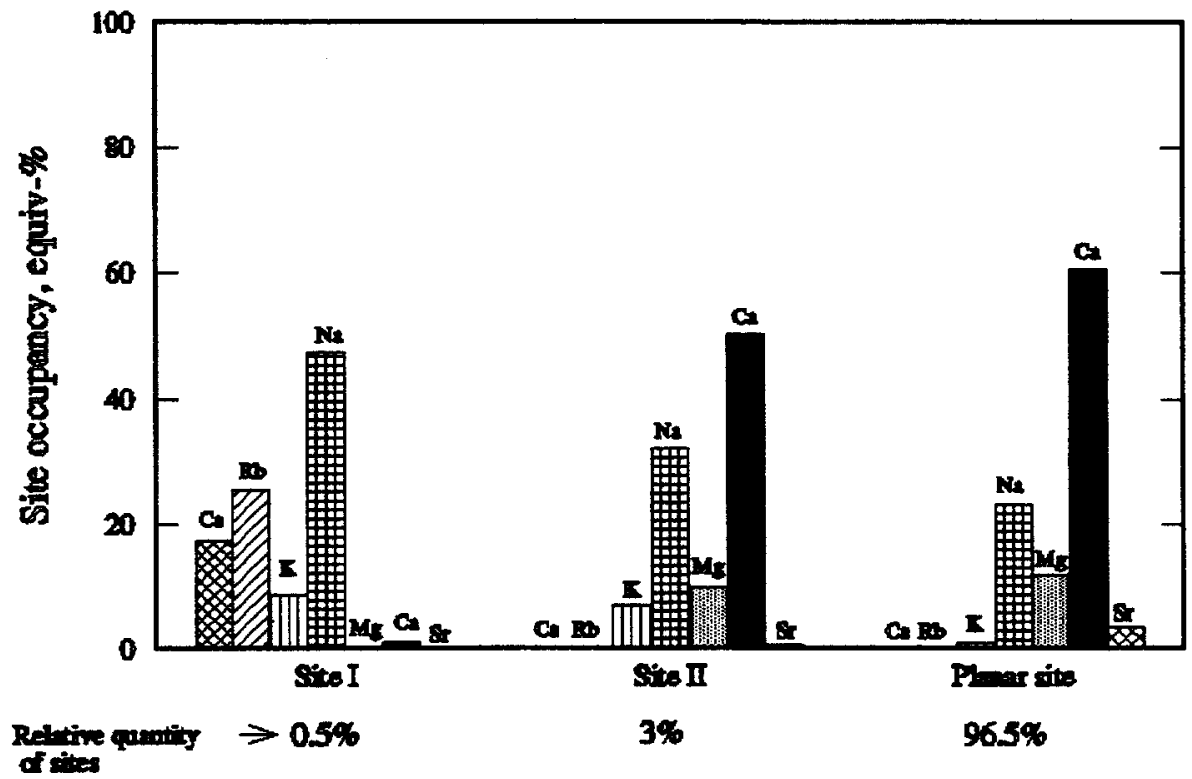

Figure 7-12. Predicted occupancies of exchange sites for illite in equilibrium with native (KA0483) groundwater. 


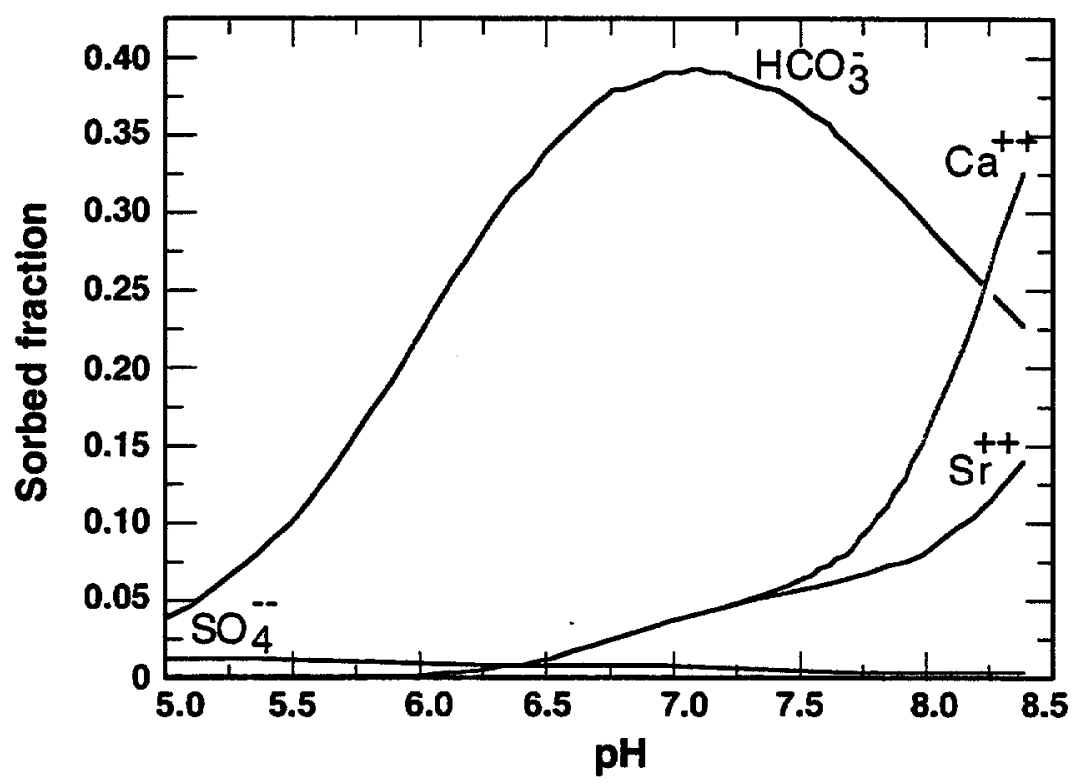

Figure 7-13. Fraction of total quantity of $\mathrm{HCO}_{3}, \mathrm{SO}_{4}, \mathrm{Ca}$, and $\mathrm{Sr}$ sorbed onto 1 g goethite $/ \mathrm{kg} \mathrm{H}_{2} \mathrm{O}$ in shallow (HBH02) groundwater at $25^{\circ} \mathrm{C}$ using Dzombak and Morel (1990) surface complexation data with carbonate surface species from Van Geen, Robertson, and Leckie (1994). Electrical balancing on $\mathrm{HCO}_{3}$.

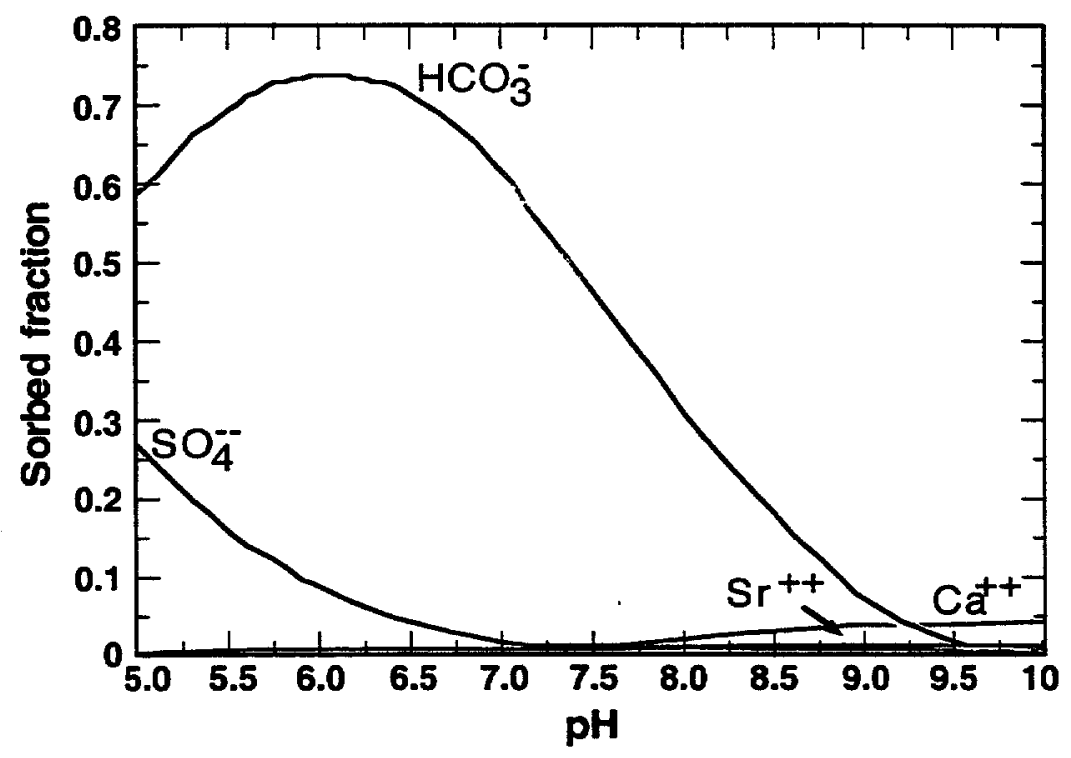

Figure 7-14. Fraction of total quantity of $\mathrm{HCO}_{3}, \mathrm{SO}_{4}, \mathrm{Ca}$, and $\mathrm{Sr}$ sorbed onto 1 g goethite $/ \mathrm{kg} \mathrm{H}$ in native (KA0483A) groundwater at $25^{\circ} \mathrm{C}$ using Dzombak and Morel (1990) surface complexation data with carbonate surface species from Van Geen, Robertson, and Leckie (1994). Electrical balancing on $\mathrm{Cl}$. 


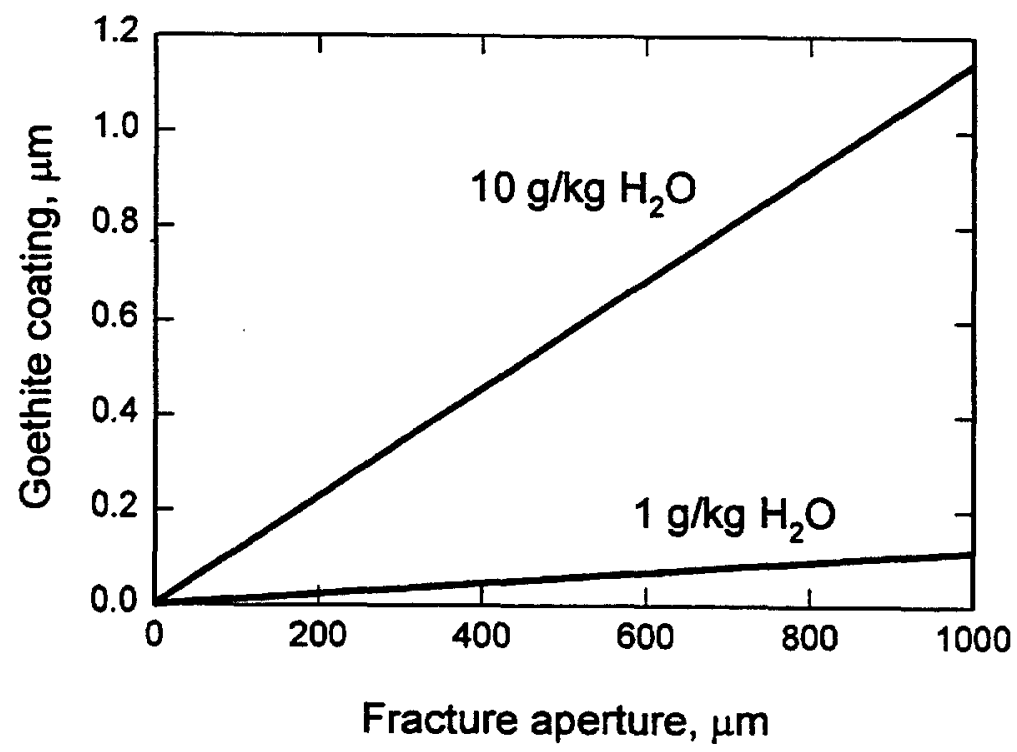

Figure 7-15. Variation in thickness of goethite coating with fracture aperture corresponding to 1 and $10 \mathrm{~g}$ of goethite per $\mathrm{kg}$ of $\mathrm{H}^{2} \mathrm{O}$ contained in fracture. 
Table 7-1. Summary of partition coefficient $\left(\mathrm{K}_{\mathrm{d}}\right)$ ranges for selected elements with selected EBS/NFE flow-path components. ${ }^{(2)}$

\begin{tabular}{|c|c|c|c|}
\hline $\begin{array}{l}\text { Flow-Path } \\
\text { Component }\end{array}$ & Cs & $\underset{\mathrm{mL} / \mathrm{g}}{\mathrm{Np}}$ & $\mathrm{U}$ \\
\hline Iron Oxide & $1 \times 10^{0}-1 \times 10^{1(2)}$ & $3 \times 10^{2}-9 \times 10^{3(3)}$ & $2 \times 10^{3}-2 \times 10^{4(4)}$ \\
\hline Cement $^{(5)}$ & $1 \times 10^{0}-1 \times 10^{1}$ & $2 \times 10^{3}-3 \times 10^{4}$ & $1 \times 10^{2}-6 \times 10^{3}$ \\
\hline Devitrified Tuff & $1 \times 10^{1}-1 \times 10^{3(6)}$ & $-1 \times 10^{1(7)}$ & $-1 \times 10^{1(\pi)}$ \\
\hline
\end{tabular}

(1) $K_{d}$ 's depend on solution composition, solid/solution ratio, specific surface of adsorbent, and concentration of uranium. The $\mathrm{K}_{\mathrm{d}}$ ranges listed for devitrified tuff and iron oxide are for dilute carbonate-bearing solutions with $\mathrm{pH}^{\prime}$ 's between $\sim 7$ to $\sim 8.5$; similar to what would be expected at Yucca Mountain. The solution composition for cements is controlled by the interaction with pore water and cement and would be expected to be similar for any dilute groundwater that interacts with it.

(2) Hematite; Cornell, 1993; Todorovic et al., 1992.

(3) Hematite; Triay et al., 1993b.

(4) Hematite; Ticknor, 1994; Ho and Miller, 1986.

(5) Yucca Mountain tuff; Meijer, 1990

(6) Portland cements; Albinsson et al., 1993.

(7) Yucca Mountain tuff; Thomas, 1987.

Table 7-2. Summary of flow tests with saw-cut Topopah Spring core sample.

\begin{tabular}{ccccc}
\hline $\begin{array}{c}\text { Temperature } \\
{ }^{\circ} \mathrm{C}\end{array}$ & $\begin{array}{c}\text { Flow Rate } \\
\mathrm{mL} / \mathrm{h}\end{array}$ & $\begin{array}{c}\text { Pore Pressure } \\
\text { bar }\end{array}$ & $\begin{array}{c}\text { Permeability }{ }^{(2)} \\
\text { md }\end{array}$ & $\begin{array}{c}\text { Hydraulic } \\
\text { Aperture } \\
\mu \mathrm{m}\end{array}$ \\
\hline 23 & $0.1,0.2,2.0$ & $0.1-2.0$ & $0.060 \pm 0.005$ & 3.1 \\
59 & $0.2,2.0$ & $0.1-2.5$ & $0.10 \pm 0.035$ & 3.6 \\
92 & $0.2,2.0$ & $0.06-0.09$ & $0.19 \pm 0.14$ & 4.5 \\
92 & $0.2,2.0$ & $0.5-3.1$ & $1.86 \pm 0.47$ & 9.6 \\
\hline
\end{tabular}

(1) Pore pressures are average values computed over the duration of each flow test. The tabulated values show the range in average pore pressures observed for runs at that temperature and the indicated flow rates.

(2) The permeabilities are average values calculated from the average of the instantaneous permeabilities for a given flow test. Instantaneous permeabilities varied with confining pressure, and over time. 
Table 7-3. Composition of feed solution and effluent from pooled samples taken after breakthrough of the tracer.

\begin{tabular}{ccccc}
\hline Element & Feed solution & \multicolumn{3}{c}{ Effluent } \\
\cline { 3 - 5 } & & $23^{\circ} \mathrm{C}$ & $92{ }^{\circ} \mathrm{C}$ & $92{ }^{\circ} \mathrm{C}$ \\
& & $0.2 \mathrm{~mL} / \mathrm{h}$ & $0.2 \mathrm{~mL} / \mathrm{h}$ & $2.0 \mathrm{~mL} / \mathrm{h}$ \\
\hline $\mathrm{Ca}$ & 0.05 & 4.54 & 3.62 & 2.46 \\
$\mathrm{Mg}$ & $<0.01$ & 1.08 & 0.83 & 0.53 \\
$\mathrm{Na}$ & 33 & 37 & 34 & 31 \\
$\mathrm{~K}$ & $<0.01$ & 0.4 & 1.7 & 1.2 \\
$\mathrm{Si}$ & 0.08 & 2.65 & 22.49 & 6.91 \\
$\mathrm{Sr}$ & $<0.02$ & 0.12 & 0.09 & 0.06
\end{tabular}

Table 7-4. Cation-exchange energies for illite and smectite at $25^{\circ} \mathrm{C}^{(1)}$.

\begin{tabular}{lcccc}
\hline & \multicolumn{3}{c}{ Exchange Energy, kcal/equiv } \\
\cline { 2 - 4 } Exchange Reaction & Site I & Site II & Planar Site & Smectite \\
\cline { 2 - 4 } $\mathrm{Na} \rightarrow 0.5(\mathrm{Ca}, \mathrm{Mg}, \mathrm{Sr}$, & 1.4 & 0.2 & $0^{(3)}$ & -0.12 \\
$\mathrm{Ba})^{(2)}$ & & & -1.22 & -0.35 \\
$\mathrm{Na} \rightarrow \mathrm{K}$ & -2.2 & -2.3 & -1.62 & -0.63 \\
$\mathrm{Na} \rightarrow \mathrm{Rb}$ & -6.5 & -4.2 & -2.10 & -1.08 \\
$\mathrm{Na} \rightarrow \mathrm{Cs}$. & -7.8 & -4.2 & 0.965 & 1.00 \\
$\mathrm{Relative}$ fraction of sites & 0.005 & 0.03 & & \\
\hline
\end{tabular}

(1) Data for illite from Brouwer et al. (1983; Tables I and II). Data for smectite from Fletcher and Sposito (1989) except for $\mathrm{Na} \rightarrow(\mathrm{Rb}, \mathrm{Cs})$ which are from Gast (1972). Note: these data are strictly accurate at $25^{\circ} \mathrm{C}$ only. It was assumed that for the purposes of these simulations, the variation of exchange energy between $25^{\circ} \mathrm{C}$ and the groundwater temperature $\left(-10^{\circ} \mathrm{C}\right)$ is a second order effect.

(2) $\mathrm{A} \mathrm{Na} \rightarrow 0.5(\mathrm{Ca}, \mathrm{Mg}, \mathrm{Sr}, \mathrm{Ba})$ signifies the conversion of 1 equivalent of exchanger from the $\mathrm{Na}$ form to the $\mathrm{Ca}, \mathrm{Mg}$, $\mathrm{Sr}$, or $\mathrm{Ba}$ form.

(3) The exchange energy for $\mathrm{Na} \rightarrow 0.5$ ( $\mathrm{Ca}, \mathrm{Mg}, \mathrm{Sr}, \mathrm{Ba})$ deduced from Brouwer et al. (1983) data for the planar site was adjusted to be consistent with their data for $\mathrm{Cs} \rightarrow \mathrm{Na}, \mathrm{Rb} \rightarrow \mathrm{Na}$, and $\mathrm{Rb} \rightarrow(\mathrm{Ca}, \mathrm{Mg}, \mathrm{Sr}, \mathrm{Ba})$ exchange. 
Table 7-5. Ratio of predicted mass of cation on exchanger ${ }^{(1)}$ to mass of cation in fluid for three groundwaters at Äspö.

\begin{tabular}{lcc}
\hline Cation & $\begin{array}{c}\text { Shallow (HBH02) } \\
15 \mathrm{~m}\end{array}$ & $\begin{array}{c}\text { Native (KA0483A) } \\
\text { tunnel depth }\end{array}$ \\
\hline $\mathrm{Na}$ & 1.3 & 0.30 \\
$\mathrm{Ca}$ & 41.7 & 1.07 \\
$\mathrm{Mg}$ & 41.7 & 1.21 \\
\hline
\end{tabular}

(1) Calculations assume 0.1 equiv $/ \mathrm{kg}$ of $\mathrm{H}_{2} \mathrm{O}$.

Table 7-6. Predicted sorbed fractions and concentrations of sorbed $\mathrm{Ca}, \mathrm{Sr}, \mathrm{SO}_{4}$, and $\mathrm{HCO}_{3}$, in $\mathrm{mg} / \mathrm{kg}$, in shallow (HBH02) groundwater as a function of mass of goethite $/ \mathrm{kg} \mathrm{H}_{2} \mathrm{O}$. ${ }^{(1)}$

\begin{tabular}{lcccc}
\hline $\begin{array}{l}\text { Mass of goethite } \\
\mathrm{g} / \mathrm{kg} \mathrm{H}_{2} \mathrm{O}\end{array}$ & \multicolumn{4}{c}{$\begin{array}{c}\text { Predicted sorbed fraction and } \\
\text { concentration } \\
(\mathrm{mg} / \mathrm{kg} \text {, in parentheses) of sorbed species. }\end{array}$} \\
\hline \multicolumn{1}{c}{$\mathrm{Ca}$} & $\mathrm{Sr}$ & $\mathrm{SO}_{4}$ & $\mathrm{HCO}_{3}$ \\
0.1 & $0.0015(0.06)$ & $0.0016(0.0003)$ & $0.0022(0.04)$ & $0.09(11.21)$ \\
1. & $0.015(0.63)$ & $0.016(0.003)$ & $0.022(0.43)$ & $0.50(112.1)$ \\
10. & $0.13(6.31)$ & $0.14(0.03)$ & $0.18(4.31)$ & $0.91(1121)$ \\
$\begin{array}{l}\text { Concentration in } \\
\text { coexisting fluid } \\
\text { phase, mg/kg }\end{array}$ & 42.8 & & & \\
\hline
\end{tabular}

(1) Calculated using Dzombak and Morel (1990) surface complexation data base with carbonate complexation constants from Van Geen, Robertson, and Leckie (1994). The sorbed fractions are calculated assuming the goethite is in equilibrium with an aqueous solution having the composition of the shallow groundwater. 




\section{Contents}

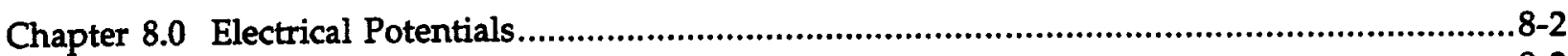

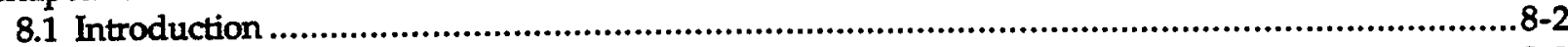

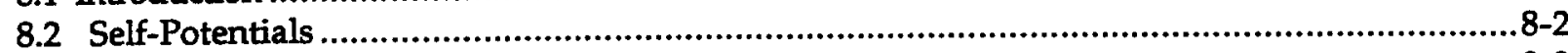

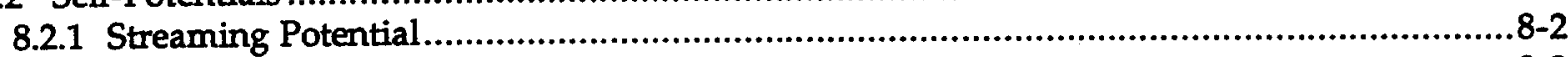

8.2.2 Thermoelectric Potential...................................................................................... 8-3

8.2.3 Electrochemical Potential...................................................................................... 8-3

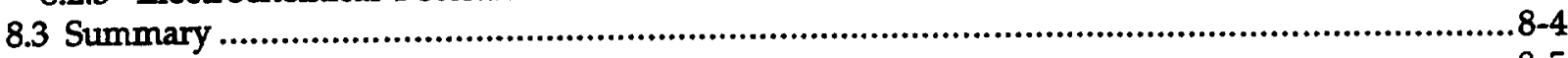

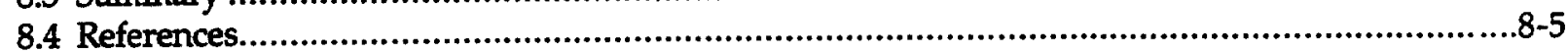




\title{
Chapter 8.0 Electrical Potentials
}

\author{
Abelardo Ramirez
}

\subsection{Introduction}

Natural and spontaneous electrical potentials, known as self-potentials (SPs), occur within the earth because of electrochemical or mechanical activity. Selfpotential anomalies have been observed in natural geothermal environments where a significant flow of hot water and steam occurs, qualitatively similar to the conditions expected in the near-field environment (NFE) of the potential nuclearwaste repository at Yucca Mountain, Nevada (Corwin and Hoover, 1979; Zohdy et al., 1973; Anderson and Johnson, 1976). Because of their potential influence on reaction processes, SPs may be significant in understanding how the NFE will evolve geochemically. In addition, SPs may generate electrical currents that may affect the performance of metallic waste containers. This chapter discusses some particular mechanisms that generate SPs in rock-water systems and provides orderof-magnitude estimates for the SPs that may be present in the NFE.

Other currents that may be present in the NFE are magnetotelluric and telluric currents; however, these currents are believed to be the result of diurnal variations, caused by solar emission, aurora, and other phenomena, in the earth's magnetic field (Telford et al., 1976). These currents are probably less significant than those caused by SPs and are outside the scope of this discussion.

\subsection{Self-Potentials}

Underground water is an important factor in most occurrences of SPs. Telford et al. (1976) found that SPs are associated with variations in rock properties at contact interfaces where corrosion occurs as a result of thermal and pressure gradients in underground fluids (thermoelectric and streaming potentials), and with variations in electrolytic concentrations of groundwater (electrochemical potential).

\subsubsection{Streaming Potential}

When two phases are placed in contact, a difference in potential between them generally develops. If one of the phases is a polar liquid, like water, its dipolar molecules will tend to be oriented in a particular direction at the interface, generating a potential difference. If there are ions or excess electrons in one or both phases, the electrical charges will tend to distribute themselves nonuniformly at the interface. The region between the two adjoining phases is always marked by a separation of electrical charges so that near, or on the surface of, phase I there is an excess charge of one sign, and the balancing charge is distributed somehow through the adjoining surface regions of phase II (Hunter, 1981). This arrangement of charges at the interface is referred to as the electrical double layer. When liquid moves through a capillary or a porous medium under a pressure gradient, the excess 
charges near the wall are carried along by the liquid, and their accumulation downstream causes the buildup of an electrical field, which drives an electrical current back (by ionic conduction through the liquid) against the direction of liquid flow (Hunter, 1981). The measured potential difference across the capillary is called the streaming potential.

Ishido et al. (1983) report that in rock-water systems the streaming potential coefficient increases exponentially with decreasing hydraulic radii $<10^{-6} \mathrm{~m}$. Klavetter and Peters (1987) show that for Topopah Spring tuff (the potential repository horizon) the pore sizes range from $10^{-6}$ to $10^{-8} \mathrm{~m}$ with most of the pore volume due to the $10^{-7} \mathrm{~m}$ fraction. This would suggest that the streaming potential coefficient for Topopah Spring tuff will be relatively high due to its small pore sizes (although to the best of our knowledge the coefficient has not been established for welded tuff). Nourbehecht (1963) reports that the streaming potential coefficients for a wide variety of rocks ranges from about 0.3 to $30 \mathrm{mV} / \mathrm{atm}$.

Chapter 1 shows numerical modeling results that predict a region of condensate accumulation with $100 \%$ saturation adjacent to the boiling region. Pressure gradients within this region of high saturation can cause liquid to flow very slowly within the porous medium. There will be streaming potential associated with the liquid flow. The magnitude of the streaming potential cannot be estimated because the streaming potential coefficient for unsaturated welded tuff is not known at this time.

\subsubsection{Thermoelectric Potential}

Temperature gradients give rise to thermoelectric potentials in rock-water systems (Telford et al., 1976). Nourbehecht (1963) reports that the thermoelectric coefficient for rock can be as high as $1 \mathrm{mV} /{ }^{\circ} \mathrm{C}$ with average values of about 0.2 to $0.4 \mathrm{mV} /{ }^{\circ} \mathrm{C}$. As reported in Chapter 1 , these numerical modeling results show that drift wall temperatures as high as $200^{\circ} \mathrm{C}$ may be present in the repository and a temperature near $96^{\circ} \mathrm{C}$ within the condensate region. If we assume an average thermoelectric coefficient of $0.3 \mathrm{mV} /{ }^{\circ} \mathrm{C}$ and a temperature difference of $100^{\circ} \mathrm{C}$, the calculated thermoelectric potential is $30 \mathrm{mV}$. Chapter 1 calculations show that the temperature gradient decreases as time after emplacement increases, which implies that the thermoelectric potential would also decrease as time after emplacement increases.

\subsubsection{Electrochemical Potential}

Electrochemical potentials arise when diffusion of ions occurs. This potential is attributed to two causes: (1) the difference in mobilities of various ions in solutions of different concentration (diffusion potential), and (2) the potential that develops when two electrodes are immersed in the same solution but at two different concentrations (Nernst potential). For example, when the concentrations are in the ratio of 5:1, the potential that develops is $\pm 50 \mathrm{mV}$ (Telford et al., 1976).

In regions where interconnected fluids exist across the potential field, ionic diffusion and reaction relationships will be influenced by the potential field. This effect needs to be evaluated in future work. 


\subsection{Summary}

We have briefly described the mechanisms that are likely to be operating in the NFE, generating natural electrical potentials and currents. The electric potential fields caused by groundwater flow, and by temperature and ionic concentration gradients will coexist in the NFE. Due to the combined effects of these fields, the resulting electric potential gradients may affect the geochemical evolution of the NFE (although this has not been evaluated to the best of our knowledge) and possibly, the performance of waste container materials. Very little information is. available with which to estimate SP generation within the NFE. We have raised the possibility that SPs may be significant in the NFE and, thus, should be investigated further. In addition, SPs may be useful as a diagnostic measurement of the near-field hydrothermal environment. 


\subsection{References}

Anderson, L. A., and G. R. Johnson (1976), "Application of the Self-Potential Method to Geothermal Exploration in Long Valley, Californaia," Journal of Geophysical Research 81, 1527-1532. (Readily available).

Corwin, R. F., and D. B. Hoover (1979), "The Self-Potential Method in Geothermal Exploration," Geophysics 44, 226-245. Readily available).

Hunter, R. J. (1981), Zeta Potential in Colloid Science, Principles and Applications (Academic Press, London) Chapters 1-3. (NNA.920916.0006)

Ishido, T., H. Mizuanti, and K. Baba (1983), "Streaming Potential Observations, Using Geothermal Wells and In Situ Electrokinetic Coupling Coefficients under High-Temperature," Tectonophysics 91(1-2), 89-104. (NNA.920506.0056)

Klavetter, E. A., and R. R. Peters (1987), An Evaluation of the Use of Mercury Porosimetry in Calculating Hydrologic Properties of Tuffs from Yucca Mountain, Nevada, Sandia National Laboratories, Albuquerque, NM, SAND86-0286-UC-70. (NNA.890327.0056)

Nourbehecht, B. (1963), Irreversible Thermodynamic Effects in Inhomogeneous Media and their Applications in Certain Geoelectic Problems, Ph.D. Thesis, Massachusetts Institute of Technology, Cambridge, MA, pp. 1, 3, and 6. (NNA.920506.0032)

Telford, W. M., L. P. Geldart, R. E. Sheriff, and D. A. Keys (1976), Applied Geophysics (Cambridge University Press, London). (NNA.891106.0192)

Zohdy, A. A. A. R., L. A. Anderson, and L. J. P. Muffler (1973), "Resistivity, SelfPotential, and Induced-Polarization Surveys of a Vapor Dominated Geothermal System, "Geophysics 38, 1130-1144. (NNA.91062.0059) 



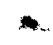

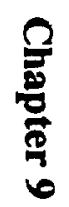


. 


\section{Contents}

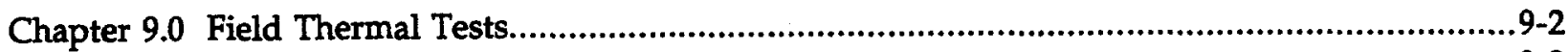

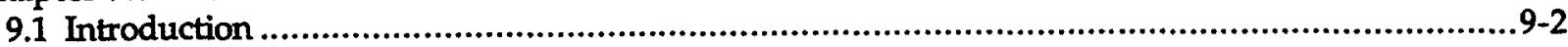

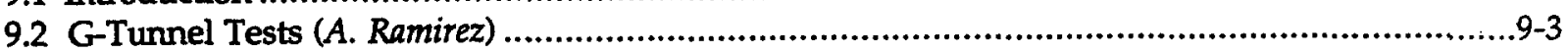

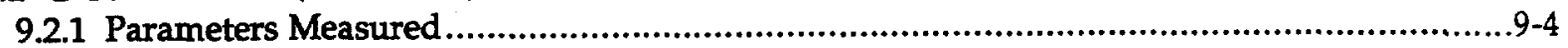

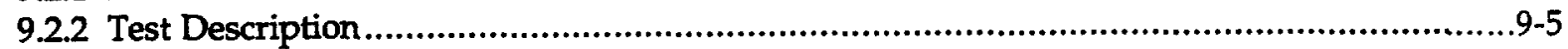

9.2.3 Changes in Rock Mass Moisture Content ....................................................................

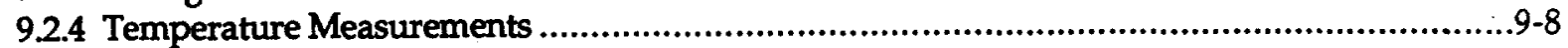

9.2.5 Changes in Air Permeability ...........................................................................9-9

9.2.6 Steam Invading the Heater Emplacement Borehole ..................................................9-10

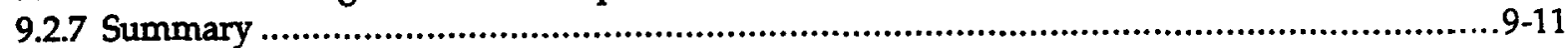

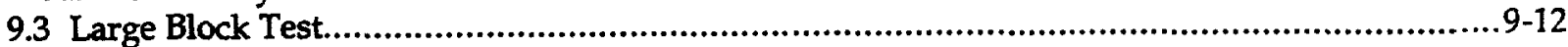

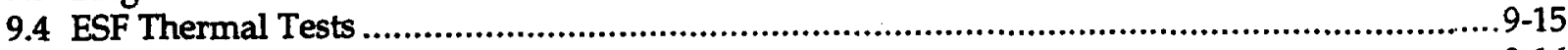

9.4.1 Single Heater Test ......................................................................................9-16

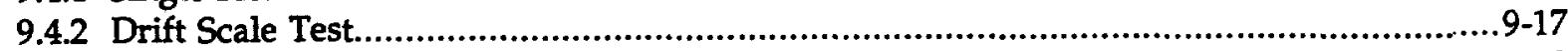

9.5 Large-Scale Long Duration Test ...............................................................................9-18

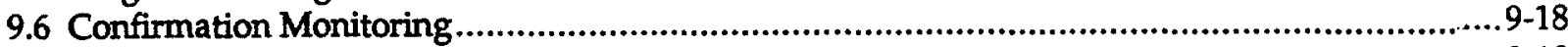

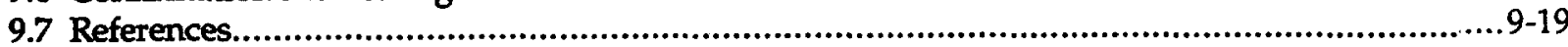




\title{
Chapter 9.0 Field Thermal Tests
}

\author{
W. Lin and A. Ramirez
}

\subsection{Introduction}

Understanding the movement of moisture, including liquid water, steam, and vapor, in the near-field environment (NFE) of the potential nuclear-waste repository at Yucca Mountain, Nevada is one of the goals of waste-package environment hydrologic investigations. This section discusses field tests to enhance our understanding of how thermal loading, resulting from waste package emplacement, will affect the hydrologic properties and processes of the NFE.

One of the main concerns in the NFE of a nuclear-waste repository is the quantity and quality of the water that may be present to contact the waste and waste packages (near field) and in the rock mass surrounding the repository since water can cause property changes in the altered zone. Processes that may affect the quantity and quality of the water are coupled thermal-mechanical-hydrological-chemical (TMHC) processes. The TMHC processes may involve the in situ pore water in the Topopah Spring tuff, water present in fractures, and/or condensate that result(s) from water mobilized by heat, as well as any introduced water (either naturally or artificially) after the emplacement of the wastes. Field and laboratory tests are conducted to: enhance our understanding of the coupled TMHC processes and to measure physical properties. This chapter discusses the field tests.

The rationales of conducting field thermal tests are to extend from laboratory tests on relatively small samples (up to 1-m, maximum), to testing of rock masses that include fractures and inhomogeneity as representative to Yucca Mountain as possible, and under test conditions as close as possible to in situ repository conditions. The logic of testing, i.e., increasing sample size from small to large, increasing the complexity of sample characteristics from intact to include multiple fractures and heterogeneity, and relaxing test boundary conditions from simple controlled to uncontrolled, is to evaluate the temporal and spatial scale effects, to increase our understanding of the test results in steps, and to enhance our confidence in modeling the tests and the coupled TMHC processes to be expected in a repository. The purposes of field thermal tests are to test the coupled TMHC processes in a rock mass which is big enough to include heterogeneity, so that the test results can be used to verify model predictions and to identify important physical processes that must be included in the conceptual models. The objectives, goals, and rationales of the field tests are described in section 8.3.4.2.4.4 Study Plan for Engineered Barrier System Field Tests (Lin, 1995). Based on the findings and logic of that report, several field thermal tests are planned to serve different purposes (described here). The G-Tunnel test was conducted in 1988-1989, in Grouse Canyon tuff in GTunnel, Nevada Test Site, to improve our understanding of the thermalhydrological processes in an underground environment and to prototype instruments and test methodologies. The Large Block Test (LBT) was designed to 
provide testing of the coupled TMHC processes in Topopah Spring tuff under controlled boundary conditions so that the results can be more directly compared with model calculations. Also, the LBT will provide three-dimensional (3-D) coverage of the test region with instruments. In addition, the LBT can provide a unique opportunity for investigating infiltration in a heated rock mass. The ESF Thermal Test (ESFTT) will be the first in situ thermal test in the potential repository horizon in Yucca Mountain. The results of the ESFTT will be used for viability analyses and license application of the repository. Although it is still in the conceptual state, the plan, if instituted, is to use the Large Scale Long Duration Test (LSLDT) to heat up a region with multiple emplacement drifts for several years so that all possible coupled TMHC processes can be tested (see section 9.5 for more details). Also planned are the Confirmation Observations of the performance of a repository. The confirmation monitoring is the only test in the true temporal and spatial scales of a repository, therefore is very critical (see section 9.6).

Basically, field thermal tests involve heating a rock mass with electrical resistor heaters and monitoring the spatial distributions and temporal variations of temperature, moisture content, concentration of certain chemical elements, and stress and displacements in the rock mass. Temperatures will be measured by using either resistance temperature devices (RTD) or thermocouples, dependent on the temperature range to be measured and accuracy required. Moisture contents will be measured in the following means: point measurement of relative humidity will be conducted using Humicaps. Line measurement of moisture content will be done using neutron logging. Two- and three-dimensional tomographs of the moisture content will be inferred from electrical resistivity tomographs (ERT). Chemical sensors will be used to monitor concentration of some chemical elements, such as $\mathrm{pH}$, conductivity, dissolved oxygen, $\mathrm{Ca}, \mathrm{Cl}$, etc. Both mechanical and optical multiple borehole extensometers (MPBXs) will be used to measure displacements. Scoping model calculations will be used to design the tests, and then model calculations with exact test configurations will be used to monitor their progress and for post-test data analyses. Chapter 1.9 presents some of the results of the model calculations. Post-test examination of the rocks are usually planned to verify some of the indirect observations by instruments during the test with direct observations. The G-Tunnel test is the only field thermal test that has been completed. The results from the G-Tunnel test are summarized in section 9.2. Recently, model analyses of the G-Tunnel test results were performed (See Chapter 1.9 for the results of those analyses). The LBT has been planned, constructed, and characterized, but instruments have not been installed. Only the pre-test characterization results of the LBT are presented here. See section 9.4 for the test design and plans for the ESFTT.

\subsection{G-Tunnel Tests (A. Ramirez)}

This discussion includes the key results and supporting data from the G-Tunnel tests in which we studied the hydrothermal perturbation of welded tuff near a horizontally oriented heater. As part of the G-Tunnel tests, we measured several 
parameters as a function of location and time so that we could examine the effects of heating and cooling during a thermal pulse that lasted $\sim 195$ days.

A schematic of the hydrologic environment expected to develop around a heater during thermal loading is shown in Fig. 9-1 [see Yow (1985), for additional details on the expected environmental conditions]. This figure depicts the primary mechanisms of heat and fluid flow for an idealized example of a horizontal heater that is intersected by a near vertical fracture. The actual heater borehole was intersected by more than a dozen fractures. The rock mass consisted of matrix blocks that were bounded by fractures and the borehole wall (for blocks immediately adjacent to the heater). Under ambient conditions, the matrix blocks are partially saturated, and the fractures and borehole are essentially dry. The heater heats the borehole surface primarily via thermal radiation. As heat is conducted through the fractured rock mass, vaporization begins on the outer surfaces of the matrix blocks closest to the borehole and then proceeds in toward the center of each block. Where temperatures are in excess of saturation conditions, vigorous boiling occurs. For water vapor to flow out of the matrix blocks, gas-phase pressures must increase from the surface of the matrix block to its interior, resulting in the elevation of the boiling temperature with distance into the matrix block. Water vapor that enters the fractures is subsequently driven by gas pressure gradients (including buoyancy effects) within the fracture network. In general, vapor flow in the fractures is directed away from the center of the boiling, either radially outward or inward toward the heater hole. Vapor flow in the fractures persists until condensation conditions are encountered. Condensed water in the fractures that is not immediately imbibed by the matrix flows under gravity and capillary forces in the fractures either (1) back toward the boiling zone where it reboils, or (2) out into the condensation zone where it is eventually completely imbibed by the matrix.

\subsubsection{Parameters Measured}

The following parameters were measured to characterize the behavior of the rock mass within a few meters of the heater before, during, and after the thermal cycle. This discussion includes the results for a subset of the measured parameters and presents interpretations pertaining to the evolution of the NFE around a simulated waste package Ifor full details refer to Ramirez et al. (1991), including those reports listed in the "References" and "Bibliography of Related Reports" section].

9.2.1.1 Rock Mass Temperatures. Rock mass temperatures were used in reconstructing the thermal response of the rock and in evaluating the performance of the test equipment.

9.2.1.2 Rock Mass Gas Pressure and Atmospheric Pressure. Rock mass gas pressure and atmospheric pressure were used in reconstructing the flow regime of the air and water vapor in the rock mass.

9.2.1.3 Borehole Measurements of the Relative Dielectric Constant and Thermal Neutron Counts. Cross borehole measurements of the relative dielectric 
constant of the rock and single borehole measurements of thermal neutron counts were used to infer the spatial and temporal changes in the moisture content of the rock mass.

9.2.1.4 Air Humidity. Air humidity measurements in the rock mass were used to calculate the pore pressure gradients that drive the movement of liquid water within the rock mass. Changes in the moisture content and pore pressure information were used to reconstruct the flow regime of liquid water in the rock mass. The spatial variations in moisture content were used to infer the flow paths of the liquid water and to define regions that are losing or gaining water as a function of time.

9.2.1.5 Air Permeability. The air permeability measurements were used to detect changes in the permeability of the rock surrounding the heater emplacement borehole. These measurements were made along the heater borehole after all of the boreholes were drilled and sealed. The measurements were repeated after the heating sequence was completed and after the heater was removed from the borehole.

9.2.1.6 Fracture Locations and Orientations. Fracture locations and orientations were measured in all boreholes by means of a borescope and/or by borehole television surveys performed before the heater was energized. The measurements were repeated along the heater emplacement borehole after heating was completed, and these data were used to:

- Determine the effects of heating on the stability of the emplacement borehole walls.

- Interpret the changes in fracture permeability caused by the heating and cooling cycle.

- Analyze the flow regime of vapor and liquid water in the rock mass as inferred from other measurements.

9.2.1.7 Condensed Volume of Steam. The measurements of the condensed volume of steam invading the heater borehole were used to estimate the amount of gas phase humidity that flows toward the heater borehole.

\subsubsection{Test Description}

Sandia National Laboratories constructed the GTUF, which consists of drifts driven in welded tuff under Rainier Mesa, NTS, for the YMP (Fig. 9-2). The GTunnel tests were conducted in the rock mass between the small-diameter heater alcove and the rock mechanics incline.

The test included an accelerated thermal cycle to examine the effects of the heating and cooling sides of a thermal pulse. Figure 9-3 shows the test's power schedule. The initial thermal loading for the 3-m $(9.8-\mathrm{ft})$ heater was $\sim 3.3 \mathrm{~kW}(1.1$ $\mathrm{kW} / \mathrm{m}$ of heater length). To increase the disturbed volume of rock within the relatively short time available for prototype testing and to create sufficiently high rock temperatures to drive two-phase fluid flow, we set the initial thermal load 
per unit length of emplacement borehole higher than the loading expected for a typical spent fuel container $(0.4-0.7 \mathrm{~kW} / \mathrm{m})$.

The duration of the heating was based on the test criteria of heating the rock mass until the boiling point isotherm moved $\sim 0.6-0.7 \mathrm{~m}(2.0-2.3 \mathrm{ft})$ radially from the heater borehole wall. Another test criteria involved achieving emplacement heater borehole temperatures similar to those expected for the repository $\left(235^{\circ} \mathrm{C}\right)$. The spatial extent of the heating affected a volume of rock large enough to include several fractures.

Figures 9-4 and 9-5 show the borehole layout and the measurement stations for the various instruments used. The test location within G-Tunnel is bounded by the small diameter heater alcove and the rock mechanics incline, as shown in Fig. 9-4. The heater borehole is inclined slightly upward (elevation increases from the collar to the end of the borehole) from the rock mechanics incline. The diameter of the heater borehole is $30.5 \mathrm{~cm}$ (12 in.).

Twelve of the boreholes were used to monitor the rock response; all of these were nearly horizontal and were inclined slightly downward. The majority of the boreholes were orthogonal to the emplacement hole axis, which provided better coverage of the spatial variations in rock responses that occur parallel to the radius of the emplacement borehole. This arrangement allowed measurements in the direction of expected maximum thermal and hydrologic gradients. Three boreholes were drilled parallel to the heater borehole axis to monitor rock response beyond the ends of the heater.

\subsubsection{Changes in Rock Mass Moisture Content}

A thorough understanding of local hydrology over the package lifetime is central to understanding waste package performance. Geophysical techniques were used to monitor changes in rock moisture content during the test. The techniques chosen included neutron logging in single boreholes and high-frequency electromagnetic measurements performed between boreholes. In this section, we interpret only the neutron log results; for the electromagnetic measurement results, see Daily et al. (1989).

The neutron logging probe contains a source of high-energy neutrons and a detector for slow (thermal) neutrons. When water is present in the rock, the hydrogen in the water slows the neutrons for detection. Seven boreholes (NE-1 through NE-7) were sampled before the heater was turned on; the measurements were repeated frequently after the heater was energized to monitor temporal and spatial changes in moisture content. A paraffin shield included with the probe was sampled at the beginning and end of each logging day to verify that the tool was functioning properly.

For each borehole, we calculated the differences between the "before" and "after" measurements ("after" heating minus "before" heating) to produce a difference log. We chose to use differences rather than absolute values of moisture content because the effects of the borehole liners and the grout within the survey boreholes are still unknown.

A spatial filter was applied to each difference log to smooth the spikes in the trace caused by the random fluctuations in the number of neutrons generated by the 
radioactive source in the probe. The precision for the filtered data is estimated to be $\pm 0.003 \mathrm{~g} / \mathrm{cm}^{3}$. This precision estimate means that for any one point on a difference trace that equals or exceeds $\pm 0.003 \mathrm{~g} / \mathrm{cm}^{3}$, there is a $95 \%$ probability that the difference is caused by true changes in the measurement and a $5 \%$ probability that it is caused by random fluctuations in the neutron output of the radioactive source.

Boreholes NE-2A, NE-6, and NE-7 are three coplanar boreholes located above and below the center of the heater as shown in Fig. 9-5. The data collected along these boreholes were combined and plotted as a function of radial distance to the center point of the heater assembly. The changes shown were calculated relative to preheating moisture measurements. Figures 9-6, 9-7, and 9-8 consist of two plots each that show the same data at two different scales so that the smaller changes occurring at the more distant locations can be examined.

Figures 9-6 and 9-7 show radial profiles of changes in moisture content during the drying and rewetting phases of the test. These figures also show the difference traces calculated from day 70 data (the heater was energized on day 0) and for day 301 (the last data set was collected 106 days after the heater was de-energized). The data in Fig. 9-6 were collected midway through the maximum power phase of the test. As expected, the rock closest to the heater (the shortest distance) lost substantial amounts of moisture. However, the rock near borehole NE-2A dried at a faster rate than the rock near NE-6. Fracture maps of the test region suggest that a higher concentration of fractures mapped along NE-2A may be one cause for this faster rate of drying. Also note that rock located between $1.75-$ and $2.25-\mathrm{m}$ radii showed a small increase in moisture content as a result of the condensation of steam generated in hotter regions closer to the heater.

Between days 70 and 127 (data are not shown) the NE-2A profile showed very little additional drying when compared to Fig. 9-6, whereas the NE-6 profile showed significant additional drying. Both profiles are closely matched with the caveat that the width of the drying region appeared to be slightly wider near NE-2A. The closely matched profiles suggest that the rock near NE-2A and NE-6 was almost completely dry because very little additional drying occurred near NE-2A during the 57 days of continued heater operation at maximum power. The radius of the dry zone achieved was $\sim 0.7 \mathrm{~m}$; this is consistent with the test objective of achieving boiling conditions within a $0.6-0.7-\mathrm{m}$ radius.

The radial profile of changes in moisture content for day 301 are shown in Fig. 9-8. These data were collected during the postheating phase of the test, 106 days after the heater was de-energized. The data show relatively little change in the rock near the heater during the power rampdown and postheating phase of the test. It also shows that the rock above the heater (borehole NE-6) rewet more quickly than the rock below the heater (borehole NE-2A) for distances less than or equal to $0.5 \mathrm{~m}$. This suggests that the gravity-driven flow plays a role in the rewetting process.

We gained further insights into the rewetting process by calculating changes in moisture content relative to the last day of full power heating. Figure 9-9 presents changes in moisture in borehole NE-2A, where "after" minus "before" changes are calculated relative to day 127 (i.e., the "before" data correspond to day 127, which was the day before the last day of maximum power heating). The data were obtained during the power rampdown and postheating phases of the test when the rock was 
cooling and rewetting. Also shown are fractures mapped along the boreholes. Note that the rock regions that show the greatest rewetting are clustered around the fractures in NE-2A. The high correlation between fracture locations and rewetting suggests that fractures play a dominant role in the rewetting process. One mechanism for rewetting along fractures may be capillary condensation of air humidity in the fractures because humid air (found in the wetter portions of the rock mass) can travel with relative ease along the fractures. Another mechanism that may be playing a role in the rewetting process is water dripping along fractures; Fig. 9-8 shows evidence consistent with this argument in that the rewetting front has penetrated more quickly above the heater (borehole.NE-6) than below the heater (NE-2A).

\subsubsection{Temperature Measurements}

Temperature measurements were made to characterize the thermal response of the medium around the heater. There were a total of 112 thermocouples used in this test. All of these thermocouples were chromel-alumel (Type K) with an accuracy of $\pm 1^{\circ} \mathrm{C}\left(1.8^{\circ} \mathrm{F}\right)$. Ten thermocouples were installed within the heated portion of the heater borehole to monitor container and borehole wall temperatures. The other 102 thermocouples were located in boreholes TC-1, TC-2, $\mathrm{P}-1, \mathrm{P}-2$, and $\mathrm{P}-3$.

Figure 9-10 shows the temperatures measured in all boreholes during the last day of the maximum power phase (day 128). The temperatures are plotted as a function of the natural log of radial distance to observe the linearity or nonlinearity of the temperature profiles. Note that with the exception of the P-3 profile, all profiles are fairly linear. This indicates that the thermal conduction is the predominant heat transfer mechanism for the regions sampled. There are a few temperature values (in both P-2 and P-3) that deviate from a straight line for values of the radial distance $<1 \mathrm{~m}$ (natural $\log <0$ ). At these locations, fractures were mapped in close proximity (within a few centimeters) of the thermocouple locations. This close proximity suggests that the depressed temperature values within the boiling region are caused by fractures. At least two explanations can be postulated:

1. The fractures create more permeable flow paths for vapor to escape the system. As water is converted to vapor and allowed to escape, energy is removed from these locations. This energy is therefore not available to elevate the rock temperatures.

2. The fractures also create flow paths along which drilling water moves downward. Borehole P-3 is lower in elevation than P-2. The matrix adjacent to these fractures might have imbibed some of the drill water, thereby increasing the initial saturation near the fractures. This elevated saturation would also tend to depress the local temperature for the same reason as stated above in explanation 1.

The temperatures along borehole TC- 2 are generally cooler than those in other boreholes at the same radial distance. The temperatures in P-2 are the highest among the five boreholes. Boreholes TC-1, P-1, and P-3 registered about the same temperatures. These differences in temperature are probably due to the heterogeneous thermal properties of the rock mass. The almost linear portion of these curves at larger radial distances indicates that conduction is probably the main heat transfer mechanism. Also, the TC-2 profile shows a more shallow slope, which 
implies that the thermal conductivity of the rock around TC-2 is higher than at other locations.

A comparison of the P-2 and P-3 temperature profiles in Fig. 9-10 shows that the temperatures in P-3 are consistently lower than those in P-2. This is probably due to the higher temperatures measured at the top of the container. Air circulation within the heater container (i.e., hotter air rising to the top of the container) may have caused the asymmetry in temperatures.

Figure 9-11 shows the temperatures for thermocouples 86 through 89 as a function of time. These thermocouples are located below and to the side of the heater (Fig. 9-12). Thermocouples 86 and 87 show typical profiles of temperatures within the boiling region. The temperature increased quickly at the beginning of heating, then became almost linear with time. At these later times, the temperaturetime plot has no obvious change of slope. A change in slope would indicate a change in the thermal conductivity and heat capacity of the rock. At later heating times, changes in slope may be attributed to the latent heat capacity of the water as the water boils or condenses in the rock mass.

Thermocouples 88 and 89 in Fig. 9-11 show very atypical temperature profiles. Note that the maximum temperature for both profiles is $\sim 97^{\circ} \mathrm{C}$. Also the profiles remained near the maximum temperature for 70 or more days even though the rest of the rock mass continued to increase in temperature during this period (maximum power phase). In addition, the slope on the left side of the flattened portions of these two profiles rapidly increased before the flattening occurred. This indicates that additional energy was being deposited at these locations. We postulate that condensed water with near-boiling temperature moved into this region from regions above the heater as illustrated by the conceptual model shown in Fig. 9-13. We recognize the possibility that this type of temperature signature is due to a heat pipe effect, but we consider this unlikely because of the rapid increase in slope observed prior to the flattening.

\subsubsection{Changes in Air Permeability}

Air permeability testing was conducted along sections of the heater emplacement borehole before heating and at the end of the power rampdown phase of the test. The objectives of this test were to characterize the in situ permeability of the fractured tuff around the heater borehole and to determine the effect of a heating and cooling cycle on rock mass permeability. A number of permeability measurements were made along packed-off sections of the borehole before the rock mass was heated and again after all heating was completed.

We used steady-state air-injection to measure the permeability. Inflatable packers were placed in preselected sections of the borehole to isolate these sections for testing. Preheating and postheating permeability values are compared in Fig. 9-14. Equivalent porous medium permeabilities along the heater borehole are also compared with mapped fracture locations. The permeabilities shown here were measured at a nominal pressure of $34 \mathrm{kPa}(5 \mathrm{psi})$. The permeability of a $36-\mathrm{cm}-10 \mathrm{ng}$ (14.2-in.-long) test zone varies from a minimum of 0.04 darcy (D) to a maximum of $150 \mathrm{D}$. The higher permeability value corresponds to a highly fractured zone, a few inches thick, at a depth of about $7.7 \mathrm{~m}(25.3 \mathrm{ft})$ from the collar. 
A comparison of the preheating and postheating profiles in Fig. 9-14 shows that portions of the measured region had increases in gas permeability as a result of the heating cycle. Note that the greatest percentage change occurred near the center of the heater element location. This is also the portion of the borehole with the fewest fractures mapped. We postulate that the increase in permeability is due to an increase in the number of small fractures (microcracks) intercepting the heater borehole. Television surveys of the borehole showed no change in the visible fractures relative to the preheating survey. This implies that any new fractures were small enough to escape detection. Given that the lowest permeabilities were measured in the region of greatest change, increases in microfractures would have a relatively greater effect here than in regions with a higher preheating permeability. Note that the increased permeability is low when compared with the natural heterogeneity in air permeability along the borehole.

\subsubsection{Steam Invading the Heater Emplacement Borehole}

The thermal loading exerted by the heater dries the partially saturated rock surrounding the emplacement borehole. Vapor pressure gradients drive steam into pressure sinks such as the borehole and fractures (see Fig. 9-1). Steam may also move along the fractures toward the borehole or move outward and condense where the temperatures are sufficiently cool. The moisture entering the heater emplacement borehole was collected to provide a measure of the resistance to vapor transport toward the heater relative to the resistance to transport away from the heater as a function of time.

The moisture migrating into the heater emplacement borehole was collected using a high-temperature inflatable packer fitted to a 51-mm (2-in.) i.d. aluminum pipe. The packer sealed the borehole $50 \mathrm{~cm}$ (19.7 in.) outward (i.e., toward the collar) from the heater and allowed the steam to flow through the aluminum center pipe, condense, and flow to the borehole collar and into a collection device (the isolated section remained unpressurized at all times). The heater emplacement borehole had a slope of $5^{\circ}$ downward to the collar to facilitate the collection of the condensed moisture.

Figure 9-15 presents the results from an analysis of the water collection rates during the test. Also shown for comparison is the partial pressure of water within $15 \mathrm{~cm}$ of the intake for the steam collection system; the partial pressure values are calculated based on relative humidity and air temperature measurements. These data show that an insignificant volume of water was collected within the first two weeks of the experiment. Thereafter, the rate of water collection reached a maximum of $\sim 0.051 /$ day, which is less than the value of $\sim 0.5 \mathrm{l} /$ day predicted by the scoping calculation. The reasons for this discrepancy are unclear at present. One possible explanation is that the packer temperature at the intake point for the system is below the dew point. This might have caused some vapor to condense, pond, and possibly drain into fractures, instead of entering the center pipe at the packer. Temperatures at some points on the packer suggest that packer surfaces could have acted as condensation points. Another possible reason for the discrepancy is that the scoping calculations assume an infinitely long heater. This assumption would result in a substantial overestimate of the steam produced. 
The water collection rate (Fig. 9-15) peaked at about day 50 and then decreased between day 50 and 90 . We did not expect this decrease and have not yet explained it. Note that the partial pressure of water in the air remained approximately constant between days 50 and 128. All other conditions being equal, we expected the moisture collection rate to remain constant if the partial pressure of the air in the heater borehole remained constant. The partial pressure of water started to decrease as expected on day 128 when the power rampdown phase began.

Another unexplained aspect of the moisture collection rate is the abrupt water collection rate decrease at about day 90 . This signature may be an indication of problems with the sensor; however, post-test calibration of the sensor did not indicate that the sensor was flawed.

\subsubsection{Summary}

The G-Tunnel tests provided valuable experience that will improve our ability to conduct the EBSFT planned for the ESF in Yucca Mountain. The results from the G-Tunnel tests indicate that many environmental conditions expected to develop around a heater in welded tuff are as described in Fig. 9-1. The test also showed us which of the applied measurement techniques performed adequately under realistic environmental conditions and which ones may need to be modified or replaced.

The G-Tunnel tests confirmed elements of the conceptual model of predicted environmental conditions. Test results confirm that a dry zone develops around the heater borehole (refer to the conceptual model in Fig. 9-13) and that the degree of drying increases with proximity to the heater. A "halo" of increased saturation develops adjacent to the dry region and migrates away from the heater as rock temperatures increase. Some of the fractures intercepting the heater borehole increase the penetration of hot-dry conditions into the rock mass. A buildup of pore gas pressure develops in rock regions where vigorous evaporation is occurring.

During the portions of the test when the heater power was gradually reduced and eventually turned off, the dry region around the heater cooled off and slowly regained water (refer to the conceptual model in Fig. 9-16). Rewetting of the dry region occurred first in the rock above the heater and in the rock adjacent to fractures.

To explain the differences in the drying and rewetting behavior above and below the heater, we developed conceptual models that are based on the results described here and on our numerical modeling study. In general, we found that water vapor generated in a matrix block moves toward the closest fracture face (or toward the surface of the heater borehole if the block is adjacent to the borehole). Upon entering the fracture, water vapor tends to move radially outward through the fracture system until encountering condensation conditions. The heater borehole moisture collection system and the condensation on the heater packer cause some of the vapor in the fractures to move radially inward toward the heater hole. Water that condenses above the heater drains downward through the fractures. Much of this downward flow intersects the boiling zone and is reboiled, thereby slowing the upward progress of the boiling front. We observed that some of the downward flowing condensate reboiled at the lower flank of the heater, thereby stabilizing the 
boiling front at that location. Water that condenses below the heater drains away from the boiling zone.

Since the matrix imbibition rate is slow relative to the condensate generation and drainage rates, most of the downward-draining condensate located below the heater left the system before it could be subsequently reboiled. We also observed that the boiling zone effectively acted as an "umbrella" shielding the rock below the heater from the downward drainage of condensate generated above the heater. Rewetting of the rock above the heater and to one side of the heater was partially the result of condensate drainage in fractures. Throughout the fractured rock mass, rewetting also occurred via binary diffusion of water vapor (driven by relative humidity gradients) and via Darcy flow (driven by pressure gradients). As this water vapor reached drier rock, it condensed along the fracture faces (by capillary condensation) and was imbibed by the matrix.

Measurements of air permeability made along the heater borehole prior to heating show that the fracture system exhibits a strong heterogeneity in fracture permeability. Measurements made after the heater was turned off show that there was an increase in air permeability as large as an order of magnitude for the rock that reached the highest temperatures.

The test also yielded some surprises in terms of environmental conditions. The temperature above the heater container was $\sim 30^{\circ} \mathrm{C}\left(54^{\circ} \mathrm{F}\right)$ higher than below the container. This condition might be a consequence of hotter air accumulating at the top of the container; it may also be related to the higher moisture content below the heater borehole. The amount of steam that invaded the heater borehole is much less than that predicted by the scoping calculations. The reasons for this discrepancy are not clearly understood, but they might be a result of an inadequate system used to collect and condense the steam or an indication of invalid assumptions used in the scoping calculations.

Recently, J. Nitao used a discrete fracture model (DFM) to re-analyze the results of the G-Tunnel test. The DFM was able to predict the observed thermal hydrological processes during the G-Tunnel test. The re-analyses show that gravity drain and buoyant gas-phase convection are likely reasons why condensate buildup in the matrix was not observed in the test. Preferential drying below and wetting above the heater lends some support for the possibility that buoyant convection in the fractures is a factor driving moisture movement. Temperature predictions by all models were good, substantiating that heat transfer in the rock was primarily by thermal conduction. Because of the short duration and small spatial scale of the test, the local condensate drainage flux during the G-Tunnel test was probably much higher than that to be expected for a repository beyond the first few hundred years. The results of the analyses are presented in Chapter 1.

\subsection{Large Block Test}

The objectives, goals, and plans of the Large Block Test (LBT) are described in Lin $(1993,1994)$. Detailed engineering plans for conducting the LBT were also completed. Originally, as described in Lin (1993), the objectives of the LBT were to conduct tests 
of the coupled TMHC processes in a $3 \times 3 \times 4.5 \mathrm{~m}$ block of Topopah Spring tuff with constant stress and adiabatic boundary conditions on the vertical sides. Particularly the LBT was designed to test thermally driven dryout and condensation, condensate refluxing, and the related mechanical and chemical responses of the block. The goals were to heat the large block from five heaters in a horizontal plane at about $2.75 \mathrm{~m}$ from the block top, with guard heaters on the sides and constant temperature controls at the top, to maintain a one-dimensional (1-D) thermal gradient in the block. The maximum temperature at the heater horizon would be about $140^{\circ} \mathrm{C}$, and the temperature at the top would be about $60^{\circ} \mathrm{C}$. A constant stress on the surfaces of the block would be maintained at about $4 \mathrm{MPa}$. The steady state of the temperatures would be maintained for about four to five months, then the heaters would be turned off to start a natural cooling process. The fore-mentioned instruments would be installed in boreholes in the block and on the block surfaces to have 3-D measurements of the parameters. Scoping model calculations have been performed to facilitate the test design (Lee, 1995a,b). Based on the scoping model calculations, we expected to observe a dryout region of about $2 \mathrm{~m}$ wide near the heater plane, a condensate zone of about $1 \mathrm{~m}$ thick at both above and below the dryout zone.

Due to budget constraints, we eliminated the load-retaining steel frame to maintain a constant stress of $4 \mathrm{Mpa}$ and replaced it with a strap system to maintain the integrity of the block during the test. Also, we gave up the plan to have the in situ monitoring of chemical species. We will depend on the post-test examinations of the evidences of rock-water interaction on the fracture surfaces to evaluate the chemical part of the coupled TMHC processes. Another modification of the original test scope was that the active controls for an adiabatic boundary condition on the sides of the block (the guard heaters) was replaced by passive thermal controls, using insulation materials. This modification of the boundary control did not have much affect on the intended test. Thermal conduction calculations indicate that using insulation materials on the sides can keep the temperature distribution in most parts of the block very similar to a 1-D case. The temperature in a region of a few centimeters in thickness from the surface of the block will have significant lateral gradient. However, more sophisticated model calculations will be required when the data are analyzed to take the lateral heat flux into consideration. Currently, the block has been isolated and all boreholes for installing instruments have been drilled. Figure 9-17 shows the boreholes in the large block. Some small blocks of the same rock type have been collected from regions adjacent to the large block for testing hydrological properties and thermal-hydrological processes in the laboratory. Some of the laboratory test results have been reported in Chapter 2. But the block has been mothballed until further notice from the Yucca Mountain Site Characterization Project.

All of the pre-test characterization of the large block has been completed. These include the bulk air permeability of the block determined by using single borehole injection before isolating the block, neutron logging to determine the initial moisture content in the block, matrix water permeability and connected porosity of cores collected during the drilling of the boreholes, the fracture distributions on the five surfaces of the block and on the surface prior to cutting the block, and video imaging in every borehole. The results of the pre-test characterization will be 
presented later in this section. The water permeability of one of LBT cores as a function of temperature is reported in Chapter 2.

Figure 9-18 shows the bulk air permeability of the block as a function of depth. The permeability was determined by single borehole injection before the block was isolated. The permeability varies from about $10^{-16} \mathrm{~m}^{2}$ to more than $7 \times 10^{-12} \mathrm{~m}^{2}$. Intersection of fractures with the injecting borehole was the deterministic factor of the permeability variation. Because the block is highly fractured (shown later in this section), the bulk air permeability of the entire block may be more homogeneous.

Some of cores collected during the drilling were used to determine the connected porosity of the matrix. Figure 9-19 shows the matrix porosity as a function of depth. The porosity varies from about $10 \%$ to about $13.5 \%$. The porosity of the TSw2 unit of the Topopah Spring tuff in Yucca Mountain is $12.1 \pm 3.6 \%$ (Reference Information Base, YMP/93-02, Rev. 0). The matrix porosity was used to determine the water saturation from the neutron logs. Figure 9-20 shows the moisture content of the block determined by neutron logging in some of the vertical holes before and after the cutting of the block boundaries. The water saturation of the block is between 60 and $80 \%$. This level of water saturation will provide enough moisture for creating an observable dryout zone and a condensate zone. Cutting of the block boundaries with water did not change the moisture content of the block interior.

Fractures on the five surfaces of the block were mapped carefully. Because the surfaces were cut smooth, it was possible to conduct very detailed fracture mapping. But it was difficult to determine dip on the top surface and strike and true dip of most of the fractures on the vertical surfaces. Figures 9-21 through 9-25 show the fractures on top, north, west, south, and east sides of the block, respectively. These fracture maps were combined into a 3-D physical model, which was used to project the fractures in the block to locate the instrument holes. These fracture maps and video images in each borehole will be used to infer fractures within the block, using fracture projecting software, such as Earth Vision.

Prior to cutting the block, the cleaned off ground surface was mapped in detail. After it was cut, this area became the top of the block and was subsequently mapped (see Fig. 9-21), but this data was not analyzed at the time of this report. Because the pre-cut surface was excavated, rather than cut smooth, dip measurements were made of many of the fracture surfaces. Block characterization indicates that the fracture system is similar to that observed underground in the ESF Access Drift. Figure 9-26 shows comparison plots of the fractures mapped on the top of the LBT prior to block cutting and that in the ESF. Comparison of the data from the ESF [Fig. 9-26(b)] and the LBT [Fig. 9-26(a)] shows that fractures in the LBT are similar to those observed in the ESF in the TSw2 unit (Barr et al., 1996) with the exception that the low-angle fractures mapped in the ESF are not represented in the LBT mapped features. This difference is because the data set is from the horizontal surface and therefore low-angle sets would not be observed. Low-angle fractures were observed on the sides of the LBT; however, that data set has not been analyzed and will be reported in subsequent revisions of the NFER.

It may also be apparent that the strike of the fracture set is more northerly in the LBT data set. This may be a result of several things. (1) It is quite likely that there is orientation bias in the data from the ESF, specifically the main drift is nearly north- 
south and therefore would not show northerly striking features that often (Yow and Wilder, 1983). (2) There may have been rotation of the near surface block that forms the Fran Ridge. or (3) There may be a declination setting difference in the compasses used for these different mapping exercises. Based on past experience, it is judged that the orientation bias is very likely, although it is impossible to know if that is the only reason for the difference in strike. Once data is available from the ESF alcoves that are oriented east-west, the significance of orientation bias can be evaluated and perhaps a composite fracture stereoplot could be produced by normalization techniques as discussed in Wilder and Yow, 1984. If compass setting errors are the reason for the difference, subsequent analyses should resolve this since there is a set of measurements that were conducted based on surveyed block corners.

Regardless of the minor differences, from the standpoint of fracture sets, the LBT rock seems to be a good representation of the fracture system that has been observed in the ESF. The fractures are dominately in one vertical set that has north to northwesterly strikes.

A comparison of fracture spacing may be somewhat misleading since the same criteria on fracture length was not applied. However, the fracture system observed in the LBT, as inspection of Fig. 9-27 indicates, is similar to that reported from the ESF. There is about 0.75 fracture/ $\mathrm{ft}$ (excluding short fractures so that the comparison with ESF is more appropriate) along any of the east-west grid lines and nearly 0.5 fracture/ $\mathrm{ft}$ along the north-south grid lines (more comparable to the drift orientation). Fracture densities in the ESF are around 3-4 fractures $/ \mathrm{m}$, which is equivalent to $1 \mathrm{fracture} / \mathrm{ft}$ seen on the LBT map. Although the fracture density mapped on the excavated surface was about half that observed in the ESF, the number of fractures observed once the top was cut (Fig. 9-21) was comparable.

The orientation bias discussed here is also indicated in the fracture spacing data from the LBT, since there are about $50 \%$ more fractures seen in the east-west transects than in the north-south transects. Thus there would be rather different fracture distributions in the north-south line surveys (essentially equivalent to the ESF drift) than in the multi-directional survey obtained by the mapping of a flat surface in the LBT. Further studies of this bias will be conducted in the future but were not available at the time of this report.

On the basis of the fracture comparisons, it appears that the fracture system exhibited in the LBT is comparable to that observed underground. Based on the permeability measurements, the fracture system permeability is comparable. Also as mentioned, the moisture content is comparable to what is understood for the saturation conditions within the ESF, and the porosity of the rock matrix is also comparable. No assessment of the geochemical or mineralogical characteristics is available at this time. However, there is every indication that tests performed on the LBT could test the process models in an appropriate rock mass.

\subsection{ESF Thermal Tests}

The ESF Thermal Tests (ESFTTs) will be conducted in Alcove 5 off the ESF Main Drift. Alcove 5 is located at about the $2.827 \mathrm{~km}$ station of the ESF Main Drift. Figure 
9-28 shows the plan view of the ESFTT facility. ESFTT consists of two tests: the Single Heater Test and the Drift Scale Test. ESFTT is in the construction state, therefore only the plans and the test designs are reported here. Detailed objectives, design, and planning of the ESFTT can be found in Test Design, Plans, and Layout for the First ESF Thermal Test, Rev.1, 1996, prepared by Civilian Radioactive Waste Management System Management and Operating Contractor.

\subsubsection{Single Heater Test}

As shown in Figure 9-28, the Single Heater Test (SHT) will be conducted on one side of the Observation Drift, at about $41 \mathrm{~m}$ from the ESF Main Drift. The main objectives of the SHT are to obtain rock mass thermal and mechanical properties at ambient and elevated temperatures, to evaluate rock bolt anchorage response to the heated conditions, and to observe thermal-hydrological-chemical changes in the rock mass due to the heating. Because the heated volume of the rock mass in the SHT is small (the test block covers an area of about $84 \mathrm{~m}^{2}$ ), the thermal-hydrologicalchemical observation will be mostly for developing in situ test experience. Figure 929 shows the layout of the SHT. The test region is the block between the Observation Drift, Thermomechanical Alcove, and Thermomechanical Alcove Extension. The construction and drilling are completed and the instruments are being installed in the holes. The heater is scheduled to be turned on by the end of August 1996.

The 5-m-long heater will be placed in a hole $(7 \mathrm{~m} \mathrm{long})$, which is drilled into the test block from the Thermomechanical Alcove. The boreholes include: (as shown in the lower portion of Fig. 9-29) four ERT holes, four neutron/RTD holes (for neutron logging and temperature measurements), two chemical holes, two hydrological holes, and two optical extensometer holes. Chemical sensors and fluid extracting devices will be mounted on Science Engineering Associates Membrane In-situ Sampling Technology (SEAMIST) in the chemical holes for monitoring chemical processes. Humicaps and gas pressure transducers will be mounted in packers in the hydrological holes for measuring relative humidity, temperature, and gas pressures. The rest of the boreholes are for mechanical, rock bolts, and temperature measurements. The power output of the heater will be about $4 \mathrm{~kW}$. The rock mass will be heated by a constant power of about $4 \mathrm{~kW}$ for about eight months; then the heater will be turned off. Monitoring of thermal mechanical responses, temperature, moisture content, chemical concentration, etc., will be started before the heater is energized, and will continue through the heating phase and the cooling phase.

Pre-test pneumatic tests to characterize the rock mass were completed, finding the air permeability of the test region to be very heterogeneous. The air permeability varies by more than two orders of magnitude. Generally speaking, the region between the heater and the Observation Drift has lower permeability than the region on the other side of the heater, i.e., between the heater and the Thermomechanical Alcove Extension. Also, the inner portion of the block, i.e., the region near the bottom of the heater hole, seems to have greater permeability than the outer portion of the block. Apparent fracturing in a borehole has no strong correlation with the permeability in that hole. 


\subsubsection{Drift Scale Test}

The Drift Scale Test is the second in situ thermal test of the ESFTT. Again, the objectives of the Drift Scale Test are described in Test Design, Plan, and Layout for the First ESF Thermal Tests, as mentioned in section 9.4. The main purpose of the Drift Scale Test (DST) is to test the coupled TMHC processes in an in situ environment. There will be some thermal mechanical tests for the repository design and construction. The heated area and the heated period will be large and long enough for us to observe the coupled TMHC processes that are relevant to a repository. Figure 9-30 shows the schematic layout of the DST. Figure 9-30(a) shows the plan view of the DST; Figure 9-30(b) shows one of the cross sections of Fig. 9-30(a).

Heaters will be placed in the heater drift and wing heater holes (as illustrated by holes 74 to 123 and 207 to 210 ). The heater drift will be about $5 \mathrm{~m}$ in diameter. The wing heater holes will be about $10 \mathrm{~cm}$ in diameter and will be spaced about $1.8 \mathrm{~m}$ along the axis of the heater drift. The heaters in the heater drift will be MPC size canisters with heating elements mounted in them so that the temperature on the canister surfaces will be uniform. The linear power density of the heater canister will be about $1 \mathrm{~kW} / \mathrm{m}$. Rod heater elements will be placed in the wing heater holes. The power density of the wing heaters will be about $125 \mathrm{w} / \mathrm{m}^{2}$ among the inner half of the wing heaters, $175 \mathrm{w} / \mathrm{m}^{2}$ for the outer half of the wing heaters. The heater drift will be about $55 \mathrm{~m}$ in length; the tip-to-tip span of the wing heaters will be about 28 $\mathrm{m}$. The heated area of the DST will be about $1540 \mathrm{~m}^{2}$, which will be big enough for observing large-scale thermal-hydrological processes, such as heat pipe, buoyant phase convection (see Chapter 1.9 for details).

Boreholes for instruments will be drilled radially from the heater drift, from the observation drift to the heater drift, and longitudinally along the heater drift. The goal is to obtain a 3-D coverage of the test region. In addition to the types of boreholes mentioned in section 9.4.1, Rapid Estimation of $\mathrm{K}$ and Alpha (REKA) probes will be installed in boreholes to perform in situ measurement of the thermal conductivity and diffusivity of the rock mass. The heaters will be heated at constant power for at least three years, which, depending on the responses of the rock mass, may be extended to four years, and a controlled cool-down period will follow the three- or four-year heating period. Similar to the SHT, monitoring of the responses of the rock mass will cover the pre-heat, heating, and cool-down periods.

Construction of the main (east-west) portion of the Observation drift has been completed. The other part of the Observation drift and the Heater drift will be constructed during FY 1997. Drilling of the boreholes will be started soon, and the heaters are scheduled to be turned on in late FY 1997. 


\subsection{Large-Scale Long Duration Test}

A large-scale long duration test (LSLDT) was incorporated into the field test planning because of the challenges of scale, both temporal and spatial, that must be considered in any testing which is both accelerated in time and therefore in gradients and in limited geometric size. This test was sized geometrically and duration was determined based on numerical analyses. This test is described in the Study Plan for Engineered Barrier System Field Tests, as cited in section 9.1; however, current budget planning does not commit to the LSLDT. But, it is discussed here since it is an essential part of the planned testing. If used, this test would have multiple heater drifts with observation drifts located both above and below the heated drifts, as shown in Fig. 9-31. Although at least three heater drifts would be used, five would better address issues such as condensate ponding. The heater drifts would be heated for at least four years, and subsequently extended, depending on the responses of the rock mass at the end of the fourth year. The heating period would be followed by a controlled cool-down period of at least one year and a natural cooldown period, which would be dictated by the cooling of the rock mass.

It is possible that the LSLDT may be merged or combined with the Confirmation Test. The configuration of the LSLDT would be the closest simulation of a repository that can possibly be achieved. Instrumentation for the LSLDT would be similar to that in the DST, with whatever improvement that we can learn from the DST. The distribution of the instruments in the LSLDT would provide a true 3-D coverage of the test region, would be much better than the DST.

\subsection{Confirmation Monitoring}

Confirmation monitoring of the repository's performance will be conducted in parts of the repository that are constructed and where early emplacement of the waste has been accomplished. Instrumentation for the confirmation monitoring will be similar to that in the DST and the propsed LSLDT. Basically, monitoring will include temperature, moisture content, mechanical responses, and chemical responses of the rock mass around the emplacement drifts. The heat source will be the radioactive decay heat from the nuclear wastes. One of the criteria for designing the methodology and instrumentation for the confirmation monitoring is the long duration of the test, which can be tens or even hundreds of years. Lessons learned from the DST and the proposed LSLDT will be used to select measurement methodologies and instruments that can provide reliable long-term monitoring. 


\subsection{References}

Daily, W., A. Ramirez, T. Ueng, and V. LaTorre (1989), "High Frequency

Electromagnetic Tomography," Proc. Nuclear Waste Isolation in the Unsaturated Zone, Focus '89 (Am. Nuc. Soc., LaGrange Park, IL), pp. 409-416.

NNA.910326.0098.

Lee, K., 1995a, Progress Report on Pre-Test Calculations for the Large Block Test, Lawrence

Livermore National Laboratory UCRL-ID-118699, Livermore, CA.

MOL.19950406.0143

Lee, K., 1995b, Second Progress Report on Pre-Test Calculations for the Large Block Test,

Lawrence Livermore National Laboratory UCRL-ID-122300, Livermore, CA.

MOL.19960417.0218

Lin, W., 1993, Scientific Investigation Plan for Large Block Testing of Coupled Thermal-

Mechanical-Hydrological-Chemical Processes, SIP-NF-02, Lawrence Livermore

National Laboratory, Livermore, CA. NNA.19930419.0032

Lin, W., 1994, Activity Plan, AP-LBT-01, Rev. 0, for Large Block Tests of Coupled Thermal-

Mechanical-Hydrological-Chemical Processes (YMP WBS Element 1.2.3.12.4),

Lawrence Livermore National Laboratory, Livermore, CA. MOL.19940908.0093

Lin, W., 1995, Study Plan for Study 8.3.4.2.4.4, Engineered Barrier System Field Tests, US.

Department of Energy, prepared by CRWMS Management and Operating

Contractor/Lawrence Livermore National Laboratory, Office of Civilian

Radioactive Waste Management, Washington, DC. MOL.19960425.0195

Ramirez, A., T. Buscheck, R. Carlson, W. Daily, K. Lee, W. Lin, N. Mao, T. Ueng, H.

Wang, and D. Watwood, 1991, Prototype Engineered Barrier System Field Test

(PEBSFT) Final Report, A. Ramirez, Scientific Editor, Lawrence Livermore

National Laboratory UCRL-ID-106159, Livermore, CA. NNA.19910711.0047

Ramirez, A., D. Wilder, J. Beatty, T. Buscheck, R. Carlson, W. Daily, R. LaTorre, K.

Lee, W. Lin, N-H. Mao, J. Nitao, D. Towse, T-S. Ueng, and D. Watwood (1991),

Prototype Engineered Barrier System Field Tests (PEBSFT), Progress Report through

November 1, 1988, Lawrence Livermore National Laboratory, Livermore, CA, UCID-21640.

Yow, J., Jr. (1985), "Test Concept for Waste Package Environment Tests at Yucca Mountain," in the Proc. of the 28th U.S. Symposium on Rock Mechanics, Tucson, AZ, pp. 1035-1042; also in Lawrence Livermore National Laboratory, Livermore, CA, UCRL-95568.

Yow, J.L. Jr, and D. G. Wilder, 1983, Planning Exploratory Drilling: The Effect of Blind Zones and Level of Logging Effort, Proceedings of 24th U.S. Symposium on Rock Mechanics, College Station, TX, pp 807-812.

Wilder, D. G., and Yow, J. L. Jr, 1984, Structural Geology Report, Spent Fuel TestClimax, Nevada Test Site, Lawrence Livermore National Laboratory UCRL53381, Livermore, CA.

Data Tracking Information:

9.3 Large Block Test

(Data Tracking Number: LL950103004244.004) 



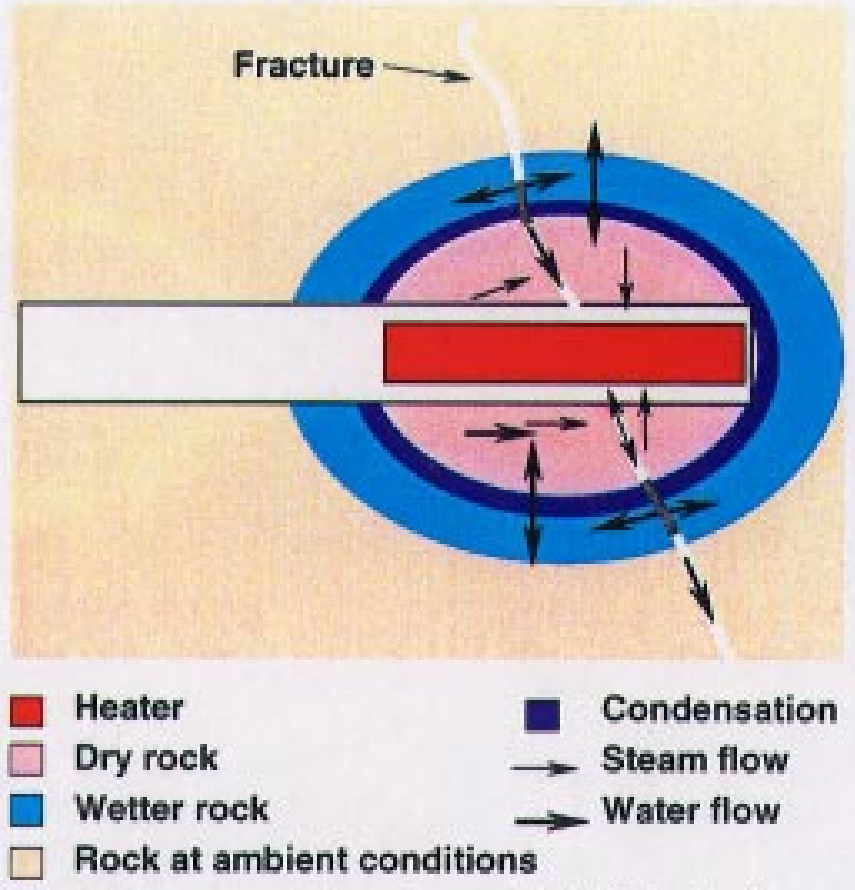

Figure 9-1. Schematic of a vertical cross-section of a probable hydrologic scenario in partially saturated welded tuff subjected to a thermal load.

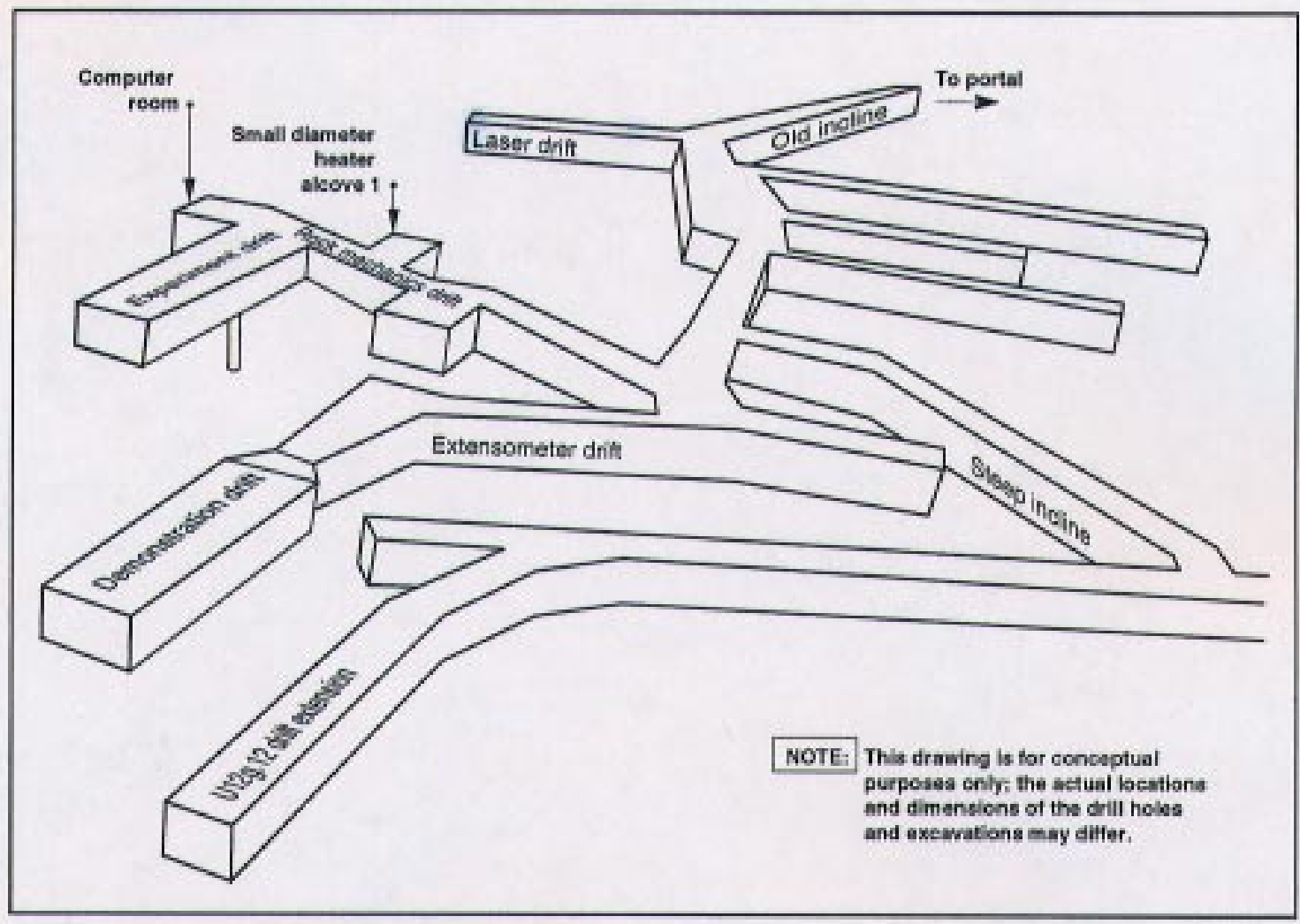

Figure 9-2. G-Tunnel Underground Facility. 



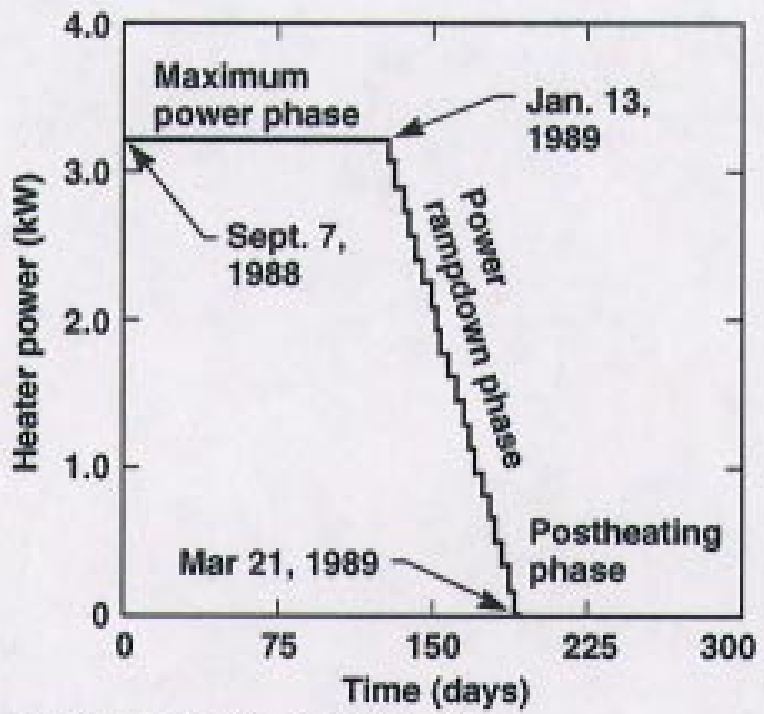

Figure 9-3. Heater power schedule used for the PEBSFT.

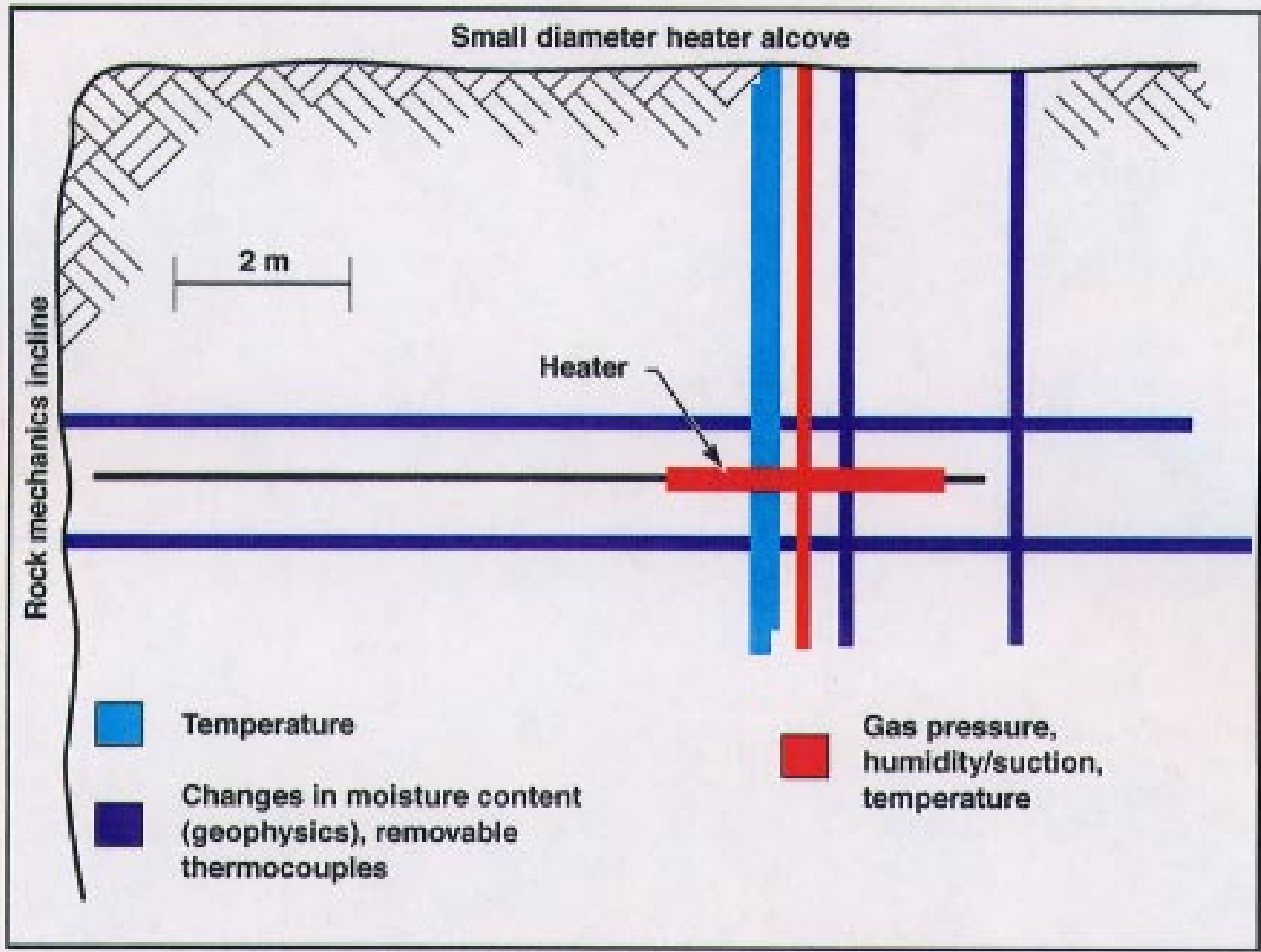

Figure 9-4. Plan view of the as-built borehole layout. The various line patterns identify the type of measurement made in each borehole. The locations of the rock mechanics incline and the small diameter heater alcove in G-Tunnel are shown for reference. 


$$
\text { . }
$$




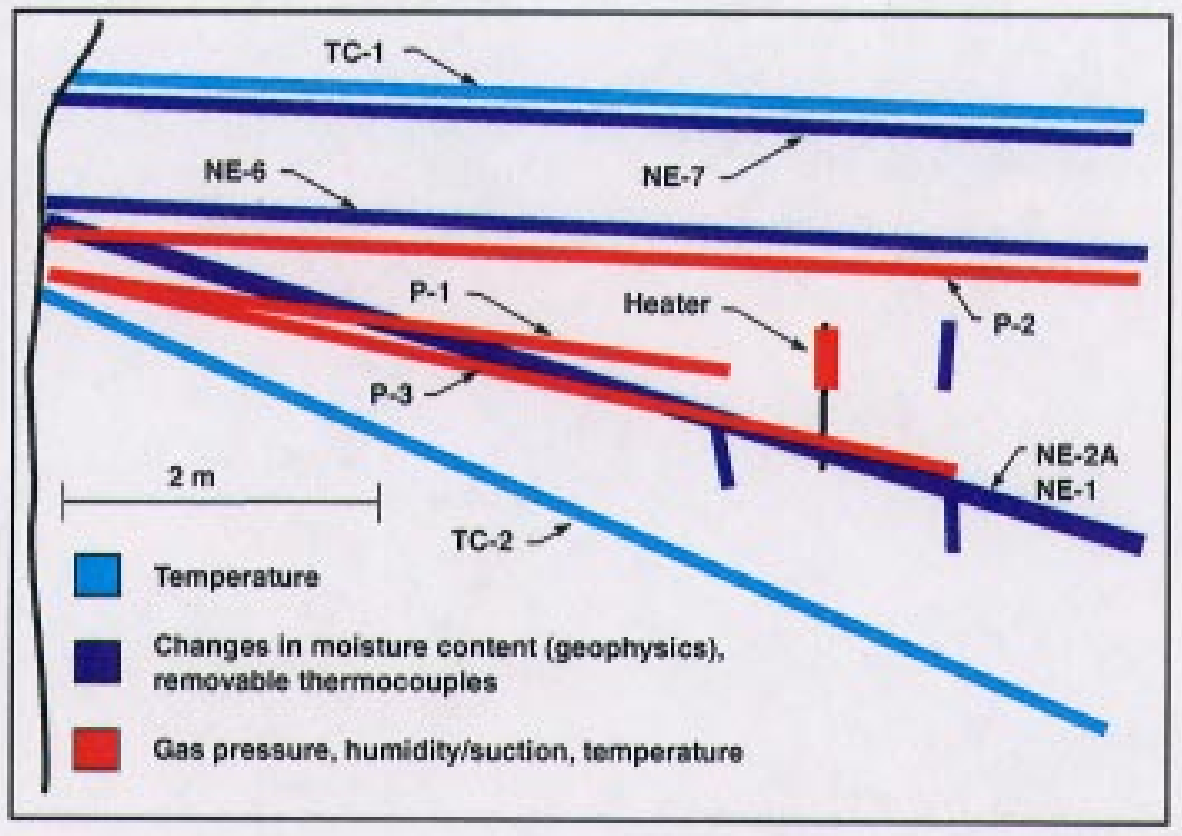

Figure 9-5. Side view of the as-built borehole layout as viewed from the rock mechanics incline. The various line patterns identify the type of measurement made in each borehole.

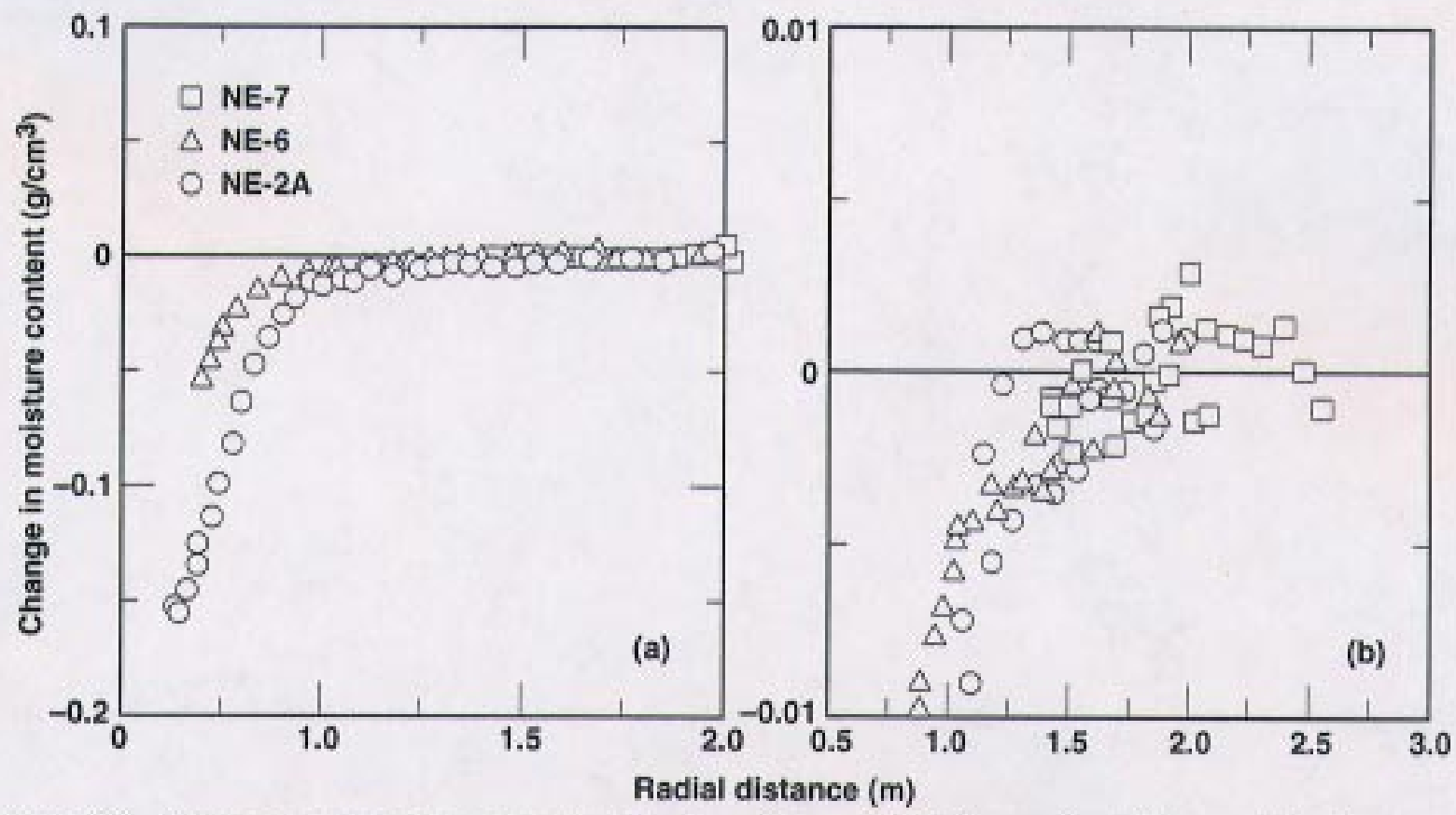

Figure 9-6. Changes in moisture content plotted against radial distance after 70 days of heating (approximately midway through the maximum power phase). A subset of the curves in (a) are shown enlarged in (b). Changes are calculated relative to preheating moisture conditions. 



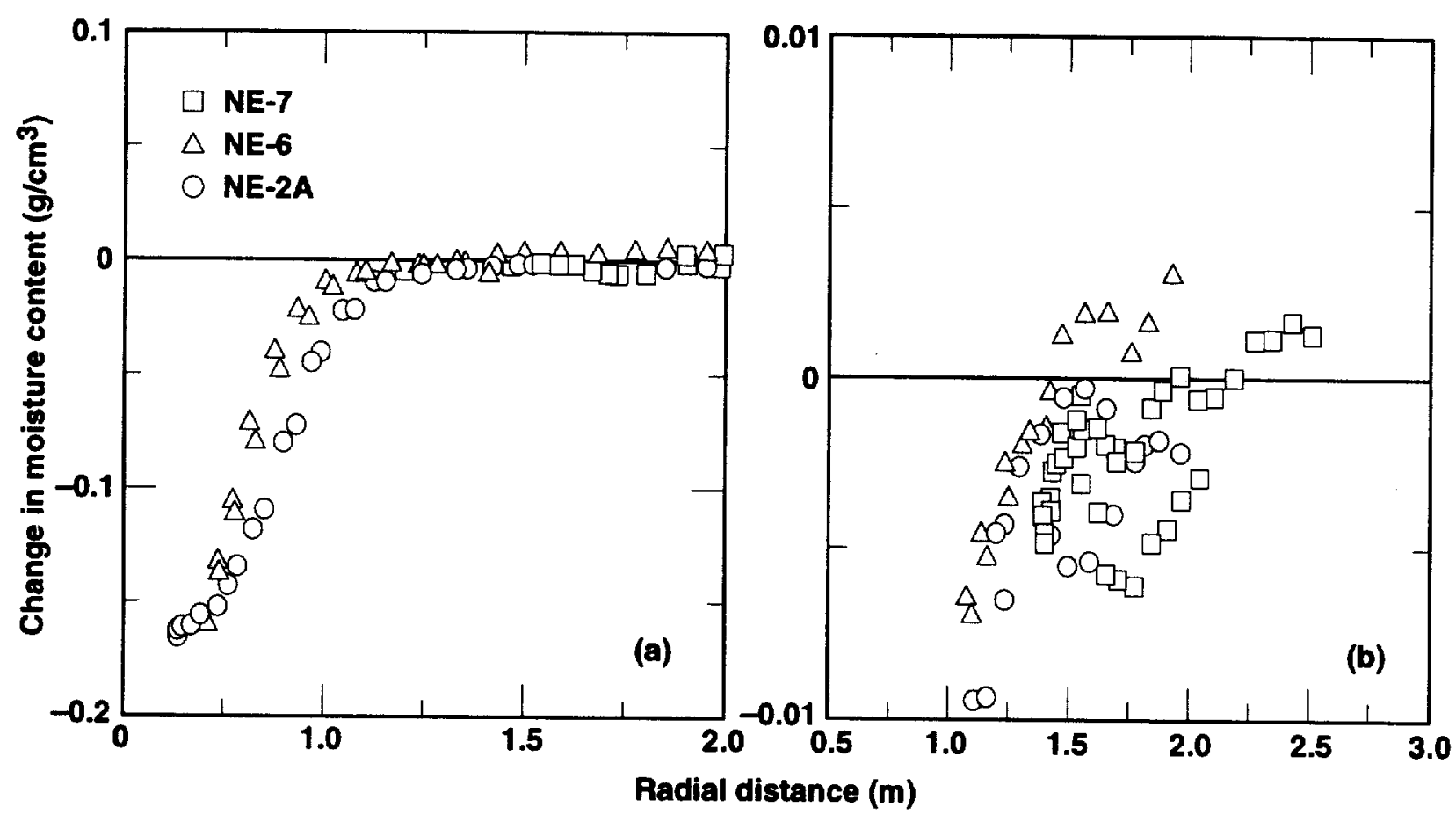

Figure 9-7. Changes in moisture content plotted against radial distance for the next to last day of maximum power heating. A subset of the curves in (a) are shown enlarged in (b). Changes are calculated relative to preheating moisture conditions.

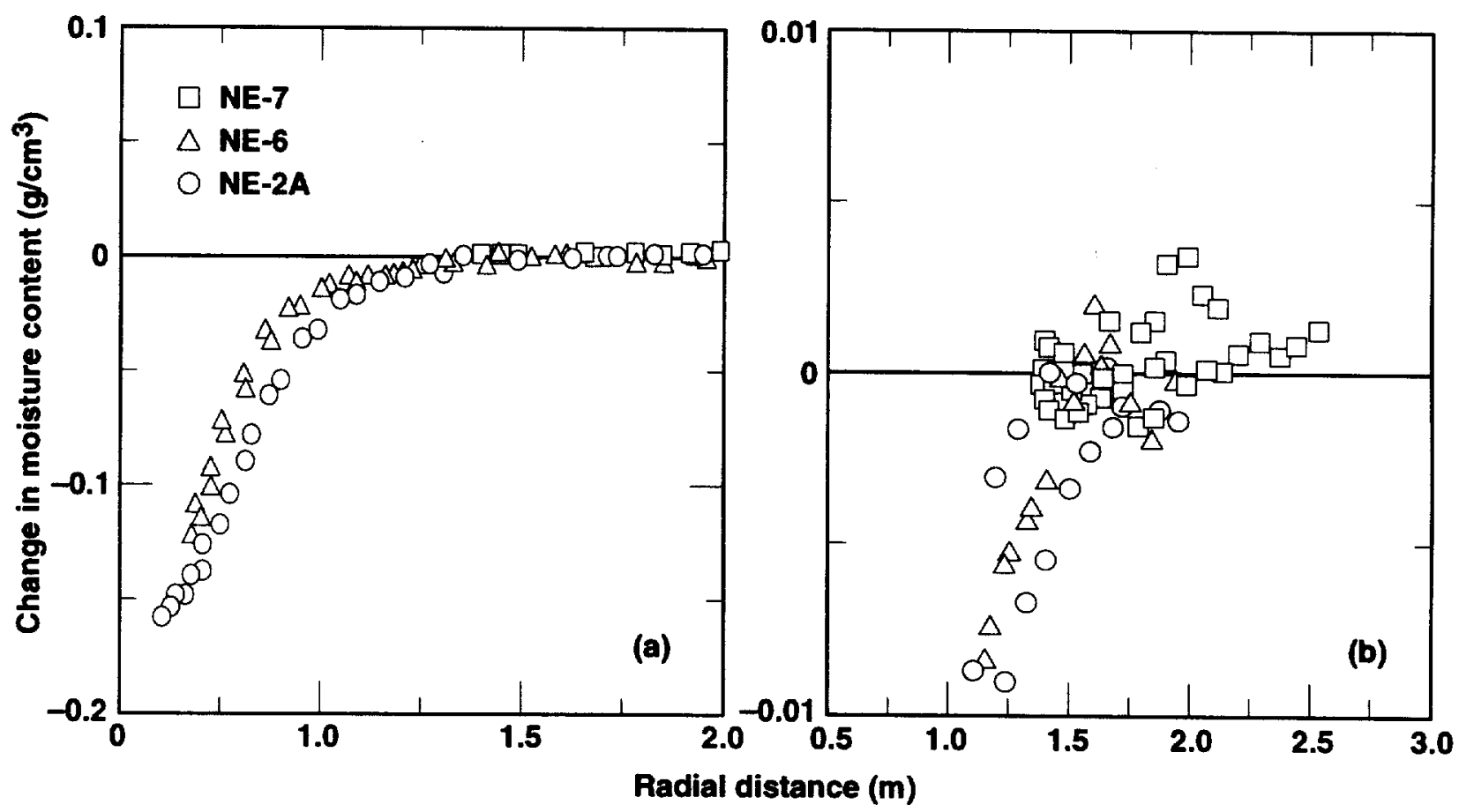

Figure 9-8. Changes in moisture content plotted against radial distance 301 days after start of heating (106 days after heater was de-energized). A subset of the curves in (a) are shown enlarged in (b). Changes are calculated relative to preheating moisture conditions. 



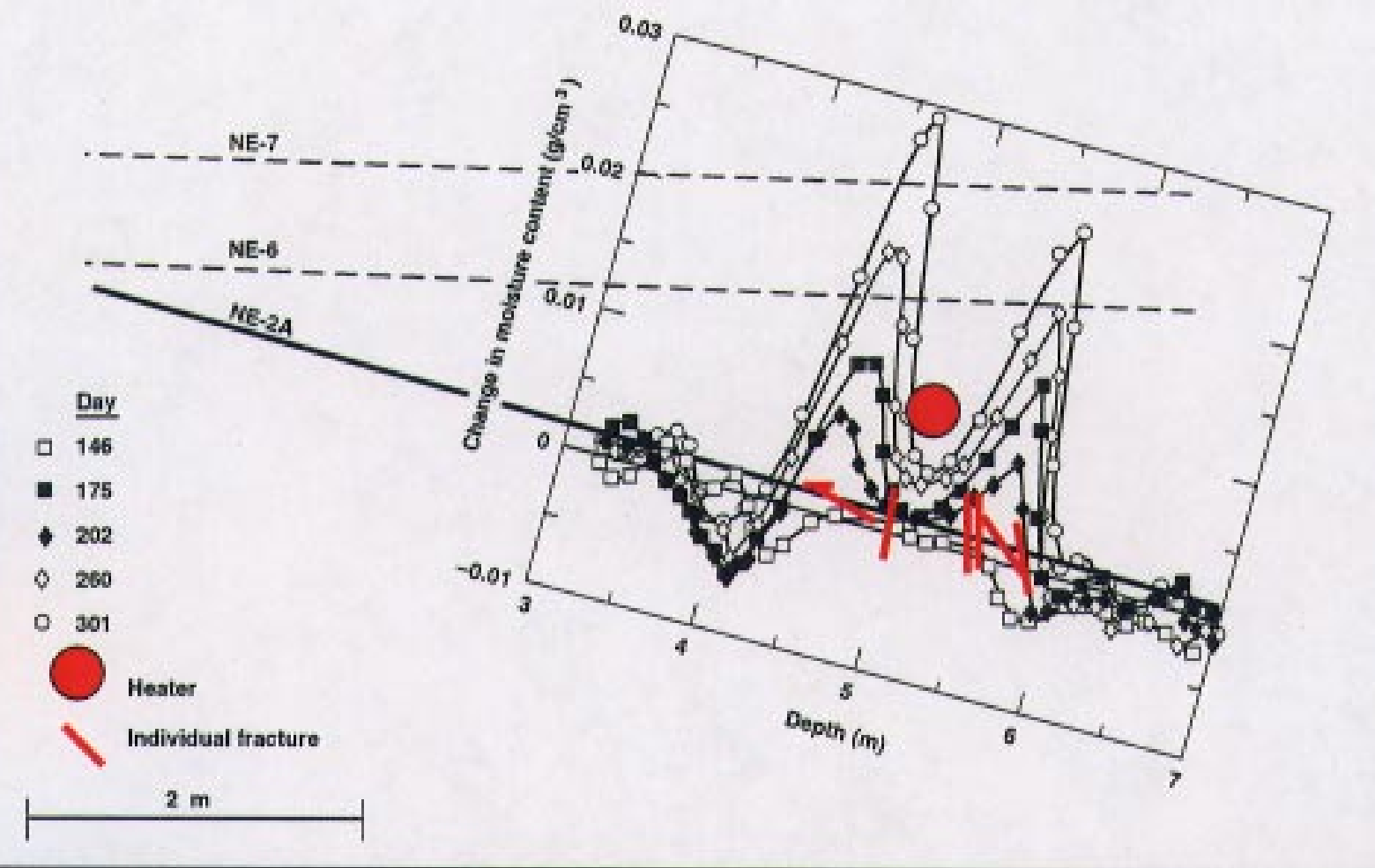

Figure 9-9. Changes in moisture content mapped along borehole NE-2A. Changes are calculated relative to the last day of full-power heating. Fractures mapped are shown for comparison. 


$$
-
$$




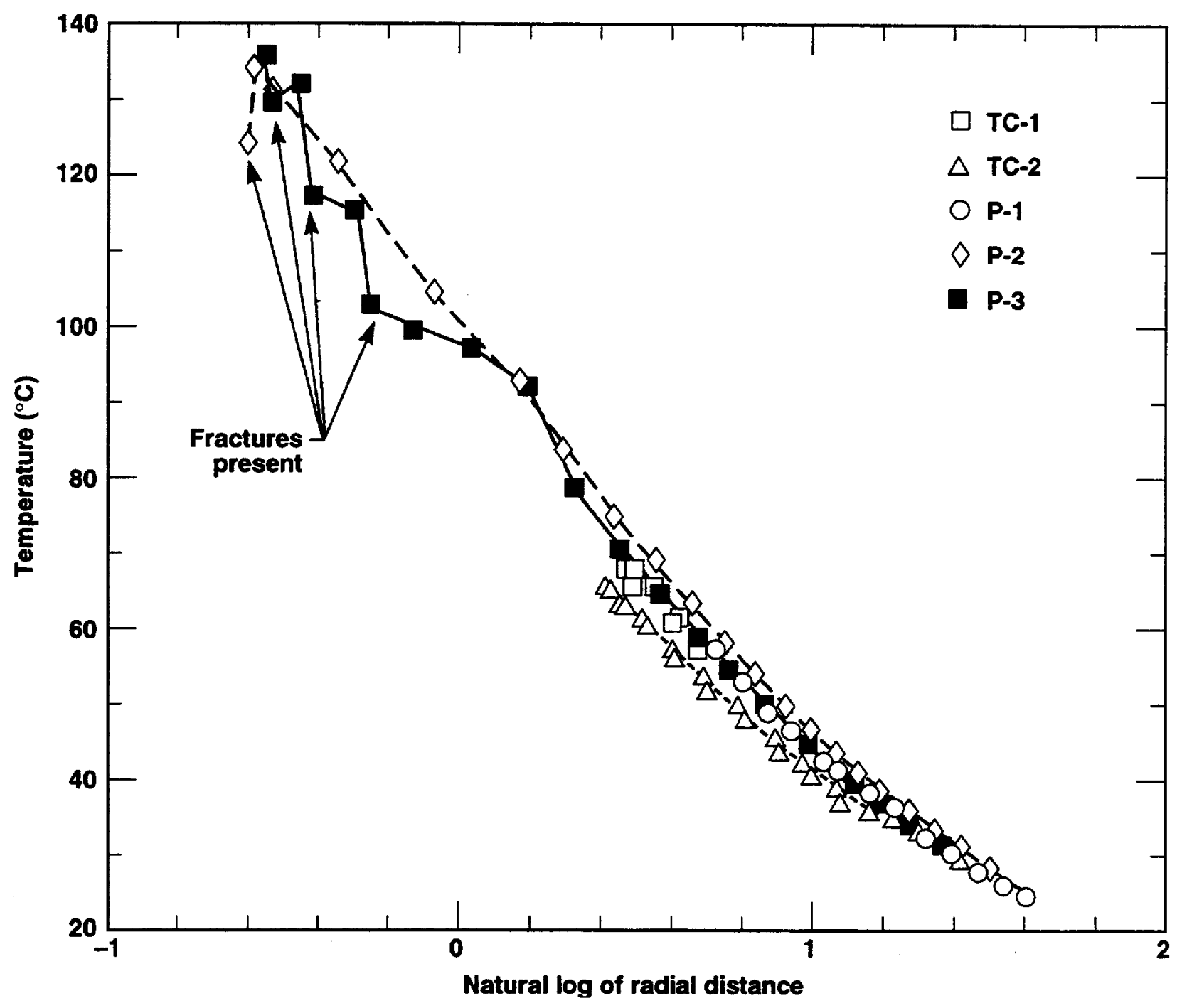

Figure 9-10. Temperatures in various boreholes measured during the last day of full-power heating. 



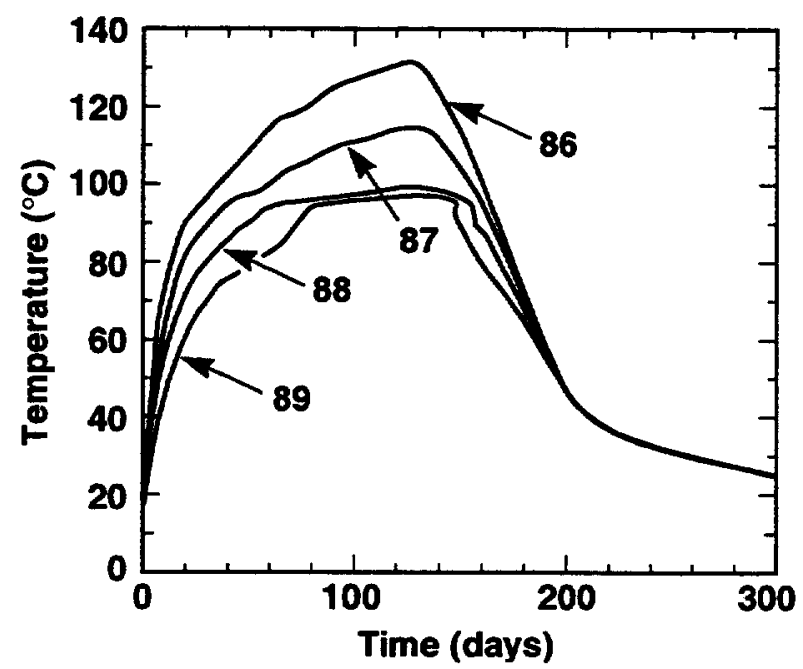

Figure 9-11. Evolution of selected temperatures in the P-3 borehole as a function of time. Thermocouples 88 and 89 show a flattening of the profiles between days 50 and 150 that may be due to the movement of condensed water in this region.

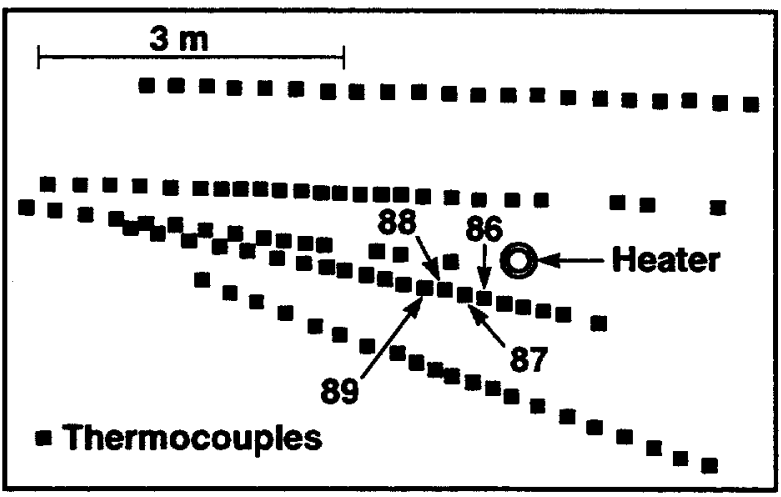

Figure 9-12. Cross-section near the heater midplane, showing thermocouple locations relative to the heater. Data for thermocouples 86 to 89 are shown in Fig. 9-11. 



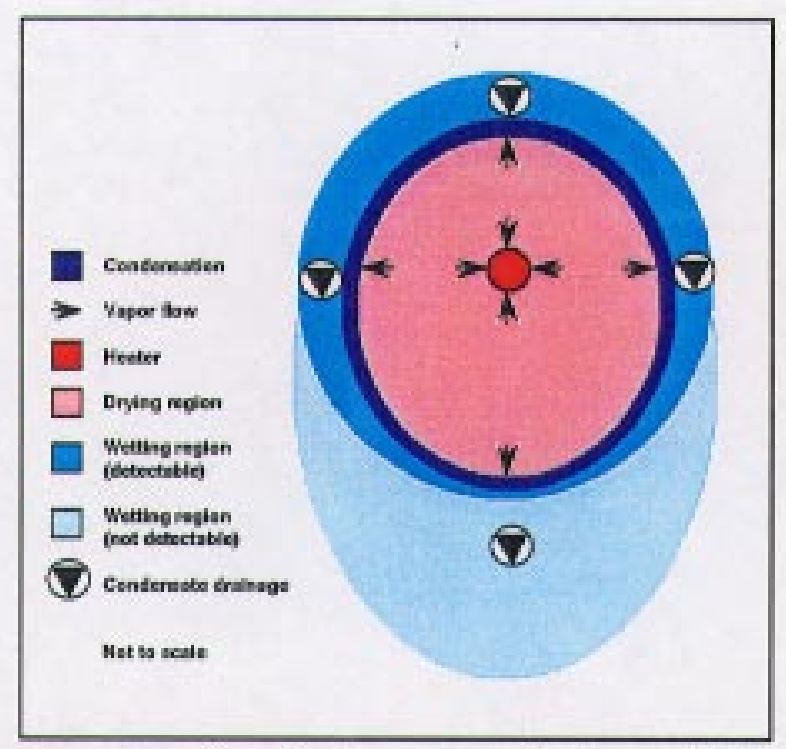

Figure 9-13. Proposed flow phenomena for a fracture perpendicular to the heater axis. The view is along the fracture plane. This conceptual model was proposed as an explanation for the atypical temperatures shown by thermocouples 88 and 89 (shown in Fig. 9-11). Also shown is the increased region of drying and wetting fronts along the fracture.

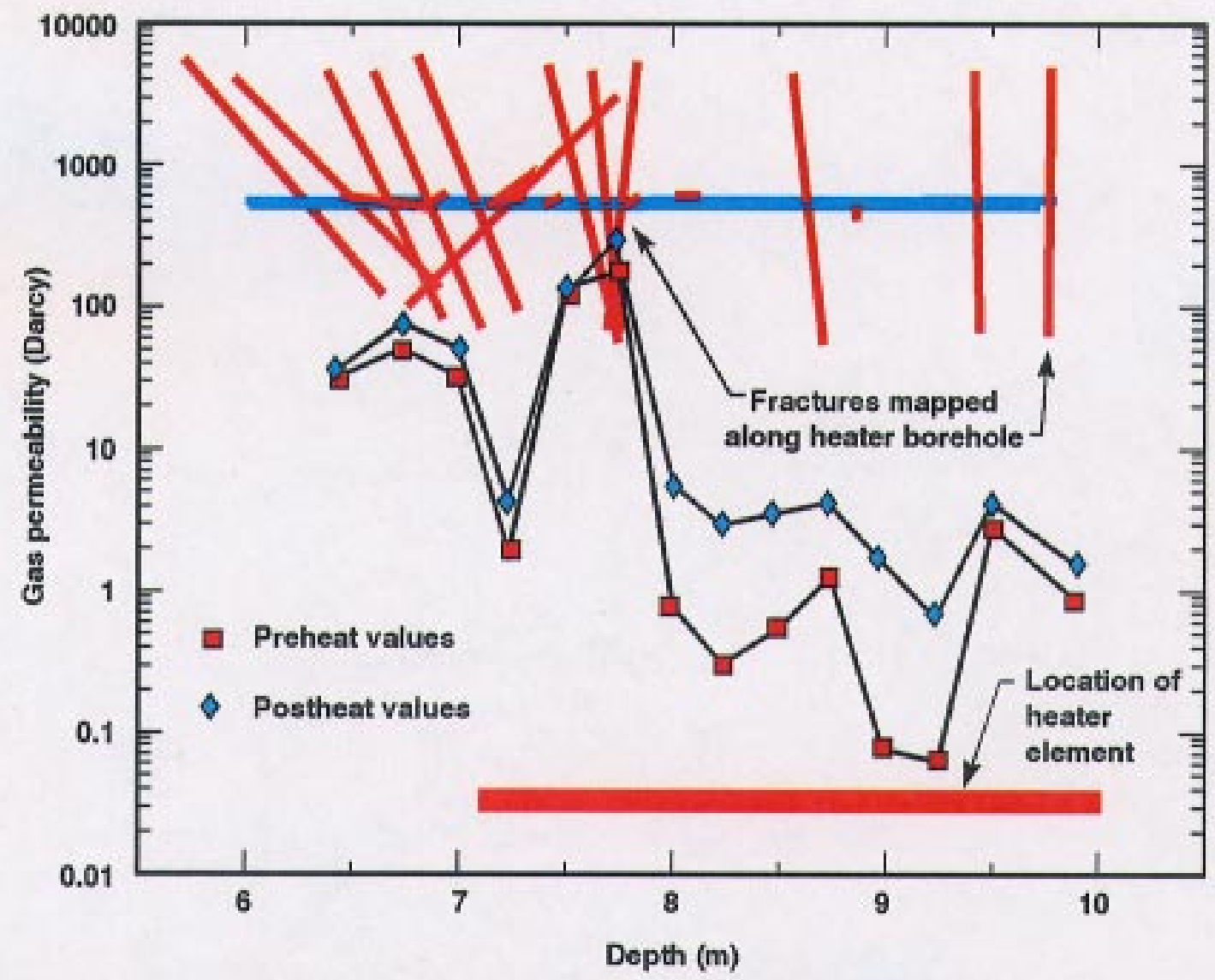

Figure 9-14. Gas permeability measurements made along the heater borehole before and after heating on the borehole. 
7
4
7
$?$
7
7
$?$
7
$?$
7
7
$?$
7
7
7
$?$
7 


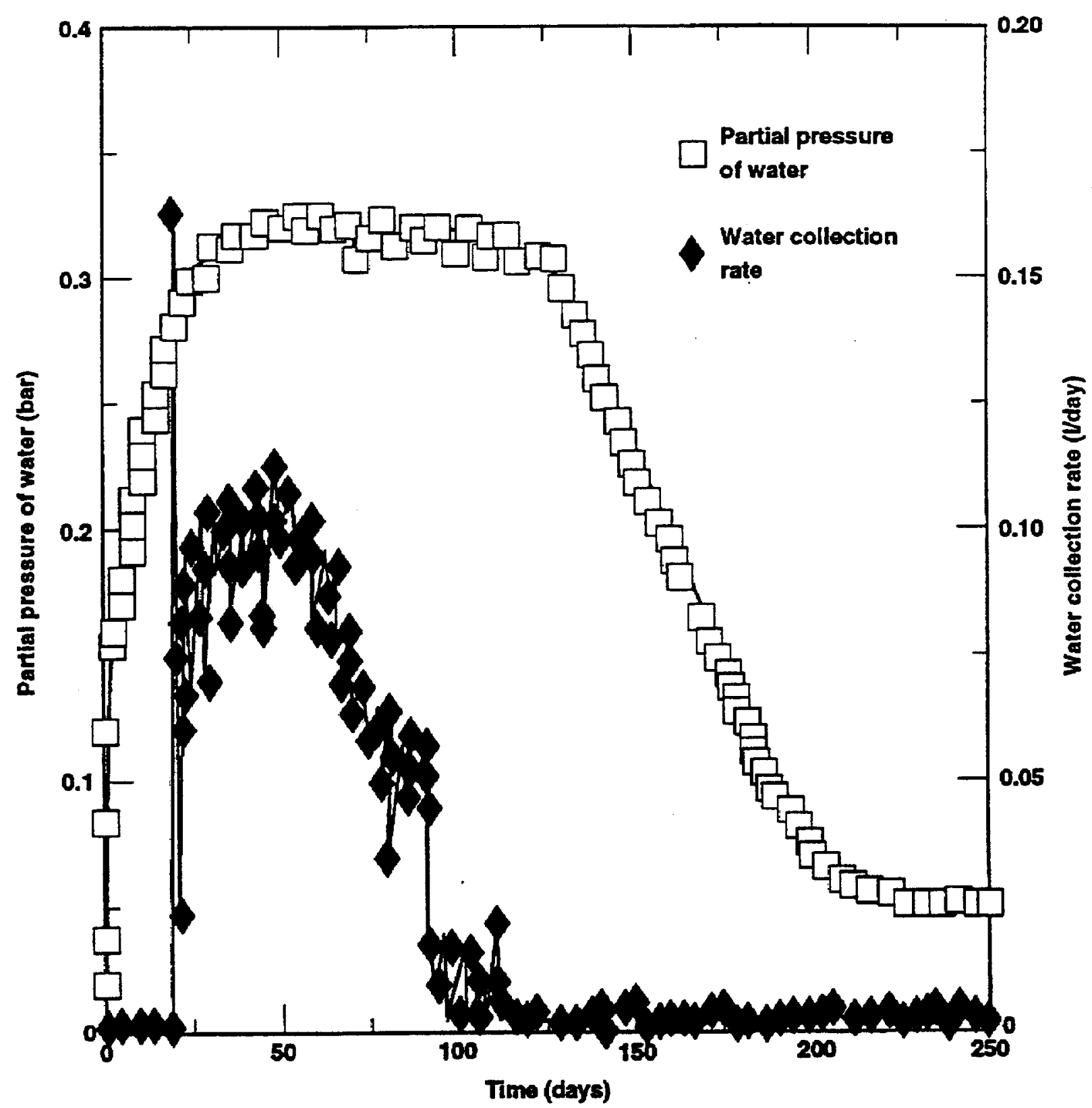

Figure 9-15. Water collection rate and partial pressure of water in the heater borehole air as a function of time. 
$-$ 


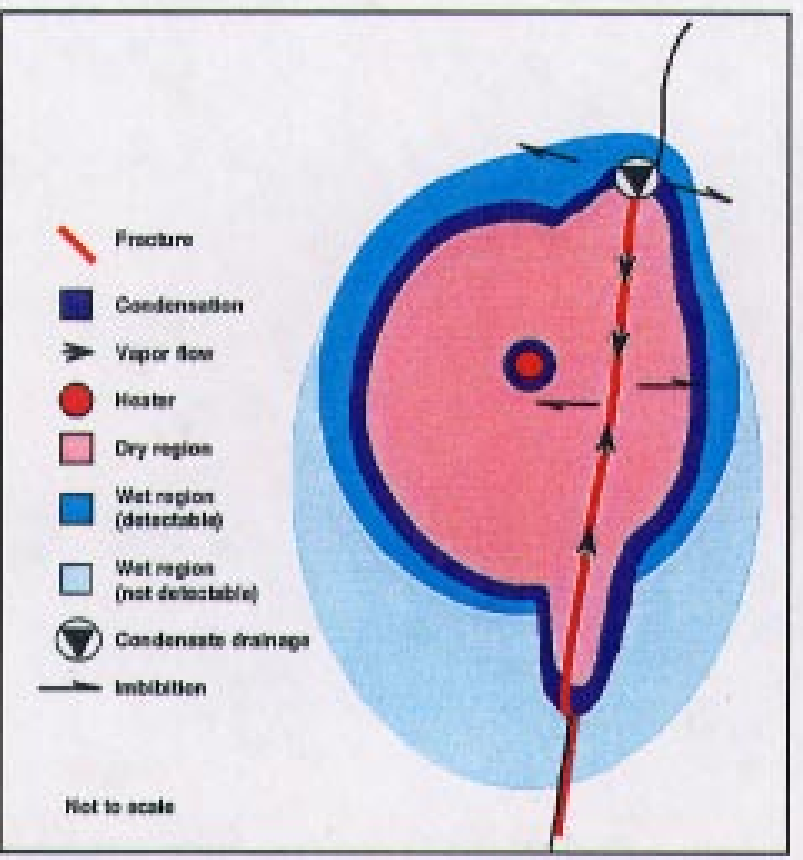

Figure 9-16. Proposed conceptual model of the mechanisms that dominate the dry region rewetting process during cooldown of the rock mass. A transect along a matrix block intersected by a fracture is shown.

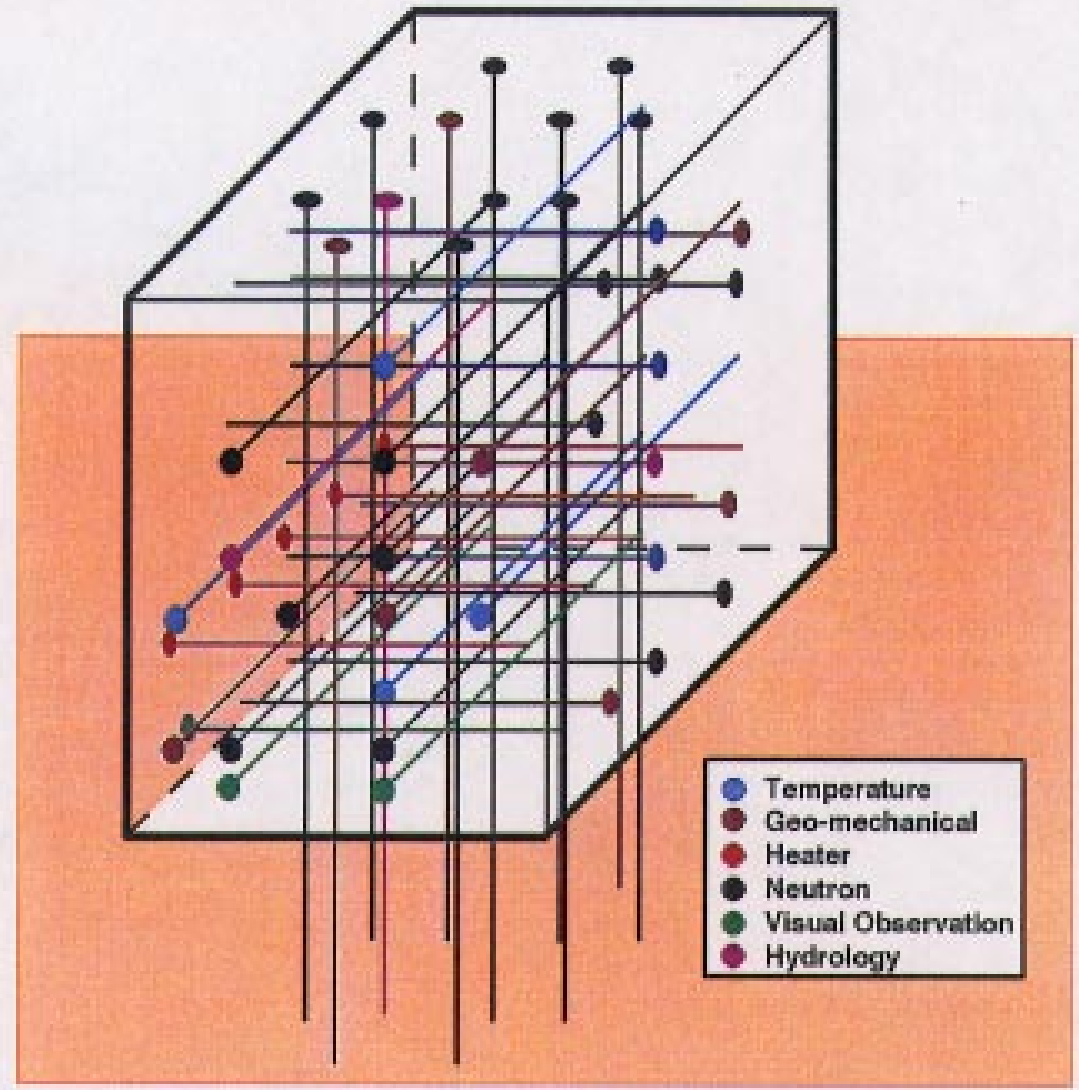

Figure 9-17. Instrument boreholes drilled in the large block for LBT. 



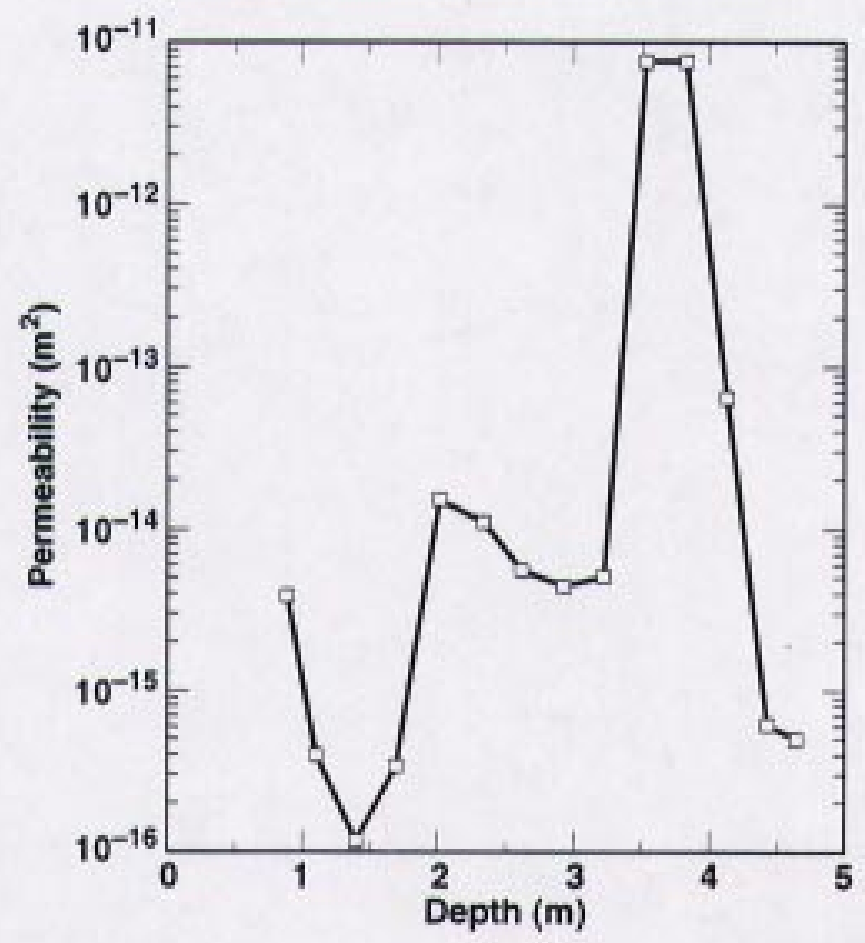

Figure 9-18. Air permeability of the large block as a function of depth measured from a single borehole air injection test in $\mathrm{N} 1$ hole.

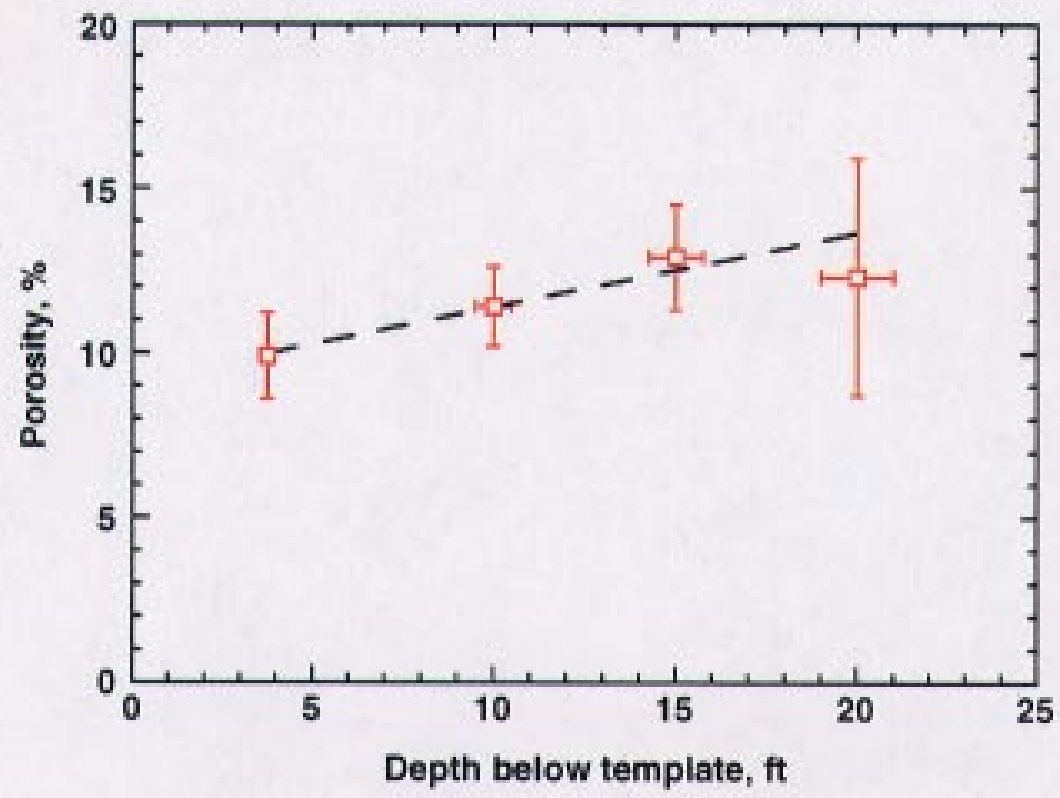

Figure 9-19. Matrix porosity of cores from the LBT as a function of depth. 
$?$
$?$
$?$
7
7

7

7

7

7

7

9

7

7

7 


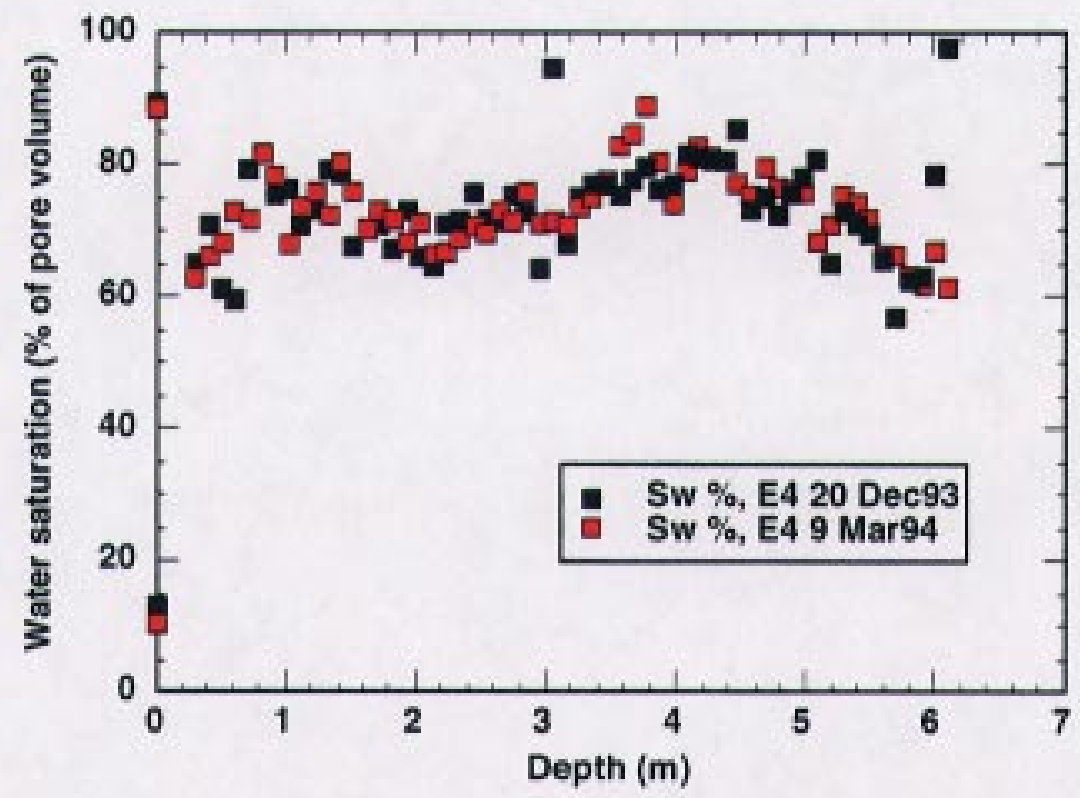

Figure 9-20. Water saturation (percent of pore volume) in a vertical hole, near the middle of the block as a function of depth, determined by neutron logging before and after the sawing.

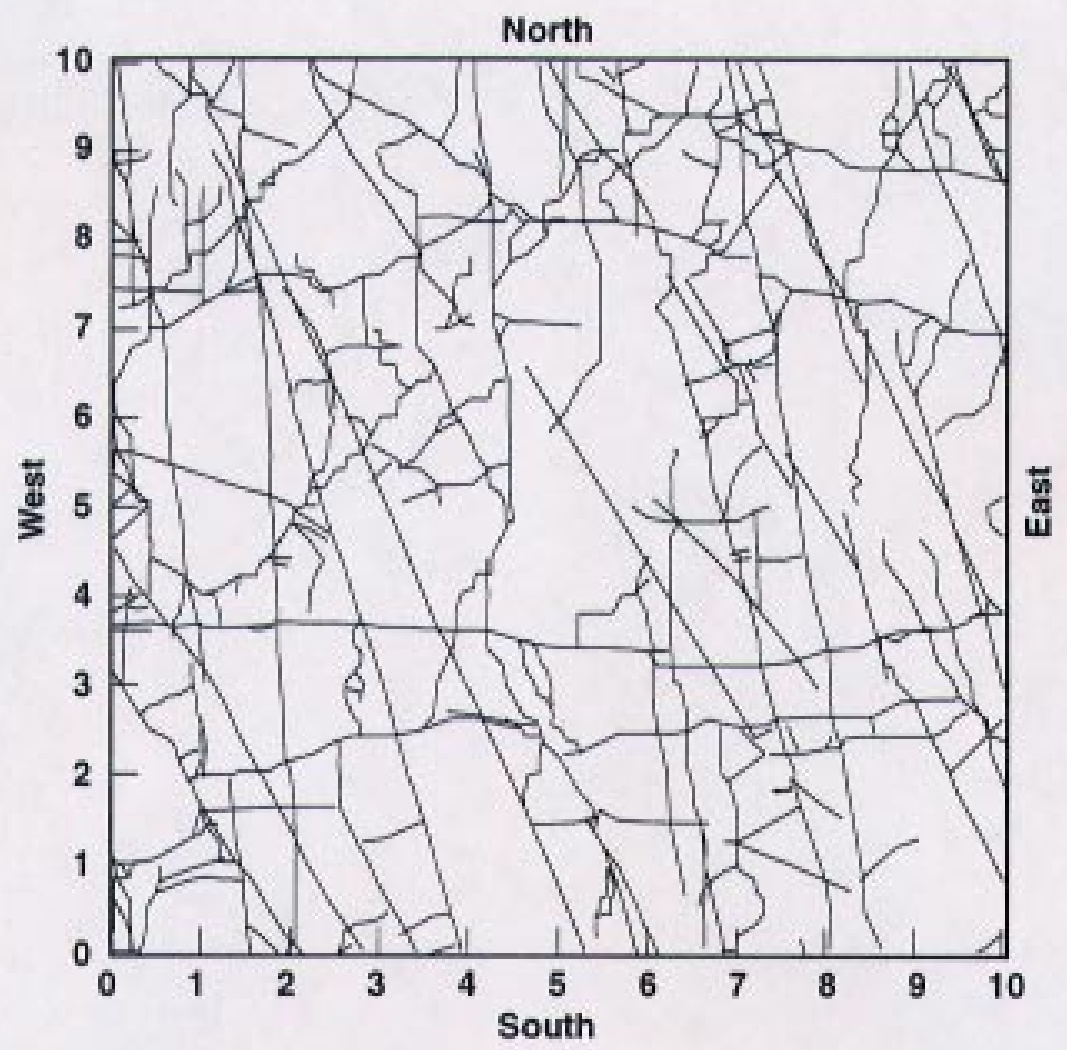

Figure 9-21. The fracture location maps on top of the block, after the top was cut smooth. 



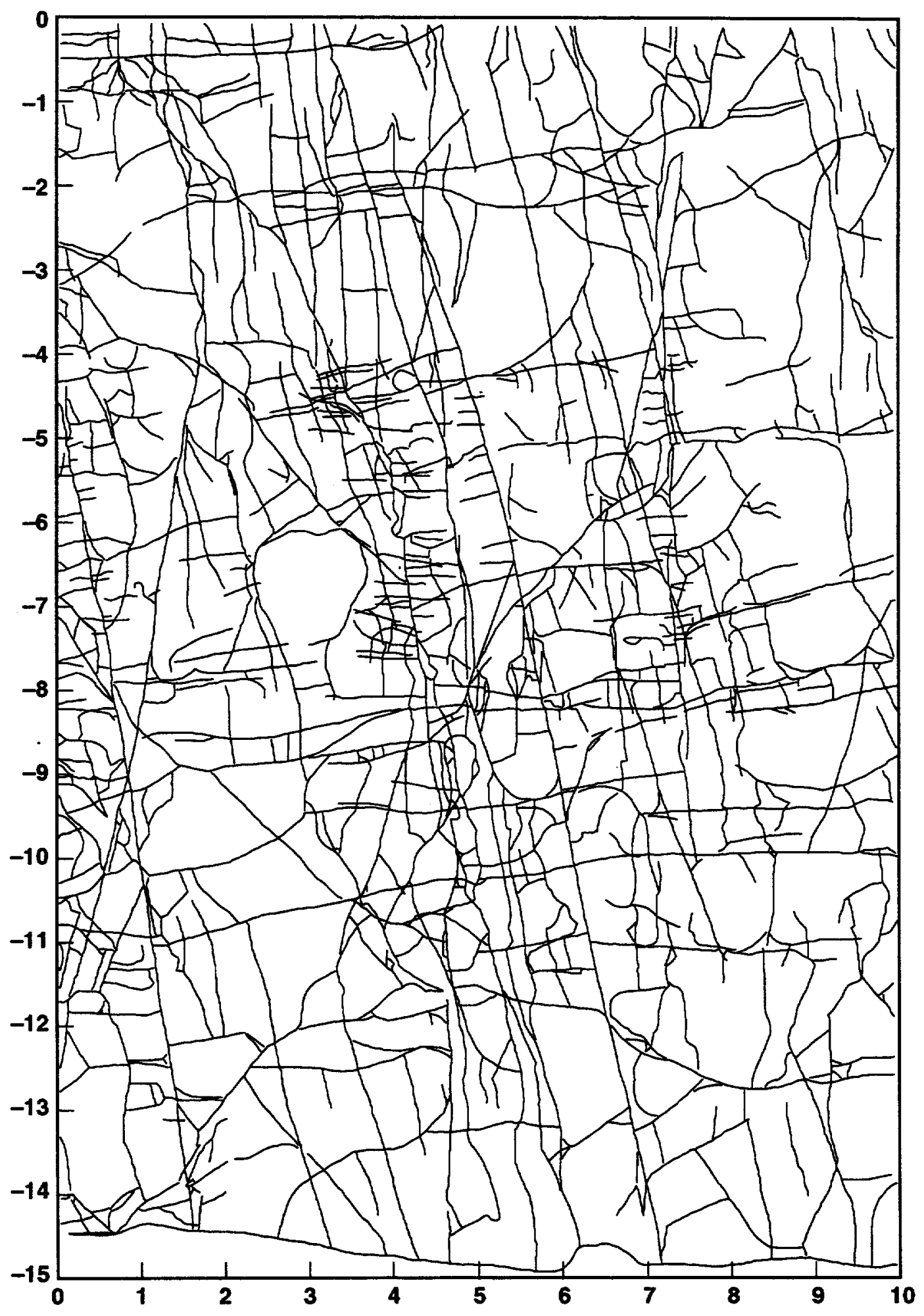

Figure 9-22. Fractures on the north face of the large block. The distance marks are in feet. 


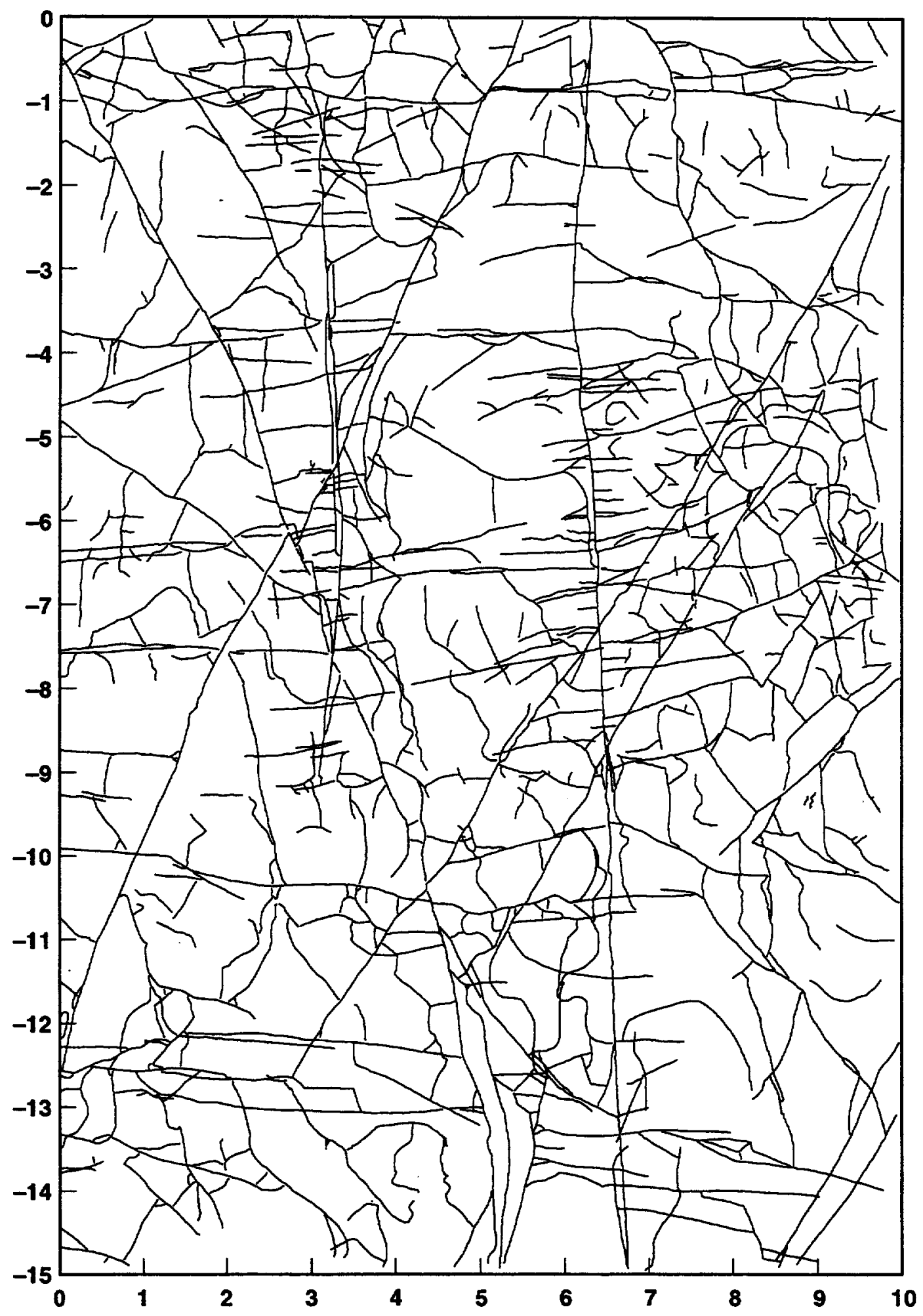

Figure 9-23. Fractures on the west face of the large block. The distance marks are in feet. 



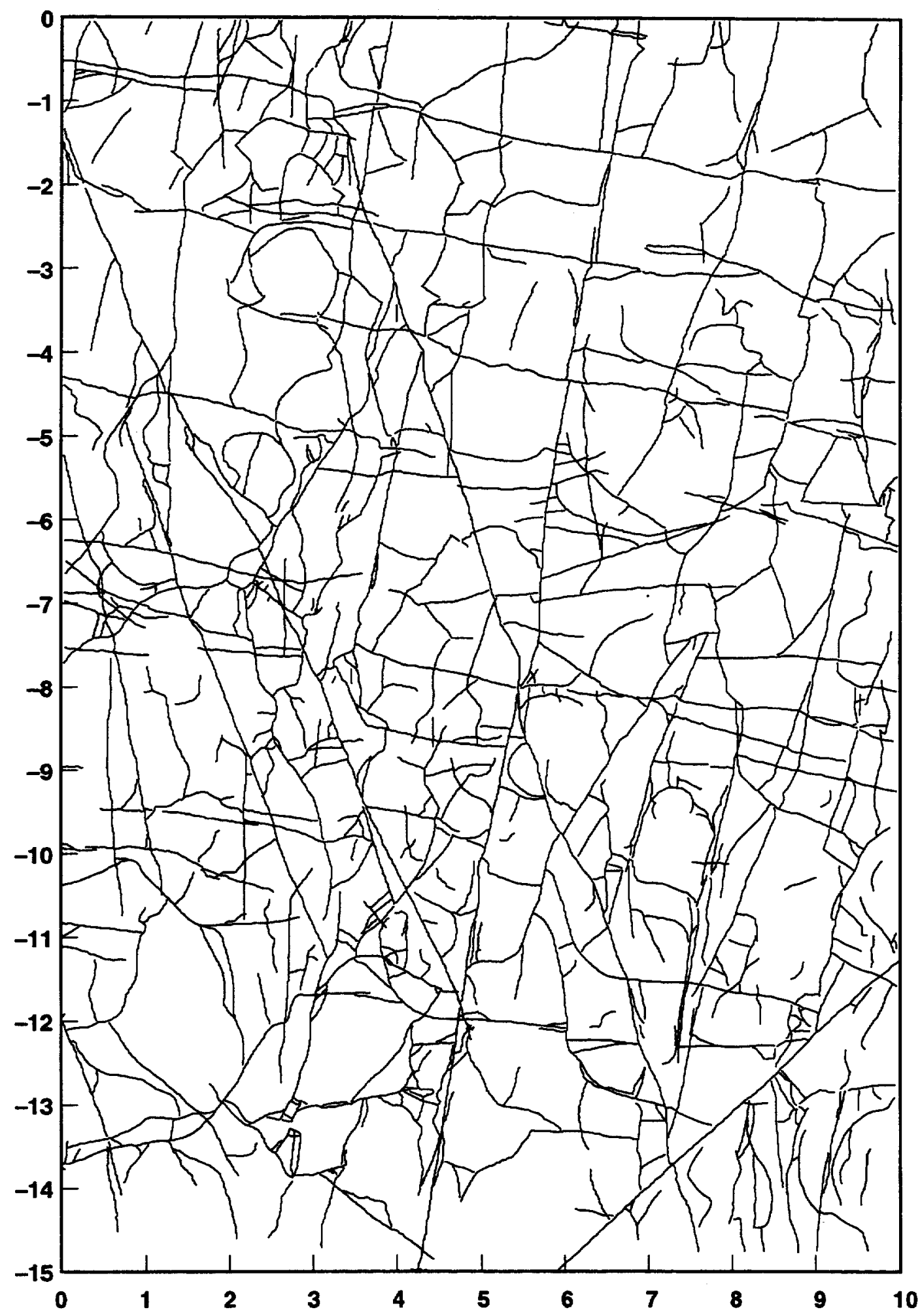

Figure 9-24. Fractures on the south face of the large block. The distance marks are in feet. 


\section{.}




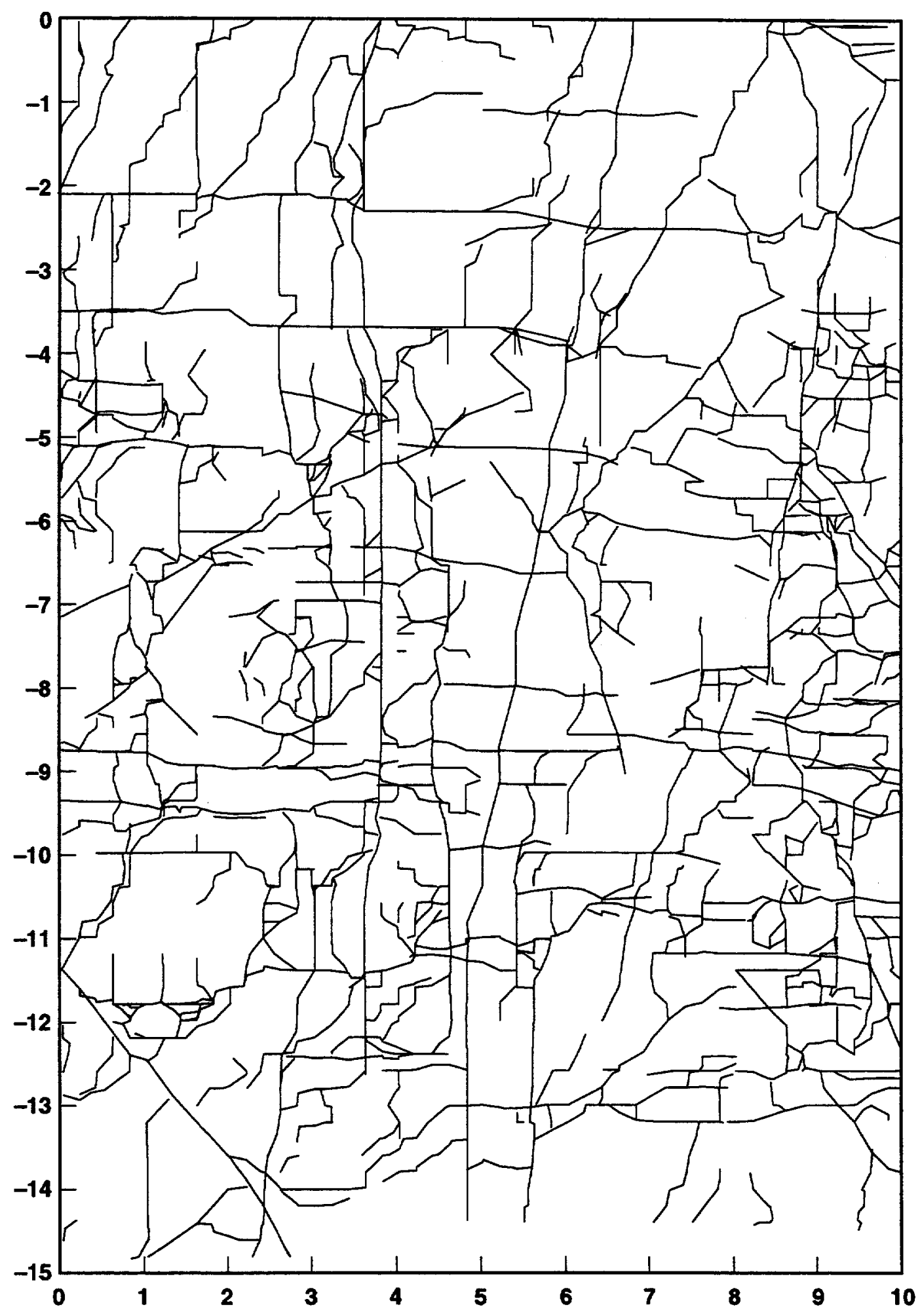

Figure 9-25. Fractures on the east face of the large block. The distance marks are in feet. 


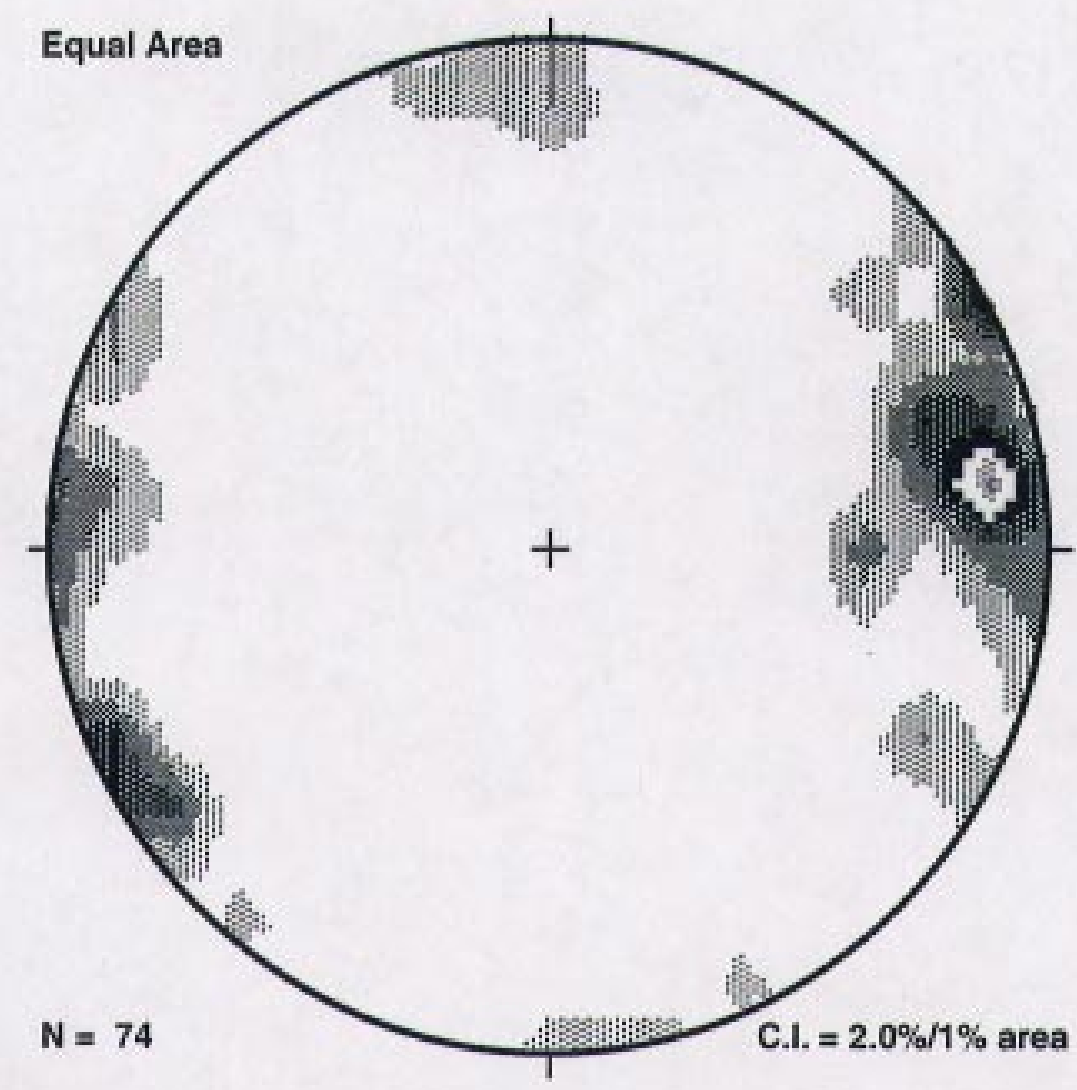

Figure 9-26a. Strike and dip of the fractures on top of the larger block, before the top was cut smooth.

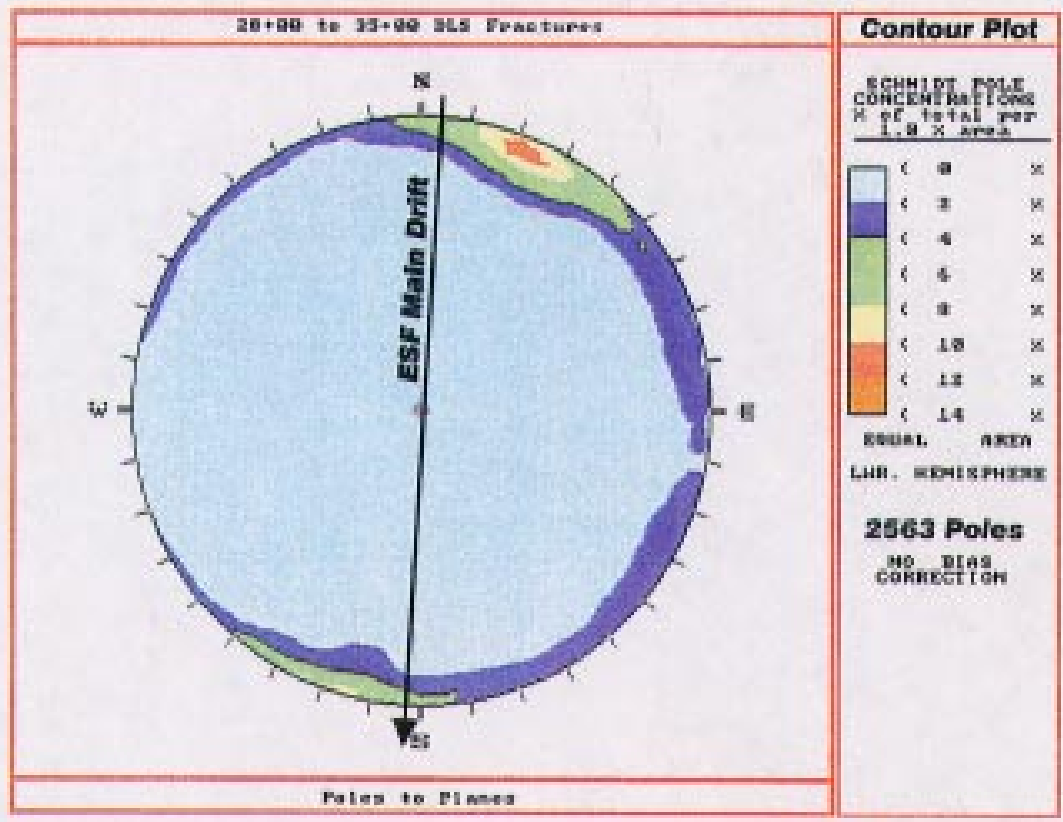

Figure 9-26b. Strike and dip plot of the fractures in the ESF main drift taken from Barr et al 1996. 
7

$-7$

$m$

9

4

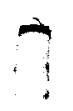

7

7

7

$-4$

7

7

$?$

$?$

7

?

?

7

7

7 


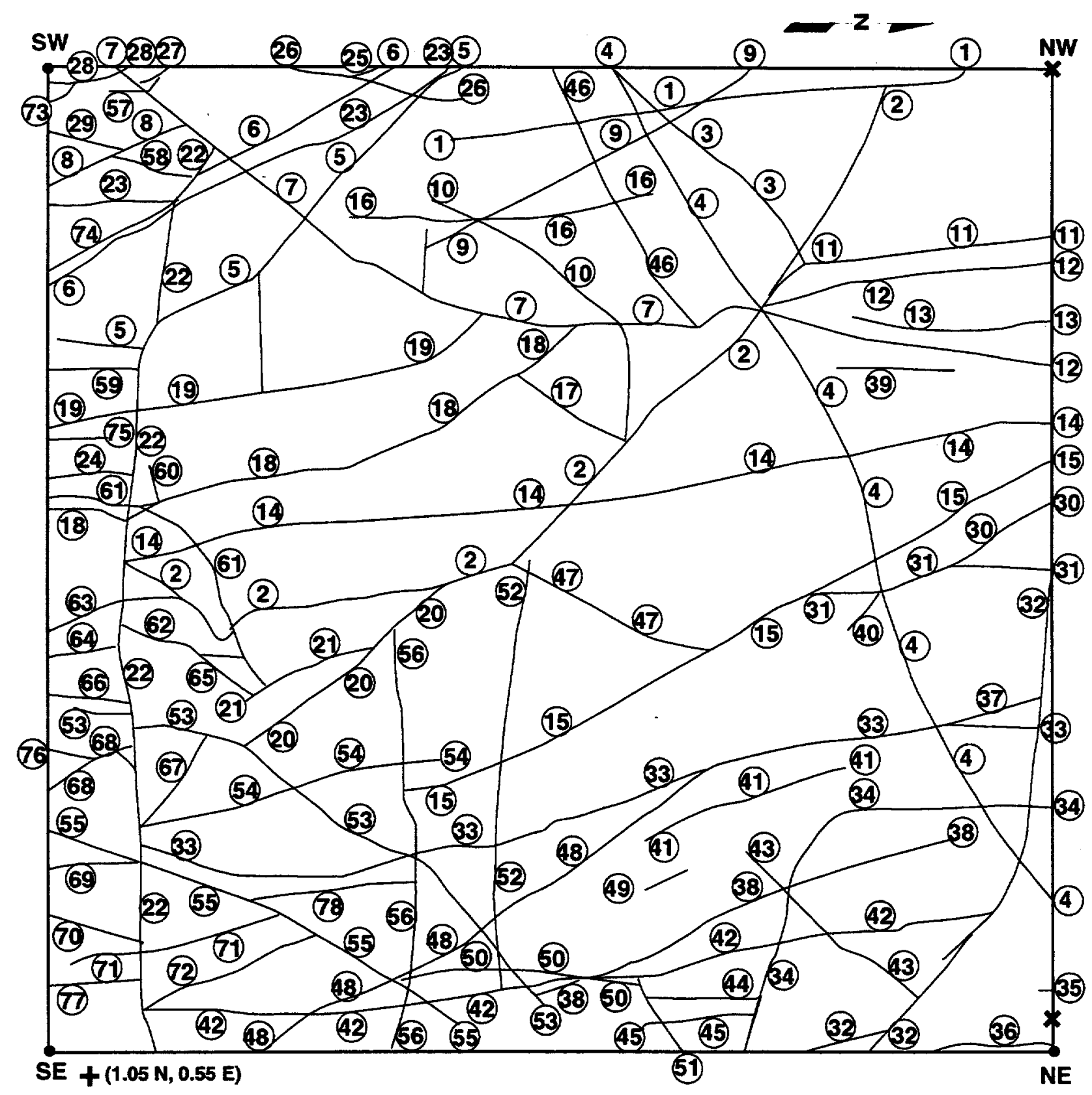

Figure 9-27. Fractures on the top of the large block before the top was cut smooth. 


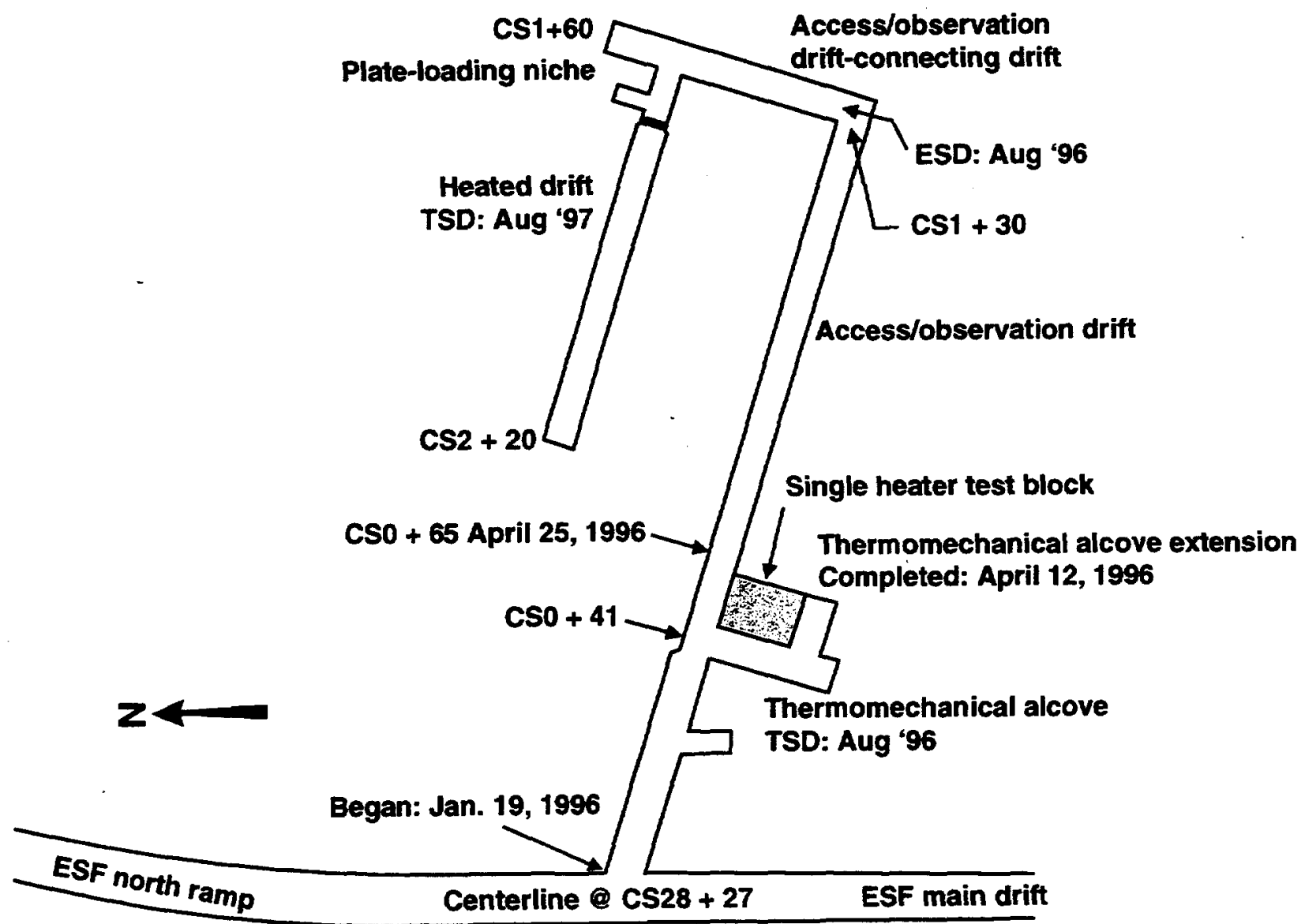

ESD: Expected excavation start date

TSD: Expected testing start date

Figure 9-28. Plan view of ESFTT facility. 
$-$ 

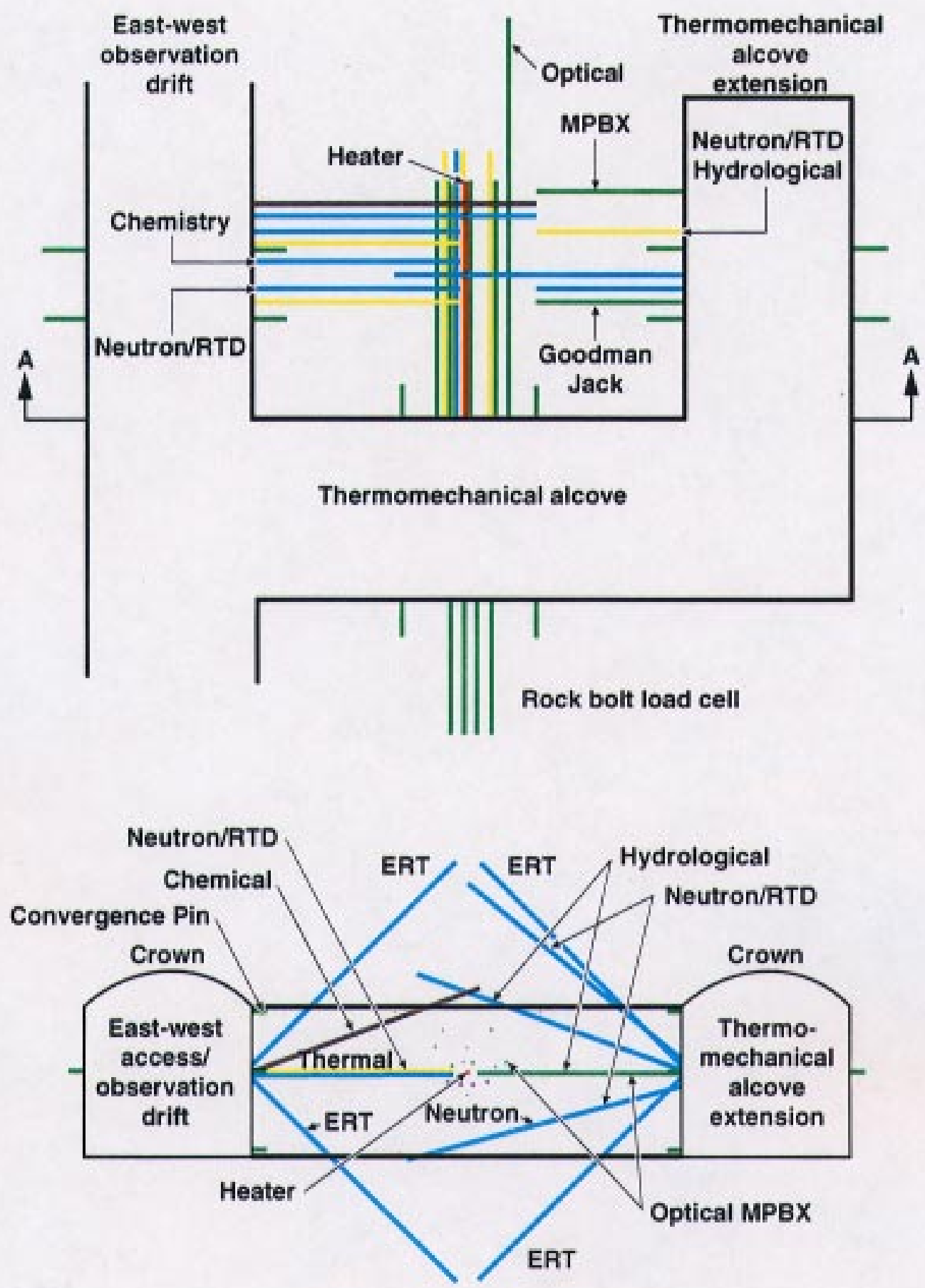

Cross-section A-A

\section{PRELIMINARY}

(Not to scale)

Figure 9-29. Layout of Single Heater Test. 
7

$?$

7

7

7
7

9

$m$

7

7

7

?

7

7

7

7

7

7 


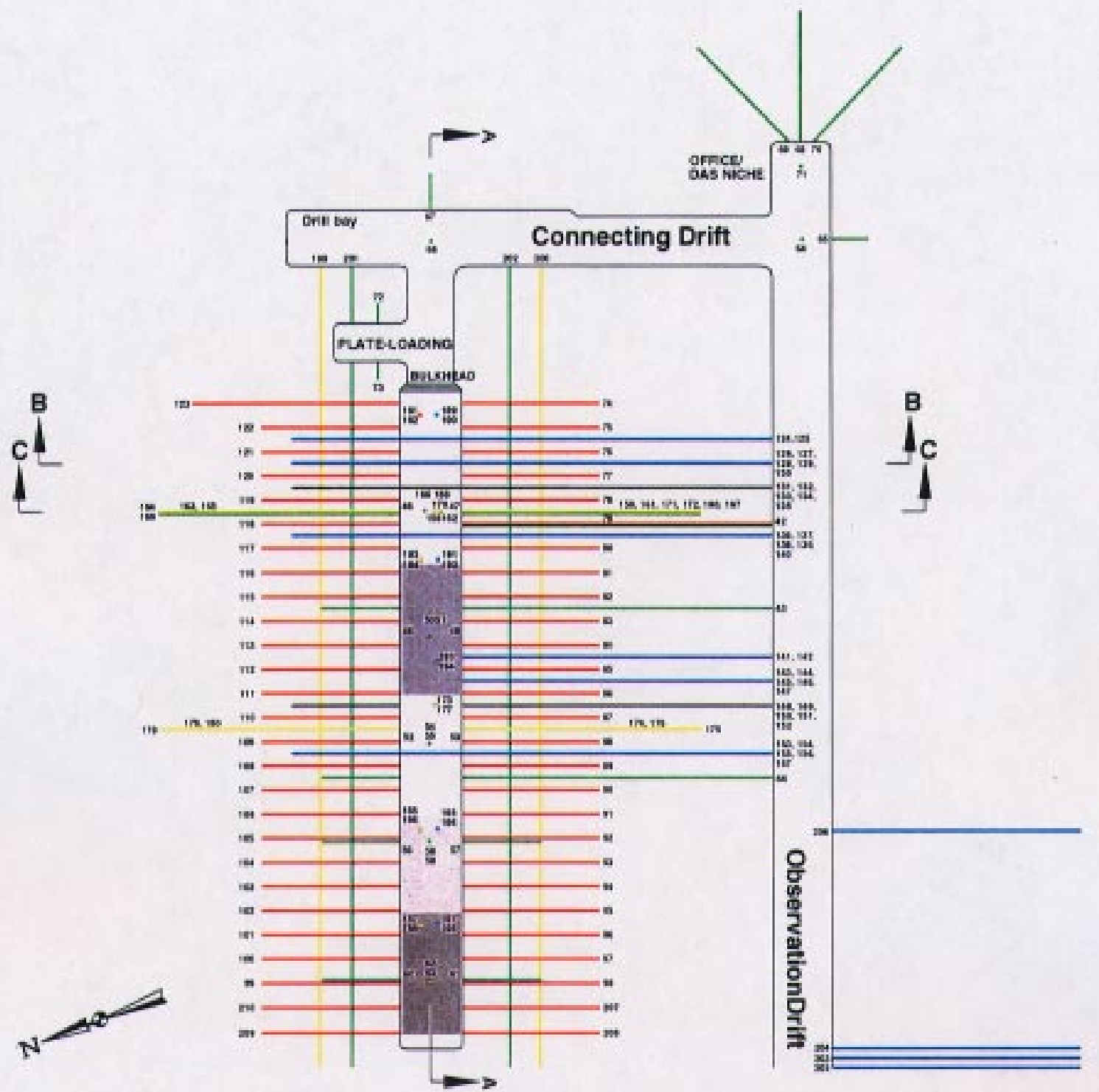

LEGEND: Boreholes

Heated drift
Wing heaters

Thermal

Mechanical

Hydrological

Chemical
LEGEND: Ground Support System

Rockbolts and weided wire

Steel sets and partial lagging

Cast-in-place concrete

Rockbolts and shotcrete

Reference only

(Not to scale)

Figure 9-30a. Layout of Drift Scale Test. 
9

7

7

7

7

7

7

7

7

7

"

7

7

7

7

7

7

7 


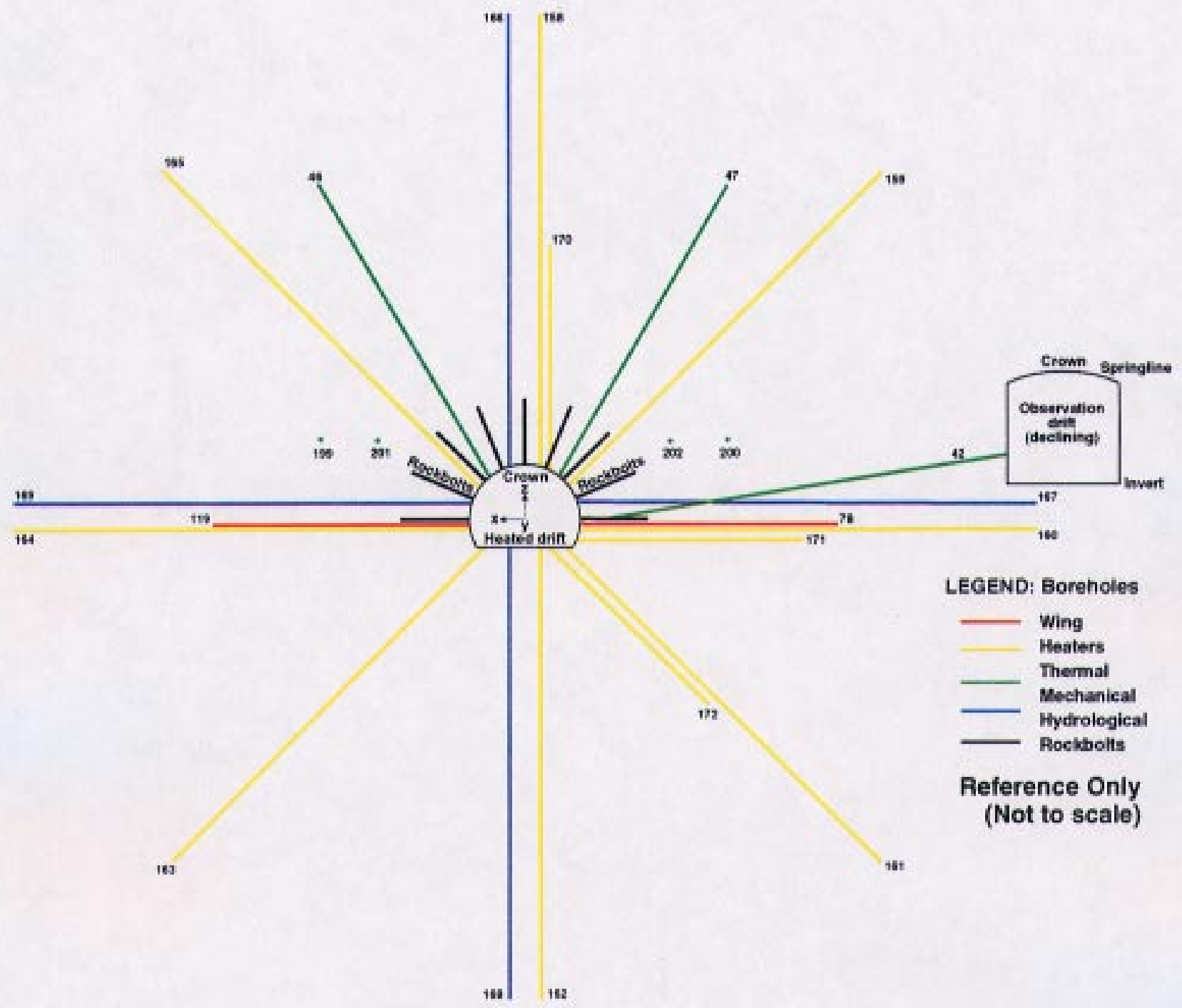

Figure 9-30b. Drift Scale Test (Cross-Section C-C) 
7

7

7

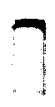

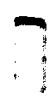

$-$

$?$ 

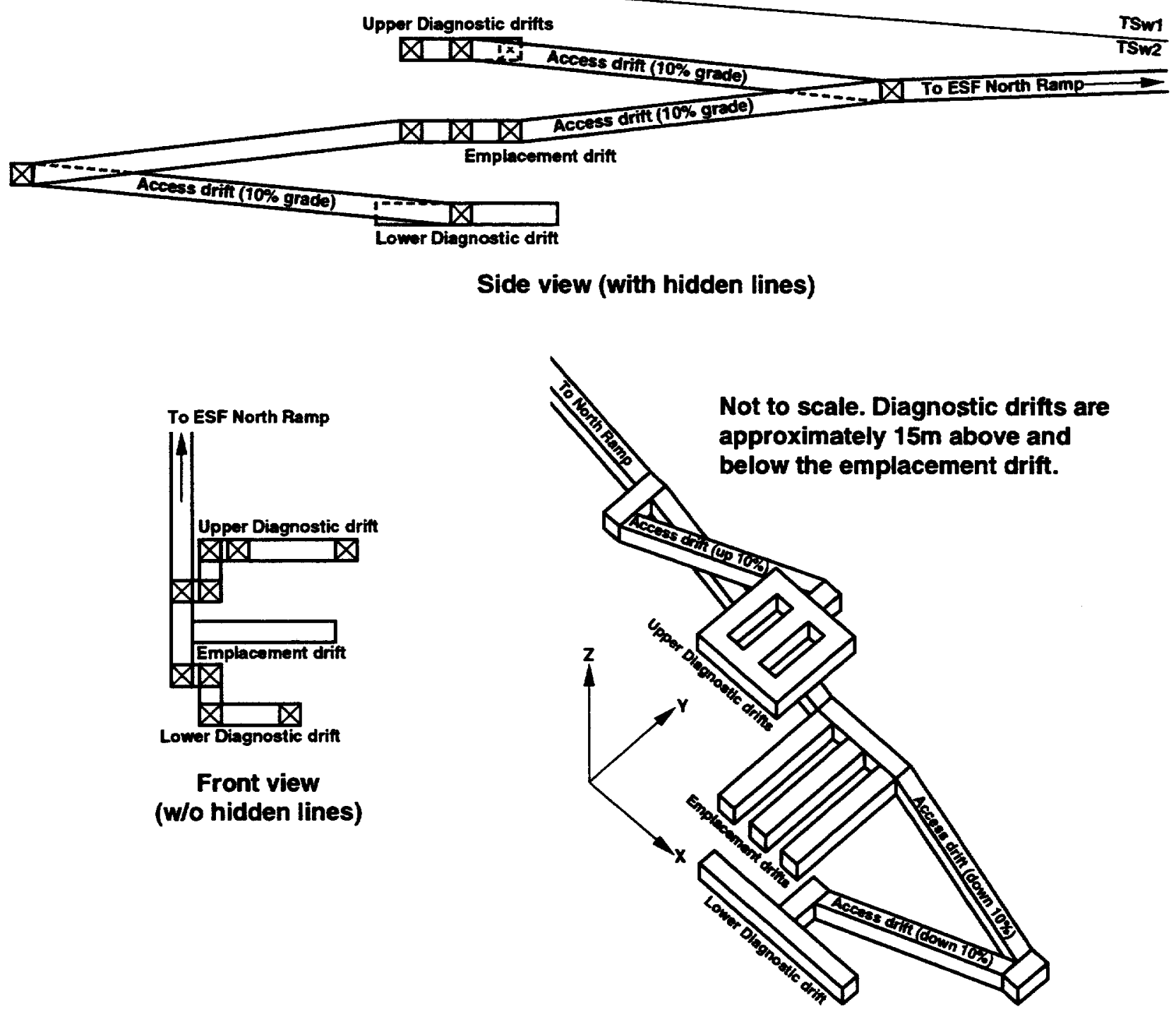

3-D Isometric view

Figure 9-31. A conceptual layout for the Large Scale Long Duration Test. 


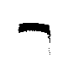

7

7

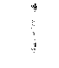




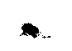




$$
\text { . }
$$




\section{Contents}

10.0 Altered Zone Environment ............................................................................................................ 10.1-2

Introduction.................................................................................................................................................10.1-2

10.1 Mountain-Scale Unsaturated Zone (UZ) Thermal-Hydrology ......................................................... 10.1-3

10.1.1 Models and Assumptions..................................................................................................................10.1-7 


\section{Chapter 10.0 Altered Zone Environment}

\section{Introduction}

The Preliminary Near-Field Environment Report (PNFER) focused attention on the environmental conditions that impact directly on the waste package container materials and on the waste form. That report pointed out that the environmental conditions for the waste packages and waste form would be very much a function of interactions between the environment and the waste, particularly the heat generated by the waste emplacement. As a result of the work that supported the PNFER, it was recognized that those same processes or interactions could potentially cause significant or fundamental property changes that could extend for considerable distances into the rock mass or natural system. However, the processes that dominated the system in the Altered Zone (AZ) were not necessarily the same as the ones that dominated either the Near-Field Environment (NFE) or even the Far-Field Environment (FFE). Therefore, a zone termed the Altered Zone was defined wherein fundamental changes to hydrologic, mineralogical, or chemical conditions may take place within the natural system, but where these conditions do not interact directly with the waste packages (rather interact with the NFE) and where changes are more significant than in the FFE where ambient conditions tend to prevail.

The environmental conditions that impact upon waste packages and radionuclides will be strongly perturbed by the heat of decay from the waste for many hundreds or thousands of years. Because of the strong thermal gradients that will exist for the first $1000 \mathrm{yr}$, the near-field or waste package environment will be dominated by kinetic effects. After the thermal pulse is transferred further into the rock mass, the rapidity of movement of the thermal isotherms slows down and equilibrium conditions begin to have more of an impact. Thus, to some degree the distinction between AZ and NFE is one of which processes dominate.

For any given emplacement scenario, the rate at which temperature changes occur depends, in general, on the distance from the heat source: the further the distance, the slower the heating rate. As just mentioned, this temperature behavior provides the basis for defining or distinguishing the NFE from the AZ. In the near-field region, hydrological processes will be dominated by water vaporization, water movement by means of gas-phase transport, and condensation in those outer regions of the NFE where temperatures are below the boiling point. Geochemical processes will be dominated by evaporation and boiling, mineral dehydration, and solid-vapor interactions. The system will be a very dynamic one in which the dryout regions will increase in size and therefore incorporate what had been zones of condensation. Because of the dynamics, coupling between hydrology and geochemistry may not be well developed (water removed before geochemical reactions changes the system in significant or fundamental ways).

In the altered zone, hydrologic processes will be dominated by an increase in water availability and increased saturation, associated with vapor condensation. There will be general elevation of temperatures several tens of degrees centigrade. The geochemical processes will be dominated by fluid-rock interactions and reactive transport. The altered zone will tend to be less dynamic than the NFE in that the residence times for water will be much longer, the dryout zone will not incorporate the condensation zones until long periods of time, if at all. Within the altered zone, these interactions will result in significant coupling between hydrological and geochemical processes, such that fluid pathways and geochemical conditions will evolve in a synergistic way.

Although the geochemical processes ( e.g., recrystallizations, hydration or dehydration of mineral phases, or both; dissolution and precipitation; rock-water interaction involving water in pores and fractures; cation exchange, sorption, etc.) in both regions are the same, their impact on rock properties will be different, due to contrasts in heating and cooling rates, and in the abundance and temperature of liquid water. These differences will be expressed as differences in the magnitude and nature of chemical 
and mineralogical changes, and the duration of specific processes. As a result, the repository performance will be affected differently in the two regions as a result of water-mineral interactions. For purposes of this report, the Near-Field Environment (NFE) will be considered to be those regions that acheive temperatures well above the boiling point, and the Altered Zone (AZ) will be considered to be those regions that maintain temperatures low enough to allow liquid water to exist in pores and fractures. This distinction has the advantage of focusing attention on the dominant processes that may effect performance in different regions of the repository (e.g., evaporation of water and mineral dehydration in the NFE, and rock-water interaction and the kinetics of dissolution and precipitation in the AZ). Refer to Chapter 3 for results to date of activities investigating processes in the NFE.

\subsection{Mountain-Scale Unsaturated Zone (UZ) Thermal-Hydrology}

The geochemical environment of the near-field, the EBS, and the altered zone will affect any liquid water that may contact the WPs, the waste-form, and any radionuclides released into the near-field and transported in the altered zone. The composition of the liquid phase will depend on the isothermal and nonisothermal flow processes and reaction history experienced by packets of mobile fluid along their respective flow paths. These packets of mobile fluid will not just be affected by coupled thermalhydrological-geomechanical-geochemical (T-H-M-C) processes in the near field and EBS, but will also be influenced as they flow through the altered zone, which can extend more than hundreds of meters away from the repository. Intermediate flow processes, such as condensate refluxing and evaporation, can concentrate different dissolved components. Condensate may dissolve minerals from fracture walls as it drains down fractures and then precipitate those (or other) minerals as it evaporates. These changes may significantly increase or decrease fracture apertures along various intervals, thereby altering the bulk permeability distribution. Solubility and dissolution of minerals depend on temperature changes, among other things. The geochemistry of water from surface infiltration contacting WPs will vary depending on whether it drains quickly down fractures or migrates slowly in the matrix, and on whether it was affected by refluxing or buoyant gas-phase convection. It may also depend on the pathways followed by the water and on the temperature gradient along those pathways.

Changes in $R H$, liquid saturation, temperature, and the liquid-phase flow field can change hydrological properties in the unsaturated zone (UZ) such as fracture and matrix permeability, through precipitation, dissolution, or mineral alteration. Adsorptive properties of various units may be affected by temperature, liquid saturation, and compositional changes. The spatial and temporal extent of decayheat-driven changes in temperature, liquid saturation, and $R H$ in the $U Z$ are described in Section 10.1. The temporal extent of these changes in the near field are also described in Section 1.10.5 of Chapter 1.

The zone of two-phase refluxing overlying the boiling zone (called the heat-pipe zone) is of particular interest because the liquid saturation and relative humidity $R H$ remain high in this zone, increasing the likelihood of aqueous reactions and aqueous-transport processes occurring. Refluxing can also generate a very high liquid-phase flux in fractures, which can result in significant dissolution and precipitation of minerals along the fracture walls. The heat-pipe zone is typically manifested by temperatures that are very close to the nominal boiling point of water $\left(96^{\circ} \mathrm{C}\right)$ and a liquid saturation that is very close to $100 \%$. Vertical temperature and liquid saturation profiles are given in Section 1.10.1 to indicate where heat-pipes and related coupled T-H-M-C processes may be occurring.

Changes in temperature and the mixing of groundwater (driven by decay-heat-driven, buoyant, liquid-phase convection) could alter hydrological and adsorptive properties in the saturated zone and could thereby affect radionuclide transport in the saturated zone (SZ) [Buscheck and Nitao, 1993b]. The spatial and temporal extent of decay-heat-driven changes in temperature and in the liquid-phase flow field in the SZ are described in Section 10.2.

Fluid flow in the UZ at Yucca Mountain involves liquid- and gas-phase flow through the fractures and through the rock matrix. Under ambient conditions, the gas phase contains about $98.5 \%$ air and $1.5 \%$ water vapor. An important feature of the UZ at Yucca Mountain is its high fracture density. Moreover, 
the Topopah Spring tuff (TSw2), which occurs at the potential repository depth, is one of the most densely fractured hydrostratigraphic units. This is significant because, without fractures, the rock throughout most of the UZ (including the repository horizon) would be extremely impermeable. In general, repository heat moves moisture by (1) vaporization, (2) driving water vapor from high to low gas-phase pressure, (3) condensation, and (4) gravity- or capillary-driven flow of condensate. Without fractures, the rock would be too impermeable to allow significant vaporization and movement of water vapor. The flow of condensate would also be very slow. A system of connected fractures facilitates significant decay-heat-driven fluid flow as well as natural infiltration. Enhanced gas-phase diffusion of water vapor may significantly contribute to vaporization in unfractured (relatively impermeable) rock.

Modeling and analytical studies of high-level radioactive waste isolation have demonstrated the potential importance of nonequilibrium flow processes between the fractures and the matrix [Buscheck et al., 1991; Nitao et al., 1993]. Except for regions with a perched water table or during transient recharge episodes, capillary forces cause most fractures to be drained of liquid water. Matrix permeability is extremely low for most of the hydrostratigraphic units in the UZ (including the TCW, TSw1, TSw2, TSw3, and CHnv units), so mountain-scale, liquid-phase flow and (where applicable) radionuclide transport will primarily occur in fractures rather than in the matrix. In units with intermediate matrix permeability (including the PTn and $\mathrm{CHnv}$ ), matrix flow may also contribute to mountain-scale liquid-phase flow and transport. Liquid-phase flow in fractures may arise from three origins:

1. Ambient infiltration and percolation of rainfall and snowmelt.

2. Condensate generated under boiling conditions.

3. Condensate generated under sub-boiling conditions.

The first source arises from the ambient system; the second and third are generated by radioactive decay heat, primarily from SNF. Decay-heat-driven, buoyant vapor flow, occurring either on a sub-repository scale or on a mountain scale (Figs. 10.1.1a and b), may play an important role in generating the second and third sources of liquid water. Decay-heat-driven binary diffusion of water vapor and air (called vapor diffusion) may also play important roles in condensate generation [Buscheck and Nitao, 1994a]. A heterogeneous distribution of bulk permeability $k_{\mathrm{b}}$ can influence vapor and condensate flow under both boiling and sub-boiling conditions. Of particular concern are $k_{\mathrm{b}}$ distributions that promote the focusing of condensate flow, which could cause water to drip onto WPs [Fig. 10.1.1c] even if average behavior would indicate otherwise [Buscheck and Nitao, 1994a].

Decay heat also drives buoyant, liquid-phase convection in the SZ (Fig. 10.1.1b). Analyses of this type of flow indicate that it is likely to be the dominant means of driving radionuclide transport in the saturated zone (SZ) for tens of thousands of years [Buscheck and Nitao, 1993b; Buscheck and Nitao, 1994a]. A $k_{\mathrm{b}}$ distribution that facilitates deep convective mixing of radionuclides in the $\mathrm{SZ}$ would be more likely to meet a dose-based standard than a stagnant water table.

Table 10.1.1 summarizes the time and length scales involved in how repository heat influences the three major sources of fracture flow. Mountain-scale effects depend on the overall heating conditions for the entire repository. Several studies [Buscheck and Nitao, 1992; Buscheck and Nitao, 1993b; Buscheck and Nitao, 1994a] have shown that the most useful macroscopic thermal loading parameter quantifying the time-integrated heat content of the waste in the repository is the areal mass loading (AML, expressed in metric tons of uranium per acre, MTU/acre). Mountain-scale effects depend primarily on the AML of the entire repository, and they are insensitive to the details of WP emplacement, such as WP size and spacing, and spent nuclear fuel (SNF) age. These effects also depend on the distribution of thermal and hydrological properties throughout the UZ.

Sub-repository-scale (also called drift-scale) effects depend on the local heating conditions around WPs. Important factors include (1) the number of spent nuclear fuel assemblies per WP, (2) the axial spacing between WPs, (3) the lateral spacing between emplacement drifts, and (4) SNF age. In general, the number of fuel assemblies per WP is directly related to the WP size. Large WPs that contain a large number of assemblies, generally have a higher thermal output. Younger fuel has a higher thermal output than older fuel for some period of time. The local areal mass loading (LAML) depends on the WP size and spacing. For a given LAML, drift-scale effects are very different, depending on whether widely 
spaced, large WPs or tightly spaced, small WPs are used. These effects also depend on the near-field distribution of thermal and hydrological properties within a few tens of meters of the WPs.

Figure 10.1.2 show the effect of decay heat on the flow of water vapor and condensate in the vicinity of an emplacement drift. Heat flow away from the WPs occurs as heat conduction, the convection of latent and sensible heat, and thermal radiation. Because of the large bulk permeability of fracture networks, gas-phase pressures in the fractures remain very close to atmospheric, even during boiling. Consequently, as temperatures reach the nominal boiling point $\left(\approx 96^{\circ} \mathrm{C}\right)$, boiling first occurs along fractures (Fig. 10.1.2) and proceeds into the matrix blocks. Accordingly, dry-out due to boiling is more suppressed in sparsely fractured regions (with large matrix blocks) and less suppressed in intensely fractured regions (with small matrix blocks). As boiling continues, water vapor displaces air away from the WPs and may replace it completely for sufficiently high AMLs.

Most of the water vapor reaching the fracture network is eventually driven away from the emplacement drift by higher gas-phase pressures in the boiling zone to where cooler temperatures cause it to condense along fracture walls (Fig. 10.1.2). Buoyant, gas-phase convection can cause more of the vapor flow to be driven upward to where it condenses above the dry-out zone. In general, regardless of where the condensate is generated, there are three things that can happen to it:

(1) It can drain away from the boiling zone.

(2) It can drain back toward the boiling zone.

(3) It can be imbibed by the matrix.

Because the small matrix permeability limits the rate at which the matrix can imbibe the condensate by capillary suction, it can drain for considerable distances down fractures before being completely imbibed. Below the boiling zone, condensate drainage is away from the boiling zone (Fig. 10.1.2), enhancing the dry-out rate. Above the boiling zone, condensate tends to drain back toward the boiling zone, where it reboils, thereby retarding the net rate of dry-out.

The return flow of condensate back toward the heat source causes refluxing, which is the countercurrent flow of water vapor and condensate. It is important to note that refluxing does not require boiling conditions [Buscheck and Nitao, 1994a]. Heat-driven, buoyant gas-phase flow can drive refluxing under sub-boiling conditions. Under boiling conditions, refluxing results in a heat transfer mechanism (driven by the convection of latent heat) called the heat-pipe effect. Given adequately high mass flux rates of water vapor and condensate, heat pipes are capable of sustaining a given heat flux with a much flatter temperature gradient than is associated with heat conduction. Consequently, heat pipes are manifested by a flat temperature profile, with temperatures close to the nominal boiling point. Pruess and others [1984, 1990] were the first to model the heat-pipe effect in the context of thermal-hydrological performance at Yucca Mountain. Depending on the AML, these effects can occur at the sub-repository scale or on a mountain scale (Table 10.1.1).

Figure 10.1.3 shows the various decay-heat-driven processes and ambient site conditions that may significantly affect the moisture balance in the UZ. The moisture balance in the $U Z$ (and, in particular, in the region above the repository) may play a very important role in the performance of the EBS, the natural barriers, and the total system. In general, decay heat will result in regions of dryout and condensate buildup in the UZ. Modeling studies [Buscheck and Nitao, 1993a; Buscheck and Nitao, 1993b; Buscheck and Nitao, 1994a; Buscheck et al., 1994] have indicated that decay-heat-driven changes in the saturation distribution can persist for more than 100,000 yr, even for low AMLs that never drive temperatures close to the boiling point. These effects, along with temperature changes, can alter the hydrological, geochemical, and geomechanical properties that influence fluid flow and radionuclide transport. Decay heat might drive enough water vapor out of the top of the mountain to significantly reduce the $U Z$ moisture content for tens of thousands of years. Conversely, mountain-scale, buoyant gasphase convection might drive enough water vapor up from the $S Z$ (into the $U Z$ ) to increase the UZ moisture content for tens of thousands of years [Buscheck and Nitao, 1994a; Buscheck et al., 1994].

The important site-scale features that may significantly affect decay-heat-driven, mountain-scale, thermal-hydrological flow include: 
Paintbrush vitic nonwelded tuff (PTn): This unit probably plays an important role in (1) attenuating (in space and time) episodic nonequilibruim fracture flow and (2) reducing the ambient percolation flux in the host rock (the TSw2 unit). Imbibition in the PTn serves to dampen the influence of episodic infiltration and thereby provide more time for exfiltration and lateral flow to influence the moisture balance in the PTn; all of which tend to reduce the percolation flux in the TSw2. Because it has a much lower $k_{b}$ than the densely welded tuff units that lie above it (the TCw unit) and below it (the TSw1 unit), the PTn significantly influences mountain-scale gasphase flow under both ambient and decay-heat-disturbed conditions. Analyses of mountain-scale buoyant gas-phase convection [Buscheck and Nitao, 1994a; see also Chapter 10.0 of this report] indicate that it will probably significantly limit (or cap) the upper spatial extent of large-scale gasphase convection cells in the UZ. This could significantly affect the magnitude of moisture redistribution in the $U Z$ by this mechanism.

Basal vitrophyre of the Topopah Spring tuff (TSw3): This unit (sometimes colloquially called the "tin basement") appears to be associated with regions of perched water, which may be the result of restricted fracture flow arising from clay fillings. If fracture and bulk permeabilty $k_{\mathrm{b}}$ are signicantly reduced in the TSw3, this would have a significant effect on condensate drainage and on mountain-scale buoyant gas-phase convection. A reduced $k_{\mathrm{b}}$ could significantly limit the lower spatial extent of large-scale gas-phase convection cells in the UZ. This could significantly affect the magnitude of moisture redistribution in the $\mathrm{UZ}$ by this mechanism.

Calico Hills nonwelded tuff ( $\mathrm{CHn}$ ): Both the zeolitic ( $\mathrm{CHnz}$ ) and vitric ( $\mathrm{CHnv}$ ) portions of this unit probably have a significantly lower $k_{\mathrm{b}}$ than the overlying TSw sequence. If $k_{\mathrm{b}}$ is not reduced in the TSw $3, k_{b}$ values in the $\mathrm{CHnv}$ and $\mathrm{CHnz}$ are probably small enough to significantly limit the lower spatial extent of large-scale gas-phase convection cells in the UZ. This could significantly affect the magnitude of moisture redistribution in the UZ by this mechanism. 


\subsubsection{Models and Assumptions}

10.1.1.1 V-TOUGH and NUFT Thermal-Hydrological Flow Codes. All thermal-hydrological calculations were carried out using the V-TOUGH (Vectorized Transport gf Unsaturated Groundwater and Heat) code [Nitao, 1989] and NUFT (Nonisothermal Unsaturated-Saturated Flow and Transport) code [Nitao, 1993]. V-TOUGH is Lawrence Livermore National Laboratory's enhanced version of the TOUGH code, which is a member of the Mulkom family of multiphase, multicomponent codes developed at Lawrence Berkeley Laboratory [Pruess, 1987]. Both V-TOUGH and NUFT are multidimensional numerical simulators capable of modeling the coupled transport of water, vapor, air, and heat in fractured porous media. In addition to coupled multiphase heat and fluid flow, NUFT can handle multicomponent aqueous- and nonaqueous-phase species transport. NUFT is a highly efficient and robust integrated finite difference code that describes the flow of multiple phases and transport of multiple components in porous media under isothermal or nonisothermal conditions [Nitao, 1993]. NUFT solves the (nonlinear) partial differential equations for the balance of component mass and energy. NUFT has an extensive suite of linear equation solvers that allows efficient solution of practical threedimensional problems that have tens of thousands of elements, large contrasts in element size, and sharp nonlinearities in the governing equations. For this work NUFT was configured to solve the flow and transport of air, water, and energy. V-TOUGH has been qualified for use in qualitiy affecting work. NUFT has been benchmarked against the V-TOUGH code for a wide range of problems related to decayheat-altered nonisothermal flow and transport at Yucca Mountain; for all of the cases compared, NUFT and V-TOUGH predicted essentially identical results.

For both V-TOUGH and NUFT, the flow of fluid phases is governed by the multiphase version of Darcy's law, the diffusion of air and water vapor by Fick's law, and thermal conduction by Fourier's law. Air, water vapor, and heat are transported by fluid advection in two phases, aqueous and gaseous. Local thermodynamic equilibrium is assumed between solid and fluid phases. Water property values are calculated from steam tables. The code calculates the vaporization and condensation of water, and the resulting absorption or release of latent heat, based on local thermodynamic equilibrium.

10.1.1.2 Equivalent Continuum Model. Because of the impracticality of discretely accounting for all of the fractures at Yucca Mountain, it is often found to be necessary to account for fractures using the equivalent continuum model (ECM). The assumption of capillary-pressure and thermal equilibrium between fractures and matrix allows the fracture and matrix properties to be pore-volume-averaged into an equivalent medium. One of the objectives of lab-scale and field-scale thermal tests is to determine the validity of assumptions and approximations used in our models, including the ECM approximation. For purposes for which the existing ECM-based analyses have been used, the ECM approximation has been considered adequate. The bulk porosity $\phi_{b}$, bulk saturation $S_{b}$, and bulk hydraulic conductivity $K_{b}$ of the equivalent medium are given by the relations

$$
\begin{aligned}
& \phi_{\mathrm{b}}=\phi_{\mathrm{f}}+\left(1-\phi_{\mathrm{f}}\right) \phi_{\mathrm{m}}, \\
& S_{\mathrm{b}}=\frac{S_{\mathrm{f}} \phi_{\mathrm{f}}+S_{\mathrm{m}}\left(1-\phi_{\mathrm{f}}\right) \phi_{\mathrm{m}}}{\phi_{\mathrm{f}}+\left(1-\phi_{\mathrm{f}}\right) \phi_{\mathrm{m}}}, \\
& K_{\mathrm{b}}=K_{\mathrm{f}} \phi_{\mathrm{f}}+K_{\mathrm{m}}\left(1-\phi_{\mathrm{f}}\right),
\end{aligned}
$$


where the subscripts $m$ and $f$ refer to the matrix and fractures, respectively. Because of the low $K_{m}$ in the $\mathrm{UZ}$, the value of $K_{\mathrm{b}}$ is almost completely determined by $K_{\mathrm{f}}$ and $\phi_{\mathrm{f}}$ for most fracture spacings and permeabilities.

10.1.1.3 Thermal-Hydrological Properties. All major hydrostratigraphic units in the UZ at Yucca Mountain are included in the models. The hydrostratigraphic profile employed here has been used in several modeling studies [Buscheck et al., 1993; Buscheck and Nitao, 1992, 1993a, 1993b, 1993c, 1994a, 1994b; Buscheck et al., 1994]. The wet and dry thermal conductivity, $K_{\text {th }}$, data were obtained from the Reference Information Base [DOE, 1990]. We assume the steady-state liquid saturation profile obtained for a net infiltration flux (also called percolation flux) of $0 \mathrm{~mm} / \mathrm{yr}$, yielding a repository horizon saturation of 68\% [Buscheck et al., 1991]. Other studies [Buscheck and Nitao, 1992; Buscheck and Nitao, 1993a; Buscheck and Nitao, 1993c] also considered the steady-state saturation profile obtained for percolation fluxes of 0.045 and $0.132 \mathrm{~mm} / \mathrm{yr}$, resulting in repository saturations of 85 and $95 \%$, respectively. For the reference case, we used the matrix hydrological properties given in the Reference Information Base [1990] and Klavetter and Peters [1986]. We also considered the impact of more recent matrix hydrological property data reported by Pruess and Tsang [1994], which are based on measurements by Flint and others [1983].

The reference case assumed a bulk permeability, $k_{\mathrm{b}}$, of $2.8 \times 10^{-13} \mathrm{~m}^{2}(280$ millidarcy), which is equivalent to three $100-\mu \mathrm{m}$ fractures per meter. The sensitivity of buoyant, gas-phase convection, boiling and dryout behavior to $k_{\mathrm{b}}$ was examined by considering the following values of $k_{\mathrm{b}}: 1.9$ microdarcy (no fractures), 10 microdarcy (three 3 - $\mu \mathrm{m}$ fractures per meter), 100 microdarcy (three $7-\mu \mathrm{m}$ fractures per meter), 1 millidarcy (three 15- $\mu \mathrm{m}$ fractures per meter), 10 millidarcy (three $33-\mu \mathrm{m}$ fractures per meter), 1 darcy (three 153- $\mu \mathrm{m}$ fractures per meter), 5 darcy (three $262-\mu \mathrm{m}$ fractures per meter), 10 darcy (three 330$\mu \mathrm{m}$ fractures per meter), 20 darcy (three $416-\mu \mathrm{m}$ fractures per meter), 40 darcy (one 781- $\mu \mathrm{m}$ fracture per meter), 84 darcy (one $1000-\mu \mathrm{m}$ fracture per meter), 168 darcy (one $1260-\mu \mathrm{m}$ fracture per meter), 414 darcy (one $1700-\mu \mathrm{m}$ fracture per meter), and 840 darcy (one $2150-\mu \mathrm{m}$ fracture per meter).

10.1.1.4 Initial and Boundary Conditions. The vertical temperature distribution, $T$, in the models is initialized to correspond to the nominal geothermal gradient in the region. For the reference case, the repository is assumed to be at a depth of $343.1 \mathrm{~m}$. The initial temperature and saturation at the repository horizon in the $\mathrm{UZ}$ model are $23.3^{\circ} \mathrm{C}$ and $68 \%$, respectively. The atmosphere at the ground surface is represented by a constant-property boundary, with $T$ and gas-phase pressure fixed at $13^{\circ} \mathrm{C}$ and $0.86 \mathrm{~atm}$, respectively. The relative humidity $R H$ at the ground surface is also fixed at a value that represents thermodynamic equilibrium with respect to the initial saturation conditions at the top of the TCw unit. Therefore, under initial (ambient) saturation and temperature conditions, there is no mass flux of water vapor between the atmosphere and upper TCw. In some previous work [e.g., Buscheck and Nitao, 1992], it was assumed that because of the large fracture permeability, buoyant convective mixing in the saturated zone (SZ) results in it acting as a heat sink. The large $k_{\mathrm{b}}$ and storativity of the SZ were also assumed to result in the water table being at a fixed depth $(z=568.1 \mathrm{~m})$. For the drift-scale calculations reported here, we also assume that the water table has a fixed depth $(z=568.1 \mathrm{~m})$ and a constant temperature $\left(31^{\circ} \mathrm{C}\right)$; this causes the water table to act as a heat sink. Because this model does not explicitly model hydrothermal flow in the SZ, it is called the "UZ" model. In comparing the UZ model with the UZ$\mathrm{SZ}$ model, which is described below, we found that, for the first $1000 \mathrm{yr}$, repository temperatures are insensitive to the treatment of heat flow at the water table [Buscheck and Nitao, 1993; Buscheck and Nitao, 1993cl.

We conduct most of our calculations with a UZ-SZ model (which includes hydrothermal flow in the upper $1000 \mathrm{~m}$ of the SZ). The vertical domain of our models is a key aspect to consider when conducting mountain-scale calculations. Calculations that use a fixed-depth constant-temperature boundary at the water table substantially underpredict mountain-scale temperature rise as well as the overall magnitude of decay-heat-altered T-H effects in the UZ (see Section 10.2.1). Therefore, to adequately model the temporal and spatial extent of decay-heat-altered T- $\mathrm{H}$ behavior, it is essential that the lower boundary of a mountain-scale T-H model does not function as a heat sink. Moreover, it is not possible to analyze the effects of decay heat on SZ flow and transport unless the model domain include the SZ. Conductive and convective heat flow, including buoyancy flow, are modeled in the SZ. Because the RIB [DOE, 1990] lacks 
thermal property and hydrological data below the PPw unit (the lowermost hydrostratigraphic unit in our UZ model), we assumed that the PPw data were applicable to the upper $1000 \mathrm{~m}$ of the SZ (down to the lower boundary of the UZ-SZ model). The lower boundary of the UZ-SZ model has a constant temperature of $53.5^{\circ} \mathrm{C}$ and a fixed pressure corresponding to the hydrostatic pressure and temperature profile of the upper $1000 \mathrm{~m}$ of the $\mathrm{SZ}$.

For the reference-overburden case, the repository is assumed to be at a depth of $343.1 \mathrm{~m}$. In Section 10.1.4, we also consider a "minimum-overburden" case (with an overburden thickness of $200 \mathrm{~m}$ ) and a "maximum-overburden" case (with an overburden thickness of $420 \mathrm{~m}$ ). For the reference-overburden case, the initial temperature and saturation at the repository horizon in the $\mathrm{UZ}-\mathrm{SZ}$ model are $23.5^{\circ} \mathrm{C}$ and $68 \%$, respectively.

For most of the calculations in Sections 10.1 and 10.2, we assume a Youngest Fuel First Spent Nuclear Fuel (SNF) receipt scenario with a 10-yr cut-off for the youngest fuel, referred to as YFF(10), and account for the emplacement of BWR waste packages (WPs), containing 40 assemblies per WP, and PWR WPs, containing 21 assemblies per WP. The waste receipt schedule was supplied by John King [1993] of the WAST organization. areal mass loadings (AMLs) of 24.2, 35.9, 55.3, 70, 83.4, 100, 110.5, and 150.0 MTU/acre were considered in our calculations.

10.1.1.5 Mountain-Scale and Sub-Repository-Scale Models. For an AML of 49.2 MTU/acre, we assumed that the heated area of the repository is 1747 acres. Note that this AML was once the reference thermal load in the Site Characterization Plan-Conceptual Design Report [SNL, 1987], which is called the SCP-CDR. For 10-yr-old SNF, this AML results in an aeal power density (APD) of $57 \mathrm{~kW} /$ acre. For a $1747-$ acre repository, the mountain-scale model represents the repository as a 3-km-diameter, 4.6-m-thick, disk-shaped heat source with a uniformly distributed thermal load. Repository areas of 559,1118 , and 3162 acres were also modeled for AMLs of 154.7,77.3, and 27.1 MTU/acre, respectively. The model, which is similar to models used by Pruess and Tsang [1993], utilizes an axisymmetric coordinate system centered at the repository center. This model is useful for calculating temperature and saturation behavior (averaged from one emplacement drift to the next) as a function of location relative to the center (or edge) of the repository area. The assumption was also made that the thermal loading of the repository can be represented by the heat generation curve of pressurized water reactor (PWR) SNF of an average age. Calculations were made for APDs ranging from 10 to $114 \mathrm{~kW} /$ acre and SNF ages of 10, 20, and $30 \mathrm{yr}$ with a burnup of $33,000 \mathrm{MWd} / \mathrm{MTU}$.

Because it areally averages the thermal load, the mountain-scale model cannot represent differences in temperature and saturation behavior within (1) the pillars (i.e., the rock separating neighboring emplacement drifts), (2) the emplacement drifts, or (3) the waste packages (WPs) themselves. The driftscale model used in this section is a two-dimensional cross-sectional model that explicitly represents the details of the WPs and emplacement drifts in the plane orthogonal to the drift axes. This model is useful in representing details of thermal-hydrological behavior at the drift (or sub-repository) scale. In particular, we are interested in how drift-scale, buoyant, gas-phase convection (which is driven by temperature differences between the drifts and pillars) affects vapor and condensate flow and thermal performance. To take advantage of symmetry, the drift-scale model assumes an infinite repository with uniformly spaced emplacement drifts. The assumption of an infinite repository area is applicable to the interior of the repository, which is not affected by cooling at the edge. This region includes most of the repository area during (at least) the first $1000 \mathrm{yr}$.

The drift-scale model assumes the 38.4-m center-to-center spacing between emplacement drifts that is found in the SCP-CDR [SNL, 1987]. The model represents a symmetry element from the symmetry plane down the center of the WP to the symmetry plane in the pillar between neighboring drifts. The thermal load is axially averaged along the axis of the drift. The WP has a cross section of $1.6 \times 1.6 \mathrm{~m}$ and is located in the center of an emplacement drift that is $4.8 \mathrm{~m}$ high by $6.0 \mathrm{~m}$ wide. The drifts are assumed to remain open; therefore, heat flow from the WP surface to the drift wall occurs as thermal radiation, convection, and conduction. The drift-scale model can represent heterogeneity that occurs at the scale of the drifts. For some of our calculations, a 1.6-m-wide, high- $k_{\mathrm{b}}$ zone is oriented vertically, intersecting either the midline of the emplacement drift or the midline of the pillar separating the drifts. The $k_{\mathrm{b}}$ of this zone can be several orders of magnitude larger than $k_{\mathrm{b}}$ throughout the rest of the model (the nominal $k_{\mathrm{b}}$ zone). The 
center-to-center spacing between the high- $k_{\mathrm{b}}$ zones is $38.4 \mathrm{~m}$ (the same as the center-to-center drift spacing).

Heterogeneity that occurs at a larger scale is represented by a third model, which we call the crosssectional uniform heat flow (CSUHF) model. Like the drift-scale model, the CSUHF model assumes an infinite repository, thereby enabling it to take advantage of symmetry. The CSUHF model represents an infinite series of vertical, uniformly spaced, $1.0-\mathrm{m}$-wide, high- $k_{b}$ zones. We considered high $k_{b}$ zone spacings of 100 and $1000 \mathrm{~m}$. For the high- $k_{b}$ zones, we considered $10,84,414$, and 840 darcy. For the nominal $-k_{\mathrm{b}}$ zones, we considęred 1.9 and 100 microdarcy; $1,10,100$, and 280 millidarcy; and 10 darcy. 


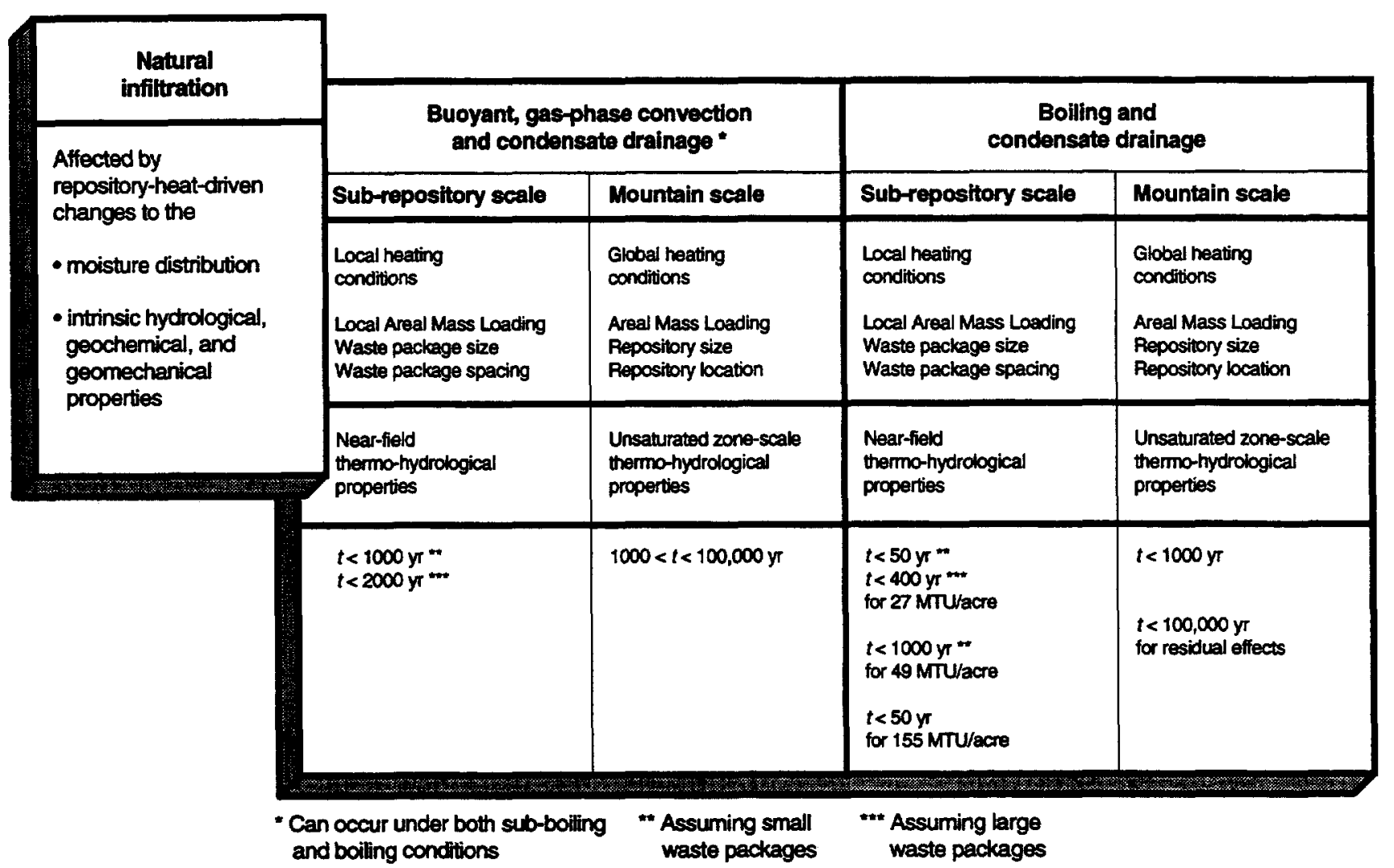

Table 10.1.1. The various time and length scales involved in how decay heat influences the three major sources of vapor and condensate flow. 


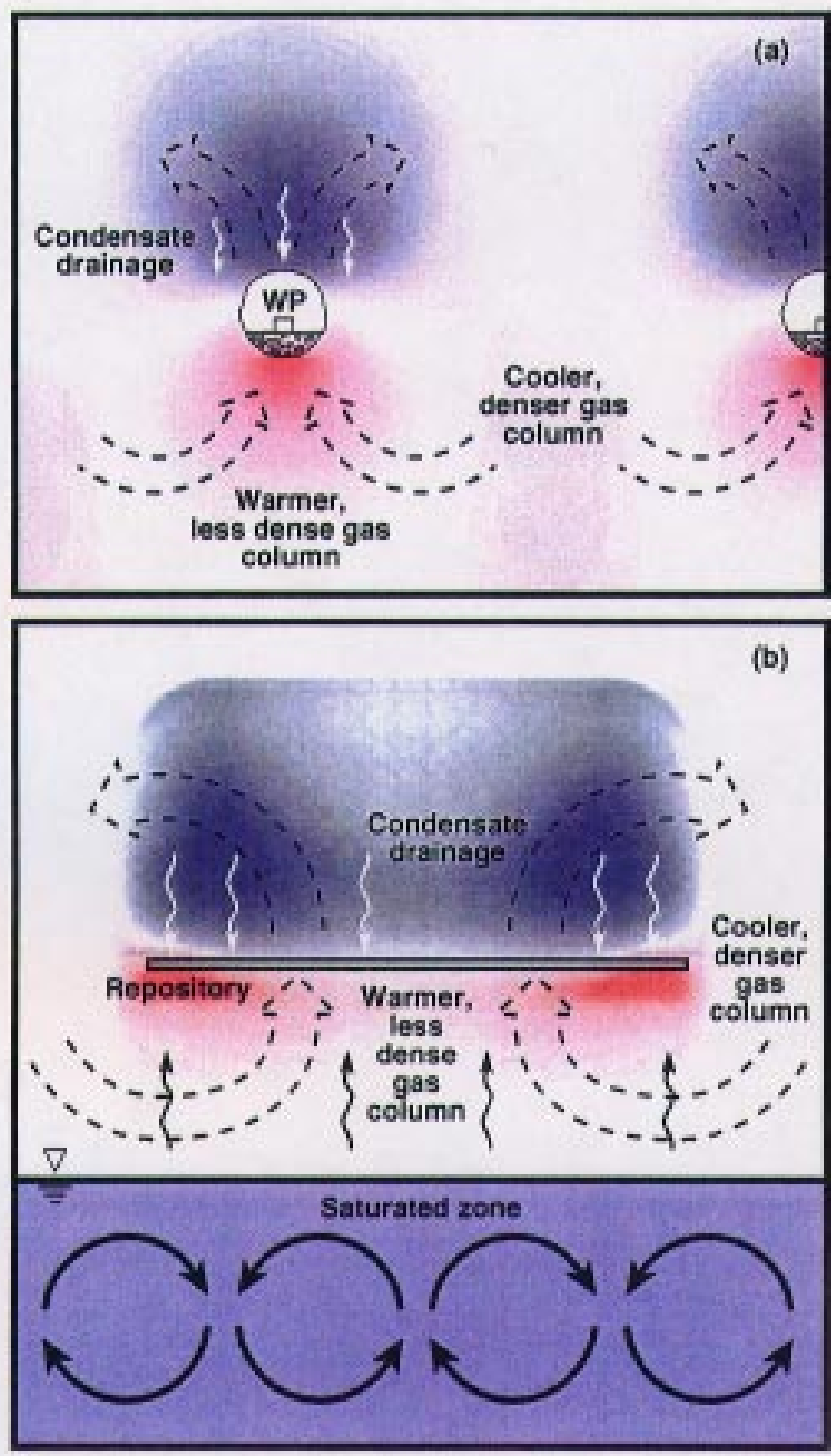

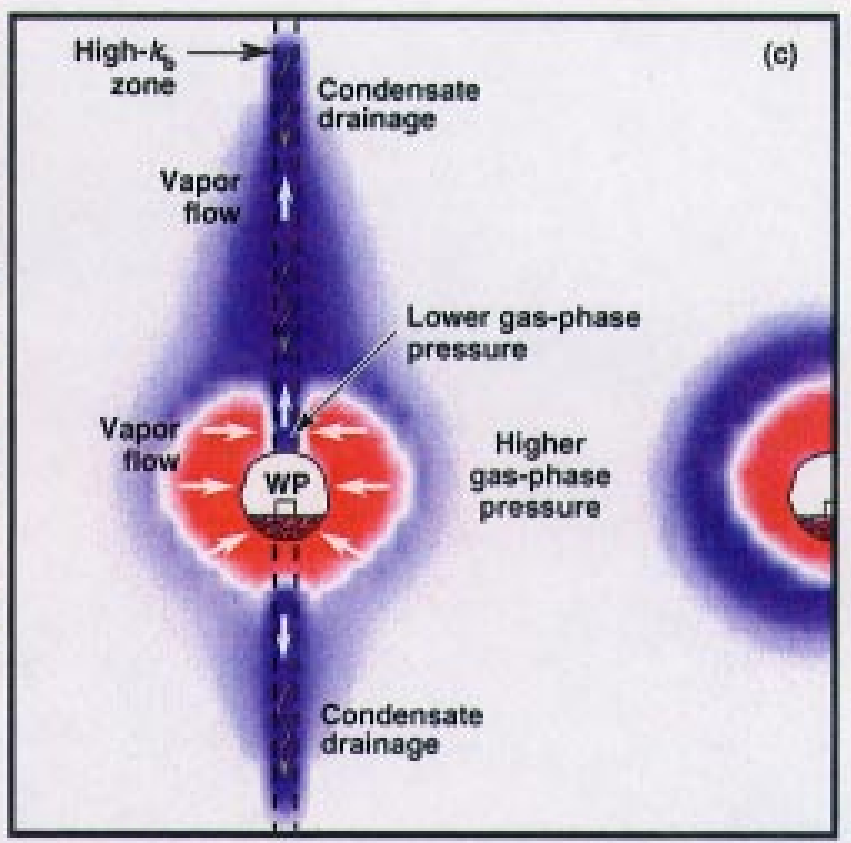

Figure 10.1.1. Model calculations of repository-heat-driven vapor and condensate flow. Buoyant vapor flow, occurring on either the (a) sub-repository scale, or (b) mountain scale. drives moisture from below the repository to above, where it condenses. Condensate drains down fractures back toward the repository and/or is imbibed by the matrix, possibly causing a saturation buildup above the repository. Water removed below the repository may be replenished by water imbibed from the saturated zone. Repository heat also drives buoyant, liquid-phase convection in the saturated zone.

(c) Zones of sharply contrasting bulk permeability, $k_{b}$, result in gas-phase pressure differentials that drive vapor flow into the high- $k_{b}$ zone, where it condenses and drains, possibly causing persistent two-phase refluxing conditions in the vicinity of the waste package (WP). 



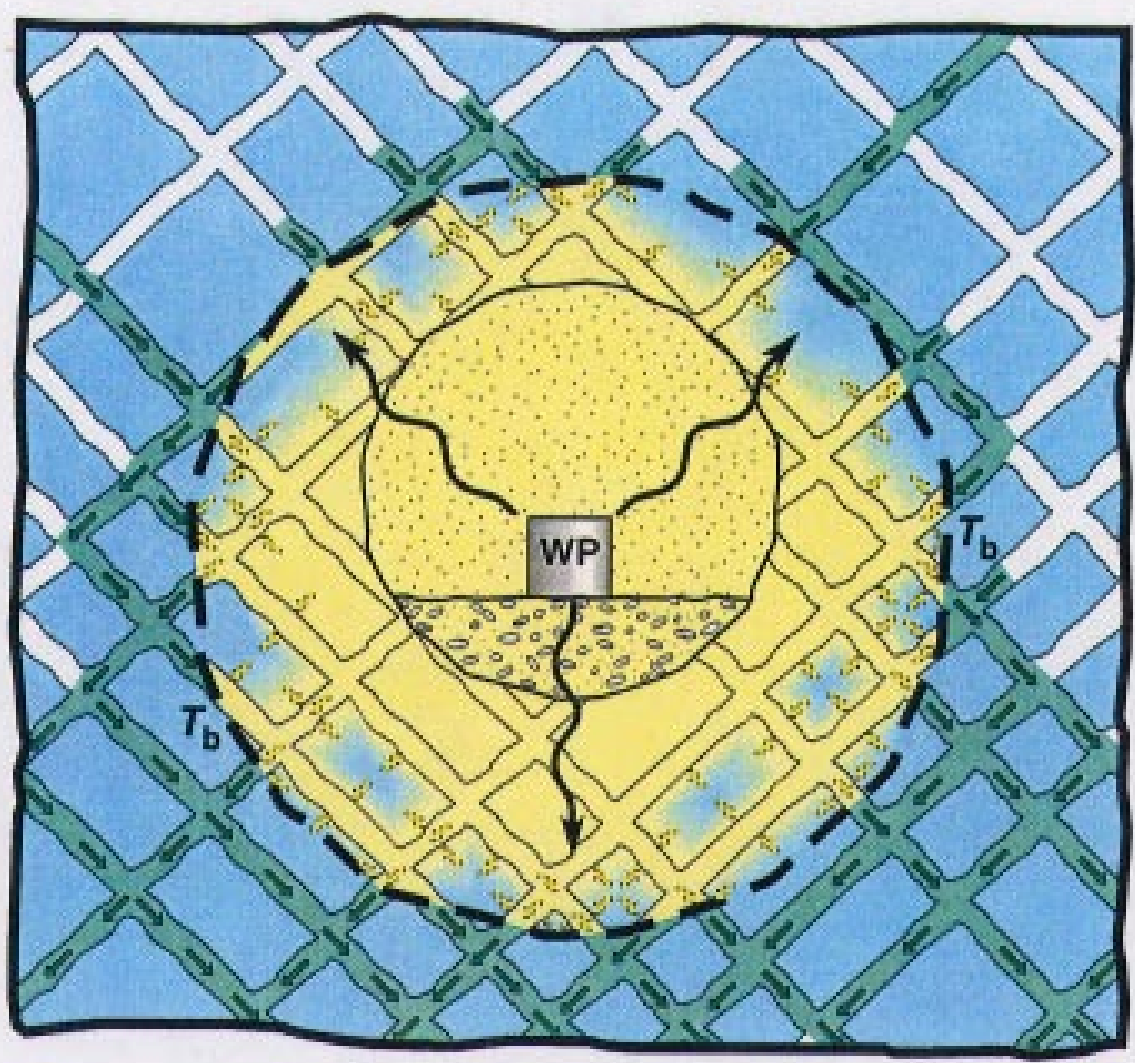

Figure 10.1.2. Schematic of hydrothermal flow near the emplacement drift. Rock dry-out occurs as boiling drives water vapor out of the rock matrix. Upon reaching the fracture network, vapor is driven away from the boiling zone to where cooler temperatures cause it to condense along fracture walls. Because the small matrix permeability limits the rate of matrix imbibition, condensate drainage persists for considerable distances down fractures. 


\section{'}




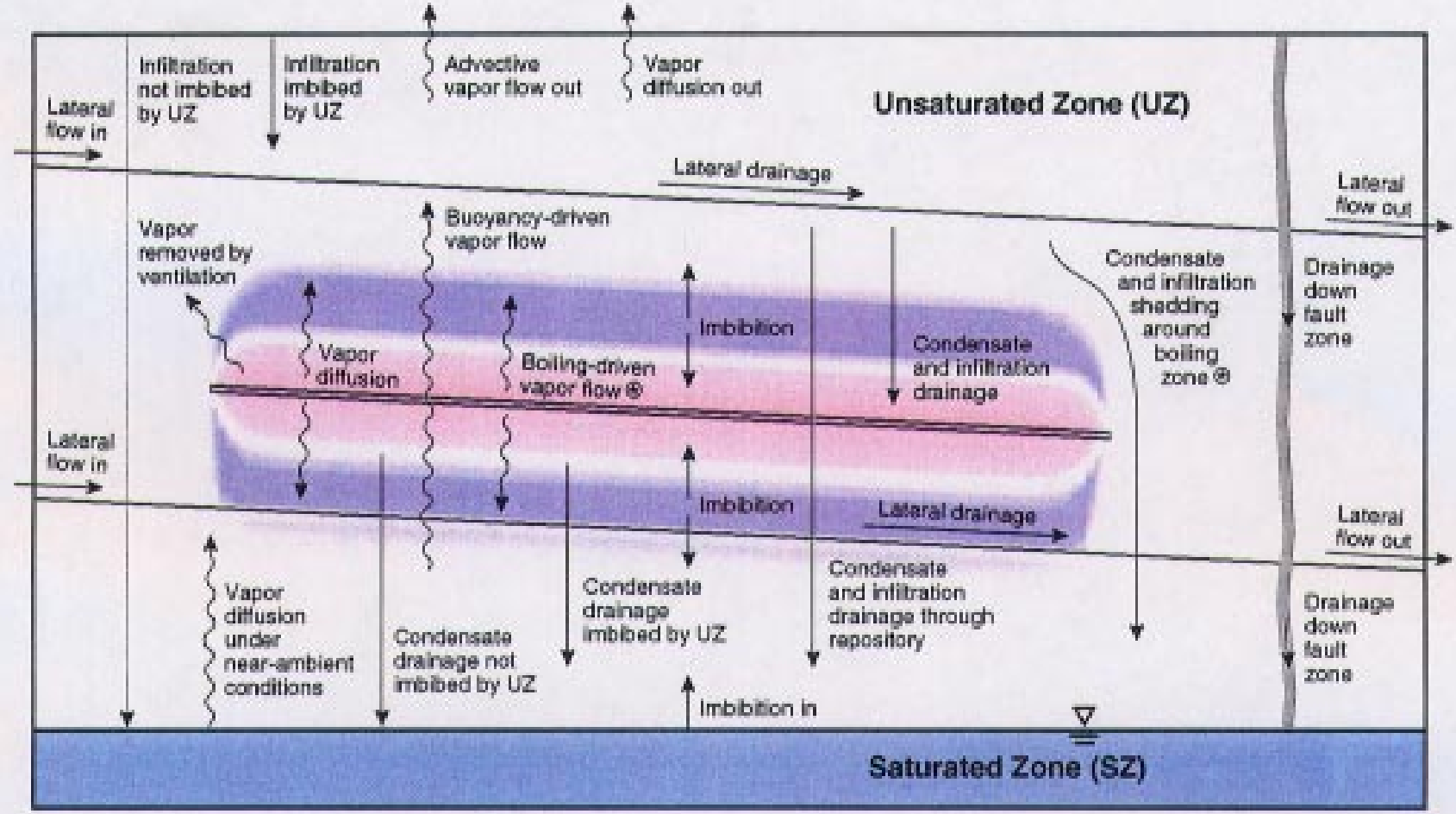

Figure 10.1.3. Moisture balance in the unsaturated zone (and above the repository itself) is affected by both ambient and decay-heat-driven processes. The two processes labeled with an asterisk ( $\left.{ }^{*}\right)$ are applicable only to above-boiling conditions; all other processes shown can occur under both sub-boiling and above-boiling conditions. 



\section{Contents}

10.1.2 Influence of Fracture Permeability Distribution ...............................................................10.1-16 


\subsubsection{Influence of Fracture Permeability Distribution}

10.1.2.1 Temperature and Liquid Saturation Distribution. The vertical temperature and saturation profiles are given for three different radial distances $r$ from the repository center (Figs. 10.1.2.1.110.1.2.1.5) for six different AMLs (24.2, 35.9,55.3,70,83.4, and 110.5 MTU/acre). The first value of $r(r=$ $0 \mathrm{~m}$ ) corresponds to the center of the repository. The second value of $r$ corresponds to the radial position that encloses $50 \%$ of the repository. This position is the "median" location in the repository that is representative of "average" conditions because half of the WPs are inside this radial position and half are outside this position. The third value of $r$ corresponds to the radial position that encloses $95 \%$ of the repository and is a good representation of conditions at the repository edge (or perimeter) because only $5 \%$ of the WPs lie outside of this position.

Figure 10.1.2.1.1 shows the vertical temperature and saturation profiles for the 83.4-MTU/acre case at various times after emplacement. Notice that the thermal and dryout behavior are very similar for the 0 and $50 \%$ radial positions of the repository for the first thousand years, and edge-cooling effects influence at least the outer $5 \%$ of the repository during this period; the percentage of the repository that is influenced by edge-cooling effects increases with time. The flattening of the temperature profile at the nominal boiling temperature $T_{\mathrm{b}}\left(\approx 96^{\circ} \mathrm{C}\right)$, corresponds to the two-phase flow refluxing zone (called the heat-pipe zone), which result from the countercurrent flow of water vapor away from the repository and condensate drainage back to the repository. These effects are described in more detail in other reports [Buscheck and Nitao, 1993a, 1993b, 1993c; Pruess and Tsang, 1993]. This zone is of particular interest because the liquid saturation and relative humidity $R H$ remain high in this zone, increasing the likelihood of aqueous reactions and aqueous-transport processes occurring. Refluxing also generates a very high liquid-phase flux in fractures (see Section 1.10.6 in Chapter 1), which can result in significant dissolution and precipitation of minerals along the fracture walls.

Dryout due to boiling results in a 150 - to 200 -m-thick dryout zone for the inner $50 \%$ of the repository. The low liquid saturation in the dryout zone decreases the likelihood of aqueous reactions and aqueoustransport processes altering the flow and transport properties in this zone. Edge-cooling effects substantially reduce the vertical extent of dryout in the outer region of the repository. Temperatures in the outer edge of the repository only rise to $98^{\circ} \mathrm{C}$, while at the center of the repository, $T_{\text {peak }}=146^{\circ} \mathrm{C}$. Temperatures for the entire repository have declined to below $T_{b}$ within 5000 yr; however, a zone of lessthan-ambient saturations persist after that (Figs. 10.1.2.1.1g and $h$ ). The outer $5 \%$ of the repository rewets back to ambient saturation within $10,000 \mathrm{yr}$ (10.1.2.1.1g), while the repository center remains below ambient saturation for more than 30,000 yr (Fig. 10.1.2.1.1h).

Figure 10.1.2.1.2 shows the vertical temperature profiles for the 35.9- and 24.2-MTU/acre cases. The mountain-scale model does not predict temperatures above $T_{b}$, indicating that averaged temperature conditions throughout the repository remain below boiling. However, as discussed later, local temperatures around the emplacement drift may be well above boiling for WPs containing a large number of SNF assemblies. Because of the absence of boiling conditions in the mountain-scale model, and because 280 millidarcy is below the threshold where mountain-scale, buoyant, gas-phase convection results in significant moisture movement, the 24.2- and 35.9-MTU/acre cases show only a minor change in saturation relative to ambient conditions. Therefore, we did not provide the vertical saturation profiles for these two cases.

Figure 10.1.2.1.3 shows the vertical temperature and saturation profiles for the 55.3-MTU/acre case. The thermal and dryout behavior are similar to that of the 83.4-MTU/acre case except that the vertical extent of boiling and dryout effects is much less. Moreover, the duration of boiling and sub-ambient liquid saturation conditions is much less for the 55.3-MTU/acre case than for the 83.4-MTU/acre case. Liquid saturation for the inner half of the repository has rewetted to ambient conditions within $30,000 \mathrm{yr}$ (Fig. 10.1.2.1.3h); at the edge, liquid saturation has rewetted to ambient liquid saturation within 10,000 (Fig. 10.1.2.1.3g). There are two important observations to make about the heat-pipe zone for the 55.3MTU/acre case: (1) the duration of refluxing conditions (i.e., high liquid-phase flux and high liquid 
saturation) is nearly the same as in the higher AML cases and (2) the heat-pipe zone remains close to the repository. Both of these conditions increase the likelihood (relative to the higher AML cases) that significant decay-heat-driven alteration of flow and transport properties will occur in the vicinity of the repository. This observation also applies to the edge of a high-AML repository because edgecooling/rewetting/shedding effects may prevent the heat-pipe zone at the repository edge from being displaced far away from the repository horizon.

Figure 10.1.2.1.4 shows the vertical temperature and saturation profiles for the 70-MTU/acre case. The thermal and dryout behavior are similar to that of the 83.4-MTU/acre case except that the vertical extent of boiling and dryout effects is halved. Moreover, the duration of boiling and sub-ambient liquid saturation conditions is somewhat less for the 70-MTU/acre case than for the 83.4-MTU/acre case [Buscheck and Nitao, 1994]. Liquid saturation for the inner half of the repository has not rewetted to ambient conditions at 30,000 yr (Fig. 10.1.2.1.4h); at the edge, liquid saturation has rewetted to ambient liquid saturation within 10,000 yr (Fig. 10.1.2.1.4g).

Figure 10.1.2.1.5 shows the vertical temperature and saturation profiles for the 110.5-MTU/acre case. The thermal and dryout performance are very similar for the 0 and $50 \%$ radial positions of the repository for the first thousand years, and edge-cooling effects influence at least the outer $5 \%$ of the repository. The heat-pipe zone (the zone of near-boiling temperatures above the repository) has a greater length and gets $75 \mathrm{~m}$ closer to the ground surface than in the 83.4-MTU/acre case (compare Figs. 10.1.2.1.1 and 10.1.2.1.5). Dryout due to boiling results in a 200 - to 300 -m-thick dryout zone for the inner $50 \%$ of the repository. Edge-cooling effects substantially reduce the vertical extent of dryout in the outer region of the repository. Temperatures at the outer edge of the repository drop below boiling at about $2000 \mathrm{yr}$, while the center remains above $T_{\mathrm{b}}$ for more than $7000 \mathrm{yr}$. Temperatures for the entire repository have declined to below $T_{\mathrm{b}}$ within $7000 \mathrm{yr}$; however, a large zone of less-than-ambient saturations persists long after that (Figs. 10.1.2.1.5 $\mathrm{g}$ and $\mathrm{h}$ ). The outer $5 \%$ of the repository rewets back to ambient saturation within 30,000 $\mathrm{yr}$, while the center remains below ambient saturation for more than $100,000 \mathrm{yr}$.

The spatial and temporal extent of boiling and dryout effects are substantially greater for the 110.5MTU/acre case than for the 83.4-MTU/acre case. Likewise, the spatial and temporal extent of these effects are much greater for the 83.4-MTU/acre case than for the 70-MTU/acre case. Therefore, for relatively high AMLs, mountain-scale T-H behavior depends strongly on AML. Moreover, the heat-pipe zone is displaced further away from the repository horizon for the 110.5-MTU/acre case than for the 83.4MTU/acre case. Edge-cooling/rewetting/shedding effects will probably have less of an impact on the edge of a 110.5-MTU/acre repository than for the edge of a 83.4-MTU/acre repository. Wide drift spacing will encourage more drift-scale condensate shedding (i.e., condensate shedding that occurs in the rock pillar between drifts), which will decrease the amount of condensate that can be displaced to the edge of the repository (see Section 1.10.6); this would lessen the contribution of edge-shedding to the liquid-phase flux at the edge of the repository, thereby lessening the impact on heat pipes at the repository edge.

10.1.2.2 Boiling-Driven and Buoyancy-Driven Vapor and Heat Flow. If the bulk permeability, $k_{b}$, of the fractured rock mass is large enough, repository heat can lead to the development of large-scale, buoyant convection cells transporting water vapor from regions below the repository to regions above. These cells also have the potential to redistribute heat within the mountain and reduce temperatures in the repository as well as in the altered zone. We conducted a mathematical analysis and a numerical modeling study [Buscheck and Nitao, 1994] to determine the conditions under which these effects may be significant.

Mountain-scale, buoyant, gas-phase convection occurs within fracture networks having a connectivity with length scale comparable to the $U Z$ thickness and repository width (Fig. 10.1.1b). For the modeling study we used the mountain-scale, UZ-SZ model, and considered a wide range of $k_{\mathrm{b}}$ values and AMLs, including 27.1, 49.2 (the reference SCP-CDR thermal load), and 154.7 MTU/acre. We analyzed these effects for (1) a homogeneous and isotropic $k_{\mathrm{b}}$ distribution, and (2) a layered, heterogeneous $k_{\mathrm{b}}$ distribution. Because the matrix permeability is so small for most of the UZ, differences in $k_{b}$ reflect differences in fracture permeability. We begin with a discussion of the mathematical analysis.

As repository heat propagates into the rock, a column of warmer, less-dense gas develops that encompasses the repository area (see Fig. 10.1.1b). The result is that gas-phase pressures, especially those 
at the lowest portion of the column, are lowered relative to those at the same depth in the cooler, denser column of gas outside the repository footprint. Consequently, gas from outside the repository footprint is drawn into the region below the repository and flows upward through the repository, in a fashion similar to the updraft in a chimney. Buoyant, gas-phase convection cells develop as the warmer, less-dense column of gas within the repository footprint is displaced by the cooler, denser gas from outside the repository footprint. As the initially cooler gas is heated, its relative humidity is lowered, causing it to evaporate water from the rock matrix below the repository. This warm moist air is convected upward to where it cools above the repository, generating condensate that drains down fractures back toward the repository and/or is imbibed by the matrix, causing a saturation buildup above the repository. Because water removed below the repository may be replenished by water imbibed from the $\mathrm{SZ}$, this process can result in a net buildup of liquid water in the UZ. For large enough $k_{\mathrm{b}}$, mountain-scale, buoyant, vapor flow can dominate moisture movement on the order of 100,000 yr (see Table 10.1.1).

Under sub-boiling conditions, this phenomenon always occurs and is significant unless the $k_{\mathrm{b}}$ is very small. Under boiling conditions, steam generation causes a gas pressure buildup that can dominate the buoyancy forces, thereby suppressing large-scale buoyant convection cells. For either large $k_{b}$, or as boiling diminishes, the gas pressure buildup may not be sufficient to suppress buoyancy, and convection cells form. As these cells develop, they can transport steam (or moist air) from below the repository to the condensation zone above.

For buoyant convection cells to dominate over the boiling-generated, gas-phase pressure buildup, $k_{\mathrm{b}}$ must be larger than a threshold bulk permeability for moisture movement, $k_{\mathrm{b}}>k_{\mathrm{b}}^{\text {uyu }}$, where $k_{\mathrm{b}}^{\text {ayu }}$ is given by

$$
k_{\mathrm{b}}^{\text {hyd }}=\frac{q_{\mathrm{H}}}{h_{\mathrm{fg}} \rho_{\mathrm{s}}} \frac{L_{\mathrm{b}}}{L} \frac{T_{\mathrm{amb}}}{\Delta T_{\mathrm{av}}} \frac{\mu_{\mathrm{g}}}{\rho_{\mathrm{g}, \mathrm{amb}} g}
$$

where

$$
\begin{aligned}
& \mathrm{q}_{\mathrm{H}} \text { is the instantaneous areal heat load }\left(\mathrm{W} / \mathrm{m}^{2}\right), \\
& \mathrm{h}_{\mathrm{fg}} \quad \text { is latent heat of vaporization }(\mathrm{J} / \mathrm{kg}), \\
& \rho_{\mathrm{s}} \quad \text { is steam density }\left(\mathrm{kg} / \mathrm{m}^{3}\right), \\
& \rho_{\mathrm{g}, \mathrm{amb}} \text { is mean gas-phase density under ambient conditions }\left(\mathrm{kg} / \mathrm{m}^{3}\right), \\
& L_{\mathrm{b}} \quad \text { is thickness of the boiling zone around the repository }(\mathrm{m}), \\
& L \quad \text { is thickness of the thermally perturbed zone }(\mathrm{m}), \\
& \mathrm{T}_{\mathrm{amb}} \text { is the mean ambient unsaturated zone temperature }(\mathrm{K}), \\
& \Delta \mathrm{T}_{\mathrm{av}} \quad \text { is the mean vertical change in temperature from ambient }(\mathrm{K}), \\
& \mu_{\mathrm{g}} \quad \text { is gas-phase viscosity }(\mathrm{kg} / \mathrm{m}-\mathrm{s}) \text {, and } \\
& g \quad \text { is gravity acceleration }\left(\mathrm{m} / \mathrm{s}^{2}\right) .
\end{aligned}
$$

Large-scale, buoyant convection cells will reduce repository temperatures when gas-phase convective heat flow through the repository domain is significant compared to the areally averaged heat load. This condition occurs when $k_{\mathrm{b}}$ is sufficiently large, that is, $k_{\mathrm{b}}>k_{\mathrm{b}}^{\mathrm{m}}$, where the threshold bulk permeabilityf for thermal effects, $k_{\mathrm{b}}^{\text {th }}$, is given by

$$
k_{\mathrm{b}}^{\text {th }}=\frac{q_{\mathrm{H}}}{h_{\mathrm{g}} \rho_{\mathrm{g}}} \frac{T_{\mathrm{amb}}}{\Delta T_{\mathrm{av}}} \frac{\mu_{\mathrm{g}}}{\rho_{\mathrm{g}, \mathrm{amb}}}
$$

Here, $h_{\mathrm{g}}$ is specific enthalpy of the gas phase $(\mathrm{J} / \mathrm{kg})$, and $\rho_{\mathrm{g}}$ is the gas-phase density $\left(\mathrm{kg} / \mathrm{m}^{3}\right)$. Because $\mathrm{q}_{\mathrm{H}}$ is a function of time, the threshold permeabilities are functions of time. Effective values of $\mathrm{q}_{\mathrm{H}}$, averaged over time, should be applied in making estimates of $k_{\mathrm{b}}^{\text {hyd }}$ and $k_{\mathrm{b}}^{\text {th }}$.

The critical bulk permeabilities, $k_{\mathrm{b}}^{\mathrm{nyu}}$ and $k_{\mathrm{b}}^{\mathrm{m}}$, are proportional to the repository heat load, $\mathrm{q}_{\mathrm{H}}$, and inversely proportional to the average increase in temperature, $\Delta T_{\mathrm{av}}$. The latter term depends on $\mathrm{q}_{\mathrm{H}}$ and is approximately proportional to $\mathrm{q}_{\mathrm{H}}$ under sub-boiling conditions so that increasing $\mathrm{q}_{\mathrm{H}}$ only weakly affects 
$k_{\mathrm{b}}^{\text {tn }}$. Therefore, under sub-boiling conditions, the likelihood of buoyant, gas-phase convection impacting repository temperatures is relatively insensitive to AML. Note that $k_{\mathrm{b}}^{\text {ayu }}$ is not applicable to sub-boiling conditions. Under above-boiling conditions, the term $\Delta T_{a v}$ depends weakly on $\mathrm{q}_{H}$ because most of the energy goes toward latent heat of boiling. Therefore, under boiling conditions, the critical bulk permeabilities, $k_{\mathrm{b}}^{\text {nyu }}$ and $k_{\mathrm{b}}^{\mathrm{tn}}$, are approximately proportional to $\mathrm{q}_{\mathrm{H}}$. Because higher AMLs increase the critical bulk permeabilities for both moisture and heat flow, the likelihood of buoyant, gas-phase convection cells dominating moisture and heat flow is reduced.

Because $\rho_{\mathrm{s}} h_{\mathrm{fg}} \approx \rho_{\mathrm{g}} h_{\mathrm{g}}$, the following approximate relationship holds:

$$
k_{\mathrm{b}}^{\mathrm{hyd}} \approx \frac{L_{\mathrm{b}}}{L} k_{\mathrm{b}}^{\mathrm{th}}
$$

and, therefore,

$$
k_{\mathrm{b}}^{\text {hyd }}<k_{\mathrm{b}}^{\text {th }}
$$

Values of $k_{\mathrm{b}}$ that are large enough for large-scale, buoyant convection to affect repository temperatures will also be large enough to affect the large-scale movement of water vapor produced by boiling. Conversely, if $k_{\mathrm{b}}$ is small enough for the large-scale movement of water vapor to be negligible, then large-scale, buoyant convection cells will not be significant enough to reduce repository temperatures. Although this method of analysis is approximate, it gives a good order-of-magnitude estimate of critical bulk permeabilities that have been verified by numerical simulations.

As an example, we consider a repository with $q_{H}=14.1 \mathrm{~W} / \mathrm{m}^{2}$, which is equivalent to an APD of 57 $\mathrm{kW} /$ acre. We use $T_{\mathrm{amb}}=300^{\circ} \mathrm{K}$ and $\Delta T_{\mathrm{av}}=50^{\circ} \mathrm{K}$. Values for $\rho_{\mathrm{s}}, h_{\mathrm{g}}$, and $h_{\mathrm{fg}}$ were taken at conditions for saturated water vapor at a temperature of $95^{\circ} \mathrm{C}$. The values for the lengths were $L=400 \mathrm{~m}$ and $L_{b}=20 \mathrm{~m}$. We then obtain $k_{\mathrm{b}}^{\text {hyd }}=0.7$ darcy, and $k_{\mathrm{b}}^{\text {th }}=14$ darcy.

Buscheck and Nitao [1993b] found that mountain-scale, buoyant, gas-phase convection does not influence temperatures at the repository center until after they peak. Depending on the AML and $k_{\mathrm{b}}$, the cooling effect of mountain-scale, buoyant, gas-phase convection can substantially reduce the duration of the boiling period, $t_{\mathrm{bp}}$ in the repository. Depending on the proximity to the outer edge of the repository, edge-cooling effects can also substantially reduce $t_{\mathrm{bp}}$. The details of how edge-cooling effects influence $t_{\mathrm{bp}}$ throughout the repository are described later in this section [Buscheck et al., 1994].

\section{Influence of Buoyant Gas-Phase Convection on the Duration of Boiling Conditions in the Repository Rock}

Figure 10.1.2.2.1 shows the area-weighted boiling period duration, $t_{\mathrm{bp}}$, as a function of $k_{\mathrm{b}}$ for the 49.2and 154.7-MTU/acre cases. Because $t_{\mathrm{bp}}$ is the boiling period duration averaged over the entire repository area, and the mountain-scale model assumes a uniform AML, $t_{b p}$ effectively represents conditions in the repository rock at an average location in the repository. For $k_{\mathrm{b}}<k_{\mathrm{b}}^{\mathrm{in}}, t_{\mathrm{bp}}$ is insensitive to $k_{\mathrm{b}}$. For an AML of $154.7 \mathrm{MTU} / \mathrm{acre}, k_{\mathrm{b}}^{\text {th }}$ is about 5 darcy, while for $49.2 \mathrm{MTU} / \mathrm{acre}$, it is about 1 darcy. For $k_{\mathrm{b}}>k_{\mathrm{b}}^{\mathrm{tn}}, t_{\mathrm{bp}}$ decreases with increasing $k_{\mathrm{b}}$. The cooling effect of mountain-scale, buoyant, gas-phase convection increases with proximity to the edge of the repository.

Relative to the 1 -millidarcy case, increasing $k_{\mathrm{b}}$ to 1 darcy only reduces $t_{\mathrm{bp}}$ by $2.4 \%$ for an AML of 154.7 MTU/acre, while for 49.2 MTU/acre, it is reduced by 19.7\% (Fig. 10.1.2.2.1). Increasing $k_{\mathfrak{b}}$ to 5 darcy reduces $t_{\text {bp }}$ by $11.4 \%$ for an AML of $154.7 \mathrm{MTU} /$ acre, while for $49.2 \mathrm{MTU} /$ acre, the reduction is $48.9 \%$. Consistent with Equation (5), boiling behavior for the 49.2-MTU/acre repository was found to be more sensitive to mountain-scale, buoyant, gas-phase convection than for the 154.7-MTU/acre repository. The boiling-generated, gas-phase pressure buildup increases with AML, and it opposes the tendency for thermal buoyancy for some period of time [Buscheck and Nitao, 1993b]. 
Figures 10.1.2.2.2a-c show the duration of the boiling period, $t_{\mathrm{bp}}$ as a function of repository location for the 110.5-, 83.4-, and 55.3-MTU/acre cases and all of the values of $k_{b}$ considered. The influence of edge cooling is evident. Mountain-scale, buoyant, gas-phase convection begins to significantly reduce repository temperatures for $k_{\mathrm{b}}>1$ darcy. For $k_{\mathrm{b}} \leq 1$ darcy, $t_{\mathrm{bp}}$ is insensitive to $k_{\mathrm{b}}$. Notice that the sensitivity of $t_{\mathrm{bp}}$ to $k_{\mathrm{b}}$ increases with decreasing AML.

Figure 10.1.2.2.2d shows the area-weighted boiling period duration, $t_{\mathrm{bp}}$, for various $k_{\mathrm{b}}$ values as a function of AML. For the 280-millidarcy cases, $t_{\mathrm{bp}}$ is 5450,3390, and $1420 \mathrm{yr}$ for AMLs of 110.5, 83.4, and 55.3 MTU/acre, respectively. The cooling effect that mountain-scale, buoyant, gas-phase convection has on $t_{\mathrm{bp}}$ increases with decreasing AML. Accordingly, the 110.5-MTU/acre case is least sensitive to this effect.

\section{Influence of Buoyant Gas-Phase Convection on Mountain-Scale Moisture Redistribution}

We compared the net buildup of liquid water above the repository, $\Delta V_{k}$, for a wide range of $A M L$ and values of $k_{\mathrm{b}}$ analyzed by Buscheck and others [1994] (Fig. 10.1.2.2.3). For the high- $k_{\mathrm{b}}$, high-AML cases (10, 40 , and 84 darcy; 83.4 and $110.5 \mathrm{MTU} /$ acre), a very early peak in $\Delta V_{1}$ occurs at 500 to $800 \mathrm{yr}$ (Figs. 10.1.2.2.3c-e), coinciding with the maximum extent of boiling conditions. After the initial peak, $\Delta V_{1}$ declines for the high- $k_{b}$, high-AML cases, with a trough occurring at $3000 \mathrm{yr}$, coinciding with the maximum vertical extent of dry-out. For $110.5 \mathrm{MTU} / \mathrm{acre}, \Delta V_{1}$ declines to below zero (Figs. 10.1.2.2.3d and e). For 83.4 MTU/acre, the trough is less pronounced as $\Delta V_{1}$ stays well above zero (Figs. 10.1.2.2.3ce). After the trough occurs in the 83.4- and 110.5-MTU/acre cases, the increase in $\Delta V_{1}$ resumes until a second peak in $\Delta V_{1}$ occurs at around 20,000 to 30,000 yr. For the 55.3-MTU/acre case, there is no trough, and the increase in $\Delta V_{1}$ is uninterrupted (Figs. 10.1.2.2.3a-e). For 10,40, and 84 darcy, the 55.3-, 83.4-, and 110.5-MTU/acre cases undergo the same initial rate of increase in $\Delta V_{1}$ until $500 \mathrm{yr}$, when the 110.5MTU/acre case reaches its initial peak, and $800 \mathrm{yr}$, when the 83.4-MTU/acre case reaches its initial peak (Figs. 10.1.2.2.3c-e). This initial peak is related to the interaction of the heat-pipe effect and mountainscale, buoyant, gas-phase convection.

It can be seen that $\Delta V_{1}$ is always greater in the 55.3- and 83.4-MTU/acre cases than in the 110MTU/acre case. We plot the maximum $\Delta V_{1}$ (called $\Delta V_{1}^{\max }$ ) for all of the AMLs and values of $k_{\mathrm{b}}$ considered (Fig. 10.1.2.2.3f). For 55.3 MTU/acre, $\Delta V_{1}^{\max }$ is 1.5, 1.3, 2.4, 2.6, and 2.5 times greater than in the 110.5-MTU/acre case for 280 millidarcy and 1, 10, 40, and 84 darcy, respectively. For $83.4 \mathrm{MTU} / \mathrm{acre}$, $\Delta V_{1}^{\max }$ is $1.5,1.7,1.4,1.4$, and 1.5 times greater than in the 110.5-MTU/acre case for 280 millidarcy and 1 , 10,40 , and 84 darcy, respectively. To the first order, for intermediate to high AMLs, $\Delta V_{1}^{\max }$ is proportional to the repository area if $k_{\mathrm{b}}$ is large enough $\left(k_{\mathrm{b}}>1-10\right.$ millidarcy) for unthrottled advective dryout to dominate (see Section 1.8.5).

If the large-scale connected $k_{\mathrm{b}}$ is small enough, mountain-scale, buoyant, gas-phase convection does not result in a liquid water buildup above the repository. For intermediate $k_{\mathrm{b}} k_{\mathrm{b}}<110$ darcy), for which buoyant gas-phase convection does not dominate vapor flow, the cumulative effects of vapor flow and condensate buildup depend on the magnitude of boiling effects. Because low AMLs generate less boilingdriven dryout, there is less net liquid water buildup than the high AMLs, which generate more boilingdriven dryout. Because buoyant gas-phase convection governs dryout effects for high enough $k_{\mathrm{b}}\left(k_{\mathrm{b}}>40\right.$ darcy), $\Delta V_{1}^{\max }$ is proportional to the repository area. Although buoyancy forces are less per unit area (of repository) for a low-AML repository than for a high-AML repository, these forces are integrated over the larger area of the low-AML repository, which results in the roughly the same overall magnitude of buoyancy-driven dryout and condensate buildup effects.

We also compared the net buildup of liquid water above the repository, $\Delta V_{l}$ for all of the AMLs and values of $k_{\mathrm{b}}$ considered by Buscheck and Nitao [1994]. For an AML of 27.1 MTU/acre and $k_{\mathrm{b}}<280$ millidarcy, mountain-scale, buoyant, gas-phase convection results in a very small net change to the liquid saturation distribution (Fig. 10.1.2.2.4b); however, significant refluxing occurs, with buoyant vapor flow being balanced by condensate drainage and imbibition. For $k_{\mathrm{b}}>280$ millidarcy, condensate drainage and imbibition cannot keep up with buoyant vapor flow, and regions of net dryout below the repository and condensate buildup above develop and persist for tens of thousands of years. With the ECM, we cannot 
determine whether the resulting condensate flux results in nonequilibrium fracture flow down to the repository horizon (and possibly down to the water table). However, the potential for nonequilibrium condensate drainage exists even for situations that do not result in a net redistribution of liquid saturation. In situ thermal tests that are of sufficient size and duration are needed to determine the potential for mountain-scale, buoyant, vapor flow to drive nonequilibrium condensate drainage in the vicinity of WPs [Buscheck et al., 1993a; Buscheck et al., 1993b; Buscheck and Nitao, 1995].

For an AML of 27.1 MTU/acre, $\Delta V_{1}$ increases gradually until it peaks, and declines even more gradually (Fig. 10.1.2.2.4a). A substantial $\Delta V_{1}$ persists well beyond $100,000 \mathrm{yr}$ for the high- $k_{\mathrm{b}}$ cases. The peak $\Delta V_{1}$ occurs at 20,000,20,000,30,000,40,000, and 40,000 yr for the 168-, 84-, 40-, 20-, and 10-darcy cases, respectively (Figs. 10.1.2.2.4a and b). For the 280-millidarcy case (Fig. 10.1.2.2.4b), the peak occurs beyond 100,000 yr. For $k_{\mathrm{b}} \geq 10$ darcy, the maximum $\Delta V_{1}$ (called $\Delta V_{1}^{\max }$ ) increases nearly linearly with $k_{\mathrm{b}}$. Because it cannot represent nonequilibrium fracture-matrix flow, the ECM probably underpredicts the condensate drainage flux and, consequently, may overpredict $\Delta V_{1}$. However, $\Delta V_{1}$ is a useful indicator of the overall magnitude of condensate drainage and buildup effects. The slope of the $\Delta V_{1}$ vs $t$ curve is indicative of the overall rate of condensate generation that arises from mountain-scale, buoyant, vapor flow. For high AMLs, it is indicative of the competition between vapor flow driven by the gas-pressure buildup due to boiling and vapor flow driven by thermal buoyancy.

For an AML of 49.2 MTU/acre, $\Delta V_{1}$ increases gradually until it peaks, and declines even more gradually (Fig. 10.1.2.2.4c). A substantial $\Delta V_{1}$ persists well beyond $100,000 \mathrm{yr}$ for the high- $k_{\mathrm{b}}$ cases. The peak $\Delta V_{1}$ occurs at $20,000,15,000,15,000,10,000,6600,5000$, and $1300 \mathrm{yr}$ for the 168-, 84-, 40-, 20-, 10-, 5-, and 1-darcy cases, respectively (Figs. 10.1.2.2.4c and d). For the 280- and 10-millidarcy cases, the $\Delta V_{1}$ peak occurs at $1000 \mathrm{yr}$ (Fig. 10.1.2.2.4d). For AMLs of 27.1 and 49.2 MTU/acre, $\Delta V_{1}$ is never less than zero.

For an AML of $154.7 \mathrm{MTU} / \mathrm{acre}$, the high- $k_{\mathrm{b}}$ cases $\left(k_{\mathrm{b}}>5\right.$ darcy) show two peaks in the $\Delta V_{\mathrm{l}}$ curve, with an early peak occurring at 300 to $500 \mathrm{yr}$ and a late peak occurring beyond 20,000 $\mathrm{yr}$ (Fig. 10.1.2.2.4e). For the 1-darcy case, the early and late peaks occur at 900 and 20,000 yr, respectively (Fig. 10.1.2.2.4f). The early peak approximately coincides with the maximum vertical extent of boiling conditions and is related to the interaction of the heat-pipe effect and mountain-scale, buoyant, gas-phase convection. After the initial peak, $\Delta V_{1}$ quickly declines for the high- $k_{\mathrm{b}}$ cases, with a trough occurring at $3000 \mathrm{yr}$, coinciding with the maximum vertical extent of dryout. For the 40-,84-, and 168-darcy cases, $\Delta V_{1}$ declines to below zero. After the trough occurs, $\Delta V_{1}$ resumes a gradual increase until a late peak occurs. This peak occurs at $60,000,50,000,50,000$, and $25,000 \mathrm{yr}$ for the 168-, 84-, 40-, and 5-darcy cases, respectively. For 10 millidarcy $<k_{\mathrm{b}}<1$ darcy, there is no early peak in $\Delta V_{\mathrm{l}}$ and a late peak occurs at 20,000 yr (Fig. 10.1.2.2.4f). For $k_{\mathrm{b}} \leq$ 10 millidarcy, after a brief early period with very small positive values, $\Delta V_{1}$ is always negative (Fig. 10.1.2.2.4f). Therefore, if the large-scale connected $k_{b}$ is small enough, mountain-scale, buoyant, gas-phase convection does not result in a liquid water buildup above the repository for the 154.7-MTU/acre case.

Figure 10.1.2.2.5 shows the $\Delta V_{1}^{\max }$ as a function of $k_{\mathrm{b}}$ for AMLs of 27.1, 49.2, and 154.7 MTU/acre. Notice that the shape of this curve varies significantly among the various AML cases. For an AML of 154.7 MTU/acre, the slope of the curve is nearly constant, with $\Delta V_{1}^{\max }$ increasing gradually with $k_{\mathrm{b}}$. The dependence of $\Delta V_{1}^{\max }$ on $k_{\mathrm{b}}$ is very nonlinear for AMLs of 27.1 and $49.2 \mathrm{MTU} / \mathrm{acre}$. For small $k_{\mathrm{b}}$, the slope is very shallow. For an AML of $49.2 \mathrm{MTU} / \mathrm{acre}$, the slope increases abruptly at $k_{\mathrm{b}}=1$ darcy, while for 27.1 MTU/acre, it increases abruptly at 10 darcy.

Over the range of 1 millidarcy to 168 darcy, the following observations can be made from Fig. 10.1.2.2.5. Where the impact of mountain-scale, buoyant, gas-phase convection is greatest, low-tointermediate AMLs result in the largest $\Delta V_{1}^{\max }$. For intermediate $k_{\mathrm{b}}$ (280 millidarcy to 1 darcy), where the impact of mountain-scale, buoyant, gas-phase convection is relatively moderate, $\Delta V_{1}^{\max }$ for the various AML cases generally varies by less than a factor of 2 .

It is likely that the $k_{\mathrm{b}}$ distribution at Yucca Mountain will be highly variable. Some of that variability will be random, while some may be correlated with discrete hydrological features such as fault zones or hydrostratigraphic units like the nonwelded vitric tuff units (PTn and CHnv). If the $k_{\mathrm{b}}$ distribution spans a significant fraction of the range shown in Fig. 10.1.2.2.5 (including regions in which $k_{\mathrm{b}}>10$ darcy), then mountain-scale hydrothermal behavior will be more variable for low-to-intermediate AMLs than for high 
AMLs. If the $k_{\mathrm{b}}$ distribution only spans the lower end of the $k_{\mathrm{b}}$ range $\left(k_{\mathrm{b}}<1\right.$ darcy), then mountain-scale hydrothermal behavior will be less variable for all AMLs.

Because the ECM cannot represent nonequilibrium fracture-matrix flow, it underpredicts the condensate drainage flux and, consequently, overpredicts $\Delta V_{1}$. However, $\Delta V_{1}$ is a useful indicator (or surrogate) of the overall magnitude of condensate drainage flux and saturation buildup effects. The slope of the $\Delta V_{1}$ vs $t$ curve is indicative of the overall rate of condensate generation that arises from mountainscale, buoyant vapor flow. For high AMLs, it is indicative of the competition between vapor flow driven by the gas-pressure buildup due to boiling, and vapor flow driven by thermal buoyancy.

The purpose of these mountain-scale calculations is to illustrate the general sensitivity of large-scale $\mathrm{T}-\mathrm{H}$ behavior to a wide range of conditions through the use of macroscopic parameters such as $t_{\mathrm{bp}}, \Delta V_{1}$, and $\Delta V_{l}^{\max }$. Moreover, these parameters are indicative of the magnitude of liquid-phase flux (particularly occurring in fractures) that may give rise to aqueous reactions and aqueous-transport processes that can alter the flow and transport properties in fractures. Any attempt to make specific inferences of this behavior on WP performance and radionuclide transport would require a far more detailed look at the spatial distribution of the decay-heat-driven changes to temperatures, liquid saturations, and vapor and liquid fluxes (as is done in Section 1.10.5 of Chapter 1) than can be addressed with the mountain-scale models alone.

10.1.2.3 Influence of Layered Heterogeneous Bulk Permeability Distribution on Buoyancy-Driven Vapor and Heat Flow. We also considered cases in which the $k_{\mathrm{b}}$ distribution varies vertically, which results in a layered heterogeneous $k_{\mathrm{b}}$ distribution. This is applicable in light of recent data analysis [Bodvarsson et al., 1996], which indicates considerable layering of $k_{\mathrm{b}}$. In particular, it appears that $k_{\mathrm{b}}$ may be far smaller in the nonwelded vitric units (PTn and CHnv) and the nonwelded zeolitized unit (CHnz) than in the welded units (TCw, TSw1, TSw2, and TSw3). For AMLs of 27.1 and 154.7 MTU/acre, we considered four $k_{\mathrm{b}}$ distributions:

(1) $k_{\mathrm{b}}=84$ darcy everywhere.

(2) $k_{\mathrm{b}}=320$ millidarcy in the PTn; otherwise, $k_{\mathrm{b}}=84$ darcy.

(3) $k_{\mathrm{b}}=280$ millidarcy in the CHn; otherwise, $k_{\mathrm{b}}=84$ darcy.

(4) $k_{\mathrm{b}}=320$ millidarcy in the PTn and 280 millidarcy in the CHn; otherwise, $k_{\mathrm{b}}=84$ darcy.

Figure 10.1.2.3.1 shows the net buildup of liquid water above the repository, $\Delta V_{l}$ for these four cases. For the 27.1-MTU/acre repository, a reduced $k_{b}$ in the PTn reduces $\Delta V_{1}$ by half (Fig. 10.1.2.3.1a). For the uniform- $k_{\mathrm{b}}$ case, mountain-scale, buoyant, gas-phase convection behaves as though it is in an "open" system with respect to the ground surface. In this open system, the gas-phase velocity vectors are orthogonal to the ground surface in the vicinity of the ground surface. Buoyant vapor flow results in a substantial increase in liquid saturation from the repository horizon all the way to the ground surface. When $k_{b}$ in the PTn is reduced, this unit functions as a gas-phase flow barrier or "vapor cap." Consequently, the direction of gas-phase flow below the PTn/TSw1 contact becomes tangential to this contact rather than crossing it. The PTn effectively isolates the buoyant, gas-phase, convection cells from the ground surface, thereby causing the convective system to be "closed" with respect to the ground surface. The resulting decrease in the gas-phase flow velocities causes an overall reduction in $\Delta V_{1}$ (Fig. 10.1.2.3.1a).

For the 154.7-MTU/acre repository, a reduced $k_{\mathrm{b}}$ in the PTn has a much different effect on $\Delta V_{1}$ (Fig. 10.1.2.3.1b). As in the 27.1-MTU/acre case, the reduced $k_{b}$ in the PTn causes the buoyant convective system to be closed with respect to the ground surface, reducing the magnitude of gas-phase flow. The resulting decrease in the gas-phase flow velocities reduces the initial peak in $\Delta V_{1}$ by $40 \%$ (Fig. 10.1.2.3.1b). Recall that for the high- $k_{b}$ cases (Fig. 10.1.2.2.3d,e and 10.1.2.2.4e), we observed an initial peak in $\Delta V_{1}$ at about 300 to $500 \mathrm{yr}$, followed by a steep decline (and trough) in the $\Delta V_{1}$ curve. The steep decline arises from buoyant convection driving water vapor to the ground surface. Figure 10.1.2.3.1b clearly indicates that an open convective system driven by a high-AML repository results in a substantial loss of water vapor to the atmosphere. However, an open convective system driven by a low-AML repository does not result in such a loss. The key difference is that boiling in the high-AML case drives most of the moisture buildup to the upper $100 \mathrm{~m}$ of the unsaturated zone (UZ), while for the low-AML case, the moisture 
buildup is spread over the upper $340 \mathrm{~m}$ of the UZ. Proximity of the moisture buildup to the ground surface, and larger gas-phase velocities, facilitate the loss of moisture to the atmosphere for the high-AML case. When the PTn acts as a vapor cap, the loss of moisture to the atmosphere is impeded, trapping much of the moisture convected to the upper UZ. Consequently, the trough in the $\Delta V_{1}$ curve is less pronounced, and the following increase in $\Delta V_{1}$ is steeper (Fig. 10.1.2.3.1b).

For the 154.7-MTU/acre repository, the reduced $k_{\mathrm{b}}$ in the PTn causes the second peak in the $\Delta V_{1}$ curve to occur much earlier $(15,000 \mathrm{yr})$ than in the uniform- $k_{\mathrm{b}}$ case $(50,000 \mathrm{yr})$. The earlier occurrence of the second peak is caused by the gas-phase diffusive loss of moisture to the atmosphere. Note that the value assumed for the effective diffusion factor, $\tau_{\text {eff }}\left(\tau_{\text {eff }}=0.2\right)$, may be low compared to experimental values measured by soil physicists (see Section 10.1.3.2). A larger value of $\tau_{\text {eff }}$ would result in a larger diffusive loss of moisture to the atmosphere and an overall reduction in $\Delta V_{1}$.

For the 27.1-MTU/acre repository, a reduced $k_{\mathrm{b}}$ in the $\mathrm{CHn}$ reduces $\Delta V_{1}$ by half, which is almost identical to the effect that a reduced- $k_{\mathrm{b}}$ PTn has on $\Delta V_{1}$ (Fig. 10.1.2.3.1a). The reduction in $k_{\mathrm{b}}$ in the CHn impedes buoyant flow through it, effectively decoupling it from the mountain-scale, buoyant convective system. The resulting reduction in the vertical extent of the buoyant convective system has the effect of reducing the gas-phase velocities and the quantity of water that can be vaporized and convected from below the repository to above, where it condenses. Reducing $k_{\mathrm{b}}$ in both the PTn and CHn reduces $\Delta V_{1}$ by another factor of 2 relative to the case with the reduced $k_{\mathrm{b}}$ in the PTn (Fig. 10.1.2.3.1a).

For the 154.7-MTU/acre repository, a reduced $k_{\mathrm{b}}$ in the CHn reduces $\Delta V_{1}$ by nearly half (Fig. 10.1.2.3.1b), which is similar to the effect shown for the 27.1-MTU/acre repository (Fig. 10.1.2.3.1a). Reducing $k_{\mathrm{b}}$ in both the PTn and CHn reduces $\Delta V_{1}$ by nearly half relative to the case with the reduced $k_{\mathrm{b}}$ in the PTn (Fig. 10.1.2.3.1a). Figure 10.1.2.3.2 shows the impact that a reduced $k_{b}$ in the PTn and CHn has on the boiling period duration, $t_{\mathrm{bp}}$. The reduction in gas-phase velocities decreases the overall convective cooling effect, thereby increasing $t_{b p}$, particularly at the outer repository area.

10.1.2.4 Sub-Repository-Scale, Boiling-Driven and Buoyancy-Driven Vapor and Heat Flow. Sub-repository-scale (or drift-scale), buoyant, gas-phase convection occurs within fracture networks having a connectivity with length-scale comparable to the distance between the hot and cold regions of the repository (see Fig. 10.1.1a). Buoyant, gas-phase convection cells develop as the warmer, less-dense column of gas within the footprint of the waste packages (WPs) is displaced by the cooler, denser column of gas in the adjacent areas. As the initially cooler gas is heated up, its relative humidity is lowered, causing it to evaporate water from the rock matrix below hot regions of the repository. This warm moist air is convected upward to where it cools above the WPs. This generates condensate that drains down fractures back toward the repository and/or is imbibed by the matrix, causing a saturation buildup above the WPs. High AMLs result in a large zone of above-boiling temperatures, which suppresses the effects of sub-repository-scale, buoyant vapor flow [Buscheck and Nitao, 1993]. Sub-repository-scale, buoyant, gasphase convection continues as long as significant temperature differences persist within the repository. It can dominate moisture movement for up to $1000 \mathrm{yr}$ for the drift spacing described in the SCP-CDR [SNL, 1987].

More recently, there has been considerable momentum toward the use of larger WPs contains more fuel assemblies, and therefore have a higher thermal output per WP. Larger drift spacing, which is consistent with the use of larger WPs, will result in temperature differences within the repository persisting longer. Consequently, the effects of sub-repository-scale, buoyant vapor flow (if important) will also be more persistent, possibly lasting thousands of years [Buscheck et al., 1994].

Buscheck and others [1994] analyzed sub-repository-scale performance for large WPs containing either 21 PWR or 40 BWR spent nuclear fuel (SNF) assemblies with a center-to-center WP spacing of $12 \mathrm{~m}$. These calculations also apply to a 12-PWR/21-BWR SNF emplacement scenario with a center-to-center WP spacing of $6.86 \mathrm{~m}$. An important observation from that study concerns the substantial difference between thermal-hydrological performance predicted by mountain-scale models and that predicted by drift-scale models. For an AML of 24.2 MTU/acre, the repository-scale model predicts a peak temperature, $T_{\text {peak }}$ of $65^{\circ} \mathrm{C}$, while the drift-scale model predicts $T_{\text {peak }}$ of up to $172^{\circ} \mathrm{C}$ on the WP surface and $144^{\circ} \mathrm{C}$ in the rock adjacent the drift. While the repository-scale model predicts no boiling period, the drift-scale model predicts a boiling period duration, $t_{\mathrm{bp}}$, of 180 to $200 \mathrm{yr}$ in the rock and 300 to $350 \mathrm{yr}$ on 
the WP surface. Similarly, the repository-scale model predicts no boiling period for an AML of 35.9 MTU/acre, while the drift-scale model predicts $t_{\mathrm{bp}}$ of 960 to $1010 \mathrm{yr}$ in the rock and 1110 to $1160 \mathrm{yr}$ on the WP surface.

Another important observation about sub-repository-scale performance is that $T_{\text {peak }}$ varies modestly for AMLs ranging from 24.2 to 55.3 MTU/acre [Buscheck et al. 1994]. Because it occurs so early (12 to 25 $\mathrm{yr}), T_{\text {peak }}$ is insensitive to whether the distance to the adjacent emplacement drift is $43.4 \mathrm{~m}$ or $99.0 \mathrm{~m}$. For the high-AML cases, the drift spacing is small enough to cause $T_{\text {peak }}$ to be sensitive to drift spacing. Consequently, $T_{\text {peak }}$ is significantly greater for the 110.5-MTU/acre case than for the 83.4-MTU/acre case [Buscheck et al. 1994].

The boiling-period duration $t_{\mathrm{bp}}$ is insensitive to sub-repository-scale, buoyant, gas-phase convection for both the low- and high-AML cases (24.2,35.9, and 110.5 MTU/acre). For intermediate-AML cases (55.3 and 83.4 MTU/acre), $t_{\mathrm{bp}}$ is modestly sensitive. For high AMLs, the extent of dryout is insensitive to sub-repository-scale, buoyant, gas-phase convection. For low AMLs, the extent of moisture movement (i.e., dryout and condensate buildup) is very dependent on the magnitude of sub-repository-scale, buoyant, gas-phase convection.

Some have equated the term "sub-boiling repository" with a repository system for which the hydrological impact of heat is insignificant. Some also define a "sub-boiling repository" to be one in which the average repository temperature is below the boiling point. Our analyses show that boiling conditions can persist around an emplacement drift even if the average repository temperature is well below boiling. Moreover, if buoyant, gas-phase convection is found to be significant, it can drive substantial vapor and condensate fluxes (over a very extensive region of the $U Z$ ) whether or not boiling ever occurs. Buoyancy-driven T-H effects can extend from the water table all the way to the ground surface, possibly resulting in coupled $\mathrm{T}-\mathrm{H}-\mathrm{C}$ processes that alter the flow and transport properties over a comparable region. On the other hand, if buoyant, gas-phase convection is found to be insignificant, a boiling period of sufficiently limited duration may be shown to generate condensate fluxes that result in coupled T-H-C processes that alter flow and transport properties over a much smaller region. The absence of local boiling conditions is not, in itself, an adequate indicator of whether repository heat drives significant vapor and condensate flow. Average repository temperatures are an even poorer indicator of whether decay-heat-driven alteration of flow and transport properties have a negligible effect on the performance of a low-AML repository. Diagnosing whether sub-boiling conditions can be equated with the absence of significant decay-heat-driven effects will require in situ thermal tests that are of sufficient size and duration [Buscheck et al., 1993a, 1993b; Buscheck and Nitao, 1995].

10.1.2.5 Heterogeneity-Enhanced Heat-Pipe Behavior. Refluxing, or the heat-pipe effect, is important to consider because it can affect coupled T-H-M-C processes (that may alter flow and transport properties) in two ways. First, refluxing maintains local temperatures near the boiling point, making it more difficult to dry the rock out. Consequently, the liquid saturation and relative humidity $R H$ remain high, increasing the likelihood of aqueous reactions and aqueous-transport processes occurring. Second, refluxing can generate a very high liquid-phase flux in fractures, which can results in significant dissolution and precipitation of minerals along the fracture walls.

To investigate the impact of heterogeneity on the focusing of vapor flow and condensate drainage (and how that focusing affects the development of heat pipes in the near field and altered zone), we used a cross-sectional drift-scale model and a cross-sectional uniform heat flow (CSUHF) model [Buscheck and Nitao, 1994]. Both models are used to investigate the effect of lateral variability of $k_{\mathrm{b}}$. In particular, we consider the situation in which $k_{\mathrm{b}}$ in vertically contiguous high $k_{\mathrm{b}}$ zones is much larger than $k_{\mathrm{b}}$ throughout the rest of the fractured rock (the nominal- $k_{b}$ zones). These models specifically address how focused condensate drainage might arise from gas-phase focusing. Recent analytical work by Nitao and Bradford [1996] addresses how focused condensate drainage might arise from liquid-phase focusing.

The degree of vapor flow focusing into the high- $k_{\mathrm{b}}$ zone, and the resulting duration of refluxing at the repository horizon (as well as in the altered zone in general), depends on three factors. First, $k_{\mathrm{b}}$ in the nominally fractured zone must be large enough not to significantly throttle the rate of vapor generation due to boiling (or due to evaporation under sub-boiling conditions). Second, a large contrast in $k_{\mathrm{b}}$ between the high- and nominal- $k_{\mathrm{b}}$ zones results in a gas-phase pressure differential between these zones 
that preferentially drives vapor flow into the high- $k_{\mathrm{b}}$ zone (Fig. 10.1.1c). If enough vapor enters and condenses in the high- $k_{b}$ zone, the return condensate flux will be large enough to maintain refluxing at the repository horizon, possibly resulting in water dripping on to WPs. Third, there must be sufficient spacing between the high- $k_{\mathrm{b}}$ zones to drive enough water vapor into these zones to result in the local condensate drainage flux being substantially greater than the mean condensate flux. Effectively, the high$k_{b}$ zones are competing for a finite quantity of vapor flow and condensate generation. Consequently, there is a trade-off between the duration of refluxing and the number of locations where it can occur in the repository. If there are too many such zones, there will be insufficient condensate focusing to cause persistent refluxing at the repository horizon. The degree of focusing necessary to cause persistent refluxing limits the number of locations where it can occur. Therefore, it is unlikely that refluxing can dominate the overall thermal behavior in the repository (or throughout the altered zone).

Figure 10.1.2.5.1 shows the effect of focused vapor and condensate flow on the normalized liquid saturation, $S_{1}$, distribution [see Eq. (8)] in the vicinity of an emplacement drift containing 30-yr-old SNF with an AML of 154.7 MTU/acre for two cases of a heterogeneous $k_{\mathrm{b}}$ distribution. The normalized liquid saturation, $\overline{S_{I}}$, which is given by

$$
\bar{S}_{1}=\frac{S_{1}}{S_{1, \text { init }}}
$$

where $S_{1}$ is the current liquid saturation and $S_{1, \text { init }}$ is the initial (or ambient) liquid saturation. For both cases, 1.6-m-wide, 84-darcy, high- $k_{\mathrm{b}}$ zones alternate with 36.8-m-wide, 10-millidarcy, nominal- $k_{\mathrm{b}}$ zones. For the first case of $k_{\mathrm{b}}$ heterogeneity (Figs. 10.1.2.5.1a-c), the high $k_{\mathrm{b}}$ zones are vertically aligned along the axis of the emplacement drifts. For the second case of $k_{\mathrm{b}}$ heterogeneity (Figs. 10.1.2.5.1d-f), the high $-k_{\mathrm{b}}$ zones are vertically aligned along the midline of the pillar separating emplacement drifts. For the first case, we also considered an AML of 49.2 MTU/acre for 10-yr-old SNF (Figs. 10.1.2.5.2a-c) and 20-yr-old SNF (Figs. 10.1.2.5.2d-e).

For the first case of $k_{\mathrm{b}}$ heterogeneity, the gas-phase pressure differential between the high- and nominal- $k_{\mathrm{b}}$ zones drives water vapor back toward the drift and into the high- $k_{\mathrm{b}}$ zone (Figs. 10.1.2.5.1a and b). Water vapor flows up the high- $k_{\mathrm{b}}$ zone until it condenses and drains back down. In effect, the emplacement drift functions as a manifold that enhances the gas-phase communication between the highand nominal- $k_{b}$ zones. If enough water vapor enters and condenses in this zone, the condensate drainage flux will be large enough to maintain refluxing in the repository. The resulting heat-pipe effect enables the temperature at the top of the drift to remain at the boiling point, causing a depression in the dryout zone (Figs. 10.1.2.5.1a). In spite of persistent refluxing, the temperatures along most of the remainder of the drift wall, the air in the drift, and the WP itself are well above boiling. Therefore, although liquid water may be dripping in the drift, $R H$ around the WP can still be low. This situation creates very large gradients in temperature, liquid saturation and $R H$, all of which need to be considered in assessing the potential for coupled T-H-M-C processes.

The heat-pipe zone attracts heat flow (mainly by conduction) from the neighboring, nominal- $k_{b}$ rock. In effect, the heat-pipe zone functions as a "cooling fin" that is manifested by an elongated region of liquid saturation buildup (Fig. 10.1.2.5.1). The process of gas-phase focusing into the heat-pipe zone develops more quickly than the process of attracting heat from the neighboring rock. Within $8.5 \mathrm{yr}$, enough heat is being conducted into the heat-pipe zone for the 154.7-MTU/acre case to overwhelm the heat pipe, causing the top of the drift to begin to dry out. Although the top of the drift has dried out, focused vapor and condensate flow continues to cause refluxing in the high- $k_{\mathrm{b}}$ zone, resulting in a depression in the upper dryout zone (Fig. 10.1.2.5.1b). Preferential heat conduction into the high- $k_{b}$ zone continues to dry it out, and the manifestation of focused vapor and condensate flow on the dryout zone gradually diminishes, until at $200 \mathrm{yr}$, it is no longer evident (Fig. 10.1.2.5.1c). Thereafter, the dryout zone continues to develop as though the rock had a homogeneous $k_{\mathrm{b}}$ of 3.5 darcy, which is the bulk average of rock comprised of a 1.6-m-wide, 84-darcy zone and a 36.8-m-wide, 10-millidarcy zone. 
For the second case of $k_{\mathrm{b}}$ heterogeneity, the duration of refluxing at the repository horizon (Figs. 10.1.2.5.1d and $\mathrm{e}$ ) is considerably longer $(40 \mathrm{yr})$ than in the first case (Fig. 10.1.2.5.1a). However, the ramifications of refluxing on WP performance are beneficial for the second case rather than deleterious as in the first case of $k_{\mathrm{b}}$ heterogeneity. Instead of potentially contributing to liquid contact on the WP, the refluxing zone in the pillar provides a conduit for condensate drainage through the repository horizon. This shedding of condensate around the emplacement drift may benefit WP performance by mitigating the buildup of condensate above the repository horizon. The refluxing zone continues to completely penetrate through the dryout zone at $30 \mathrm{yr}$ (Fig. 10.1.2.5.1d). As in the preceding example, the refluxing zone functions as a cooling fin that preferentially attracts heat flow from the neighboring rock. However, when the refluxing zone is not coincident with the heat sources (the WPs), as it is in the pillar, it takes longer for preferential heat flow to overwhelm the refluxing zone and begin to dry it out (Fig. 10.1.2.5.1e). Consequently, heat pipes further away from the WP heat sources are more likely to persist longer than heat pipes that are closer. Similarly, heat pipes that are closer to cold WPs in a thermal design which the WPs are thermally isolated from one another (such as occurs in the ACD rev 00 design) will be more persistent than those close to hot WPs. This variability in the likelihood and/or duration of heat pipes could lead to a highly heterogeneous distribution of decay-heat-driven alteration in the near field and altered zone.

At $200 \mathrm{yr}$, the manifestation of focused vapor and condensate flow on the dryout zone is no longer evident, and the two cases have nearly identical dryout zones (Figs. 10.1.2.5.1c and $f$ ). Thereafter, the dryout zone continues to develop as though the rock had a homogeneous $k_{\mathrm{b}}$ of 3.5 darcy.

For 10-yr-old SNF and an AML of 49.2 MTU/acre, refluxing persists at the top of the drift for $65 \mathrm{yr}$ (Fig. 10.1.2.5.2a), which is considerably longer than the 8.5-yr duration of refluxing for the 154.7MTU/acre case (Fig. 10.1.2.5.1a). Focused vapor and condensate flow continue to cause a depression in the upper dryout front (Figs. 10.1.2.5.2b and c) for 1000 yr. It is important to note that this case is only able to generate marginal boiling conditions; consequently, there is insufficient heat to coalesce the dryout zones between neighboring drifts. Moreover, the local heat flux from the WP is at best only sufficient to drive the rewetting front in the high- $k_{\mathrm{b}}$ zone $1.5 \mathrm{~m}$ away from the top of the drift (Fig. 10.1.2.5.2b). After boiling ceases, condensate drainage in the high- $k_{\mathrm{b}}$ zone rewets the top of the drift (Fig. 10.1.2.5.2c). However, the liquid saturation is less than the critical saturation for a mobile liquid phase in the fractures; consequently, the equivalent continuum model (ECM) predicts matrix-dominated condensate drainage at $1000 \mathrm{yr}$ (Fig. 10.1.2.5.2c). With the ECM, we cannot determine whether this condensate flux results in nonequilibrium fracture flow and dripping onto WPs.

We also analyzed a 49.2-MTU/acre case, with the subtle difference that it contains 20-yr-old SNF rather than the 10-yr-old SNF in the previous example. In past studies, we found that long-term, mountain-scale, thermal-hydrological behavior primarily depends on AML and is less sensitive to SNF age. However, at the drift scale, sub-to-marginal boiling conditions result in thermal-hydrological behavior that is extremely sensitive to SNF age. For 20-yr-old SNF and an AML of 49.2 MTU/acre, refluxing (with a mobile liquid phase in the fractures) persists at the top of the drift for at least $1575 \mathrm{yr}$ (Figs. 10.1.2.5.2d and e; note that $1575 \mathrm{yr}$ is not shown). This thermal load generates marginal boiling conditions, which last only $160 \mathrm{yr}$, and is insufficient to coalesce the dryout zones between neighboring drifts. There is also not enough heat to overwhelm the heat pipe and dry out the rock at the top of the drift. At $2534 \mathrm{yr}$, the liquid saturation in the high- $k_{\mathrm{b}}$ zone is quite high relative to ambient conditions (Fig. 10.1.2.5.2f), although it is less than the critical saturation for a mobile liquid phase in the fractures. However, with the ECM, we cannot determine whether this condensate flux results in nonequilibrium fracture flow and dripping onto WPs. The effect of gravity-driven refluxing is evident in Figs. 10.1.2.5.2e and $f$. Notice that, although focused condensate drainage ceases below the repository horizon, it continues above. The condensate buildup in the high- $k_{\mathrm{b}}$ zone persists for more than $5000 \mathrm{yr}$. It is important to note that decay heat continues to generate a significant condensate flux well after boiling has stopped. Consequently, decay-heat-driven coupled T-H-M-C processes may alter flow and transport properties for a considerable period even for a low-AML repository. To diagnose the potential for these coupled T-H-M-C effects to alter flow and transport properties, in situ thermal tests that are of sufficient size and duration are required[Buscheck et al., 1993a, 1993b; Buscheck and Nitao, 1995]. 
Figure 10.1.2.5.3 shows the temperature history at various locations in the emplacement drift, including the WP surface, for AMLs of 49.2, 77.4, and 154.7 MTU/acre. This example is similar to the first case of $k_{\mathrm{b}}$ heterogeneity described above with one difference; for the high $k_{\mathrm{b}}$ zone, $k_{\mathrm{b}}=414$ darcy rather than 84 darcy. We made this change to further enhance the degree of gas-phase focusing and the resulting duration of refluxing in the vicinity of the drift. For all three examples, focused vapor and condensate flow causes refluxing to persist in the high $-k_{\mathrm{b}}$ zone at the top of the drift. As long as refluxing persists at the top of the drift, it prevents the temperature there from exceeding the boiling point. For the 10-yr-old SNF, 49.2-MTU/acre case, refluxing persists at the top of the drift for more than $2000 \mathrm{yr}$, long after boiling has ceased (Fig. 10.1.2.5.3a). For the 30-yr-old SNF, 77.4-MTU/acre case, refluxing persists at the top of the drift for $150 \mathrm{yr}$ (Fig. 10.1.2.5.3b), while for the 154.7-MTU/acre case, refluxing persists for 30 yr (Fig. 10.1.2.5.3c). During the time that refluxing prevented the temperature in the high- $k_{\mathrm{b}}$ zone from exceeding the boiling point, temperatures throughout the rest of drift were well above boiling. For example, the temperature at the upper corner of the drift (only $2.8 \mathrm{~m}$ away from the high- $k_{\mathrm{b}}$ zone) managed to climb to 105,111 , and $144^{\circ} \mathrm{C}$ for the $49.2-, 77.4-$, and 154.7-MTU/acre cases, respectively (Fig. 10.1.2.5.3). The corresponding WP surface temperatures were 121,128 , and $176^{\circ} \mathrm{C}$ (Fig. 10.1.2.5.3).

Based on experience with geothermal reservoirs, some have suggested that heat-pipe zones, spaced every $100 \mathrm{~m}$, have the potential of convecting enough heat away from the repository to prevent its temperature from rising above the boiling point. However, we found in these examples, covering a wide range of AMLs, that the heat-pipe zone could not prevent the temperature at a location only $2.8 \mathrm{~m}$ away from exceeding the boiling point. Convection-dominated heat flow occurs in the heat-pipe zone, while in the neighboring rock, heat flow primarily occurs as heat conduction. Heat must be conducted from the heat sources (the WPs) to the heat-pipe zone in order for that zone to significantly influence repository temperatures. Heat cannot be conducted in relatively low thermal conductivity rock unless a significant temperature gradient is established, thereby causing temperatures away from the heat-pipe zone to be elevated above the boiling point. 

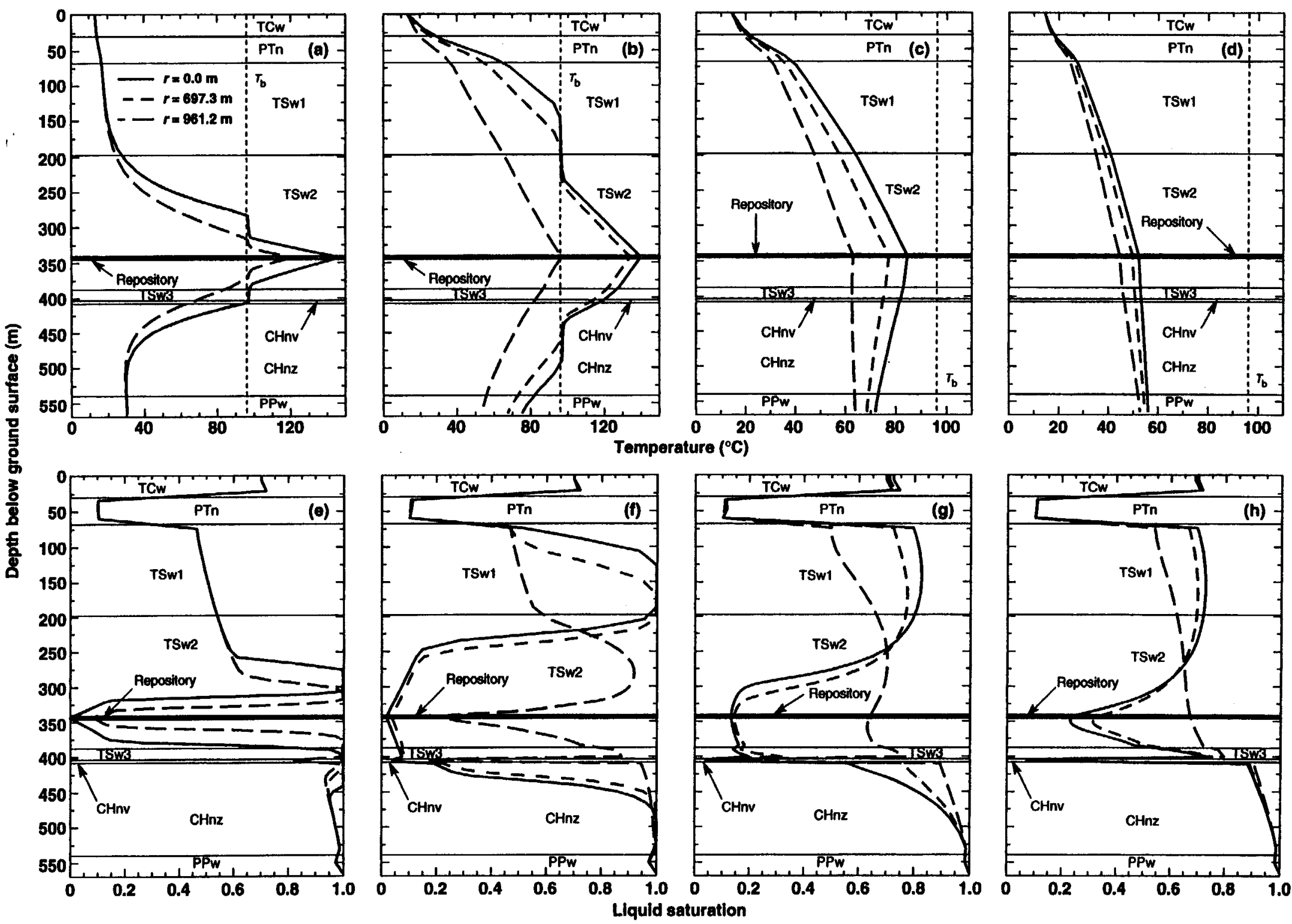

Figure 10.1.2.1.1. Vertical temperature profiles at various radial distances, $r$, for AML $=83.4 \mathrm{MTU} / \mathrm{acre}$ at (a) $t=100 \mathrm{yr}$, (b) $t=1000 \mathrm{yr}$, (c) $t=10,000 \mathrm{yr}$, and (d) $t=33,000 \mathrm{yr}$. Note different temperature scales. Vertical liquid saturation profiles are also plotted at (e) $t=100 \mathrm{yr}$, (f) $t=1000 \mathrm{yr}$, (g) $t=10,000 \mathrm{yr}$, and (h) $t=33,000$ yr. Matrix properties for the TSw1 and TSw2 are based on Klavetter and Peters (1986). Binary gas-phase tortuosity factor $\tau_{\mathrm{eff}}=0.2$ for all units. 

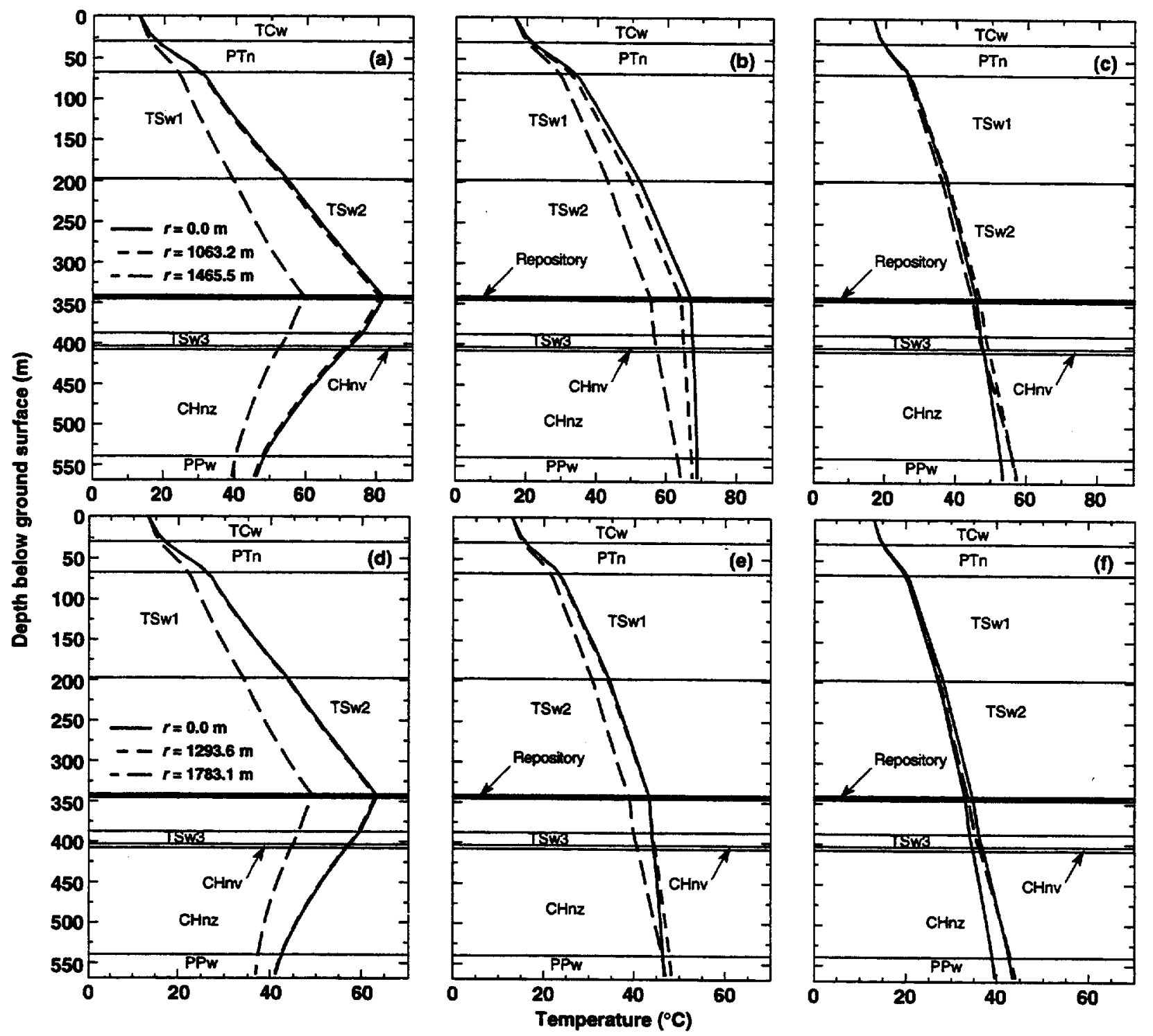

Figure 10.1.2.1.2. Vertical temperature profiles at various radial distances, $r$, from the repository centerline for an AML of $35.9 \mathrm{MTU} / \mathrm{acre}$ at (a) $t=1000 \mathrm{yr}$, (b) $t=10,000 \mathrm{yr}$, and (c) $t=32,000 \mathrm{yr}$. Vertical temperatures profiles for an AML of $24.2 \mathrm{MTU} /$ acre are also plotted at (d) $t=1000 \mathrm{yr}$, (e) $t=10,000 \mathrm{yr}$, and (f) $t=32,000 \mathrm{yr}$. Note different temperature scales. 

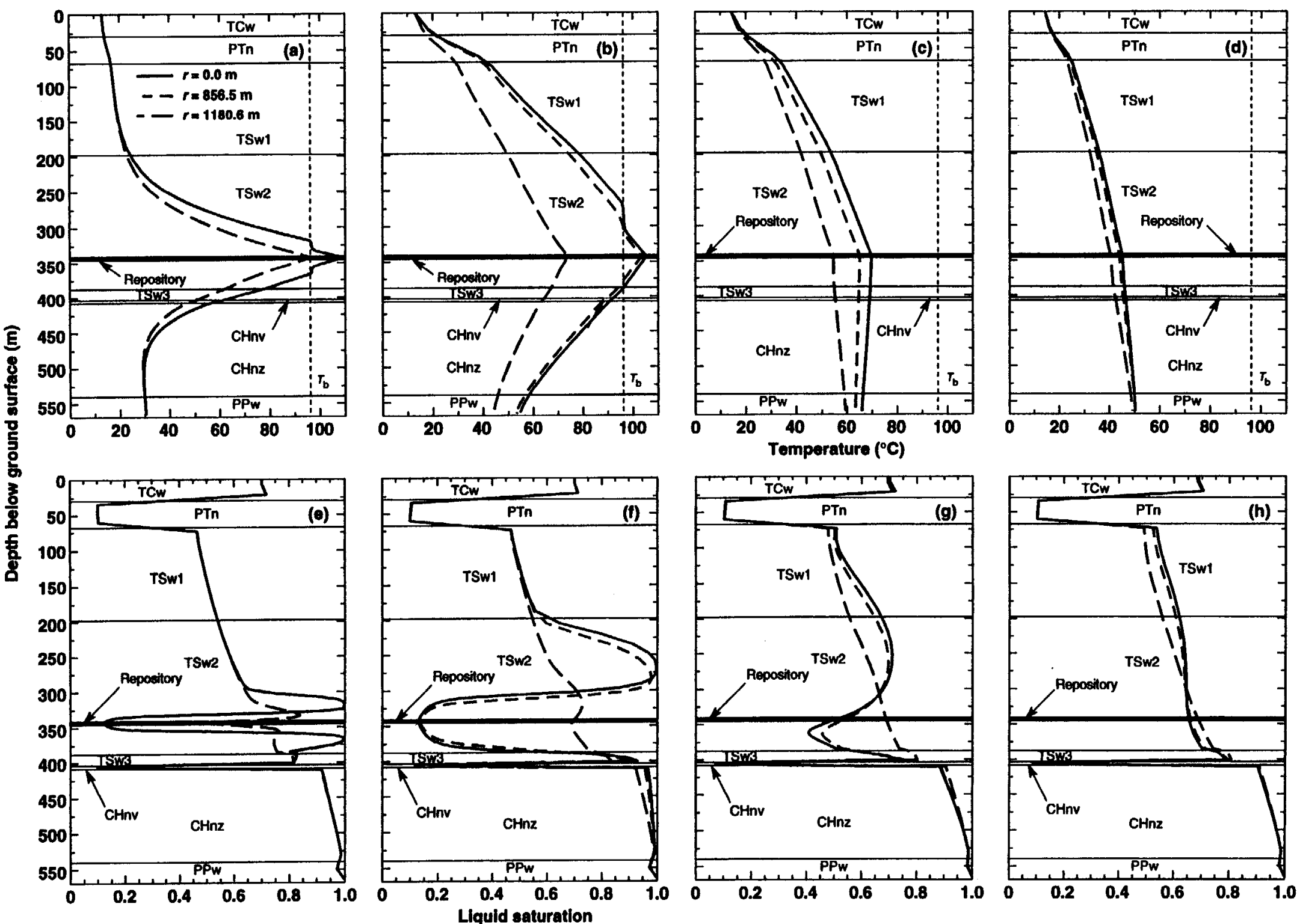

Figure 10.1.2.1.3. Vertical temperature profiles at various radial distances, $r$, for $\mathrm{AML}=55.3 \mathrm{MTU} / \mathrm{acre}$ at (a) $t=100 \mathrm{yr}$, (b) $t=1000 \mathrm{yr}$, (c) $t=10,000 \mathrm{yr}$, and (d) $t=33,000 \mathrm{yr}$. Vertical liquid saturation profiles are also plotted at (e) $t=100 \mathrm{yr}$, (f) $t=1000 \mathrm{yr},(\mathrm{g}) t=10,000 \mathrm{yr}$, and (h) $t=33,000 \mathrm{yr}$. Matrix properties for the TSw 1 and TSw2 are based on Klavetter and Peters (1986). Binary gas-phase tortuosity factor $\tau_{\text {eff }}=0.2$ for all units. 

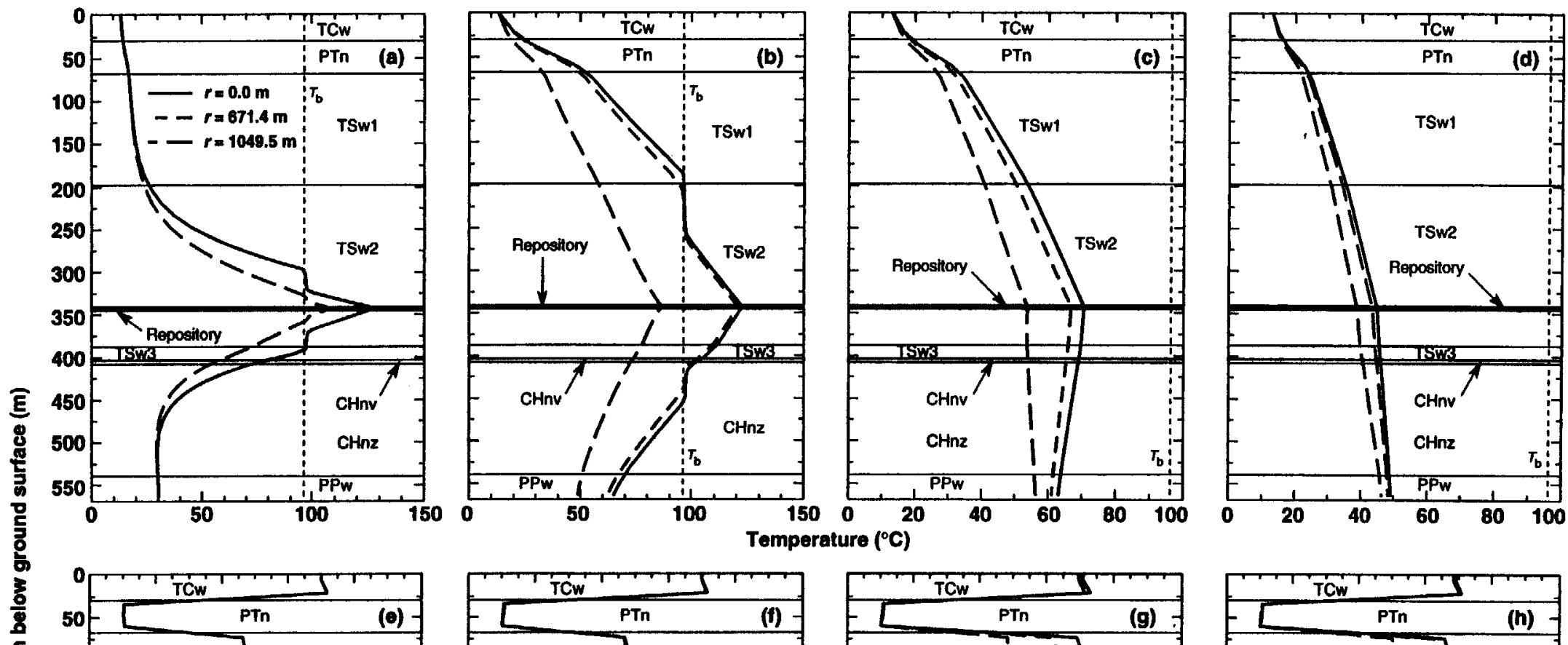

吾 1
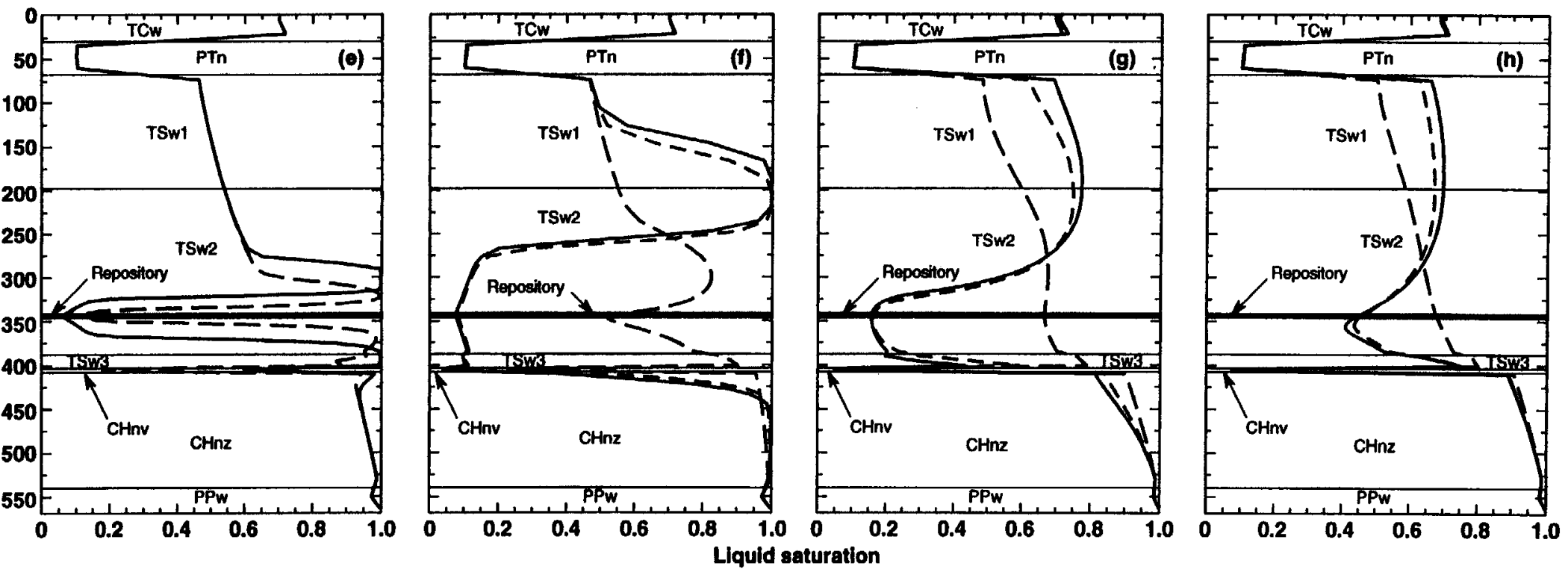

Figure 10.1.2.1.4. Vertical temperature profiles at various radial distances, $r$, for AML $=70.0$ MTU/acre at (a) $t=100 \mathrm{yr}$, (b) $t=1000 \mathrm{yr}$, (c) $t=10,000 \mathrm{yr}$, and (d) $t=32,750 \mathrm{yr}$. Note different temperature scales. Vertical liquid saturation profiles are also plotted at (e) $t=100 \mathrm{yr}$, (f) $t=1000 \mathrm{yr}$, (g) $t=10,000 \mathrm{yr}$, and (h) $t=32,750$ yr. Matrix properties for the TSw1 and TSw2 are based on Klavetter and Peters (1986). Binary gas-phase tortuosity factor $\tau_{\text {eff }}=0.2$ for all units. 


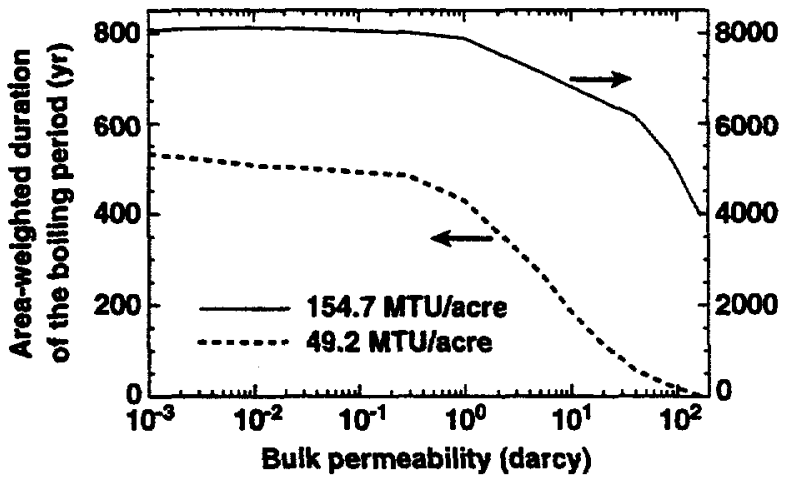

Figure 10.1.2.2.1. Area-weighted duration of the boiling period as a function of bulk permeability for AMLs of 49.2 and 154.7 MTU/acre. Note that the time scales differ by a factor of 10 . 

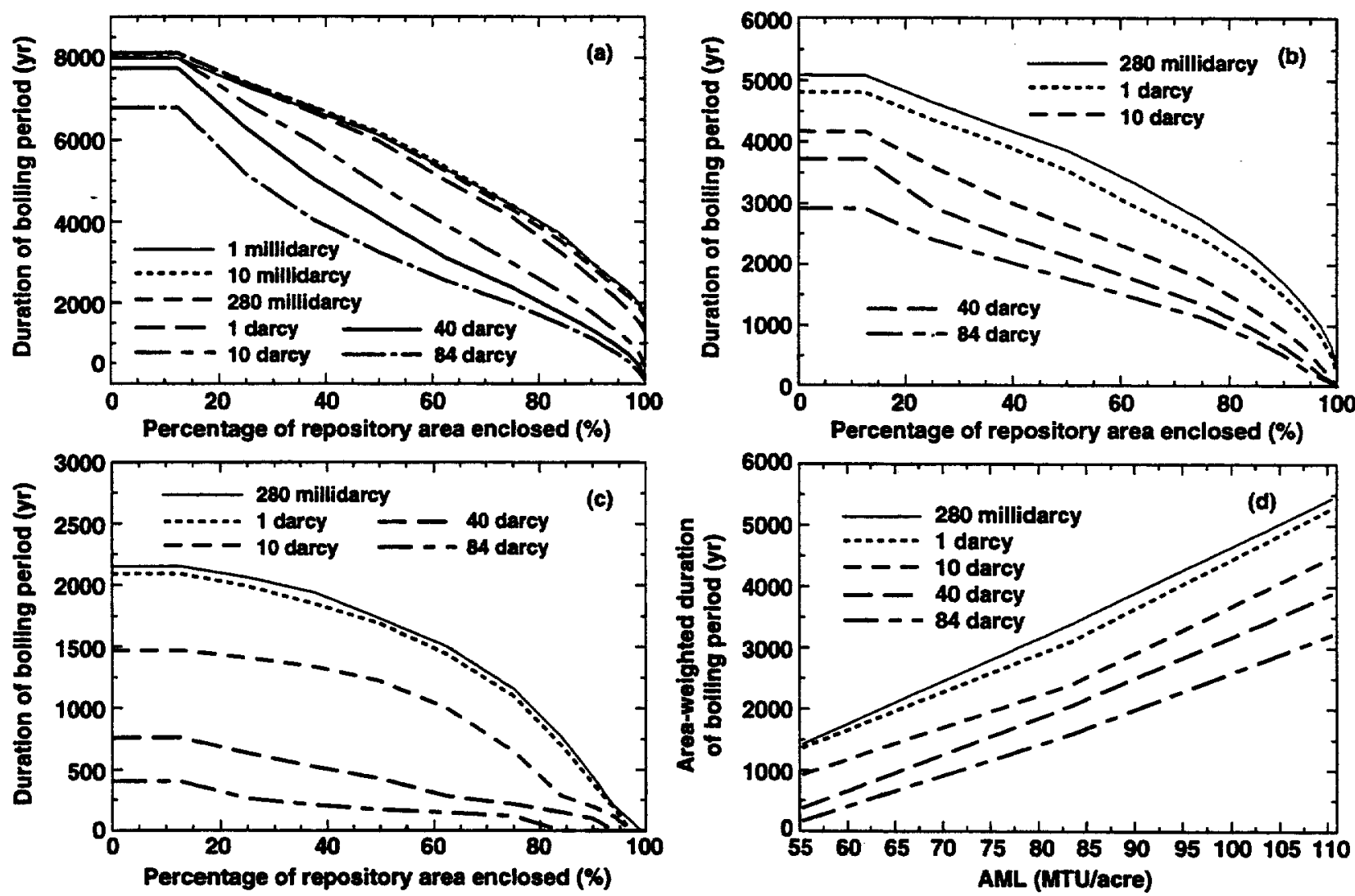

Figure 10.1.2.2.2. Duration of the boiling period at various repository locations for AMLs of (a) 110.5,

(b) 83.4, and (c) $55.3 \mathrm{MTU} / \mathrm{acre}$. The locations are identified as the percentage of the repository area enclosed, with $0 \%$ corresponding to the repository center, and $100 \%$ corresponding to the outer perimeter. (d) Area-weighted duration of the boiling period as a function of AML. 

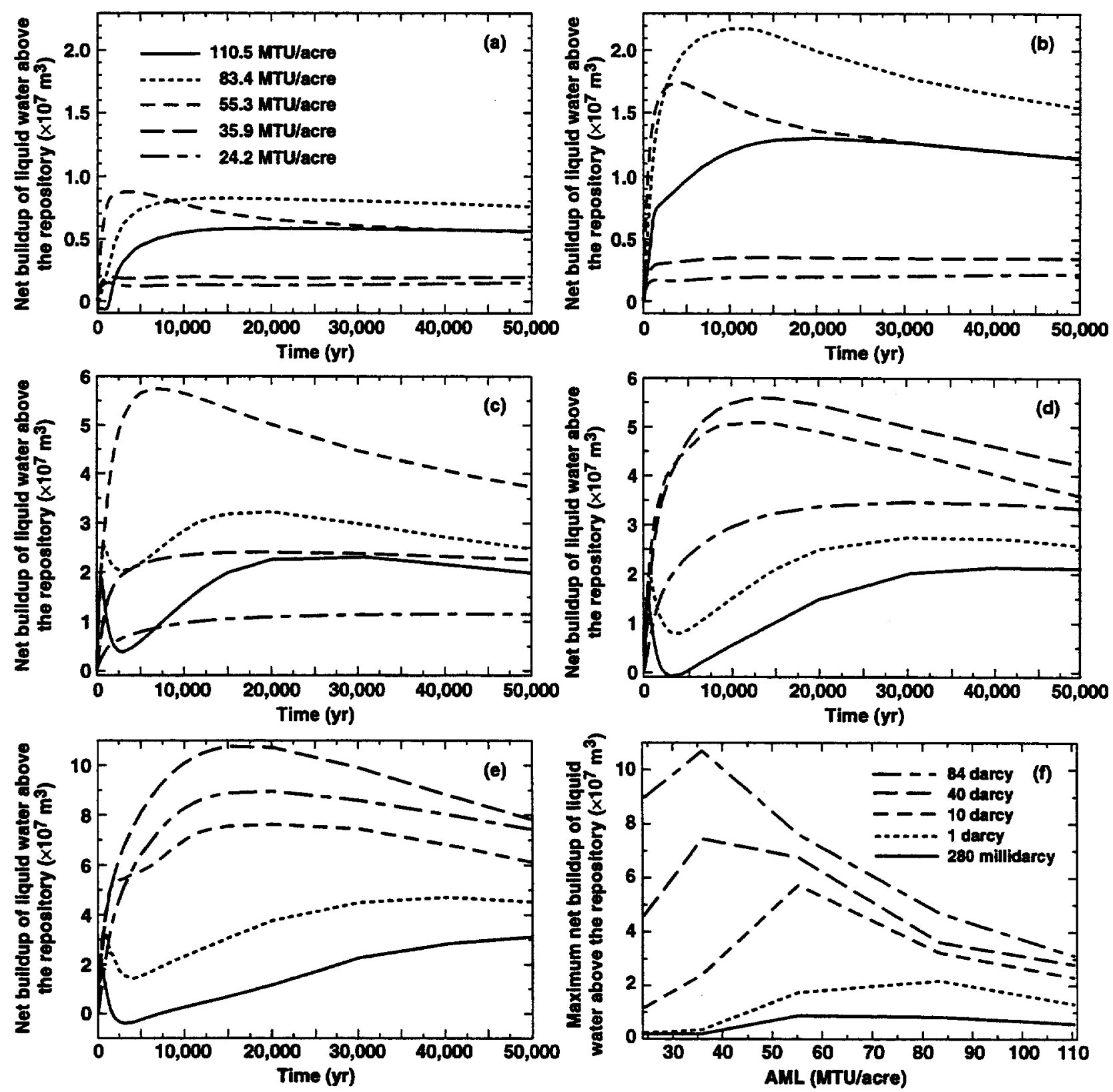

Figure 10.1.2.2.3. Net buildup of liquid water above the repository vs time for various AMLs and $k_{\mathrm{b}}$ values of (a) 280 millidarcy and (b) 1, (c) 10, (d) 40, and (e) 84 darcy. (f) Maximum net buildup of liquid water above the repository as a function of AML for various values of $k_{\mathrm{b}}$. 


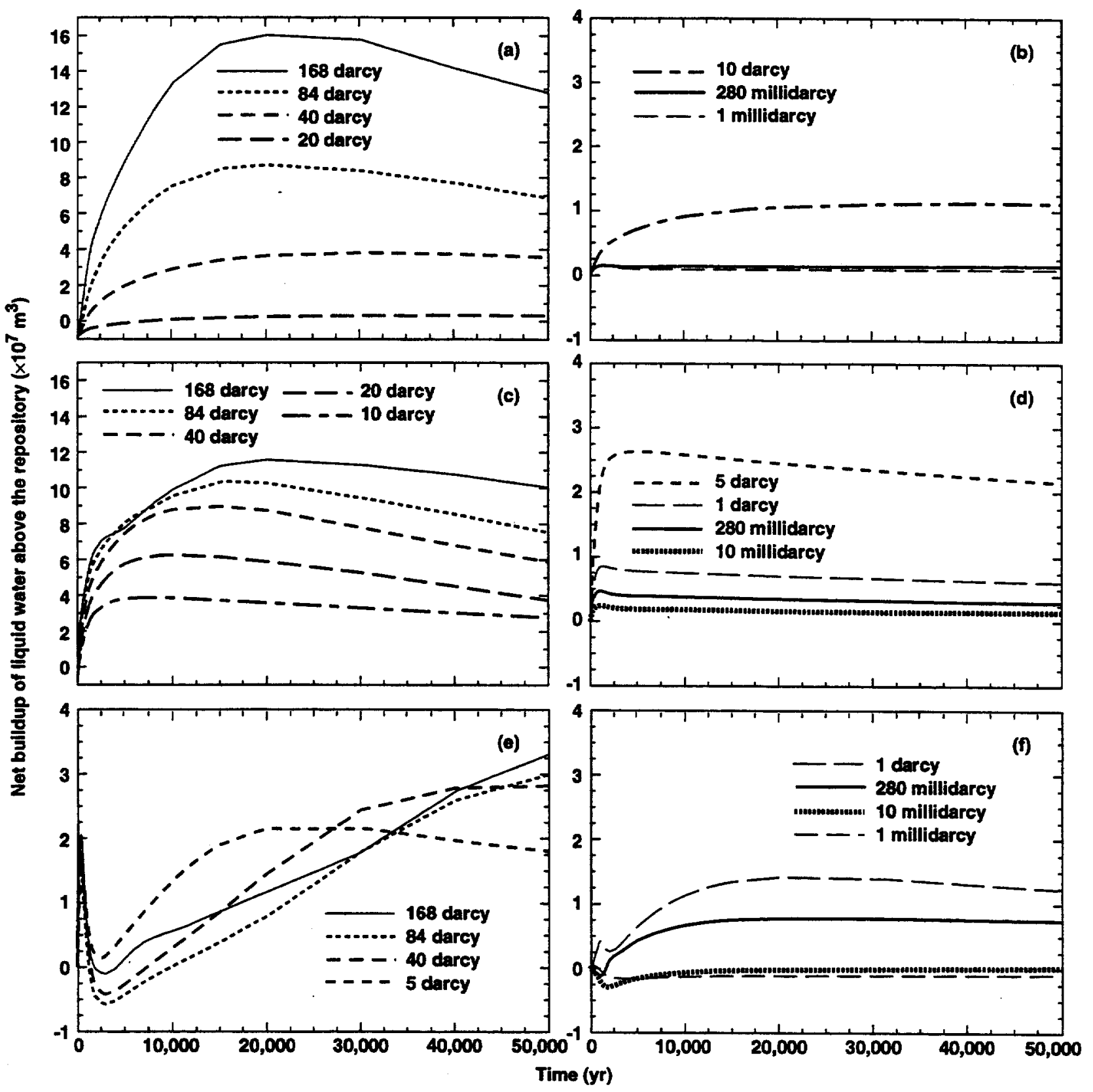

Figure 10.1.2.2.4. Net buildup of liquid water above the repository for various values of $k_{\mathrm{b}}$ and AMLs of 27.1 MTU/acre ( $a$ and b), 49.2 MTU/acre ( $c$ and d), and 154.7 MTU/acre (e and f). 


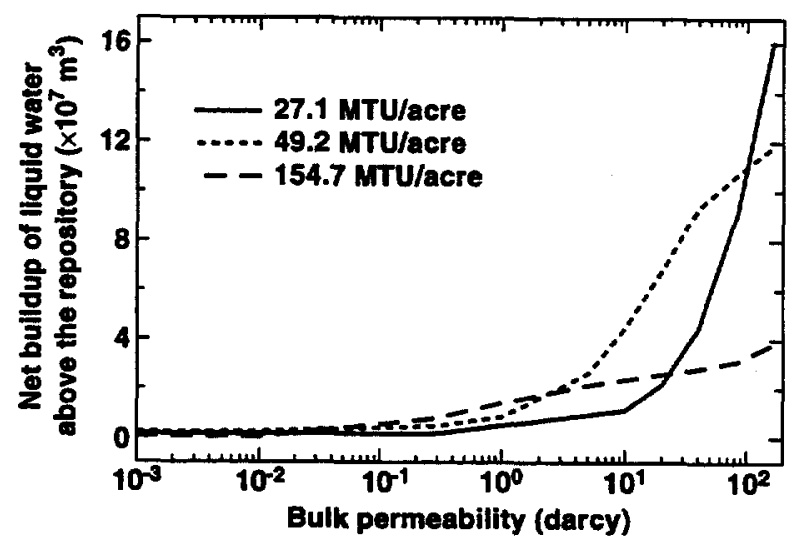

Figure 10.1.2.2.5. Maximum net buildup of liquid water above the repository as a function of bulk permeability for various AMLs. 


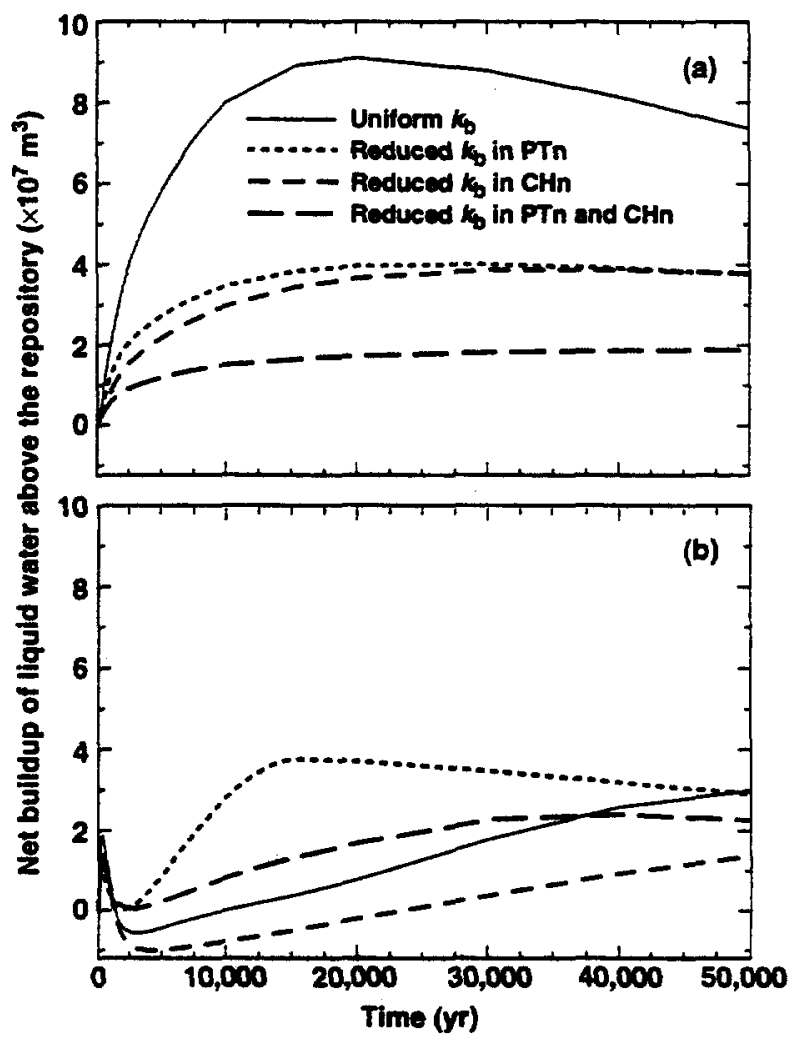

Figure 10.1.2.3.1. Net buildup of liquid water above the repository for various vertical $k_{\mathrm{b}}$ distributions and AMLs of (a) 27.1, and (b) 154.7 MTU/acre. Uniform $k_{\mathrm{b}}=84$ darcy. The value of $k_{\mathrm{b}}$ in the PTn is reduced to 320 millidarcy, and in the $\mathrm{CHn}$, to 280 millidarcy. 


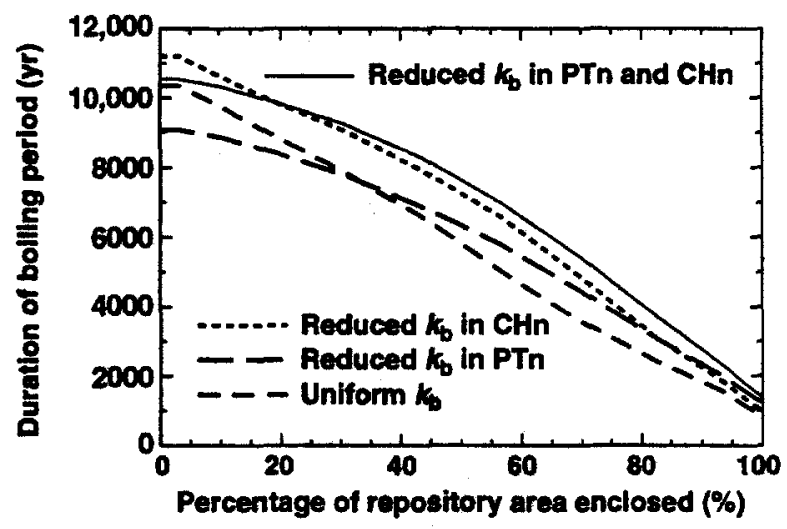

Figure 10.1.2.3.2. Duration of the boiling period at various repository locations for various vertical $k_{\mathrm{b}}$ distributions and an AML of 154.7 MTU/acre. Uniform $k_{\mathrm{b}}=84$ darcy. The value of $k_{\mathrm{b}}$ in the PTn is reduced to 320 millidarcy, and in the $\mathrm{CH}$, to 280 millidarcy. The repository locations are identified as the percentage of the repository area enclosed, with $0 \%$ corresponding to the repository center, and $100 \%$ corresponding to the outer perimeter. 

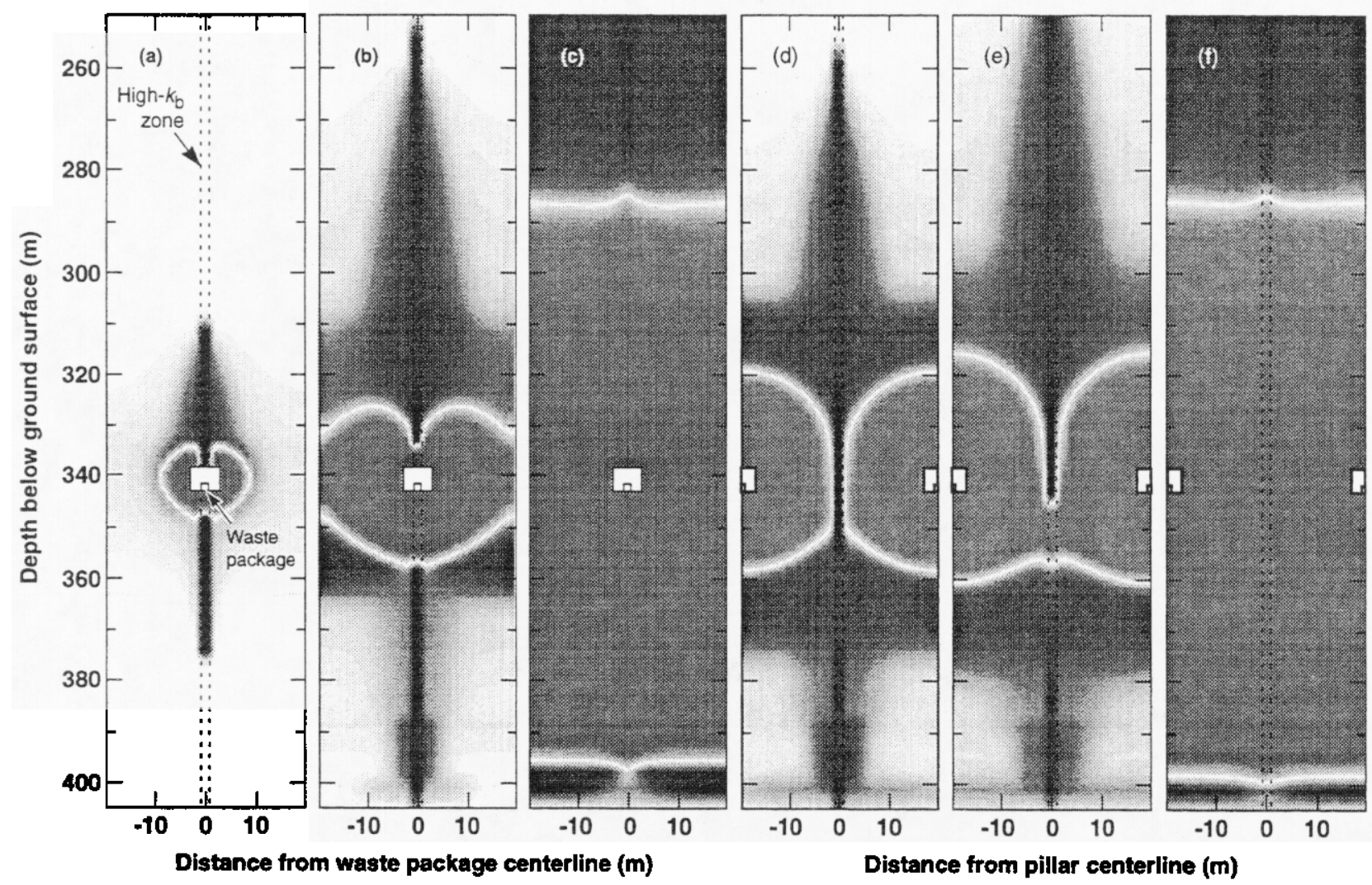

Figure 10.1.2.5.1. Dimensionless liquid saturation distribution orthogonal to an emplacement drift containing 30-yr-old SNF, for an AML of $154.7 \mathrm{MTU} / \mathrm{acre}$ and and APD of $114 \mathrm{~kW} / \mathrm{acre}$. Within the 1.6-m-wide, high- $k_{\mathrm{b}}$ zone, $k_{\mathrm{b}}=84$ darcy; otherwise $k_{\mathrm{b}}=10$ millidarcy. Distributions are shown at time $t$ of (a) 8 , (b) 30 , (c) $200 \mathrm{yr}$ for a $k_{\mathrm{b}}$ distribution in which the high- $k_{\mathrm{b}}$ zone intersects the center of the emplacement drift. Distributions are also shown at time $t$ of (d) 30 , (e) 40 , and (f) $t=200 \mathrm{yr}$ for a $k_{\mathrm{b}}$ distribution in which the high- $k_{\mathrm{b}}$ zone intersects the center of the pillar separating the emplacement drifts. The medium-shaded area surrounding the drift corresponds to a region that is drier than ambient saturation (dry-out zone). The dark-shaded areas correspond to regions that are wetter than ambient saturation (condensation zones). The lighter shading surrounding the dark-shaded area corresponds to a decreasing buildup in saturation (outer edges of condensation zones). No shading indicates no change in saturation. Note that the transition from drier to wetter conditions is shown as a white ring at early time which becomes a white band at later time. 


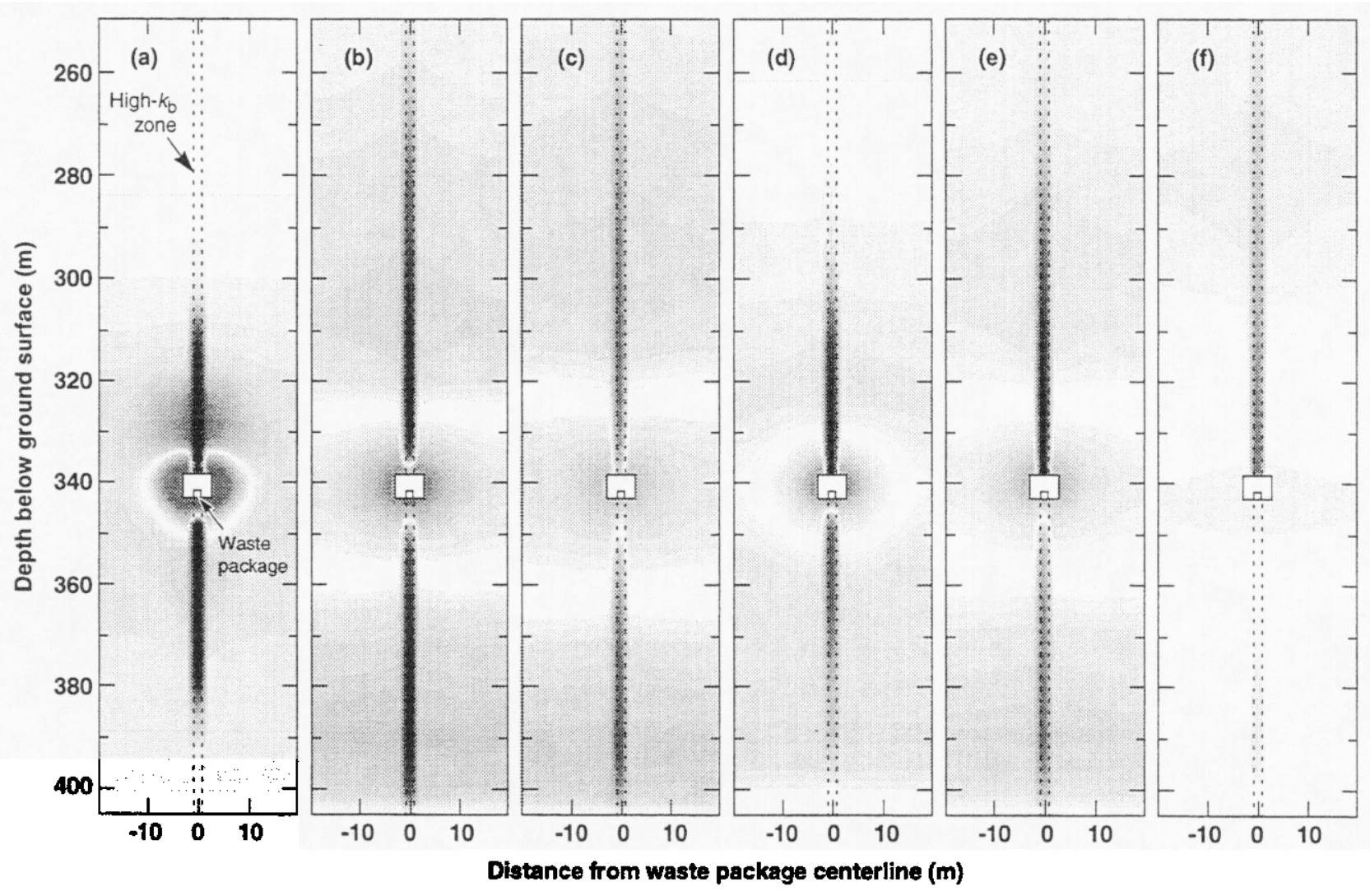

Figure 10.1.2.5.2. Dimensionless liquid saturation distribution orthogonal to an emplacement drift containing SNF, for an AML of $49.2 \mathrm{MTU} / \mathrm{acre}$. Within the 1.6-m-wide, high- $k_{\mathrm{b}}$ zone, $k_{\mathrm{b}}=84$ darcy; otherwise $k_{\mathrm{b}}=10$ millidarcy. Distributions are shown at time $t$ of (a) 62, (b) 663, (c) $1000 \mathrm{yr}$ for 10-yr-old SNF and an APD of $57 \mathrm{~kW} / \mathrm{acre}$. Distributions are also shown at time $t$ of (d) 159, (e) 661, and (f) $2534 \mathrm{yr}$ for 20-yr-old SNF and an APD of $43.7 \mathrm{~kW} / \mathrm{acre}$. The medium-shaded area surrounding the drift corresponds to a region that is drier than ambient saturation (dry-out zone). The dark-shaded areas correspond to regions that are wetter than ambient saturation (condensation zones). The lighter shading surrounding the dark-shaded area corresponds to a decreasing buildup in saturation (outer edges of condensation zones). No shading indicates no change in saturation. Note that the transition from drier to wetter conditions is shown as a white ring at early time which becomes a white band at later time. 

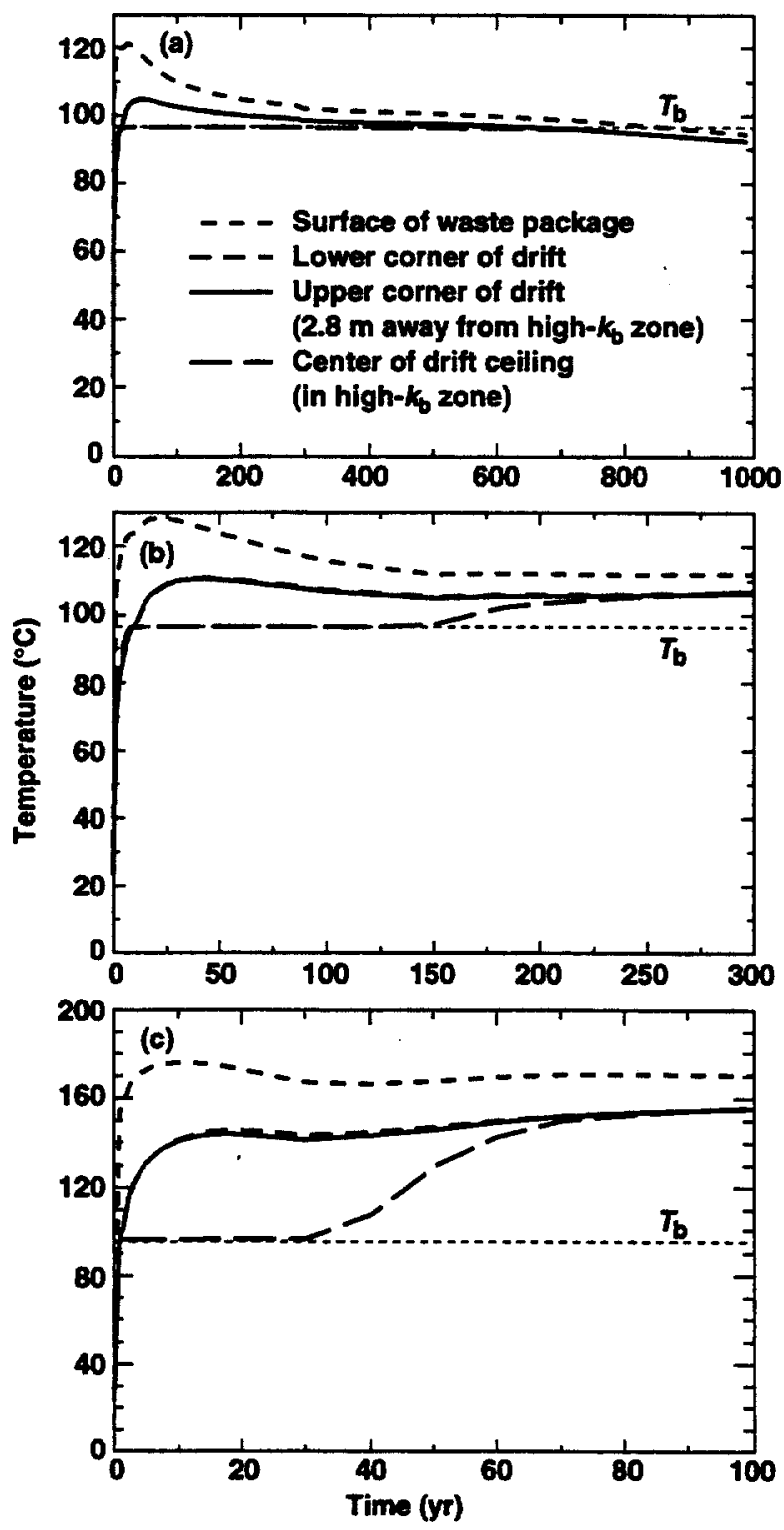

Figure 10.1.2.5.3. Temperature history at various locations in the emplacement drift for (a) 10-yr-old SNF, an APD of $57 \mathrm{~kW} / \mathrm{acre}$, and an AML of 49.2 MTU/acre, (b) 30-yr-old SNF, an APD of $57 \mathrm{~kW} / \mathrm{acre}$, and an AML of 77.4 MTU/acre, and (c) 30-yr-old SNF, an APD of $114 \mathrm{~kW} / a c r e$, and an AML of $154.7 \mathrm{MTU} / \mathrm{acre}$. Vertically oriented, 1.6-m-wide, 414-darcy zones are separated by 36.8 -m-wide, 10 -millidarcy zones. 


\section{Content}

10.1.3 Influence of Matrix Hydrological Property Distribution...................................................10.1-44 


\subsubsection{Influence of Matrix Hydrological Property Distribution}

10.1.3.1 Boiling-Driven Vapor and Heat Flow. The mountain-scale analysis in the preceding section (Section 10.1.2), which focused on the influence of the fracture permeability distribution on thermalhydrological $(T-H)$ behavior, assumed the matrix hydrological data from the RIB [DOE, 1990] and Klavetter and Peters [1986]. In this section, we investigate the sensitivity of mountain-scale T-H behavior to more recently obtained matrix property data for the TSw1 and TSw2 units. As in the preceding section (Section 10.1.2), a zero ambient percolation flux is assumed. Because more recent assessments of the ambient percolation flux [Bodvarsson et al., 1996] indicate the likelihood of greater than zero net infiltration (resulting in a nonzero ambient percolation flux in the host rock), the calculations reported in this section probably overpredict the spatial and temporal extent of less-than-ambient liquid saturation and relative humidity $R H$ conditions in the $U Z$, in general, and in the repository rock, in particular. Nonetheless, a quantitative understanding about the influence of matrix hydrological properties on dryout and rewetting behavior can be obtained from the wide range of cases that are presented in this section.

Much of the following information is presented as tables of temperature $T$ and relative humidity $R H$ at various locations in the repository rock. This information is provided to facilitate evaluating the likelihood of aqueous reactions and aqueous-transport processes giving rise to significant alteration of flow and transport properties. These processes depend on $T$ and $R H$. For example, low $R H$ (which corresponds to low liquid saturation and generally lower liquid-phase flux) reduces the likelihood of many of these processes generating significant effects; where these processes may be significant, the rate at which aqueous reactions occur depends on $T$.

The temporal extent of $R H$ reduction in the repository rock (which is provided in the tables) is also a good indication of the spatial extent of $R H$ reduction in the altered zone in general. Long-duration $R H$ reduction in the repository rock requires that $R H$ be reduced over a very large spatial extent. Vertical liquid saturation profiles are provided to help interpret the spatial extent of reduced $R H$ conditions in the altered zone. Liquid saturations well below ambient correspond to low $R H$. Liquid saturations that are moderately below ambient correspond to intermediate-to-high $\mathrm{RH}$; liquid saturations that are close to ambient correspond to $R H \approx 98-99 \%$.

Vertical temperature profiles are also provided to facilitate evaluating the impact of $T$ on the likelihood of aqueous reactions and aqueous-transport processes giving rise to significant alteration of flow and transport properties. The zone of two-phase refluxing overlying the boiling zone (called the heat-pipe zone) is of particular interest because the liquid saturation and relative humidity $\mathrm{RH}$ remain high in this zone, increasing the likelihood of aqueous reactions and aqueous-transport processes occurring. Refluxing can also generate a very high liquid-phase flux in fractures, which can result in significant dissolution and precipitation of minerals along the fracture walls. The heat-pipe zone is typically manifested by temperatures that are very close to the nominal boiling point of water $\left(96^{\circ} \mathrm{C}\right)$ and a liquid saturation that is very close to $100 \%$.

Table 10.1.3.1.1 summarizes the time required to attain the indicated relative humidity $R H$ in the rock at various repository locations and the temperature $T$ at which that value of $R H$ is attained for the "reference" case based on the RIB [1990] and Klavetter and Peters [1986] data for AMLs of 55.3, 110.5, and $150 \mathrm{MTU} /$ acre. We repeated the mountain-scale calculations for the five sets of matrix properties for the Topopah Spring welded tuff (Table 10.1.3.1.2) that are reported in Pruess and Tsang [1994], which based on measurements by Flint and others [1993]. For zero percolation flux, the initial liquid saturation at the repository horizon is calculated to be $68,76,78,74,66$, and $64 \%$ for the six cases in Table 10.1.3.1.2, respectively. In order to result in nearly the same initial liquid water content in the TSw1 and TSw2, a porosity $\left(\phi_{\mathrm{m}}\right)$ of 0.11 was assumed for the three cases that yielded lower initial liquid saturation $S_{\ell, \text { init }}$ (reference case, LBL-USGS-3.4, and LBL-USGS-3.3) and $\phi_{m}=0.10$ for the three cases that yielded higher $S_{\ell, \text { init }}($ LBL-USGS-3.5, LBL-USGS-3.2, and LBL-USGS-3.1/3.6). Although these six cases have different 
values of saturated matrix permeability, $k_{\mathrm{m}}$ they all share the same bulk permeability $k_{\mathrm{b}}$ of 280 millidarcy.

For AMLs of 55.3, 110.5, and $150 \mathrm{MTU} /$ acre, and for the five sets of LBL-USGS matrix property data, Tables 10.1.3.1.3-10.1.3.1.3-5 summarize $R H$ and $T$ in the rock at the same repository locations reported in Table 10.1.3.1.1 for the reference-case properties. Figures 10.1.3.1.1-10.1.3.1.6 give the vertical temperature and liquid saturation profiles for these six matrix-property cases and an AML of $110.5 \mathrm{MTU} / \mathrm{acre}$. To show the influence of edge-cooling/rewetting/shedding effects on $\mathrm{T}-\mathrm{H}$ behavior, vertical profiles are given at three repository locations, including: (1) $r=0.0 \mathrm{~m}$, which is at the center of the repository, (2) $r=$ $606.0 \mathrm{~m}$, which is the "median" repository location that encloses $50 \%$ of the repository (i.e., $50 \%$ of the repository lies between that location and the repository edge), and (3) $r=835.2 \mathrm{~m}$, which encloses $95 \%$ of the repository (i.e., only $5 \%$ of the repository area lies outside of that location).

For all matrix-property cases, similar thermal and dryout behavior occur over the inner half of the repository, particularly during the first $1000 \mathrm{yr}$; thereafter, edge-cooling/rewetting effects cause the $50 \%$ repository location to have slightly cooler temperatures and a slightly less extensive dryout zone than the center of the repository. For the $95 \%$ repository location, edge-cooling/rewetting/shedding effects significantly reduce temperatures and reduce both the vertical extent and magnitude of rock dryout. (Note that Section 1.10.6 of Chapter 1 also discusses the influence of edge-cooling/rewetting/shedding effects on mountain-scale and drift-scale T-H behavior.)

For AML = 110.5 MTU/acre, the five LBL-USGS matrix property cases fall into four categories with respect to the rate at which the repository rock rewets to humid ambient $R H$ :

Fast rewetting rate: LBL-USGS-3.2 results in much faster rewetting to ambient $R H$ than the reference case (compare Tables 10.1.3.1.1b and 10.1.3.1.4a). Consequently, when a given $R H$ is attained $T$, is substantially higher for LBL-USGS-3.2 than in the reference case. For example, $T$ at the repository center is $96^{\circ} \mathrm{C}$ when $\mathrm{RH}=70 \%$ as compared with $68^{\circ} \mathrm{C}$ in the reference case. The spatial extent of dryout is much less for the LBL-USGS-3.2 matrix-property case than for the reference matrixproperty case (compare Figs. 10.1.3.1.1 and 10.1.3.1.2). The reduced vertical extent of dryout reduces the magnitude of the temperature increase in the above-boiling region for LBL-USGS-3.2. For the sub-boiling region and at later time $(t>1000 \mathrm{yr})$, the vertical temperature profiles are very similar for these two cases.

Medium rewetting rate: LBL-USGS-3.5 rewets at nearly the same rate as the reference case (compare Tables 10.1.3.1.1b and 10.1.3.1.4b). Consequently, there is a similar relationship between $T$ and $R H$ in the rock. The spatial extent of dryout is slightly less for the LBL-USGS-3.5 matrix-property case than for the reference matrix-property case (compare Figs. 10.1.3.1.1 and 10.1.3.1.3). The slightly reduced vertical extent of dryout reduces the magnitude of the temperature increase in the above-boiling region for the LBL-USGS-3.5 case. For the sub-boiling region and at later time ( $t$ $>1000 \mathrm{yr}$ ), the vertical temperature profiles are very similar for these two cases.

Slow rewetting rate: LBL-USGS-3.1/3.6 and LBL-USGS-3.4 have very similar rewetting rates that are much slower than the reference case in the inner $75 \%$ of the repository (compare Tables 10.1.3.1.1b and 10.1.3.1.4c-d). For the outer $10 \%$ of the repository, these three cases have similar rewetting rates (compare Tables 10.1.3.1.1b and 10.1.3.1.4c-d). These three matrix-property cases have similar spatial extents of dryout and have similar spatial temperature distributions (compare Figs. 10.1.3.1.1, 10.1.3.1.4, and 10.1.3.1.5).

Very slow rewetting rate: LBL-USGS-3.3 has a much slower rewetting rate than all of the other cases, except at the outer $3 \%$ of the repository where rewetting is moderately slower (compare Table 10.1.3.1.4e with Tables 10.1.3.1.1b and 10.1.3.1.4a-d). The spatial extent of dryout is about the same for the LBL-USGS-3.3 matrix-property case and the reference matrix-property case, while slower rewetting in LBL-USGS-3.3 allows the dryout zone to remain broad for a longer duration (compare Figs. 10.1.3.1.1 and 10.1.3.1.6).

For all six matrix property cases, the outer $3 \%$ of the repository has a similar $T$ versus $R H$ relationship. Regardless of case, the outer $3 \%$ of the $110.5-\mathrm{MTU} /$ acre repository is relatively hot $\left(106^{\circ} \mathrm{C}\right)$ at 
the time that RH returns to 70\%. Except for LBL-USGS-3.2, the inner 75\% of the repository has cooled to relatively low $T\left(49-76^{\circ} \mathrm{C}\right)$ at the time that $R H=70 \%$.

For $A M L=55.3 \mathrm{MTU} /$ acre, the five LBL-USGS matrix property cases fall into four categories with respect to the rate at which the repository rock rewets to humid (ambient) $R H$ :

Fast rewetting rate: LBL-USGS-3.2 results in much faster rewetting to ambient $R H$ than the reference case (compare Tables 10.1.3.1.1a and 10.1.3.1.3a)

Medium rewetting rate: LBL-USGS-3.5 rewets to ambient $R H$ at about the same rate as the reference case (compare Tables 10.1.3.1.1 $\mathrm{a}$ and 10.1.3.1.3b).

Slow rewetting rate: LBL-USGS-31/3.6 and LBL-USGS-3.4 rewet somewhat more slowly to ambient RH than the reference case (compare Table 10.1.3.1.1 with Tables 10.1.3.1.3c and 10.1.3.1.3d).

Very slow rewetting rate: LBL-USGS-3.3 rewets much more slowly to ambient $R H$ than the reference case (compare Tables 10.1.3.1.1a and 10.1.3.1.3e).

Regardless of the rewetting rate, relatively warm conditions prevail for the 55.3-MTU/acre cases, (105 to $107^{\circ} \mathrm{C}$ ) at the time that $R H=70 \%$. With the exception of LBL-USGS-3.2, there is not a great degree of variability in the relationship between $T$ and $R H$ in the repository rock.

For $\mathrm{AML}=150 \mathrm{MTU} / \mathrm{acre}$, the five LBL-USGS matrix property cases fall into four categories with respect to the rate at which the repository rock rewets to ambient $R H$ :

Fast rewetting rate: LBL-USGS-3.2 results in much faster rewetting than the reference case (compare Table 10.1.3.1.1c and 10.1.3.1.5a). Consequently, $T$ is much greater with respect to $R H$. For example $T$ at the center of the repository is $97^{\circ} \mathrm{C}$ when $R H=70 \%$ as compared with $68^{\circ} \mathrm{C}$ in the reference case.

Medium rewetting rate: LBL-USGS-3.5 results in nearly the same rewetting rate as the reference case (compare Table 10.1.3.1.1c and 10.1.3.1.5b); consequently, there is a similar relationship between $T$ and $R H$.

Slow rewetting rate: LBL-USGS-3.1/3.6 and LBL-USGS-3.4 result in very similar rewetting rates that are substantially slower than the reference case in the inner $75 \%$ of the repository (compare Tables 10.1.3.1.5c and 10.1.3.1.5d with Table 10.1.3.1.1c). For the outer $10 \%$ of the repository, these three cases have similar rewetting rates.

Very slow rewetting rate: LBL-USGS-3.3 has a much slower rewetting rate throughout the entire repository (compare Table 10.1.3.1.5e with Tables 10.1.3.1.5a-d and 10.1.3.1.1c).

Rewetting to $R H=90 \%$ and $95 \%$ is very slow for the 150-MTU/acre cases (except for the LBL-USGS3.2 case). Unlike the 55.3- and 110.5-MTU/acre cases, the slower rewetting rates for 150-MTU/acre LBLUSGS-3.1/3.6, LBL-USGS-3.4, and LBL-USGS-3.3 cases allow $T$ at the outer $3 \%$ of the repository to decrease to relatively low $T\left(83-90^{\circ} \mathrm{C}\right)$ when $R H=70 \%$. With the exception of LBL-USGS-3.2, the inner $75 \%$ of the repository has decreased to relatively low temperatures $\left(51-70^{\circ} \mathrm{C}\right)$ at the time that $R H=70 \%$, and to $40-59^{\circ} \mathrm{C}$ at the time that $\mathrm{RH}=80 \%$.

Dryout behavior is the net result of processes that drive water vapor away from the repository and the processes that cause water to return to the repository. Processes that drive water (both gas- and liquid-phase) away from the repository (and dryout zone) include:

- Molecular diffusion of water vapor from regions of high mole fraction of water vapor to regions of low mass fraction, which is called binary gas-phase diffusion (Section 10.1.3.2).

- Advective gas-phase transport of water vapor from regions of vaporization to regions of condensation driven by:

- Gas-phase pressure buildup from the generation of steam (Section 10.1.2.2).

- Buoyant gas-phase convection (Section 10.1.2.2).

- Advective liquid-phase flow consisting of:

- Condensate shedding down the flanks of the dryout zone.

- Condensate drainage below the dryout zone. 
Processes that return water to the repository (and dryout zone) include:

- Binary gas-phase diffusion of air and water vapor (Section 10.1.3.2).

- Buoyant gas-phase convection of water vapor (Section 10.1.2.2).

- Advective liquid-phase flow consisting of:

- Ambient percolation flux (Section 1.10.6 of Chapter 1).

- Condensate drainage above the dryout zone.

- Matrix imbibition, occurring from regions of high matric potential (wetter areas) to regions of low matric potential (drier areas). This is the focus of this section.

Buoyant gas-phase convection causes rock dryout to occur primarily below the repository and can enhance the buildup of condensate above the dryout zone, thereby increasing the return condensate flux above the dryout zone. Buoyant gas-phase convection can also enhance the rate of vaporization. If $k_{b}$ is large enough (> 1-10 darcy), this mechanism can be important whether or not boiling occurs. Gas-phase convection driven by boiling conditions can suppress the impact of buoyant gas-phase convection. In general, rewetting is the result of both liquid-phase transport of moisture (called liquid-phase rewetting) and gas-phase transport of moisture (called gas-phase rewetting) back to the dryout zone.

Some of the properties listed in Table 10.1.3.1.2 have stronger influence on the noted differences in rewetting behavior than other listed properties. Liquid-phase rewetting by matrix imbibition increases with increasing $k_{\mathrm{m}, \text { sat }}$ and increasing $\mathrm{m}$, and with decreasing $\alpha$. The fact that $k_{\mathrm{m} \text {,sat }}$ for LBL-USGS-3.2 is two orders of magnitude larger than for the other property sets is the primary reason it has such a high rewetting rate. The other five matrix-property sets have values of $k_{\mathrm{m} \text {,sat }}$ that vary by a factor of five; differences between these sets arise from differences in their respective values of the van Genuchten curve-fitting parameters $\alpha$ and $\mathrm{m}$.

Gas-phase rewetting is primarily affected by (1) $\tau_{\text {eff }}$ and (2) the influence of $k_{\mathrm{b}}$ in determining the magnitude of buoyant gas-phase convection. As will be discussed in the following section (Section 1.10.3.2), the van Genuchten curve-fitting parameters $\alpha$ and $\mathrm{m}$ also affect binary gas-phase diffusion (Table 10.1.3.1.2). A comparison of Table 10.1.3.1.3c with 10.1.3.1.3d, Table 10.1.3.1.4c with 10.1.3.1.4d, and Table 10.1.3.1.5c with 10.1.3.1.5d, shows that the rewetting rates are almost identical for the LBL-USGS3.1/3.6 and LBL-USGS-3.4 property sets. Because these two property sets have the same value of $\alpha$, the fivefold difference in their respective values of $k_{\mathrm{m} \text {, sat }}$ is offset by the small difference in the van Genuchten curve-fitting parameter $m(0.29$ versus 0.25$)$. LBL-USGS-3.3 has the lowest overall rewetting rate because it has the largest $\alpha$ and the second-smallest $m$ of the six matrix-property sets (Table 10.1.3.1.2). 


\section{Table 10.1.3.1.1}

Time required to attain the indicated relative humidity $R H$ at various repository locations and the temperature at which that value of $R H$ is attained for 22.5-yr-old SNF, gas-phase diffusion tortousity factor, $\tau_{\text {eff, }}=0.2, k_{\mathrm{b}}=280$ millidarcy, and assuming the matrix properties from Klavetter and Peters (1986) for the TSw1 and TSw2 units. The locations are identified as the percentage of the repository area enclosed, with $0 \%$ corresponding to the repository center, and $100 \%$ corresponding to the edge.

\begin{tabular}{|c|c|c|c|c|c|c|c|c|}
\hline \multicolumn{9}{|c|}{ Table 10.1.3.1.1a: AML = 55.3 MTU/acre } \\
\hline \multirow{2}{*}{$\begin{array}{l}\text { Percentage of } \\
\text { repository area } \\
\text { enclosed (\%) }\end{array}$} & \multicolumn{4}{|c|}{$\begin{array}{l}\text { - Time required to attain } \\
\text { the indicated } R H(\mathrm{yr})\end{array}$} & \multicolumn{4}{|c|}{$\begin{array}{c}\text { Temperature at which the indicated } \\
R H \text { is attained ( }(\mathrm{C})\end{array}$} \\
\hline & $70 \%$ & $80 \%$ & $90 \%$ & $95 \%$ & $70 \%$ & $80 \%$ & $90 \%$ & $95 \%$ \\
\hline 50 & 670 & 1660 & 3330 & 4630 & 107 & 97 & 80 & 72 \\
\hline 75 & 410 & 940 & 1610 & 2280 & 107 & 99 & 89 & 81 \\
\hline 90 & NA & 200 & 380 & 490 & NA & 103 & 97 & 94 \\
\hline 97 & NA & NA & NA & NA & NA & NA & NA & $\mathrm{NA}$ \\
\hline \multicolumn{9}{|c|}{ Table 10.1.3.1.1b: AML = 110.5 MTU/acre } \\
\hline \multirow{2}{*}{$\begin{array}{l}\text { Percentage of } \\
\text { repository area } \\
\text { enclosed (\%) }\end{array}$} & \multicolumn{4}{|c|}{$\begin{array}{l}\text { Time required to attain } \\
\text { the indicated } R H(\mathrm{yx})\end{array}$} & \multicolumn{4}{|c|}{$\begin{array}{c}\text { Temperature at which the indicated } \\
R H \text { is attained }\left({ }^{\circ} \mathrm{C}\right)\end{array}$} \\
\hline & $70 \%$ & $80 \%$ & $90 \%$ & $95 \%$ & $70 \%$ & $80 \%$ & $90 \%$ & $95 \%$ \\
\hline 50 & 15,960 & 27,910 & 40,990 & 49,980 & 68 & 54 & 45 & 42 \\
\hline 75 & 9540 & 15,520 & 24,950 & 32,590 & 76 & 64 & 53 & 48 \\
\hline 90 & 3190 & 4890 & 7460 & 9890 & 93 & 82 & 73 & 68 \\
\hline 97 & 1410 & 1810 & 2360 & 2890 & 106 & 101 & 93 & 88 \\
\hline \multicolumn{9}{|c|}{ Table 10.1.3.1.1c $\mathrm{AML}=150 \mathrm{MTU} / \mathrm{acre}$} \\
\hline \multirow{2}{*}{$\begin{array}{l}\text { Percentage of } \\
\text { repository area } \\
\text { enclosed (\%) }\end{array}$} & \multicolumn{4}{|c|}{$\begin{array}{l}\text { Time required to attain } \\
\text { the indicated } R H(\mathrm{yr})\end{array}$} & \multicolumn{4}{|c|}{$\begin{array}{c}\text { Temperature at which the indicated } \\
\left.R H \text { is attained ( }{ }^{\circ} \mathrm{C}\right)\end{array}$} \\
\hline & $70 \%$ & $80 \%$ & $90 \%$ & $95 \%$ & $70 \%$ & $80 \%$ & $90 \%$ & $95 \%$ \\
\hline 50 & 20,630 & 34,850 & 50,920 & 64,150 & 68 & 52 & 45 & 41 \\
\hline 75 & 16,400 & 24,520 & 32,700 & 43,360 & 70 & 59 & 51 & 46 \\
\hline 90 & 8660 & 12,090 & 16,520 & 19,780 & 81 & 72 & 64 & 59 \\
\hline 97 & 4330 & 6020 & 8180 & 10,060 & 93 & 84 & 77 & 72 \\
\hline
\end{tabular}

Table 10.1.3.1.2: Matrix hydrological property data for the TSw1 and TSw2 units.

\begin{tabular}{|l|c|c|c|c|c|}
\hline \multicolumn{1}{|c|}{ Sample Name } & $\mathrm{S}_{\mathrm{r}}$ & $\phi_{\mathrm{m}}$ & $k_{\mathrm{msat}}\left(\mathrm{m}^{2}\right)$ & $\alpha\left(10^{-5} \mathrm{~Pa}^{-1}\right)$ & $\mathrm{m}$ \\
\hline Reference Case & 0.08 & 0.11 & $1.9 \times 10^{-18}$ & 0.058 & 0.4438 \\
\hline LBL-USGS-3.2 & 0.0 & 0.10 & $4.0 \times 10^{-16}$ & 0.125 & 0.18 \\
\hline LBL-USGS-3.5 & 0.0 & 0.10 & $5.0 \times 10^{-18}$ & 0.133 & 0.25 \\
\hline LBL-USGS-3.1/3.6 & 0.0 & 0.10 & $1.0 \times 10^{-18}$ & 0.067 & 0.29 \\
\hline LBL-USGS-3.4 & 0.0 & 0.11 & $5.0 \times 10^{-18}$ & 0.067 & 0.25 \\
\hline LBL-USGS-3.3 & 0.0 & 0.11 & $4.0 \times 10^{-18}$ & 0.2 & 0.22 \\
\hline
\end{tabular}

The properties listed are $S_{r}, \alpha$, and $m$ (the three van Genuchten characteristic curve-fitting parameters), matrix porosity $\left(\phi_{m}\right)$, and saturated matrix permeability $\left(k_{m, s a t}\right)$. 
Table 10.1.3.1.3: AML = 55.3 MTU/acre

Time required to attain the indicated relative humidity $R H$ at various repository locations and the temperature at which that value of $R H$ is attained for 22.5 -yr-old SNF, gas-phase diffusion tortousity factor $\tau_{\text {eff, }}=0.2$, and $k_{\mathrm{b}}=$ 280 millidarcy. The locations are identified as the percentage of the repository area enclosed, with $0 \%$ corresponding to the repository center, and $100 \%$ corresponding to the edge

Table 10.1.3.1.3a: Matrix properties for LBL-USGS sample 3.2 in the TSw1 and TSw2 units.

\begin{tabular}{|c|c|c|c|c|c|c|c|c|}
\hline \multirow{2}{*}{$\begin{array}{c}\text { Percentage of } \\
\text { repository area } \\
\text { enclosed (\%) }\end{array}$} & \multicolumn{4}{|c|}{$\begin{array}{c}\text { Time required to attain } \\
\text { the indicated } R H(\mathrm{yr})\end{array}$} & \multicolumn{2}{c|}{$\begin{array}{c}\text { Temperature at which the indicated } \\
R H \text { is attained ( }\end{array}$} \\
\cline { 2 - 10 } & $70 \%$ & $80 \%$ & $90 \%$ & $95 \%$ & $70 \%$ & $80 \%$ & $90 \%$ & $95 \%$ \\
\hline 50 & NA & 750 & 1240 & 1480 & NA & 103 & 99 & 97 \\
\hline 75 & NA & 280 & 700 & 870 & NA & 103 & 100 & 98 \\
\hline 90 & NA & NA & 160 & 210 & NA & NA & 100 & 98 \\
\hline 97 & NA & NA & NA & NA & NA & NA & NA & NA \\
\hline
\end{tabular}

Table 10.1.3.1.3b: Matrix properties for LBL-USGS sample 3.5 in the TSw1 and TSw2 units.

\begin{tabular}{|c|c|c|c|c|c|c|c|c|}
\hline \multirow{2}{*}{$\begin{array}{l}\text { Percentage of } \\
\text { repository areaq } \\
\text { enclosed (\%) }\end{array}$} & \multicolumn{4}{|c|}{$\begin{array}{l}\text { Time required to attain } \\
\text { the indicated } R H(\mathrm{yr})\end{array}$} & \multicolumn{4}{|c|}{$\begin{array}{c}\text { Temperature at which the indicated } \\
R H \text { is attained }\left({ }^{\circ} \mathrm{C}\right)\end{array}$} \\
\hline & $70 \%$ & $80 \%$ & $90 \%$ & $95 \%$ & $70 \%$ & $80 \%$ & $90 \%$ & $95 \%$ \\
\hline 50 & 490 & 1570 & 2520 & 3490 & 107 & 98 & 87 & 79 \\
\hline 75 & 290 & 900 & 1350 & 1700 & 107 & 100 & 93 & 87 \\
\hline 90 & NA & 190 & 330 & 400 & $\mathbf{N A}$ & 103 & 98 & 96 \\
\hline 97 & NA & NA & NA & NA & NA & NA & NA & NA \\
\hline
\end{tabular}

Table 10.1.3.1.3c: Matrix properties for LBL-USGS sample 3.1 and LBL-USGS 3.6 in the TSw1 and TSw2 units.

\begin{tabular}{|c|c|c|c|c|c|c|c|c|}
\hline \multirow{2}{*}{$\begin{array}{l}\text { Percentage of } \\
\text { repository area } \\
\text { enclosed (\%) }\end{array}$} & \multicolumn{4}{|c|}{$\begin{array}{l}\text { Time required to attain } \\
\text { the indicated } R H(\mathrm{yr})\end{array}$} & \multicolumn{4}{|c|}{$\begin{array}{c}\text { Temperature at which the indicated } \\
R H \text { is attained }\left({ }^{\circ} \mathrm{C}\right)\end{array}$} \\
\hline & $70 \%$ & $80 \%$ & $90 \%$ & $95 \%$ & $70 \%$ & $80 \%$ & $90 \%$ & $95 \%$ \\
\hline 50 & 690 & 2240 & 7170 & 12,050 & 107 & 90 & 65 & 57 \\
\hline 75 & 430 & 1270 & 3340 & 5930 & 107 & 95 & 72 & 63 \\
\hline 90 & NA & 220 & 450 & 640 & NA & 102 & 95 & 91 \\
\hline 97 & NA & NA & NA & NA & NA & NA & NA & $\overline{\mathrm{NA}}$ \\
\hline
\end{tabular}

Table 10.1.3.1.3d: Matrix properties for LBL-USGS sample 3.4 in the TSw1 and TSw2 units.

\begin{tabular}{|c|c|c|c|c|c|c|c|c|}
\hline \multirow{2}{*}{$\begin{array}{c}\text { Percentage of } \\
\text { repository area } \\
\text { enclosed (\%) }\end{array}$} & \multicolumn{4}{|c|}{$\begin{array}{c}\text { Time required to attain } \\
\text { the indicated } R H(\mathrm{yr})\end{array}$} & \multicolumn{3}{c|}{ Temperature at which the indicated } \\
\cline { 2 - 9 } & $70 \%$ & $80 \%$ & $90 \%$ & $95 \%$ & $70 \%$ & $80 \%$ & $90 \%$ & $95 \%$ \\
\hline 50 & 870 & 2390 & 6660 & 10,600 & 106 & 89 & 67 & 59 \\
\hline 75 & 510 & 1330 & 3210 & 5300 & 106 & 94 & 73 & 65 \\
\hline 90 & 130 & 270 & 580 & 880 & 107 & 101 & 93 & 87 \\
\hline 97 & NA & NA & NA & NA & NA & NA & NA & NA \\
\hline
\end{tabular}

Table 10.1.3.1.3e: Matrix properties for LBL-USGS sample 3.3 in the TSw1 and TSw2 units.

\begin{tabular}{|c|c|c|c|c|c|c|c|c|}
\hline \multirow{2}{*}{$\begin{array}{l}\text { Percentage of } \\
\text { repository area } \\
\text { enclosed (\%) }\end{array}$} & \multicolumn{4}{|c|}{$\begin{array}{l}\text { Time required to attain } \\
\text { the indicated } R H(\mathrm{yr})\end{array}$} & \multicolumn{4}{|c|}{$\begin{array}{c}\text { Temperature at which the indicated } \\
R H \text { is attained ( }(\mathrm{C})\end{array}$} \\
\hline & $70 \%$ & $80 \%$ & $90 \%$ & $95 \%$ & $70 \%$ & $80 \%$ & $90 \%$ & $95 \%$ \\
\hline 50 & 960 & 3180 & 14,200 & 29,100 & 105 & 81 & 54 & 43 \\
\hline$\overline{75}$ & 580 & 1790 & 7430 & 15,050 & 106 & 87 & 60 & 50 \\
\hline 90 & 140 & 320 & 910 & 1910 & 107 & 99 & 86 & 72 \\
\hline 97 & NA & NA & $\mathbf{N A}$ & NA & $\mathbf{N A}$ & NA & NA & NA \\
\hline
\end{tabular}


Table 10.1.3.1.4: AML = 110.5 MTU/acre

Time required to attain the indicated relative humidity $R H$ at various repository locations and the temperature at which that value of $R H$ is attained for 22.5-yr-old SNF, gas-phase diffusion tortousity factor $\tau_{\text {eff, }}=0.2$,and $k_{b}=280$ millidarcy. The locations are identified as the percentage of the repository area enclosed, with $0 \%$ corresponding to the repository center, and $100 \%$ corresponding to the edge.

Table 10.1.3.1.4a: Matrix properties for LBL-USGS sample 3.2 in the TSw1 and TSw2 units.

\begin{tabular}{|c|c|c|c|c|c|c|c|c|}
\hline \multirow{2}{*}{$\begin{array}{l}\text { Percentage of } \\
\text { repository area } \\
\text { enclosed (\%) }\end{array}$} & \multicolumn{4}{|c|}{$\begin{array}{l}\text { Time required to attain } \\
\text { the indicated } R H(\mathrm{yr})\end{array}$} & \multicolumn{4}{|c|}{$\begin{array}{c}\text { Temperature at which the indicated } \\
R H \text { is attained ( } \mathrm{C} \text { (C) }\end{array}$} \\
\hline & $70 \%$ & $80 \%$ & $90 \%$ & $95 \%$ & $70 \%$ & $80 \%$ & $90 \%$ & $95 \%$ \\
\hline 50 & 5970 & 6410 & 7060 & 8740 & 96 & 93 & 90 & 85 \\
\hline 75 & 3480 & 3830 & 4170 & 4800 & 100 & 98 & 95 & 91 \\
\hline 90 & 1760 & 2070 & 2440 & 2640 & 106 & 102 & 99 & 97 \\
\hline 97 & 840 & 1120 & 1450 & 1720 & 107 & 103 & 100 & 98 \\
\hline
\end{tabular}

Table 10.1.3.1.4b: Matrix properties for LBL-USGS sample 3.5 in the TSw1 and TSw2 units.

\begin{tabular}{|c|c|c|c|c|c|c|c|c|}
\hline \multirow{2}{*}{$\begin{array}{c}\text { Percentage of } \\
\text { repository area } \\
\text { enclosed (\%) }\end{array}$} & \multicolumn{4}{|c|}{$\begin{array}{c}\text { Time required to attain } \\
\text { the indicated } R H(\mathrm{yr})\end{array}$} & \multicolumn{4}{|c|}{ Temperature at which the indicated } \\
\cline { 2 - 9 } & $70 \%$ & $80 \%$ & $90 \%$ & $95 \%$ & $70 \%$ & $80 \%$ & $90 \%$ & $95 \%$ \\
\hline 50 & 22,280 & 28,530 & 34,780 & 42,390 & 59 & 54 & 48 & 45 \\
\hline 75 & 9580 & 12,710 & 17,200 & 23,350 & 75 & 68 & 61 & 55 \\
\hline 90 & 2720 & 3680 & 4920 & 6760 & 97 & 89 & 82 & 75 \\
\hline 97 & 1160 & 1530 & 1920 & 2290 & 107 & 103 & 98 & 93 \\
\hline
\end{tabular}

Table 10.1.3.1.4c: Matrix properties for LBL-USGS samples 3.1 and 3.6 in the TSw1 and TSw2 units.

\begin{tabular}{|c|c|c|c|c|c|c|c|c|}
\hline \multirow{2}{*}{$\begin{array}{c}\text { Percentage of } \\
\text { repository area } \\
\text { enclosed (\%) }\end{array}$} & \multicolumn{4}{|c|}{$\begin{array}{c}\text { Time required to attain } \\
\text { the indicated } R H(\mathrm{yr})\end{array}$} & \multicolumn{3}{|c|}{ Temperature at which the indicated } \\
\cline { 2 - 9 } & $70 \%$ & $80 \%$ & $90 \%$ & $95 \%$ & $70 \%$ & $80 \%$ & $90 \%$ & $95 \%$ \\
\hline 50 & 31,570 & 48,790 & 72,310 & 94,690 & 51 & 42 & 37 & 34 \\
\hline 75 & 16,160 & 30,080 & 45,930 & 58,990 & 63 & 49 & 41 & 38 \\
\hline 90 & 3450 & 6560 & 12,010 & 18,980 & 91 & 76 & 64 & 54 \\
\hline 97 & 1130 & 1620 & 2260 & 2820 & 107 & 102 & 94 & 88 \\
\hline
\end{tabular}

Table 10.1.3.1.4d: Matrix properties for LBL-USGS sample 3.4 in the TSw1 and TSw2 units.

\begin{tabular}{|c|c|c|c|c|c|c|c|c|}
\hline \multirow{2}{*}{$\begin{array}{c}\text { Percentage of } \\
\text { repository area } \\
\text { enclosed (\%) }\end{array}$} & \multicolumn{4}{|c|}{$\begin{array}{c}\text { Time required to attain } \\
\text { the indicated } R H(\mathrm{yr})\end{array}$} & \multicolumn{4}{|c|}{ Temperature at which the indicated } \\
\cline { 2 - 10 } & $70 \%$ & $80 \%$ & $90 \%$ & $95 \%$ & $70 \%$ & $80 \%$ & $90 \%$ & $95 \%$ \\
\hline 50 & 31,290 & 47,260 & 71,840 & 93,860 & 51 & 43 & 37 & 34 \\
\hline 75 & 16,470 & 29,220 & 44,140 & 57,350 & 62 & 50 & 42 & 38 \\
\hline 90 & 3940 & 7260 & 12,780 & 19,080 & 87 & 74 & 62 & 54 \\
\hline 97 & 1330 & 1830 & 2510 & 3490 & 107 & 100 & 91 & 83 \\
\hline
\end{tabular}

Table 10.1.3.1.4e: Matrix properties for LBL-USGS sample 3.3 in the TSw1 and TSw2 units.

\begin{tabular}{|c|c|c|c|c|c|c|c|c|}
\hline \multirow{2}{*}{$\begin{array}{l}\text { Percentage of } \\
\text { repository area } \\
\text { enclosed (\%) }\end{array}$} & \multicolumn{4}{|c|}{$\begin{array}{l}\text { Time required to attain } \\
\text { the indicated } R H(\mathrm{y})\end{array}$} & \multicolumn{4}{|c|}{$\begin{array}{l}\text { Temperature at which the indicated } \\
R H \text { is attained ( } \\
\end{array}$} \\
\hline & $70 \%$ & $80 \%$ & $90 \%$ & $95 \%$ & $70 \%$ & $80 \%$ & $90 \%$ & $95 \%$ \\
\hline 50 & 33,940 & 61,360 & 119,890 & 185,850 & 49 & 38 & 32 & 31 \\
\hline 75 & 19,730 & 39,340 & 78,500 & 112,770 & 57 & 44 & 35 & 33 \\
\hline 90 & 4770 & 11,340 & 26,180 & 39,140 & 83 & 65 & 49 & 42 \\
\hline 97 & 1350 & 1990 & 3410 & 5360 & 107 & 98 & 84 & 74 \\
\hline
\end{tabular}




\section{Table 10.1.3.1.5: AML = 150 MTU/acre}

Time required to attain the indicated relative humidity $R H$ at various repository locations and the temperature at which that value of $R H$ is attained for 22.5-yr-old SNF, gas-phase diffusion tortousity

factor $\tau_{\text {eff }}=0.2$, and $k_{b}=280$ millidarcy. The locations are identified as the percentage of the repository area enclosed, with $0 \%$ corresponding to the repository center, and $100 \%$ corresponding to the edge.

Table 10.1.3.1.5a: Matrix properties for LBL-USGS sample 3.2 in the TSw1 and TSw2 units.

\begin{tabular}{|c|c|c|c|c|c|c|c|c|}
\hline \multirow{2}{*}{$\begin{array}{l}\text { Percentage of } \\
\text { repository area } \\
\text { enclosed }(\%)\end{array}$} & \multicolumn{4}{|c|}{$\begin{array}{l}\text { Time required to attain } \\
\text { the indicated } R H(\mathrm{yr})\end{array}$} & \multicolumn{4}{|c|}{$\begin{array}{c}\text { Temperature at which the indicated } \\
R H \text { is attained }\left({ }^{\circ} \mathrm{C}\right)\end{array}$} \\
\hline & $70 \%$ & $80 \%$ & $90 \%$ & $95 \%$ & $70 \%$ & $80 \%$ & $90 \%$ & $95 \%$ \\
\hline 50 & 8960 & 9600 & 10,840 & 12,030 & 97 & 95 & 91 & 87 \\
\hline 75 & 5690 & 6180 & 6830 & 8170 & 101 & 98 & 96 & 91 \\
\hline 90 & 2980 & 3510 & 4060 & 4400 & 105 & 102 & 98 & 96 \\
\hline 97 & 2020 & 2300 & 2650 & 2940 & 107 & 103 & 100 & 98 \\
\hline
\end{tabular}

Table 10.1.3.1.5b: Matrix properties for LBL-USGS sample 3.5 in the TSw1 and TSw2 units.

\begin{tabular}{|c|r|r|r|r|r|r|r|r|}
\hline \multirow{2}{*}{$\begin{array}{c}\text { Percentage of } \\
\text { repository area } \\
\text { enclosed (\%) }\end{array}$} & \multicolumn{4}{|c|}{$\begin{array}{c}\text { Time required to attain } \\
\text { the indicated } R H(\mathrm{yr})\end{array}$} & \multicolumn{3}{|c|}{ Temperature at which the indicated } \\
\cline { 2 - 9 } & \multicolumn{1}{|c|}{$70 \%$} & $80 \%$ & $90 \%$ & $95 \%$ & $70 \%$ & $80 \%$ & $90 \%$ & $95 \%$ \\
\hline 50 & 31,240 & 38,690 & 46,850 & 54,100 & 54 & 49 & 45 & 43 \\
\hline 75 & 18,750 & 23,780 & 28,990 & 35,380 & 66 & 59 & 54 & 49 \\
\hline 90 & 7740 & 9930 & 12,830 & 17,520 & 83 & 77 & 70 & 62 \\
\hline 97 & 3480 & 4420 & 5820 & 8020 & 98 & 91 & 84 & 77 \\
\hline
\end{tabular}

Table 10.1.3.1.5c: Matrix properties for LBL-USGS samples 3.1 and 3.6 in the TSw1 and TSw2 units.

\begin{tabular}{|c|c|c|c|c|c|c|c|c|}
\hline \multirow{2}{*}{$\begin{array}{c}\text { Percentage of } \\
\text { repository area } \\
\text { enclosed (\%) }\end{array}$} & \multicolumn{4}{|c|}{$\begin{array}{c}\text { Time required to attain } \\
\text { the indicated } R H(\mathrm{yr})\end{array}$} & \multicolumn{3}{|c|}{ Temperature at which the indicated } \\
\cline { 2 - 9 } & $70 \%$ & $80 \%$ & $90 \%$ & $95 \%$ & $70 \%$ & $80 \%$ & $90 \%$ & $95 \%$ \\
\hline 50 & 36,740 & 54,710 & 76,450 & 103,600 & 50 & 42 & 38 & 35 \\
\hline 75 & 29,790 & 46,930 & 67,180 & 81,860 & 52 & 43 & 38 & 36 \\
\hline 90 & 13,140 & 23,350 & 36,290 & 47,780 & 70 & 55 & 45 & 41 \\
\hline 97 & 4630 & 7810 & 13,500 & 21,390 & 90 & 77 & 65 & 55 \\
\hline
\end{tabular}

Table 10.1.3.1.5d: Matrix properties for LBL-USGS sample 3.4 in the TSw1 and TSw2 units.

\begin{tabular}{|c|c|c|c|c|c|c|c|c|}
\hline \multirow{2}{*}{$\begin{array}{c}\text { Percentage of } \\
\text { repository area } \\
\text { enclosed (\%) }\end{array}$} & \multicolumn{4}{|c|}{$\begin{array}{c}\text { Time required to attain } \\
\text { the indicated } R H(\mathrm{yr})\end{array}$} & \multicolumn{3}{|c|}{ Temperature at which the indicated } \\
\cline { 2 - 9 } & $70 \%$ & $80 \%$ & $90 \%$ & $95 \%$ & $70 \%$ & $80 \%$ & $90 \%$ & $95 \%$ \\
\hline 50 & 36,240 & 53,670 & 77,150 & 106,290 & 51 & 43 & 38 & 35 \\
\hline 75 & 28,920 & 44,800 & 65,090 & 79,720 & 53 & 44 & 39 & 36 \\
\hline 90 & 13,070 & 22,110 & 34,020 & 44,680 & 70 & 57 & 47 & 42 \\
\hline 97 & 4970 & 7960 & 12,920 & 19,230 & 88 & 77 & 66 & 57 \\
\hline
\end{tabular}

Table 10.1.3.1.5e: Matrix properties for LBL-USGS sample 3.3 in the TSw1 and TSw2 units.

\begin{tabular}{|c|c|c|c|c|c|c|c|c|}
\hline \multirow{2}{*}{$\begin{array}{l}\text { Percentage of } \\
\text { repository area } \\
\text { enclosed (\%) }\end{array}$} & \multicolumn{4}{|c|}{$\begin{array}{l}\text { Time required to attain } \\
\text { the indicated } R H(\mathrm{yr})\end{array}$} & \multicolumn{4}{|c|}{$\begin{array}{c}\text { Temperature at which the indicated } \\
R H \text { is attained }\left({ }^{\circ} \mathrm{C}\right)\end{array}$} \\
\hline & $70 \%$ & $80 \%$ & $90 \%$ & $95 \%$ & $70 \%$ & $80 \%$ & $90 \%$ & $95 \%$ \\
\hline 50 & 38,530 & 67,740 & 136,540 & 224.430 & 49 & 40 & 34 & 32 \\
\hline 75 & 31,910 & 56,830 & 111,490 & 171,140 & 51 & 40 & 34 & 33 \\
\hline 90 & 16,730 & 32,050 & 60,180 & 86,980 & 63 & 48 & 38 & 35 \\
\hline 97 & 6120 & 11,790 & 23,940 & 36,410 & 83 & 68 & 52 & 44 \\
\hline
\end{tabular}




\subsubsection{Influence of Vapor Diffusion.}

\section{Gas-Phase Diffusion of Water Vapor}

Transport of water vapor in the gas phase takes place by two mechanisms: (1) advective transport from movement of the gas phase, and (2) diffusive transport by the process of molecular diffusion. The binary diffusive mass flux of a component in a gas phase is governed by Fick's law, which for a porous medium takes the form

$$
q=-\phi S_{g} \rho_{g} \tau \eta D \nabla \omega
$$

where $\phi$ is porosity, $S_{\mathrm{g}}$ is gas-phase saturation, $\rho_{\mathrm{g}}$ is gas density, $\tau$ is the tortuosity factor, $\eta$ is the diffusion enhancement factor, $D$ is the binary diffusion coefficient, and $\omega$ is the mass fraction of the component. The tortuosity factor, $\tau$, is the reciprocal of the tortuosity and takes into account the increased path length within the porous medium. Its value is always less than or equal to unity.

The diffusion enhancement factor, $\eta$, which appears in Equation (8), can be taken to be unity for a noncondensible component or isothermal conditions. For diffusion of a condensible component, such as water vapor, driven by a thermal gradient, the diffusive flux is enhanced, so that $\eta$ is greater than unity. The well-known paper by Philip and de Vries (1967) gives an explanation for this enhancement. Normally, diffusive transport of water vapor is obstructed by liquid water that blocks pore throats; consequently, diffusion is reduced at higher liquid saturations. However, the thermal gradient sets up a vapor pressure gradient in the gas phase which causes water to evaporate from a blockage and diffuse in the gas phase to a cooler blockage, where it condenses. The process continues as the water evaporates on the other side of the blockage. The mechanism whereby liquid water flows through a blockage is the pressure difference caused by the difference in meniscus curvature between the two sides.

Another phenomenon further increases diffusive fluxes under nonisothermal conditions. The gasphase thermal conductivity is much less than that in the liquid and solid phases, so that the temperature gradient in the gas phase between liquid blockages is greater than the average temperature gradient of the bulk porous medium. The resulting increase in water vapor concentration gradients within the gas phase further increases diffusive fluxes compared to isothermal systems.

The diffusion enhancement factor is a function of liquid saturation and appears to increase significantly at sufficiently large saturations when blockages can occur, which is consistent with the above theory. The diffusion enhancement factor, $\eta$, appears to have been measured only for soils. Cass and others (1984) obtained values of $\eta$ for sand that ranged from unity at $0 \%$ liquid saturation (i.e., no enhancement) to 12 at $80 \%$ liquid saturation. The value of $\eta$ appears to decrease with increasing temperature. The maximum value of $\eta$ decreased by almost $50 \%$ as temperature was increased from 3.5 to $32.5^{\circ} \mathrm{C}$. This trend can be explained by the theory of Philip and de Vries. At greater temperatures, the higher latent heat carried by diffusive transport enhances heat transfer across the gas phase between blockages. The resulting decrease in gas-phase temperature gradients reduces the vapor-pressure gradients that drive diffusive transport.

The values of $\eta$ are not directly input to the V-TOUGH code. Instead, V-TOUGH requires an effective gas-phase diffusion factor, $\tau_{\text {eff }}$ which combines $\eta$ with the tortuosity factor, $\tau$, as follows:

$$
\tau_{\text {eff }}=\eta \tau
$$

V-TOUGH treats $\tau_{\text {eff }}$ as a constant. If we take $\tau$ to be 0.2 , and consider the upper value of 12 measured

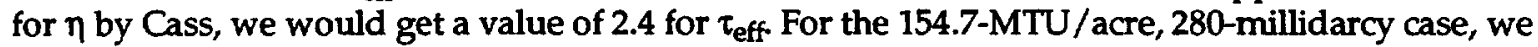
considered three values of $\tau_{\text {eff }} 0.2,1$, and 2 . Note that, unless specified otherwise, our calculations assume a value of 0.2 for $\tau_{\text {eff. }}$ Increasing $\tau_{\text {eff }}$ from 0.2 to 1 (thereby increasing gas-phase diffusion) results in a minor cooling effect (Fig. 10.1.3.2.1a). This cooling effect, which arises because of the increased transport of latent heat away from the repository, reduces the area-weighted boiling period duration, $t_{\mathrm{bp}}$, from 7984 to $7622 \mathrm{yr}$. Increasing $\tau_{\text {eff }}$ from 0.2 to 1 also has a minor drying effect, modestly reducing the net 
buildup of liquid water above the repository, $\Delta V_{1}$ (Fig. 10.1.3.2.1c). The maximum value of $\Delta V_{1}$ is only reduced by $3.2 \%$.

As in past studies [Buscheck and Nitao, 1994], when analyzing dryout and rewetting behavior, we use the term, normalized liquid saturation, $S_{1}$, which is given by Eq.(8). The rewetting behavior of various AMLs is examined by comparing the duration of time that $S_{1}$ in the repository is below $90 \%$ of ambient as a function of repository location [Buscheck et al., 1994]. Because $S_{1}=0.9$ when $S_{1}$ has been restored to $90 \%$ of ambient, we call this time $t\left(S_{1}=0.9\right)$. The area-weighted value of $t\left(S_{1}=0.9\right)$ for the entire repository is called $\bar{t}\left(\bar{S}_{1}=0.9\right)$, which is essentially the mean rewetting time for the repository.

Figure 10.1.3.2.1b utilizes $t\left(S_{1}=0.9\right)$ to illustrate rewetting behavior as a function of repository location for a range of $\tau_{\text {eff }}$ Notice that the drying effect that results from enhanced gas-phase diffusion of water vapor increases the duration of time that most of the repository is below ambient saturation. For the inner $25 \%$ of the repository, $t\left(S_{1}=0.9\right)$ is reduced somewhat (Fig. 10.1.3.2.1b) because of the reduction of $t_{\mathrm{bp}}$ (Fig. 10.1.3.2.1a). Because temperatures decrease with vertical distance from the repository horizon, gas-phase diffusion drives water vapor vertically away from the repository. Because temperatures also decrease with increasing radial distance, gas-phase diffusion also drives water vapor radially away from the repository. Notice that the enhanced dryout effect is greatest at the outer repository area, where temperature gradients drive water vapor radially as well as vertically away from the repository. Increasing $\tau_{\text {eff from }} 0.2$ to 1 has the effect of increasing $t\left(S_{1}=0.9\right)$ for the outer $75 \%$ of the repository. Consequently, $\bar{i}\left(\bar{S}_{1}=0.9\right)$ is increased from 63,440 to $68,720 \mathrm{yr}$ for the entire repository.

Increasing $\tau_{\text {eff }}$ from 0.2 to 2 results in a more substantial cooling effect, reducing $t_{\mathrm{bp}}$ from 7980 to 7320 yr (Fig. 10.1.3.2.1a). The greatest cooling effect occurs at the repository center (where the highest temperatures occur) and decreases with increasing distance from the repository center. At the repository edge, the cooling effect is minor. Increasing $\tau_{\text {eff }}$ from 0.2 to 2 also has a drying effect, reducing the maximum value of $\Delta V_{1}$ by $9.7 \%$ (Fig. 10.1.3.2.1c). The drying effect also increases $t\left(S_{1}=0.9\right)$ for the outer $80 \%$ of the repository (Fig. 10.1.3.2.1b). Consequently, $\bar{t}\left(S_{1}=0.9\right.$ ) is increased from 63,440 to $77,420 \mathrm{yr}$ for the entire repository. In general, for the range of $\tau_{\text {eff considered, enhanced gas-phase diffusion results in a }}$ minor cooling effect and a minor drying effect. We plan to consider larger values of $\tau_{\text {eff }}$ and a larger range of AMLs in examining the influence of enhanced gas-phase diffusion.

\section{Role of Vapor Diffusion in Dryout}

The mole fraction of water vapor is considerably greater at the repository in response to higher temperatures there. The mole fraction $n_{\mathrm{v}}$ of water vapor under conditions of local thermodynamic equilibrium within the rock is a function of liquid saturation $S_{1}$, absolute temperature, $T$, and gas-phase pressure, $P_{\mathrm{g}}$ and is given by the formula

$$
n_{\mathrm{v}}=\left[P_{\mathrm{sat}}(T) / P_{\mathrm{g}}\right] \exp \left[\psi \mathrm{M}_{\mathrm{w}} /\left(\rho_{\mathrm{l}} R T\right)\right]
$$

which is a generalization of Kelvin's law to porous media. Here, $P_{\text {sat }}(T)$ is the saturation pressure, $\psi=\psi\left(S_{l} T\right)$ is matric potential, $M_{W}$ is molecular weight of water, $\rho_{1}$ is the density of liquid water, and $R$ is the universal gas constant. Note that $\psi<0$; therefore, the greater the magnitude of $\psi$, the greater the vapor-pressure lowering effect. Note that the matric potential is a function of $S_{1}$ and $T$. For ambient liquid saturation conditions at the repository horizon $\left(S_{1} \approx 60-90 \%\right)$, the absolute value of $\psi$ is sufficiently small such that the exponential term is essentially unity. Only at very low $S_{1}$ does value of $\psi$ become large enough for the exponential factor to have a significant effect on $n_{\mathrm{v}}$.

As temperatures rise in the repository, the equilibrium amount of water vapor in the gas phase increases because of the increase in $P_{\text {sat }}(T)$. As temperatures reach the boiling point of water, $P_{\text {sat }}$ approaches $P_{g}$ and the mole fraction of water vapor approaches unity (i.e., the gas phase becomes $100 \%$ water vapor). The water in the rock near the fractures also starts to boil, causing the gas-phase pressure in the fractures and the rock matrix to rise, which leads to the advective transport of water vapor as long as steam is being generated. Gas-phase advection is likely to be the dominant mechanism transporting water vapor from the boiling zone to the condensation zone except for a rock mass where $k_{b}$ is sufficiently small 
$\left(k_{\mathrm{b}}<1-10\right.$ millidarcy) to substantially throttle gas-phase advection and the rate of boiling. Beyond the condensation zone, vapor diffusion is the dominant mechanism of vapor movement except where $k_{b}$ is sufficiently large ( $k_{\mathrm{b}}>1-10$ darcy) for buoyant gas-phase convection to dominate. Because temperatures in the vicinity of the condensation zone are close to the boiling point, the water vapor mole fraction according to Eq. (11) is nearly unity, whereas for the region farther away from the repository (i.e., beyond the condensation zone), the temperatures are cooler and the mole fractions are much less (approximately $2 \%$ at ambient conditions). This gradient in mole fraction leads to diffusive fluxes that transport water vapor away from the condensation zone. Diffusive vapor fluxes can dominate over convective vapor fluxes around the repository if the vapor generation rate is very low or if temperatures are close to, but below, the boiling point.

\section{Role of Vapor Diffusion in Rewetting}

As the repository heat generation decays, water vapor continues to diffuse away from the repository because of the higher temperatures there. This diffusion of water vapor contributes to latent heat transport, thereby enhancing cooling of the repository. If $S_{1}$ in the dryout zone is very low, the matric potential will be substantially higher than in the surrounding wetter rock. The exponential factor in Eq. (11) reduces the value of $n_{\mathrm{v}}$ in the dryout zone, and as temperatures decline, the value of $n_{\mathrm{v}}$ in the dryout zone will become smaller than that in the wetter rock away from the repository, even though temperatures are somewhat greater in the dryout zone. Thus, vapor diffusion can occur from cooler to hotter regions that have lower $S_{1}$. In general, water vapor diffuses away from the repository until repository temperatures have decreased enough so that the temperature effect (that drives water vapor away from the repository) in Eq. (11) can no longer overcompensate for the vapor-pressure lowering effect (that drives water vapor back towards the repository). This "vapor-pressure lowering" effect on $n_{\mathrm{v}}$ is significant only at lower $S_{l}$ which, for TSw2 tuff, occurs for $S_{1}<20-30 \%$. Consequently, vapor diffusion will only significantly contribute to rewetting the dryout zone for $S_{1}<20-30 \%$. For $S_{1}>20-30 \%$, rewetting of the dryout zone will be dominated by liquid-phase advection driven by matric potential gradients and gravity. Note that the range of liquid saturation over which vapor-pressure lowering is not important depends strongly on the shape of the curve of matric potential versus $S_{1}$. The length of the time period during which diffusive vapor transport dominates rewetting behavior depends on:

- How dry the dryout zone becomes.

- The range of $S_{1}$ that is associated with high matric potential.

- How quickly repository rock temperatures decline.

The longer that the dryout zone remains dry, the higher the value of $S_{1}$ limit for which vapor-pressure lowering dominates rewetting behavior. The faster repository temperatures decrease while still in the high-matric-potential (i.e., dry) regime, the longer the duration of significant gas-phase diffusion of water vapor back to the dryout zone.

\section{Influence of Enhanced Vapor Diffusion on Temperature and Relative} Humidity in the Repository Rock

In the preceding section (Section 10.1.3.1), we presented the results of mountain-scale calculations for AMLs of 55.3, 110.5, and $150 \mathrm{MTU} /$ acre, for six different sets of matrix properties for the TSw1 and TSw2 (Table 10.1.3.1.2), including five sets of matrix property data that are reported by Pruess and Tsang [1994], which are based on measurements by Flint and others [1993] and the reference matrix properties from the RIB [DOE, 1990]. Those calculations assumed a nominal value of gas-phase diffusion tortuosity factor $\left(\tau_{\text {eff }}\right.$ $=0.2$ ). From Eq. (9) we see that $\tau_{\text {eff }}$ is the product of the tortuosity factor $\tau$ and the vapor diffusion enhancement factor $\eta$. In this section we consider the possibility of "enhanced" binary gas-phase diffusion $\left(\tau_{\text {eff }}=2.0\right.$ ) for the two high AML cases (AML $=110.5$ and $150 \mathrm{MTU} /$ acre). As discussed in Section 10.1.3.1, the value of matrix porosity, $\phi_{m}$ was adjusted in order to yield roughly the same initial liquid water content in the TSw1 and TSw2. Accordingly, a value of $\phi_{m}=0.11$ was assumed for the three cases that yielded lower initial liquid saturation $S_{1, \text { init }}$ (the reference case with the RIB values, LBL-USGS3.4, and LBL-USGS-3.3), and a value of $\phi_{m}=0.10$ was assumed for the three cases that yielded higher initial $S_{1, \text { init }}$ (LBL-USGS-3.5, LBL-USGS-3.2, and LBL-USGS-3.1/3.6). 
Table 10.1.3.2.1 summarizes the time required to attain the indicated relative humidity $R H$ in the rock at various repository locations and the temperature $T$ at which that value of $R H$ is attained for the "reference" matrix-property case based on the RIB [DOE, 1990] and Klavetter and Peters [1986] for AMLs of 110.5 and $150 \mathrm{MTU} /$ acre and for $\tau_{\text {eff }}=2.0$. For the five sets of LBL-USGS matrix-property data and AMLs of 110.5 and 150 MTU/acre, Tables 10.1.3.2.2 and 10.1.3.2.3 summarize the same $R H$ and $T$ information given in Table 10.1.3.2.1. Note that, although these cases have different values of saturated matrix permeability $k_{\mathrm{m}, \mathrm{sat}}$ they all share the same bulk permeability $k_{\mathrm{b}}=280$ millidarcy.

For $\mathrm{AML}=110.5 \mathrm{MTU} /$ acre, the five LBL-USGS matrix property cases fall into four categories with respect to the rate at which the repository rock rewets to (humid) ambient $R H$ :

Fast rewetting rate: LBL-USGS-3.2 results in much faster rewetting to ambient $R H$ than the reference case (compare Tables 10.1.3.2.1a and 10.1.3.2.2a). Consequently, when a given $R H$ is attained, $T$ is substantially higher for LBL-USGS-3.2 than in the reference case. For example, $T$ at the repository center is $87^{\circ} \mathrm{C}$ when $R H=70 \%$ as compared with $70^{\circ} \mathrm{C}$ in the reference case. For LBL-USGS-3.2, enhanced binary gas-phase diffusion results in slower rewetting (compare Table 10.1.3.2.2a with 10.1.3.1.4a). Because $k_{\mathrm{m} \text { sat }}$ for LBL-USGS-3.2 is two orders of magnitude larger than in any of the other cases, advective liquid-phase rewetting (by matrix imbibition) proceeds much more quickly. This faster liquid-phase rewetting increases $S_{1}$ to above the $S_{1}$ range associated with the high matric-potential regime. This allows the vapor-pressure lowering in Eq. (11) to cease to be important at a time when there is still a steep temperature gradient away from the repository. Therefore, throughout the period that gas-phase diffusion is important, the temperature effect in Eq. (11) dominates over the vapor-pressure-lowering effect. Consequently, for LBL-USGS-3.2, the primary contribution of enhanced vapor diffusion is to enhance drying, while having little effect on gas-phase rewetting.

Medium rewetting rate: LBL-USGS-3.5 results in about the same rewetting rate as the reference case (compare Tables 10.1.3.2.1a and 10.1.3.2.2b). For LBL-USGS-3.5, enhanced vapor diffusion slightly increases the rewetting rate (relative to the nominal diffusion case) for the inner $75 \%$ of the repository, and slightly decreases the rewetting rate for the outer $25 \%$ (compare Table 10.1.3.2.2b with Table 10.1.3.1.4b).

Slow rewetting rate: LBL-USGS-3.1/3.6 and LBL-USGS-3.4 result in similar rewetting rates (to each other) that, for $R H>80 \%$, are slower than the reference case in the inner $75 \%$ of the repository (compare Tables 10.1.3.2.1a, 10.1.3.2.2c, and 10.1.3.2.2d). For the outer $10 \%$ of the repository, these three cases have similar rewetting rates for $R H<80 \%$. For the outer $10 \%$ of the repository and $R H$ $>80 \%$, these cases rewet more slowly than the reference case. A comparison of Tables 10.1.3.2.2c and $\mathrm{d}$ with Tables 10.1.3.1.4c and $\mathrm{d}$ shows that enhanced vapor diffusion increases the rewetting rate for the inner $75 \%$ of the repository and for $R H<95 \%$, while it decreases the rewetting rate for the outer $10 \%$ of the repository. Because liquid-phase rewetting is slower for the inner $75 \%$ of LBL-USGS-3.1/3.6 and LBL-USGS-3.4 than in the reference case, the temperature gradient away from the repository becomes relatively shallow while the repository rock is still relatively dry; consequently, the temperature effect in Eq. (11) can no longer offset the vapor-pressure-lowering effect and vapor diffusion contributes to rewetting longer than in the reference case. In general, enhanced vapor diffusion increases the rewetting rate more substantially for LBL-USGS-3.1/3.6 and LBL-USGS-3.4 than for the reference case.

Very slow rewetting rate: LBL-USGS-3.3 results in slower rewetting rate than all of the other matrixproperty sets (compare Table 10.1.3.2.2e with Tables 10.1.3.2.1 a and 10.1.3.2.2a-d). A comparison of Table 10.1.3.2.2e with Table 10.1.3.1.4e shows that enhanced vapor diffusion increases the rewetting rate for the inner $75 \%$ of the repository, and slightly decreases the rewetting rate for the outer $25 \%$. Because the advective liquid-phase rewetting rate is much slower for the inner $75 \%$ of USGS-LBL-3.3 than in the other cases, repository rock temperatures decline more quickly with respect to liquid saturation. Consequently, for LBL-USGS-3.3, the vapor-pressure-lowering effect significantly influences rewetting much longer than in the other cases, and enhanced vapor diffusion enhances rewetting more substantially than in the other cases. 
For $110.5 \mathrm{MTU} /$ acre and for the inner $75 \%$ of the repository, LBL-USGS-3.1/3.6, LBL-USGS-3.4, and LBL-USGS-3.3 have similar relationships between $T$ and $R H$. In general, with the exception of LBL-USGS3.2 , there is not a great degree of variability in the relationship between $T$ and $R H$. For all six matrix property cases, the outer $3 \%$ of the repository has a similar $T$ versus $R H$ relationship. Regardless of case, the outer $3 \%$ of the $110.5-\mathrm{MTU} /$ acre repository is relatively hot $\left(103\right.$ to $107^{\circ} \mathrm{C}$ at the time that $R H=70 \%$ is attained). With the exception of LBL-USGS-3.2, the inner 75\% of the repository has cooled to relatively low temperatures $\left(61\right.$ to $72^{\circ} \mathrm{C}$ ) at the time that $R H=70 \%$ is attained.

For AML = $150 \mathrm{MTU} /$ acre, the five LBL-USGS matrix property cases fall into four categories with respect to the rate at which the repository rock rewets to (humid) ambient $R H$ :

Fast rewetting rate: LBL-USGS-3.2 results in much faster rewetting than the reference case (compare Tables 10.1.3.2.1b and 10.1.3.2.3a). Consequently, temperatures are significantly greater with respect to $R H$. For LBL-USGS-3.2, enhanced vapor diffusion results in slower rewetting than the nominal diffusion case (compare Table 10.1.3.2.3a with Table 10.1.3.1.5a). During the time that the temperature gradient away from the repository is still relatively steep, faster advective liquidphase rewetting increases $S_{1}$ to above the $S_{1}$ range where vapor-pressure lowering is important. Throughout the period that gas-phase diffusion is important, the temperature effect in Eq. (11) dominates over the vapor-pressure-lowering effect. Consequently, for LBL-USGS-3.2, the primary contribution of enhanced vapor diffusion is to enhance drying, while having little effect on gas-phase rewetting.

Medium rewetting rate: LBL-USGS-3.5 results in nearly the same rewetting rate as the reference case (compare Tables 10.1.3.2.1b and 10.1.3.2.3b).

Slow rewetting rate: LBL-USGS-3.1/3.6 and LBL-USGS-3.4 result in similar rewetting rates (to each other) that are much slower than in the reference case (compare Tables 10.1.3.2.3c and $\mathrm{d}$ with Table 10.1.3.2.1b). A comparison of Tables 10.1.3.2.3c and $\mathrm{d}$ with Tables 10.1.3.1.5c and $\mathrm{d}$ of Section 10.1.3.1 shows that enhanced vapor diffusion increases the rewetting rate for the inner $50 \%$ of the repository and $\mathrm{RH}<90 \%$. For the outer $10 \%$ of the repository, enhanced vapor diffusion decreases the rewetting rate, particularly for $R H>80 \%$.

Very slow rewetting rate: LBL-USGS-3.3 has a slower rewetting rate at any given repository location than any of the other cases (compare Table 10.1.3.2.3e with Table 10.1.3.2.1b and Tables 10.1.3.2.3a-d). A comparison of Table 10.1.3.2.3e with Table 10.1.3.1.5e shows that enhanced vapor diffusion increases the rewetting rate for the inner $75 \%$ of the repository, and substantially decreases the rewetting rate for the outer $3 \%$. Because the advective liquid-phase rewetting rate is slower for the inner 75\% of USGS-LBL-3.3 than in the other cases, repository temperatures decline quickly with respect to liquid saturation. Consequently, the vapor-pressure-lowering effect significantly impacts rewetting longer than in the other cases, and enhanced vapor diffusion enhances rewetting more substantially for LBL-USGS-3.3 than in any of the other cases.

Unlike the 110.5-MTU/acre case, the slower rewetting rates for LBL-USGS-3.1/3.6, LBL-USGS-3.4, and LBL-USGS-3.3 at $150 \mathrm{MTU} /$ acre allow the outer $3 \%$ to decline to somewhat lower $T\left(74-81^{\circ} \mathrm{C}\right)$ as $R H$ $=70 \%$ is attained. With the exception of LBL-USGS-3.2, the inner $75 \%$ of the repository has declined to relatively low temperatures $\left(61-71^{\circ} \mathrm{C}\right)$ as $R H=70 \%$ is attained. With the exception of LBL-USGS-3.2, the inner $75 \%$ of the repository has declined to even lower $T\left(49-61^{\circ} \mathrm{C}\right)$ as $R H=80 \%$ is attained.

In general, enhanced vapor diffusion enhances rewetting rate only where the advective liquid-phase rewetting rate is relatively slow to begin with (i.e., the cases with slow liquid-phase rewetting rates and at the center of the repository). Enhanced vapor diffusion reduces the overall rewetting rate where the advective liquid-phase rewetting rate is fastest (i.e., LBL-USGS-3.2 and at the edge of the repository). Therefore, enhanced vapor diffusion (if it actually exists) may be thought to function as somewhat of an "equalizer" of thermal-hydrological conditions in the repository rock, countering some of the effects of heating variability and natural system heterogeneity. For the LBL-USGS-3.3 properties, $150 \mathrm{MTU} /$ acre and $\tau_{\text {eff }}=0.2$ (Table 10.1.3.1.5e), as $R H=70 \%$ is attained, temperatures range from 49 to $83^{\circ} \mathrm{C}$ from the 50 to $97 \%$ repository location (resulting in a $34^{\circ} \mathrm{C}$ spread), while for $\tau_{\text {eff }}=2.0$ (Table 10.1.3.2.3e), the temperature range is only 63 to $74^{\circ} \mathrm{C}$. 

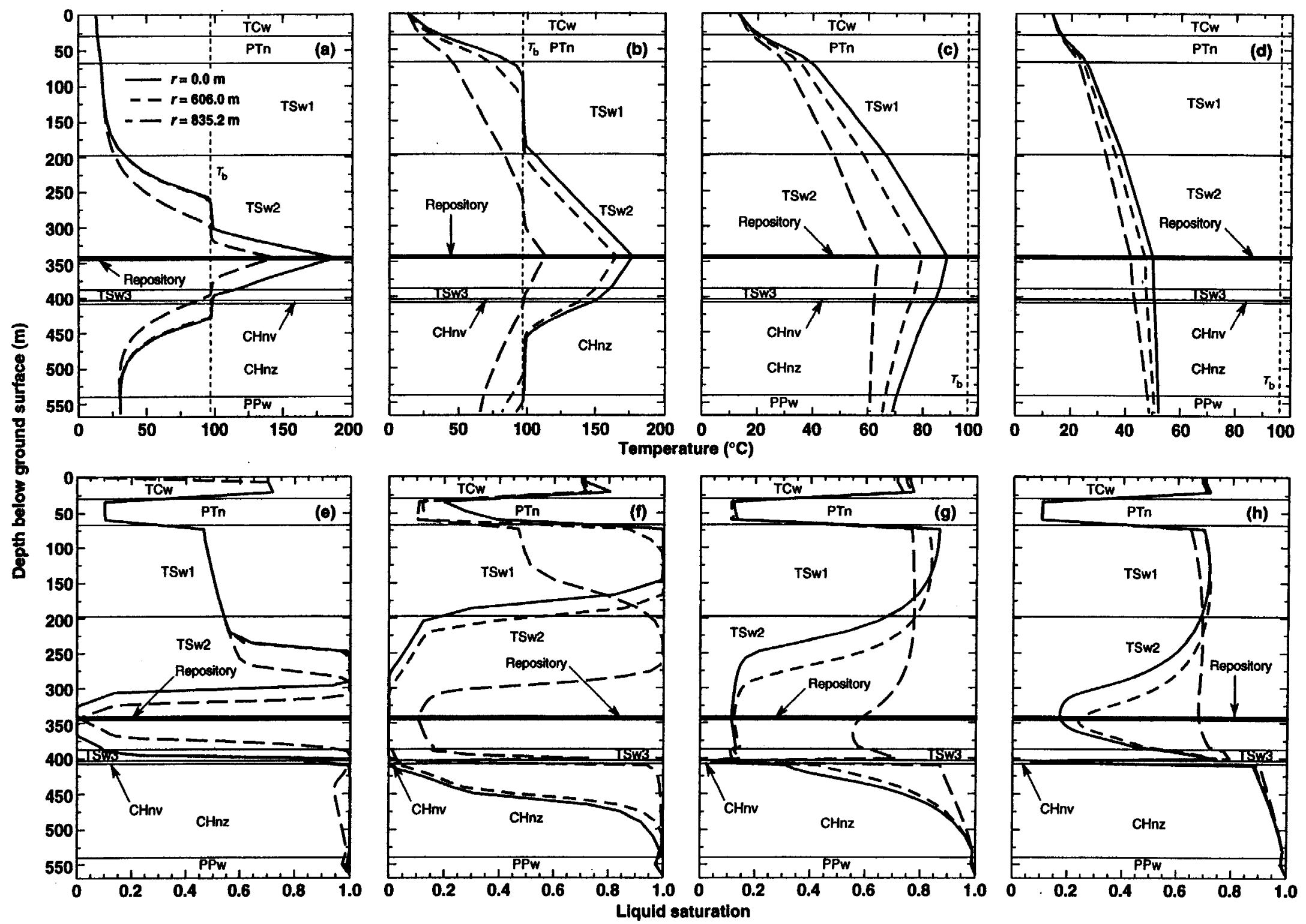

Figure 10.1.3.1.1. Vertical temperature profiles at various radial distances, $r$, for AML $=110.5 \mathrm{MTU} / \mathrm{acre}$ at (a) $t=100 \mathrm{yr}$, (b) $t=1000 \mathrm{yr}$, (c) $t=10,000 \mathrm{yr}$, and (d) $t=36,000 \mathrm{yr}$. Note different temperature scales. Vertical liquid saturation profiles are also plotted at (e) $t=100 \mathrm{yr}$, (f) $t=1000 \mathrm{yr}$, (g) $t=10,000 \mathrm{yr}$, and (h) $t=36,000 \mathrm{yr}$. Matrix properties for the TSw1 and TSw2 are based on Klavetter and Peters (1986). Binary gas-phase tortuosity factor $\tau_{\text {eff }}=0.2$ for all units. 

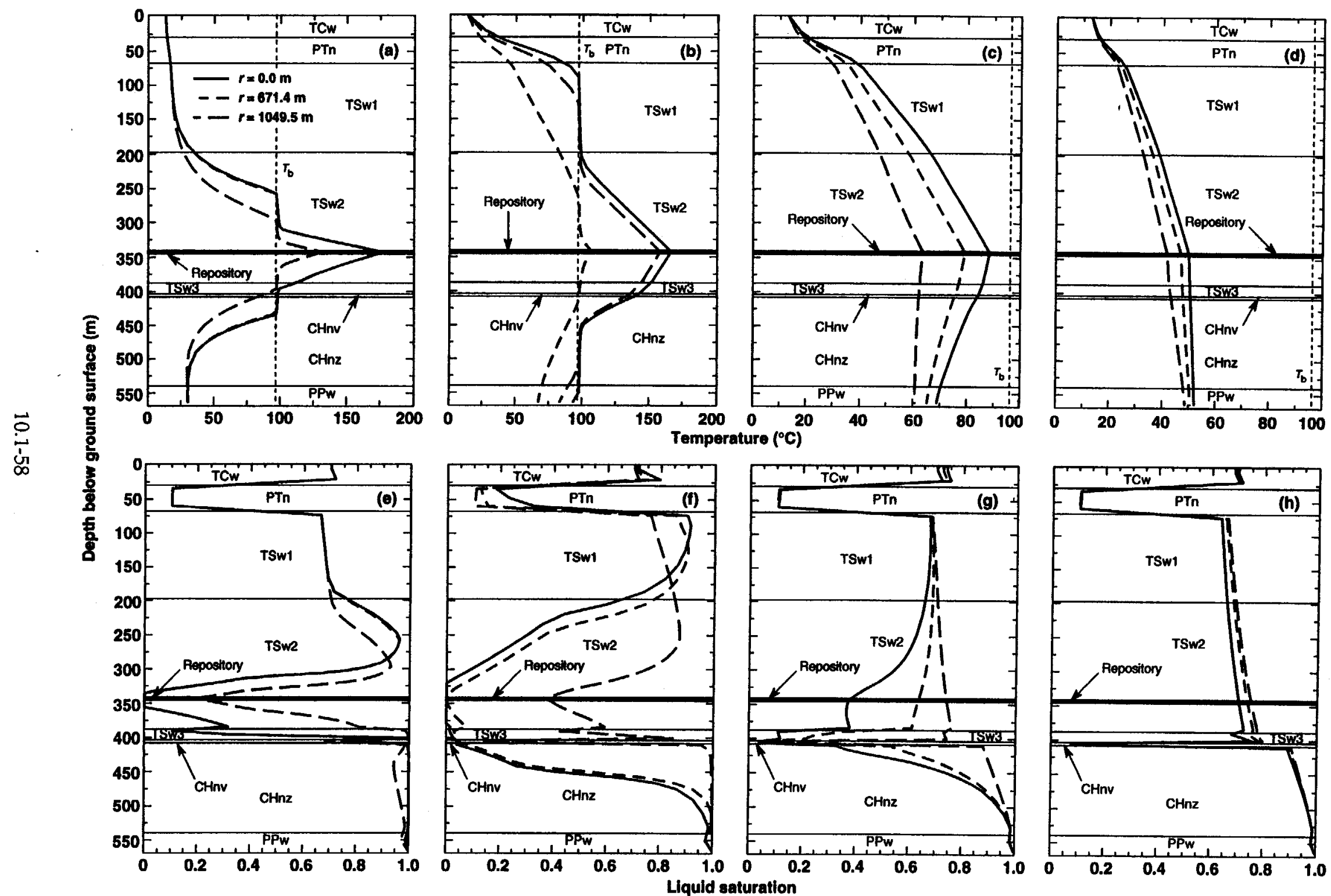

Figure 10.1.3.1.2. Vertical temperature profiles at various radial distances, $r$, for AML $=110.5 \mathrm{MTU} / \mathrm{acre}$ at (a) $t=100 \mathrm{yr}$, (b) $t=1000 \mathrm{yr}$, (c) $t=10,000 \mathrm{yr}$, and (d) $t=36,250 \mathrm{yr}$. Note different temperature scales. Vertical liquid saturation profiles are also plotted at (e) $t=100 \mathrm{yr}$, (f) $t=1000 \mathrm{yr}$, (g) $t=10,000 \mathrm{yr}$, and (h) $t=36,250 \mathrm{yr}$. Matrix properties for the TSw1 and TSw2 are based on LBL-USGS sample 3.2. Binary gas-phase tortuosity factor $\tau_{\mathrm{eff}}=0.2$ for all units. 

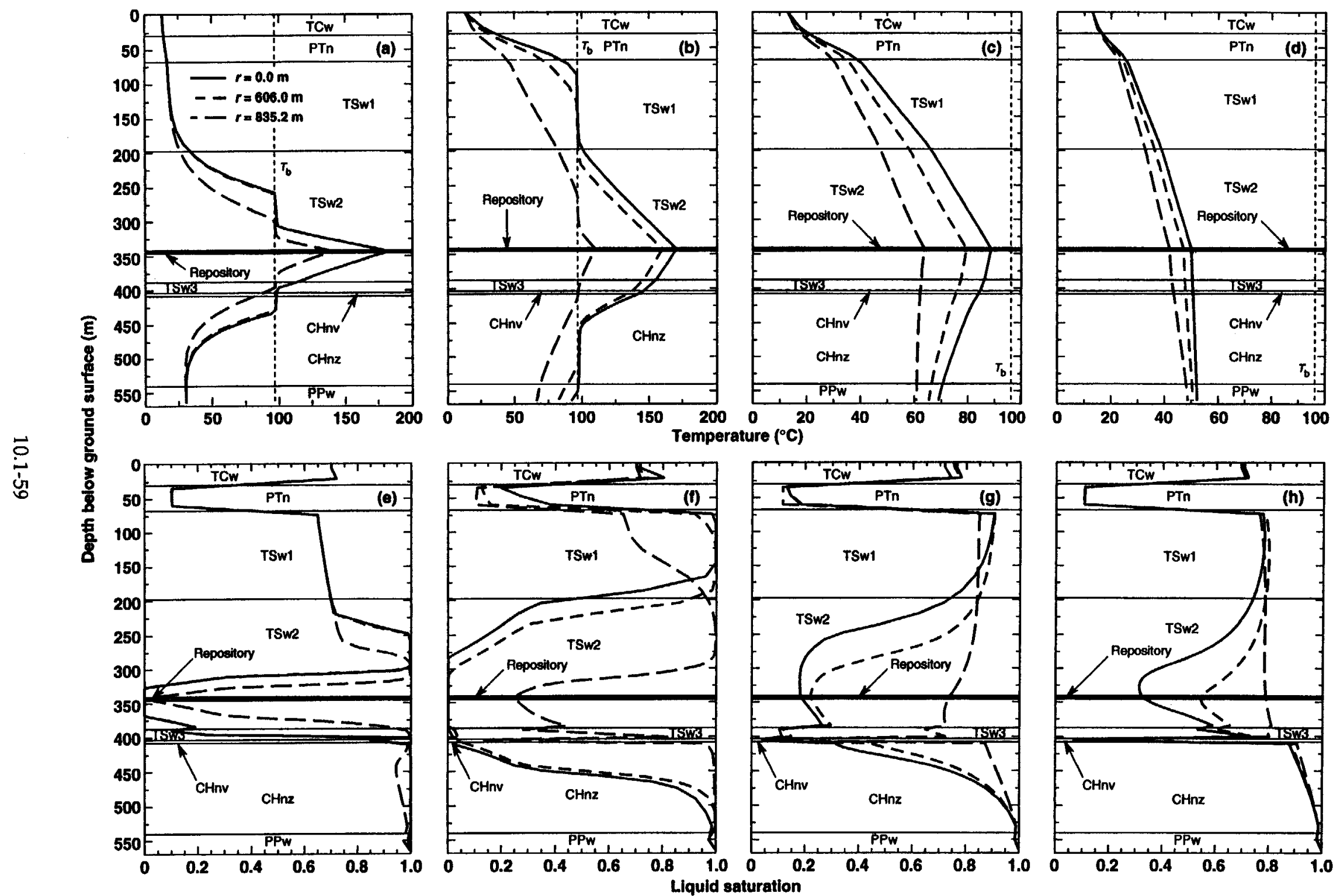

Figure 10.1.3.1.3. Vertical temperature profiles at various radial distances, $r$, for $\mathrm{AML}=110.5 \mathrm{MTU} / \mathrm{acre}$ at (a) $t=100 \mathrm{yr}$, (b) $t=1000 \mathrm{yr}$, (c) $t=10,000 \mathrm{yr}$, and (d) $t=35,730 \mathrm{yr}$. Note different temperature scales. Vertical liquid saturation profiles are also plotted at (e) $t=100 \mathrm{yr}$, (f) $t=1000 \mathrm{yr}$, (g) $t=10,000 \mathrm{yr}$, and (h) $t=35,730$ yr. Matrix properties for the TSw 1 and TSw2 are based on LBL-USGS sample 3.5. Binary gas-phase tortuosity factor $\tau_{\mathrm{eff}}=0.2$ for all units. 

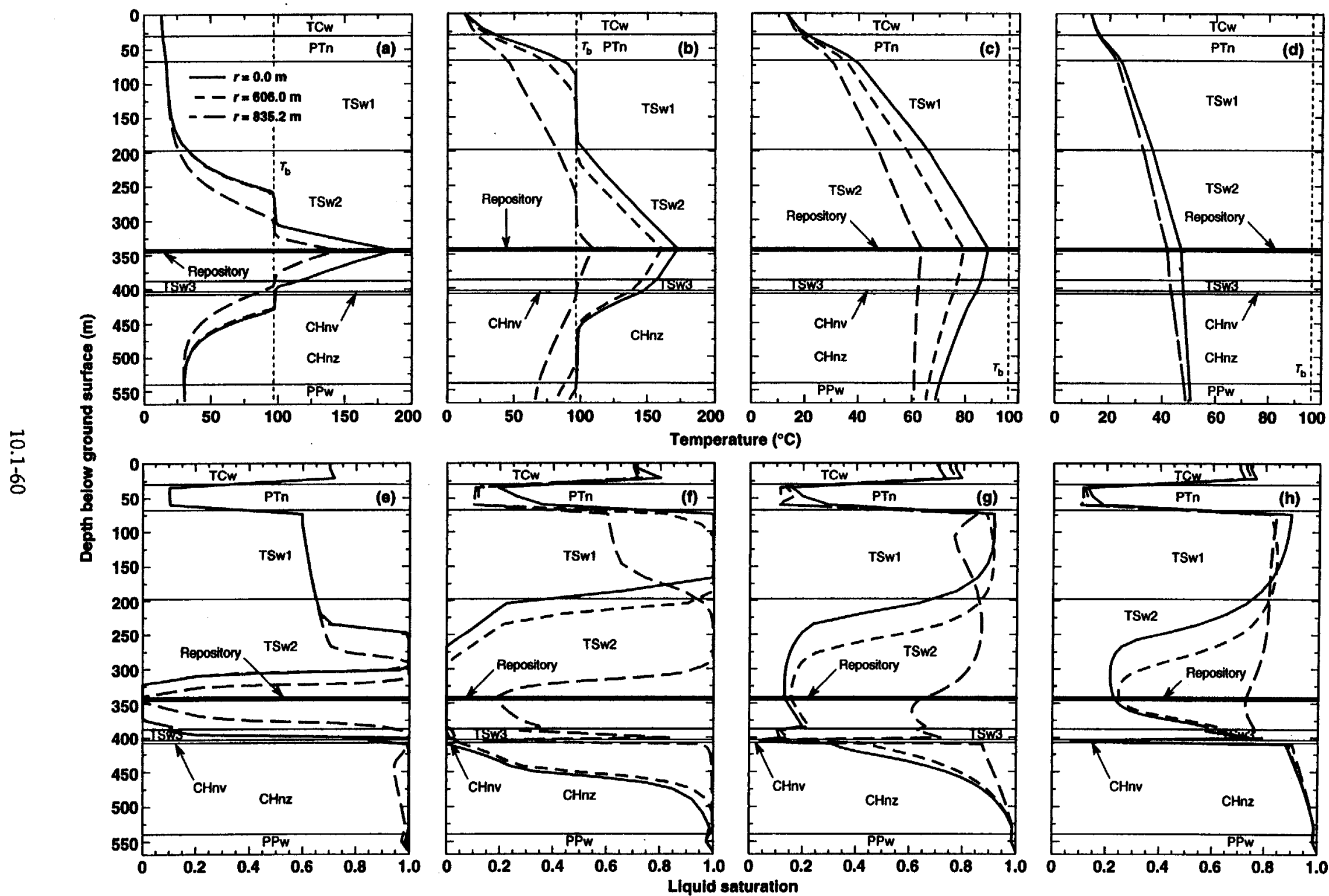

Figure 10.1.3.1.4. Vertical temperature profiles at various radial distances, $r$, for $A M L=110.5 \mathrm{MTU} / \mathrm{acre}$ at (a) $t=100 \mathrm{yr}$, (b) $t=1000 \mathrm{yr}$, (c) $t=10,000 \mathrm{yr}$, and (d) $t=35,400 \mathrm{yr}$. Note different temperature scales. Vertical liquid saturation profiles are also plotted at (e) $t=100 \mathrm{yr}$, (f) $t=1000 \mathrm{yr}$, (g) $t=10,000 \mathrm{yr}$, and (h) $t=35,400 \mathrm{yr}$. Matrix properties for the TSw1 and TSw2 are based on LBL-USGS sample 3.1/3.6. Binary gas-phase tortuosity factor $\tau_{\mathrm{eff}}=0.2$ for all units. 

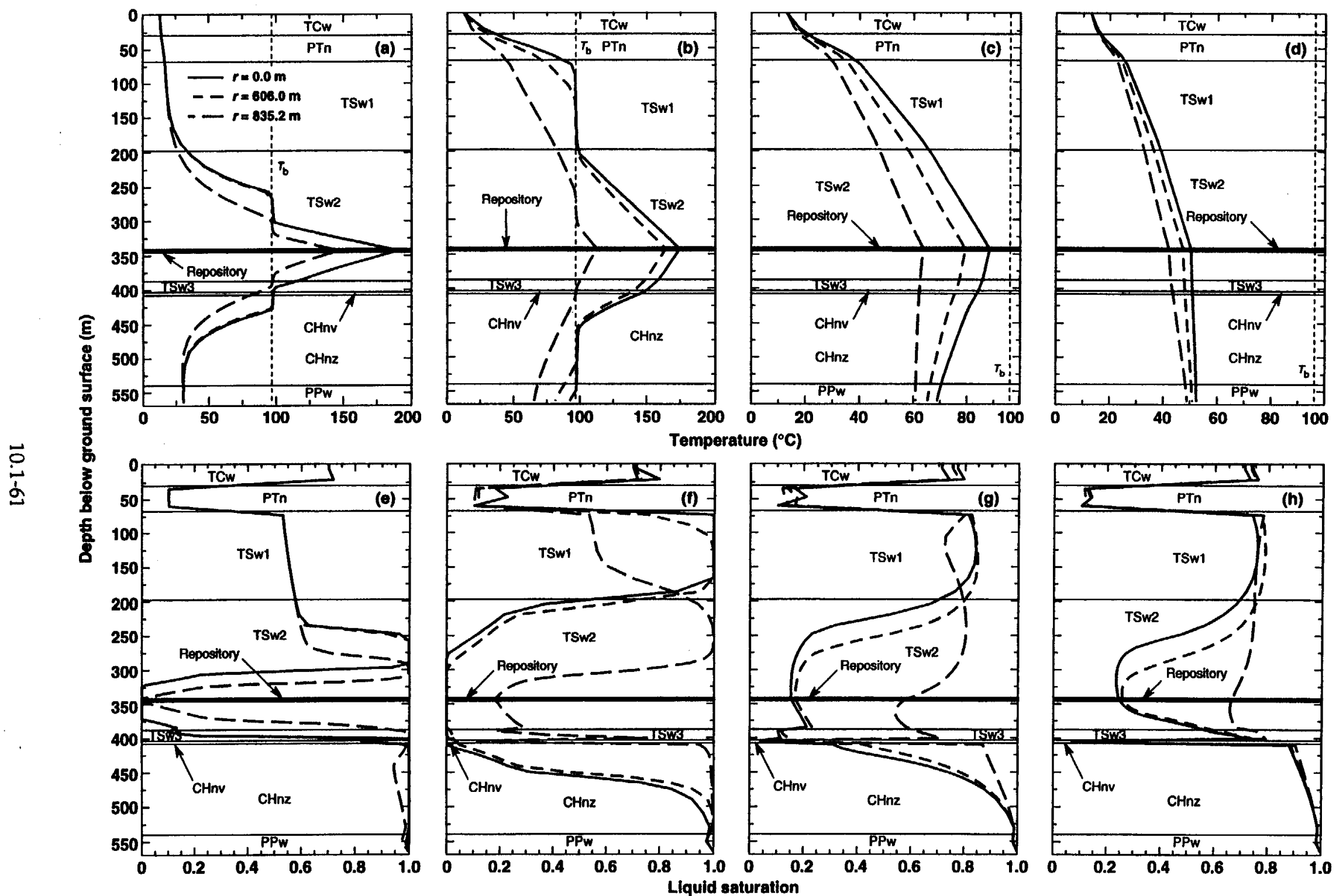

Figure 10.1.3.1.5. Vertical temperature profiles at various radial distances, $r$, for $A M L=110.5 \mathrm{MTU} / \mathrm{acre}$ at (a) $t=100 \mathrm{yr}$, (b) $t=1000 \mathrm{yr}$, (c) $t=10,000 \mathrm{yr}$, and (d) $t=35,150 \mathrm{yr}$. Note different temperature scales. Vertical liquid saturation profiles are also plotted at (e) $t=100 \mathrm{yr}$, (f) $t=1000 \mathrm{yr}$, (g) $t=10,000 \mathrm{yr}$, and (h) $t=35,150$ yr. Matrix properties for the TSwl and TSw2 are based on LBL-USGS sample 3.4. Binary gas-phase tortuosity factor $\tau_{\text {eff }}=0.2$ for all units. 

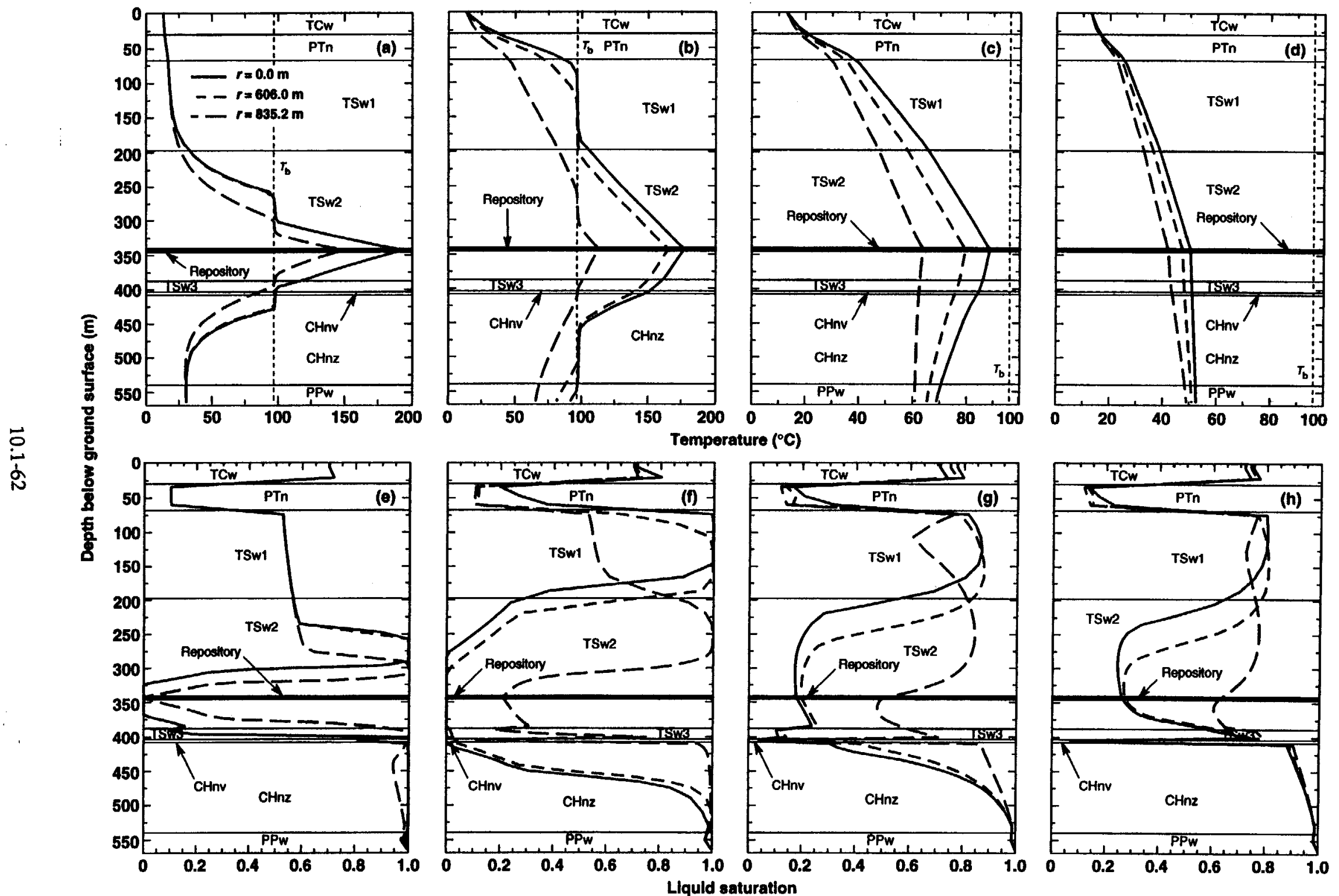

Figure 10.1.3.1.6. Vertical temperature profiles at various radial distances, $r$, for $\mathrm{AML}=110.5 \mathrm{MTU} / \mathrm{acre}$ at (a) $t=100 \mathrm{yr}$, (b) $t=1000 \mathrm{yr}$, (c) $t=10,000 \mathrm{yr}$, and (d) $t=34,630 \mathrm{yr}$. Note different temperature scales. Vertical liquid saturation profiles are also plotted at (e) $t=100 \mathrm{yr}$, (f) $t=1000 \mathrm{yr}$, (g) $t=10,000 \mathrm{yr}$, and (h) $t=34,630 \mathrm{yr}$. Matrix properties for the TSw1 and TSw2 are based on LBL-USGS sample 3.3. Binary gas-phase tortuosity factor $\tau_{\text {eff }}=0.2$ for all units. 

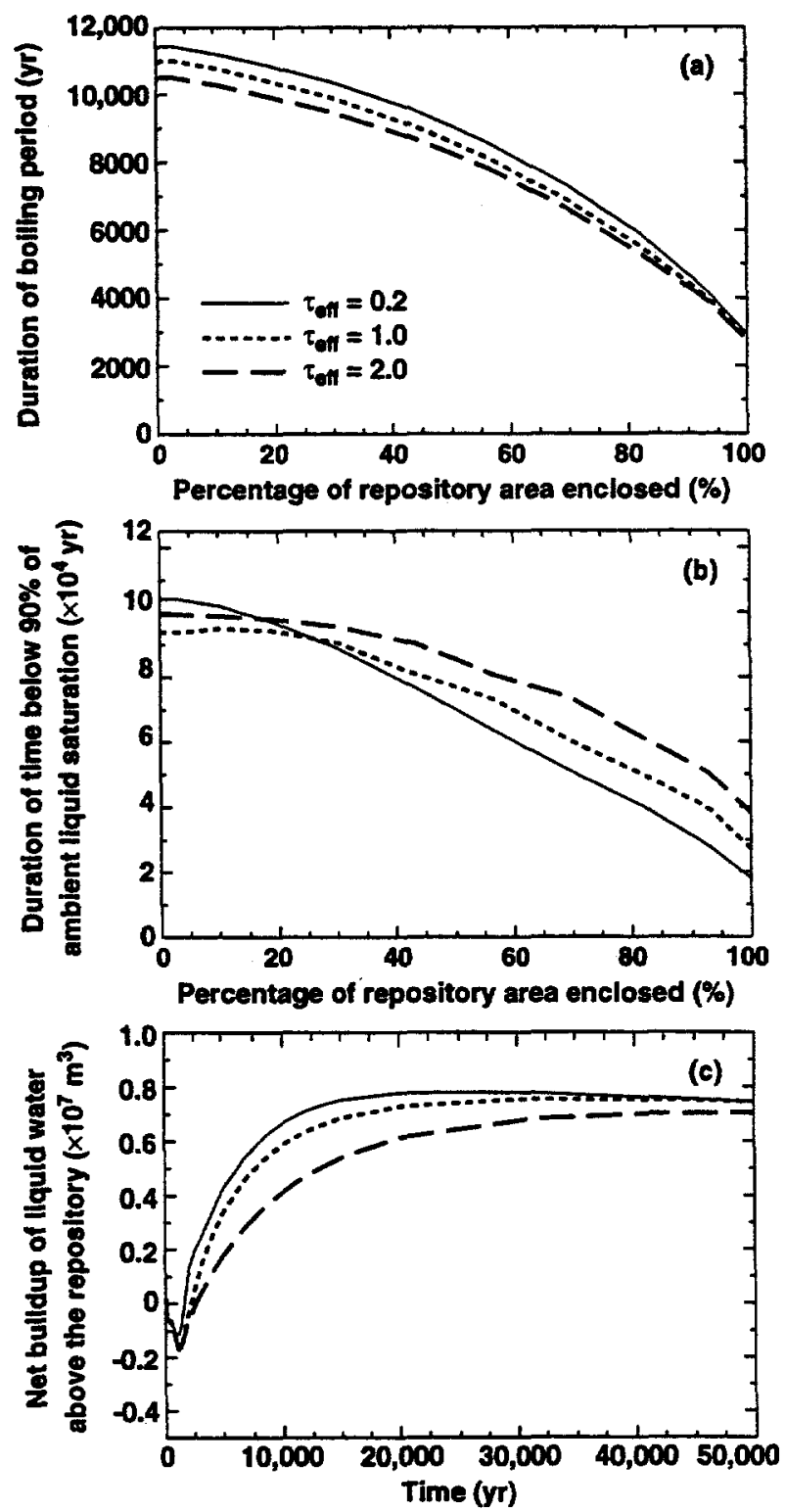

Figure 10.1.3.2.1. Duration of the boiling period (a) and duration of time below $90 \%$ of ambient liquid saturation (b) at various repository locations for an AML of $154.7 \mathrm{MTU} / \mathrm{acre}, k_{\mathrm{b}}=280$ millidarcy, and various values of the effective diffusion factor, $\tau_{\text {eff- }}$. The repository locations are identified as the percentage of the repository area enclosed, with $0 \%$ corresponding to the repository center, and $100 \%$ corresponding to the outer perimeter. (c) The net buildup of liquid water above the repository is also plotted for these cases. 


\section{Table 10.1.3.2.1}

Time required to attain the indicated relative humidity $R H$ at various repository locations and the temperature at which that value of $R H$ is attained for 22.5-yr-old SNF, gas-phase diffusion tortousity factor, $\tau_{\text {eff, }}=2.0, k_{\mathrm{b}}=280$ millidarcy, and assuming the matrix properties from Klavetter and Peters (1986) for the TSw1 and TSw2 units. The locations are identified as the percentage of the repository area enclosed, with $0 \%$ corresponding to the repository center, and $100 \%$ corresponding to the edge.

\section{Table 10.1.3.2.1a: $A M L=110.5$ MTU/acre}

\begin{tabular}{|c|c|c|c|c|c|c|c|c|}
\hline \multirow{2}{*}{$\begin{array}{l}\text { Percentage of } \\
\text { repository area } \\
\text { enclosed (\%) }\end{array}$} & \multicolumn{4}{|c|}{$\begin{array}{l}\text { Time required to attain } \\
\text { the indicated } R H(\mathrm{yI})\end{array}$} & \multicolumn{4}{|c|}{$\begin{array}{c}\text { Temperature at which the indicated } \\
R H \text { is attained }\left({ }^{\circ} \mathrm{C}\right)\end{array}$} \\
\hline & $70 \%$ & $80 \%$ & $90 \%$ & $95 \%$ & $70 \%$ & $80 \%$ & $90 \%$ & $95 \%$ \\
\hline 50 & 14,260 & 23,850 & 42,270 & 59,750 & 70 & 57 & 44 & 38 \\
\hline 75 & 10,180 & 17,870 & 33,350 & 47,150 & 72 & 59 & 46 & 41 \\
\hline 90 & 3920 & 7730 & 16,040 & 26,640 & 85 & 71 & 57 & 48 \\
\hline 97 & 1490 & 2240 & 4490 & 8130 & 104 & 93 & 76 & 65 \\
\hline \multicolumn{9}{|c|}{ Table 10.1.3.2.1b: $\mathrm{AML}=150 \mathrm{MTU} / \mathrm{acre}$} \\
\hline \multirow{2}{*}{$\begin{array}{l}\text { Percentage of } \\
\text { repository area } \\
\text { enclosed (\%) }\end{array}$} & \multicolumn{4}{|c|}{$\begin{array}{l}\text { Time required to attain } \\
\text { the indicated } R H(\mathrm{yr})\end{array}$} & \multicolumn{4}{|c|}{$\begin{array}{c}\text { Temperature at which the indicated } \\
R H \text { is attained }\left({ }^{\circ} \mathrm{C}\right)\end{array}$} \\
\hline & $70 \%$ & $80 \%$ & $90 \%$ & $95 \%$ & $70 \%$ & $80 \%$ & $90 \%$ & $95 \%$ \\
\hline 50 & 19,470 & 29,380 & 48,260 & 64,180 & 69 & 56 & 45 & 41 \\
\hline 75 & 15,390 & 23,380 & 36,100 & 45,900 & 71 & 59 & 48 & 44 \\
\hline 90 & 9610 & 14,520 & 23,170 & 29,140 & 76 & 66 & 55 & 50 \\
\hline 97 & 5310 & 8420 & 13,500 & 18,330 & 84 & 74 & 64 & 57 \\
\hline
\end{tabular}




\section{Table 10.1.3.2.2: AML $=110.5 \mathrm{MTU} / \mathrm{acre}$}

Time required to attain the indicated relative humidity $R H$ at various repository locations and the temperature at which that value of $R H$ is attained for 22.5-yr-old SNF, gas-phase diffusion tortousity

factor $\tau_{\text {eff, }}=2.0$, and $k_{\mathrm{b}}=280$ millidarcy. The locations are identified as the percentage of the repository area enclosed, with $0 \%$ corresponding to the repository center, and $100 \%$ corresponding to the edge.

Table 10.1.3.2.2a: Matrix properties for LBL-USGS sample 3.2 in the TSw1 and TSw2 units.

\begin{tabular}{|c|c|c|c|c|c|c|c|c|}
\hline \multirow{2}{*}{$\begin{array}{l}\text { Percentage of } \\
\text { repository area } \\
\text { enclosed (\%) }\end{array}$} & \multicolumn{4}{|c|}{$\begin{array}{l}\text { Time required to attain } \\
\text { the indicated } R H(\mathrm{yr})\end{array}$} & \multicolumn{4}{|c|}{$\begin{array}{c}\text { Temperature at which the indicated } \\
R H \text { is attained }\left({ }^{\circ} \mathrm{C}\right)\end{array}$} \\
\hline & $70 \%$ & $80 \%$ & $90 \%$ & $95 \%$ & $70 \%$ & $80 \%$ & $90 \%$ & $95 \%$ \\
\hline 50 & 7590 & 9440 & 12,060 & 16,690 & 87 & 81 & 74 & 66 \\
\hline 75 & 4000 & 4880 & 6490 & 8670 & 95 & 89 & 83 & 76 \\
\hline 90 & 1860 & 2280 & 2760 & 3760 & 105 & 99 & 94 & 85 \\
\hline 97 & 870 & 1170 & 1520 & 1800 & 107 & 103 & 99 & 97 \\
\hline
\end{tabular}

Table 10.1.3.2.2b: Matrix properties for LBL-USGS sample 3.5 in the TSw1 and TSw2 units.

\begin{tabular}{|c|r|r|r|r|r|r|r|r|}
\hline $\begin{array}{c}\text { Percentage of } \\
\text { repository area } \\
\text { enclosed (\%) }\end{array}$ & \multicolumn{4}{|c|}{$\begin{array}{c}\text { Time required to attain } \\
\text { the indicated } R H(\mathrm{yr})\end{array}$} & \multicolumn{3}{|c|}{$\begin{array}{c}\text { Temperature at which the indicated } \\
\text { (1) attained }{ }^{\circ} \mathrm{C} \text { C) }\end{array}$} \\
\cline { 2 - 10 } & $70 \%$ & $80 \%$ & $90 \%$ & $95 \%$ & $70 \%$ & $80 \%$ & $90 \%$ & $95 \%$ \\
\hline 50 & 14,610 & 23,000 & 36,210 & 46,260 & 69 & 57 & 47 & 42 \\
\hline 75 & 9340 & 14,790 & 24,090 & 30,120 & 75 & 64 & 53 & 48 \\
\hline 90 & 3080 & 5490 & 10,040 & 14,690 & 92 & 78 & 67 & 59 \\
\hline 97 & 1190 & 1680 & 2560 & 4160 & 106 & 100 & 89 & 78 \\
\hline
\end{tabular}

Table 10.1.3.2.2c: Matrix properties for LBL-USGS samples 3.1 and 3.6 in the TSw1 and TSw2 units.

\begin{tabular}{|c|c|c|c|c|c|c|c|c|}
\hline \multirow{2}{*}{$\begin{array}{l}\text { Percentage of } \\
\text { repository area } \\
\text { enclosed (\%) }\end{array}$} & \multicolumn{4}{|c|}{$\begin{array}{l}\text { Time required to attain } \\
\text { the indicated } R H(\mathrm{yr})\end{array}$} & \multicolumn{4}{|c|}{$\begin{array}{c}\text { Temperature at which the indicated } \\
R H \text { is attained }\left({ }^{\circ} \mathrm{C}\right)\end{array}$} \\
\hline & $70 \%$ & $80 \%$ & $90 \%$ & $95 \%$ & $70 \%$ & $80 \%$ & $90 \%$ & $95 \%$ \\
\hline 50 & 17,290 & 30,120 & 61,960 & 99,580 & 63 & 49 & 38 & 34 \\
\hline 75 & 11,690 & 22,050 & 44,490 & 69,530 & 68 & 53 & 41 & 36 \\
\hline 90 & 4070 & 9370 & 22,480 & 36,080 & 84 & 66 & 50 & 42 \\
\hline 97 & 1220 & 1930 & 5290 & 12,620 & 106 & 97 & 72 & 57 \\
\hline
\end{tabular}

Table 10.1.3.2.2d: Matrix properties for LBL-USGS sample 3.4 in the TSw1 and TSw2 units.

\begin{tabular}{|c|c|c|c|c|c|c|c|c|}
\hline \multirow{2}{*}{$\begin{array}{l}\text { Percentage of } \\
\text { repository area } \\
\text { enclosed (\%) }\end{array}$} & \multicolumn{4}{|c|}{$\begin{array}{l}\text { Time required to attain } \\
\text { the indicated } R H(\mathrm{yr})\end{array}$} & \multicolumn{4}{|c|}{$\begin{array}{c}\text { Temperature at which the indicated } \\
R H \text { is attained }\left({ }^{\circ} \mathrm{C}\right)\end{array}$} \\
\hline & $70 \%$ & $80 \%$ & $90 \%$ & $95 \%$ & $70 \%$ & $80 \%$ & $90 \%$ & $95 \%$ \\
\hline 50 & 17,640 & 30,050 & 60,100 & 102,350 & 62 & 49 & 38 & 34 \\
\hline 75 & 12,320 & 22,860 & 45,340 & 73,170 & 66 & 52 & 40 & 36 \\
\hline 90 & 4950 & 10,870 & 25,310 & 39,660 & 79 & 63 & 47 & 40 \\
\hline 97 & 1510 & 2520 & 8360 & 17,600 & 104 & 90 & 64 & 51 \\
\hline
\end{tabular}

Table 10.1.3.2.2e: Matrix properties for LBL-USGS sample 3.3 in the TSw1 and TSw2 units.

\begin{tabular}{|c|r|r|r|r|r|r|r|r|}
\hline $\begin{array}{c}\text { Percentage of } \\
\text { repository area } \\
\text { enclosed (\%) }\end{array}$ & \multicolumn{4}{|c|}{$\begin{array}{c}\text { Time required to attain } \\
\text { the indicated } R H(\mathrm{yr})\end{array}$} & \multicolumn{3}{|c|}{ Temperature at which the indicated } \\
\cline { 2 - 10 } & $70 \%$ & $80 \%$ & $90 \%$ & $95 \%$ & $70 \%$ & $80 \%$ & $90 \%$ & $95 \%$ \\
\hline 50 & 17,940 & 30,420 & 68,620 & 149,230 & 61 & 48 & 37 & 31 \\
\hline 75 & 12,980 & 24,460 & 52,390 & 103,200 & 65 & 51 & 38 & 33 \\
\hline 90 & 5800 & 13,010 & 32,010 & 59,600 & 75 & 60 & 43 & 36 \\
\hline 97 & 1620 & 3240 & 13,740 & 29,650 & 103 & 83 & 55 & 43 \\
\hline
\end{tabular}




\section{Table 10.1.3.2.3: $\mathrm{AML}=150 \mathrm{MTU} / \mathrm{acre}$}

Time required to attain the indicated relative humidity $R H$ at various repository locations and the temperature at which that value of $R H$ is attained for 22.5-yr-old SNF, gas-phase diffusion tortousity

factor $\tau_{\text {eff, }}=2.0$, and $k_{\mathrm{b}}=280$ millidarcy. The locations are identified as the percentage of the repository area enclosed, with $0 \%$ corresponding to the repository center, and $100 \%$ corresponding to the edge.

Table 10.1.3.2.3a: Matrix properties for LBL-USGS sample 3.2 in the TSw1 and TSw2 units.

\begin{tabular}{|c|c|c|c|c|c|c|c|c|}
\hline \multirow{2}{*}{$\begin{array}{l}\text { Percentage of } \\
\text { repository area } \\
\text { enclosed (\%) }\end{array}$} & \multicolumn{4}{|c|}{$\begin{array}{l}\text { Time required to attain } \\
\text { the indicated } R H(\mathrm{yx})\end{array}$} & \multicolumn{4}{|c|}{$\begin{array}{c}\text { Temperature at which the indicated } \\
R H \text { is attained }\left({ }^{\circ} \mathrm{C}\right)\end{array}$} \\
\hline & $70 \%$ & $80 \%$ & $90 \%$ & $95 \%$ & $70 \%$ & $80 \%$ & $90 \%$ & $95 \%$ \\
\hline 50 & 11,790 & 13,940 & 17,810 & 22,390 & 86 & 80 & 72 & 65 \\
\hline 75 & 7260 & 8640 & 10,930 & 13,650 & 93 & 88 & 81 & 74 \\
\hline 90 & 3570 & 4260 & 5670 & 7200 & 101 & 96 & 89 & 83 \\
\hline 97 & 2120 & 2490 & 2990 & 4020 & 106 & 102 & 97 & 90 \\
\hline
\end{tabular}

Table 10.1.3.2.3b: Matrix properties for LBL-USGS sample 3.5 in the TSw1 and TSw2 units.

\begin{tabular}{|c|c|c|c|c|c|c|c|c|}
\hline \multirow{2}{*}{$\begin{array}{c}\text { Percentage of } \\
\text { repository area } \\
\text { enclosed (\%) }\end{array}$} & \multicolumn{4}{|c|}{$\begin{array}{l}\text { Time required to attain } \\
\text { the indicated } R H(\mathrm{yr})\end{array}$} & \multicolumn{4}{|c|}{$\begin{array}{c}\text { Temperature at which the indicated } \\
R H \text { is attained }\left({ }^{\circ} \mathrm{C}\right)\end{array}$} \\
\hline & $70 \%$ & $80 \%$ & $90 \%$ & $95 \%$ & $70 \%$ & $80 \%$ & $90 \%$ & $95 \%$ \\
\hline 50 & 20,720 & 30,360 & 44,280 & 55,940 & 67 & 56 & 47 & 43 \\
\hline 75 & 15,270 & 22,040 & 30,860 & 39,420 & 71 & 61 & 52 & 47 \\
\hline 90 & 8750 & 12,680 & 18,420 & 25,440 & 79 & 70 & 60 & 53 \\
\hline 97 & 4250 & 6690 & 10,440 & 14,050 & 90 & 79 & 70 & 63 \\
\hline
\end{tabular}

Table 10.1.3.2.3c: Matrix properties for LBL-USGS samples 3.1 and 3.6 in the TSw1 and TSw2 units.

\begin{tabular}{|c|r|r|r|r|r|r|r|r|}
\hline $\begin{array}{c}\text { Percentage of } \\
\text { repository area } \\
\text { enclosed (\%) }\end{array}$ & \multicolumn{4}{|c|}{$\begin{array}{c}\text { Time required to attain } \\
\text { the indicated } R H(\mathrm{yr})\end{array}$} & \multicolumn{4}{c|}{ Temperature at which the indicated } \\
\cline { 2 - 9 } & $70 \%$ & $80 \%$ & $90 \%$ & $95 \%$ & $70 \%$ & $80 \%$ & $90 \%$ & $95 \%$ \\
\hline 50 & 24,020 & 38,160 & 72,900 & 119,100 & 61 & 49 & 38 & 34 \\
\hline 75 & 18,990 & 31,390 & 58,600 & 89,100 & 63 & 50 & 40 & 35 \\
\hline 90 & 11,590 & 19,780 & 36,860 & 53,670 & 71 & 57 & 45 & 39 \\
\hline 97 & 5910 & 10,810 & 21,280 & 32,270 & 81 & 68 & 53 & 45 \\
\hline
\end{tabular}

Table 10.1.3.2.3d: Matrix properties for LBL-USGS sample 3.4 in the TSw1 and TSw2 units.

\begin{tabular}{|c|r|c|c|r|r|r|r|r|}
\hline \multirow{2}{*}{$\begin{array}{c}\text { Percentage of } \\
\text { repository area } \\
\text { enclosed (\%) }\end{array}$} & \multicolumn{4}{|c|}{$\begin{array}{c}\text { Time required to attain } \\
\text { the indicated } R H(\mathrm{yr})\end{array}$} & \multicolumn{3}{|c|}{ Temperature at which the indicated } \\
\cline { 2 - 10 } & $70 \%$ & $80 \%$ & $90 \%$ & $95 \%$ & $70 \%$ & $80 \%$ & $90 \%$ & $95 \%$ \\
\hline 50 & 25,430 & 38,420 & 73,620 & 129,110 & 64 & 51 & 39 & 34 \\
\hline 75 & 19,590 & 31,890 & 59,570 & 95,320 & 62 & 50 & 40 & 35 \\
\hline 90 & 12,540 & 21,500 & 39,160 & 59,060 & 69 & 56 & 44 & 38 \\
\hline 97 & 6970 & 12,400 & 24,890 & 37,160 & 77 & 65 & 51 & 43 \\
\hline
\end{tabular}

Table 10.1.3.2.3e: Matrix properties for LBL-USGS sample 3.3 in the TSw1 and TSw2 units.

\begin{tabular}{|c|r|c|c|r|r|r|r|r|}
\hline \multirow{2}{*}{$\begin{array}{c}\text { Percentage of } \\
\text { repository area } \\
\text { enclosed (\%) }\end{array}$} & \multicolumn{4}{|c|}{$\begin{array}{c}\text { Time required to attain } \\
\text { the indicated } R H(\mathrm{yr})\end{array}$} & \multicolumn{3}{|c|}{\begin{tabular}{c} 
Temperature at which the indicated \\
\cline { 2 - 9 }
\end{tabular}} & \multicolumn{4}{|c|}{$70 \%$} & $80 \%$ & $90 \%$ & $95 \%$ & $70 \%$ & $80 \%$ & $90 \%$ & $95 \%$ \\
\hline 50 & 25,830 & 38,820 & 84,630 & 204,630 & 63 & 51 & 37 & 31 \\
\hline 75 & 20,150 & 33,150 & 70,500 & 142,420 & 61 & 49 & 38 & 33 \\
\hline 90 & 13,570 & 24,230 & 48,240 & 88,390 & 67 & 53 & 41 & 35 \\
\hline 97 & 8040 & 14,690 & 31,250 & 53,880 & 74 & 61 & 46 & 38 \\
\hline
\end{tabular}




\section{Contents}

10.1.4 Influence of Overburden Thickness.

$. .10 .1-68$ 


\subsubsection{Influence of Overburden Thickness}

10.1.4.1 Temperature and Relative Humidity in the Repository Rock. All of the mountain-scale (and drift-scale) analyses of temperature $T$ and relative humidity $R H$ conditions in the repository have assumed a repository depth of $343.1 \mathrm{~m}$; in effect, the reference-overburden case has assumed a $343.1-\mathrm{m}$ thick overburden. Table 10.1.4.1.1 summarizes $T$ and $R H$ in the repository rock for the referenceoverburden case and various AMLs; these cases assume $k_{\mathrm{b}}=280$ millidarcy, and "nominal" binary gasphase diffusion, where the binary gas-phase diffusion tortuosity factor $\tau_{\text {eff }}=0.2$. Table 10.1.4.1.2a summarizes the duration of the boiling period, $t_{\mathrm{bp}}$ and the value of $R H$ at the end of the boiling period for the same suite of cases. Tables 10.1.4.1.3 and 10.1.4.1.2b summarize $T$ and $R H$ in the repository rock for the same suite of cases, but with a minimum-overburden of $200 \mathrm{~m}$. (The 200 -m-thick overburden case was chosen because it is the shallowest overburden thickness allowed by regulation.) For the reference 343.1-m-thick overburden case, the repository is $225 \mathrm{~m}$ above the water table, while in the 200-m-thick overburden case, it is $330 \mathrm{~m}$ above the water table. Because of the additional $105 \mathrm{~m}$ standoff from the water table, the liquid saturation at the repository horizon in the minimum-overburden case is about $10 \%$ less than in the reference-overburden case. Therefore, some of the following observations concerning $R H$ in the repository rock may be influenced by that factor.

A comparison of Tables 10.1.4.1.2a and 10.1.4.1.2b clearly shows the influence of the overburden thickness in containing decay heat in Yucca Mountain. Effectively, the overburden acts like a thermal insulator (or blanket), determining how long it takes for decay heat to eventually be dissipated to the atmosphere. Therefore, we find that removing $143.1 \mathrm{~m}$ of this "thermal blanket" has the effect of reducing the duration of the boiling period, $t_{b p}$ especially in the center of the repository. In general, removing $143.1 \mathrm{~m}$ of the overburden has the following effects:

1. A substantial reduction in $t_{\mathrm{bp}}$ in areas associated with large $t_{\mathrm{bp}}$ such as:
a. The entire 150-MTU/acre repository.
b. The inner $90 \%$ of the $110.5-\mathrm{MTU} /$ acre repository.
c. The inner $50 \%$ of the 83.4-MTU/acre repository.

2. A moderate reduction in $t_{\mathrm{bp}}$ in areas associated with intermediate $t_{\mathrm{bp}}$ such as:
a. The inner $50 \%$ of the 55.3-MTU/acre repository.
b. The inner $75 \%$ of the $70.0-\mathrm{MTU} /$ acre repository.
c. The outer $10 \%$ of the $110.5-\mathrm{MTU} /$ acre repository.

3. A negligible reduction in $t_{\mathrm{bp}}$ in areas associated with small $t_{\mathrm{bp}}$ such as:

a. The outer $50 \%$ of the 55.3-MTU/acre repository.

b. The outer $10 \%$ of the $70.0-\mathrm{MTU} /$ acre repository.

c. The outer $3 \%$ of the $83.4-\mathrm{MTU} /$ acre repository.

In general, the edge-cooling effect influences $t_{b p}$ at the repository edge more than the impact of overburden thickness. We also generally observe for the minimum-overburden cases, a reduction in $R H$ associated with the end of the boiling period relative to the reference-overburden cases.

In past work [Buscheck and Nitao, 1992] we have observed for cases where boiling effects (both convective and diffusive) dominate net moisture movement away from the dryout zone, roughly $95 \%$ of the cumulative dryout occurs during the first $1000 \mathrm{yr}$. Because the reduction in the insulating effect of the overburden does not begin to reduce repository temperatures until after $1000 \mathrm{yr}$, it does not significantly reduce the cumulative dryout effects. Consequently, we find in comparing Tables 10.1.4.1.1 and 10.1.4.1.3 that the duration of drier-than-ambient $R H$ in the repository rock is generally similar for the referenceoverburden and minimum-overburden case. Perhaps had we adjusted the standoff to the water table to be the same (thereby, yielding nearly identical initial liquid saturation profiles), the shallow-overburden 
cases may have resulted in slightly shorter periods of drier-than-ambient $R H$ in the repository rock than in the reference-overburden cases.

It is important to note that all of our modeling work has assumed a very humid value of $R H$ in the atmosphere ( $99 \%$ for the cases that are in gravity-capillary-pressure equilibrium with the water table). Under ambient conditions, the partial pressure vapor of water vapor $P_{\mathrm{v}}$ in the atmosphere is assumed to be in equilibrium with $P_{v}$ in the upper TCw unit. This prevents any diffusive loss of moisture to the atmosphere under ambient conditions. The decay-heat-driven temperature gradient near the ground surface is substantially greater than the temperature gradient under ambient conditions. For the reference-overburden, 150.0-MTU/acre case the temperature gradient at the ground surface exceeds the ambient temperature gradient by factors of $34,25,8,5,2.2$, and 1.1 at $t=500,1000,10,000,20,000,50,000$, and $100,000 \mathrm{yr}$, respectively. For the minimum-overburden, 150.0-MTU/acre case, the temperature gradient at the ground surface exceeds the ambient temperature gradient by factors of $62,44,11,6,3$, and 1.6 at $t=200,1000,10,000,20,000,50,000$, and $100,000 \mathrm{yr}$, respectively. The effect of a shallower overburden is to significantly steepen the temperature gradient at the ground surface relative to the reference-overburden case. In Section 10.1.3.2, we noted that binary gas-phase diffusion is primarily driven by temperature gradients. It is possible that binary gas-phase diffusion drives a substantial vapor flux to the atmosphere even under the ambient geothermal temperature gradient. As noted, because we assume $R H=99 \%$ in the atmosphere, our models do not yield any diffusive vapor flux to the atmosphere under ambient conditions. Had our models represented the actual atmospheric $R H$ conditions, it is likely that we would have observed:

1. Moisture loss to the atmosphere under the ambient geothermal temperature gradient.

2. A substantially greater decay-heat-driven moisture loss to the atmosphere for both the referenceand shallow-overburden cases.

3. The greatest atmospheric moisture loss would occur for the shallow-overburden cases, resulting in lower $R H$ in the repository rock than in the reference-overburden cases.

This last observation implies that had we modeled the actual $R H$ conditions in the atmosphere, repository $R H$ conditions may be substantially drier for the shallow-overburden cases than for the reference-overburden cases.

Enhanced binary gas-phase diffusion would result in even larger evaporative losses to the atmosphere under both ambient and decay-heat-disturbed conditions. It is possible that a substantial evaporative loss could significantly reduce the liquid-phase saturation all the way down to the PTn unit (and perhaps even below the PTn), thereby significantly reducing much of the condensate buildup that may occur above a high-AML repository. Shallow in situ heater tests would provide valuable information concerning the influence of decay heat on the moisture balance near the ground surface at Yucca Mountain and to help validate $\mathrm{T}-\mathrm{H}$ models that are required to assess the influence of decay heat on the overall moisture balance at Yucca Mountain.

Because the stored decay heat in Yucca Mountain is dissipated to the atmosphere significantly earlier in the minimum-overburden cases, $T$ associated with a given value of $R H$ is significantly lower than in the reference-overburden cases (compare Tables 10.1.4.1.1 and 10.1.4.1.3). For the 150-MTU/acre case, $T$ associated with $R H=70 \%$ is reduced by $20^{\circ} \mathrm{C}$ for the inner $50 \%$ of the repository and by 11 to $12^{\circ} \mathrm{C}$ for the outer $25 \%$ of the repository. This reduction in $T$ associated with a given $R H$ reduces the likelihood of generating significant aqueous reactions and aqueous-transport processes that could give rise to altered flow and tranport properties in the repository rock. 


\section{Table 10.1.4.1.1: Reference-Overburden Cases}

Time required to attain the indicated relative humidity $R H$ at various repository locations and the temperature at which that value of $R H$ is attained for 22.5-yr-old SNF, gas-phase diffusion tortousity factor $\tau_{\text {eff, }}=0.2, k_{\mathrm{b}}=280$ millidarcy, and a repository depth of $343.1 \mathrm{~m}$. The locations are identified as the percentage of the repository area enclosed, with $0 \%$ corresponding to the repository center, and $100 \%$ corresponding to the edge.

\begin{tabular}{|c|r|r|r|r|r|r|r|r|}
\hline \multicolumn{7}{|c|}{ Table 10.1.4.1.1a: AML $=55.3$ MTU/acre } \\
\hline $\begin{array}{c}\text { Percentage of } \\
\text { repository area } \\
\text { enclosed (\%) }\end{array}$ & \multicolumn{7}{|c|}{$\begin{array}{c}\text { Temperature at which the indicated to attain } \\
\text { the inded } R H(\mathrm{yr})\end{array}$} \\
\cline { 2 - 11 } & $70 \%$ & $80 \%$ & $90 \%$ & $95 \%$ & $70 \%$ & $80 \%$ & $90 \%$ & $95 \%$ \\
\hline 50 & 670 & 1660 & 3330 & 4630 & 107 & 97 & 80 & 72 \\
\hline 75 & 410 & 940 & 1610 & 2280 & 107 & 99 & 89 & 81 \\
\hline 90 & NA & 200 & 380 & 490 & NA & 103 & 97 & 95 \\
\hline 97 & NA & NA & NA & NA & NA & NA & NA & NA \\
\hline
\end{tabular}

\begin{tabular}{|c|c|c|c|c|c|c|c|c|}
\hline \multicolumn{9}{|c|}{ Table 10.1.4.1.1b: AML = 70 MTU/acre } \\
\hline \multirow{2}{*}{$\begin{array}{l}\text { Percentage of } \\
\text { repository area } \\
\text { enclosed (\%) }\end{array}$} & \multicolumn{4}{|c|}{$\begin{array}{l}\text { Time required to attain } \\
\text { the indicated } R H(\mathrm{yr})\end{array}$} & \multicolumn{4}{|c|}{$\begin{array}{c}\text { Temperature at which the indicated } \\
R H \text { is attained }\left({ }^{\circ} \mathrm{C}\right)\end{array}$} \\
\hline & $70 \%$ & $80 \%$ & $90 \%$ & $95 \%$ & $70 \%$ & $80 \%$ & $90 \%$ & $95 \%$ \\
\hline 50 & 3350 & 8700 & 16,150 & 23,560 & 91 & 69 & 56 & 49 \\
\hline 75 & 1940 & 4080 & 7630 & 10,450 & 97 & 77 & 66 & 61 \\
\hline 90 & 630 & 1030 & 1760 & 2460 & 105 & 97 & 85 & 78 \\
\hline 97 & 80 & 170 & 290 & 390 & 107 & 103 & 99 & 96 \\
\hline
\end{tabular}

\begin{tabular}{|c|c|c|c|c|c|c|c|c|}
\hline \multicolumn{9}{|c|}{ Table 10.1.4.1.1c: AML = 83.4 MTU/acre } \\
\hline \multirow{2}{*}{$\begin{array}{l}\text { Percentage of } \\
\text { repository area } \\
\text { enclosed (\%) }\end{array}$} & \multicolumn{4}{|c|}{$\begin{array}{l}\text { Time required to attain } \\
\text { the indicated } R H(\mathrm{yr})\end{array}$} & \multicolumn{4}{|c|}{$\begin{array}{c}\text { Temperature at which the indicated } \\
R H \text { is attained }\left({ }^{\circ} \mathrm{C}\right)\end{array}$} \\
\hline & $70 \%$ & $80 \%$ & $90 \%$ & $95 \%$ & $70 \%$ & $80 \%$ & $90 \%$ & $95 \%$ \\
\hline 50 & 8110 & 17,710 & 29,290 & 38,360 & 76 & 58 & 48 & 43 \\
\hline 75 & 3910 & 8250 & 13,820 & 19,040 & 86 & 70 & 59 & 53 \\
\hline 90 & 1240 & 2030 & 3530 & 4800 & 104 & 91 & 78 & 73 \\
\hline 97 & 370 & 590 & 890 & 1140 & 107 & 103 & 98 & 94 \\
\hline \multicolumn{9}{|c|}{ Table 10.1.4.1.1c: $\mathrm{AML}=110.5 \mathrm{MTU} / \mathrm{acre}$} \\
\hline \multirow{2}{*}{$\begin{array}{l}\text { Percentage of } \\
\text { repository area } \\
\text { enclosed (\%) }\end{array}$} & \multicolumn{4}{|c|}{$\begin{array}{l}\text { Time required to attain } \\
\text { the indicated } R H(\mathrm{yr})\end{array}$} & \multicolumn{4}{|c|}{$\begin{array}{c}\text { Temperature at which the indicated } \\
R H \text { is attained }\left({ }^{\circ} \mathrm{C}\right)\end{array}$} \\
\hline & $70 \%$ & $80 \%$ & $90 \%$ & $95 \%$ & $70 \%$ & $80 \%$ & $90 \%$ & $95 \%$ \\
\hline 50 & 15,960 & 27,910 & 40,990 & 49,980 & 68 & 54 & 45 & 42 \\
\hline 75 & 9540 & 15,520 & 24,950 & 32,590 & 76 & 64 & 53 & 48 \\
\hline 90 & 3190 & 4890 & 7460 & 9890 & 93 & 82 & 73 & 68 \\
\hline 97 & 1410 & 1810 & 2360 & 2890 & 106 & 101 & 93 & 88 \\
\hline \multicolumn{9}{|c|}{ Table 10.1.4.1.1e: $\mathrm{AML}=150 \mathrm{MTU} / \mathrm{acre}$} \\
\hline \multirow{2}{*}{$\begin{array}{c}\text { Percentage of } \\
\text { repository area } \\
\text { enclosed (\%) }\end{array}$} & \multicolumn{4}{|c|}{$\begin{array}{l}\text { Time required to attain } \\
\text { the indicated } R H(\mathrm{yr})\end{array}$} & \multicolumn{4}{|c|}{$\begin{array}{c}\text { Temperature at which the indicated } \\
R H \text { is attained }\left({ }^{\circ} \mathrm{C}\right)\end{array}$} \\
\hline & $70 \%$ & $80 \%$ & $90 \%$ & $95 \%$ & $70 \%$ & $80 \%$ & $90 \%$ & $95 \%$ \\
\hline 50 & 20,630 & 34,850 & 50,920 & 64,150 & 68 & 52 & 45 & 41 \\
\hline 75 & 16,400 & 24,520 & 32,700 & 43,360 & 70 & 59 & 51 & 46 \\
\hline 90 & 8660 & 12,090 & 16,520 & 19,780 & 81 & 72 & 64 & 59 \\
\hline 97 & 4330 & 6020 & 8180 & 10,060 & 93 & 84 & 77 & 72 \\
\hline
\end{tabular}


Table 10.1.4.1.2a: Reference-Overburden Cases

Duration of boiling period at various repository locations and relative humidity $R H$ attained at the end of the boiling period for 22.5-yr-old SNF, and various AMLs, gas-phase diffusion tortousity factor $\tau_{\text {eff }}=0.2, k_{\mathrm{b}}=280$ millidarcy, and a repository depth of $343.1 \mathrm{~m}$. The repository locations are identified as the percentage of the repository area enclosed, with $0 \%$ corresponding to the repository center, and $100 \%$ corresponding to the edge.

Table 10.1.4.1.2a: Reference-Overburden Cases repository depth $=343.1 \mathrm{~m}$

\begin{tabular}{|c|c|c|c|c|c|}
\hline \multirow{2}{*}{$\begin{array}{l}\text { Percentage of } \\
\text { repository area } \\
\text { enclosed (\%) }\end{array}$} & \multicolumn{5}{|c|}{$\begin{array}{l}\text { Duration of boiling period (yr) and } R H(\%) \\
\text { at end of boiling period for indicated AMLs }\end{array}$} \\
\hline & $55.3 \mathrm{MTU} /$ acre & $70.0 \mathrm{MTU} /$ acre & 83.4 MTU/acre & $110.5 \mathrm{MTU} /$ acre & $150.0 \mathrm{MTU} / \mathrm{acre}$ \\
\hline 50 & 1760 yr $80.8 \%$ & $2830 \mathrm{yr} 68.1 \%$ & 3870 yr $57.2 \%$ & 6130 yr $44.3 \%$ & $9590 \mathrm{yr} 46.8 \%$ \\
\hline 75 & 1100 yr $83.7 \%$ & 2000 yr $70.5 \%$ & $2740 \mathrm{yr} 65.2 \%$ & 4290 yr $51.4 \%$ & 7210 yr $45.1 \%$ \\
\hline 90 & 440 yr $92.7 \%$ & $1090 \mathrm{yr} 81.0 \%$ & 1700 yr $76.6 \%$ & 2870 yr $67.6 \%$ & 5010 yr $54.1 \%$ \\
\hline 97 & $80 \mathrm{yr} 98.5 \%$ & $410 \mathrm{yr} 95.5 \%$ & 990 yr $92.5 \%$ & $2150 \mathrm{yr} 86.6 \%$ & $3960 \mathrm{yr} 66.8 \%$ \\
\hline \multicolumn{6}{|c|}{$\begin{array}{l}\text { Table 10.1.4.1.2b: Minimum-Overburden Cases } \\
\text { repository depth }=200 \mathrm{~m}\end{array}$} \\
\hline \multirow{2}{*}{$\begin{array}{l}\text { Percentage of } \\
\text { repository area } \\
\text { enclosed }(\%)\end{array}$} & \multicolumn{5}{|c|}{$\begin{array}{l}\text { Duration of boiling period }(\mathrm{yr}) \text { and } R H(\%) \\
\text { at end of boiling period for indicated AMLs }\end{array}$} \\
\hline & 55.3 MTU/acre & $70.0 \mathrm{MTU} /$ acre & 83.4 MTU/acre & $110.5 \mathrm{MTU} /$ acre & $150.0 \mathrm{MTU} /$ acte \\
\hline 50 & $1390 \mathrm{yr} 76.7 \%$ & 1960 yr $61.8 \%$ & 2450 yr $54.7 \%$ & 3600 yr $43.1 \%$ & 5720 yr $27.6 \%$ \\
\hline 75 & 1070 yr $77.4 \%$ & 1550 yr $61.3 \%$ & 1930 yr $54.8 \%$ & 2700 yr $47.6 \%$ & 4170 yr $36.3 \%$ \\
\hline 90 & $460 \mathrm{yr} 86.3 \%$ & $980 \mathrm{yr} 76.7 \%$ & $1360 \mathrm{yr} 67.5 \%$ & 1960 yr $56.9 \%$ & 2970 yr $49.0 \%$ \\
\hline 97 & $80 \mathrm{yr} 96.9 \%$ & 450 yr $92.0 \%$ & 900 yr $86.2 \%$ & 1590 yr $73.7 \%$ & 2440 yr $60.7 \%$ \\
\hline
\end{tabular}




\section{Table 10.1.4.1.3: Minimum-Overburden Cases}

Time required to attain the indicated relative humidity $R H$ at various repository locations and the temperature at which that value of $R H$ is attained for 22.5-yr-old SNF, gas-phase diffusion tortousity factor $\tau_{\text {eff }}=0.2, k_{\mathrm{b}}=280$ millidarcy, and a repository depth of $200 \mathrm{~m}$. The locations are identified as the percentage of the repository area enclosed, with $0 \%$ corresponding to the repository center, and $100 \%$ corresponding to the edge.

\begin{tabular}{|c|c|c|c|c|c|c|c|c|}
\hline \multicolumn{9}{|c|}{ Table 10.1.4.1.3a: $\mathrm{AML}=55.3 \mathrm{MTU} / \mathrm{acre}$} \\
\hline \multirow{2}{*}{$\begin{array}{l}\text { Percentage of } \\
\text { repository area } \\
\text { enclosed (\%) }\end{array}$} & \multicolumn{4}{|c|}{$\begin{array}{l}\text { Time required to attain } \\
\text { the indicated } R H(\mathrm{yr})\end{array}$} & \multicolumn{4}{|c|}{$\begin{array}{c}\text { Temperature at which the indicated } \\
R H \text { is attained }\left({ }^{\circ} \mathrm{C}\right)\end{array}$} \\
\hline & $70 \%$ & $80 \%$ & $90 \%$ & $95 \%$ & $70 \%$ & $80 \%$ & $90 \%$ & $95 \%$ \\
\hline 50 & 960 & 1820 & 4270 & 6320 & 105 & 87 & 61 & 55 \\
\hline 75 & 680 & 1260 & 2640 & 4120 & 105 & 91 & 68 & 57 \\
\hline 90 & 130 & 280 & 620 & 810 & 106 & 100 & 93 & 86 \\
\hline 97 & NA & NA & NA & NA & NA & NA & NA & NA \\
\hline \multicolumn{9}{|c|}{ Table 10.1.4.1.3b: AML = 70 MTU/acre } \\
\hline \multirow{2}{*}{$\begin{array}{l}\text { Percentage of } \\
\text { repository area } \\
\text { enclosed (\%) }\end{array}$} & \multicolumn{4}{|c|}{$\begin{array}{l}\text { Time required to attain } \\
\text { the indicated } R H(\mathrm{yr})\end{array}$} & \multicolumn{4}{|c|}{$\begin{array}{c}\text { Temperature at which the indicated } \\
R H \text { is attained }\left({ }^{\circ} \mathrm{C}\right)\end{array}$} \\
\hline & $70 \%$ & $80 \%$ & $90 \%$ & $95 \%$ & $70 \%$ & $80 \%$ & $90 \%$ & $95 \%$ \\
\hline 50 & 4680 & 10,270 & 16,370 & 24,020 & 67 & 54 & 47 & 41 \\
\hline 75 & 3340 & 7350 & 12,070 & 18,150 & 69 & 55 & 48 & 43 \\
\hline 90 & 680 & 1210 & 2410 & 3930 & 104 & 90 & 68 & 58 \\
\hline 97 & 120 & 200 & 380 & 560 & 106 & 102 & 97 & 93 \\
\hline \multicolumn{9}{|c|}{ Table 10.1.4.1.3c: $\mathrm{AML}=83.4 \mathrm{MTU} / \mathrm{acre}$} \\
\hline \multirow{2}{*}{$\begin{array}{l}\text { Percentage of } \\
\text { repository area } \\
\text { enclosed (\%) }\end{array}$} & \multicolumn{4}{|c|}{$\begin{array}{l}\text { Time required to attain } \\
\text { the indicated } R H(\mathrm{yr})\end{array}$} & \multicolumn{4}{|c|}{$\begin{array}{c}\text { Temperature at which the indicated } \\
\left.R H \text { is attained ( }{ }^{\circ} \mathrm{C}\right)\end{array}$} \\
\hline & $70 \%$ & $80 \%$ & $90 \%$ & $95 \%$ & $70 \%$ & $80 \%$ & $90 \%$ & $95 \%$ \\
\hline 50 & 8300 & 15,510 & 24,760 & 31,050 & 62 & 50 & 43 & 389 \\
\hline 75 & 6300 & 10,905 & 16,210 & 21,800 & 62 & 53 & 47 & 43 \\
\hline 90 & 1550 & 3110 & 5660 & 8000 & 91 & 67 & 57 & 53. \\
\hline 97 & 420 & 680 & 1090 & 1500 & 106 & 101 & 91 & 82 \\
\hline \multicolumn{9}{|c|}{ Table 10.1.4.1.3c: AML = $110.5 \mathrm{MTU} / \mathrm{acre}$} \\
\hline \multirow{2}{*}{$\begin{array}{l}\text { Percentage of } \\
\text { repository area } \\
\text { enclosed (\%) }\end{array}$} & \multicolumn{4}{|c|}{$\begin{array}{l}\text { Time required to attain } \\
\text { the indicated } R H(\mathrm{yr})\end{array}$} & \multicolumn{4}{|c|}{$\begin{array}{c}\text { Temperature at which the indicated } \\
\left.R H \text { is attained }{ }^{\circ} \mathrm{C}\right)\end{array}$} \\
\hline & $70 \%$ & $80 \%$ & $90 \%$ & $95 \%$ & $70 \%$ & $80 \%$ & $90 \%$ & $95 \%$ \\
\hline 50 & 15,710 & 24,480 & 34,490 & 48,000 & 57 & 48 & 41 & 36 \\
\hline 75 & 10,230 & 14,850 & 19,410 & 28,820 & 61 & 54 & 49 & 42 \\
\hline 90 & 4120 & 6480 & 8830 & 11,040 & 71 & 63 & 58 & 54 \\
\hline 97 & 1360 & 1920 & 2910 & 4220 & 101 & 87 & 73 & 65 \\
\hline \multicolumn{9}{|c|}{ Table 10.1.4.1.3e: AML = 150 MTU/acre } \\
\hline \multirow{2}{*}{$\begin{array}{c}\text { Percentage of } \\
\text { repository area } \\
\text { enclosed (\%) }\end{array}$} & \multicolumn{4}{|c|}{$\begin{array}{l}\text { Time required to attain } \\
\text { the indicated } R H(\mathrm{yr})\end{array}$} & \multicolumn{4}{|c|}{$\begin{array}{c}\text { Temperature at which the indicated } \\
R H \text { is attained }\left({ }^{\circ} \mathrm{C}\right)\end{array}$} \\
\hline & $70 \%$ & $80 \%$ & $90 \%$ & $95 \%$ & $70 \%$ & $80 \%$ & $90 \%$ & $95 \%$ \\
\hline 50 & 30,780 & 45,790 & 68,730 & 100,200 & 48 & 41 & 35 & 32 \\
\hline 75 & 16,930 & 23,230 & 30,370 & 44,000 & 58 & 51 & 45 & 40 \\
\hline 90 & 8000 & 10,650 & 13,380 & 17,070 & 69 & 63 & 58 & 53 \\
\hline 97 & 3600 & 5190 & 6870 & 8680 & 82 & 72 & 66 & 62 \\
\hline
\end{tabular}



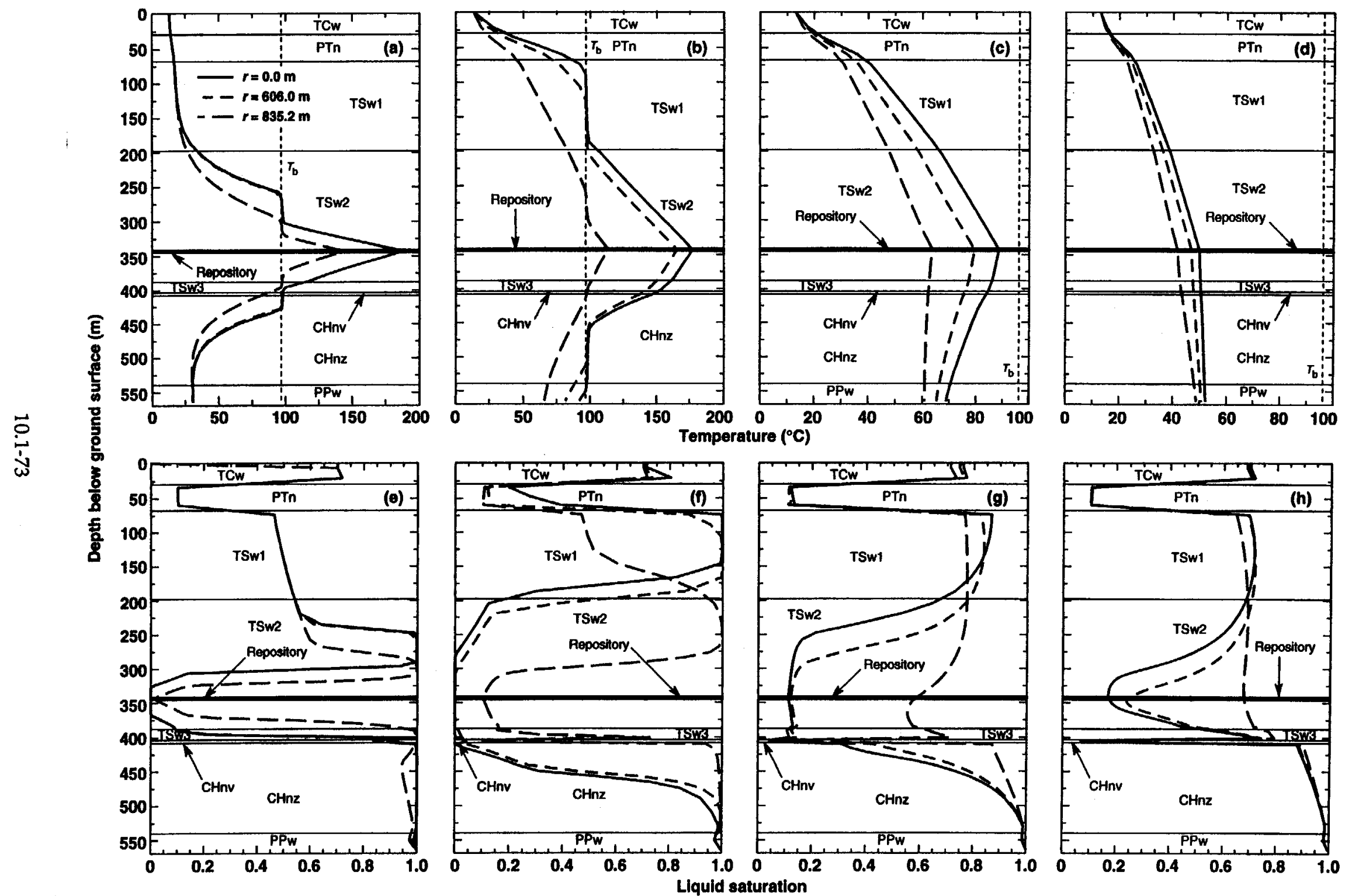

Figure 10.1.4.2.1. Vertical temperature profiles at various radial distances, $r$, for AML $=110.5 \mathrm{MTU} / \mathrm{acre}$ at (a) $t=100 \mathrm{yr}$, (b) $t=1000 \mathrm{yr}$, (c) $t=10,000 \mathrm{yr}$, and (d) $t=36,000 \mathrm{yr}$. Note different temperature scales. Vertical liquid saturation profiles are also plotted at (e) $t=100 \mathrm{yr},(\mathrm{f}) t=1000 \mathrm{yr}$, (g) $t=10,000 \mathrm{yr}$, and (h) $t=36,000$ yr. Matrix properties for the TSw 1 and TSw2 are based on Klavetter and Peters (1986). Binary gas-phase tortuosity factor $\tau_{\mathrm{eff}}=0.2$ for all units. 

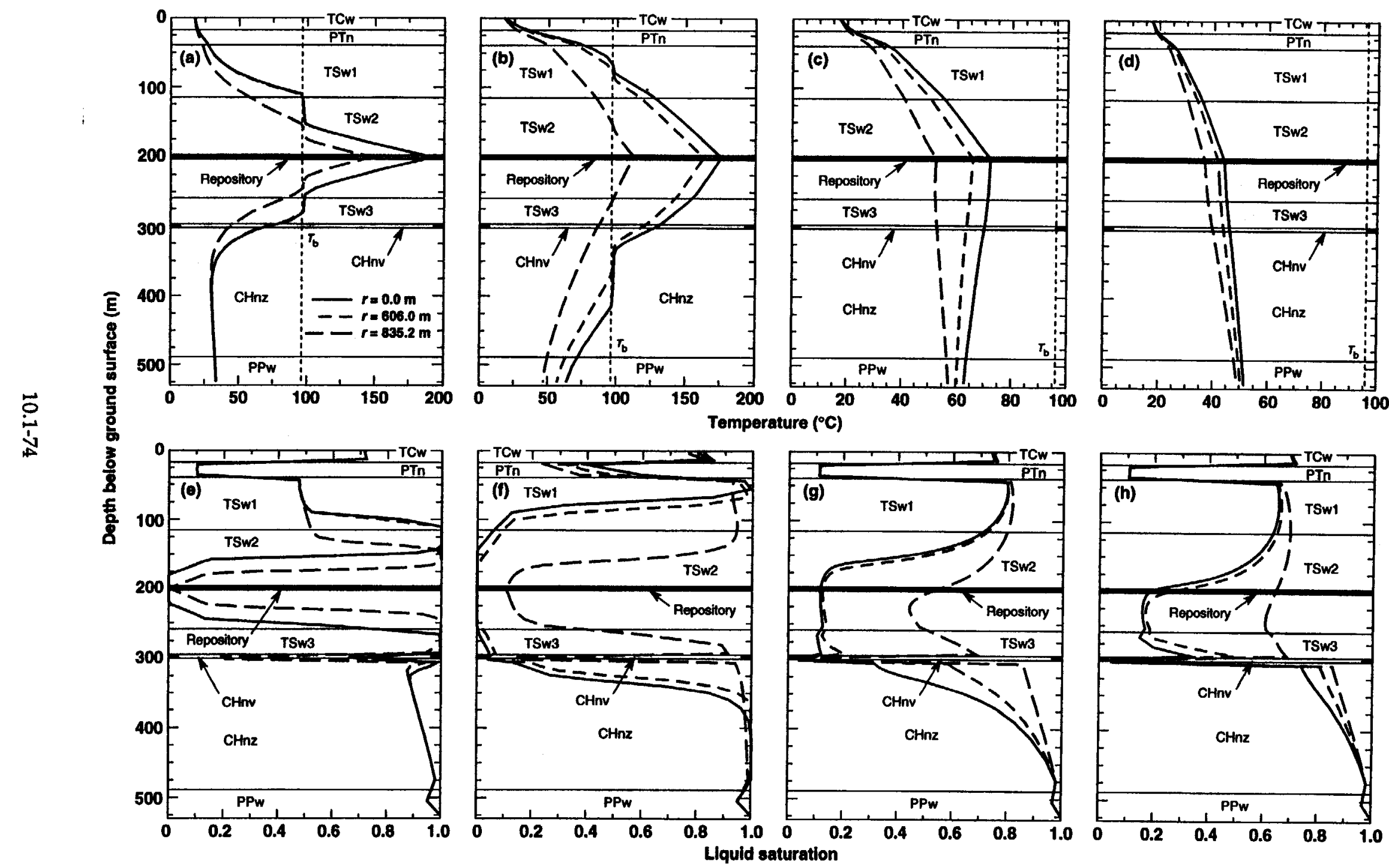

Figure 10.1.4.2.2. Vertical temperature profiles at various radial distances, $r$, for $\mathrm{AML}=110.5 \mathrm{MTU} /$ acre and the minimum-overburden-thickness $(200 \mathrm{~m}$ ) case at (a) $t=100 \mathrm{yr}$, (b) $t=1000 \mathrm{yr}$, (c) $t=10,000 \mathrm{yr}$, and (d) $t=32,730 \mathrm{yr}$. Note the different temperature scales. Vertical liquid saturation profiles are also plotted at $(\mathrm{e}) t=100 \mathrm{yr},(\mathrm{f}) t=1000 \mathrm{yr},(\mathrm{g}) t=10,000 \mathrm{yr}$, and $(\mathrm{h}) t=32,730 \mathrm{yr}$. The water table is at a depth of $530 \mathrm{~m}$. Matrix poperties for all units (including the TSw1 and TSw2) are based on Klavetter and Peters [1986]. Binary gas-phase tortuosity factor $\tau_{\mathrm{eff}}=0.2$ for all units. 

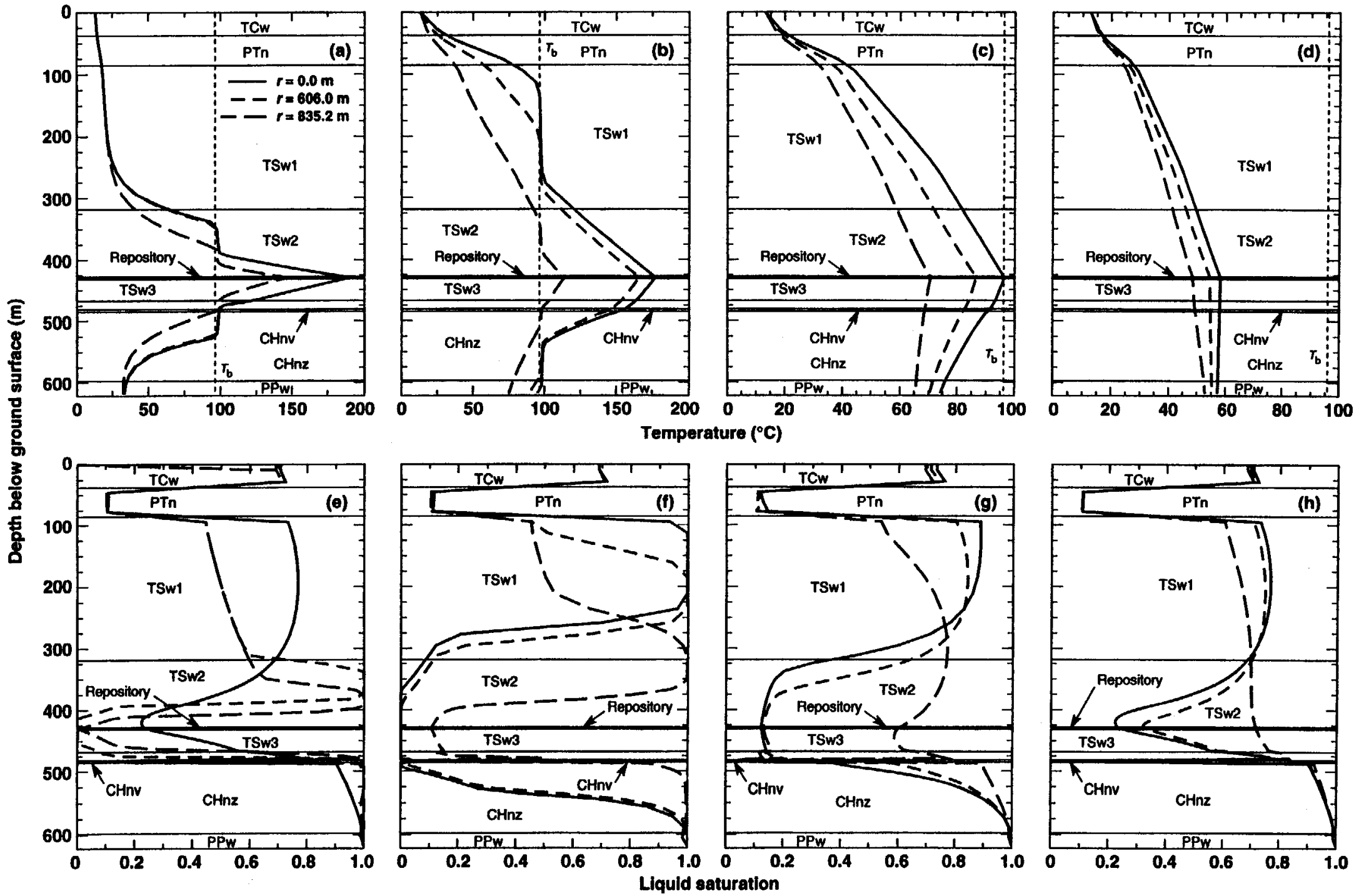

Figure 10.1.4.2.3. Vertical temperature profiles at various radial distances, $r$, for AML $=110.5 \mathrm{MTU} /$ acre and the maximum-overburden-thickness $(430 \mathrm{~m}$ ) case at (a) $t=100 \mathrm{yr}$, (b) $t=1000 \mathrm{yr}$, (c) $t=10,000 \mathrm{yr}$, and (d) $t=31,680 \mathrm{yr}$. Note the different temperature scales. Vertical liquid saturation profiles are also plotted at (e) $t=100 \mathrm{yr},(\mathrm{f}) t=1000 \mathrm{yr},(\mathrm{g}) t=10,000 \mathrm{yr}$, and $(\mathrm{h}) t=31,680 \mathrm{yr}$. The water table is at a depth of $622 \mathrm{~m}$. Matrix poperties for all units (including the TSw1 and TSw2) are based on Klavetter and Peters [1986]. Binary gas-phase tortuosity factor $\tau_{\text {eff }}=0.2$ for all units. 
10.1.4.2 Heat-Pipe Behavior. Figures 10.1.4.2.1-10.1.4.2.3 give the vertical liquid saturation profiles for $\mathrm{AML}=110.5 \mathrm{MTU} /$ acre and three repository depths, including: (1) the reference-overburden case with a repository depth of $343.1 \mathrm{~m}$, (2) the minimum-overburden case with a repository depth of $200 \mathrm{~m}$, and (3) the maximum-overburden case with a repository depth of $430 \mathrm{~m}$. To show the influence of edgecooling/rewetting/shedding effects on T-H behavior (see Section 1.10.6 of Chapter 1), vertical profiles are given at three repository locations, including: (1) $r=0.0 \mathrm{~m}$, which is at the center of the repository, (2) $r=$ $606.0 \mathrm{~m}$, which is the "median" repository location that encloses $50 \%$ of the repository (i.e., $50 \%$ of the repository lies between that location and the repository edge), and (3) $r=835.2 \mathrm{~m}$, which encloses $95 \%$ of the repository (i.e., only $5 \%$ of the repository area lies outside that location).

For the range $200-430 \mathrm{~m}$, overburden thickness has a very pronounced affect on mountain-scale thermal-hydrological behavior. At very early time $(t<100 \mathrm{yr})$, thermal interference with the constanttemperature boundary at the ground surface has not yet developed; consequently, the vertical temperature profiles and liquid saturation profiles are similar for these three cases (compare Figs. 10.1.4.2.1a,b; 10.1.4.2.2a,b; and 10.1.4.2.3a,b). At $1000 \mathrm{yr}$ (approximately corresponding to the maximum extent of dryout effects), the minimum-overburden case results in an almost negligible heat-pipe zone of near-96 ${ }^{\circ} \mathrm{C}$ temperatures (Fig 10.1.4.2.2b), while the maximum-overburden case results in a 180 -m-thick heat-pipe zone (Fig. 10.1.4.3b). In the reference-overburden case, the heat-pipe zone at $1000 \mathrm{yr}$ is about 100 -m thick (Fig. 10.1.4.1b). The maximum-overburden case has a 100-m-thick zone where liquid saturation is nearly $100 \%$ (Fig. 10.1.4.2.3f), while in the minimum-overburden case, the zone of near-100\% liquid saturation is only 25-m thick (Fig. 10.1.4.2.2f).

The extra $230 \mathrm{~m}$ of insulating rock above the maximum-overburden case (compared with the minimum-overburden case) results in four major effects:

- It conserves the decay heat better than the shallower-overburden cases, thereby providing thermal energy with which to vaporize (i.e., mobilize) in situ water from the rock matrix.

- It contains much more in situ water (than the shallower-overburden cases) that can be vaporized and mobilized by decay heat.

- It imposes a longer pathway for vapor to escape out of the top of the mountain; therefore, it loses a smaller fraction of the mobilized water than the shallower-overburden cases.

- It takes longer to develop a steady-state temperature profile with the constant-temperature boundary at the ground surface.

The last point is significant because the heat-pipe will continue to increase in length until there is full interference between the heat source at the repository and the ground surface. During this initial heatpipe-development period, the cooling effect of heat pipes is greatest. In theory, if the repository were infinitely deep and heat generation from the repository did not decay with time the heat pipes could continue to increase in length indefinitely. Taken together, the deeper repository has (1) more heat, (2) more water, and (3) more time to develop heat pipes; moreover, the deeper repository provides a greater distance over which near-boiling temperatures can exist.

The differences between the minimum- and maximum-overburden cases in condensate buildup above the repository would be even larger if the atmosphere was not assumed to have a relative humidity $R H=99 \%$. The much steeper temperature gradient close to the ground surface (compare Figs. 10.1.4.2.2a$\mathrm{d}$ with Figs. 10.1.4.3a-d), and the fact that the condensate buildup zone is driven closer to the ground surface (compare Figs. 10.1.4.2.2e-h with Figs. 10.1.4.3e-h) would result in a greater moisture loss to the atmosphere, driven by the diffusive and advective transport of water vapor. The assumption of near$100 \% R H$ in the atmosphere virtually precludes any diffusive flux of water vapor to the ground surface.

Because the actual overburden thickness varies at Yucca Mountain as a result of its topography, these calculations indicate that $\mathrm{T}-\mathrm{H}$ behavior above the repository can vary significantly with areal location. 


\section{Contents}

10.2 Mountain-Scale Saturated Zone (SZ) Thermal-Hydrology ............................................................. 10.2-2

10.2.1 Influence of SZ Heatflow on UZ Heatflow ............................................................................. 10.2-2

10.2.2 Buoyancy-Driven SZ Flow and Transport..............................................................................10.2-3 


\subsection{Mountain-Scale Saturated Zone (SZ) Thermal-Hydrology}

\subsubsection{Influence of SZ Heatflow on UZ Heatflow}

We investigated the effect of hydrothermal flow in the saturated zone (SZ) on repository temperatures by comparing results from the UZ model (which assumes a fixed-depth, constanttemperature water table) with those obtained with the UZ-SZ model (which includes hydrothermal flow in the SZ down to an effectively infinite depth). For all of the cases considered (AMLs of 27.1 to 154.7 MTU/acre; 30- and 60-yr-old SNF), the treatment of the water table and the SZ has little effect on repository temperatures during the first $1000 \mathrm{yr}$ (Fig. 10.2.1.1). Because temperatures peak within $1000 \mathrm{yr}$, $T_{\text {peak }}$ is not affected by the treatment of the water table and SZ. For 30-yr-old SNF and an AML $=49.2$ MTU/acre (Fig. 10.2.1.1a), $T_{\text {peak }}=114.9$ and $115.3^{\circ} \mathrm{C}$ for the UZ and UZ-SZ models, respectively. For $30-$ yr-old SNF and an AML $=154.7 \mathrm{MTU} /$ acre (Fig. 10.2.1.1b), $T_{\text {peak }}=201.6$ and $202.9^{\circ} \mathrm{C}$ for the UZ and UZ$\mathrm{SZ}$ models, respectively.

For $t>1000 \mathrm{yr}$ (after repository temperatures have peaked), the SZ begins to heat up significantly (Fig. 10.2.1.2), thereby reducing the rate at which heat can flow from the UZ to the SZ. Consequently, the duration of boiling $t_{\mathrm{bp}}$ substantially increases, particularly for higher AMLs ( $t_{\mathrm{bp}}$ " $1000 \mathrm{yr}$ ). For lower AMLs $\left(t_{\mathrm{bp}}<1000 \mathrm{yr}\right)$, the increase in $t_{\mathrm{bp}}$ is less substantial. For the reference SCP-CDR thermal load (AML $=49.2 \mathrm{MTU} / \mathrm{acre}$; 10 -yr-old SNF), $t_{\mathrm{bp}}$ increases from 550 to $670 \mathrm{yr}$ (Fig. 10.2.1.1c). For 30-yr-old SNF and an $A M L=77.4 \mathrm{MTU} / \mathrm{acre}, t_{\mathrm{bp}}$ increases from 2080 to $3510 \mathrm{yr}$ (Fig. 10.2.1.1a). For 30-yr-old SNF and an $\mathrm{AML}=154.7 \mathrm{MTU} /$ acre (Fig. 10.2.1.1b), $t_{\mathrm{bp}}$ increases from 6500 to 11,450 yr. For 60-yr-old SNF and an $\mathrm{AML}=248.5 \mathrm{MTU} / \mathrm{acre}$ (not shown), $t_{\mathrm{bp}}$ increases from 12,630 to $18,120 \mathrm{yr}$.

Low AMLs (with $t_{\text {peak }}<t_{\mathrm{bp}}$ ) are also affected by the treatment of the water table and SZ. For 30-yrold SNF and an AML = 27.1 MTU/acre, hydrothermal flow in the SZ extends the duration of time the repository is above $50^{\circ} \mathrm{C}$ from 2200 to $3600 \mathrm{yr}$ and extends the duration of time the repository is above $40^{\circ} \mathrm{C}$ from 5060 to $14,150 \mathrm{yr}$. 


\subsubsection{Buoyancy-Driven SZ Flow and Transport}

In the previous section, we investigated the impact of hydrothermal flow in the SZ on thermalhydrological $(T-H)$ behavior in the UZ. Here we examine T-H behavior of the SZ itself. We examine the sensitivity of SZ T-H behavior to thermal loading design parameters as well as to the T-H properties. We also address the question of whether decay-heat-driven $\mathrm{T}-\mathrm{H}$ behavior in the $\mathrm{SZ}$ will dominate hydrological flow and transport in the SZ, and begin to investigate the magnitude of convective effects on heat flow between the UZ and SZ. Note that our model assumes no lateral flow in the SZ at $t=0 \mathrm{yr}$.

We compare the magnitude of decay-heat-driven buoyancy flow in the $S Z$ for three cases of 30-yr-old SNF having the same total mass of SNF: (a) $27.1 \mathrm{MTU} /$ acre over a repository area of 3162 acres, (b) 77.4 MTU/acre over 1118 acres, and (c) $154.7 \mathrm{MTU} /$ acre over 559 acres. We have observed that temperatures in the SZ build up considerably, even for low thermal loads (Fig. 10.2.1.2). Although convection does not dominate heat flow in the $S Z$, after $1000 \mathrm{yr}$, heat flow in the SZ appears to dominate fluid flow in the SZ. This dominant influence of decay-heat-driven flow was found to occur for all AMLs investigated, 27.1 to 154.7 MTU/acre. As the SZ temperatures (below the repository footprint) rise, the accompanying decrease in mass density results in significant upward component of flow from considerable depth, generating buoyant convection cells.

Decay-heat-driven convection cells in the $S Z$ require tens of thousands of years to fully develop. As the thermal pulse from the repository propagates both vertically and radially into the $S Z$, the region over which decay-heat-driven convection occurs continues to expand during (at least) the first $20000 \mathrm{yr}$ (Figs. 10.2.2.1 and 10.2.2.2). As this region expands, additional parallel convection cells are added to the convective system. After $1000 \mathrm{yr}$, two convection cells (one on each side of the symmetry axis) have developed (in cross section), extending radially $\sim 2$ to $3 \mathrm{~km}$ from the repository center (Fig. 10.2.2.1a); after $5000 \mathrm{yr}$, the radial extent of repository-heat-driven convection is $\sim 5 \mathrm{~km}$ (Fig. 10.2.2.1b); after $10000 \mathrm{yr}$, the radial extent of the convection cells is $\sim 8$ to $10 \mathrm{~km}$ (Fig. 10.2.2.2a); after $20000 \mathrm{yr}$, the radial extent of the convection cells exceeds $10 \mathrm{~km}$ from the repository center (Fig. 10.2.2.2b). Because the matrix permeability of the $\mathrm{SZ}$ is presumably quite small, these large-scale, buoyant convection cells require large-scale connectivity within the fracture system.

The connectivity and bulk permeability $k_{\mathrm{b}}$ of the fracture system in the $\mathrm{SZ}$ will be determined through the analysis of multiple-well, multiple-level, packer tests. However, the use of in situ heater tests in the SZ would give us much more direct evidence that the fracture properties are sufficient to result in significant buoyant convection. Because the driving force for buoyant convection is primarily propagated by heat conduction (rather than by direct hydraulic communication through connected fracture networks), the use of heater tests would provide valuable information about the bulk fracture network properties that cannot be obtained through conventional packer tests. The temperature field acts as a signature for convective effects. Diagnostic thermal probes, which are extremely sensitive to differences between conductive and convective heat flow, would also assist in the interpretation of convective effects [Danko and Buscheck, 1993]. The heater tests would provide a valuable tool in understanding the ambient system as well as how the $\mathrm{SZ}$ system responds to heat.

Although the geometric details of the convection cells differed, we found that the overall magnitude of decay-heat-driven buoyancy flow is relatively insensitive to AML. For example, at $t=5000 \mathrm{yr}$, the maximum horizontal fracture velocity $\left(\mathrm{w}_{\mathrm{h}}\right)_{\max }$ is $1180 \mathrm{~m} / \mathrm{yr}$ for $27.1 \mathrm{MTU} / \mathrm{acre}$ (Fig. 10.2.2.3a), and 1580 $\mathrm{m} / \mathrm{yr}$ for 154.7 MTU/acre (Fig. 10.2.2.3b). Although the AML varies by a factor of 5.7, the difference in $\left(v_{\mathrm{h}}\right)_{\max }$ is only $33 \%$ between these two cases. For $77.4 \mathrm{MTU} / \mathrm{acre},\left(v_{\mathrm{h}}\right)_{\max }$ is $1510 \mathrm{~m} / \mathrm{yr}$ at $t=5000 \mathrm{yr}$ (Fig. 10.2.2.1b). The fracture velocity is obtained by multiplying $Q_{\mathrm{ECM}}$ (which is the bulk-porosity-averaged liquid-phase velocity) by the ratio of the bulk porosity divided by the fracture porosity. Using the same $k_{\mathrm{b}}$ applied in these calculations ( $k_{\mathrm{b}}=\mathbf{2 8 0}$ millidarcy) and applying a relatively steep hydraulic gradient of $10^{-3} \mathrm{~m} / \mathrm{m}$ results in an ambient $v_{\mathrm{h}}$ of only $63 \mathrm{~m} / \mathrm{yr}$. Therefore, it appears that decay-heat-driven flow may dominate SZ flow and transport for tens of thousands of years. The large difference between the 
decay-heat-driven $v_{\mathrm{h}}$ and that driven by even a very steep hydraulic gradient indicates that the effect of assuming an initially stagnant $\mathrm{SZ}$ in our model should be negligible.

Decay-heat-driven buoyancy flow in the $S Z$ is a result of changes in fluid volume $\Delta V$ that occur as the region below the repository is heated. Because $\Delta V$ increases with $\Delta T$, the magnitude of buoyancy flow generally increases with $\Delta T$. Although $\Delta V$ per unit volume of heated $\mathrm{SZ}$ is less for lower $\mathrm{AML}$, the larger footprint associated with the low-AML repository results in a larger overall region where this heat-driven change in volume takes place (compare Figs. 10.2.2.3a and 10.2.2.3b). Consequently, for a given amount of time-integrated heat, the cumulative effect of repository heating on driving convection cells in the $S Z$ is similar over a wide range of AML. In general, the magnitude of decay-heat-driven buoyancy flow in the $\mathrm{SZ}$ is insensitive to the actual design of the repository and is primarily sensitive to the time-integrated heat (i.e., total mass of SNF emplaced in the repository). Consequently, the T-H and potential geochemical consequences of heat in the SZ should not be considered a design issue but rather the inherent response of the $S Z$ to the emplacement of a given quantity of SNF.

For $t \geq 5000 \mathrm{yr}$, the isotherms of the temperature buildup (Figs. 10.2.2.1b, 10.2.2.2a, 10.2.2.2b, 10.2.2.3a, and 10.2.2.3b) show significant deviations relative to what would be expected for conduction-dominated heat flow. These deviations do not arise from the convection of repository heat; instead, they are caused by the convection of hotter water from below (hotter because of the geothermal gradient). Because a constant-temperature boundary is maintained $1 \mathrm{~km}$ below the water table, and liquid flow is both entering and leaving this boundary, the convection cells are not within a closed loop. Consequently, the model-boundary effect prevents cooler water that enters the boundary from cooling the warmer water leaving the boundary. Therefore, it is possible that this boundary effect may introduce additional heat that would not have occurred had the finite extent of the convection cell been fully represented in our model. On the other hand, the close proximity of a constant-temperature boundary to significant temperature changes would tend to lower temperatures. To evaluate which of these effects might dominate or whether their combined effect is negligible (with respect to $\mathrm{SZ}$ heat flow), we analyzed several cases with no fracture flow (effectively causing heat flow to be entirely dominated by conduction) and found negligible differences in heat flux crossing the water table. Therefore, the model-boundary effect that occurs $1 \mathrm{~km}$ below the water table does not influence heatflow at the water table; moreover, it does not affect temperature rise in the UZ and the upper SZ. It should be noted that few data exist concerning the vertical extent of connected fracture networks in the $S Z$ and that the thermal property data below the PPw unit is lacking in the RIB [DOE, 1990]. We plan to continue our study of decay-heatdriven $\mathrm{T}-\mathrm{H}$ behavior in the $\mathrm{SZ}$, utilizing other available sources of thermal property data [Sass et al., 1988]. 

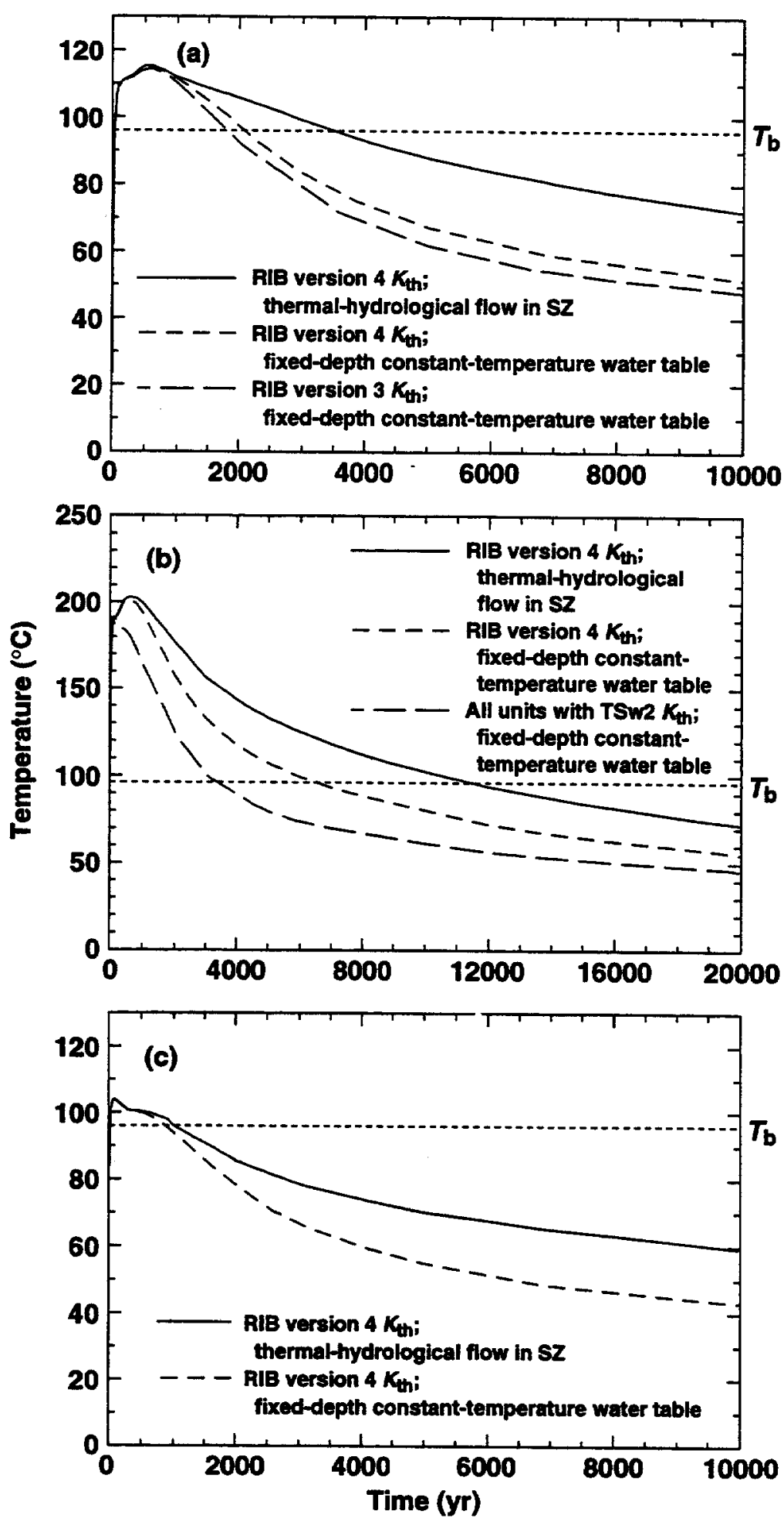

Figure 10.2.1.1. Temperature history at the center of the repository for ambient percolation flux $=0.0 \mathrm{~mm} / \mathrm{yr}$. Curves are plotted for (a) AML = 77.4 MTU/acre and 30-yr-old SNF, (b) AML = 154.7 MTU/acre and 30-yr-old SNF, (c) AML = 49.2 MTU/acre and 10-yr-old SNF. 


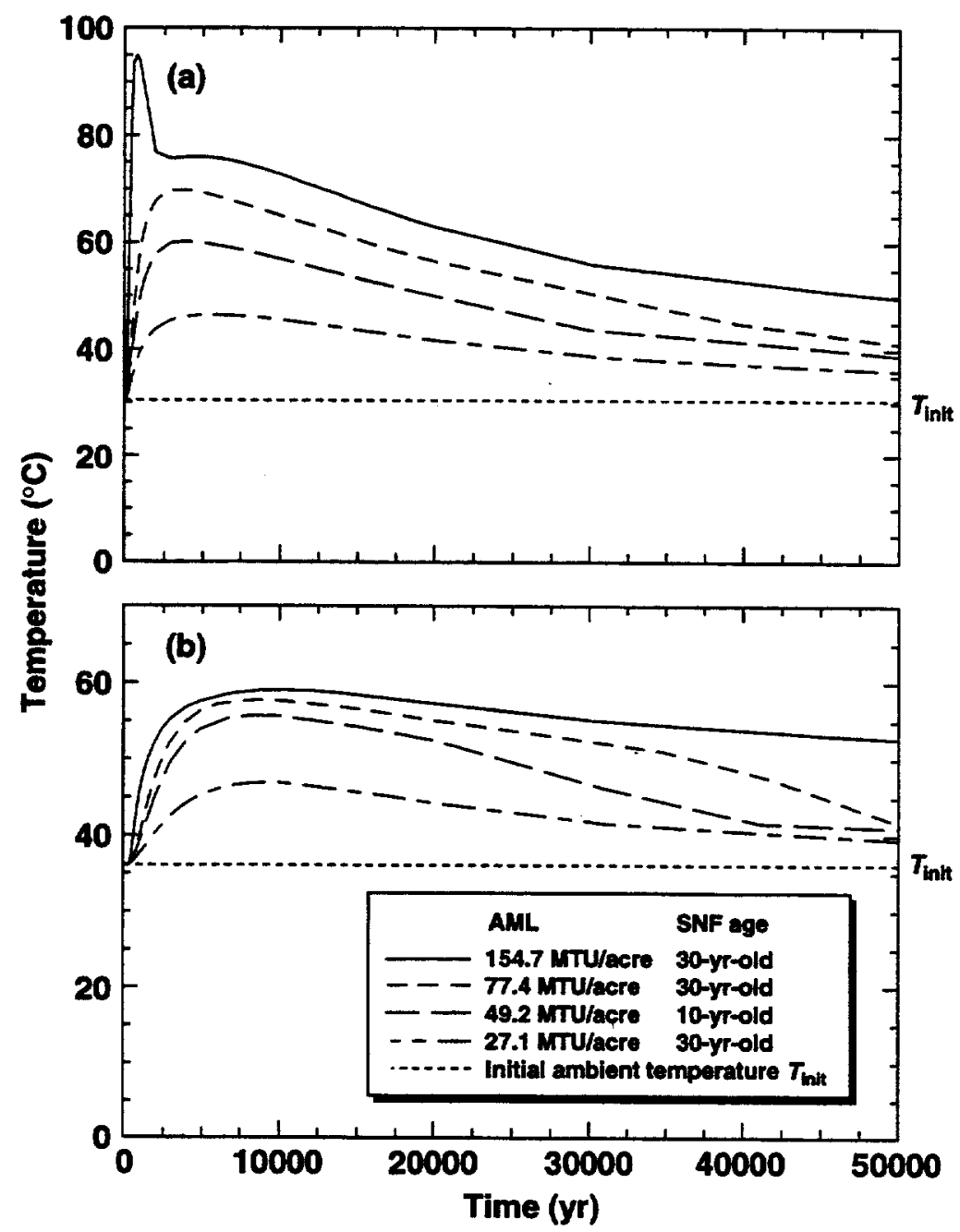

Figure 10.2.1.2. Temperature history at locations below the center of the repository for various AMLs and SNF ages, including (a) the water table and (b) $250 \mathrm{~m}$ below the water table. 


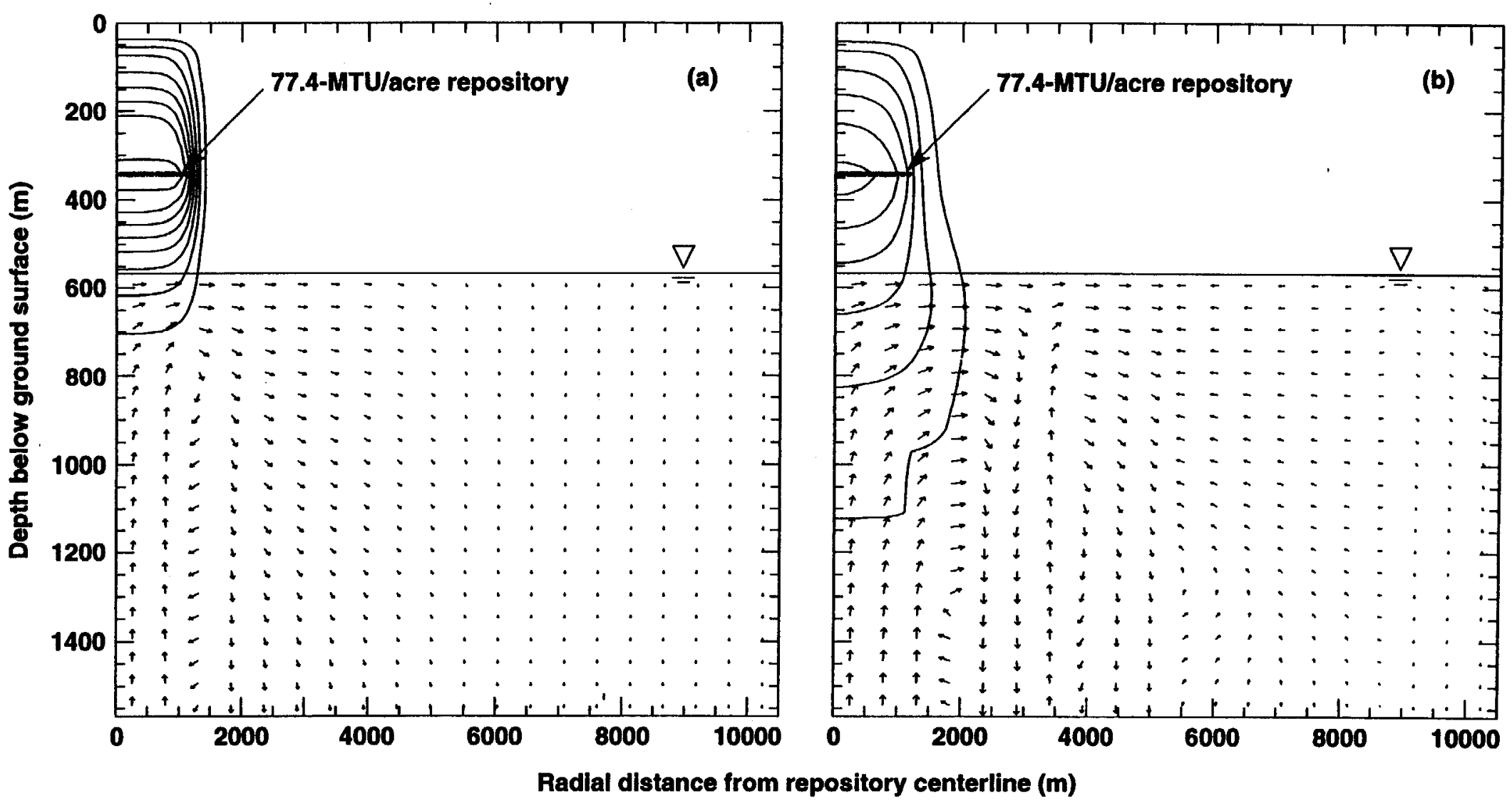

Figure 10.2.2.1. Temperature buildup contours (temperature rise above ambient temperature) and velocity vectors for liquid-phase flow in fractures in the SZ for AML $=77.4 \mathrm{MTU} / \mathrm{acre}, 30$-yr-old SNF, 1118-acre repository area, and ambient percolation flux $=0.0 \mathrm{~mm} / \mathrm{yr}$ at (a) $t=1000 \mathrm{yr}$ and (b) $t=5000 \mathrm{yr}$. Temperature contour interval is $5^{\circ} \mathrm{C}$. Liquid-phase velocity vectors are scaled logarithmically from $0.03 \mathrm{~m} / \mathrm{yr}$ to $1600 \mathrm{~m} / \mathrm{yr} /$. 


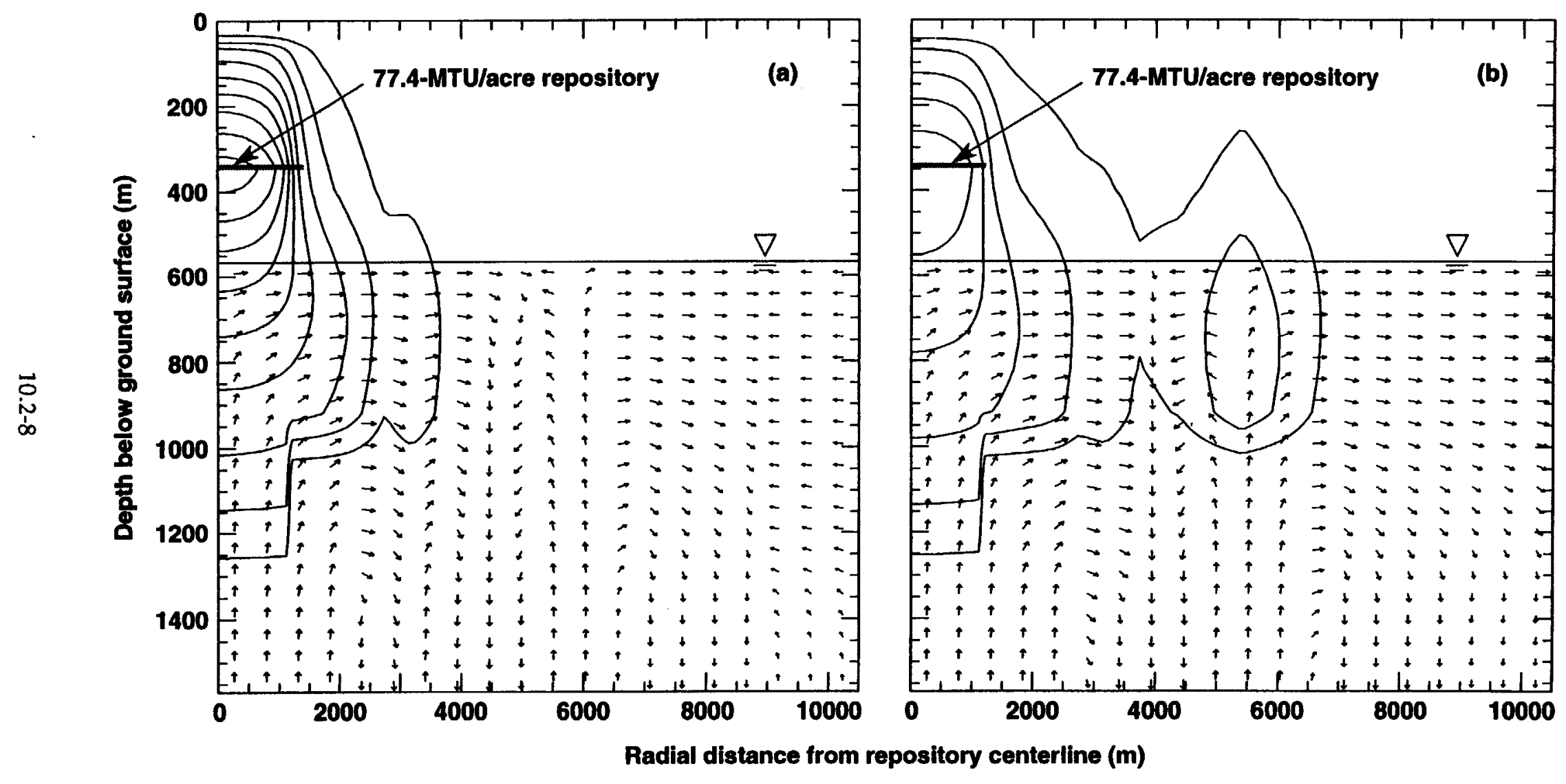

Figure 10.2.2.2. Temperature buildup contours (temperature rise above ambient temperature) and velocity vectors for liquid-phase flow in fractures in the SZ for AML = 77.4 MTU/acre, 30-yr-old SNF, 1118-acre repository area, and ambient percolation flux $=0.0 \mathrm{~mm} / \mathrm{yr}$ at (a) $t=10,000 \mathrm{yr}$ and (b) $t=20,000 \mathrm{yr}$. Temperature contour interval is $5^{\circ} \mathrm{C}$. Liquid-phase velocity vectors are scaled logarithmically from $0.03 \mathrm{~m} / \mathrm{yr}$ to $1600 \mathrm{~m} / \mathrm{yr} /$. 


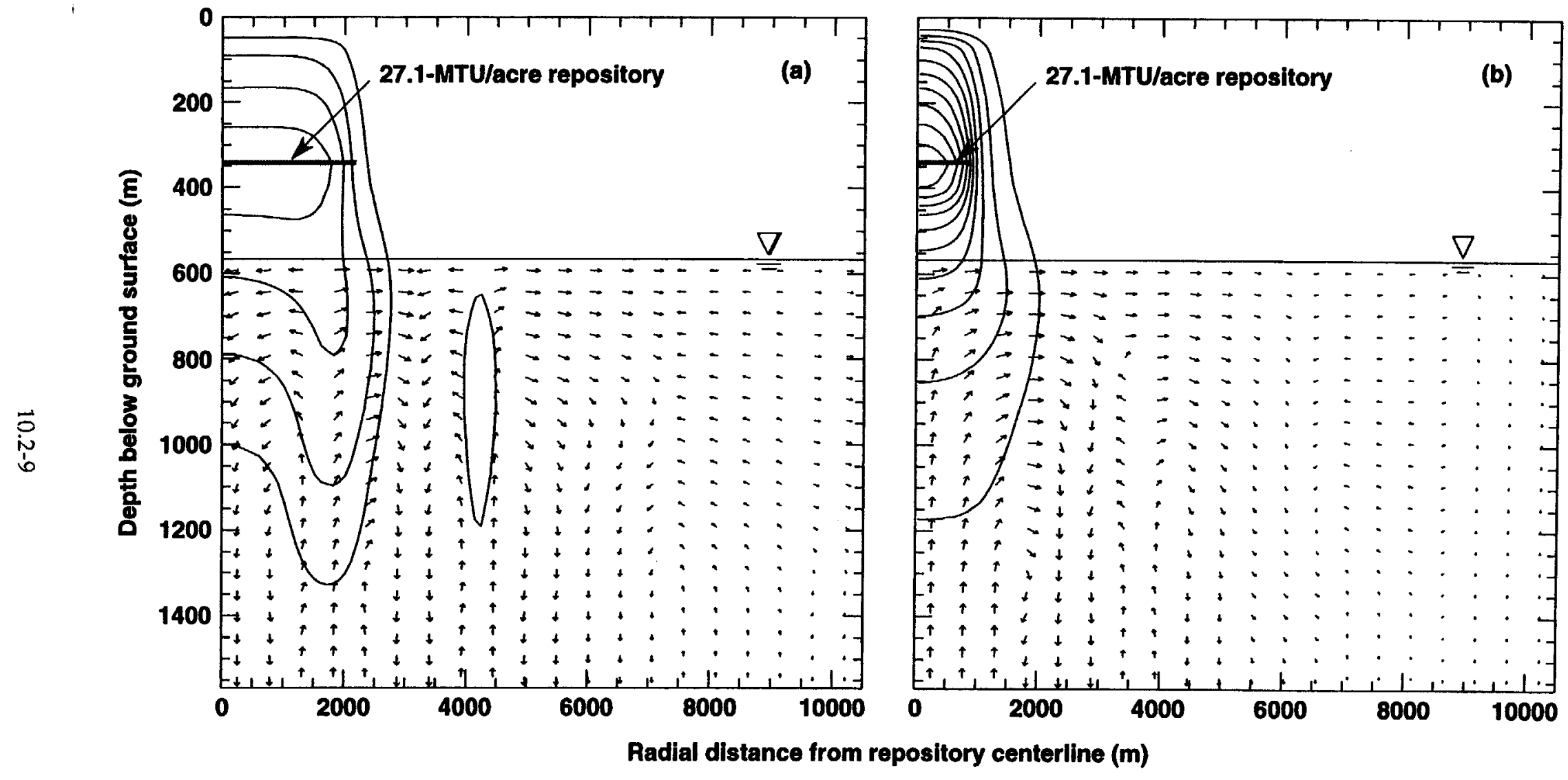

Figure 10.2.2.3. Temperature buildup contours (temperature rise above ambient temperature) and velocity vectors for liquid-phase flow in fractures in the SZ for $\mathrm{AML}=27.1 \mathrm{MTU} / \mathrm{acre}, 30$-yr-old SNF, 3162-acre repository area, and ambient percolation flux $=0.0 \mathrm{~mm} / \mathrm{yr}$ at (a) $t=1000 \mathrm{yr}$ and (b) $t=5000 \mathrm{yr}$. Temperature contour interval is $5^{\circ} \mathrm{C}$. Liquid-phase velocity vectors are scaled logarithmically from $0.03 \mathrm{~m} / \mathrm{yr}$ to $1600 \mathrm{~m} / \mathrm{yr} /$. 


\section{References}

Buscheck, T.A. and J.J. Nitao, "Estimates of the Width of the Wetting Zone Along a Fracture Subjected to an Episodic Infiltration Event in Variably Saturated, Densely Welded Tuff," UCID-21579, Lawrence Livermore National Laboratory, Livermore, CA (1988).

Buscheck, T.A. and J.J. Nitaó, "Modeling Hydrothermal Flow in Variably Saturated, Fracture, Welded Tuff During the Prototype Engineered Barrier System Field Test of the Y ucca Mountain Project," UCRL-JC-1106521, Lawrence Livermore National Laboratory, Livermore, CA (1991).

Buscheck, T.A., J.J. Nitao, and D.A. Chesnut, "The Impact of Episodic Nonequilibrium Fracture-Matrix Flow on Geological Repository Performance," Proceedings American Nuclear Society Topical Meeting on Nuclear Waste Packaging (Focus 91), Las Vegas, NV, Sept. 30-Oct. 2, 1991. Also, UCRL-JC-106759, Lawrence Livermore National Laboratory, Livermore, CA (1991).

Buscheck, T.A., and J.J. Nitao, "The Impact of Thermal Loading on Repository Performance at Yucca Mountain," American Nuclear Society, Proceedings Third International High-Level Radioactive Waste Management Conference, Las Vegas, NV, April 12-16, 1992. Also, UCRL-JC-109232, Lawrence Livermore National Laboratory, Livermore, CA (1992).

Buscheck, T.A., and J.J. Nitao, "The Impact of Repository Heat on Thermo-Hydrological Performance at Yucca Mountain," Proceedings American Nuclear Society Topical Meeting on Site Characterization and Model Validation (Focus 93), Las Vegas, NV, Sept. 26-30, (1993a).

Buscheck, T.A., and J.J. Nitao, "Repository-Heat-Driven Hydrothermal Flow at Yucca Mountain, Part I: Modeling and Analysis," Nuclear Technology, Vol. 104, No. 3, pp. 418-448, (1993b).

Buscheck, T.A., D.G. Wilder, and J.J. Nitao, "Large-Scale In Situ Heater Tests for the Characterization of Hydrothermal Flow at Yucca Mountain," American Nuclear Society, Proceedings Fourth International High-Level Radioactive Waste Management Conference, Las Vegas, NV, April 1993. Also, UCRL-JC-112445, Lawrence Livermore National Laboratory, Livermore, CA (1993a).

Buscheck, T.A., D.G. Wilder, and J.J. Nitao, "Repository-Heat-Driven Hydrothermal Flow at Yucca Mountain, Part II: Large-Scale In Situ Heater Tests," Nuclear Technology, Vol. 104, No. 3, pp. 449471 (1993b).

Buscheck, T.A., and J.J. Nitao, "The Impact of Buoyant Gas-Phase Flow and Heterogeneity on ThermoHydrological Behavior at Yucca Mountain," American Nuclear Society, La Grange Park, IL, Proceedings Fifth International High-Level Radioactive Waste Management Conference, Las Vegas, NV, May 1994a. Also UCRL-JC-115351, Lawrence Livermore National Laboratory, Livermore, CA, (1994a).

Buscheck, T.A: and J.J. Nitao, "The Importance of Thermal Loading Conditions to Waste Package Performance at Yucca Mountain," Materials Research Society, Pittsburgh, PA, Proceedings Materials Research Society XVIII International Symposium on the Scientific Basis for Nuclear Waste Management, Oct. 23-27, 1994. Also UCRL-JC-116429, Lawrence Livermore National Laboratory, Livermore, CA, (1994b).

Buscheck, T.A., J.J. Nitao, and L.D. Ramspott, "Localized Dry-Out: An Approach for Managing the Thermal-Hydrological Effects of Decay Heat at Yucca Mountain," Materials Research Society, Pittsburgh, PA, Proceedings Materials Research Society XIX International Symposium on the Scientific Basis for Nuclear Waste Management, Nov. 27-Dec. 1, (1995).

Buscheck, T.A., J.J. Nitao, and S.F. Saterlie, "Evaluation of Thermo-Hydrological Performance in Support of the Thermal Loading Systems Study," American Nuclear Society, Proceedings Fifth International High-Level Radioactive Waste Management Conference, Las Vegas, NV, May 1994; Also UCRL-JC-115352, Lawrence Livermore National Laboratory, Livermore, CA, (1994).

Buscheck, T.A. and J.J. Nitao, "Thermal-Hydrological Analysis of Large-Scale Thermal Tests in the Exploratory Studies Facility at Yucca Mountain," UCRL-ID-121791, Lawrence Livermore National Laboratory, Livermore, CA (1995).

DOE (U.S. Dept. of Energy), "Site Characterization Plan: Yucca Mountain Site, Nevada Research and Development Area," DOE/RW-0199 (1988). 
DOE (U.S. Dept. of Energy), "Yucca Mountain Project Reference Information Base," YMP/CC-0002 (Version 04.002), Nevada Operations Office, Las Vegas, NV (1990).

Forsythe, P.A., "Radioactive Waste Disposal Heating Effects in Unsaturated Fractured Rock," Numerical Heat Transfer Part A-Applications 17 (1), 29-51 (1990).

Jones, D.A., Principles and Prevention of Corrosion, Macmillan Publishing Company, New York (1992).

Klavetter, E.A., and R.R. Peters, "Estimation of Hydrologic Properties of an Unsaturated Fractured Rock Mass," SAND84-2642, Sandia National Laboratories, Albuquerque, NM (1986).

Konikow, L.F., and J.D. Bredehoeft, "Ground-water Models Cannot Be Validated," Advances in Water Resources, Vol. 15, pp. 75-83 (1992).

Lin, W., D.G. Wilder, J.A. Blink, S.C. Blair, T.A. Buscheck, R.S. Glass, W.E. Glassley, K. Lee, R.D. McCright, M.W. Owen, and J.J. Roberts, "A Large Block Heater Test for High Level Nuclear Waste Management," Materials Research Society, Pittsburgh, PA, Proceedings Materials Research Society XVIII International Symposium on the Scientific Basis for Nuclear Waste Management, Oct. 23-27, 1994. Also UCRL-JC-116431, Lawrence Livermore National Laboratory, Livermore, CA (1994).

Montazer, P., and W.E. Wilson, "Conceptual Hydrologic Model of Flow in the Unsaturated Zone, Yucca Mountain, Nevada," Water Resources Investigation Report 84-4345, U.S. Geological Survey (1984).

Nuclear Regulatory Commission, "Generic Technical Position on In Situ Testing During Site Characterization for High-Level Nuclear Waste Repositories," Engineering Branch, Division of Waste Management (December 1985).

U.S. Code of Federal Regulations Part 60, "Disposal of High-Level Radioactive Waste in a Geologic Repository," March (1990).

Nitao, J.J., "Numerical Modeling of the Thermal and Hydrological Environment Around a Nuclear Waste Package Using the Equivalent Continuum Approximation: Horizontal Emplacement," UCID-21444, Lawrence Livermore National Laboratory, Livermore, CA (1988).

Nitao, J.J., "V-TOUGH - An Enhanced Version of the TOUGH Code for the Thermal and Hydrologic Simulation of Large-Scale Problems in Nuclear Waste Isolation," UCID-21954, Lawrence Livermore National Laboratory, Livermore, CA (1989).

Nitao, J.J., "The NUFT Code for Modeling Nonisothermal, Multiphase, Multicomponent Flow and Transport in Porous Media," EOS, American Geophysical Union, Vol. 74, no. 3, pr. 3 (1993).

Nitao, J.J., T.A. Buscheck, and D.A. Chesnut, "Implications of Episodic Nonequilibrium FractureMatrix Flow on Repository Performance," Nuclear Technology, Vol. 104, No. 3, pp. 385-402, (1993).

Nitao, J.J., "The NUFT Code for Modeling Nonisothermal, Multiphase, Multicomponent Flow and Transport in Porous Media," EOS Supplement 74 (3), 313 (1993).

Nitao, JJ, and T.A. Buscheck, "Discrete-Fracture Modeling of Thermal-Hydrological Processes at Yucca Mountain and the LLNL G-Tunnel Field Test," Materials Research Society, Pittsburgh, PA, Proceedings Materials Research Society XIX International Symposium on the Scientific Basis for Nuclear Waste Management, Nov. 27-Dec. 1, (1995).

Peters, R.R., E.A. Klavetter, I.J. Hall, S.C. Blair, P.R. Hellers, and G.W. Gee, "Fracture and Matrix Hydrologic Characteristics of Tuffaceous Materials from Yucca Mountain, Nye County, Nevada," SAND84-1471, Sandia National Laboratories, Albuquerque, NM (1984).

Popper, K., The Logic of Scientific Discovery, Harper and Row, New York (1959).

Pruess, K., "TOUGH User's Guide," NUREG/CR-4645, Nuclear Regulatory Commission (1987).

Pruess, K., J.S.Y. Wang, and Y.W. Tsang,"Numerical Modeling Studies of Fluid and Heat Flow near High-Level Nuclear Waste Packages in Partially Saturated Fractured Tuff," LBL-18522, Lawrence Berkeley Laboratory, Berkeley, CA (1984).

Ramirez, A.L., T.A. Buscheck, R. Carlson, W. Daily, K. Lee, W. Lin, N. Mao, T.S. Ueng, H. Wang, and D. Watwood, "Prototype Engineered Barrier System Field Test (PEBSFT) Final Report," UCRLID-106159, Lawrence Livermore National Laboratory, Livermore, CA (1991).

Stahl, D., J.K. McCoy, and R.D. McCright, "Impact of Thermal Loading on Waste Package Material Performance," Material Research Society, Pittsburgh, PA, Proceedings Material Research Society XVIII Symposium on the Scientific Basis for Nuclear Waste Management, Oct. 23-27 (1994). 


\section{Contents}

10.3 Geochemistry and Mineralogy of the Altered Zone (William E. Glassley).

$10.3-2$

10.4 Summary of Recent Studies Concerning Geochemical and Mineralogical Evolution of the Altered Zone (William E. Glassley)....

10.4.1 Hydrothermal Alteration of Vitric Tuff from Yucca Mountain, by Kevin G. Knauss and Sally A. Copenhaver, Lawrence Livermore National Laboratory

10.4.2 Kinetics of Rock-Water Interaction: Amorphous Silica Precipitation (60 to $120^{\circ} \mathrm{C}$ ); Comparison of Laboratory and Field Rates, by Susan Carroll, Edward Mroczek, Maureen Alai, and Margeret Ebert; Earth Sciences Division, Lawrence Livermore National Laboratory, Livermore CA, USA, Institute of Geological \& Nuclear Sciences, Wairakei Research Center, Wairakei, New Zealand.

10.4.3 Thermal Effects in the Altered Zone: Preliminary Bounds on the Water Composition and Secondary Mineral Development in the Altered Zone That May Influence the Near-Field Environment, by Michael Whitbeck and William Glassley, Lawrence Livermore National Laboratory

10.4.4 Formation of Flow and Transport Barriers Within the Altered Zone, by James W. Johnson and William Glassley, Lawrence Livermore National Laboratory 


\subsection{Geochemistry and Mineralogy of the Altered Zone (William E. Glassley)}

\section{Introduction}

Geochemical processes that will occur as a result of emplacement of high-level radioactive waste will be driven by heat transferred into the rock surrounding the emplacement drifts. The consequences of these geochemical effects will depend upon the rate of temperature change, and the maximum temperature reached, as well as the flux of water and vapor through the rock. In some waste emplacement scenarios, temperature changes of more than $10^{\circ} \mathrm{C}$ extend hundreds to thousands of meters away from the emplacement drifts. In other scenarios, temperature changes of this magnitude are restricted to regions less than 100 meters from emplacement drifts. For any given emplacement scenario, the rate at which temperature changes occur depend, in general, on the distance from the heat source: the further the distance, the slower the heating rate. Regardless of emplacement scenarios, within the immediate vicinity (several tens of meters) of emplacement drifts, temperatures will increase relatively rapidly to more than $100^{\circ} \mathrm{C}$.

This temperature behavior has led to a conceptual model in which "near-field" effects (the NearField Environment) are distinguished from "altered zone" effects (the Altered Zone). In the near-field region, hydrological processes will be dominated by water vaporization, water movement by means of gas phase transport, and condensation in those outer regions of the near-field environment where temperatures are below the boiling point. Geochemical processes will be dominated by evaporation and boiling, mineral dehydration, and solid-vapor interactions. In the altered zone, hydrological processes will be dominated by an increase in water availability and increased saturation, associated with vapor condensation. The geochemical processes will be dominated by fluid-rock interactions, and reactive transport. Within the altered zone, these interactions will result in significant coupling between hydrological and geochemical processes, such that fluid flow pathways and geochemical conditions will evolve in a synergistic way.

Although the geochemical processes ( e.g., recrystallizations, hydration or dehydration of mineral phases, or both; dissolution and precipitation; rock-water interaction involving water in pores and fractures; cation exchange, sorption, etc.) in both regions are the same, their impact on rock properties will be different, due to contrasts in heating and cooling rates, and in the abundance and temperature of liquid water. These differences will be expressed as differences in the magnitude and nature of chemical and mineralogical changes, and the duration of specific processes. As a result, the repository performance will be affected differently in the two regions as a result of water-mineral interactions. For purposes of this report, the Near-Field Environment (NFE) will be considered to be those regions that acheive temperatures well above the boiling point, and the Altered Zone (AZ) will be considered to be those regions that maintain temperatures low enough to allow liquid water to exist in pores and fractures. This distinction has the advantage of focusing attention on the dominant processes that may effect performance in different regions of the repository (e.g., evaporation of water and mineral dehydration in the NFE, and rock-water interaction and the kinetics of dissolution and precipitation in the AZ). Refer to Chapter 3 for results to date of activities investigating processes in the NFE. 


\subsection{Summary of Recent Studies Concerning Geochemical and Mineralogical Evolution of the Altered Zone (William E. Glassley)}

The results of four studies are reported here. These studies consider the geochemical and mineralogical evolution of the AZ.

One study (Section 10.4.2.1 Hydrothermal Alteration of Vitric Tuff from Yucca Mountain) considers the effects of liquid water interacting with vitric material typical of the Tsw3 unit and the vitric Calico Hills lithology. The results indicate that extent of alteration, as a function of time, is sensitive to temperature (as expected from well established models of reaction kinetics), and to the extent of prior alteration. The latter interpretation is based on the observation that reaction progress, for any given time or temperature was less for vitric material in which clay occured as a ubiquitous, but trace, component covering the surfaces of vitric material. As with previous experiments using glassy material from the region, secondary minerals that form are primarily zeolites and clays.

A second study (Section 10.4.2.2. Amorphous Silica Precipitation $\left(60\right.$ to $\left.120^{\circ} \mathrm{C}\right)$ : Comparison of Laboratory and Field Rates) was concerned with evaluating apparent discrepancies between laboratory-based and field-based measurements of reaction rates. In this case, the precipitation rates for amorphous silica were measured. Rate measurements were carried out in the laboratory using collapsible-bag autoclaves, and were compared with measurements made in the field using a fluidizedbed reactor. The field measurements were made at the Wairakei geothermal field in New Zealand, which has been selected as a key site in which processes relevant for repository evolution can be examined and monitored (Bruton et al., 1995). The results show that the field-based rates are 10 to 300 times faster than those measured in the laboratory. Observations suggest that these differences are sensitive to temperature, and may be influenced by the presence of other chemical species in solution (e.g., Al). The precipitation mechanism in the field may be controlled by surface defects.

A third study (Section 10.4.2.3 Preliminary Bounds on the Water Composition and Secondary Mineral Development That May Influence the Near-Field Environment) places preliminary bounds on the chemical composition of water that may enter the NFE, and on the secondary mineralogy that may develop within the $A Z$. This study considered the effect of temperature and uncertainty in reaction kinetics to place limits on fluid composition for devitrified and vitric tuffs intereacting with a J-13 like water over a range of temperatures. The simulations were carried out assuming that fluid was in equilibrium with atmospheric gases. The results indicate that water compositions remain mildly oxidizing, and slightly to mildly alkaline ( $\mathrm{pH}$ between 7.5 and 8.8 ), for most conditions. The exception noted was that in which very large water volumes interacted with small volumes of vitric material. In that case, the buffering effect of atmospheric gases was overwhelmed and the solution became acidic ( $\mathrm{pH}$ ca. 4). Secondary minerals that formed were sensitive to extent of reaction and temperature. In most cases, zeolites and clays were present, with minor to trace amounts of other minerals present.

The effect of uncertainty in reaction kinetics was also evaluated. It is established that uncertainty in the time at which secondary minerals form can be as great as hundreds to thousands of years, for the uncertainties described in Section 10.4.2.2. These results are consistent with the conclusion in Section 3.4.2, in which it is argued that a mineral facies concept needs to be employed when considering secondary mineral development within the repository.

The fourth study describes the results of reactive transport simulations in which porosity modification is monitored during dissolution and precipitation of a wide range of silicates along a flow path that is similar to that expected for water condensed from steam generated in the near-field environment. The results show that porosity may more than double in devitrified and welded tuff, due to the dissolution of cristobalite in the regions immediately adjacent to the condensation front. As these waters migrate along and across isotherms, the dissolved constituents eventually precipitate as complex silicates, reducing porosity, and forming altered regions composed of zeolites, clays, and hydrated alumino-silicates. This complex coupling of fluid flow and reactive chemical transport 
demonstrates that large changes in bulk rock hydrological properties may occur within a few hundred years of repository operation.

These results are expected to be the foundation upon which refined estimates of mineral facies would be developed for specific repository scenarios of waste emplacement strategies, infiltration fluxes, and rock properties. These scenarios have yet to be developed. It is expected that future work will focus on developing these mineralogical and chemical scenarios, and reducing the uncertainties in key thermodynamic and kinetic data in order to better bound the behavior of the repository. 


\subsubsection{Hydrothermal Alteration of Vitric Tuff from Yucca Mountain (Kevin G. Knauss, and Sally A. Copenhaver, Lawrence Livermore National Laboratory)}

10.4.1.1 Introduction and Methods. Alteration of the basal vitrophyre of the Topopah Spring tuff (Tsw3 unit) represents a potentially profound modification of the lithologic units currently composing the potential repository block at Yucca Mountain (see Sections 3.4.3 and 10.4.3). A suite of experiments was designed to evaluate the effects of this potential alteration. An initial set of three experiments was conducted to investigate the hydrothermal alteration of the vitric tuff, the results of which were summarized earlier (Knauss and Peifer, 1986; Knauss, 1987). Additional experiments, to more fully_characterize the alteration effects, were also conducted, and are reported below. The experimental methods and analytical techniques described in the earlier papers were used in the runs described here. The only exception is that the initial fluid composition in the runs with Calico Hills tuff was 3 mmolal $\mathrm{NaHCO}_{3}$, rather than well J-13 water. The following table identifies the pertinent information for all of the vitric experiments, including the three already reported, and the two runs made with zeolitized Topopah Spring tuff.

The rock samples taken from G4-1362 (the moderately welded, essentially unaltered vitric airfall/ashflow below the basal vitrophyre) have been characterized in detail (Knauss and Peifer, 1986). The rock samples taken from GU3-1226, Ue25a1-1297 and outcrop Tchnv have been characterized in a similar fashion, and will be reported later. Briefly, the material from GU3-1226 samples the densely welded vitrophyre and is essentially unaltered glass. Both of these samples of Tpt glass (G4-1362 and GU3-1226) have low ( 2\%) phenocryst content. The material from Ue25a1-1297 also samples the Tpt vitrophyre, but at this location the glass has been extensively altered to zeolite (heulandite) and clay (smectite). It also has a low phenocryst content. The outcrop material (outcrop Tchnv), taken from the north end of Busted Butte, samples the Tuff of Calico Hills and is mostly glass $(\sim 80 \%)$ and phenocrysts $(\sim 16 \%)$, although some alteration to clay has occurred $(\sim 4 \%)$. This amount of clay alteration is similar to that observed in the vitric intervals of Tchnv in drillcore. The sample locality is equivalent to DEB 3/90-48 (Broxton et al., 1993).

\begin{tabular}{c|c|c|c|c|c|c}
\hline Run & Rock & Fluid & $\left.\mathbf{T}^{\circ} \mathbf{C}\right)$ & $\mathbf{P}($ bar $)$ & Duration(d) & Source \\
\hline DB27 & G4-1362 & $\mathrm{J}-13$ & 90 & 100 & 64 & $(1)$ \\
\hline DB20 & G4-1362 & $\mathrm{J}-13$ & 150 & 100 & 64 & $(2)$ \\
\hline DB22 & G4-1362 & $\mathrm{J}-13$ & 250 & 100 & 64 & $(2)$ \\
\hline DB29 & G4-1362 & $\mathrm{J}-13$ & 150 & 100 & 178 & $(3)$ \\
\hline DB30 & G4-1362 & $\mathrm{J}-13$ & 350 & 100 & $16(57)$ & $(3)$ \\
\hline DB25 & GU3-1226 & $\mathrm{J}-13$ & 90 & 100 & 64 & $(3)$ \\
\hline DB21 & GU3-1226 & $\mathrm{J}-13$ & 150 & 100 & 64 & $(3)$ \\
\hline DB23 & GU3-1226 & $\mathrm{J}-13$ & 250 & 100 & 64 & $(3)$ \\
\hline DB28 & Ue25a1-1297* & $\mathrm{J}-13$ & 90 & 100 & 64 & $(3)$ \\
\hline DB24 & Ue25a1-1297* & $\mathrm{J}-13$ & 150 & 100 & 64 & $(3)$ \\
\hline $\mathrm{CH} 3$ & outcrop Tchnv & $\mathrm{NaHCO}_{3}$ & 90 & 100 & 210 & $(4)$ \\
\hline $\mathrm{CH} 2$ & outcrop Tchnv & $\mathrm{NaHCO}_{3}$ & 150 & 100 & 93 & $(4)$ \\
\hline $\mathrm{CH} 1$ & outcrop Tchnv & $\mathrm{NaHCO}_{3}$ & 250 & 100 & 94 & $(4)$ \\
\hline
\end{tabular}

* = zeolitized Tpt

(1) Knauss and Peifer, 1986

(2) Knauss, 1987
(3) Knauss and Copenhaver (1995)

(4) in progress 
All of the hydrothermal experiments with Tpt core wafers used water collected from well J-13 as the fluid. The three runs with Tch core wafers used a 3 mmolal $\mathrm{NaHCO}_{3}$ solution as the fluid phase, since sufficient J-13 water was not available at the time the experiments were conducted. This solution has approximately the same carbonate alkalinity as J-13 water, but contains about $50 \%$ more $\mathrm{Na}+$ (the dominant cation in J-13 water) and, of course, lacks the other cations (and anions).

In all runs the fluids were analyzed for a suite of cations and anions, the quench $\mathrm{pH}$, and dissolved carbonate. The geochemical modeling code EQ3/6 (Wolery et al., 1990) was used to calculate the in situ $\mathrm{pH}$. The fluid chemistry data have been reported as noted. Note that the $\mathrm{pH}$ in the tables is the $25^{\circ} \mathrm{C}$ $\mathrm{pH}$ of the quenched fluid sample. The unreacted solid wafers of tuff and the reacted wafers recovered at the end of each run were characterized using XRD and SEM/EMP analyses.

10.4.1.2 Results and Discussion. The results of earlier hydrothermal alteration experiments, in which the devitrified (repository-equivalent) Tpt was reacted with well $\mathrm{J}-13$ water at $150^{\circ}$ and $250^{\circ} \mathrm{C}$, showed that the primary alteration products were the Ca-rich, mordenite-type zeolite, dachiardite, and mordenite itself (Knauss et al., 1987). The aqueous $\mathrm{SiO}_{2}$ activity was controlled by cristobalite saturation. The fluid chemistry was in accord with the production of these zeolites.

In contrast, results of earlier hydrothermal alteration experiments, in which the vitric airfall/ashflow at the base of the Tpt was reacted with well $\mathrm{J}-13$ water at $250^{\circ} \mathrm{C}$, showed production of the zeolite clinoptilolite, exclusively (Knauss, 1987). In these runs with vitric tuff the aqueous $\mathrm{SiO}_{2}$ activity was controlled by amorphous silica saturation. Runs at lower temperature $\left(150^{\circ}\right.$ and $\left.90^{\circ} \mathrm{C}\right)$ were extended for times insufficient to quite reach amorphous silica saturation and no zeolites formed, although significant changes in water chemistry occured during the course of the water-rock interaction. In all of the vitric airfall runs at temperatures of $250^{\circ}$ or below, at least some glass remained unconsumed at the end of the run.

Continuing the series of runs using vitric airfall/ashflow from the base of the Tpt, we have found that even after 6 months at $150^{\circ} \mathrm{C}(\mathrm{DB} 29)$ the $\mathrm{SiO}_{2}$ activity remained below amorphous silica saturation and no zeolites precipitated. However, at $350^{\circ} \mathrm{C}$ (DB30) amorphous silica saturation was quickly reached and the glass was completely consumed by the end of the run. The dominant run product was a non-stoichiometric feldspar (possibly orthoclase based on XRD), which had completely replaced the glass, and lesser amounts of the zeolite mordenite.

We ran three 2-month-long experiments to study the hydrothermal alteration of Tpt vitrophyre in well J-13 water at $90^{\circ} \mathrm{C}(\mathrm{DB} 25), 150^{\circ} \mathrm{C}$ (DB21) and $250^{\circ} \mathrm{C}$ (DB23). Although compositionally identical to the vitric basal airfall/ashflow material, the vitrophyre has a much smaller specific surface area, because it is densely welded. This changes the rate at which the glass dissolves and, hence, the fluid chemistry and run products differ for the same reaction time from those of the airfall. For example, in all three of these runs with Tpt vitrophyre the degree of undersaturation with respect to amorphous silica solubility was significantly greater than in the corresponding airfall/ashflow runs. We found only evidence of glass dissolution at the two lowest temperatures. At $250^{\circ} \mathrm{C}$, it is clear from SEM/EMP analyses that early in the run the dominant product was a clay, but as the run progressed the zeolite clinoptilolite became the major product. Given sufficient time/reaction progress, one would expect the vitrophyre to result in mostly zeolite alteration.

We ran two 2-month-long experiments to study the hydrothermal alteration of naturally zeolitized Tpt in well J-13 water at $90^{\circ}$ (DB28) and $150^{\circ}$ (DB24). In these samples, the starting material is predominately the zeolite heulandite, although a significant amount of smectite is also present. No new run products were identified in either run. The heulandite appeared to remain a stable phase. In fact, there was no obvious evidence of dissolution. Interestingly, the EMP analyses of the reacted wafer from the $150^{\circ} \mathrm{C}$ experiment suggested that the exchangeable cation composition of the heulandite had become more potassic and less sodic as a consequence of the hydrothermal reaction.

Preliminary results from the three experiments to study the hydrothermal alteration of vitric Calico Hills tuff (Tchnv) at $90^{\circ}(\mathrm{CH} 3), 150^{\circ}(\mathrm{CH} 2)$ and $250^{\circ} \mathrm{C}(\mathrm{CH} 1)$ contrast with those from the other experiments. Although the glass in the vitric Tch is compositionally fairly similar to the vitric Tpt, the phenocryst content is significantly higher in Tch and the phenocryst composition is distinct from 
that in the Tpt. More importantly, while the basal airfall/ashflow and vitrophyric Tpt samples were largely fresh (unaltered) glass, the vitric Tch material contains a significant amount of smectite. The smectite is observed to coat the matrix shards and pumice lapilli. This is true of both drillcore and outcrop specimens. Preliminary results suggest that this has a profound effect on the glass alteration. Even in samples with comparable specific surface area and glass composition, the Tch samples did not produce zeolite alteration. Only smectite was detected in XRD. 


\subsubsection{References}

Broxton, D. E., S. J. Chipera, F. M. Byers, and C. A. Rautman(1993) Geologic evaluation of six nonwelded tuff sites in the vicinity of Yucca Mountain, Nevada for a surface-based test facility for the Yucca Mountain Project. Los Alamos National Laboratory Report LA-12542.

Knauss, K. G., and D. W. Peifer (1986) Reaction of vitric Topopah Spring tuff and J-13 ground water under hydrothermal conditions using Dickson-type, gold-bag rocking autoclaves: Lawrence Livermore National Laboratory Report, UCRL-53795.

Knauss, K. G. (1987) Zeolitization of glassy Topopah Spring tuff under hydrothermal conditions: Mat. Res. Soc. Symp. 84, 737-745.

Knauss, K. G., W. J. Beiriger, and D. W. Peifer (1987) Hydrothermal interaction of solid wafers of Topopah Spring tuff with J-13 water at 90 and $15000 \mathrm{C}$ using Dickson-type, gold-bag rocking autoclaves: Long-term experiments: Lawrence Livermore National Laboratory Report, UCRL-53722.

Knauss, K. G., and S. A. Copenhaver (1995) Progress report on hydrothermal alteration of vitric tuff from Yucca Mountain. Lawrence Livermore National Laboratory Yucca Mountain Site Characterization Project Milestone MOL124, Data Tracking Number LL950613804241.009.

Wolery, T. J., K. J. Jackson, W. L. Bourcier, C. J. Bruton, B. E. Viani, K. G. Knauss, and J. M.Delany (1990) The EQ3/6 software package for geochemical modeling: Current Status: Amer. Chem. Soc. Symposium Series 416, Chemical Modeling in Aqueous Systems II, ed. D.C. Melchior and R.L. Bassett, p. 104-116. 


\subsubsection{Kinetics of Rock-Water Interaction: Amorphous Silica Precipitation (60 to $120^{\circ} \mathrm{C}$; Comparison of Laboratory and Field Rates, by Susan Carroll 1 , Edward Mroczek ${ }^{2}$, Maureen Alai ${ }^{1}$, and Margeret Ebert ${ }^{1.1-E a r t h ~ S c i e n c e s ~}$ Division, Lawrence Livermore National Laboratory, Livermore CA, USA, 2- Institute of Geological \& Nuclear Sciences, Wairakei Research Center, Wairakei, New Zealand}

10.4.2.1 Introduction. Dissolution of silica in response to water movement at the elevated temperatures expected in a nuclear waste repository, and subsequent precipitation of silica on cooling may have an effect on local porosity and permeability. Changes in porosity and permeability will effect flow pathways, imbibition characteristics, and heat transfer, all of which may significantly influence repsotiory performance. In order to evaluate the effect of these processes, it is important that the behavior of amorphous silica precipitation be understood and predictable over relevant conditions. To obtain these needed data, a study was conducted to measure rates of precipitation in natural and laboratory settings. This work was to form the first stage in an effort to place bounds on kinetics effects, over a range of humidities, by resolving differences between rates measured in the laboratory and in the field.

Dissolution kinetics of amorphous silica and quartz are fairly well understood at conditions far from equilibrium as a function of solution composition and temperature (Brady and Walther, 1989; Carroll et al. 1994; Dove and Crerar, 1990; Dove and Elston, 1992; El-Shamy et al., 1972; House, 1994; Knauss and Wolery; 1988; Knauss et al., 1990; Tester et al., 1994). However, silica polymorph precipitation data are limited. Rimstidt and Barnes (1980), Bird et al., (1986) and Renders et al. (1995) model quartz, cristobalite, and amorphous silica precipitation rates assuming that the mechanisms controlling dissolution and precipitation are microscopically reversible and are related to the equilibrium constants by the principal of detailed balancing (Lasaga, 1981). Although these studies cover temperatures ranging from 18 to $300^{\circ} \mathrm{C}$ at conditions near saturation, they have only been performed at near neutral pH. Bohlmann et al. (1980), Fleming (1986), Hosaka and Taki (1981a,b), Laudise (1958), Weres et al., (1981), and Yokoyama et al. $(1989,1991)$ have investigated the effect of activities of $\mathrm{OH}^{-}, \mathrm{Na}^{+}$and $\mathrm{Al}^{3+}$ on silica precipitation.

It is necessary to study silica precipitation from complex field environments as well as from well controlled laboratory experiments because some aspects of natural systems may not be adequately accounted for in laboratory studies. Laboratory rate equations would therefore be rendered useless for prediction of amorphous silica precipitation in the earth's crust. Aspects of natural systems which may be important to silica precipitation include unknown effects of dissolved major and trace elements in natural waters.

Mroczek (1994) summarized previous field silica precipitation rates from geothermal waters, and compared them with rates calculated from theoretical and empirical models based on well controlled laboratory experiments (Bohlmann et al., 1980; Rimstidt and Barnes, 1980; Weres et al., 1981). These data were selected from a larger set of field data based on the anticipated conditions at a potential radioactive waste repository at Yucca Mountain, spanning temperatures less than $150^{\circ} \mathrm{C}$ and moderate to low degrees of silica supersaturation. At these conditions, heterogeneous reactions at the solidsolution interface are expected to be the dominant precipitation mechanism. Field silica precipitation rates were determined from the buildup of silica scale over time, where reactive surface area is the most uncertain parameter. Despite this, the rates calculated from empirical equations of Weres et al. (1981) and Bohlmann et al. (1980) were within an order of magnitude of the field rates. In contrast, the rates calculated from the Rimstidt and Barnes (1980) model are slower by approximately three orders of magnitude than the observed field rates. Their laboratory experiments were conducted under much smaller degrees of silica supersaturation than the field experiments and in pure water. The rates measured by Rimstidt and Barnes (1980) are very similar in magnitude to those measured by (Bird et al., 1986) in a similar experimental study. 
In this work, we discuss the impact of temperature $\left(60\right.$ to $120^{\circ} \mathrm{C}$ ) and solution composition ( $\mathrm{pH} 3-10$, and aqueous silica, alkali, and aluminum concentrations) on amorphous silica precipitation by comparing field rates determined from Wairakei, New Zealand, geothermal waters and laboratory rates using simple buffer solutions and Wairakei geothermal waters. For details of the study, see Carroll et al. (1996).

\subsubsection{Experimental Methods}

10.4.2.2.1 Starting Materials. A fine grained, well rounded 99\% pure quartz sand from Glorit, New Zealand was used in the field experiments. $X$-ray diffraction analysis showed no indication of other crystalline material. The initial and final surface area were calculated to be 0.8 and $0.4 \mathrm{~m}^{2} \mathrm{~g}^{-1}$ from BET Kr gas adsorption isotherms, respectively. These BET determinations of surface area are approximately 1.7 orders of magnitude higher than the geometric determination of surface area $(1.13 \times$ $10^{-2} \mathrm{~m}^{2} \mathrm{~g}^{-1}$ ) assuming spherical non-porous particles with a density of $2.65 \mathrm{~g} \mathrm{~cm}^{-3}$ (Gregg and Sing, 1982). This discrepancy is consistent with other reported differences between BET and geometric surface area determinations of quartz sand (White and Peterson, 1990) and is probably due to significant surface roughness and the non-spherical nature of the sand.

Amorphous silica used in the laboratory experiments was Mallickrodt Silicar Silica Gel, which was repeatedly cleaned ultrasonically with Milli-Q filtered water to remove fines, dried at $40^{\circ} \mathrm{C}$ for 24 hours, and then stored in a plastic container at room temperature. Initial total surface area determined from BET $\mathrm{N}_{2}$ gas adsorption isotherm is $270 \mathrm{~m}^{2} \mathrm{~g}^{-1}$; final total surface areas range from 50 to $280 \mathrm{~m}^{2} \mathrm{~g}^{-1}$.

Simple solutions used to control solution $\mathrm{pH}$ in the laboratory experiments are $\mathrm{HCl} / \mathrm{KHphthalate}$ buffer at $\mathrm{pH} 3, \mathrm{Na}$-acetate buffer at $\mathrm{pH} 5, \mathrm{NaOH} / \mathrm{Na}$-borate buffer at $\mathrm{pH} 8$ and 9 . With the exception of one experiment, the total alkali concentration of all the experiments is $0.13 \mathrm{M}$. The composition of the Wairakei geothermal waters used in the laboratory and field experiments is listed in Table 10.4-1.

10.4.2.2.2 Geochemical Calculations. Solution speciation, $\mathrm{pH}$, and extent of saturation with respect to silica phases at the experimental temperatures were calculated from the measured solution compositions at room temperature using React (Bethke, 1994) and EQ3/EQ6 (Wolery, 1992) geochemical codes and the SUPCRT92 thermodynamic data base (Johnson et al., 1992), augmented with o-phthalic acid stability constants at $25^{\circ} \mathrm{C}$ (Martell and Smith, 1989). Differences in program algorithms result in very small differences in calculated Gibb's free energy of reaction (200 $\left.\mathrm{Jmol}^{-1}\right)$ with respect to amorphous silica solubility between 60 and $120^{\circ} \mathrm{C}$.

10.4.2.2.3 Laboratory Experiments. The precipitation experiments were run in Dickson-type, gold bag autoclaves $(250 \mathrm{ml})$ capped with a commercially pure titanium head fitted with titanium or gold capillary-lined stainless steel sampling tube that allowed the experiment to be sampled in situ (Seyfried et al., 1987). A copper coil around the sampling tube allowed fluids to be quenched prior to sampling.

At the beginning of each experiment, the gold bag was filled with the reactants (approximately 5 grams of amorphous silica, and buffer solution or Wairakei geothermal waters), sealed with the titanium head, pressure tested with an inert gas, and placed in a pressure vessel filled with de-ionized water, which served as the pressure medium. Throughout the experiment, the furnace temperature was controlled by digital proportioning controllers, and the internal vessel temperature was monitored with chromel-alumel thermocouples and digital thermometers accurate to $\pm 1^{\circ} \mathrm{C}$.

Reaction was allowed to proceed at temperature until amorphous silica saturation was achieved, and then the temperature was lowered to yield a solution supersaturated with respect to amorphous silica by a factor of approximately 1.3. One experiment contained geothermal waters alone to determine whether silica precipitation occurs via homogeneous nucleation in the bulk solution. During sampling, a nominal pressure ( $35-70$ bar) was maintained by externally pumping water into the pressure vessel as the sample was taken. The sampling port was maintained in an up-right position, keeping the amorphous silica at the bottom of the gold bag, which allowed only the aqueous phase to be sampled. At the completion of the experiment, the amorphous silica was removed, rinsed in MilliQ filtered water five times, and dried. 
10.4.2.2.4 Field Experiments. Silica precipitation was measured in the field with a fluidized bed reactor, FBR, constructed at the Wairakei geothermal energy plant in New Zealand (Fig. 10.4-1). Geothermal waters were passed through steam grade iron pipe, at approximately $130^{\circ} \mathrm{C}$ and 2 bars, to a heat exchanger. A 100 mesh stainless steel filter upstream of the heat exchanger removed fines from the fluid. Temperature and flow of the fluid through the FBR were controlled by valves on the bypass line and prior to the FBR inlet, respectively. Flow rate was measured at the effluent stream. Inlet and outlet sampling points were located at the bypass line and at the top of the reactor column. The FBR unit was insulated with $50 \mathrm{~mm}$ thick fiberglass covered with aluminum foil to minimize conductive heat loss.

The reactor was loaded with 4.5 to $6 \mathrm{~kg}$ of sand, desired temperature and flow regime were adjusted, and the FBR was then left for at least 48 hours to coat sand particles with amorphous silica. After each adjustment of temperature or flow rate, at least 2 to 4 hours elapsed prior to sampling, which was more than ample time to reach steady-state conditions for the 3 to 5 minute fluid residence times within the FBR. Inlet and outlet samples were collected, preserved with $\mathrm{HCl}$ to avoid polymerization, and analyzed for monomeric silica within 30 minutes. Filtered samples $(0.2$ um pore size) were analyzed for total silica at a later time.

On shutdown, the bed was dismantled, the sand was washed, dried and weighed. The inside of the reactor wall was evenly coated with a very thin, hard, translucent layer of silica almost to the top. Precipitation was also observed in the mesh filters at the base of the reactor and was much softer than along the FBR walls.

\subsubsection{Analytical Techniques}

10.4.2.3.1 Solution Analysis. All aqueous samples were analyzed by inductively coupled plasmaatomic emission spectrometry (ICP-AES) or atomic absorption spectrometry (AA) for total dissolved silica. In addition, ICP-AES was used to analyze for $\mathrm{Al}, \mathrm{B}, \mathrm{Ca}, \mathrm{Fe}, \mathrm{K}, \mathrm{Li}, \mathrm{Mg}, \mathrm{Na}, \mathrm{Rb}$, and $\mathrm{S}$ concentrations, inductively coupled plasma-mass spectrometry (ICP-MS) was used to analyze for total As, $\mathrm{Cs}$, and $\mathrm{Rb}$ and ion chromatography (IC) was used to analyze for $\mathrm{Cl}^{-}, \mathrm{F}^{-}$, and $\mathrm{SO}_{4}{ }^{2-}$ concentrations in the initial geothermal waters. Samples were pretreated to remove $\mathrm{Cl}^{-}$to quantitatively analyze $\mathrm{F}^{-}$ and $\mathrm{SO}_{4}{ }^{2-}$ by IC. Reproducibility of each of these analytical techniques is better than $2 \%$ and analyte concentrations are at least one order of magnitude greater than the detection limits of the analytical technique. The relative standard deviation for the analyses was typically less than $3 \%$. Monomeric silica was measured using a UV photospectrometer and the yellow- $\beta$ silicomolybdate method (ller, 1979). This method has a detection limit of approximately $1 \mathrm{ppm}$ and an error typically less than $6 \%$.

10.4.2.3.2 Solid Phase Analysis. Starting materials and run products were analyzed by powder xray diffraction (XRD), scanning electron microscopy (SEM), energy dispersive spectroscopy (EDS), and BET gas adsorption, to check for changes in crystalinity, morphology, chemical composition, and surface area, respectively. Krypton and nitrogen were the gas adsorbents used to determine the surface area of the solids in the field and laboratory experiments, respectively.

10.4.2.4 A General Rate Equation. For amorphous silica precipitation, the reaction of interest is:

$$
\begin{gathered}
\Leftarrow \leftarrow \text { precipitation } \\
\mathrm{SiO}_{2}(\mathrm{Am} . \text { Si. })+2 \mathrm{H}_{2} \mathrm{O} \Leftrightarrow \mathrm{H}_{4} \mathrm{SiO}_{4} . \\
\text { dissolution } \Rightarrow \Rightarrow
\end{gathered}
$$

where the Gibb's free energy of reaction, $\Delta G_{r}$ :

$$
\Delta G_{r}=R T \ln Q / K_{e q}
$$

and solution saturation is equal to the ratio of the aqueous ion activity quotient and amorphous silica solubility constant, $Q / k_{e q}$, assuming ideal unit activity of the solid phase. 
A generalized equation which relates net precipitation rate, Rateppt to reaction affinity may be written as:

$$
\text { Rateppt }=-d[S i] / d t=-k_{p p t}{ }^{*}\left[1-n \exp \left(\Delta G_{r} / R T\right)\right]^{m}
$$

where $k_{p p t}$ is a rate constant that may be dependent on temperature, pressure, total reactive surface area, surface defect density, and on any unidentified effect of the solution composition (such as the activities of $\mathrm{OH}^{-}, \mathrm{Na}^{+}$, or $\mathrm{Al}^{3+}$ ), and $n$ and $m$ are empirical constants. The form of the Gibb's free energy function, $f\left(\Delta G_{r}\right)$, in equation (3):

$$
f\left(\Delta G_{r}\right)=\left[1-n \exp \left(\Delta G_{r} / R T\right)\right]
$$

and the overall order of reaction affinity, $m$, provide insight to the rate controlling mechanism, which may include elementary reactions at the solid-solution interface or growth at the surface defect sites.

Although mineral kinetics are likely to be controlled by complex reactions at the solid-solution interface, transition state theory (Lasaga, 1981; Aagaard and Helgeson, 1982) and surface complexation theory (Stumm and Wieland, 1990) have played critical roles in the development and application of generalized rate expressions for dissolution and precipitation reactions. Irreversible thermodynamics may be applied to complex solid-solution reactions, if a single elementary reaction or several elementary reactions at steady-state control the precipitation reaction (Nagy et al., 1991; Nagy and Lasaga, 1992). For both of these cases Rateppt is linearly dependent on $f\left(\Delta G_{r}\right)$. If precipitation involves a series of elementary reactions, where the rate is controlled by the slowest elementary reaction, then equation (3) simplifies to:

$$
\text { Rateppt }^{=}-k_{p p t} *\left[1-\exp \left(\Delta G_{r} / R T\right)\right]
$$

where $n$ and $m$ equal 1 . If the reaction rate is controlled by more than one elementary reaction at steady-state, then the equation (3) may be expressed by:

$$
\text { Rate }_{p p t}=-k_{p p t} t^{*}\left[1-n \exp \left(\Delta G_{r} / R T\right)\right]
$$

where $n$ is a constant not equal to 1 and $m$ equals 1 .

Mineral precipitation rates controlled by surface defects, such as dislocations and impurities, have a non-linear dependence on $f\left(\Delta G_{r}\right)$ :

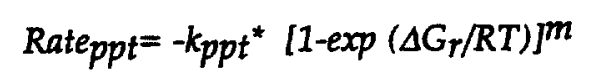

where $n$ equals 1 and $m$ does not equal 1. For example, the BCF model (Burton et al., 1951, Ohara and Reid, 1973) describes continuous spiral growth along energetically favorable sites, and has a second order dependence on $f\left(\Delta G_{r}\right)$. Heterogeneous nucleation is not required with this model, allowing precipitation to occur from slightly supersaturated solutions $\left(Q / K_{e q}=1.05\right)$. Nielson $(1986)$ has successfully predicted experimental precipitation rates for a variety of chloride, sulfate, carbonate, and oxalate salts using the BCF model. Several amorphous silica precipitation experiments mathematically describe the rates with a second order dependence on $f\left(\Delta G_{r}\right.$ ) (Bohlmann et al., 1980; Weres et al., 1981).

\subsubsection{Results and Discussion}

10.4.2.5.1 Laboratory Experiments. For our calculations, we assume that the reactive surface area available for precipitation is proportional to the BET surface area of amorphous silica at the end of each experiment. The final BET surface areas deviate from the initial value of $270 \mathrm{~m}^{2} \mathrm{~g}^{-1}$ and range from 50 to $280 \mathrm{~m}^{2} \mathrm{~g}^{-1}$ (Table 10.4-2). We assume that most of the surface area reduction occurs during reaction at elevated temperature prior to the decrease to precipitation run temperature. This is 
reasonable, because the solutions have reached amorphous silica saturation at elevated temperature, and because there is a systematic decrease in BET surface area with increasing $\mathrm{pH}$. This trend is in agreement with decreasing surface area of silica gels synthesized at increasing $\mathrm{pH}$ (ller, 1979). No observable changes in surface morphology are observed in SEM images of initial and final solids to account for a two to five factor change in surface area. Therefore, the reduction in surface area must be due to a reduction in internal porosity. No crystalline phases were detected in the solid phases with XRD.

To calculate amorphous silica precipitation rates from the laboratory experiments, curves are fit to the exponential decrease in aqueous silica concentrations normalized with respect to surface area as a function of time. Only data from the first 10 days of precipitation are used in the exponential curve fit to minimize potential artifacts of increasing relative surface area as aqueous samples are extracted from the reaction vessel over time.

Amorphous silica precipitation rates (Fig. 10.4-2) are best modeled with the following form of the general rate equation (3):

$$
\text { Rate } p t=-d[S i] m^{-2} / d t=-k_{p p t}(p H, T)^{*}\left(1-\exp \Delta G_{r} / R T\right)
$$

where $n=m=1$ and $k_{p p t}\left([S i] m^{-2} d^{-1}\right)$ is dependent on $\mathrm{pH}$ and temperature. For each experiment, there is a linear relationship between Rateppt and $f\left(\Delta \mathrm{G}_{\mathrm{r}}\right)$ with a slope proportional to $k_{p p t}$. At all $\mathrm{pH}$, precipitation rates approach zero in solutions slightly undersaturated with respect to amorphous silica, corresponding to $\Delta G_{r}$ between 0 to $-670 \mathrm{Jmo}^{-1}$.

The $\mathrm{pH}$-dependence of amorphous silica precipitation is shown in Fig. 10.4-3 as $\log k_{p p t}$ versus $\mathrm{pH}$. At $100^{\circ} \mathrm{C}, k_{p p t}$ is proportional to $\left\{\mathrm{H}^{+}\right\}-0.2$ from $\mathrm{pH} 3$ to 8.7 . At $80^{\circ} \mathrm{C}, k_{p p t}$ is proportional to $\left\{\mathrm{H}^{+}\right\}-0.3$ from $\mathrm{pH} 3$ to 7 ; no experiments were conducted at greater $\mathrm{pH}$. At $120^{\circ} \mathrm{C}$, there is not enough data to establish a pH-dependence of $k_{\text {ppt }}$. These results are in agreement with lower temperature results; amorphous silica precipitation rates increase from $\mathrm{pH} 4$ to 8 at $25^{\circ} \mathrm{C}$ (Fleming 1986). Additionally, these results qualitatively agree with aqueous silica polymerization, which occurs within a couple hours at acid $\mathrm{pH}$ and within a couple of minutes at $\mathrm{pH}>7$ (ller, 1979).

Dissolved components other than silica and $\mathrm{pH}$ do not significantly impact amorphous silica precipitation rates (Fig. 10.4-3). At 80 and $100^{\circ} \mathrm{C}, k_{p p t}$ determined from experiments containing chemically complex Wairakei geothermal waters are consistent with the $\mathrm{pH}$-dependence of the rate constant observed from batch experiments containing simple buffer solutions. At $120^{\circ} \mathrm{C}$ and approximately $\mathrm{pH} 7, k_{\text {ppt }}$ determined from the experiments containing geothermal waters is about 0.5 orders of magnitude higher than $k_{p p t}$ determined from the experiment containing $\mathrm{NaCl}$ solution.

Temperature dependence of amorphous silica precipitation rates is evaluated in an Arrhenius plot of $\log k_{p p t}$ versus $1 / \mathrm{T}(\mathrm{K})$ (Fig. 10.4-4), where activation energy, $E_{a}$, is equal to:

$$
E_{a}=-2.303 R(d \log k(p p t) / d(1 / T))
$$

Activation energies range from 51.6 to $82.6\left(\mathrm{~kJ} \mathrm{~mol}^{-1}\right)$ at $\mathrm{pH} 7$ and 3, respectively. These values are consistent for rates controlled by reactions at the solid-solution interface, and in the same range as activation energies ( 30 to $150 \mathrm{~kJ} \mathrm{~mol}^{-1}$ ) determined for a variety of silica polymorphs over a temperature range of 20 to $500^{\circ} \mathrm{C}$ (Table 10.4-3).

Amorphous silica precipitation is controlled by reactions at the solid-solution interface, and not by homogeneous nucleation. This conclusion is supported by the lack of silica precipitation in the absence of amorphous silica seed material (Fig. 10.4-5A). Wairakei geothermal waters are slightly supersaturated with respect to amorphous silica at $120^{\circ} \mathrm{C}$. In the presence of amorphous silica, aqueous silica decreases to amorphous silica saturation value at $100^{\circ} \mathrm{C}$ within 24 hours after the drop in temperature. In the absence of amorphous silica, there is no measurable decrease in silica concentrations up to 3 days after the temperature is decreased from 120 to $100^{\circ} \mathrm{C}$. Additionally, for experiments in which both total and monomeric silica were measured, all silica is present as monomeric 
silica with the exception of one experiment at $\mathrm{pH} 8.7$ and $100^{\circ} \mathrm{C}$ (Fig. 10.4-5B). At $\mathrm{pH}>7$ polymerization kinetics are rapid (ller 1979), therefore it is possible that monomeric silica polymerized in the 30 minute period between sample extraction at $100^{\circ} \mathrm{C}$ and sample analysis at room temperature for this experiment.

The results of this study do not support the principle of detailed balancing as applied to silica dissolution and precipitation kinetics. According to the principle of detailed balancing, precipitation, $k_{p p t}$, and dissolution rate constants, $k_{\text {diss, }}$, are related to each other through the equilibrium constant, thus requiring $k_{p p t}$ and $k_{\text {diss }}$ to have the same dependence on solution composition (i.e. $f\left(\Delta G_{r}\right)$ and $\mathrm{pH}$ ). Amorphous silica precipitation (this study) and dissolution (Rimstidt and Barnes, 1980) rates have the same form of $f\left(\Delta G_{r}\right)$ :

$$
f\left(\Delta G_{r}\right)=\left(1-\exp \Delta G_{r} / R T\right),
$$

but the pH-dependencies of $k_{p p t}$ and $k_{\text {diss }}$ are distinct. Amorphous silica precipitation increases with increasing $\mathrm{pH}$ from $\mathrm{pH} 3$ to 8.7. In contrast, quartz and amorphous silica dissolution rates at conditions far from equilibrium are independent of solution $\mathrm{pH}$ in the acid to near neutral region, and increase with increasing $\mathrm{pH}$ at more alkaline $\mathrm{pH}$ (Brady and Walther, 1989; Carroll et al., 1994, Knauss and Wolery, 1988). Silica precipitation rate equations based on the experimental data of Rimstidt and Barnes (1980) and Renders et al. (1996) should not be extrapolated to acid and alkaline pH solutions. All of their experiments were conducted in deionized water.

Other studies find that the principle of detailed balancing does not adequately model mineral dissolution and precipitation reactions over a wide range of solution compositions. Nagy and Lasaga (1992) observe that the principle of detailed balancing describes gibbsite dissolution and precipitation kinetics at $80^{\circ} \mathrm{C}$ and $\mathrm{pH} 3$ in solutions close to equilibrium, $-0.8<\Delta \mathrm{G}_{r}<0.8(\mathrm{~kJ} / \mathrm{mol})$, but not at greater degrees of understaturation. For more complicated mineral phases, it is not clear that this model applies even very close to equilibrium (Burch et al, 1993; Nagy and Lasaga, 1993).

10.4.2.5.2 Field Experiments. The steady-state precipitation rate, Rateppt ([Si] $m^{-2} d-1$ ) from FBR experiments may be calculated from the following equation:

$$
\text { Rate }_{p p t}=\frac{v \times \Delta[S i]}{S A}
$$

where $v\left(\mathrm{~L} \mathrm{~d}^{-1}\right)$ is the flux of fluids flowing through the reactor, $\Delta[\mathrm{Si}](\mathrm{mol} / \mathrm{L})$ is change between inlet and outlet $\mathrm{Si}$ concentrations, and $S A\left(\mathrm{~m}^{2}\right)$ is the total surface area of the particles in the FBR. Equation (10) applies if the FBR behaves as a continuously stirred reactor, such that fluid velocity approximates the settling velocity of the particles, resulting in a dynamic suspension (Posey-Dowty et al., 1986). The use of equation (10) to calculate amorphous silica precipitation rates is supported by the linear decrease in $\Delta[\mathrm{Si}]$ as a function of increasing fluid flow rate over limited temperature intervals \pm $2^{\circ}$ ) and constant surface area (Fig. 10.4-6).

Amorphous silica precipitation was measured from Wairakei geothermal solutions supersaturated with respect to amorphous silica by as much as a factor of two ranging in temperature from 60 to $117^{\circ} \mathrm{C}$. The results are summarized in Table 10.4-4 and Fig. 10.4-7. Overall, precipitation rates increase with decreasing temperature and increasing supersaturation; $\left(1-\exp \left(\Delta \mathrm{G}_{\mathrm{r}} / \mathrm{RT}\right)\right)$ becomes more negative with increasing supersaturation. The effects of supersaturation and temperature are interrelated, because an approximately constant inlet silica concentration from the geothermal waters yields an increase in supersaturation with decreasing temperature. The error in the precipitation rate shown in Fig. 10.4-7 is due to the uncertainty in the silica analysis. The difference in the silica concentration between the inlet and outlet solutions was only a small fraction of the total, between 1 and 8 mol.\%, which translates to a 3 to $23 \%$ error in the calculated rates. Another source of error in the calculated precipitation rates is the BET surface area measurements; surface areas for the reacted and unreacted sand are 0.4 and $0.8 \mathrm{~m}^{2} \mathrm{~g}^{-1}$, respectively. A limitation of the FBR is that surface area cannot be evaluated at each run temperature. 
However, measured rates are reproducible over the duration of the experiments, indicating no major changes in the solid surface area. We have chosen to normalize the field precipitation rates to initial BET surface area.

In these experiments, we assume that amorphous silica rapidly coats the quartz grains, and therefore steady-state values of $\Delta[\mathrm{Si}]$ are controlled by heterogenous precipitation at the amorphous silica-solution interface. This reasoning is consistent with the results of Axtmann and Grant-Taylor (1986) and Bohlmann et al. (1980), who have shown that rutile and quartz grains are quickly coated with amorphous silica. Homogeneous nucleation of amorphous silica from the bulk solution is minimized by the short residence time of the solutions in the FBR ( $3-5 \mathrm{~min}$.). Induction times observed before the onset of polymerization are typically 0.5 and 2 hours at 70 and $100^{\circ} \mathrm{C}$, respectively (Rothbaum and Rhode, 1979). With the exception of two sample sets at 69 and $61^{\circ} \mathrm{C}$, inlet and outlet polymeric silica concentrations calculated from the difference between total silica and monomeric measurements are constant and typically within analytical error, between 2 and $4 \%$ of the total silica (Fig. 10.4-8).

Evidence of silica precipitation is seen in SEM images comparing morphology of the unreacted and reacted sand. The reacted sand is covered with hemispherical silica precipitates with 1 to $2 \mathrm{wt} . \%$ aluminum. No aluminum was detected in the unreacted sand. The presence of significant surface roughness in both the reacted and unreacted sand supports the use of BET determined surface areas in the precipitation rate calculations.

It is not possible to unequivocally determine the exact nature of the surface reaction mechanism controlling amorphous silica precipitation. If Rateppt is modeled within the framework of transition state theory, where $n=m=1$, there is an almost linear trend between Rateppt and $\left(1-\exp \left(\Delta \mathrm{G}_{\mathrm{r}} / \mathrm{RT}\right)\right.$ with $k_{p p t}=-1.99 e-4$ ([Si] $m^{-2} d^{-1}$ ) (Fig. 10.4-7). Although this expression mathematically describes the relationship between measured rate and solution silica concentrations, it is doubtful that the form of $f\left(\Delta G_{r}\right)$ is indicative of a rate-limiting elementary reaction, because $k_{p p t}$, and consequently Rateppt, would be independent of temperature. Recall that temperature and the extent of solution saturation mask one another in the field study. Surface controlled reactions are strongly temperature dependent (White and Brantley, 1995 and references therein). Table 10.4-3 lists a range of activation energies reported for a variety of silica polymorphs. Only Bohlmann et al. (1980) observed zero temperature dependence for amorphous silica precipitation rates.

10.4.2.5.3 Comparison Of Laboratory and Field Precipitation Rates. Figure 10.4-9 is a comparison of laboratory and field rates using field chemistry and the laboratory rate equation describing the amorphous silica precipitation as a function of temperature from those experiments containing Wairakei geothermal waters:

$$
\text { Rate } p t_{p t}=-10^{\left(1.77-(E a / 2.303 R)^{*}(1 / T)\right)}\left(1-\exp \left(\Delta G_{r} / R T\right)\right.
$$

At field conditions most similar to the laboratory experiments, $f\left(\Delta G_{r}\right)>-0.4$ and temperatures between 90 and $115^{\circ} \mathrm{C}$, rates are 10 to 20 times faster than laboratory rates. At lower temperature and more supersaturated solutions, the field rates may be as much as $\mathbf{2 5 0}$ times greater than predicted with the laboratory rate equation.

Rate equations derived from static laboratory experiments cannot be used to model amorphous silica precipitation in complex natural environments, because amorphous silica precipitation appears to be controlled by different mechanisms in laboratory and field studies. The first order dependence of the laboratory rates on reaction affinity indicates amorphous silica precipitation kinetics are controlled by a rate-limiting elementary reaction at the solid-solution interface. By comparison, the second order dependence of the field rates on reaction affinity and the hemispherical surface morphology of the reacted sand in the field study indicates that reactions at surface defects control amorphous silica precipitation rates.

Other factors that may contribute to the observed discrepancy between the field and laboratory experiments are effective surface area, precipitation of quartz, and effect of dissolved aluminum. It is 
doubtful that the reactive surface area in the field experiments increases by two orders of magnitude at lower temperature in the more supersaturated solutions. The final surface area of the reacted sand, which reflects precipitation from a highly supersaturated solution at ambient temperatures as the FBR was dismantled, is only a factor of two higher than initial surface area.

Another possibility is that quartz, and not amorphous silica, precipitates at the sand-solution interface. If this is the case, then the calculated field precipitation rate would increase by approximately one order of magnitude, because the solution would be more saturated with respect to quartz. It is not likely that quartz precipitates, given the high aluminum content of reacted sand surfaces. Additionally, quartz precipitation does not explain the increasing precipitation rates at lower temperature in more supersaturated experiments.

A third possible explanation is the impact of dissolved aluminum on amorphous silica precipitation. The aluminum concentration in the reacted sand surfaces (1-2 wt.\%) is enriched by four orders of magnitude over the low concentrations in the geothermal waters (>1 ppm). The fact that no significant effects of the geothermal waters on amorphous silica precipitation occur in the laboratory experiments may be an artifact of the two different types of experiments. The total dissolved aluminum available for precipitation in the laboratory experiments is limited by the volume of the reaction vessel. In the field experiments, the FBR design allows for continual preferential removal of the aluminum and silica as high volumes of fluid flow through the reactor.

10.4.2.6 Conclusions. The results of this study confirm the need for complementary laboratory and field studies to determine the factors that control mineral-water interactions in tuff. Amorphous silica precipitation rates appear to be controlled by distinct mechanisms in the laboratory and field studies. Amorphous silica precipitation rates determined from the field study at Wairakei, New Zealand, are 10 to 300 times higher than rates predicted from the laboratory experiments. The deviation between the rates increases as temperatures decrease and the solution composition increases.

Amorphous silica precipitation rates determined from the batch experiments are controlled by reactions at the solid-solution interface and are dependent on temperature, solution $\mathrm{pH}$, and aqueous silica concentration. The presence of trace elements in the Wairakei geothermal waters does not significantly enhance or inhibit amorphous silica precipitation in these experiments. The precipitation rate constant has a fractional dependence on solution $\mathrm{pH} ; k_{p p t}$ is proportional to $\left\{\mathrm{H}^{+}\right\}-0.3$ and $\left\{\mathrm{H}^{+}\right\}-0.2$ at 80 and $100^{\circ} \mathrm{C}$, respectively. $E_{a}$ measured at $\mathrm{pH} 7$ is $51.6 \mathrm{~kJ} \mathrm{~mol}^{-1}$. The first order dependence of precipitation rate on reaction affinity $\left(1-\exp \Delta G_{r} / R T\right)$ is consistent with an elementary rate-limiting surface reaction. However, the $\mathrm{pH}$-dependencies of amorphous silica precipitation and dissolution rates show that the principle of detailed balancing cannot be applied to amorphous silica kinetics.

Amorphous silica precipitation behavior in the field experiments is distinct from the laboratory experiments. Amorphous silica precipitation may be controlled by surface defects, such as dislocation or impurities, but it does not appear to be controlled by elementary rate-limiting reactions at the solidsolution interface. Aluminum is enriched in the precipitating phase by four orders of magnitude. However, the enrichment mechanism or the impact of dissolved aluminum on amorphous silica precipitation rates is not known.

\subsubsection{References}

Aagaard, P., and H. C. Helgeson(1982) Thermodynamic and kinetic constraints on reaction rates among minerals and aqueous solutions. I. Theoretical consideration. Amer. J. Sci. 282, 237-285.

Axtmann , R. C., and D. Grant -Taylor (1986) Desilication of geothermal waste waters in fluidized beds. Geothermics 15, 185-191.

Bethke, C. M. (1994) The Geochemist's Workbench. A Users Guide to Rxn, Act2, Tact, React, and Gtplot. Board of Trustees of the University of minois.

Bird, G., J. Boon, and T. Stone (1986) Silica transport during steam injection into oil sands. 1. Dissolution and precipitation kinetics of quartz: new results and review of existing data. Chem. Geol. 54, 69-80. 
Bohlmann, E. G., R. E. Mesmex, and P. Berlinski (1980) Kinetics of silica deposition from simulated geothermal brines. Soc. Petroleum Engineers J., 239-248.

Brady P. V. and Walther J. V. (1989) Controls on silicate dissolution rates in neutral and basic pH solutions at $25^{\circ} \mathrm{C}$. Geochim. Cosmochim. Acta 53, 2823-2830.

Burch, T. E., K. L. Nagy, and A. C. Lasaga (1993) Free energy dependence of albite dissolution kinetics at $80^{\circ} \mathrm{C}$ and $\mathrm{pH} 8.8$. Chemical Geology 105, 137-172.

Burton, W. K., N. Cabrera, and F. C. Frank (1951) The growth of crystals and the equilibrium structure of their surfaces. Phil. Trans. Roy. Soc. London A243, 299-358.

Carroll, S. A., W. L. Bourcier, and B. L. Phillips (1994) Surface chemistry and durability of borosilicate glass. Mat. Res. Soc. Sym. 333, 533-540.

Carroll, S. A., E. Mroczek, B. Bourcier, M. Alai, and M. Ebert (1995) Comparison of field and laboratory precipitation of amorphous from geothermal waters at $100^{\circ} \mathrm{C}$. Lawrence Livermore National Laboratory Yucca Mountain Site Characterization Project Milestone MOL207.

Dove, P. M., and D. A. Crerar (1990) Kinetics of quartz dissolution in electrolyte solutions using a hydrothermal mixed flow reactor. Geochim. Cosmiochim. Acta 54, 955-969.

Dove, P. M., and S. F. Elston (1992) Dissolution kinetics of quartz in sodium chloride solution: Analysis of existing data and a rate model for $25^{\circ} \mathrm{C}$. Geochim. Cosmochim. Acta 56, 4147-4156.

El-Shamy, T. M., J. Lewins, and R. W. Douglas (1972) The dependence on the $\mathrm{pH}$ of the decomposition of glasses by aqueous solutions. Glass Technology 13, 81-87.

Fleming, B. A. (1986) Kinetics of reaction between silicic acid and amorphous silica surfaces in $\mathrm{NaCl}$ solutions. J. Colloid Interface Sci. 110, 40-64.

Gregg, S. J., and K. S. W. Sing (1982) Adsorption, Surface Area and Porosity. Academic Press, London.

Hosaka, M., and S. Taki (1981a) Hydrothermal growth of quartz crystals in NaCl solution. J. Crystal Growth 52, 837-842.

Hosaka, M., and S. Taki (1981b) Hydrothermal growth of quartz crystals in $\mathrm{KCl}$ solution. J. Crystal Growth 53, 542-546.

House, W. A. (1994) The role of surface complexation in the dissolution kinetics of silica: Effects of monovalent and divalent ions at $25^{\circ} \mathrm{C}$. J. Colloid Interface Sci. 163, 379-390.

Iler, R. K. (1979) The Chemistry of Silica. Solubility, Polymerization, Colloid and Surface Properties, and Biochemistry. John Wiley and Sons, 866p.

Johnson, J. W., E. H. Oelkers, and H. C. Helgeson (1992) SUPCRT92: A software package for calculating the standard molal thermodynamic properties of minerals, gases, aqueous species and reactions from 1 to 5000 bar and 0 to $1000^{\circ} \mathrm{C}$. Computers and Geosciences 8, 899-947.

Knauss, K., and T. J. Wolery (1988) The dissolution kinetics of quartz as a function of $\mathrm{pH}$ and time at $70^{\circ} \mathrm{C}$. Geochim. Cosmochim. Acta 52, 43-53.

Lasaga, A. C. (1981) Transition State Theory. In Kinetics of Geochemical Processes (eds. A.C. Lasaga and R.J. Kirkpatrick); Reviews in Mineralogy 8, 135-169.

Laudise, R. A. (1959) Kinetics of hydrothermal quartz crystallization. J. Amer. Chem. Soc. 81, 562-566.

Martell, A. E. and R. M. Smith (1989) Critical Stability Constants: Other Organic Ligands. Plenum Press, New York. V. 3. 495p.

Mroczek, E. K. (1994). Review of silica deposition rates at Ohaaki, Rotokawa, and Wairakei geothermal fields and comparison of observed rates with predicted deposition rates calculated using three different kinetic deposition models. Report No. 722305.15. Institute of Geological and Nuclear Sciences.

Nagy, K. L., A. E. Blum, and A. C. Lasaga (1991) Dissolution and precipitation kinetics of kaolinite at $80^{\circ} \mathrm{C}$ and $\mathrm{pH}$ 3: The dependence on solution saturation state. Am. J. Sci. 291, 649-686.

Nagy, K. L., and A. C. Lasaga (1992) Dissolution and precipitation kinetics of gibbsite at $80^{\circ} \mathrm{C}$ and $\mathrm{pH}$ 3: The dependence on solution saturation state. Geochim. Cosmochim. Acta 56, 3093-3111.

Nagy, K. L., and A. C. Lasaga (1993) Simultaneous precipitation kinetics of kaolinite and gibbsite at $80^{\circ} \mathrm{C}$ and $\mathrm{pH}$ 3. Geochim. Cosmochim. Acta 57, 4329-4336.

Nielsen, A. E. (1986) Mechanisms and rate laws in electrolyte crystal growth from aqueous solution. In Geochemical Processes at Mineral Surfaces (ed. J. A. Davis and D. F. Hayes); ACS Symp. Ser. 323, 600-614. 
Ohara, M., and R. C. Reid (1973) Modeling Crystal Growth Rates from Solution. Prentice-Hall.

Posey-Dowty, J., D. Crerar, R. Hellmann, and C. D. Chang (1986) Kinetics of mineral-water reactions: theory, design and application of circulating hydrothermal equipment. American Mineralogist 71, 85-94.

Renders, P. J. N., C. H. Gammons, and H. L. Barnes (1995) Precipitation and dissolution rate constants for cristobalite from 150 to $300^{\circ} \mathrm{C}$. Geochim. Cosmochim. Acta 59, 77-85.

Rimstidt, J. D., and H. L. Barnes (1980) The kinetics of silica-water reactions. Geochim. Cosmochim. Acta 44, 1683-1699.

Rothbaum, H. P., and A. G. Rhode (1979) Kinetics of silica polymerization and deposition from dilute solutions between 5 and $180^{\circ} \mathrm{C}$. J. Colloid Interface Sci., 71, 533-559.

Seyfried, W. E., D. R. Janecky, and M. E. Berndt (1987) Rocking autoclaves for hydrothermal experiments. II. The flexible reaction-cell system. In Hydrothermal Experimental Techniques (eds. G. C. Ulmer and H. L. Barnes). 216-239.

Stumm, W., and E. Wieland (1990) Dissolution of oxide and silicate minerals: Rates depend on surface speciation. In Aquatic Chemical Kinetics (ed. W. Stumm), pp. 367-400. J. Wiley \& Sons.

Tester, J. W., W. G. Worely, B. A. Robinson, C. O. Grigsby, and J. L. Feerer (1994) Correlating quartz dissolution kinetics in pure water from 25 to $625^{\circ} \mathrm{C}$. Geochim. Cosmochim. Acta 58, 2407-2420.

Walther, J. V., and H. C. Helgeson (1977) Calculation of the thermodynamic properties of aqueous silica and the solubility of quartz and its polymorphs at high pressures and temperatures. Amer. J. Sci. 277, 1315-1351.

Weres, O., A. Yee, and L. Tsao (1981). Kinetics of silica polymerization. J. Colloid Interface Sci., 84, 379402.

White, A. F., and S. L. Brantley (1995) Chemical Weathering Rates of Silicate Minerals. (ed. A. F. White and S. L. Brantley). Reviews in Mineralogy 31, 583p.

White, A. F., and M. L. Peterson (1990) Role of reactive-surface-area characterization in geochemical kinetic models. In Chemical Modeling of Aqueous Systems II (ed. D. C. Melchior and R. L. Bassett, ACS Symp. Ser. 416, 461-475.

Wolery, T. J. (1992) EQ3NR, A computer program for geochemical aqueous speciation-solubility calculations: Theoretical manual, user's guide, and related documentation. Lawrence Livermore National Laboratory, UCRL-MA-110662 PTII.

Yokoyama, T., Y. Takahshi, C. Yamanaka, and T. Tarutani (1989). Effect of aluminum on the polymerization of silicic acid in aqueous solution and the deposition of silica. Geothermics, 18(1/2),321-325.

Yokoyama, T., Y. Takahshi, C. Yamanaka, and T. Tarutani (1991). Retarding and accelerating effects of aluminum on the growth of polysilicic acid particles. J. Colloid Interface Sci. 141(2), 559-569. 


\subsubsection{Thermal Effects in the Altered Zone: Preliminary Bounds on the Water Composition and Secondary Mineral Development in the Altered Zone That May Influence the Near-Field Environment, by Michael Whitbeck and William E. Glassley, Lawrence Livermore National Laboratory}

10.4.3.1 Introduction. The proposed repository site is within the unsaturated zone, where ambient saturation of matrix pore volumes is as high as $75 \%$. Heat-driven evaporation, boiling, and condensation processes will lead to movement of water vapor away from the repository, resulting in increased saturation of some rocks within some parts of the repository block (Nitao, 1988; Buscheck and Nitao, 1992, 1993). In some cases, the saturation may approach $100 \%$ under some operation scenarios after waste is emplaced. During cool down, or as a result of fracture flow or dehydration of hydrous minerals, it is possible that liquid water may return to or enter the near-field environment (NFE), or may affect rock units bounding the repository horizon. Most of the minerals currently present in the rock making up the potential repository horizon are not in thermodynamic equilibrium with water at elevated temperatures, nor is the glassy material preserved within the PTn or the TSw3 units. As a result, water will interact with existing minerals and glass, causing new minerals to form, existing minerals to change their compositions or dissolve, and modifying the water chemistry in the process. In order to bound these effects, an effort to model reaction processes was undertaken. The focus of this effort was on identifying the likely minerals that would form, the effect on water chemistry, and determine the rates at which these changes would occur. It was also the intent to determine the uncertainty in these calculations, considering the known uncertainty in the kinetics of dissolution and precipitation reactions.

10.4.3.2 Approach. Rock units considered in the simulations were the TSw2 and TSw3 units of the Topopah Spring tuff. The mineral abundances for the TSw2 unit were taken from Delany (1985). The dissolution rates of the mineral phases, and their respective surface areas, were also taken from Delany (1985). The glass composition was taken to be that of Sample 2A from Table II of Broxton et al (1989). The EQ3/6 code, version 7.2a, (Wolery, 1992 a,b; Wolery et al., 1990; Wolery and Daveler, 1992) was used for the simulations. The database used was COM, version 22a. All calculations were done using the "B-dot" activity coefficient model (see Wolery, 1992b for a description of this model).

The initial water composition reacting with the rock materials was assumed to be that of J-13 water. The composition used was the average composition reported in Harrar et al (1990).

Since the purpose of these simulations was to consider the effect of reaction progress on water chemistry and mineral assemblages, it was necessary to develop a conceptual model in which there was sufficient water available to allow reactions to procede until steady state was achieved. However, the extent to which reactions will progress in the near-field and altered zone systems may be limited by water availability. In such cases, the natural systems will only progress part way along the reaction paths suggested by the modleing described here.

It was also assumed that reaction would take place in a system open to the atmosphere. Hence, the coexisting gas phase had a constant $\mathrm{H}_{2} \mathrm{O}$ and $\mathrm{CO}_{2}$ partial pressure equivalent to that of present day atmosphere ( 0.2 and 0.003 bars, respectively). Reaction progress was constrained to be sufficiently large to allow steady state to be achieved for the tuffs. In the case of the water-glass simulations, the extent of reaction progress was determined by the amount of glass present and the dissolution rate.

Simulations were conducted for both rock types at $40,50,60,75$ and $90^{\circ} \mathrm{C}$. This temperature interval was selected because it covers the range between ambient conditions and boiling. Reaction of rock and water at higher temperatures will be conducted at a later time when the EQ3/ 6 code has been modified to simulate reactions off the liquid-vapor saturation curve of water. Detailed simulations involving flow pathways with restricted flux will also be conducted at a later time. Preliminary results are presented in Section 10.4.4.

Quartz, talc, and tridymite were suppressed from precipitation in all of the runs. This was done because these phases, although less soluble than other silica polymorphs or hydrous Mg-silicates, do 
not readily precipitate due to kinetic barriers. It may be, however, that after sufficient time has passed in natural systems, these phases would appear, as the kinetic barriers are overcome. In that case, inclusion of these phases would be appropriate at some point in the reaction progress. When sufficient information is available to reasonably simulate this process, the type of simulations reported here will be redone.

To evaluate the effect of uncertainty in the dissolution rate, two methods were used. One method evaluated the propagation of error in a generalized reaction sequence:

$$
A \Leftrightarrow B \Leftrightarrow C
$$

This simple system has an exact analytical solution yet is sufficiently general to represent many of the subsets of more complex geochemical systems that are not strongly coupled with other parts of the system. The results of this evaluation will not be treated in detail here, but are described in Whitbeck and Glassley (1995). The second method used is simulation of the reactions of water with the volcanic rocks, using different rate constants. This method allows representation of the specific effects on the simulations described in this study. To illustrate these effects, we consider dissolution of sanidine, which has a measured dissolution rate constant of $5 \times 10^{-15}$ moles $/ \mathrm{cm}^{2}-\mathrm{sec}$ (Holdren and Speyer, 1985). The effect of different rates of glass dissolution was examined by using a slow relative rate constant (8.66 E-14) and a very fast relative rate constant $(4.0 \mathrm{E}-4)$ in different suites of runs. This wide range of rates was selected because the effective surface area that the fluid will interact with is unknown. Overall reaction rate is a function of surface area, and can vary over many orders of magnitude depending, for example, whether water flows only along a preferred flow pathway in a fracture, or permeates a rock with small glass shards and a large effective surface area. In order to evaluate these effects, the runs with a slow reaction rate constant had a total mass of .1735 grams (.08029 moles) of glass per $\mathrm{kg}$ of water and the runs with the fast reaction rate constants had 17.29 grams ( 8.0 moles) of glass (where the glass molecular weight was arbitrarily chosen to be 2.21454 grams per mole).

10.4.3.3 Results. The water compositions and secondary mineralogies obtained at steady state conditions, at a given temperature, for the tuffs are constrained by the fixed composition of the starting material, and the solubilities of the starting phases. For the vitric material, however, dissolution is treated as though it is congruent, hence, the amount of material dissolved (or, in other words, the extent of reaction progress) will determine the mineralogical products and water chemistry. In this case, therefore, a steady state composition will not be achieved, except under extreme conditions in which very high absolute amounts of glass are dissolved. The simulations conducted here were not taken to steady state for the glasses, because this would require dissolution of unrealistically large volumes of glass. Described below are the mineralogical and chemical results obtained for the different rock types.

As noted by Bruton (1995 and Section 3.4.2, this volume) the accuracy of predictions of mineral occurences at any given time in a numerical simulation is limited by a variety of constraints, including inaccuracies in, or a complete absence of thermodynamic data or kinetic data for specific minerals. Hence, the mineral suites described below must be considered representative "facies" of the assemblage of minerals that may form, and not absolute descriptions of the specific identities of minerals that will be present. In particular, the occurrence of zeolites such as mesolite, clinoptilolite, and stilbite, or the occurrence of muscovite in simulations must be taken to indicate that a zeolite(s) and a sheet silicate are expected to form, but the specific composition of those phases will depend on local effects that cannot be accounted for a priori.

10.4.3.3.1 Secondary Mineralogy of the Tuffs (Fig. 10.4-10 (a-e). Throughout reaction progress saponite (a clay), carbonate, and fluorapatite are present at low abundances at all temperatures. These phases are joined by clays (celadonite and smectite), authigenic feldspar (microcline), and zeolites (clinoptilolite at low temperature, stilbite at 50 and $75^{\circ} \mathrm{C}$, with mesolite present throughout the temperature range), relatively early in the reaction progress period, and they persist to steady state conditions. The actual time of appearance of specific phases depends upon temperature. At $40^{\circ} \mathrm{C}$, important secondary alumino-silicate phases do not appear until after approximately 100 days of reaction progress. At temperatures greater than $50^{\circ} \mathrm{C}$, important alumino-silicates appear within a few 
days. However, in all cases, steady state conditions with relatively high abundances of secondary minerals are not approached until thousands of days have elapsed. In all cases, one of the last phases to appear is a silica polymorph (in this case, chalcedony), but it quickly becomes the most abundant secondary phase. At high temperatures $\left(90^{\circ} \mathrm{C}\right)$, garnet and tremolite appear in the secondary mineral assemblage. As discussed below, these phases probably would not be the stable phases that would form under these conditions, given evidence from metamorphic petrology in low temperature systems. Their presence in the simulations attests to the limitations of the thermodynamic data currently available, and emphasizes the importance of the facies concept to describe future mineral alteration, as described by Bruton in Section 3.4.2.

10.4.3.3.2 Water Chemistry of the Tuffs (Fig. 10.4-11 (a-g). The initial water composition reflects equilibration of J-13 water at the temperature of the simulation. At all temperatures, this initial composition is moderately alkaline ( $\mathrm{pH}$ of ca. 8.5), oxidizing (Eh between 580 and 680 millivolts), and has a low ionic strength (ca. 0.0028 molal). Concentrations of the dissolved elements are low. In decreasing order of abundance, they are:

- $\mathrm{Na}$ [ca. $40 \mathrm{mg} / \mathrm{kg}$ ]

- $\mathrm{Si}$ [ ca. $30 \mathrm{mg} / \mathrm{kg}$ ]

- $\mathrm{Cl}[\mathrm{ca} .10 \mathrm{mg} / \mathrm{kg}]$

- $S[c a .6 .0 \mathrm{mg} / \mathrm{kg}]$

- Ca [ca. $5 \mathrm{mg} / \mathrm{kg}]$

- $F[c a .2 .0 \mathrm{mg} / \mathrm{kg}]$

- $\mathrm{Mg}[\mathrm{ca} .0 .1 \mathrm{mg} / \mathrm{kg}]$

- Li [ca. $0.05 \mathrm{mg} / \mathrm{kg}$ ]

- $\mathrm{Al}[<1.0 \mathrm{E}-4 \mathrm{mg} / \mathrm{kg}]$

- $\quad \mathrm{P}[2.0 \mathrm{E}-5 \mathrm{mg} / \mathrm{kg}]$ ).

Water composition remains relative constant, at a given temperature, until reaction progress reaches approximately 100 days, at which point the composition changes significantly due to formation of secondary mineral phases, and dissolution of significant quantities of the rock components. Calcium and magnesium are both largely removed from solution due to precipitation of carbonates and, to a lesser extent, a variety of silicates.

The elements $\mathrm{Na}, \mathrm{Si}$, and $\mathrm{Al}$ increase significantly, even though they are incorporated in the secondary minerals, due to the fact that the amount added to solution by dissolution of the solids, is much greater than the amount removed by precipitation. Nevertheless, the final concentration reached for these elements is controlled by the solubilities of the major secondary phases. Silicon, for example, is buffered at chalcedony saturation, at steady state conditions. Other elements are controlled by a combination of secondary phases, since many of these phases are complex, multi-component solid solutions.

The redox state is effectively determined by the assumption that the solution is in equilibrium with atmospheric gases. Hence, total oxygen is assumed to be maintained at approximately $20 \%$ of the coexisting gas phase. This assumption ignores the temperature effect on fugacity, since the calculations are actually carried out on the liquid vapor saturation curve for $\mathrm{H}_{2} \mathrm{O}$. This assumption, however, has negligible effect on the results presented here, which are generated for the purpose of providing gross bounds to the water composition.

The variation in $\mathrm{pH}$ is strongly controlled by the fact that $\mathrm{CO}_{2}$ fugacity is fixed in the simulations. This parameter, in turn influences carbonic acid equilibria in such a way that $\mathrm{pH}$ remains slightly alkaline throughout reaction progress. However, the final steady state achieved differs by approximately one log unit between the $40^{\circ} \mathrm{C}$ and $90^{\circ} \mathrm{C}$ simulations. These results differ somewhat from those described in Section 3.4.1, where water evaporation is modeled. In the latter study, the effect of including rock interaction with the water was not considered. In addition, changes in elemental concentrations, due to loss of $\mathrm{H}_{2} \mathrm{O}$ during evaporation, lead to the different results. Nevertheless, the 
overall character of the systems are similar, in that $\mathrm{pH}$ remains relatively alkaline when $\mathrm{CO}_{2}$ is controlled by atmospheric gases.

The conservative elements $\mathrm{Cl}, \mathrm{F}, \mathrm{Li}$ and $\mathrm{P}$ show no significant variation during reaction progress because they are not incorporated into any secondary phases that form in significant quantities, other than apatite which maintains a constant abundance throughout the reaction progress.

10.4.3.3.3 Secondary Mineralogy of the Vitric Material (Fig. 10.4-10(a-e). For dissolution of relatively small volumes of glass, the secondary phases that form during reaction progress are similar to those formed in the tuffs (pyrolusite, clays, and zeolites). The principal differences that occur are in the respective amounts of secondary phases, and the specific zeolites that form. These results are qualitatively consistent with the description of glass alteration (Levy, 1984a,b) in the vicinity of Yucca Mountain. At the end of the reaction progress, very similar end points are achieved. The main exception to this is calcite, which persists to the end point of the calculations for all temperatures except $40^{\circ} \mathrm{C}$.

For dissolution of large volumes of glass, the reaction progress is similar to that for small volumes of glass dissolution, for small values of reaction progress, but rather quickly achieves a state in which the only secondary phases that are present are pyrolusite, chalcedony and hematite.

Finally, in none of the simulations with vitric material was muscovite or microcline present as reaction products at any temperature, in contrast to the tuff runs where these two phases are present throughout.

10.4.3.3.4 Water Chemistry of the Vitric Material (Fig. 10.4-12, (a-g). Water composition in simulations involving small degrees of glass dissolution reaches end points that are nearly identical to those for the tuff-water system, and tend to follow very similar trends during reaction progress. The simulations involving large volumes of glass dissolution followed the same trends early in the simulations, but ultimately achieved much higher total concentrations of all elements except $\mathrm{Si}$, which drops to very low values controlled by large volumes of precipitated chalcedony. The latter buffers aqueous $\mathrm{SiO}_{2}$. In addition, at high degrees of glass dissolution, $\mathrm{pH}$ drops, reaching acidic values (ca. 3.8 ) in the low temperature simulations and slightly alkaline (ca. 7.8) at the $90^{\circ} \mathrm{C}$ simulation. This $\mathrm{pH}$ behavior primarily reflects the effects of temperature, the glass chemistry components, and the solubility of $\mathrm{C}$-bearing aqueous species (e.g., $\mathrm{HCO}_{3}{ }^{-}$) and solids on $\mathrm{pH}$. In these simulations, total dissolved elemental carbon decreased by three orders of magnitude during reaction progress, which will profoundly influence alkalinity, as vitric material dissolves and other elements are added to the solution. The magnitude of this effect is also implied by the fact that the concentration of solutes increases from ca. $0.02 \%$ (on a weight basis) at the beginning of the reaction progress, to $\mathrm{ca} .0 .6 \%$ at the end of reaction progress.

The conservative elements $\mathrm{Cl}, \mathrm{F}, \mathrm{Li}$ and $\mathrm{P}$ were not included in the simulations of the glasses because no analyses were available for them.

10.4.3.3.5 Propagation of Time Errors. To examine the effects of differences in rates on specific simulations, variation in the sanidine dissolution rate was examined. To determine the propagated uncertainty in the amount of sanidine formed at a given time, we used the results shown in Fig. 10.4-13. Approximate error bars, indicated in Fig. 10.4-14, were generated by differencing the runs shown in Figure 10.4-13. The results (Fig. 10.4-14) demonstrate that the propagated error increases with time, until sanidine vanishes. The 'error', or uncertainty, represents uncertainty regarding the amount of the mineral present at any given time, or uncertainty regarding the time at which a specific abundance of the mineral is achieved. The error in predicting when a phase appears or disappears from the model can be substantially greater than the prediction of the amount made. For example, the maximum uncertainty in the amount of sanidine produced is ca $50 \%$, but the uncertainty of when it is consumed is ca $-60 \%$ to $+2100 \%$.

10.4.3.4 Discussion. The simulations that were conducted were designed to be the preliminary simulations for bounding water compositions that could evolve within the Altered Zone and migrate into the Near-Field Environment, and for bounding the mineralogy that could evolve in the Altered Zone. Emphasis, therefore, is placed on establishing a baseline upon which refinements would be made 
at a future date. The key constraints upon which the simulations were based were: 1) constant gas fugacity, equivalent to atmospheric values; 2) suppression of precipitation of certain phases; 3) selection of rate constants and surface areas; 4) water volume to surface area ratios for the tuff simulations typical of experiments conducted in Dickson rocking autoclaves, thus representing scenarios in which very large volumes of water are available, relative to the accessible effective surface area. The simulations involving the vitric material, on the other hand, cover a very wide range of possible accessible surface areas, and thus represent a range of conditions from water flow in fractures, to water wetting non-welded, highly porous vitric materials.

10.4.3.4.1 Baseline Secondary Mineralogy. Under all conditions, clays and zeolites occur within the secondary mineral assemblages. The specific time in the reaction progress when these phases may appear, and the compositions and structures that will occur may vary, depending on the evolving chemical conditions and temperatures. The respective volumes that develop, at steady state conditions, are generally less than other coexisting alumino-silicates. These phases, nevertheless, form an important part of the secondary assemblages, due to their potentially important role as materials in which radionuclides may be sequestered.

Silica polymorphs develop early on in reaction progress. This is an important observation, since silica polymorphs are the most abundant secondary phases to form, in all conditions. This suggests that silica may play an important role in coupling hydrology and geochemistry/mineralogy via precipitation/dissolution-induced changes in porosity and permeability, and transport (see Section 10.4.4).

In all of the simulations, carbonates play an important role in the secondary mineral assemblage, but they are not always present when steady state is reached. Because carbonates may be important in both influencing water composition and sequestering ${ }^{14} \mathrm{C}$ through isotope exchange, the ubiquitous presence of this phase in various stages during reaction progress may be significant.

10.4.3.4.2 Baseline Water Composition. The composition of water that may enter the NFE is restricted to a relatively narrow range, except for the condition in which large volumes of glass are dissolved. For those conditions not involving large volumes of glass, the bounds suggest that the solution will be approximately neutral to slightly basic, relatively oxidizing, saturated in a silica polymorph, and with low to moderate concentrations of dissolved species. Total ionic strength remains below 0.1 molal. For the case where large volumes of glass are dissolved, $\mathrm{pH}$ may become strongly acidic, and total dissolved species can be quite high.

Despite these characteristics, solution composition changes significantly during the course of reaction progress. For the non-conservative elements, changes in concentration of many times are evident, and correlated with the dissolution or precipitation of a specific phase or phases.

10.4.3.4.3 Uncertainty. The uncertainty in final amounts of a mineral is shown to be problem specific and potentially significant with respect to long-term predictions of geochemical properties in slowly reacting systems, such as systems involving mineral dissolution or precipitation. The results in which sanidine was considered demonstrate that there is an increase in the uncertainty of the amount of mineral that may be present, or when that mineral may appear or disappear from an assemblage, for a relatively small initial uncertainty in the rate parameter. The results show that, in this case, an order of magnitude uncertainty in the rate results in the disappearance of sanidine sometime between a few hundred days to nearly a hundred years.

10.4.3.5 Conclusions. The results presented here provide initial bounds on secondary mineralogy and water chemistry, for a very specific set of conditions and simulation constraints. These constraints, along with similar efforts to bound pore water chemistry during evaporation (Glassley, 1995, and Section 3.4.1), provide baseline information from which to further refine simulation strategies and thus refine bounds on water chemistry and secondary mineralogy.

These results also document the very great uncertainties that exist in establishing the nature of secondary minerals that may form, the resulting water chemistry, and the absolute times at which specific changes might be expected to develop during reaction progress. This is consistent with the results described in Section 3.4.2 (Bruton, 1995) in which it was demonstrated that mineral facies may 
be identified, as a function of time, but that specific and detailed projections of mineral assemblages cannot be provided, due to uncertainty in thermodynamic and kinetic data. Much work is still needed before quantitative bounds can be confidently placed on the evolution of water chemistry entering the NFE, and the resulting secondary mineral assemblages that may influence radionuclide migration.

These results clearly document that both the times at which mineral phases may be present or absent during reaction progress, and their respective amounts, may be uncertain by orders of magnitude. Because these parameters are also important for describing water chemistry as a function of time, it is clear that only very gross bounds can be placed on either the mineralogical or water chemistry evolution, unless more measurements of dissolution and precipitation rates are obtained.

This point is also important for radionuclide retardation in the EBS or Altered Zone. The magnitude of retardation depends upon the mineral phases that are present, and their respective amounts. However, these results demonstrate that there is substantial uncertainty about when any specific phase may form or be consumed in reactions. This uncertainty will remain until further work is

completed to establish more precise values for dissolution and precipitation kinetics rate constants.

It should also be borne in mind that these water chemistries are not the chemistries that a waste package is likely to see. Materials introduced into the repository during construction and waste emplacement will probably be the primary controls on water chemistry in the NFE.

\subsubsection{References}

L. Brisqueu \& $\mathrm{H}$ de la Boisse (1990), “U-Pb geochronology; Systematic development of mixing equations and application of Monte Carlo numerical simulation to the error propagation in the Concordia diagram," Chemical Geology, 88, 69-83.

Broxton, D. E., W. G. Warren, R. C. Hagen, and G. Luedemann (1989), Chemistry of Diagenetically Altered Tuffs At A Potential Nuclear Waste Repository at Yucca mountain, Nevada. Los Alamos National Laboratory, Los Alamos, New Mexico, LANL-10802-MS.

Buscheck, T. A., and J. J. Nitao (1992), The Impact of Thermal Loading on Repository Performance at Yucca Mountain, in Third International Conference on High Level Radioactive Waste Management, Las Vegas, American Nuclear Society, LaGrange Park, 11., pp. 1003-1017.

Buscheck, T. A., and J. J. Nitao (1993), The Impact of Repository-Heat-Driven Hydrothermal Flow on Hydrological Performance at Yucca Mountain, Lawrence Livermore National Laboratory, Livermore, Calif., UCRL-JC-112444.

Delany, J. M. (1985), Reaction of Topopah Spring Tuff with J-13 Water: A Geochemical Modeling Approach Using the EQ3/6 Reaction Path modeling Code, Lawrence Livermore National Laboratory, Livermore, Calif., UCRL-53631, 48p.

Glassley, W. E. (1995), Report on Near-Field Geochemistry: Water Composition Changes Due to Evaporation. Yucca Mountain Milestone MOL 206.

Harrar, J. E, J. F. Carley, W. F. Isherwood, and E. Raber (1990), Report of the Committee to Review the Use of J-13 Well Water in the Neoada Nuclear Waste Storage Investigation, Lawrence Livermore National Laboratory, Livermore, Calif., UCID-21867.

Holdren, G. R. Jr., and P. M. Speyer (1985), "Reaction rate-surface area relationships during the early stages of weathering: II. Data on eight additional feldspars," Geochim. Cosmochim. Acta 51, 23112318.

Levy, S. S. (1984a), "Studies of altered vitrophyre for the prediction of nuclear-waste-repository induced thermal alteration at Yucca Mountain, Nevada," in Scientific Basis for Nuclear Waste Management VII, G. L. McVay, ed., Materials Research Society, pp. 959-966.

Levy S. S. (1984b), Petrology of samples from drill holes USW H-3, H-4, and H-5, Yucca Mountain, Nevada. Los Alamos National laboratory Report LA-9706-MS, 77 pp.

Nitao, J. (1988), Numerical Modeling of the Thermal and Hydrological Environment Around a Nuclear Waste Package Using the Equivalent Continuum Approximation: Horizontal Emplacement, Lawrence Livermore National Laboratory, Livermore, CA, UCID-21444.

Thompson, A.M., and R.W. Stewart, (1991), "Effect of Chemical Kinetics Uncertainties on Calculated Constituents in a Tropospheric Photochemical Model," J. Geophysical Research 96, 13089-13108. 
Whitbeck, M., and W. E., Glassley (1995), Preliminary Bounds on the Water Composition and Secondary Mineral Deoelopment That May Influence The Near-Field Environment. Lawrence Livermore National Laboratory, Yucca Mountain Site Characterization project milestone MOL205.

Wolery, T. (1992a), EQ3/6, A Software Package for Geochemical Modeling of Aqueous Systems: Package Ooeroiew and Installation Guide (Version 7.0), Lawrence Livermore National Laboratory, Livermore, CA, UCRL-MA-110662

PT I.

Wolery, T. (1992b), EQ3NR, A Computer Program for Geochemical Aqueous Speciation-Solubility Calculations: Theoretical Manual, User's Guide and Related Documentation (Version 7.0), Lawrence Livermore National Laboratory, Livermore, CA, UCRL-MA-110662 PT. III.

Wolery, T., and S. A. Daveler (1992), EQ6, A Computer Program for Reaction Pat

$h$ Modeling of Aqueous Geochemical Systems: Theoretical Manual, User's Guide and Related Documentation (Version 7.0), Lawrence Livermore National Laboratory, Livermore, CA, UCRLMA-110662 PT. IV.

Wolery, T., K. J. Jackson, W. L. Bourcier, C. J. Bruton, B. E. Viani, K. G. Knauss, and J. M. Delany (1990), "Current Status of the EQ3/6 Software Package for Geochemical Modeling," in Chemical Modeling in Aqueous Systems II.

\subsubsection{Formation of Flow and Transport Barriers Within The Altered Zone (James W. Johnson and William E. Glassley)}

10.4.4.1 Introduction. Radioactive decay within the waste package will establish and maintain lateral thermal gradients and resultant advective mass transport within the altered zone. This hydrothermal activity will invariably lead to porosity evolution as a consequence of reactioncontrolled mineral dissolution and precipitation both along fractures and within bounding matrix blocks. Preliminary reactive transport modeling conducted in FY 1995 suggested that these processes might result in significant modification of flow porosity both above and below the repository (Glassley, 1995). However, owing to limitations of the software available at that time, these preliminary studies considered only the equilibrium dissolution/precipitation of silica polymorphs and advective transport of silica as $\mathrm{SiO}_{2}(\mathrm{aq})$; as a result, they provided only a first-order approximation of the effect. Subsequently, new reactive transport simulators have been developed that facilitate analogous modeling of systems that involve complex fluid-rock compositions and explicitly account for temperature-dependent reaction kinetics as well as advective, diffusive, and dispersive transport. A hands-on review of several such simulators (Glassley et al., 1995) concluded that the modeling capabilities of GIMRT (Steefel and Yabusaki, 1995; Steefel and Lasaga, 1994) most closely matched those required for detailed simulation of porosity evolution in the post-emplacement altered zone. Specifically, GIMRT permits direct monitoring of kinetically controlled, reaction-dependent porosity evolution in compositionally complex porous media where the full range of transport phenomena are considered. Hence, GIMRT was selected for use in the series of one-dimensional simulations described in this section, which provide a significantly more rigorous predictive representation of porosity evolution in the altered zone than was previously possible.

Reactive transport simulations can be viewed as an iterative five-stage process: (1) precise specification of the initial chemical and hydrologic state of the fluid-rock system, (2) translation (which often includes approximation) of these specifications into the analogous model parameters of the software, (3) specification of certain system-independent numerical parameters, (4) successful execution of the software, and (5) interpretation of calculated results. The process is iterative in that several cycles through (1-3) are often required for initial achievement of (4); subsequently, additional cycles through (1-3) can be used to further refine the simulation to provide the closest possible representation of the natural system. Using this five-stage process, the approach taken in this study was to first establish validity of the software-encoded numerical model by successfully predicting the outcome of two well-characterized, experimentally verifiable "benchmark" problems. Next, increasingly complex, yet still experimentally verifiable problems having some relevance to porosity 
evolution in the backfill zone were addressed. Finally, a critical simulation that cannot be addressed directly by physical experiment was carried out: modeling of long-term porosity evolution in the altered-zone.

10.4.4.2 Benchmark Simulations. Accurate simulation of a well-constrained physical experiment is the critical first step in any numerical modeling study; this is particularly true in the case of reactive transport modeling, where the use of approximate numerical methods to mathematically represent coupled processes and the uncertainties in many different data (thermodynamic, kinetic, diffusioncoefficient, dispersivity, etc.) make it exceedingly difficult to assess the accuracy of simulations that involve even relatively simple chemistry and hydrology. Hence, in order to ensure the possibility that meaningful conclusions can be drawn from complex simulations, one must first provide clear evidence that the model accurately predicts the outcome of simple reactive transport problems. Toward this end, two plug-flow reactor (PFR) experiments were designed, carried out, and simulated using GIMRT.

In the first experiment, Suprasil material ${ }^{\mathrm{ji}}$ was pulverized to $125-75 \mu \mathrm{m}$ size fraction, placed within a Ti-cylinder of $3.1-\mathrm{cm}$ length and $0.66-\mathrm{cm}$ effective diameter, and infiltrated by distilled water at an outflow rate of $26 \mathrm{ml} /$ day for two weeks at $238^{\circ} \mathrm{C}$ and 84.1 bar. As silica-charged fluid exited the PFR during progressive dissolution of the Suprasil plug, aqueous silica concentrations were systematically monitored; these attained approximately steady-state values of $300-320 \mathrm{ppm} \mathrm{Si}(\log$ $\mathrm{a}\left[\mathrm{SiO}_{2}(\mathrm{aq})\right]=-1.97$ to -1.94$)$, well below the limit of amorphous silica saturation $\left(\log \mathrm{a}\left[\mathrm{SiO}_{2}(\mathrm{aq})\right]=-\right.$ 1.709) in 3-4 days. In this experiment involving the simple system $\mathrm{SiO}_{2}-\mathrm{H}_{2} \mathrm{O}$, the temperature, pressure ${ }^{i i j}$, fluid flux $\left(277.4 \mathrm{~m}^{3} / \mathrm{m}^{2} / \mathrm{yr}\right)$, initial porosity $(40 \%)$, size fraction, thermodynamic and kinetic data (Johnson et al., 1992; Rimstidt and Barnes, 1980), and outlet aqueous silica concentrations are all tightly constrained. As a result, GMRT can be used iteratively to independently calculate specific surface area of the crushed amorphous silica, which was measured prior to the experiment. Optimal fits to the experimental data were obtained for a predicted value of $1050 \mathrm{~cm}^{2} / \mathrm{g}$ (Fig. 10.4-15), which is in close agreement with BET measurements for this mineral of $\mathrm{ca} .900 \mathrm{~cm}^{2} / \mathrm{gm}$.

The second experiment was conducted under the same conditions as the first except that crushed quartz was used in place of the Suprasil material. This quartz substitution removes the potential ambiguity associated with thermodynamic approximation of the Suprasil material as amorphous silica in the first experiment. Again, GMMRT was used iteratively to determine specific surface of the pulverized quartz. The experimental data were most closely fit by a predicted value $\left(920 \mathrm{~cm}^{2} / \mathrm{g}\right.$; Fig. 10.4-16) that falls within the range determined by BET measurement $\left(460-940 \mathrm{~cm}^{2} / \mathrm{gm}\right.$, Knauss and Wolery, 1988).

Close agreement between GIMRT-predicted and BET-measured specific surface areas for amorphous silica and quartz has significance beyond accuracy validation of the various PFR measurements (fluid flux, aqueous silica concentrations, etc.) and thermodynamic and kinetic data (standard molal properties, equation-of-state parameters, dissolution rate constants, activation energies, etc.). Specifically, it also demonstrates the reasonableness of values employed in the GIMRT simulations for several geochemical and hydrologic parameters (bulk diffusion coefficient, longitudinal and transverse dispersivity, etc.) and numerical variables (initial/maximum timestep, cementation exponent, etc.) which in many cases are imprecisely known. Sensitivity of the reactive transport calculations to variations in these variables was examined as an aid to obtaining optimal values.

Having demonstrated GIMRT's ability to accurately simulate amorphous-silica and quartz dissolution in the PFR experiments, the same experimental-verification approach can be extended to

\footnotetext{
'These PFR experiments were carried out by Kevin Knauss in support of WBS 1.2.3.10.2.

iSupracil material is essentially silica glass, which from a structural and thermodynamic standpoint can be approximated as amorphous silica.

"Although the PFR experiment was carried out at $238^{\circ} \mathrm{C}$ and $84.1 \mathrm{bar}$, the thermodynamic data base used in the GIMRT-simulation analog is constructed for Psat(T), which at $238^{\circ} \mathrm{C}$ is 32.3 bar. However, this pressure discrepancy is insignificant (e.g., amorphous silica saturation at $238^{\circ} \mathrm{C}, 84.1$ bar and $238^{\circ} \mathrm{C}, 32.3$ bar corresponds to $\log \mathrm{a}\left[\mathrm{SiO}_{2}\right.$ (aq)] values of -1.709 and -1.720 , respectively).
} 
address problems that involve the more complex fluid-rock compositions characteristic of the preemplacement altered zone.

10.4.4.3 Compositional Specifications and Parameterization of the Altered Zone. The composition and relative abundance of mineral phases in the potential repository host rock, the Topopah Spring Member of the Paintbrush Tuff (TSw2), have been determined experimentally by Warren et al. (1984), and translated into model compositions/abundances by Delany (1985) for use in EQ3 / 6 calculations. Because GIMRT, unlike EQ3/6, is not yet configured to account for solid solutions, for the present work it is necessary to further approximate Delany's (1985) model TSw2 mineralogy by resolving its alkali feldspar and plagioclase compositions into the corresponding end-member $\mathrm{K}$ feldspar, albite, and anorthite components. Although the Mg-beidellite and biotite compositions could be similarly resolved, these phases together compose only 1.1 vol.\% of the TSw2 (Delany, 1985); in addition, they represent the only $\mathrm{Mg}$ - and Fe-bearing phases in the system, and inclusion of these elements in the simulation would necessitate tremendous expansion of the set of mineral and aqueous species considered. Hence, in these preliminary simulations, $\mathrm{Mg}$-beidellite and biotite have been eliminated from the model TSw2 composition. Although these phases will be incorporated into future simulations, such inclusion is anticipated to represent a second-order effect. The model TSw2 mineralogy given by Delany (1985) and its approximated form used in this study are summarized in Table 10.4-5.

The fluid phase anticipated to form within, and react with, the TSw2 in the altered zone is derived from condensation of a vapor phase moving radially outward from the repository (Buscheck et al., 1993). This condensate is likely to be a highly dilute, neutral-pH fluid. In the simulations, this fluid is modeled to initially contain very low concentrations of aqueous ions and complexes within the chemical system defined by TSw2 mineralogy $\left(\mathrm{Na}_{2} \mathrm{O}-\mathrm{K}_{2} \mathrm{O}-\mathrm{CaO}-\mathrm{SiO}_{2}-\mathrm{Al}_{2} \mathrm{O}_{3}-\mathrm{H}_{2} \mathrm{O}\right)$ augmented by the additional component $\mathrm{CO}_{2}$, which is necessary owing to the presence of atmospheric gases (Bruton et al., 1993). The initial fluid composition, specified as the log molal concentration of basis species, is given in Table 10.4-6. Note that this solution is much more dilute than J-13 and other relevant fluid compositions in the vicinity of Yucca Mountain, reflecting its condensation from a vapor phase.

Following specification of the model TSw2 and vapor condensate compositions, it is necessary to select a thermodynamic data base that includes all of the relevant species as well as kinetic and surface-area data for the minerals. For this work, we have employed the thermodynamic data base typically used with both the original and our modified version of GIMRT, mastertemp.data, which is a reformatted version of the "composite" data base distributed with the EQ3/6 software package (Wolery, 1992). Although this data base contains reference-state and elevated P-T data taken from numerous sources and extrapolated using a variety of equations, the particular subset relevant to the present altered-zone modeling is for the most part taken from the SUPCRT92 database and software package (Johnson et al., 1992). Reference-state dissolution-rate constants, activation energies, and specific surface areas needed for the primary and potential alteration minerals were taken from a variety of experimental and theoretical studies (Renders et al., 1995; Oelkers and Schott, 1995; Gautier et al., 1994; Rose, 1991; Knauss and Wolery, 1989, 1988, 1986; Helgeson et al., 1984; Rimstidt and Barnes, 1980).

Using the model TSw2 fluid-rock compositions and specified thermodynamic/kinetic database, there are two distinct altered-zone environments whose porosity evolution can be addressed with GIMRT. The first of these is the localized, interior backfill environment, for which crushed, unaltered TSw2 has been discussed as a possible backfill material; the second is the much larger-scale, relatively outlying condensation zone (Buscheck et al., 1993), where gravity-driven flow of vapor-exsolved fluid represents the most likely catalyst for significant, long-term porosity evolution in the altered zone.

10.4.4.4 Backfill Simulations. Because the backfill environment bridges the EBS/WP and pristine TSw2, postemplacement porosity evolution within this spatially restricted zone is a potentially critical variable affecting overall repository performance. Reactive transport simulations of this evolution are analogous to those described above for the silica dissolution experiments in that experimental PFR analogs can be constructed, carried out, and used to refine and verify the calculations. Two such simulations were completed; in both cases, an inlet fluid was streamed through a 31-cm length 
of crushed Tpt material having an initial porosity of $40 \%$, where constant outlet flux of $266.7 \mathrm{~m}^{3} / \mathrm{m}^{2} / \mathrm{yr}$ is maintained over six months. This flow length, porosity, outlet flux, and duration were selected for consistency with the existing PFR geometry, measured value for crushed Tsw2 material (125-75 $\mu \mathrm{m}$ size fraction), attainable experimental outflow rate $(25 \mathrm{ml} /$ day for a plug having an effective diameter of $0.66 \mathrm{~cm}$ ), and the anticipated maximum duration of the experiment, respectively. Because the porosity of actual backfill material and especially the in situ fluid flux are likely to be lower than these adopted values, the simulations provide an upper bound to the potential magnitude of porosity evolution. In both simulations, boundary conditions are set such that the entire one-dimensional reaction domain is initialized (but not fixed) to contain the model TSw2 fluid-rock system summarized in Tables 10.4-5 and 10.4-6, while only the inlet fluid composition is initialized and fixed per Table 10.4-6.

In the first TSw2-backfill simulation, the fluid-rock system is maintained in isothermal equilibrium at $90^{\circ} \mathrm{C}$, a conservative yet representative value for this environment. As the inlet fluid flows through and reacts with the crushed TSw2, spatial and temporal variations in porosity, mineral volume fractions and saturation indices, and fluid composition are continuously monitored. At the inlet node ( $1 \mathrm{~cm}$ into the $31-\mathrm{cm}$ reaction domain), steady-state saturation indices for all primary and potential secondary minerals are achieved within one hour (Fig. 10.4-17). As can be seen in Fig. 10.4-17, the fluid remains undersaturated with respect to all primary and potential secondary minerals at this inlet node (all $\log (\mathrm{Q} / \mathrm{K})<0$ ) throughout the simulation; hence, at this location all primary phases will dissolve to varying degrees controlled by the encoded kinetic rate law, and no secondary minerals will precipitate. At the outlet node, mineral saturation indices reach steady-state values in about 9 hours; here again the fluid remains undersaturated with respect to all primary minerals, but in contrast to the initial node, several secondary phases (kaolinite, gibbsite, diaspore, boehmite, and muscovite) do achieve steady-state supersaturation with the fluid (Fig. 10.4-18). Because steady-state saturation indices are attained throughout the reaction domain within just a few hours of this six-month run, time-integrated saturation-indices across this domain together with calculated reaction rates can be used to assess the spatial zoning of secondary phases and the magnitude of mineral dissolution/precipitation and porosity evolution (Fig. 10.4-19).

At $90^{\circ} \mathrm{C}$, kinetic dissolution rates for the undersaturated primary phases are on the order of $-10^{-1}$ vol.\%/yr for cristobalite and albite, $-10^{-2}$ vol.\%/yr for quartz, and $<-10^{-3}$ vol.\%/yr for K-feldspar and anorthite. As a result, over six months the aggregate dissolution of primary minerals will be $<0.25$ vol.\%. Some of this minute volume loss will be filled by precipitation of secondary phases following their sequential supersaturation along the flowpath. Specifically, gibbsite will precipitate first (at node 2; nodes were located at each cm along the flowpath), subsequently joined by diaspore (node 4), kaolinite (node 9), boehmite (node 14), and finally muscovite (node 29). However, because maximum precipitation rates for these phases are so slow at $90^{\circ} \mathrm{C}$ (ranging from $10^{-11} \mathrm{vol} . \% / \mathrm{yr}$ for kaolinite to $10^{-14}$ vol.\%/yr for muscovite and boehmite), the aggregate precipitation of secondary minerals is $<2.5\left(10^{-3}\right)$ vol.\%/yr throughout the domain, i.e., negligible. As a consequence, six months of reactive flow through crushed Tpt at $90^{\circ} \mathrm{C}$ results in a relatively uniform but minute increase in porosity (from 40 to approx. $40.25 \%$ ) as a function of minor dissolution of primary phases and trace precipitation of alteration minerals (Figs. 10.4-[20-21]).

Hence, at $90^{\circ} \mathrm{C}$, despite likely overestimation of initial porosity and fluid flux in the simulation, post-emplacement porosity evolution of TSw2 backfill will be insignificant. Because the predicted porosity variations and alteration-phase concentrations are well below what one could reasonably expect to discern from post-mortem analysis of the analogous PRF experiment, such an experiment was not conducted. Rather, a second GIMRT simulation was performed, identical to the first except for the temperature, which was increased to $250^{\circ} \mathrm{C}$. Although this temperature exceeds the maximum likely to be attained in the backfill zone, thermodynamic and kinetic considerations suggest that it will lead to readily observable porosity evolution and alteration-phase precipitation; hence, the corresponding PFR experiment can be run and analyzed to provide validation for both this and, by implication, the experimentally unverifiable $90^{\circ} \mathrm{C}$ run. 
Although the time-scale for attainment of steady-state saturation indices is similar for the $90^{\circ}$ and $250^{\circ} \mathrm{C}$ simulations ( $c f$. Figs. 10.4-17 and 10.4-22, 10.4-18 and 10.4-24), the enhanced solubilities and faster reaction rates of primary Tsw2 minerals at the higher temperature and their effect on dissolution (and secondary phase precipitation) are readily apparent. At the $250^{\circ} \mathrm{C}$ inlet node (Fig. 10.4-22), all primary minerals are far less undersaturated than at $90^{\circ} \mathrm{C}$, and six secondary phases are supersaturated-versus none at $90^{\circ} \mathrm{C}$. Because initial dissolution rates for albite $(-130 \mathrm{vol} . \% / \mathrm{yr})$, cristobalite $(-118 \mathrm{vol} . \% / \mathrm{yr})$, and quartz $(-23 \mathrm{vol} . \% / \mathrm{yr})$ are orders of magnitude higher here than at $90^{\circ} \mathrm{C}$, the continuous stream of dilute fluid through this node dissolves these phases rapidly: albite has disappeared after 90 days, and after 150 days, cristobalite and quartz have been reduced to less than 1.0 and 2.5 vol.\%, respectively. Despite concomitant precipitation of kaolinite, whose reaction rate and volume fraction ultimately attain $50 \mathrm{vol} . \% / \mathrm{yr}$ and $14 \mathrm{vol} . \%$, respectively, this near-complete consumption of cristobalite, albite, and quartz causes porosity to increase from 40 to $70 \%$ at the initial node (Fig. 10.4-23), and, of course, results in the late marked decline in saturation indices for these and all other silica-bearing phases (Fig. 10.4-22).

At the outlet node, the fluid is supersaturated with not only the same six secondary minerals that characterize the inlet node, but also with albite and quartz (Fig 10.4-24) as a consequence of the continuous introduction of relatively concentrated solutions generated by the large-scale dissolution upstream. Hence, although the initial dissolution rates for primary phases are identical to their large inlet-node values, here they diminish quickly owing to rapid increase in $\log Q$; in fact, primary albite ceases to dissolve and secondary albite begins to precipitate within 20 minutes, quartz follows suit about 40 minutes later, and within nine hours the cristobalite dissolution rate has dropped to and essentially leveled off at about $20 \%$ of its original magnitude. As a result, after six months, total quartz and albite volume fractions have actually increased (Fig. 10.4-25), and the net volume fraction of cristobalite, albite, and quartz has only declined from $45.9 \%$ to $37.2 \%$ (versus the inlet node where the six-month aggregate value is only $1.4 \%$ ). Hence, despite slightly reduced precipitation of secondary kaolinite relative to the inlet (10.2\% versus $15.2 \%$ ), the six-month outlet porosity has actually decreased from 40 to $38.8 \%$ (Fig. 10.4-25).

In the $250^{\circ} \mathrm{C}$ simulation, the inlet node can essentially be viewed as a pure "dissolution" node, since infiltrating fluid is never concentrated by upstream reactions, while the outlet node continuously encounters the most concentrated fluid from such reactions. Within the intervening domain, one would expect the gradient in dissolution/precipitation behavior to be sharpest across the first few nodes, where the fluid concentration gradient is steep, and relatively flat across the last few, where this fluid gradient is relatively flat. This is exactly the case, as illustrated by the time-integrated spatial distribution of saturation indices and porosity/volume fractions (Figs. 10.4-[26-27]). Here, the functional form of spatial variation in $\log (\mathrm{Q} / \mathrm{K})$, which for this isothermal-isobaric simulation is just the spatial variation in $\log Q$, closely mirrors that of the corresponding mineral volume fractions. Differences in the relative position of minerals in the $\log (\mathrm{Q} / \mathrm{K})$ and volume fraction plots are accounted for almost entirely by differences in their reference-state $\left(25^{\circ} \mathrm{C}\right)$ reaction rate constants and activation energies. Note that the region of enhanced porosity is restricted to the first few nodes and characterized by very steep gradients, while that of reduced porosity accounts for roughly $90 \%$ of the reaction domain and is characterized by much subtler variations.

The spatial variations in porosity and in the volume fractions of primary and secondary minerals illustrated in Fig. 10.4-27 are sufficient to be detected by post-mortem analysis of the proposed PFR analog. As a result, this experiment was set-up and initiated. Unfortunately, owing to a malfunction in one of the pressure regulators, the run was unavoidably terminated after five weeks, well short of the planned six-month duration. As can be seen in, and implied from, Figs. 10.4-23 and 10.4-25, at five weeks the predicted spatial variations in porosity and mineral volume fractions are far smaller than would have been realized in six months, and therefore much more difficult to discern and accurately characterize in the PFR post-mortem analysis. Nevertheless, such an analysis is currently under way, with results expected by early FY 1997. The availability of these PFR results are anxiously anticipated, as they will be of critical importance in refining and validating the predictions described above. 
However, even prior to such experimental validation these two short-term TSw2-backfill simulations provide insight into the time-scale of potential porosity evolution in this highly localized environment. Comparison of the $90^{\circ}$ and $250^{\circ} \mathrm{C}$ dissolution rates for silica polymorphs and feldspars and examination of the dependent six-month spatial variations in porosity and mineral volume fractions at these two temperatures leaves little doubt that significant porosity evolution in the $90^{\circ} \mathrm{C}$ backfill zone will not be realized for at least $100 \mathrm{yr}$. Moreover, recalling the likely overestimation of initial porosity and almost certain overestimation of fluid flux, this time frame must be considered extremely conservative. Because accurate values for the initial porosities and flow rates relevant to the potential crushed-TSw2 backfill environment are currently unavailable, a more detailed, longer time-scale simulation addressing porosity evolution here cannot be pursued at this time. Instead, we now address such long-term porosity variation in a critical environment where initial porosity and likely fluid fluxes are relatively well constrained: the pre-emplacement altered zone.

10.4.4.5 Altered-Zone Simulations. The potential repository horizon lies well above the present-day water table within the welded, devitrified section, which is characterized by low porosity (11\%) and extremely low, fracture-controlled permeability $\left(10^{-18} \mathrm{~m}^{2}\right)$ (Klavetter and Peters, 1988). As described by Buscheck et al. (1993), hydrology of the post-emplacement NFE may be characterized by a boiling zone, where vapor moves radially outward from the EBS/WP and an outer but partially overlapping condensation zone, where temperature-dependent condensation of the vapor leads to primarily gravity-driven flow of a fluid phase. In the vicinity of emplacement drifts, average calculated trajectories (Buscheck, pers. comm.) indicate that the condensate may flow along pathlines characterized by an initial isothermal segment (at $90-100^{\circ} \mathrm{C}$ ) of several meters and subsequent cooling segment $\left(-1^{\circ}\right.$ to $\left.-3^{\circ} \mathrm{C} / \mathrm{m}\right)$, also of several meters. Although these average flow trajectories and thermal gradients represent a relatively wide range of potential trajectories and gradients, they do provide a representative model framework for the reactive transport simulation of potential long-term porosity evolution in the altered zone.

In the model system, a fixed-composition inlet fluid (Table 10.4-6) flows through and reacts with a 10- $\mathrm{m}$ length of 11\%-porosity TSw2 material (Table 10.4-5); over the first $5 \mathrm{~m}$, the temperature is maintained at $95^{\circ} \mathrm{C}$, while a gradient of $-1{ }^{\circ} \mathrm{C} / \mathrm{m}$ is imposed on the last $5 \mathrm{~m}$. Fluid flux is maintained at $2.67 \mathrm{~m}^{3} / \mathrm{m}^{2} / \mathrm{yr}$, which is appropriate for this setting, but reduced two orders of magnitude relative to the earlier models. This "double" thermal gradient flow regime is maintained for $10,000 \mathrm{yr}$, which facilitates an analysis of long-term porosity evolution.

The temporal evolution of mineral saturation indices at the inlet $(0.25 \mathrm{~m})$, center $(5 \mathrm{~m})$, and outlet $(10 \mathrm{~m})$ nodes are illustrated in Figs. 10.4-[28-30]. As can be seen in these plots, initial steady-state mineral saturation indices are attained after about 1 month, during which time the fluid obtains supersaturation with quartz and the secondary phases kaolinite and pyrophyllite, but remains undersaturated with respect to cristobalite (and the primary feldspars) throughout the reaction domain. As a result, over the entire reactive flowpath, cristobalite (and the feldspars) will dissolve, while quartz, kaolinite, and pyrophyllite will precipitate. Given the relatively sluggish dissolution rates of the feldspars at $90-95^{\circ} \mathrm{C}$, dissolution of these primary aluminous phases and dependent precipitation of kaolinite and pyrophyllite will be very minor; hence, the fundamental mechanism of porosity evolution in this environment is expected to be metasomatic replacement of cristobalite by quartz.

That this hypothesis is valid can be seen in Figs. 10.4-[32-33], where the temporal evolution of porosity and mineral volume fractions at the central and outlet nodes is effectively controlled by cristobalite (and relatively minor, late-stage [ $>1,000 \mathrm{yr}]$ albite) dissolution and quartz precipitation. At the inlet (pure dissolution) node (Fig. 10.4-31), behavior analogous to the center and outlet of the domain is observed until cristobalite has been completely dissolved at about $650 \mathrm{yr}$; subsequently, the dilute inlet fluid begins to dissolve quartz, which disappears completely after $3,100 \mathrm{yr}$, and then albite.

The time-integrated spatial variations in porosity and mineral volume fractions are illustrated in Figs. 10.4-[34-37]. Because the reference-state standard molal volume of cristobalite exceeds that of quartz by approximately $13.5 \%$, the complete replacement of cristobalite (initial volume fraction: 
$39.6 \%$ ) by quartz throughout the reaction domain leads directly to a background increase in porosity from $11 \%$ to about $16 \%$ after roughly 3,100 yr (Figs. 10.4-[36-37]). Superimposed on this is a secondary porosity enhancement, resulting from quartz dissolution (initiated following complete cristobalite consumption) at the first few inlet nodes, beginning with the inlet node at $650 \mathrm{yr}$. Because the $90-95^{\circ} \mathrm{C}$ dissolution rate of quartz is only about $40 \%$ that of cristobalite, it takes dilute inlet fluid roughly 2,500 years to completely dissolve the inlet-node quartz from its maximum concentration ( 29 vol.\%), which coincided with cristobalite disappearance at $650 \mathrm{yr}$. Hence, this secondary quartz dissolution front advances quite slowly, and the advection of quartz-derived $\mathrm{SiO}_{2}$ (aq) maintains nearly uniform levels of slight quartz supersaturation and resultant minor quartz precipitation over the entire downstream reaction domain. As a result, this secondary porosity enhancement is characterized by steep gradients that advance downstream quite slowly (cf. Figs. 10.4-[36-37]).

Important implications for the post-emplacement evolution of porosity in the altered zone can be drawn from this simulation. First, thermodynamic, kinetic, and volumetric constraints strongly suggest that long-term $(>3,000 \mathrm{yr})$, gravity-driven flow of vapor-derived dilute condensate at $90-95^{\circ} \mathrm{C}$ will result in nearly $50 \%$ background porosity enhancement (from $11 \%$ to $16 \%$ ) as a consequence of mole-for-mole, quartz-for-cristobalite replacement. Should this local "condensation" zone (Buscheck et al., 1993) persist for longer time periods, the in situ porosity may further increase dramatically, albeit slowly, to more than $65 \%$ as quartz dissolution occurs. Hence, it is conceivable, if not in fact likely, that the post-emplacement altered zone will evolve toward extreme porosity heterogeneity, characterized by relatively large porosities in the condensation-zone "cap" above the repository and relatively low porosities (which nevertheless exceed pre-emplacement porosity) in the outlying margins of this cap; in addition, these extremes may be joined by a narrow, steep-gradient interface. All of this dissolved silica will, of course, eventually precipitate farther downstream, presuming this gravity-driven flow continues down thermal gradients. Hence, it is anticipated that a zone of very low (less than ambient) porosity may develop at depth, perhaps below and radially outward from the repository.

10.4.4.6 Concluding Remarks. In this study, the reactive transport simulator GIMRT (Steefel and Yabusaki, 1995) has been used to accurately predict experimentally verifiable specific surface areas of amorphous silica and quartz, to predict potentially verifiable porosity and mineralogic evolution during reaction between idealized TSw 2 and infiltrating fluid compositions, and to model unverifiable, long-term porosity evolution in the post-emplacement altered zone. The successful simulation of dissolution experiments involving silica polymorphs provided valuable benchmarking for the code; and the short-term, high-porosity simulations involving fluid-TSw2 interaction facilitated its necessary extension to potentially verifiable systems of considerably greater compositional complexity. But most clearly, the use of GIMRT to simulate long-term porosity and mineralogic variation in the post-emplacement altered zone demonstrates its value as a powerful investigative tool. Recognizing the abundance of compositional and hydrologic approximations, assumptions, and simplifications that are necessarily embodied in these still preliminary models, they nevertheless serve to elucidate the fundamental time scales (thousands of years) and geochemical processes (e.g., cristobalite for quartz replacement) likely to govern active evolution of the altered zone, and can be used to imply the distant-future porosity distributions that are so critically important. As described above, our initial modeling efforts suggest that post-emplacement reactive transport will lead to porosity enhancement in the altered zone, most dramatically in the condensation "cap" overlying the repository. Further modeling of fluid transport to regions below the emplacement drifts will evaluate the extent to which flow barriers may form due to porosity reduction.

The simulation results presented herein are extremely preliminary in nature, and the quantitative accuracy of our models will steadily improve as a function of advances in reactive transport theory, numerical methods, computer science, reaction kinetics, and thermodynamic/kinetic data on the modeling side, and in our understanding of the pre-emplacement TSw2 chemistry, hydrology, and heterogeneity on the field-data side. Nevertheless, our results to date strongly suggest that significant porosity changes will occur in the post-emplacement, repository-block environment. Long-term performance assessment of this environment must explicitly account for such porosity evolution and its effect on dependent geochemical and hydrologic processes. 


\subsubsection{References}

Bruton, C.J., W.E. Glassley, and B.E. Viani, (1993), Geochemistry, in Preliminary Near-Field Environment report Volume II. Scientific overoiew of near-field environment and phenomena: Lawrence Livermore National Laboratory, Livermore, CA, UCRL-LR-107476 Vol 2, p. 37-60.

Buscheck, T.A., J.J. Nitao, and D.A. Chesnut, (1993), Hydrologic modeling, in Preliminary Near-Field Environment report Volume II. Scientific overoiew of near-field environment and phenomena: Lawrence Livermore National Laboratory, Livermore, CA, UCRL-LR-107476 Vol 2, p. 5-27.

Delany, J.M., 1985, Reaction of Topopah Spring Tuff with J-13 water: A geochemical modeling approach using the EQ3/6 reaction path code: Lawrence Livermore National Laboratory, UCRL-53631, $46 \mathrm{p}$.

Gautier, J.-M., E.H. Oelkers, and J. Schott, (1994), Experimental study of K-feldspar dissolution rates as a function of chemical affinity at $150^{\circ} \mathrm{C}$ and $\mathrm{pH}$ 9: Geochim. Cosmochim. Acta, v. 58, n. 21, p. 4549-4560.

Glassley, W.E., 1995, Preliminary, scoping estimates of rates and magnitudes of changes of coupled hydrological-geochemical properties: LLNL-YMP MOL79, $18 \mathrm{p}$.

Glassley, W.E., W.L. Bourcier, and J.W. Johnson, (1995), Review of existing reactive transport software: LLNL-YMP MOL25, 24 p.

Helgeson, H.C., W.M. Murphy, and P. Aagaard, (1984), "Thermodynamic and kinetic constraints on reaction rates among minerals and aqueous solutions: II. Rate constants, effective surface area, and the hydrolysis of feldspar:" Geochim. Cosmochim. Acta, V. 48, p. 2405-2432.

Johnson, J.W., E.H. Oelkers, and H.C. Helgeson, (1992), "SUPCRT92: A software package for calculating the standard molal thermodynamic properties of minerals, gases, and aqueous species from $0^{\circ}$ to $1000^{\circ} \mathrm{C}$ and 1 to 5000 bar:" Comp. Geosci., V. 18, (7) p. 799-847.

Klavetter, E.A., and R.R. Peters., (1988), "A continuum model for water movement in an unsaturated fracture rock mass:" Water Resour. Res., V. 24, p. 416-430.

Knauss, K.G., and T.J. Wolery, (1989), "Muscovite dissolution kinetics as a function of $\mathrm{pH}$ and time at $70^{\circ} \mathrm{C}: "$ Geochim. Cosmochim. Acta, V. 53, p. 1493-1501.

Knauss, K.G., and T.J. Wolery, (1988), "The dissolution kinetics of quartz as a function of $\mathrm{pH}$ and time at $70^{\circ} \mathrm{C}: "$ Geochim. Cosmochim. Acta, V. 52, p. 43-53.

Knauss, K.G., and T.J. Wolery, (1986), "Dependence of albite dissolution kinetics on $\mathrm{pH}$ and time at $25^{\circ} \mathrm{C}$ and $70^{\circ} \mathrm{C}: "$ Geochim. Cosmochim. Acta, V. 50, p. 2481-2497.

Oelkers, E.H., and J. Schott, (1995), "Experimental study of anorthite dissolution and the relative mechanism of feldspar hydrolysis:" Geochim. Cosmochim. Acta, V.59, (24), p. 5039-5053.

Renders, P.J.N., C.H. Gammons, and H.L. Barnes, (1995), "Precipitation and dissolution rate constants for cristobalite from 150 to $300^{\circ} \mathrm{C}: "$ Geochim. Cosmochim. Acta, V. 59, (1), p. 77-85.

Rimstidt, J.D., and H.L. Barnes, (1980), "The kinetics of silica-water reactions:" Geochim. Cosmochim. Acta, V. 44, p. 1683-1699.

Rose, N.M., (1991), "Dissolution rates of prehnite, epidote, and albite:" Geochim. Cosmochim. Acta, V. 55, p. 3273-3286.

Steefel, C.I., and A.C. Lasaga, 1994, "A coupled model for transport of multiple chemical species and kinetic precipitation/dissolution reactions with application to reactive flow in single phase hydrothermal systems:" Amer. J. Sci., V. 294, p. 529-592.

Steefel, C.I., and S.B. Yabusaki, (1995), "OS3D/GIMRT: Software for modeling multicomponentmultidimensional reactive transport:" User's manual and programmer's guide, Version 1.0, $58 \mathrm{p}$.

Warren, R.G., F.M. Byers, and F.A. Caporuscio, (1984), Petrography and mineral chemistry of units of the Topopah Spring, Calico Hills and Crater Flat Tuffs, and older volcanic units, with emphasis on samples from drill hole USW G-1, Yucca Mountain, Neoada Test Site: Los Alamos National Laboratory, Los Alamos, NM, LA-10003-MS.

Wolery, T.W., (1992), "EQ3/6, a software package for geochemical modeling of aqueous systems:" Package ooeroiew and installation guide (Version 7.0): Lawrence Livermore National Laboratory, Livermore, CA, UCRL-MA-110662 PT I, 66 p. 


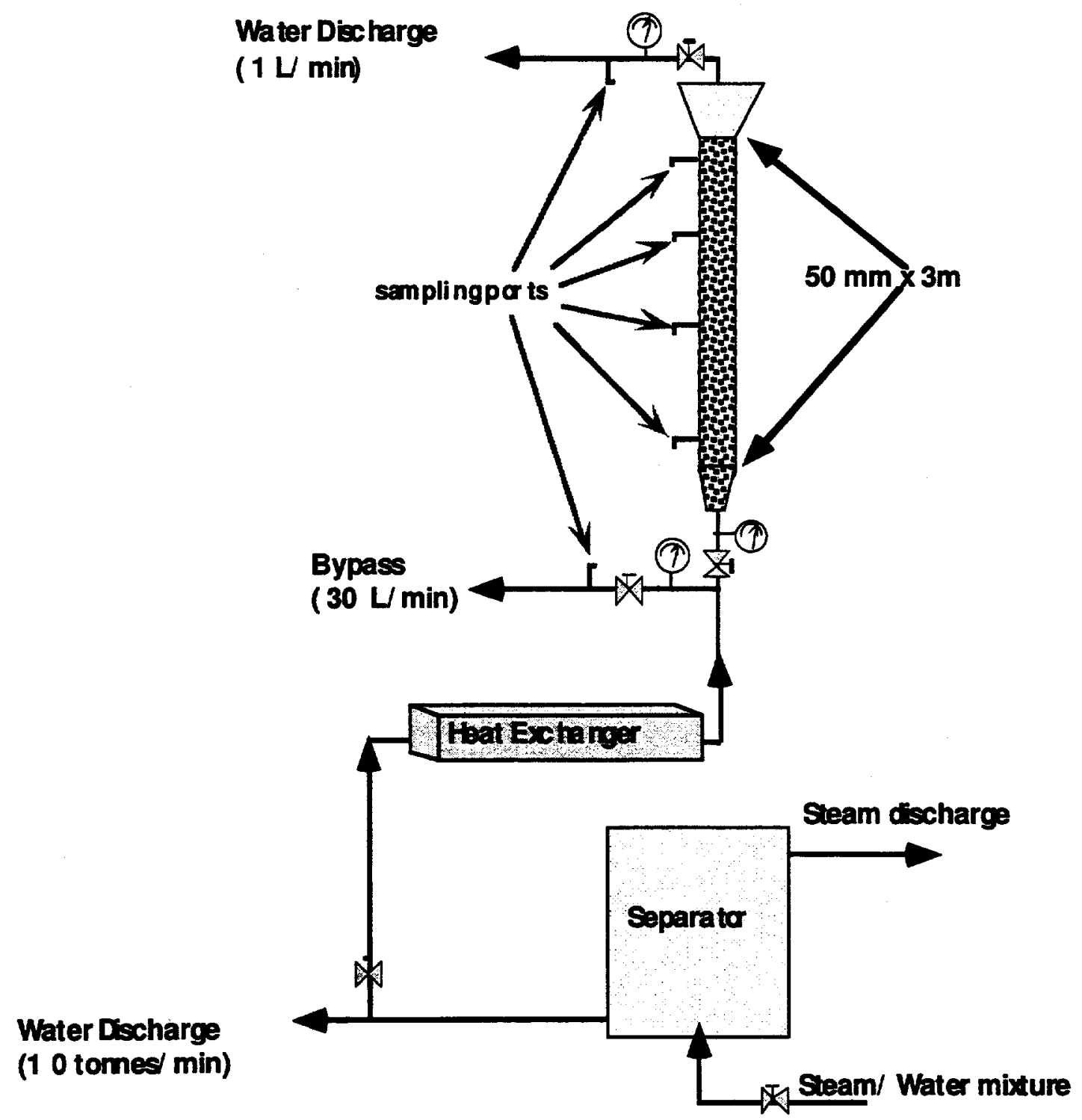

Figure 10.4-1. Schematic of the fluidized bed reactor used in the amorphous silica precipitation field experiments. 

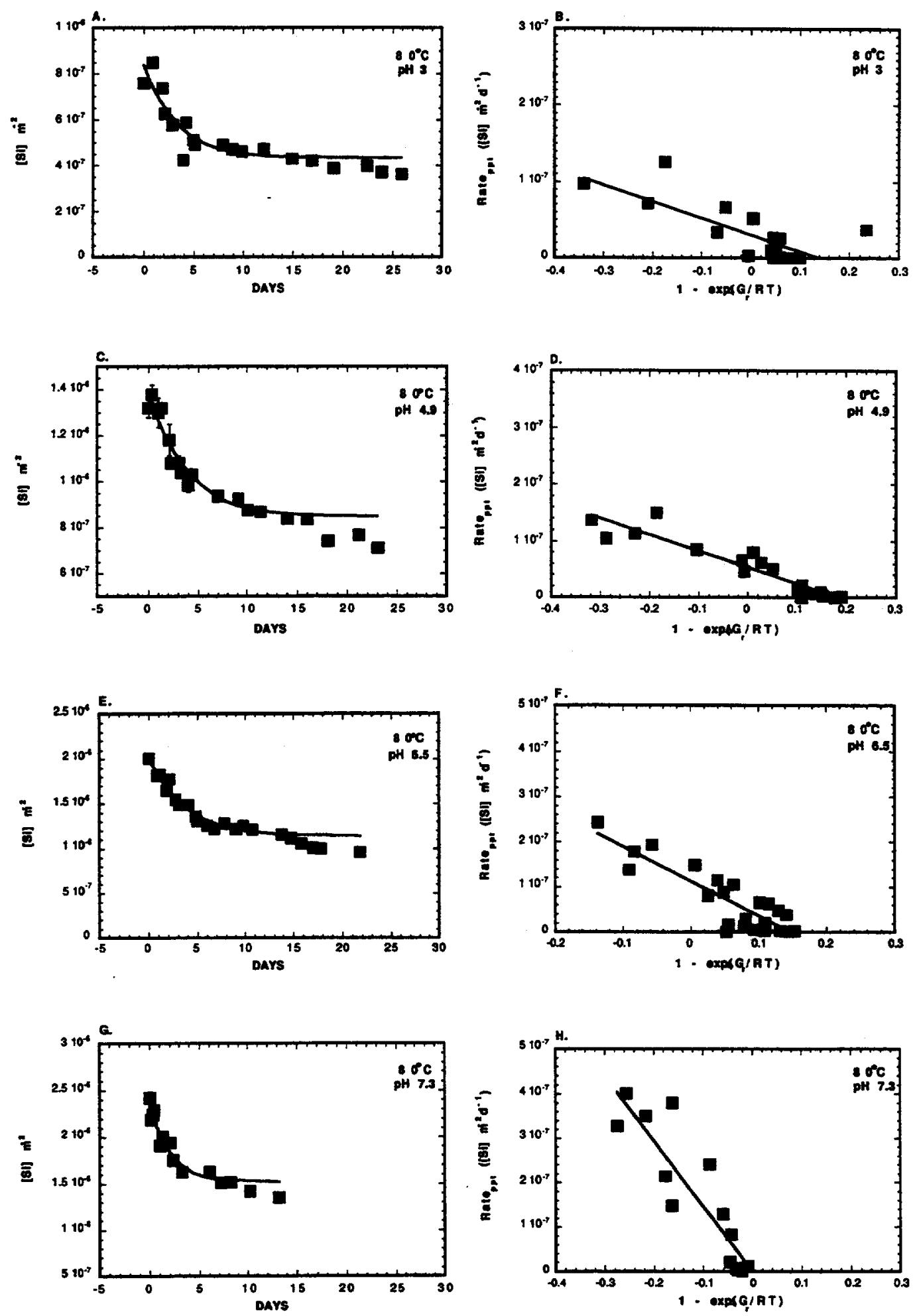

Figure 10.4-2. Amorphous silica precipitation rates plotted as [Si] $\mathrm{m}^{-2} \mathrm{vs.} \mathrm{Days} \mathrm{and} \mathrm{as}$ Rateppt $\left([\mathrm{Si}] \mathrm{m}^{-2} \mathrm{~d}^{-1}\right)$ vs. $[1-\exp (\Delta \mathrm{Gr} / \mathrm{RT})]$ at $80(\mathrm{~A}-\mathrm{H}), 100(\mathrm{I}-\mathrm{T})$ and $120^{\circ} \mathrm{C}(\mathrm{U}-\mathrm{X})$. 

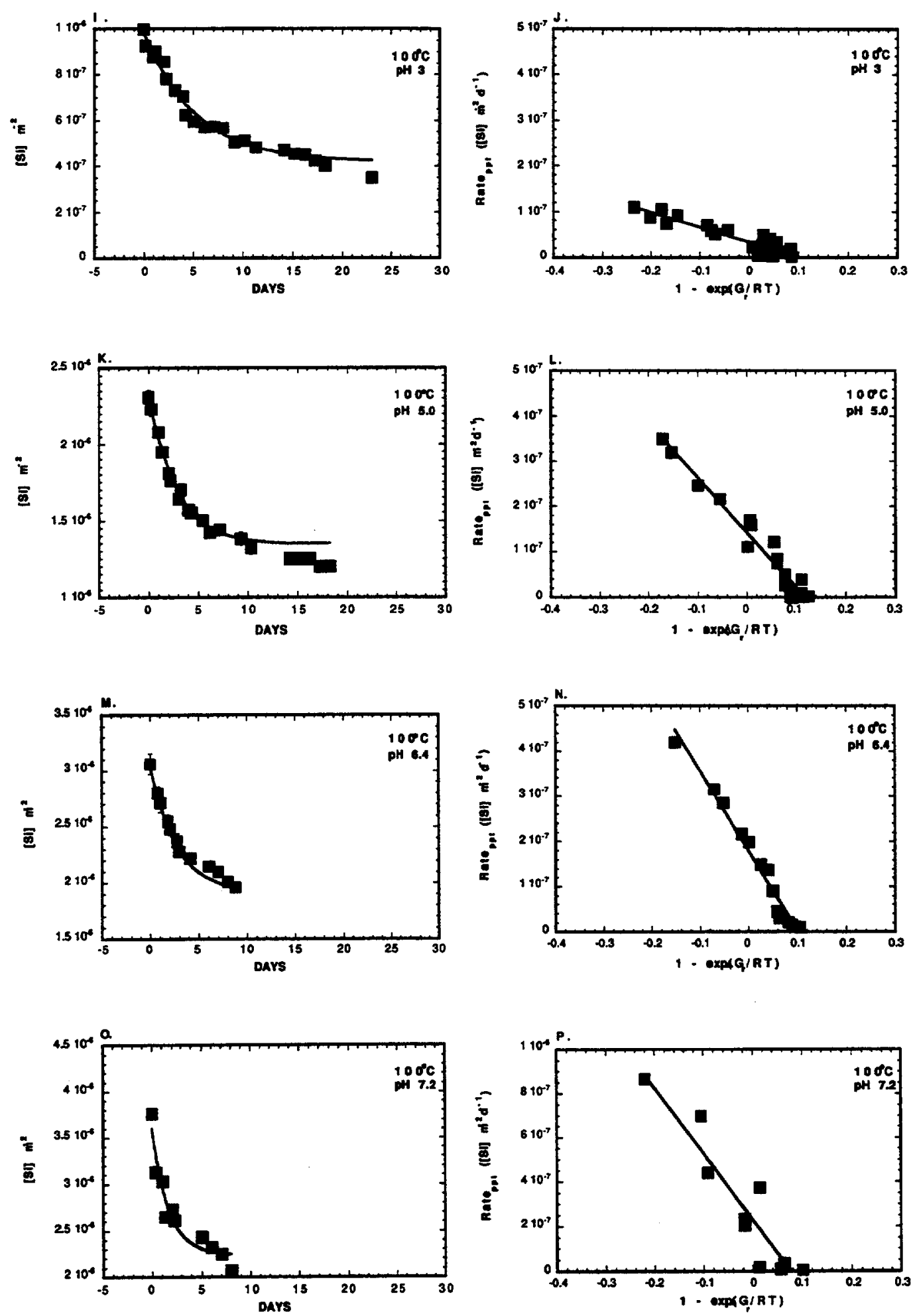

Figure 10.4-2. Continued. 

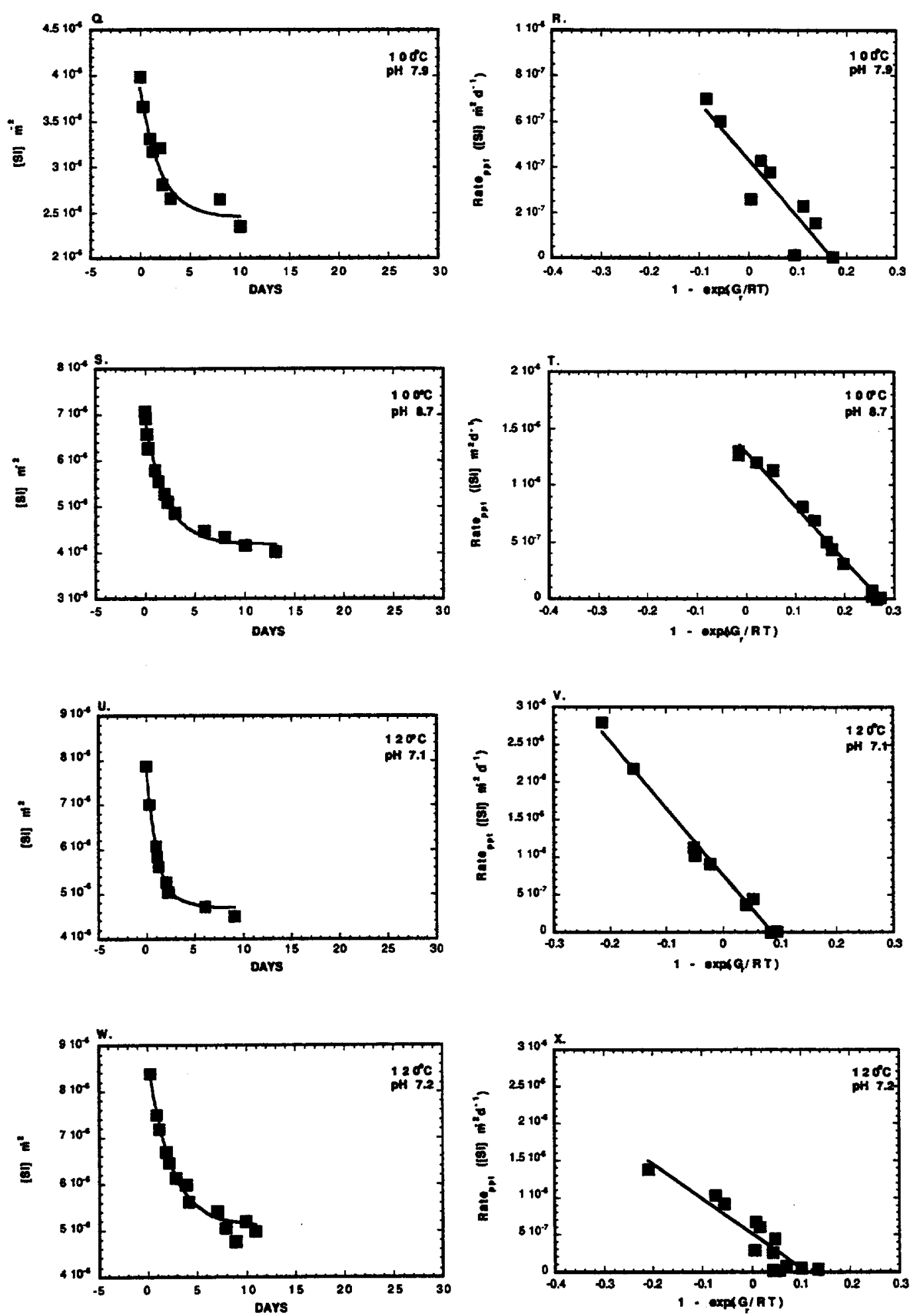

Figure 10.4-2. Continued. 


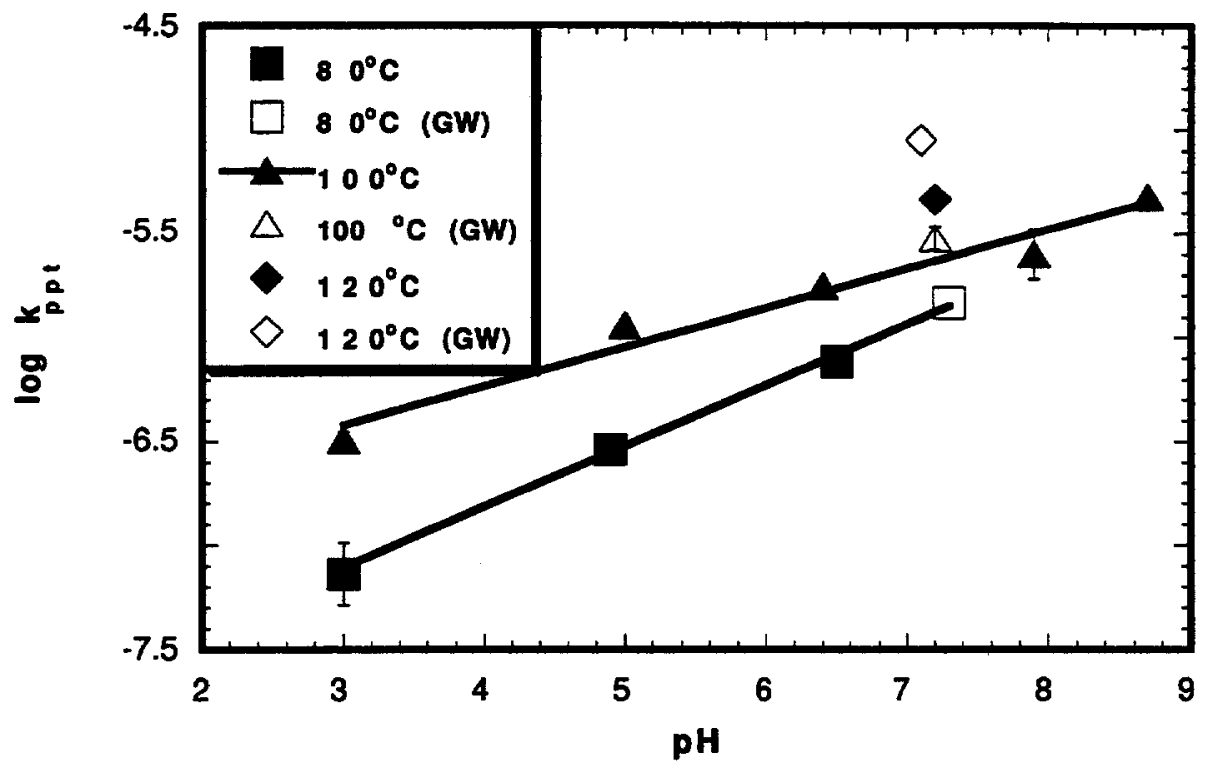

Figure 10.4-3. $\mathrm{pH}$-dependence of amorphous silica precipitation rates plotted as $\log \mathrm{kppt}_{\mathrm{pp}}$ ([Si] $\mathrm{m}^{-2} \mathrm{~d}^{-1}$ ) vs. $\mathrm{pH}$ at 80,100 , and $120^{\circ} \mathrm{C}$. GW refers to amorphous silica precipitation from Wairakei geothermal waters.

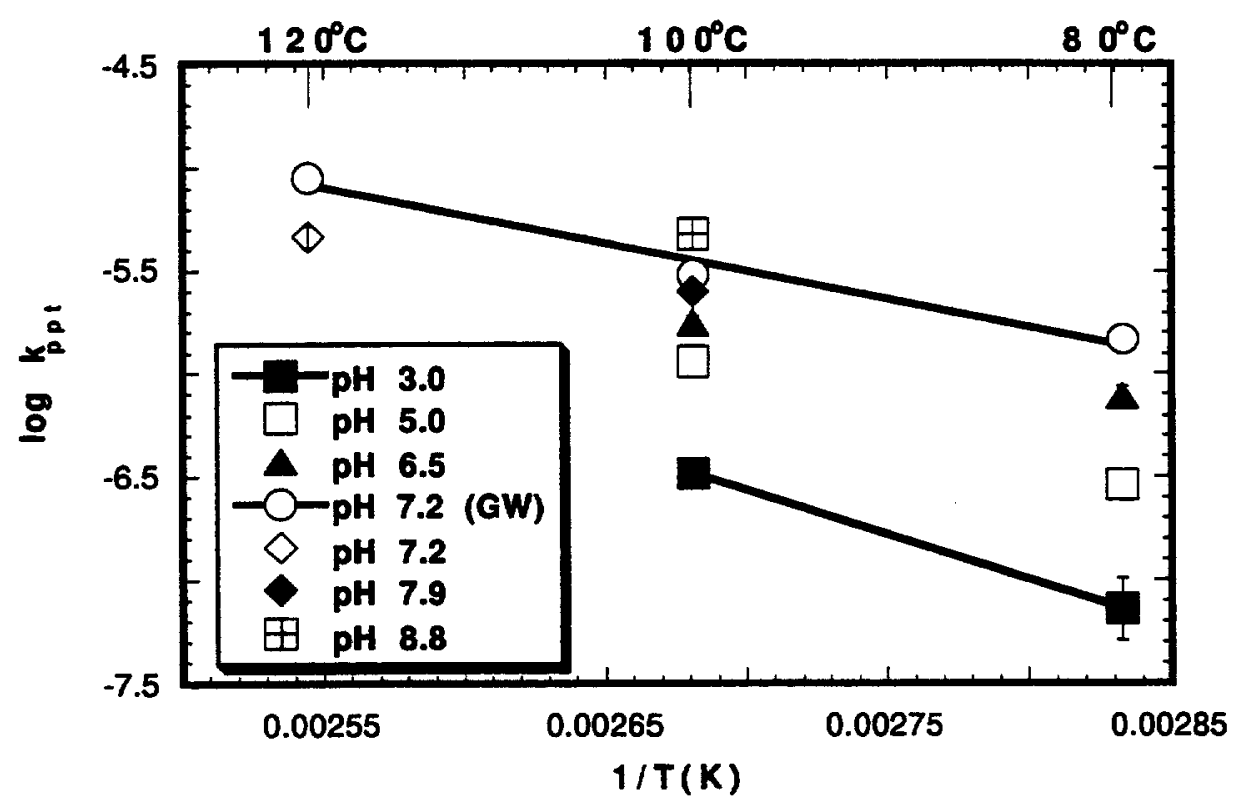

Figure 10.4-4. Temperature dependence of amorphous silica precipitation rates plotted as $\log k_{\text {ppt }}\left([\mathrm{Si}] \mathrm{m}^{-2} \mathrm{~d}^{-1}\right)$ vs. $1 / \mathrm{T}(\mathrm{K})$. GW refers to amorphous silica precipitation from Wairakei geothermal waters. 

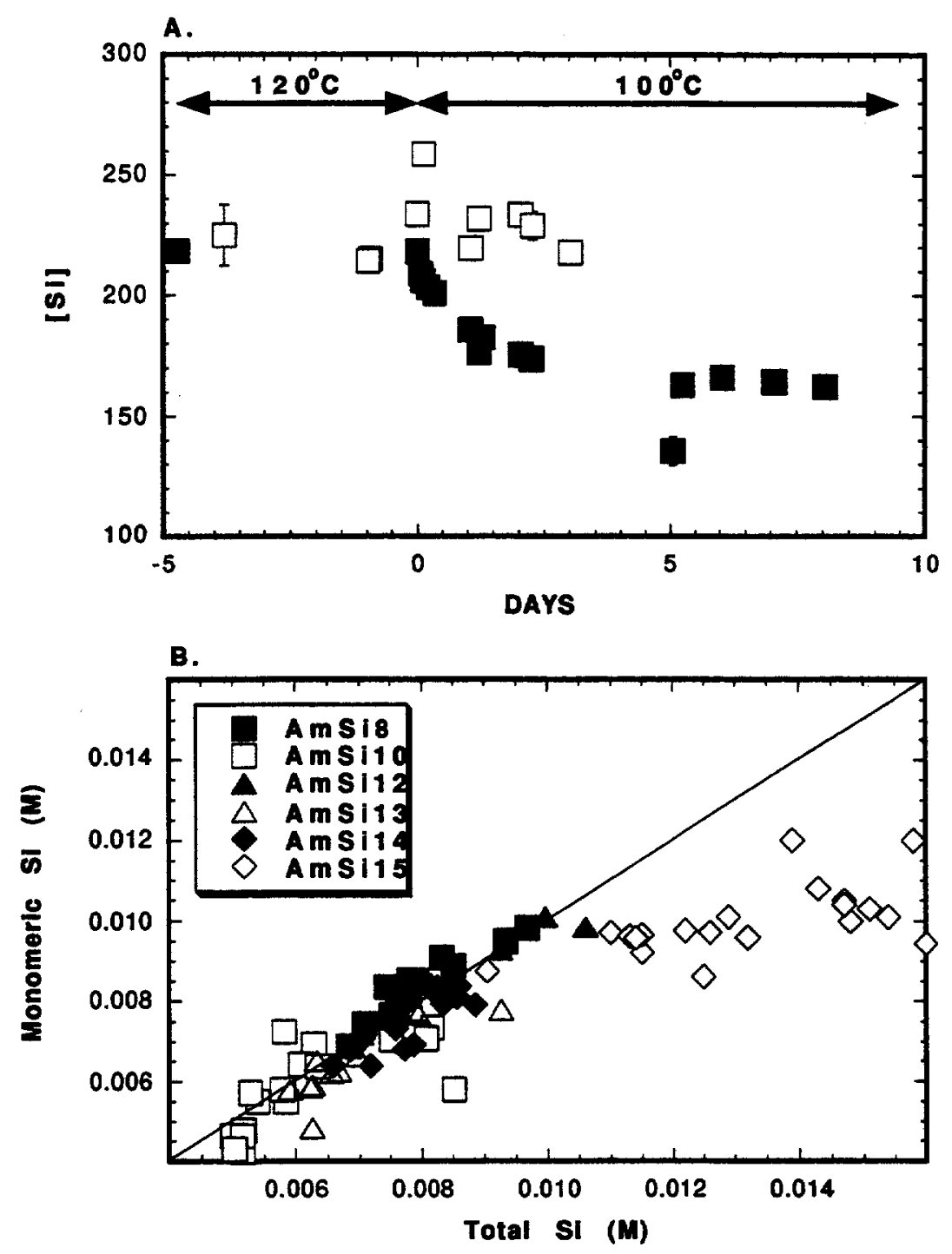

Figure 10.4-5. A. Monomeric silica concentrations vs. time in Wairakei geothermal waters in the absence (open squares) and presence (solid squares) of amorphous silica seed material. Negative days refer to time before temperature change. $B$. Ratio of monomeric to total silica. 


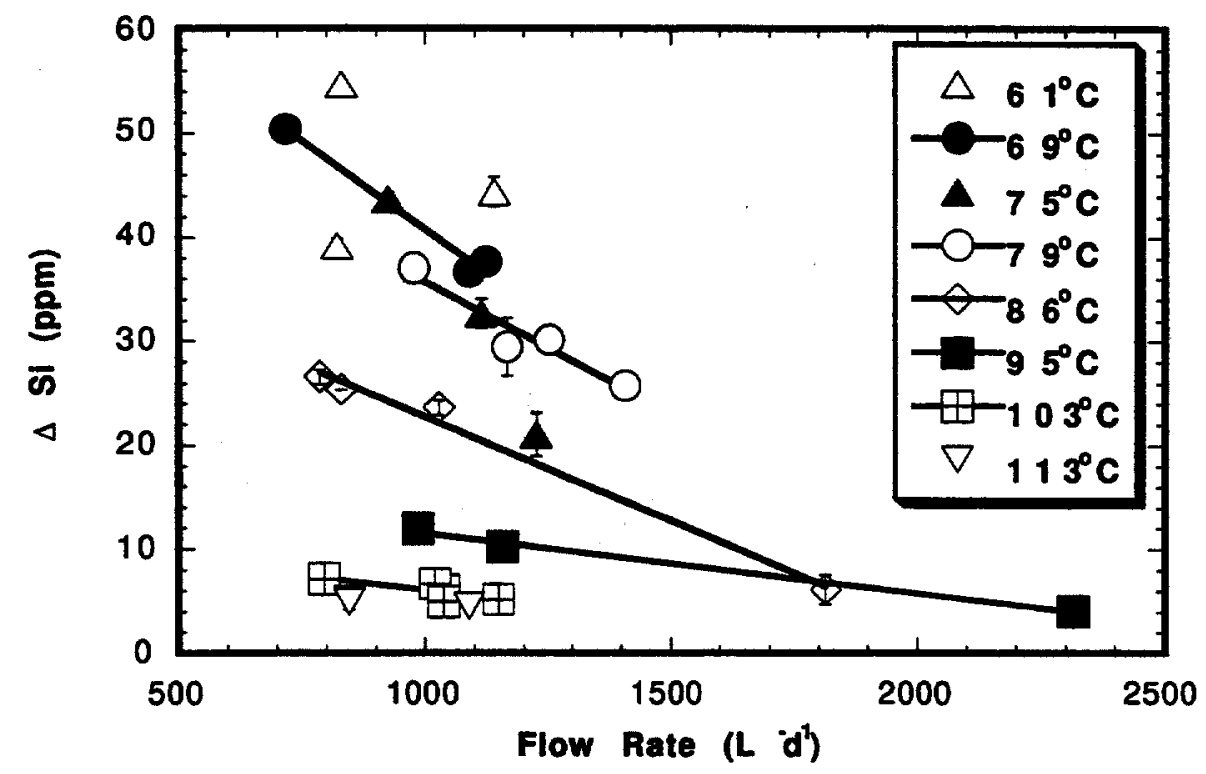

Figure 10.4-6. Amorphous silica precipitation from Wairakei Flash Plant 10 FBR experiments. Shown as the net silica removed from solution as a function of flow rate over discreet temperature intervals $\left(61,69 \pm 1,75 \pm 1,79 \pm 1,86 \pm 2,95 \pm 2,103 \pm 2\right.$, and $\left.113 \pm 2^{\circ} \mathrm{C}\right)$.

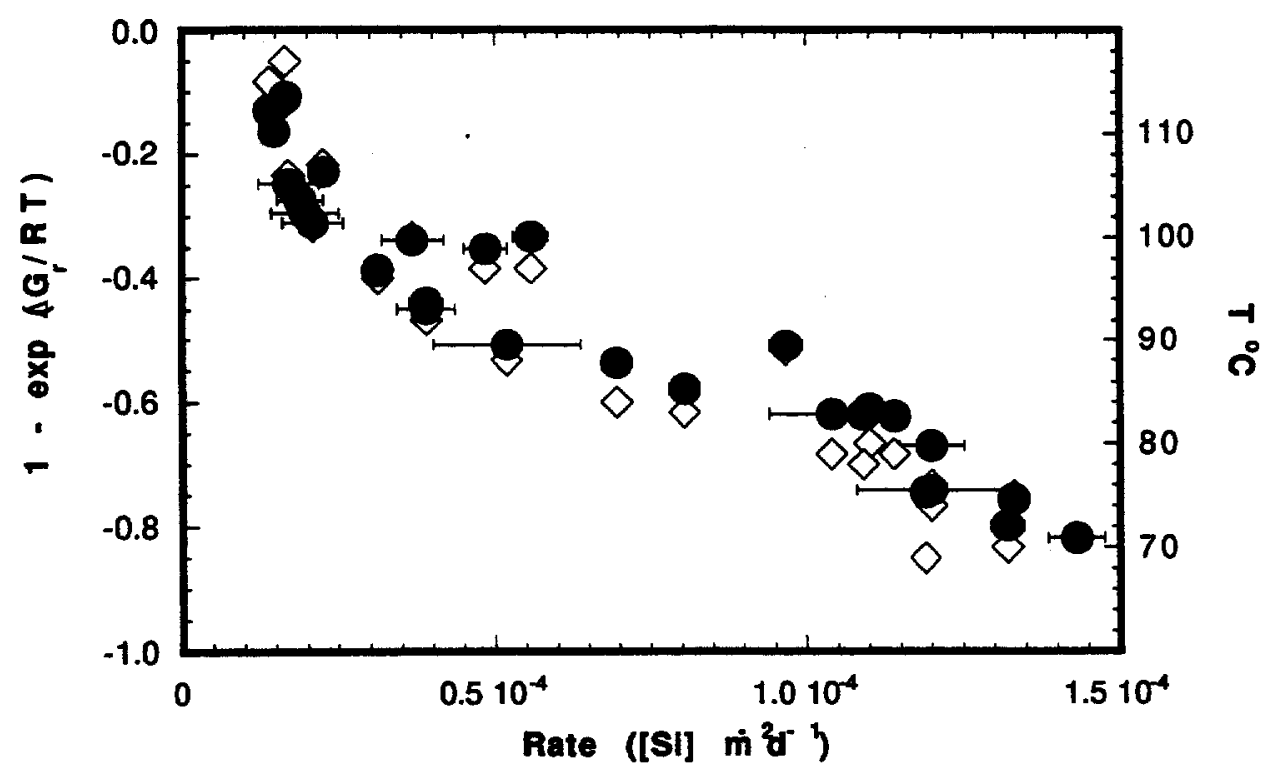

Figure 10.4-7. Precipitation rates determined in the fluidized bed reactor at Wairakei plotted as a function of $T^{\circ} \mathrm{C}$ (open diamonds) and $\left(1-\exp \left(\Delta \mathrm{G}_{\mathrm{r}} / \mathrm{RT}\right)\right.$ ) (solid circles). 


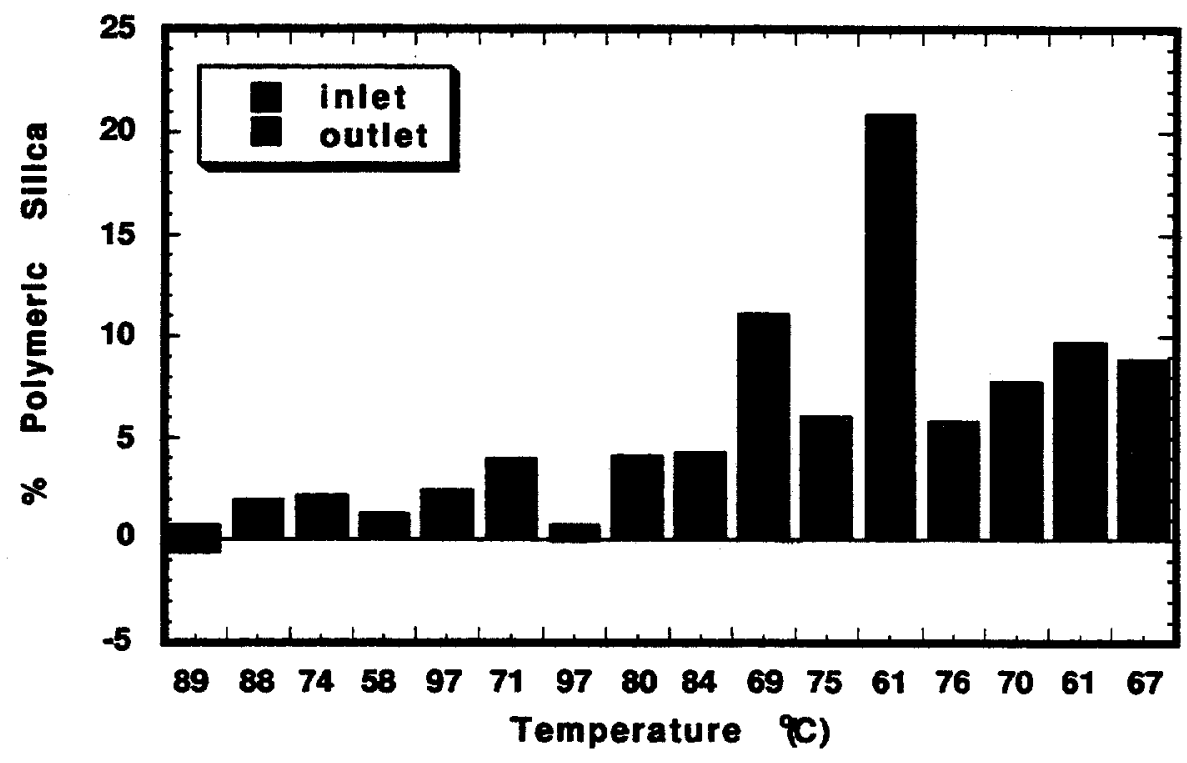

Figure 10.4-8. Stacked percentage of polymeric silica in inlet and outlet samples taken at a given time and temperature calculated from measurements of total $\mathrm{Si}$ and monomeric silica.

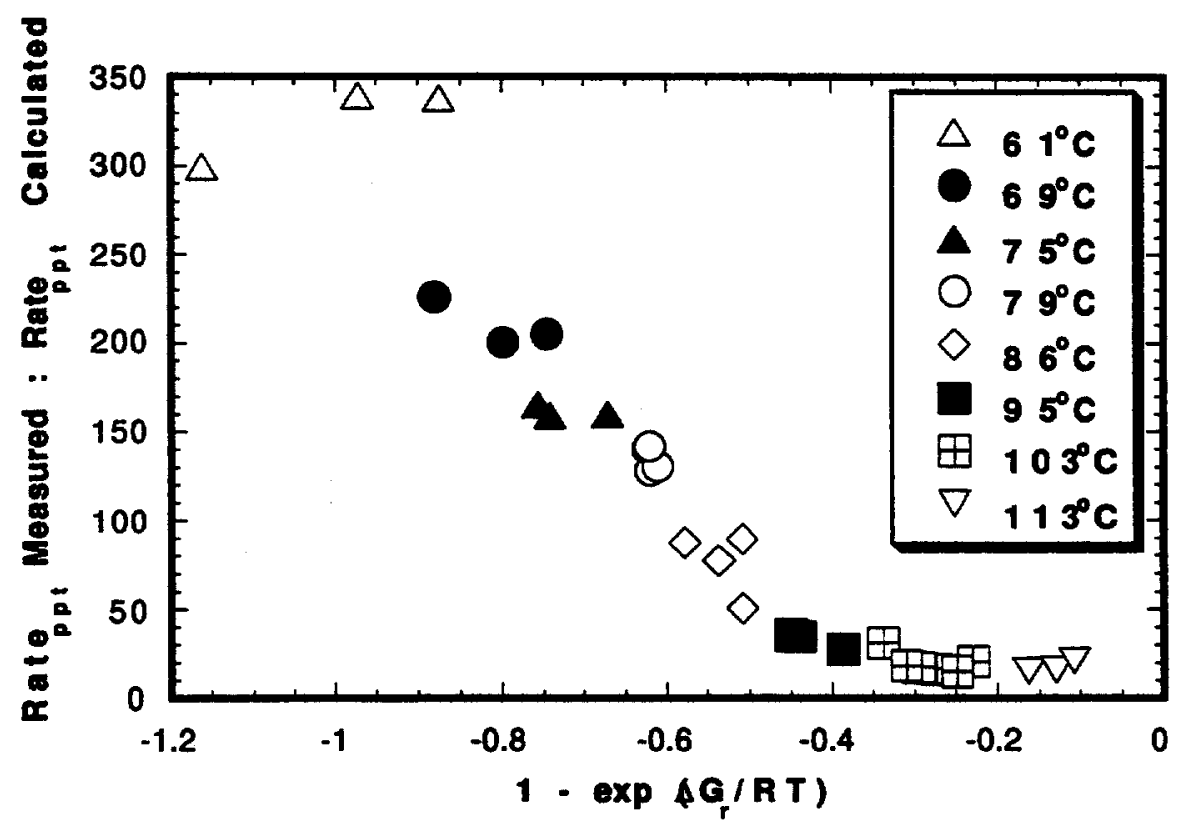

Figure 10.4-9. Comparison of field and laboratory amorphous silica precipitation rates by plotting the ratio of the measured and calculated rates from the Wairakei, New Zealand, field study. The rates were calculated based on the laboratory results (see text). 

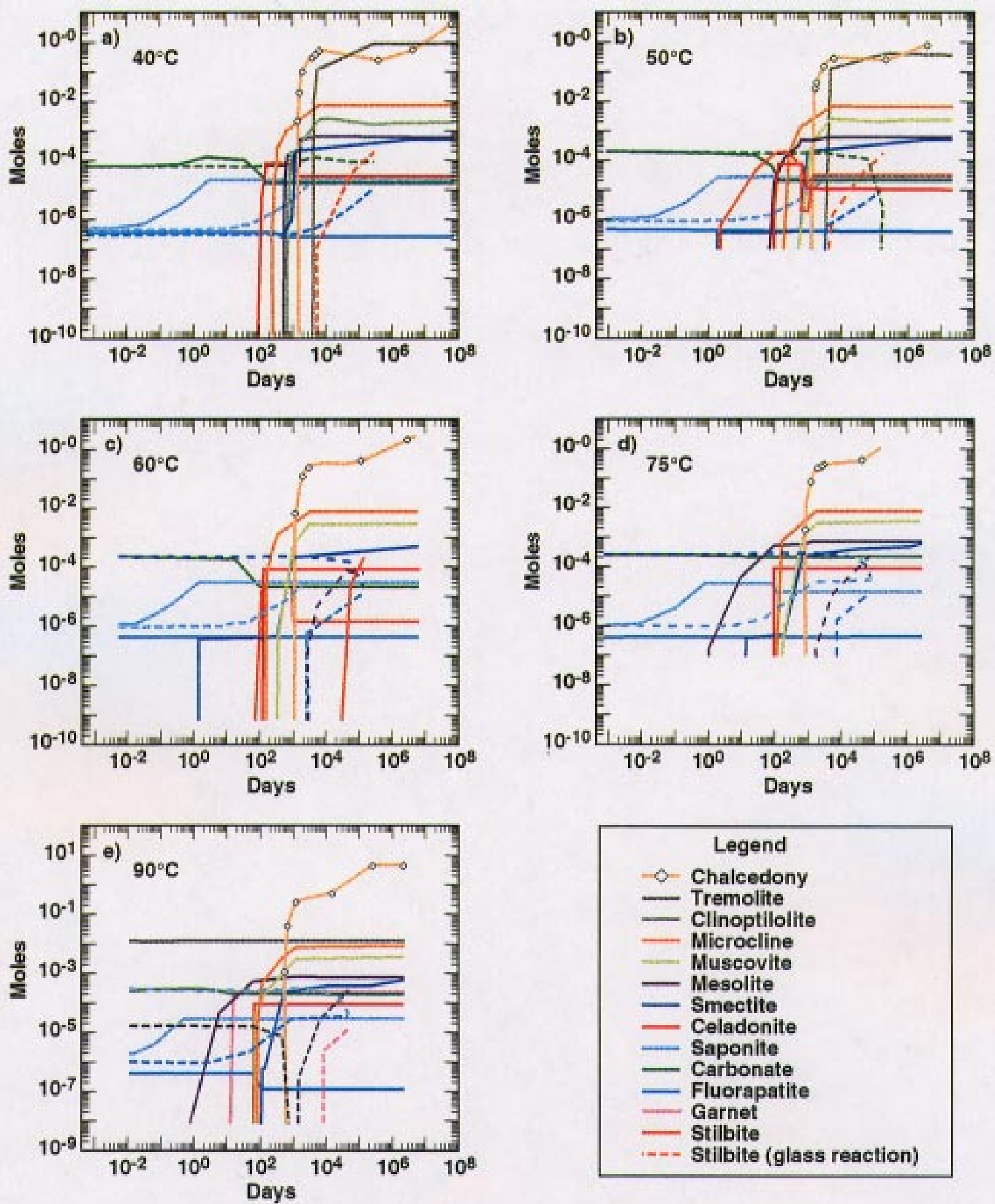

Figure $10.4-10$. Secondary mineralogy as a function of time. a) $40^{\circ} \mathrm{C}$; b) $50^{\circ} \mathrm{C}$; c) $60^{\circ} \mathrm{C} ;$ d) $75^{\circ} \mathrm{C} ;$ e) $90^{\circ} \mathrm{C}$. Mineralogy of the tuffs is shown as solid lines, mineralogy of the vitrophyre is shown as broken lines. These relationships for the vitrophyre are for the case in which the waterglass mass ratio is 5763 . Rate constants and surface areas for the vitrophyre case were adjusted so that the time at which most of the secondary minerals developed was similar to that for the tuff. For the case in which the water:rock mass ratio was much lower (57.8), the same mineral phases developed for the vitrophyre during the early stages of reaction progress, but were eventually superseded by chalcedony and hematite. 


\section{Tuff Water Chemistry}

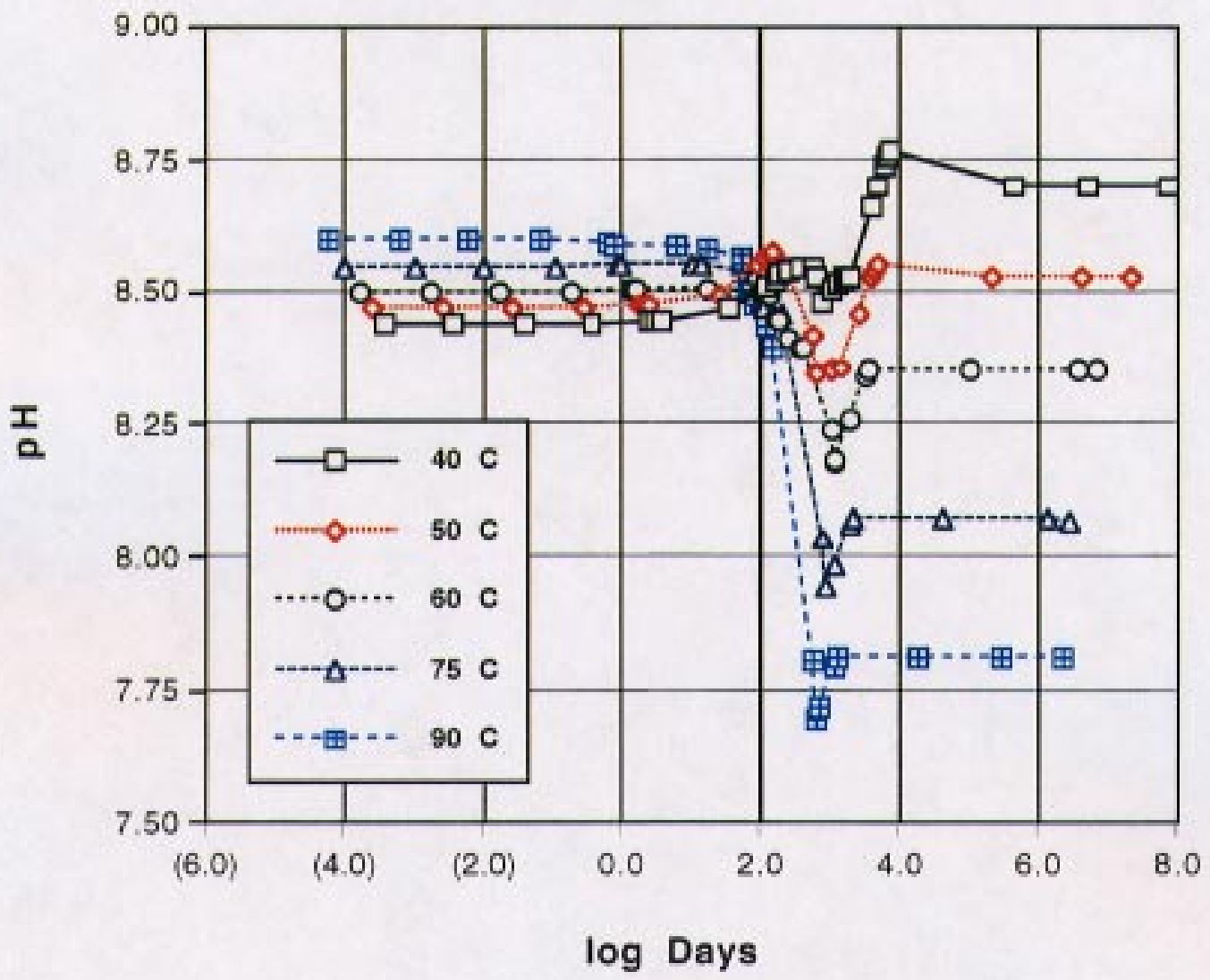

Figure $10.4-11$ (a) $\mathrm{pH}$

Figure 10.4-11. Tuff-water system aqueous compositions, as a function of time and temperature. a) $\mathrm{pH}$; b) Eh; c) $\mathrm{Si}$; d) $\mathrm{Na}$; e) $\mathrm{Ca}$; f) $\mathrm{Mg}$; g) Al. All elemental values are for total element concentrations. 


\section{Tuff Water Chemistry}

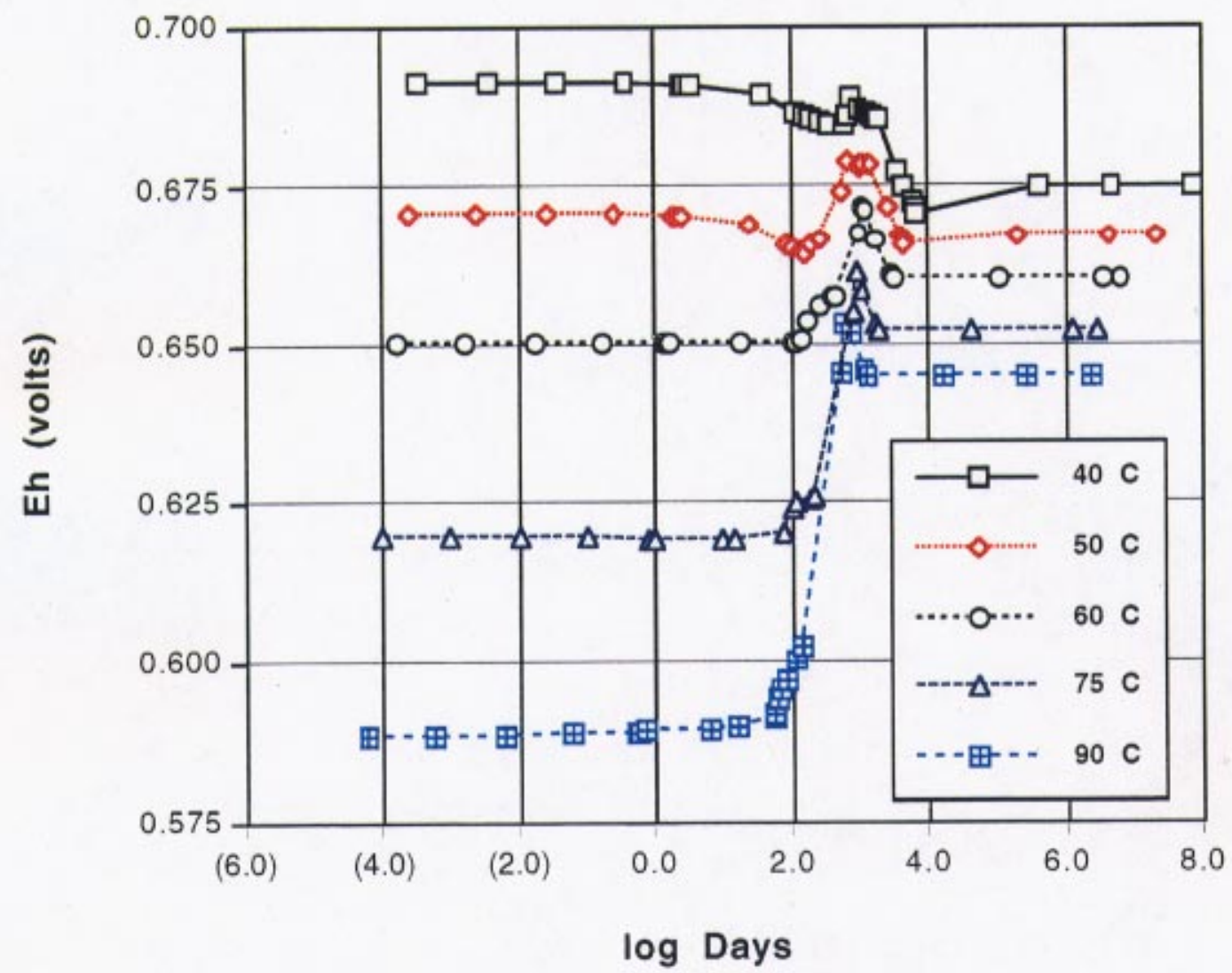

Figure 10.4-11(b) Eh

Figure 10.4-11. Tuff-water system aqueous compositions, as a function of time and temperature. a) $\mathrm{pH}$; b) $\mathrm{Eh}$; c) $\mathrm{Si}$; d) $\mathrm{Na}$; e) $\mathrm{Ca}$; f) $\mathrm{Mg}$; g) Al. All elemental values are for total element concentrations. 



\section{Tuff Water Chemistry}

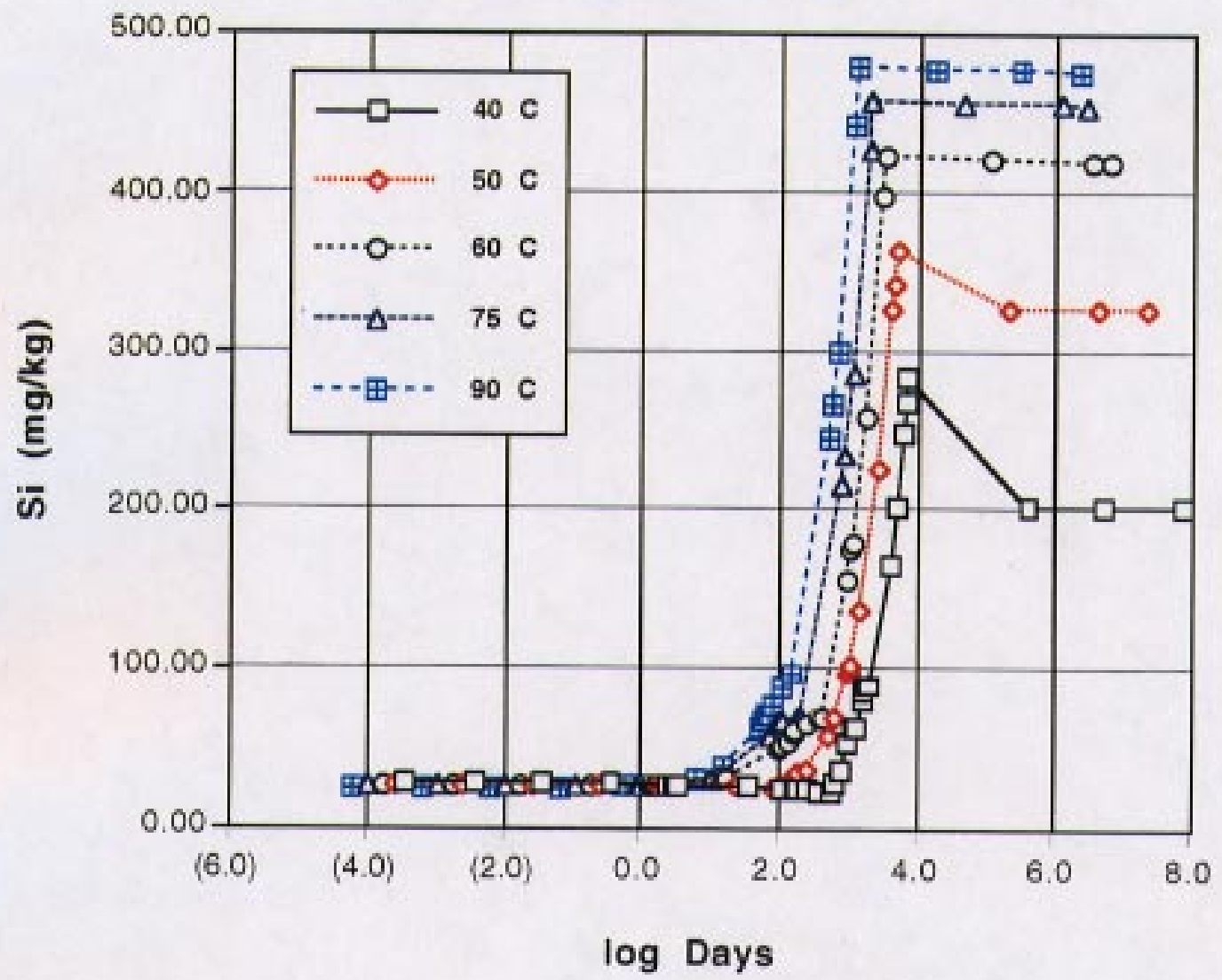

Figure $10.4-11$ (c) $\mathrm{Si}$

Figure 10.4-11. Tuff-water system aqueous compositions, as a function of time and temperature. a) $\mathrm{pH}$; b) $\mathrm{Eh}$; c) $\mathrm{Si}$; d) $\mathrm{Na}$; e) $\mathrm{Ca}$; f) $\mathrm{Mg}$; ) $\mathrm{Al}$. All elemental values are for total element concentrations. 



\section{Tuff Water Chemistry}

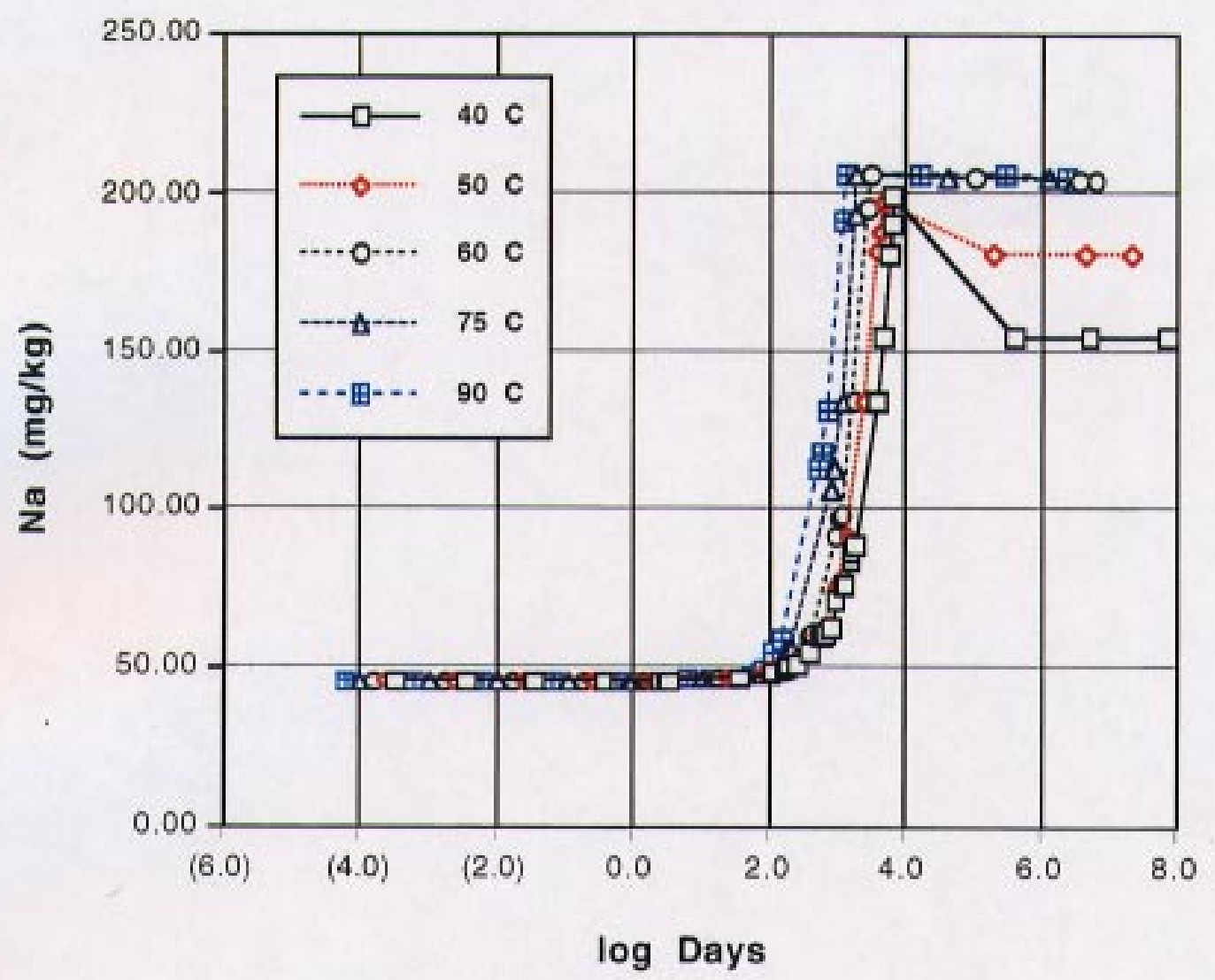

Figure 10.4-11(d) $\mathrm{Na}$

Figure 10.4-11. Tuff-water system aqueous compositions, as a function of time and temperature. a) $\mathrm{pH}$; b) Eh; c) Si; d) $\mathrm{Na}$; e) $\mathrm{Ca}$; f) $\mathrm{Mg} ; \mathrm{g}$ ) Al. All elemental values are for total element concentrations. 


\section{Tuff Water Chemistry}

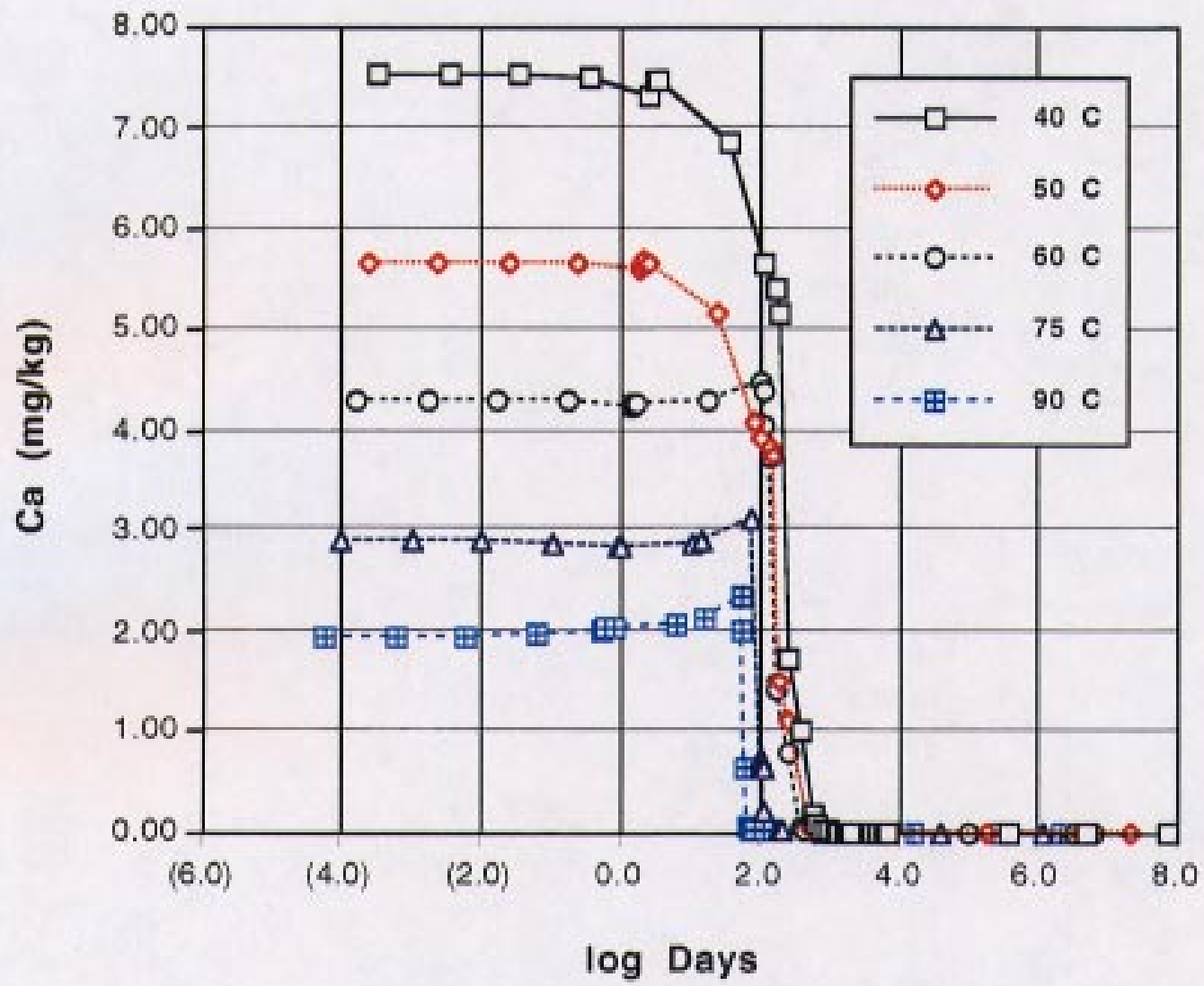

Figure 10.4-11(e) Ca

Figure 10.4-11. Tuff-water system aqueous compositions, as a function of time and temperature. a) $\mathrm{pH}$; b) Eh; c) $\mathrm{Si}$; d) $\mathrm{Na}$; e) $\mathrm{Ca}$; f) $\mathrm{Mg}$; g) Al. All elemental values are for total element concentrations. 



\section{Tuff Water Chemistry}

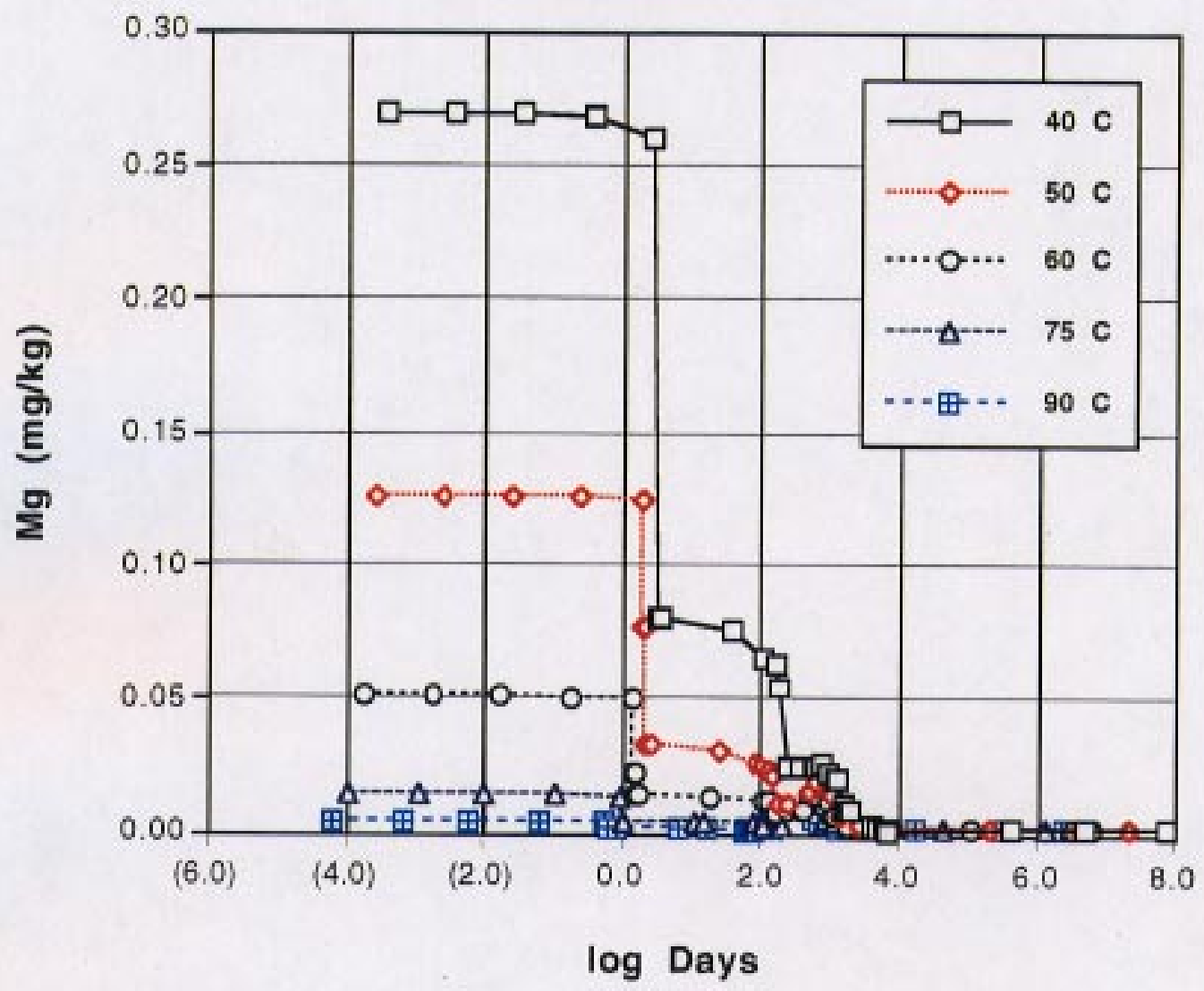

Figure 10.4-11(f) Mg

Figure 10.4-11. Tuff-water system aqueous compositions, as a function of time and temperature. a) $\mathrm{pH}$; b) $\mathrm{Eh}$; c) $\mathrm{Si}$; d) $\mathrm{Na}$; e) $\mathrm{Ca}$; f) $\mathrm{Mg}$; ) Al. All elemental values are for total element concentrations. 



\section{Tuff Water Chemistry}

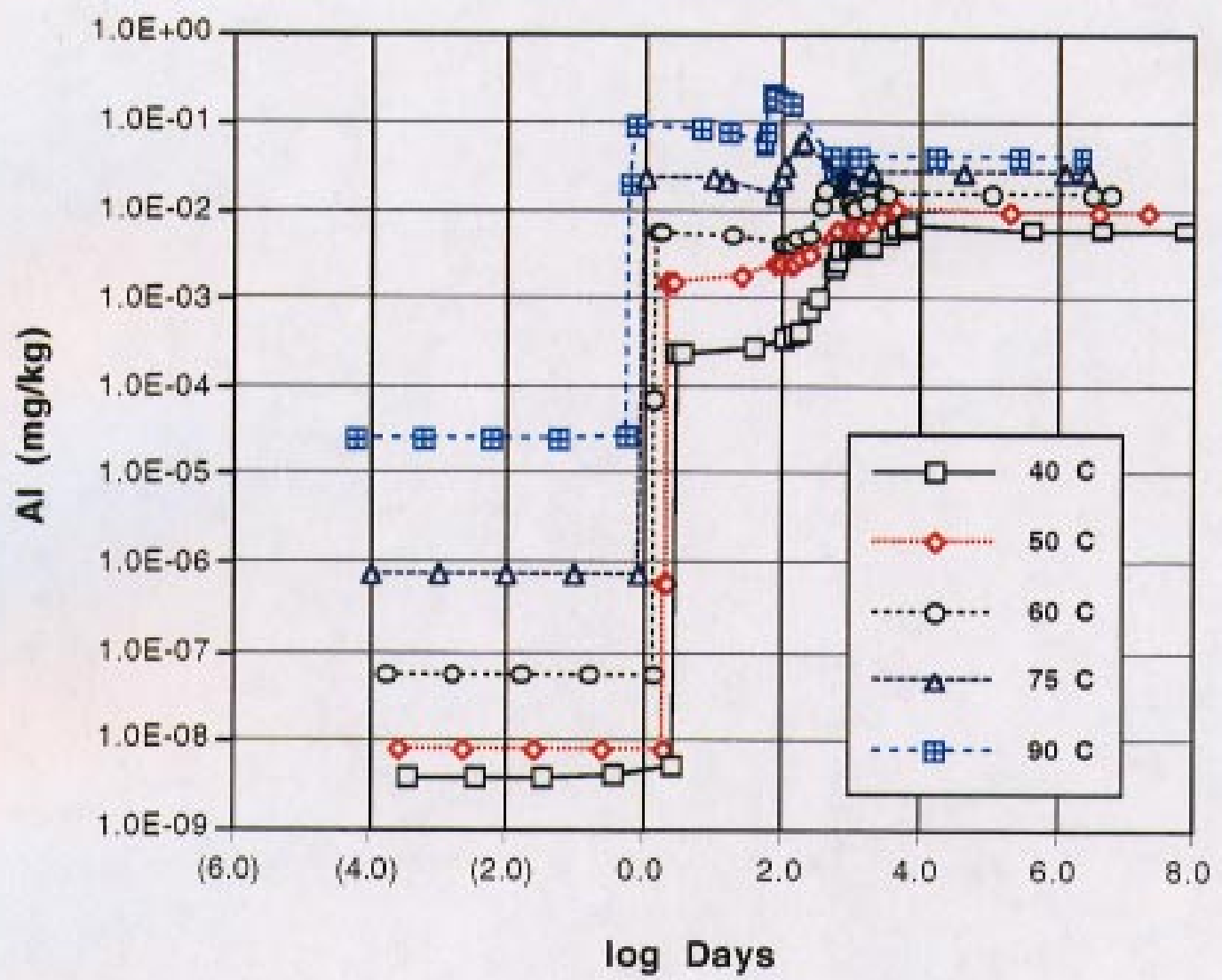

Figure 10.4-11(g) Al

Figure 10.4-11. Tuff-water system aqueous compositions, as a function of time and temperature. a) $\mathrm{pH}$; b) $\mathrm{Eh} ;$ c) $\mathrm{Si}$;) $\mathrm{Na}$; e) $\mathrm{Ca}$; f) $\mathrm{Mg}$; g) Al. All elemental values are for total element concentrations. 


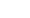




\section{Glass - Water Chemistry (Long Duration)}

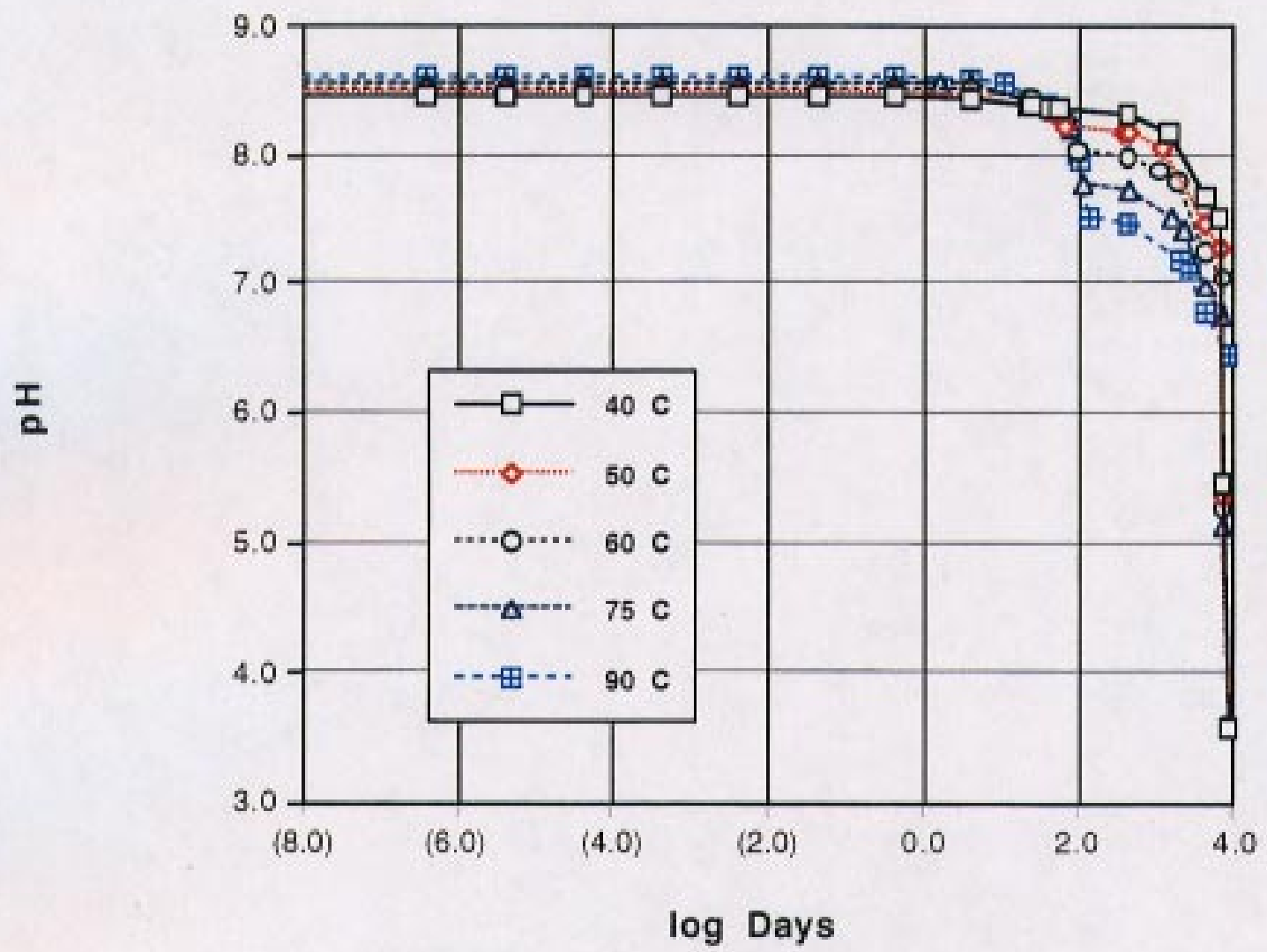

Figure 10.4-12(a) $\mathrm{pH}$

Figure 10.4-12. Vitrophyre-water system aqueous compositions for waterrock mass ratio of 57.8, as a function of time and temperature. a) $\mathrm{pH}$; b) Eh; c) $\mathrm{Si}$; d) $\mathrm{Na}$; e) Ca; f) $\mathrm{Mg}$; g) Al. All elemental values are for total element concentrations. For the case in which the waterirock mass ratio was 5763 , the water compositions reached the values shown in these figures at ca. $10^{2}$ days, although in those simulations reaction rates were such that these values were not acheived until ca. $4 \times 10^{5}$ days. 
, 


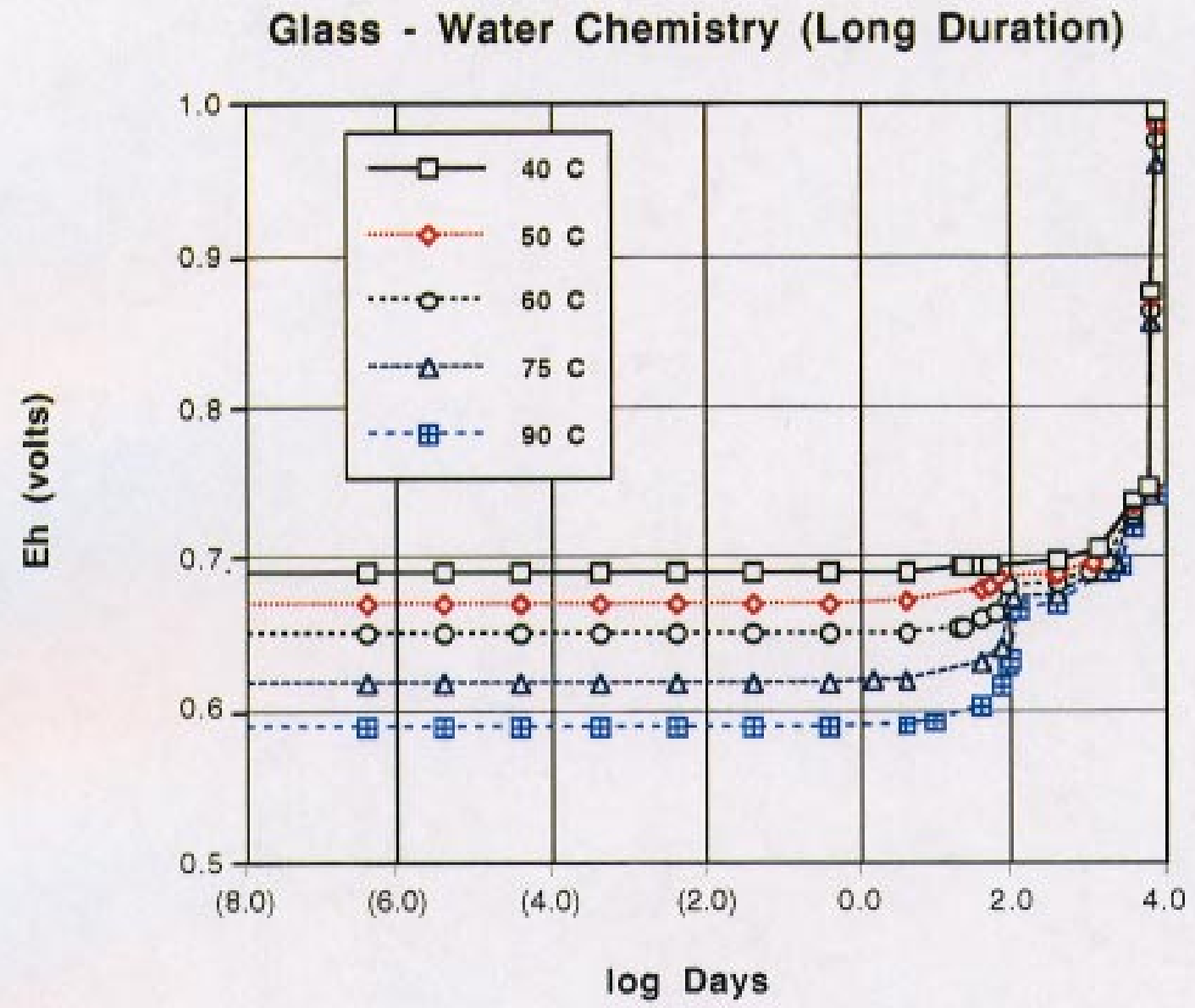

Figure 10.4-12(b) Eh

Figure 10.4-12. Vitrophyre-water system aqueous compositions for water:rock mass ratio of 57.8, as a function of time and temperature. a) $\mathrm{pH}$; b) Eh; c) $\mathrm{Si}$; d) $\mathrm{Na}$; e) $\mathrm{Ca}$; ) $\mathrm{Mg}$; g) Al. All elemental values are for total element concentrations. For the case in which the water:rock mass ratio was 5763 , the water compositions reached the values shown in these figures at ca. $10^{2}$ days, although in those simulations reaction rates were such that these values were not acheived until ca. $4 \times 10^{5}$ days. 


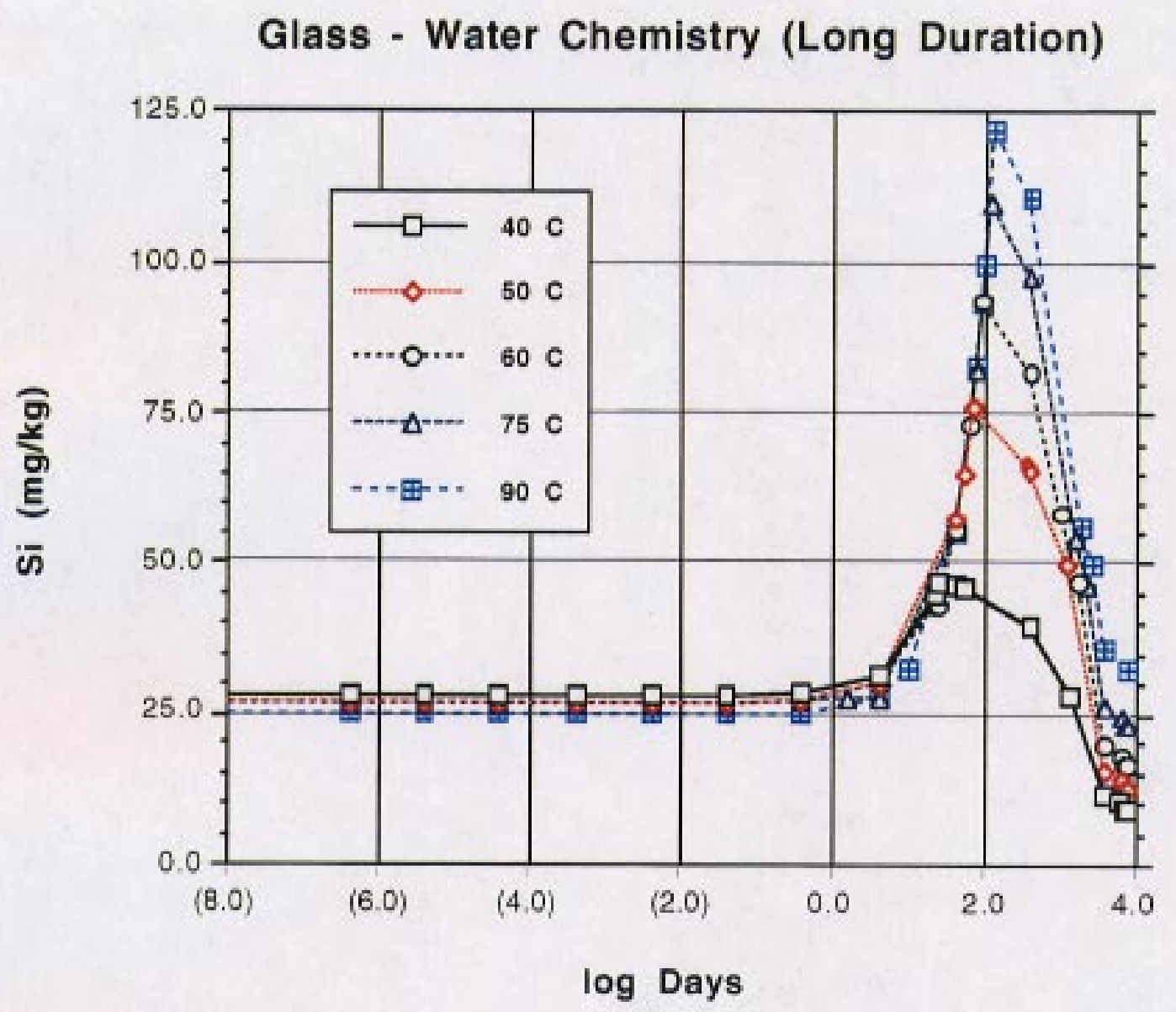

Figure 10.4-12(c) Si

Figure 10.4-12. Vitrophyre-water system aqueous compositions for water:rock mass ratio of 57.8, as a function of time and temperature. a) $\mathrm{pH}$; b) Eh; c) $\mathrm{Si}$; d) $\mathrm{Na}$; e) $\mathrm{Ca}$; f) $\mathrm{Mg}$; g) Al. All elemental values are for total element concentrations. For the case in which the water:rock mass ratio was 5763 , the water compositions reached the values shown in these figures at ca. $10^{2}$ days, although in those simulations reaction rates were such that these values were not acheived until ca, $4 \times 10^{5}$ days. 


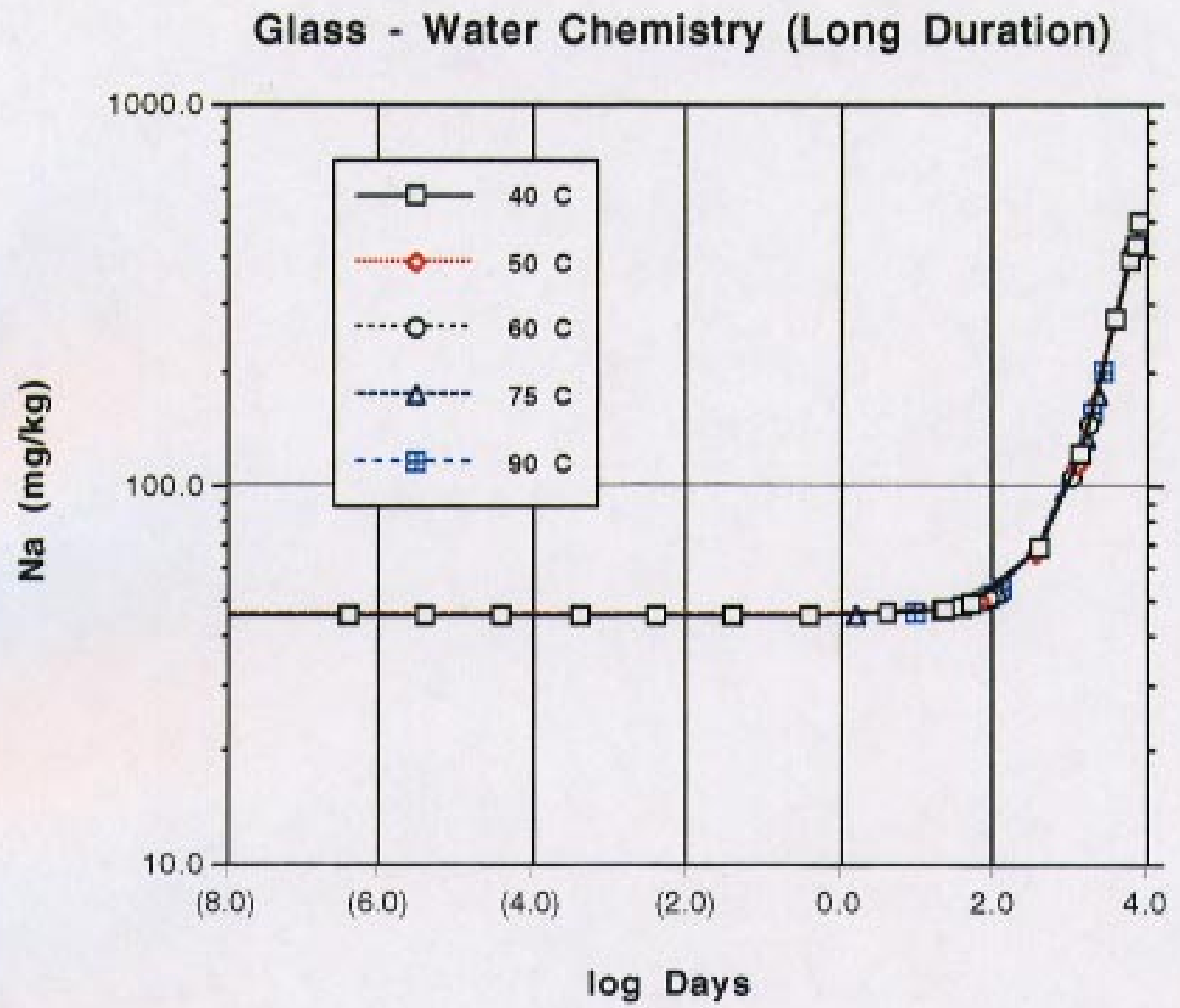

Figure 10.4-12(d) $\mathrm{Na}$

Figure 10.4-12. Vitrophyre-water system aqueous compositions for water:rock mass ratio of 57.8, as a function of time and temperature. a) $\mathrm{pH}$; b) Eh; c) $\mathrm{Si}$; d) $\mathrm{Na}$; e) $\mathrm{Ca}$; f) $\mathrm{Mg}$; g) Al. All elemental values are for total element concentrations. For the case in which the waterrock mass ratio was 5763 , the water compositions reached the values shown in these figures at ca. $10^{2}$ days, although in those simulations reaction rates were such that these values were not acheived until ca. $4 \times 10^{5}$ days. 



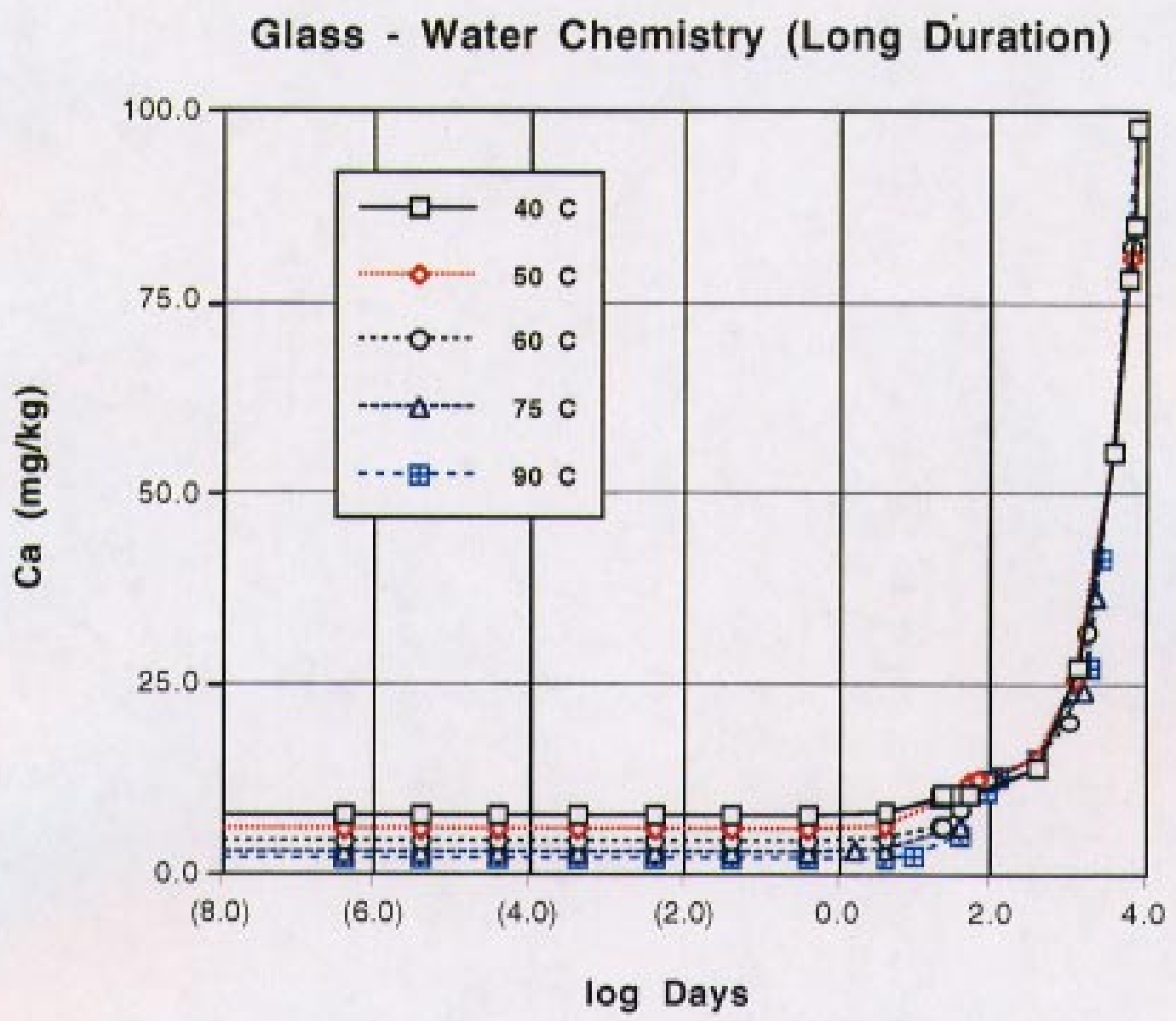

Figure 10.4-12(e) Ca

Figure 10.4-12. Vitrophyre-water system aqueous compositions for water:rock mass ratio of 57.8, as a function of time and temperature. a) $\mathrm{pH}$; b) Eh; c) $\mathrm{Si}$; d) $\mathrm{Na}$; e) $\mathrm{Ca}$; f) $\mathrm{Mg}$; g) Al. All elemental values are for total element concentrations. For the case in which the water:rock mass ratio was 5763 , the water compositions reached the values shown in these figures at ca. $10^{2}$ days, although in those simulations reaction rates were such that these values were not acheived until ca, $4 \times 10^{5}$ days. 


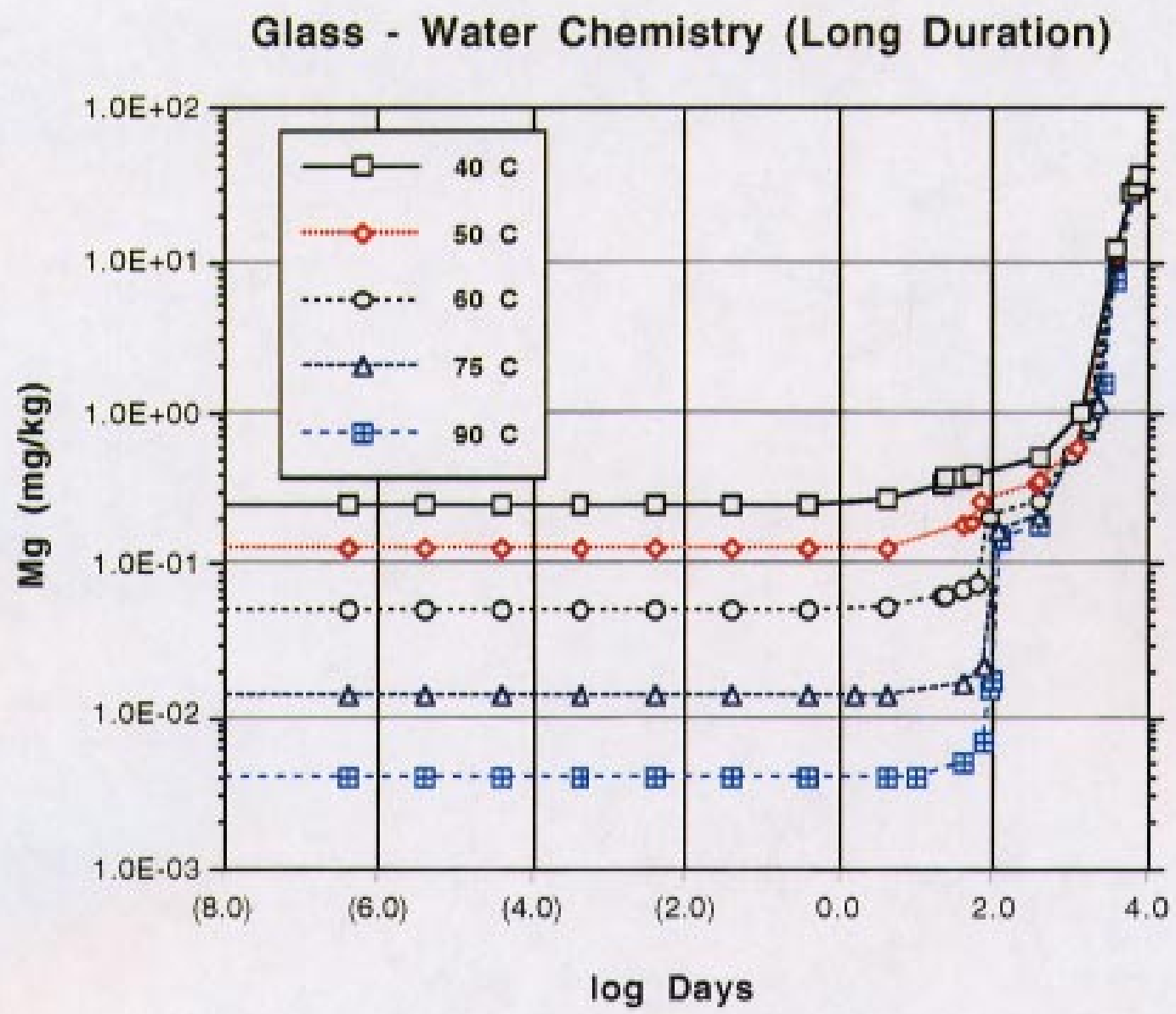

Figure 10.4-12(f) $\mathrm{Mg}$

Figure 10.4-12. Vitrophyre-water system aqueous compositions for water:rock mass ratio of 57.8, as a function of time and temperature. a) $\mathrm{pH}$; b) Eh; c) $\mathrm{Si}$;) $\mathrm{Na}$; e) $\mathrm{Ca}$; f) $\mathrm{Mg}$; g) Al. All elemental values are for total element concentrations. For the case in which the water:rock mass ratio was 5763 , the water compositions reached the values shown in these figures at ca. $10^{2}$ days, although in those simulations reaction rates were such that these values were not acheived until ca. $4 \times 10^{5}$ days. 


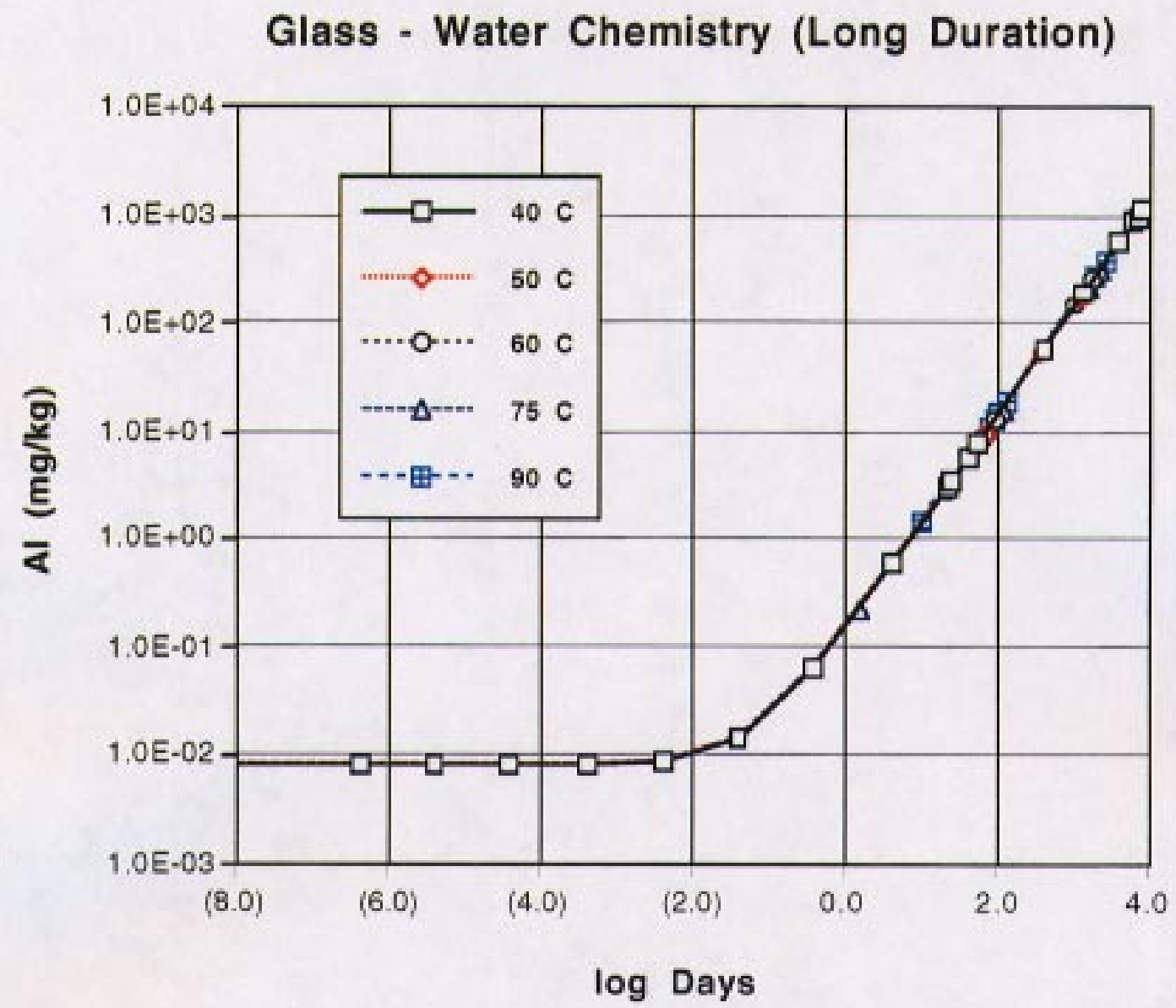

Figure $10.4-12(\mathrm{~g}) \mathrm{Al}$

Figure 10.4-12. Vitrophyre-water system aqueous compositions for water:rock mass ratio of 57.8, as a function of time and temperature. a) $\mathrm{pH}$; b) Eh; c) $\mathrm{Si}$; d) $\mathrm{Na}$; e) $\mathrm{Ca}$; f) $\mathrm{Mg}$; g) Al. All elemental values are for total element concentrations. For the case in which the water:rock mass ratio was 5763 , the water compositions reached the values shown in these figures at ca. $10^{2}$ days, although in those simulations reaction rates were such that these values were not acheived until ca. $4 \times 10^{5}$ days. 
. 


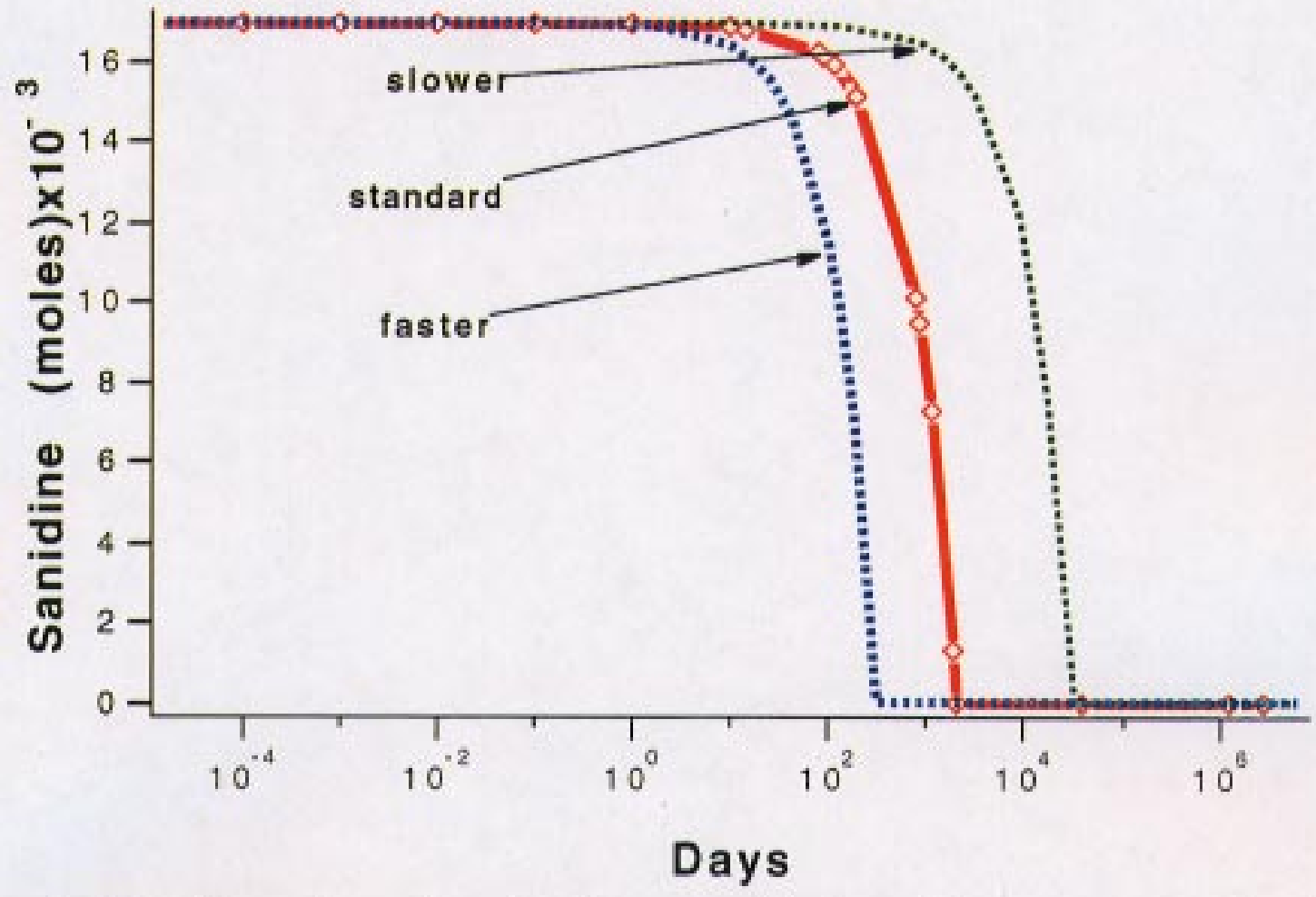

Figure 10.4-13. Changes in sanidine abundance resulting from plus or minus one order of magnitude change in its dissolution rate. 


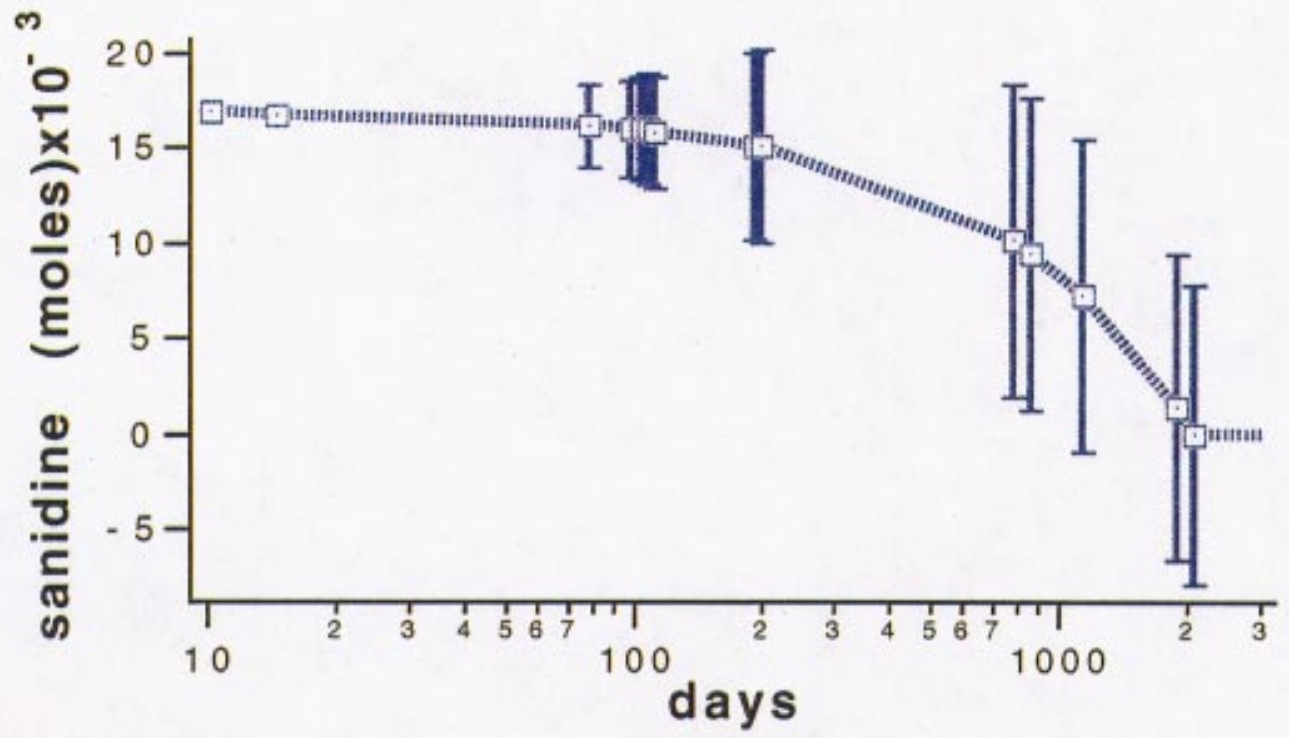

Figure 10.4-14. Estimates of sanidine abundance, assuming the dissolution rates used to construct Fig. 10.4-13. The error bars represent the abundances computed from the curves in Fig. 10.4-13. 

Figure 10.4-21. GIMRT sim2e: vol\%(sec.min.)(x) at 6 mo.

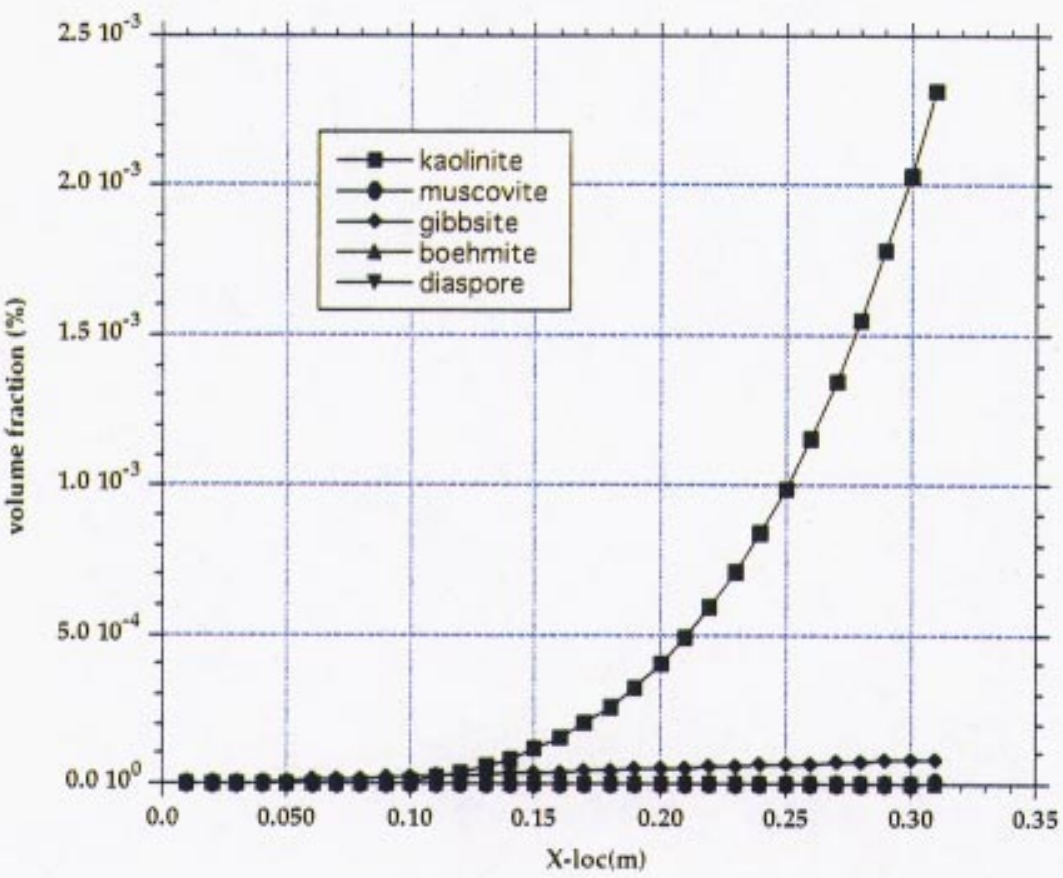

Figure. 10.4-21. Porosity and volume fractions of trace secondary minerals as a function of distance after six months for GIMRT simulation $2 \mathrm{c}$.

Figure 10.4-22. GIMRT $\operatorname{sim} 3 a: \log (Q / K)(t)$ at $1 \mathrm{~cm}$ (inlet)

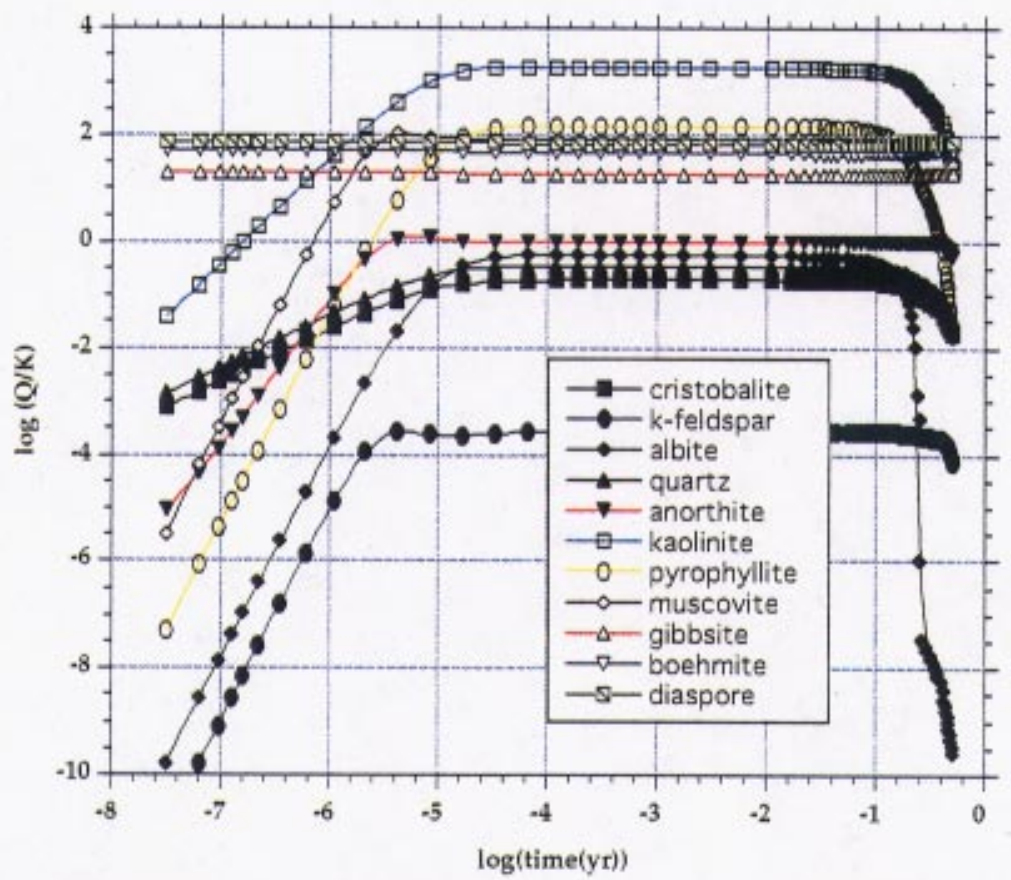

Figure. 10.4-22. Mineral saturation indices $(\log Q / K)$ as a function of time $(\log y r)$ at the inlet node $(1 \mathrm{~cm})$ of GIMRT simulation $3 \mathrm{a}$, where initial composition of the $31-\mathrm{cm}$ one-dinensional fluid-rock system is given in Tables $10.4-5$ and $10.4-6, T=250^{\circ} \mathrm{C}, \mathrm{P}=$ vapor saturation, fluid flux $=25 \mathrm{ml} /$ day $\left(266.7 \mathrm{~m}^{3} / \mathrm{m}^{2} / \mathrm{yr}\right)$, and porosity $=40 \%$. Primary and secondary minerals are represented by solid and open symbols, respectively. 
. 
Figure 10.4-17. GIMRT $\operatorname{sim} 2 \mathrm{c}: \log (\mathrm{Q} / \mathrm{K})(\mathrm{t})$ at $1 \mathrm{~cm}$ (inlet)

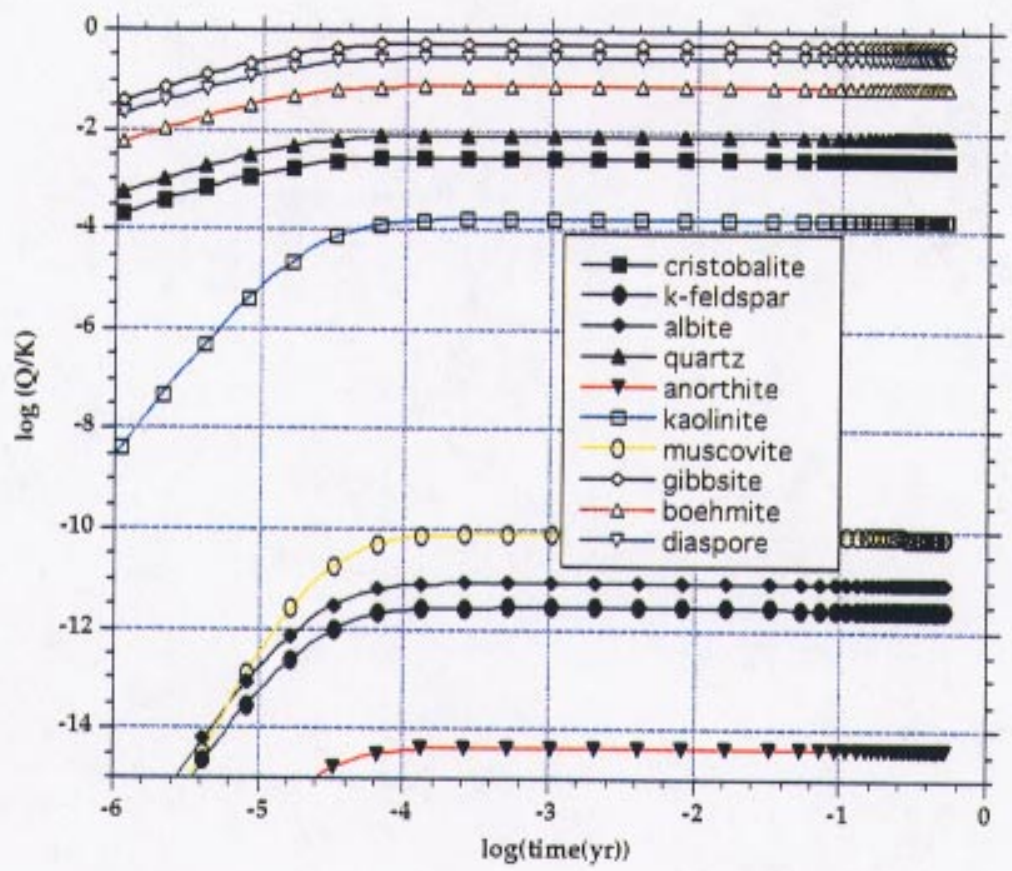

Figure. 10.4-17. Mineral saturation indices $(\log Q / K)$ as a function of time $(\log y r)$ at the inlet node $(1 \mathrm{~cm})$ of GIMRT simulation 2c, where initial composition of the 31-cm one-dinensional fluid-rock system is given in Tables 10.4-5 and 10.4-6, $\mathrm{T}=90^{\circ} \mathrm{C}, \mathrm{P}=$ vapor saturation, fluid flux $=25 \mathrm{ml} /$ day $\left(266.7 \mathrm{~m}^{3} / \mathrm{m}^{2} / \mathrm{yr}\right)$, and porosity $=40 \%$. Primary and secondary minerals are represented by solid and open symbols, respectively.

Figure 10.4-18. GIMRT $\operatorname{sim} 2 \mathrm{c}: \log (\mathrm{Q} / \mathrm{K})(\mathrm{t})$ at $31 \mathrm{~cm}$ (outlet)

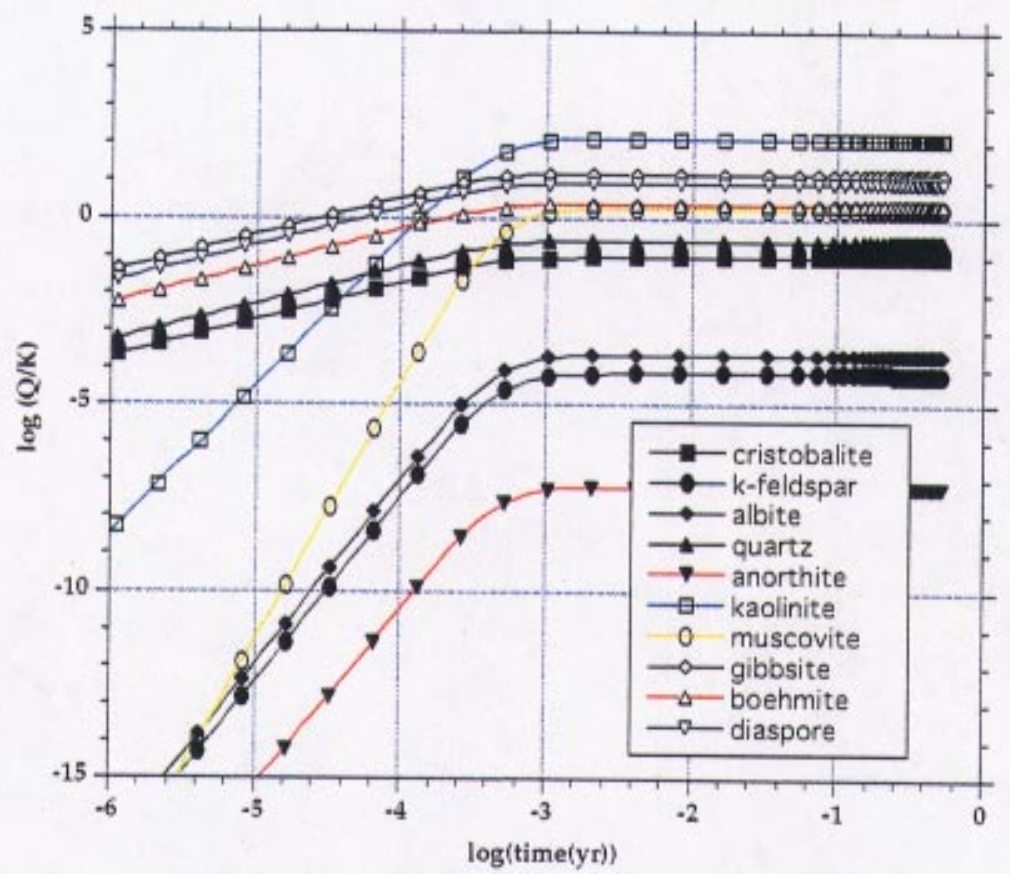

Figure. 10.4-18. Mineral saturation indices $(\log Q / K)$ as a function of time (log yr) at the outlet node $(31 \mathrm{~cm})$ of GIMRT simulation 2c. 
. 
Figure 10.4-19. GIMRT $\operatorname{sim} 2 \mathrm{c}: \log (\mathrm{Q} / \mathrm{K})(\mathrm{x})$ at $6 \mathrm{mo}$.

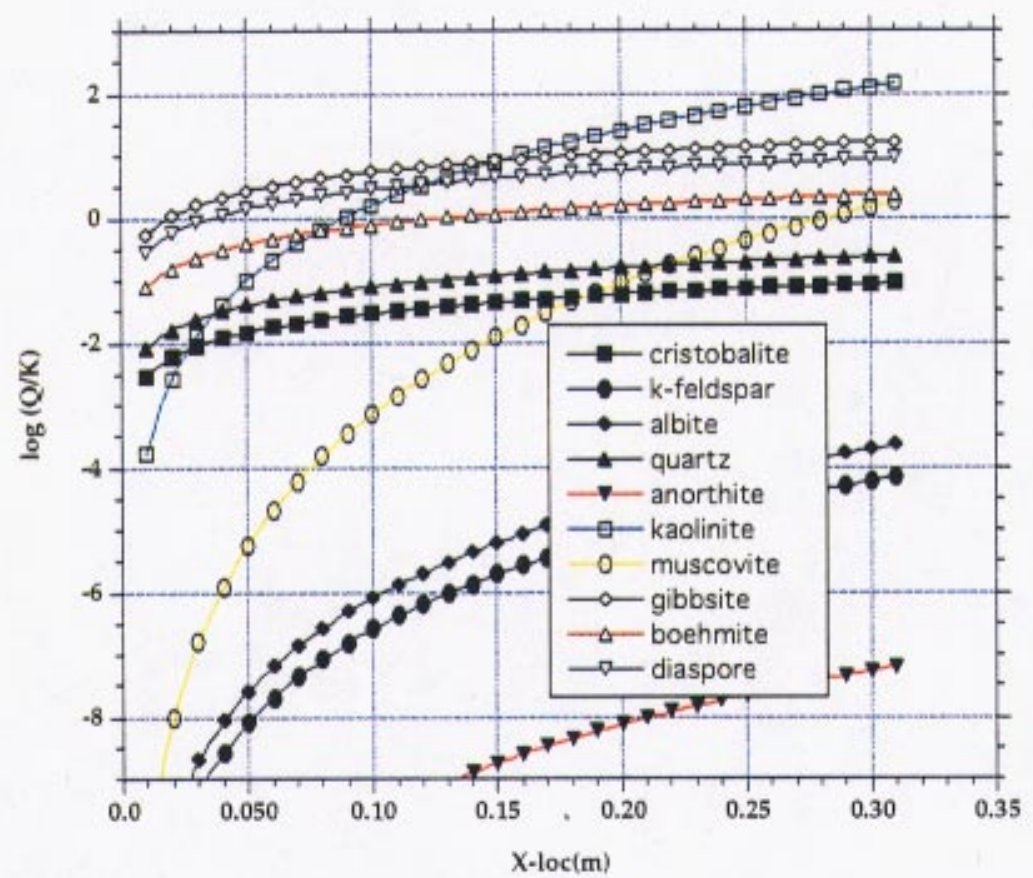

Figure. 10.4-19. Mineral saturation indices $(\log \mathrm{Q} / \mathrm{K})$ as a function of distance $(\mathrm{m})$ after six months for GIMRT simulation $2 \mathrm{c}$.

Figure 10.4-20. GIMRT $\operatorname{sim} 2 \mathrm{ct}$ vol\%(x) at 6 mo.

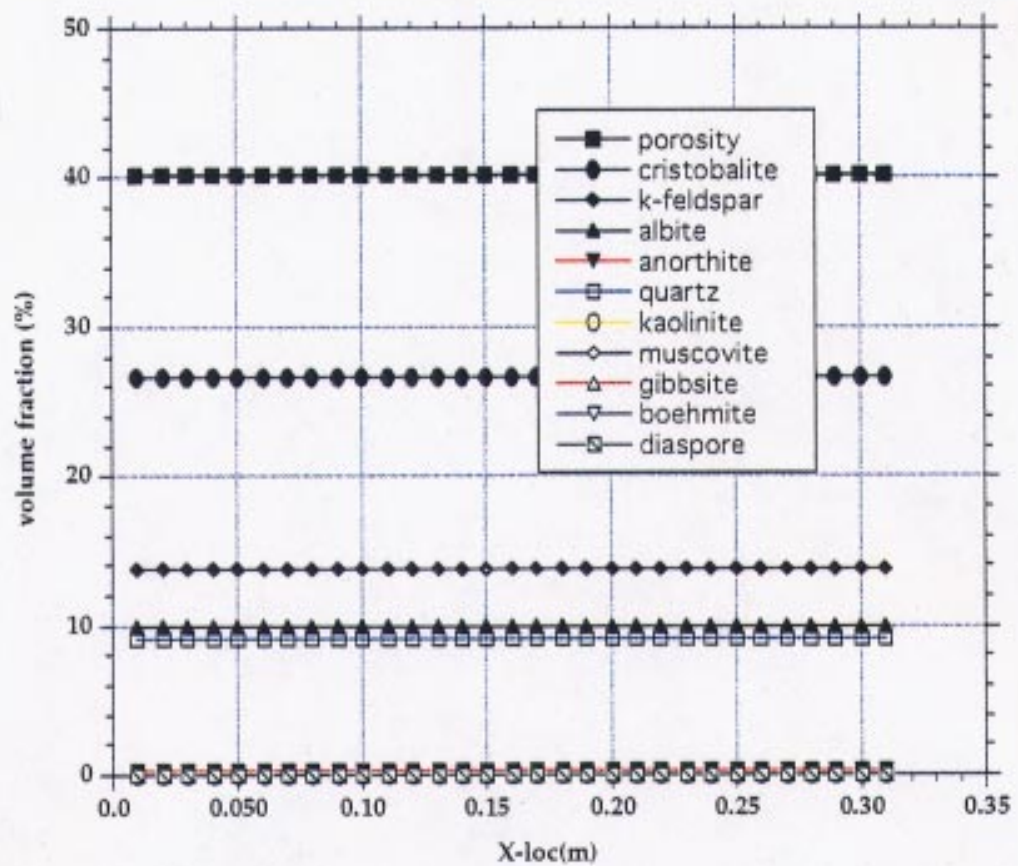

Figure. 10.4-20. Porosity and volume fractions of primary and secondary minerals as a function of distance at six months for GIMRT simulation 2c, where initial composition of the 31-cm one-dinensional fluid-rock system is given in Tables 10.4-5 and 10.4-6, $\mathrm{T}=90^{\circ} \mathrm{C}, \mathrm{P}=$ vapor saturation, fluid flux $=25 \mathrm{ml} /$ day $(266.7$ $\mathrm{m}^{3} / \mathrm{m}^{2} / \mathrm{yr}$ ), and porosity $=40 \%$. Primary and secondary minerals are represented by solid and open symbols, respectively. 
. 


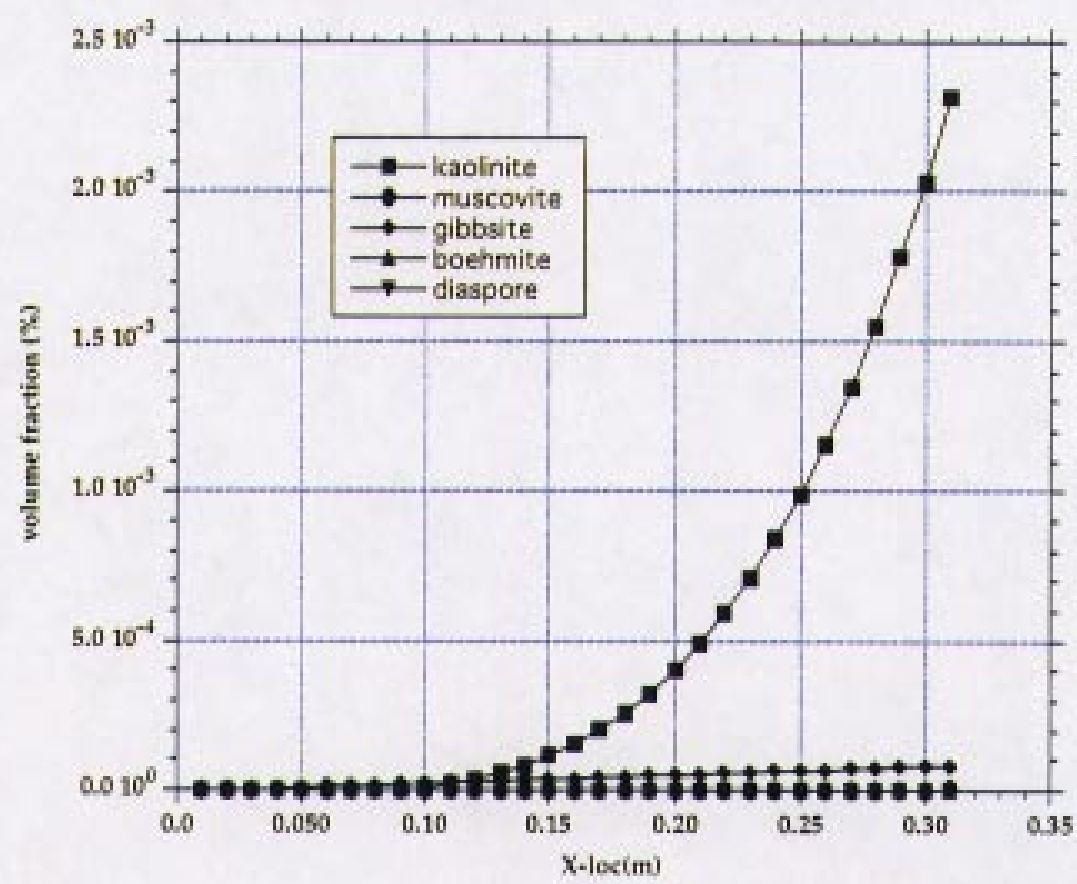

Figure, 10-4-21. Porosity and volume fractions of trace secondary minerals as a function of distance after six months for GIMRT simulation 2c.

Figure 10,4-22. GIMRT sim3a: $\log (\mathrm{Q} / \mathrm{K})(\mathrm{t})$ at $1 \mathrm{~cm}$ (inlet)

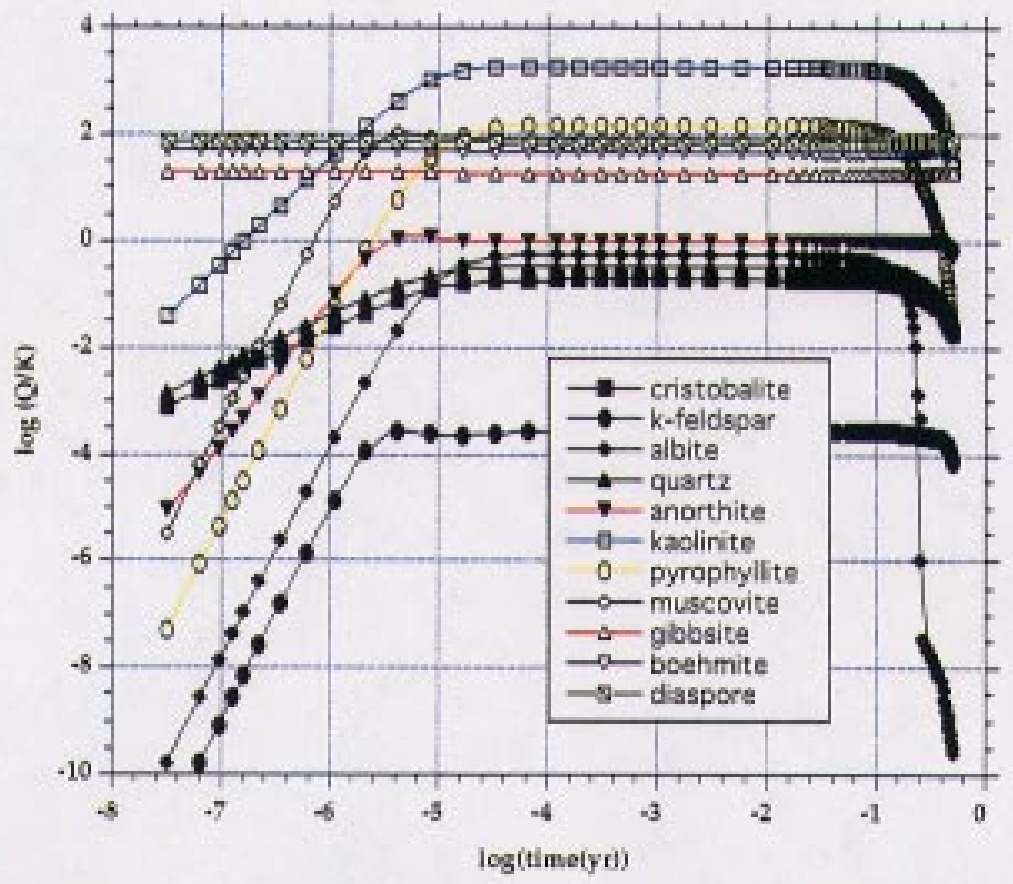

Figure. 10.4-22. Mineral saturation indices (log Q/K) as a function of time (log yr) at the inlet node $(1 \mathrm{~cm})$ of GIMRT simulation 3a, where initial composition of the $31-\mathrm{cm}$ one-dinensional fluid-rock system is given in Tables $10.4-5$ and $10.4-6, T=250^{\circ} \mathrm{C}, \mathrm{P}=$ vapor saturation, fluid flux $=25 \mathrm{ml} / \mathrm{day}\left(266.7 \mathrm{~m}^{3} / \mathrm{m}^{2} / \mathrm{yr}\right)$, and porosity $=40 \%$. Primary and secondary minerals are represented by solid and open symbols, respectively. 
Figure 10.4-23. GIMRT sim3a: vol\%(t) at $1 \mathrm{~cm}$ (inlet)

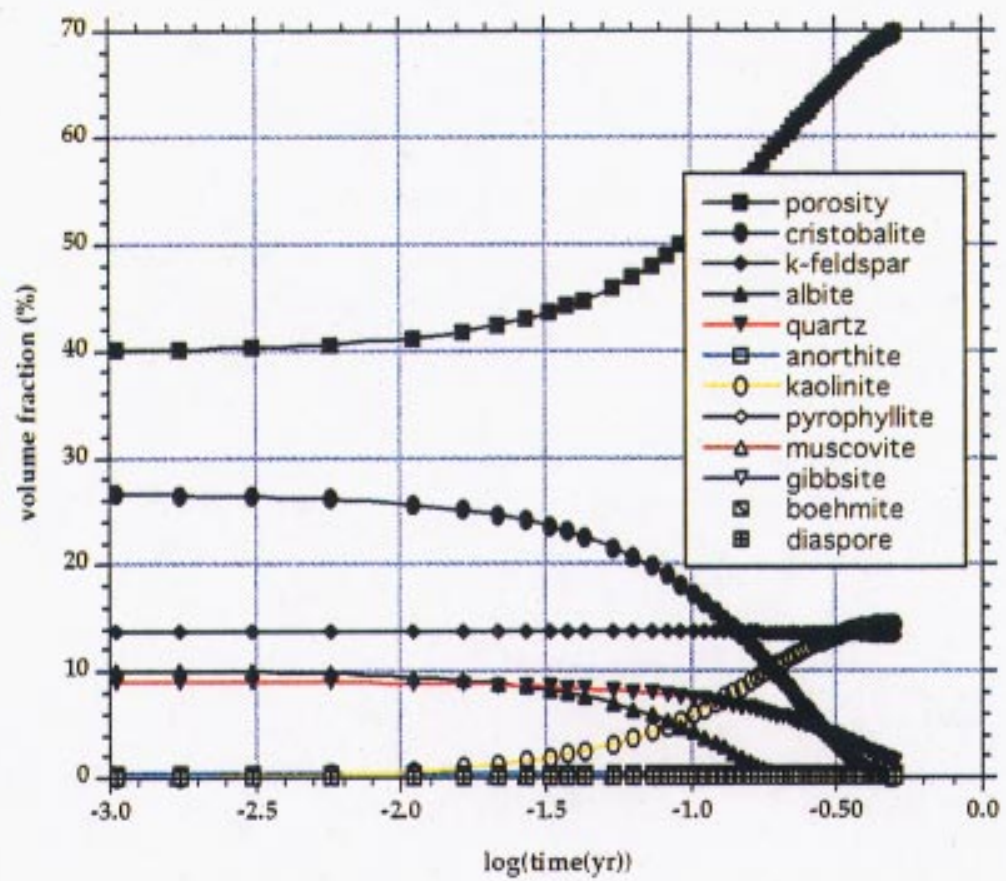

Figure 10.4-23. Porosity and volume fractions of primary and secondary minerals as a function of time (log yr) at the inlet node $(1 \mathrm{~cm})$ of GIMRT simulation $3 \mathrm{a}$.

Figure 10.4-24. GIMRT $\operatorname{sim} 3 \mathrm{a}: \log (\mathrm{Q} / \mathrm{K})(\mathrm{t})$ at $31 \mathrm{~cm}$ (outlet)

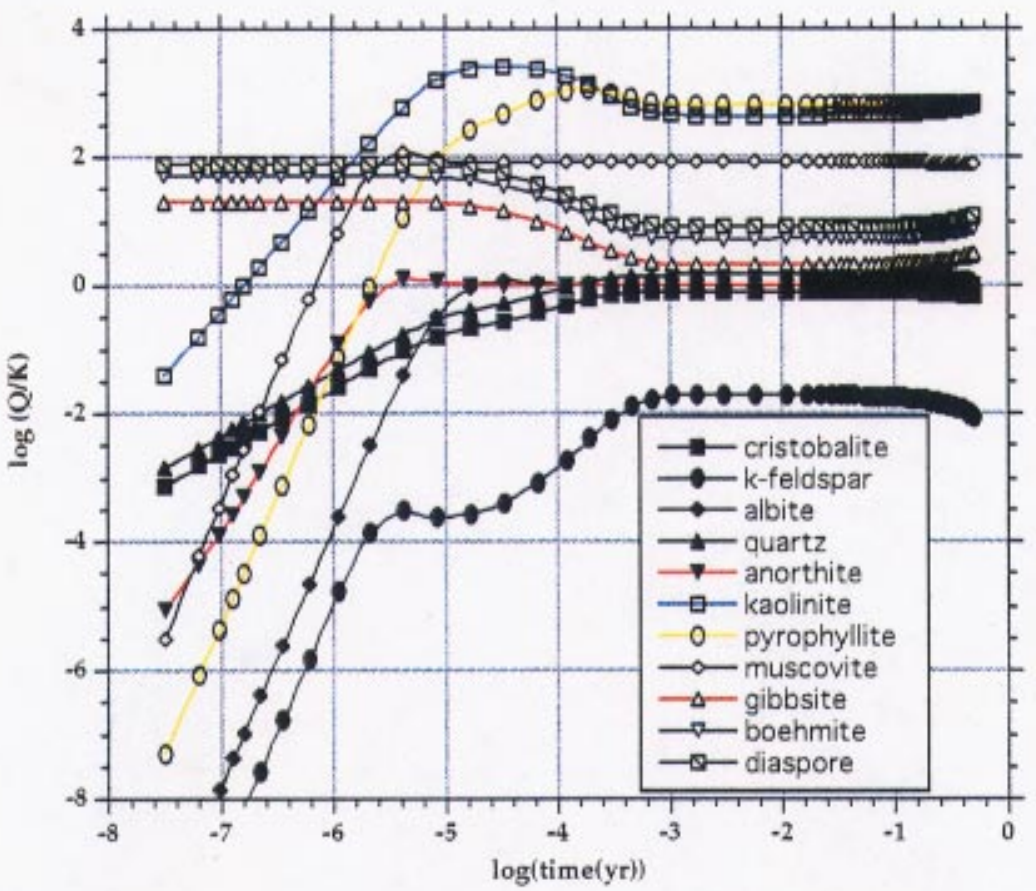

Figure 10.4-24. Mineral saturation indices $(\log Q / K)$ as a function of time $(\log y r)$ at the oulet node $(31 \mathrm{~cm})$ of GIMRT simulation 3a. 
Figure 10.4-25. GIMRT sim3a: vol\%(t) at $31 \mathrm{~cm}$ (outlet)

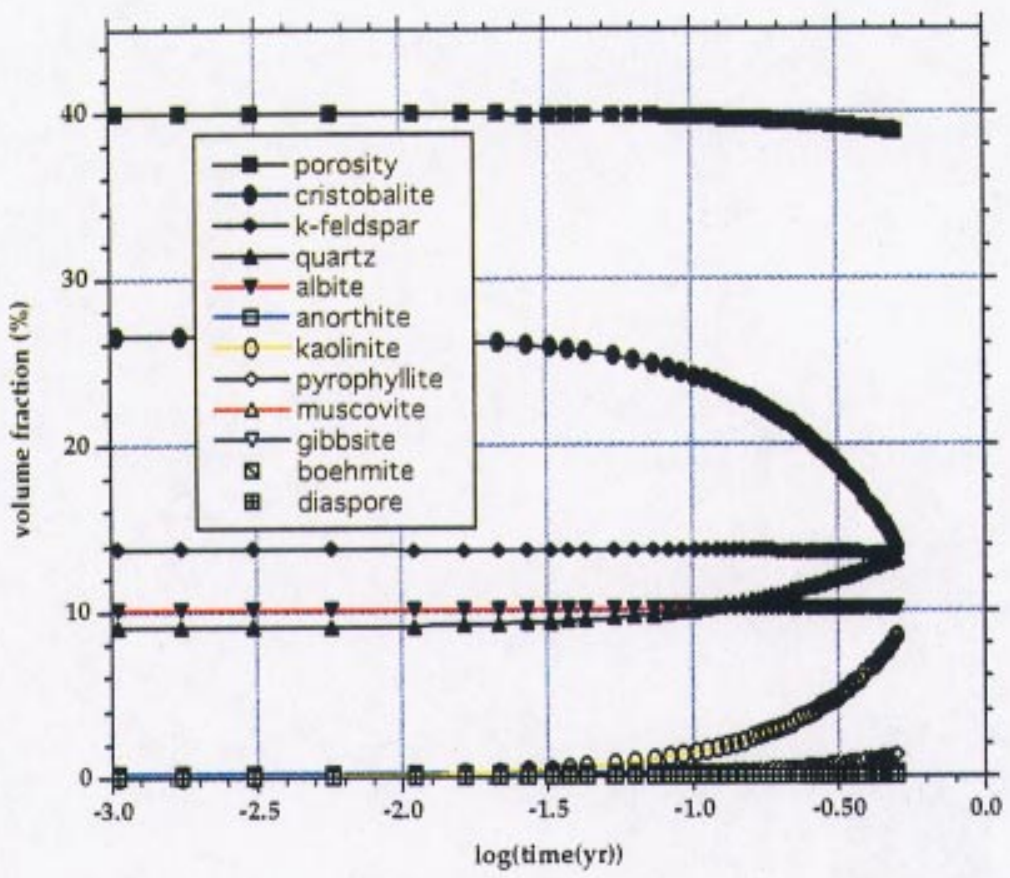

Figure 10.4-25. Porosity and volume fractions of primary and secondary minerals as a function of time (log $y r)$ at the outlet node $(31 \mathrm{~cm})$ of GIMRT simulation $3 a$.

Figure 10.4-26. GIMRT $\operatorname{sim} 3 \mathrm{a}: \log (\mathrm{Q} / \mathrm{K})(\mathrm{x})$ at $6 \mathrm{mo}$.

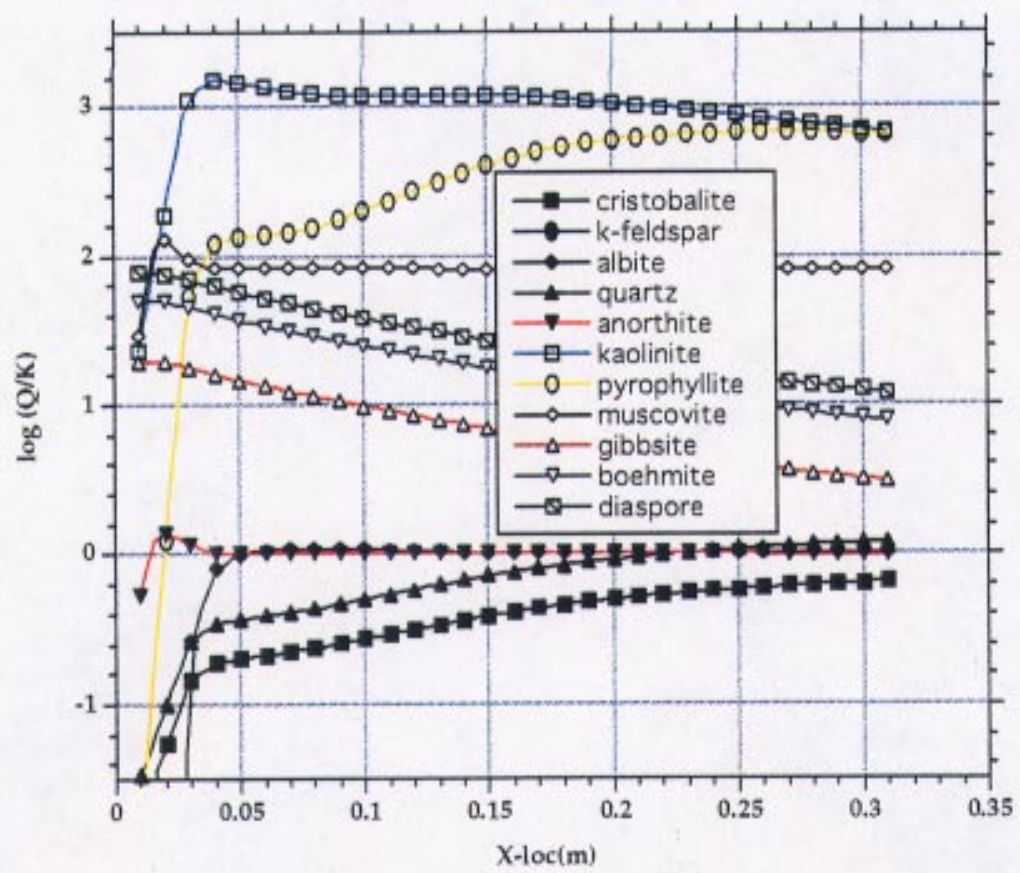

Figure 10.4-26. Mineral saturation indices $(\log Q / K)$ as a function of distance after six months for GIMRT simulation $3 a$. 



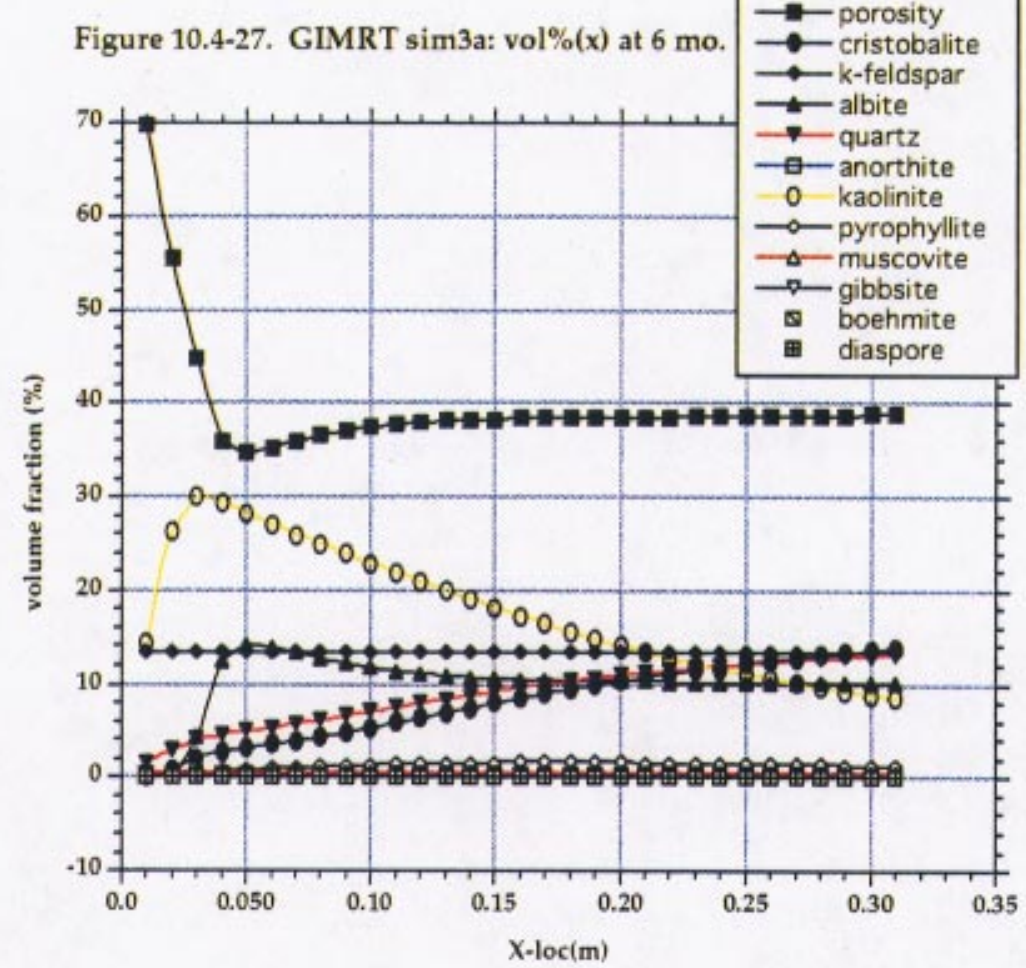

Figure 10.4-27. Porosity and volume fractions of primary and secondary minerals as a function of distance after six months for GIMRT simulation 3a.

Figure 10.4-28. GIMRT $\operatorname{sim} 6 \mathrm{dg} 2: \log (\mathrm{Q} / \mathrm{K})(\mathrm{t})$ at $0.25 \mathrm{~m}$ (inlet)

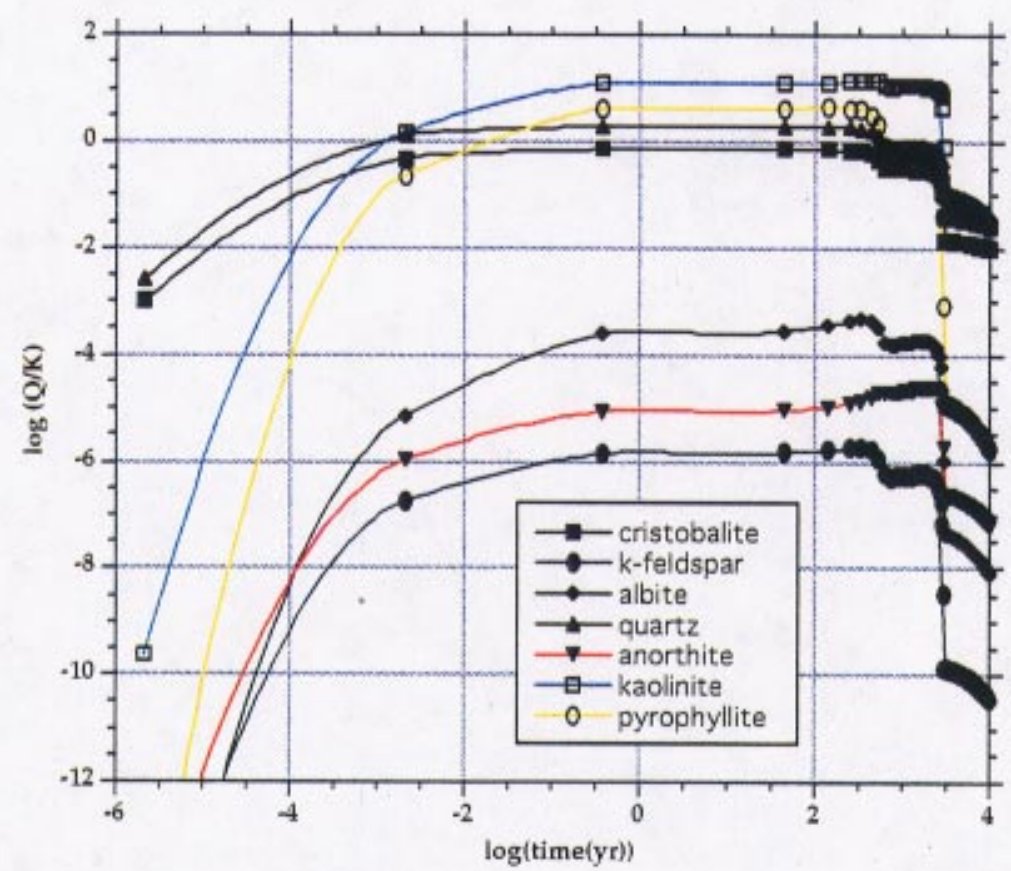

Figure 10.4-28. Mineral saturation indices $(\log \mathrm{Q} / \mathrm{K})$ as a function of time $(\log \mathrm{yr})$ at the inlet node $(0.25 \mathrm{~m})$ of GIMRT simulation $6 \mathrm{dg} 2$, where initial composition of the $10-\mathrm{m}$ one-dinensional fluid-rock system is given in Tables $10.4-5$ and $10.4-6, T=950 \mathrm{C}$ over the first $5 \mathrm{~m}$ with a gradient of $-1{ }^{\circ} \mathrm{C} / \mathrm{m}$ over the last $5 \mathrm{~m}, \mathrm{P}=1 \mathrm{bar}$, fluid flux $=2.67 \mathrm{~m}^{3} / \mathrm{m}^{2} / \mathrm{yr}$ ), and porosity $=11 \%$. Primary and secondary minerals are represented by solid and open symbols, respectively. 

Figure 10.4-29. GIMRT sim6dg2: $\log (\mathrm{Q} / \mathrm{K})(\mathrm{t})$ at $5 \mathrm{~m}$ (center)

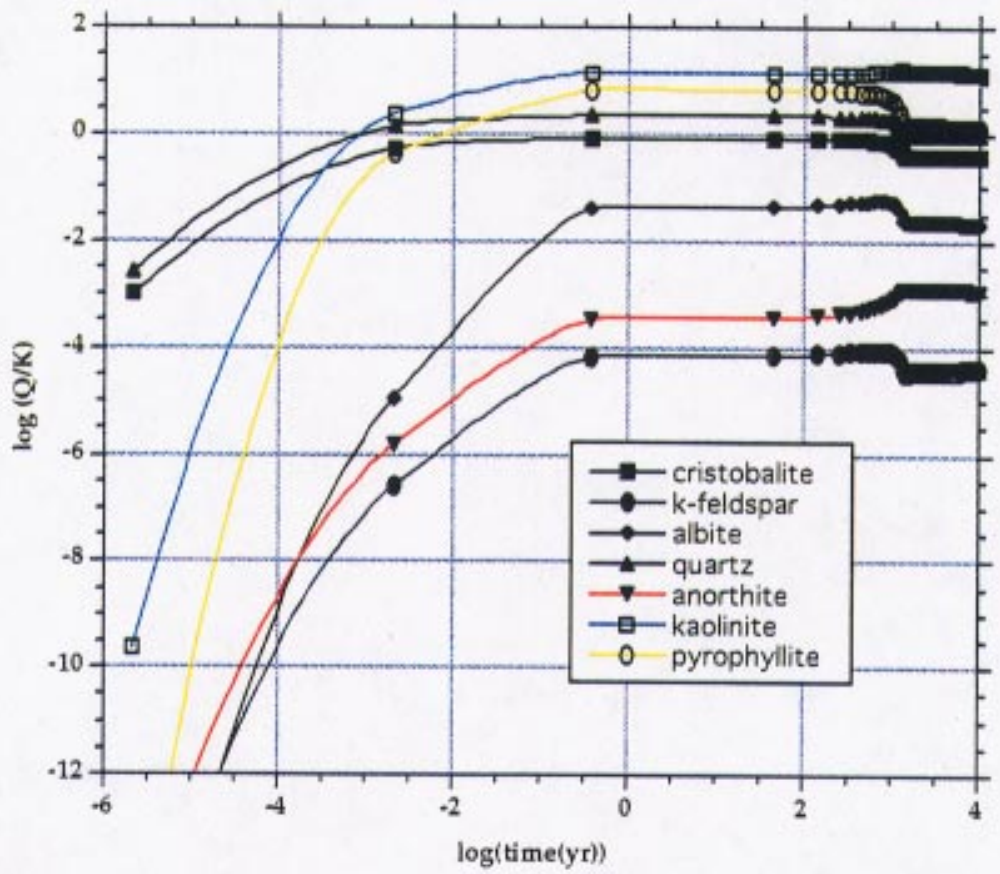

Figure 10.4-29. Mineral saturation indices $(\log \mathrm{Q} / \mathrm{K})$ as a function of time (log yr) at the center node $(5 \mathrm{~m})$ of GIMRT simulation 6dg2.

Figure 10.4-30. GIMRT sim6dg2: $\log (\mathrm{Q} / \mathrm{K})$ at $10 \mathrm{~m}$ (outlet)

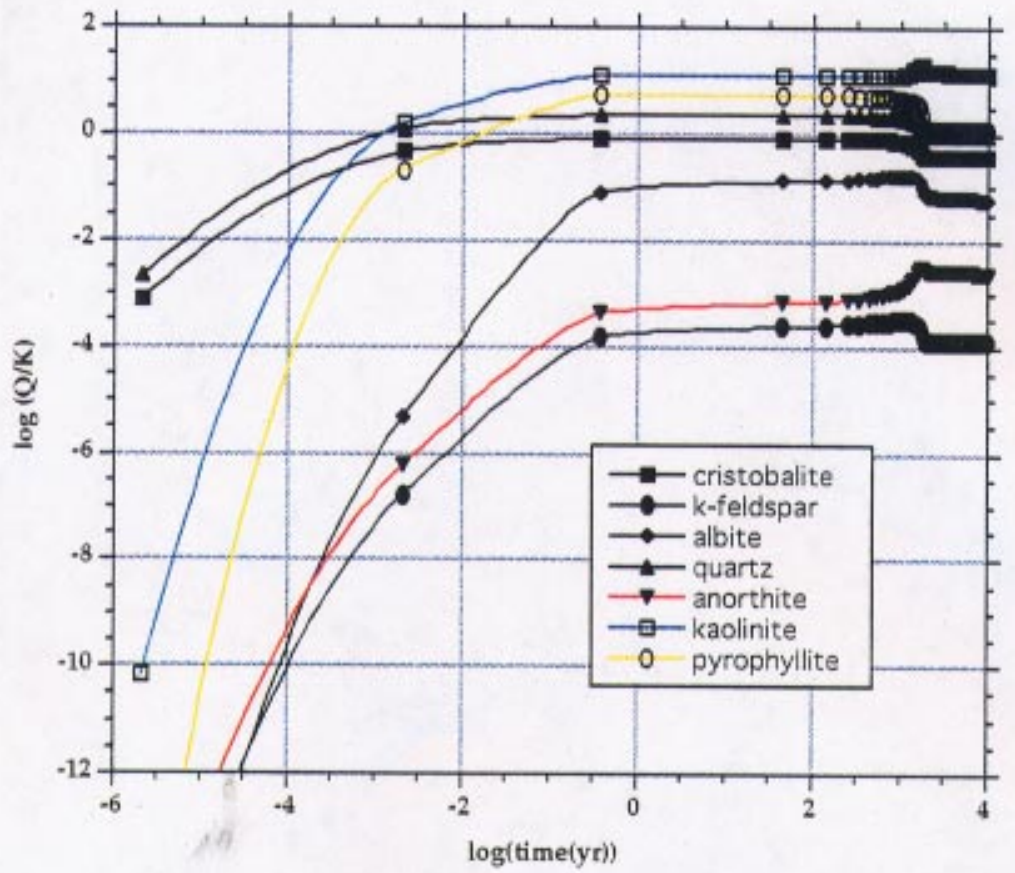

Figure 10.4-30. Mineral saturation indices $(\log \mathrm{Q} / \mathrm{K})$ as a function of time $(\log \mathrm{yr})$ at the outlet node $(10 \mathrm{~m})$ of GIMRT simulation $6 \mathrm{dg} 2$. 
Figure 10.4-31: GIMRT sim6dg2: vol\%(t) at $0.25 \mathrm{~m}$ (inlet)

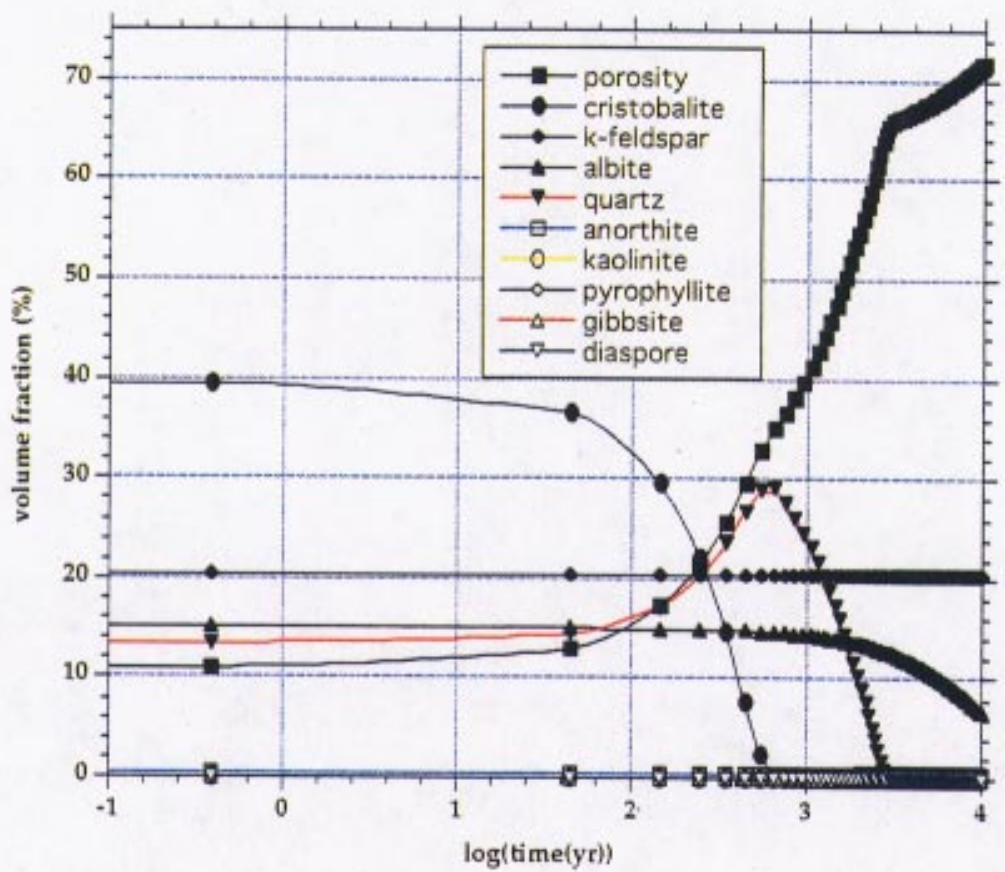

Figure. 10.4-31. Porosity and volume fractions of primary and secondary minerals as a function of time (log $\mathrm{yr})$ at the inlet node $(0.25 \mathrm{~m})$ of GIMRT simulation $6 \mathrm{dg} 2$.

Figure 10.4-32. GIMRT sim6dg2: vol\%(t) at $5 \mathrm{~m}$ (center)

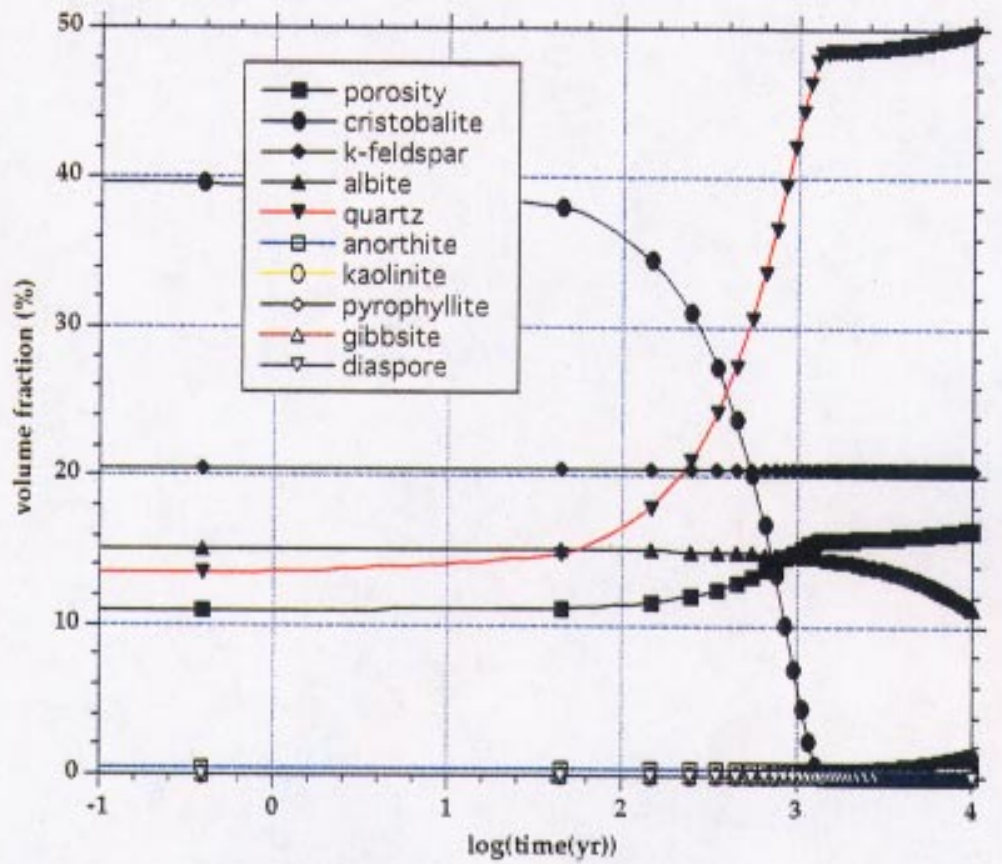

Figure. 10.4-32. Porosity and volume fractions of primary and secondary minerals as a function of time (log yr) at the center node ( $5 \mathrm{~m}$ ) of GIMRT simulation $6 \mathrm{dg} 2$. 

Figure 10.4-33. GIMRT sim6dg2: vol\%(t) at $10 \mathrm{~m}$ (outlet)

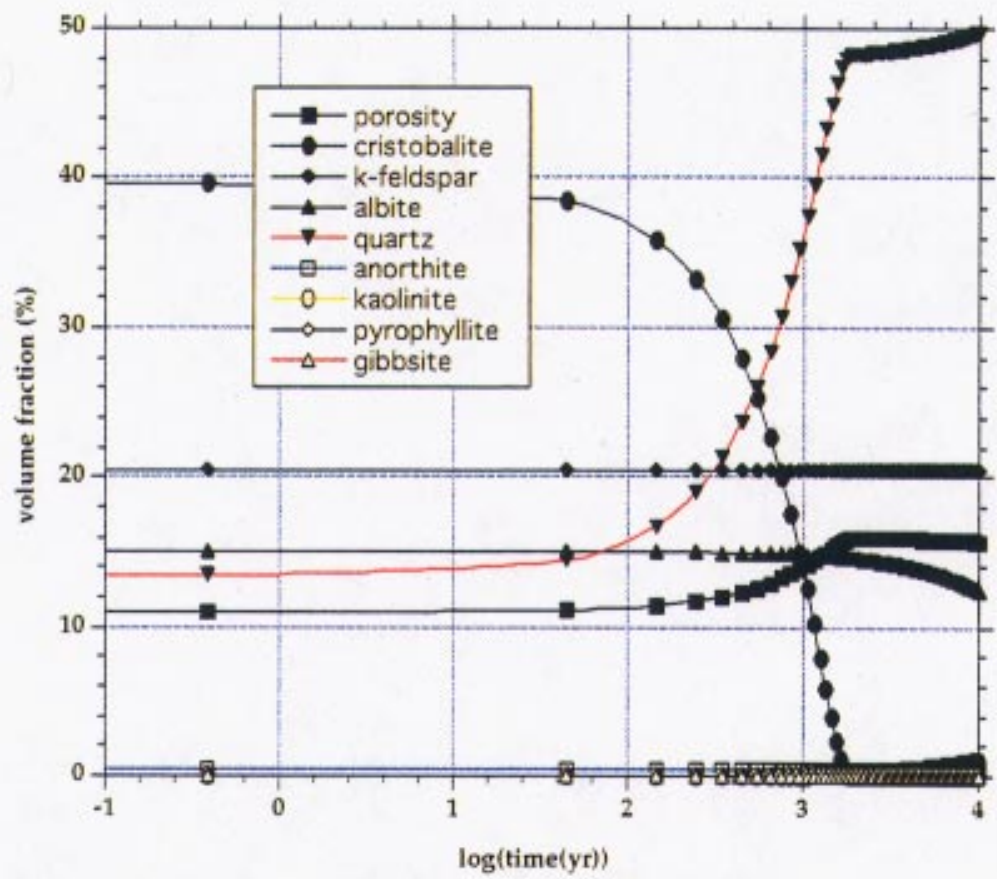

Figure. 10.4-33. Porosity and volume fractions of primary and secondary minerals as a function of time (log $\mathrm{yr})$ at the outlet node $(10 \mathrm{~m})$ of GIMRT simulation $6 \mathrm{dg} 2$.

Figure 10.4-34. GIMRT sim6dg2: $v 0 l \%(x)$ at $100 \mathrm{yr}$

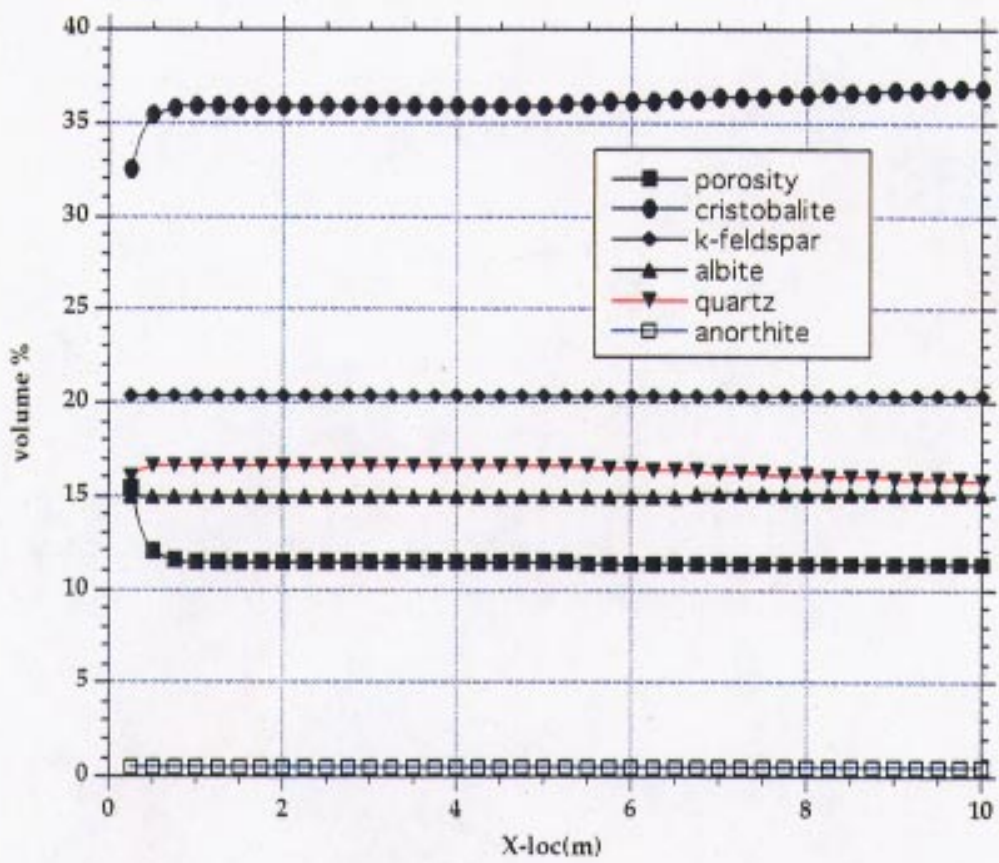

Figure. 10.4-34. Porosity and volume fractions of primary and secondary minerals as a function of distance after $100 \mathrm{yr}$ for GIMRT simulation $6 \mathrm{dg} 2$. 
Figure 10.4-35: GIMRT sim6dg2: vol\%(x) at $1,000 \mathrm{yr}$

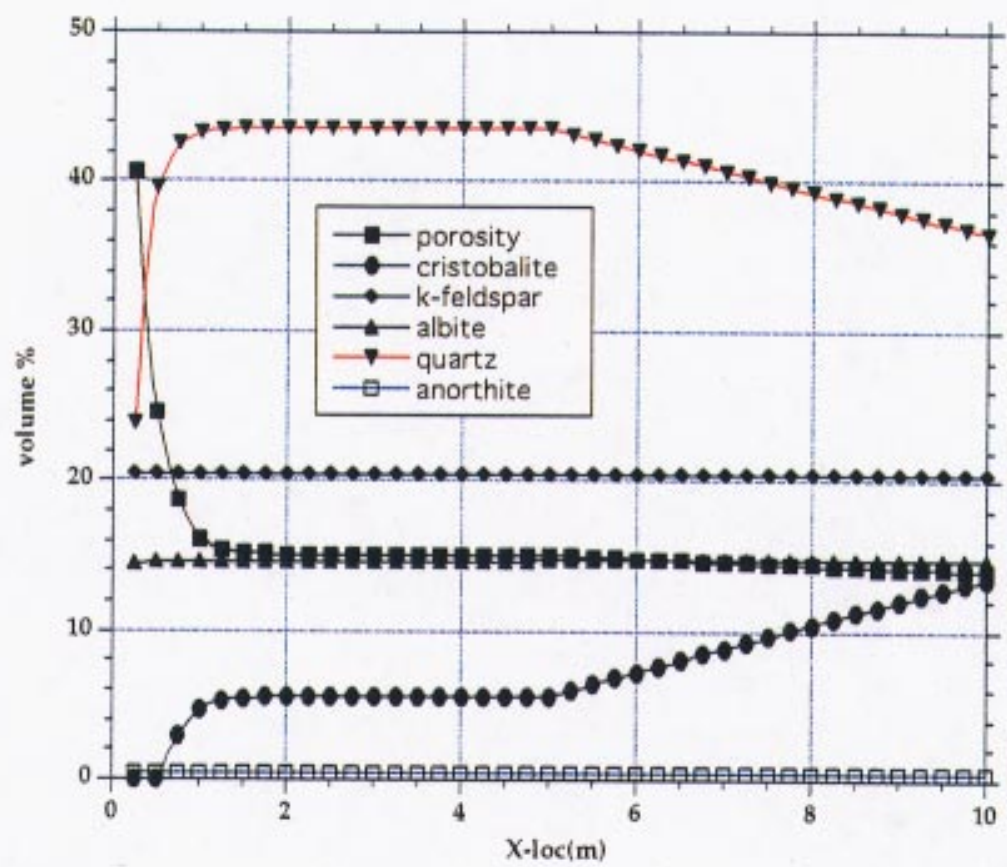

Figure. 10.4-35. Porosity and volume fractions of primary and secondary minerals as a function of distance after $1,000 \mathrm{yr}$ for GIMRT simulation $6 \mathrm{dg} 2$.

Figure 10.4-36. GIMRT sim6dg2: vol $\%(x)$ at $5,000 \mathrm{yr}$

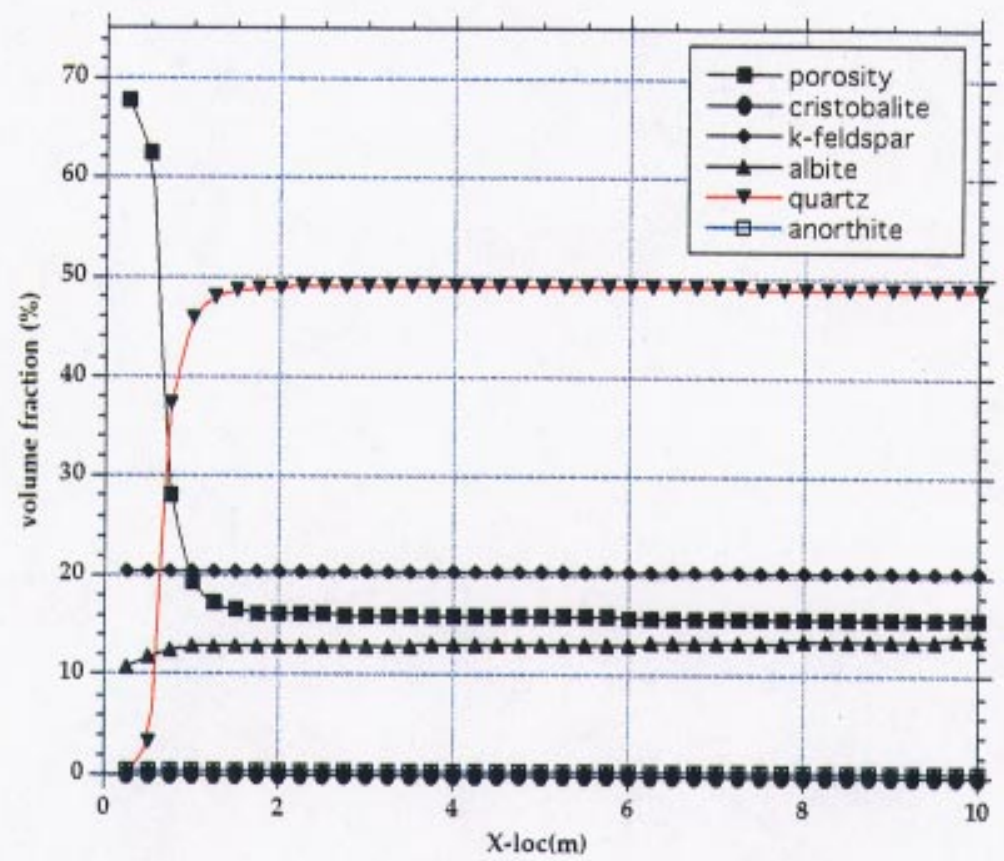

Figure. 10.4-36. Porosity and volume fractions of primary and secondary minerals as a function of distance after 5,000 yr for GIMRT simulation $6 \mathrm{dg} 2$. 

Figure 10.4-37. GIMRT sim6dg2: vol $\%(x)$ at $10,000 \mathrm{yr}$

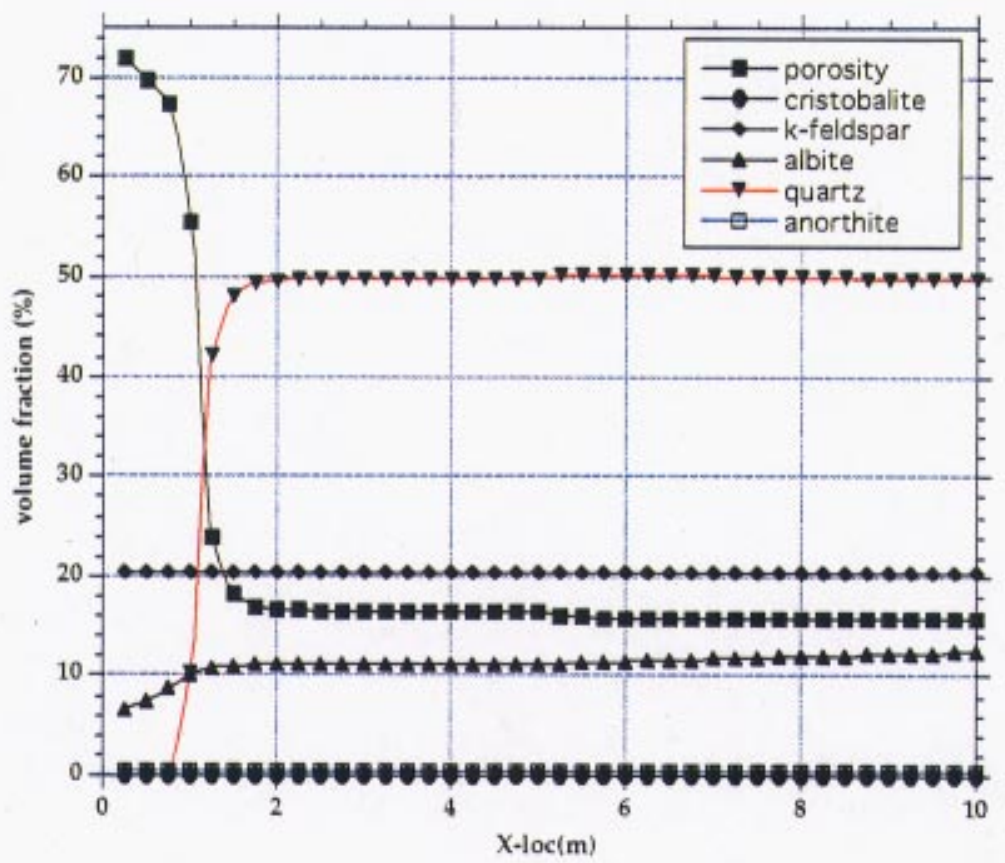

Figure. 10.4-37. Porosity and volume fractions of primary and secondary minerals as a function of distance after $10,000 \mathrm{yr}$ for GIMRT simulation $6 \mathrm{dg} 2$. 

Table 10.4-1. Chemical composition of geothermal waters from Flash Plant 10, Wairakei, New Zealand.

\begin{tabular}{lc}
\hline & Total Concentration \\
\hline $\mathrm{pH}(25 \infty \mathrm{C})$ & 7.8 \\
$\mathrm{Na}$ & $\mathrm{ppm}$ \\
$\mathrm{Li}$ & 1314 \\
$\mathrm{~K}$ & 12.8 \\
$\mathrm{Ca}$ & 211 \\
$\mathrm{Mg}$ & 18.3 \\
$\mathrm{Rb}$ & 0.08 \\
$\mathrm{Cs}$ & 2.77 \\
$\mathrm{~S}$ & 2.59 \\
$\mathrm{~B}$ & 11 \\
$\mathrm{Si}$ & 26.9 \\
$\mathrm{~F}$ & 234.0 \\
$\mathrm{As}$ & 7.0 \\
$\mathrm{Al}$ & 4.86 \\
$\mathrm{Fe}$ & 0.6 \\
$\mathrm{Cl}$ & 0.13 \\
\hline
\end{tabular}


Table 10.4-2. Laboratory Amorphous Silica Precipitation Results. $T_{i}$ is the temperature at which the starting materials were saturated with respect to amorphous silica, $T_{p p t}$ is the precipitation run temperature, $k_{p p t}$ is the precipitation rate constant, and SA is BET surface area of the amorphous silica at the end of the experiment.

\begin{tabular}{|c|c|c|c|c|c|c|}
\hline EXPT & Solution Composition & $\mathbf{T}_{\mathbf{i}} \infty \mathbf{C}$ & $\mathbf{T}_{\text {ppt }}{ }^{\circ} \mathrm{C}$ & pH(T) & $\mathbf{k}_{\text {ppt }}$ & $S A\left(m^{2} g^{-1}\right)$ \\
\hline AmSil & $0.1 \mathrm{M} \mathrm{NaCl}$ (unbuffered) & 120 & 100 & 6.4 & $\begin{array}{l}1.77 e-6 \\
\pm 9 e-8\end{array}$ & 118 \\
\hline AmSi2 & $\begin{array}{l}0.1 \mathrm{M} \mathrm{NaCl}+0.013 \mathrm{M} \mathrm{HCl}+ \\
0.03 \mathrm{M} \mathrm{KHphthalate}\end{array}$ & 120 & 100 & 5.0 & $\begin{array}{l}1.15 e-6 \\
\pm 7 e-8\end{array}$ & 168 \\
\hline AmSi3 & $\begin{array}{l}0.1 \mathrm{M} \mathrm{NaC}+0.03 \mathrm{M} \mathrm{Na} \text { Acetate + } \\
0.02 \mathrm{M} \text { Acetic Acid }\end{array}$ & 120 & 100 & 3.0 & $\begin{array}{l}3.23 \mathrm{e}-7 \\
\pm 3 e-8\end{array}$ & 260 \\
\hline AmSi5 & $0.13 \mathrm{M} \mathrm{NaCl}$ (unbuffered) & 100 & 80 & 6.5 & $\begin{array}{l}7.68 \mathrm{e}-7 \\
\pm 9 \mathrm{e}-8\end{array}$ & 135 \\
\hline AmSi6 & $\begin{array}{l}0.1 \mathrm{M} \mathrm{NaCl}+0.013 \mathrm{M} \mathrm{HCl}+ \\
0.03 \mathrm{M} \mathrm{KH} \text { phthalate }\end{array}$ & 100 & 80 & 3.0 & $\begin{array}{l}7.27 \mathrm{e}-8 \\
\pm 3 \mathrm{e}-8\end{array}$ & 280 \\
\hline AmSi7 & $\begin{array}{l}0.1 \mathrm{M} \mathrm{NaCl}+0.03 \mathrm{M} \mathrm{Na} \text { Acetate + } \\
0.02 \mathrm{M} \text { Acetic Acid }\end{array}$ & 100 & 80 & 4.9 & $\begin{array}{l}2.89 \mathrm{e}-7 \\
\pm 3 e-8\end{array}$ & 209 \\
\hline AmSi8 & $0.13 \mathrm{M} \mathrm{NaCl}$ (unbuffered) & 150 & 120 & 7.2 & $\begin{array}{l}4.61 \mathrm{e}-6 \\
\pm 6 \mathrm{e}-7\end{array}$ & 53 \\
\hline AmSi10 & Geothermal Water (Table 10.4-1) & 100 & 80 & 7.3 & $\begin{array}{l}1.48 \mathrm{e}-6 \\
\pm 2 \mathrm{e}-7\end{array}$ & 135 \\
\hline AmSi11 & Geothermal Water (Table 10.4-1) & 120 & 100 & 7.2 & & \\
\hline Amsi12 & Geothermal Water (Table 10.4-1) & 150 & 120 & 7.1 & $\begin{array}{l}8.92 e-6 \\
\pm 5 e-7\end{array}$ & 66 \\
\hline Amsi13 & Geothermal Water (Table 10.4-1) & 120 & 100 & 7.2 & $\begin{array}{l}2.99 \mathrm{e}-6 \\
\pm 4 \mathrm{e}-7\end{array}$ & 108 \\
\hline AmSi14 & $\begin{array}{l}0.121 \mathrm{M} \mathrm{NaCl}+0.009 \mathrm{M} \mathrm{NaOH}+ \\
0.05 \mathrm{M} \text { Boric Acid }\end{array}$ & 120 & 100 & 7.9 & $\begin{array}{l}2.53 e-6 \\
\pm 8 e-7\end{array}$ & 107 \\
\hline AmSi15 & $\begin{array}{l}0.094 \mathrm{M} \mathrm{NaCl}+0.036 \mathrm{M} \mathrm{NaOH}+ \\
0.05 \mathrm{M} \text { Boric Acid }\end{array}$ & 120 & 100 & 8.7 & $\begin{array}{l}4.76 \mathrm{e}-6 \\
\pm 1 \mathrm{e}-8\end{array}$ & 99 \\
\hline
\end{tabular}


Table 10.4-3. Summary of silica polymorph precipitation experiments.

\begin{tabular}{|c|c|c|c|c|c|}
\hline Phase & $\mathrm{T}^{\circ} \mathrm{C}$ & $\frac{E_{\mathrm{a}}}{(\mathrm{kJ} / \mathrm{mol})}$ & $\mathbf{Q} / \mathbf{K}_{\text {eq }}$ & $\begin{array}{c}\text { Solution } \\
\text { Composition }\end{array}$ & Reference \\
\hline Quartz & $18-300$ & 49.8 & 1.7 & distilled water & Rimstidt and Barnes, 1980 \\
\hline a-cristobalite & $18-30$ & 49.8 & 1.7 & distilled water & Rimstidt and Barnes, 1980 \\
\hline b-cristobalite & $18-30$ & 49.8 & 1.7 & distilled water & Rimstidt and Barnes, 1980 \\
\hline Amorphous Silica & $18-30^{-}$ & 49.8 & 1.7 & distilled water & Rimstidt and Barnes, 1980 \\
\hline \multirow[t]{2}{*}{ Amorphous Silica } & $60-120$ & 0 & 4 & pH 5-8 & Bohlmann et al., 1980 \\
\hline & & & & $1 \mathrm{~N} \mathrm{NaCl}$ & \\
\hline a-cristobalite & $150-300$ & 52.9 & 2 & & Renders et al., 1995 \\
\hline \multirow[t]{2}{*}{ Amorphous Silica } & $25-50$ & 54.8 & 10 & pH 4-8 & Fleming, 1985 \\
\hline & & & & $0.1-1 \mathrm{~m} \mathrm{NaCl}$ & \\
\hline Quartz & $120-255$ & 34 & 2 & & Bird and Boon, 1986 \\
\hline Quartz & $300-420$ & $57-164$ & - & $0.5 \mathrm{~m} \mathrm{NaCl}$ & Laudise, 1958 \\
\hline Quartz & $300-500$ & $88-159$ & - & $0.1-1 \mathrm{~m} \mathrm{NaCl}$ & Hosaka and Taki, 1981a \\
\hline Quartz & $300-500$ & $29.3-33.5$ & - & $0.1-1 \mathrm{~m} \mathrm{KCl}$ & Hosaka and Taki, 1981b \\
\hline
\end{tabular}


Table 10.4-4. Amorphous silica precipitation rates determined in the field using a fluidized bed reactor with waters from Wairakei geothermal Flash Plant 10, New Zealand.

\begin{tabular}{|c|c|c|c|c|c|c|}
\hline Date & $\begin{array}{c}\mathrm{T} \\
\left({ }^{\circ} \mathrm{C}\right)\end{array}$ & $\left(\begin{array}{c}v \\
d^{-1}\end{array}\right)$ & $\underset{p p m}{\Delta}$ & $\begin{array}{c}\mathbf{p H} \\
\left(\mathrm{T}^{\circ} \mathrm{C}\right)\end{array}$ & $\log \left(Q / K_{e q}\right)$ & $\begin{array}{c}\text { Rate (ppt) } \\
\left(m o l m^{-2} d^{-1}\right)\end{array}$ \\
\hline 3 July 95 & 89 & 786.2 & $26.6 \pm 0.7$ & 7.66 & .1787 & $9.67 e-5$ \\
\hline 4 July 95 & 88 & 1814.4 & $6.2 \pm 1.4$ & 7.63 & .1784 & $5.20 e-5$ \\
\hline 5 July 95 & 74 & 1226.9 & $21.1 \pm 2.1$ & 7.73 & .2408 & $1.20 \mathrm{e}-4$ \\
\hline 10 July 95 & 58 & 820.8 & $39.2 \pm 0.7$ & 7.86 & .3348 & $1.49 e-4$ \\
\hline 11 July 95 & 97 & 1071.4 & $9.8 \pm 0.7$ & 7.58 & .1310 & $4.85 e-5$ \\
\hline 12 July 95 & 71 & 1417.0 & $21.8 \pm 0.7$ & 7.75 & .2596 & $1.43 e-4$ \\
\hline 13 July 95 & 97 & 838.1 & $14.4 \pm 0.7$ & 7.58 & .1248 & $5.58 \mathrm{e}-5$ \\
\hline 28 Sept 95 & 79 & 1166.4 & $29.5 \pm 2.8$ & 7.70 & .2093 & $1.04 e-4$ \\
\hline 28 Sept 95 & 79 & 1252.8 & $30.2 \pm 0.0$ & 7.70 & .2102 & $1.14 \mathrm{e}-4$ \\
\hline 28 Sept 95 & 80 & 1408.3 & $25.8 \pm 0.0$ & 7.69 & .2070 & $1.10 \mathrm{e}-4$ \\
\hline 28 Sept 95 & 78 & 976.3 & $37.1 \pm 1.4$ & 7.71 & .2097 & $1.09 \mathrm{e}-4$ \\
\hline 29 Sept 95 & 96 & 2315.5 & $4.1 \pm 0.0$ & 7.58 & .1418 & $3.14 e-5$ \\
\hline 29 Sept 95 & 84 & 829.4 & $25.4 \pm 0.0$ & 7.66 & .1866 & $6.96 e-5$ \\
\hline 29 Sept 95 & 69 & 717.1 & $50.4 \pm 0.0$ & 7.79 & .2417 & $1.19 e-4$ \\
\hline 2 Oct 95 & 92 & 985.0 & $12.0 \pm 1.4$ & 7.61 & .1611 & $3.90 \mathrm{e}-5$ \\
\hline 2 Oct 95 & 75 & 924.5 & $43.7 \pm 0.7$ & 7.73 & .2446 & $1.33 e-4$ \\
\hline 2 Oct 95 & 61 & 829.4 & $54.7 \pm 0.0$ & 7.86 & .2731 & $1.50 \mathrm{e}-4$ \\
\hline 3 Oct 95 & 93 & 1158.0 & $10.2 \pm 0.7$ & 7.60 & .1579 & $3.90 \mathrm{e}-4$ \\
\hline 3 Oct 95 & 100 & 1062.7 & $10.5 \pm 1.4$ & 7.61 & .1264 & $3.68 \mathrm{e}-5$ \\
\hline 3 Oct 95 & 83 & 1028.2 & $23.7 \pm 0.7$ & 7.67 & .1981 & $8.05 e-5$ \\
\hline 4 Oct 95 & 76 & 1114.6 & $32.7 \pm 1.4$ & 7.72 & .2226 & $1.20 \mathrm{e}-4$ \\
\hline 4 Oct 95 & 70 & 1088.6 & $36.7 \pm 0.7$ & 7.77 & .2549 & $1.32 \mathrm{e}-4$ \\
\hline 5 Oct 95 & 61 & 1140.5 & $44.4 \pm 1.4$ & 7.85 & .2951 & $1.67 e-4$ \\
\hline 5 Oct 95 & 67 & 1123.2 & $37.7 \pm 0.7$ & 7.79 & .2743 & $1.40 \mathrm{e}-4$ \\
\hline 6 Oct 95 & 112 & 846.7 & $5.3 \pm 0.7$ & 7.51 & .0654 & $1.48 \mathrm{e}-4$ \\
\hline 6 Oct 95 & 115 & 846.7 & $5.0 \pm 0.7$ & 7.50 & .0530 & $1.40 e-5$ \\
\hline 6 Oct 95 & 104 & 794.9 & $7.2 \pm 1.4$ & 7.54 & .1050 & $1.89 \mathrm{e}-5$ \\
\hline 9 Oct 95 & 102 & 1149.1 & $5.2 \pm 1.4$ & 7.55 & .1123 & $1.97 \mathrm{e}-5$ \\
\hline 9 Oct 95 & 117 & 1088.6 & $4.6 \pm 0.0$ & 7.49 & .0445 & $1.65 e-5$ \\
\hline 9 Oct 95 & 107 & 1019.5 & $6.7 \pm 0.7$ & 7.53 & .0893 & $2.26 \mathrm{e}-5$ \\
\hline 10 Oct 95 & 101 & 1036.8 & $6.1 \pm 1.4$ & 7.6 & .1173 & $2.09 e-5$ \\
\hline 10 Oct 95 & 106 & 1036.8 & $5.0 \pm 1.4$ & 7.53 & .0962 & $1.71 \mathrm{e}-5$ \\
\hline
\end{tabular}


Table 10.4-5. Summary of Tpt mineralogy as modeled by Delany (1985) and in this study.

\begin{tabular}{|c|c|c|c|c|c|}
\hline Mineral & Mineral Composition & $\begin{array}{c}\text { Vol.\% } \\
\text { (Delany, } \\
\text { 1985: no por.: }\end{array}$ & $\begin{array}{l}\text { Vol.\% } \\
\text { (this study: } \\
\text { no por.) }\end{array}$ & $\begin{array}{l}\text { Vol. } \% \\
\text { (this study: } \\
11 \% \text { por.) }\end{array}$ & $\begin{array}{c}\text { Vol.\% } \\
\text { (this study: } \\
\text { 40\% por.) }\end{array}$ \\
\hline Cristobalite & $\mathrm{SiO}_{2}$ & 44.0 & 44.49 & 39.60 & 26.69 \\
\hline Alkali feldspar & $\mathrm{Or}_{0.58} A \mathrm{~b}_{0.11} A n_{0,01}$ & 39.0 & --- & --- & --- \\
\hline Quartz & $\mathrm{SiO}_{2}$ & 14.9 & 15.07 & 13.41 & 9.04 \\
\hline Plagioclase & $O r_{0.07} A b_{0.76} A n_{0.17}$ & 1.0 & -- & --- & --- \\
\hline Mg-beidellite & $\mathrm{Mg}_{0.165} \mathrm{Al}_{2.39} \mathrm{Si}_{3.67} \mathrm{O}_{10}(\mathrm{OH})_{2}$ & 1.0 & --- & -- & -- \\
\hline Biotite & $\mathrm{Phl}_{0.43} \mathrm{Ann}_{0.57}$ & 0.1 & --- & --- & -- \\
\hline K-feldspar (Or) & $\mathrm{KAlSi}_{3} \mathrm{O}_{8}$ & $\cdots$ & 22.94 & 20.42 & 13.77 \\
\hline Albite (Ab) & $\mathrm{NaAlSi}_{3} \mathrm{O}_{8}$ & -- & 16.94 & 15.07 & 10.16 \\
\hline Anorthite (An) & $\mathrm{CaAl}_{2} \mathrm{Si}_{2} \mathrm{O}_{8}$ & $\cdots$ & 0.57 & 0.50 & 0.34 \\
\hline TOTAL & & 100.0 & 100.0 & 89.0 & 60.0 \\
\hline
\end{tabular}

Table 10.4-6. Summary of infiltrating fluid composition used in this study. Note that in the simulations, $\mathrm{Ca}^{+2}$ and $\mathrm{HCO}_{3}^{-}$represent the mass and charge balancing species, respectively.

\begin{tabular}{lc}
\hline \multicolumn{1}{c}{ Basis species } & Log Activity \\
\hline $\mathrm{H}^{+}$ & -7 \\
$\mathrm{~K}^{+}$ & -10 \\
$\mathrm{Na}^{+}$ & -10 \\
$\mathrm{Ca}^{+2}$ & -5 \\
$\mathrm{Al}^{+3}$ & -20 \\
$\mathrm{SiO}_{2}(\mathrm{aq})$ & -10 \\
$\mathrm{HCO}_{3}^{-}$ & -5 \\
\hline
\end{tabular}


兽

- 
, 


\section{Contents}

Chapter 11.0 Introduction to the Thermodynamic Data Determination.............................11-2

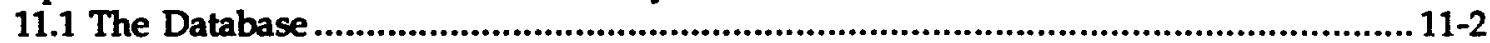

11.2 U.S. Contribution to the NEA Organization for Economic Co-operation and Development (OECD) Critical Reviews of the Chemical Thermodynamics of the Actinides and Fission Products.....................................................................................................11-3

11.2.1 Lawrence Livermore National Laboratory's Role........................................11-3

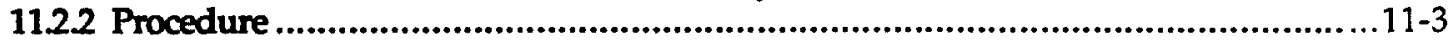

11.2.3 Auxiliary Data....................................................................................11-4

11.3 Qualification of Data for Using in Quality Affecting Calculations ...........................11-4

11.4 Review of Thermodynamic Data............................................................................11-4

11.4.1 Chemical Thermodynamics of Uranium..........................................................11-4

11.4.2 Chemical Thermodynamics of Americium ........................................................11-5

11.4.3 Chemical Thermodynamics of Technetium ........................................................11-6

11.4.4 Chemical Thermodynamics of Plutonium and Neptunium..................................11-7

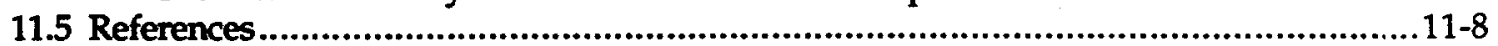




\title{
Chapter 11.0 Introduction to the Thermodynamic Data Determination
}

\author{
Cynthia Palmer
}

In the Thermodynamic Data Determination area, actinide and fission product solubility limits are determined, evaluated, and delivered to the database. The solubility limits can be an important control on potential release rates from the waste package under aqueous conditions as they represent the upper limit to noncolloidal solution concentrations measured in leach rate experiments. Chemical thermodynamic data are needed to model the solubility limits and speciation for changes in the groundwater parameters, e.g., temperature, $\mathrm{pH}$, Eh, and chemical composition. Chemical equilibria are affected by changes in temperature, and reaction constants are in general a function of temperature. To predict solubility limits for actinides under a wide variety of temperature and complex groundwater compositions, two types of information are needed:

1. Actual actinide solubility and speciation measurements, both individually and in mixtures, in appropriate groundwaters actual or synthetic, as a function of temperature;

2. Measurements of thermodynamic constants from the formation of solid phases and solution species as a function of temperature (i.e., solubility product and complexation constants). Both are required for reliable modeling of solubility limits. As the model is being assembled its reliability must be assured by comparing results predicted from the database with experimental results. This is an interactive process and requires a close working relationship between the database development task and the data determination task.

\subsection{The Database}

"The thermodynamic data base is a summary of the available thermodynamic data for aqueous species, solids, and gases in tabular form that are necessary to serve as input to the geochemical modeling codes EQ3NR and EQ6. The data base will be evaluated by testing predictions of host-rock phases, secondary phases, solution species, and total solution concentrations against the results of laboratory measurements made over a range of identified parameters that include: temperature, ionic strength, redox conditions, and solution composition" (ref. UCID-20864 Geochemical Modeling (EQ3/6) Plan, Office of Civilian Radioactive Waste Management Program (8/86)-Section 4.0 "Thermodynamic Data Base").

Recent revisions of the thermodynamic data for several of the aqueous and solid species of $\mathrm{U}, \mathrm{Am}, \mathrm{Np}$, and $\mathrm{Pu}$ have demonstrated the need for an experimental data base activity that would be able to provide data that is currently lacking for solubility limiting solid phases and/or solution species. Measurements will be made as a function of temperature, ionic strength, and oxidation state, as required. The 
activity, which commenced in mid-FY 1986, has been divided into three sections: sensitivity analysis, development of thermodynamic data, and validation.

Two members of the EQ3/6 data base staff are participants on critical review teams for the International Thermodynamic Data Base, sponsored by the Nuclear Energy Agency (NEA). As a result of this work, the following principles have been accepted for the EQ3/ 6 data base.

1. Incorporate results of peer reviewed data. This will provide compatibility with CODATA (Committee on Data for Science and Technology) task group recommended key values and with NEA as their data values are released.

2. Implement EQ3/6 data base methodology for new and existing data.

3. Create and maintain a data base library on the computer for all documented sources of thermodynamic data.

A significant review and revising of thermodynamic data for the actinides was performed. A Nuclear Energy Agency (NEA) document, Chemical Thermodynamics of Americium (NEA, 1995) was reviewed and data is ready to be entered into the GEMBOCHS data base.

\subsection{U.S. Contribution to the NEA Organization for Economic Co-operation and Development (OECD) Critical Reviews of the Chemical Thermodynamics of the Actinides and Fission Products}

In 1984, the NEA/OECD initiated the writing and publication of a series of critical reviews of the chemical thermodynamics of those elements that are of particular importance in the safety assessment of radioactive waste disposal systems. The U.S., through the Yucca Mountain Site Characterization Project, has participated in this international project.

\subsubsection{Lawrence Livermore National Laboratory's Role}

Lawrence Livermore National Laboratory (LLNL), through the Yucca Mountain Site Characterization Project (YMP), has been responsible for coordinating the United States' role in the NEA's Critical Reviews of the Chemical Thermodynamics of the Actinides and Fission Products. FY 1995 was the last year the U.S. participated in the Reviews through the Yucca Mountain Project.

The YMP Activity under which these reviews were completed is graded "Quality Affecting." All Procurements reflected this grading and included appropriate Quality Assurance training to comply with the grading. The coordinator represented the U.S. participants during Quality Assurance Audits.

\subsubsection{Procedure}

The process of reviewing experimentally obtained data that has been published in the open literature is described in a series of publications that address:

- Guidelines for the Review Procedure and Data Selection

- Guidelines for the Extrapolation to Zero Ionic Strength

- Guidelines for the Assignment of Uncertainties

- Guideline for Temperature Corrections (Draft) 
- Standards and Conventions for TDB Publications

- Guidelines for the Independent Peer Review of TDB Reports

To serve as the reviewers, the NEA assembled teams of internationally recognized chemists with backgrounds in actinide and physical chemistry. These panel members evaluated the reported experiments, considered the results, and decided whether each data set warranted inclusion in the final volume. As needed, reports were rejected from further consideration and reported data reinterpreted using different sets of species. Written comments describing the analysis of each literature report are included in the review. A second panel of reviewers was convened to verify that the initial panel's decisions were sound and consistent and to confirm that the published procedures were followed. This second review process was added at the United States' request to address the NUREG 1297, 1298 which describes the NRC process for qualification of existing data.

\subsubsection{Auxiliary Data}

The interpretation of chemical thermodynamic data for the actinides and fission products require the use of auxiliary data, for example, acid dissociation constants. These data, themselves, must be internally consistent. It is, therefore, necessary to always use the identified auxiliary data in conjunction with the selected NEA values. The NEA project selected the database available from the Committee on Data for Science and Technology (CODATA) as their principle source of auxiliary data. The qualification of the actinide and fission product data from the NEA requires (and implies) the qualification of the CODATA database. Data not available from CODATA were evaluated as part of the uranium review and made available to the other review teams.

\subsection{Qualification of Data for Using in Quality Affecting Calculations}

Publications describing the process for qualifying existing data are listed below:

- OCRWM QAP 2.5, "Peer Review"

- Letter addressed to Susan Jones, Assistant Manager for Scientific Programs, YMSCO, NV (ID: LLYMP9503063), describing the process that the Solubility Working Group will use to qualify radionuclide thermochemical data.

- YAP 2.1Q "Technical Assessment"

- YAP SIII.1Q, "Qualification of Existing Data"

- YMP AP-5.9Q, "Qualification of Data"

\subsection{Review of Thermodynamic Data}

\subsubsection{Chemical Thermodynamics of Uranium}

In 1992, the NEA published the volume, Chemical Thermodynamics of Uranium (NEA, 1992), which includes the U.S. contributions. Individual contributions are not separable. 
- As the only U.S. scientist to participate in the technical review of the Uranium data, Anthony Muller initiated the Uranium volume work during his assignment at the NEA. Muller left the NEA in 1986 and is currently affiliated with SAIC in McLean, VA. There are no records that any of his efforts were supported by the YMP.

- Donald Langmuir participated in an early meeting of the Uranium team and was unable to continue his participation due to lack of funding.

- U.S. scientists, R.E. Mesmer, D.A. Palmer, and C.F. Baes, Jr., all from Oak Ridge National Laboratory, were acknowledged by the technical reviewers in the Uranium volume.

The U.S., through the YMP, supplied three independent experts to the second review panel. They were as follows:

- Dr. C.F. Baes, Jr., Oak Ridge National Laboratory, Oak Ridge, TN

- Dr. D.L. Hildenbrand, SRI International, Menlo Park, CA

- Dr. F. J. Pearson, Jr., Ground-Water Geochemistry, Irving, TX

Other U.S. scientists were thanked for their technical comments and suggestions: M.W. Chase, National Institute of Standards and Technology, Gaithersburg, MD; K. Czyscinski, Roy Weston Inc., Washington, D.C.; D. Garvin, National Institute of Standards and Technology, Gaithersburg, MD; L. Maya, Oak Ridge National Laboratory, Oak Ridge, TN; L.R. Morss, Argonne National Laboratory, Argonne, IL; T.W. Newton, Los Alamos National Laboratory, Los Alamos, NM; D.K. Nordstrom, U.S. Geological Survey, Menlo Park, CA; V.B. Parker, National Institute of Standards and Technology, Gaithersburg, MD; S.L. Phillips, Lawrence Berkeley Laboratory, Berkeley, CA; J.A. Rard, Lawrence Livermore National Laboratory, Livermore, CA; W.J. Ullman, University of Delaware, Lewes, DE; and E.F. Westrum, Jr., University of Michigan, Ann Arbor, MI.

11.4.1.1 Corrections to the Uranium NEA-TDB review. In Appendix D of the Americium volume (NEA, 1995), there are corrections and additions to the Uranium volume. These data have not be submitted for independent peer review and, therefore, are not considered qualified by YMP.

\subsubsection{Chemical Thermodynamics of Americium}

In 1995, the NEA published the volume, Chemical Thermodynamics of Americium, which includes the U.S. contributions. Individual contributions are not separable.

Following discussions in 1986 with Dr. Robert Silva (USA), Hans Wanner initiated the Americium volume work during his assignment at the NEA. The review committee was selected and met at the NEA Data Bank, Saclay, France in the fall of 1987.

The U.S., through the YMP, supplied all three independent experts to the second review panel, listed as follows:

- Dr. C.F. Baes, Jr., Oak Ridge National Laboratory, Oak Ridge, TN

- Dr. Lester Morss, Argonne National Laboratory, Argonne, $\Pi \mathrm{L}$

- Dr. Arthur Martell, Texas A\&M University, College Station, TX 
Dr. Edward Patera (currently of Los Alamos National Laboratory, Los Alamos, NM) was on assignment to the NEA Division for Radiation Protection and Waste Management during the compilation of the Americium volume.

\subsubsection{Chemical Thermodynamics of Technetium}

A volume covering the Thermodynamics of Technetium was part of the initial NEA Review project design in 1984 . When complete, this volume will contain a comprehensive review of material related to the inorganic compounds of technetium and their aqueous solutions. While there is extensive literature covering the organometallic chemistry of technetium, only a small portion of these complexes are of interest to the radioactive waste management community. Consequently, the review committee will limit their coverage of the organometallic chemistry to those systems containing thermodynamic or kinetic data. Technetium containing compounds of radiopharmaceutical interest will be covered in the review volume.

YMP funding for this volume has not been continuous during the project. There is no FY 1996 funding supporting the completion of the final draft. As a result, YMP can neither gain access to the information that will be contained therein, nor influence the priorities of the work of the review committee members. Since this work is not completed, it can not be discussed in this revision of the NFER but will be included in the future.

A working draft of the volume, Chemistry and Thermodynamics of Technetium, was published in 1992, and a final draft is expected this calendar year. Internal LLNL contributions provide some idea of the material to be included, summarized as follows:

1. Chemical Thermodynamics of Technetium $I-$ Contributions to the NEA volume on Technetium Thermodynamics: hydrides, polynuclear halides, oxohalides, hydroxohalide salts, oxohalide salts, chalcogenides and calcogen complexes, oxosulphur complexes, nitrogen compounds, nitrogen complexes, phosphorus compounds, other pnictide compounds and complexes (As, Sb, and $\mathrm{Bi}$ ), pseudo-halide and oxopseudo-halide complexes, nitrosyl complexes, and tin complexes (Rard, 1989).

2. Chemical Thermodynamics of Technetium II-Contributions to the NEA volume on Technetium Thermodynamics: mononuclear halides (binary and ternary), phosphorus complexes, silicon complexes, and update of Chemical Thermodynamics of Technetium I (Rard, 1989).

3. Chemical Thermodynamics of Technetium III-Contributions to the NEA volume on Technetium Thermodynamics: hydroxide compounds and complexes containing other ligands, inorganic carbon complexes, and update of Chemical Thermodynamics of Technetium II (Rard, 1990).

4. Chemical Thermodynamics of Technetium IV - Contributions to the NEA Book on Technetium Thermodynamics: anhydrous binary oxides, hydrated oxides and hydrous oxides, $\mathrm{Tc}_{2} \mathrm{O}_{7} \cdot \mathrm{H}_{2} \mathrm{O}$, pertechnetate and oxypertechnetate salts, aqueous halide complexes, aqueous TcO4, and aqueous ions of $\mathrm{Tc}(\mathrm{VI})$ through Tc(III) (Rard, 1991). 
5. Chemical Thermodynamics of Technetium V - Contributions to the NEA Book on Technetium Thermodynamics: anhydrous binary oxides, hydrous oxides, $\mathrm{Tc}_{2} \mathrm{O}_{7} \mathrm{H}_{2} \mathrm{O}$, pertechnetate salts, undissociated $\mathrm{HTCO}_{4}$, and comments on Tc(III) and Tc(II) (Rard, 1992).

6. Chemical Thermodynamics of Technetium VI - Contributions to the NEA Book on Technetium Thermodynamics: $\mathrm{TcO}_{2}(\mathrm{cr})$, ternary technetium sulphides and selenides, new oxyhalides, additional calculations for $\operatorname{TcF}_{6}(\mathrm{~g})$, and updating of previous contributions (Rard, 1995, unpublished).

\subsubsection{Chemical Thermodynamics of Plutonium and Neptunium}

Volumes covering the thermodynamics of Plutonium and Neptunium were part of the initial NEA Review project design in 1984. When this volume is complete it will contain a comprehensive review of material related to the inorganic compounds of neptunium and plutonium and their aqueous solutions.

YMP funding for this volume has not been continuous during the project. There is no FY 1996 funding supporting the completion of the final draft. As a result, YMP can neither gain access to the information that will be contained therein, nor influence the priorities of the work of the review committee members. Since this work is not completed, it can not be discussed in this revision of the NFER but will be included in the future. 


\subsection{References}

Geochemical Modeling (EQ3/6) Plan, Office of Civilian Radioactive Waste Management Program (8/86)-Section 4.0 "Thermodynamic Data Base," Lawrence Livermore National Laboratory, Livermore, CA, UCID-20864, Nuclear Energy Agency (NEA, 1995), Chemical Thermodynamics 2: Chemical Thermodynamics of Americium, Nuclear Energy Agency, Organization for Economic Co-Operation and Development, Elsevier, 1995.

Nuclear Energy Agency (NEA, 1992), Chemical Thermodynamics 1: Chemical

Thermodynamics of Uranium, Nuclear Energy Agency, Organization for Economic Co-Operation and Development, North-Holland, 1992.

Rard, J. A. (1989), Chemical Thermodynamics of Technetium I, Lawrence Livermore National Laboratory, Livermore, CA, UCRL-JC-100554.

Rard, J. A. (1989), Chemical Thermodynamics of Technetium II, Lawrence Livermore National Laboratory, Livermore, CA, UCRL-JC-102708.

Rard, J. A. (1990), Chemical Thermodynamics of Technetium III, Lawrence Livermore National Laboratory, Livermore, CA, UCRL-JC-103728.

Rard, J. A. (1991), Chemical Thermodynamics of Technetium IV, Lawrence Livermore National Laboratory, Livermore, CA, UCRL-JC-108178.

Rard, J. A. (1992), Chemical Thermodynamics of Technetium V, Lawrence Livermore National Laboratory, Livermore, CA, UCRL-JC-109638.

Rard, J. A. (1995), Chemical Thermodynamics of Technetium VI, Lawrence Livermore National Laboratory, Livermore, CA, (to be published at a later date). 
율

*. 

Appendix A

A-1 


\section{References (copied from the PNFER document)}

Aagaard, P., and H. C. Helgeson (1983), "Activity/Composition Relations among Silicates and Aqueous Solutions: II. Chemical and Thermodynamic Consequences of Ideal Mixing of Atoms on Homological Sites in Montmorillonites, Ilites, and Mixed-Layer Clays," Clays and Clay Miner. 31, 207217.

Ames, L. L., Jr. (1964a), "Some Zeolite Equilibria with Alkali Metal Cations," Am. Miner. 49, 127-145.

Ames, L. L., Jr. (1964b), "Some Zeolite Equilibria with Alkaline Earth Metal Cations," Am. Miner. 49, 1099-1110.

Anderson, L. A. (1984), Rock Property Measurements on Large-Volume Core Samples From Yucca Mountain USW GU-3/G-3 and USW G-4 Boreholes, Neoada Test Site, Neoada, U.S. Geological Survey, Denver, CO, OFR-84-552.

Anderson, L. A., and G. R. Johnson (1976), "Application of the Self-Potential Method to Geothermal Exploration in Long Valley, California," Journal of Geophysical Research 81, 1527-1532.

Andersson, K., B. Allard, M. Bengtsson, and B. Magnusson (1989), "Chemical Composition of Cement Pore Solutions," Cem. Concr. Res. 19, 327-332.

Arulmoli, K., and C. M. St. John (1987), Analysis of Horizontal Waste Emplacement Boreholes of a Nuclear Waste Repository in Tuff, Sandia National Laboratories, Albuquerque, NM, SAND86-7133.

Atkinson, B. K., and P. G. Meredith (1987), "The Theory of Subcritical Crack Growth with Applications to Minerals and Rocks," Fracture Mechanics of Rocks, B. K. Atkinson, Ed. (Academic Press, London).

Babushkin, V. I., G. M. Matveyev, and O. P. Mchedlov-Petrossyan (1985),

Thermodynamics of Silicates (Springer-Verlag).

Barnes, I., T. S. Presser, M. Saines, P. Dickson, and A. F. K. van Groos (1982), "Geochemistry of Highly Basic Calcium Hydroxide Groundwater in Jordan," Chem. Geol. 35, 147-154.

Barnes, M. W., and D. M. Roy (1983), "The Buffering Mechanisms in Leaching of Composites of Cement with Radioactive Waste," Mat. Res. Soc. Symp. Proc. 15, 159-166.

Barrenblatt, G. I., Y. P. Zheltov, and I. N. Kochina (1960), "Basic Concepts in the Theory of Seepage of Homogeneous Liquids in Fissured Rocks," PMM 24(5), 852864.

Barrer, R. M., R. Papadopoulos, and L. V. C. Rees (1967), "Exchange of Sodium in Clinoptilolite by Organic Cations," J. Inorg. Nucl. Chem. 29, 2047-2063.

Barrer, R. M. (1978a), "Cation-Exchange Equilibria in Zeolites and Feldspathoids," Natural Zeolites, L. B. Sand and F. A. Mumpton, Eds. (Pergamon Press), pp. 385396.

Barrer, R. M. (1978b), Zeolites and Clay Minerals as Sorbents and Molecular Sieves (Academic Press, New York). 
Barret, P., and D. Bertrandie (1986), "Fundamental Hydration Kinetic Features of the

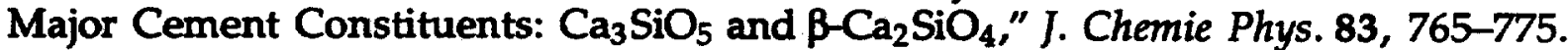

Bates, J. K., W. L. Ebert, D. F. Fischer, and T. J. Gerding (1988), "The Reaction of Reference Commercial Nuclear Waste Glasses During Gamma Irradiation in a Saturated Tuff Environment," J. Mater. Res. 3(3), 576-597.

Bauer, S. J., and J. F. Holland (1987), "Analysis of In Situ Stress at Yucca Mountain," Proc. of the 28th U.S. Symp. on Rock Mechanics, I. Farmer, Ed. (A. A. Balkema, Rotterdam, The Netherlands), pp. 707-713.

Bauer, S. J., and L. S. Costin (1990), Thermal and Mechanical Codes First Benchmark Exercise Part II: Elastic Analysis, Sandia National Laboratories, Albuquerque, NM, SAND89-0757.

Bauer, S. J., J. F. Holland, and D. K. Parrish (1985), "Implications About In Situ Stress at Yucca Mountain," Proc. of the 26th U.S. Symp. on Rock Mechanics, E. Ashworth, Ed. (A. A. Balkema, Rotterdam, The Netherlands), pp. 1113-1120.

Baulch, D. L., R. A. Cox, R. F. Hampson, Jr., J. A. Kerr, J. Troe, and R. T. Watson (1980), "Evaluated Kinetic and Photochemical Data for Atmospheric Chemistry," J. Phys. Chem. Ref. Data 9, 295.

Baulch, D. L., R. A. Cox, R. F. Hampson, Jr., J. A. Kerr, J. Troe, and R. T. Watson (1982), "Evaluated Kinetic and Photochemical Data for Atmospheric Chemistry," J. Phys. Chem. Ref. Data 11, 327.

Benson, L. V. and P. W. McKinley (1985), Chemical Composition of Ground Water in the Yucca Mountain Area, Nevada, 1971-84, U.S. Geological Survey, Denver, CO, OFR-85-484.

Benson, L. V., J. H. Robison, R. K. Blankennagel, and A. E. Ogard (1983), Chemical Composition of Ground Water and the Locations of Permeable Zones in the Yucca Mountain Area, Nevada, U.S. Geological Survey, Denver, CO, OFR-83-854.

Bensted, J. (1983a), "Early Hydration of Portland Cement-Effects of Water/Cement Ratio," Cem. Concr. Res. 13, 493-498.

Bensted, J. (1983b), “Hydration of Portland Cement,” S. N. Ghosh, Ed., pp. 307-347.

Bensted, J. (1989), "Oil Well Cements-A General Review," Chem. Ind., 20 February 1989, pp. 100-105.

Berner, U. R. (1987), "Modelling Porewater Chemistry in Hydrated Portland Cement," Mat. Res. Soc. Symp. Proc. 84, 319-330.

Bish, D. L. (1988), "Effects of Composition on the Dehydration Behavior of Clinoptilolite and Heulandite," Occurrence, Properties and Utilization of Natural Zeolites, D. Kallo and H. S. Sherry, Eds. (Akademiai Kiado Pub., Budapest).

Bish, D. L. (1989), Evaluation of Past and Future Alterations in Tuff at Yucca Mountain, Nevada, Based on the Clay Mineralogy of Drill Cores USW G-1, G-2, and G-3, Los Alamos National Laboratory, Los Alamos, NM, LA-10667-MS.

Bish, D. L., A. E. Ogard, D. T. Vaniman, and L. Benson (1984), "Mineralogy, Petrology and Groundwater Chemistry at Yucca Mountain Tuffs," Mat. Res. Soc. Symp. Proc. (Elsevier, New York), vol. 26, pp. 283-291.

Bish, D. L., and S. J. Chipera (1986), Mineralogy of Drill Holes J-13, UE-25A\#1, and USW G-1 at Yucca Mountain, Neoada, Los Alamos National Laboratory, Los Alamos, NM, LA-10764-MS. 
Bish, D. L., and S. J. Chipera (1989), Reoised Mineralogic Summary of Yucca Mountain, Neoada, Los Alamos National Laboratory, Los Alamos, NM, Report LA-11497.

Bish, D. L., D. T. Vaniman, F. M. Byers, Jr., and D. E. Broxton (1982), Summary of the Mineralogy-Petrology of Tuffs of Yucca Mountain and the Secondary Phase Thermal Stability in Tuffs, Los Alamos National Laboratory, Los Alamos, NM, LA-9321-MS.

Bish, D. L., F. A. Caporuscio, J. F. Copp, B. M. Crowe, J. D. Purson, J. R. Smyth, and R. G. Warren (1981), Los Alamos National Laboratory, Los Alamos, NM, LA-8840-MS.

Blum, A. E., R. A. Yund, and A. C. Lasaga (1990), "The Effect of Dislocation Density on the Dissolution Rate of Quartz," Geochim. Cosmochim. Acta 54, 283-297. Blum, A. E., R. A. Yund, and A. C. Lasaga (1988), "The Effect of Dislocation Density on the Aqueous Dissolution Rate of Quartz," Geol. Soc. Amer. Abstracts with Programs, A41.

Bourcier, W. L., D. W. Peifer, K. G. Knauss, K. D. McKeegan, and D. K. Smith (1990), "A Kinetic Model for Borosilicate Glass Dissolution Based on the Dissolution Affinity of a Surface Alteration Layer," Mat. Res. Soc. Symp. Proc., vol. 176, pp. 209-216.

Braester, C. (1986), “One-phase and Multiphase Flow through Fractured Rock Formations," Fragmentation, Form, and Flow in Fractured Media, R. Engleman and Z. Jaeger, Eds. (Adam Hilger, Bristol, UK), pp. 325-340.

Breck, D. W. (1974), Zeolite Molecular Sieves (J. Wiley and Sons, New York). Brouwer, E., B. Baeyens, A. Maes, and A. Cremers (1983), "Cesium and Rubidium Ion Equilibria in Illite Clay," J. Phys. Chem. 87, 1213-1219.

Brown, P. W., E. Franz, G. Frohnsdorff, and H. F. W. Taylor (1984), "Analyses of the Aqueous Phase during Early $\mathrm{C}_{3} \mathrm{~S}$ Hydration," Cem. Concr. Res. 14, 257-262.

Brown, P. W., J. Pommersheim, and G. Frohnsdorff (1985), "A Kinetic Model for the Hydration of Tricalcium Silicate," Cem. Concr. Res. 15, 35-41.

Broxton, D. E. (1987), "Clinoptilolite Compositions in Diagenetically-Altered Tuffs at a Potential Nuclear Waste Repository, Yucca Mountain, Nevada," The Technology of High-Level Nuclear Waste Disposal, P. L. Hofmann, Ed., vol. 3, pp. 179-194.

Broxton, D. E., D. L. Bish, and R. G. Warren (1987), "Distribution and Chemistry of Diagenetic Minerals at Yucca Mountain, Nye County, Nevada," Clays and Clay Miner. 35, 89-110.

Broxton, D. E., R. G. Warren, R. C. Hagan, and G. Luedemann (1986), Chemistry of Diagenetically-Altered Tuffs at a Potential Nuclear Waste Repository, Yucca Mountain, Nye County, Neoada, Los Alamos National Laboratory, Los Alamos, NM, LA-10802.

Broxton, D., D. Vaniman, F. Caporuscio, B. Arney, and G. Heiken (1982), Detailed Patrographic Descriptions and Microprobe Data for Drill Holes USW-G2 and UE25b-1H, Yucca Mountain, Neoada, Los Alamos National Laboratory, Los Alamos, NM, LA-9324-MS. 
Burch, T. E., K. L. Nagy, and A. C. Lasaga (1990), "Precipitation Kinetics of Albite and Kaolinite at ph 8 to 9 and $80^{\circ} \mathrm{C}$, Geol. Soc. Amer. Abstracts with Programs 22, A292.

Burnett, N. C., R. D. Hooton, R. B. Heimann, and M. Onofrei (1985), "The Development of Durable Cementitious Materials for Use in a Nuclear Fuel Waste Disposal Facility," Mat. Res. Soc. Symp. Proc. 50, 461-468.

Buscheck, T. A., and J. J. Nitao (1988), Estimates of the Width of the Wetting Zone Along a Fracture Subjected to an Episodic Infiltration Event in Variably Saturated, Densely Welded Tuff, Lawrence Livermore National Laboratory, Livermore, CA, UCID-21579.

Buscheck, T. A., and J. J. Nitao (1991a), Nonequilibrium Fracture-Matrix Flow During Episodic Infiltration Events in Yucca Mountain, Lawrence Livermore National Laboratory, Livermore, CA, UCRL-ID-108311.

Buscheck, T. A., and J. J. Nitao (1991b), Modeling Hydrothermal Flow in Variably Saturated, Fractured, Welded Tuff During the Prototype Engineered Barrier System Field Test of the Yucca Mountain Project, Lawrence Livermore National Laboratory, Livermore, CA, UCRL-ID-106521.

Buscheck, T. A., J. J. Nitao, and D. A. Chesnut (1991a), The Impact of Hydrology on the Engineered Barrier System of the Potential Yucca Mountain Repository Site, Lawrence Livermore National Laboratory, Livermore, CA, UCRL-ID-107910.

Buscheck, T. A., J. J. Nitao, and D. A. Chesnut (1991b), "The Impact of Episodic Nonequilibrium Fracture-Matrix Flow on Geological Repository Performance," Proc. of the ANS Topical Mtg. on Nuclear Waste Packaging, Focus '91, Las Vegas, NV, Sept. 30-Oct. 2, 1991; Lawrence Livermore National Laboratory, Livermore, CA, UCRL-JC-106759.

Carlos, B. (1985), Minerals in Fractures of the Unsaturated Zone from Drill Core USW-G4, Yucca Mountain, Nye County, Neoada, Los Alamos National Laboratory, Los Alamos, NM, LA-10415-MS.

Carlos, B. (1989), Fracture-Coating Minerals in the Topopah Spring Member and Upper Tuff of Calico Hills from Drill Hole J-13, Los Alamos National Laboratory, Los Alamos, NM, LA-11504-MS.

Chipera, S. J., and D. L. Bish (1989), Quantitative X-ray Diffraction Analyses of Samples Used for Sorption Studies by the Isotope and Nuclear Chemistry Division, Los Alamos National Laboratory, Los Alamos, NM, LA-11669-MS.

Christiansen, R. L., P. W. Lipman, W. J. Carr, F. M. Byers, Jr., P. P. Orkild, and K. A. Sargent (1977), "Timber Mountain-Oasis Valley Caldera Complex of Southern Nevada," Bull. Geol. Soc. Am. 88, 2573-2593.

Christianson, M. C., and B. Brady (1989), Analysis of Alternative Waste Isolation Concepts, U.S. Nuclear Regulatory Commission, Washington, DC, NRC-FIN D1016, NUREG/CR-5389.

Cohen, L. H., and W. Klement, Jr. (1975), "Differential Thermal Analysis Investigation of the High-Low Cristobalite Inversion under Hydrostatic Pressure to $7 \mathrm{kbar}, "$ Jour. Am. Cerm. Soc. 58(5-6), 206-208.

Cooper, H. W., and G. Simmons (1977), "The Effects of Cracks on Thermal

Expansion of Rocks," Earth and Planetary Science Letters 36, 404. 
Corwin, R. F., and D. B. Hoover (1979), "The Self-Potential Method in Geothermal Exploration," Geophysics 44, 226-245.

Daily, W., A. Ramirez, T. Ueng, and V. LaTorre (1989), "High Frequency Electromagnetic Tomography," Proc. of the ANS Topical Mtg. on Nuclear Waste Isolation in an Unsaturated Zone, Focus ' 89 (Amer. Nuc. Soc., La Grange Park, II), pp. 409-416. (NNA.910326.0098)

Daily, W., and W. Lin (1991), Laboratory Determined Suction Potential of Topopah Spring Tuff, Lawrence Livermore National Laboratory, Livermore, CA, UCRL102127.

Daily, W., W. Lin, and T. Buscheck (1987), "Hydrological Properties of Topopah Spring Tuff-Laboratory Measurements," J. Geophys. Res. 92(B8), 7854-7864.

Delany, J. M. (1985), Reaction of Topopah Spring Tuff with J-13 Water: A Geochemical Modeling Approach Using the EQ3/6 Reaction Path Code, Lawrence Livermore National Laboratory, Livermore, CA, UCRL-53631.

Delany, J. M., and S. R. Lundeen (1991), The LLNL Thermochemical Data Base: Reoised Data and File Format for the EQ3/6 Package, Lawrence Livermore National Laboratory, Livermore, CA, UCID-21658.

Dixon, R. S. (1970), "Dissociation of Water Vapor by Photolytic, Radiolytic and Electron Impact Methods," Rad. Res. Rev. 2, 237.

DOE (U.S. Department of Energy) (1986), Environmental Assessment: Yucca Mountain Site, Nevada Research and Development Area, Nevada, Volume II, DOE/RW-0073.

DOE (U.S. Department of Energy) (1988), o, Yucca Mountain Site, Nevada Research and Deolopment Area, Neoada, Office of Civilian Radioactive Waste Management, Washington, DC, DOE/RW-0199.

DOE (U.S. Department of Energy) (1990), Yucca Mountain Project Reference Information Base, Version 4, Yucca Mountain Site Characterization Project Office, Las Vegas, NV, YMP/CC-0002. (NNA 890330.0077)

Duffy, C. J. (1984), "Hydrothermal Chemistry," Research and Development Related to the Neoada Nuclear Waste Storage Investigations, Los Alamos National Laboratory, Los Alamos, NM, LA-10032.

Durham, W. B., J. M. Beiriger, M. Axelrod, and S. Trettenaro (1986), "The Effect of Gamma Radiation on the Strength and Elasticity of Climax Stock and Westerly Granites," Nuclear and Chemical Waste Management 6, 159-168.

Ederova, J., and V. Satava (1979), "Heat Capacities of $\mathrm{C}_{3} \mathrm{AH}_{6}, \mathrm{C}_{4} \mathrm{ASH}_{12}$ and $\mathrm{C}_{6} \mathrm{AS}_{3} \mathrm{H}_{32}$," Thermochim. Acta 31, 126-128.

Ehgartner, B. L., and R. C. Kalinski (1988), A Synopsis of Analyses (1981-1987) Performed to Assess the Stability of Underground Excavations at Yucca

Mountain, Sandia National Laboratories, Albuquerque, NM, SAND88-2294.

Ellezer, I., N. Ellezer, R. A. Howald, and P. Viswanadham (1981), "Thermodynamic Properties of Calcium Aluminates," J. Phys. Chem. 85, 2835-2838.

Fletcher, P., and G. Sposito (1989), "The Chemical Modelling of Clay/Electrolyte Interactions for Montmorillonite," Clay Miner. 24, 375-391.

Flint, A. (1991), personal communication with Alan Flint from the U.S. Geological Survey on the topic of "Annual Precipitation Measurements at Yucca Mountain." 
Frysinger, G. R. (1962), "Caesium-Sodium Ion Exchange on Clinoptilolite," Nature 194, 351-353.

Fuentes, H. R, W. L. Polzer, J. Gruber, B. Lauctes, and E. H. Essington (1987), Preliminary Report on Sorption Modeling, Los Alamos National Laboratory, Los Alamos, NM, LA-10952.

Fujii, X., and W. Kondo (1983), "Estimation of Thermochemical Data for Calcium Silicate Hydrate (C-S-H)," Am. Ceram. Soc. J. 66, C220-C221.

Gartner, E. M., F. J. Tang, and S. J. Weiss (1985), "Saturation Factors for Calcium Hydroxide and Calcium Sulfates in Fresh Portland Cement Pastes," Am. Ceram. Soc. J. $-68,667-673$.

Gast, R. G. (1972), "Alkali Metal Cation Exchange on Chambers Montmorillonite," Soil Sci. Soc. Amer. Proc., vol. 36, pp. 14-19.

Gauthier, J. (1990), seminar presentation by Jack Gauthier from SPECTRA Research Institute at the Performance Assessment Calculation Exercise (PACE 90) Year-End Review, October 3-4, 1990, Las Vegas, Nevada.

Ghosh, S. N. (1983), "Portland Cement Phases: Polymorphism, Solid Solution, Defect Structure and Hydraulicity," Advances in Cement Technology, S. N. Ghosh, Ed. (Pergamon Press), pp. 289-305.

Glasser, F. P., A. A. Rahman, D. Macphee, M. Atkins, N. Beckley, and E. E. Lachowski (1986), Immobilization of Radioactive Waste in Cement-Based Matrices, United Kingdom Department of the Environment, DOE RW 86.084.

Glasser, F. P., and Marr (1984), 'The Effect of Mineral Additives on the Composition of Cement Pore Fluids," The Chemistry and Chemically Related Properties of Cement, F. P. Glasser, Ed., pp. 419-429.

Glasser, F. P., M. J. Angus, C. E. McCulloch, D. Macphee, and A. A. Rahman (1985), "The Chemical Environment in Cements," Mat. Res. Soc. Symp. Proc. 44, 849858.

Glasser, F. P., S. Diamond, and D. M. Roy (1987), "Hydration Reactions in Cement Pastes Incorporating Fly Ash and Other Pozzolanic Materials," Mat. Res. Soc. Symp. Proc. 85, 167-186.

Glassley, W. E. (1986), Reference Waste Package Environment Report, Lawrence Livermore National Laboratory, Livermore, CA, UCRL-53726.

Grounds, T., H. G. Midgley, and D. V. Nowell (1985), "The Use of Thermal Methods to Estimate the State of Hydratic of Calcium Trisulpho Aluminate Hydrate $3 \mathrm{CaO}_{9} \mathrm{Al}_{2} \mathrm{O}_{3} \cdot 3 \mathrm{CaSO}_{4} \cdot n \mathrm{H}_{2} \mathrm{O}$," Thermochim. Acta 85, 215-218.

Grutzeck, M. W., and A. R. Ramachandran (1987), "An Integration of Tricalcium Silicate Hydration Models in Light of Recent Data," Cem. Concr. Res. 17, 164-170.

Haas, J. L. Jr., G. R. Robinson, Jr., and B. S. Hemingway (1981), "Thermodynamic Tabulations for Selected Phases in the System $\mathrm{CaO}-\mathrm{Al}_{2} \mathrm{O}_{3}-\mathrm{H}_{2} \mathrm{O}$ at $101.325 \mathrm{kPa}(1$ atm) between 273.15 and $1800^{\circ} \mathrm{K}, "$ J. Phys. Chem. Ref. Data 10, 575-669.

Harrar, J. E., (Chairman), J. F. Carley, W. F. Isherwood, E. Raber (1990), Report of the Committee to Review the Use of J-13 Well Water in Nevada Nuclear Waste Storage Investigations, Lawrence Livermore National Laboratory, Livermore, CA, UCID-21867. 
Heimann, R. B. (1988a), "Interaction of Cement and Radioactive Waste Forms in Multicomponent Systems Tests at $200^{\circ} \mathrm{C}$. Part 1: Leaching and Sorption of Cesium, Strontium and Actinides," Cem. Concr. Res. 18, 389-400.

Heimann, R. B. (1988b), "Interaction of Cement and Radioactive Waste Forms in Multicomponent Systems Tests at $200^{\circ} \mathrm{C}$. Part 2: Mineralogical Changes of Cement," Cem. Concr. Res. 18, 554-560.

Heimann, R. B., and R. D. Hooton (1986), "Mineralogical Changes of Various Cement Formulations during Reaction with Groundwater in the Presence of $\mathrm{Ca}$ and Na-bentonite at $150^{\circ} \mathrm{C}, "$ Can. Min. 24, 289-302.

Hopkins, P. L., R. R. Eaton, S. Sinnock (1986), Effect of Drift Ventilation on Repository Hydrology and Resulting Solute Transport Implications, Sandia National Laboratories, Albuquerque, NM, SAND86-1571.

Howell, D. A., G. K. Johnson, I. R. Tasker, P. A. G. O'Hare, and W. S. Wise (1989), "Thermodynamic Properties of the Zeolite Stilbite," Zeolites, vol. 10, pp. 525-531.

Howery, D. G., and H. C. Thomas (1965), "Ion Exchange on the Mineral Clinoptilolite," J. Phys. Chem. 69, 531-537.

Hunter, R. J. (1981), Zeta Potential in Colloid Science, Principles and Applications (Academic Press, London).

lijima, A., (1988), "Diagenetic Transformations of Minerals as Exemplified by Zeolites and Silica Minerals-A Japanese View," Diagenesis, II, G. V. Chilingarian, and K. H. Wolf, Eds. (Elsevier, New York), pp. 147-211.

Ishido, T., H. Mizuanti, and K. Baba (1983), "Streaming Potential Observations, Using Geothermal Wells and In Situ Electrokinetic Coupling-Coefficients under High-Temperature," Tectonophysics 91(1-2), 89-104.

Jeffrey, J. W. (1964), "The Crystal Structures of the Anhydrous Compounds," The Chemistry of Cements, H. F. W. Taylor, Ed. (Academic Press), pp. 131-164.

Johnson, G. K., I. R. Tasker, H. E. Flotow, P. A. G. O'Hare, and W. S. Wise (1989a), "Thermodynamic Studies of Mordenite, Dehydrated Mordenite, and Gibbsite," to be submitted to Amer. Miner.

Johnson, G. K., I. R. Tasker, R. Jurgens, and P. A. G. O'Hare (1989b), "Thermodynamic Studies of Zeolites: Clinoptilolite," J. Chem. Therm., in review.

Johnson, G. L., and D. N. Montan (1990), Thermal Calculations Pertaining to a Proposed Yucca Mountain Nuclear Waste Repository, Lawrence Livermore National Laboratory, Livermore, CA, UCRL-ID-103534.

Jones, A. R. (1959), "Radiation-Induced Reactions in the $\mathrm{N}_{2}-\mathrm{O}_{2}-\mathrm{H}_{2} \mathrm{O}$ System," Rad. Res. 10, 655.

Kana, D. D., B. H. G. Brady, B. W. Vanzant, and P. K. Nair (1989), Critical Assessment of Seismic and Geomechanics Literature Related to a High-Level Nuclear Waste Underground Repository, Nuclear Regulatory Commission, Center for Nuclear Waste Regulatory Analyses, San Antonio, Texas.

Kemeny, J., and N. Cook (1990), "Rock Mechanics and Crustal Stress," Demonstration of a Risk-Based Approach to High-Level Waste Repository Evaluation, R. K. McGuire, Ed., Electric Power Research Institute, Palo Alto, CA, EPRI-NP-7057. 
Kerrisk, J. F. (1983), Reaction-Path Calculations of Groundwater Chemistry and Mineral Formation at Rainier Mesa, Nevada, Los Alamos National Laboratory, Los Alamos, NM, LA-9912.

Khoury, H. N., E. Salameh, and Q. Abdul-Jaber (1985), "Characteristics of an Unusual Highly Alkaline Water from the Maqarin Area, Northern Jordan," J. Hydrol. 81, 79-91.

Klavetter, E. A., and R. R. Peters (1987), An Evaluation of the Use of Mercury Porosimetry in Calculating Hydrologic Properties of Tuffs from Yucca Mountain, Nevada, Sandia National Laboratories, Albuquerque, NM, SAND86-0286-UC-70. (NNA.890327.0056)

Klavetter, E. A., and R. R. Peters (1988), "A Continuum Model for Water Movement in an Unsaturated Fracture Rock Mass," Water Resources Research 24, 416-430.

Knauss, K. G. (1987), "Zeolitization of Glassy Topopah Spring Tuff under Hydrothermal Conditions," Mat. Res. Soc. Symp. Proc., vol. 84, pp. 737-745.

Knauss, K. G., and D. W. Peifer (1986), Reaction of Vitric Topopah Spring Tuff and J13 Groundwater under Hydrothermal Conditions Using Dickson-Type, Gold-Bag Rocking Autoclaves, Lawrence Livermore National Laboratory, Livermore, CA, UCRL-53795.

Knauss, K. G., and T. J. Wolery (1988), "The Dissolution Kinetics of Quartz as a Function of $\mathrm{pH}$ and Time at $70^{\circ} \mathrm{C}, "$ Geochim. Cosmochim. Acta 52, 43-53.

Knauss, K. G., and T. J. Wolery (1989a), "Reply to Comment by J. Gaffner, N. A. Marley, and D. R. Janecky, The Dissolution Kinetics of Quartz as a Function of pH and Time at $70^{\circ} \mathrm{C}$,'" Geochim. Cosmochim. Acta 53, 1471-1474.

Knauss, K. G., and T. J. Wolery (1989b), "Muscovite Dissolution Kinetics as a Function of $\mathrm{pH}$ and Time at $70^{\circ} \mathrm{C}$," Geochim. Cosmochim. Acta 53, 1493-1501.

Knauss, K. G., J. M. Delany, W. J. Beiriger, and D. W. Peifer (1986), "Hydrothermal Interaction of Topopah Spring Tuff with J-13 Water as a Function of

Temperature," Mat. Res. Soc. Symp. Proc., vol. 44, pp. 539-546,

Knauss, K. G., W. L. Bourcier, K. D., McKeegan, G. C. Merzbacher, S. N. Nguyen, F. J.

Ryerson,

D. K. Smith, H. C. Weed, and L. Newton (1990), "Dissolution Kinetics of a Simple Analogue Nuclear Waste Glass as a Function of pH, Time and Temperature," Mat. Res. Soc. Symp. Proc., vol. 176, pp. 371-383.

Komarneni, S., and D. M. Roy (1983), "Hydrothermal Interactions of Cement or Mortar with Zeolites or Montmorillonites," Mat. Res. Soc. Symp. Proc. 15, 55-62. Levy, S. S. (1984), Petrology of Samples from Drill Holes USW H-3, H-4, and H-5, Yucca Mountain, Nevada, Los Alamos National Laboratory, Los Alamos, NM, Report LA-9706.

Levy, S. S. (1990), personal communication with Schon Levy from Los Alamos National Laboratory on the topic of "Unsaturated Zone Zeolite Compositions." Lin, W. (1990a), Laboratory Investigations of Fracture Healing, SEG Summer Workshop: Permeability, Fluid Pressure, and Pressure Seals in the Crust, Lawrence Livermore National Laboratory, Livermore, CA, UCRL-JC-103627. Lin, W. (1990b), Variation of Permeability with Temperature in Fractured Topopah Spring Tuff Samples, Lawrence Livermore National Laboratory, Livermore, CA, UCRL-JC-104765. 
Lin, W., A. Ramirez, and D. Watwood (1990), Temperature Measurements from Prototype Engineered Barrier System Field Test, Lawrence Livermore National Laboratory, Livermore, CA, UCRL-ID-104757.

Lin, W., and W. D. Daily (1989), "Laboratory Study of Fracture Healing in Topopah Spring Tuff-Implications for Near Field Hydrology," Proc. of the ANS Topical Mtg. on Nuclear Waste Isolation in an Unsaturated Zone, Focus '89 (American Nuclear Society, La Grange Park, IL), p. 443.

Lin, W., and W. Daily (1984), Transport Properties of Topopah Springs Tuff, Lawrence Livermore National Laboratory, Livermore, CA, UCRL-53602.

Lin, W., and W. Daily (1990a), "Hydrological Properties of Topopah Spring Tuff under a Thermal Gradient-Laboratory Results," Int. J. Rock Mech. Min. Sci. and Geom. Abs. 27(5), 373-385.

Lin, W., and W. Daily (1990b), Role of Water in Fracture Healing of Topopah Spring Tuff Samples, Lawrence Livermore National Laboratory, Livermore, CA, UCRLJC-103240-ABS.

Linacre, J. K., and W. R. Marsh (1981), "The Radiation Chemistry of Heterogeneous and Homogeneous Nitrogen and Water Systems," Chemistry Division, AERE Harwell, Didcot, Berkshire, England, AERE-R-10027.

Lipman, P. W., R. L. Christiansen, and J. T. O'Connor (1966), A Compositionally Zoned Ash-Flow Sheet in Southern Nevada, U. S. Geological Survey, Prof. Pap. 524-F.

MacDougall, H. R., L. W. Scully, and J. R. Tillerson, (Compilers) (1987), Site Characterization Plan Conceptual Design Report, Sandia National Laboratories, Albuquerque, NM, SAND84-2641.

Macphee, D. E., K. Luke, F. P. Glasser, and E. E. Lachowski (1989), "Solubility and Aging of Calcium Silicate Hydrates in Alkaline Solutions at $25^{\circ} \mathrm{C}, " \mathrm{Am}$. Ceram. Soc. J. 72, 646-654.

Majling, J., V. Tomkova, and E. Istenikova (1985), "Calorimetric Study of Reactions in the System $\mathrm{C}_{4} \mathrm{~A}_{3} \mathrm{~S}-\mathrm{CH}-\mathrm{CS}-\mathrm{H}_{, "}$ Thermochim. Acta 85, 219-222.

Marshall, T. J., and J. W. Holmes (1979), Soil Physics (Cambridge University Press, England).

Matzing, H. (1989), Chemical Kinetics of Flue Gas Cleaning by Electron Beam, Kenforschung Szentrum Karlsruhe Laboratorium für Aerosophysik und Filter Technik, Karlsruhe, West Germany, KFK 4494.

Maycock, J. N., J. Skalny, and R. S. Kalyoncu (1974), "Thermal Decomposition of Cementitious Hydrates," Analytical Calorimetry, R. S. Porter and J. F. Johnson, Eds. (Plenum), pp. 697-711.

McNeil, M. B., D. W. Mohr, and B. J. Little (1990), "Correlation of Laboratory Results with Observations on Long-Term Corrosion of Iron and Copper Alloys," Mat. Res. Soc. Symp. Proc., 1990 Spring Meeting on Materials Science in Archeology (in press).

Meike, A., and W. Glassley (1989), In-Situ Observation of the Alpha/Beta Cristobalite Transition Using High Voltage Electron Microscopy, Lawrence Livermore National Laboratory, Livermore, CA, UCRL-ID-101323 
Milestone, N. B., T. Sugama, L. E. Kukacka, and N. Carciello (1987), “Carbonation of Geothermal Grouts. Part 3: $\mathrm{CO}_{2}$ Attack on Grouts Containing Bentonite," Cem. Concr. Res. 17, 295-306.

Montazer, P., and W. E. Wilson (1984), Conceptual Hydrologic Model of Flow in the Unsaturated Zone, Yucca Mountain, Nevada, U. S. Geological Survey, Lakewood CO, Water Resources Investigation Report 84-4345.

Montazer, P., E. P. Weeks, F. Thamir, S. N. Yard, and P. B. Hofrichter (1985), "Monitoring the Vadose Zone in Fractured Tuff, Yucca Mountain, Nevada," Characterization and Monitoring of the Vadose Zone, National Water Well Assoc. Symp., Denver, CO, Nov 19-21, 1985.

Moore, D. E., C. Morrow, and J. Byerlee (1986), "High-Temperature Permeability and Groundwater Chemistry of Some Nevada Test Site Tuffs," J. Geophys. Res. 91(B2), 2163-2171.

Mor, E. D., and A. M. Beccaria (1975), "Behaviour of Copper in Artificial Sea Water Containing Sulphides," Br. Corros. J. 10, 33-38.

Moragues, A., A. Macias, and C. Andrade (1987), "Equilibria of the Chemical Composition of the Concrete Pore Solution. Part I: Comparative Study of Synthetic and Extracted Solutions," Cem. Concr. Res. 17, 173-182.

Moragues, A., A. Macias, and J. Losada (1988), "Equilibria of the Chemical Composition of the Concrete Pore Solution. Part II: Calculation of the Equilibria Constants of the Synthetic Solutions," Cem. Concr. Res. 18, 342-350.

Morrow, C., D. Moore, and J. Byerlee (1985), "Permeability Changes in Crystalline Rocks due to Temperature: Effect of Mineral Assemblage," Mat. Res. Soc. Symp. Proc. (Boston, MA), vol. 44, pp. 467-473.

Nagy, K. L., A. C. Lassaga, and A. E. Blum (1990a), "Kinetics of Dissolution and Precipitation of the Clay Minerals Kaolinite and Gibbsite," Symposium on Aqueous Surface Chemistry and Kinetics, V.M. Goldschmidt Conference Program and Abstracts, 68.

Nagy, K. L., A. E. Blum, A. C. Lasaga (1989), "Kaolinite Precipitation and Dissolution Rates: Effects on Porosity and Permeability in Diagenetic Environments," Amer. Assoc. Petrol. Geol. Annual Meeting.

Nagy, K. L., A. E. Blum, and A. C. Lasaga (1988), "Precipitation Kinetics and Solubility of Kaolinite in Dilute Aqueous Solutions at $80^{\circ} \mathrm{C}$," Geol. Soc. Amer. Abstracts with Programs, A42.

Nagy, K. L., A. E. Blum, and A. C. Lasaga (1991), "Dissolution and Precipitation Kinetics of Kaolinite at $80^{\circ} \mathrm{C}$ and pH3: The Dependence on Solution Saturation State," Amer. Jour. Science, in press.

Nagy, K. L., and A. C. Lasaga (1990a), "The Effect of Deviation from Equilibrium on the Kinetics of Dissolution and Precipitation of Kaolinite and Gibbsite," Chemical Geology 84, 283-285.

Nagy, K. L., and A. C. Lasaga (1990b), "A Full Rate Law for Dissolution and Precipitation of Gibbsite and Simultaneous Precipitation of Gibbsite and Kaolinite at $80^{\circ} \mathrm{C}$ and pH3," Geol. Soc. Amer. Abstracts with Programs 22, A151. Nagy, K. L., C. I. Steefel, A. E. Blum, and A. C. Lasaga (1990b), "Dissolution and Precipitation Kinetics of Kaolinite: Initial Results at $80^{\circ} \mathrm{C}$ with Application to 
Porosity Evolution in a Sandstone," AAPG Memoir, Predicition of Reserooir Quality through Chemical Modeling, in press.

Neal, C., and G. Stanger (1984), "Calcium and Magnesium Hydroxide Precipitation from Alkaline Groundwaters in Oman, and their Significance to the Process of Serpentinization," Min. Mag. 48, 237-241.

Neretneiks, I. (1985), "Transport in Fractured Rocks," Proceedings, Memoires of the 17th International Congress of IAH, Tucson, AZ, Vol. XVII, pp. 301-318.

Nimick, F. B. (1990), The Thermal Conductivity of Seven Thermal Mechanical Units at Yucca Mountain, Neoada, Sandia National Laboratories, Albuquerque, NM, SAND88-1387.

Nimick, F. B., R. G. Van Buskirk, and A. F. McFarland (1987), Uniaxial and Triaxial Compression Test Series on Topopah Spring Member from USW G-2, Yucca Mountain, Neoada, Sandia National Laboratories, Albuquerque, NM, SAND850703.

Nimick, F. G., and B. M. Schwartz (1987), Bulk, Thermal, and Mechanical Properties of the Topopah Spring Member of the Paintbrush Tuff, Yucca Mountain, Neoada, Sandia National Laboratories, Albuquerque, NM, SAND85-0762.

Nitao, J. J. (1988a), Numerical Modeling of the Thermal and Hydrological

Environment Around a Nuclear Waste Package Using the Equivalent Continuum Approximation: Horizontal Emplacement, Lawrence Livermore National Laboratory, Livermore, CA, UCID-21444. (NNA.890317.0021)

Nitao, J. J. (1988b), Simulations of the Near-Field Transport of Radionuclides by Liquid Diffusion at Yucca Mountain-Comparisons with and without Emplacement Backfill, Lawrence Livermore National Laboratory, Livermore, CA, UCID-21466.

Nitao, J. J. (1989a), V-TOUGH-An Enhanced Version of the TOUGH Code for the Thermal and Hydrologic Simulation of Large-Scale Problems in Nuclear Waste Isolation, Lawrence Livermore National Laboratory, Livermore, CA, UCID-21954. Nitao, J. J. (1989b), On the Infiltration of a Liquid Front in an Unsaturated, Fractured Porous Media, Part II, Lawrence Livermore National Laboratory, Livermore, CA, UCID-21743.

Nitao, J. J. (1991), Theory of Matrix and Fracture Flow Regimes in Unsaturated, Fractured Porous Media, Lawrence Livermore National Laboratory, Livermore, CA, UCRL-JC-104933.

Nitao, J. J., and T. A. Buscheck (1989), "On the Infiltration of a Liquid Front in an Unsaturated, Fractured Porous Medium," Proc. of the ANS Topical Mtg on Nuclear Waste Isolation in an Unsaturated Zone, Focus '89 (Amer. Nuc. Soc., La Grange, IL).

Norris, A. E. (1989), "The Use of Chlorine Isotope Measurements to Trace Water Movements at Yucca Mountain," Proc. of the ANS Topical Mtg on Nuclear Waste Isolation in an Unsaturated Zone, Focus '89 (Amer. Nuc. Soc., La Grange, IL).

Nourbehecht, B. (1963), Irreversible Thermodynamic Effects in Inhomogeneous Media and their Applications in Certain Geoelectric Problems, Ph.D. Thesis, Massachusetts Institute of Technology, Cambridge, MA. 
Ogard, A. E., and J. F. Kerrisk (1984), Groundwater Chemistry along Flow Paths between a Proposed Repository Site and the Accessible Environment, Los Alamos National Laboratory, Los Alamos, NM, LA-10188.

Olofsson, U., B. Allard, B. Torstenfelt, and K. Andersson (1982b), "Properties and Mobilities of Actinide Colloids in Geologic Systems," Scientific Basis For Nuclear Waste Management 5, W. Lutze, Ed., pp. 755-764.

Olofsson, U., B. Allard, K. Andersson, and B. Torstenfelt (1981), Formation and Properties of Radiocolloids in Aqueous Solution-A Literature Survey, Programrådet för Radioaktivt Avfall, National Council for Radioactive Waste, Department of Nuclear Chemistry, Chalmers University of Technology, Göteborg, Sweden, Report Prav 4.25.

Olofsson, U., B. Allard, K. Andersson, and B. Torstenfelt (1982a), "Formation and Properties of Americium Colloids in Geologic Systems," Scientific Basis For Nuclear Waste Management 4, S. Topp, Ed.

Olsson, W. A. (1987), Rock Joint Compliance Studies, Sandia National Laboratories, Albuquerque, NM, SAND86-0177.

Olsson, W. A. (1988), Compliance and Strength of Artificial Joints in Topopah Spring Tuff, Sandia National Laboratories, Albuquerque, NM, SAND88-0660.

Olsson, W. A., and A. K. Jones (1980), Rock Mechanics Properties of Volcanic Tuffs from the Neoada Test Site, Sandia National Laboratories, Albuquerque, NM, SAND80-1453.

O'Neal, W. C., D. W. Gregg, J. N. Hockman, E. W. Russell, and W. Stein (1984), Preclosure Analysis of Conceptual Waste Package Designs for a Nuclear Waste Repository in Tuff, Lawrence Livermore National Laboratory, Livermore, CA, UCRL-53595.

Onofrei, M. (1987), "Leaching Studies of Concrete Materials for Nuclear Fuel Waste Immobilization Containers," The Geological Disposal of High Level Radioactive Wastes, D. G. Brookins, Ed. (Theophrastus Publications, Athens, Greece), pp. 351396.

Ortiz, T. S., R. L. Williams, F. B. Nimick, B. C. Whittet, and D. L. South (1985), A Three-Dimensional Model of Reference Thermal/Mechanical and Hydrologic Stratigraphy at Yucca Mountain, Southern Nevada, Sandia National Laboratories, Albuquerque, NM, SAND84-1076.

Peters, R. R., E. A. Klavetter, I. J. Hall, S. C. Blair, P. R. Hellers, and G. W. Gee (1984), Fracture and Matrix Hydrologic Characteristics of Tuffaceous Materials from Yucca Mountain, Nye County, Nevada, Sandia National Laboratories, Albuquerque, NM, SAND84-1471.

Pollard, A. M., R. G. Thomas, and P.A. Williams (1989), "Synthesis and Stabilities of the Basic Copper (II) Chlorides Atacamite, Paratacamite, and Botallackite," Min. Mag. 53, 557-563.

Price, R. H. (1983), Analysis of Rock Mechanics Properties of Volcanic Tuff Units from Yucca Mountain, Neoada Test Site, Sandia National Laboratories, Albuquerque, NM, SAND82-1315.

Price, R.H. (1986), Effects of Sample Size on the Mechanical Behavior of Topopah Spring Tuff, Sandia National Laboratories, Albuquerque, NM, SAND85-0709 
Price, R. H., and A. K. Jones (1982), Uniaxial and Triaxial Compression Tests Series on Calico Hills Tuff, Sandia National Laboratories, Albuquerque, NM, SAND821314.

Price, R. H., F. B. Nimick, J. R. Connolly, K. Keil, B. M. Schwartz, and S. J. Spense (1985), Preliminary Characterization of the Petrologic, Bulk, and Mechanical Properties of a Lithophysal Zone Within the Topopah Spring Member of the Paintbrush Tuff, Sandia National Laboratories, Albuquerque, NM, SAND84-0860.

Price, R. H., J. R. Connolly, and K. Keil (1987), Petrologic and Mechanical Properties of Outcrop Samples of the Welded, Devitrified Topopah Spring Member of the Paintbrush Tuff, Sandia National Laboratories, Albuquerque, NM, SAND86-1131. Pruess, K. (1987), Tough User's Guide, Nucl. Regul. Comm. Rep., Washington, DC, NUREG/CR-4645.

Pusch, R. (1989), Influence of Various Excavation Techniques on the Structure and Physical Properties of Near-Field Rock around Large Boreholes, Swedish Nuclear Fuel and Waste Management Co. (SKB), Stockholm, Sweden, Technical Report 89-32.

Ragnarsdottir, K. V. (1990), "Zeolite Stability in the Diagenetic Environment," abstract submitted to Mineralogical Society of Great Britain, December 1989 Meeting, London.

Raloff, J. (1990), "The Colloid Threat," Science News, March 17, 1990, p. 169.

Ramirez, A., D. Wilder, J. Beatty, T. Buscheck, R. Carlson, W. Daily, R. LaTorre, K.

Lee, W. Lin, N-H. Mao, J. Nitao, D. Towse, T-S. Ueng, and D. Watwood (1991), Prototype Engineered Barrier System Field Tests (PEBSFT), Progress Report through November 1, 1988, Lawrence Livermore National Laboratory, Livermore, CA, UCID-21640.

Ramirez, A., R. Carlson, and T. Buscheck (1990), In Situ Changes in the Moisture Content of Heated Welded Tuff Based on Thermal Neutron Measurements, Lawrence Livermore National Laboratory, Livermore, CA, UCRL-ID-104715. Ramirez, A., T. Buscheck, R. Carlson, W. Daily, K. Lee, W. Lin, N-H. Mao, T-S. Ueng, H. Wang, and D. Watwood (1991), Prototype Engineered Barrier System Field Tests (PEBSFT), Final Report, Lawrence Livermore National Laboratory, Livermore, CA, UCRL-ID-106159.

Reed, D. T., and R. A. Van Konynenburg (1988), "Effect of Ionizing Radiation on Moist Air Systems," Mat. Res. Soc. Symp. Proc.: Scientific Basis for Nucl. Waste Mgmt. XI (Mat. Res. Soc., Pittsburg, PA).

Reed, D. T., and R. A. Van Konynenburg (1991), "Corrosion of Copper-Based Materials in Irradiated Moist Air Systems," Mat. Res. Soc. Symp. Proc.: Scientific Basis for Nucl. Waste Mgmt. XIV, T. Abrajano, Jr. and L. H. Johnson, Eds. (Mat. Res. Soc., Pittsburg, PA), vol. 212, pp. 317-325.

Reed, D. T., V. Swayambunathan, B. S. Tani, and R. A. Van Konynenburg (1990), "Corrosion Product Identification and Relative Rates of Corrosion of Candidate Metals in an Irradiated Air-Steam Environment," Mat. Res. Soc. Symp. Proc.: Scientific Basis for Nucl. Waste Mgmt. XIII (Mat. Res. Soc., Pittsburg, PA), p. 517. Rhoderick, J. E. (1981), Examination of Samples of Grout after 63 Years Exposure Underground," Office of Nuclear Waste Isolation, Washington, DC, ONWI-248. 
Roy, D. M., and C. A. Langton (1983), Characterization of Cement Based Ancient Building Materials in Support of Repository Seal Materials Study, Batelle Memorial Institute, BMI/ONWI-523.

Roy, D. M., and C. A. Langton (1989), Studies of Ancient Concrete as Analogs of Cementitious Sealing Materials for a Repository in Tuff, Los Alamos National Laboratory, Albuquerque, NM, LA-11527-MS

Sarker, A. K., M. W. Barnes, and D. M. Roy (1982), Longevity of Borehole and Shaft Sealing Materials: Thermodynamic Properties of Cements and Related Phases Applied to Repository Sealing, U.S. Department of Energy, Office of Nuclear Waste Isolation, Washington, DC, ONWI-201.

Scheetz, B. E., and D. M. Roy (1989a), Preliminary Suroey of the Stability of Silicarich Cementitious Mortars 82-22 and 84-12 with Tuff, Los Alamos National Laboratory, Albuquerque, NM, LA-11222-MS.

Scheetz, B. E., and D. M. Roy (1989b), Reactivity of a Tuff-Bearing Concrete: CL-40 CON-14, Los Alamos National Laboratory, Albuquerque, NM, LA-114532-MS.

Schuraytz, B. D., T. A. Vogel, L. W. Younker (1986), Geochemical Gradients in the Topopah Spring Member of the Paintbrush Tuff: Evidence for Eruption Across a Magmatic Interface, Lawrence Livermore National Laboratory, Livermore, CA, UCRL-53698.

Scott, D. A. (1985), "Periodic Corrosion Phenomena in Bronze Antiquities," Studies in Conservation 30, 49-57.

Scott, R. B., and M. Catellanos (1984), Stratigraphic and Structural Relations of Volcanic Rocks in Drill Holes USW GU-3 and USW G-3, Yucca Mountain, Nye County, Neoada, U.S. Geological Survey, Denver, CO, OFR-84-491.

Shrivastava, O. P., and F. P. Glasser (1986), "Ton-Exchange Properties of 11- $\AA$ Tobermorite," React. Solids 2, 261-268 .

Soo, P., and L. W. Milian (1989), "Sulfate-Attack Resistance and Gamma-Irradiation Resistance of Some Portland Cement Based Mortars," U.S. Nuclear Regulatory Commission, Washington, D.C., NUREG/CR-5279.

Spengler, R. W., M. P. Chornack, D. C. Muller, and J. E. Kibler (1984), Stratigraphic and Structural Characteristics of Volcanic Rocks in Core Hole USW G-4, Yucca Mountain, Nye County, Nevada, U.S. Geological Survey, Denver, CO, OFR-84789.

Sposito, G. (1981), Thermodynamics of Soil Solutions (Oxford University Press, New York).

Stock, J. M., J. H. Healy, and S. H. Hickman (1984), Report on Televiewer Log and Stress Measurements in Core Hole USW G-2, Neoada Test Site, U.S. Geological Survey, Denver, CO, OFR-84-172.

Stock, J. M., J. H. Healy, S. H. Hickman, and M. D. Zoback (1985), “Hydraulic Fracturing Stress Measurements at Yucca Mountain, Nevada, and Relationship to Regional Stress Field," J. Geophys. Res. 90(B10), 8691-8706.

Subramanian, C. V., J. L. King, D. M. Perkias, R. W. Modd, A. M. Richardson, J. C. Calovini, E. VanEeckhout, and D. D. Emerson (1990), Exploratory Shaft Seismic Design Basis Working Group Report, Sandia National Laboratories, Albuquerque, NM, SAND88-1203. 
Taylor, H. F. W. (1964), "The Calcium Silicate Hydrates," The Chemistry of Cement, H. F. W. Taylor, Ed., vol. 1, pp. 167-232.

Taylor, H. F. W. (1987), "Bound Water in Cement Pastes and Its Significance for Pore Solution Compositions," Mat. Res. Soc. Symp. Proc. 85, 47-53.

Telford, W. M., L. P. Geldart, R. E. Sheriff, and D. A. Keys (1976), Applied Geophysics (Cambridge University Press, London).

Thomas, K. W. (1987), Summary of Sorption Measurements Performed with Yucca Mountain, Nevada, Tuff Samples and Water from Well J-13, Los Alamos National Laboratory, Los Alamos, NM, LA-10960-MS.

Thordarson, W. (1983), Geohydrologic Data and Test Results from Well J-13, Nevada Test Site, Nye County, Nevada, U.S. Geological Survey, Denver, CO, Water Resources Investigations Report 83-4171.

Thorstenson, D. C., E. P. Weeks, H. Haas, and J. C. Woodward (1989), "Physical and Chemical Characteristics of Topographically Affected Airflow in an Open Borehole at Yucca Mountain, Nevada," Proc. of the ANS Topical Mtg on Nuclear Waste Isolation in an Unsaturated Zone, Focus '89,(Amer. Nuc. Soc., La Grange, II).

Van Konynenburg, R. A. (1986a), Radiation Chemical Effects in Experiments to Study the Reaction of Glass in Environment of Gamma-Irradiated Air, Groundwater, and Tuff, Lawrence Livermore National Laboratory, Livermore, CA, UCRL-53719.

Van Konynenburg, R. A. (1986b), Radiation Doses in Granite Around Emplacement Holes in the Spent Fuel Test-Climax (Final Report), Lawrence Livermore National Laboratory, Livermore, CA, UCRL-53580.

Vaniman, D., D. Bish, D. Broxton, F. Byers, G. Heiken, B. Carlos, E. Semarge, F. Caporuscio, and R. Gooley (1984), Variations in Authigenic Mineralogy and Sorptive Zeolite Abundance at Yucca Mountain, Nevada, Based on Studies of Drill Cores USW GU-3 and G-3, Los Alamos National Laboratory, Los Alamos, NM, LA-9707.

Viani, B. E., and C. J. Bruton (1991), Modeling Fluid-Rock Interaction at Yucca Mountain, Nevada: Progress Report, Lawrence Livermore National Laboratory, Livermore, CA, UCRL-ID-109921.

Vortman, L. J. (1980), Prediction of Ground Motion From Underground Nuclear Weapons Tests As It Relates to Siting a Nuclear Waste Storage Facility at NTS and Compatibility With the Weapons Test Program, Sandia National Laboratories, Albuquerque, NM, SAND80-1020/1.

Warren, J. W., and P. J. Root (1963), "The Behavior of Naturally Fractured Reservoirs," Society of Petroleum Engineers Journal 3(3), 245-255.

Warren, R. G., F. M. Byers, Jr., and F. A. Caporuscio (1984), Petrography and Mineral Chemistry of Units of the Topopah Spring, Calico Hills, and Crater Flat tuffs, and Older Volcanic Units, with Emphasis on Samples from Drill Hole USW G-1, Yucca Mountain, Nevada Test Site, Los Alamos National Laboratory, Los Alamos, NM, LA-10003-MS.

West, K. A. (1988), Nevada Nuclear Waste Storage Investigations Exploratory Shaft Facility Fluids and Materials Evaluation, Los Alamos National Laboratory, Albuquerque, NM, LA-11398-MS. 
Wilder, D. G. (1990), "Engineered Barrier Systems and Canister Orientation Studies for the Yucca Mountain Project, Nevada," Proc. of International Symp. on Unique Underground Structures (Colorado School of Mines Press, Colorado).

Wilder, D. G. (1991), Performance Implications of Waste Package Emplacment Orientation, Lawrence Livermore National Laboratory, Livermore, CA, UCID21607.

Wolery, T. J. (1983), EQ3NR: A Computer Program for Geochemical Aqueous Speciation-Solubility Calculations, User's Guide and Documentation, Lawrence Livermore National Laboratory, Livermore, CA, UCRL-53414.

Wolery, T. J., and S. A. Daveler (1991), EQ6, A Computer Program for Reaction Path Modeling of Aqueous Geochemical Systems: User's Guide and Documentation, Lawrence Livermore National Laboratory, Livermore, CA, in preparation.

Wood, B. J., and D. G. Fraser (1977), Elementary Thermodynamics for Geologists, (Oxford University Press, UK).

Wu, Z-Q., and J. F. Young (1984), "Formation of Calcium Hydroxide from Aqueous Suspensions of Tricalcium Silicate," Am. Ceram. Soc. J. 67, 48-51.

Xiuji, F., and L. Shizong (1986), "Investigation of the Effect of Minor Ions on the Stability of $\beta-\mathrm{C}_{2} \mathrm{~S}$ and the Mechanism of Stabilization," Cem. Concr. Res. 16, 587601.

Yang, I. C., A. K. Turner, T. M. Sayre, and P. Montazer (1988), Triaxial-Compression Extraction of Pore Water from Unsaturated Tuff, Yucca Mountain, Nevada, U. S. Geological Survey, Water Resources Investigations Report 88-4189.

Yow, Jr., J. (1985a), Concept for WP Environment Tests in the Yucca Mountain Exploratory Shaft, Lawrence Livermore National Laboratory, Livermore, CA, UCID-20450.

Yow, Jr., J. (1985b), "Test Concept for Waste Package Environment Tests at Yucca Mountain," in the Proc. of the 28th U.S. Symp. on Rock Mechanics, Tucson, AZ (A. A. Balkema, Brookfield, VT), pp. 1035-1042; also in Lawrence Livermore National Laboratory, Livermore, CA, UCRL-95568.

Zimmerman, R. M., and R. E. Finley (1986), Summary of Geomechanical Measurements Taken in and around the G-Tunnel Underground Facility, NTS, Sandia National Laboratories, Albuquerque, NM, SAND86-1015.

Zohdy, A. A. A. R., L. A. Anderson, and L. J. P. Muffler (1973), "Resistivity, SelfPotential, and Induced-Polarization Surveys of a Vapor Dominated Geothermal System," Geophysics 38, 1130-1144. 
Appendix B

B-1 


\section{Appendix B \\ Identification of $Q$ and non- $Q$ data}

The NFER and the LLNL conducted work reported in the NFER have all been performed in accordance with QARD or predecessor QA program procedures and therefore the material in the NFER is considered " $Q$ ". This determination is in accordance with DOE guidance dated 8/19/96 states "All reports, analyses, or models must be done under the QA program and are considered " $Q$ ", if they describe, predict, or defend how the natural barriers will or are performing their function to isolate waste (their safety function). These $\mathrm{Q}$ reports/analyses/models can use non-Q data that is clearly identified as such-the report is still $\mathrm{Q} . . . . "$

The planning for the activities reported in the NFER has long recognized that studies to understand mechanistic processes, lab tests on non YM materials or on non-qualified samples, or scoping calculations and lab tests may not be used directly in license activities related to Site Characterization, but will provide a basis for design, planning, or judging the ranges of conditions within which the conditions of Yucca Mountain will fall. As such the strategy incorporated in planning of these activities included a series of studies that were performed under the LLNL approved QA program that implements the QARD or predecessor YMP QA programs. The strategy provided for qualification of any data that had been determined to be non- $Q$, but later was deemed necessary for licensing etc., through any of a number of possible approaches including: peer review; comparison of the results with studies in which the stringent controls were applied; reperforming of the specific studies that were found applicable, or review of the procedures applied to determine if they met all requirements of qualified data. In keeping with the DOE guidance discussed above, the $Q$ status of data used or reported in the NFER are reflected in Appendix $\mathrm{C}$ following the TDIF number. This $\mathrm{Q}$ status is listed to identify which data would need to be qualified or verified for use in quality affecting work.

Model results (viewed by some as data, but not rigorously defined as data) fall into another category which needs to be considered. First, for the results to be relied on, any codes used in the analyses must be properly qualified. Qualification of the codes is only a small part of the process of qualifying results of models. Other portions relate to whether the parameters used were appropriate, whether the model itself (which includes the conceptualization and the abstraction process) is appropriate to, or valid for, Yucca Mountain. The codes used in work reported in this Rev 1 of the NFER are as follows:

\section{Hydrologic Codes:}

\begin{tabular}{|l|l|}
\hline $\begin{array}{l}\text { V-Tough } \\
\text { NUFT }\end{array}$ & $\begin{array}{l}\text { Fully QA qualified } \\
\text { LLNL developed outside of YMP. Not } \\
\text { qualified, but comparisons to qualified } \\
\text { codes have been performed }\end{array}$ \\
\hline Geochemistry Codes: & $\begin{array}{l}\text { Fully QA qualified } \\
\text { Some data qualified, some QA status } \\
\text { indeterminate } \\
\text { GEMBOCHS (data base) } \\
\text { not qualified--qualification left to user by } \\
\text { comparison with analytical solutions of the } \\
\text { appropriate sets. } \\
\text { commercialacademic code-not qualified }\end{array}$ \\
\hline
\end{tabular}




\begin{tabular}{|c|c|}
\hline $\begin{array}{l}\text { (data base) } \\
\text { OS3D/GIMRT } \\
\text { REACT }\end{array}$ & $\begin{array}{l}\text { Published (peer reviewed) but not qualified } \\
\text { Commercial Code-- } \\
\text { Commercial Code }\end{array}$ \\
\hline \multicolumn{2}{|l|}{ Geomechanics Codes } \\
\hline $\begin{array}{l}\text { FLAC } \\
\text { ABAQUS } \\
\text { FRACROCK }\end{array}$ & $\begin{array}{l}\text { commercial code-not qualified } \\
\text { commercial code-not qualified } \\
\text { LLNL developed outside of YMP. Not } \\
\text { qualified. }\end{array}$ \\
\hline \multicolumn{2}{|l|}{ Man-Made Materials Codes } \\
\hline $\begin{array}{l}\text { EQ3/6 } \\
\text { GEMBOCHS (data base) } \\
\text { GEMBOCHS suite of codes }\end{array}$ & $\begin{array}{l}\text { Fully QA qualified } \\
\text { Some data qualified, some QA status } \\
\text { indeterminate. Microbial will be added. } \\
\text { not qualified--qualification left to user by } \\
\text { comparison with analytical solutions of the } \\
\text { appropriate sets. }\end{array}$ \\
\hline
\end{tabular}

As was the case for data qualification, the codes that are found to be of importance in characterization of the Near-Field Environment, if not already qualified, will need to be qualified. The QA procedures for qualifying codes will be followed which will start with an Individual Software Plan to determine the appropriate way to qualify the code. 
- 
Appendix C

C-1 


\section{Appendix C \\ NFER Chapter Data Status \\ (TDIF and Q status of data)}

\section{Overall NFER--LL960807504241.012 (non-Q)}

\section{Chapter 1: Hydrothermal Modeling}

This chapter does not report data, it reports results of modeling only, using data from RIB or referenced data from other sources. Because the codes used in the models varies, model information by section is listed.

Section 1.1 Introduction--no data

Section 1.2 No new data--refers to published data or data from other sources

Section 1.3 No data--model analyses only using V-TOUGH (This section is

Rev 0 and therefore was based on V-TOUGH prior to its qualification)

Section 1.4 No data, refers to work of others

Section 1.5 No new data, refers to work of others

Utilizes Log-Normal Model which is unqualified but used and reported in outside literature

Section 1.6 No new data, analyses based on V-TOUGH prior to qualification

Section 1.7 No data, analyses/models only based on V-TOUGH

Section 1.8 No data, model results based on Qualified V-TOUGH

Section 1.9 No data, model results based on Qualified V-TOUGH

Section 1.10.1-1.10.3 No data, model results based on both V-TOUGH and NUFT as well as hybrid model.

Section 1.10.4 No data, model results based on V-TOUGH and hybrid.

Sections 1.10.5.1 through 1.10.5.3 used qualified V-Tough code.

Sections 1.10.5.4 through 1.10.7 are model results (no data) using NUFT

Chapter 2: Laboratory Determined Hydrologic Properties and Processes

LL950404604242.012 (non-Q)
LL950812704242.017 (non-Q)
LL960201404244.011 (non-Q)
LL960100604244.007 (non-Q)
LL960201304244.010 (non-Q)
LL960100704244.008 (non-Q)
LL950916504242.018 (non-Q)
LL950406104242.016 (non-Q)
LL940800704242.002 (non-Q)

Chapter 3: Geochemistry

None. Modeling only based on use of qualified EQ3/6 as well as unqualified GMIRT and REACT. 
Chapter 4: Geomechanics

LL960101004243.005 (non-Q)

LL960401704243.008 (non-Q)

LL960201104243.006 (non-Q)

Modeling results based on use of non-qualified codes.

Chapter 5: Radiation Effects

No new data.

Chapter 6: Man-Made Materials

LL950813104245.004 (Q)

LL940803904245.001 (non-Q)

LL960807404245.008 (non-Q)

Chapter 7: Integrated Testing

LL960401051051.007 (non-Q)

LL960400951051.006 (non-Q)

LL940803851051.002 (non-Q)

Chapter 8: Electrical Potentials

No new data.

Chapter 9: Field Thermal Tests

LL950103004244.004 (non-Q)

Chapter 10: Altered Zone, Geochemistry (10.4)

Section 10.1, and 10.2 contain no data, model results only based on qualified VTOUGH code.

Section 10.3 No data

Section 10.4 LL960201004241.011 (non-Q)

Chapter 11: Introduction to the Thermodynamic Data Determination

Data from NEA sources. 


$-$

